Beiträge aus der Nordwestdeutschen Forstlichen Versuchsanstalt Band 5

\title{
Fichtenherkunftsversuch von 1962 und IUFRO-Fichtenherkunftsversuch von 1972
}

Ergebnisse von mehr als 30-jähriger Beobachtung in Deutschland

Mirko Liesebach, Hans-Martin Rau, Armin O. König

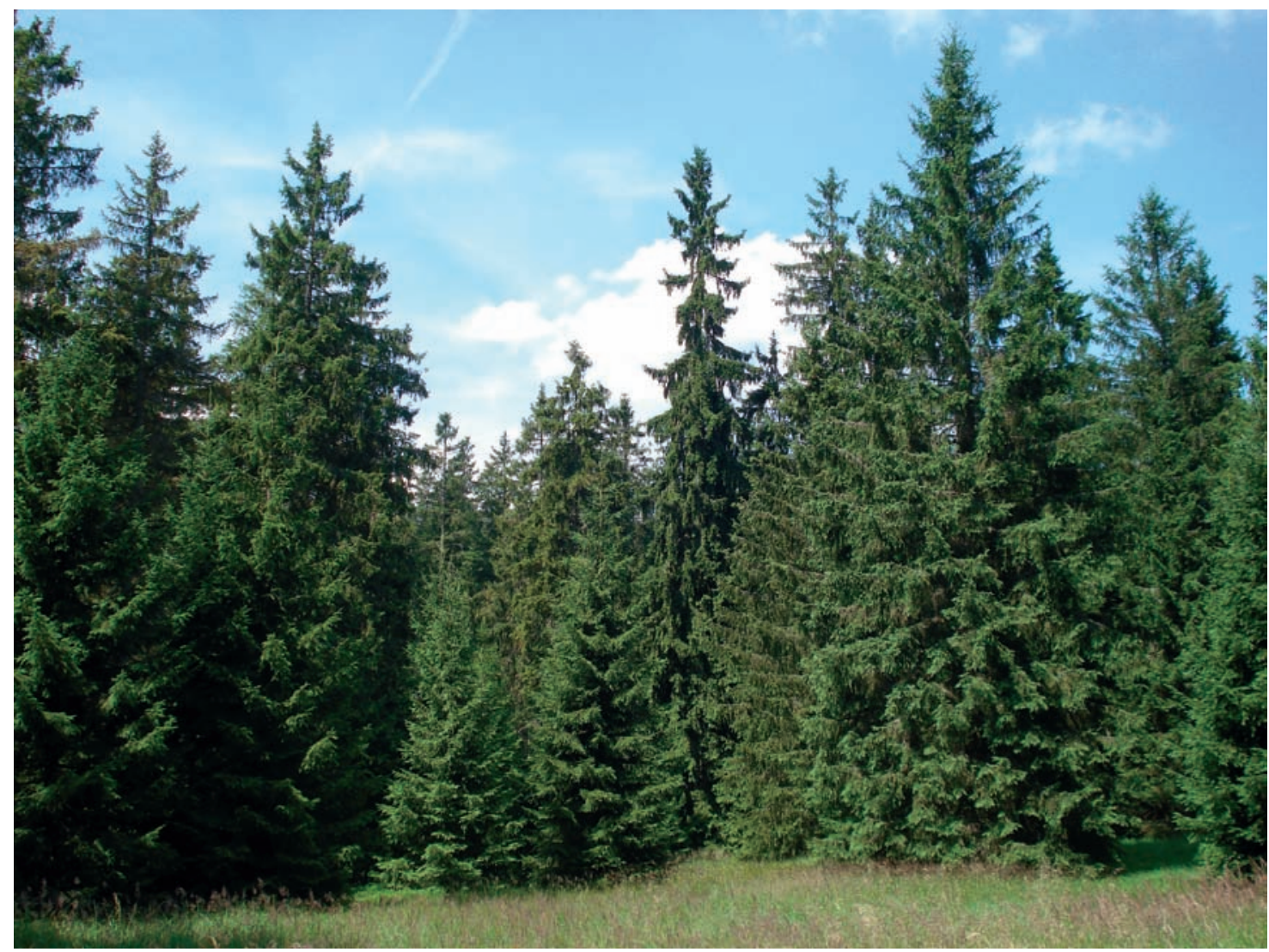

Universitätsdrucke Göttingen

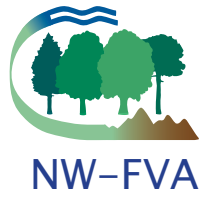



Mirko Liesebach, Hans-Martin Rau, Armin O. König Fichtenherkunftsversuch von 1962 und IUFRO-Fichtenherkunftsversuch von 1972

This work is licensed under the Creative Commons License 3.0 "by-nd", allowing you to download, distribute and print the document in a few copies for private or educational use, given that the document stays unchanged and the creator is mentioned. You are not allowed to sell copies of the free version.

SOMERIGGHSRESERVED 
erschienen als Band 5 der Reihe

„Beiträge aus der Nordwestdeutschen Forstlichen Versuchsanstalt“

in den Universitätsdrucken im Universitätsverlag Göttingen 2010 
Mirko Liesebach, Hans-Martin Rau, Armin O. König

Fichtenherkunftsversuch

von 1962 und

IUFRO-Fichtenherkunftsversuch von 1972

Ergebnisse von mehr als

30-jähriger Beobachtung in Deutschland

Beiträge aus der

Nordwestdeutschen

Forstlichen Versuchsanstalt

Band 5

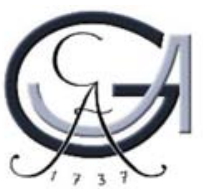

Universitätsverlag Göttingen

2010 


\section{Bibliographische Information der Deutschen Nationalbibliothek}

Die Deutsche Nationalbibliothek verzeichnet diese Publikation in der Deutschen Nationalbibliographie; detaillierte bibliographische Daten sind im Internet über $<$ http://dnb.ddb.de> abrufbar

Global Forest Decimal Classification: 232.12 : 174.7 Picea abies

\section{Herausgeber}

Nordwestdeutsche Forstliche Versuchsanstalt (NW-FVA)

Grätzelstr. 2, D-37079 Göttingen

Tel.: +49 (0)551-69401-0, Fax: +49 (0)551-69401-160

E-Mail: zentrale@nw-fva.de

www.nw-fva.de

Schriftleitung der Reihe: Prof. Dr. Hermann Spellmann

Redaktion: Inge Kehr, Ulrike Gaertner

Titelfoto: Unterschiedliche Kronenformen bei einer Fichtengruppe im Harz 2008 (M. Liesebach)

Dieses Buch ist auch als freie Onlineversion über die Homepage der NW-FVA, des Verlages sowie über den OPAC der Niedersächsischen Staats- und Universitätsbibliothek (http:/ /www.sub.uni-goettingen.de) erreichbar und darf gelesen, heruntergeladen sowie als Privatkopie ausgedruckt werden. Es gelten die Lizenzbestimmungen der Onlineversion. Es ist nicht gestattet, Kopien oder gedruckte Fassungen der freien Onlineversion zu veräußern.

(C) 2010 Universitätsverlag Göttingen

http:/ / univerlag.uni-goettingen.de

ISBN: 978-3-941875-76-0

ISSN: $1865-6994$ 


\section{Inhaltsverzeichnis}

Zusammenfassung $\quad 3$

$\begin{array}{lr}\text { Abstract } & 8\end{array}$

1 Einleitung 13

1.1 Verbreitungsgebiet und geografisch-genetische Variation 13

1.2 Fichtenherkunftsversuche unter besonderer Berücksichtigung internationaler Einsammlungen $\quad 15$

1.2.1 Die IUFRO-Fichtenherkunftsversuche von 1938 und $1939 \quad 16$

1.2.2 Versuche aus der Einsammlung von 1959 bis 1964

$\begin{array}{ll}1.2 .3 & \text { Der IUFRO-Versuch von 1964/1968 }\end{array}$

1.2.4 Der IUFRO-Fichtenherkunftsversuch von 1972

$\begin{array}{ll}1.3 & \text { Weitere Fichtenherkunftsversuche } \\ & 22\end{array}$

2 Der Fichtenherkunftsversuch von 1962

2.1 Material und Methoden 24

2.1.1 Versuchsmaterial 24

2.1.2 Versuchsorte 25

2.1.3 Verteilung der Prüfglieder auf die Versuchsflächen 32

2.1.4 Behandlung und Beschreibung des Gesamteindrucks der Versuchsflächen 33

2.1.5 Aufnahmen von Merkmalen 38

2.1.6 Methoden 41

2.2 Ergebnisse und Diskussion $\quad 44$

2.2.1 Gruppierung von Herkünften 45

2.2.2 Versuchsflächen 49

2.2.2.1 Reinhardshagen / Hessen 49

2.2.2.2 Hasbruch / Niedersachsen 73

2.2.2.3 Sonthofen und Berchtesgaden / Bayern 91

2.2.2.4 Münsingen / Baden-Württemberg 102

2.2.3 Vergleich der Versuchsflächen 104

2.2.3.1 Entwicklung der Pflanzenanzabl 105

$\begin{array}{lll}\text { 2.2.3.2 Schadmerkmale } & 105\end{array}$

2.2.3.3 Formmerkmale 106

2.2.3.4 Höhen- und BHD-Wachstum 110

2.2.3.5 Einzelbaumvolumen und Vorrat pro Hektar 121

3 Der IUFRO-Fichtenherkunftsversuch von 1972

3.1 Material und Methoden 132

3.1.1 Versuchsmaterial 132

3.1.2 Versuchsorte und Versuchsaufbau 138 
3.1.3 Behandlung und Beschreibung des Gesamteindrucks der Versuchsflächen

3.1.4 Aufnahme von Merkmalen 151

3.1.5 Methoden 155

3.2 Ergebnisse und Diskussion 158

$\begin{array}{lll}3.2 .1 & \text { Hessen } & 158\end{array}$

3.2.1.1 Reinhardshagen 158

3.2.1.2 Wanfried 171

$\begin{array}{lll}3.2 .2 & \text { Niedersachsen } & 185\end{array}$

3.2.2.1 Dassel 185

3.2.2.2 Seesen 198

$\begin{array}{lll}\text { 3.2.3 } & \text { Baden-Württemberg } & 209\end{array}$

3.2.3.1 Ochsenhausen $A \quad 209$

3.2.3.2 Ocbsenhausen B 214

$\begin{array}{lll}3.2 .4 & \text { Bayern } & 219\end{array}$

3.2.4.1 Sauerlach $A \quad 219$

3.2.4.2 Sauerlach B 226

3.2.4.3 Neureichenau (BFH) 233

3.2.5 Vergleich der IUFRO-Herkünfte zwischen den Versuchsflächen 243

3.2.5.1 Entwicklung der Pflanzenanzabl 244

3.2.5.2 Schadmerkmale 248

3.2.5.3 Formmerkmale 249

3.2.5.4 Höhen-und BHD-Wachstum 254

3.2.5.5 Einzelbaumvolumen und Vorrat 280

4 Abschließende Wertung 286

4.1 Reinhardshagen / Hessen - zwei Versuche an einem Standort 288

4.2 Einflussfaktor Ernte 289

4.3 Standortabhängigkeit am Beispiel der polnischen Herkünfte des IUFRO-Fichtenherkunftsversuchs von 1972

4.4 Sonderherkünfte und als ,geprüft“ zugelassene Bestände im Herkunftsversuch von $1962 \quad 298$

4.5 Angepasstheit an Klimaänderungen 307

Literatur

Danksagung $\quad 322$

$\begin{array}{ll}\text { Autoren } & 324\end{array}$

Anhang $\quad 325$

Anhang: Übersicht $\quad 325$

Anhang 1: Der Fichtenherkunftsversuch von 1962

Anhang 2: Der IUFRO-Fichtenherkunftsversuch von 1972 


\title{
Fichtenherkunftsversuch von 1962 und IUFRO-Fichtenherkunftsversuch von 1972. Ergebnisse von mehr als 30-jähriger Beobachtung in Deutschland
}

\author{
The 1962 Norway spruce provenance trial and 1972 \\ IUFRO Norway spruce provenance trial. \\ Results of over 30 years of observation in Germany
}

Von M. Liesebach, H.-M. Rau und A.O. König

\section{Zusammenfassung}

Mit der weit über ihr natürliches Verbreitungsgebiet hinaus angebauten, in Deutschland wirtschaftlich bedeutendsten Baumart Fichte (Picea abies [L.] Karst.) wurden in der zweiten Hälfte des letzten Jahrhunderts mehrere größere Herkunftsversuche angelegt. Aus dieser Zeit stammen auch der Fichtenherkunftsversuch von 1962 und der IUFRO-Fichtenherkunftsversuch von 1972. Die Auswertung der über 30-jährigen Beobachtung dieser Versuche ist Gegenstand dieser Arbeit.

Ziel der beiden Versuche ist es, insbesondere zur weiteren Klärung folgender Fragestellungen beizutragen: 
- Erfassung der Merkmalsvariation der Prüfglieder unter den jeweiligen Anbaubedingungen

- Ermittlung der Herkünfte, die sich hinsichtlich ihres Wuchsverhaltens und ihrer Betriebssicherheit für den zukünftigen Anbau auf den Fichtenstandorten in (West-)Deutschland eignen

- Beurteilung des Anpassungsvermögens der Prüfglieder an unterschiedliche Standortverhältnisse

\section{Versuchsmaterial und Versuchsflächen}

Der Fichtenherkunftsversuch von 1962

Das Saatgut für den Fichtenherkunftsversuch von 1962 stammt aus der Einsammlung für die Anlage des IUFRO-Versuchs von 1964/1968. Mit ihm wurde eine eigene Versuchsreihe von der Arbeitsgemeinschaft der Länderinstitutionen für Forstpflanzenzüchtung in der Bundesrepublik Deutschland angelegt. Es wurden insgesamt 286 Herkünfte überwiegend aus dem zentraleuropäischen Raum an fünf Standorten auf zusammen neun Versuchsflächen ausgebracht. Vier Flächen enthalten 169 Herkünfte, zwei Flächen weitere 81 Herkünfte und drei Flächen weitere 36 Herkünfte. Auf den Flächen mit 81 und 36 Herkünften sind einige Prüfglieder nicht parallel vertreten.

Das Saatgut wurde im Frühjahr 1962 in Hessen ausgesät. Im Frühjahr 1964 erfolgte die Verschulung der Sämlinge jeweils an den Orten der vier beteiligten Länderinstitute. Die Anlage der Feldversuche erfolgte im Frühjahr 1967 in Hessen, Niedersachsen und Baden-Württemberg an je einem Standort und in Bayern an zwei Standorten. Die Behandlung während der Anzuchtphase und der Freilandpflanzung erfolgte nach einheitlichen Versuchsbedingungen. Die spätere Behandlung der Flächen und die Messungen wurden von der Hessischen Forstlichen Versuchsanstalt (heute Nordwestdeutsche Forstliche Versuchsanstalt) koordiniert.

\section{Der IUFRO-Fichtenherkunftsversuch von 1972}

Das Saatgut für den IUFRO-Fichtenherkunftsversuch von 1972 stammt aus einer eigens initiierten Einsammlung aus dem guten Mastjahr 1971. Den Kern dieser Versuchsserie bilden 20 Herkünfte (i. d. R. mind. 20 Elternbäume beerntet) aus Polen, die für den Anbau im mitteleuropäischen Raum eine größere Leistungsfähigkeit und ein höheres $\mathrm{Maß}$ an Widerstandsfähigkeit gegenüber Sommertrocknis aufweisen als Herkünfte aus dem südwestdeutschen Verbreitungsgebiet.

Zusätzlich zu den polnischen Herkünften sind bis zu 90 weitere Herkünfte oder Einzelbaumabsaaten getestet worden. Das Saatgut wurde von drei Versuchsanstalten in Hessen, Niedersachsen und Baden-Württemberg ausgesät und die Sämlinge verschult. In den Frühjahren der Jahre 1976 bis 1979 wurden 12 Versuchsflächen angelegt. Drei Flächen wurden nach wenigen Jahren aufgegeben. 
Auf je zwei Flächen in Hessen und Niedersachsen erfolgte die Koordinierung der Messungen durch die Hessische Forstliche Versuchsanstalt. Die Messung auf den beiden Flächen in Baden-Württemberg und den anfangs vier, später zwei Flächen in Bayern wurde vom Waldbau-Institut der Universität Freiburg vorgenommen. Eine Fläche in Bayern wurde von der Bundesforschungsanstalt für Forst- und Holzwirtschaft (heute Johann Heinrich von Thünen-Institut), Großhansdorf, betreut.

\section{Ergebnisse und Wertung}

Neben der Entwicklung der Pflanzenanzahl, Schäden und Stammform wurden die Wachstums- und Vorratsentwicklungen besonders intensiv untersucht.

Die Entwicklung der Pflanzenanzahl verlief auf den Flächen beider Versuchsserien unterschiedlich. Durch Nachbesserungen und Durchforstungen wurde die Anzahl der Pflanzen auf den Flächen immer wieder in vergleichbare Größenordnungen gebracht. Aussagen zur Mortalität und damit zur Angepasstheit an den jeweiligen Versuchsstandort sind daher über die Pflanzenanzahl häufig nicht möglich.

Auf den Flächen sind die Schäden insgesamt gering. Am häufigsten wurden Schäden durch Schneedruck / Windwurf notiert. Die beobachteten Schäden kommen auf den Flächen geklumpt vor und sind daher zufällig und nicht herkunftsbedingt.

Anders sieht es auf der Fläche Berchtesgaden / Bayern (1360 m ü. NN) des Fichtenherkunftsversuchs von 1962 aus. Hier traten Schäden durch Schneebruch und Schneedruck in größerem Umfang auf. Dabei wurden an den Herkünften aus Hochlagen weniger Schäden als an Herkünften aus tieferen Lagen beobachtet.

Im IUFRO-Fichtenherkunftsversuch von 1972 ist auf der in $950 \mathrm{~m}$ ü. NN gelegenen Fläche Neureichenau / Bayern hervorzuheben, dass die polnischen Herkünfte aus dem nordostpolnischen Verbreitungsgebiet und aus der Mittelpolnischen Hochebene mehr Schneebrüche hatten als jene aus den Sudeten und den schlesischen Beskiden.

Die Stammform wurde anhand von drei Kriterien analysiert: Schaftformbonitur, Ovalität, H/D-Verhältnis. Die Stammform ist auf den Flächen unterschiedlich. So ist der Anteil der geraden Fichten auf den beiden Teilflächen in den Hochlagen Bayerns (Fichtenherkunftsversuch von 1962) deutlich geringer als auf Flächen in Hessen und Niedersachsen. Herkünfte, die aus tieferen Lagen (200-650 m ü. NN) stammen, haben weniger gerade Stämme als die aus höheren Lagen (über $1000 \mathrm{~m}$ ü. NN). Auch zwischen den politisch-geografisch gruppierten Herkünften gibt es Unterschiede: So haben zum Beispiel Herkünfte aus Polen und Deutschland weniger gerade Stämme als solche der Gruppe ehemalige Tschechoslowakei. 
Zusammenfassung

Zwischen den Versuchsflächen des IUFRO-Fichtenherkunftsversuchs von 1972 gibt es keine Zusammenhänge zwischen dem Anteil gerader Stämme und der Herkunft. Hier ist davon auszugehen, dass die Stammform unabhängig von ökologischen Variablen und somit zufällig verteilt ist.

Die Abweichung von der Kreisform (Ovalität) und das H/D-Verhältnis hatten in beiden Versuchen keine Unterschiede ergeben und sind damit zufällig verteilt.

Die fünf auf allen Versuchsflächen des Fichtenherkunftsversuchs von 1962 angebauten „Standard“-Herkünfte sind im Wachstum, im mittleren Einzelbaumvolumen und im errechneten Vorrat pro Hektar vom Standort beeinflusst. Die Rangfolge der fünf „Standard“-Herkünfte variiert stark.

Auf den vier sich standörtlich stark unterscheidenden Flächen mit 169 Prüfgliedern gibt es nur wenige Herkünfte, die auf allen Flächen ähnliches Wachstum zeigen. Die meisten Herkünfte reagieren auf die unterschiedlichen Standortbedingungen. Auf den beiden im Norden Deutschlands gelegenen Flächen Hasbruch und Reinhardshagen ist das Wachstum der Herkünfte ähnlicher, dies wird besonders in dem Teilversuch mit den 81 Herkünften deutlich, der nur dort angelegt wurde. Korrelations- und Varianzanalysen bestätigen, dass die Merkmalsausprägung nicht nur von der Herkunft sondern ganz entscheidend vom Standort beeinflusst wird.

Insgesamt haben Herkünfte aus Deutschland und aus der ehemaligen Tschechoslowakei im Mittel ein besseres Wachstum als Herkünfte aus Frankreich und der Schweiz.

Für die beiden Flächen in Hessen und Niedersachsen liegen Höhen- und BHD-Werte aus einem Messjahr vor, so dass sich ein mittlerer Vorrat errechnen ließ. Für die Flächen in Hessen beträgt der rechnerische mittlere Bestandesvorrat $409 \mathrm{~m}^{3} /$ ha und variiert zwischen den Herkünften zwischen 163 und $805 \mathrm{~m}^{3} / \mathrm{ha}$ im Alter 39. Auf der standörtlich für Fichte ungeeigneten Fläche Hasbruch / Niedersachsen wird ein mittlerer Bestandesvorrat von nur $77 \mathrm{~m}^{3} /$ ha errechnet. Hier variiert der Vorrat zwischen vorratsärmster und -reichster Herkunft zwischen 13 und $196 \mathrm{~m}^{3} / \mathrm{ha}$.

Für den Vergleich des Wachstums wurden die einzelnen Herkünfte zum Mittelwert der sieben auf allen Flächen des IUFRO-Fichtenherkunftsversuchs von 1972 vertretenen Herkünfte (Standard) ins Verhältnis gesetzt. Ein auf allen Flächen unter dem Standard liegendes Höhenwachstum haben drei Herkünfte (Witów, Stronie Śląskie und Rycerka II), nur eine Herkunft (Tarnawa) ist mindestens so wüchsig wie der Standard. Etwa je die Hälfte der Herkünfte zeigte ein von den Standortbedingungen abhängiges Höhenwachstum.

Beim BHD sind es auch drei Herkünfte (Witów, Nowe Ramuki und Krzyze), deren Wachstum auf allen Flächen geringer ist als das des Standards und zwei Herkünfte (Wisła und Istebna 149h), deren BHD-Wachstum dem des Standards entspricht oder besser ist. Vier Herkünfte (Miedzygórze, Krzyze, Lubelski und 
Wigry) zeigen ein von den Standortbedingungen unabhängiges Wachstum, während 16 ein umweltabhängiges Dickenwachstum haben.

Im Alter 32 lässt sich für die vier Flächen in Hessen und Niedersachsen ein mittlerer Vorrat errechnen. Dieser variiert zwischen den Flächen von 236 bis $333 \mathrm{~m}^{3} /$ ha und zwischen den Herkünften von 135 bis $408 \mathrm{~m}^{3} /$ ha. Für die Flächen Neureichenau / Bayern (Alter 34) errechnet sich nach einem Nassschneeereignis ein mittlerer Vorrat von $111 \mathrm{~m}^{3} /$ ha, der von 33 bis $236 \mathrm{~m}^{3} /$ ha zwischen den Herkünften variiert.

Die zahlreichen in den Versuchen enthaltenen deutschen Herkünfte zeigen hinsichtlich Wüchsigkeit und Standortanpassung beträchtliche Unterschiede. Dennoch konnte im höheren Alter statistisch keine Herkunft gefunden werden, die unter allen Standortbedingungen gute Wuchsleistungen verspricht. Es zeigte sich aber, dass insbesondere die Höhenlage des Einsammlungsortes auf die Wuchsleistung entscheidenden Einfluss hat. Herkünfte aus tieferen Lagen haben im Durchschnitt ein besseres Wachstum als Herkünfte aus höheren Lagen. Es gibt einige Hochlagenherkünfte, die durchgehend oder zumindest fast durchgehend schlechten Wuchs auf allen Flächen zeigen.

Die Ergebnisse stimmen weitgehend mit denen anderer Versuchsansteller sowie zum Teil auch mit Erkenntnissen aus älteren Fichtenversuchen überein.

Abschließend werden die Ergebnisse kritisch gewertet und die Angepasstheit der Fichte an Klimaänderungen diskutiert. Die Auswertung der beiden Versuche hat auch ergeben, dass neben den aktuellen Problemen Klimaänderung und Herkunftsempfehlung in drei weiteren Bereichen Forschungsbedarf besteht:

1. Dem Einfluss unterschiedlicher Anzuchtorte sollte in Feldversuchen nachgegangen werden.

2. In Feldversuchen sollte der Einfluss unterschiedlicher Erntejahrgänge eines Bestandes auf die Merkmalsausprägung untersucht werden.

3. Spezifizierung des Wachstums nach weiteren zehn Jahren von Hochlagen- und Tieflagenherkünften auf den Versuchsflächen in Bayern und Hessen.

Schlüsselworte: Fichte, Picea abies, Herkünfte, Vitalität, Wachstum, Anpassungsfähigkeit 


\begin{abstract}
In the second half of the last century many large provenance trials were established for Norway spruce (Picea abies [L.] Karst.), economically the most important tree species in Germany. N. spruce has been planted widely in Europe, in and outside its natural distribution range, and in North America. The 1962 Norway spruce provenance trial and the 1972 IUFRO Norway spruce provenance trial originate from that period. This paper presents the analysis of these trials after over 30 years of observation.

The goals of the trials were to further improve the knowledge of the variation in traits of provenances under specific growing conditions, recommend provenances suitable for planting in (West) Germany on the basis of their reliable growth and yield, and assess the adaptability of provenances to different site conditions.
\end{abstract}

\title{
Plant material and experimental sites
}

The 1962 Norway spruce provenance trial

The seed for the 1962 Norway spruce provenance trial was obtained from the seed collection undertaken for the establishment of the IUFRO 1964/1968 Norway spruce provenance experiment. The Working Group of State Forest Tree Breeding Institutes used this seed to establish a separate field experiment in Germany, which included 286 provenances primarily from central Europe. Nine provenance trials were planted at five study sites. These trials consist of 169 provenances at four sites, 81 provenances at two sites and a further 36 provenances at three sites. In the latter two trials, some provenances are not represented at both.

The seed was sown in Hesse in spring 1962. In spring 1964, the seedlings were transplanted to locations managed by the four state forest experimental stations participating in the trial. In spring 1967, the field trials were established at one site in Hesse, Lower Saxony and Baden-Württemberg, and at two sites in Bavaria. The seedlings received the same treatment during nursery stage and field planting. Afterwards, treatments and measurements were coordinated by the Hessian Forest Experimental Station (now known as Northwest German Forest Research Station).

\section{The 1972 IUFRO Norway spruce provenance trial}

Seed from the good crop in 1971 was collected specifically for the establishment of the IUFRO Norway spruce provenance trial in 1972. Twenty provenances from Poland (mostly from seed from at least 20 mother trees) promising higher yields and better adaptability to summer drought than those from the south-western distribution range formed the core of the trial. 
As well as the provenances from Poland, up to 90 additional provenances or single tree progenies also were tested. The Forest Experimental Stations in Hesse, Lower Saxony and Baden-Württemberg sowed the seed and raised the seedlings. Between spring 1976 and spring 1979, twelve field experiments were established. At three sites, however, the trial was discontinued after a few years.

The Hessian Forest Experimental Station coordinated the measurements at two sites both in Hesse and in Lower Saxony, while the Institute of Silviculture, Freiburg University, conducted the trials at two sites in Baden-Württemberg and four - later only two - sites in Bavaria. One site in Bavaria was supervised by the Federal Research Centre for Forestry and Forest Products at Großhansdorf (now known as Johann Heinrich von Thuenen Institute).

\section{Results and conclusions}

In addition to the changes in plant number, damage and stem quality, special attention was given to growth and yield.

The change in plant number differed in the two provenance trials. However a comparable plant number was maintained at these sites by replanting and repeated thinning so that conclusions about mortality, and hence adaptability could not be drawn from plant number at the different sites.

Observed damage at the study sites was generally low. Most damage was caused by snow pressure and windthrow, and occurred in clumps, indicating a random occurrence unrelated to provenance.

On the Berchtesgaden/Bavaria site (1360 m a.s.l.) in the 1962 Norway spruce provenance trial, damage by snow pressure and snow breaks occurred more frequently. Provenances from higher elevations showed less damage than provenances from lower elevations.

On the Neureichenau / Bavaria site (950 m a.s.l.) in the 1972 IUFRO Norway spruce trial, more snow damage was found in provenances from north-eastern Poland and central Polish Plateau than those from Sudety and the Silesian Beskids.

Stem quality was analysed in terms of three traits: stem straightness, ovalness of the stem cross-section and height/diameter ratio. The number of straight stems was lower on the two Bavarian sites at higher elevations (1962 Norway spruce provenance trial) than those on sites in Hesse and Lower Saxony. Tree stems of provenances from higher elevations (above $1000 \mathrm{~m}$ a.s.l.) were straighter than those from lower elevations (200-650 $\mathrm{m}$ a.s.l.). There were also differences between provenances grouped according to political and geographical criteria. For example, the stems of provenances from former Czechoslovakia were straighter than those from Poland and Germany. 
In the 1972 IUFRO Norway spruce provenance trial, no relationship between stem straightness and provenance was found. Consequently, ecological variables did not appear to influence stem form.

Furthermore, differences in deviation of stems from a circular form and the height/diameter ratio could not be distinguished in either trial, and therefore, these traits occurred randomly.

The growth, mean stem volume and estimated volume per hectare of all five provenances grown on all sites in the 1962 Norway spruce provenance trial as control provenances were influenced by site conditions. The ranking of these five provenances also varied greatly between sites.

Only a few of the 169 provenances demonstrated comparable growth on the four study sites with their markedly different site conditions. Most provenances were affected by the different site conditions. Growth of provenances was more similar on the two sites Hasbruch and Reinhardshagen in northern Germany. This was evident particularly in the trials with 81 provenances, which were established only on these sites. Analyses of variance and correlation analyses confirmed that these measurements clearly were influenced more by site factors than by provenance.

On average, provenances from Germany and the former Czechoslovakia grew better than those from France and Switzerland.

Height and diameter growth of provenances on the sites in Hesse and Lower Saxony were measured in the same year, facilitating estimations of the mean standing volume. On the sites in Hesse, this volume was $409 \mathrm{~m}^{3} /$ ha, which varied between provenances from 163 to $805 \mathrm{~m}^{3} /$ ha at the age of 39 years. On the Lower Saxony site Hasbruch, unsuitable for Norway spruce, mean standing volume was only $77 \mathrm{~m}^{3} / \mathrm{h}$. Here the standing volume of provenances ranged from 13 to $196 \mathrm{~m}^{3} /$ ha.

The mean growth of the seven Polish provenances present on all 1972 IUFRO Norway spruce provenance trial sites (control provenances) provided a standard with which to compare mean growth of all provenances. The mean growth of three Polish provenances (Witów, Stronie Śląskie and Rycerka II) was lower than the standard mean growth on all sites; only one provenance (Tarnawa) demonstrated equivalent or better growth. Height growth of approximately half the Polish provenances was influenced by site-specific conditions.

Two Polish provenances (Wisła and Istebna 149h) revealed better diameter growth than the standard mean. The diameter growth of three Polish provenances (Witów, Nowe Ramuki and Krzyze) was lower than this value on all sites. Diameter growth of 16 Polish provenances was influenced by site-specific conditions whereas diameter growth of four provenances (Miedzygórze, Krzyze, Lubelski and Wigry) was independent of site. 
On the sites in Hesse and Lower Saxony, the estimated mean standing volume was estimated at age 32 years. This varied between 236 and $333 \mathrm{~m}^{3} /$ ha for the four sites, and between 135 and $408 \mathrm{~m}^{3} /$ ha for the Polish provenances. At the study site Neureichenau (Bavaria), the estimated mean standing volume of the 34 year old trials following severe snow damage was $111 \mathrm{~m}^{3} / \mathrm{ha}$. Here the standing volume between the provenances varied from 33 to $236 \mathrm{~m}^{3} /$ ha.

Considerable variation in growth and site adaptability was found for the many German provenances represented in the trials. Yet, at this age, statistical analysis revealed no provenances with good growth at all sites. However, it was shown that the elevation of the seed origin had an important effect on growth and yield. On average, the growth of provenances from lower elevations was better than those from higher elevations. Some provenances from higher elevations exhibited mainly poor growth more or less on all test sites.

The results are largely in accordance with those from other institutes participating in the trial, and with results from older Norway spruce trials.

Finally, the results were reviewed in the context of the adaptability of Norway spruce to climate change. In addition to current research into climate change and provenance recommendations, the evaluation of these two trials highlights the need for further research in the following three areas:

1. The effect of different nursery sites (elevation) in field trials.

2. The effect of different seed harvest years on the traits in field trials.

3. Growth performance of provenances from high and low elevations at the sites in Bavaria and Hesse in the next ten years.

Keywords: Norway spruce, Picea abies, provenances, vitality, growth, adaptability 



\section{Einleitung}

\subsection{Verbreitungsgebiet und geografisch-genetische Variation}

Die Auffassungen über das natürliche Verbreitungsgebiet der Gemeinen Fichte (Picea abies [L.] Karst.), im Folgenden kurz Fichte genannt, unterlagen in den vergangenen Jahrzehnten einem gewissen Wandel. RUBNER (1932, zitiert nach SCHMIDT-VOGT 1987, S. 191) teilte das ursprüngliche Verbreitungsgebiet der Fichte in Europa in drei voneinander getrennte Areale auf, und bezeichnete diese als:

1. Alpin-südosteuropäisches Fichtengebiet

2. Herzynisch-karpatisches Fichtengebiet

3. Baltisch-nordisches Fichtengebiet

Maßgebend für diese Dreigliederung sind zwei fichtenfreie Streifen oder zumindest „Minimalareale“, von denen angenommen wird, dass sie von der Fichte bei der Rückwanderung nach der Eiszeit nicht überschritten wurden.

SCHMIDT-VOGT selbst (1987, S. 197) dagegen vertritt die Auffassung, dass alle Verbreitungsgebiete einmal in Verbindung gestanden haben, und dass die fichtenfreien Streifen in Mittelpolen und den Karpaten vor allem auf anthropogene Einflüsse zurückzuführen seien. Er fasst die ersten beiden Verbreitungsgebiete RUBNERs zu einem zusammen und weitet das dritte nach Osten bis zum Ural aus. Weiterhin wird die sibirische Form der Fichte Picea abies var. obovata in das Gesamtgebiet der Gemeinen Fichte einbezogen. Die Bezeichnungen der Verbreitungsgebiete nach SCHMIDT-VOGT lauten:

1. Mittel- und südosteuropäisches Fichtengebiet

2. Nordosteuropäisches Fichtengebiet

3. Sibirisches Fichtengebiet

SCHMIDT (2002) schließt sich mehr der Gliederung RUBNERs (1960) an und bezeichnet die Verbreitungsgebiete als:

1. Alpisch-illyrisch-balkanisches Fichtengebiet

2. Herzynisch-karpatisches Fichtengebiet

3. Skandinavisch-sarmatisches Fichtengebiet

Die Teilgebiete entstanden im Postglazial durch Rückwanderung aus verschiedenen Refugien (SCHMIDT-VOGT 1987, S. 195). Die europäischen Rückzugsgebiete der Fichte lagen im Wesentlichen in vier Gebieten (SCHMIDT-VOGT 1987, S. 172):

- In Mittelrussland zwischen den nördlichen subarktischen Kältesteppen und den im Süden anschließenden Lösssteppen

- Am Fuß der Karpaten und der Transsilvanischen Alpen

- Im Bereich der dinarischen Gebirge mit Ausläufern bis zum Ostrand der Alpen

- Auf der Apenninen-Halbinsel 
Baumarten mit einem großen Verbreitungsgebiet zeigen im Allgemeinen eine hohe Variation phänotypischer Merkmale. Dies gilt insbesondere für die Fichte mit ihrem riesigen Verbreitungsgebiet in West-Ost-Richtung von den West- und Seealpen in Frankreich bis an das Ochotskische Meer und von Norden nach Süden von der Nähe des Polarkreises in Westnorwegen bis in die Rhodopen in Griechenland. Eine hohe phänotypische Variation kann ihre Ursache in einer über das Verbreitungsgebiet differenzierten genetischen Variation haben, die teilweise folgendermaßen erklärt werden kann: Refugialpopulationen stellen im Allgemeinen Restpopulationen mit eingeschränkter Populationsgröße dar. Sowohl beim Rückzug in die Refugien als auch durch genetische Drift in denselben können Gene verloren gegangen sein. Neue Gene können durch Mutation entstanden sein. Es kann somit davon ausgegangen werden, dass die Refugialpopulationen unterschiedliche genetische Konstitutionen (Genpools) besaßen, die sich bei der Rückwanderung in ihre oben beschriebenen Verbreitungsgebiete durch Drift, Gründereffekte, Mutationen und Selektionsprozesse noch vergrößerten. Weiterhin erfolgt über neue Rekombinationen eine ständige Anpassung an die gegebenen Standortsbedingungen.

Mit genetischer Differenzierung ist bei allen isolierten Fichtenvorkommen zu rechnen, wie sie vor allem im Süden des Verbreitungsgebietes auftreten, so bei dem Fichtenrelikt in den Apenninen oder bei den oft mehrere $100 \mathrm{~km}$ voneinander entfernten Fichteninseln im südlichen Balkan.

Picea abies gehört in vielen Ländern zu den wichtigsten Wirtschaftsbaumarten und wird weit über ihr natürliches Areal hinaus angebaut. Erste urkundlich belegte Saat mit Fichte erfolgte in Deutschland 1423 im Stadtwald Frankfurt (SCHMIDTVOGT 1987, S. 247). Beim künstlichen Anbau der Fichte (außerhalb ihres natürlichen Verbreitungsgebiets) wurden jedoch nur selten Aufzeichnungen über die verwendeten Herkünfte gemacht. Durch deren zunächst wahllose Verwendung und Verschiebung entstanden der Forstwirtschaft aber auch schwere Schäden. Die künstliche Begründung von Beständen hatte ihre Ursache in großen, freien oder devastierten Waldflächen, die, um der Holzverknappung zu begegnen, schnell wieder unter Bestockung genommen werden sollten. Bei Nadelbaumarten waren die Saatgutbeschaffung, der Transport und die Lagerung der Sämereien sowie die Bestandesbegründung einfacher als bei Laubbaumarten. Dadurch entstanden auf vielen Laub- und Mischwald-Standorten in den vergangenen beiden Jahrhunderten instabile Nadelbaum-Reinbestände. Dazu trug auch die Bewirtschaftung im Kahlschlagverfahren bei. Die Fichte wurde selbst in ehemals fichtenarmen und -freien Gebieten landschaftsprägend. Andererseits stehen auf geeigneten Standorten den ökologischen Nachteilen ökonomische Vorteile gegenüber. Aufgrund ihrer oft höheren Reinerträge wird die Fichte als der „Brotbaum“ der Forstwirtschaft bezeichnet (z. B. THOMASIUS 1990).

Umfassende Studien zur Variation anpassungsrelevanter phänotypischer Merkmale bei verschiedenen Herkünften, Familien und Klonen unter gleichartigen Standortbedingungen belegen eine beträchtliche Variabilität und deutlich differen- 
zierte Anpassungsmuster. In Herkunftsversuchen ist die Variation von Individuen innerhalb anbauwürdiger Herkünfte oft größer als zwischen den Herkunftsmittelwerten (KLEINSCHMIT et al. 1996).

Die große forstliche Bedeutung geografischer Rassen wurde bei der Fichte bis gegen Ende des 19. Jahrhunderts im Waldbau weitgehend nicht beachtet. Das geringere Interesse der Schiffbauer an der Fichte wird als Grund angeführt, warum die Herkunftsforschung bei der Fichte später als bei der Kiefer einsetzte (KÖNIG 2005). Durch den umfangreichen künstlichen Anbau der Fichte fielen Unterschiede zwischen Pflanzen mit Ursprung aus verschiedenen Höhenlagen auf. So fand KIENITZ (1879), Hann. Münden, bereits 1879 Unterschiede im Wachstum und in der Nadelfärbung verschiedener Fichtenherkünfte. 1896 legte CIESLAR (1899), Wien, einen Feldversuch mit 17 Herkünften an und beschrieb das langsame Wachstum von nordischen und Hochlagenherkünften. Wiederholte Aufnahmen dieses Versuchs bestätigten die grundlegenden Folgerungen, auch wenn einige Rangverschiebungen bis zum Alter von 57 Jahren auftraten (MELZER 1937; GÜNZL 1979). In einem von ENGLER, Zürich, 1899 angelegten Versuch zeigte sich, dass mit höherem Alter die geringwüchsigsten Bäume ausfielen und dadurch die Variation in den Herkünften abnahm (FISCHER 1949/50).

RUBNER begründete 1937 einen Versuch mit 31 deutschen Fichtenherkünften auf sieben Versuchsflächen, über den mehrfach berichtet wurde (z. B. RUBNER 1957, ROHMEDER und BEUSCHEL 1970). Dabei ergab sich, dass auf allen Standorten Herkünfte aus dem Erzgebirge und aus Ostpreußen in der Spitzengruppe lagen, während die Herkunft Sachsenried schlecht abschnitt. SCHMIDTVOGT (1972) zeigte allerdings, dass in der Herkunftsregion Sachsenried erhebliche Wachstumsunterschiede zwischen Bestandesabsaaten bestehen, was auf unterschiedliche Ursprünge der Bestände zurückgeführt wird. Ein weiteres Ergebnis der RUBNER'schen Versuche ist die Erkenntnis, dass im Verhalten der Herkünfte Interaktionen mit dem Anbaustandorten auftreten können und einige Herkünfte eine relativ weite Standortsamplitude haben.

\subsection{Fichtenherkunftsversuche unter besonderer Berücksichtigung internationaler Einsammlungen}

Im Folgenden wird eine Auswahl von Fichtenherkunftsversuchen behandelt, die ihren Ursprung in bilateraler oder internationaler Zusammenarbeit haben. Dabei finden einleitend Versuche des Internationalen Verbandes Forstlicher Forschungsanstalten (engl. International Union of Forest Research Organizations [IUFRO]) besondere Berücksichtigung. Bei der Auswertung liegt der Schwerpunkt auf den in Deutschland angelegten Versuchsflächen der Einsammlung von 1959 bis 1964 und dem IUFRO-Versuch von 1972. 


\subsubsection{Die IUFRO-Fichtenherkunftsversuche von 1938 und 1939}

Auf dem IX. IUFRO-Kongress in Budapest / Ungarn 1936 wurde unter anderem der Beschluss gefasst, unter der Leitung von Werner SCHMIDT, Eberswalde, einen internationalen Herkunftsversuch mit Fichte anzulegen. Das Saatgut wurde von 1936 bis 1938 in 36 Beständen, meist von nur wenigen Bäumen, eingesammelt und für die erste Versuchsserie 1938 ausgesät. Für die folgende Serie wurden 1939 15 Herkünfte ausgesät, wobei acht Versuchsglieder die gleichen waren wie im Versuch (GIERTYCH 1984). Als Empfehlung galt, 22 Herkünfte obligatorisch zu verwenden, und wenn möglich, weitere 14 hinzuzufügen (Tab. 1.1). Bei den Herkünften handelte es sich um Bestandesabsaaten. Die einzelnen Teilnehmer sind jedoch von den Empfehlungen z. T. erheblich abgewichen. Die Versuchsflächen wurden von 1940 bis 1944 mit unterschiedlich alten, zwei- bis sechsjährigen Pflanzen begründet. Für IUFRO 1938 wurden 24 und für IUFRO 1939 zwei Versuchsflächen angelegt (Abb. 1.1 und 1.4). Von der von deutscher Seite in Guttentag / Schlesien (heute: Dobrozień / Polen) angelegten Versuchsfläche sind keine Versuchsunterlagen auffindbar. Ungeachtet der großen klimatischen und edaphischen Unterschiede der Anbauorte waren die herzynisch-karpatischen Herkünfte sehr einheitlich mit ihrem mittelspäten Austrieb und in der Wuchsleistung den anderen Herkünften überlegen.

Tab.1.1: Herkunftsorte des IUFRO-Fichtenherkunftsversuchs von 1938 (SCHMIDT-VOGT 1977)

\begin{tabular}{llll}
\hline \multicolumn{2}{l}{ Obligatorische Herkünfte } & Fakultative Herkünfte & \\
\hline Rovaniemi (SF) & Murat (F) & Bromarv (SF) & Bialowieża (PL) \\
Vilppula (SF) & Winterthur (CH) & Ásnes (N) & Radom (PL) \\
Tyldal (N) & Val di Fiemme (I) & Griva (UdSSR) & Dolina (UdSSR) \\
Nesbyen (N) & Plánice (CSSR) & Scanfs (CH) & \\
Follafoss (N) & Lankowitz (A) & Svinosice (ČSSR) & \\
Drängsered (S) & Obervellach (A) & Pokljuka (YU) & \\
Vecmoka (UdSSR) & Obervellach (A) & Muntele (RU) & \\
Brody (PL) & Sarajevo (YU) & Valea Bistrei (RU) & \\
Stolpce (UdSSR) & Crucea (RU) & Garmisch (D) & \\
Istebna (PL) & Vadul Rau (RU) & St. Blasien (D) & \\
Bullange (B) & Peštera (BG) & Wilna (UdSSR) & \\
\hline
\end{tabular}




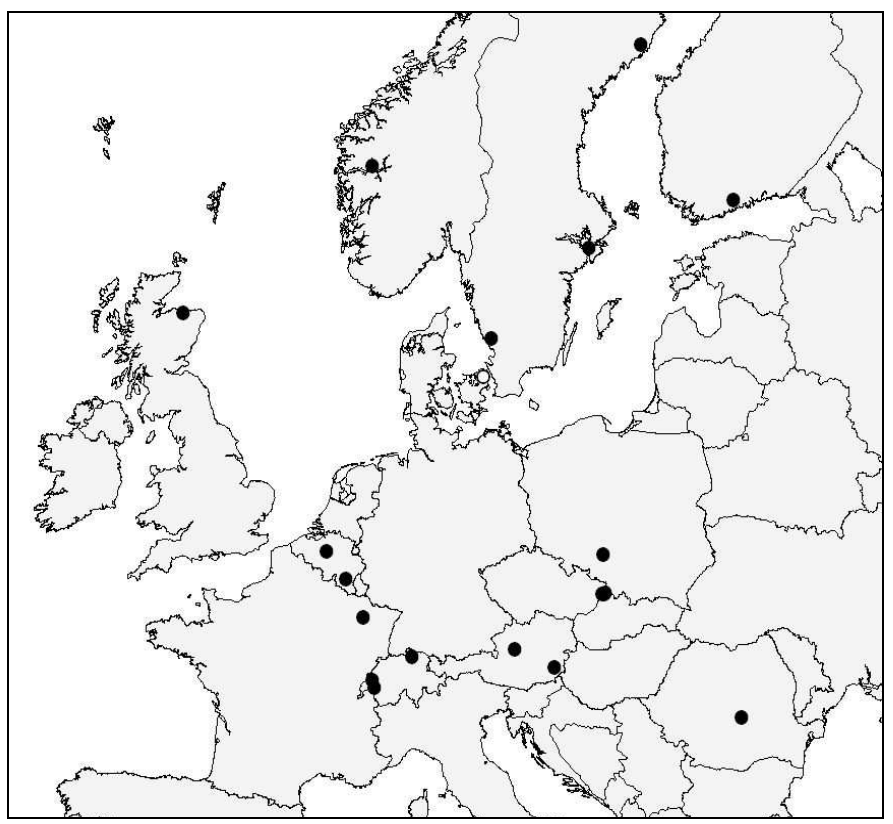

1. IUFRO 1938

Österreich (2)

Belgien (2)

Finnland (1)

Frankreich (1)

Großbritannien (1)

Norwegen (1)

Polen (1)

Rumänien (1)

Schweden (3)

Schweiz (3)

Tschechische Rep. (3)

USA (5) s. Abb. 1.4

2. IUFRO 1939

Dänemark (1)

Kanada (1) s. Abb. 1.4

Abb.1.1: IUFRO-Fichtenherkunftsversuche 1938 (• 19 Flächen) und 1939 (O 1 Fläche) (in Klammern jeweils Anzabl der Versuchsflächen). In der Schweiz überlappen sich zwei und in Tschechien drei Punkte.

\subsubsection{Versuche aus der Einsammlung von 1959 bis 1964}

Die Herkunftsversuche IUFRO 1938 und 1939 erbrachten vielversprechende Ergebnisse zum geografisch-genetischen Variationsmuster der Fichte und die Anpassungsfähigkeit von Populationen selbst nach weitem Transfer. Allerdings wurde die Stichprobe als zu klein angesehen, um von der Ausprägung der Merkmale einer Herkunft auf Wuchsleistung, Phänologie und andere Merkmale von benachbarten Populationen des gleichen Wuchsgebietes/-bezirkes schließen zu können. Olof LANGLET von der Königlich Forstlichen Hochschule in Stockholm fasste daher den Entschluss, eine weitere Einsammlung von Saatgut der Fichte über ihr gesamtes (europäisches) Verbreitungsgebiet zu initiieren. Dabei sollten nicht nur bekannte oder vermutete autochthone Bestände beerntet werden, sondern auch künstlich begründete und solche außerhalb des natürlichen Verbreitungsgebiets. Angesichts der wirtschaftlichen Bedeutung der Baumart, insbesondere für Schweden (LANGLET 1960), war an eine Inventur der Fichte gedacht. Das Unterfangen wurde deshalb auch als ,inventierender Fichtenherkunftsversuch“ bezeichnet. Die Einsammlung fand von 1959 bis 1964 statt und ergab insgesamt 1617 Saatgutproben, die durch eine so genannte Stockholm-Nummer dokumentiert wurden. Das Material war sehr heterogen. Es enthielt von Einzelstamm- über definierte Bestandesabsaaten auch Proben, bei denen nur das Herkunftsgebiet 
registriert werden konnte. Andererseits wurden aber auch in besonders interessierenden Herkunftsgebieten, wie in den Karpaten, Bestände gezielt mit mindestens 20 Bäumen beerntet und Bestandes- und geografische Daten festgehalten. Zwecks Vereinfachung werden im Folgenden die einzelnen Versuchsglieder auch als Herkünfte bezeichnet.

Aus der schwedischen Initiative entwickelte sich in den Folgejahren eine deutsch-schwedische Zusammenarbeit. Mit rund 1000 Herkünften wurde 1962 in Lugnet bei Stockholm ein Baumschulversuch angelegt (KRUTZSCH 1975). Von diesem Material erhielt außerdem Hans Joachim FrÖHLICH, Hann. Münden, 530 Herkünfte, die für einen Anbau in Deutschland von Interesse sein könnten. Mit diesem Saatgut begründeten die Länderinstitutionen für Forstpflanzenzüchtung in der Bundesrepublik Deutschland eine eigene Versuchsreihe: den „Fichtenherkunftsversuch von 1962"1. Aus der Einsammlung 1959 bis 1964 erhielten auch Wilhelm KNABE, Recklinghausen, und Helmut SCHMIDT-VOGT, Freiburg, Saatgut für weitere Untersuchungen (z. B. KNABE et al. 1990, KANNENBERG und GROsS 1999).

Aufgrund seines Umfanges wird der IUFRO-Versuch von 1964/1968 im Folgenden noch etwas genauer dargestellt. Auf den Fichtenherkunftsversuch von 1962 wird ausführlich in Kapitel 2 eingegangen und dabei auch die Verbindung (bei gleichen Versuchsgliedern) zum IUFRO-Versuch von 1964/1968 hergestellt.

\subsubsection{Der IUFRO-Versuch von 1964/1968}

Die deutsch-schwedische Zusammenarbeit wurde fortgeführt, indem 1964 Wolfgang LANGNER, Schmalenbek (Schleswig-Holstein), 1300 Saatgutproben erhielt, die in Schmalenbek ausgesät und als zweijährige Pflanzen in Halstenbek verschult wurden. In der Zwischenzeit hatte sich die bilaterale Zusammenarbeit zu einem internationalen Unternehmen entwickelt. Zahlreiche Länder bekundeten ihr Interesse an dem Versuch teilzunehmen. 1100 Versuchsglieder wurden für einen internationalen Herkunftsversuch ausgewählt. Er bekam (zunächst) die Bezeichnung „Inventory Provenance Test with Norway Spruce (I.P.T.N.S.)“ (KRUTZSCH 1973, 1975). Aufgrund der großen Anzahl der Versuchsglieder und den daraus resultierenden Problemen in Feldversuchen wurde eine Gruppierung in elf Kohorten mit jeweils 100 Herkünften vorgenommen. Dabei wurde nach dem

\footnotetext{
${ }^{1}$ In der Literatur und in den Versuchsakten ist diese Versuchsreihe auch wie folgt bezeichnet: Internationaler Fichten-Provenienzversuch 1962 (WeISGERBER et al. 1976b, 1977, 1984), Internationaler FichtenProvenienzversuch (IUFRO 1962/64) (WEISGERBER 1983), IUFRO 1964/68 Norway spruce provenance trial (RAU 1993), International Norway spruce Provenance Trial from 1964/68 (DIETZE und RACZ 1973), Fichten-Provenienzversuch Schweden-Deutschland 1962 (Versuchspläne), Schwedisch-deutscher FichtenProvenienzversuch, Deutsch-schwedischer Fichten-Provenienzversuch.
} 
Prinzip einer randomisierten Auswahl aus einer stratifizierten Grundgesamtheit vorgegangen, d. h. es wurden für jede Kohorte Proben aus jeder Herkunftsregion gezogen (in Abhängigkeit von der Verfügbarkeit von Proben). Auf diese Weise sollten sich für die Mittelwerte jeder Kohorte gleiche Erwartungswerte ergeben und eine Verknüpfung der Kohorten möglich werden. Unterschiede entstehen somit nur durch Stichprobenunterschiede, vor allem aber durch Standortsunterschiede. Weiterhin kann so jede mit einer Kohorte von Herkünften begründete Versuchsfläche als eigener Herkunftsversuch angesehen werden.

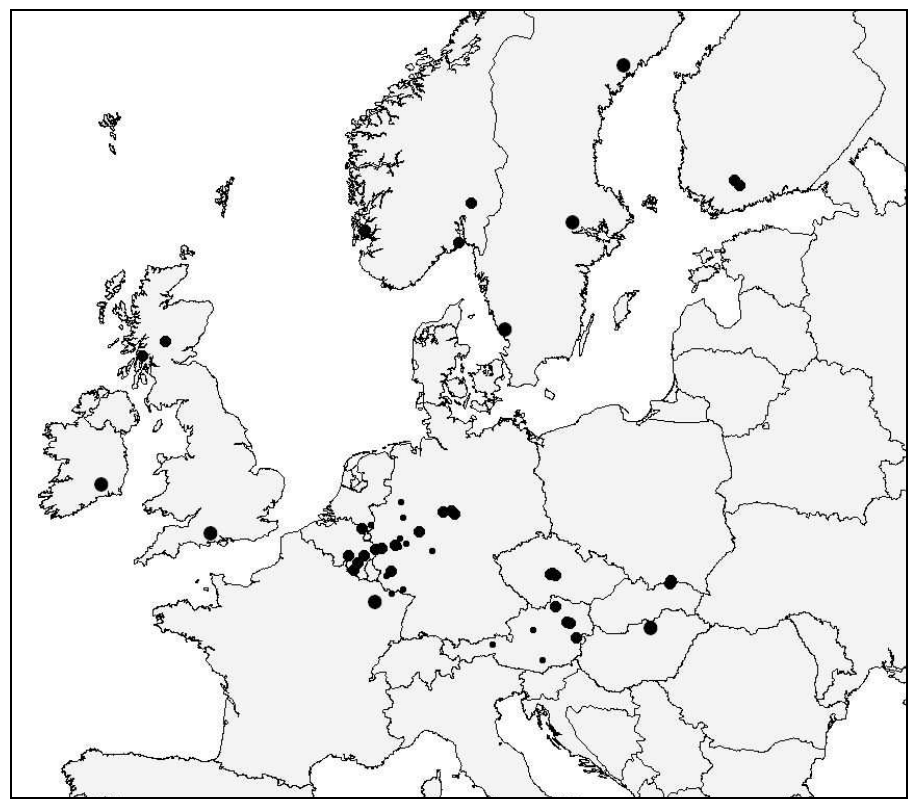

IUFRO 1964/1968

Belgien $\left(2^{*}\right)$

Deutschland $\left(3^{*}\right)$

Tschechische Rep. (1)

Finnland (1)

Frankreich (1)

Irland (1)

Norwegen $\left(2^{*}\right)$

Österreich $\left(1^{*}\right)$

Polen $\left(1^{*}\right)$

Schweden (3)

Ungarn (1)

Großbritannien $\left(2^{*}\right)$

Kanada (1) s. Abb. 1.4

* z. T. auf mehreren

Teilflächen

Abb.1.2: Versuchsflächen des IUFRO-Fichtenherkunftsversuchs von 1964/1968. In der Karte bedeutet ein großer Punkt, alle elf Kohorten liegen an einem Ort, mittelgroßer Punkt 2 bis 8 Kohorten an einem Ort und Kleiner Punkt 1 Kohorte. Einige Punkte können sich in der Karte überlappen. Eine tabellarische Übersicht über die Versuchsorte mit den jeweils ausgebrachten Koborten findet man bei DIETRICHSON et al. (1976).

Die Versuchsflächen wurden in der Regel 1968 als randomisierte, vollständige Blockversuche mit Einbaum-Parzellen und 25 Wiederholungen begründet. In Deutschland wurde der gesamte Satz der 1100 Herkünfte dreimal mit nur 20 Wiederholungen angelegt. Die Versuchsflächen des dritten Satzes wurden erst 1969 ausgepflanzt. Die drei deutschen Versuchsanlagen mit zusammen 33 Teilflächen werden vom Institut für Forstgenetik und Forstpflanzenzüchtung der Bundesforschungsanstalt für Forst und Holzwirtschaft (heute Johann Heinrich von Thünen-Institut) betreut. Auf zwei Versuchsflächen in Schottland und Finnland wurde ein abweichendes Design gewählt. Insgesamt wurden 21 Feldver- 
suche (20 in Europa und einer in Kanada) in 13 Ländern begründet (Abb. 1.2 und 1.4). Auf dem IUFRO-Treffen der Arbeitsgruppe Fichtenprovenienzen in Biri / Norwegen im Jahre 1973 wurde beschlossen, dass der Versuch zukünftig als „The IUFRO experiment of 1964/1968“ (IUFRO-Versuch von 1964/1968) bezeichnet werden sollte (DIETRICHSON 1973).

Zum IUFRO-Versuch von 1964/1968 wurden von den deutschen Versuchsflächen folgende (Teil-)Ergebnisse publiziert: DIETRICHSON et al. (1976), KÖNIG (1981, 1989, 2002), LIESEBACH (1994, 2005), LIESEBACH et al. (2001); eine Endauswertung wurde noch nicht veröffentlicht.

\subsubsection{Der IUFRO-Fichtenherkunftsversuch von 1972}

Wegen unzureichender Kenntnisse über die morphologische Variation der Fichte und des Interesses an polnischen Fichtenherkünften aufgrund der Ergebnisse des IUFRO-Provenienzversuches von 1938/39 führte das Forstliche Forschungsinstitut Warschau mit U.S.-amerikanischer Förderung umfangreiche Untersuchungen auf zahlreichen Dauerbeobachtungsflächen der Fichte in Polen durch (ANONYMUS 1968). Außerdem wurde die Meinung vertreten, dass im IUFROHerkunftsversuch von 1964/1968 die polnische Fichte nur unzureichend vertreten sei (Mängel in der Stichprobe und/oder Dokumentation). Eine gute Fruktifikation begünstigte die Initiative von Stanislaw Tyskiewicz, Warschau, eine dritte internationale Herkunftsversuchsserie zu etablieren. Als Konsequenz der Zusammenarbeit innerhalb der IUFRO wird der Versuch, dessen Material 1972 ausgesät wurde, als IUFRO-Fichtenherkunftsversuch von 1972 bezeichnet $^{2}$. Als Tyskiewicz in den Ruhestand trat, wurde die Arbeit von seinem langjährigen Mitarbeiter Stefan Kocięcki fortgeführt. Derzeit koordiniert Jan Matras den Versuch.

Der Kern dieser Versuchsserie beinhaltet 20 Prüfglieder aus dem polnischen Tiefland, Mittelpolen und dem Bergland (Karpaten, Beskiden usw.). Für jedes Prüfglied wurden in der Regel mindestens 20 Bäume beerntet und Daten, die den Ausgangsbestand charakterisieren, erhoben (ANONYMUS 1968, KRUTZSCH 1992). 44 Versuchsflächen (Abb. 1.3 und 1.4), die häufig mit weiteren nationalen Herkünften für Vergleichszwecke ergänzt worden sind, wurden angelegt. Die Ergebnisse der deutschen Versuchsflächen dieser Versuchsserie werden im 3. Kapitel vorgestellt. Eine Liste mit den bis zum Jahr 1984 erschienenen Publikationen zu den o. a. Fichten-Herkunftsversuchen ist in SCHMIDT-VOGT („Die Fichte“, Band II/1 [1986], S. 224) abgedruckt.

\footnotetext{
${ }^{2}$ Dieser Versuch wird auch mit folgenden Bezeichnungen geführt: Internationaler Fichtenherkunftsversuch IUFRO 1972 bzw. IUFRO-Fichtenherkunftsversuch 1972 (SCHMIDT-VOGT und KOCIĘCKI 1985), Deutsch-polnischer Fichten-Provenienzversuch (RAU 1983), Polnischer IUFRO-Fichtenherkunftsversuch von 1972 (KRUTZSCH 1992).
} 


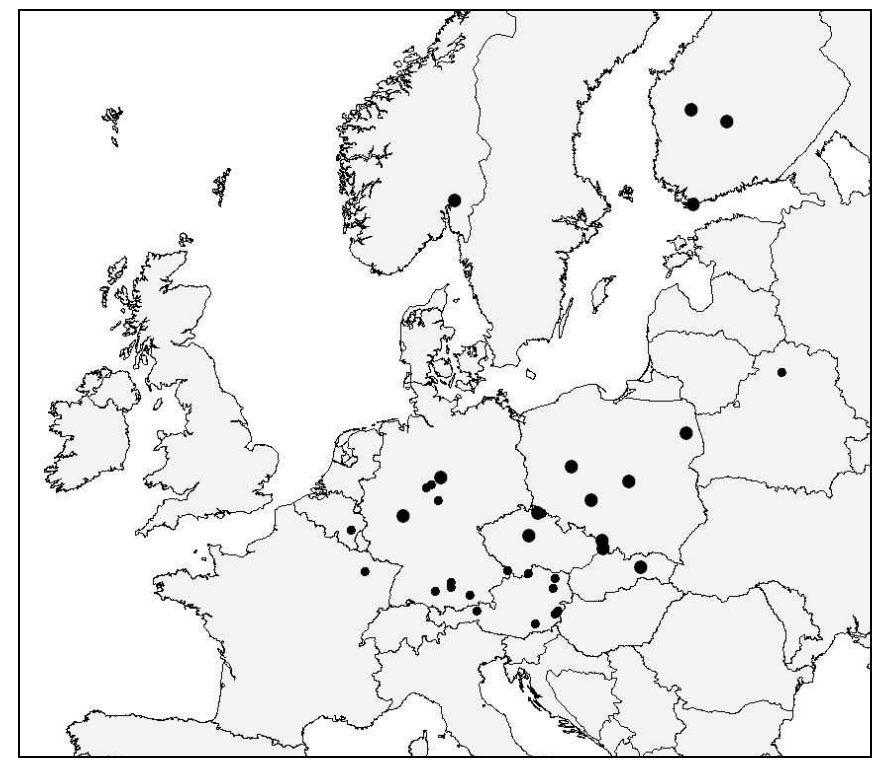

IUFRO 1972

Belgien (1)

Deutschland (11)

Tschechische Rep. (3)

Frankreich (1)

Finnland (3)

Österreich (7)

Polen (5)

Norwegen (1)

Slowakische Rep. (3)

Weißrussland (1)

Kanada (6) s. Abb. 1.4

Abb. 1.3: Versuchsflächen des IUFRO-Fichtenherkunftsversuch von 1972 (geändert nach KRUTZSCH 1992, SCHMIDT-VOGT und KOCIECKI 1985). In der Karte besagt ein großer Punkt, dass mindestens 18 polnische Herkïnfte auf der Fläche getestet werden und ein kleiner Punkt maximal 17 Herkünfte. Einige Punkte können sich in der Karte überlappen.

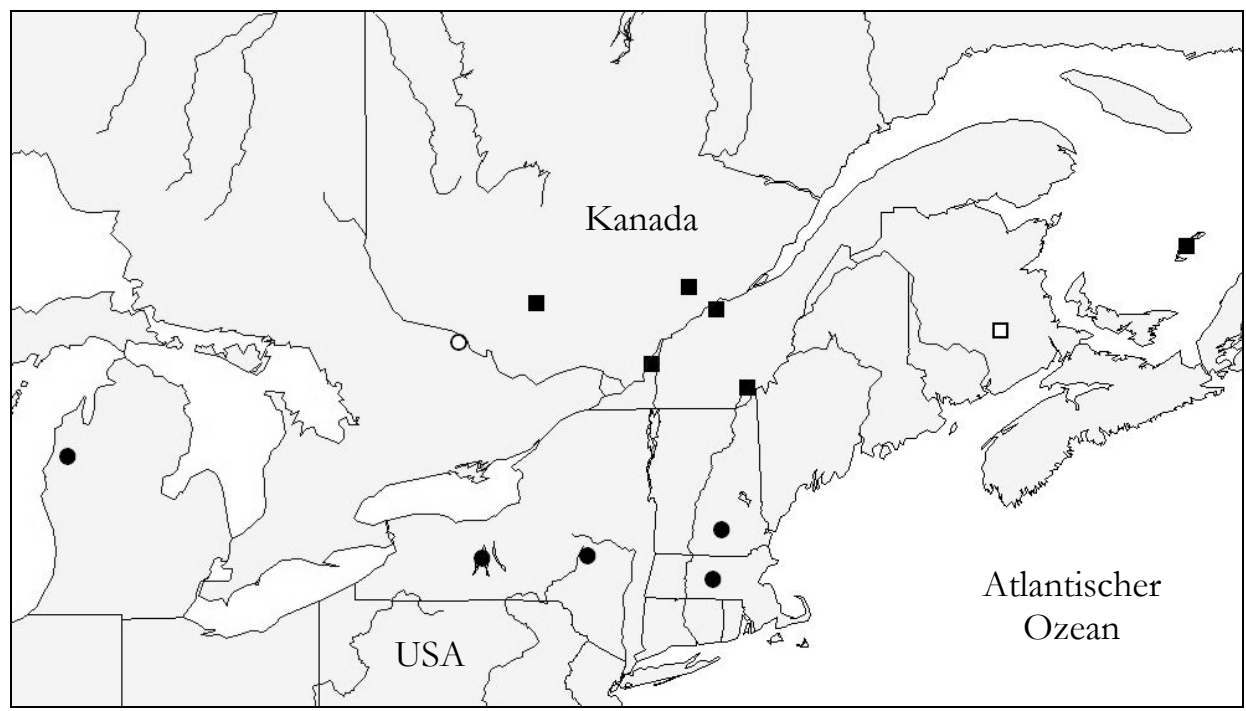

Abb. 1.4: Versuchsflächen der IUFRO-Fichtenherkunftsversuche von 1938 (• 5 Flächen) und 1939 (O 1 Fläche), 1964/1968 ( 1 Fläche) sowie 1972 (ロ 6 Flächen) in Nordamerika 


\subsection{Weitere Fichtenherkunftsversuche}

Neben den internationalen Versuchen wurde in den einzelnen Ländern eine Vielzahl kleinerer Versuche angelegt, die zum Teil der Klärung lokaler Fragen dienten. In Deutschland zeigten die Versuche, dass auf engem Raum eine erhebliche Variation der Herkunftsmittel besteht, die auch auf künstliche Anbauten zurückgeführt werden kann. Zu den nicht autochthonen Herkünften, die in den Versuchen hervorragende Nachkommenschaften haben, zählt die Herkunft Westerhof (WEISGERBER et al. 1976b, RAU 2007).

Intensive Fichtenherkunftsforschung wurde in Skandinavien (z. B. DIETRICHSON 1969, DiETRICHSON et al. 1985, FOTTLAND und SKRøppa 1989, PersSon und PERSSON 1992) betrieben. Aber auch in anderen europäischen Ländern wurden weitere Versuche begründet. Eine Auflistung und die wichtigsten Ergebnisse weiterer Fichten-Herkunftsversuche findet sich z. B. in SCHMIDT-VOGT (1977-1991), GIERTYCH (1977).

Über die in den letzten Jahrzehnten begonnenen Fichtenherkunftsversuche haben in Deutschland z. B. folgende Autoren berichtet: DIETZE und RÁCZ (1973); KÖNIG (2002); RAU (1983, 1993); RAU et al. (1998); SCHMIDT-VOGT und KOCIĘCKI (1985); WEISGERBER 1983, 1990; WEISGERBER et al. 1976a, b, 1977, 1984). Mit zunehmendem Alter der Versuchsflächen ist häufig mit einem Informationsgewinn zu rechnen. 


\section{Der Fichtenherkunftsversuch von 1962}

Von der Arbeitsgemeinschaft der Länderinstitutionen für Forstpflanzenzüchtung in der Bundesrepublik Deutschland wurde eine eigene Versuchsreihe angelegt. Auf Initiative von Hans Joachim FRÖHLICH erhielten 1962 die Institute für Forstpflanzenzüchtung der Länder Hessen, Niedersachsen, Bayern und BadenWürttemberg 530 Saatgutpartien aus der Anfangsphase der Einsammlung zum IUFRO-Versuch von 1964/1968. Das Saatgut wurde noch im selben Frühjahr im hessischen Institut für Forstpflanzenzüchtung ausgesät. Im Frühjahr 1964 erfolgte die Verschulung jeweils an den Orten der Länderinstitute, und zwar in Hann. Münden, Escherode, Teisendorf/Laufen und Stuttgart. Zur Charakterisierung der Anzuchtorte sind in Tabelle 2.1 die geografischen und wichtigsten Klimadaten aufgeführt (WEISGERBER et al. 1976b).

Tab. 2.1 Geografische und Klimadaten zur Charakterisierung der Anzuchtorte

\begin{tabular}{l|c|c|c|c|c|c|c}
\hline \multirow{2}{*}{ Anzuchtort } & \multicolumn{2}{|c|}{ Geogr. Lage } & \multicolumn{2}{c|}{ Höhe } & \multicolumn{2}{c|}{ Temperatur } & \multicolumn{2}{c}{ Niederschlag } \\
& Breite N & Länge O & $\mathrm{m} \mathrm{ü} \mathrm{NN}$ & $\mathrm{t}_{\mathrm{j}}{ }^{\circ} \mathrm{C}$ & $\mathrm{t}_{\mathrm{Veg}}{ }^{\circ} \mathrm{C}$ & $\mathrm{mm}_{\mathrm{j}}$ & $\mathrm{mm}_{\mathrm{Veg}}$ \\
\hline Hann. Münden* & $51^{\circ} 25^{\prime}$ & $09^{\circ} 38^{\prime}$ & 130 & 8,5 & 15,0 & 780 & 375 \\
Escherode & $51^{\circ} 25^{\prime}$ & $09^{\circ} 42^{\prime}$ & 350 & 7,6 & 14,6 & 760 & 360 \\
Teisendorf & $47^{\circ} 54^{\prime}$ & $12^{\circ} 54^{\prime}$ & 420 & 7,3 & 14,5 & 1160 & 674 \\
Stuttgart & $48^{\circ} 48^{\prime}$ & $09^{\circ} 05^{\prime}$ & 340 & 9,5 & 16,2 & 701 & 381 \\
\hline
\end{tabular}

* Aussaat- und Anzuchtort $\mathrm{j}=$ durchschnittliches Jahresmittel

Veg $=$ durchschnittliches Mittel in der Vegetationsperionde (Mai-September)

Die Feldversuche wurden 1967 in Hessen im Forstamt Reinhardshagen, in Niedersachsen im Forstamt Hasbruch, in Bayern in den Forstämtern Berchtesgaden und Sonthofen sowie in Baden-Württemberg im Forstamt Münsingen ausgepflanzt.

Der Versuch soll zur Klärung folgender Fragestellungen beitragen (WEISGERBER et al. 1976b):

1. Erfassung der Merkmalsvariation der Prüfglieder unter den jeweiligen Anbaubedingungen

2. Ermittlung der Herkünfte, die sich hinsichtlich ihres Wuchsverhaltens und ihrer Betriebssicherheit für den zukünftigen Anbau auf den Fichtenstandorten in (West-)Deutschland eignen

3. Beurteilung des Anpassungsvermögens der Prüfglieder an unterschiedliche Standortverhältnisse

4. Erfassung von Herkünften mit ähnlichem Reaktionsverhalten aus künstlichen Anbaugebieten 
5. Zusammenstellung von Herkunftsgruppen mit ähnlichem Wuchs- und Adaptionsverhalten und Ableitung von Herkunftsempfehlungen

6. Ggf. Zulassung von Ausgangsbeständen zur Erzeugung von „Geprüftem Vermehrungsgut"،

Über Ergebnisse dieser Versuchsreihe wurde bereits auf der IUFRO-Tagung zur Herkunftsfrage der Fichte in Biri / Norwegen 1973 (DIETZE und RÁCZ 1973) und auf dem XVI. IUFRO-Weltkongress in Oslo / Norwegen berichtet (WEISGERBER et al. 1976a). Ausführlich wurden die Ergebnisse von Beobachtungen an den Prüfgliedern im Anzuchtstadium bis zum Alter von 18 Jahren in drei Beiträgen der Allgemeinen Forst- und Jagdzeitung (WEISGERBER et al. 1976b, 1977, 1984) beschrieben. Auf der IUFRO-Arbeitsgruppentagung „Fichtenherkünfte und -züchtung“ in Riga / Lettland stellte RAU (1993) die Ergebnisse bis zum Alter 25 vor. Hier wird nun über die weitere Entwicklung der Feldversuche bis 2006 berichtet. Zum besseren Verständnis werden wesentliche, den Verlauf der Untersuchungen kennzeichnende Fakten aus den zuvor genannten Veröffentlichungen in zusammenfassender Form nochmals erläutert.

\subsection{Material und Methoden}

\subsubsection{Versuchsmaterial}

Bei den ursprünglich 530 Prüfgliedern handelt es sich hinsichtlich ihrer Beerntung um sehr unterschiedliche Proben. Unter den Proben sind 22 Einzelbaumabsaaten (Ernteklasse 1), 179 Bestandesabsaaten (Ernteklassen 2, 3, 5) und 329 Beerntungen größerer Gebiete (Ernteklassen 4, 6) (WEISGERBER et al. 1976b). Bei der Auswahl der Prüfglieder versuchte man vorrangig Herkünfte, deren Verwendung in (West-) Deutschland besondere Bedeutung zukommen könnte, zu berücksichtigen.

Von den 530 Prüfgliedern war von 286 ausreichend Pflanzenmaterial verfügbar, um es in den Feldversuchen anzubauen. Das Einsammlungsgebiet der Herkünfte erstreckt sich von Süd-Finnland im Norden bis Bulgarien im Süden und von Zentral-Frankreich im Westen bis nach Russland einige Hundert Kilometer westlich von Moskau. Um die Aussagekraft der Ergebnisse besser werten zu können, wurden die bei der Beerntung ausgeschiedenen Ernteklassen (Saatgutkategorien) berücksichtigt (Tab. 2.2). Zumindest die Versuchsglieder der Ernteklassen 5 und 6 sind im Allgemeinen nicht genau definiert, so dass eine Reproduzierbarkeit einer gleichen Saatgutprobe nicht garantiert werden kann (KRUTZSCH 1974, 1975). Vermutlich wird man dieses auch für die Klasse 4 unterstellen müssen.

Da insbesondere beim Anbau der Fichte außerhalb ihres natürlichen Verbreitungsgebiets nur selten Aufzeichnungen über die Autochthonie vorlagen, wurde dieses bei der Einsammlung des Saatgutes nicht erfasst. 
Tab.2.2 Zusammenstellung der in den Feldversuchen enthaltenen 286 Prüfglieder nach ibrer Ernteklasse

\begin{tabular}{c|lc}
\hline Klasse & Ernteklasse (Saatgutkategorie) & Anzahl Prüfglieder \\
\hline 1 & Einzelbaumnachkommenschaft (frei abgeblüht) & 14 \\
2 & Bestandesabsaat von mind. 10 Bäumen & 19 \\
3 & Bestandesabsaaten von mehreren Bäumen & $45+7$ (fraglich) \\
4 & Saatgut mehrerer Bestände eines Gebietes & 59 \\
5 & Saatgut aus ,anerkannten Beständen“ & 22 \\
6 & Handelssaatgut eines Erntegebietes & 18 \\
- & keine Angabe & 102 \\
\hline
\end{tabular}

Von den 530 Prüfgliedern konnten im Anzuchtstadium 473 beobachtet werden. 286 Prüfglieder sind in den gemeinsamen Freilandversuchen der Institute enthalten (Tab. 2.3, Anhang 1.1). 144 der Prüfglieder sind auch in dem zwei Jahre später zur Aussaat gekommenen IUFRO-Fichtenherkunftsversuch 1964/1968 zur Testung angebaut. Über diese Prüfglieder lassen sich Vergleichswerte errechnen und der Fichtenherkunftsversuch von 1962 mit dem IUFRO-Fichtenherkunftsversuch 1964/1968 verbinden. Die in beiden Versuchsserien gemeinsamen Prüfglieder sind dem Anhang 1 zu entnehmen.

\subsubsection{Versuchsorte}

Im Frühjahr bzw. in den höheren Lagen im Frühsommer 1967 wurden die Feldversuche in den vier Bundesländern Baden-Württemberg, Bayern, Hessen und Niedersachsen mit fünfjährigen (2+3-jährigen, verschulten) Pflanzen angelegt. Der Grundplan der Feldversuche sind quadratische Dreisatzgitter, da man sich hiervon eine höhere Effizienz als von einer randomisierten, vollständigen Blockanlage versprach. In jedem der Bundesländer wurde je eine Fläche als 13 x 13-Dreisatzgitter begründet. Zusätzlich haben Hessen und Niedersachsen ein 9 $x$ 9-Dreisatzgitter ausgepflanzt. Außerdem wurde in Bayern, Hessen und Niedersachsen noch ein $6 \times$ 6-Dreisatzgitter begründet. Hieraus wird ersichtlich, dass es sich streng genommen um drei Versuche mit vier, zwei bzw. drei Parallelflächen handelt. In Hessen und Niedersachsen liegen die drei Versuche benachbart, während in Bayern die beiden Versuche in zwei Forstämtern angelegt wurden (Abb. 2.1). Zur Charakterisierung der Feldversuche sind die geografischen Angaben und ausgewählte Klimadaten in Tabelle 2.4 zusammengestellt. 
Tab. 2.3: Zusammenstellung der in den Feldversuchen enthaltenen 286 Prüfglieder nach Ländern bəw. Großregionen

\begin{tabular}{l|cc}
\hline Region & Land & Anzahl Prüfglieder \\
\hline nordeuropäische Länder (13) & Schweden (S) & 9 \\
& Finnland (SF) & 3 \\
& Dänemark (DK) & 1 \\
osteuropäische Länder (80) & Weißrussland (BY), Russland (SU) & 9 \\
& Polen (PL) & 33 \\
& Tschech. (CS) + Slowak. Rep. (SK) & 32 \\
& Ungarn (H) & 6 \\
Balkanländer (15) & Rumänien (RU) & 9 \\
& Serbien (YU), Kroatien (HR) & 3 \\
Alpenländer (72) & Bulgarien (BG) & 3 \\
& Österreich (A) & 10 \\
& Schweiz (CH) & 1 \\
Deutschland (92) & Italien (I) & 92 (3 Herkünfte doppelt) \\
westeuropäische Länder (14) & Deutschland (D) & 12 \\
& Frankreich (F) & 2 \\
\hline
\end{tabular}

Zwischen den Parzellen, die einheitlich aus 16 (4 x 4) Pflanzen bestehen, wurden keine Trennstreifen ausgehalten. Der Pflanzverband beträgt $2 \mathrm{~m} \times 2 \mathrm{~m}$. Ein abweichender Pflanzverband von 1,5 m x 1,5 m wurde für die Fläche Berchtesgaden gewählt und von 1,6 m x 1,6 m für die Fläche Münsingen. Die Pflanzung erfolgte einheitlich als Winkelpflanzung.

Tab. 2.4: $\quad$ Geografische und ausgewäblte Klimadaten zur Charakterisierung der Feldversuche

\begin{tabular}{|c|c|c|c|c|c|c|c|}
\hline \multirow{2}{*}{ Feldversuch } & \multicolumn{2}{|c|}{ Geogr. Lage } & \multirow{2}{*}{$\begin{array}{c}\text { Höhe } \\
\text { m ̈̈ NN }\end{array}$} & \multicolumn{2}{|c|}{ Temperatur } & \multicolumn{2}{|c|}{ Niederschlag } \\
\hline & Breite N & Länge $\mathrm{O}$ & & $t_{j}{ }^{\circ} \mathrm{C}$ & $\mathrm{t}_{\mathrm{Veg}}{ }^{\circ} \mathrm{C}$ & $\mathrm{mm}_{\mathrm{j}}$ & $\mathrm{mm}_{\mathrm{Veg}}$ \\
\hline Reinhardshagen(HE) & $51^{\circ} 25^{\prime}$ & $09^{\circ} 38^{\prime}$ & 260 & 8,0 & 14,3 & 725 & 352 \\
\hline Hasbruch (NI) & $53^{\circ} 00^{\prime}$ & $08^{\circ} 30^{\prime}$ & 20 & 8,8 & 15,0 & 746 & 380 \\
\hline Sonthofen (BY) & $47^{\circ} 30^{\prime}$ & $10^{\circ} 17^{\prime}$ & 1250 & 5,5 & 12,0 & 2000 & 1000 \\
\hline Berchtesgaden (BY) & $47^{\circ} 38^{\prime}$ & $12^{\circ} 55^{\prime}$ & 1360 & 5,5 & 13,0 & 1800 & 980 \\
\hline Münsingen (BW) & $48^{\circ} 44^{\prime}$ & $09^{\circ} 30^{\prime}$ & 780 & 6,4 & 13,2 & 888 & 463 \\
\hline
\end{tabular}




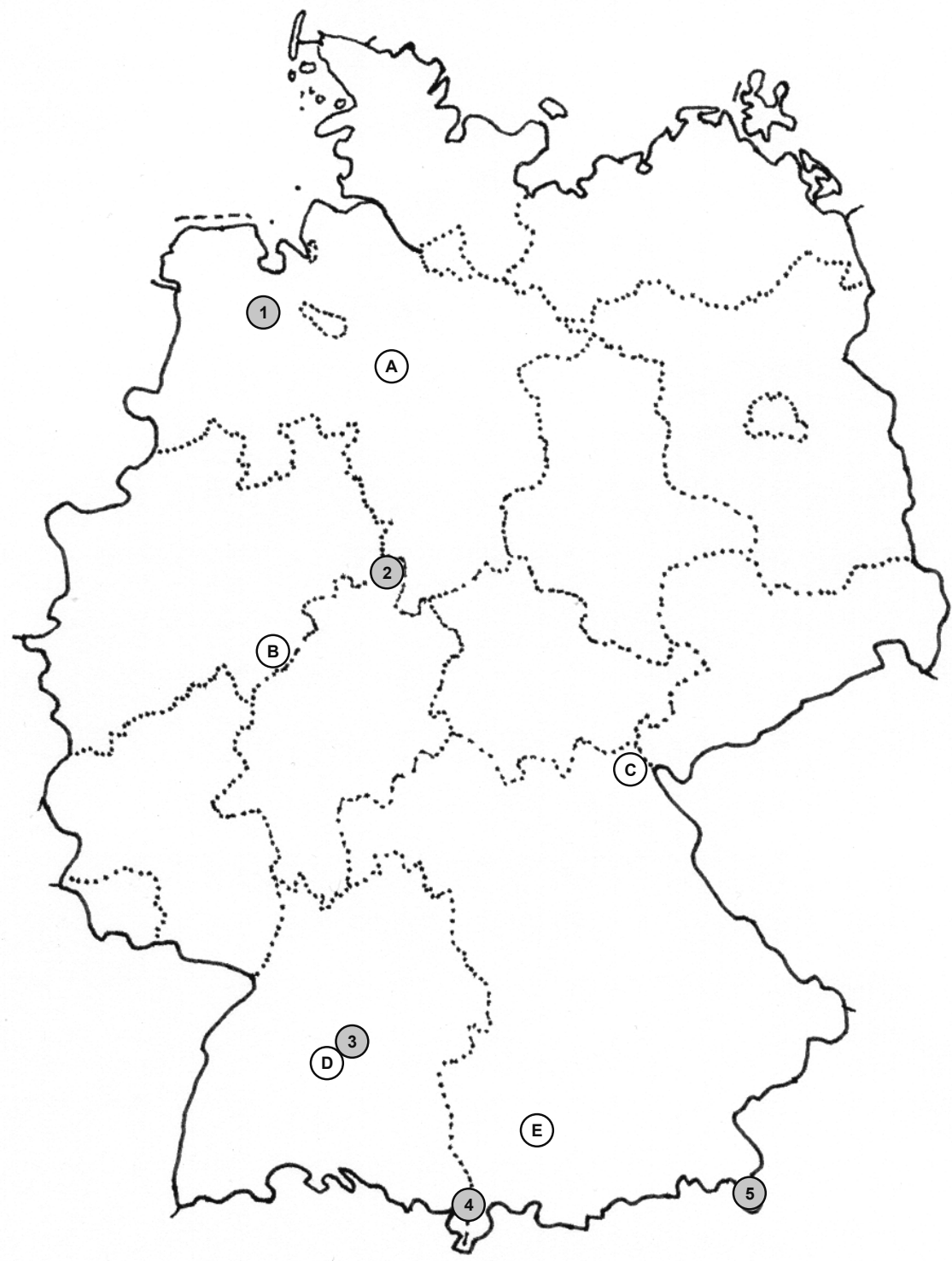

Abb. 2.1: Lage der Versuchsflächen ( $\quad 1=$ Hasbruch, $2=$ Reinhardshagen, $3=$ Münsingen, $4=$ Sonthofen, $5=$ Berchtesgaden) und die Herkunftsorte der 5 gemeinsamen Prïfglieder (O: $A=W$ alsrode, $B=$ Marsberg, $\quad C=$ Selb-Kirchenlamitz, $\quad D=$ Koblstetten, $E=$ Diessen)

Im Jahr 1979 verständigten sich die vier Länderinstitute auf eine einheitliche Nummerierung der Flächen (Tab. 2.5). 
Tab. 2.5: $\quad$ Nummerierung der Versuchsflächen

\begin{tabular}{l|ll|ll}
\hline Grundplan & Bundesland & & \\
& HE & NI & BY & BW \\
\hline 13 x 13-Gitter & Reinhardshagen 34 & Hasbruch 44 & Sonthofen 24 & Münsingen 14 \\
9 9 9-Gitter & Reinhardshagen 35 & Hasbruch 45 & & \\
6 x 6-Gitter & Reinhardshagen 36 & Hasbruch 46 & Berchtesgaden 26 & \\
\hline
\end{tabular}

Im Versuchsrevier Beberbeck des Forstamtes Reinhardshagen (Abt. 481 A, B, D) wurden die drei Teilversuche der Hessischen Forstlichen Versuchsanstalt angelegt (Abb. 2.2). Die nahezu ebene Fläche liegt auf einer spätfrostgefährdeten Plateaulage in $260 \mathrm{~m}$ Seehöhe in der unteren Buchen-Mischwald-Zone. Beim Ausgangsmaterial für die Bodenbildung handelt es sich um eine Lössauflage über rotem Sandstein. Die Bodenart wurde als schluffig-feinsandiger Lehm angesprochen. Der tiefgründige Boden ist frisch und mesotroph. Der Vorbestand in den drei Unterabteilungen war Fichte, gepflanzt 1869, mit $80 \%$ Rotfäuleanteil, Eichen-Altholz bzw. Buchen-Altholz mit einzelnen Eichen.

\section{Abb. 2.2: Versuchsfläche Reinhardshagen / \\ Hessen $(1=13 \times 13$-Gitter; \\ $2=9 \times 9$-Gitter; $3=6 \times 6$-Gitter)}

1

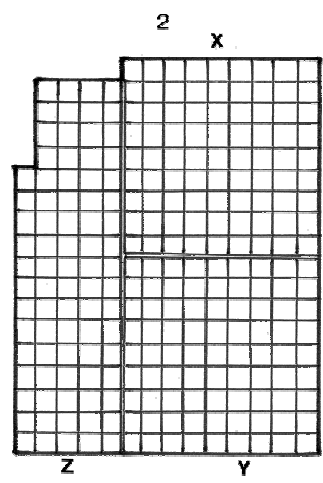

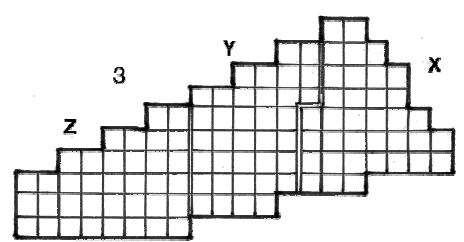
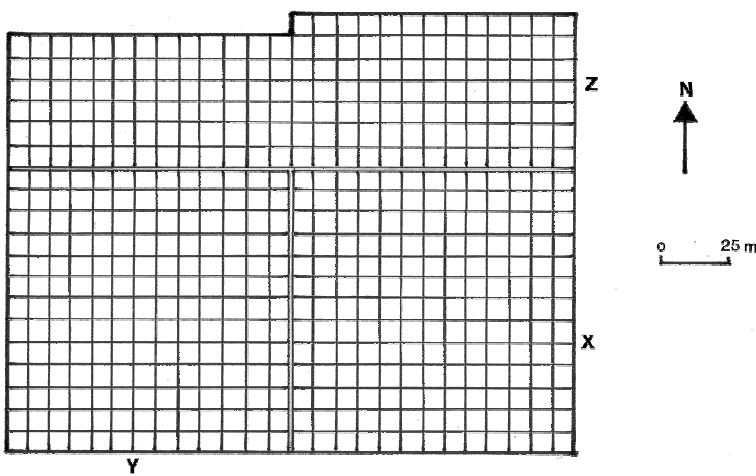

Im nordwestlichsten Wuchsgebiet Deutschlands „Niedersächsischer Küstenraum“ befinden sich drei weitere Teilversuche des Fichtenherkunftsversuchs von $1962 \mathrm{im}$ Forstamt Hasbruch, Rfö. Reiherholz, Abt. 438 (Abb. 2.3). Der niedersächsische Standort ist eben bis schwach nach Nordwesten geneigt. Die glazialen Lehme des Standortes sind wechselfeucht und mesotroph. Den Vorbestand bildete ein Kiefern-Altholz. 


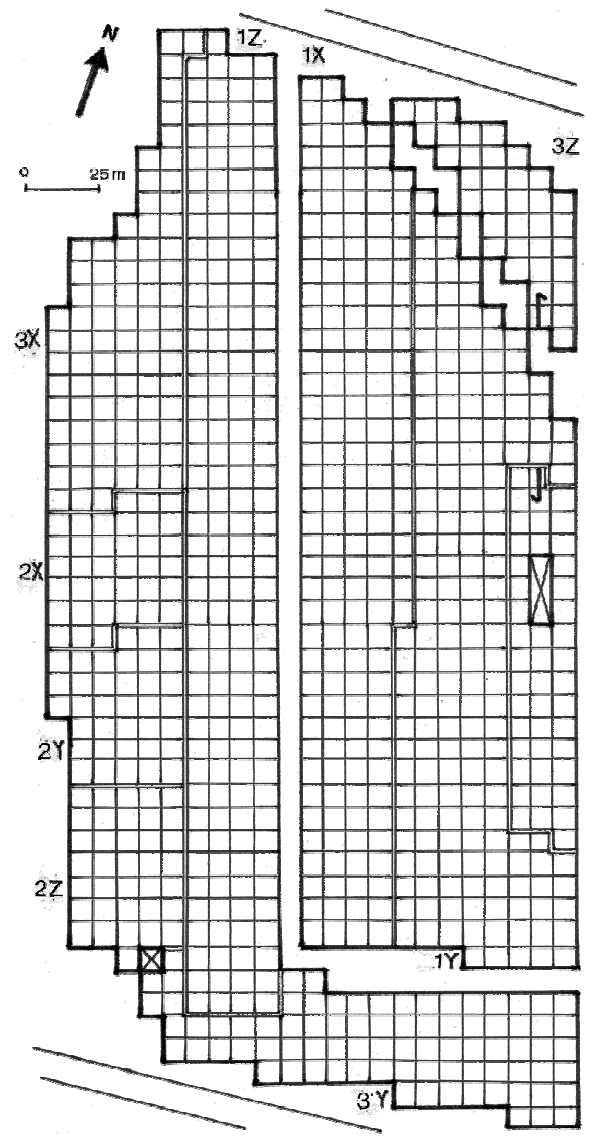

$\begin{array}{ll}\text { Abb. 2.3: } & \text { Versuchsfläche Hasbruch / } \\ & \text { Niedersachsen } \\ & (1=13 \times 13 \text {-Gitter; } \\ & 2=9 \times 9 \text {-Gitter; } \\ & 3=6 \times 6 \text {-Gitter })\end{array}$

In Bayern sollte ein Teilversuch, das $13 \times 13$-Gitter, ursprünglich im Forstamt Marquartstein-West $(1200 \mathrm{~m})$ angelegt werden. Als diese Teilfläche wider Erwarten nicht mehr verfügbar war, bot sich im Forstamt Sonthofen/Allgäu (I $4^{3}$ „Vorsäss") in ähnlicher Höhenlage eine neue Fläche (Abb. 2.4). Diese Fläche ist schwach geneigt und liegt in 1235 bis $1265 \mathrm{~m}$ Seehöhe. Das geologische Ausgangssubstrat bilden Formationen des Schweizer Kalksteins. Durch die Fläche zieht sich ein teilweise tief eingeschnittener Bach mit mäßiger Schüttung. Die Fläche ist umgeben von Fichtenhochlagenbeständen (Abb. 2.5).

Etwa die Hälfte der Fläche wurde vor der Versuchsanlage als Almwiese genutzt. Im Nordosten und Südwesten handelt es sich auf zusammen etwa 1/3 ha um alten Waldboden. Im Nordwesten wird die Fläche als anmoorig bis hochmoorartig beschrieben und weist Pseudo- und Stagnogleye als Bodentypen auf. Auf den anderen Flächenteilen sind Rendzinen anzutreffen. Insgesamt wird die Fläche als frisch mit mesotropher Nährstoffversorgung eingestuft. 
Fichtenherkunftsversuch von 1962

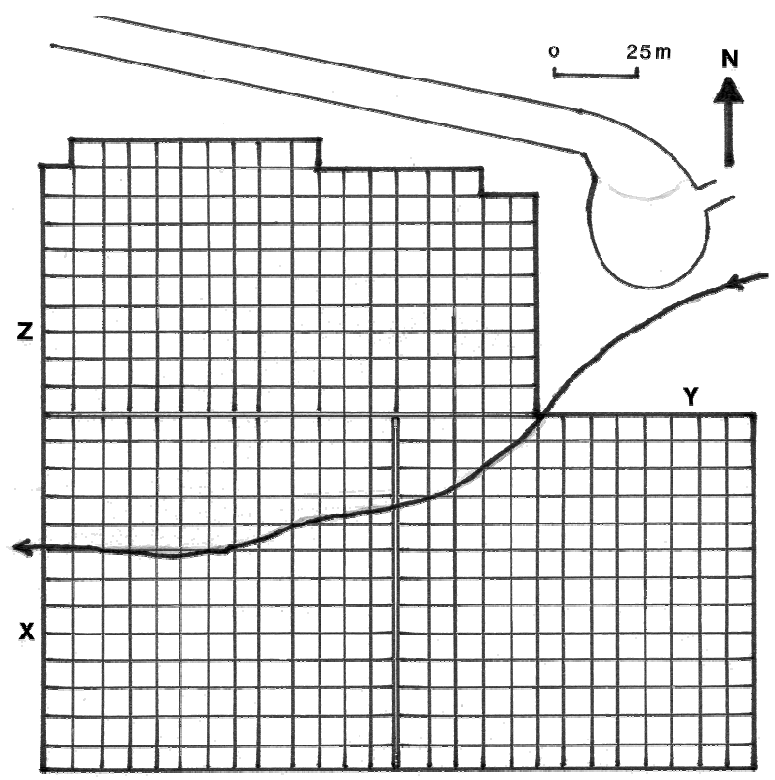

Abb. 2.4: Versuchsfläche

Sonthofen / Bayern

$(13 \times 13$-Gitter)

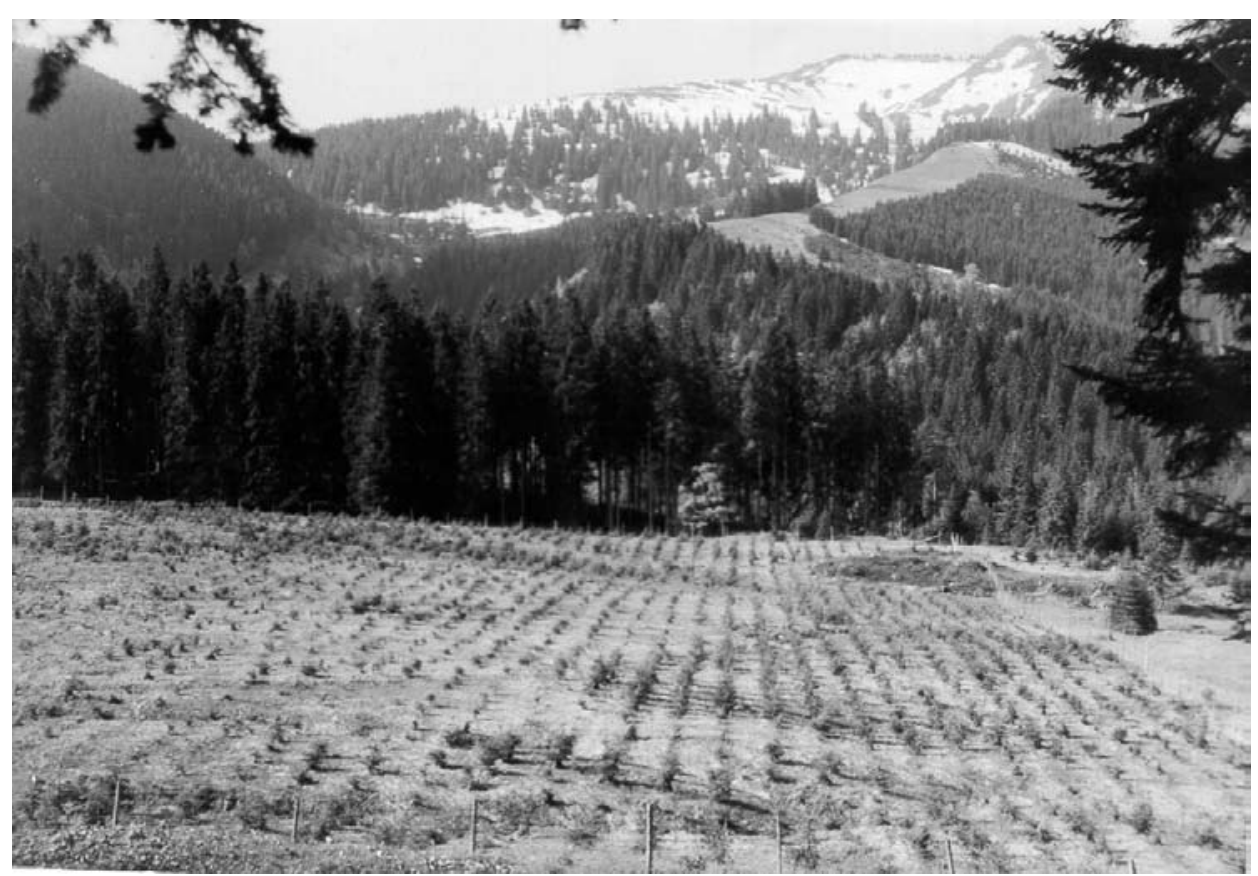

Abb. 2.5: Blick auf die Versuchsfläche Sonthofen (Foto: W. Ruetz 1975) 
Der zweite Teilversuch, das 6 x 6-Gitter, liegt im Forstamt Berchtesgaden (FoDSt. Schönau, VIII f „Hirscheck“) in 1345 bis 1380 m ü. NN (Abb. 2.6). Der DolomitStandort wird von der Wasserversorgung als frisch und der Nährstoffversorgung als mesotroph beurteilt. Der flachgründige Boden entspricht dem Typ einer Rendzina. Die Fläche liegt am Hang und fällt im Osten steil ab. Zu den standörtlichen Besonderheiten zählt, dass auf der Fläche regelmäßig mit Schneelagen von bis zu $2 \mathrm{~m}$ Höhe und Schneedruck zu rechnen ist. Vor der Nutzung als Versuchsfläche wurde der im Vorbestand stockende lichte Fichtenwald stark beweidet. Durch eine Wegebaumaßnahme wurden im Nordwesten mindestens zwei Parzellen beeinträchtigt.

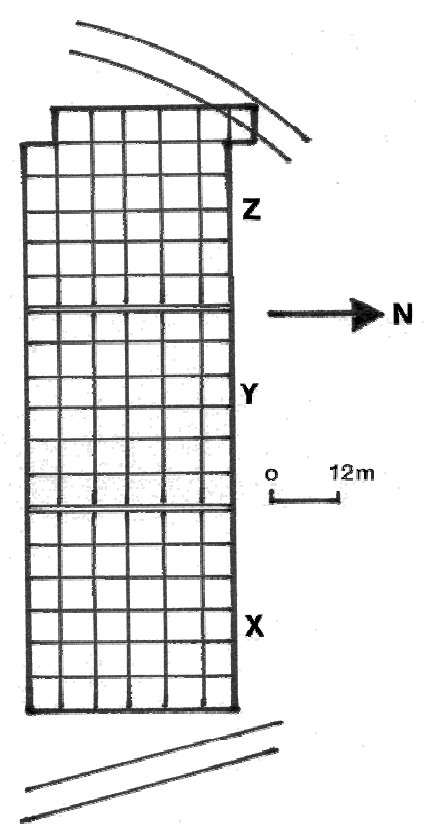

Abb. 2.6: Versuchsfläche Berchtesgaden / Bayern $(6 \times 6$-Gitter)

Die Versuchsfläche im Forstamt Münsingen, FoDSt. Wertbach („Beutenley“), liegt in 770 bis $790 \mathrm{~m}$ ü. NN in der Schwäbischen Alb an einem leicht nach Südosten geneigten Hang (Abb. 2.7). Das geologische Ausgangssubstrat sind Plattenkalke des Weißjura-Kalkstein. Der sehr flachgründige Standort wird als mäßig trocken und eutroph beschrieben. Vor der Versuchsanlage wurde die Fläche überwiegend als Schafweide genutzt. Im Nordosten wurde auf etwa $1 / 4$ des ersten Blocks Ackerbau betrieben. Auf nahezu der gesamten Fläche wurde steinig-mergeliger Bauschutt und Bauaushub abgelagert und eingeebnet und mit einer ungleichmäßig mächtigen Humuslage abgedeckt. 


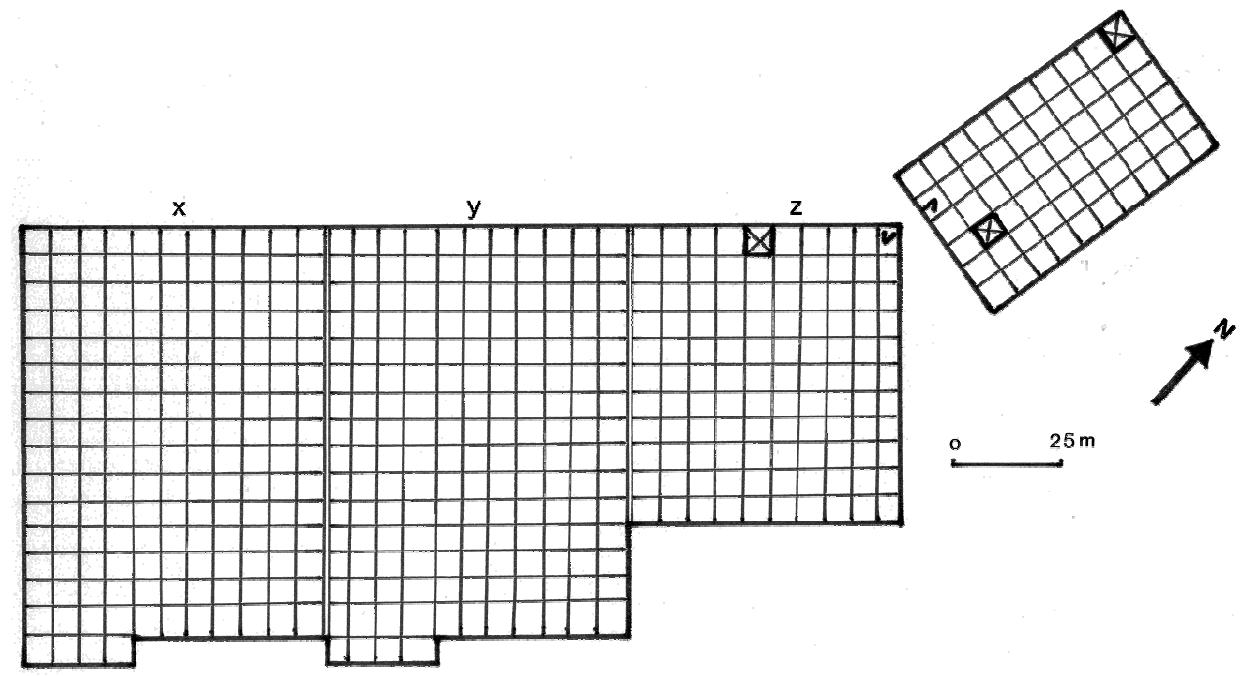

Abb. 2.7: Versuchsfläche Münsingen / Baden-Württemberg (13 $\times 13$-Gitter)

\subsubsection{Verteilung der Prüfglieder auf die Versuchsflächen}

Unter den 286 Prüfgliedern des Fichtenherkunftsversuchs von 1962 gibt es fünf Prüfglieder, die auf allen Flächen der drei Teilversuche (Gitter) vertreten sind. Es handelt sich um die Prüfglieder Marsberg / NW (Nr. 3417), Kohlstetten / BW (3423), Diessen / BY (3430), Walsrode / NI (3432) und Selb-Kirchenlamitz / BY (später: Weißenstadt, Schlossberg, „Taubenschüssel“) (3433). Die Herkunftsorte sind in Abbildung 2.1 eingezeichnet.

Alle vier Flächen des $13 \times 13$-Gitters sind mit identischen Prüfgliedern ausgestattet. Beim $9 \times$ 9-Gitter sind je neun Prüfglieder auf nur einer Fläche in Hessen bzw. in Niedersachsen angepflanzt. Im 6 x 6-Gitter unterscheiden sich die beiden Teilflächen in Bayern und Niedersachsen von der in Hessen in zwei Prüfgliedern. Tabelle 2.6 gibt einen Überblick über die Verteilung der Prüfglieder. Im oberen Teil ist die Anzahl der Prüfglieder aufgelistet, die nur im Fichtenherkunftsversuch von 1962 geprüft werden, während im unteren Teil der Tabelle 2.6 die Anzahl der mit dem IUFRO-Fichtenherkunftsversuchs 1964/1968 gemeinsamen Prüfglieder getrennt nach Kohorten folgt. Im Anhang 1 sind die einzelnen Herkünfte mit ihrer Zugehörigkeit zu den einzelnen Versuchen aufgelistet. 
Tab. 2.6: Anzabl der Prüfglieder der Aussaat 1962 (oben) und Anzabl der Prüfglieder, die gleichzeitig den Kohorten des IUFRO-Versuchs 1964/1968 entsprechen (unten)

\begin{tabular}{|c|c|c|c|}
\hline \multirow{2}{*}{ Versuche } & \multicolumn{3}{|c|}{ Anzahl der Prüfglieder in den Versuchen } \\
\hline & $13 \times 13$-Gitter & $9 \times 9-$-Gitter & $6 \times 6-$-Gitter \\
\hline \multicolumn{4}{|c|}{ Anzahl der Prüfglieder, nur im 1962er Versuch } \\
\hline & $(96)$ & $(18+18)$ & $(17+4)$ \\
\hline gemeinsame PG & 5 & 5 & 5 \\
\hline in einem Gitter & 90 & 13 & 12 \\
\hline auf einzelnen Flächen & $1 *$ & $18^{* *}$ & $4^{* * *}$ \\
\hline
\end{tabular}

Anzahl gemeinsamer Prüfglieder (1962 und IUFRO 1964/1968)

(73)

Kohorte 1

Kohorte 2

Kohorte 3

Kohorte 4

Kohorte 5

Kohorte 6

Kohorte 7

Kohorte 8

Kohorte 9

Kohorte 10

Kohorte 11

Prüfglieder pro Gitter
5

8

8

6

8

7

7

5

6

5

8

169

\section{6}

10

\section{5}

6

4

\section{5}

2

3

3

6

4

$72+18$

$72+18$

* nicht auf der Fläche in NI angebaut

** je 9 Prüfglieder auf der Fläche in HE und 9 andere in NI

*** je 2 Prüfglieder auf den Flächen in BY und NI und 2 andere in HE

\subsubsection{Behandlung und Beschreibung des Gesamteindrucks der Versuchsflächen}

Aus den Akten der vier die Versuche betreuenden Institute geht hervor, dass die Verpfählung und Kennzeichnung der Parzellen regelmäßig kontrolliert und erneuert wurde. Im Laufe der Jahre erzielten die vier Institute hinsichtlich der notwendigen Stammzahlreduktionen dahingehend Konsens, dass nach der ersten Durchforstung zehn bis zwölf Bäume pro Parzelle verbleiben sollten. Auf der Tagung der Arbeitsgemeinschaft der Länderinstitutionen für Forstpflanzenzüchtung im Herbst 1983 verständigte man sich darauf, dass die Art der Durchforstung vom jeweiligen Institut festgelegt wird. Nach der zweiten Durchforstung sollten noch vier bis fünf Fichten pro Parzelle verbleiben. 
Die Versuchsfläche im hessischen Versuchsrevier Reinhardshagen ist seit der Anlage im Jahre 1967 gegattert. Die Gatter ließen sich nicht immer wildfrei halten, so dass im September 1974 erwähnenswerte Schäl- und Fegeschäden auftraten. Bei der Durchforstung im Herbst 1996 wurden die Zwischenzäune entfernt. Das Gatter um den Versuchskomplex blieb wegen der akuten Gefahr erneuter Schälschäden erhalten. Das Forstamt wurde gebeten, den Zaun regelmäßig auf Dichtheit zu kontrollieren, damit die bis dahin insgesamt geringen Wildschäden auf den Versuchsflächen nicht zunehmen.

Im September 1974 wurde das Forstamt gebeten, die Anflugfichten und die zwischen den Reihen verbliebenen Reservepflanzen zu beseitigen. Auf einem Teilversuch (6 x 6-Gitter) wurde die Maßnahme nicht durchgeführt und musste bei der routinemäßigen Aufnahme der Fläche im September 1979 nachgeholt werden. Damit man sich auf der Fläche orientieren konnte, wurden die Bäume dieses Teilversuchs auf zwei Meter aufgeastet, was später auch auf den anderen Teilversuchen geschah. Bei der Erhebung im Herbst 1979 trat kein Befall durch Käfer oder Triebwickler auf. An wenigen Bäumen waren Anzeichen von Spätfrostschäden zu beobachten. Auch Gallen der Fichtengallläuse, Schälschaden und Schneebruch traten nur vereinzelt auf. Zapfenbehang wurde auf den drei Teilversuchen nicht beobachtet. Insgesamt scheint der Teilversuch im 9 x 9-Gitter standörtlich bevorzugt zu sein. Auch bei der Erfassung im Sommer 1987 wurden keine Schäden auf den Teilflächen notiert.

Im August 1983 erfolgte die erste Stammzahlreduktion schematisch und selektiv. Auf der Grundlage eines von der Hessischen Forstlichen Versuchsanstalt unterbreiteten Vorschlags wurden eine Reihe (teilschematisch) und zusätzlich zwei Bäume (selektiv) in jeder Parzelle entnommen. Angestrebt war, dass nach der ersten Durchforstung etwa zehn Bäume pro Parzelle verbleiben. Bei einer zweiten Durchforstung wurde im Herbst 1996 die Stammzahl pro Parzelle auf vier bis fünf gesenkt.

Bei der Anlage der Fläche Hasbruch im Frühjahr 1967 herrschte längere Zeit Trockenheit. Die im Einschlag liegenden Pflanzen wurden mit mehreren Tausend Litern Wasser versorgt.

Versehentlich wurde eine Teilfläche des Versuchs mit dem Kulturherbizid Top KH (Schering AG) gespritzt. Da keine Schäden bei den Fichten aufgetreten waren, wurde in den folgenden Jahren gegen die aufkommenden Birken, Ebereschen, Brombeeren, Heidelbeeren und das Heidekraut die gesamte Versuchsfläche mit dem Kulturherbizid Top KH gespritzt. Bei den Erhebungen im Winter 1969/70 wurden hohe Ausfälle durch anstehendes Wasser insbesondere im Nordosten und Süden der Fläche beobachtet. Aus den Akten geht nicht eindeutig hervor, ob auf der Fläche nachgebessert wurde. Einer Notiz vom März 1974 ist zu entnehmen, dass eine Nachbesserung nicht mehr möglich war. Zu diesem Zeitpunkt wurden die Ausfälle mit $20 \%$ beziffert. 
In den folgenden Jahren wurde wiederholt der Anflug von Faulbaum, Eberesche, Birke und Kiefer entfernt. Im Frühjahr 1973 wurde dem zuständigen Forstamt mitgeteilt, dass bei den kleineren Fichten ein Einzelschutz gegen Verbiss vorzunehmen ist, da die Fläche nicht gezäunt war. Bei den Messungen im Herbst 1974 fielen Wuchsdifferenzierungen auf, die auf die unterschiedliche Vernässung der Fläche zurückgeführt wurden. Auffällig waren auch die Frostschäden und der Wildverbiss, während der Befall durch die Fichten-Blattwespe und den Fichtentriebwickler als gering eingestuft wurde.

Im Sommer 1986 wurden die Fichten auf zwei Meter Höhe geastet. Im Dezember desselben Jahres wurde beobachtet, dass die Fichten zum Teil sehr hohe Nadelverluste aufwiesen (Abb. 2.8). Zahlreiche Bäume waren bereits eingegangen und weitere Abgänge wurden befürchtet. Im September 1987 wurde die Versuchsfläche geläutert, so dass pro Parzelle zehn Fichten stehen blieben.

Im Winter 2000/01 wurde die Vitalität der Fichten als allgemein schlecht beurteilt. Viele Fichten zeigten hohe Nadelverluste. An zwei Stellen waren die Fichten auf jeweils etwa 0,5 ha nach Käferbefall und Windwurf abgestorben. Herkunftsbedingte Unterschiede waren nicht offensichtlich.

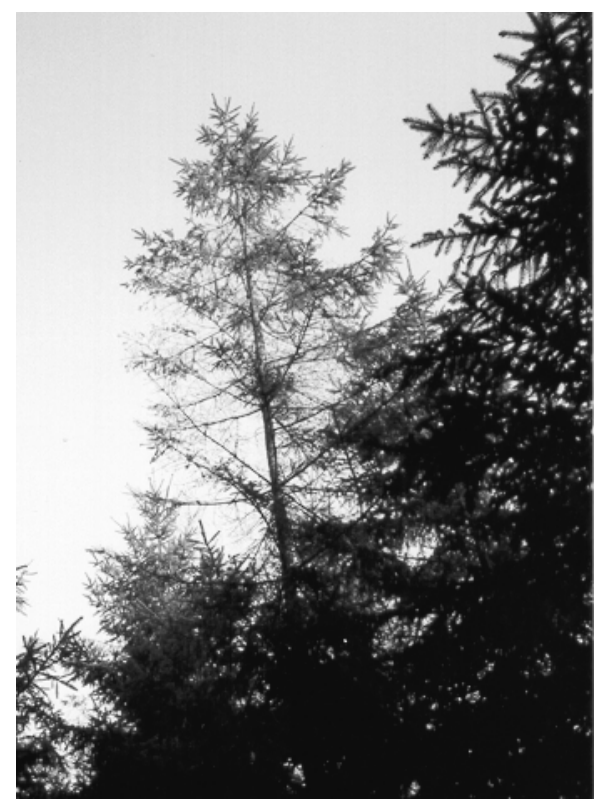

Abb. 2.8: Fichte mit schütterer Benadelung (Foto: M. Liesebach 1991)

In der Akte zur Versuchsfläche Sonthofen befindet sich eine detaillierte Beschreibung zur Anlage. Ihr ist zu entnehmen, dass die Fichten im Großpflanzengarten Laufen-Lebenau angezogen, im März 1967 ausgehoben und bis zum Juni im Kühlhaus eingelagert wurden. Einige Pflanzen wurden von den anderen Versuchsanstal- 
ten nach Laufen geschickt und ebenfalls bis zur Pflanzung im Kühlhaus eingelagert. Das gut gestufte und überwiegend frische Pflanzgut wurde per Lkw am 7. Juni 1967 zur Versuchsfläche transportiert, gegossen und im Erdreich eingeschlagen. Die Bündel zu je 16 Pflanzen wurden kurz vor dem Auspflanzen zu den betreffenden Parzellen ausgetragen. Die Pflanzung selbst war durch äußerst schlechte Witterung behindert und musste bereits am ersten Tag wegen unablässiger Regen- und Schneefälle für vier Tage unterbrochen werden. Der Abschluss der Pflanzarbeiten musste wegen erneuter starker Schneefälle und $10 \mathrm{~cm}$ hoher Schneedecke um einen weiteren Tag verschoben werden. Nach der Pflanzung wurde die Fläche mit einem zwei Meter hohen Knotengeflecht wilddicht eingezäunt.

Zur Nachbesserung wurden im Frühjahr 1968 Pflanzen aus Hessen und Niedersachsen nach Laufen geschickt und im Kühlhaus eingelagert. Ein Teil der Pflanzen hatte eingetrocknete Wurzeln und gelbe Nadeln. Das gesamte Pflanzenmaterial wurde vor der Einlagerung in eine Alginatlösung getaucht. Auf der Versuchsfläche waren einzelne Herkünfte komplett ausgefallen, was auf eine Kühlhausschädigung zurückgeführt wurde. Die Pflanzen dieser Prüfglieder wiesen durchwegs eine gelbe schüttere Benadelung auf. Häufig war auch der Beginn einer Wipfeldürre zu beobachten. In diesem Jahr wurde nur mit den zusätzlichen Reservepflanzen aus Hessen und Niedersachsen nachgebessert. Bei der Nachbesserung regnete es, und der Boden war sehr nass. Der Zaun war in gutem Zustand.

Im Frühjahr 1969 wurde mit Dowpon-Granulat (25 kg/ha) das Gras zurückgedrängt und die Fichten mit Nitrophoska-Blau (25-30 g/Pflanze) gedüngt. Im Oktober 1969 wurde die Nachbesserung mit den eigenen Reservepflanzen von der Versuchsfläche fortgesetzt. Sie wurden als Ballenpflanzenpflanzen mit der Wiedehopfhaue ausgegraben und im Loch-, Lochhügel- oder Rabattenpflanzverfahren eingesetzt. Die eigenen und die zusätzlichen Reservepflanzen reichten nicht aus, um alle Fehlstellen auszubessern. Die Qualität der Nachbesserungspflanzen war gut. Im Zuge der Nachbesserung wurden Zwieselwüchse ausgeschnitten. Die Fichten auf dem hochmoorartigen Standort im Nordwesten der Fläche waren gelblich und zeigten einen geringen Wuchs. Insgesamt wurde der Zustand der Versuchspflanzen besser als in Berchtesgaden beurteilt.

Im folgenden Jahr wurde die Düngung mit $30 \mathrm{~g} /$ Pflanze wiederholt und der die Versuchspflanzen bedrängende Begleitwuchs mechanisch entfernt. Außerdem legte man im hochmoorartigen Teil Entwässerungsgräben an.

Wiederholt wurde der Fichtenanflug entfernt und regelmäßig der im Winter durch Schnee beschädigte Zaun repariert. Dennoch ließ es sich nicht vermeiden, dass ein einwechselnder Bock einige Fichten fegte.

Weitere Ausfälle wurden 1972 mit Randpflanzen nachgebessert, durch Schnee niedergedrückte Fichten hochgebunden, die Versuchspflanzen freigeschnitten und Anflug entfernt. Die 1970 durchgeführte Entwässerungsmaßnahme hatte sich 
positiv auf die Versuchspflanzen ausgewirkt, die jetzt grün waren und mit Höhenwuchs reagiert hatten.

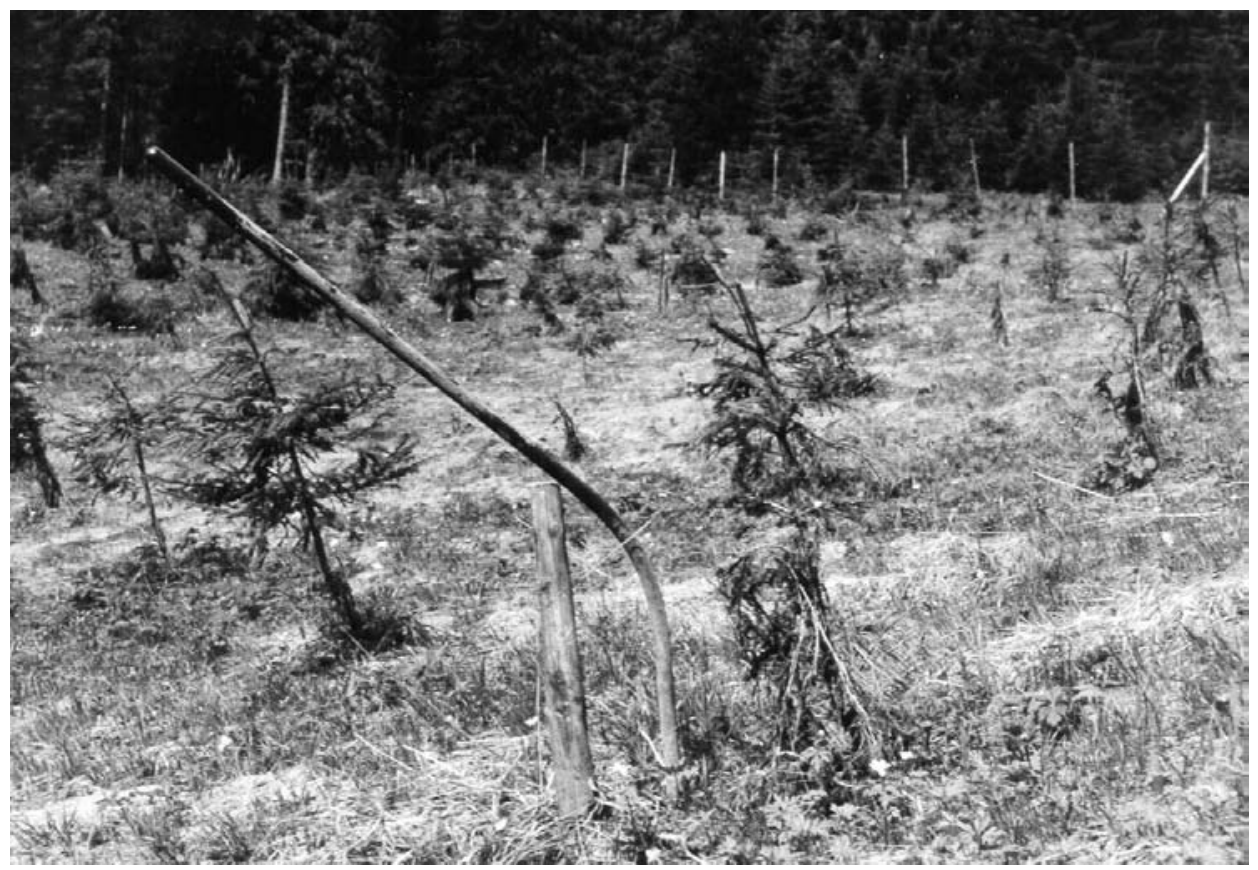

Abb. 2.9:

Durch die Kraft des Schneeschubs wurden sogar Markierungspflöcke aus Eisenrohr verbogen (Foto: W. Ruetz. 1975)

Im Sommer 1975 wurde der Zustand der Versuchspflanzen nach einem langen Winter mit Schnee von September bis Mai als insgesamt schlecht beschrieben. Zahlreiche Bäume litten unter Schneeschimmelbefall. Durch den Wechsel von Frost- und Tauperioden und damit verbundenen Schneeschub waren viele Fichten umgebogen (Abb. 2.9). Im Winter konnte Rotwild durch die hohe Schneelage ( $2 \mathrm{~m})$ und den durch Schneeschub beschädigten Zaun auf die Fläche gelangen. Abgesehen von einigen gefegten Bäumen richtete es keinen Wildschaden an. Die Fläche hatte immer noch einen sehr starken Kräuter- und Grasbewuchs. Trotz der Anlage einiger Gräben waren Teile der Versuchsfläche weiterhin sehr feucht und moorig.

Die Fichten auf der Fläche Berchtesgaden werden im Herbst 1974 als deformiert durch den Schnee der vorangegangenen Winter beschrieben. Obwohl die Fläche gezäunt ist, weisen die Pflanzen starken Verbiss durch Schafe auf, da der Weideberechtigte der angrenzenden Matten den Zaun geöffnet hatte. Zwölf Jahre später (1984) weisen nahezu alle Bäume Schäden durch Schneedruck und -bruch auf. Einige Bäume scheinen mehrere Meter hangabwärts zu wachsen, bis es ihnen wieder gelingt, einen senkrechten Trieb aufzusetzen. Viele Bäume sind so sehr 
deformiert, dass eine sinnvolle und genaue Höhenmessung schwierig war. Gemessen wurde daher die Höhe und der BHD des höchsten Triebes, obwohl die Fichte zum Teil schon $3 \mathrm{~m}$ am Boden entlang wuchs und dann erst den Terminaltrieb nach oben schob. Zur Bewertung des Schneeschadens wurde die Boniturskala um die Stufe „stark“ ergänzt ( 1 = gering, 2 = mittel, 3 = stark). Weitere Schäden traten nicht auf. Trotz des extremen Schneeschadens waren die Bäume in einem guten vitalen Zustand.

Bei der routinemäßigen Erfassung der Merkmale wurde auf der Fläche Münsingen zusätzlich Triebsterben, verursacht durch den Pilz Septoria parasitica, festgestellt. Im November 1988 traten durch Nassschneefälle starke Schneebruchschäden in der gesamten Fläche auf. Im Herbst 1993 wurde die Fläche durchforstet. Die Durchforstung erfolgte jedoch nicht wie von der Hessischen Forstlichen Versuchsanstalt vorgeschlagen, sondern ausschließlich nach forstüblichen Gesichtspunkten. Das heißt, dass die Parzellen unter anderem durch die Feinerschließung sehr unterschiedlich behandelt wurden. Die FVA hielt daher weitere Erhebungen für nicht mehr zweckmäßig und schlug vor, die Versuchsfläche aufzugeben.

\subsubsection{Aufnabmen von Merkmalen}

In der Anzuchtphase wurden bereits erste Merkmale in den Jahren 1965 und 1966 erfasst. Die Erhebungen wurden in den Verschulbeeten der vier Institute an 50 gekennzeichneten Pflanzen je Herkunft durchgeführt. Die Ergebnisse wurden von WEISGERBER et al. (1976b) veröffentlicht. Beobachtet wurden seinerzeit die Merkmale:

- Frühjahrsaustrieb $(1965,1966): 0=$ Knospe geschlossen, $1=$ Seitentriebe entfaltet, 2 = Terminaltrieb entfaltet. Die Aufnahme begann mit dem ersten Einsetzen der Stufe 1, also Seitentrieb entfaltet. Sie wurde so lange durchgeführt, bis die letzte gekennzeichnete Pflanze Stufe 2 erreicht hatte. Die Bonituren erfolgten jeweils montags und donnerstags.

- Johannistrieb (1966)

- Pflanzenhöhe (Herbst 1966)

In den Feldversuchen erfolgten die Messungen und Erhebungen unter Federführung der Hessischen Forstlichen Versuchsanstalt einheitlich nach einem vorgegebenen Schema. In der Regel wurden diese Parameter im selben Alter aufgenommen. Die von der Versuchsanstalt herausgegebene Versuchsanleitung sah die Erhebung folgender Parameter vor, wobei die Verschlüsselung zwischen den Jahren wechselte (Tab. 2.7). Bei Messwerten wurden im Feld die Dezimalen eins bis vier ab- und fünf bis neun aufgerundet. 
Tab. 2.7

Zu erfassende Parameter und Gegenüberstellung der Aufnabmeanleitungen vom Herbst 1974, 1986/87 und 2000/01

\begin{tabular}{l|l|l|l|l}
\hline I. Ordnungsdaten & & & & \\
\hline Versuchsort & Versuch & Provenienz & Wiederholung & Block \\
\hline Parzelle & Aufnahmezeitpunkt & Land & Pflanzennummer & - \\
\hline
\end{tabular}

\begin{tabular}{|c|c|c|c|}
\hline $\begin{array}{l}\text { II. Messdaten, } \\
\text { Bonituren }\end{array}$ & Herbst 1974 & $1986 / 87$ & $2000 / 01$ \\
\hline Ausfälle / Vitalität & - & - & $\begin{array}{l}1=\text { Baum voll } \\
\text { lebensfähig } \\
2=\text { Überleben fraglich } \\
3=\text { tot, fehlt } \\
4=\text { durchforstet } \\
5=\text { nicht bepflanzt }\end{array}$ \\
\hline Höhe in dm & alle & ggf. nur Stichprobe/Parzelle & $\begin{array}{l}3 \text { herrschende } \\
\text { Fichten/Parzelle }\end{array}$ \\
\hline BHD in $\mathrm{mm}$ & - & - & kreuzweise gekluppt \\
\hline $\begin{array}{l}\text { Schaftform } \\
\text { (Form A) }\end{array}$ & $\begin{array}{l}1 \text { = gerade } \\
2=\text { schwach gebogen } \\
3=\text { stark gebogen } \\
4=\text { verbuscht, kriechend, } \\
\text { niedergebogen oder dgl. }\end{array}$ & $\begin{array}{l}1=\text { gerade } \\
2=\text { schwach gebogen } \\
3=\text { stark gebogen, verbuscht, } \\
\text { kriechend, niedergebogen oder } \\
\text { dgl. }\end{array}$ & - \\
\hline $\begin{array}{l}\text { Zwiesel } \\
\text { (Form B) }\end{array}$ & $\begin{array}{l}1=\mathrm{ja} \\
2=\text { nein }\end{array}$ & $\begin{array}{l}1=\text { keine } \\
2=\text { Tiefzwiesel (in der unteren } \\
\text { Stammhälfte) } \\
3=\text { Hochwiesel (in der oberen } \\
\text { Stammhälfte) }\end{array}$ & - \\
\hline Aststellung & $\begin{array}{l}1=\text { steil } \\
2=\text { aufgebogen } \\
3=\text { waagerecht } \\
4=\text { abgesenkt }\end{array}$ & - & - \\
\hline Astlänge in $\mathrm{dm}$ & längster Ast eines Quirls & - & - \\
\hline Astigkeit & - & - & $\begin{array}{l}1=\text { auffallend fein } \\
2=\text { auffallend stark }\end{array}$ \\
\hline Fruktifikation & - & $\begin{array}{l}1=\text { keine } \\
2=\text { gering bis mittel } \\
3=\text { stark }\end{array}$ & - \\
\hline
\end{tabular}

(Fortsetzung) 
(Fortsetzung Tabelle 2.7)

\begin{tabular}{|c|c|c|c|}
\hline Schäden & 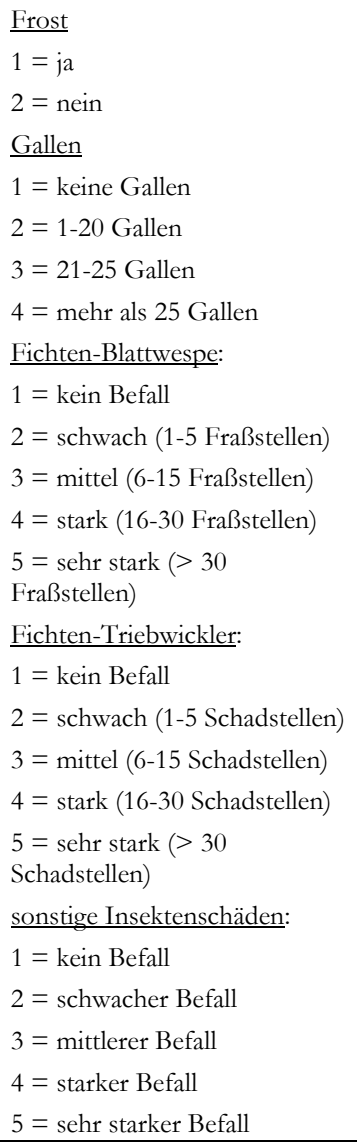 & $\begin{array}{l}\underline{\text { Schadensart: (bis 3/Baum) }} \\
1=\text { Schneebruch/druck } \\
2=\text { Windwurf } \\
3=\text { sonst. mechan. Schäden } \\
4=\text { Käferschaden } \\
5=\text { Nadelverlust } \\
6=\text { Nadelverfärbung } \\
\text { Grad bei Schadensart 1-4: } \\
1=\text { gering } \\
2=\text { mäßig } \\
3=\text { stark } \\
\text { Grad bei } \\
\text { Schadensart } 5 \text { oder 6: } \\
1=\text { keine } \\
2=\text { bis } 10 \% \text { der grünen } \\
\text { Krone } \\
3=11-25 \% \quad \text {-“- } \\
4=26-60 \% \quad \text {-“- } \\
5=>60 \% \quad \text {-“- }\end{array}$ & $\begin{array}{l}\text { Art } \\
1=(\text { keine Vorgaben }) \\
2= \\
3= \\
\text { Grad } \\
1=\text { leicht } \\
2=\text { mittel } \\
3=\text { stark }\end{array}$ \\
\hline
\end{tabular}

Auf der Fläche Reinhardshagen wurden in den Jahren 1969 (8-j.), 1974 (13-j.), 1979 (18-j.), 1987 (26-j.), 1993 (32-j.) und 2001 (39-j.) Messungen und Erhebungen durchgeführt (Tab. 2.8). Im Dezember 1969 wurde zusätzlich die Länge des letzten Jahrestriebes $(\mathrm{cm})$ gemessen. Zehn Jahre später war die Erfassung der Astlängen und des Auftretens von Johannistriebquirlen nicht mehr möglich, da sich der Bestand schon weit geschlossen hatte. Ab 1987 wurden die Höhen nur noch von vier bis fünf Bäumen je Parzelle gemessen. Für die Messung 1987 enthält die Versuchsakte den Hinweis, dass die Baumhöhen nur „relativ grob“ erhoben wurden. Das Merkmal Nadelverfärbung konnte 1987 nicht angesprochen werden, da der Versuch als letzter der Serie erst im Juni aufgenommen wurde.

Die Erhebungen auf der Fläche Hasbruch erfolgten in den Jahren 1969 (8-j.), 1974 (13-j.), 1979 (18-j.), 1987 (26-j.) und 2000 (39-j.) (Tab. 2.8). Im Winter 2000/01 wurden die Baumhöhen von drei Fichten je Parzelle erhoben. Im Alter 
von 18 Jahren (1979) sind auf der Fläche Hasbruch die Fruktifikation und die Johannistriebquirle zusätzlich beurteilt worden.

Die beiden Flächen in Bayern, Sonthofen und Berchtesgaden, wurden zusammen aufgenommen. Im Herbst 1974 konnten wegen bereits einsetzender Schneefälle keine Parameter mehr aufgenommen werden, dies wurde auf das folgende Frühjahr verschoben. Aufgrund der Höhenlage und des damit verbundenen geringeren Ertragsniveaus wurden auf beiden Flächen die Baumhöhen von allen Bäumen gemessen.

Im Herbst 1974 (Alter 13-j.) und 1979 (18-j.) wurden in Münsingen die üblichen Parameter Ausfälle, Wachstum, Form, Schäden und Aststellung (nur 1974) aufgenommen. Astlängen wurden nicht gemessen. Johannistriebe wurden in den letzten Jahren keine beobachtet, daher entfiel die Erhebung dieses Merkmals. Bei der Erhebung 1987/88 (26-j.) wurde die Nadelfärbung nicht aufgenommen, da diese auf Standorteinflüsse zurückgeführt wird.

Tab. 2.8: Zusammenstellung der auf den Flächen gemessenen bzw. erbobenen Merkmale nach Pflanzenalter, die in die vorliegende Auswertung eingegangen sind

\begin{tabular}{l|l|l|l|l}
\hline Merkmal & Reinhardshagen & Hasbruch & $\begin{array}{l}\text { Sonthofen, } \\
\text { Berchtesgaden }\end{array}$ & Münsingen \\
\hline Pflanzenanzahl* & 32,39 & 32,39 & 32 & $13,18,26$ \\
Höhe & $13,18,26,39$ & $13,18,26,39$ & $13,18,26$ & \\
BHD & 32,39 & 32,39 & 32 & \\
Schaftform & 32 & 32 & 32 & \\
Zwiesel & 32 & & 26 & \\
Astigkeit & 32,39 & & & \\
Aststellung & 13 & 13 & 13 & \\
Schäden & 32,39 & 32 & 32 & \\
Spätfrost & 13,18 & 13,18 & 13,18 & \\
Schneebruch/druck & 32,39 & 32 & 26 & \\
Nadelverlust & & 32 & & \\
Nadelverfärbung & & 32 & & \\
\hline
\end{tabular}

* Vitalitätsbeurteilung, Ausfallgrund

\subsubsection{Methoden}

Die Auswertung erfolgt in mehreren Stufen. Zunächst werden die Flächen jeweils getrennt ausgewertet. Bei der deskriptiven Analyse werden die Flächen eines Bundeslandes gemeinsam untersucht, da sie, mit Ausnahme von Bayern, an einem Standort angelegt sind. Die analytische Statistik erfolgt für die einzelnen Versuchsflächen getrennt. Es folgen versuchsflächenübergreifend Auswertungen auf Ebene der einzelnen Merkmale. 
Soweit möglich, werden für die relevanten metrischen Merkmale Mittelwerte und Streuungen pro Versuchsfläche, Prüfgliedgruppe, Prüfglied, Wiederholung und Parzelle berechnet. Für qualitativ erfassbare Merkmale werden Häufigkeitsverteilungen erstellt und verglichen. Aus den erhobenen Messwerten werden weitere Kenngrößen (z. B. H/D-Wert, Stammzahl pro Hektar, Volumen) errechnet. Aufgrund der hohen Anzahl der Prüfglieder werden diese auch nach unterschiedlichen Kriterien zu Gruppen zusammengefasst, die verglichen werden.

Bei der Auswertung der einzelnen Versuchsflächen werden die Merkmale in folgender Reihenfolge abgehandelt:

\section{Entwicklung der Pflanzenanzabl}

Die Anzahl der lebenden Fichten bzw. die Ausfälle wurden als Verhältnis der im jeweiligen Jahr gemessenen Fichten und der ursprünglich gepflanzten Anzahl der Fichten errechnet. Für einige Versuchsflächen liegen für bestimmte Aufnahmejahre zusätzlich eigene Erhebungen zur Vitalität der Fichten vor.

\section{Schäden}

Für die einzelnen Schadmerkmale werden Häufigkeitsverteilungen der Boniturnoten analysiert. Im Ergebnis wird entschieden, ob es herkunftsbedingte Unterschiede gibt und ob Fichten, an denen bestimmte Schäden auftreten, bei den nachfolgend beschriebenen Parametern berücksichtigt werden oder nicht.

\section{Qualitätsparameter}

Die Qualitätsparameter sind Stammform, Ovalität (RICHTER 2002, 2007) und H/D-Verhältnis. Für die Bonitur der Stammform werden die Häufigkeitsverteilungen analysiert. Bei den beiden jüngsten Erhebungen im Alter von 32 und 39 Jahren liegen für den BHD zwei Messwerte vor. Aus diesen wurde die Abweichung von der Kreisform nach folgender Formel bestimmt:

$$
\begin{array}{lll}
\text { ov }=100 *\left|\mathrm{~d}_{1}-\mathrm{d}_{2}\right| / \mathrm{d}_{\mathrm{m}}[\%] & \text { ov } & \text { Ovalität } \\
& \mathrm{d}_{1}, \mathrm{~d}_{2} & \text { gemessene BHD } \\
& \mathrm{d}_{\mathrm{m}} & \text { mittlerer BHD eines Baumes }
\end{array}
$$

Der dritte Qualitätsparameter, das Höhen-Durchmesser-Verhältnis (HD), wurde für alle Fichten, von denen beide Werte als Messwerte vorliegen, in den entsprechenden Jahren errechnet. Das H/D-Verhältnis bzw. der Schlankheitsgrad ist der Quotient von Baumhöhe und Brusthöhendurchmesser. Es ist einerseits ein grober formbestimmender Faktor und andererseits ein Stabilitätsfaktor für einen Bestand. Ein niedriger H/D-Wert trägt mit zur Bestandessicherheit bei. 


\section{Höhen- und BHD-Wachstum}

Die Analyse der beiden Wachstumsparameter Baumhöhe und Brusthöhendurchmesser wird in den Jahren, in denen die Baumhöhe nur an einer Zufallsstichprobe gemessen ist, nur anhand der gemessenen Werte durchgeführt. Für den Vergleich zwischen den Versuchsflächen werden neben den absoluten Werten auch das Wachstum im Verhältnis zum jeweiligen Versuchsflächenmittel und Rangfolgen berücksichtigt.

Für die Volumenschätzung werden die fehlenden Baumhöhen aus dem H/DVerhältnis einer Versuchsfläche für den jeweiligen BHD berechnet:

$$
\mathrm{h}=\mathrm{BHD} * \mathrm{HD} \text {. }
$$

\section{Einzelbaumvolumen und Vorrat pro Hektar}

Aus Baumhöhe und BHD erfolgt die Schätzung des Einzelbaumvolumens nach der einfachen Formel:

$$
\mathrm{V}=\mathrm{BHD}^{2} * \mathrm{~h} * 0,00004 * 0,9
$$

Dabei wird eine Derbholz-Formzahl von 0,45 unterstellt.

Für jede Parzelle wird unter Berücksichtigung der Parzellengröße und des Pflanzverbandes aus den Einzelbaumvolumina und der Anzahl lebender Bäume zum Aufnahmezeitpunkt der Bestandesvorrat berechnet und zur Vergleichbarkeit auf einen Hektar bezogen. Da die Durchforstungsmengen häufig nicht bekannt sind, lässt sich die Gesamtwuchsleistung nicht berechnen.

Bei der Bearbeitung von Herkunftsversuchen sind Aussagen über Populationen und nicht über Einzelbäume herzuleiten. Daher bilden, außer in besonders vermerkten Fällen (z. B. Varianzkomponentenschätzung), arithmetische Mittelwerte der Einzelbäume je Prüfglied und Parzelle die Grundlage der statistischen Auswertung, die überwiegend mit den Methoden der Varianz- und der Korrelationsanalyse erfolgt. Da von den Versuchsflächen zum Teil unbalancierte Daten vorliegen, werden auf der Ebene von Parzellenmittelwerten multiple Mittelwertvergleiche (1) für alle Prüfglieder untereinander (Tukey-Kramer-Test, $\alpha=0,05$ ) und (2) im Vergleich mit einem Standard (Dunnett-Test, $\alpha=0,05)$ anhand von adjustierten Erwartungswerten (Least Square Means) durchgeführt (MOLL et al. 2004). Die Ergebnisse der Tests sind im Anhang vereinfacht zusammengestellt, d. h. es werden die Herkünfte aufgelistet, die sich von mindestens einer anderen unterscheiden. In der oberen Hälfte der Tabellen sind die besseren Herkünfte aufgelistet und in der unteren, die mit den nicht gewünschten Eigenschaften. Die Herkünfte, die sich von keiner anderen Herkunft unterscheiden, sind in diese Tabellen nicht aufgenommen.

Als Standard dienen die fünf auf allen Versuchsflächen vertretenen deutschen Herkünfte: Marsberg (Nr. 3417), Kohlstetten (Nr. 3423), Diessen (Nr. 3430), Walsrode (Nr. 3432) und Selb-Kirchenlamitz (Nr. 3433). Eine kleine Einschrän- 
kung liegt vor: die Herkunft Walsrode (3432) ist auf der Fläche 35 in Hessen in einer Parzelle nicht vollständig vertreten.

Die Versuchsflächen werden als (einfaktorielle) randomisierte vollständige Blockversuche ausgewertet. Bei der Auswertung des IUFRO-Fichtenherkunftsversuchs 1972 (Abschnitt 3) hat sich gezeigt, dass sich bei einer Auswertung als Gitterversuch der mittlere Standardfehler nur marginal verringert. Es wird daher von einer Auswertung unter Berücksichtigung des Gitters (Alpha-Design) abgesehen.

Es schließen sich auf der Ebene der einzelnen Merkmale die versuchsflächenübergreifenden Auswertungen an. In diesem Abschnitt werden weitere Methoden an den jeweiligen Stellen direkt beschrieben.

Verwendete Abkürzungen:

PG Prüfglied / Prüfglieder

n Anzahl

s\% Variationskoeffizient in der Stichprobe

$\mathrm{r}_{\mathrm{p}}$ Produkt-Momenten-Korrelationskoeffizient nach PEARSON

$\chi^{2}$ Chi-Quadrat (-Test)

$\alpha$ Risiko 1. Art, Signifikanzniveau

ns nicht signifikant

* signifikant $(\alpha<0,05)$

erfolgt kein Hinweis auf $\alpha<0,05$ so gilt:

$$
\begin{aligned}
& * \quad<0,05 \\
& * *<0,01 \\
& * * *<0,001
\end{aligned}
$$

adj. adjustierter Erwartungswert

\subsection{Ergebnisse und Diskussion}

In der Karte (Abb. 2.10) wird ein Überblick über die Verteilung der insgesamt 286 Prüfglieder gegeben, die in den drei Versuchen an fünf Standorten getestet werden. Die Koordinaten stammen aus verschiedenen Listen und Dateien der Versuchsansteller. Zu einigen Punkten wurden die Koordinaten aus der Karte abgelesen und im Datensatz ergänzt. Bei Punkten, deren Lage offensichtlich falsch eingegeben war (d. h. falscher Staat), wurden die Koordinaten nach bestem Wissen korrigiert. Kleinere Abweichungen wurden nicht korrigiert (schwedische Herkünfte, die in der Ostsee liegen). 


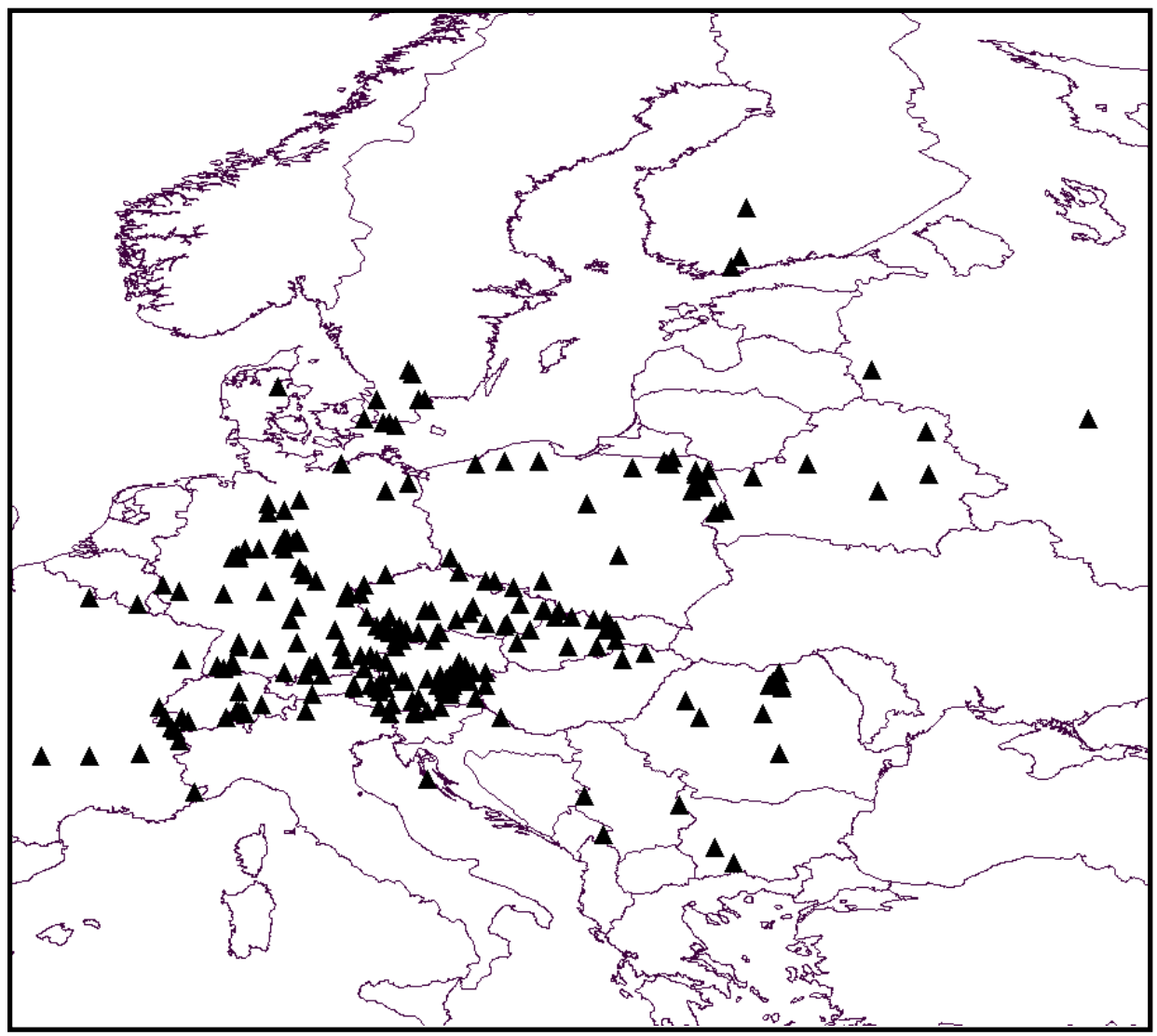

Abb. 2.10: Lage der 286 Herkünfte, die im Fichtenherkunftsversuch von 1962 geprïft werden. Einige Punkte überlappen sich.

\subsubsection{Gruppierung von Herkü̈ften}

Um die Ergebnisse übersichtlich zu halten, sind Prüfglieder zu Gruppen zusammengefasst worden. Diese zusammengefassten Ergebnisse sind in den folgenden Kapiteln dargestellt. Tabellen mit den Ergebnissen zu den einzelnen Herkünften sind im Anhang 1 enthalten.

Zur Gruppierung sind vorhandene Einteilungen genutzt worden. Zusätzlich sind neue Gruppierungen vorgenommen worden. Eine der vorhandenen Einteilungen geht auf KRUTZSCH (1975) zurück. Er hat, um die Darstellung des Materials einigermaßen übersichtlich zu halten, geografische Gebiete ausgeschieden. Die Gebiete sollten einerseits klein genug sein, um eine eventuelle Einheitlichkeit der Herkünfte deutlich werden zu lassen, andererseits sollten die Gebiete natürlich auch genügend Herkünfte umfassen, um einen generellen Überblick zu erhalten. 
Für den Fichtenherkunftsversuch von 1962 ist es von Nachteil, dass diese Gruppierung nur für die Herkünfte vorliegt, die sowohl im 1962er als auch im IUFRO 1964/1968er Versuch enthalten sind, d. h. etwa die Hälfte der Prüfglieder. Dieses gilt auch für die drei Teilversuche. Das Histogramm (Abb. 2.11) mit den absoluten Häufigkeiten der Herkünfte je Gebiet nach KRUTZSCH (1975) für den großen Versuch mit 169 Herkünften je Fläche zeigt, dass die Gebiete überwiegend nur durch eine oder zwei Herkünfte repräsentiert werden. Eine ähnliche Verteilung ergibt sich auch für den mittleren Versuch mit 81 Herkünften je Fläche. Auf dem kleinen Versuch mit 36 Herkünften je Fläche sind die 16 bzw. 17 Gebiete mit nur je einer Herkunft besetzt, lediglich zwei Herkünfte gehören dem gleichen Gebiet an. Für die weiteren untersuchten Herkünfte liegt keine Einteilung vor. Die schwache Besetzung eines Gebietes ist ein weiterer Nachteil dieser Gruppierung. Wegen dieser Nachteile wird die Gruppierung nicht weiter verfolgt.

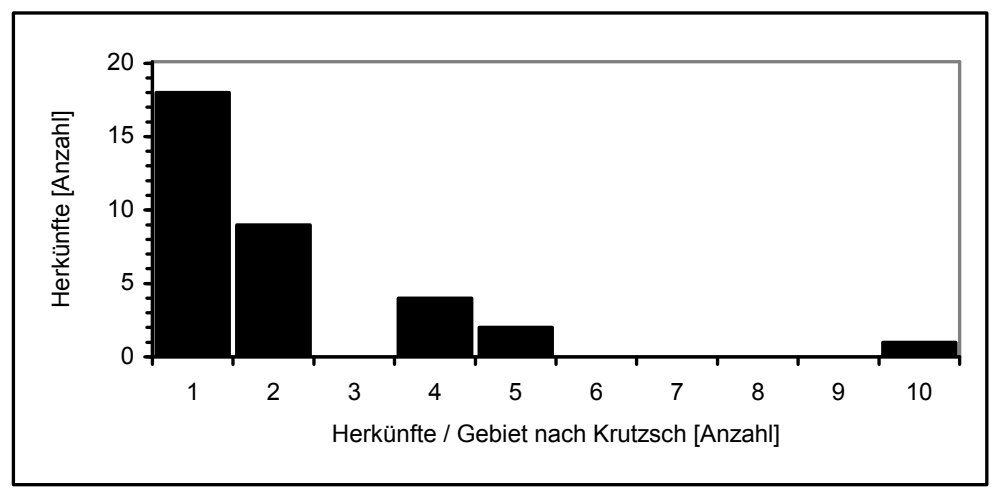

Abb. 2.11: Histogramm für die absoluten Häufigkeiten der Herkünfte je Gebiet nach KRUTZSCH (1975) für den Versuch mit den 169 Herkünften

Zwei weitere Einteilungen sind von den hessischen Versuchsanstellern vorgenommen worden. Die eine umfasst 20 Prüfgliedgruppen (Tab. 2.9). Die einzelnen Prüfgliedgruppen sind sehr unterschiedlich besetzt. Im Gegensatz zur Einteilung von KRUTZSCH (1975) sind alle Herkünfte einer Gruppe zugeordnet. Von Nachteil ist jedoch wie bei KRUTZSCH, dass häufig nur eine oder wenige Herkünfte zu einer Gruppe gehören (Tab. 2.9). Wegen der nicht repräsentativen Besetzung einzelner Gruppen wird diese Einteilung nicht weiter untersucht. 
Tab. 2.9: Gruppierung der Herkünfte durch den hessischen Versuchsansteller und Besetzung der einzelnen Gruppen. Unterschiedliche Herkunftsanzablen stammen von der ungleichen Herkunftsausstattung der einzelnen Versuchsflächen.

\begin{tabular}{c|l|c|c|c}
\hline \multirow{2}{*}{ Nr. } & \multirow{2}{*}{ Gruppe } & \multicolumn{3}{|c}{ Anzahl Herkünfte je Versuch } \\
& & 169 (groß) & 81 (mittel) & 36 (klein) \\
\hline 1 & Alpenvorland & 3 & 2 & 5 \\
2 & Beskiden & 14 & 3 & 1 \\
3 & Chausseehaus & 1 & - & - \\
4 & Balkan & 3 & 3 & - \\
5 & Erzgebirge & 2 & $6 / 2$ & - \\
6 & Fichtelgebirge & 2 & 1 & 1 \\
7 & Schwarzwald & 1 & 2 & 1 \\
8 & Burgjoss & 1 & - & - \\
9 & Karpaten & 2 & 5 & 2 \\
10 & Masuren & 3 & 1 & 1 \\
11 & Böhmen & 9 & 6 & 1 \\
12 & Stryck & 2 & - & - \\
13 & Svealand & 8 & - & 1 \\
14 & Thüringer Wald & 1 & 3 & - \\
15 & Sudeten & 1 & 5 & 1 \\
16 & Vorharz & - & 2 & - \\
17 & Süd-/West-Alpen & 7 & - & 1 \\
18 & Oberpfalz & 15 & $7 / 5$ & 1 \\
19 & Ost-/Nord-/Zentral-Alpen $<1300 \mathrm{~m}$ & 40 & 11 & 5 \\
20 & Ost-/Nord-/Zentral-Alpen $>1300 \mathrm{~m}$ & 7 & 1 & 1 \\
\hline
\end{tabular}

Einer weiteren Unterteilung durch den hessischen Versuchsansteller ist die refugiale Zugehörigkeit zugrunde gelegt. In diesem Fall werden fünf Gruppen ausgeschieden. Von Nachteil ist, dass nicht alle Herkünfte einem Refugialraum zugeordnet sind. Der Tabelle 2.10 ist zu entnehmen, dass die einzelnen Refugialräume der Fichte durch eine unterschiedlich hohe Anzahl an Herkünften vertreten sind.

In Anlehnung an eine Einteilung von WEISGERBER et al. $(1977,1984)$ sind die Herkünfte auch nach dem Einsammlungsland gruppiert worden. Anders als bei WEISGERBER et al. $(1977,1984)$ ist keine weitere Unterteilung vorgenommen worden. Die vorliegende Unterteilung führt zu 17 Gruppen und unterscheidet sich letztendlich nur geringfügig in der Besetzung der einzelnen Gruppen von der des hessischen Versuchsanstellers (Tab. 2.9). Deshalb und wegen der nicht repräsentativen Besetzung einzelner Gruppen wird diese Einteilung nicht weiter analysiert. 
Tab. 2.10: Gruppierung der Herkünfte nach den Refugialräumen der Fichte und Besetzung der einzelnen Gruppen. Unterschiedliche Herkunftsanzablen stammen von der ungleichen Herkunftsausstattung der einz̨elnen Versuchsflächen.

\begin{tabular}{c|lcccc}
\hline \multirow{2}{*}{ Nr. } & \multirow{2}{*}{ Gruppe } & \multicolumn{3}{|c}{ Anzahl Herkünfte je Versuch } \\
& & 169 (groß) & 81 (mittel) & 36 (klein) \\
\hline 1 & Baltisch-Nordisch & 11 & 1 & 2 \\
2 & Herzynisch-Karpatisch & 28 & $21 / 25$ & 5 \\
3 & Alpin & 61 & 19 & 13 \\
4 & Kontaktbereich Herzyn.-Karpat. zu Alpin & 18 & $11 / 13$ & 2 \\
5 & künstliches Verbreitungsgebiet & 4 & - & - \\
\hline
\end{tabular}

Auf der Grundlage der rein politischen Einteilung nach Staatenzugehörigkeit sind benachbarte Staaten, die mit wenigen Herkünften im Versuch vertreten sind zusammengefasst worden. Nach der Zusammenfassung sind sieben Ländergruppen entstanden. Diese Gruppen sind unterschiedlich häufig besetzt, aber insgesamt von wenigen Ausnahmen abgesehen, insbesondere der Gruppe West im Versuch mit den 81 Herkünften, ausreichend besetzt (Tab. 2.11).

Tab.2.11: Gruppierung der Herkünfte nach politischen und geografischen Gebieten (,Staatengruppen“) und Besetzung der einzelnen Gruppen. Unterschiedliche Herkunftsanzablen stammen von der ungleichen Herkunftsausstattung der einzelnen Versuchsflächen.

\begin{tabular}{c|lcccc}
\hline \multirow{2}{*}{ Nr. } & \multirow{2}{*}{ Gruppe (Abk. s. Tab. 2.3) } & \multicolumn{3}{|c}{ Anzahl Herkünfte je Versuch } \\
& & 169 (groß) & 81 (mittel) & 36 (klein) \\
\hline 1 & Österreich & 41 & 12 & 8 \\
2 & Tschech. und Slowak. Rep. (CS, SK) & 20 & 9 & 3 \\
3 & Deutschland & 50 & $30 / 31$ & $13 / 14$ \\
4 & Nord-Europa (DK, S, SF, BY, SU) & 10 & 6 & $4 / 5$ \\
5 & Polen & 16 & $13 / 14$ & 3 \\
6 & Südost-Europa (H, RU, BG, YU, HR) & 11 & 8 & 2 \\
7 & Südwest-Europa (B, F, CH, I) & 21 & 2 & 2 \\
\hline
\end{tabular}

Für die meisten Herkünfte sind Angaben zur Höhenlage bekannt. Teilweise liegen jedoch nur Spannweiten bzw. Ober- oder Untergrenzen vor. In diesen Fällen wurde bei Spannweiten das Mittel aus beiden Werten gebildet, um eine Höhenangabe zu erhalten. Liegt nur eine Ober- bzw. Untergrenze vor, sind jeweils $50 \mathrm{~m}$ addiert bzw. subtrahiert worden. Mit den nun punktbezogenen Angaben sind fünf Höhenklassen ausgeschieden worden, die jeweils etwa 20 Prozent der 286 Herkünfte enthalten. Die Verteilung, die sich für die einzelnen Versuche ergibt, ist in Tabelle 2.12 zusammengestellt. 
Tab. 2.12: Gruppierung der Herkünfte nach Höhenlagen und Besetzung der einzelnen Gruppen. Unterschiedliche Herkunftsanzablen stammen von der ungleichen Herkunftsausstattung der einzelnen Versuchsflächen.

\begin{tabular}{c|l|ccc}
\hline \multirow{2}{*}{ Nr. } & \multirow{2}{*}{ Höhenlage } & \multicolumn{3}{|c}{ Anzahl der Herkünfte je Versuch } \\
& & 169 (groß) & 81 (mittel) & 36 (klein) \\
\hline 1 & unter $200 \mathrm{~m}$ ü. NN & 29 & $15 / 16$ & $7 / 9$ \\
2 & $200-<650 \mathrm{~m}$ ü. NN & 33 & $14 / 16$ & $11 / 12$ \\
3 & $650-<850 \mathrm{~m}$. ü. NN & 34 & $19 / 20$ & $5 / 6$ \\
4 & $850-1000 \mathrm{~m}$ ü. NN & 36 & $17 / 18$ & 4 \\
5 & über $1000 \mathrm{~m}$ ü. NN & 37 & $13 / 14$ & 7 \\
\hline
\end{tabular}

Bei den zusammengesetzten Merkmalen Einzelbaumvolumen (aus Höhe und BHD) und Vorrat pro Hektar (aus Höhe, BHD und Stammzahl) werden neben den Einzelherkünften auch die drei Gruppierungen Refugialräume, Staatengruppe und Höhenlage zur weiteren Analyse genutzt.

\subsubsection{Versuchsflächen}

\subsubsection{Reinhardshagen / Hessen}

Entwicklung der Pflanzenanzabl

Einer handschriftlichen Notiz in der Versuchsakte ist zu entnehmen, dass von den 13.728 Pflanzstellen $182(1,3 \%)$ bei der Anlage des Versuchs nicht ausgepflanzt wurden, da nicht ausreichend Pflanzenmaterial vorhanden war.

Es handelt sich auf der Versuchsfläche 34 um die Herkünfte

204 Spisske Pochradie / CS (14 Pflanzen),

1111 Peisey-Nancroix / F (11 Pflanzen),

1202 Manderfeld, 63A / B (14 Pflanzen),

2141 Foelz, Greith / A (2 Pflanzen),

3416 SHK Höhenfichten / D (11 Pflanzen),

6250 Augustow / PL (5 Pflanzen),

6254 Mikaszowka / PL (3 Pflanzen),

6260 Knyszyn / PL (14 Pflanzen),

7401 Gzatsk / SU (13 Pflanzen),

8703 Lohja + Laakspohjan Kartano / SF (8 Pflanzen),

auf der Versuchsfläche 35 um die Herkünfte

3432 Walsrode / D (3 Pflanzen),

4123 Javorova Dolina 155 A / CS (1 Pflanze), 
6251 Bialobrzegi / PL (16 Pflanzen),

8705 Mänttä 7 C + Kasvuala / SF (38 Pflanzen),

8707 Janakkala Keskivari Uhkoila / SU (5 Pflanzen),

und auf der Versuchsfläche 36 um die Herkünfte

5425 Cimpeni, Nedei, XIV Val. Bistrei 51 / RU (6 Pflanzen) und

7400 Kaluga /SU (18 Pflanzen).

Bei der Herkunft Walsrode (Nr. 3432) auf der Versuchsfläche 35 handelt es sich um eine Herkunft, die zum Standard gehört und auf allen Versuchsflächen angebaut ist. Zwei Parzellen, die auf der Fläche 35 für die finnische Herkunft Nr. 8705 vorgesehen waren, sind nicht bepflanzt worden. Auffallend ist, dass besonders Herkünfte, die von der Versuchsfläche weit entfernt eingesammelt wurden (z. B. SF, SU, RU), nicht in allen Parzellen vollständig vertreten sind.

Bei der Erhebung im Jahr 1993 ist auf den drei Flächen in Reinhardshagen erfasst worden, ob ein Baum vorhanden ist oder entnommen wurde. Außerdem enthält die Datei Fehlstellen. Hierbei handelt es sich um nicht gepflanzte Bäume und solche, die im Laufe der Jahre ausgefallen sind bzw. bei früheren Stammzahlreduktionen entnommen wurden. Von den auf den drei Versuchsflächen (34, 35 und 36) zusammen bei der Versuchsanlage vorgesehenen 13.728 Pflanzstellen sind im Alter von 32 Jahren noch 5.200 Fichten $(38 \%)$ vorhanden. In der Rubrik „entnommen“ sind 6.285 Fichten (46\%) aufgelistet. Für die verbleibenden 2.243 Pflanzstellen fehlt die Angabe. Auf den drei Versuchsflächen ist im Alter von 32 Jahren die Pflanzenanzahl pro Hektar bzw. Parzelle gleich. Der Anteil der entnommenen Bäume und der der fehlenden Werte variiert stärker (Abb. 2.11).

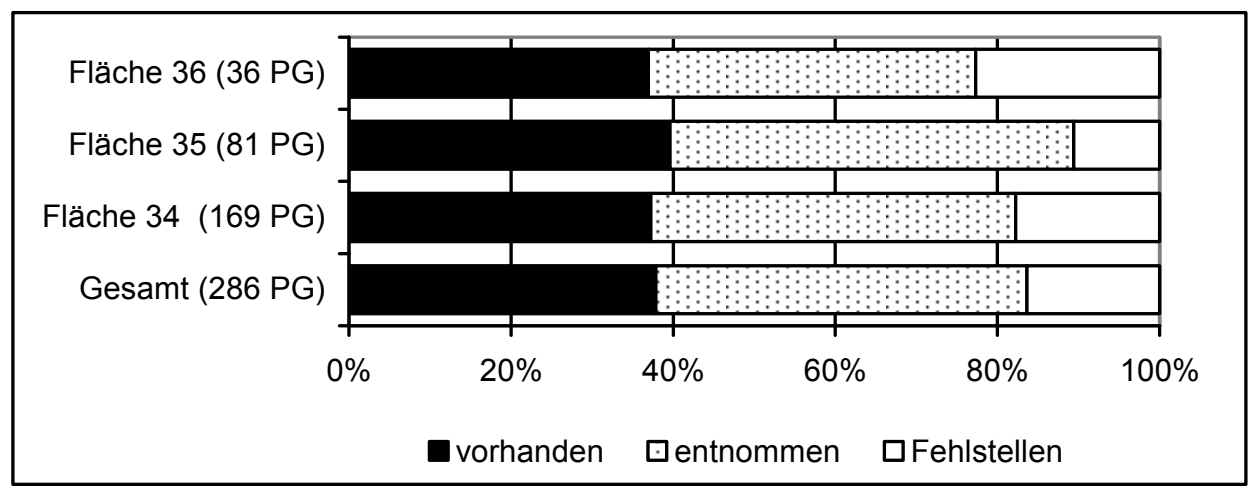

Abb. 2.11: Ergebnis der Erbebung des Vorhandenseins der Fichten im Alter von 32 Jabren auf den Flächen Reinhardshagen / Hessen (PG = Prüfglieder) 
Bei der jüngsten Erfassung der Vitalität im Alter von 39 Jahren sind auf den drei Flächen in Hessen $3.798(28 \%)$ als voll lebensfähig angesprochen worden (Abb. 2.12). 6.374 Fichten (46\%) fehlten oder waren tot, und 122 Bäume (knapp $1 \%$ ) sind als nicht gepflanzt eingruppiert. Die Erfassungsskala sah noch die beiden Rubriken „Überleben fraglich“ und „durchforstet“ vor. Je eine Fichte ist diesen Gruppen zugeordnet. Von 3.432 Fichten (25\%) fehlt eine Angabe. Diese 3.432 Fichten sind bei der Erschließung der Fläche, d. h. der systematischen Entnahme einer Reihe je Parzelle, entfernt worden. In dieser Zahl sind auch 54 Bäume enthalten, die nie gepflanzt wurden. In der Abbildung 2.12 sind diese Fichten als bei der Durchforstung entnommen aufgeführt. Die Pflegeeingriffe erfolgten derart, dass zwischen den Versuchsflächen keine Unterschiede bestehen.

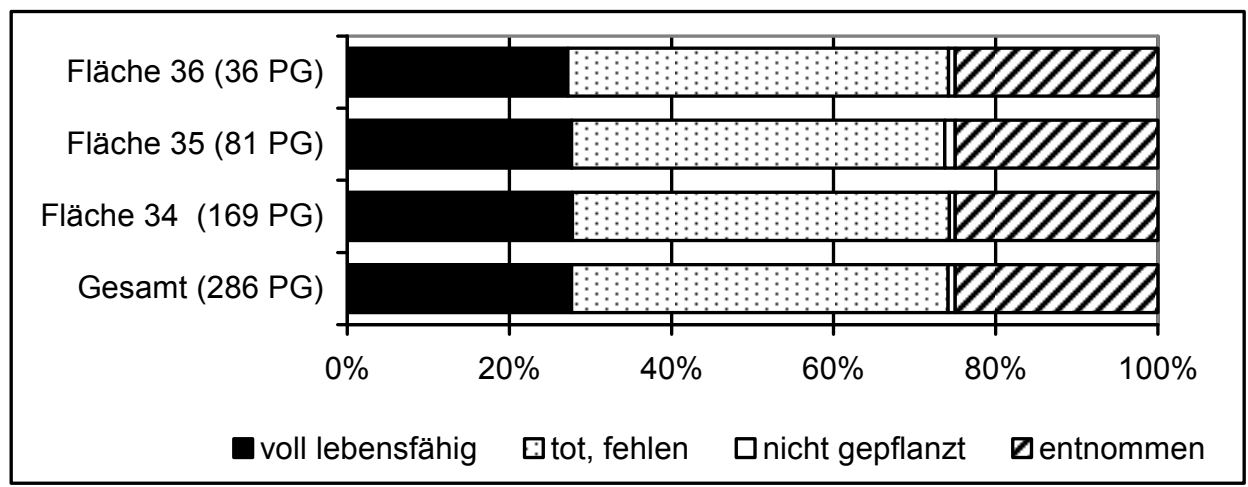

Abb. 2.12 Ergebnis der Erhebung des Vorbandenseins der Fichten im Alter von 39 Jahren auf den Flächen Reinhardshagen / Hessen (PG = Prüfglieder)

Die Anzahl der im Alter von 32 bzw. 39 Jahren lebenden Fichten pro Herkunft, an denen die Merkmale Höhe bzw. BHD gemessen wurden, sind im Anhang 1.2 getrennt für die drei Versuchsflächen zusammengestellt.

\section{Schäden}

Im Alter von 32 Jahren (1993) sind die beiden Schadmerkmale „Schneedruck / Windwurf“ bzw. „Schnee- und Windbruch“ erfasst worden. Auf den drei Flächen sind zusammen nur 35 Bäume, und zwar 29 mit Schneedruck/Windwurf und sechs mit Schnee- und Windbruch notiert worden. Die Schäden sind äußerst selten aufgetreten und gleichmäßig über die Herkünfte verteilt (Abb. 2.13). Nur bei der Herkunft Mechterstedt / D (Nr. 3519) sind vier Bäume mit einem Schaden aufgefallen, und zwar drei angeschobene und eine gebrochene Fichte. Am häufigsten (11 Fichten) sind Schäden in der dritten Wiederholung der Versuchsfläche 35 aufgetreten, d. h. im Westen des Versuchskomplexes der drei Versuchsflächen. 


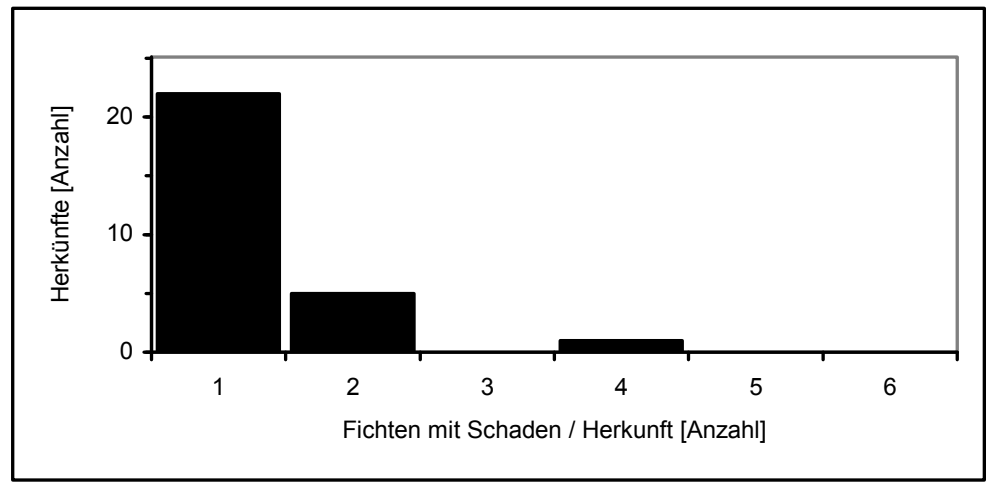

Abb. 2.13: Histogramm für die absoluten Häufigkeiten der Fichten je Herkunft mit einem Schadmerkmal bei der Erfassung im Alter von 32 Jahren auf den Flächen Reinhardshagen / Hessen

Bei der sieben Jahre später erfolgten Aufnahme im Alter von 39 Jahren sind 455 Fichten mit Schäden notiert worden. Bei den Schäden handelt es sich fast ausschließlich um Schneedruck bzw. Windwurf. Nur bei zwei Bäumen ist ein Schaden durch Schnee- oder Windbruch beobachtet worden. Die Schäden sind meist an nur einer oder zwei Fichten einer Herkunft aufgetreten (Abb. 2.14). Die meisten Schäden (171 Fichten) sind in der dritten Wiederholung der Versuchsfläche 34 notiert worden, d. h. im Norden des Versuchsflächenkomplexes. Bei der Herkunft Mechterstedt / D (Nr. 3519) ist im Alter von 39 Jahren nur eine angeschobene Fichte aufgefallen. Die drei Herkünfte, von denen je sechs Fichten einen Schaden aufweisen, sind Schneegattern / A (Nr. 2184), Marsberg / D (Nr. 3417, zum Standard gehörend) und Ujsoly / PL (Nr. 6864).

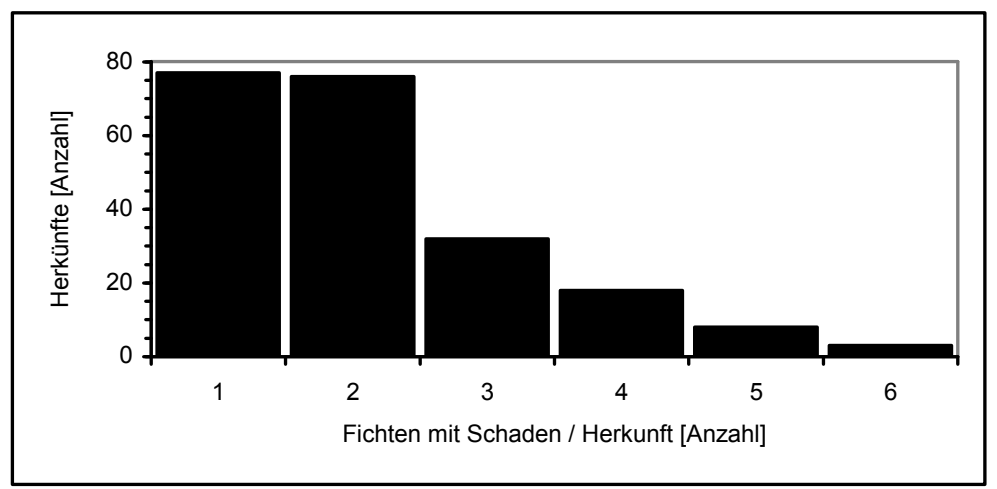

Abb. 2.14: Histogramm für die absoluten Häufigkeiten der Fichten je Herkunft mit einem Schadmerkmal bei der Erfassung im Alter von 39 Jahren auf den Flächen Reinhardshagen I Hessen 
Zwischen dem Standard aus fünf deutschen Herkünften und den weiteren Herkünften lassen sich keine Unterschiede in der Anfälligkeit zu den erfassten Schäden sichern $\left(\chi^{2}=0,0132^{\mathrm{ns}}\right)$. Eine herkunftsbedingte Neigung zu den erfassten Schäden kann anhand der beiden Beobachtungszeitpunkte von den Flächen in Hessen nicht abgeleitet werden.

\section{Stammform}

Im Alter von 32 Jahren liegt für 5.151 Fichten auf den drei Flächen in Hessen eine Bonitur der Stammform vor. Im Ergebnis sind 77 \% der Stämme gerade und $22 \%$ stark gekrümmt. Weitere 59 Fichten haben entweder einen Zwiesel oder einen Korb bzw. ein Bajonett oder eine nicht näher bezeichnete Deformation (Abb. 2.15). Zwischen den Flächen variiert der Anteil der geraden Stämme zwischen $73 \%$ auf der Fläche 34 mit 169 Herkünften und $83 \%$ auf der Fläche 36 mit 36 Herkünften. Im globalen Test werden keine Unterschiede zwischen dem Standard und den restlichen Herkünften aufgedeckt $\left(\chi^{2}=0,3228^{\text {ns }}\right)$.

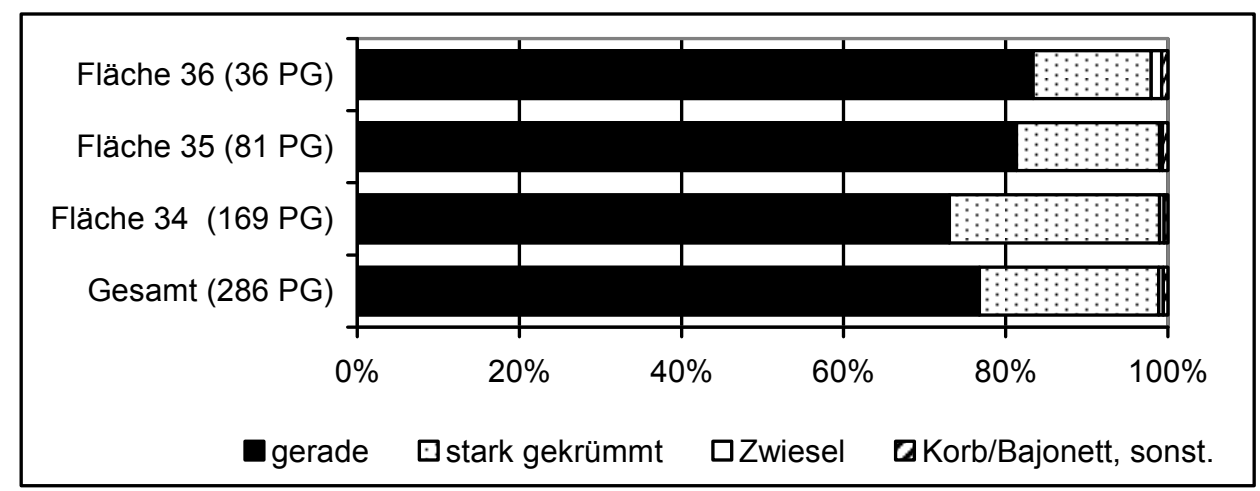

Abb. 2.15: Ergebnis der Stammformbonitur im Alter von 32 Jabren auf den Flächen Reinhardsbagen / Hessen (PG = Prüfglieder)

\section{Astigkeit}

Das Merkmal Astigkeit gibt den subjektiven Eindruck wieder, inwieweit eine Fichte durch wenige feine Äste positiv oder durch viele starke Äste negativ auf der Versuchsfläche auffällt.

Der Anteil der positiv auffallenden Fichten ist bei der Erfassung im Alter von 32 Jahren (1993) äußerst gering. Häufiger sind Fichten mit vielen starken Ästen aufgefallen. Bei der Erfassung im Alter von 39 Jahren (2000) sind der Anteil der vom Durchschnitt abweichenden Fichten insgesamt und der der negativ auffallenden Fichten etwas geringer. Höher ist dagegen der Anteil der Fichten mit wenigen feinen Ästen (Abb. 2.16). 


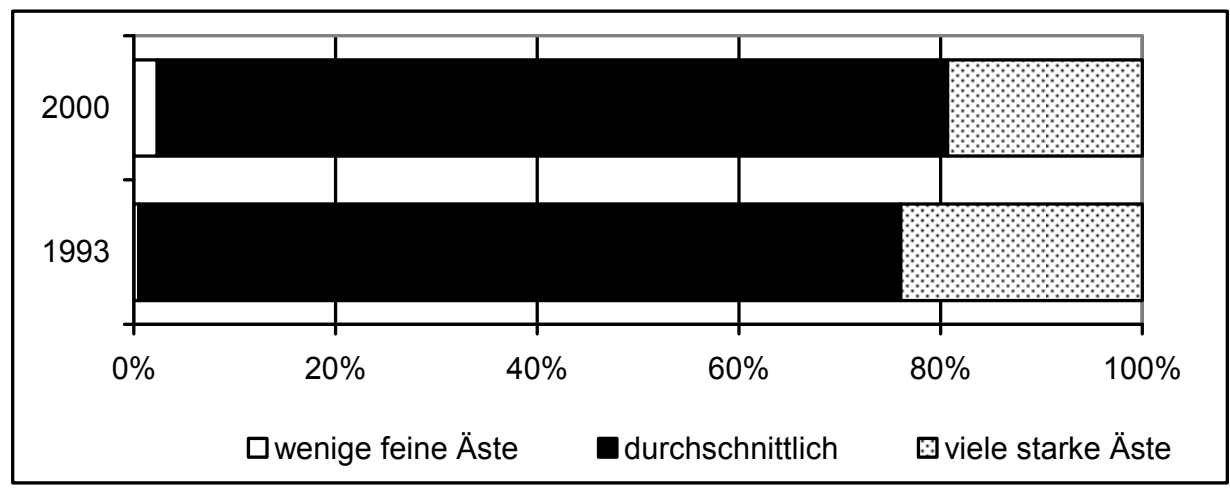

Abb. 2.16: Ergebnis der Bonitur der Astigkeit im Alter von 32 (1993) und 39 (2000) Jahren auf den Flächen Reinhardshagen / Hessen

Die Histogramme für die Häufigkeit der grobastigen Fichten fallen für die beiden Erhebungen im Alter 32 und 39 unterschiedlich aus (Abb. 2.17 und 2.18). Im Alter von 32 Jahren nähert sich die Verteilung einer Normalverteilung, während sie im Alter von 39 Jahren linksschief ist, was vermutlich auf die 1996 erfolgte Durchforstung zurückzuführen ist. Für die feinastigen Fichten fallen die Histogramme (Abb. 2.19) ähnlich aus, sie sind beide linksschief.

Bis auf vier der 18 Herkünfte, die mindestens einen auffallend feinastigen Baum haben, sind auch auffallend grobastige Fichten im Alter von 32 Jahren vertreten. Die vier Herkünfte ohne grobastige Fichten zeichnen sich aber auch jeweils nur durch eine feinastige Fichte aus. Im Alter von 39 Jahren haben 29 der 37 Herkünfte mit feinastigen Fichten auch grobastige Bäume. Unter den acht Herkünften sind fünf mit jeweils einem feinastigen und drei Herkünfte (189 GrazSüd / A, 3503 Eibenstock Carlsf. Wiesenh. / D, 4103 Tatranska Lesna / CS) mit jeweils zwei feinastigen Fichten.

Unter den Herkünften mit feinastigen Fichten befinden sich fünf (1114 Passy / F, 3102 Schluchsee / D, 3432 Walsrode / D [dem Standard angehörend], 3518 Oberhof / D und 4075 Vitov-Budisov / CS), bei denen in beiden Erhebungen feinästige Bäume bonitiert sind. 


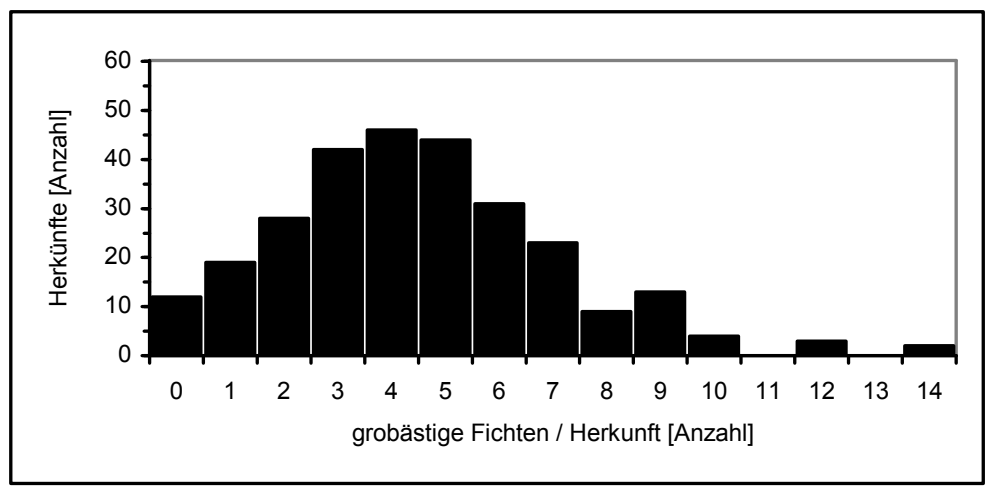

Abb. 2.17: Histogramm für die absoluten Häufigkeiten der grobastigen Fichten je Herkunft im Alter von 32 Jabren auf den Flächen Reinhardshagen / Hessen

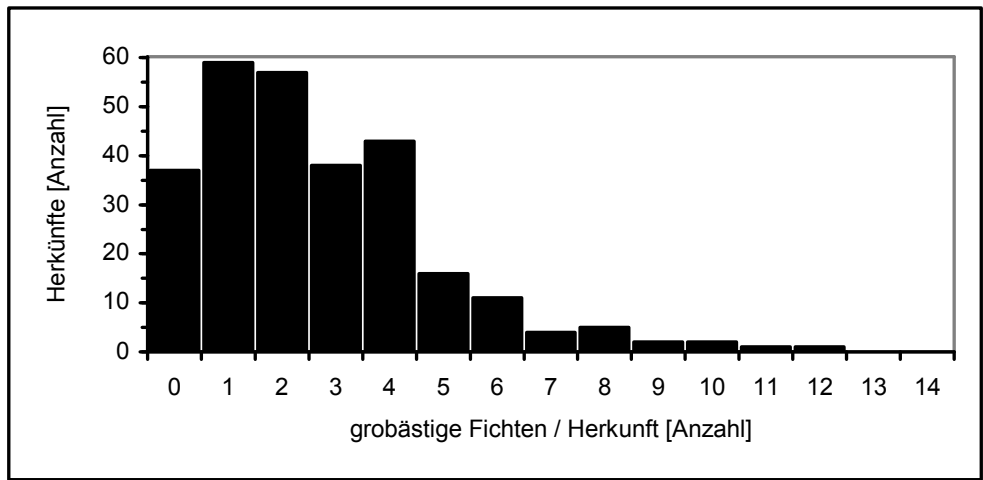

Abb. 2.18: Histogramm für die absoluten Häufigkeiten der grobastigen Fichten je Herkunft im Alter von 39 Jahren auf den Flächen Reinhardshagen / Hessen

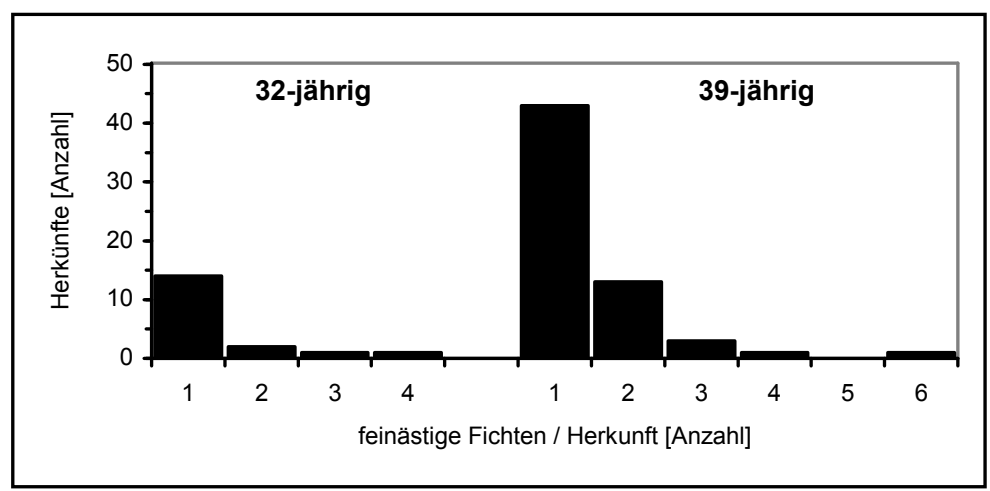

Abb. 2.19: Histogramme für die absoluten Häufigkeiten der feinastigen Fichten je Herkunft im Alter von 32 (links) und 39 (rechts) Jabren auf den Flächen Reinhardshagen / Hessen 


\section{Ovalität}

Ein weiteres Maß zur Beurteilung der Qualität ist die Abweichung des Stammquerschnittes von der Kreisform. Die Ovalität lässt sich für das Alter von 32 und 39 Jahren bestimmen, da in diesen Jahren der BHD durch zwei Messungen (kreuzweise) mit der Kluppe gemessen wurde und beide Werte aufgenommen wurden. Sie beträgt im Mittel über alle Fichten der drei Versuchsflächen in Hessen 3,3\% im Alter von 32 Jahren und 3,4\% im Alter von 39 Jahren. Für die einzelnen Versuche sind die Werte in Tabelle 2.13 zusammengestellt. Die ermittelten Ovalitäten sind zwischen den beiden Messjahren über alle Herkünfte und über die Herkünfte innerhalb der einzelnen Versuchsflächen korreliert (Tab. 2.13). Die mittleren Ovalitäten der einzelnen Herkünfte auf den drei Versuchsflächen sind im Anhang 1.3 zusammengestellt.

Tab. 2.13: $\quad$ Mittlere Ovalitäten [\%] der Herkünfte im Alter von 32 und 39 Jahren auf den Flächen in Hessen und deren Korrelation

\begin{tabular}{c|c|c|c|c}
\hline Versuch & $\begin{array}{c}\text { Anzahl } \\
\mathrm{n}\end{array}$ & $\begin{array}{c}32-\mathrm{j} . \\
\text { Min. Mittel Max }\end{array}$ & $\begin{array}{c}39-\mathrm{j} . \\
\text { Min Mittel Max }\end{array}$ & $\begin{array}{c}\text { Korrelation } \\
\mathrm{r}_{\mathrm{P}}\end{array}$ \\
\hline 34 & 159 & $1,6 \ldots 3,4 \ldots 8,5$ & $1,4 \ldots 3,7 \ldots 7,4$ & $0,214^{* *}$ \\
35 & 81 & $1,5 \ldots 3,0 \ldots 7,4$ & $1,6 \ldots 3,0 \ldots 6,1$ & $0,270^{*}$ \\
36 & 36 & $2,1 \ldots 3,8 \ldots 6,7$ & $1,7 \ldots 3,3 \ldots 5,8$ & $0,364^{*}$ \\
gesamt & 286 & $1,5 \ldots 3,3 \ldots 8,5$ & $1,4 \ldots 3,4 \ldots 7,4$ & $0,262^{* * *}$ \\
\hline
\end{tabular}

Im Alter von 39 Jahren lassen sich auf der Versuchsfläche 34 die Unterschiede zwischen der Herkunft 2150 Wildalpen / A (mit der geringeren Abweichung von der Kreisform 1,4\%) und der Herkunft 5205 Begliga / BG (mit der großen Abweichung 7,4\%) statistisch sichern (Tukey-Kramer-Test, $\alpha=0,05)$. Auch vom Standard (3,5\%) unterscheidet sich die Herkunft 5205 Begliga / BG (DunnettTest, $\alpha=0,05)$.

Auf den Flächen 35 und 36 lassen sich keinen Unterschiede sichern (TukeyKramer- bzw. Dunnett-Test, $\alpha=0,05)$.

Die Varianzkomponentenschätzung zeigt (Tab. 2.14), dass der durch die Herkunft und Wiederholung erklärte Anteil äußerst gering ist. Auf der Fläche 36 treten Wechselwirkungen zwischen Herkunft und Wiederholung auf.

Tab. 2.14: Varianzkomponentenschätzung des Merkmals Ovalität im Alter 39

\begin{tabular}{c|ccccc}
\hline Versuch & Prüfglied & Wiederholung & Prüfglied $*$ Wiederh. & Rest \\
\hline 34 & $1 \% \mathrm{~ns}$ & $2 \% * * *$ & $0 \%$ & $97 \%$ \\
35 & $2 \% \mathrm{~ns}$ & $1 \% * *$ & $0 \%$ & $97 \%$ \\
36 & $0 \%$ & $0 \%$ & $9 \% *$ & $91 \%$ \\
\hline
\end{tabular}


Im Alter von 32 Jahren sichert der Tukey-Kramer-Test Unterschiede zwischen der am stärksten von der Kreisform abweichenden Herkunft Nr. 293 (Trolleholm / S) und 110 Herkünften auf der Fläche 34 (Anhang 1.4). Die schwedische Herkunft unterscheidet sich auch vom Standard (Dunnett-Test, $\alpha=0,05$ ).

Auf der Fläche 35 ist es die Herkunft Nr. 3417 (Marsberg [zum Standard gehörend]), die sich durch ihren von der Kreisform abweichenden Stammquerschnitt von 34 Herkünften unterscheidet (Anhang 1.5). Der Dunnett-Test deckt keine Unterschiede gegenüber dem Standard auf.

Auf der Fläche 36 lassen sich keine Unterschiede zwischen den Herkünften (Tukey-Kramer-Test, $\alpha=0,05$ ) bzw. zum Standard (Dunnett-Test, $\alpha=0,05$ ) sichern.

Die Güte des Maßes „Ovalität“ lässt sich jedoch nicht beurteilen, da keine Aufzeichnungen vorliegen, aus denen hervorgeht, dass jeweils der dickste und dünnste Durchmesser in 1,3 m Höhe gemessen wurde.

\section{$H / D$-Verbältnis}

Für die 286 Herkünfte beträgt das mittlere Höhen-Durchmesser-Verhältnis 78 im Alter 39 und variiert zwischen 66 (Nr. 131 Vizovice / CS im Versuch 34) und 97 (Nr. 8705 Mänttä 7 C + Kasvuala / SF im Versuch 35). Die mittleren H/DVerhältnisse der drei Versuchsflächen sind in Tabelle 2.15 zusammengestellt. Sie sind auf den drei Flächen sehr ähnlich und variieren im Mittel zwischen 77 (Versuch 34) und 80 (Versuch 35).

Tab. 2.15: $\quad$ Mittlere H/D-Verbältnisse der Herkünfte im Alter von 39 Jahren auf den Flächen in Hessen

\begin{tabular}{c|c}
\hline Versuch & $\begin{array}{c}39-j . \\
\end{array}$ \\
\hline 34 & $66 \ldots 77 \ldots 89$ \\
35 & $69 \ldots 80 \ldots 97$ \\
36 & $66 \ldots 79 \ldots 91$ \\
gesamt & $66 \ldots 78 \ldots 97$ \\
\hline
\end{tabular}

Die H/D-Verhältnisse der einzelnen Prüfglieder im Alter von 39 Jahren sind in Anhang 1.3 zusammengestellt. Die Unterschiede $(\alpha=0,05)$ zwischen den 169 Herkünften auf der Fläche 34 und den 81 Herkünften auf der Fläche 35 im Alter von 39 Jahren lassen sich im multiplen Mittelwertvergleich (Tukey-Kramer-Test) nicht absichern. Auf der Fläche 36 gibt es einen Unterschied zwischen der abholzigsten Herkunft Nr. 172 (Mittersill / A) einerseits und den beiden schlanken Herkünften Nr. 6236 (Bialowieza / PL) und Nr. 7400 (Kaluga / SU) andererseits. Im Vergleich zum Standard (Dunnett-Test, $\alpha=0,05)$ lässt sich nur auf der Versuchsfläche 35 ein 
Unterschied zur Herkunft 8705 Mänttä 7 C + Kasvuala / SF (adjustierter H/DWert $=94$ ) sichern.

Die Varianzkomponentenschätzung zeigt (Tab. 2.16), dass der durch die Herkunft und Wiederholung erklärte Anteil des H/D-Verhältnisses gering ist. Auf den Flächen 34 und 35 treten Wechselwirkungen zwischen Herkunft und Wiederholung auf.

Tab. 2.16: Varianzkomponentenschätzung des H/D-Verbältnisses im Alter 39

\begin{tabular}{c|ccccc}
\hline Versuch & Prüfglied & Wiederholung & Prüfglied * Wiederh. & Rest \\
\hline 34 & $3 \% * * *$ & $2 \% * * *$ & $6 \% *$ & $89 \%$ \\
35 & $7 \% * * *$ & $10 \% * * *$ & $8 \% *$ & $75 \%$ \\
36 & $7 \% *$ & $1 \% \mathrm{~ns}$ & 0 & $92 \%$ \\
\hline
\end{tabular}

\section{Höhen- und BHD-Wachstum}

Im Vergleich zur Ertragstafel (WIEDEMANN 1936/1942) ist das Wachstum der Fichte auf den drei Flächen in Reinhardshagen sehr gut. Über alle Herkünfte der drei Versuchsflächen wird im Alter von 39 Jahren ein mittlerer BHD von $26,9 \mathrm{~cm}$ und eine mittlere Höhe von 22,2 m errechnet. Beim BHD beträgt der Variationskoeffizient $8 \%$ und bei der Baumhöhe $6 \%$ der Herkunftsmittelwerte. Die mittleren Wachstumswerte der einzelnen Herkünfte sind in Anhang 1.6 zusammengestellt.

Die Berechnung der Baumhöhen beruht auf einer Stichprobe von in der Regel drei Bäumen je Herkunft und Wiederholung, zusammen 1491 Fichten. In Abbildung 2.20 sind ausgewählte statistische Parameter zum Höhenwachstum für die drei Versuchsflächen in Hessen gegenübergestellt. Im Mittel sind die Baumhöhen auf den drei Versuchsflächen gleich. Auf der Versuchsfläche 36 stehen im Vergleich zu den beiden anderen Flächen keine im Höhenwachstum mattwüchsigen Herkünfte. Zwischen dem Mittel des Standards aus fünf deutschen Herkünften und dem jeweiligen Versuchsflächenmittel bestehen keine Unterschiede. 


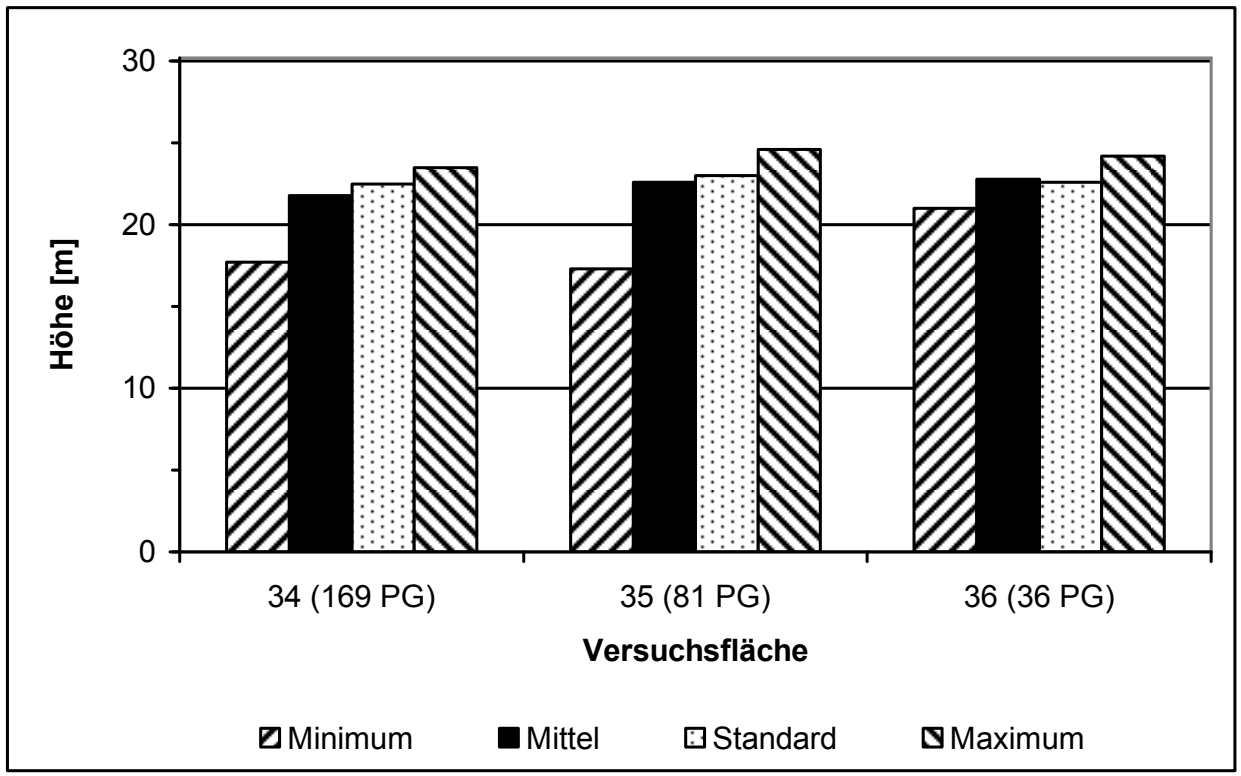

Abb. 2.20: Höhenwachstum (Mittel aller Herkünfte, mattwüchsigste und wüchsigste Herkunft sowie Mittel des Standards) auf den drei Flächen Reinhardshagen / Hessen im Alter 39

Die Varianzkomponentenschätzung zeigt (Tab. 2.17), dass der durch die Herkunft erklärte Anteil des Höhenwachstums auf den Flächen 34 und 3518 bzw. 26 \% beträgt. Auf allen drei Flächen treten auch Wechselwirkungen zwischen Herkunft und Wiederholung auf.

Tab. 2.17: Varianそkomponentenschätzung des Höhenwachstums im Alter 39

\begin{tabular}{c|c|c|c|c}
\hline Versuch & Prüfglied & Wiederholung & Prüfglied * Wiederh. & Rest \\
\hline 34 & $18 \% * * *$ & $3 \% * * *$ & $25 \% * * *$ & $54 \%$ \\
35 & $26 \% * * *$ & $17 \% * * *$ & $19 \% * * *$ & $38 \%$ \\
36 & $5 \% * * *$ & $1 \% \mathrm{~ns}$ & $26 \% * * *$ & $68 \%$ \\
\hline
\end{tabular}

Die Gegenüberstellung der mittleren Baumhöhen der Herkünfte auf den drei Flächen in Hessen zeigt, dass das Wachstum in den vier Beobachtungsjahren ähnlich war (Abb. 2.21). 


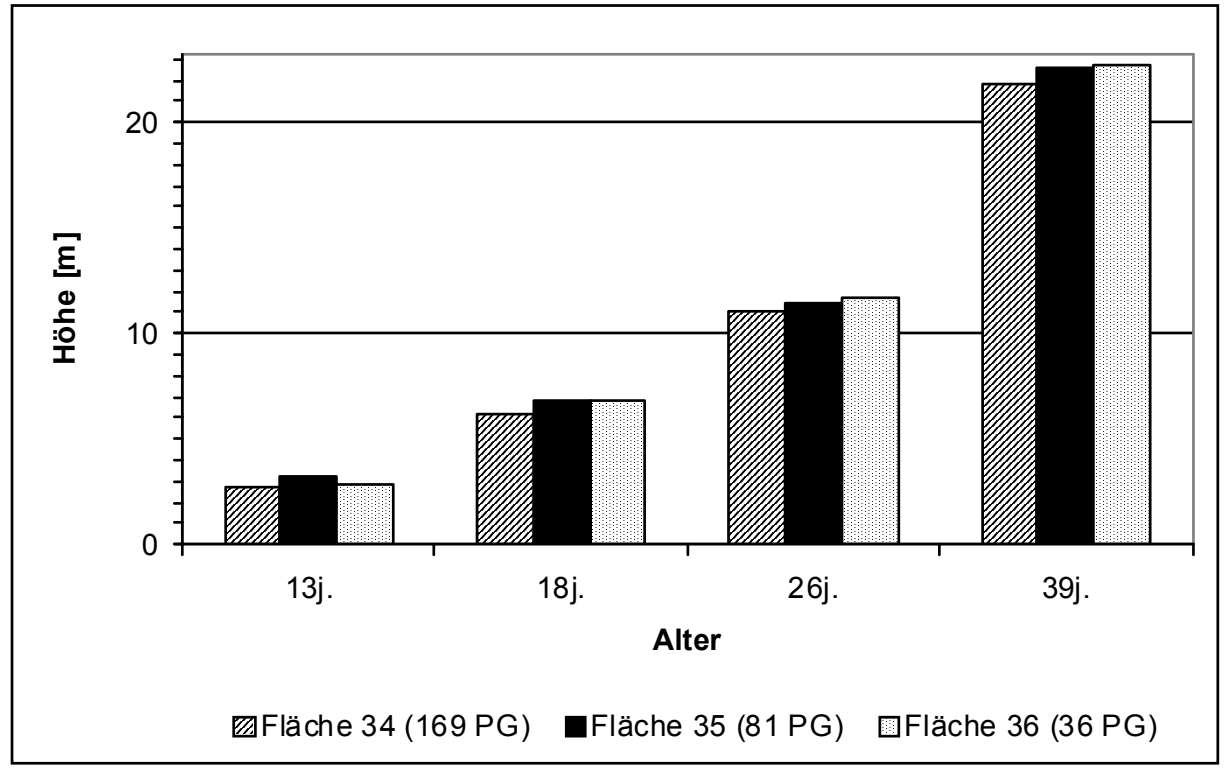

Abb. 2.21: Gegenüberstellung des mittleren Höhenwachstums im Alter 13, 18, 26 und 39 auf den drei hessischen Versuchsflächen Reinhardshagen / Hessen

Der multiple Mittelwertvergleich (Tukey-Kramer-Test, $\alpha=0,05)$ der 169 Herkünfte der Fläche 34 ergibt 160 statistische Unterschiede (Anhang 1.7). Fünf mattwüchsige Herkünfte (Nr. 150 Schlanders / I; 734 Airolo, Bedretto / CH; 740 Bex, Tarejanne / CH; 5303 Borovec/BG und 9170 Ryssby / S) unterscheiden sich von bis zu 67 gutwüchsigen Herkünften. Bis auf die schwedische Herkunft 9170 stammen die anderen vier mattwüchsigen Herkünfte aus Hochlagen. Unter den gutwüchsigen Herkünften (Anhang 1.7) sind z. B. Burgjoß (3498), Chausseehaus (3499), Diessen (3430), Marsberg (3417, 9417), Neureichenau (3435, 3436), Oderhaus (3427) und Istebna (208) sowie Istebna-Wisła (202).

Gegenüber dem Standard sind folgende elf Herkünfte signifikant mattwüchsiger: Schlanders / I (150), La Genolière / CH (711), Forêt du Risoud / CH (712), Airolo, Bedretto / CH (734), Bex, Tarejanne / CH (740), Autrans / F (1112), Passy / F (1114), Nedzinant / YU (5101), Borovec / BG (5303), Lohja + Laakspohjan Kartano / SF (8703) und Ryssby / S (9170).

Der multiple Mittelwertvergleich (Tukey-Kramer-Test, $\alpha=0,05)$ der 81 Herkünfte der Fläche 35 ergibt 120 statistische Unterschiede (Anhang 1.8). Von den bis zu 70 gutwüchsigen Herkünften, z. B. Diessen / D (3430), Westerhof / D (115, 3404), Schneegattern / A (2184) und Istebna-Ujsoly / PL (6894), unterscheiden sich fünf Herkünfte: Smrceve Dolina Abt. 138 / HR (5107), Mänttä / SF (8705), St. Oswald I/3,4,6 Typengemisch / D (3331), Belogradchik-Tschu- 
preno / BG (5301) und Janakkala Keskivari Uhkoila / SF (8707). Die mattwüchsigen Herkünfte stammen aus Hochlagen bzw. aus Finnland.

Folgende vier Herkünfte sind gegenüber dem Standard signifikant mattwüchsiger: Smrceve Dolina Abt. 138 / HR (5107), Belogradchik-Tschupreno / BG (5301), Mänttä / SF (8705) und Janakkala Keskivari Uhkoila / SF (8707).

Für die 36 Herkünfte auf der Fläche 36 ergeben die multiplen Mittelwertvergleiche (Tukey-Kramer- bzw. Dunnett-Test, $\alpha=0,05)$ keine gesicherten Unterschiede.

Für die Ermittlung der BHD sind auf den Flächen im Alter 39 alle Bäume gemessen worden. In Abbildung 2.22 sind ausgewählte statistische Parameter zum BHD-Wachstum für die drei Versuchsflächen in Hessen gegenübergestellt. Auf der Versuchsfläche 36 ist der Mittelwert beim BHD etwas größer als auf den beiden anderen Flächen. Die wüchsigsten Herkünfte erreichen auf den drei Versuchsflächen gleiche BHD. Auf der Versuchsfläche 36 stehen keine mattwüchsigen Herkünfte im Vergleich zu den beiden anderen Flächen. Auf allen drei Flächen ist der Standard aus fünf deutschen Herkünften im Durchmesserwuchs besser als das jeweilige Versuchsflächenmittel.

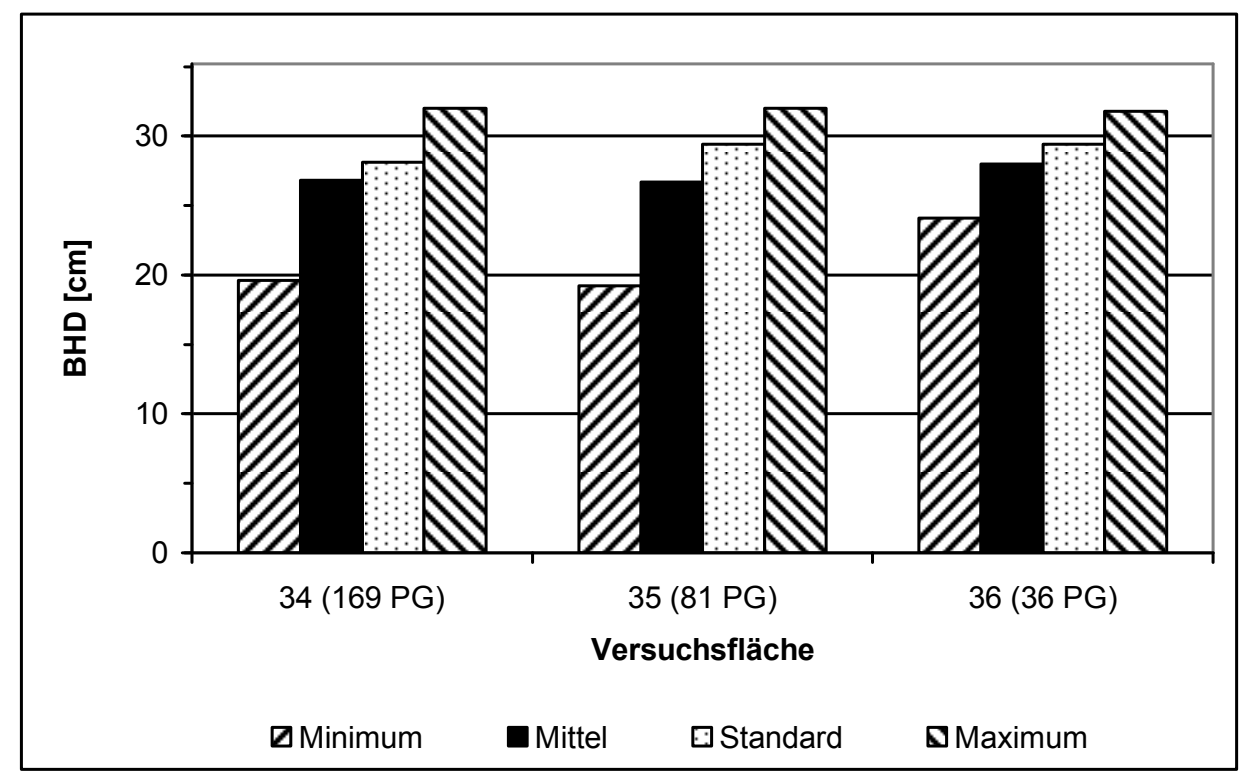

Abb. 2.22: $\quad$ BHD-Wachstum (Mittel aller Herkünfte, mattwüchsigste und wüchsigste Herkunft sowie Mittel des Standards) auf den drei Flächen Reinhardshagen / Hessen im Alter 39 
Der BHD der Fichten, an denen die Baumhöhen gemessen wurden, beträgt im Mittel über die drei hessischen Flächen 29,1 cm und liegt damit über dem der Vollerhebung. Somit sind die Höhen überwiegend an Bäumen gemessen worden, die einen stärkeren BHD haben.

Die Varianzkomponentenschätzung (Tab. 2.18) ergibt einen durch die Herkunft erklärten Anteil zwischen $1 \%$ auf der Fläche 36 und $10 \%$ auf der Fläche 35. Der durch die Wiederholung erklärte Anteil ist gering. Wechselwirkungen zwischen Herkunft und Wiederholung lassen sich auf keiner der drei Flächen sichern.

Tab. 2.18: Varianzkomponentenschätzung des BHD-Wachstums im Alter 39

\begin{tabular}{c|c|c|c|c}
\hline Versuch & Herkunft & Wiederholung & Herkunft * Wiederh. & Rest \\
\hline 34 & $8 \% * * *$ & $1 \% * *$ & $0 \%$ & $91 \%$ \\
35 & $10 \% * * *$ & $1 \% *$ & $0 \%$ & $89 \%$ \\
36 & $1 \% *$ & $1 \% *$ & $5 \% \mathrm{~ns}$ & $93 \%$ \\
\hline
\end{tabular}

Der multiple Mittelwertvergleich (Tukey-Kramer-Test, $\alpha=0,05)$ der 169 Herkünfte der Fläche 34 ergibt 56 statistische Unterschiede beim BHD-Wachstum im Alter von 39 Jahren (Anhang 1.9). Sechs mattwüchsige Herkünfte (Nr. 711 La Genolière / CH; 734 Airolo, Bedretto / CH; 740 Bex, Tarejanne / CH; 1112 Autrans / F; 5101 Nedzinant / YU und 5303 Borovec / BG) unterscheiden sich von bis zu 22 gutwüchsigen Herkünften. Unter den gutwüchsigen Herkünften sind z. B. Litschau / A (62), Spiegelau / D (3329), Istebna-Wisła / PL (124). Die mattwüchsigen Herkünfte stammen aus Hochlagen. Diese sechs mattwüchsigen Herkünfte sind auch gegenüber dem Standard signifikant mattwüchsiger (DunnettTest, $\alpha=0,05)$.

Der multiple Mittelwertvergleich (Tukey-Kramer-Test, $\alpha=0,05)$ der 81 Herkünfte der Fläche 35 ergibt 19 statistisch gesicherte Unterschiede (Anhang 1.10). Unter den bis zu elf wüchsigen Herkünften befinden sich z. B. Marsberg / D (3417), Westerhof / D (115) und Bischofsreut/D (3320). Diese und weitere Herkünfte unterscheiden sich signifikant (Tukey-Kramer-Test, $\alpha=0,05$ ) von den drei mattwüchsigen Herkünften: Smrceve Dolina Abt. 138 / HR (5107), Belogradchik-Tschupreno / BG (5301) und Mänttä / SF (8705).

Folgende sieben Herkünfte sind gegenüber dem Standard signifikant mattwüchsiger: Lobming-Obertal / A (2138), Walchensee / D (3042), Rabenstein, Typengemisch / D (3337), Szentgotthard 1 C / H (5202), Smrceve Dolina Abt. 138 / HR (5107), Belogradchik-Tschupreno / BG (5301) und Mänttä / SF (8705).

Für die 36 Herkünfte auf der Fläche 36 ergibt der multiple Mittelwertvergleich (Tukey-Kramer-Test, $\alpha=0,05)$ keine gesicherten Unterschiede. Gegenüber dem Standard zeigen die Herkünfte Javorova Dolnia 155 A / CZ (4127) und Kaluga / SU (7400) ein signifikant geringeres Dickenwachstum. 
Im Alter von 32 Jahren hat der BHD im Mittel aller Herkünfte auf den drei Versuchsflächen in Hessen 20,8 cm betragen und variierte zwischen der wüchsigsten und mattwüchsigsten Herkunft zwischen $14,6 \mathrm{~cm}$ und 24,8 cm. Der Variationskoeffizient beträgt $8 \%$. Ausgewählte statistische Parameter zum BHDWachstum im Alter 32 sind für die drei Versuchsflächen in Hessen in Abbildung 2.23 gegenübergestellt. Die geringste Spannweite zwischen best- und mattwüchsigster Herkunft ist auf der Fläche 36 anzutreffen.

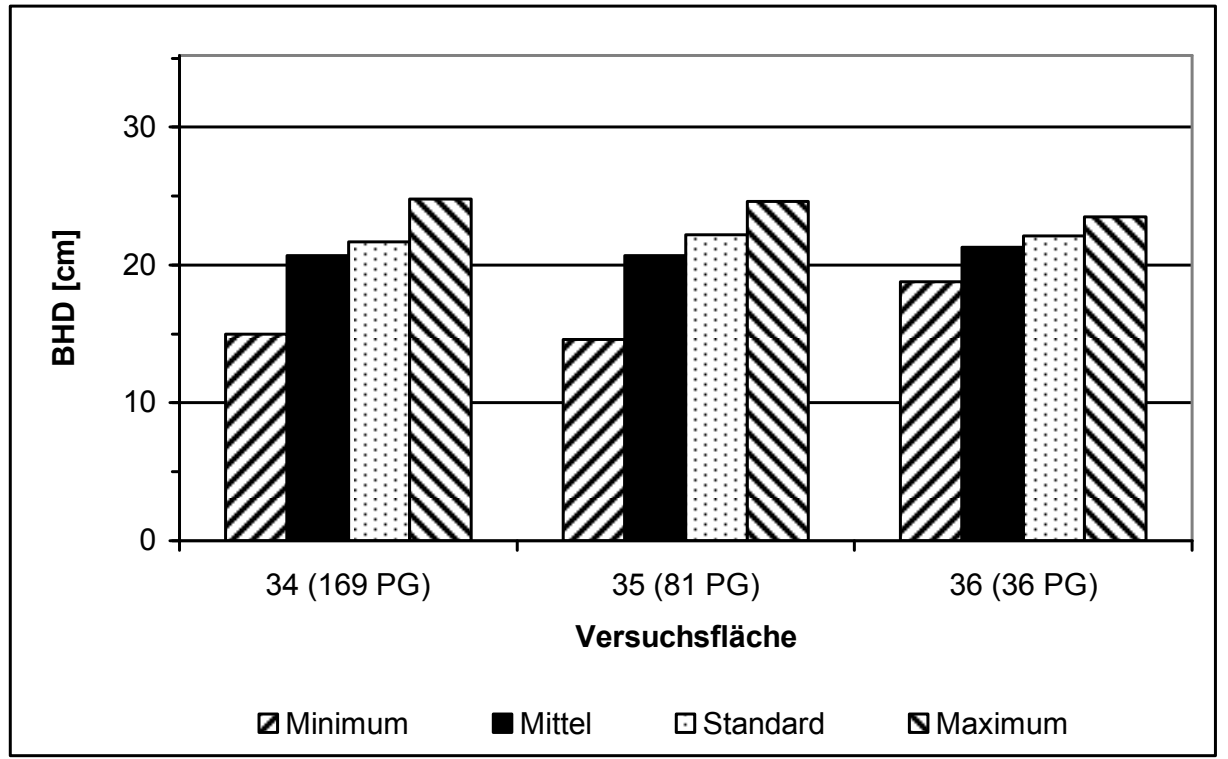

Abb. 2.23: BHD-Wachstum (Mittel aller Herkünfte, mattwüchsigste und wüchsigste Herkunft sowie Mittel des Standards) auf den drei Flächen Reinhardshagen / Hessen im Alter 32

Die signifikanten Unterschiede aus den Tukey-Kramer-Tests des BHD-Wachstums im Alter von 32 Jahren sind in den Anhängen 1.11 und 1.12 zusammengestellt. Beim BHD-Wachstum im Alter von 32 Jahren führt der multiple Mittelwertvergleich (Tukey-Kramer-Test, $\alpha=0,05)$ der 169 Herkünfte der Fläche $34 \mathrm{zu}$ 84 statistisch gesicherten Unterschieden (Anhang 1.11). Bis zu 51 wüchsige Herkünfte unterschieden sich von 14 mattwüchsigen Herkünften.

Im Vergleich zum Standard lassen sich fünf Herkünfte als mattwüchsiger absichern (Dunnett-Test, $\alpha=0,05)$. Es sind dieses: Cazis / CH (704), Airolo, Bedretto / CH (734), Bex, Tarejanne / CH (740), Lohja + Laakspohjan / SF (8703) und Ryssby / S (9170).

Auf der Fläche 35 lassen sich bei 67 Vergleichen Unterschiede sichern (TukeyKramer-Test, $\alpha=0,05$ ) (Anhang 1.12). Auf dieser Fläche unterschieden sich bis zu 48 wüchsige Herkünfte von bis zu neun mattwüchsigen Herkünften. Bei Letzteren 
handelt es sich um Herkünfte aus den Hochlagen, aus Finnland bzw. der ehemaligen Sowjetunion (SU).

Der Vergleich des BHD- und Höhenwachstums im Alter von 32 und 39 Jahren zeigt, dass die Wachstumsmerkmale hoch korreliert sind (Tab. 2.19). Die Güte der Korrelation zwischen mittlerer Baumhöhe einer Herkunft und dem BHD aller Bäume bzw. nur derer, von denen auch die Höhen gemessen sind, ist gleich.

Tab. 2.19: Produkt-Momenten-Korrelationsmatrix der Wachstumsmerkmale Höhe und BHD im Alter 32 und 39 (alle Prüfglieder der drei Flächen in Hessen, $n=286$ )

\begin{tabular}{l|c|c|c|c}
\hline & $\begin{array}{c}\text { BHD } \\
\text { 32-j. }\end{array}$ & $\begin{array}{c}\text { BHD } \\
\text { 39-j. }\end{array}$ & $\begin{array}{c}\text { BHD } \\
39-j . *\end{array}$ & $\begin{array}{c}\text { Höhe } \\
39-\mathrm{j} .\end{array}$ \\
\hline BHD 32-j. & - & $0,863^{* * *}$ & $0,799 * * *$ & $0,612^{* * *}$ \\
BHD 39-j. & & - & $0,897 * * *$ & $0,621^{* * *}$ \\
\cline { 1 - 1 } BHD 39-j.* & & & - & $0,618^{* * *}$ \\
\cline { 1 - 2 } Höhe 39-j. & & & & - \\
\hline
\end{tabular}

* nur die Bäume, von denen auch die Höhe bekannt ist

\section{Einzelbaumvolumen}

Aus den Merkmalen Baumhöhe und BHD wurde das mittlere Einzelbaumvolumen je Herkunft errechnet. Es beträgt im Alter von 39 Jahren 0,592 $\mathrm{m}^{3}$ im Mittel über die 286 Prüfglieder der drei Versuchsflächen Reinhardshagen.

Die höchste mittlere Stückmasse $\left(0,966 \mathrm{~m}^{3}\right)$ hat die Absaat 3417 Marsberg / D auf der Fläche 35 und die geringste $\left(0,241 \mathrm{~m}^{3}\right)$ die Herkunft 5107 Smrceve Dolina Abt. 138 / HR ebenfalls auf der Fläche 35. Die mittleren Einzelbaumvolumina der einzelnen Herkünfte sind absolut und im Verhältnis zum Mittel der drei Versuchsflächen Reinhardshagen im Anhang 1.13 aufgelistet. Wie bereits beim Höhen- und BHD-Wachstum ist die Streuung zwischen Herkünften auf der Fläche 36 am geringsten (Tab. 2.20).

Tab. 2.20: Mittlere Einzelbaumvolumina auf den drei Flächen Reinhardshagen, Standardabweichung, Variationskoeffizient (VK), Minimum und Maximum

\begin{tabular}{c|c|c|c|c|c|c}
\hline Fläche & $\begin{array}{c}\text { Herkünfte } \\
{[\mathrm{n}]}\end{array}$ & $\begin{array}{c}\text { Mittel } \\
{\left[\mathrm{m}^{3}\right]}\end{array}$ & $\begin{array}{c}\text { Standardabw. } \\
{\left[\mathrm{m}^{3}\right]}\end{array}$ & $\begin{array}{c}\mathrm{VK} \\
{[\%]}\end{array}$ & $\begin{array}{c}\text { Min } \\
{\left[\mathrm{m}^{3}\right]}\end{array}$ & $\begin{array}{c}\text { Max } \\
{\left[\mathrm{m}^{3}\right]}\end{array}$ \\
\hline 34 & 169 & 0,578 & 0,106 & 18 & 0,289 & 0,911 \\
35 & 81 & 0,593 & 0,126 & 21 & 0,241 & 0,966 \\
36 & 36 & 0,653 & 0,083 & 13 & 0,467 & 0,873 \\
gesamt & 286 & 0,592 & 0,112 & 19 & 0,241 & 0,966 \\
\hline
\end{tabular}


Der multiple Mittelwertvergleich (Tukey-Kramer-Test, $\alpha=0,05)$ der 169 Herkünfte der Fläche 34 ergibt statistisch gesicherte Unterschiede zwischen den bis zu neun volumenreichsten Herkünften und 18 volumenärmsten Herkünften. Diese Herkünfte sind im Anhang 1.14 aufgelistet. Unter den Herkünften mit hohem mittlerem Einzelbaumvolumen sind die deutschen Herkünfte Spiegelau $1200 \mathrm{~m}$ ü. NN (3329) und Villingen (3429). Unter den Herkünfte mit einem geringen mittleren Einzelbaumvolumen sind die deutschen Absaaten: SHK Höhenfichte (3416), Nationalpark Filzwald (3448), Waldmünchen (3425) und Spiegelau $750 \mathrm{~m}$ ü. NN (41).

Gegenüber dem Standard sind folgende sieben Herkünfte signifikant massenärmer (Dunnett-Test, $\alpha=0,05)$ : La Genolière / CH (711), Airolo, Bedretto / CH (734), Bex, Tarejanne / CH (740), Autrans / F (1112), Nedzinant / YU (5101) und Borovec / BG (5303).

Der multiple Mittelwertvergleich (Tukey-Kramer-Test, $\alpha=0,05)$ der 81 Herkünfte der Fläche 35 ergibt 31 statistisch signifikante Unterschiede. Unter den elf Herkünften mit hohem mittlerem Einzelbaumvolumen befinden sich die deutschen Herkünfte Marsberg (3417), Westerhof (115), Eibenstock Carlsf. (3503), Rungstock (3501), Bischofsreut (3320), Selb-Kirchenlamitz (3433) und Templin (3606). Diese Herkünfte unterschieden sich von mindestens einer von 15 Herkünften mit geringem mittlerem Einzelbaumvolumen. Unter den 15 Herkünften mit geringem Einzelbaumvolumen sind fünf deutsche Herkünfte: Suhl (3518), St. Oswald (3331), Donaueschingen (107), Walchensee (3042) und Rabenstein (3337). Hierbei handelt es sich überwiegend um Herkünfte aus höheren Lagen. Die Herkünfte, die sich von mindestens einer anderen unterscheiden, sind im Anhang 1.15 zusammengestellt.

Folgende neun Herkünfte sind gegenüber dem Standard signifikant volumenärmer: Donaueschingen / D (107), Lobming-Obertal / A (2138), Walchensee / D (3042), Rabenstein Typengemisch / D (3337), Kaludjerske Bare / YU (5102), Smrceve Dolina Abt. 138 / HR (5107), Belogradchik-Tschupreno / BG (5301), Mänttä / SF (8705) und Janakkala Keskivari Uhkoila / SF (8707).

Für die 36 Herkünfte auf der Fläche 36 ergeben die multiplen Mittelwertvergleiche (Tukey-Kramer- und Dunnett-Test, $\alpha=0,05)$ keine gesicherten Unterschiede.

In den Varianzanalysen der Flächen 34 und 35 sind die Einflüsse der Herkunft mit einer Irrtumswahrscheinlichkeit von unter $0,1 \%$ und für die Wiederholung mit unter $1 \%$ abgesichert (Tab. 2.21). Der Einfluss der Herkunft liegt bei etwa $10 \%$, während der der Wiederholung mit $1 \%$ deutlich geringer ist. Auf der Fläche 36 lässt sich kein Einfluss der Herkunft nachweisen. Es gibt keine signifikanten Wechselwirkungen Herkunft x Wiederholung $(\alpha=0,05)$. 
Tab. 2.21: Varianzkomponenten für das Einzelbaumvolumen auf den drei Flächen in Hessen

\begin{tabular}{c|c|c|c|c}
\hline Fläche & Herkunft & Wiederholung & Wechselwirkung & Rest \\
\hline 34 & $8 \% * * *$ & $<1 \% * *$ & 0 & $>91 \%$ \\
35 & $11 \% * * *$ & $1 \% * *$ & 0 & $88 \%$ \\
36 & 0 & $1 \% *$ & $5 \% \mathrm{~ns}$ & $95 \%$ \\
\hline
\end{tabular}

Für das Einzelbaumvolumen, das aus den Wachstumsmerkmalen Höhe und BHD errechnet wird, sind neben den einzelnen Herkünften auch Gruppen von Herkünften analysiert worden.

Bei der Einteilung der Herkünfte nach Herkunftsgruppen, die die Refugialräume der Fichte berücksichtigen, ergibt der multiple Mittelwertvergleich (TukeyKramer-Test, $\alpha=0,05)$ einen gesicherten Unterschied für die Gruppe „Herzynisch-Karpatisch“ mit einem höheren Einzelbaumvolumen gegenüber der Gruppe „Alpin“ auf den Flächen 34 und 35. Auf diesen beiden Flächen hat letztere Gruppe auch ein signifikant geringeres Einzelbaumvolumen als der „Kontaktbereich Herzynisch-Karpatisch zu Alpin“. Auf der Fläche 35 ist das mittlere Einzelbaumvolumen der Gruppe „Baltisch-Nordisch“ außerdem noch höher als das der Gruppe „Alpin“. Die weiteren Unterschiede lassen sich nicht absichern, ebensowenig wie auf der Fläche 36 (Abb. 2.24).

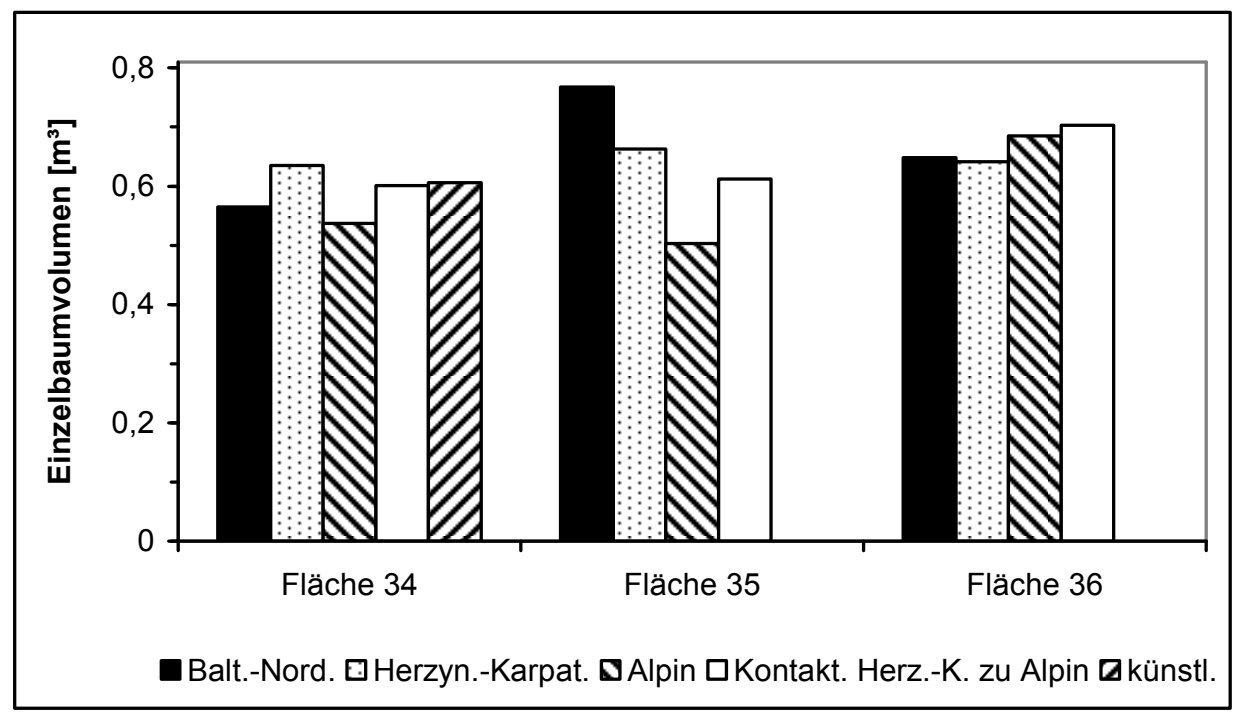

Abb. 2.24: Erwartungswerte für das mittlere Einzelbaumvolumen der Herkunftsgruppen auf den drei Flächen Reinhardshagen / Hessen 
Für die sieben, sich an politisch-geografischen Regionen orientierenden Gruppen sichert der multiple Mittelwertvergleich (Tukey-Kramer-Test, $\alpha=0,05$ ) einen Unterschied auf der Fläche 34 zwischen „Südwest-Europa“ mit einem geringen Einzelbaumvolumen auf der einen Seite gegenüber den vier mitteleuropäischen Gruppen „Österreich“, „ehemalige Tschechoslowakei“, „Deutschland“ und „Polen“ auf der anderen Seite (Abb. 2.25).

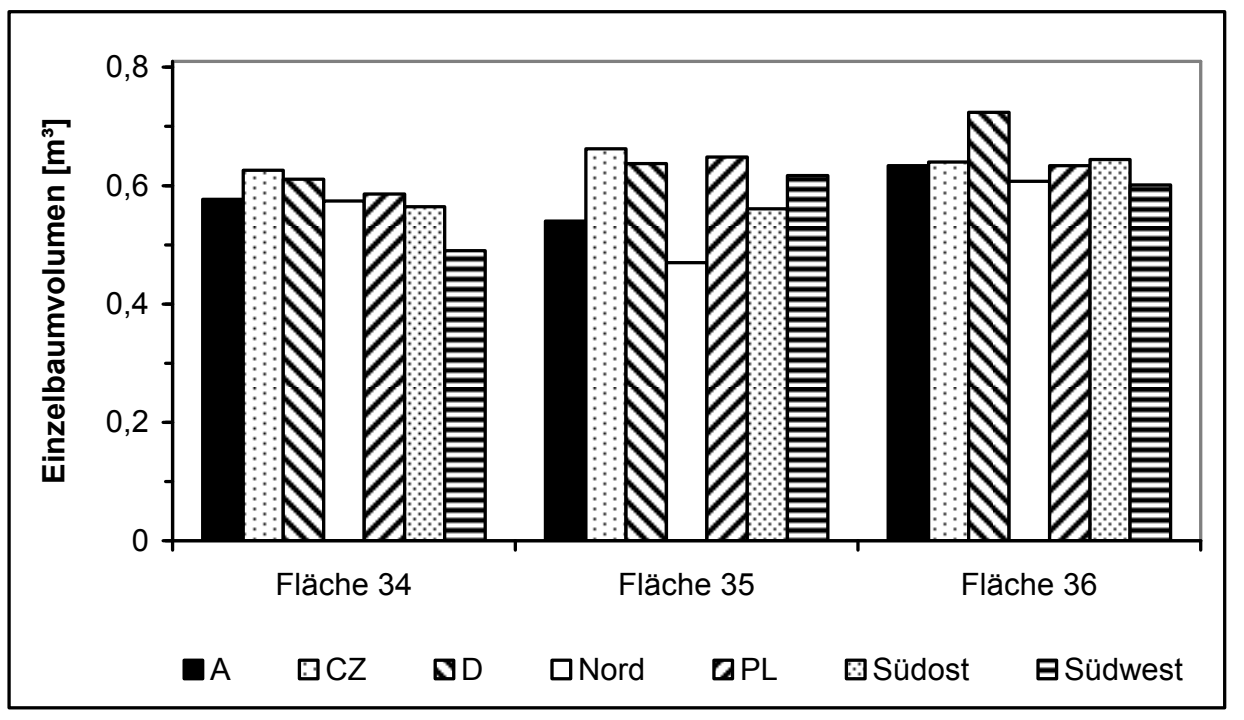

Abb. 2.25: Erwartungswerte für das mittlere Einzelbaumvolumen der Herkünfte gruppiert nach politisch-geografischen Regionen auf den drei Flächen Reinhardshagen / Hessen

Auf der kleineren Fläche 35 mit anderen Herkünften lassen sich Unterschiede zwischen den beiden mitteleuropäischen Gruppen „ehemalige Tschechoslowakei“ und „Deutschland“ mit einem hohen Einzelbaumvolumen gegenüber der Gruppe „Nord-Europa“ sichern. Auf der Fläche 36 gibt es keine gesicherten Unterschiede.

Eine weitere Gruppierung berücksichtigt ausschließlich die Höhenlage der Einsammlungsorte der Saatgutproben. Die Versuchsfläche Reinhardshagen liegt in der Höhenlage zwischen 200 und $650 \mathrm{~m}$ ü. NN. Das größte mittlere Einzelbaumvolumen erzielen auch die Fichten auf den Flächen 34 und 35, deren Einsammlungsorte in dieser Höhenlage liegen (Abb. 2.26). Auf der Fläche 34 lässt sich das höhere Einzelbaumvolumen gegenüber den Höhenlagen „unter 200 m“, „850-

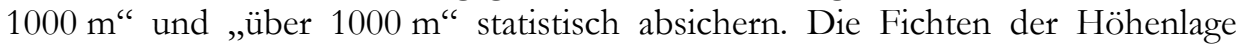
„über 1000 m“ sind außerdem denen aus einer Höhe von „650-850 m“ unterlegen.

Auf der Fläche 35 sind die Unterschiede zwischen der Höhenlage „200-650 m“ gegenüber den Fichten aus den beiden Höhenlagen von über $850 \mathrm{~m}$ signifikant überlegen. Die Fichten aus ,über $1000 \mathrm{~m}$ “ haben außerdem ein geringeres Einzel-

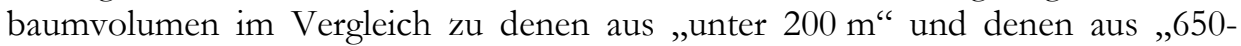
850 m“. Auf der Fläche 36 sind die Unterschiede nicht signifikant. 


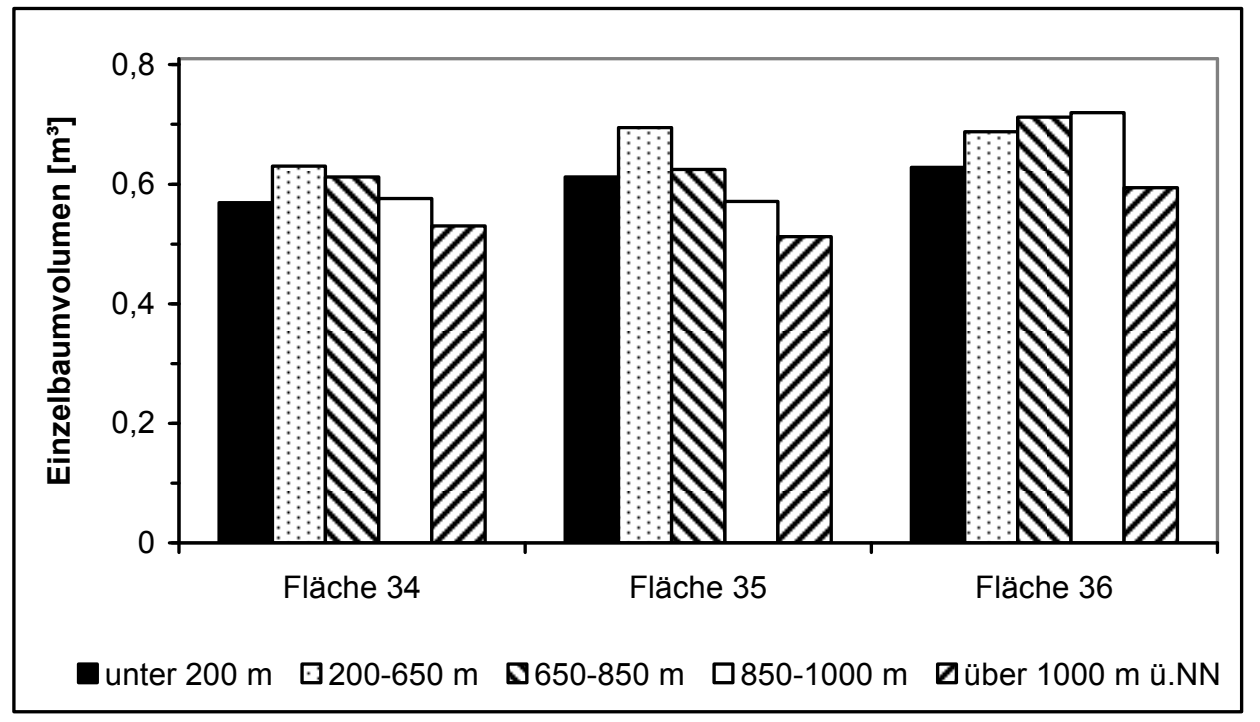

Abb. 2.26: Erwartungswerte für das mittlere Einzelbaumvolumen der Herkünfte gruppiert nach fünf Höhenlagen auf den drei Flächen Reinhardshagen / Hessen

\section{Vorrat pro Hektar}

In die Vorratsermittlung je Hektar gehen die drei Merkmale Stammzahl sowie BHD- und Höhenwachstum im Alter von 39 Jahren ein. Im Mittel über alle 286 Herkünfte beträgt der mittlere Vorrat $409 \mathrm{~m}^{3} /$ ha (Tab. 2.22). Zwischen den Herkünften (Anhang 1.13) variiert der errechnete Vorrat zwischen $40 \mathrm{~m}^{3} / \mathrm{ha}(8705$ Mänttä / SF) und $805 \mathrm{~m}^{3} /$ ha (3417 Marsberg / D). Dies entspricht $10 \%$ bzw. 197 \% vom Mittel der drei hessischen Flächen. Beide Herkünfte werden auf der Versuchsfläche 35 getestet. Der geringe Vorrat der finnischen Herkunft hat seine Ursache auch in der Tatsache, dass diese Herkunft nicht in allen Parzellen vollständig ausgepflanzt wurde. Bei den weiteren Analysen der Vorräte pro Hektar bleiben daher die zehn Herkünfte, bei denen bei der Versuchsanlage auf den einzelnen Flächen in Hessen keine ausreichende Pflanzenanzahl verfügbar war, unberücksichtigt. 
Tab. 2.22: $\quad$ Mittlerer Vorrat/ha (alle 286 Herkïnfte) auf den drei Flächen Reinhardshagen, Standardabweichung, Variationskoeffizient (VK), Minimum und Maximum

\begin{tabular}{c|c|c|c|c|c|c}
\hline Fläche & $\begin{array}{c}\text { Herkünfte } \\
{[\mathrm{n}]}\end{array}$ & $\begin{array}{c}\text { Mittel } \\
{\left[\mathrm{m}^{3} / \mathrm{ha}\right]}\end{array}$ & $\begin{array}{c}\text { Standardabw. } \\
{\left[\mathrm{m}^{3} / \mathrm{ha}\right]}\end{array}$ & $\begin{array}{c}\text { VK } \\
{[\%]}\end{array}$ & $\begin{array}{c}\text { Min. } \\
{\left[\mathrm{m}^{3} / \mathrm{ha}\right]}\end{array}$ & $\begin{array}{c}\text { Max. } \\
{\left[\mathrm{m}^{3} / \mathrm{ha}\right]}\end{array}$ \\
\hline 34 & 169 & 400 & 88 & 22 & 165 & 664 \\
35 & 81 & 413 & 111 & 27 & 41 & 805 \\
36 & 36 & 444 & 79 & 18 & 296 & 620 \\
gesamt & 286 & 409 & 95 & 23 & 41 & 805 \\
\hline
\end{tabular}

Der multiple Mittelwertvergleich (Tukey-Kramer-Test, $\alpha=0,05)$ der 159 Herkünfte der Fläche 35 ergibt 24 statistisch gesicherte Unterschiede zwischen den bis $\mathrm{zu}$ sieben vorratsreichsten Herkünften und zwölf vorratsärmsten Herkünften. Diese Herkünfte sind im Anhang 1.16 aufgelistet. Unter den Herkünften mit hohem Vorrat pro Hektar sind die deutschen Herkünfte Winterberg (3412) und Dombühl (3421). Unter den Herkünften mit einem geringen Vorrat pro Hektar, die überwiegend aus Hochlagen oder aus Schweden stammen, ist die deutsche Absaat: Neureichenau 1200 m ü. NN (3326).

Gegenüber dem Standard sind folgende zwei Herkünfte aus der Schweiz signifikant vorratsärmer (Dunnett-Test, $\alpha=0,05)$ : Airolo, Bedretto / CH (734) und Bex, Tarejanne / CH (740).

Auf der Fläche 35 sind bei der Versuchsanlage 76 der 81 Herkünfte vollständig ausgepflanzt worden. 58 der Vergleiche (Tukey-Kramer-Test, $\alpha=0,05$ ) ergeben statistisch gesicherte Unterschiede zwischen den bis zu elf vorratsreichsten Herkünften und 41 vorratsärmsten Herkünften. Diese Herkünfte sind im Anhang 1.17 aufgelistet. Unter den Herkünften mit hohem Vorrat pro Hektar sind die deutschen Herkünfte Marsberg (3417), Selb-Kirchenlamitz (3433), Eibenstock Carlsf. (3503), Templin (3606) und Westerhof (115).

Bei den Herkünften mit einem geringen Vorrat pro Hektar handelt es sich überwiegend um solche aus höheren bzw. niedrigeren Lagen oder um Absaaten, die weit vom Versuchsort entfernt eingesammelt wurden.

Gegenüber dem Standard sind 19 Herkünfte signifikant vorratsärmer (Dunnett-Test, $\alpha=0,05$ ) (Tab. 2.23). Dies sind Herkünfte aus Hochlagen oder aus niederen Lagen des nordöstlichen Verbreitungsgebiets der Fichte (PL, SU). 
Tab. 2.23: $\quad$ Zusammenstellung der gegenüber dem Standard $\left(601 \mathrm{~m}^{3} / \mathrm{ha}\right)$ vorratsärmeren Herkü̈fte der Fläche 35 im Alter 39

\begin{tabular}{c|cl|c|c}
\hline Land & Herkunft & $\begin{array}{c}\text { Höhe } \\
{[\mathrm{m} \mathrm{ü.} \mathrm{NN]}]}\end{array}$ & $\begin{array}{c}\text { Erwartungswert } \\
{\left[\mathrm{m}^{3} / \text { ha }\right]}\end{array}$ \\
\hline D & 107 & Donaueschingen & 750 & 348 \\
D & 111 & Bodenmais & 1225 & 346 \\
D & 3042 & Walchensee & 1100 & 303 \\
D & 3102 & Schluchsee & 1200 & 342 \\
D & 3139 & Isny & 850 & 300 \\
D & 3334 & Zwiesel-Ost, Plattenfichten & 1200 & 284 \\
D & 3337 & Rabenstein & 1200 & 298 \\
A & 2137 & Buchberg Flachwald & 1300 & 321 \\
A & 2138 & Buchberg Aegidiwald & 925 & 322 \\
A & 2151 & Breitenau Mixnitz & 970 & 273 \\
A & 2158 & Rohr im Geb. & 825 & 359 \\
A & 2207 & Seewiesen & 875 & 309 \\
YU & 5102 & Kaludjerske Bare & 1000 & 275 \\
HR & 5107 & Smrceve Dolina & 1350 & 163 \\
BG & 5301 & Belogradtschik, Tschuprene & 1400 & 221 \\
PL & 6732 & Szczytna Slaska & 700 & 352 \\
PL & 6235 & Zwierzyniec & 150 & 354 \\
SU & 7224 & Ostrovsk & 200 & 339 \\
SU & 7422 & Rjasan, Moshary & 150 & 303 \\
\hline
\end{tabular}

Für die 36 Herkünfte auf der Fläche 36 ergeben die multiplen Mittelwertvergleiche (Tukey-Kramer- und Dunnett-Test, $\alpha=0,05$ ) keine gesicherten Unterschiede.

In den Varianzanalysen der Flächen 34 und 35 sind die Einflüsse der Herkunft und der Wiederholung mit einer Irrtumswahrscheinlichkeit von unter 0,1\% abgesichert (Tab. 2.24). Der Einfluss der Herkunft liegt auf den Flächen 34 und 35 bei 26 bzw. $36 \%$ und der der Wiederholung bei maximal $5 \%$. Auf der Fläche 36 lässt sich kein Einfluss von Herkunft bzw. Wiederholung nachweisen.

Tab. 2.24: Varianzkomponenten für den Vorrat pro Hektar auf den drei Flächen in Hessen

\begin{tabular}{c|c|c|c}
\hline Fläche & Herkunft & Wiederholung & Rest \\
\hline 34 & $26 \% * * *$ & $3 \% * * *$ & $71 \%$ \\
35 & $36 \% * * *$ & $5 \% * * *$ & $59 \%$ \\
36 & 0 & 0 & $100 \%$ \\
\hline
\end{tabular}


Wie für das Einzelbaumvolumen sind auch beim Vorrat pro Hektar, der aus den Wachstumsmerkmalen Höhe und BHD sowie der Stammzahl errechnet wird, neben den einzelnen Herkünften auch Gruppen von Herkünften analysiert worden.

Bei der Einteilung der Herkünfte in Refugialräume ergibt der multiple Mittelwertvergleich (Tukey-Kramer-Test, $\alpha=0,05$ ) einen gesicherten Unterschied für die Gruppe „Herzynisch-Karpatisch“ mit einem höheren Vorrat gegenüber der Gruppe „Alpin“ und der „Baltisch-Nordischen“ auf der Fläche 34. Auf der Fläche 35 ist der Unterschied nur zur Gruppe „Alpin“ signifikant. Auf beiden Flächen 34 und 35 gibt es auch einen Unterschied zwischen dem vorratsreicheren „Kontaktbereich Herzynisch-Karpatisch zu Alpin“ und der Gruppe „Alpin“. Keine Unterschiede lassen sich auf der Fläche 36 absichern (Abb. 2.27).

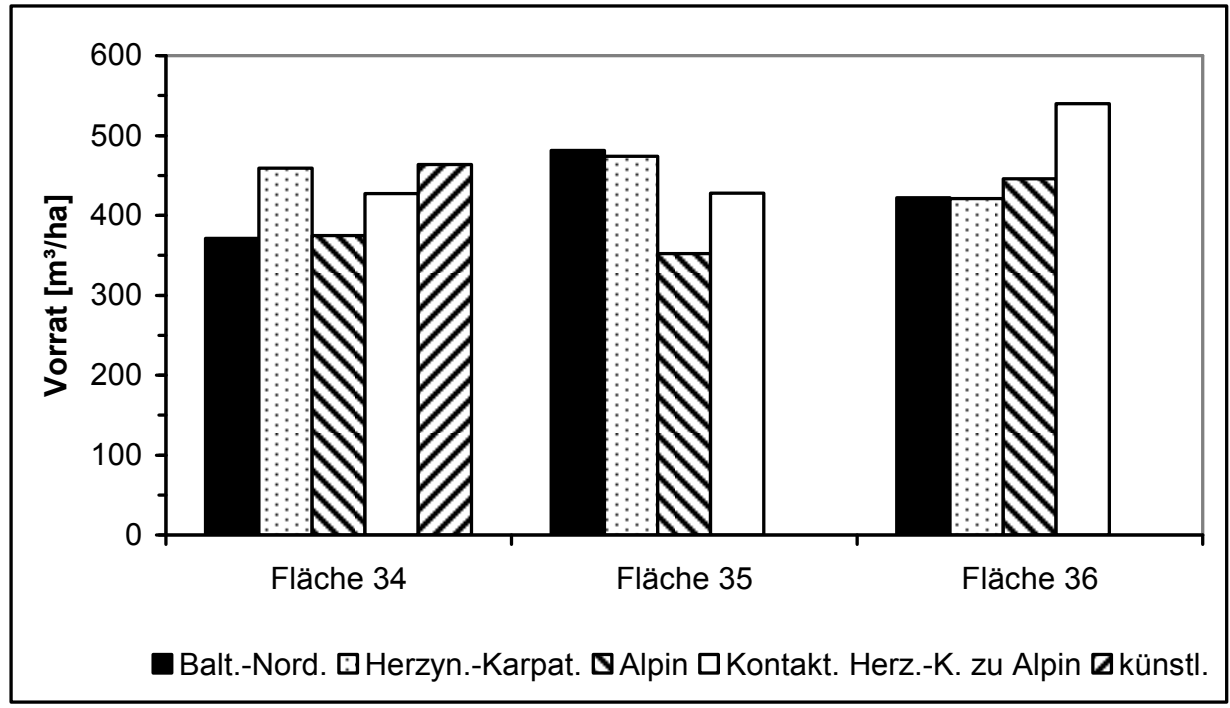

Abb. 2.27: Erwartungswerte für den Vorrat pro Hektar der Herkunftsgruppen auf den drei Flächen Reinhardshagen / Hessen 


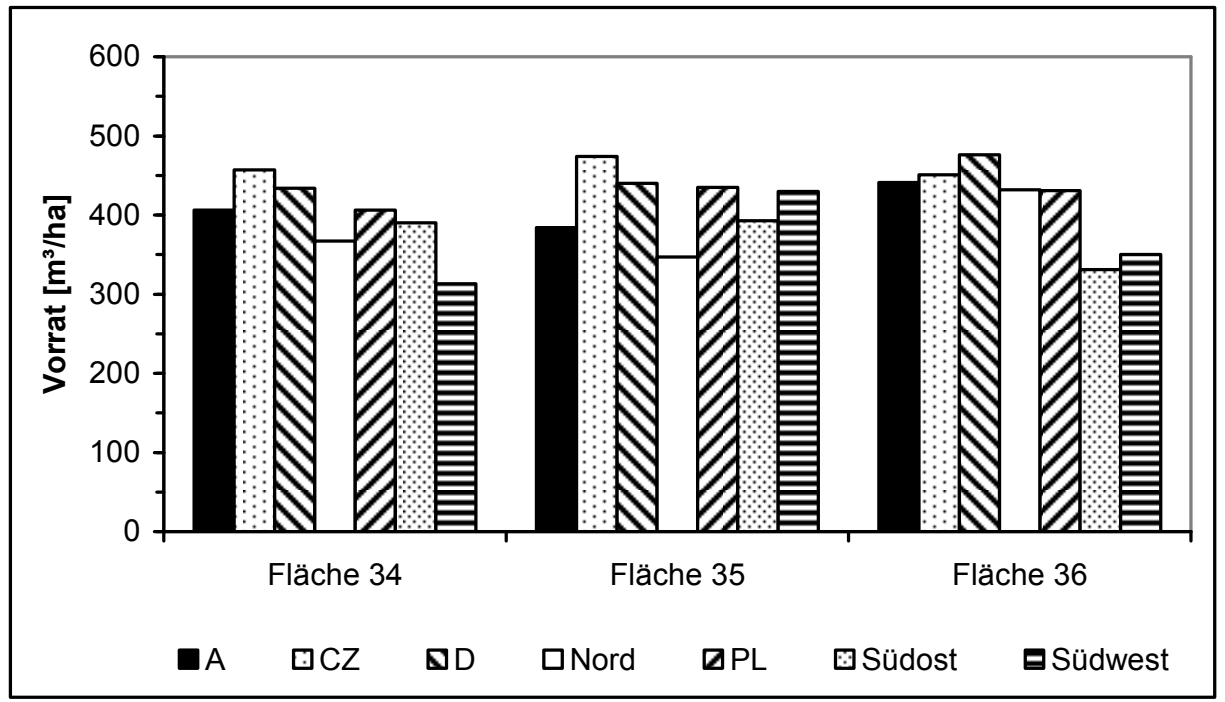

Abb. 2.28: Erwartungswerte für den Vorrat pro Hektar der Herkïnfte gruppiert nach politisch-geografischen Regionen auf den drei Flächen Reinhardshagen / Hessen

Für die sieben, sich an politisch-geografischen Regionen orientierenden Gruppen sichert der multiple Mittelwertvergleich (Tukey-Kramer-Test, $\alpha=0,05$ ) nur Unterschiede auf der Fläche 34 (Abb. 2.28). Hier unterscheidet sich das vorratsarme „Südwest-Europa“ von den mitteleuropäischen Gruppen „Österreich“, „ehemalige Tschechoslowakei“, „Deutschland“ und „Polen“ sowie zur Gruppe „SüdostEuropa“. Außerdem lassen sich Unterschiede zwischen der „ehemaligen Tschechoslowakei“ und dem vorratsärmeren „Nord-Europa“ absichern. Auf den Flächen 35 und 36 gibt es keine gesicherten Unterschiede.

Der höchste Vorrat wird auf den Flächen 34 und 35 für die Höhenlage zwischen 200 und $650 \mathrm{~m}$ ü. NN. geschätzt, in der auch die Versuchsfläche Reinhardshagen liegt (Abb. 2.29). Auf der Fläche 34 lassen sich Unterschiede im Vorrat zwischen den Fichten aus der vorratsarmen Höhenlage „über 1000 m“ und den Höhenlagen zwischen 200 und 1000 ü. NN absichern. Außerdem ist der Unterschied zwischen der Höhenlage „unter 200 m“ und der von „200-650 m“ signifikant.

Die Fichten der Höhenlage ,200-650 m“ sind auf der Fläche 35 statistisch vorratsreicher als die der Höhenlagen „unter $200 \mathrm{~m}$ “, „850-1000 m“ und „über 1000 m“. Gegenüber der Höhenlage „über 1000 m“ ist auch die Höhenlage „650850 m“ signifikant vorratsreicher. Der letztere Unterschied lässt sich auf der Fläche 36 statistisch absichern. 


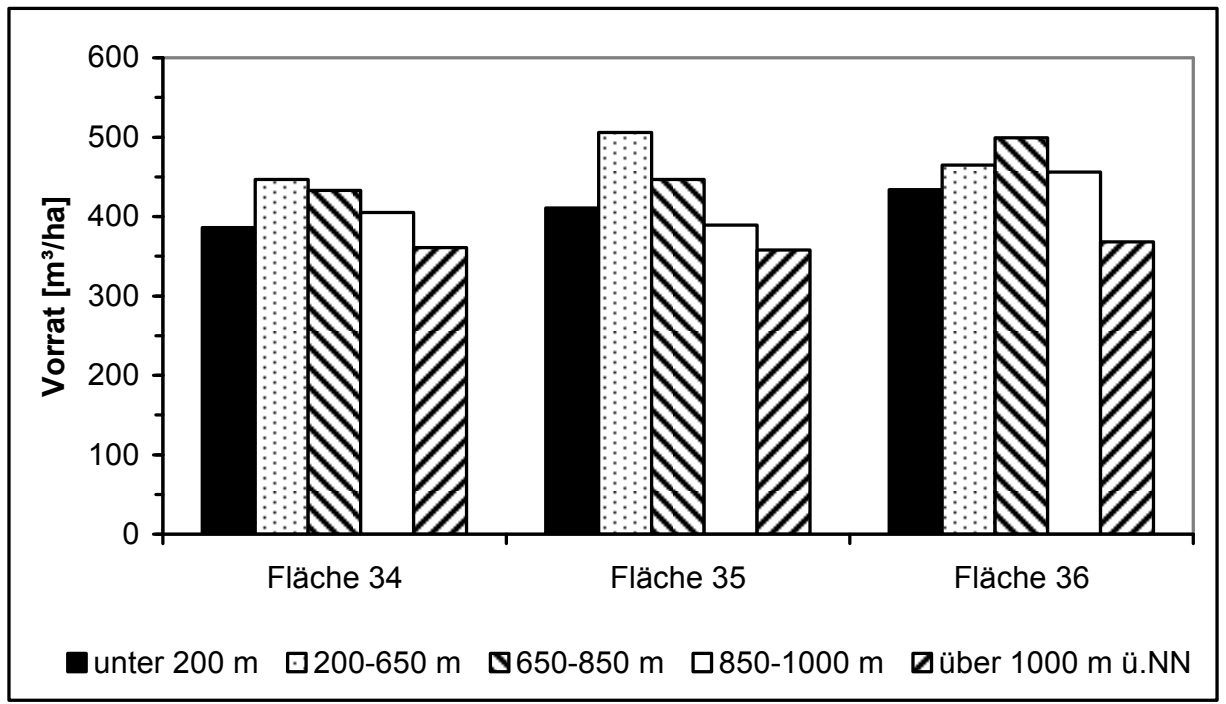

Abb. 2.29: $\quad$ Erwartungswerte für den mittleren Vorrat pro Hektar der Herkü̈fte gruppiert nach fünf Höhenlagen auf den drei Flächen Reinhardshagen/ Hessen

\subsubsection{Hasbruch / Niedersachsen}

\section{Entwicklung der Pflanzenanzabl}

Im Alter von 32 Jahren befinden sich im Jahr 1993 auf der Versuchsfläche Hasbruch $61 \%$ der ursprünglich gepflanzten Fichten. Zwischen den drei Teilflächen variiert der Anteil der lebenden Fichten zwischen 60\% (Fläche mit 168 Herkünften, eine Herkunft wurde nicht ausgepflanzt) und $67 \%$ (36 Herkünfte).

Sieben Jahre später sind im Alter von 39 Jahren noch $21 \%$ der ursprünglich gepflanzten Fichten auf den drei Flächen anzutreffen. Für die einzelnen drei Flächen beträgt der Anteil der lebenden Bäume 18\% (Fläche mit 81 Herkünften), $19 \%$ (36 Herkünfte) und $22 \%$ (168 Herkünfte). Für alle drei Teilflächen ergibt die Auswertung der Erfassung aus dem Jahr 2000 somit einen Anteil der fehlenden Bäume von etwa 80 \% (Abb. 2.30). Der Rückgang der Pflanzenanzahl ist vor allem auf natürliche Ausfälle und Absterbeerscheinungen zurückzuführen. Dies bestätigen die starken Nadelschäden der noch lebenden Fichten. Die abgestorbenen Bäume sind vermutlich entfernt worden, ohne dass es sich um eine Durchforstung gehandelt hat. 


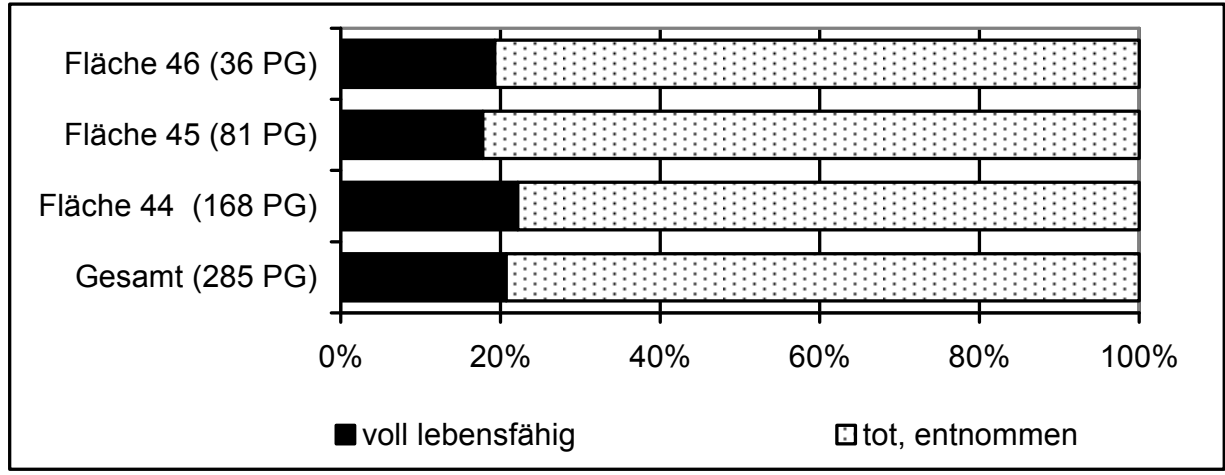

Abb. 2.30: Ergebnis der Erhebung des Vorbandenseins der Fichten im Alter von 39 Jahren auf den Versuchsflächen Hasbruch (PG = Prüfglieder)

Die Anzahl der im Alter von 32 bzw. 39 Jahren lebenden Fichten pro Herkunft, an denen die Merkmale Höhe bzw. BHD gemessen wurden, sind im Anhang 1.18 getrennt für die drei Versuchsflächen zusammengestellt.

\section{Schäden}

Aus dem Jahr 1993 liegt für das Alter von 32 Jahren eine Erfassung der Schadmerkmale „Schneedruck / Windwurf“, „Schnee- und Windbruch“ und „Käferfraß" vor. Auf den drei Flächen sind zusammen nur 64 Bäume, und zwar 57 mit Schneedruck / Windwurf, vier mit Schnee- und Windbruch und drei mit Käferfraß notiert worden. Die Schäden sind äußerst selten aufgetreten und gleichmäßig über die drei Teilversuche sowie über die Herkünfte verteilt (Abb. 2.31). Etwa die Hälfte der mit einem Schaden bonitierten Bäume ist in der zweiten Wiederholung der Fläche 45 aufgetreten. Diese Wiederholung bildet den südlichen Abschluss der Versuchsfläche und grenzt an eine landwirtschaftliche Fläche. Nur bei der Herkunft Spiegelau / D (Nr. 3229) sind vier Fichten und bei der Herkunft Westerhof 51 B (3404) drei Fichten vom Wind geworfen worden. 


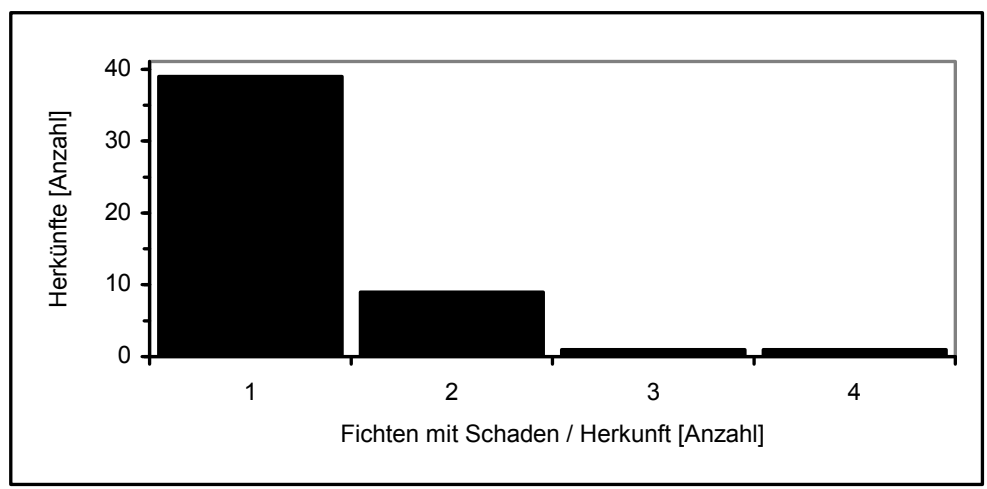

Abb. 2.31: Histogramm für die absoluten Häufigkeiten der Fichten je Herkunft mit einem Schadmerkmal bei der Erfassung im Alter von 32 Jahren auf den Flächen Hasbruch

Als weitere Schädigung sind „Nadelverfärbungen/ -verluste“ aufgenommen worden. Das Ergebnis der Erfassung zeigt, dass auf allen drei Teilversuchen nur $10 \%$ der Fichten eine leichte Nadelverfärbung aufweisen. Der überwiegende Anteil der Fichten hat starke Nadelverfärbungen bzw. zumindest leichte Nadelverluste (47\%) oder starke Nadelverluste (43\%). Auffallend hoch ist der Anteil mit starken Nadelverlusten (49\%) auf der Fläche 44 (168 Herkünfte) und gering der Anteil der Fichten mit leichten Nadelverfärbungen (7\%) (Abb. 2.32).

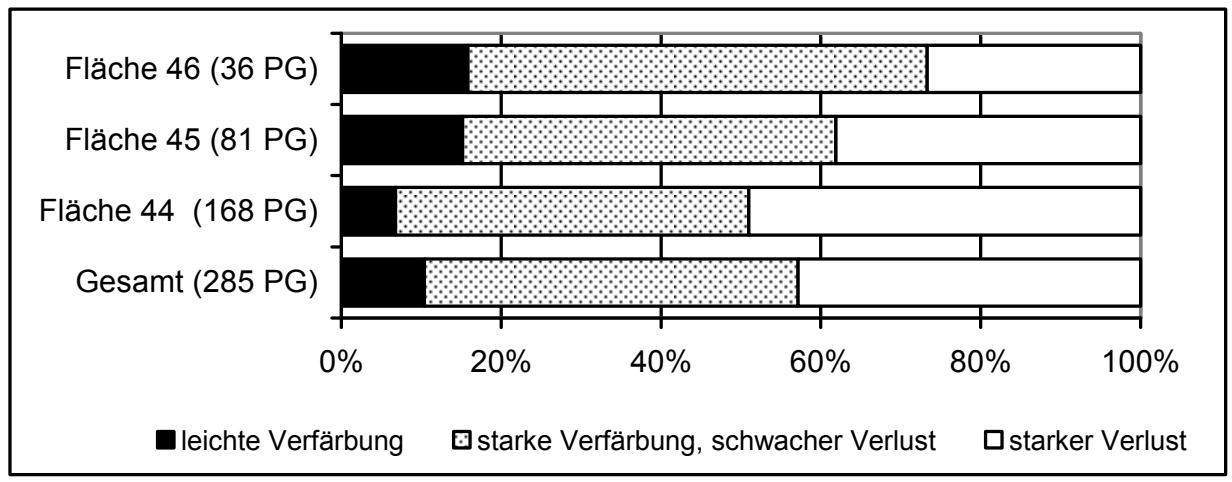

Abb. 2.32: Ergebnis der Bonitur von Nadelverfärbung/-verlust im Alter von 32 Jabren auf den drei Versuchsflächen Hasbruch / Niedersachsen (PG = Prüfglieder)

Bei der sieben Jahre später erfolgten Aufnahme im Alter von 39 Jahren sind keine Bonituren von Schädigungen durchgeführt worden. Insgesamt werden die Fichten als wenig vital mit hohen Nadelverlusten beschrieben - der Grund, warum die Versuchsfläche aufgegeben wird. 


\section{Stammform}

Im Alter von 32 Jahren liegt von 8.428 Fichten auf den drei Flächen in Niedersachsen eine Bonitur der Stammform vor. Im Ergebnis sind $83 \%$ der Stämme gerade und $16 \%$ stark gekrümmt. Weitere 61 Fichten haben einen Zwiesel und bei einer ist ein Korb bzw. Bajonett notiert worden (Abb. 2.33). Zwischen den Flächen gibt es keine Unterschiede im Anteil der geraden Stämme. Der Anteil variiert zwischen $82 \%$ auf der Fläche 44 mit 168 Herkünften und auf der Fläche 46 mit 36 Herkünften sowie $85 \%$ auf der Fläche 45 mit 81 Herkünften. Bei der jüngsten Erhebung im Jahre 2000 ist die Form nicht beurteilt worden.

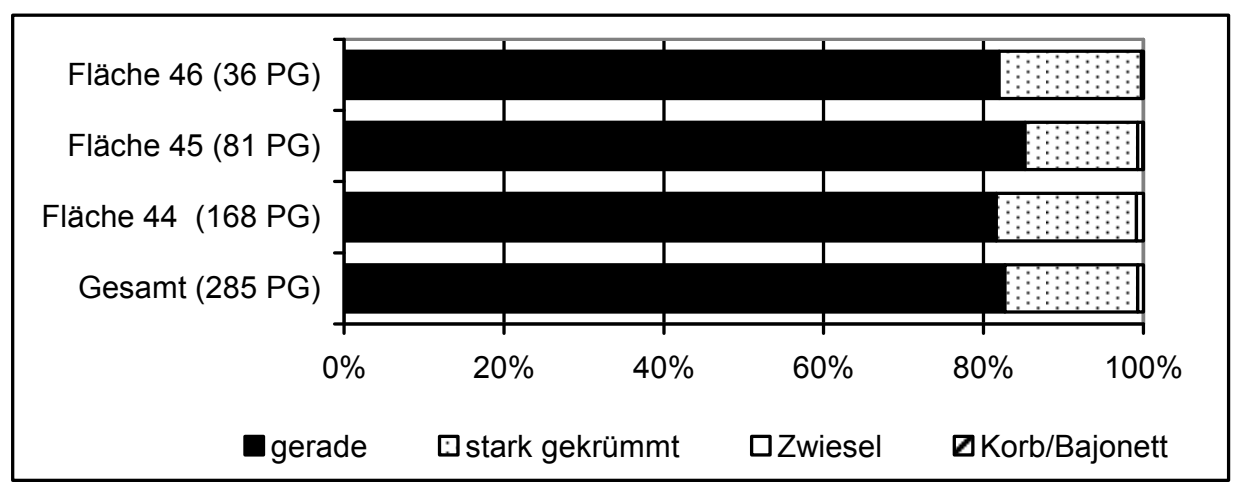

Abb. 2.33: Ergebnis der Stammformbonitur im Alter von 32 Jahren auf den drei Versuchsflächen Hasbruch / Niedersachsen (PG = Prüfglieder)

\section{Ovalität}

Ein weiteres Maß zur Beurteilung der Qualität ist die Abweichung des Stammquerschnittes von der Kreisform. Die Ovalität lässt sich für das Alter von 32 und 39 Jahren bestimmen, da in diesen Jahren der BHD durch zwei Messungen (kreuzweise) mit der Kluppe ermittelt und beide Werte aufgenommen wurden. Sie beträgt im Mittel über alle Fichten der drei Versuchsflächen in Niedersachsen 3,3 \% im Alter von 32 Jahren und 3,4 \% im Alter von 39 Jahren. Für die einzelnen Versuche sind die Werte in Tabelle 2.25 zusammengestellt. Die ermittelten Ovalitäten sind zwischen den beiden Messjahren über alle Herkünfte und über die Herkünfte innerhalb der Versuchsfläche 44 korreliert (Tab. 2.25). Die mittleren Ovalitäten der einzelnen Herkünfte auf den drei Versuchsflächen 44, 45 und 46 sind im Anhang 1.19 zusammengestellt. 
Tab. 2.25: $\quad$ Mittlere Ovalitäten [\%] der Herkünfte im Alter von 32 und 39 Jahren auf den Flächen in Niedersachsen und deren Korrelation

\begin{tabular}{c|c|c|c|c}
\hline Versuch & $\begin{array}{c}\text { Herkünfte } \\
{[\mathrm{n}]}\end{array}$ & $\begin{array}{c}32-\mathrm{j} . \\
\text { Min Mittel Max }\end{array}$ & $\begin{array}{c}39-\mathrm{j} . \\
\text { Min Mittel Max }\end{array}$ & $\begin{array}{c}\text { Korrelation } \\
\mathrm{r}_{\mathrm{P}}\end{array}$ \\
\hline 44 & 168 & $2,2 \ldots 3,3 \ldots 5,3$ & $1,0 \ldots 3,2 \ldots 11,0$ & $0,243^{* *}$ \\
45 & 81 & $2,4 \ldots 3,4 \ldots 6,1$ & $1,7 \ldots 3,9 \ldots 16,2$ & $0,130 \mathrm{~ns}$ \\
46 & 36 & $2,2 \ldots 3,4 \ldots 4,4$ & $1,9 \ldots 3,3 \ldots 5,2$ & $0,169 \mathrm{~ns}$ \\
gesamt & 285 & $2,2 \ldots 3,3 \ldots 6,1$ & $1,0 \ldots 3,4 \ldots 16,2$ & $0,194^{* * *}$ \\
\hline
\end{tabular}

Im Alter von 39 Jahren lassen sich auf der Versuchsfläche 44 die Unterschiede zwischen der Herkunft 178 Abtenau / A (mit der größten Abweichung von der Kreisform, adjustierter Erwartungswert 14,4\%) von allen Herkünften außer der Herkunft 3410 Traunstein / D (adjustierter Erwatungswert 6,5\%) statistisch absichern (Tukey-Kramer-Test, $\alpha=0,05$; Anhang 1.20). Auch vom Standard (4,0 \%) unterscheidet sich die Herkunft 178 Abtenau / A (Dunnett-Test, $\alpha=0,05)$.

Auf den Flächen 45 und 46 lassen sich keine Unterschiede sichern (TukeyKramer-Test, $\alpha=0,05)$. Auf der Fläche 45 liegt ein signifikanter Unterschied zwischen der Herkunft 6624 Przysucha / PL mit der größten Abweichung von der Kreisform (adjustierter Erwartungswert 11,3\%) und dem Standard (3,6\%) vor. Auf der Fläche 46 lassen sich keine Unterschiede zum Standard sichern (DunnettTest, $\alpha=0,05)$.

Im Alter von 32 Jahren sichert der Tukey-Kramer-Test $(\alpha=0,05)$ keine Unterschiede zwischen den Herkünften. Auch der Dunnett-Test $(\alpha=0,05)$ deckt keine Unterschiede gegenüber dem Standard auf.

Die Varianzkomponentenschätzung zeigt (Tab. 2.26), dass sich weder mit der Herkunft noch der Wiederholung bzw. deren Wechselwirkung die Merkmalsausprägung im Alter 32 erklären lässt. Auch im Alter von 39 Jahren erklären diese Einflussgrößen die Merkmalsausprägung nicht oder nur gering (Tab. 2.27).

Tab. 2.26: Varianzkomponentenschätzung des Merkmals Ovalität im Alter 32

\begin{tabular}{c|c|c|c|c}
\hline Versuch & Prüfglied & Wiederholung & Prüfglied * Wiederh. & Rest \\
\hline 44 & $0 \%$ & $0 \%$ & $1 \% \mathrm{~ns}$ & $99 \%$ \\
45 & $0 \%$ & $0 \%$ & $1 \% \mathrm{~ns}$ & $99 \%$ \\
46 & $0 \%$ & $0 \%$ & $1 \% \mathrm{~ns}$ & $99 \%$ \\
\hline
\end{tabular}


Tab. 2.27: Varianzkomponentenschätzung des Merkmals Ovalität im Alter 39

\begin{tabular}{c|c|c|c|c}
\hline Versuch & Prüfglied & Wiederholung & Prüfglied * Wiederh. & Rest \\
\hline 44 & $0 \%$ & $0 \%$ & $9 \% * * *$ & $91 \%$ \\
45 & $3 \% \mathrm{~ns}$ & $1 \% * *$ & $0 \%$ & $96 \%$ \\
46 & $0 \%$ & $0 \%$ & $9 \% \mathrm{~ns}$ & $91 \%$ \\
\hline
\end{tabular}

Die Güte dieses Maßes lässt sich jedoch nicht beurteilen, da keine Aufzeichnungen vorliegen, aus denen hervorgeht, dass jeweils die dickste und dünnste Richtung in 1,3 m Höhe gemessen wurde.

\section{H/D-Verbältnis}

Für die 285 Herkünfte beträgt das mittlere Höhen-Durchmesser-Verhältnis $76 \mathrm{im}$ Alter 39 und variiert zwischen 63 (Nr. 3505 Eibenstock Carlsfeld 275 / D im Versuch 44) und 115 (Nr. 4123 Javorova Dolina 155 A / CS im Versuch 45). Die mittleren H/D-Verhältnisse der drei Versuchsflächen sind in Tabelle 2.28 zusammengestellt. Sie sind auf den drei Flächen sehr ähnlich und variieren im Mittel zwischen 75 (Versuch 44) und 79 (Versuch 46).

Tab. 2.28: $\quad$ Mittlere H/D-Verbältnisse der Herkünfte im Alter von 39 Jahren auf den Flächen in Niedersachsen

\begin{tabular}{c|c|c|c|c}
\hline Versuch & $\begin{array}{c}\text { Herkünfte } \\
{[\mathrm{n}]}\end{array}$ & $\begin{array}{c}39-\mathrm{j} . \\
\text { Min Mittel Max }\end{array}$ & $\begin{array}{c}\text { Standard- } \\
\text { abweichung }\end{array}$ & $\begin{array}{c}\text { Variations- } \\
\text { koeffizient [\%] }\end{array}$ \\
\hline 44 & 168 & $63 \ldots 75 \ldots 87$ & 6 & 7 \\
45 & 81 & $67 \ldots 77 \ldots 115$ & 7 & 9 \\
46 & 36 & $69 \ldots 79 \ldots 93$ & 5 & 7 \\
Hasbruch & 285 & $63 \ldots 76 \ldots 115$ & 6 & 8 \\
\hline
\end{tabular}

Die H/D-Verhältnisse der einzelnen Prüfglieder im Alter von 39 Jahren sind in Anhang 1.19 zusammengestellt. Die Unterschiede $(\alpha=0,05)$ zwischen den 168 Herkünften auf der Fläche 44 lassen sich in multiplen Mittelwertvergleichen (Tukey-Kramer- bzw. Dunnett-Test, $\alpha=0,05$ ) nicht absichern.

Auf der Fläche 45 gibt es einen Unterschied zwischen dem schlanksten Prüfglied Nr. 4123 (Javorova Dolina 155 A / CS) einerseits und 75 abholzigeren Herkünften andererseits, die im Anhang 1.21 aufgelistet sind. Auch im Vergleich zum Standard $\left(\mathrm{HD}_{\mathrm{adj} .}=74\right)$ lässt sich auf der Versuchsfläche 45 ein Unterschied zum Prüfglied 4123 Javorova Dolina 155 A / CS (HD adj. = 125) sichern (Dunnett-Test, $\alpha=0,05)$. 
Im multiplen Mittelwertvergleich (Tukey-Kramer-Test, $\alpha=0,05)$ lassen sich im Alter von 39 Jahren beim H/D-Verhältnis keine Unterschiede $(\alpha=0,05)$ zwischen den 36 Herkünften auf der Fläche 46 absichern. Im Vergleich zum Standard $\left(\mathrm{HD}_{\text {adj. }}=74\right)$ ist die Herkunft 7240 Witebsk / SU $\left(\mathrm{HD}_{\text {adj. }}=91\right)$ signifikant schlanker (Dunnett-Test, $\alpha=0,05$ ).

Die Varianzkomponentenschätzung zeigt (Tab. 2.29), dass auf den Flächen 44 und 45 der durch die Herkunft und Wiederholung erklärte Anteil des H/DVerhältnisses gering ist und dass Wechselwirkungen zwischen Herkunft und Wiederholung auftreten. Auf der Fläche 46 lässt sich kein Einfluss der berücksichtigten Parameter nachweisen.

Tab. 2.29: Varianækomponentenschätzung des H/D-Verhältnisses im Alter 39

\begin{tabular}{c|c|c|c|c}
\hline Versuch & Prüfglied & Wiederholung & Prüfglied * Wiederh. & Rest \\
\hline 44 & $4 \% * * *$ & $4 \% * * *$ & $13 \% * *$ & $79 \%$ \\
45 & $3 \% * * *$ & $2 \% * *$ & $17 \% * *$ & $78 \%$ \\
46 & $4 \% \mathrm{~ns}$ & $0 \%$ & $0 \%$ & $96 \%$ \\
\hline
\end{tabular}

\section{Höhen- und BHD-Wachstum}

Im Vergleich zur Ertragstafel (WIEDEMANN 1936/1942) ist das Wachstum der Fichte auf den drei Flächen in Hasbruch gut. Über alle Herkünfte der drei Versuchsflächen wird im Alter von 39 Jahren ein mittlerer BHD von 16,1 cm und eine mittlere Höhe von 14,0 m errechnet. Beim BHD beträgt der Variationskoeffizient $18 \%$ und bei der Baumhöhe $11 \%$ der Herkunftsmittelwerte. Die mittleren Wachstumswerte der einzelnen Herkünfte sind in Anhang 1.22 zusammengestellt.

Die Berechnung der Baumhöhen beruht auf einer Stichprobe von meist zwei oder drei Bäumen je Herkunft und Wiederholung, zusammen 1.726 Fichten $(60 \%$ der noch vorhandenen Bäume). In Abbildung 2.34 sind ausgewählte statistische Parameter zum Höhenwachstum für die drei Versuchsflächen in Niedersachsen gegenübergestellt. Im Mittel sind die Baumhöhen auf den drei Versuchsflächen ähnlich. Zwischen dem Mittel des Standards aus fünf deutschen Herkünften und dem jeweiligen Versuchsflächenmittel bestehen keine Unterschiede. 


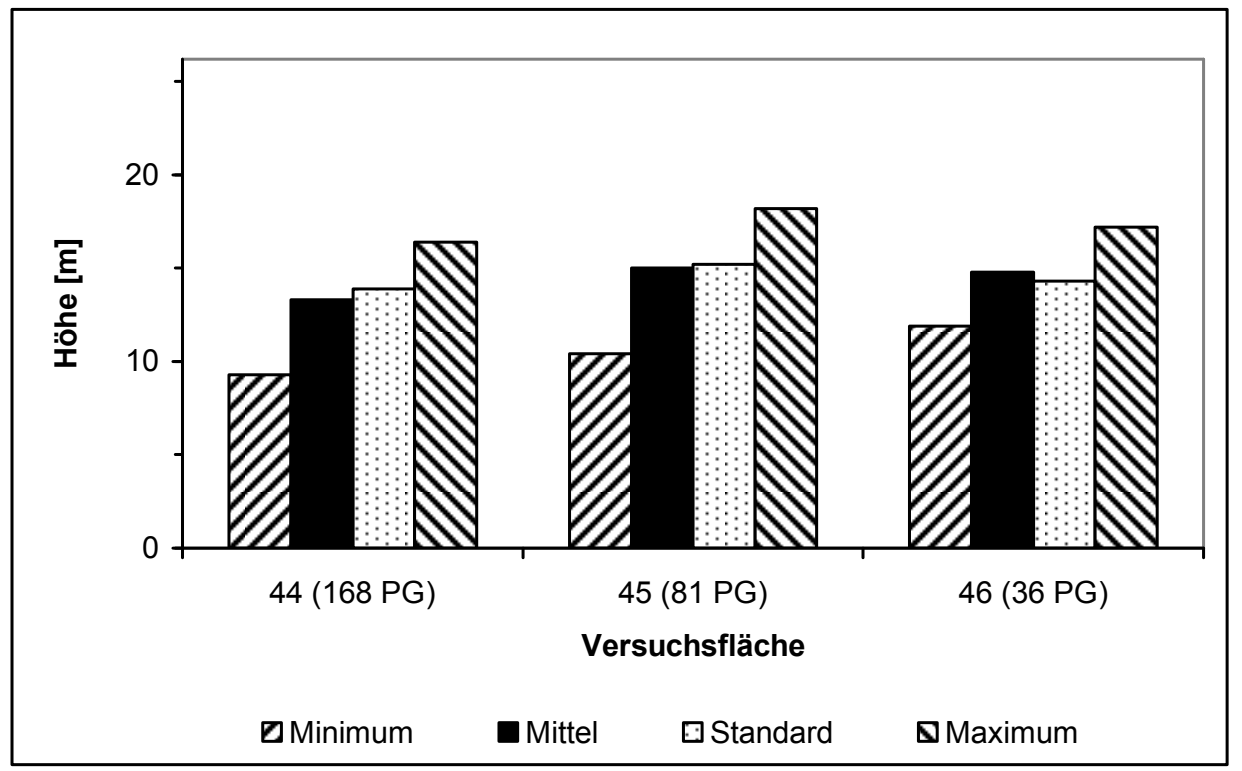

Abb. 2.34: Höhenwachstum (Mittel aller Herkünfte, mattwüchsigste und wüchsigste Herkunft sowie Mittel des Standards) auf den drei Flächen Hasbruch / Niedersachsen im Alter 39

Die Varianzkomponentenschätzung zeigt (Tab. 2.30), dass der durch die Herkunft und Wiederholung erklärte Anteil des Höhenwachstums auf der Fläche 44 etwa $10 \%$ beträgt. Auf der Fläche 45 ist dieser Anteil geringer und auf der Fläche 46 liegt kein Einfluss vor. Auf den Flächen 44 und 46 lässt sich ein Einfluss der Wiederholung von 7 bzw. $17 \%$ nachweisen. Auf allen drei Flächen treten auch Wechselwirkungen zwischen Herkunft und Wiederholung auf. Der hohe Anteil der Wechselwirkungen kann nur durch standörtliche Unterschiede auf den verhältnismäßig großen Versuchsflächen, der Anordnung der Wiederholungen und der geringen Anzahl der Wiederholungen erklärt werden.

Tab. 2.30: Varianzkomponentenschätzung des Höhenwachstums im Alter 39

\begin{tabular}{c|c|c|c|c}
\hline Versuch & Prüfglied & Wiederholung & Prüfglied * Wiederh. & Rest \\
\hline 44 & $9 \% * * *$ & $7 \% * * *$ & $21 \% * * *$ & $63 \%$ \\
45 & $3 \% * * *$ & $0 \%$ & $33 \% * * *$ & $64 \%$ \\
46 & $0 \%$ & $17 \% * * *$ & $39 \% * * *$ & $54 \%$ \\
\hline
\end{tabular}


Die Gegenüberstellung der mittleren Baumhöhen der Herkünfte auf den drei Flächen in Niedersachsen zeigt, dass das Wachstum in den vier Beobachtungsjahren ähnlich war (Abb. 2.35).

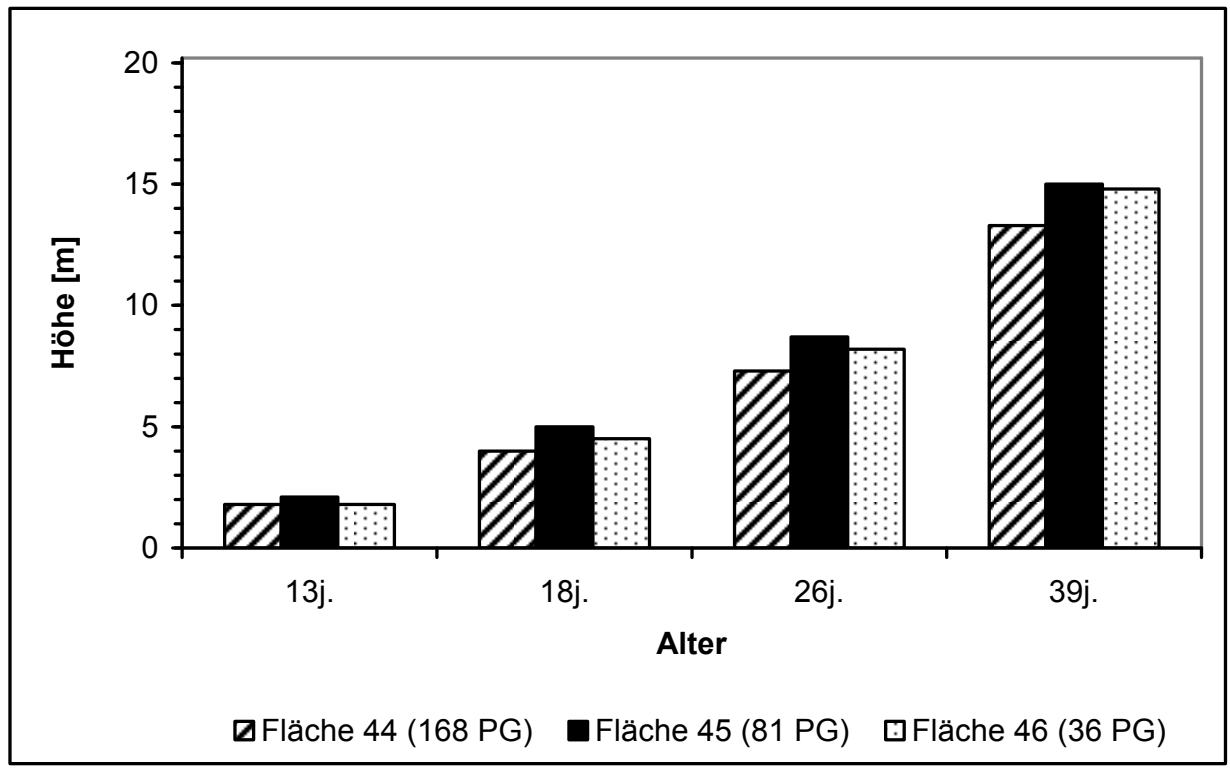

Abb. 2.35: Gegenüberstellung des mittleren Höhenwachstums im Alter von 13, 18, 26 und 39 Jabren auf den drei Versuchsflächen Hasbruch / Niedersachsen

Die multiplen Mittelwertvergleiche (Tukey-Kramer-Test, $\alpha=0,05)$ der 168 Herkünfte der Fläche 44, der 81 Herkünfte der Fläche 45 und der 36 Herkünfte der Fläche 46 ergeben keine statistisch signifikanten Unterschiede. Auch im Vergleich zum Standard gibt es auf den Flächen 44 und 46 keine Unterschiede (DunnettTest, $\alpha=0,05)$; lediglich auf der Fläche 45 ist die Herkunft 149 Einsiedeln / CH $\left(\mathrm{h}_{\text {adj. }}=10,6 \mathrm{~m}\right)$ signifikant geringer im Höhenwuchs als der Standard ( $\mathrm{h}_{\text {adj. }}=15,6$ $\mathrm{m})$.

Für die Ermittlung der BHD sind auf den Flächen alle Bäume gemessen worden. In Abbildung 2.36 sind ausgewählte statistische Parameter zum BHDWachstum für die drei Versuchsflächen in Niedersachsen gegenübergestellt. Auf der Versuchsfläche 44 ist das BHD-Wachstum etwas geringer als auf den beiden anderen Flächen. Auf allen drei Flächen entspricht das Durchmesserwachstum des Standards aus fünf deutschen Herkünften dem jeweiligen Versuchsflächenmittel.

Der BHD der Fichten, an denen die Baumhöhen gemessen wurden, beträgt im Mittel über die drei Flächen Hasbruch / Niedersachsen 18,3 cm und liegt damit über dem der Vollerhebung. Somit sind die Höhen überwiegend an Bäumen gemessen worden, die einen stärkeren BHD haben. 


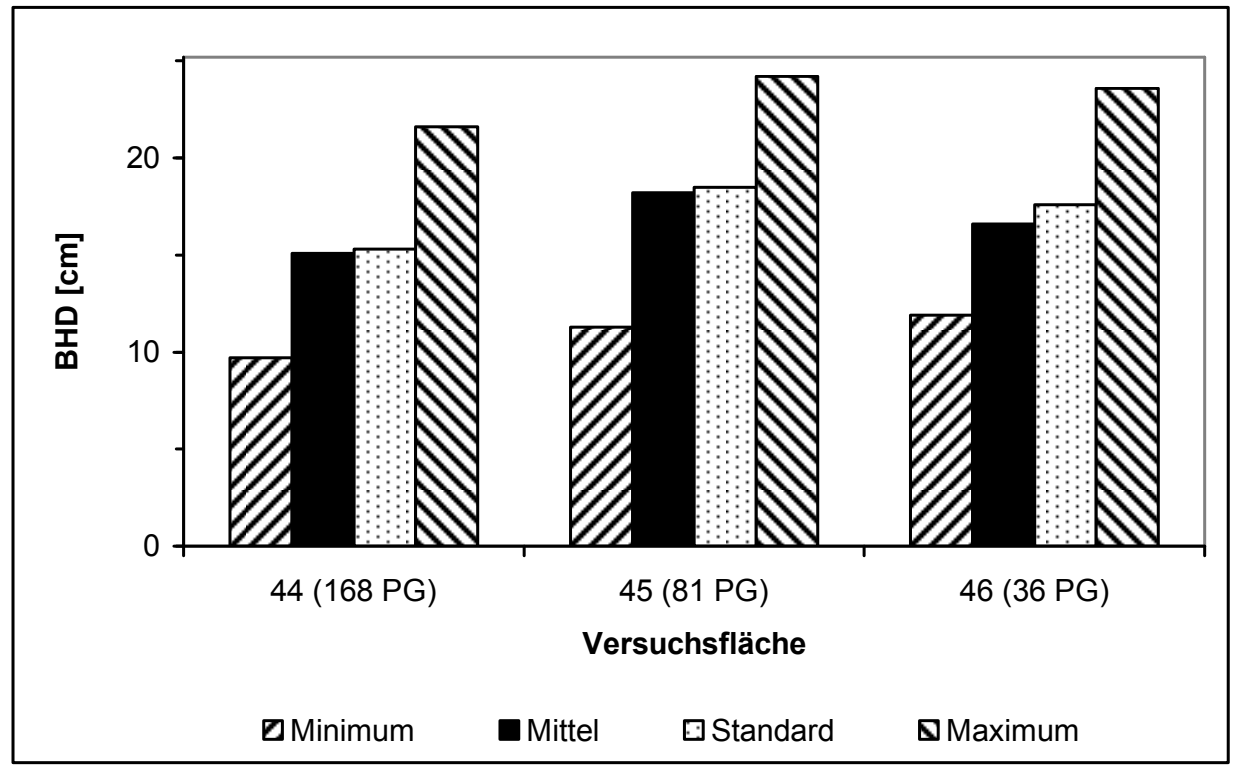

Abb. 2.36: BHD-Wachstum (Mittel aller Herkünfte, mattwüchsigste und wüchsigste Herkunft sowie Mittel des Standards) auf den drei Flächen Hasbruch / Niedersachsen im Alter 39

Die Varianzkomponentenschätzung (Tab. 2.31) ergibt einen durch die Herkunft erklärten Anteil zwischen $1 \%$ auf der Fläche 45 und $6 \%$ auf der Fläche 44. Der durch die Wiederholung erklärte Anteil ist ebenso gering. Wechselwirkungen zwischen Herkunft und Wiederholung lassen sich auf der Fläche 45 absichern.

Tab. 2.31: Varian₹komponentenschätzung des BHD-Wachstums im Alter 39

\begin{tabular}{c|c|c|c|c}
\hline Versuch & Herkunft & Wiederholung & Herkunft * Wiederh. & Rest \\
\hline 44 & $6 \% * * *$ & $6 \% * *$ & $3 \% \mathrm{~ns}$ & $85 \%$ \\
45 & $1 \% * *$ & $1 \% *$ & $19 \% * * *$ & $79 \%$ \\
46 & $2 \% \mathrm{~ns}$ & $4 \% * *$ & $1 \% \mathrm{~ns}$ & $93 \%$ \\
\hline
\end{tabular}

Die multiplen Mittelwertvergleiche (Tukey-Kramer- und Dunnett-Test, $\alpha=0,05$ ) der 168 Herkünfte der Fläche 44, der 81 Herkünfte der Fläche 45 und der 36 Herkünfte der Fläche 46 ergeben keine statistisch signifikanten Unterschiede. Auch im Vergleich zum Standard gibt es keine Unterschiede (Dunnett-Test, $\alpha=0,05)$.

Im Alter von 32 Jahren hat der BHD im Mittel aller Herkünfte auf den drei Versuchsflächen Hasbruch / Niedersachsen 13,1 cm betragen und variierte zwischen der wüchsigsten und mattwüchsigsten Herkunft zwischen 9,4 cm und $18,2 \mathrm{~cm}$. Der Variationskoeffizient beträgt $12 \%$. Ausgewählte statistische Parameter zum BHD-Wachstum im Alter 32 sind für die drei Versuchsflächen in Niedersachsen in Abbildung 2.37 gegenübergestellt. 


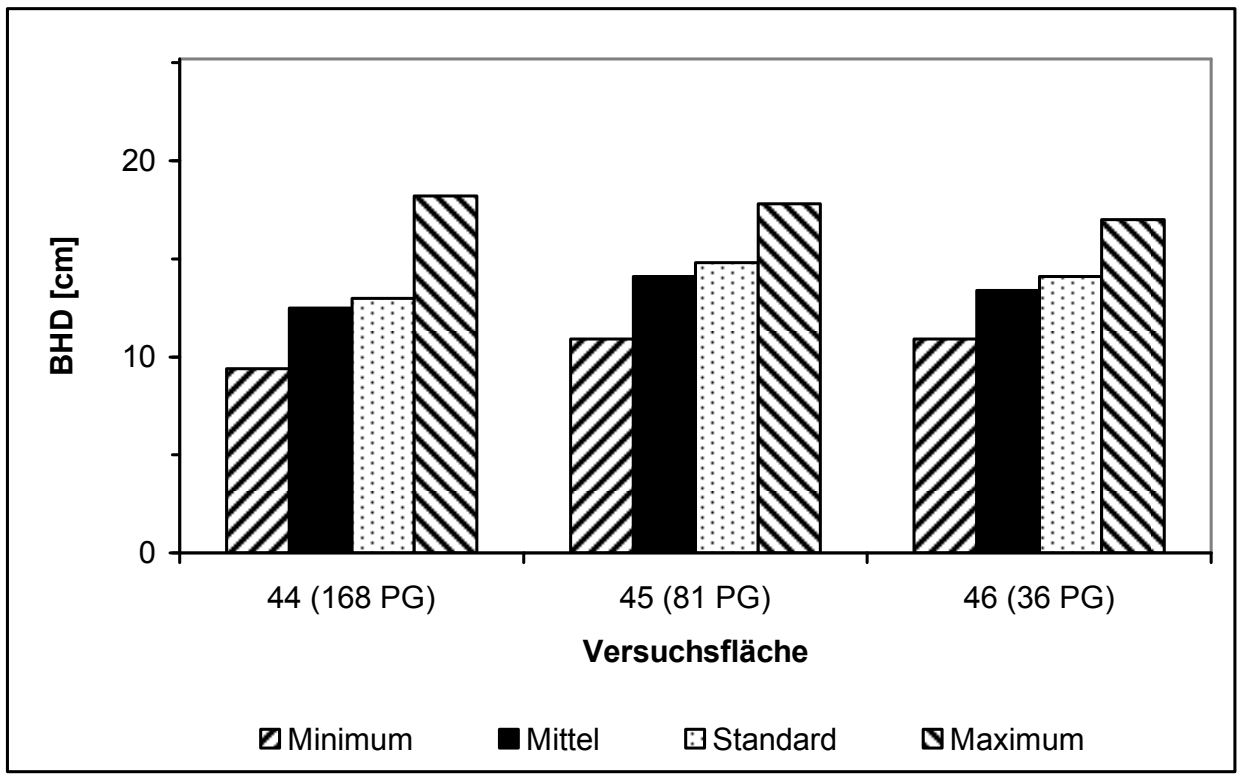

Abb. 2.37: BHD-Wachstum (Mittel aller Herkünfte, mattwüchsigste und wüchsigste Herkunft sowie Mittel des Standards) auf den drei Flächen Hasbruch / Niedersachsen im Alter 32

Beim BHD-Wachstum im Alter von 32 Jahren führt der multiple Mittelwertvergleich (Tukey-Kramer-Test, $\alpha=0,05)$ der 168 Herkünfte der Fläche $44 \mathrm{zu}$ 48 statistisch gesicherten Unterschieden (Anhang 1.23). Bis zu 42 mattwüchsige Herkünfte unterschieden sich von drei wüchsigen Herkünften (139 Vapenkova Skala / CS, 4157 Hnusta / CS und 3505 Eibenstock Carlsfeld 275/D). Im Vergleich zum Standard lässt sich die Herkunft 3505 Eibenstock Carlsfeld 275 / D als wüchsiger absichern (Dunnett-Test, $\alpha=0,05$ ).

Auf der Fläche 45 lassen sich in den multiplen Mittelwertvergleichen keine Unterschiede sichern (Tukey-Kramer- bzw. Dunnett-Test, $\alpha=0,05$ ).

Von den 36 Herkünften der Fläche 46 ist die Herkunft 3423 Kohlstetten / D wüchsiger als die Herkunft 6236 Bialowieza / PL (Tukey-Kramer-Test, $\alpha=0,05$ ). Im Vergleich zum Standard lassen sich keine Unterschiede absichern.

Der Vergleich des BHD- und Höhenwachstums im Alter von 32 und 39 Jahren zeigt, dass die Wachstumsmerkmale hoch korreliert sind (Tab. 2.32). Die Güte der Korrelation zwischen mittlerer Baumhöhe einer Herkunft und dem BHD aller Bäume bzw. nur derer, von denen auch die Höhen gemessen sind, ist gleich. 
Tab. 2.32: $\quad$ Produkt-Momenten-Korrelationsmatrix der Wachstumsmerkmale Höhe und BHD im Alter 32 und 39 (alle Prüfglieder der 3 Flächen in Niedersachsen, $n=285$ )

\begin{tabular}{|c|c|c|c|c|}
\hline & $\begin{array}{c}\text { BHD } \\
32-j .\end{array}$ & $\begin{array}{l}\text { BHD } \\
39-j .\end{array}$ & $\begin{array}{l}\text { BHD } \\
39-\mathrm{j} *\end{array}$ & $\begin{array}{l}\text { Höhe } \\
39-\text { j. }\end{array}$ \\
\hline BHD 32-j. & \multirow[t]{4}{*}{-} & \multirow{4}{*}{$\begin{array}{c}0,841 * * * \\
-\end{array}$} & \multirow{4}{*}{$\begin{array}{c}0,763^{* * *} \\
0,831^{* * *} \\
-\end{array}$} & $0,738^{* * *}$ \\
\hline BHD 39-j. & & & & $0,786^{* * *}$ \\
\hline BHD 39-j.* & & & & $0,861 * * *$ \\
\hline Höhe 39-j. & & & & - \\
\hline
\end{tabular}

* nur die Bäume, von denen auch die Höhe bekannt ist

\section{Einzelbaumvolumen}

Aus den Merkmalen Baumhöhe und BHD wurde das mittlere Einzelbaumvolumen je Herkunft errechnet. Es beträgt im Alter von 39 Jahren 0,158 $\mathrm{m}^{3}$ im Mittel über die 285 Prüfglieder der drei Versuchsflächen Hasbruch.

Die höchste mittlere Stückmasse $\left(0,384 \mathrm{~m}^{3}\right)$ hat die Absaat 115 Westerhof / D auf der Fläche 45 und die geringste $\left(0,041 \mathrm{~m}^{3}\right)$ die Herkunft 734 Airolo, Bedretto / $\mathrm{CH}$ auf der Fläche 44. Die mittleren Einzelbaumvolumina der einzelnen Herkünfte sind absolut und im Verhältnis zum Mittel der drei Versuchsflächen Hasbruch im Anhang 1.24 aufgelistet. In Tabelle 2.33 sind deskriptive statistische Kenngrößen für die drei Versuchsflächen und den Versuchsflächenkomplex Hasbruch zusammengestellt.

Tab. 2.33: Mittlere Einzelbaumvolumina auf den drei Flächen Hasbruch, Standardabweichung, Variationskoeffizient (VK), Minimum und Maximum

\begin{tabular}{c|c|c|c|c|c|c}
\hline Fläche & $\begin{array}{c}\text { Herkünfte } \\
{[\mathrm{n}]}\end{array}$ & $\begin{array}{c}\text { Mittel } \\
{\left[\mathrm{m}^{3}\right]}\end{array}$ & $\begin{array}{c}\text { Standardabw. } \\
{\left[\mathrm{m}^{3}\right]}\end{array}$ & $\begin{array}{c}\text { VK } \\
{[\%]}\end{array}$ & $\begin{array}{c}\text { Min } \\
{\left[\mathrm{m}^{3}\right]}\end{array}$ & $\begin{array}{c}\text { Max } \\
{\left[\mathrm{m}^{3}\right]}\end{array}$ \\
\hline 44 & 168 & 0,130 & 0,048 & 37 & 0,041 & 0,302 \\
45 & 81 & 0,209 & 0,071 & 34 & 0,057 & 0,384 \\
46 & 36 & 0,177 & 0,061 & 35 & 0,074 & 0,359 \\
Hasbruch & 285 & 0,158 & 0,067 & 42 & 0,041 & 0,384 \\
\hline
\end{tabular}

Die multiplen Mittelwertvergleiche (Tukey-Kramer-Test, $\alpha=0,05)$ der 168 Herkünfte der Fläche 44, der 81 Herkünfte der Fläche 45 und der 36 Herkünfte der Fläche 46 ergeben keine statistisch signifikanten Unterschiede. Auch im Vergleich zum Standard gibt es auf den drei Flächen keine Unterschiede (Dunnett-Test, $\alpha=0,05)$. 
In den Varianzanalysen der drei Flächen sind die Einflüsse der Herkunft und der Wiederholung gering (Tab. 2.34). Auf der Fläche 45 lässt sich kein Einfluss der Herkunft nachweisen. Auf den Flächen 44 und 45 gibt es signifikante Wechselwirkungen von Herkunft $\mathrm{x}$ Wiederholung $(\alpha=0,05)$.

Tab. 2.34: Varian₹komponenten für das Einzelbaumvolumen auf den drei Flächen Hasbruch / Niedersachsen

\begin{tabular}{c|ccccc}
\hline Fläche & Herkunft & Wiederholung & Wechselwirkung & Rest \\
\hline 44 & $3 \% * * *$ & $6 \% * * *$ & $12 \% * * *$ & $79 \%$ \\
45 & $0 \%$ & $0 \%$ & $27 \% * * *$ & $73 \%$ \\
46 & $1 \% *$ & $3 \% * *$ & $6 \% \mathrm{~ns}$ & $90 \%$ \\
\hline
\end{tabular}

Für das Einzelbaumvolumen, das aus den Wachstumsmerkmalen Höhe und BHD errechnet wird, sind neben den einzelnen Herkünften auch Gruppen von Herkünften analysiert worden.

Bei der Einteilung aller Herkünfte am Testort Hasbruch nach Herkunftsgruppen, die die Refugialräume der Fichte berücksichtigen, ergibt der multiple Mittelwertvergleich (Tukey-Kramer-Test, $\alpha=0,05$ ) einen gesicherten Unterschied zwischen den Gruppen „Baltisch-Nordisch“ und „Alpin“ mit geringem Einzelbaumvolumen und den Gruppen „Herzynisch-Karpatisch“ und „Kontaktbereich Herzynisch-Karpatisch zu Alpin“ mit höherem Einzelbaumvolumen (Abb. 2.38).

Auf der Fläche 44 hat die Gruppe „Alpin“ ein signifikant geringeres Einzelbaumvolumen gegenüber den Gruppen „Herzynisch-Karpatisch“, „Kontaktbereich Herzynisch-Karpatisch zu Alpin“ und „künstliches Verbreitungsgebiet“. Außerdem hat die Gruppe „Baltisch-Nordisch“ ein geringeres Einzelbaumvolumen im Vergleich mit der Gruppe „Herzynisch-Karpatisch“. Auf den Flächen 45 und 46 lassen sich keine Unterschiede absichern (Abb. 2.38). 


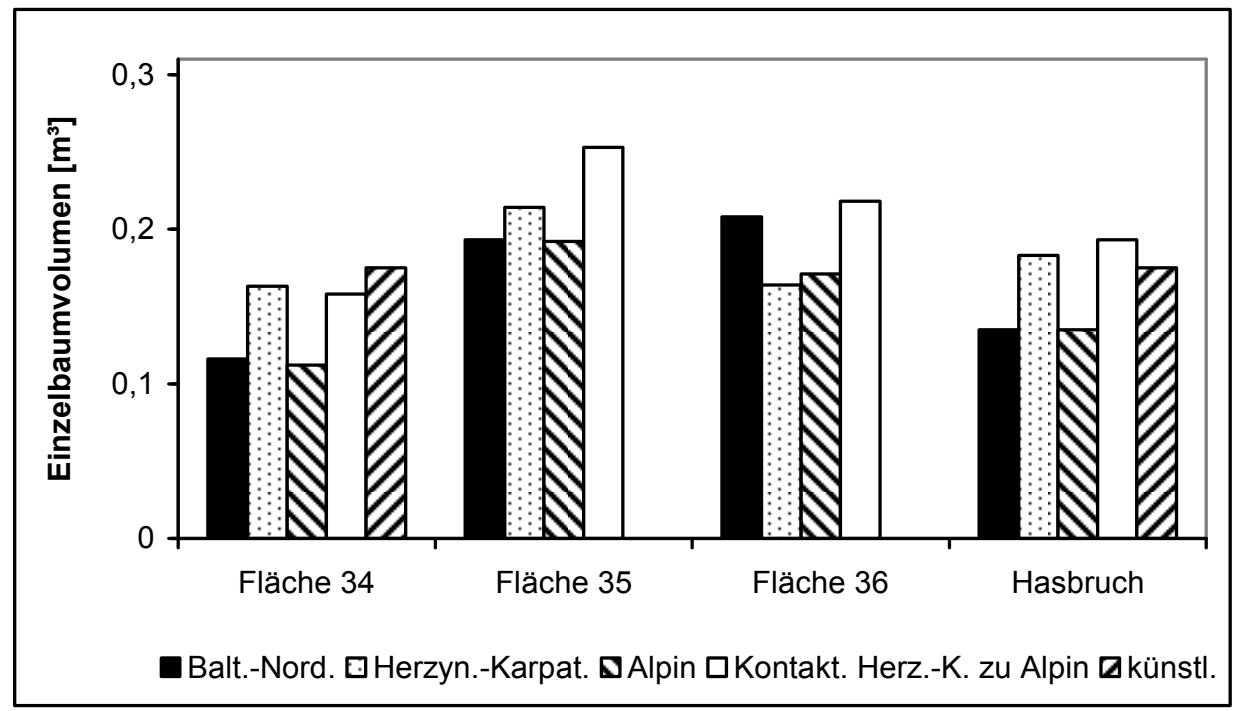

Abb. 2.38: $\quad$ Erwartungswerte für das mittlere Einzelbaumvolumen der Herkunftsgruppen auf den drei Flächen und über alle Flächen Hasbruch / Niedersachsen

Von den sieben sich an politisch-geografischen Regionen orientierenden Gruppen unterscheidet sich die volumenarme Gruppe „Südwesteuropa“ von allen weiteren mit Ausnahme der Gruppe „Nord-Europa“. Außerdem ist „Deutschland“ volumenreicher als die Gruppen „Österreich“ und „Nord-Europa“ (Abb. 2.39).

Auf der Fläche 44 sichert der multiple Mittelwertvergleich (Tukey-KramerTest, $\alpha=0,05)$ einen Unterschied zwischen den Gruppen „ehemalige Tschechoslowakei“ und „Deutschland“ mit einem höheren Einzelbaumvolumen auf der einen Seite gegenüber den zwei Gruppen „Österreich“ und „Südwest-Europa“ auf der anderen Seite ab. Außerdem ist die Gruppe „Deutschland“ volumenreicher als die beiden Gruppen „Nord-Europa“ und „Polen“.

Auf den beiden kleineren Versuchsflächen 45 und 46 gibt es keine gesicherten Unterschiede (Abb. 2.39). 


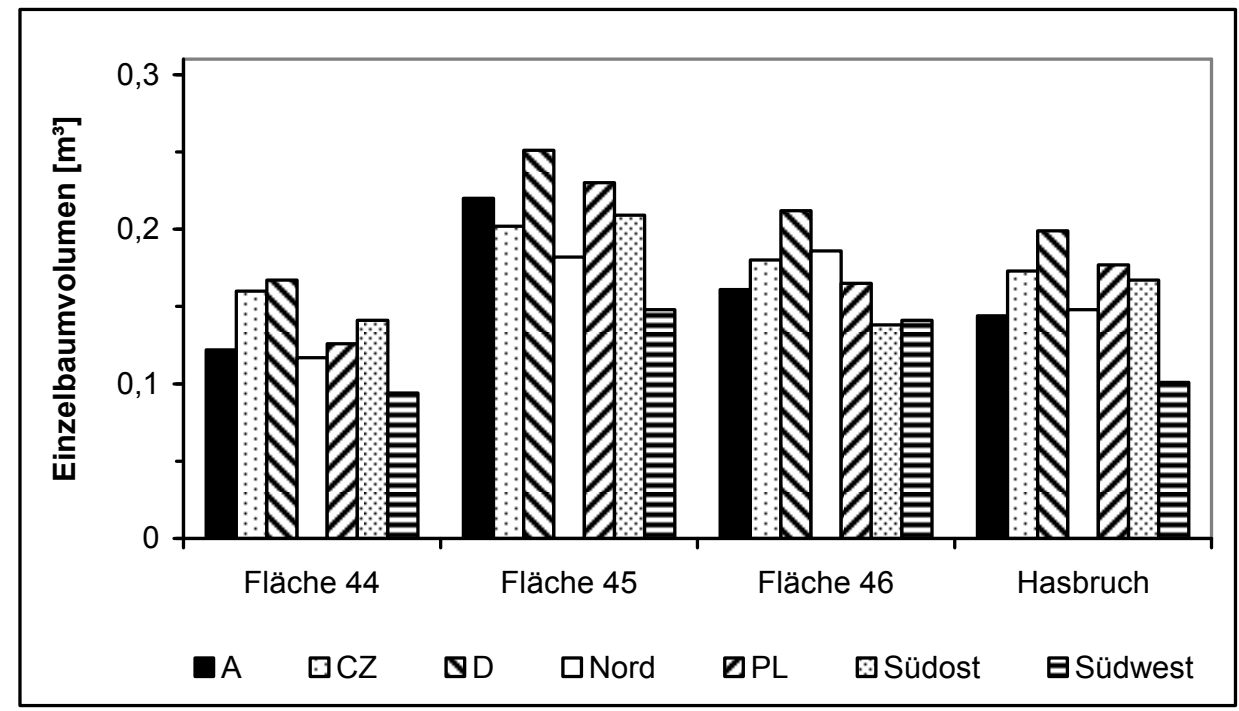

Abb. 2.39: Erwartungswerte für das mittlere Einzelbaumvolumen der Herkünfte gruppiert nach politisch-geografischen Regionen auf den drei Flächen und über alle Flächen Hasbruch / Niedersachsen

Eine weitere Gruppierung berücksichtigt ausschließlich die Höhenlage der Einsammlungsorte der Saatgutproben. Die Versuchfläche Hasbruch liegt in einer Höhenlage von $20 \mathrm{~m}$ ü. NN. Die multiplen Tests über die nach Höhenlagen gruppierten Prüfglieder der drei Flächen sichern Unterschiede zwischen der volumenarmen Höhenlage „über $1000 \mathrm{~m}^{\text {“ }}$ auf der einen Seite und den weiteren Höhenlagen auf der anderen Seite ab (Abb. 2.40).

Auf der Teilfläche 44 sind die Einzelbaumvolumina aller Höhenlagen im Vergleich zu den beiden weiteren Teilflächen 45 und 46 am geringsten (Abb. 2.40). Auf der Fläche 44 sind die Unterschiede zwischen den Höhenlagen gering, dennoch lässt sich das geringere Einzelbaumvolumen der Höhenlage „über 1000 m“ gegenüber den Höhenlagen „200-650 m“, „650-850 m“ und „,850-1000 m“ statistisch absichern.

Auf der Fläche 45 sind die Volumendifferenzen etwas größer als auf der Fläche 44, sie sind aber statistisch nicht abzusichern.

Die größte Spanne zwischen der volumenreichsten und der volumenärmsten Höhenlage findet sich auf der Fläche 46. Absichern lassen sich hier die Unterschiede zwischen der volumenreichen Höhenlage ,650-850 m“ gegenüber der volumenarmen Höhenlage „über 1000 m“ (Tukey-Kramer-Test, $\alpha=0,05)$. 


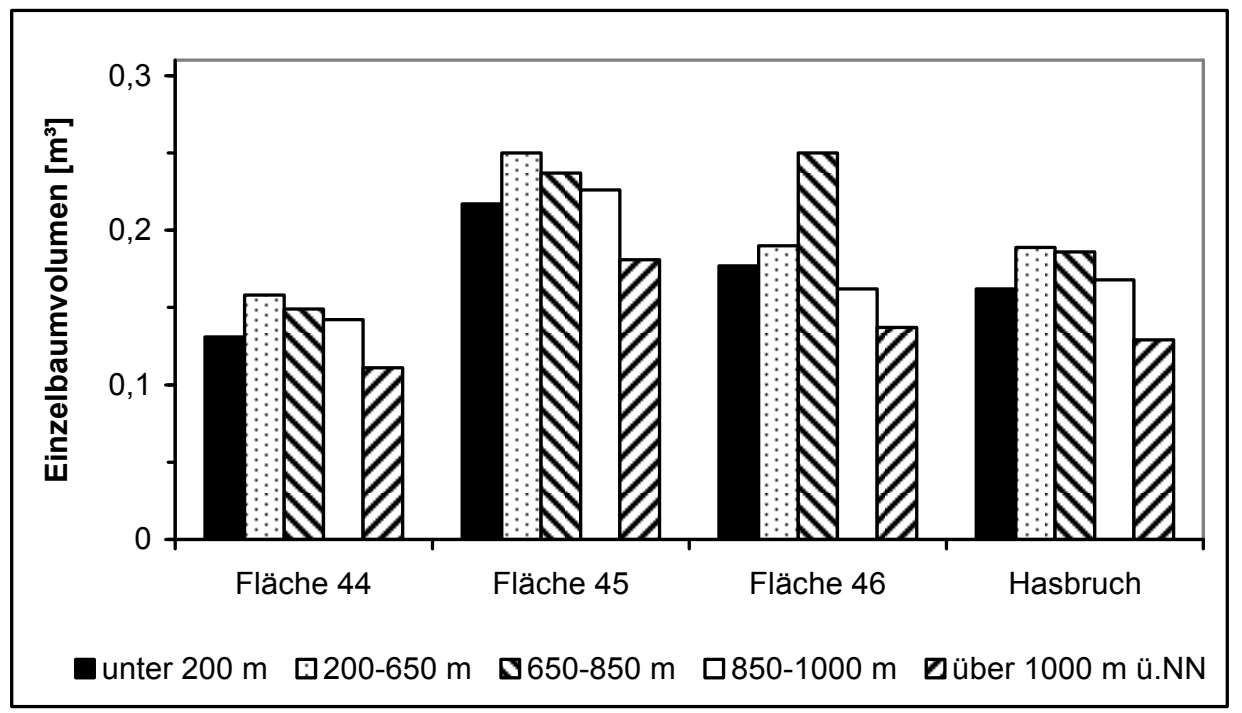

Abb. 2.40: $\quad$ Erwartungswerte für das mittlere Einzelbaumvolumen der Herkünfte gruppiert nach fünf Höhenlagen auf den drei Flächen und über alle Flächen Hasbruch / Niedersachsen

\section{Vorrat pro Hektar}

In die Vorratsermittlung je Hektar gehen die drei Merkmale Stammzahl sowie BHD- und Höhenwachstum im Alter von 39 Jahren ein. Im Mittel über alle 285 Herkünfte beträgt der mittlere Vorrat $77 \mathrm{~m}^{3} /$ ha (Tab. 2.35). Zwischen den Herkünften (Anhang 1.24) variiert der errechnete Vorrat zwischen $13 \mathrm{~m}^{3} / \mathrm{ha}(2128$ Lobming-Obertal / A auf der Fläche 44 und 4123 Javorova Dolina 155 A / CS auf der Fläche 45) und $196 \mathrm{~m}^{3} /$ ha (7235 Bricalovic / SU auf der Fläche 45). Dies entspricht $17 \%$ bzw. $254 \%$ vom Mittel der drei niedersächsischen Flächen.

Tab. 2.35: Mittlerer Vorrat/ba auf den drei Flächen Hasbruch / Niedersachsen, Standardabweichung, V ariationskoeffizient (VK), Minimum und Maximum

\begin{tabular}{c|c|c|c|c|c|c}
\hline Fläche & $\begin{array}{c}\text { Herkünfte } \\
{[\mathrm{n}]}\end{array}$ & $\begin{array}{c}\text { Mittel } \\
{\left[\mathrm{m}^{3} / \mathrm{ha}\right]}\end{array}$ & $\begin{array}{c}\text { Standardabw. } \\
{\left[\mathrm{m}^{3} / \mathrm{ha}\right]}\end{array}$ & $\begin{array}{c}\mathrm{VK} \\
{[\%]}\end{array}$ & $\begin{array}{c}\text { Min. } \\
{\left[\mathrm{m}^{3} / \mathrm{ha}\right]}\end{array}$ & $\begin{array}{c}\text { Max. } \\
{\left[\mathrm{m}^{3} / \mathrm{ha}\right]}\end{array}$ \\
\hline 44 & 168 & 70 & 24 & 34 & 13 & 134 \\
45 & 81 & 90 & 33 & 37 & 13 & 196 \\
46 & 36 & 84 & 37 & 44 & 30 & 182 \\
Hasbruch & 285 & 77 & 30 & 39 & 13 & 196 \\
\hline
\end{tabular}

Trotz der hohen Differenzen zwischen vorratsreichster und -ärmster Herkunft lassen sich die Unterschiede in multiplen Mittelwertvergleichen (Tukey-Kramerbzw. Dunnett-Test, $\alpha=0,05)$ auf keiner der drei Flächen 44, 45 und 46 absichern. 
Auf den drei Flächen Hasbruch lässt sich in den Varianzanalysen kein Einfluss der Herkunft bzw. Wiederholung, abgesehen von einem geringen Einfluss der Wiederholung auf Fläche 44, nachweisen (Tab. 2.36).

Tab. 2.36: Varianzkomponenten für den Vorrat pro Hektar auf den drei Flächen Hasbruch / Niedersachsen

\begin{tabular}{c|c|c|c}
\hline Fläche & Herkunft & Wiederholung & Rest \\
\hline 44 & $2 \% \mathrm{~ns}$ & $8 \% * * *$ & $90 \%$ \\
45 & $6 \% \mathrm{~ns}$ & $0 \%$ & $94 \%$ \\
46 & $9 \% \mathrm{~ns}$ & $3 \% \mathrm{~ns}$ & $88 \%$ \\
\hline
\end{tabular}

Wie für das Einzelbaumvolumen sind auch beim Vorrat pro Hektar neben den einzelnen Herkünften auch Gruppen von Herkünften analysiert worden.

Über alle Herkünfte der Versuchsflächen Hasbruch ergibt der multiple Mittelwertvergleich (Tukey-Kramer-Test, $\alpha=0,05$ ) bei einer Einteilung der Herkünfte in Refugialräume einen gesicherten Unterschied für die Gruppen „Herzynisch-Karpatisch“ und „Kontaktbereich Herzynisch-Karpatisch zu Alpin“ mit einem höheren Vorrat gegenüber den Gruppen „Baltisch-Nordisch“ und „Alpin“ (Abb. 2.41).

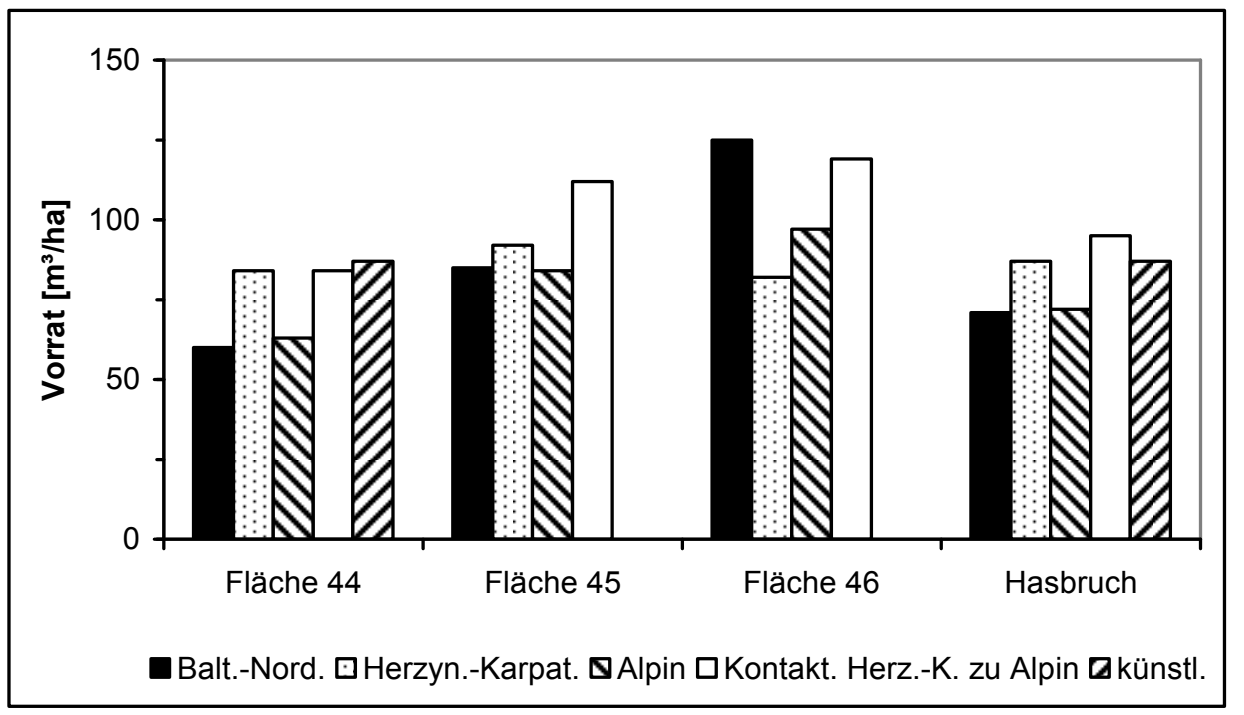

Abb. 2.41: Erwartungswerte für den Vorrat pro Hektar der Herkunftsgruppen auf den drei Flächen Hasbruch / Niedersachsen 
Auf der Fläche 44 lassen sich Unterschiede zwischen den vorratsreicheren Gruppen „Herzynisch-Karpatisch“, „Kontaktbereich Herzynisch-Karpatisch zu Alpin“ und „künstliches Verbreitungsgebiet“ einerseits und der vorratsärmeren Gruppe „Alpin“ andererseits absichern. Auch die Gruppe „Herzynisch-Karpatisch“ hat einen signifikant höheren Vorrat als die Gruppe „Baltisch-Nordisch“. Auf den beiden weiteren Flächen 45 und 46 lassen sich die Unterschiede nicht absichern.

Für die sieben, sich an politisch-geografischen Regionen orientierenden Gruppen sichert der multiple Mittelwertvergleich (Tukey-Kramer-Test, $\alpha=0,05$ ) über alle Herkünfte auf den Flächen Hasbruch Unterschiede zwischen der vorratsreicheren Gruppe „Deutschland“ und den vorratsärmeren Gruppen „SüdwestEuropa“, „Polen“ sowie „Österreich“. Außerdem ist die Gruppe „ehemalige Tschechoslowakei“ vorratsreicher als die Gruppe „Südwest-Europa“ (Abb. 2.42).

Auf der Fläche 44 unterscheiden sich die vorratsreichen Gruppen „ehemalige Tschechoslowakei“" und „Deutschland“ von den vorratsärmeren Gruppen „Österreich“, „Nord-Europa“, „Polen“ und „Südwest-Europa“. Auf den beiden anderen Flächen 45 und 46 lassen sich die Unterschiede nicht absichern.

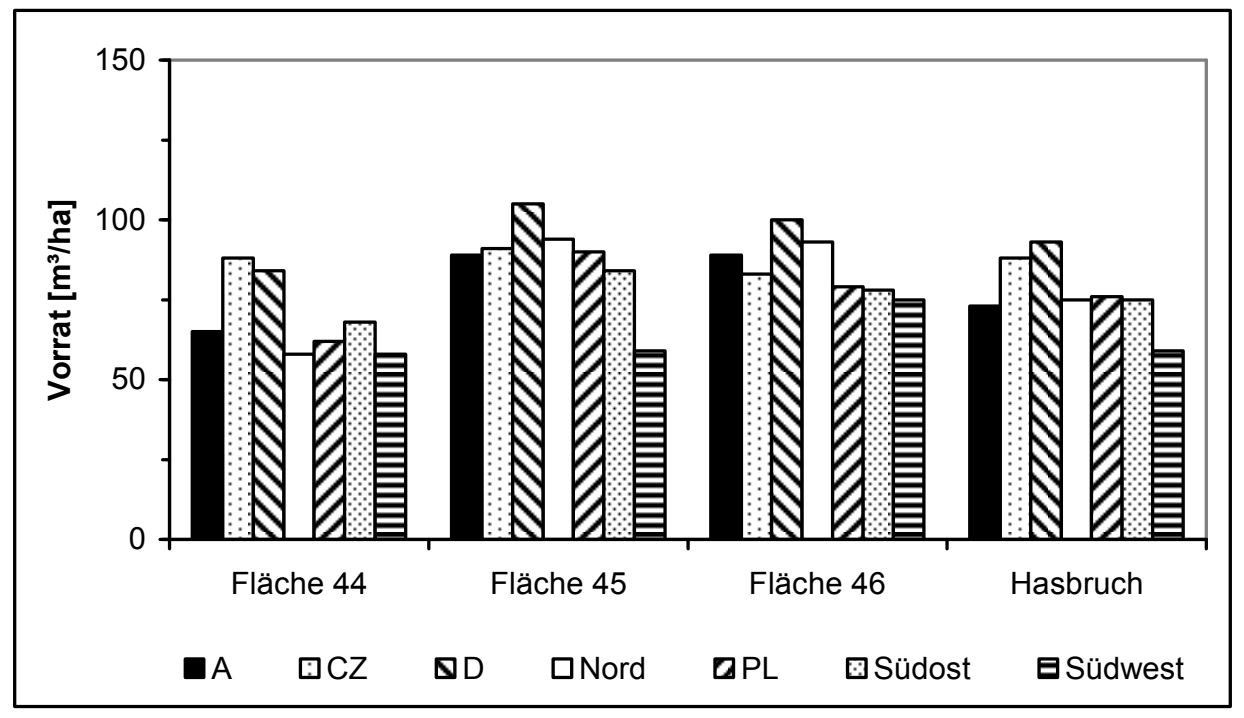

Abb. 2.42: Erwartungswerte für den Vorrat pro Hektar der Herkünfte gruppiert nach politischgeografischen Regionen auf den drei Flächen Hasbruch / Niedersachsen

Bei einer Gruppierung der Herkünfte nach Höhenlagen ihrer Einsammlungsorte ist die Gruppe „über $1000 \mathrm{~m}$ “ signifikant vorratsärmer als die beiden Gruppen „200-650 m“ und „650-850 m“ auf den Flächen Hasbruch (Abb. 2.43).

Auch auf der Fläche 44 unterscheidet sich die Gruppe „über 1000 m“ von allen anderen Höhenlagen (Tukey-Kramer-Test, $\alpha=0,05$ ). Auf der Fläche 45 
lassen sich die Unterschiede zwischen den Höhenlagen statistisch nicht absichern. Die Herkünfte der Höhenlage „,650-850 m“ sind auf der Fläche 46 statistisch vorratsreicher als die der Höhenlagen ,über 1000 m“.

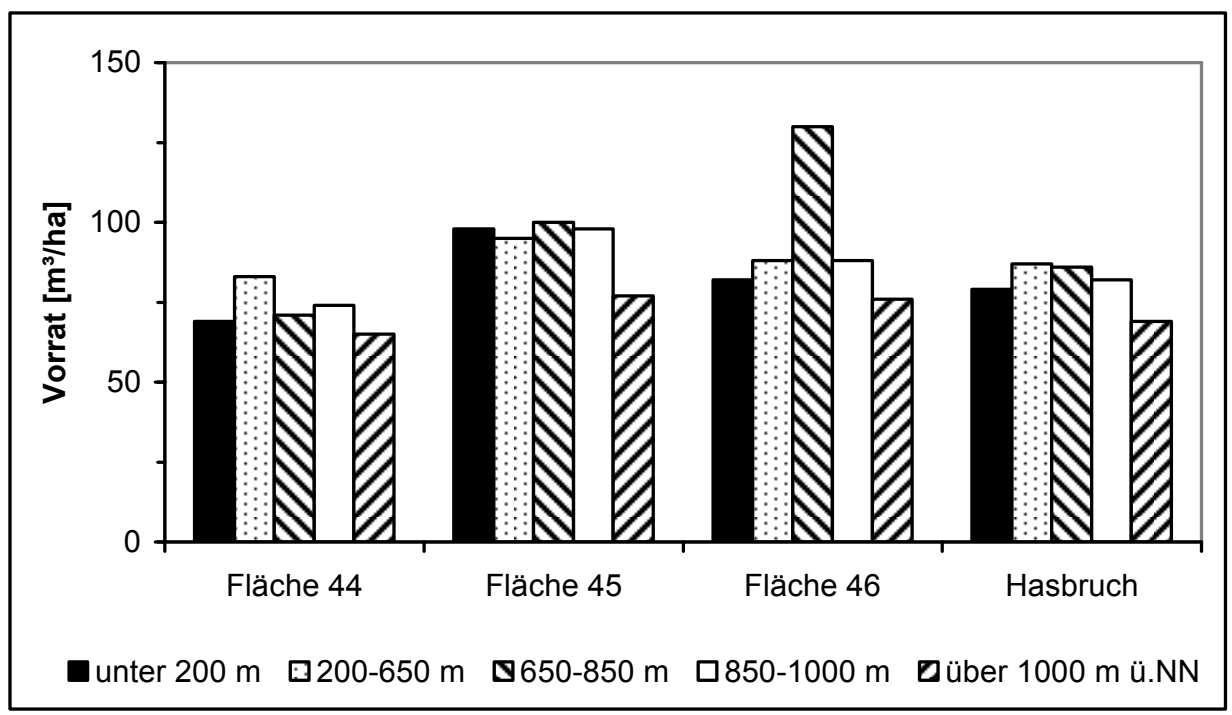

Abb. 2.43: $\quad$ Erwartungswerte für den mittleren Vorrat pro Hektar der Herkünfte gruppiert nach fünf Höhenlagen auf den drei Flächen Hasbruch / Niedersachsen

\subsubsection{Sonthofen und Berchtesgaden / Bayern}

Die beiden Flächen in Bayern liegen etwa 200 km voneinander entfernt. Sie sind in einer Höhenlage von 1250 bzw. $1360 \mathrm{~m}$ ü. NN angelegt und somit auch die höchstgelegenen in dem Versuch. Sie werden daher in der folgenden Auswertung sowohl zusammengefasst als auch einzeln analysiert.

\section{Entwicklung der Pflanzenanzahl}

Im Alter von 32 Jahren haben auf den beiden Hochlagenflächen in Bayern zusammen noch $42 \%$ (4.156) der gepflanzten Fichten gelebt. Auf der Fläche Berchtesgaden (36 Herkünfte) ist der Anteil der vorhandenen Pflanzen mit 45\% (782 Fichten) etwas höher als auf der Fläche Sonthofen (42\%, 3.374 Fichten).

Die Anzahl der im Alter von 32 lebenden Fichten pro Herkunft, an denen das Merkmal BHD gemessen wurde, sind im Anhang 1.25 getrennt für die zwei Versuchsflächen dargestellt. Von jeder Herkunft stehen im Alter 32 im Mittel 20 Fichten auf einer Versuchsfläche. Die Anzahl der vorhandenen Fichten variiert zwischen 3 und 38 (Fläche 24) bzw. 35 (Fläche 26) (Abb. 2.44). 


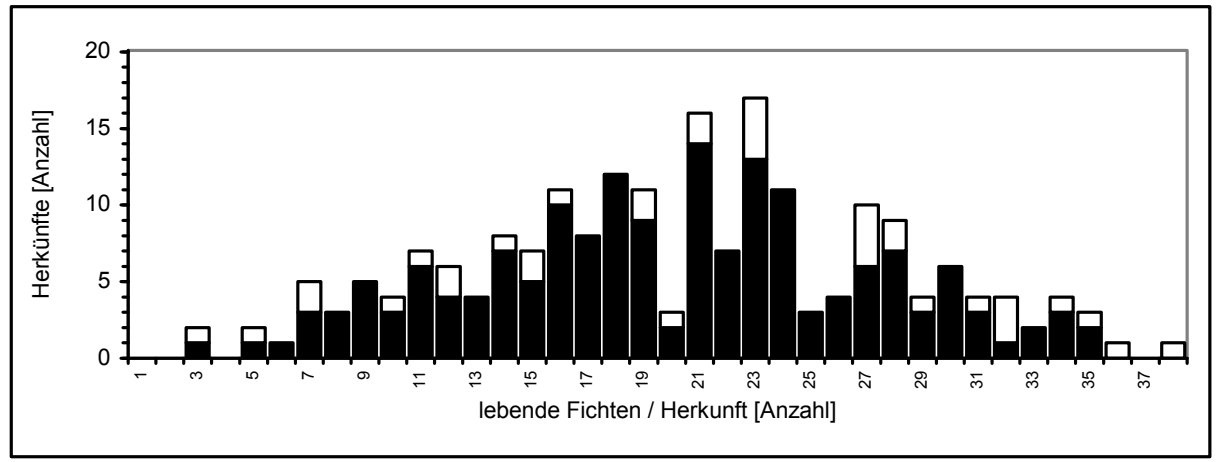

Abb. 2.44: Histogramm für die absoluten Häufigkeiten der Ficbten je Herkunft bei der Erfassung im Alter von 32 Jahren auf den Flächen in Bayern: 24 Sonthofen (dunkel) und 26 Berchtesgaden (bell)

\section{Schäden}

Auf den Flächen in Bayern sind viele Schädigungen aufgetreten und notiert worden, was sich auch in den Histogrammen der beiden Flächen widerspiegelt. Die Anzahl der geschädigten Bäume variiert zwischen 0 und 30 je Herkunft. Dabei sind auf der Fläche Sonthofen (24) im Mittel 8 ( \pm 3,8) Fichten pro Herkunft geschädigt und auf der Fläche Berchtesgaden (26) im Mittel 14 ( \pm 7,6). Nur auf der Fläche Sonthofen gibt es eine Herkunft (3505 Carlsfeld / D), bei der kein Baum geschädigt war. Weiterhin gibt es vier Herkünfte (142 Rosice/CS, 229 Olsztyn / PL, 3412 Winterberg / D und 6237 Puszcza Bialowieza / PL) mit einem und drei Herkünfte (227 Thüringen / D, 3420 Daun-Ost / D und 4157 Hnusta / CS) mit zwei geschädigten Fichten.

Die beiden häufigsten Schäden sind Schneedruck / Windwurf (17\% der Fichten) und Schnee- und Windbruch (19\%). Die weiteren Schäden sind unbedeutend. Beide Schäden, Schneedruck und Schneebruch, sind in auffällig unterschiedlicher Häufigkeit auf den beiden Versuchsflächen in Bayern aufgetreten.

Während auf der Fläche Sonthofen (24) die Schäden durch Schneedruck / Windwurf unbedeutend sind (4\%) und sich nicht weiter differenzieren lassen, belaufen sie sich auf der Fläche Berchtesgaden (26) auf $60 \%$. Die durch Schneedruck geschädigten Fichten setzen sich auf der Fläche Berchtesgaden aus $6 \%$ leicht angeschobenen, $21 \%$ stark angeschobenen und 33\% liegenden Fichten zusammen. Am geringsten war der Anteil der durch Schneedruck geschädigten Fichten aus den Höhenlagen über $1000 \mathrm{~m}$ ü. NN (Abb. 2.45 oben). Bei den politisch-geografisch gruppierten Herkünften fällt auf (Abb. 2.45 unten), dass die geringsten Schneedruckschäden bei den Fichten aus den Gebieten „SüdostEuropa“ und „ehemalige Tschechoslowakei“ auftraten und die meisten Schäden bei denen aus „Deutschland“ und „Polen“. 


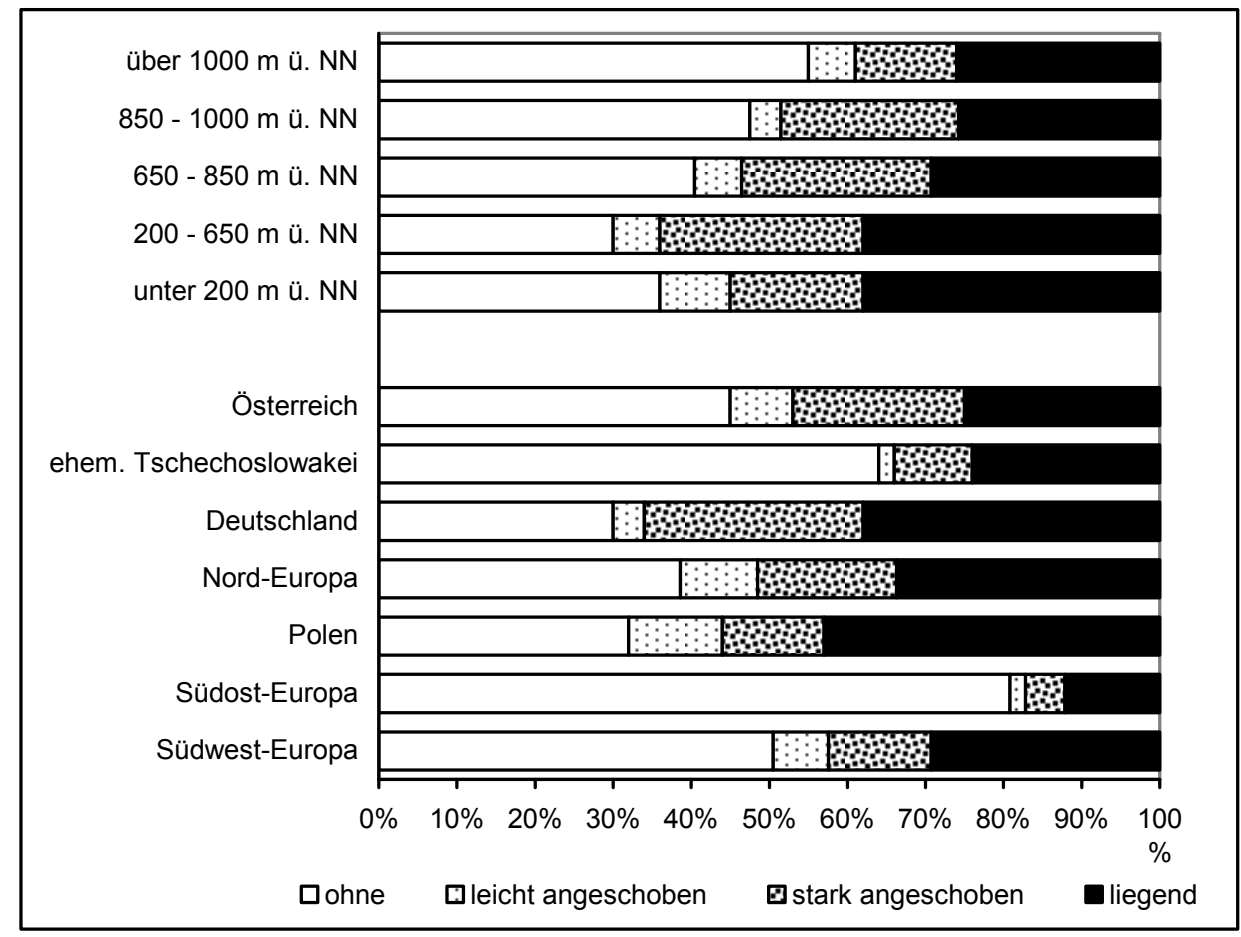

Abb. 2.45: Ergebnis der Erfassung der Schäden durch Schneedruck / Windwurf auf der Fläche Berchtesgaden (26) für die nach Höhenlagen (oben) und politisch-geografisch (unten) gruppierten Herkünfte

Wie beim Schneedruck sind auch die Schäden durch Schnee- und Windbruch auf der Fläche Sonthofen gering ausgefallen (7\%). Zwischen den Höhenlagen und den politisch-geografischen Regionen gibt es keine Unterschiede.

Auf der Fläche Berchtesgaden sind dagegen bei 61\% der Fichten Schäden durch Schneebruch notiert worden. Hier zeigt sich, dass bei den Herkünften aus höheren Lagen, insbesondere über $1000 \mathrm{~m}$ ü. NN, deutlich seltener Kronenbrüche beobachtet wurden (Abb. 2.46 oben). Bei den politisch-geografisch gruppierten Herkünften sind am seltensten Kronenbrüche in den Regionen „Südost-Europa“ und „ehemalige Tschechoslowakei“ zu verzeichnen (Abb. 2.46 unten). Den geringsten Anteil ungebrochener Kronen weisen die Regionen „Deutschland“ und „Polen“ auf. 


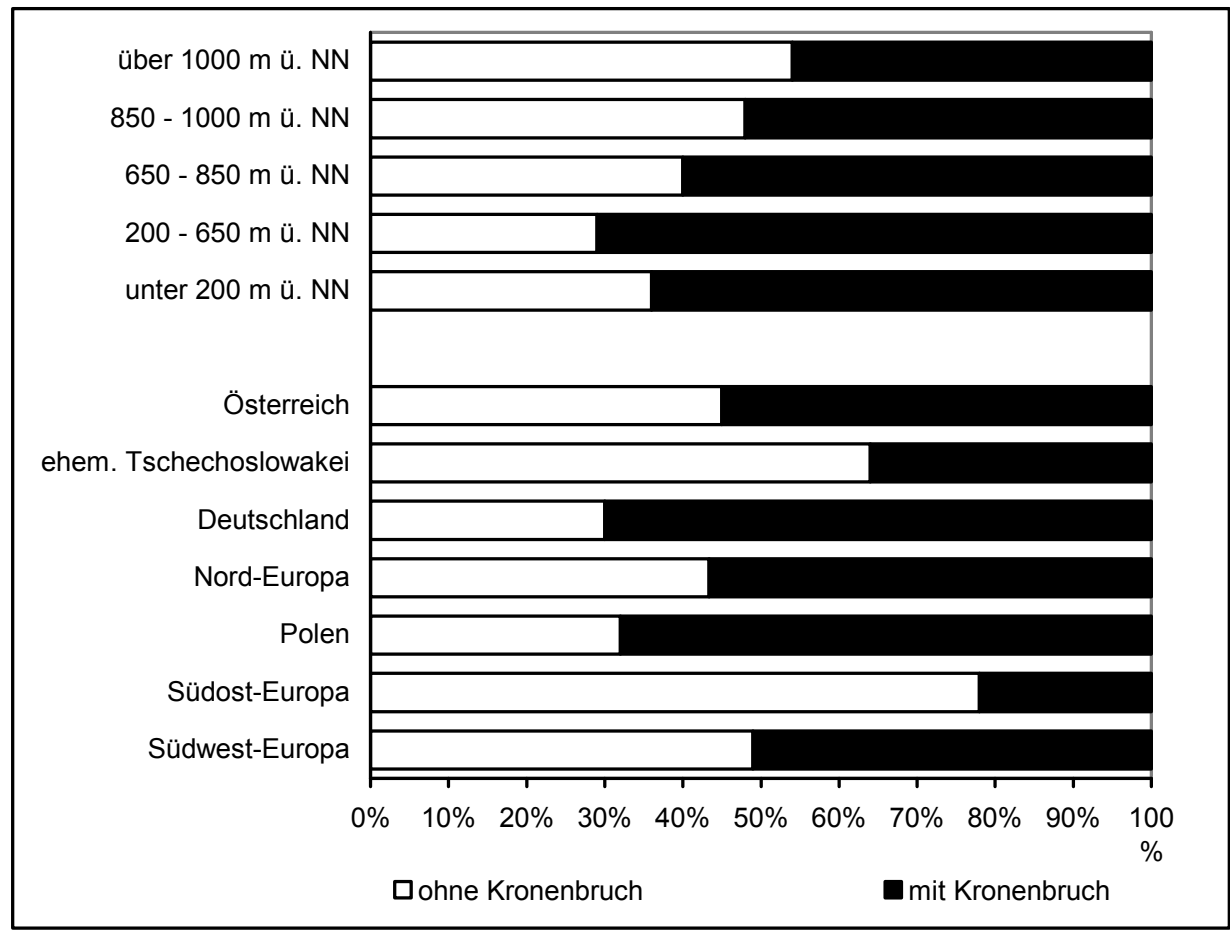

Abb. 2.46: Ergebnis der Erfassung der Schäden durch Schnee- und Windbruch auf der Fläche Berchtesgaden (26) für die nach Höhenlagen (oben) und politisch-geografisch (unten) gruppierten Herkünfte

\section{Stammform}

Im Alter von 32 Jahren liegt von 4.147 Fichten auf den zwei Flächen in Bayern eine Bonitur der Stammform vor. Im Ergebnis sind $57 \%$ der Stämme gerade und $16 \%$ stark gekrümmt. Weitere $4 \%$ haben einen Zwiesel und bei $22 \%$ ist ein Korb bzw. Bajonett notiert worden (Abb. 2.47). Zwischen den Flächen gibt es Unterschiede im Anteil der geraden Stämme $\left(\chi^{2}=159 * * *\right)$. Der Anteil variiert zwischen $37 \%$ auf der Fläche 26 (Berchtesgaden) mit 36 Herkünften und $62 \%$ auf der Fläche 24 (Sonthofen) mit 169 Herkünften. Ebenso stark, jedoch reziprok, variiert der Anteil der stark gekrümmten Fichten. Auffallend hoch ist der Anteil der Fichten mit einem Korb bzw. Bajonett, der auf beiden Flächen etwa 22 \% beträgt. 


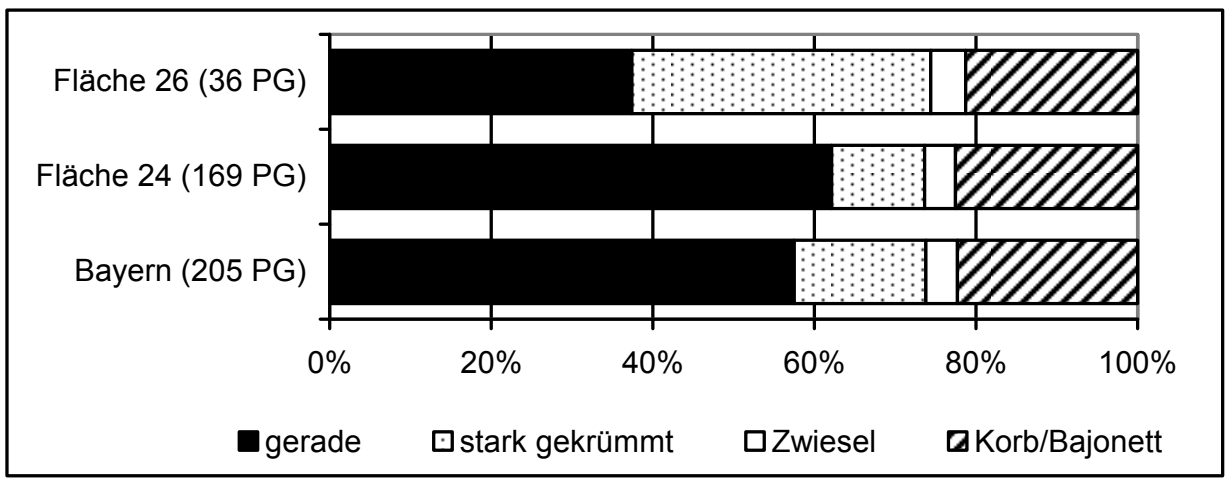

Abb. 2.47: Ergebnis der Stammformbonitur im Alter von 32 Jabren auf den zwei Versuchsflächen Sonthofen und Berchtesgaden / Bayern (PG = Prüfglieder)

\section{Ovalität}

Ein Maß zur Beurteilung der Qualität ist die Abweichung des Stammquerschnittes von der Kreisform. Die Ovalität lässt sich für die Fläche Berchtesgaden (26) im Alter von 32 Jahren bestimmen, da in diesem Jahr der BHD durch zwei Messungen (kreuzweise) mit der Kluppe ermittelt wurde. Die Ovalität beträgt im Mittel $3,1 \%$ und variiert von $0 \%$ bis $50 \%$. Die mittleren Ovalitäten der einzelnen Herkünfte sind im Anhang 1.25 zusammengestellt. Zwischen den 36 Herkünften der Fläche Berchtesgaden lassen sich keine Unterschiede absichern (TukeyKramer- bzw. Dunnett-Test, $\alpha=0,05)$.

Auch bei einer Gruppierung der 36 Herkünfte in vier Refugialräume, in fünf Höhenlagen bzw. in sieben politisch-geografische Gruppen sind keine Unterschiede statistisch nachzuweisen.

Die Varianzkomponentenschätzung zeigt, dass sich ein geringer Anteil der Merkmalsausprägung durch die Herkunft $(1 \% * *)$ und die Wechselwirkung Herkunft x Wiederholung $(6 \% * *)$ erklären lässt.

Die Güte dieses Maßes lässt sich jedoch nicht beurteilen, da keine Aufzeichnungen vorliegen, aus denen hervorgeht, dass jeweils der dickste und dünnste Durchmesser in 1,3 m Höhe gemessen wurde.

\section{Höhen- und BHD-Wachstum}

Von den beiden Flächen Sonthofen und Berchtesgaden / Bayern liegen Messungen zum Höhenwachstum im Alter von 13, 18 und 26 Jahren vor. Der BHD ist im Alter von 32 Jahren gemessen worden. Da die beiden räumlich getrennten Flächen im Wuchs unterschiedlich sind, werden sie beim Wachstum nur getrennt analysiert. 
In Tabelle 2.37 und Abbildung 2.48 sind ausgewählte statistische Parameter zum Höhenwachstum für die Versuchsflächen Sonthofen (169 Herkünfte) und Berchtesgaden (36 Herkünfte) im Alter 13, 18 und 26 gegenübergestellt. Das Wachstum ist auf der etwa $100 \mathrm{~m}$ höher gelegenen Fläche Berchtesgaden geringer als auf der Fläche Sonthofen. Das Versuchsmittel beträgt auf der Fläche Sonthofen (24) im Vergleich zum Standard aus fünf deutschen Herkünften im Alter von 13 Jahren $102 \%$, im Alter von 18 Jahren $116 \%$ und im Alter von 26 Jahren $118 \%$. Im Beobachtungszeitraum sind die anderen Herkünfte besser gewachsen als der Standard.

Tab. 2.37: $\quad$ Mittlere Höhe im Alter 13, 18 und 26 auf den Flächen Sonthofen (oben) und Berchtesgaden (unten) / Bayern, Standardabweichung, Variationskoeffirient (VK), Minimum und Maximum

\begin{tabular}{|c|c|c|c|c|c|c|}
\hline Alter & $\begin{array}{c}\text { Herkünfte } \\
{[\mathrm{n}]}\end{array}$ & $\begin{array}{c}\text { Mittel } \\
{[\mathrm{m}]}\end{array}$ & $\begin{array}{c}\text { Standardabw. } \\
{[\mathrm{m}]}\end{array}$ & $\begin{array}{l}\text { VK } \\
{[\%]} \\
\end{array}$ & $\begin{array}{l}\text { Min. } \\
{[\mathrm{m}]}\end{array}$ & $\begin{array}{l}\text { Max. } \\
{[\mathrm{m}]}\end{array}$ \\
\hline \multicolumn{7}{|c|}{$\underline{\text { Sonthofen (24) }}$} \\
\hline 13 & 169 & 1,0 & 0,2 & 23 & 0,2 & 1,5 \\
\hline 18 & 169 & 2,1 & 0,5 & 24 & 0,5 & 3,6 \\
\hline 26 & 169 & 4,3 & 1,2 & 27 & 1,6 & 7,9 \\
\hline \multicolumn{7}{|c|}{ Berchtesgaden (26) } \\
\hline 13 & 36 & 0,8 & 0,1 & 18 & 0,5 & 1,0 \\
\hline 18 & 36 & 1,5 & 0,3 & 23 & 0,7 & 2,1 \\
\hline 26 & 36 & 3,0 & 0,6 & 21 & 1,6 & 4,2 \\
\hline
\end{tabular}




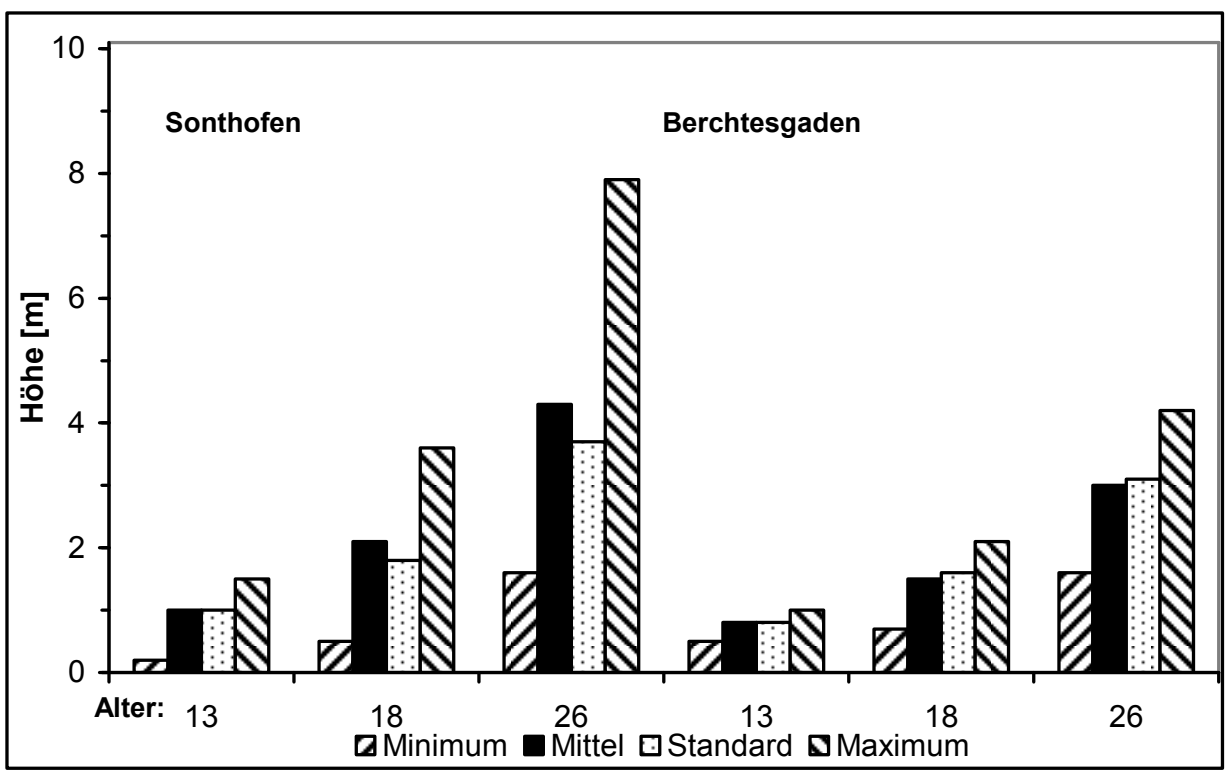

Abb. 2.48: Höhenwachstum (Mittel aller Herkünfte, mattwüchsigste und wüchsigste Herkunft sowie Mittel des Standards) auf den Flächen Sonthofen (links) und Berchtesgaden (rechts) I Bayern im Alter 13, 18 und 26

Auf der Fläche Berchtesgaden (26) beträgt das Versuchsmittel im Vergleich zum Standard aus fünf deutschen Herkünften im Alter von 13 Jahren $101 \%$, im Alter von 18 Jahren $95 \%$ und im Alter von 26 Jahren $96 \%$. Anders als auf der Fläche 24 ist in Berchtesgaden der Standard wüchsiger.

Der Vergleich des Höhenwachstums im Alter von 13, 18 und 26 Jahren zeigt, dass die Wachstumsmerkmale auf beiden Flächen hoch korreliert sind (Tab. 2.38 und 2.39). Am engsten ist die Korrelation zwischen dem Höhenwachstum im Alter 18 und 26.

Tab. 2.38: $\quad$ Produkt-Momenten-Korrelationsmatrix des Wachstumsmerkmals Höhe im Alter 13, 18 und 26 auf der Fläche Sonthofen $(n=169)$

\begin{tabular}{l|c|c|c}
\hline & $\begin{array}{c}\text { Höhe } \\
13-j .\end{array}$ & $\begin{array}{c}\text { Höhe } \\
18-j .\end{array}$ & $\begin{array}{c}\text { Höhe } \\
26-j .\end{array}$ \\
\hline Höhe $13-\mathrm{j}$. & - & $0,552^{* * *}$ & $0,505^{* * *}$ \\
Höhe $18-\mathrm{j}$. & & - & $0,883^{* * *}$ \\
\cline { 1 - 1 } Höhe $26-\mathrm{j}$. & & & - \\
\hline
\end{tabular}


Tab. 2.39: Produkt-Momenten-Korrelationsmatrix des Wachstumsmerkmals Höhe im Alter 13, 18 und 26 auf der Fläche Berchtesgaden $(n=36)$

\begin{tabular}{l|c|c|c}
\hline & $\begin{array}{c}\text { Höhe } \\
13-j .\end{array}$ & $\begin{array}{c}\text { Höhe } \\
18-j .\end{array}$ & $\begin{array}{c}\text { Höhe } \\
26-j .\end{array}$ \\
\hline Höhe $13-\mathrm{j}$. & - & $0,471^{* *}$ & $0,444 * *$ \\
Höhe $18-\mathrm{j}$. & & - & $0,880^{* * *}$ \\
\cline { 1 - 1 } Höhe $26-\mathrm{j}$. & & & - \\
\hline
\end{tabular}

Im Vergleich zur Ertragstafel (GUTTENBERG 1915) ist das BHD-Wachstum der Fichte auf der Fläche Sonthofen (169 Herkünfte) sehr gut und auf der Fläche Berchtesgaden (36 Herkünfte) mäßig. Im Alter von 32 Jahren haben die Fichten einen mittleren BHD von $13,5 \mathrm{~cm}$ über alle 205 Herkünfte beider Versuchsflächen. Die mittleren BHD der einzelnen Herkünfte sind im Anhang 1.25 getrennt für die beiden Versuchsflächen zusammengestellt.

Im Alter von 32 Jahren hat der BHD im Mittel aller 169 Herkünfte auf der Versuchsfläche Sonthofen (24) $14,5 \mathrm{~cm}$ betragen und variierte zwischen der mattwüchsigsten und wüchsigsten Herkunft zwischen 3,6 cm und 24,7 cm. Der Variationskoeffizient beträgt $25 \%$. Ausgewählte statistische Parameter zum BHDWachstum im Alter 32 sind für die zwei Versuchsflächen in Bayern in Abbildung 2.49 gegenübergestellt.

Auf der 100 m höher gelegenen Fläche Berchtesgaden (26) sind die Fichten deutlich weniger wüchsig (Abb. 2.49). Hier beträgt der mittlere BHD der 36 Herkünfte $8,6 \mathrm{~cm}$ und variiert zwischen $5,7 \mathrm{~cm}$ und $11,9 \mathrm{~cm}$. Der Variationskoeffizient beträgt $18 \%$. 


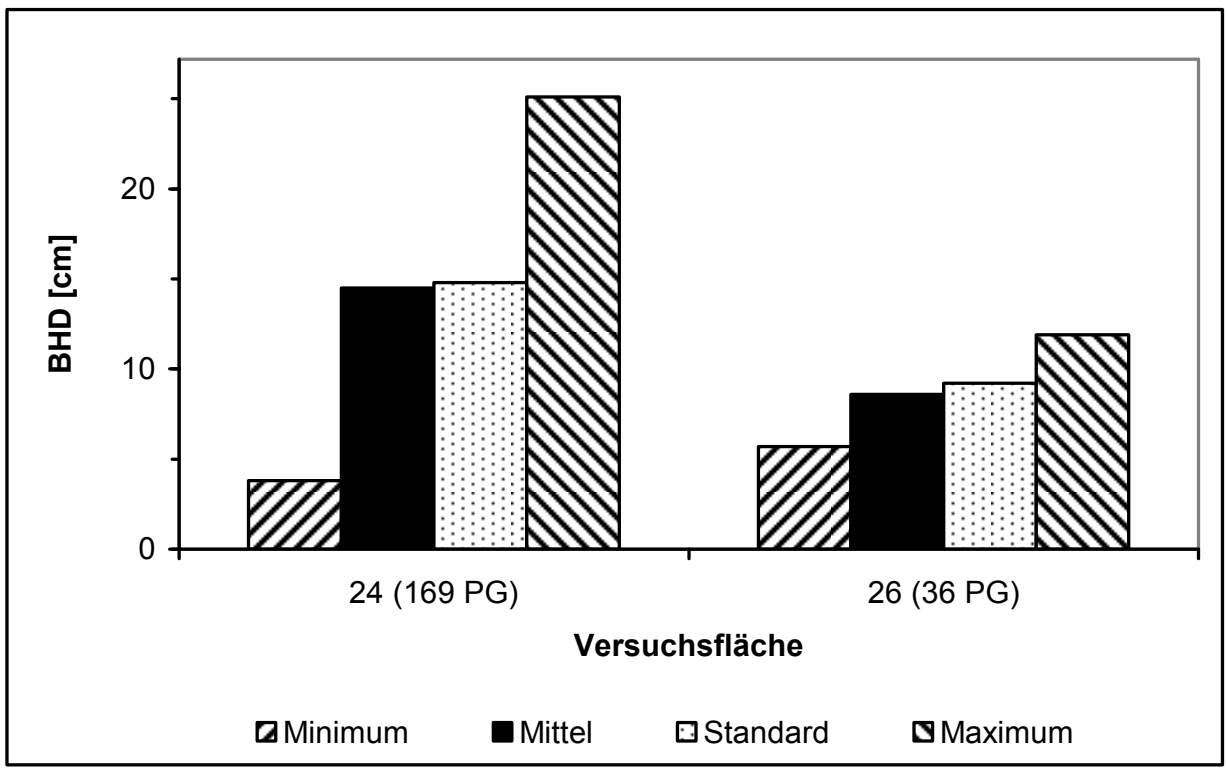

Abb. 2.49: BHD-Wachstum (Mittel aller Herkünfte, mattwüchsigste und wüchsigste Herkunft sowie Mittel des Standards) auf den zwei Flächen Sonthofen (24) und Berchtesgaden (26) / Bayern im Alter 32

Die Varianzkomponentenschätzung (Tab. 2.40) ergibt einen geringen, durch die Herkunft erklärten Anteil von 3 bzw. 4 \% auf den Flächen 24 bzw. 26. Auf der Fläche 26 erklärt die Wiederholung einen ebenso geringen Anteil. Die Wechselwirkung zwischen Herkunft und Wiederholung hat auf der Fläche 24 einen hohen Anteil an der Merkmalsausprägung.

Tab. 2.40: Varianzkomponentenschätzung des BHD-Wachstums im Alter 39

\begin{tabular}{c|c|c|c|c}
\hline Versuch & Herkunft & Wiederholung & Herkunft * Wiederh. & Rest \\
\hline 24 & $3 \% * * *$ & $0 \%$ & $32 \% * * *$ & $65 \%$ \\
26 & $4 \% *$ & $5 \% * * *$ & $0 \%$ & $91 \%$ \\
\hline
\end{tabular}

Die multiplen Mittelwertvergleiche (Tukey-Kramer- und Dunnett-Test, $\alpha=0,05$ ) der 169 Herkünfte der Fläche 24 (Sonthofen) ergeben keine statistischen Unterschiede.

Auf der kleineren Fläche Berchtesgaden (26) führt der multiple Mittelwertvergleich (Tukey-Kramer-Test, $\alpha=0,05$ ) beim BHD-Wachstum im Alter von 32 Jahren zu zwei statistisch gesicherten Unterschieden. Es unterscheiden sich statistisch signifikant im BHD-Wachstum die beiden gutwüchsigen Herkünfte SelbKirchenlamitz (3433, $800 \mathrm{~m}$ ü. NN) und Sieber (93, $400 \mathrm{~m}$ ü. NN) aus Deutschland von der mattwüchsigen Herkunft Witebsk / SU (7240; $150 \mathrm{~m}$ ü. NN). Die 
mattwüchsige Herkunft 7240 Witebsk / SU unterscheidet sich auch vom besser wüchsigen Standard (Dunnett-Test, $\alpha=0,05)$.

Wie für die Ovalitäten sind auch beim BHD-Wachstum neben den einzelnen Herkünften auch Gruppen von Herkünften analysiert worden.

Für die Herkünfte der Versuchsfläche Sonthofen (24) ergibt der multiple Mittelwertvergleich (Tukey-Kramer-Test, $\alpha=0,05)$ bei einer Einteilung der Herkünfte in Refugialräume einen gesicherten Unterschied für die Gruppen „Herzynisch-Karpatisch“, „Kontaktbereich Herzynisch-Karpatisch zu Alpin“ und „künstliches Verbreitungsgebiet“ mit einem höheren BHD gegenüber der Gruppe „Alpin“ (Abb. 2.50). Auf der Fläche 26 Berchtesgaden lassen sich keine Unterschiede absichern.

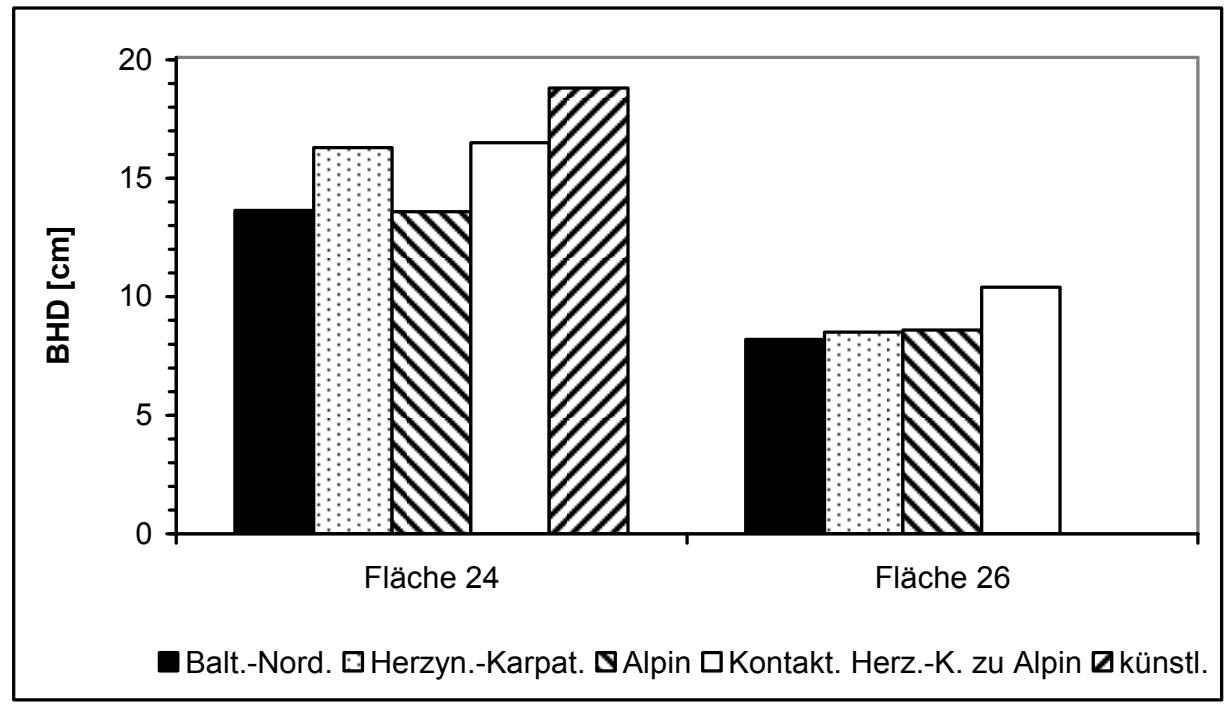

Abb. 2.50: Erwartungswerte für den mittleren BHD der Herkunftsgruppen auf den Flächen Sonthofen (24) und Berchtesgaden (26) / Bayern

Für die sieben, sich an politisch-geografischen Regionen orientierenden Gruppen sichert der multiple Mittelwertvergleich (Tukey-Kramer-Test, $\alpha=0,05$ ) auf der Fläche Sonthofen (24) Unterschiede zwischen den wüchsigeren Gruppen „ehemalige Tschechoslowakei“ sowie „Deutschland“ und den nicht so wüchsigen Gruppen „Nord-Europa“ sowie „Südwest-Europa“ ab. Außerdem ist die Gruppe „Polen“ vorratsreicher als die Gruppe „Nord-Europa“ (Abb. 2.51). Auf der Fläche Berchtesgaden (26) lassen sich keine Unterschiede absichern. 


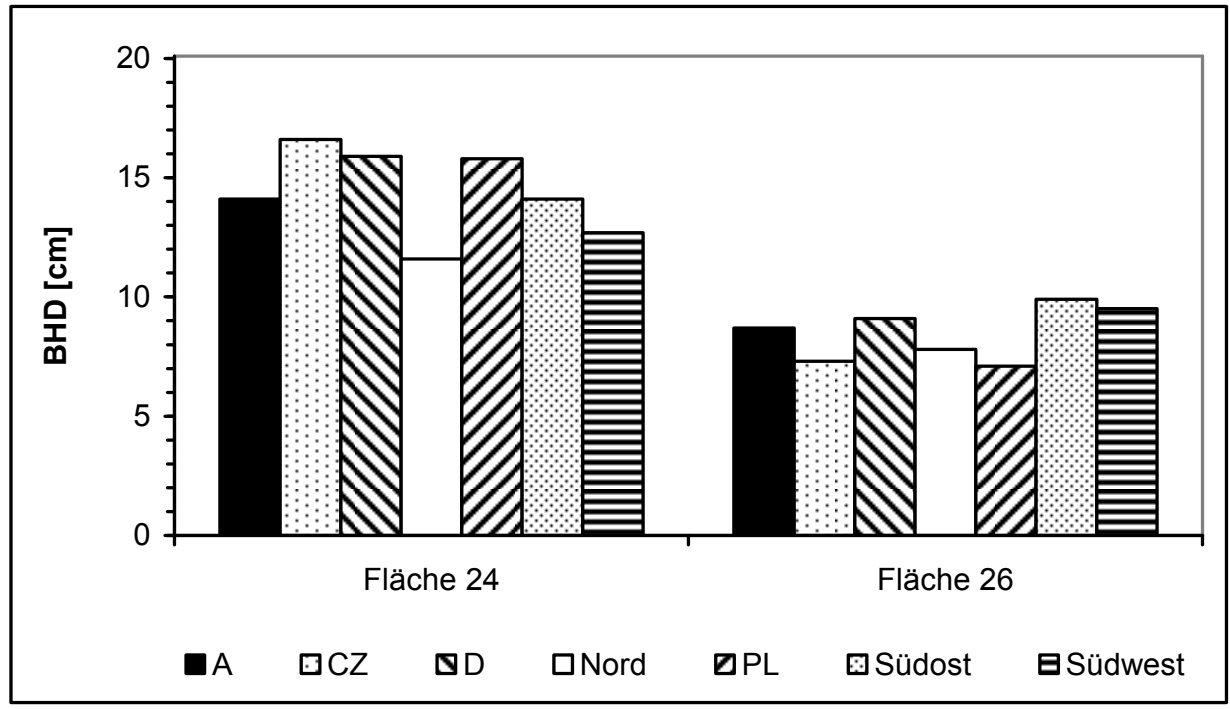

Abb. 2.51: Erwartungswerte für den mittleren BHD der Herkünfte gruppiert nach politisch-geografischen Regionen auf den Flächen Sonthofen (24) und Berchtesgaden (26) / Bayern

Bei einer Gruppierung der Herkünfte nach Höhenlagen ihrer Einsammlungsorte sind die Gruppen ,200-650 m“ und ,über 1000 m“ signifikant wuchsschwächer als die beiden Gruppen und „650-850 m“ und „850-1000 m“ auf der Fläche Sonthofen (24) (Abb. 2.52). Auf der Fläche Berchtesgaden (26) lassen sich keine Unterschiede absichern. 


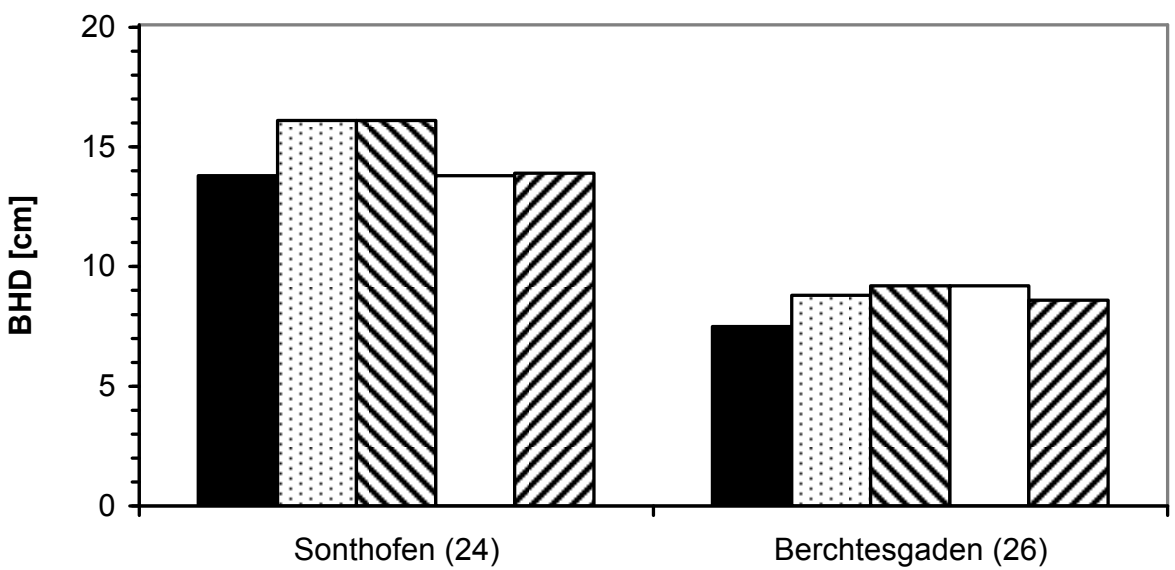

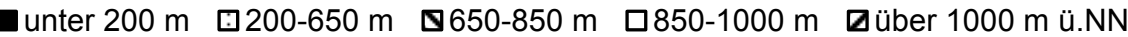

Abb. 2.52: Erwartungswerte für den mittleren BHD der Herkünfte gruppiert nach fünf Höhenlagen auf den Flächen Sonthofen (24) und Berchtesgaden (26) / Bayern

\subsubsection{Münsingen / Baden-Württemberg}

Von der Fläche Münsingen in Baden-Württemberg standen für die abschließende Auswertung des Fichtenversuchs von 1962 nur die Höhenwachstumswerte aus dem Alter 13, 18 und 26 zur Verfügung.

\section{Höhenwachstum}

Im Vergleich zur Ertragstafel (ASSMANN u. FRANZ 1963 und WIEDEMANN 1936/1942) ist das Wachstum der Fichte auf der Fläche Münsingen gering. Über alle Herkünfte der Versuchsfläche wird im Alter von 26 Jahren eine mittlere Höhe von 7,8 m errechnet. Der Variationskoeffizient beträgt $12 \%$ der Herkunftsmittelwerte (Tab. 2.41).

Tab. 2.41: Mittlere Höhe im Alter 13, 18 und 26 auf der Fläche Münsingen / Baden-Württemberg, Standardabweichung, Variationskoeffizient (VK), Minimum und Maximum

\begin{tabular}{c|c|c|c|c|c|c}
\hline Alter & $\begin{array}{c}\text { Herkünfte } \\
{[\mathrm{n}]}\end{array}$ & $\begin{array}{c}\text { Mittel } \\
{[\mathrm{m}]}\end{array}$ & $\begin{array}{c}\text { Standardabw. } \\
{[\mathrm{m}]}\end{array}$ & $\begin{array}{c}\text { VK } \\
{[\%]}\end{array}$ & $\begin{array}{c}\text { Min. } \\
{[\mathrm{m}]}\end{array}$ & $\begin{array}{c}\text { Max. } \\
{[\mathrm{m}]}\end{array}$ \\
\hline 13 & 169 & 1,5 & 0,4 & 24 & 0,4 & 2,4 \\
18 & 169 & 3,7 & 0,6 & 16 & 2,1 & 5,4 \\
26 & 169 & 7,8 & 0,9 & 12 & 5,1 & 10,2 \\
\hline
\end{tabular}




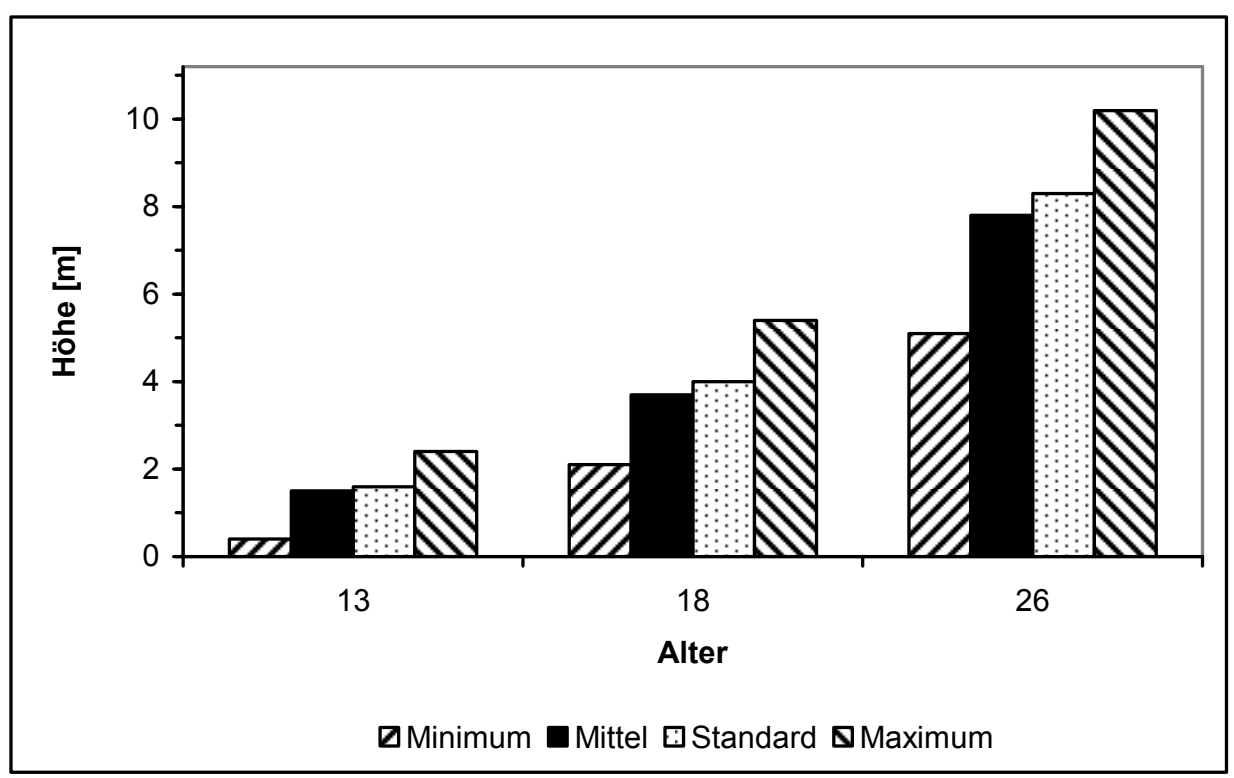

Abb. 2.53: Höhenwachstum (Mittel aller Herkünfte, mattwüchsigste und wüchsigste Herkunft sowie Mittel des Standards) auf der Fläche Münsingen / Baden-Württemberg im Alter 13, 18 und 26

In Abbildung 2.53 sind ausgewählte statistische Parameter zum Höhenwachstum für die Versuchsfläche Münsingen im Alter 13, 18 und 26 gegenübergestellt. Die Relationen zwischen den einzelnen Größen sind im jeweiligen Alter gleich. Das Versuchsmittel ist im Vergleich zum Standard aus fünf deutschen Herkünften in den drei Altern annähernd gleich. Es beträgt im Alter von 13 Jahren $92 \%$, im Alter von 18 Jahren $94 \%$ und im Alter von 26 Jahren $95 \%$.

Der Vergleich des Höhenwachstums im Alter von 13, 18 und 26 Jahren zeigt, dass die Wachstumsmerkmale hoch korreliert sind (Tab. 2.42). Am engsten ist die Korrelation zwischen dem Höhenwachstum im Alter 18 und 26.

Tab. 2.42: $\quad$ Produkt-Momenten-Korrelationsmatrix des Wachstumsmerkmals Höhe im Alter 13, 18 und $26(n=169)$

\begin{tabular}{c|c|c|c}
\hline & $\begin{array}{c}\text { Höhe } \\
13-j .\end{array}$ & $\begin{array}{c}\text { Höhe } \\
18-j .\end{array}$ & $\begin{array}{c}\text { Höhe } \\
26-j .\end{array}$ \\
\hline Höhe 13-j. & - & $0,676^{* * *}$ & $0,546^{* * *}$ \\
\cline { 1 - 1 } Höhe 18-j. & & - & $0,904 * * *$ \\
\cline { 1 - 1 } Höhe 26-j. & & & - \\
\hline
\end{tabular}




\subsubsection{Vergleich der Versuchsflächen}

Der Fichtenherkunftsversuch von 1962 setzt sich aus drei Teilversuchen zusammen. Die drei Teilversuche sind nicht von allen vier Versuchsanstellern angelegt worden. Außerdem gibt es in der Zusammensetzung der Herkünfte innerhalb der Teilversuche Unterschiede (Tab. 2.43). Die meisten Gemeinsamkeiten gibt es im Teilversuch mit den 169 Herkünften. In diesem Teilversuch fehlt auf der Fläche Hasbruch / Niedersachsen die Herkunft Klodzko, 72 K / PL (Nr. 6713). Im Teilversuch mit den 81 Herkünften gibt es 72 gemeinsame Prüfglieder und im Teilversuch mit den 36 Herkünften 34 gemeinsame Prüfglieder.

Tab. 2.43: Zusammenstellung der auf den Versuchsflächen des Fichtenherkunftsversuchs von 1962 gemeinsamen Herkünfte

\begin{tabular}{|c|c|c|c|c|}
\hline $\begin{array}{l}\text { Gemeinsame } \\
\text { Herkünfte im ... }\end{array}$ & Reinhardshagen & Hasbruch & $\begin{array}{l}\text { Sonthofen, } \\
\text { Berchtesgaden }\end{array}$ & Münsingen \\
\hline \multicolumn{5}{|c|}{ 1. Teilversuch mit 169 Herkünften } \\
\hline auf 4 Flächen & 168 & 168 & 168 & 168 \\
\hline auf 3 Flächen & 1 & - & 1 & 1 \\
\hline \multicolumn{5}{|c|}{ 2. Teilversuch mit 81 Herkünften } \\
\hline auf 2 Flächen & 72 & 72 & - & - \\
\hline auf 1 Fläche & 9 & - & - & - \\
\hline auf 1 Fläche & - & 9 & - & - \\
\hline \multicolumn{5}{|c|}{ 3. Teilversuch mit 36 Herkünften } \\
\hline auf 3 Flächen & 34 & 34 & 34 & - \\
\hline auf 2 Flächen & - & 2 & 2 & - \\
\hline auf 1 Fläche & 2 & - & - & - \\
\hline
\end{tabular}

Die folgenden Vergleiche werden jeweils zwischen den Versuchsflächen eines Teilversuches geführt, da in den Rangvergleichen mit gleicher Anzahl an Herkünften keine Verzerrungen auftreten. Außerdem unterschieden sich die beiden Flächen in Bayern standörtlich.

Bei der Anlage der Flächen ist ein Versuchsansteller von der Gitteranlage (Alpha-Design) abgewichen. Daher und da sich bei der Auswertung des IUFROFichtenherkunftsversuchs von 1972 (Abschnitt 3) gezeigt hat, dass sich bei einer Auswertung als Gitterversuch der mittlere Standardfehler nur marginal verringert, wird von der Berücksichtigung des Gitters abgesehen. 


\subsubsection{Entwicklung der Pflanzenanzabl}

Die Entwicklung der Pflanzenanzahlen ist auf den einzelnen Versuchsflächen unterschiedlich. Einige Ursachen gehen aus Kapitel „2.1.4 Behandlung und Beschreibung des Gesamteindrucks der Versuchsflächen" hervor. Die Flächen sind von den Versuchsanstellern der einzelnen Bundesländer unterschiedlich behandelt worden, so sind die Durchforstungen nach unterschiedlichen Kriterien erfolgt.

Die Dokumentation der Behandlung der einzelnen Versuchsflächen enthält nicht immer eindeutige Angaben, ob ausgefallene Pflanzen durch Reservepflanzen in den ersten Jahren nach der Flächenanlage ersetzt wurden. Durch die Nachbesserungen ausgefallener Pflanzen, die sich zum Teil über längere Zeiträume erstrecken, wird die natürliche Entwicklung der Pflanzenanzahl beeinflusst.

Auch die Durchforstungen, die mit der Vorgabe erfolgten, eine bestimmte Anzahl von Fichten zu erhalten, haben dazu geführt, dass bei Herkünften mit geringen Ausfällen mehr Bäume entnommen wurden als bei Herkünften mit höheren Ausfällen und damit eine Vereinheitlichung der Stammzahl erwirkt wurde. Aussagen zur natürlichen Mortalität und damit zur Angepasstheit an den jeweiligen Versuchsstandort sind daher nicht möglich.

\subsubsection{Schadmerkmale}

Die Erfassung von Schädigungen erfolgte auf den einzelnen Versuchsflächen nicht einheitlich. Auf den Flächen Hasbruch / Niedersachsen, Reinhardshagen / Hessen und Sonthofen / Bayern ist der Anteil der geschädigten Fichten gering. Am häufigsten wurden auf diesen Versuchsflächen „Schneedruck / Windwurf“" notiert. Diese Schädigung trat auf den Flächen Hasbruch / Niedersachsen und Reinhardshagen / Hessen mit Schwerpunkten auf. So war eine Häufung der Schäden in Reinhardshagen im Jahr 1993 (Fichtenalter 32) im westlichen Flächenteil und sieben Jahre später im nördlichen Teil beobachtet worden. Auf der Fläche Hasbruch / Niedersachsen wurden in dem an das Feld angrenzenden Teil die meisten Windwurfschäden notiert. Die beobachteten Schäden sind daher zufällig und nicht herkunftsbedingt. Auf der Fläche Sonthofen / Bayern gehen die Schäden dagegen auf Schneeeinwirkung zurück. Auch hier sind die Schäden zufällig und nicht herkunftsbedingt, da sich kein Muster finden ließ.

Anders sieht es auf der in $1360 \mathrm{~m}$ ü. NN gelegenen Fläche Berchtesgaden aus. Hier sind die Schäden um ein Vielfaches häufiger aufgetreten. Außerdem zeigt sich, dass die Schäden durch Schneedruck und Schneebruch bei den Herkünften, die in Hochlagen eingesammelt wurden, geringer ausfielen als jene bei Herkünften aus tieferen Lagen. 


\subsubsection{Formmerkmale}

\section{Stammform}

Die Bonitur der Stammform ist zwischen den Versuchsflächen unterschiedlich ausgefallen. Auf den beiden Flächen Hasbruch / Niedersachsen und Reinhardshagen / Hessen sind etwa $80 \%$ gerade Fichten notiert. Zwischen den einzelnen Teilversuchen dieser Flächen sind keine Unterschiede aufgetreten. Deutlich geringer ist der Anteil der geraden Fichten auf den beiden Teilflächen in den Hochlagen Bayerns. Auf der Fläche Sonthofen beträgt der Anteil gerader Fichten $62 \%$ und auf der $100 \mathrm{~m}$ höher gelegenen Fläche Berchtesgaden nur $37 \%$.

Zwischen den Versuchsflächen in Hessen und in Niedersachsen gibt es einen statistisch gesicherten Zusammenhang im Anteil der geraden Stämme einer Herkunft (Produkt-Momenten-Korrelation), während zur Fläche „Bayern“ kein signifikanter Zusammenhang besteht (Tab. 2.44).

Tab. 2.44: $\quad$ Produkt-Momenten-Korrelationsmatrix des Anteils der geraden Stämme auf den Flächen in Bayern, Hessen und Niedersachsen im Alter 32 (Anzabl Herkünfte)

\begin{tabular}{|c|c|c|c|}
\hline Flächen & $\begin{array}{l}\text { Bayern } \\
(24,26) \\
\end{array}$ & $\begin{array}{c}\text { Hessen } \\
(34,35,36) \\
\end{array}$ & $\begin{array}{c}\text { Niedersachsen } \\
(44,45,46) \\
\end{array}$ \\
\hline $\begin{array}{l}\text { Bayern } \\
(24,26)\end{array}$ & - & $\begin{array}{l}0,041 \mathrm{~ns} \\
(\mathrm{n}=198) \\
\end{array}$ & $\begin{array}{c}0,093 \mathrm{~ns} \\
(\mathrm{n}=199) \\
\end{array}$ \\
\hline $\begin{array}{l}\text { Hessen } \\
(34,35,36)\end{array}$ & & - & $\begin{array}{l}0,205 * * * \\
(\mathrm{n}=264)\end{array}$ \\
\hline $\begin{array}{l}\text { Niedersachsen } \\
(44,45,46)\end{array}$ & & & - \\
\hline
\end{tabular}

Bei der Analyse der einzelnen Teilflächen ergibt sich folgendes Bild: Zwischen den Versuchsflächen mit den 169 Herkünften besteht ein signifikanter Zusammenhang zwischen Reinhardshagen (34) und Sonthofen (24) sowie zwischen den Flächen Reinhardshagen (34) und Hasbruch (44) (Tab. 2.45). Auch zwischen den Flächen Reinhardshagen (35) und Hasbruch (45) mit 81 Herkünften besteht ein Zusammenhang zwischen den Herkünften im Anteil der geradstämmigen Fichten $\left(\mathrm{r}_{\mathrm{P}}=0,329^{* *}\right)$. Kein Zusammenhang lässt sich für die Herkünfte auf den Versuchsflächen mit den 36 Prüfgliedern nachweisen. 
Tab. 2.45: $\quad$ Produkt-Momenten-Korrelationsmatrix des Anteils der geraden Stämme auf den Flächen mit 169 Herkünften in Bayern, Hessen und Niedersachsen im Alter 32 (Anzabl Herkünfte)

\begin{tabular}{l|c|c|c}
\hline Flächen & Bayern (24) & Hessen (34) & Niedersachsen (44) \\
\hline Bayern (24) & - & $\begin{array}{c}0,248^{* *} \\
(\mathrm{n}=169)\end{array}$ & $\begin{array}{c}0,128 \mathrm{~ns} \\
(\mathrm{n}=168)\end{array}$ \\
\hline Hessen (34) & \multicolumn{3}{c}{$\begin{array}{c}0,196 * \\
(\mathrm{n}=168)\end{array}$} \\
\hline Niedersachsen (44) & & - & - \\
\hline
\end{tabular}

Um zu prüfen, ob die geraden Fichten zufällig über die Herkünfte verteilt sind, wurden die Herkünfte in Gruppen eingeteilt, die einem Homogenitätstest (RASCH et al. 1998) unterzogen wurden. Die Herkünfte der bayerischen Flächen sind dazu in Refugialgruppen, Höhenlagen bzw. politisch-geografische Gruppen eingeteilt worden. Getestet wurde, ob das Verhältnis von geraden Bäumen zu solchen mit einem Mangel zwischen den Gruppen gleich ist. Das Ergebnis der Homogenitätstests $\left(\chi^{2}\right.$-Test, $\left.\alpha=0,05\right)$ weist einen allgemeinen Unterschied zwischen den Höhenlagen und den politisch-geografischen Gruppen aus. Zwischen den Refugialgruppen gibt es keine Unterschiede.

Im zweiten Schritt sind in paarweisen Vergleichen die Höhenlagen bzw. die politisch-geografischen Gruppen auf Homogenität getestet worden ( $\chi^{2}$-Test, $\alpha=0,05)$. Das Ergebnis dieser Vergleiche zeigt, dass die Höhenlage ,unter 200 m“ signifikant weniger geradstämmige Fichten aufweist als die weiteren vier Höhenlagen. Auch die Fichten, die aus einer Höhenlage von „200-650 m“ stammen, haben weniger gerade Stämme als die aus einer Höhenlage von „über 1000 m“ (Abb. 2.54).

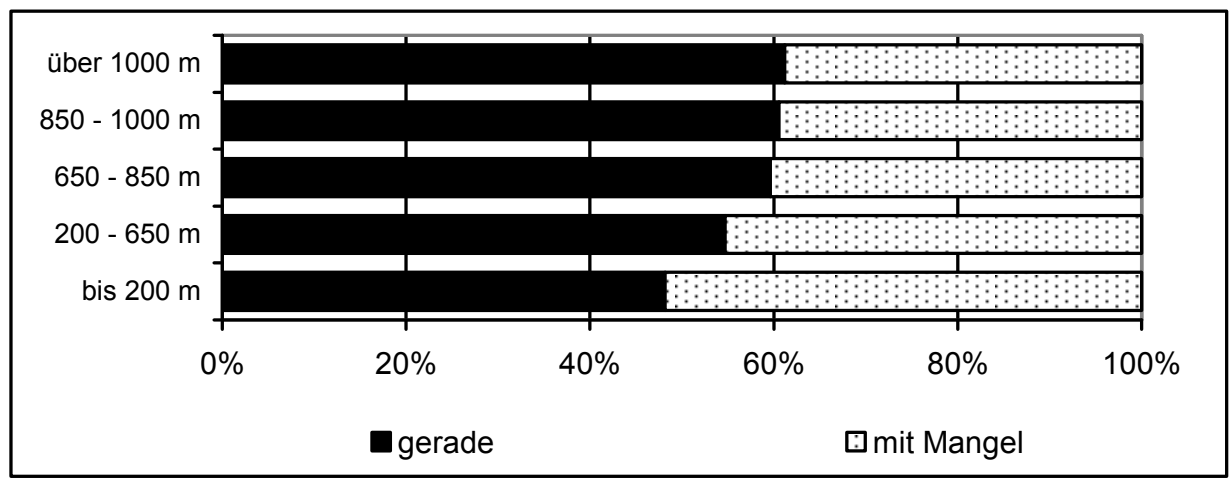

Abb. 2.54: Anteil der Fichten aus verschiedenen Höhenlagen mit geraden Stämmen bzw. mit mangelbehafteten Formen auf den Flächen Sonthofen und Berchtesgaden 
Der Vergleich der politisch-geografischen Gruppen ergibt, dass die Fichten aus „Polen“ signifikant weniger gerade Stämme haben als die der Gruppen „SüdwestEuropa“, „Südost-Europa“, „ehemalige Tschechoslowakei“ und „Österreich“. Sowohl die Gruppe „Österreich“ als auch „ehemalige Tschechoslowakei“ haben auch signifikant mehr geradstämmige Fichten als die Gruppen „Deutschland“ und „Nord-Europa“ (Abb. 2.55).

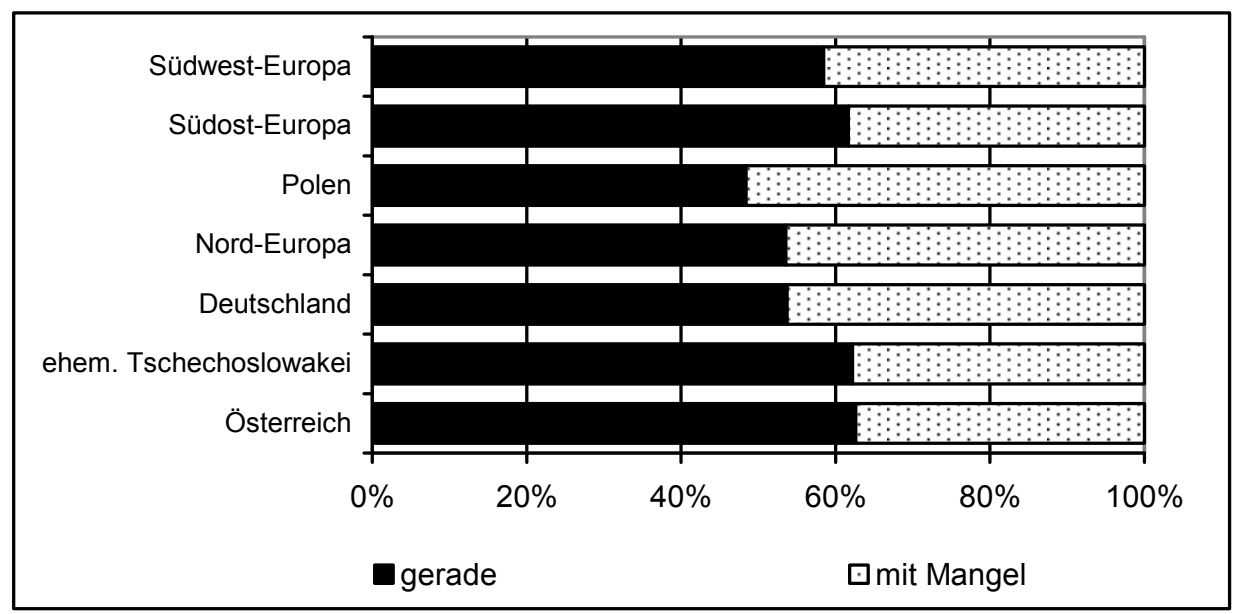

Abb. 2.55: Anteil der Fichten mit geraden Stämmen bzw. mit mangelbehafteten Formen auf den Flächen Sonthofen und Berchtesgaden in politisch-geografischen Gruppen

\section{Ovalität}

Vom Qualitätsmerkmal Ovalität, das die Abweichung des Stammquerschnittes in 1,3 m Höhe von der Kreisform beschreibt, liegen Ergebnisse für die Flächen in Hessen und Niedersachsen im Alter von 32 und 39 Jahren sowie für die Fläche Berchtesgaden / Bayern im Alter von 32 Jahren vor.

Für die Teilversuche mit den 169 Herkünften decken die Korrelationsanalysen Zusammenhänge jeweils zwischen den Messungen im Alter 32 und 39 auf den Flächen Reinhardshagen (34) bzw. Hasbruch (44) auf. Zwischen den Flächen gibt es keine Zusammenhänge.

Auf den Flächen mit den 81 Herkünften gibt es keinen Zusammenhang zwischen den Messungen im Alter 32 und 39 auf der Fläche Reinhardshagen (35) bzw. Hasbruch (45).

Bei den Flächen mit den 36 Herkünften gibt es Zusammenhänge bei den Ovalitäten der Herkünfte zwischen den beiden Messungen im Alter 32 und 39 auf der Fläche Reinhardshagen / Hessen (36). Einen weiteren Zusammenhang decken die Korrelationsanalysen zwischen der Fläche Berchtesgaden (26) und der Fläche Reinhardshagen (36) im Alter 32 auf (Tab. 2.46). Dieses Ergebnis wird als zufällig beurteilt. 
Tab. 2.46: Produkt-Momenten-Korrelationsmatrix der mittleren Ovalität der Ficbten auf den Flächen mit 36 Herkünften in Bayern, Hessen und Niedersachsen im Alter 32 (Anzabl Herkë̈nfte)

\begin{tabular}{|c|c|c|c|c|c|c|}
\hline \multirow[t]{2}{*}{ Fläche } & \multirow[b]{2}{*}{ Alter } & \multirow{2}{*}{$\begin{array}{c}\text { Sonthofen (26) } \\
32-j .\end{array}$} & \multicolumn{2}{|c|}{ Reinhardshagen (36) } & \multicolumn{2}{|c|}{ Hasbruch (46) } \\
\hline & & & $32-j$. & $39-\mathrm{j}$. & $32-j$. & 39-j. \\
\hline $\begin{array}{l}\text { Sonthofen } \\
(26)\end{array}$ & $32-\mathrm{j}$. & - & $\begin{array}{c}0,431 * \\
(\mathrm{n}=34)\end{array}$ & $\begin{array}{l}0,119 \mathrm{~ns} \\
(\mathrm{n}=34)\end{array}$ & $\begin{array}{l}0,178 \mathrm{~ns} \\
(\mathrm{n}=36)\end{array}$ & $\begin{array}{l}0,121 \mathrm{~ns} \\
(\mathrm{n}=36)\end{array}$ \\
\hline \multirow[t]{2}{*}{$\begin{array}{l}\text { Reinhardshagen } \\
\text { (36) }\end{array}$} & $32-\mathrm{j}$. & & - & $\begin{array}{c}0,364^{*} \\
(\mathrm{n}=36) \\
\end{array}$ & $\begin{array}{l}-0,307 \mathrm{~ns} \\
(\mathrm{n}=34)\end{array}$ & $\begin{array}{l}0,080 \mathrm{~ns} \\
(\mathrm{n}=34)\end{array}$ \\
\hline & $39-j$. & & & - & $\begin{array}{c}-0,114 \mathrm{~ns} \\
(\mathrm{n}=34)\end{array}$ & $\begin{array}{c}-0,155 \mathrm{~ns} \\
(\mathrm{n}=34)\end{array}$ \\
\hline \multirow[t]{2}{*}{$\begin{array}{l}\text { Hasbruch } \\
(46)\end{array}$} & $32-j$. & & & & 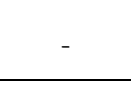 & $\begin{array}{l}0,169 \mathrm{~ns} \\
(\mathrm{n}=36)\end{array}$ \\
\hline & $39-\mathrm{j}$. & & & & & - \\
\hline
\end{tabular}

Da von keiner der Messungen Aufzeichnungen vorliegen, aus denen hervorgeht, ob jeweils die Bäume an der dicksten bzw. dünnsten Stelle in 1,3 m Höhe gemessen wurden, lässt sich über die Güte dieses Maßes keine Aussage treffen. Es wird daher davon ausgegangen, dass die gefundenen Zusammenhänge eher zufällig sind.

\section{H/D-Verhältnis}

Das H/D-Verhältnis hat sich für die Flächen Reinhardshagen / Hessen und Hasbruch / Niedersachsen ermitteln lassen. Auf allen drei Teilflächen sind die H/D-Verhältnisse nahezu gleich (Abb. 2.56). Die Korrelationsanalysen ergeben keinen Zusammenhang zwischen den Herkünften auf den Versuchsflächen. 


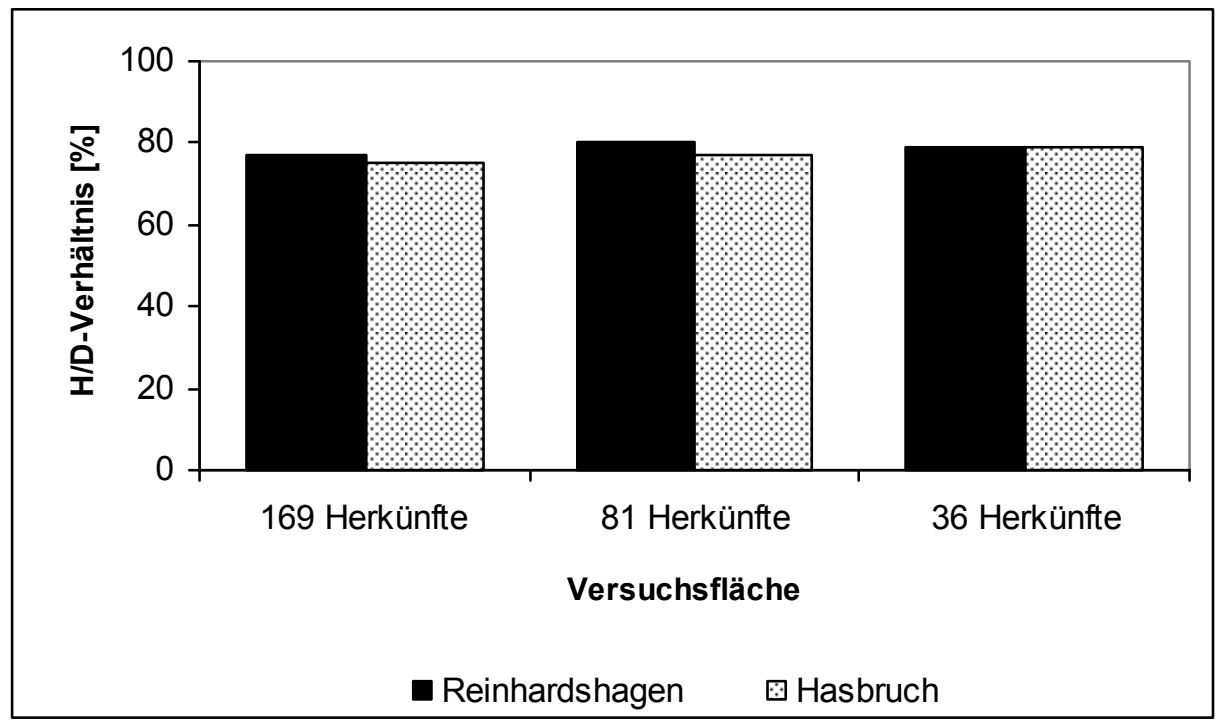

Abb. 2.56: Mittlere H/D-Verbältnisse auf den Flächen Reinhardshagen und Hasbruch im Alter 39

\subsubsection{Höhen- und BHD-W achstum}

\section{Herkünfte des Standards}

Bevor auf das Wachstum aller Herkünfte eingegangen wird, werden erst die fünf Herkünfte des Standards analysiert. Dazu sind für die einzelnen Höhen- und BHD-Messungen je Versuchsfläche Rangfolgen vergeben worden. Die wüchsigste Herkunft einer Fläche erhielt die Rangziffer 1, die mattwüchsigste die Rangziffer 5. Je Fläche ist eine mittlere Rangziffer je Standardherkunft errechnet worden. Dazu sind die einzelnen Ränge addiert worden und durch die Anzahl der Summanden (entspricht Messzeitpunkte) dividiert worden.

In der Abbildung 2.57 sind die mittleren Rangsummen für die fünf Herkünfte des Standards je Versuchsfläche abgetragen. Zu erkennen ist, dass sich keine Herkunft auf allen Flächen bei allen Messungen als die best- bzw. mattwüchsigste Herkunft herausgestellt hat. Die bestwüchsigste Herkunft des Standards ist auf den beiden Flächen in Bayern $(24,26)$ die Herkunft 3433 (Selb-Kirchenlamitz / BY, $800 \mathrm{~m}$ ü. NN). Diese Herkunft hat bei fast allen Messungen den ersten Rang belegt. Auf je einer Fläche in Niedersachsen $(44,46)$ haben zwei Herkünfte bei fast allen Messungen den letzten Rang belegt. Auf der Fläche Hasbruch 44 (169 Herkünfte) ist es die Herkunft 3417 (Marsberg / NW, $500 \mathrm{~m}$ ü. NN) und auf der Fläche 46 (36 Herkünfte) die Herkunft 3430 (Diessen / BY, bis 900 m ü. NN). 
Das Mittel der mittleren Ränge variiert nur gering zwischen 2,6 (3417, 3433) und 3,7 (3423). Die fünf Herkünfte werden daher als umweltvariabel eingestuft und können nur bedingt als Maßstab zum Vergleich zwischen Flächen herangezogen werden.

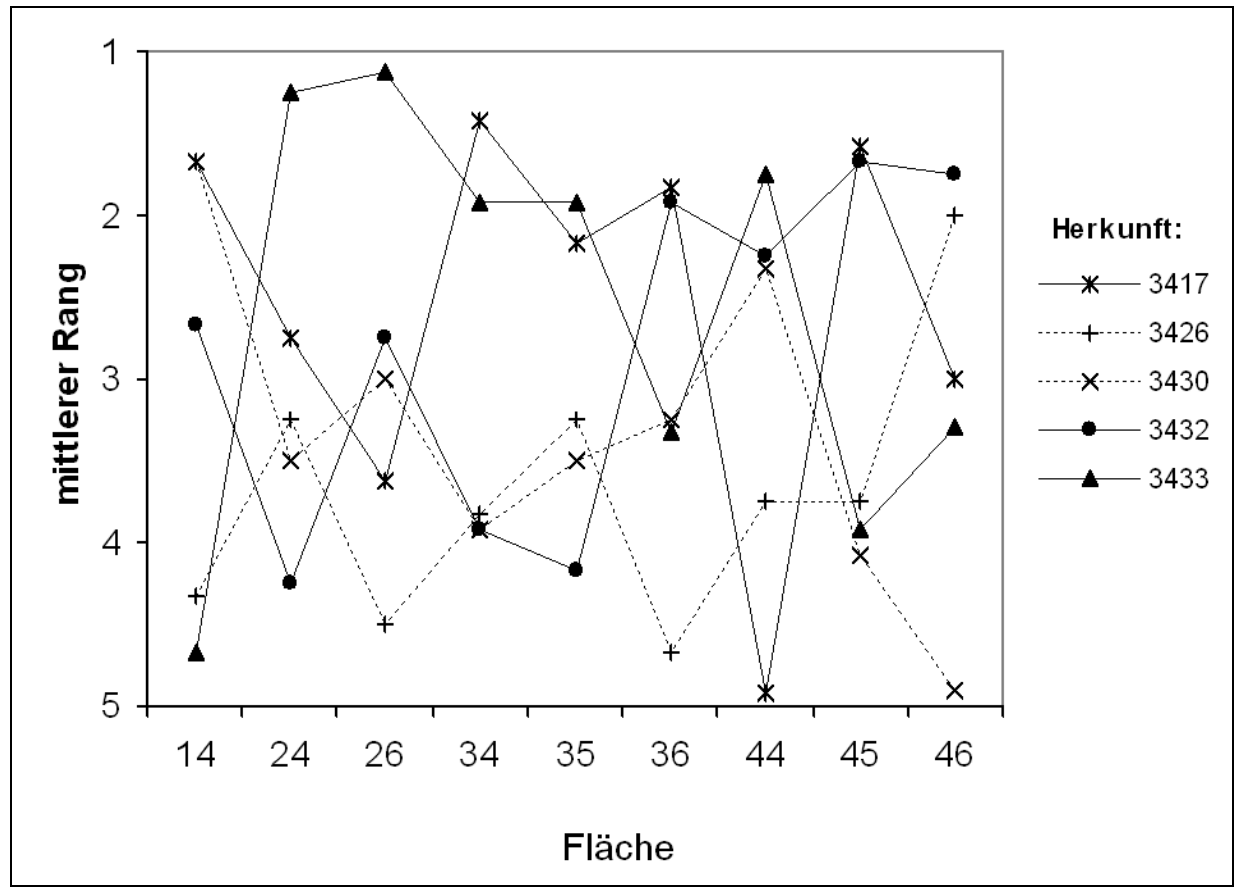

Abb. 2.57: Mittlere Rangsummen der fünf Herkünfte des Standards auf den neun Teilflächen des Fichtenherkunftsversuchs von 1962 (Zur Verdeutlichung der Rangwechsel auf den einzelnen Flächen sind die Ränge einer Herkunft jeweils verbunden.)

\section{Alle Herkünfte}

Auf den Versuchsflächen sind wiederholt Messungen zum Wachstum vorgenommen worden. Für alle Flächen liegen Messungen im Alter 13, 18 und 26 Jahren vor. Im Alter von 32 Jahren ist eine Fläche in Baden-Württemberg (14) bereits aufgegeben gewesen und wurde nicht mehr aufgenommen. Sieben Jahre später sind keine Messungen mehr auf den beiden Teilflächen in Bayern $(24,26)$ erfolgt.

Die Produkt-Momenten-Korrelationen der Höhenmessungen von den vier Versuchsflächen mit 169 Herkünften ergeben im Alter von 13 Jahren nur einen signifikanten Zusammenhang (Tab. 2.47). Ein schwacher Zusammenhang ergibt sich zwischen den Flächen Reinhardshagen / Hessen (34) und Hasbruch / Niedersachsen (44). In diesem Ergebnis kann sich noch ein Einfluss der Anzuchtorte widerspiegeln. Die Pflanzen für die Versuchsflächen Reinhardshagen und Hasbruch sind in zwei nahe beieinander gelegenen Baumschulen angezogen worden. 
Tab. 2.47: Produkt-Momenten-Korrelationsmatrix des Höhenwachstums auf den vier Flächen mit 169 Herkü̈ften im Alter 13 ( $n=$ Anzabl Herkünfte)

\begin{tabular}{l|c|c|c|c}
\hline Fläche & Münsingen (14) & Sonthofen (24) & $\begin{array}{c}\text { Reinhardshagen } \\
(34)\end{array}$ & Hasbruch (44) \\
\hline Münsingen (14) & - & $\begin{array}{c}0,086 \mathrm{~ns} \\
(\mathrm{n}=169)\end{array}$ & $\begin{array}{c}-0,020 \mathrm{~ns} \\
(\mathrm{n}=169)\end{array}$ & $\begin{array}{c}0,144 \mathrm{~ns} \\
(\mathrm{n}=168)\end{array}$ \\
\hline Sonthofen (24) & - & $\begin{array}{c}-0,060 \mathrm{~ns} \\
(\mathrm{n}=169)\end{array}$ & $\begin{array}{c}-0,009 \mathrm{~ns} \\
(\mathrm{n}=168)\end{array}$ \\
\hline Reinhardshagen (34) & \multicolumn{5}{c}{$\begin{array}{c}0,179 * \\
(\mathrm{n}=168)\end{array}$} \\
\hline Hasbruch (44) & \multicolumn{4}{c}{} \\
\hline
\end{tabular}

Der Vergleich der Messungen im Alter 18 bzw. 26 zeigt einen stärkeren Zusammenhang des Höhenwachstums zwischen den Herkünften auf den unterschiedlichen Versuchsflächen. Sowohl im Alter von 18 Jahren (Tab. 2.48) als auch im Alter 26 (Tab. 2.49) besteht jedoch kein Zusammenhang der Herkünfte im Höhenwachstum auf den Flächen Münsingen (14) und Sonthofen (24).

Tab. 2.48: Produkt-Momenten-Korrelationsmatrix des Höhenwachstums auf den vier Flächen mit 169 Herkünften im Alter 18 ( $n=$ Anzabl Herkünfte)

\begin{tabular}{l|c|c|c|c}
\hline Fläche & Münsingen (14) & Sonthofen (24) & $\begin{array}{c}\text { Reinhardshagen } \\
(34)\end{array}$ & Hasbruch (44) \\
\hline Münsingen (14) & - & $\begin{array}{c}0,062 \mathrm{~ns} \\
(\mathrm{n}=169)\end{array}$ & $\begin{array}{c}0,162^{*} \\
(\mathrm{n}=169)\end{array}$ & $\begin{array}{c}0,196^{*} \\
(\mathrm{n}=168)\end{array}$ \\
\hline Sonthofen (24) & - & $\begin{array}{c}0,479 * * * \\
(\mathrm{n}=169)\end{array}$ & $\begin{array}{c}0,245^{* *} \\
(\mathrm{n}=168)\end{array}$ \\
\hline Reinhardshagen (34) & \multicolumn{5}{c}{$\begin{array}{c}0,541^{* * *} \\
(\mathrm{n}=168)\end{array}$} \\
\hline Hasbruch (44) & \multicolumn{4}{c}{} \\
\hline
\end{tabular}


Tab. 2.49: Produkt-Momenten-Korrelationsmatrix des Höhenwachstums auf den vier Flächen mit 169 Herkïnften im Alter 26 ( $n=$ Anzabl Herkünfte)

\begin{tabular}{l|c|c|c|c}
\hline Fläche & Münsingen (14) & Sonthofen (24) & $\begin{array}{c}\text { Reinhardshagen } \\
(34)\end{array}$ & Hasbruch (44) \\
\hline Münsingen (14) & - & $\begin{array}{c}0,107 \mathrm{~ns} \\
(\mathrm{n}=169)\end{array}$ & $\begin{array}{c}0,262^{* * *} \\
(\mathrm{n}=169)\end{array}$ & $\begin{array}{c}0,215^{* *} \\
(\mathrm{n}=168)\end{array}$ \\
\hline Sonthofen (24) & - & $\begin{array}{c}0,333^{* * *} \\
(\mathrm{n}=169)\end{array}$ & $\begin{array}{c}0,232^{* *} \\
(\mathrm{n}=168)\end{array}$ \\
\hline Reinhardshagen (34) & \multicolumn{5}{c}{$\begin{array}{c}0,468^{* * *} \\
(\mathrm{n}=168)\end{array}$} \\
\hline Hasbruch (44) & \multicolumn{5}{c}{} & - \\
\hline
\end{tabular}

Im Alter von 32 Jahren ist auf den Flächen in Bayern, Hessen und Niedersachsen der Durchmesser ermittelt worden. Die Werte sind zwischen den drei Flächen korreliert (Tab. 2.50). Bei der jüngsten Messung sind im Alter von 39 nur noch die Flächen Reinhardshagen (34) und Hasbruch (44) gemessen worden. Auf diesen Flächen wurden der BHD vollständig und die Baumhöhen an einer Stichprobe gemessen. Auch hier sind alle Werte korreliert. Dabei sind die Korrelation von Höhe und BHD auf einer Fläche enger als die eines Merkmals zwischen den Flächen (Tab. 2.51).

Tab. 2.50: $\quad$ Produkt-Momenten-Korrelationsmatrix des BHD-Wachstums auf drei Flächen mit 169 Herkünften im Alter 32 ( $n=$ Anzabl Herkünfte)

\begin{tabular}{l|c|c|c}
\hline Fläche & Sonthofen (24) & Reinhardshagen (34) & Hasbruch (44) \\
\hline Sonthofen (24) & - & $\begin{array}{c}0,291^{* * *} \\
(\mathrm{n}=169)\end{array}$ & $\begin{array}{c}0,318^{* *} \\
(\mathrm{n}=168)\end{array}$ \\
\hline Reinhardshagen (34) & \multicolumn{3}{|}{} \\
\hline Hasbruch (44) & \multicolumn{3}{c}{$\begin{array}{c}0,479^{* * *} \\
(\mathrm{n}=168)\end{array}$} \\
\hline
\end{tabular}


Tab. 2.51: Produkt-Momenten-Korrelationsmatrix des Höhen- und BHD-Wachstums auf zwei Flächen mit 169 Herkünften im Alter 39 ( $n=$ Anzabl Herk:ünfte)

\begin{tabular}{|c|c|c|c|c|c|}
\hline \multirow[t]{2}{*}{ Fläche } & \multirow[b]{2}{*}{ Merkmal } & \multicolumn{2}{|c|}{ Reinhardshagen (34) } & \multicolumn{2}{|c|}{ Hasbruch (44) } \\
\hline & & Höhe & BHD & Höhe & BHD \\
\hline \multirow[t]{2}{*}{ Reinhardshagen (34) } & Höhe & - & $\begin{array}{l}0,633^{* * *} \\
(\mathrm{n}=169)\end{array}$ & $\begin{array}{l}0,397 * * * \\
(\mathrm{n}=168)\end{array}$ & $\begin{array}{l}0,404 * * * \\
(\mathrm{n}=168)\end{array}$ \\
\hline & BHD & & - & $\begin{array}{l}0,389 * * * \\
(\mathrm{n}=168)\end{array}$ & $\begin{array}{c}0,232 * * \\
(\mathrm{n}=168)\end{array}$ \\
\hline \multirow[t]{2}{*}{ Hasbruch (44) } & Höhe & & & - & $\begin{array}{l}0,761 * * * \\
(\mathrm{n}=168)\end{array}$ \\
\hline & BHD & & & & - \\
\hline
\end{tabular}

Auf den beiden Teilflächen mit 81 Herkünften sind 72 Prüfglieder gemeinsam. Die Korrelationsanalysen der gemeinsamen Herkünfte haben vergleichbare Ergebnisse wie auf den Flächen mit den 169 Herkünften (Tab. 2.52). Im Alter von 13 Jahren besteht kein Zusammenhang im Höhenwachstum der 71 Herkünfte. Bei den Messungen im Alter 18, 26, 32 und 39 liegen Zusammenhänge vor. Im Alter von 39 Jahren sind die Zusammenhänge nicht mehr so eng wie bei den drei zuvor durchgeführten Messungen. Zwischen mittlerer Höhe und mittlerem BHD der Herkünfte sind die Zusammenhänge auf einer Fläche deutlich enger.

Tab. 2.52: $\quad$ Produkt-Momenten-Korrelationsmatrix ( $\left.\mathrm{r}_{\mathrm{P}}\right)$ des Höhen- bzw. BHD-Wachstums auf den beiden Flächen (35) und (45) mit 72 gemeinsamen Herkünften

\begin{tabular}{l|c|l|l|c}
\hline Fläche & Merkmal & Fläche & Merkmal & r $_{\mathrm{P}}$ \\
\hline Reinhardshagen (35) & Höhe 13-j. & Hasbruch (45) & Höhe 13-j. & $0,015 \mathrm{~ns}$ \\
Reinhardshagen (35) & Höhe 18-j. & Hasbruch (45) & Höhe 18-j. & $0,675^{* * *}$ \\
Reinhardshagen (35) & Höhe 26-j. & Hasbruch (45) & Höhe 26-j. & $0,503^{* * *}$ \\
Reinhardshagen (35) & BHD 32-j. & Hasbruch (45) & BHD 32-j. & $0,383^{* * *}$ \\
Reinhardshagen (35) & Höhe 39-j. & Hasbruch (45) & Höhe 39-j. & $0,270^{*}$ \\
Reinhardshagen (35) & BHD 39-j. & Hasbruch (45) & BHD 39-j. & $0,293^{*}$ \\
Reinhardshagen (35) & Höhe 39-j. & Reinhardsh. (35) & BHD 39-j. & $0,716^{* * *}$ \\
Hasbruch (45) & Höhe 39-j. & Hasbruch (45) & BHD 39-j. & $0,726^{* * *}$ \\
\hline
\end{tabular}

Auf den drei Flächen mit 36 Herkünften sind auf den Flächen Berchtesgaden (26) und Hasbruch (46) alle Herkünfte gemeinsam vertreten. Im Vergleich mit der Fläche Reinhardshagen (36) haben die beiden Flächen (26, 46) 34 gemeinsame Herkünfte. Auch in diesem Versuchsteil ist das Höhenwachstum im Alter 13 zwischen den Flächen nicht korreliert. Im Alter von 18 und 26 Jahren besteht ein 
Zusammenhang im Höhenwachstum der Herkünfte auf den Flächen Reinhardshagen (36) und Hasbruch (46): $\mathrm{r}_{\mathrm{p}}=0,533^{* * *}$ bzw. $\mathrm{r}_{\mathrm{P}}=0,345^{*}$. Auch im Alter von 32 Jahren bestätigt sich nur ein Zusammenhang im Durchmesserwachstum auf den Flächen Reinhardshagen (36) und Hasbruch (46): $\mathrm{r}_{\mathrm{p}}=0,367^{*}$. Im Alter von 39 Jahren sind nur Höhe und BHD auf der Fläche Hasbruch / Niedersachsen (46) korreliert: $\mathrm{r}_{\mathrm{P}}=0,579 * * *$.

Die mittlere Merkmalsausprägung der Baumhöhe im Alter 13, 18, 26 und 39 sowie des BHD im Alter 32 und 39 ist für die vier Versuchsflächen mit 169, die beiden Flächen mit 81 Herkünften und die drei Flächen mit 36 Herkünften varianzanalytisch untersucht worden. Dabei wurde der Einfluss der Versuchsflächen und der Herkünfte auf das Höhen- bzw. Durchmesserwachstum berücksichtigt. Die Ergebnisse sind in Tabelle 2.53 zusammengestellt. Die Varianzmodelle sind signifikant und weisen einen statistisch gesicherten Einfluss der Versuchsflächen auf die Baumhöhe und den BHD aus. Mit der Varianzkomponentenschätzung lässt sich der Anteil der Komponente der Versuchsfläche zwischen $73 \%$ und $98 \%$ quantifizieren. Der Einfluss der Herkunft auf die Höhe ist gering, aber meistens auch signifikant. Am stärksten (14\%) ist der Einfluss der Herkunft im Alter von $18 \mathrm{im}$ Versuch mit den 81 Herkünften, der jedoch nur an zwei Standorten angelegt ist. 
Tab. 2.53: V Varian₹komponentenschätzung des Höhen- und BHD-Wachstums

\begin{tabular}{|c|c|c|c|c|c|}
\hline Versuch (Flächen) & Merkmal & $\begin{array}{c}\text { Modell } \\
\mathrm{r}^{2} \\
\end{array}$ & Herkunft & Fläche & Rest \\
\hline \multicolumn{6}{|l|}{169 Herkünfte } \\
\hline$(14,24,34,44)$ & Höhe 13-j. & 0,82 & $1 \% *$ & $79 \% * * *$ & $20 \%$ \\
\hline$(14,24,34,44)$ & Höhe 18-j. & 0,92 & $3 \% * * *$ & $89 \% * * *$ & $8 \%$ \\
\hline$(14,24,34,44)$ & Höhe 26-j. & 0,92 & $3 \% * * *$ & $89 \% * * *$ & $8 \%$ \\
\hline$(24,34,44)$ & BHD 32-j. & 0,84 & $6 \% * * *$ & $76 \% * * *$ & $18 \%$ \\
\hline$(34,44)$ & Höhe 39-j. & 0,98 & $2 \% * * *$ & $96 \% * * *$ & $2 \%$ \\
\hline$(34,44)$ & BHD 39-j. & 0,96 & $3 \% * * *$ & $92 \% * * *$ & $5 \%$ \\
\hline \multicolumn{6}{|l|}{$\underline{81 \text { Herkünfte }}$} \\
\hline$(35,45)$ & Höhe 13-j. & 0,81 & $0 \%$ & $73 \% * * *$ & $27 \%$ \\
\hline$(35,45)$ & Höhe 18-j. & 0,94 & $14 \% * * *$ & $78 \% * * *$ & $8 \%$ \\
\hline$(35,45)$ & Höhe 26-j. & 0,92 & $8 \% * * *$ & $82 \% * * *$ & $10 \%$ \\
\hline$(35,45)$ & BHD 32-j. & 0,95 & $4 \% * * *$ & $90 \% * * *$ & $6 \%$ \\
\hline$(35,45)$ & Höhe 39-j. & 0,96 & $2 \% *$ & $93 \% * * *$ & $5 \%$ \\
\hline$(35,45)$ & BHD 39-j. & 0,91 & $3 \% *$ & $86 \% * * *$ & $11 \%$ \\
\hline \multicolumn{6}{|l|}{$\underline{36 \text { Herkünfte }}$} \\
\hline$(26,36,46)$ & Höhe 13-j. & 0,93 & $3 \% \mathrm{~ns}$ & $89 \% * * *$ & $8 \%$ \\
\hline$(26,36,46)$ & Höhe 18-j. & 0,98 & $1 \% *$ & $96 \% * * *$ & $3 \%$ \\
\hline$(26,36,46)$ & Höhe 26-j. & 0,98 & $0 \%$ & $98 \% * * *$ & $2 \%$ \\
\hline$(26,36,46)$ & BHD 32-j. & 0,96 & $1 \% *$ & $95 \% * * *$ & $4 \%$ \\
\hline$(36,46)$ & Höhe 39-j. & 0,98 & $2 \% *$ & $96 \%$ *** & $2 \%$ \\
\hline$(36,46)$ & BHD 39-j. & 0,96 & $0 \%$ & $95 \% * * *$ & $5 \%$ \\
\hline
\end{tabular}

Für eine Bewertung im Beobachtungszeitraum ist für die Teilversuche das Wachstum für die einzelnen Messjahre in Rangfolgen standardisiert worden. Je Fläche wurde ein mittlerer Rang im Wachstum aus der Summe der einzelnen Ränge dividiert durch die Anzahl der Erfassungsjahre berechnet. Außerdem ist ein mittlerer Rang für die Teilflächen mit gleicher Herkunftsanzahl gebildet worden. Im Weiteren ist die Spannweite zwischen dem niedrigsten und dem höchsten Rang einer Herkunft errechnet worden.

Die mittleren Ränge im Wachstum der einzelnen Herkünfte sind getrennt für die Teilflächen mit den 169 Herkünften und als Mittel über die vier Flächen im Anhang 1.26 aufgelistet. In der Tabelle 2.54 sind nach Länderzugehörigkeit je 17 Herkünfte mit den niedrigsten Rängen, d. h. den wüchsigsten Herkünften, bzw. den höchsten Rängen, den mattwüchsigsten Herkünften, zusammengestellt. Die insgesamt wüchsigste Herkunft ist die Herkunft 4082 Ostravice / CS mit dem mittleren Rang 27. Es folgen mit einem mittleren Rang von 33 bzw. 34 die deutschen Herkünfte 3499 Chausseehaus bzw. 114 Winterberg. Unter den Her- 
künften mit den niedrigsten mittleren Rängen sind zahlreiche französische Herkünfte zu finden.

Die zwischen dem niedrigsten und dem höchsten Rang einer Herkunft errechneten Spannweiten variieren auf den Flächen 14, 24, 34, 44 zwischen 10 und 158. Die Spannweiten der einzelnen Herkünfte sind im Anhang 1.27 zusammengestellt. Es zeigt sich, dass unter den 17 (10\%) Herkünften mit den niedrigsten Spannweiten zwei Herkünfte aus dem Drittel mit den niedrigsten mittleren Rängen stammen (114 Winterberg / D und 3421 Dombühl / D), zehn Herkünfte aus dem mittleren Drittel und fünf aus dem Drittel mit den höchsten Rängen (4 aus Frankreich und 1 aus der Schweiz). Die 17 Herkünfte mit den größten Spannweiten gehören alle dem Drittel der mittleren Ränge an. Darunter sind sechs deutsche Herkünfte: 3434 Miele, 3406 SHK Stryck Willingen, 3410 Traunstein, 3505 Eibenstock Carlsf. 275, 3424 Winterberg und 3617 Torgelow.

Tab. 2.54: Zusammenstellung der Herkünfte (jeweils 10\%) mit den niedrigsten (= bestwüchsig) bzw. höchsten (= mattwüchsig) mittleren Rängen zusammengefasst nach Staaten in den drei Teilversuchen

\begin{tabular}{|c|c|c|c|c|}
\hline \multirow{3}{*}{ Versuch } & \multicolumn{4}{|c|}{ Herkünfte der } \\
\hline & \multicolumn{2}{|c|}{$10 \%$ niedrigsten Ränge } & \multicolumn{2}{|c|}{$10 \%$ höchsten Ränge } \\
\hline & Land & Anzahl & Land & Anzahl \\
\hline \multirow{7}{*}{$\begin{array}{l}14,24,34,44 \\
\text { (17 von } 168 \\
\text { gemeinsamen } \\
\text { Herkünften) }\end{array}$} & ehem. Tschechoslowakei & 7 & Frankreich & 7 \\
\hline & Deutschland & 5 & Schweiz & 4 \\
\hline & Polen & 2 & Österreich & 2 \\
\hline & Ungarn & 1 & Italien & 1 \\
\hline & Österreich & 1 & Schweden & 1 \\
\hline & Rumänien & 1 & Bulgarien & 1 \\
\hline & & & Serbien & 1 \\
\hline \multirow{6}{*}{$\begin{array}{l}35,45 \\
\text { (8 von } 72 \\
\text { gemeinsamen } \\
\text { Herkünften) }\end{array}$} & Deutschland & 3 & Deutschland & 2 \\
\hline & Rumänien & 3 & Finnland & 2 \\
\hline & Polen & 1 & Schweiz & 1 \\
\hline & ehem. Tschechoslowakei & 1 & $\begin{array}{l}\text { ehem. } \\
\text { Tschechoslowakei }\end{array}$ & 1 \\
\hline & & & Bulgarien & 1 \\
\hline & & & Croatien & 1 \\
\hline \multirow{4}{*}{$\begin{array}{l}26,36,46 \\
\text { (4 von } 34 \\
\text { gemeinsamen } \\
\text { Herkünften) }\end{array}$} & Deutschland & 2 & Österreich & 1 \\
\hline & Frankreich & 1 & $\begin{array}{l}\text { ehem. } \\
\text { Tschechoslowakei }\end{array}$ & 1 \\
\hline & Schweden & 1 & Frankreich & 1 \\
\hline & & & Polen & 1 \\
\hline
\end{tabular}


Im Mittel über die 168 Herkünfte beträgt die Spannweite 73 und liegt damit nur geringfügig unter der halben Anzahl der Herkünfte. Ein Histogramm für die Häufigkeit der Spannweiten ist in Abbildung 2.58 wiedergegeben. Auf den vier sich standörtlich stark unterscheidenden Flächen gibt es nur wenige Herkünfte, die auf allen Flächen ähnlichen Wuchs zeigen. Die meisten Herkünfte reagieren auf die unterschiedlichen Standortbedingungen.

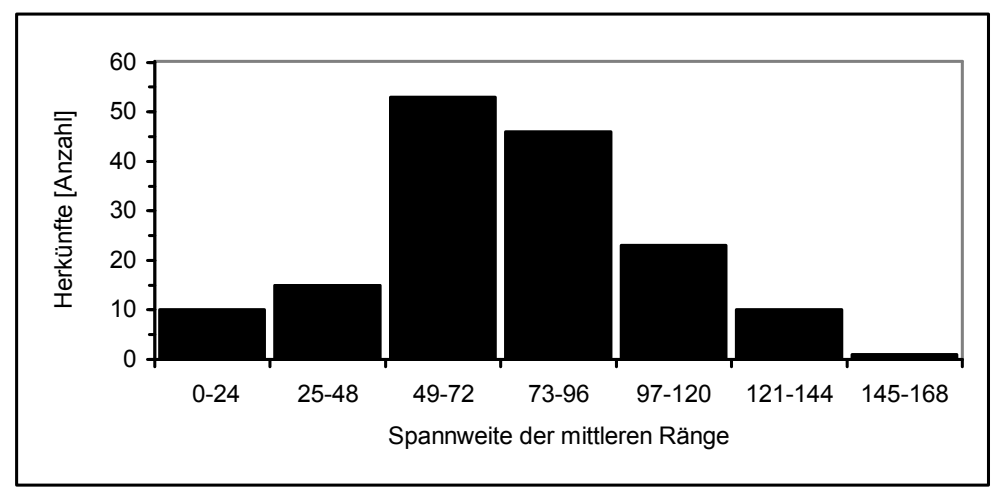

Abb. 2.58: Histogramm für die absoluten Häufigkeiten der Spannweiten der mittleren Ränge im Wachstum auf den Flächen Münsingen (14), Sonthofen (24), Reinhardshagen (34) und Hasbruch (44)

Mit der multiplen Regressionsanalyse ist untersucht worden, inwieweit ein Einfluss von geografischer Breite, geografischer Länge und Seehöhe des Erntebestandes auf die Ausprägung des mittleren Rangs beim Wachstum vorliegt. Die multiple Regressionsanalyse zeigt, dass der mittlere Rang von der Seehöhe (partielles $R^{2}=0,07$ ) und der geografischen Länge (partielles $\mathrm{R}^{2}=0,02$ ) des Erntestandorts abhängt.

Wird die multiple Regressionsanalyse für die Ränge beim Wachstum der einzelnen Flächen durchgeführt, ergibt sich eine Abhängigkeit für die Fläche Reinhardshagen (34) von der Höhenlage (partielles $\mathrm{R}^{2}=0,10$ ) und der geografischen Länge (partielles $\mathrm{R}^{2}=0,03$ ) des Erntebestandes. Im Fall der Fläche Hasbruch (44) gibt es eine Abhängigkeit der mittleren Ränge im Wachstum von der Höhenlage des Erntebestandes $\left(R^{2}=0,07\right)$.

Die mittleren Ränge der einzelnen Herkünfte sind für das Wachstum der Teilflächen mit den 81 Herkünften pro Versuchsfläche und als Mittel über die beiden Flächen im Anhang 1.28 aufgelistet. In Tabelle 2.54 sind nach Länderzugehörigkeit je acht Herkünfte mit den niedrigsten Rängen, d. h. den wüchsigsten Herkünften, bzw. den höchsten Rängen, den mattwüchsigsten Herkünften, zusammengestellt. Die insgesamt wüchsigste Herkunft ist die Herkunft 3503 Eibenstock Carlsf. Wiesenh. 214 / D mit dem mittleren Rang 11. Es folgen mit einem mittleren Rang von 16 bzw. 17 die deutschen Herkünfte 115 Westerhof bzw. 3519 Mechterstädt. Unter den acht Herkünften mit den niedrigsten mittleren Rängen sind die deutschen Herkünfte 107 Donaueschingen und 3337 Rabenstein zu finden. 
Die Spannweiten zwischen dem niedrigsten und dem höchsten Rang einer Herkunft variieren auf den Flächen 35 und 45 zwischen 0 und 59. Die Spannweiten der einzelnen Herkünfte sind im Anhang 1.29 zusammengestellt. Unter den acht $(10 \%)$ Herkünften mit den niedrigsten Spannweiten sind vier Herkünfte, die auf beiden Flächen den gleichen Rang einnehmen. Es zeigt sich weiter, dass zwei Herkünfte (6510 Bunzlau/Boleslawiec und 3417 Marsberg) zu dem Drittel mit den niedrigsten Rängen gehören und sechs Herkünfte zu dem mittleren Drittel. Die acht Herkünfte mit den größten Spannweiten gehören alle dem Drittel der mittleren Ränge an. Darunter sind zwei deutsche Herkünfte: 3433 Selb-Kirchenlamitz und 3518 Suhl, Oberhofer Schlossbergkopf.

Im Mittel über die 72 gemeinsamen Herkünfte beträgt die Spannweite 16 und liegt damit deutlich unter der halben Anzahl der Herkünfte. Ein Histogramm für die Häufigkeit der Spannweiten ist in Abbildung 2.59 wiedergegeben. Auf den zwei in Norddeutschland gelegenen Flächen gibt es zahlreiche Herkünfte, die auf beiden Flächen ein ähnliches Wachstum zeigen. Dennoch reagiert ein nicht unbeträchtlicher Anteil an Herkünften auf die unterschiedlichen Standortbedingungen zwischen dem niedersächsischen Flachland und dem hessischen Mittelgebirge.

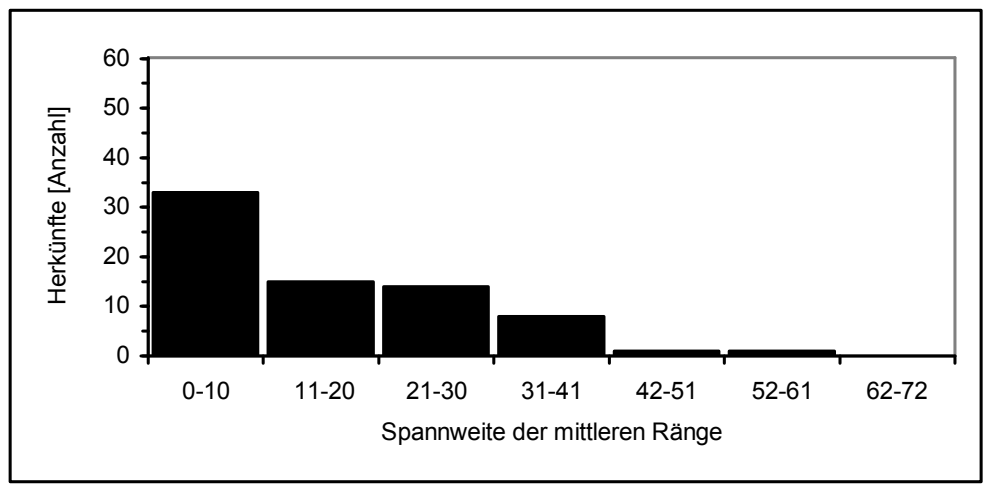

Abb. 2.59: Histogramm für die absoluten Häufigkeiten der Spannweiten der mittleren Ränge im Wachstum auf den Flächen Reinhardshagen (35) und Hasbruch (45)

Mit der multiplen Regressionsanalyse ist untersucht worden, inwieweit ein Einfluss von geografischer Breite, geografischer Länge und Seehöhe des Erntebestandes auf die Ausprägung des mittleren Rangs beim Wachstum vorliegt. Die multiple Regressionsanalyse zeigt, dass der mittlere Rang von der Seehöhe (partielles $\mathrm{R}^{2}=0,12$ ) und der geografischen Breite (partielles $\mathrm{R}^{2}=0,11$ ) des Erntestandorts abhängt.

Wird die multiple Regressionsanalyse für die Ränge beim Wachstum der einzelnen Flächen durchgeführt, ergeben sich für die Flächen Reinhardshagen (35) und Hasbruch (45) Abhängigkeiten von der Höhenlage (partielles $\mathrm{R}^{2}=0,06$ bzw. 0,07) und der geografischen Breite (partielles $\mathrm{R}^{2}=0,11$ bzw. 0,02) des Erntebestandes. 
Die mittleren Ränge der einzelnen Herkünfte sind für das Wachstum der Teilflächen mit den 36 Herkünften pro Versuchsfläche und als Mittel über die beiden Flächen im Anhang 1.30 aufgelistet. In Tabelle 2.54 sind nach Länderzugehörigkeit je vier Herkünfte mit den niedrigsten Rängen, d. h. den wüchsigsten Herkünften, bzw. den höchsten Rängen, den mattwüchsigsten Herkünften, zusammengestellt. Die insgesamt wüchsigste Herkunft ist die Herkunft 1201 Mellier, Bois Bayai / B mit dem mittleren Rang 9. Es folgen mit einem mittleren Rang von 11 drei Herkünfte darunter zwei aus Deutschland: 3432 Walsrode und 3414 Bodensee Oberschwaben VIII/13. Unter den neun Herkünften mit den höchsten mittleren Rängen sind keine deutschen Herkünfte.

Die Spannweiten zwischen dem niedrigsten und dem höchsten Rang einer Herkunft variieren auf den drei Flächen 26, 36 und 46 zwischen 3 und 25. Die Spannweiten der einzelnen Herkünfte sind im Anhang 1.31 zusammengestellt. Unter den vier $(10 \%)$ Herkünften mit den niedrigsten Spannweiten sind drei Herkünfte, die zu dem Drittel mit den höchsten Rängen gehören, und eine Herkunft aus dem mittleren Drittel. Von den vier Herkünften mit den größten Spannweiten gehören drei dem Drittel der mittleren Ränge an und eine dem mit den niedrigsten Rängen. Darunter ist die deutsche Herkunft 3423 Kohlstetten.

Im Mittel über die 34 Herkünfte beträgt die Spannweite 13 und liegt damit geringfügig unter der halben Anzahl der Herkünfte. Ein Histogramm für die Häufigkeit der Spannweiten ist in Abbildung 2.60 wiedergegeben. Auf den drei sich standörtlich stark unterscheidenden Flächen gibt es nur wenige Herkünfte, die auf allen Flächen ähnlichen Wuchs zeigen. Die meisten Herkünfte reagieren auf die unterschiedlichen Standortbedingungen.

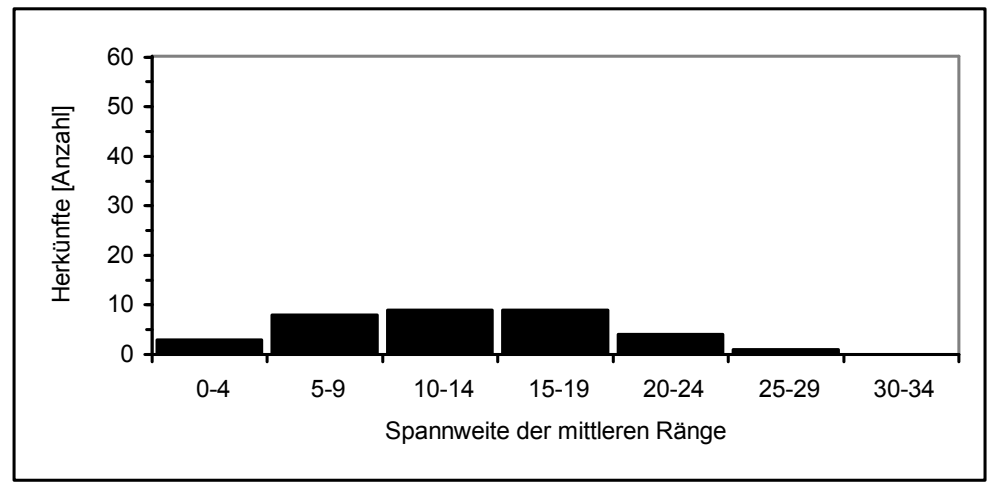

Abb. 2.60: Histogramm für die absoluten Häufigkeiten der Spannweiten der mittleren Ränge im Wachstum auf den Flächen Berchtesgaden (26), Reinhardshagen (36) und Hasbruch (46)

Mit der multiplen Regressionsanalyse ist untersucht worden, inwieweit ein Einfluss von geografischer Breite, geografischer Länge und Seehöhe des Erntebestandes auf die Ausprägung des mittleren Rangs beim Wachstum vorliegt. Die multiple Regres- 
sionsanalyse zeigt, dass der mittlere Rang von der Seehöhe (partielles $\mathrm{R}^{2}=0,15$ ) und der geografischen Länge (partielles $\mathrm{R}^{2}=0,12$ ) des Erntestandorts abhängt.

Wird die multiple Regressionsanalyse für die Ränge beim Wachstum der einzelnen Flächen durchgeführt, ergibt sich eine Abhängigkeit für die Fläche Berchtesgaden (26) von der geografischen Länge (partielles $\left.R^{2}=0,10\right)$ und für die Fläche Reinhardshagen (36) von der Höhenlage (partielles $\mathrm{R}^{2}=0,14$ ), der geografischen Länge (partielles $\mathrm{R}^{2}=0,04$ ) und der Breite (partielles $\mathrm{R}^{2}=0,01$ ) des Erntebestandes. Im Fall der Fläche Hasbruch (46) gibt es eine Abhängigkeit der mittleren Ränge im Wachstum von der Höhenlage (partielles $\left.\mathrm{R}^{2}=0,16\right)$ und der geografischen Länge (partielles $\left.\mathrm{R}^{2}=0,09\right)$ des Erntebestandes.

\subsubsection{Einzelbaumvolumen und Vorrat pro Hektar}

\section{Herkïnfte des Standards}

Analog zum Wachstum werden auch beim Einzelbaumvolumen und Vorrat pro Hektar erst die fünf Herkünfte des Standards analysiert, bevor auf alle Herkünfte eingegangen wird. Dazu sind für die einzelnen Höhen- und BHD-Messungen je Versuchsfläche Rangfolgen vergeben worden. Die wüchsigste Herkunft einer Fläche erhielt die Rangziffer 1, die mattwüchsigste die Rangziffer 5.

Die Ränge für die fünf Herkünfte des Standards sind je Versuchsfläche für das Einzelbaumvolumen in der Abbildung 2.61 und für den Vorrat pro Hektar in der Abbildung 2.62 dargestellt. Zu erkennen ist, dass auf den sechs Flächen keine Herkunft bei den beiden Merkmalen weder nur den besten noch nur den schlechtesten Rang einnimmt. Die geringste Spannweite bei den Rängen hat die Herkunft 3433 (Selb-Kirchenlamitz / BY, $800 \mathrm{~m}$ ü. NN) beim Einzelbaumvolumen, die hier zwischen zwei und vier variieren.

Beim Einzelbaumvolumen und beim Vorrat pro Hektar zeigt sich, dass die fünf Herkünfte auf Standortunterschiede sowohl an dem Versuchsort in Niedersachsen als auch in Hessen reagieren. 


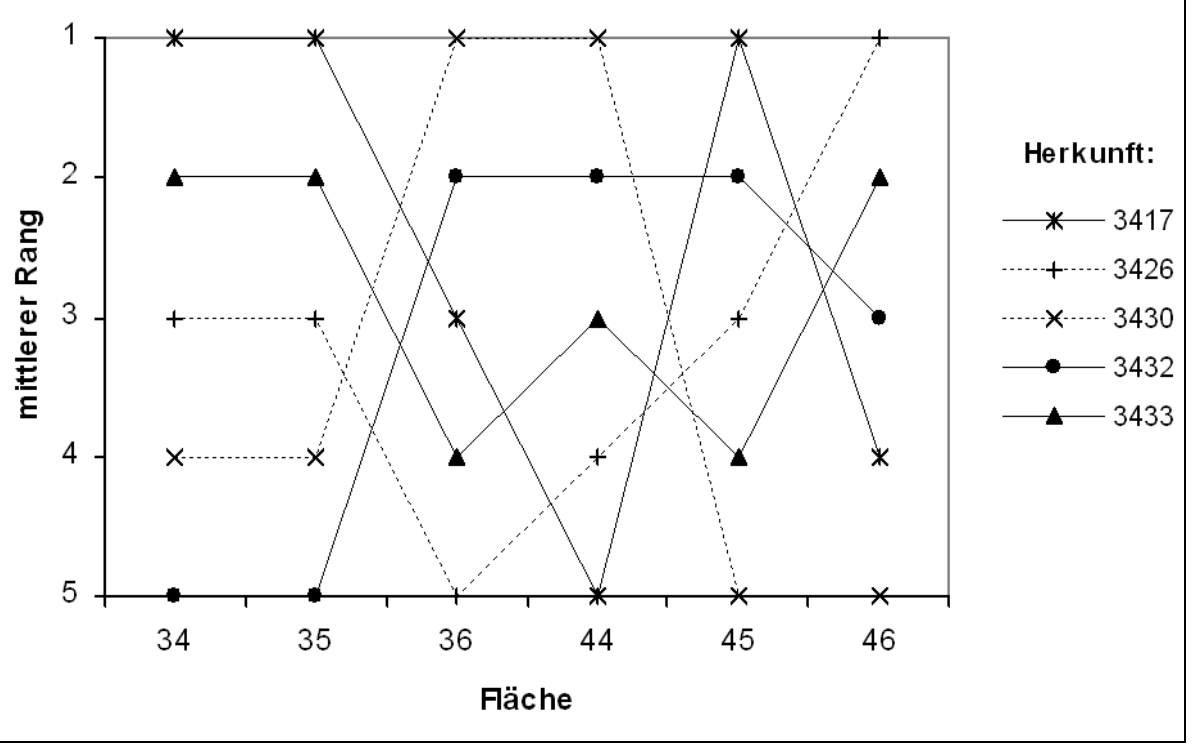

Abb. 2.61: Ränge der fünf Herkünfte des Standards beim Einzelbaumvolumen auf den sechs Teilflächen des Fichtenherkunftsversuchs von 1962 (Zur Verdeutlichung der Rangwechsel auf den einzelnen Flächen sind die Ränge einer Herkunft jeweils verbunden.)

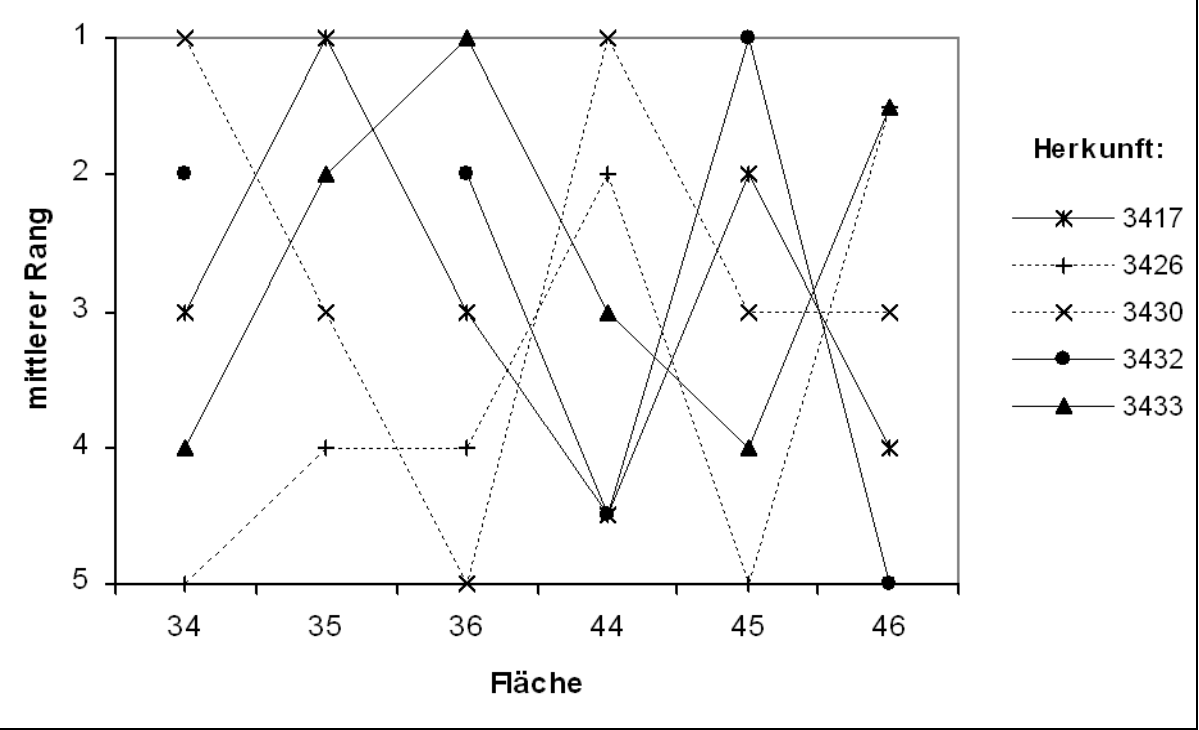

Abb. 2.62: Ränge der fünf Herkünfte des Standards beim Vorrat pro Hektar auf den sechs Teilflächen des Fichtenherkunftsversuchs von 1962 (Zur Verdeutlichung der Rangwechsel auf den einzelnen Flächen sind die Ränge einer Herkunft jeweils verbunden.) 


\section{Alle Herkïnfte}

Zwischen dem Einzelbaumvolumen und dem Vorrat pro Hektar im Alter 39 besteht für alle gemeinsamen Herkünfte der beiden Versuchsflächenkomplexe (Reinhardshagen und Hasbruch) ein statistisch gesicherter Zusammenhang (Tab. 2.55). Bei der Analyse der einzelnen Teilflächen ergibt sich ein derartiger Zusammenhang auch für die Teilflächen $(34,44)$ mit den 169 Herkünften (Tab. 2.55). Auf der Teilfläche mit den 81 Herkünften lässt sich der Zusammenhang nur beim Einzelbaumvolumen nachweisen. Keinen Zusammenhang deckt die Korrelationsanalyse zwischen der Teilflächen $(36,46)$ mit den 36 Herkünften auf.

Tab. 2.55: $\quad$ Produkt-Momenten-Korrelationsmatrix ( $\mathrm{r}_{\mathrm{P}}$ ) des Einzelbaumvolumens und Vorrats pro Hektar auf den sechs Flächen Reinhardshagen und Hasbruch

\begin{tabular}{l|l|c|c|c|c}
\hline Fläche & Fläche & \multicolumn{2}{|c|}{ Einzelbaumvol. } & \multicolumn{2}{c}{ Vorrat /ha } \\
& & $\mathrm{n}$ & $\mathrm{r}$ & $\mathrm{n}$ & $\mathrm{r}_{\mathrm{P}}$ \\
\hline Reinhardshagen $(34,35,36)$ & $\begin{array}{l}\text { Hasbruch (44, } \\
\text { 45, 46) }\end{array}$ & 274 & $0,310^{* * *}$ & 258 & $0,258^{* * *}$ \\
Reinhardshagen (34) & Hasbruch (44) & 168 & $0,359^{* * *}$ & 158 & $0,319^{* * *}$ \\
Reinhardshagen (35) & Hasbruch (45) & 72 & $0,306^{* *}$ & 67 & $0,153 \mathrm{~ns}$ \\
Reinhardshagen (36) & Hasbruch (46) & 34 & $0,079 \mathrm{~ns}$ & 33 & $0,146 \mathrm{~ns}$ \\
\hline
\end{tabular}

Das Einzelbaumvolumen und der Bestandesvorrat im Alter von 39 Jahren sind jeweils für die zwei Versuchsflächen mit 169, mit 81 und mit 36 Herkünften varianzanalytisch untersucht worden. Dabei wurde der Einfluss der Versuchsflächen und der Herkünfte auf die Merkmalsausprägung berücksichtigt. Die Varianzmodelle sind signifikant und weisen alle einen statistisch gesicherten Einfluss der Versuchsflächen (etwa $90 \%$ ) aus. Die Ergebnisse sind in Tabelle 2.56 zusammengestellt.

Für die flächenübergreifende Bewertung ist das Einzelbaumvolumen und der rechnerische Bestandesvorrat für die Teilversuche in Rangfolgen standardisiert worden. Außerdem ist je Teilfläche für die gemeinsamen Herkünfte ein mittlerer Rang gebildet worden. Im Weiteren ist für die gemeinsamen Herkünfte die Spannweite zwischen dem niedrigsten und dem höchsten Rang einer Herkunft errechnet worden. 
Tab. 2.56: Varianzkomponentenschätzung des Einzelbaumvolumens und Bestandesvorrats im Alter 39

\begin{tabular}{|c|c|c|c|c|c|}
\hline $\begin{array}{l}\text { Versuch } \\
\text { (Flächen) }\end{array}$ & $\begin{array}{c}\text { Merkmal } \\
(39-\mathrm{j} .)\end{array}$ & $\begin{array}{c}\text { Modell } \\
\mathrm{r}^{2}\end{array}$ & Herkunft & Fläche & Rest \\
\hline \multicolumn{6}{|c|}{169 Herkünfte } \\
\hline$(34,44)$ & Einzelbaumvol. & 0,96 & $2 \% * * *$ & $93 \% * * *$ & $5 \%$ \\
\hline$(34,44)$ & Vorrat/ha & 0,95 & $1 \% * * *$ & $93 \% * * *$ & $6 \%$ \\
\hline \multicolumn{6}{|c|}{81 Herkünfte } \\
\hline$(35,45)$ & Einzelbaumvol. & 0,93 & $3 \% *$ & $88 \% * * *$ & $9 \%$ \\
\hline$(35,45)$ & Vorrat/ha & 0,93 & $0 \%$ & $91 \% * * *$ & $9 \%$ \\
\hline \multicolumn{6}{|c|}{$\underline{36 \text { Herkünfte }}$} \\
\hline$(36,46)$ & Einzelbaumvol. & 0,98 & $0 \%$ & $96 \% * * *$ & $4 \%$ \\
\hline$(36,46)$ & Vorrat/ha & 0,96 & $0 \%$ & $95 \%$ *** & $5 \%$ \\
\hline
\end{tabular}

\section{Einzelbaumvolumen}

Die zwischen dem niedrigsten und dem höchsten Rang einer Herkunft errechneten Spannweiten beim Einzelbaumvolumen variieren auf den Flächen 34 und 44 zwischen 0 und 142. Die Ränge und die Spannweiten der einzelnen Herkünfte sind im Anhang 1.32 zusammengestellt. Es zeigt sich, dass unter den 18 (10\%) Herkünften mit den niedrigsten Spannweiten drei Herkünfte aus dem Drittel mit den niedrigsten mittleren Rängen stammen (170 Groß Arl / A, 3429 Villingen / D und 215 Stinava / SK), fünf Herkünfte aus dem mittleren Drittel und zehn aus dem Drittel mit den höchsten Rängen.

Von den 17 Herkünften mit den größten Spannweiten gehören 16 dem Drittel der mittleren Ränge und eine (4081 Frenstat / CS) dem Drittel der niedrigen Ränge an. Unter den Herkünften mit den größten Spannweiten sind sechs deutsche Herkünfte: 3422 Stryck, 3417 Marsberg, 3426 Uelzen, 9432 Walsrode, 3425 Waldmünchen und 3448 Nationalpark Filzwald.

Im Mittel über die 168 Herkünfte beträgt die Spannweite 43 und liegt damit bei einem Viertel der Anzahl der Herkünfte. Ein Histogramm für die Häufigkeit der Spannweiten ist in Abbildung 2.63 wiedergegeben. Auf den beiden $180 \mathrm{~km}$ entfernt liegenden Flächen gibt es zahlreiche Herkünfte, die auf beiden Flächen ähnlichen Wuchs zeigen. 


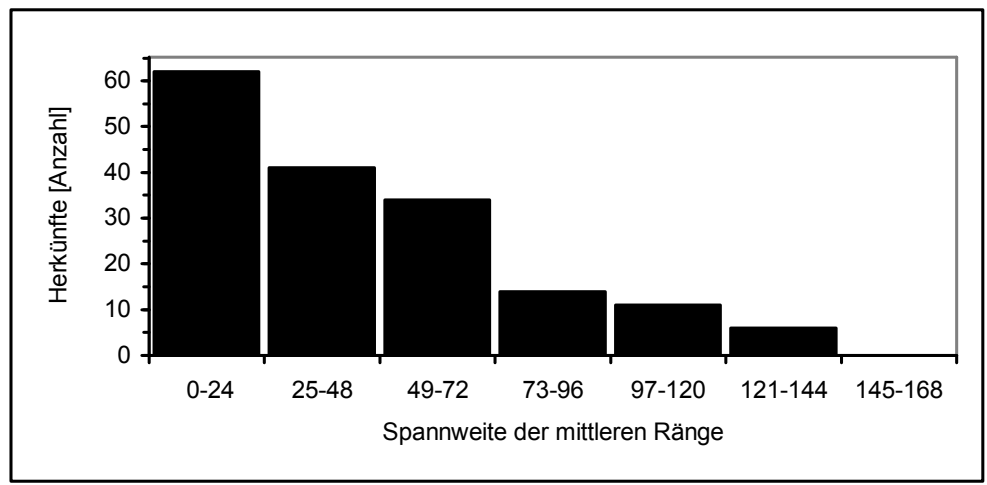

Abb. 2.63: Histogramm für die absoluten Hänfigkeiten der Spannweiten der mittleren Ränge beim Einzelbaumvolumen auf den Flächen Reinhardshagen (34) und Hasbruch (44); Bequg 168 Herkünfte

Auf den Flächen 35 und 45 mit je 81 Herkünften variieren die Spannweiten zwischen dem niedrigsten und dem höchsten Rang einer Herkunft zwischen 0 und 66. Die Spannweiten und die Ränge der einzelnen Herkünfte sind im Anhang 1.32 zusammengestellt. Es zeigt sich, dass unter den acht $(10 \%)$ Herkünften mit den niedrigsten Spannweiten drei Herkünfte aus dem Drittel mit den niedrigsten mittleren Rängen stammen (115 Westerhof/D, 3503 Eibenstock/D und 3511 Innenau / D), eine Herkunft aus dem mittleren Drittel und vier aus dem Drittel mit den höchsten Rängen. Von den acht Herkünften mit den größten Spannweiten gehören sieben dem Drittel der mittleren Ränge und eine (4051 Vysoky / CS) dem Drittel der höchsten Ränge an. Unter den Herkünften mit den größten Spannweiten sind drei deutsche Herkünfte: 3433 Selb-Kirchenlamitz, 3331 St. Oswald und 3518 Suhl.

Im Mittel über die 72 Herkünfte beträgt die Spannweite 22 und liegt damit deutlich unter der Hälfte der Anzahl der Herkünfte. Ein Histogramm für die Häufigkeit der Spannweiten ist in Abbildung 2.64 wiedergegeben. Auf den beiden $180 \mathrm{~km}$ entfernt liegenden Flächen gibt es zahlreiche Herkünfte, die auf beiden Flächen ähnlichen Wuchs zeigen. Relativ hoch ist in diesem Teilversuch der Anteil der Herkünfte mit großer Spannweite. 


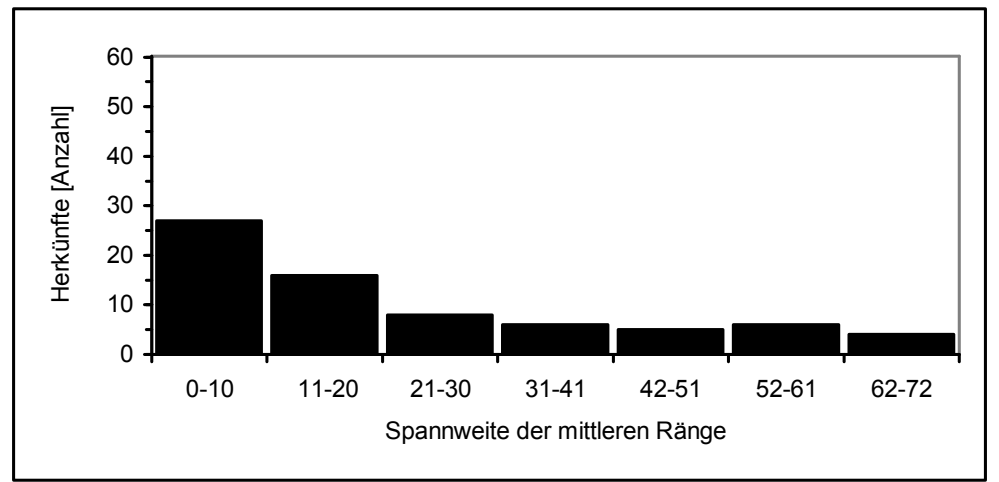

Abb. 2.64: Histogramm für die absoluten Häufigkeiten der Spannweiten der mittleren Ränge beim Einzelbaumvolumen auf den Flächen Reinhardshagen (35) und Hasbruch (45); Bequg 72 Herkïnfte

Auf den Flächen 36 und 46 mit je 36 Herkünften variieren die Spannweiten zwischen dem niedrigsten und dem höchsten Rang einer Herkunft zwischen 0 und 33. Die Spannweiten und die Ränge der einzelnen Herkünfte sind im Anhang 1.32 zusammengestellt. Die sieben Herkünfte mit einer Spannweite von 0 bzw. 1 haben einen mittleren Rang zwischen 9 und 31. Die Herkunft, die auf beiden Flächen den neunten Rang hat, ist 3433 Selb-Kirchenlamitz / D. Unter den vier Herkünften mit den größten Spannweiten sind zwei deutsche Herkünfte: 3430 Diessen und 105 Hohenschwangau.

Im Mittel über die 34 gemeinsamen Herkünfte beträgt die Spannweite 10 und liegt damit unter der Hälfte der Anzahl der Herkünfte. Ein Histogramm für die Häufigkeit der Spannweiten ist in Abbildung 2.65 wiedergegeben. Auf den beiden $180 \mathrm{~km}$ entfernt liegenden Flächen gibt es zahlreiche Herkünfte, die auf beiden Flächen ähnlichen Wuchs zeigen. 


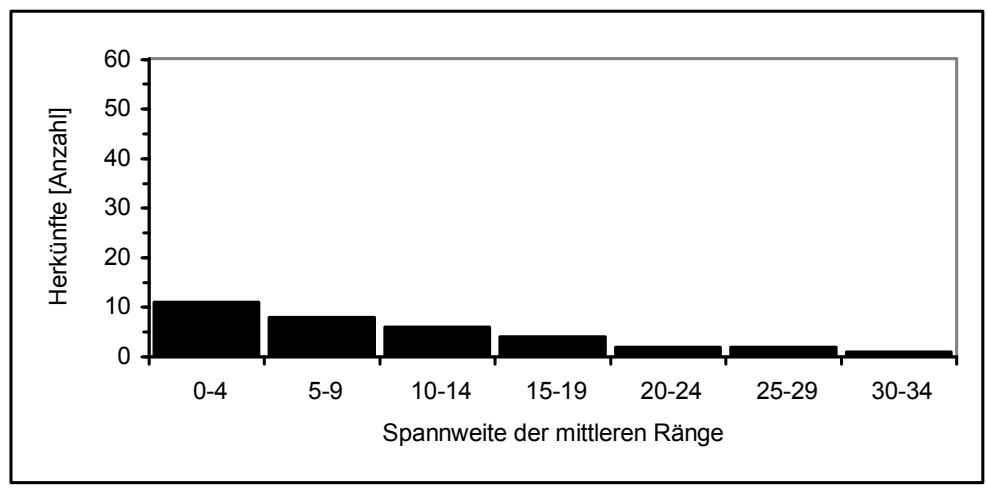

Abb. 2.65: Histogramm für die absoluten Häufigkeiten der Spannweiten der mittleren Ränge beim Einzelbaumvolumen auf den Flächen Reinhardshagen (36) und Hasbruch (46); Bezug 34 gemeinsame Herk.̈̈fte

Mit der multiplen Regressionsanalyse ist untersucht worden, inwieweit ein Einfluss von geografischer Breite, geografischer Länge und Seehöhe des Erntebestandes auf die Ausprägung des mittleren Rangs beim Einzelbaumvolumen vorliegt. Die multiple Regressionsanalyse zeigt, dass der mittlere Rang über die 276 Herkünfte der drei Teilflächen am Standort Reinhardshagen von der Seehöhe (partielles $\left.\mathrm{R}^{2}=0,04\right)$ des Erntestandorts abhängt. Für den Standort Hasbruch wird derselbe Wert errechnet.

\section{Vorrat pro Hektar}

Die zwischen dem niedrigsten und dem höchsten Rang einer Herkunft errechneten Spannweiten beim Bestandesvorrat variieren auf den Flächen 34 und 44 zwischen 0 und 163. Die Spannweite ist damit größer als beim Einzelbaumvolumen. Die Ränge und die Spannweiten der einzelnen Herkünfte sind im Anhang 1.33 zusammengestellt. Es zeigt sich, dass unter den 17 (10\%) Herkünften mit den niedrigsten Spannweiten zwei Herkünfte aus dem Drittel mit den niedrigsten mittleren Rängen stammen (5206 Sopron / H und 293 Trolleholm / S), fünf Herkünfte aus dem mittleren Drittel und zehn aus dem Drittel mit den höchsten Rängen.

Von den 17 Herkünften mit den größten Spannweiten gehören 14 dem Drittel der mittleren Ränge und drei dem Drittel der niedrigen Ränge an. Unter den Herkünften mit den größten Spannweiten sind vier deutsche Herkünfte: 3431 Riedenburg, 3412 Winterberg, 3326 Neureichenau und 3423 Kohlstetten. Im Mittel über die 168 gemeinsamen Herkünfte beträgt die Spannweite 42 und liegt damit bei einem Viertel der Anzahl der Herkünfte. Ein Histogramm für die Häufigkeit der Spannweiten ist in Abbildung 2.66 wiedergegeben. Auf den beiden $180 \mathrm{~km}$ entfernt liegenden Flächen gibt es zahlreiche Herkünfte, die auf beiden Flächen ähnlichen Wuchs zeigen. 


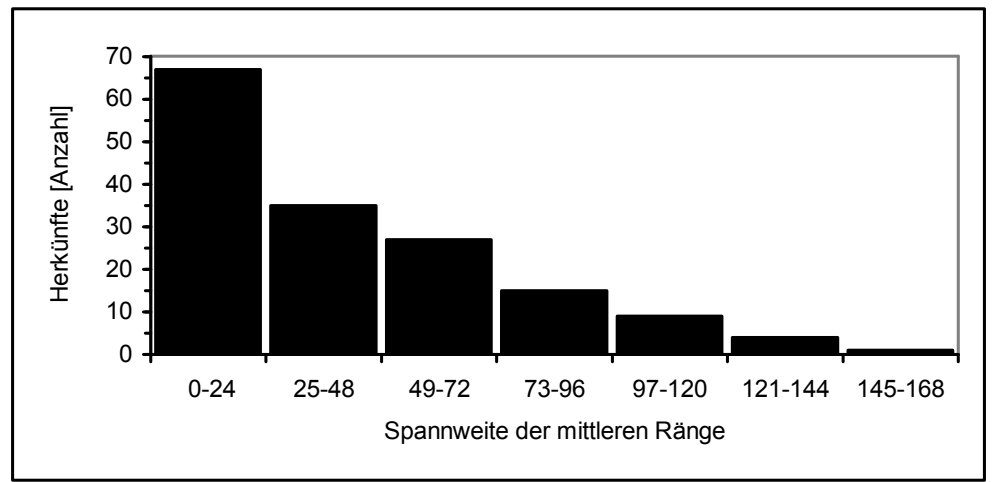

Abb. 2.66: Histogramm für die absoluten Häufigkeiten der Spannweiten der mittleren Ränge beim Vorrat/ha auf den Flächen Reinhardshagen (34) und Hasbruch (44); Bezug 168 gemeinsame Herkünfte

Auf den Flächen 35 und 45 mit je 81 Herkünften variieren die Spannweiten zwischen dem niedrigsten und dem höchsten Rang einer Herkunft zwischen 0 und 67. Die Spannweiten und die Ränge der einzelnen Herkünfte sind im Anhang 1.33 zusammengestellt. Es zeigt sich, dass unter den neun (etwa 10\%) Herkünften mit den niedrigsten Spannweiten je drei Herkünfte aus dem Drittel mit den niedrigsten mittleren Rängen, aus dem mittleren Drittel und aus dem Drittel mit den höchsten Rängen stammen. Unter den Herkünften sind vier aus Deutschland: 3404 Westerhof, 3139 Isny, 3310 Zwiesel-West und 3615 Neustrelitz.

Von den zehn Herkünften mit den größten Spannweiten gehören neun dem Drittel der mittleren Ränge und eine (5107 Smrceve / HR) dem Drittel der höchsten Ränge an. Unter den Herkünften mit den größten Spannweiten sind drei deutsche Herkünfte: 3423 Kohlstetten, 3503 Eibenstock und 3433 Selb-Kirchenlamitz. Im Mittel über die 72 gemeinsamen Herkünfte beträgt die Spannweite 22 und liegt damit deutlich unter der Hälfte der Anzahl der Herkünfte. Ein Histogramm für die Häufigkeit der Spannweiten ist in Abbildung 2.67 wiedergegeben. Auf den beiden $180 \mathrm{~km}$ entfernt liegenden Flächen gibt es zahlreiche Herkünfte, die auf beiden Flächen ähnlichen Wuchs zeigen. Relativ hoch ist in diesem Teilversuch der Anteil der Herkünfte mit großer Spannweite.

Auf den Flächen 36 und 46 mit je 36 Herkünften variieren die Spannweiten zwischen dem niedrigsten und dem höchsten Rang einer Herkunft zwischen 0 und 29. Die Spannweiten und die Ränge der einzelnen Herkünfte sind im Anhang 1.33 zusammengestellt. 


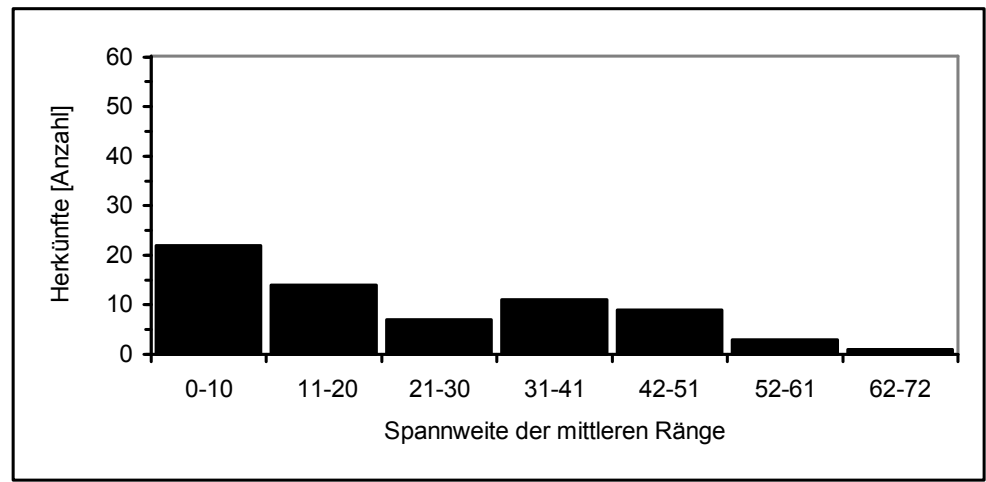

Abb. 2.67: Histogramm für die absoluten Hänfigkeiten der Spannweiten der mittleren Ränge beim Vorrat/ ha auf den Flächen Reinhardshagen (35) und Hasbruch (45); Bezug 72 gemeinsame Herkünfte

Die drei $(10 \%)$ Herkünfte mit einer Spannweite von 0 bzw. 1 haben einen mittleren Rang zwischen 6 und 26. Die Herkunft, die auf beiden Flächen den sechsten Rang hat, ist 4075 Vitov-Budisov / CS. Unter den fünf Herkünften mit den größten Spannweiten sind drei deutsche Herkünfte: 105 Hohenschwangau, 3417 Marsberg und 3432 Walsrode.

Im Mittel über die 34 gemeinsamen Herkünfte beträgt die Spannweite 11 und liegt damit unter der Hälfte der Anzahl der Herkünfte. Ein Histogramm für die Häufigkeit der Spannweiten ist in Abbildung 2.68 wiedergegeben. Auf den beiden $180 \mathrm{~km}$ entfernt liegenden Flächen gibt es zahlreiche Herkünfte, die auf beiden Flächen ähnlichen Wuchs zeigen.

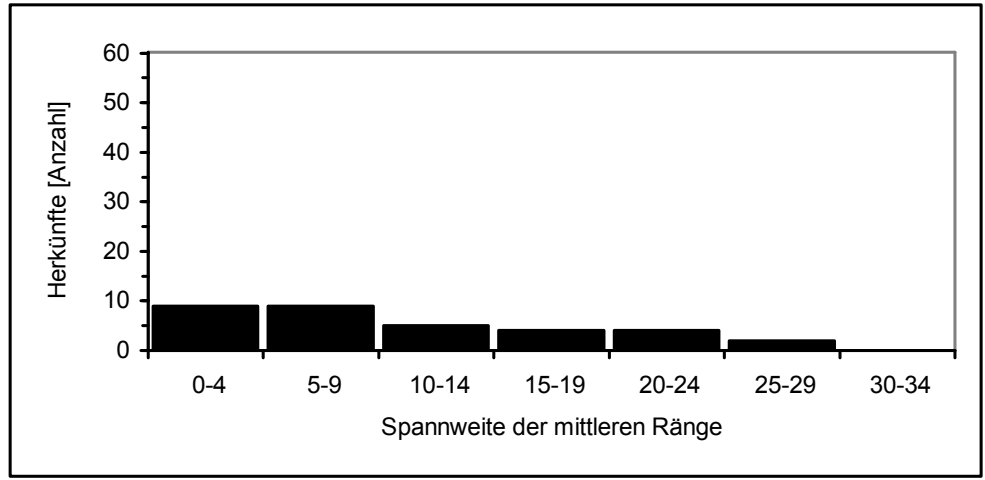

Abb. 2.68: Histogramm für die absoluten Hänfigkeiten der Spannweiten der mittleren Ränge beim Vorrat/ ha auf den Flächen Reinhardshagen (36) und Hasbruch (46); Bezug 34 gemeinsame Herkünfte 
Mit der multiplen Regressionsanalyse ist untersucht worden, inwieweit ein Einfluss von geografischer Breite, geografischer Länge und Seehöhe des Erntebestandes auf die Ausprägung des mittleren Rangs beim Bestandesvorrat vorliegt. Die multiple Regressionsanalyse zeigt, dass der mittlere Rang über alle Herkünfte der drei Teilflächen am Standort Reinhardshagen von der Seehöhe (partielles $\left.\mathrm{R}^{2}=0,04\right)$ des Erntestandorts abhängt. Für den Standort Hasbruch lässt sich keine Abhängigkeit bestätigen. 


\section{Der IUFRO-Fichtenherkunftsversuch von 1972}

Nach SCHMIDT-VOGT (1977-1991) entstammen die polnischen Herkünfte zwei unterschiedlichen Refugien. In dem nördlichen Teil Polens ist die Fichte aus dem mittleren Russland eingewandert. Nach Südpolen kehrte sie aus dem Fußbereich der Karpaten und der Transsilvanischen Alpen zurück. Dazwischen befindet sich ein von Natur aus fichtenfreier Streifen. Trotz der unterschiedlichen Abstammung haben sich sowohl Fichten aus Nordost-Polen als auch Fichten aus den polnischen Beskiden in verschiedenen Versuchen immer wieder als besonders viel versprechend erwiesen (RAU 1983).

Ältere Herkunftsversuche, insbesondere der Gahrenberger Fichten-Provenienzversuch, hatten gezeigt, dass Fichtenherkünfte aus dem polnischen Verbreitungsgebiet der Fichte beim Anbau im mitteleuropäischen Raum offensichtlich eine größere Leistungsfähigkeit und ein höheres $\mathrm{Maß}$ an Widerstandsfähigkeit gegenüber Sommertrocknis aufweisen als die mitangebauten Herkünfte aus dem südlichen und südwestlichen deutschen Verbreitungsgebiet. Des Weiteren sind die hervorragenden Qualitätseigenschaften der Fichtenherkünfte aus dem nordöstlichen Verbreitungsgebiet bekannt sowie ihre Spätfrostfestigkeit (z. B. WEISGERBER et al. 1976b, 1977; SCHMIDT-VOGT 1977-1991; DIETRICHSON 1969; GÜNZL 1969). Um diese Eigenschaften in einem Versuch mit breiterer ökologischer Standortamplitude testen zu können, haben sich mehrere Institute in Deutschland an einem internationalen Fichtenversuch, der von der Forstlichen Forschungsanstalt Polen initiiert wurde, beteiligt.

Ziele des Versuchs, dessen gemeinsamen Kern bis zu 20 polnische Herkünfte bilden, sind:

- Erweiterung der bisherigen Erkenntnisse über die aus zwei Refugien stammenden Fichten in Polen

- Erfassung der Variation einzelner Merkmale innerhalb und zwischen den Herkünften

- Prüfung der Abhängigkeit der Merkmalsausprägung von verschiedenen Anbauorten

- Zusammenfassung von Herkünften mit ähnlichen Eigenschaften zu Gruppen

Durch die Ergänzung der Versuchflächen mit weiteren Prüfgliedern wurden weitere Fragestellungen vertieft:

- Prüfung der Anbaueignung von Fichtenherkünften aus Polen im Vergleich zu einigen bewährten deutschen Herkünften (BW, BY, HE)

- Vergleich der Variation zwischen Einzelbaumabsaaten (Halbgeschwister) und Herkunftsabsaaten (NI)

- Vergleich des Wachstums mit anderen Versuchen (BW, BY) 
Zum IUFRO-Fichtenherkunftsversuch von 1972 gehörten ursprünglich 43 Versuchsflächen in 10 Staaten (in den Grenzen von 1972). Darin ist eine vom Institut für Forstgenetik und Forstpflanzenzüchtung der Bundesforschungsanstalt für Forst- und Holzwirtschaft (BFH, heute Johann Heinrich von Thünen-Institut) betreute Fläche nicht enthalten, die in der folgenden Auswertung jedoch berücksichtigt wird.

Im Gegensatz zum Fichtenherkunftsversuch von 1962 wurde im vorliegenden Versuch das Saatgut den einzelnen Versuchanstalten übergeben. Hessen und Niedersachsen säten jeweils im Frühjahr 1973 aus und verschulten die Pflanzen. Unter der Leitung von SCHMIDT-VOGT erfolgte die Aussaat am Institut für Waldbau der Universität Freiburg für Baden-Württemberg und Bayern in den Jahren 1972 und 1973. Durch die Verteilung der Arbeiten auf zwei Jahre wollte man das Risiko von schlechten Witterungsbedingungen bei der Aussaat und Auspflanzung verteilen (SCHMIDT-VOGT u. KOCIĘCKI 1985). Von Institut für Waldbau der Universität Freiburg erhielt auch die BFH 2-jährige Sämlinge im Frühjahr 1974 (KÖNIG 1998).

\subsection{Material und Methoden}

\subsubsection{Versuchsmaterial}

In Deutschland enthält der Versuch gemeinsame und zusätzliche Prüfglieder. Gemeinsam sind die polnischen Herkünfte, die jedoch in unterschiedlicher Anzahl auf den Flächen angebaut wurden. Die zusätzlichen Prüfglieder stehen meist nur auf zwei Versuchsflächen.

Das Kernstück des IUFRO-Versuchs bilden 20 Fichtenherkünfte aus Polen (Tab. 3.1, Abb. 3.2). Die zu testenden polnischen Herkünfte stammen aus Saatgut, das zwischen 1968 und 1971 in Polen geerntet wurde. Die hessische Akte enthält jedoch einen Hinweis auf die Ernte 1971 und auch KRUTZSCH (1992) schreibt, dass dieses Jahr ein gutes Mastjahr war. Aus den Versuchsakten geht nicht hervor, welche Herkünfte aus älteren Beerntungen stammen.

Anders als bei vielen früheren Fichtenherkunftsversuchen wurde bei diesem Versuch Wert darauf gelegt, dass die Herkunft den Bestand repräsentiert. Daher wurden nach Möglichkeit mindestens 20 Bäume pro Bestand beerntet. Im Mittel stammt das Saatgut der polnischen Herkünfte von 24 Bäumen. Dabei variiert die Anzahl der beernteten Bäume zwischen 10 (Nr. 15, Rycerka, Praszywka II 125c) und 40 (Nr. 18, Tarnawa, Sokoliki 130a) je nach Herkunft. Zu den Herkunftsbeständen liegen weitere Informationen vor. Einige dieser Informationen sind im Anhang 2.1 zusammengestellt. Danach lag das Alter der beernteten Bestände zwischen 69 und 152 Jahren, im Mittel bei 97 Jahren. Der Anteil der Fichten schwankte zwischen 44 und 100 \% der Stammzahl pro Hektar. Sechs Bestände der 
Karpaten werden als Fichtenreinbestände ohne Begleitbaumart beschrieben. 19 der 20 Herkünfte sind autochthon.

Tab.3.1: Gemeinsame polnische Herkünfte des IUFRO-Ficbtenherkunftsversuchs von 1972 gruppiert nach Herkunftsregionen

\begin{tabular}{|c|c|c|c|c|c|c|c|c|c|}
\hline \multirow[b]{2}{*}{$\mathrm{Nr}^{*}$} & \multirow[b]{2}{*}{ Prüfglied (alle Ernte 1971) } & \multirow{2}{*}{$\begin{array}{l}\text { Höhe } \\
\text { m ü. } \\
\text { NN }\end{array}$} & \multirow{2}{*}{$\begin{array}{c}\text { Geogr. } \\
\text { Breite } \\
\text { N }\end{array}$} & \multirow{2}{*}{$\begin{array}{c}\text { Geogr. } \\
\text { Länge } \\
\mathrm{O}\end{array}$} & \multicolumn{5}{|c|}{$\mathrm{Nr}$. in den Versuchen } \\
\hline & & & & & $\begin{array}{l}\mathrm{BW}, \\
\mathrm{BY}\end{array}$ & $\mathrm{NI}^{\#}$ & $\mathrm{NI}^{\# \#}$ & $\mathrm{HE}$ & $\mathrm{BFH}$ \\
\hline & Masuren-Podlasie & & & & & & & & \\
\hline 1 & $\begin{array}{l}\text { Zwierzyniec Biał., } \\
\text { Pogorzelece 281Ba }\end{array}$ & 160 & $52^{\circ} 48^{\prime}$ & $23^{\circ} 47^{\prime}$ & 1 & 18 & & 1 & 16 \\
\hline 2 & $\begin{array}{l}\text { Zwierzyniec Biał., Krzyze } \\
\text { 449Ca }\end{array}$ & 180 & $52^{\circ} 42^{\prime}$ & $23^{\circ} 46^{\prime}$ & 2 & 19 & & 2 & 13 \\
\hline 3 & Wigry, Krzywe 144b & 170 & $54^{\circ} 03^{\prime}$ & $23^{\circ} 03^{\prime}$ & 3 & 15 & & 3 & \\
\hline 4 & Przerwanki, Zawady 66b & 180 & $54^{\circ} 10^{\prime}$ & $22^{\circ} 05^{\prime}$ & 4 & 9 & 9 & 4 & 6 \\
\hline 5 & Borki, Sarnianka 141a & 180 & $54^{\circ} 06^{\prime}$ & $22^{\circ} 04^{\prime}$ & 5 & 2 & 2 & 5 & 10 \\
\hline \multirow[t]{2}{*}{6} & $\begin{array}{l}\text { Nowe Ramuki, Przykop } \\
128 \mathrm{~d}\end{array}$ & 160 & $53^{\circ} 41^{\prime}$ & $20^{\circ} 34^{\prime}$ & 6 & 7 & 7 & 6 & 7 \\
\hline & Sudeten & & & & & & & & \\
\hline 8 & Miedzygórze, Wodospad 81a & 580 & $50^{\circ} 13^{\prime}$ & $16^{\circ} 45^{\prime}$ & 8 & 6 & 6 & 7 & 17 \\
\hline \multirow[t]{2}{*}{9} & Stronie Slaskie, Kletno 200b & 820 & $50^{\circ} 14^{\prime}$ & $16^{\circ} 50^{\prime}$ & 9 & 9 & & 8 & 4 \\
\hline & Karpaten (Beskiden) & & & & & & & & \\
\hline 10 & Wisła, Malinka 89c & 710 & $49^{\circ} 38^{\prime}$ & $18^{\circ} 58^{\prime}$ & 10 & 16 & & 9 & 11 \\
\hline 11 & Istebna, Bukowiec 149h & 630 & $49^{\circ} 34^{\prime}$ & $18^{\circ} 53^{\prime}$ & 11 & 3 & 3 & 10 & 15 \\
\hline 12 & Istebna, Zapowiedz $115 f$ & 600 & $49^{\circ} 32^{\prime}$ & $18^{\circ} 57^{\prime}$ & 12 & $4 \# \#$ & 4 & 11 & 18 \\
\hline 13 & Rycerka, Zwardon 68d & 620 & $49^{\circ} 31^{\prime}$ & $19^{\circ} 01^{\prime}$ & 13 & 10 & 10 & 12 & 9 \\
\hline 14 & Rycerka, Praszywka I 125c & 700 & $49^{\circ} 29^{\prime}$ & $19^{\circ} 00^{\prime}$ & 14 & 11 & & 13 & 12 \\
\hline 15 & Rycerka, Praszywka II 125c & 950 & $49^{\circ} 29^{\prime}$ & $19^{\circ} 00^{\prime}$ & 15 & 12 & & & 3 \\
\hline 16 & Orawa Stancowa 40c & 1050 & $49^{\circ} 34^{\prime}$ & $19^{\circ} 33^{\prime}$ & 16 & 8 & 8 & 15 & \\
\hline 17 & $\begin{array}{l}\text { Witów (Tatry), ur. Chotorz } \\
125 \mathrm{f}\end{array}$ & 1420 & $49^{\circ} 13^{\prime}$ & $19^{\circ} 48^{\prime}$ & 17 & 17 & & 16 & 5 \\
\hline \multirow[t]{2}{*}{18} & Tarnawa, Sokoliki 130a & 750 & $49^{\circ} 05^{\prime}$ & $22^{\circ} 52^{\prime}$ & 18 & 14 & & 17 & 2 \\
\hline & Mittelpolnische Hochebene & & & & & & & & \\
\hline 19 & $\begin{array}{l}\text { Zwierzyniec Lubelski, } \\
\text { Obrocz 119f }\end{array}$ & 260 & $50^{\circ} 34^{\prime}$ & $22^{\circ} 58^{\prime}$ & 19 & 20 & & 18 & 14 \\
\hline \multirow[t]{2}{*}{20} & Blizyn, Swinia Gora $134 \mathrm{i}$ & 310 & $51^{\circ} 04^{\prime}$ & $20^{\circ} 41^{\prime}$ & 20 & 1 & 1 & & 1 \\
\hline & Baltisches Gebiet & & & & & & & & \\
\hline 21 & Kartuzy, Kosowo 67d ** & 200 & $54^{\circ} 23^{\prime}$ & $18^{\circ} 08^{\prime}$ & 21 & 5 & 5 & 20 & 8 \\
\hline
\end{tabular}


Der Fichtenwald von Istebna-Bukowiec, Forstbetrieb Wisła, Abt. 149, Beskiden / Polen, ist eine der bekanntesten Fichtenherkünfte Europas (Abb. 3.1). In ihm steht die Enar Andersson-Fichte, die nach dem schwedischen Forstgenetiker benannt ist.

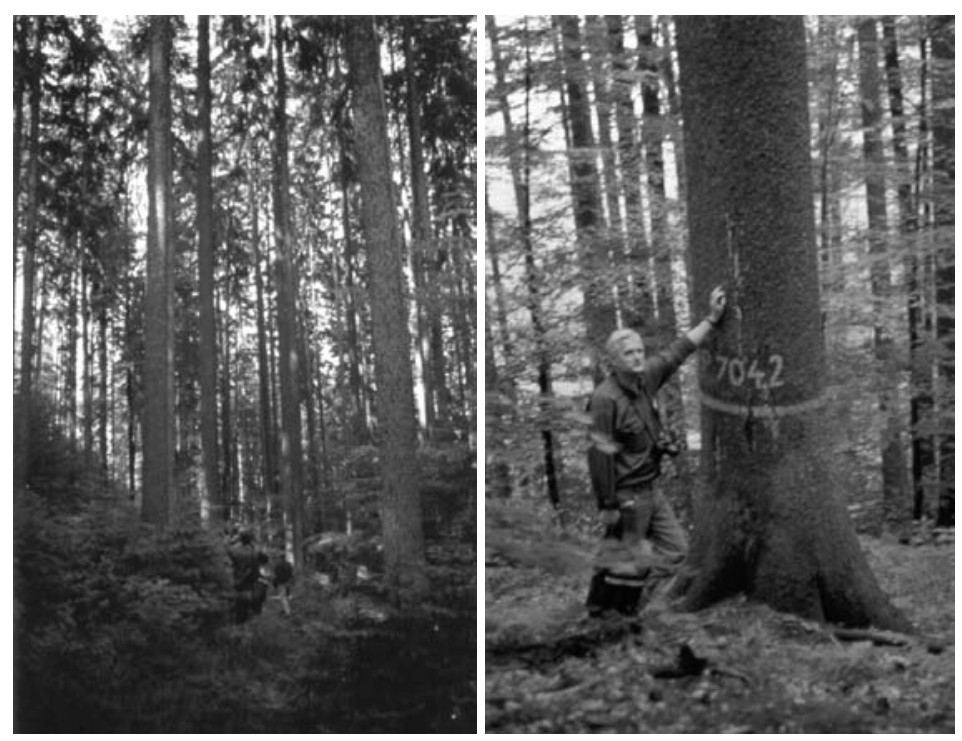

Abb.3.1: Fichtenwald von Istebna-Bukoniec, Forstbetrieb Wista, Abt. 149 (Alter 150-jäbrig) Beskiden / Polen, mit Uwe Tabel (ehem. Leiter der Darre Elmstein) an der Enar Andersson-Fichte (rechts). (Fotos: M. Liesebach 1989) 


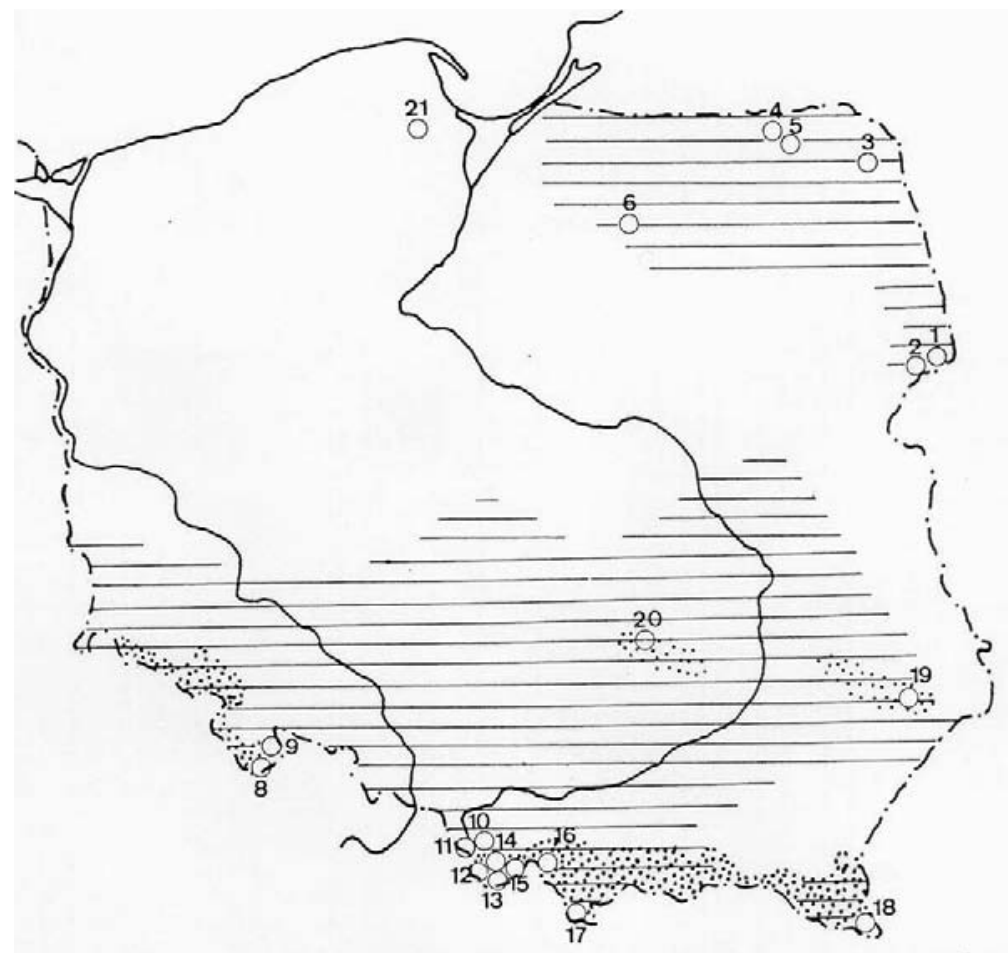

Abb. 3.2: $\quad$ Lage der Herkunftsorte der polnischen Prüfglieder (Herkunftsangaben: s. Tab. 3.1)

Auf den Versuchsflächen in Baden-Württemberg und Bayern wurden neben den polnischen Herkünften 21 Prüfglieder, alles Herkunftsabsaaten aus Deutschland bzw. der Schweiz, zur Prüfung mit angebaut (Tab. 3.2). Elf der Herkünfte sind auf all diesen Versuchsflächen angebaut, wobei es sich bei drei der Herkünfte (Nr. 30 Krumbach, Nr. 31 Gessertshausen und Nr. 32 Bischofswiesen) um so genannte Standardherkünfte (SCHMIDT-VOGT u. KOCIECKI 1985) handelt, die auf allen Fichtenherkunftsversuchsflächen des Waldbau-Instituts der Universität Freiburg angebaut sind, um Vergleichswerte errechnen zu können. Die weiteren zehn Herkünfte sind je zur Hälfte auf den Versuchsflächen enthalten, deren Prüfglieder aus den Aussaaten des Jahres 1972 bzw. 1973 stammen. 
Tab.3.2: $\quad$ Zusammenstellung der zusätzlichen Prüfglieder nach den Aussaatjabren auf den Versuchsflächen in Baden-Württemberg und Bayern

\begin{tabular}{|c|c|c|c|c|c|c|c|c|}
\hline \multirow{3}{*}{ Nr. } & \multirow{3}{*}{ Prüfglied } & \multirow{3}{*}{$\begin{array}{c}\text { Höhe } \\
\text { ü. NN } \\
{[\mathrm{m}]}\end{array}$} & \multicolumn{6}{|c|}{ Versuchsfläche** } \\
\hline & & & $\begin{array}{l}\text { Och. } \\
\text { A }\end{array}$ & $\begin{array}{l}\text { Och. } \\
\text { B }\end{array}$ & $\begin{array}{c}\text { Sau. } \\
\text { A }\end{array}$ & $\begin{array}{c}\text { Sau. } \\
\text { B }\end{array}$ & $\begin{array}{c}\text { Bi- } \\
\text { burg }\end{array}$ & Sch. \\
\hline & & & \multicolumn{6}{|c|}{ Aussaatjahr } \\
\hline $7 \mathrm{a}$ & Urwald Scatlè, Graubünden CH & 1650 & 1972 & & 1972 & 1972 & & \\
\hline $7 \mathrm{~b}$ & $\begin{array}{l}\text { Sonderherkunft Westerhof „Elite- } \\
\text { Bestände“ }\end{array}$ & 200 & & 1973 & & & 1973 & 1973 \\
\hline $22 \mathrm{a}$ & $\begin{array}{l}\text { F. F. Wolfach, V } 4 \text { Eichberg F1 } \\
\text { Westteil }\end{array}$ & 640 & 1972 & & 1972 & 1972 & & \\
\hline $22 \mathrm{~b}$ & Vohenstrauß, Opf., Ernte 71/72 & 620 & & 1973 & & & 1973 & 1973 \\
\hline 23 & F. F. Wolfach, V 4 Eichberg F1 Ostteil & 640 & 1972 & 1973 & 1972 & 1972 & 1973 & 1973 \\
\hline 24 & F. F. Wolfach, V 14 Hölle F1 Osttteil & 620 & 1972 & 1973 & 1972 & 1972 & 1973 & 1973 \\
\hline 25 & F. F. Wolfach, VI 7 Wiestenbach F1 & 660 & 1972 & 1973 & 1972 & 1972 & 1973 & 1973 \\
\hline 26 & F. F. Wolfach, VI 9 Güte Gottes F1 & 670 & 1972 & 1973 & 1972 & 1972 & 1973 & 1973 \\
\hline 27 & F. F. Wolfach, V 11 Schwarzenbühl F1 & 770 & 1972 & 1973 & 1972 & 1972 & 1973 & 1973 \\
\hline 28 & Zwiesel, Bayer. Wald, VI 12 a Haselau & 650 & 1972 & 1973 & 1972 & 1972 & 1973 & 1973 \\
\hline $29 \mathrm{a}$ & Zwiesel II $4 \mathrm{c}^{0}$ Sulzschachten & 1240 & 1972 & & 1972 & 1972 & & \\
\hline $29 \mathrm{~b}$ & Schernfeld, Mittelfranken & 500 & & 1973 & & & 1973 & 1973 \\
\hline $30^{*}$ & $\begin{array}{l}\text { Krumbach, Schwaben, X } 2 \text { b } \\
\text { Weilerschlucht }\end{array}$ & 600 & 1972 & 1973 & 1972 & 1972 & 1973 & 1973 \\
\hline $31 *$ & $\begin{array}{l}\text { Gessertshausen, Schwaben VI } 10 \mathrm{a}^{0} \\
\text { Wasengehau }\end{array}$ & 510 & 1972 & 1973 & 1972 & 1972 & 1973 & 1973 \\
\hline $32 *$ & $\begin{array}{l}\text { Bischofswiesen, Oberbayern, IV } 5 \mathrm{a}^{0} \\
\text { Am Moos, spättreibend }\end{array}$ & 750 & 1972 & 1973 & 1972 & 1972 & 1973 & 1973 \\
\hline $33 \mathrm{a}$ & $\begin{array}{l}\text { Klingenbrunn, Bayer. Wald, III } 2 \text { a } \\
\text { Hohe Wand (Ernte 1958) }\end{array}$ & 1330 & 1972 & & 1972 & 1972 & & \\
\hline $33 \mathrm{~b}$ & Dinkelsbühl, Mittelfranken & 500 & & 1973 & & & 1973 & 1973 \\
\hline $34 \mathrm{a}$ & $\begin{array}{l}\text { Klingenbrunn III 2a Hohe Wand } \\
\text { (Ernte 1971) }\end{array}$ & 1330 & 1972 & & 1972 & 1972 & & \\
\hline $34 \mathrm{~b}$ & Kehlheim-Nord, Niederbayern & 350 & & 1973 & & & 1973 & 1973 \\
\hline 35 & Passau-Süd, Niederbayern & 400 & 1972 & 1973 & 1972 & 1972 & 1973 & 1973 \\
\hline 36 & Eichstätt-West, Mittelfranken & 500 & 1972 & 1973 & 1972 & 1972 & 1973 & 1973 \\
\hline
\end{tabular}

* Standardherkünfte

** Versuchsfläche: Och. A + B $=$ Ochsenhausen A + B, Sau. A + B $=$ Sauerlach A + B, Sch $=$ Schwabmünchen

Auf der von der BFH betreuten Versuchsfläche in Bayern sind keine zusätzlichen Prüfglieder angebaut worden. 
Auf die Versuchsflächen in Hessen wurden zusätzlich sieben Prüfglieder aus Deutschland eingebracht (Tab. 3.3), die sich in verschiedenen Anbauten bereits bewährt hatten. Dabei handelt es sich um fünf Bestandesabsaaten und zwei Einzelbaumabsaaten von Samenplantagen (Halbgeschwister; Nr. 27 und Nr. 28) aus freier Abblüte.

Tab.3.3: Zusammenstellung der zusätzlichen Prüfglieder auf den Versuchsflächen in Hessen (Herkunftsgebietsnummern zum Zeitpunkt der Beerntung)

\begin{tabular}{|c|c|c|c|c|}
\hline Nr. & Prüfglied & $\begin{array}{l}\text { Höhe ü. NN } \\
{[\mathrm{m}]}\end{array}$ & Ernte & Nr. HE \\
\hline 22 & $\begin{array}{l}\text { Frankenwald unter } 650 \text { m (84011), SHK „Rothenkirchen“ } \\
\text { als „geprüft“" zugelassen] }\end{array}$ & $<650$ & 1972 & 21 \\
\hline 23 & $\begin{array}{l}\text { Schwäb. Alb und Bay. Jura (84013); Fürstlich Thurn und } \\
\text { Taxis, FoA Ebnat }\end{array}$ & & 1971 & 22 \\
\hline 24 & $\begin{array}{l}\text { Bayerischer Wald, 800-1100 m (84017); Gutsverwaltung } \\
\text { Oberzwieselau }\end{array}$ & $800-1100$ & 1971 & 23 \\
\hline 25 & $\begin{array}{l}\text { Südbayern, Oberschwaben, Bodenseegebiet (84019); Fürst } \\
\text { Fugger Babenhausen, Forst- und Güterverwaltung } \\
\text { Wellenburg }\end{array}$ & & 1971 & 24 \\
\hline 26 & $\begin{array}{l}\text { Harzvorland unter } 300 \text { m (84003), SHK „Westerhof“ Elite } \\
\text { Abt. } 48 \text { a }\end{array}$ & $<300$ & 1971 & 25 \\
\hline 27 & Stryck $12 *$, SPL Wilhelmshöhe (freie Abblüte) & & 1971 & 26 \\
\hline 28 & Mandelbeck 60/5**, SPL Gahrenberg (freie Abblüte) & & 1971 & 27 \\
\hline
\end{tabular}

Die Niedersächsische Forstliche Versuchanstalt (heute Nordwestdeutsche Forstliche Versuchsanstalt) hat Einzelbaumabsaaten in die Versuche aufgenommen. Auf der Versuchsfläche Seesen sind es 89 Einzelbaumabsaaten aus sechs Beständen (Tab. 3.4). Bei zwei dieser Bestände handelt es sich um die polnischen Herkünfte Nr. 10 Wisła und Nr. 1 Zwiezyniec, die mit neun bzw. zehn Einzelbaumabsaaten vertreten sind. Die weiteren Absaaten stammen aus vier Abteilungen (Abt. 40, 48, 49 und 50) im Kloster-Forstamt Westerhof von 2, 10, 15 bzw. 43 Einzelbäumen. 
Tab. 3.4: Zusammenstellung der zusätzlichen Prüfglieder auf der Versuchsfläche Seesen / Niedersachsen

\begin{tabular}{l|c|c|c}
\hline Nr. & Ort & HK & \multicolumn{1}{c}{ Einzelbaum } \\
\hline $102-110$ & Wisła & $10-$ & $4,11,12,15,17,33,50,55,56$ \\
$111-120$ & Zwierzyniec & $1-$ & $11,27,28,30,50,52,65,66,75,95$ \\
$121-135$ & Westerhof Abt. 50 & $50-$ & $21-35$ \\
$136-145$ & Westerhof Abt. 49 & $49-$ & $21-29,31$ \\
$146-189$ & Westerhof Abt. 40 & $40-$ & $21-64$ \\
190,191 & Westerhof Abt. 48 & $48-$ & 21,22 \\
\hline
\end{tabular}

$\mathrm{HK}=$ Herkunft

Auf der Versuchsfläche Dassel wurden 79 Einzelbaumabsaaten aus neun polnischen Beständen angebaut, die im Versuch als Bestandesabsaaten enthalten sind (Tab. 3.5). Die Anzahl der Einzelbaumabsaaten pro Bestand beträgt in der Regel 9 oder 10. Lediglich die Herkunft Nr. 10 Wisła ist nur durch eine Absaat vertreten.

Tab. 3.5: Zusammenstellung der zusätzlichen Prüfglieder auf der Versuchsfläche Dassel / Niedersachsen

\begin{tabular}{l|l|c|c}
\hline Nr. & Ort & HK & Einzelbaum \\
\hline $21-30$ & Borki & $5-$ & $91,94-96,98,99,101-104$ \\
$31-40$ & Istebna & $11-$ & $14,18,37,38,40,45,55,56,63,73$ \\
$41-50$ & Miedzygorze & $8-$ & $3,19,30,33,40,44,53,56,60,73$ \\
$51-60$ & Rycerka & $13-$ & $4,6,12,13,14,86,94,96,98,99$ \\
$61-70$ & Rycerka & $14-$ & $8,20,21,52,54,62,68,70,73,75$ \\
$71-73,75-80$ & Stronie Slaskie & $9-$ & $28,35,52,61,64,69,71,74,75$ \\
$81-90$ & Tarnawa & $18-$ & $10,48,51,62,64,67,71,73,96,103$ \\
$91-99$ & Wigry & $3-$ & $9,14,19,29,34,55,68,86,92$ \\
101 & Wisła & $10-$ & 1 \\
\hline
\end{tabular}

$\mathrm{HK}=$ Herkunft

\subsubsection{Versuchsorte und Versuchsaufbau}

Die 12 in Deutschland angelegten Versuchsflächen befinden sich in Baden-Württemberg (2), Bayern (5), Hessen (3) und Niedersachsen (2) (Abb. 3.3). Mit Ausnahme der Fläche in Neureichenau wurden die Versuchsflächen in Süddeutschland lange Zeit von SCHMIDT-VOGT betreut. 


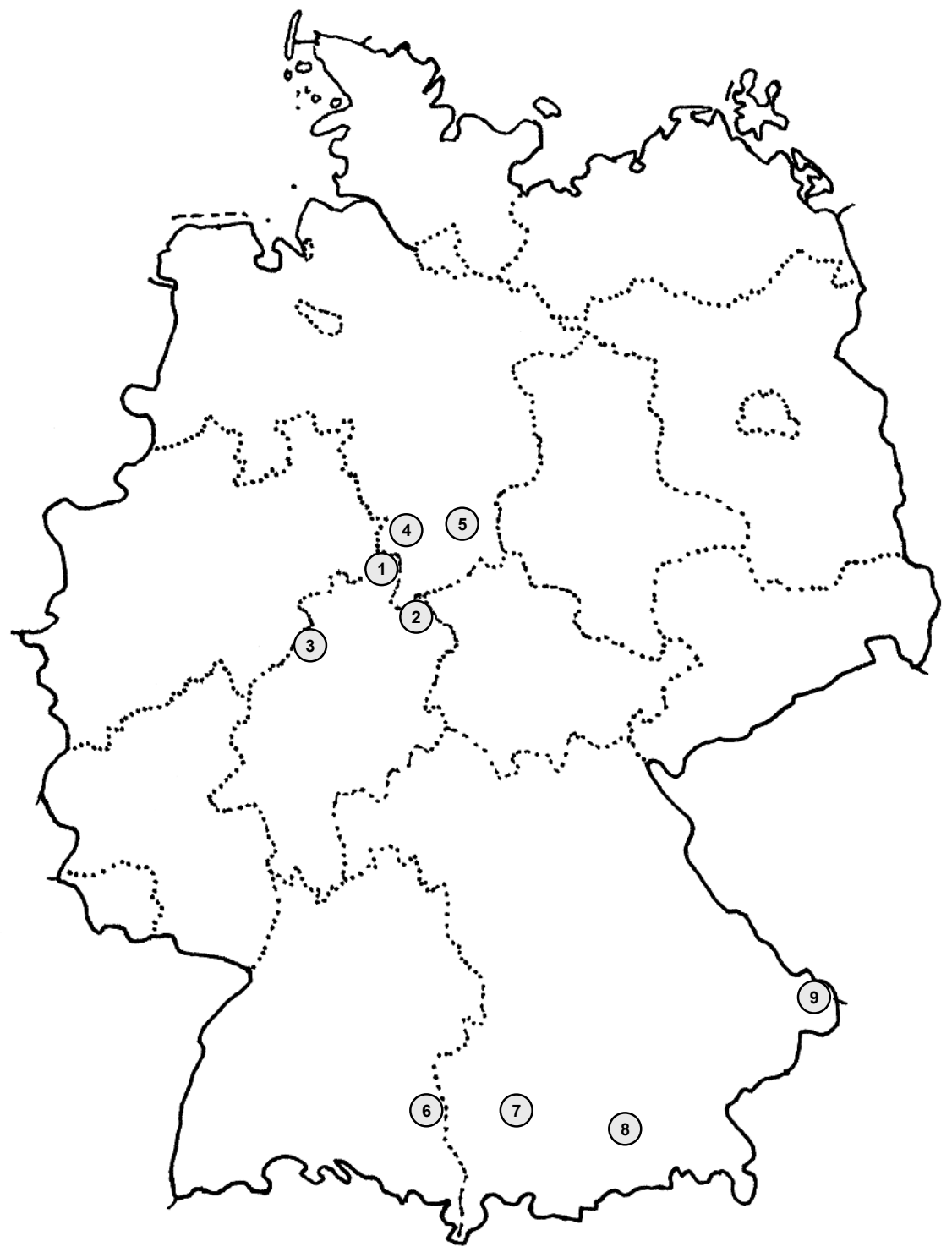

Abb. 3.3: Lage der Versuchsflächen $(1=$ Reinhardshagen, $2=$ Wanfried, $3=$ Hatrfeld, $4=$ Dassel, $5=$ Seesen; $6=$ Ochsenhausen $A+B, 7=$ Biburg und Schwabmünchen, $8=$ Sauerlach $A+B, 9=$ Neureichenau)

Die Flächen wurden in Höhenlagen zwischen 320 und 950 m Seehöhe als Dreisatzgitter angelegt (Tab. 3.6). SCHMIDT-VOGT wählte für die Flächen in Süddeutschland einen Verband von 1,5 $\mathrm{m}$ x 1,5 m. Die von den norddeutschen Instituten angelegten Flächen sind im Verband $2 \mathrm{~m}$ x $2 \mathrm{~m}$ gepflanzt. Die Parzellen sind 
in der Regel quadratisch mit 4 x 4 (16 Pflanzen), 5 x 5 (25 Pflanzen), 7 x 7 (49 Pflanzen) bzw. 9 x 9 Pflanzen (81 Pflanzen) bepflanzt. Die von der BFH betreute Fläche ist als $4 \times 4$-Gitter mit fünf Wiederholungen und $6 \times 4$ Pflanzen (24 Pflanzen) pro Parzelle angelegt. Einige Angaben zum Versuchsaufbau sind in Tabelle 3.6 zusammengestellt. $\mathrm{Zu}$ den Versuchsflächen in Hessen und Niedersachsen liegen einige Klimakennwerte vor (Tab. 3.7).

Tab. 3.6: $\quad$ Geografische und ausgewählte Daten zur Charakterisierung der Feldversuche

\begin{tabular}{|c|c|c|c|c|c|c|c|c|c|}
\hline Feldversuch & Land & $\begin{array}{c}\text { Geogr. } \\
\text { Breite } \\
\text { N }\end{array}$ & $\begin{array}{c}\text { Geogr. } \\
\text { Länge } \\
\mathrm{O}\end{array}$ & $\begin{array}{c}\text { Höhe } \\
\text { ü. NN } \\
{[\mathrm{m}]}\end{array}$ & HKG & $\begin{array}{c}\text { Verband } \\
{[\mathrm{m}]}\end{array}$ & $\begin{array}{l}\text { Pflanzen } \\
\text { / Parzelle }\end{array}$ & $\begin{array}{l}\text { Aussaat } \\
\text { Anlage }\end{array}$ & $\begin{array}{l}\text { Nr.* } \\
(* *)\end{array}$ \\
\hline $\begin{array}{l}\text { Reinhards- } \\
\text { hagen }\end{array}$ & $\mathrm{HE}$ & $51^{\circ} 33^{\prime}$ & $09^{\circ} 28^{\prime}$ & 260 & 84006 & $2 \times 2$ & 81 & $1973 / 76$ & 14 \\
\hline Wanfried & $\mathrm{HE}$ & $51^{\circ} 08^{\prime}$ & $10^{\circ} 06^{\prime}$ & 320 & 84006 & $2 \times 2$ & 81 & $1973 / 76$ & 15 \\
\hline Hatzfeld & $\mathrm{HE}$ & $50^{\circ} 40^{\prime}$ & $08^{\circ} 18^{\prime}$ & 450 & & $2 \times 2$ & 49 & $1973 / 76$ & \\
\hline Dassel & $\mathrm{NI}$ & $51^{\circ} 40^{\prime}$ & $09^{\circ} 45^{\prime}$ & 240 & 84006 & $2 \times 2$ & 16 & $1973 / 76$ & 13 \\
\hline Seesen & $\mathrm{NI}$ & $51^{\circ} 55^{\prime}$ & $10^{\circ} 15^{\prime}$ & 520 & 84009 & $2 \times 2$ & 16 & $1973 / 76$ & 12 \\
\hline $\begin{array}{l}\text { Ochsen- } \\
\text { hausen A }\end{array}$ & BW & $48^{\circ} 04^{\prime}$ & $09^{\circ} 57^{\prime}$ & 595 & 84027 & $1,5 \times 1,5$ & 25 & $1972 / 78$ & $\begin{array}{c}16 \\
(31)\end{array}$ \\
\hline $\begin{array}{l}\text { Ochsen- } \\
\text { hausen B }\end{array}$ & BW & $48^{\circ} 04^{\prime}$ & $09^{\circ} 57^{\prime}$ & 655 & 84027 & $1,5 \times 1,5$ & 25 & $1973 / 79$ & $\begin{array}{c}17 \\
(32)\end{array}$ \\
\hline Sauerlach A & BY & $47^{\circ} 56^{\prime}$ & $11^{\circ} 45^{\prime}$ & 636 & 84027 & $1,5 \times 1,5$ & 25 & $1972 / 78$ & $\begin{array}{c}20 \\
(33)\end{array}$ \\
\hline Sauerlach B & BY & $47^{\circ} 56^{\prime}$ & $11^{\circ} 45^{\prime}$ & 636 & 84027 & $1,5 \times 1,5$ & 25 & $1972 / 78$ & $\begin{array}{c}21 \\
(34)\end{array}$ \\
\hline Neureichenau & BY & $48^{\circ} 47^{\prime}$ & $13^{\circ} 44^{\prime}$ & 950 & 84021 & $2 \times 2$ & 24 & $1972 / 77$ & \\
\hline Biburg & BY & $48^{\circ} 23^{\prime}$ & $10^{\circ} 47^{\prime}$ & 500 & & $1,5 \times 1,5$ & 25 & $1973 / 79$ & $\begin{array}{c}18 \\
(35)\end{array}$ \\
\hline $\begin{array}{l}\text { Schwab- } \\
\text { münchen }\end{array}$ & BY & $48^{\circ} 11^{\prime}$ & $10^{\circ} 46^{\prime}$ & 550 & & $1,5 \times 1,5$ & 25 & $1973 / 79$ & $\begin{array}{l}19 \\
(36)\end{array}$ \\
\hline
\end{tabular}

* aus poln. Briefwechsel ** nach SCHMIDT-VOGT u. KOCIĘCKI (1985)

$\mathrm{HKG}=$ Herkunftsgebiet 
Tab. 3.7: $\quad$ Klimadaten zur Charakterisierung der Feldversuche in Hessen und Niedersachsen

\begin{tabular}{l|c|c|c|c}
\hline \multirow{2}{*}{ Feldversuch } & \multicolumn{2}{|c|}{ Temperatur } & \multicolumn{2}{c}{ Niederschlag } \\
& $\mathrm{t}_{\mathrm{j}}{ }^{\circ} \mathrm{C}$ & $\mathrm{t}_{\mathrm{Veg}}{ }^{\circ} \mathrm{C}$ & $\mathrm{mm}_{\mathrm{j}}$ & $\mathrm{mm}_{\mathrm{Veg}}$ \\
\hline Reinhardshagen (HE) & 8 & 14,3 & 725 & 352 \\
Wanfried (HE) & 7 & 12,5 & 623 & 316 \\
Hatzfeld (HE) & 6,5 & 13,0 & 940 & 370 \\
Dassel (NI) & 8,6 & 15,6 & 665 & 335 \\
Seesen (NI) & 5,5 & 12,2 & 1000 & 500 \\
\hline
\end{tabular}

$\mathrm{j}=$ durchschnittliches Jahresmittel

$\mathrm{Veg}_{\mathrm{g}}=$ durchschnittliches Mittel in der Vegetationsperionde (Mai-September)

\section{Hessen}

Im Versuchsrevier Beberbeck des Forstamtes Reinhardshagen (zwischenzeitlich Bad Karlshafen, Abt. 481 C/D) wurde eine Fläche als 5 x 5-Dreisatzgitter angelegt (Abb. 3.4). Die insgesamt ebene Fläche entwässert nach Nordosten. Auf Löss über Buntsandstein hat sich eine Pseudogley-Parabraunerde gebildet. Der tiefgründige Boden ist von mesotropher Nährstoffversorgung. Der Wasserhaushalt wird als feucht bis frisch beschrieben. Der Standort wird als Hochleistungsstandort für Fichte eingestuft.

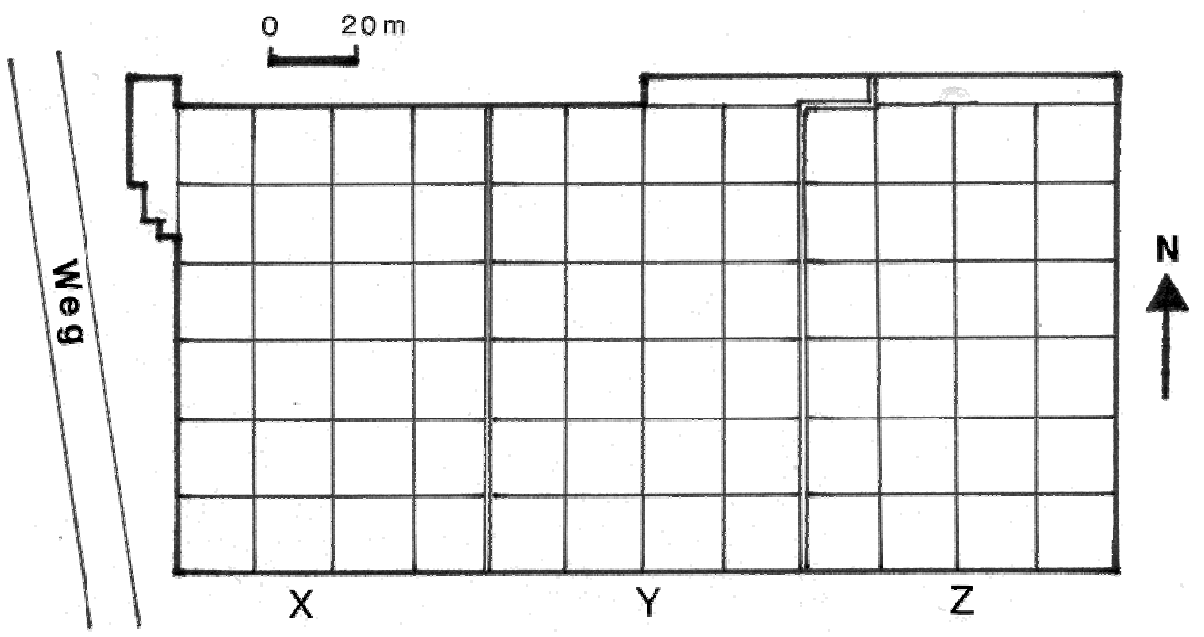

Abb. 3.4: Versuchsfläche Reinhardshagen / Hessen 
Die Fläche im ehemaligen Forstamt $W$ anfried (später Bad Sooden-Allendorf, heute Wehretal), Revier Eschwege, Abt. 241a (heute 2241a), ist auch als 5 x 5-Dreisatzgitter angelegt (Abb. 3.5). Aus Triasmaterial hat sich eine Braunerde gebildet, deren Gründigkeit über $60 \mathrm{~cm}$ Tiefe beträgt. Der Standort ist frisch bis betont frisch und von mesotropher Nährstoffversorgung.

Die dritte in Hessen angelegte Versuchsfläche lag im Forstamt Hatəfeld. Zum Standort war der Versuchsakte zu entnehmen, dass es sich um eine Braunerde auf devonischem Schiefer handelt. Die Fläche wurde bereits im Jahr nach der Anlage aufgegeben.

Abb. 3.5: Versuchsfläche Wanfried / Hessen

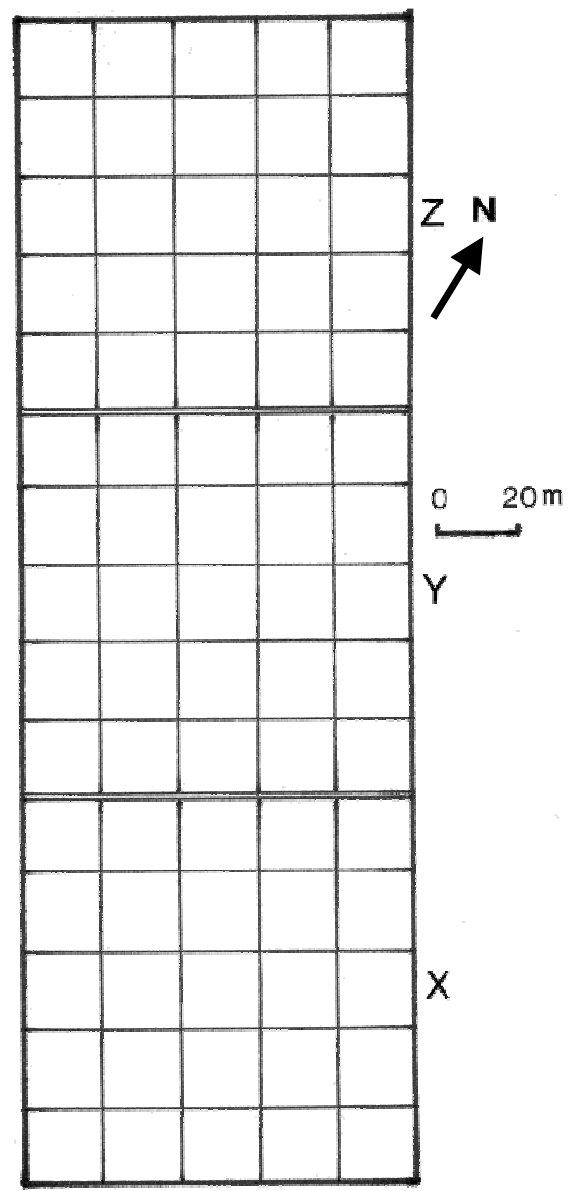




\section{Niedersachsen}

Die beiden nördlichsten Flächen in Deutschland befinden sich im Süden Niedersachsens. Eine gehört zum Solling-Forstamt Dassel (zwischenzeitlich auch Seelzerthurm), Revier Lauenberg, Abt. 1120 und liegt an einem mäßig steilen Nordhang (Abb. 3.6). Den Boden bildet eine nährstoffarme Braunerde aus lehmigem Feinsand. Die andere Fläche liegt im westlichen Harz an einem sanft nach Nordosten abfallenden Oberhang im Forstamt Seesen, Revier Luchsstein, Abt. 68 (Abb. 3.7). Die oligotrophe und sehr steinige Braunerde besteht aus sandigem Lehm. Beide Flächen sind als Gitterversuch mit drei Wiederholungen und im $2 \mathrm{~m} \times 2 \mathrm{~m}$ Verband angelegt.

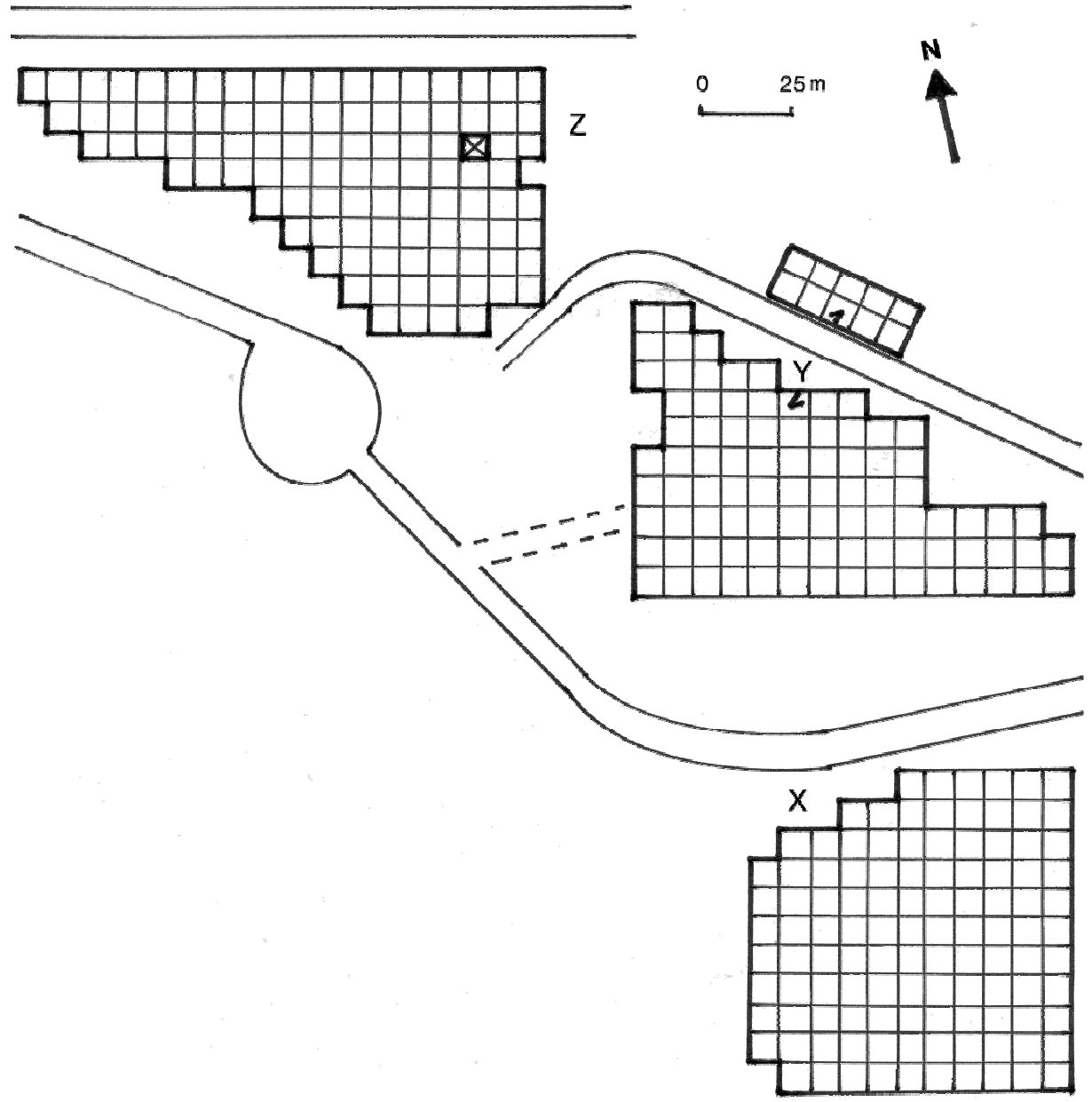

Abb. 3.6: $\quad$ Versuchsfläche Dassel / Niedersachsen 


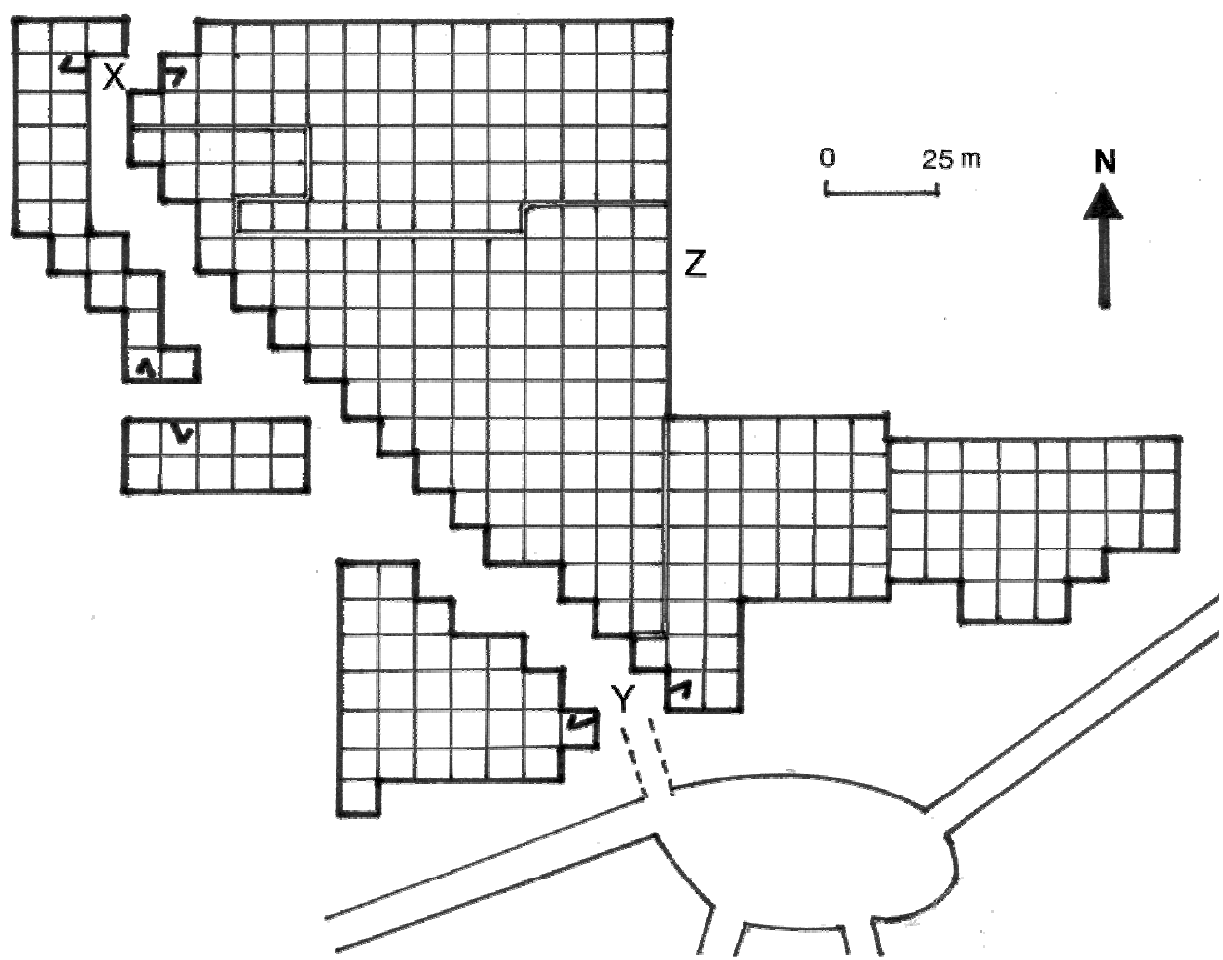

Abb. 3.7: Versuchsfläche Seesen / Niedersachsen

\section{Baden-Württemberg}

In Baden-Württemberg liegen die beiden Flächen im Forstamt Ochsenhausen (heute Landratsamt Biberach, Untere Forstbehörde). Die Fläche A wurde an einem nach Südwesten geneigten Hang im Distrikt VI, Abt. 1, Günzertal im Jahr 1978 angelegt. Die schwach saure Braunerde hat sich aus Tertiärsand gebildet. Die ein Jahr später angelegte Fläche B befindet sich im Distrikt XV, Abt. 7, Rot Äschle, an einem Osthang. Aus der Mindel-Endmoräne hat sich eine saure Braunerde gebildet. Beide Flächen sind als 5 x 5-Dreisatzgitter begründet. Von diesen Flächen liegen keine Versuchspläne mehr vor.

\section{Bayern}

Auch zwei der vier in Bayern vom Waldbau-Institut der Universität Freiburg angelegten Flächen sind als $5 \times 5$-Dreisatzgitter begründet (Biburg und Schwabmünchen). 
Zwei der Flächen wurden südlich von München im Forstamt Sauerlach, Revier Otterfing, als Blockversuch mit drei Wiederholungen angelegt (Abb. 3.8). Der Boden, ein steinig-sandiger Lehm, wurde als mäßig frisch eingestuft. Zwischen den Parzellen wurde bei der Pflanzung ein Trennstreifen mit der Breite einer Pflanzreihe freigehalten. Die ebenen Flächen liegen nebeneinander in verschiedenen Distrikten, die durch einen Weg getrennt sind. Die Fläche A liegt im Distrikt V, Abt. 1c während die Fläche B sich im Distrikt III Abt. 4c befindet. Letztere Fläche wurde zum Schutz vor Frost zusätzlich mit Schwarz-Erle überpflanzt.

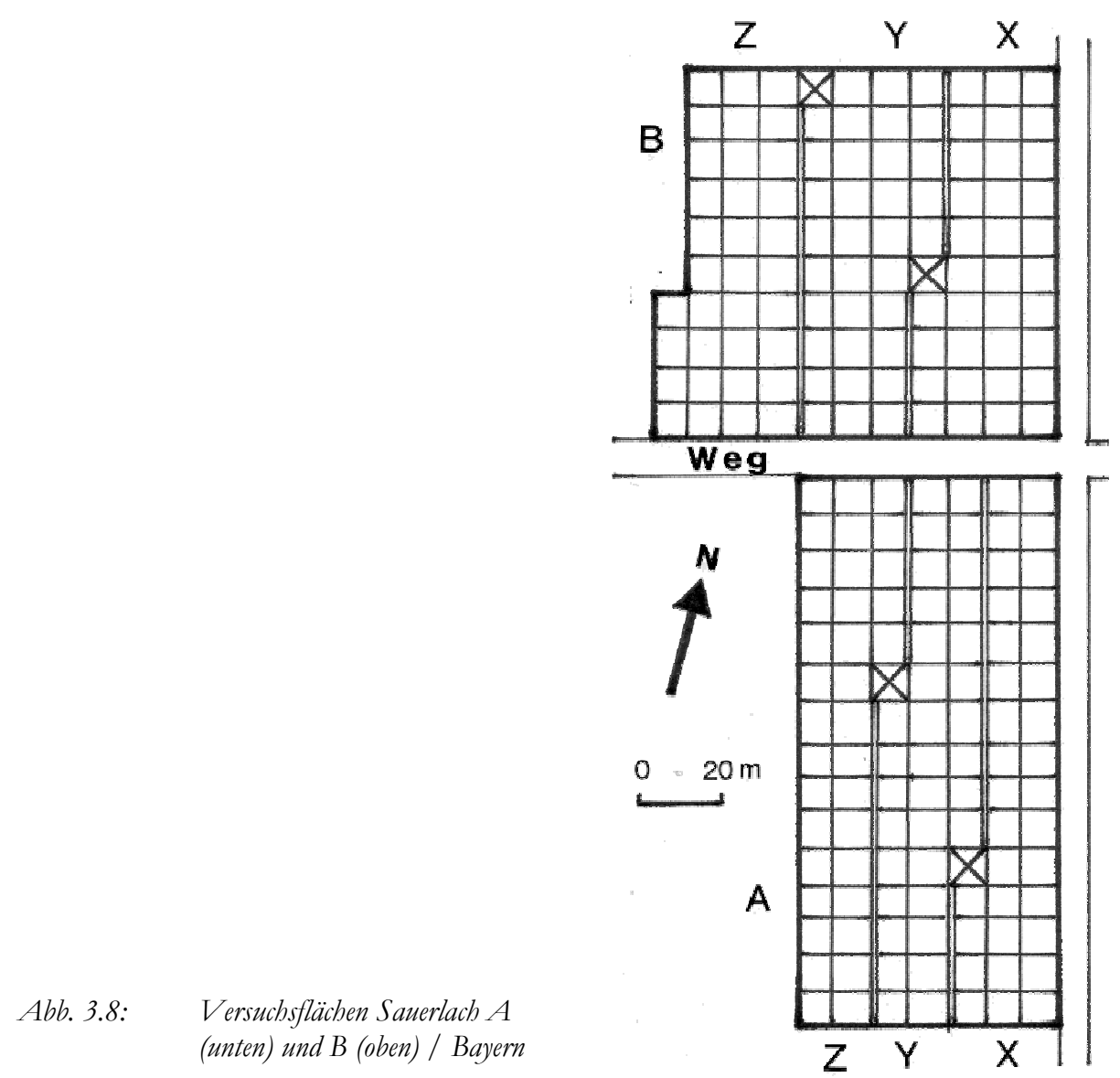

Eine weitere Fläche legte das Waldbau-Institut der Universität Freiburg im Forstamt Biburg, Distrikt V, Abt. $9 \mathrm{~b}^{0} / \mathrm{b}^{1}$ Jägerhaus, an. Der Boden dieser an einem Nordhang gelegenen Fläche besteht aus lehmigem Sand. 
Die vierte in Bayern begründete Fläche lag im Forstamt Schwabmünchen, Distrikt IV, Abt. $7 \mathrm{c}^{0}$ Lindenberg. Die ebene Fläche hat einen frischen anlehmigen Sand bis sandigen Lehm als Boden. Wegen hoher Ausfälle wurde letztgenannte Fläche kurz nach ihrer Anlage wieder aufgegeben. Von diesen Flächen liegen keine Versuchspläne mehr vor.

Die Pflanzen für die fünfte in Bayern angelegte Versuchsfläche wurden ebenfalls vom Waldbau-Institut ausgesät. Die Verschulung erfolgte anschließend bei der BFH, die auch die Versuchsfläche im Forstamt Neureichenau Revier Duschlberg, Hochgsteinet, Abt. II $5 \mathrm{a}^{4}$, anlegt hat und betreut (Abb. 3.9). Sie liegt an einem mäßig nach Süden bis Südwesten geneigten Hang. Der Boden ist eine Braunerde aus Froneis-Grundschutt über Granitzersatz. Für den Standort charakteristisch sind lange Winter mit viel Schnee. Im Gegensatz zu den anderen Versuchsflächen wurde hier das Gitter fünffach wiederholt.

Abb.3.9: Versuchsfläche Neureichenau / Bayern
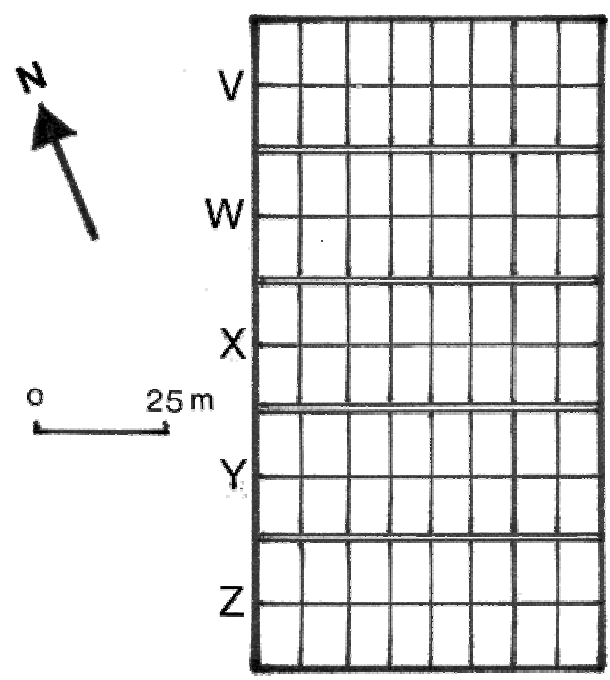

\subsubsection{Behandlung und Beschreibung des Gesamteindrucks der Versucbsflächen}

\section{Hessen}

Die insgesamt 25 Prüfglieder wurden auf dem Institutsgelände im Frühjahr 1973 ausgesät und im Kamp des Forstamtes Reinhardshagen als einjährige Sämlinge 1974 verschult. Im Frühjahr 1976 wurden die dreijährigen Pflanzen auf die drei anzulegenden Versuche aufgeteilt. Die Herkünfte Wigry (Nr. 3), Przerwanki (Nr. 4) und Witów (Nr. 17) waren schlecht aufgelaufen. Die fehlenden Pflanzen wurden von der Niedersächsischen Forstlichen Versuchsanstalt bezogen. 
Als Folge des trockenen Sommers 1976 wurde die Fläche Hatəfeld aufgegeben und die wenigen noch überlebenden Pflanzen zur Nachbesserung auf den Flächen Reinhardshagen und Wanfried verwendet.

Die Fläche Reinhardshagen wurde Ende April 1976 mit dreijährigen Fichten bei kühl trockener Witterung begründet. Das Forstamt wurde gebeten, gegebenenfalls eine Rüsselkäferbekämpfung und mechanische Kulturpflegemaßnahmen durchzuführen. Die zur Nachbesserung vorgesehenen Pflanzen von der aufgelösten Fläche Hatzfeld wurden Mitte April 1977 angeliefert. Die Nachbesserung erfolgte jedoch erst drei Wochen später mit den Pflanzen der Fläche Hatzfeld, die dort bereits stark unter Wildverbiss litten, und den auf der Fläche vorhandenen Reservepflanzen. Nach der Nachbesserung der Fehlstellen war die Versuchsfläche Reinhardshagen wieder nahezu vollständig.

Bei der Aufnahme der Flächen im Herbst 1979 wurde notiert, dass die Entwicklung der Fläche Reinhardshagen im Vergleich zu Wanfried deutlich zurückgeblieben war. Als mögliche Ursachen hierfür wurden starke Graskonkurrenz durch den feuchteren Standort und erhebliche Wildschäden (Fegeschäden und Verbiss) angeführt. Eine Freistellung der Pflanzen vom Gras (ggf. zweimal jährlich) und eine bessere Kontrolle der Zäune wurden vom Forstamt erbeten. Anlässlich der Erhebungen im Jahr 1982 wurde vermerkt, dass das Gras gemäht wurde und die Wildschäden durch stärkere Kontrollen zurückgegangen waren. Auch die schwachwüchsigen Prüfglieder waren aus dem Land-Reitgras (Calamagrostis epigejos) herausgewachsen. Seit der letzten Erhebung waren die Fichten entzwieselt und verbliebene Reservepflanzen entfernt worden.

Im Dezember 1996 traten Schäden durch Schneebruch an den polnischen Herkünften Wigry (Nr. 3), Przerwanki (Nr. 4) und Borki (Nr. 5) auf, allesamt Herkünfte aus Masuren. Derartige Schäden an ostpreußischen Herkünften waren bereits aus anderen Versuchen bekannt.

Die für 1991 vorgesehene Stammzahlreduktion um $25 \%$ erschien verfrüht, so dass nur schlecht geformte, verletzte, kranke Fichten sowie störende Begleitgehölze entfernt werden sollten. Vermutlich erfolgte zu der Zeit eine Feinerschließung der Fläche durch Entnahme einer Randreihe je Parzelle. 1994 wurde die Fläche Reinhardshagen schematisch durchforstet und alle verbleibenden Bäume auf zwei Meter geastet.

Im Frühherbst 1996 wurde die Fläche Reinhardshagen das zweite Mal durchforstet. Dabei wurde der den Versuch umgebende Zaun entfernt, so dass die Fläche nur noch zusammen mit weiteren Versuchen von einem Großgatter umgeben war.

Die gegatterte Fläche $W$ anfried wurde in der zweiten Aprilhälfte 1976 bepflanzt. Das Forstamt wurde gebeten, gegebenenfalls eine Rüsselkäferbekämpfung und mechanische Kulturpflegemaßnahmen durchzuführen. Die Nachbesserung, bei der auch verbissene Pflanzen aus Hatzfeld verwendet wurden, erfolgte Mitte April 
1977 bei typischem Aprilwetter. Danach war diese Versuchsfläche wieder fast vollständig. Trotz der trockenen Witterung im Sommer 1976 waren die Fichten in gutem Zustand, lediglich vereinzelt wurde Mäusefraß beobachtet.

Im Alter von sieben Jahren (1979) machte die Fläche Wanfried einen erfreulichen Eindruck, obgleich leichte Schäden durch Spätfrost beobachtet wurden. Weitere Schäden wurden auf der Fläche nicht beobachtet. 1982 wurden die Fichten von bedrängendem Geißblatt befreit und zwei Jahre später der Zaun entfernt. Im Sommer 1988 wurden vereinzelt fruktifizierende Bäume beobachtet.

Für die Feinerschließung der Fläche wurden 1991 die Bäume jeder 9. Reihe (Randreihe einer Parzelle) entnommen. Im folgenden Jahr wurden alle verbliebenen Bäume auf zwei Meter geastet. 1995 erfolgte eine Durchforstung, bei der die Stammzahl um $25 \%$ wie auf der Fläche Reinhardshagen reduziert wurde.

Bei einzelnen Stämmen wurde im Winter 1995/96 eine auffallende Schwarzfärbung der Rinde (Abb. 3.10) unbekannter Ursache festgestellt, die jedoch auf keine Schwächung hinwies. Fünf Jahre später war die Schwarzfärbung nicht mehr so stark ausgeprägt.
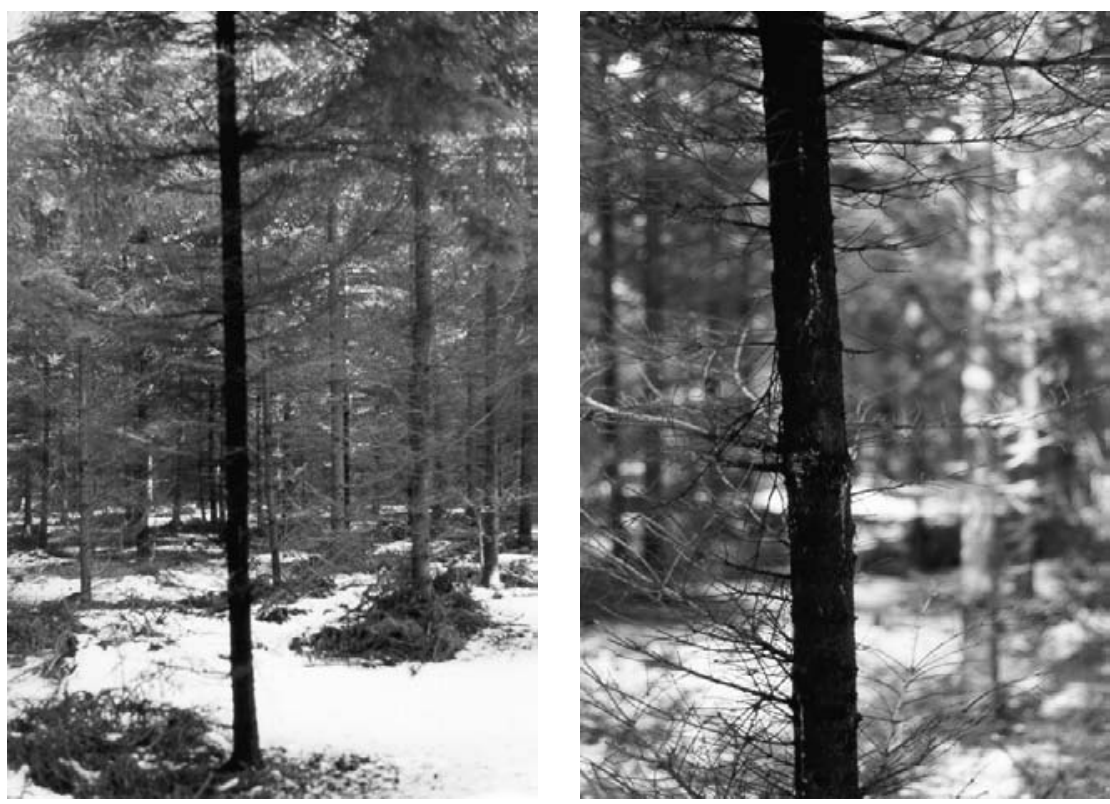

Abb. 3.10

Stämme mit auffallender Schwarafärbung der Rinde unbekannter Ursache auf der Versuchsfläche Wanfried / Hessen (Fotos: H.-M. Rau 1996)

Ende Juni 1997 riss ein Sturm eine trichterförmige Schneise in die Versuchsfläche auf der 155 Fichten geschädigt wurden: 1 geworfen, 1 am Stammfuß gebrochen, 87 im mittleren Stammbereich gebrochen, 11 im oberen Kronenbereich gebrochen und 55 angeschoben und stark gebogen, jedoch nicht entwurzelt. Zusätzlich 
wurden an mehreren Bäumen Harzfluss beobachtet, der auf Käferbefall zurückgeführt wurde. Die betroffenen Bäume wurden rasch aufgearbeitet. In den folgenden Jahren wurde weiterer Käferfraß beobachtet. Wegen der weiteren Gefährdung durch Käferbefall wurde 2004 vorerst von einer weiteren Durchforstung abgesehen.

\section{Niedersacbsen}

Die Fläche Dassel wurde im Winkelpflanzverfahren mit dreijährigen Fichten, die gegen Rüsselkäfer in eine Insektizidlösung getaucht waren, Anfang Mai 1976 begründet. Die Pflanzung erfolgte bei wechselnder Witterung mit einzelnen Schauern. Der Zustand der Pflanzen wurde als gut beschrieben. Die Fläche war bei der Flächenbegründung nicht gezäunt. Die Ausfälle waren im Vergleich zu den Flächen in Hessen sehr gering (Sommer 1976: 1,5 \%). Dennoch wurde im Frühjahr 1977 nachgebessert. Im Herbst des Jahres wurden die Pflanzen mit einem Repellentmittel gegen Wildverbiss bestrichen. Ab 1980 wurden wiederholt Weichlaubhölzer entfernt.

1990 wurden die Fichten in jeder 2. Reihe auf zwei Meter Höhe aufgeastet. Drei Jahre später wurden drei bis vier Z-Bäume pro Parzelle ausgewählt und freigestellt. Die Z-Bäume wurden ebenfalls auf zwei Meter Höhe geastet. Im Februar 1994 wurde die Fläche vom Hubschrauber aus gekalkt (Material: erdfeucht, mind. $15 \% \mathrm{MgCO}_{3}$ und $75 \% \mathrm{CaCO}_{3}$, aus dem Kalkwerk Salzhemmendorf; Menge: $3 \mathrm{t} / \mathrm{ha})$.

Anders als die Fläche Dassel war die Fläche Seesen bei der Pflanzung im Mai 1976 gezäunt. Die Pflanzung mit der Wiedehopfhaue erfolgte bei außergewöhnlich warmem, trockenem und windigem Wetter. Da die Pflanzen bei der Anlieferung bereits einen trockenen Eindruck machten, wurde bei anhaltend hohen Temperaturen und beim Ausbleiben von Niederschlägen mit höheren als normalen Ausfällen gerechnet. Infolge des Platzmangels mussten sowohl Brandstellen als auch ein durch Wiederholung Y laufender Rückeweg zugepflanzt werden. Auch auf dieser Fläche waren die Ausfälle im Winter nach der ersten Vegetationsperiode sehr gering (1,9\%). Die Nachbesserung erfolgte im Herbst 1980. Die Pflanzen wurden wiederholt von konkurrierender Vegetation befreit.

1985 wurde die Fläche mit 3 t/ha fein vermahlenem kohlensaurem Magnesiumkalk (mind. $43 \% \mathrm{MgCO}_{3}$ und $3 \% \mathrm{P}_{2} \mathrm{O}_{5}$ ) der Harzer Dolomitwerke Wülfrath gekalkt.

Im Herbst 1990 wurde jede zweite Reihe aufgeastet und der Zaun entfernt. Es wurden drei bis vier Z-Bäume je Parzelle ausgewählt und gekratzt. Die geplante Freistellung unterblieb. Bei den Erhebungen im Sommer 1996 wurde festgestellt, dass die Z-Bäume durch Astung zurückgesetzt hatten und nicht geastete Fichten stärker waren. Die dringend erforderlich gewordene Erstdurchforstung folgte. 


\section{Baden-Württemberg und Bayern}

Die Pflanzen für die Versuchsflächen in Baden-Württemberg und Bayern wurden im Forstlehrgarten Günterstal des Waldbau-Instituts der Universität Freiburg angezogen. Um das Risiko der Witterungseinflüsse einzugrenzen, verteilte man die Aussaat und die Auspflanzung der Herkünfte auf zwei Jahre. Die Samen wurden im Frühjahr 1972 und 1973 ausgesät. Nach zwei Jahren wurden die Pflanzen vermutlich verschult. Die Auspflanzung des Versuchsmaterials konnte erst im Alter von sechs Jahren im Frühjahr 1978 bzw. 1979, als die Pflanzen bereits relativ große Sprosslängen erreicht hatten, erfolgen. Die Pflanzen besaßen daher keine gute Stufung mehr. Die Feldversuche waren für eine Beobachtungsdauer von 20 bis 25 Jahren angelegt. Bei der Auspflanzung im Frühjahr 1979 herrschte über einen längeren Zeitraum Trockenheit, die zu höheren Ausfällen führte. Die Versuchsfläche im Forstamt Schwabmünchen (Bayern) musste aus diesem Grund aufgegeben werden (SCHMIDT-VOGT u. KOCIECKI 1985). Die Fläche Biburg wurde bei den Erhebungen 1993 nicht mehr berücksichtigt, da sie zuvor auch aufgegeben wurde.

\section{Sauerlach (Bayern)}

Bei wechselhaftem, kühlem mit Regenschauern durchsetztem Wetter wurden die Fichten auf den beiden Teilversuchen Sauerlach Anfang April 1978 gepflanzt. Da die Anzahl der Pflanzen nicht ausreichte, konnten nicht alle Parzellen vollständig ausgepflanzt werden. Zwischen den einzelnen Parzellen wurde ein $3 \mathrm{~m}$ breiter freier Streifen belassen. Auf der Teilfläche B wurde zusätzlich ein Erlen-Voranbau durchgeführt. Über die Anzahl der eingebrachten Erlen enthält die Versuchsakte keinen Hinweis. Im Anschluss an die Pflanzung erfolgte die Zäunung der Flächen.

\section{Neureichenau (Bayern)}

Im Frühjahr 1974 bezog das Institut für Forstgenetik und Forstpflanzenzüchtung $(\mathrm{BFH})$ in Großhansdorf zwei Jahre alte Sämlinge vom Waldbau-Institut der Universität Freiburg und verschulte sie in der Institutsgärtnerei. Da das Wachstum in der Baumschule sehr langsam verlief, wurden die Pflanzen im Alter von vier Jahren 1976 ein zweites Mal verschult. Im Mai 1977 wurde schließlich ein Feldversuch mit 16 Herkünften angelegt. Bei zwei weiteren Herkünften Nove Ramuki (6) und Witów / Tatra (17) waren die Pflanzenzahlen so gering, dass sie nicht für die Auspflanzung der Parzellen ausreichten. Diese Herkünfte sind daher nur im Rand vertreten, der jedoch bei den planmäßigen Erhebungen nicht mit aufgenommen wurde. 
Die klimatischen Bedingungen dieser in 950 m Seehöhe angelegten Versuchsfläche sind härter im Vergleich zu den restlichen Flächen in Deutschland. Die Winter sind lang und reich an Schnee, der bis lange in das Frühjahr hinein liegen bleibt. Daher kann diese Fläche für eine gemeinsame Auswertung des Versuchs von besonderem Interesse sein, was die Anpassungsfähigkeit von polnischen Herkünften, insbesondere Tieflagenherkünften, betrifft.

\subsubsection{Aufnabme von Merkmalen}

\section{Hessen}

Während der Anzucht der Pflanzen für die hessischen Versuchsflächen wurden an 50 Pflanzen pro Herkunft erste Merkmale erfasst. Die Ergebnisse wurden von RAU (1983) veröffentlicht. Zu den seinerzeit beobachteten Merkmalen zählen:

- Höhenmessung im Saat- und in den Verschulbeeten jeweils im Herbst der Jahre 1973 (1-j.), 1974 (2-j.) und 1975 (3-j.)

- Austriebsphänologie an Seitenknospen (1975): 1 = Knospen im Ruhezustand; 2 = mindestens 5 Knospen zeigen grüne Nadelspitzen; 3 = gesamte Nadelknospe sichtbar, Nadeln noch gebündelt (mind. 5 Knospen); $4=$ Nadeln abgespreizt, Beginn des Streckenwachstums (mind. 5 Knospen). Im Abstand von 2 bis 4 Tagen wurde das jeweils ausgeprägte Stadium notiert.

- Wurzelhalsdurchmesser am Ende des 2. Verschuljahres 1975 (3-j.)

- Formbonitur im Herbst 1975 (3-j.): $1=$ gerade, $2=$ gebogen, $3=$ geschlängelt, 4 = Zwiesel, 5 = buschig)

- Spät- bzw. Frühforstschäden (Frühjahr bzw. Herbst 1974 und 1975)

- Johannistriebbildung im Herbst 1974 und 1975 (2-j., 3-j.)

- Vegetationsabschluss im Herbst 1973 (1-j.), 1974 (2-j.) und 1975 (3-j.) jeweils einmal: a) Verholzung, b) Terminalknospenausbildung

Im Herbst des Jahres der Versuchsflächenanlage wurde auf den drei Flächen in Hessen die Anzahl der ausgefallen Pflanzen (4-j.) aufgenommen. Im Herbst 1979 (7-j.) wurden auf den beiden Flächen Reinhardshagen und Wanfried folgende Merkmale erhoben (RAU 1983): Baumhöhe, Stammform, Fegeschäden, Verbiss, Verfärbung, Spätfrost und Gallenlausbefall (jeweils in 3 Stufen). In den folgenden Jahren wurden auf den beiden Versuchsflächen in Hessen folgende Merkmale z. T. noch mehrfach erfasst: Ausfall 1995 (23-j.), Baumhöhe 1982 (10-j.), 1987 (15-j.), 1995 (23-j.) und 2004 (32-j.), Stammform 1982 (10-j.), 1987 (15-j.), 1995 (23-j.) und 2004 (32-j.) sowie Schäden 1982 (10-j.), 1995 (23-j.) und 2004 (32-j.). Aus den im Gelände erfassten Merkmalen wurden weitere abgeleitet. 


\section{Niedersachsen}

Auf den beiden Versuchsflächen in Niedersachsen wurden folgende Merkmale z. T. mehrfach erfasst: Baumhöhe 1980 (9-j.), 1985 (13-j.), 1995 (23-j.) und 2004 (32-j.), Stammform 1985 (13-j.), 1995 (23-j.) und 2004 (32-j.) sowie Schäden und Beastung 2004 (32-j.).

\section{Baden-Württemberg und Bayern}

Auf den vom Waldbau-Institut der Universität Freiburg angelegten Flächen in Baden-Württemberg und Bayern wurden unmittelbar nach der Auspflanzung im Freiland die Höhen gemessen, also in den Jahren 1978 und 1979 im Alter von sechs Jahren. Die nächsten Aufnahmen erfolgten im Herbst 1981/82 im Alter von zehn Jahren. Die letzten Höhenaufnahmen auf den Flächen in Ochsenhausen A und B führte das Waldbau-Institut 1993/94 im Alter von 22 bzw. 21 Jahren durch.

Von der Fläche Neureichenau sind Messungen und Erhebungen aus den Jahren 1981 (im Pflanzenalter von 10 Jahren), 1994 (23-j.) und 1996 (25-j.) bekannt (RAU et al. 1998, KÖNIG 2002). Besonderes Augenmerk wurde dabei auf die Schädigungen durch Schnee gelegt. Im Jahr 1996 wurden Baumhöhe und BHD gemessen, da diese Arbeiten 1994 nicht beendet werden konnten. Nach starken Nassschneefällen im März 1999 wurden die Schäden im Mai (27-j.) aufgenommen. Die letzten Messungen und Erhebungen fanden im August 2005 (34-j.) statt, erfasst wurden Baumhöhe und BHD, Stammform sowie Schäden.

In Tabelle 3.8 sind die Merkmale, die auf den Flächen gemessen bzw. bonitiert wurden, zusammengestellt. Um die Tabelle übersichtlich zu gestalten, wurden Versuchsflächen, die von einem Institut betreut und in der Regel im selben Alter gemessen wurden, in einer Spalte zusammengefasst. Außerdem wurde das Pflanzenalter zum Zeitpunkt der jeweiligen Messung als Bezugsgröße vermerkt. 
Tab.3.8 Zusammenstellung der auf den Flächen gemessenen bzw. erbobenen Merkmale nach Pflanzenalter

\begin{tabular}{|c|c|c|c|c|c|}
\hline Merkmal & $\begin{array}{l}\text { Reinhardshagen, } \\
\text { Wanfried / HE }\end{array}$ & $\begin{array}{l}\text { Dassel, } \\
\text { Seesen / NI }\end{array}$ & $\begin{array}{l}\text { Ochsenhau- } \\
\text { sen / BW }\end{array}$ & $\begin{array}{l}\text { Sauerlach, } \\
\text { Biburg / BY }\end{array}$ & $\begin{array}{l}\text { Neureiche- } \\
\text { nau / BY }\end{array}$ \\
\hline Ausfälle * & 4,23 & & & & 10,25 \\
\hline Höhe & $\begin{array}{l}3,7,10,15,23, \\
32\end{array}$ & $\begin{array}{l}9,13,(18 ?), \\
23,32\end{array}$ & $6,10,22$ & 6,10 & $\begin{array}{l}10,(23), 25, \\
34\end{array}$ \\
\hline BHD & 23,32 & 23,32 & & $25^{* *}$ & 25,34 \\
\hline Schaftform & $7,10,15,23,32$ & 32 & & & 34 \\
\hline Zwiesel & 15,32 & 32 & & & \\
\hline Spätfrost & 7,10 & & & & \\
\hline $\begin{array}{l}\text { Schneebruch / } \\
\text {-druck }\end{array}$ & 24 & & & & 27 \\
\hline Nadelverfärbung & 7 & & & & \\
\hline Schäden & $7,10,23,32$ & 32 & & & 34 \\
\hline Beastung & & 32 & & & \\
\hline Fruktifikation & 15 & & & & \\
\hline
\end{tabular}

* eigenständige Aufnahme, nicht abgeleitetes Merkmal ** ohne Biburg, da bereits aufgegeben

In den Feldversuchen (Reinhardshagen, Wandfried, Dassel und Seesen) erfolgten die beiden letzten Messungen und Erhebungen unter Federführung der Hessischen Forstlichen Versuchsanstalt (heute Nordwestdeutsche Forstliche Versuchsanstalt) nach einem vorgegebenen Schema. Außerdem wurde versucht, die Parameter auf allen Flächen im selben Alter aufzunehmen. Die von der Versuchsanstalt herausgegebenen Aufnahmeanleitungen (1996 und 2004) sahen die Erhebung am Einzelbaum der in Tabelle 3.9 zusammengestellten Parameter vor. Zusätzlich sind in der Tabelle noch die Merkmale mit ihren Verschlüsselungen aufgelistet, die 1988 auf den Flächen Reinhardshagen und Wanfried/Hessen erfasst wurden. Von weiteren Flächen befinden sich keine detaillierten Anleitungen in den Versuchsakten. Die Zusammenstellung zeigt, dass ein Vergleich der quantitativen Merkmale zwischen den Erhebungsjahren nicht immer uneingeschränkt möglich ist. Die jüngste Erhebung konnte auf die polnischen Herkünfte beschränkt werden. 
Tab. 3.9: $\quad Z u$ erfassende Parameter - Gegenüberstellung ausgewäblter Aufnabmeanleitungen vom Mai 1996 und August 2004 sowie die der Flächen Reinhardshagen und Wanfried 1988

\begin{tabular}{|c|c|c|c|}
\hline Merkmal & 1988 & Mai 1996 & August 2004 \\
\hline $\begin{array}{l}\text { Ausfälle / } \\
\text { Vitalität }\end{array}$ & Fehlstellen & $\begin{array}{l}1 \text { = Pflanze voll lebensfähig } \\
2=\text { Pflanze ist da, aber } \\
\text { Überleben fraglich } \\
3 \text { = Pflanze tot } \\
4=\text { Pflanze fehlt, weil sie hier } \\
\text { nicht pflanzbar war } \\
5 \text { = Pflanze fehlt, weil } \\
\text { ausgefallen } \\
6 \text { = Pflanze fehlt, weil } \\
\text { durchforstet }\end{array}$ & $\begin{array}{l}1 \text { = voll lebensfähig } \\
2=\text { eingeschränkt } \\
\text { lebensfähig } \\
3=\text { natürlicher Ausfall } \\
4=\text { nicht natürlicher Ausfall } \\
\text { (nicht gepflanzt, abgesägt ...) }\end{array}$ \\
\hline Höhe & alle $[\mathrm{dm}]$ & $\begin{array}{l}{[\mathrm{dm}] \text { von } 10 \text { Bäumen pro }} \\
\text { Parzelle, entspricht etwa } 1 / 5 \\
\text { der noch vorhandenen } \\
\text { Fichten, völlig unterdrückte, } \\
\text { unterständige Einzelexemplare } \\
\text { wurden aber weggelassen. }\end{array}$ & $\begin{array}{l}\text { [dm] bei } 1 / 5 \text { der regulären } \\
\text { Baumzahl einer Parzelle und } \\
\text { nur bei zumindest } \\
\text { mitherrschenden Bäumen }\end{array}$ \\
\hline $\mathrm{BHD}$ in $\mathrm{mm}$ & - & $\begin{array}{l}\text { alle lebenden Bäume } \\
\text { (einfache Messung) }\end{array}$ & $\begin{array}{l}\text { alle lebenden Bäume } \\
\text { (kreuzweise kluppen) }\end{array}$ \\
\hline $\begin{array}{l}\text { Schaftform } \\
\text { (Form A) }\end{array}$ & $\begin{array}{l}1=\text { gerade } \\
2=\text { leicht } \\
\text { gebogen, } \\
\text { geschlängelt } \\
3=\text { stark gebogen } \\
/ \text { geschlängelt } \\
4=\text { umliegend } \\
5=\text { buschig } \\
6=\text { nicht } \\
\text { ansprechbar }\end{array}$ & $\begin{array}{l}1=\text { (fast) gerade } \\
2=\text { leichte Formmängel, die } \\
\text { sich in absehbarer Zeit } \\
\text { auswachsen könnten } \\
3=\text { schwere Formmängel, die } \\
\text { sich wohl nicht auswachsen } \\
\text { dürften }\end{array}$ & $\begin{array}{l}1=\text { (fast) gerade } \\
2=\text { leichte Formmängel, die } \\
\text { sich in absehbarer Zeit } \\
\text { auswachsen könnten } \\
3=\text { schwere Formmängel, } \\
\text { die sich wohl nicht } \\
\text { auswachsen dürften } \\
4=\text { Sonstiges (z. B. } \\
\text { angeschoben, abgesägt und } \\
\text { wieder ausgeschlagen, ...) }\end{array}$ \\
\hline $\begin{array}{l}\text { Zwiesel } \\
\text { (Form B) }\end{array}$ & $\begin{array}{l}1=\text { kein Zwiesel } \\
2=\text { Tiefzwiesel } \\
3=\text { Hochzwiesel } \\
4=\text { korbförmige } \\
\text { Krone }\end{array}$ & $\begin{array}{l}1=\text { keine } \\
2=\text { Tiefzwiesel (in der unteren } \\
\text { Stammhälfte) } \\
3=\text { Hochzwiesel (in der } \\
\text { oberen Stammhälfte) }\end{array}$ & $\begin{array}{l}\text { (nur sofern vorhanden) } \\
1=\text { vom Boden weg } \\
\text { verzwieselt oder Steilast } \\
\text { (Vereinzelung möglich) } \\
2=\text { Zwiesel / Steilast u. dgl. } \\
\text { im Hauptstammbereich } \\
\text { (starke Entwertung des } \\
\text { Stammholzes) } \\
3=\text { Zwiesel / Steilast/ Korb } \\
\text { / Bajonett im obersten } \\
\text { Kronenbereich (geringe } \\
\text { Entwertung des Stammes) }\end{array}$ \\
\hline
\end{tabular}

(Fortsetzung) 
(Fortsetzung Tabelle 3.9)

\begin{tabular}{l|l|l|l}
\hline Beastung & - & - & $\begin{array}{l}\text { Beastung (nur bei } \\
\text { diesbezüglich auffälligen } \\
\text { Bäumen) } \\
1=\text { exzellente Beastung } \\
\text { (wenige / feine Äste, große } \\
\text { Abgangswinkel) }\end{array}$ \\
& & $\begin{array}{l}\text { 2= problematische Beastung } \\
\text { (viele / grobe Äste, steile } \\
\text { Abgangswinkel, oft beuliger } \\
\text { Stamm) }\end{array}$ \\
\hline Schäden & & $\begin{array}{l}\text { Schadensart } \\
1=\text { Nadelverfärbung } \\
2=\text { Nadelverlust } \\
\text { Schadensgrad } \\
1=\text { leicht } \\
2=\text { mittel } \\
\text { (wenn Schäden häufiger } \\
\text { anzutreffen) } \\
\text { Schadensgrad } \\
1=\text { leicht }\end{array}$ \\
& & $\begin{array}{l}\text { stark mittel } \\
3=\text { stark }\end{array}$ \\
\hline
\end{tabular}

\subsubsection{Methoden}

Die Auswertung erfolgt in mehreren Stufen, wobei im Mittelpunkt die polnischen Herkünfte des IUFRO-Versuchs stehen. Zunächst werden die Flächen jeweils getrennt ausgewertet. Es folgen versuchsflächenübergreifend Auswertungen auf Ebene der einzelnen Merkmale.

Soweit möglich werden für die relevanten metrischen Merkmale Mittelwerte und Streuungen pro Versuchsfläche, Prüfgliedgruppe, Prüfglied, Wiederholung und Parzelle berechnet. Für qualitativ erfassbare Merkmale werden Häufigkeitsverteilungen erstellt und verglichen. Aus den erhobenen Messwerten werden weitere Kenngrößen (z. B. H/D-Wert, Stammzahl pro Hektar, Volumen) errechnet. Aufgrund der geografischen Verteilung führt die vorhandene Einteilung der polnischen Herkünfte in Regionen zu Einheiten, die teilweise nur eine oder wenige Herkünfte enthalten und somit regionale Aussagen nicht ermöglichen.

Bei der Auswertung der einzelnen Versuchsflächen werden die Merkmale in folgender Reihenfolge abgehandelt:

\section{Entwicklung der Pflanz̧enanzabl}

Die Anzahl der lebenden Fichten bzw. die Ausfälle wurden als Verhältnis der im jeweiligen Jahr gemessenen Fichten und der ursprünglich gepflanzten Anzahl der Fichten errechnet. Für die hessischen Versuchsflächen Reinhardshagen und Wanfried liegt im Alter von 23 Jahren eine eigene Erhebung zur Vitalität der Fichten vor. 


\section{Schäden}

Für die einzelnen Schadmerkmale werden die Verteilungen der Häufigkeiten der Boniturnoten analysiert. Im Ergebnis wird entschieden, ob es herkunftsbedingte Unterschiede gibt und ob Fichten, an denen bestimmte Schäden auftreten, bei den nachfolgend beschriebenen Parametern berücksichtigt werden oder nicht.

\section{Qualitätsparameter}

Die Qualitätsparameter sind Stammform, Ovalität (RICHTER 2002, 2007) und H/D-Verhältnis. Für die Bonitur der Stammform werden die Häufigkeitsverteilungen analysiert. Bei der jüngsten Erhebung im Alter von 32 bzw. 34 Jahren liegen von der Messung der BHD zwei Messwerte vor. Aus diesen wurde die Abweichung von der Kreisform nach folgender Formel bestimmt:

$$
\begin{array}{lll}
\text { ov }=100 *\left|\mathrm{~d}_{1}-\mathrm{d}_{2}\right| / \mathrm{d}_{\mathrm{m}}[\%] & \text { ov } & \text { Ovalität } \\
& \mathrm{d}_{1}, \mathrm{~d}_{2} & \text { gemessene BHD } \\
& \mathrm{d}_{\mathrm{m}} & \text { mittlerer BHD eines Baumes }
\end{array}
$$

Der dritte Qualitätsparameter, das Höhen-Durchmesser-Verhältnis (HD), wurde für alle Fichten, von denen beide Werte als Messwerte vorliegen, in den entsprechenden Jahren errechnet. Das H/D-Verhältnis bzw. der Schlankheitsgrad ist der Quotient von Baumhöhe und Brusthöhendurchmesser. Es ist einerseits ein grober formbestimmender Faktor und andererseits ein Stabilitätsfaktor für einen Bestand. Ein niedriger H/D-Wert trägt mit zur Bestandessicherheit bei.

\section{Höhen- und BHD-W achstum}

Die Analyse der beiden Wachstumsparameter Baumhöhe und Brusthöhendurchmesser wird in den Jahren, in denen die Baumhöhe nur an einer Zufallsstichprobe gemessen ist, nur mit diesen gemessenen Werten durchgeführt. Für den Vergleich zwischen den Versuchsflächen werden neben den absoluten Werten auch das Wachstum im Verhältnis zum jeweiligen Versuchsflächenmittel und Rangfolgen berücksichtigt.

Für die Volumenschätzung werden die fehlenden Baumhöhen aus dem H/DVerhältnis einer Versuchsfläche für den jeweiligen BHD berechnet:

$$
\mathrm{h}=\mathrm{BHD} * \mathrm{HD} \text {. }
$$




\section{Einzelbaumvolumen und Vorrat pro Hektar}

Aus Baumhöhe und BHD erfolgt die Schätzung des Einzelbaumvolumens nach der einfachen Formel:

$$
\mathrm{V}=\mathrm{BHD}^{2} * \mathrm{~h} * 0,00004 * 0,9
$$

Dabei wird eine Derbholz-Formzahl von 0,45 unterstellt.

Für jede Parzelle wird unter Berücksichtigung der Parzellengröße und des Pflanzverbandes aus den Einzelbaumvolumina und der Anzahl lebender Bäume zum Aufnahmezeitpunkt der Bestandesvorrat berechnet und zur Vergleichbarkeit auf einen Hektar bezogen. Da die Durchforstungsmengen häufig nicht bekannt sind, lässt sich die Gesamtwuchsleistung nicht berechnen.

Auf der Ebene von Parzellenmittelwerten werden multiple Mittelwertvergleiche (1) für alle Prüfglieder untereinander (Tukey-Test, $\alpha=0,05)$ und (2) im Vergleich mit einem Standard (Dunnett-Test, $\alpha=0,05$ ) durchgeführt. Als Standard dienen die acht auf allen Versuchsflächen vertretenen polnischen Herkünfte: Przerwanki (IUFRO-Nr. 4), Borki (Nr. 5), Nowe Ramuki (Nr. 6), Miedzygórze (Nr. 8), Istebna 149h (Nr. 11), Istebna $115 f$ (Nr. 12), Zwardon (Nr. 13) und Kartuzy (Nr. 21). Auf der Versuchsfläche Neureichenau ist die Herkunft Nowe Ramuki (Nr. 6) nur im Rand ohne Wiederholung angebaut, so dass bei dieser Versuchsfläche nur sieben Herkünfte den Standard bilden.

Die Versuchsflächen werden als (einfaktorielle) randomisierte vollständige Blockversuche ausgewertet. Für das Merkmal Vorrat je Hektar wird gezeigt, dass sich bei einer Auswertung als Gitterversuch der mittlere Standardfehler nur marginal verringert. Es wird daher von einer Auswertung unter Berücksichtigung des Gitters (Alpha-Design) abgesehen.

Es schließen sich auf der Ebene der einzelnen Merkmale die versuchsflächenübergreifenden Auswertungen an. In diesem Abschnitt werden weitere Methoden an den jeweiligen Stellen direkt beschrieben.

Verwendete Abkürzungen:

PG Prüfglied / Prüfglieder

n Anzahl

$\mathrm{s} \%$ Variationskoeffizient in der Stichprobe

$\mathrm{r}_{\mathrm{P}}$ Produkt-Momenten-Korrelationskoeffizient nach PEARSON

$\mathrm{r}^{2} \quad$ Bestimmtheitsmaß

$\chi^{2}$ Chi-Quadrat (-Test)

$\alpha \quad$ Risiko 1. Art, Signifikanzniveau

ns nicht signifikant

* $\quad$ signifikant $(\alpha<0,05)$ 
erfolgt kein Hinweis auf $\alpha<0,05$ so gilt:

$$
\begin{aligned}
& * \quad<0,05 \\
& * *<0,01 \\
& * * *<0,001
\end{aligned}
$$

\subsection{Ergebnisse und Diskussion}

\subsubsection{Hessen}

\subsubsection{Reinhardshagen}

Entwicklung der Pflanzenanzahl

Im Alter von 32 Jahren leben auf der Versuchsfläche noch $51 \%$ der ursprünglich gepflanzten Fichten. Werden nur die 18 IUFRO-Herkünfte betrachtet, liegt der Anteil lebender Bäume bei $50 \%$. Zwischen den Wiederholungen sind die Unterschiede beim Anteil lebender Bäume der IUFRO-Herkünfte gering und betragen $7 \%$-Punkte.

Betrachtet man die Anteile lebender Bäume der zu fünf geografischen Regionen zusammengefassten IUFRO-Herkünfte, so sind sie sehr ähnlich. (Tab. 3.10). Es ist davon auszugehen, dass diese Unterschiede der Regionen auf die geringe Anzahl an Herkünften zurückgeführt werden können und damit zufällig sind. Im Vergleich zur Erhebung im Alter von 23 Jahren sind die Anteile lebender Bäume geringfügig zurückgegangen.

Tab. 3.10: $\quad$ Anteil lebender Bäume der zu fünf geografischen Regionen zusammengefassten polnischen Herkünfte (IUFRO), der IUFRO-PG, der zusätzlichen PG und aller PG auf der Fläche Reinhardshagen

\begin{tabular}{lccccc}
\hline Geografische Region & IUFRO-Nr. & $\begin{array}{c}\text { Anzahl } \\
\text { PG }\end{array}$ & $\begin{array}{c}1976 \\
(4-\mathrm{j} .)\end{array}$ & $\begin{array}{c}1995 \\
(23-\mathrm{j} .)\end{array}$ & $\begin{array}{c}2004 \\
(32-\mathrm{j} .\end{array}$ \\
\hline Masuren-Podlasie & $1-6$ & 6 & $80 \%$ & $52 \%$ & $49 \%$ \\
Sudeten & $8-9$ & 2 & $86 \%$ & $52 \%$ & $50 \%$ \\
Karpaten (Beskiden) & $10-14,16-18$ & 8 & $86 \%$ & $52 \%$ & $51 \%$ \\
Mittelpolnische Hochebene & 19 & 1 & $90 \%$ & $49 \%$ & $48 \%$ \\
Baltisches Gebiet & 21 & 1 & $97 \%$ & $58 \%$ & $57 \%$ \\
\hline IUFRO-Herkünfte & & 18 & $85 \%$ & $52 \%$ & $50 \%$ \\
\hline zusätzliche PG & & 7 & $90 \%$ & $56 \%$ & $54 \%$ \\
\hline alle PG & & 25 & $86 \%$ & $53 \%$ & $51 \%$ \\
\hline
\end{tabular}


Zwischen den einzelnen IUFRO-Herkünften gibt es Unterschiede beim Anteil verbleibender Bäume (Abb. 3.11). Im Alter von 32 Jahren variiert der Anteil der noch vorhandenen Fichten zwischen $57 \%$ (Nr. 21 Kartuzy) und 45\% (Nr. 8 Miedzygórze). Die sieben zusätzlichen Prüfglieder haben im Mittel einen Anteil lebender Bäume von $54 \%$. Zwischen den Prüfgliedern variiert dieser zwischen $51 \%$ („Bayerischer Wald“) und $57 \%$ („Schwäbische Alb und Bayerischer Jura“) (Abb. 3.12).

Die Unterschiede $(\alpha=0,05)$ zwischen den 25 Prüfgliedern lassen sich in multiplen Mittelwertvergleichen (Tukey-Test bzw. Dunnett-Test) nicht absichern.

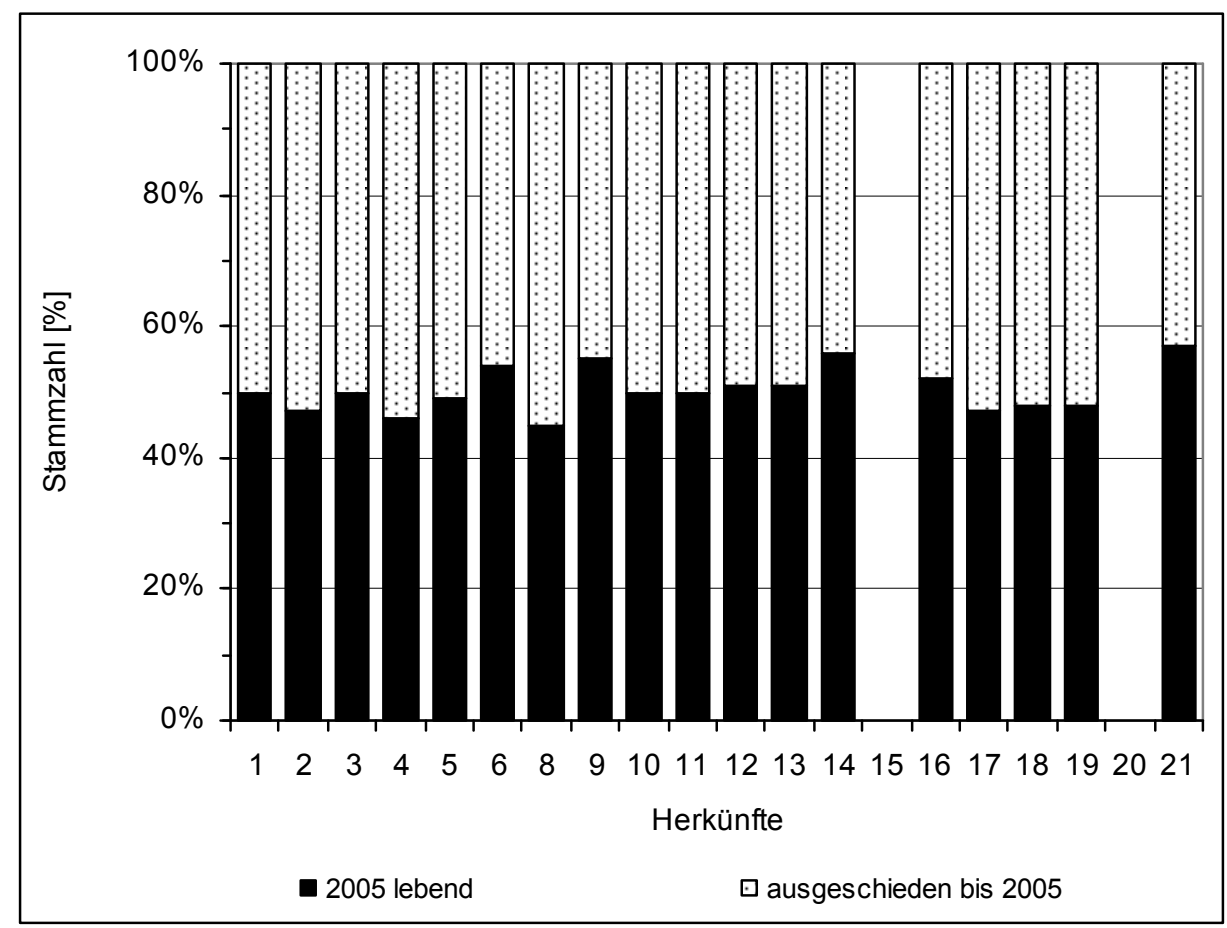

Abb. 3.11: Entwicklung der Pflanzenanzabl der 18 IUFRO-Herkünfte auf der Fläche Reinhardsbagen / Hessen 


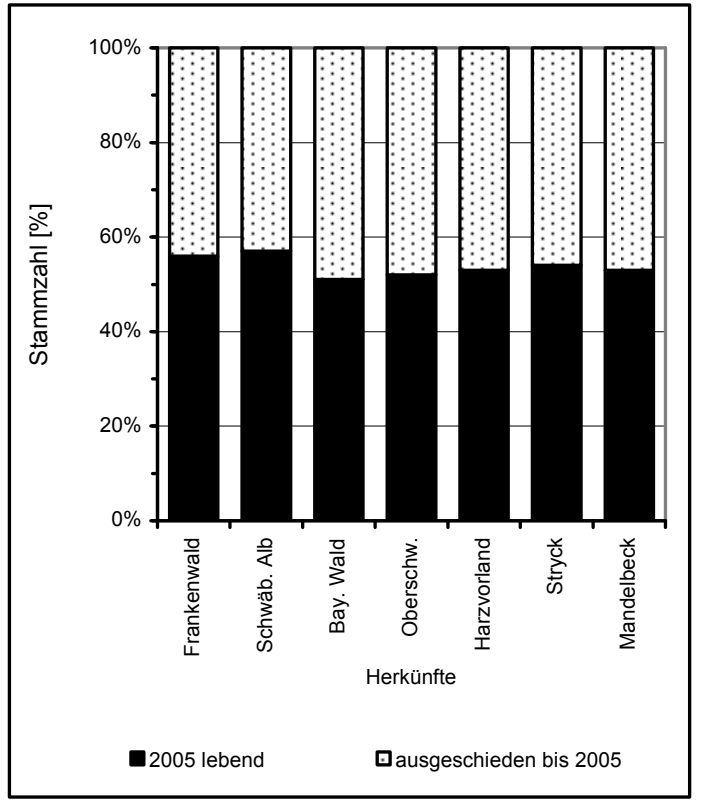

Abb. 3.12: Entwicklung der Pflanz̨enanzabl der sieben zusätz̧lich auf der Fläche Reinhardshagen / Hessen angebauten Prüfglieder

\section{Schadmerkmale}

Im Alter von 32 Jahren wurden vier Schadmerkmale aufgenommen. Die erfassten Schäden sind insgesamt sehr gering. So wurden Kronenschäden bei nur insgesamt 12 Bäumen notiert. Die Anzahl der Bäume mit einem Zwiesel beläuft sich ebenfalls auf 12. Die Anzahl ist auffallend gering, was auf die Entszwieselung der Bäume im jüngeren Alter zurückgeführt wird. Rückeschäden werden an 240 Bäumen beobachtet. $85 \%$ der Schäden sind gering, $14 \%$ mäßig und an einem Baum wird der Schaden als schwer eingestuft. Bei dem vierten Schadmerkmal, das aufgenommen wurde, handelt es sich um Stammrisse. Diese treten an fünf Bäumen auf. Eine Konzentration eines Schadens auf ein oder wenige Prüfglieder liegt nicht vor. Die Bäume mit Kronenschaden, Zwiesel und Stammrissen wurden nur in die Berechnung der Pflanzenzahlentwicklung einbezogen.

Im Jahr 1995 wurden im Alter von 23 Jahren Nadelschäden und zwar getrennt nach Verfärbung bzw. Verlust aufgenommen. Insgesamt wurden bei 1,3\% der Fichten Nadelschäden notiert. Dabei wurde der Nadelverlust (an 55 Bäumen) doppelt so häufig wie eine Nadelverfärbung (bei 24 Bäumen) angesprochen. Die Nadelschäden verteilten sich mehr oder weniger gleichmäßig über die Prüfglieder. Die meisten Nadelschäden wurden bei der Herkunft Nr. 3 (Wigry) notiert: bei 
11 Bäumen (8,6\%), gefolgt von dem Prüfglied „Südbayern, Oberschwaben, Bodenseegebiet": 7 Bäume (6,5 \%).

Als weiteres Merkmal wurde im Alter von 23 Jahren auch die Vitalität der Bäume und der Ausfallgrund angesprochen. Die Bonitur kommt zu folgendem Ergebnis:

3220 voll lebensfähige Fichten (53\%),

19 Fichten, deren Überleben fraglich ist $(0,3 \%)$,

26 tote Fichten $(0,4 \%)$,

1 nicht ausgepflanzte Pflanzstelle $(<0,02 \%)$,

968 Fichten, die zu einem früheren Zeitpunkt ausgefallen sind (16\%), und

1841 Fichten, die bei Durchforstungen entnommen wurden (30\%).

Zur Berechnung der mittleren Höhe, des mittleren BHD's, des Einzelbaumvolumens und des Vorrats wurden nur die voll lebensfähigen Bäume herangezogen.

\section{Stammform}

Für die 3110 lebensfähigen Fichten wurde im Alter von 32 Jahren die Stammform beurteilt. $99 \%$ der Stämme werden als gerade und 1\% mit einem leichten Mangel eingestuft. Sieben Bäume $(0,2 \%)$ weisen einen mittleren bzw. starken Mangel auf. Zwischen den Prüfgliedern treten keinen Unterschiede auf. Den geringsten Anteil gerader Stämme (97 \%) haben die Herkünfte Nr. 11 (Istebna, Bukowiec 149h) und Nr. 16 (Istebna, Zapowiedz 115f).

Bei der Beurteilung der Form im Alter von 23 Jahren wurden 3235 Bäume beurteilt. Seinerzeit wurde die Form in drei Stufen erfasst. Es waren $82 \%$ der Stämme gerade, $16 \%$ hatten einen leichten und 2\% einen starken Formmangel. Im Alter von 23 Jahren zeichneten sich schwache Unterschiede zwischen den Prüfgliedern ab (Abb. 3.13). Weniger als $75 \%$ gerade Stämme hatten die Prüfglieder Nr. 4 (Przerwanki) $70 \%$ und Nr. 18 (Tarnawa) $71 \%$. Die meisten geraden Stämme treten bei den polnischen Prüfgliedern Nr. 9 (Stronie Slaskie) $93 \%$, Nr. 11 (Istebna 149h) $93 \%$ und Nr. 21 (Kartuzy) $91 \%$ auf. Diese Unterschiede lassen sich jedoch neun Jahre später nicht bestätigen. Gründe hierfür können sein,

(1) dass bei der Durchforstung schlechte Stammformen entnommen wurden,

(2) dass die Beurteilung kritischer erfolgte,

(3) dass die Formmängel bei der früheren Aufnahme offensichtlicher waren oder

(4) dass die Mängel bereits ausgewachsen waren. 


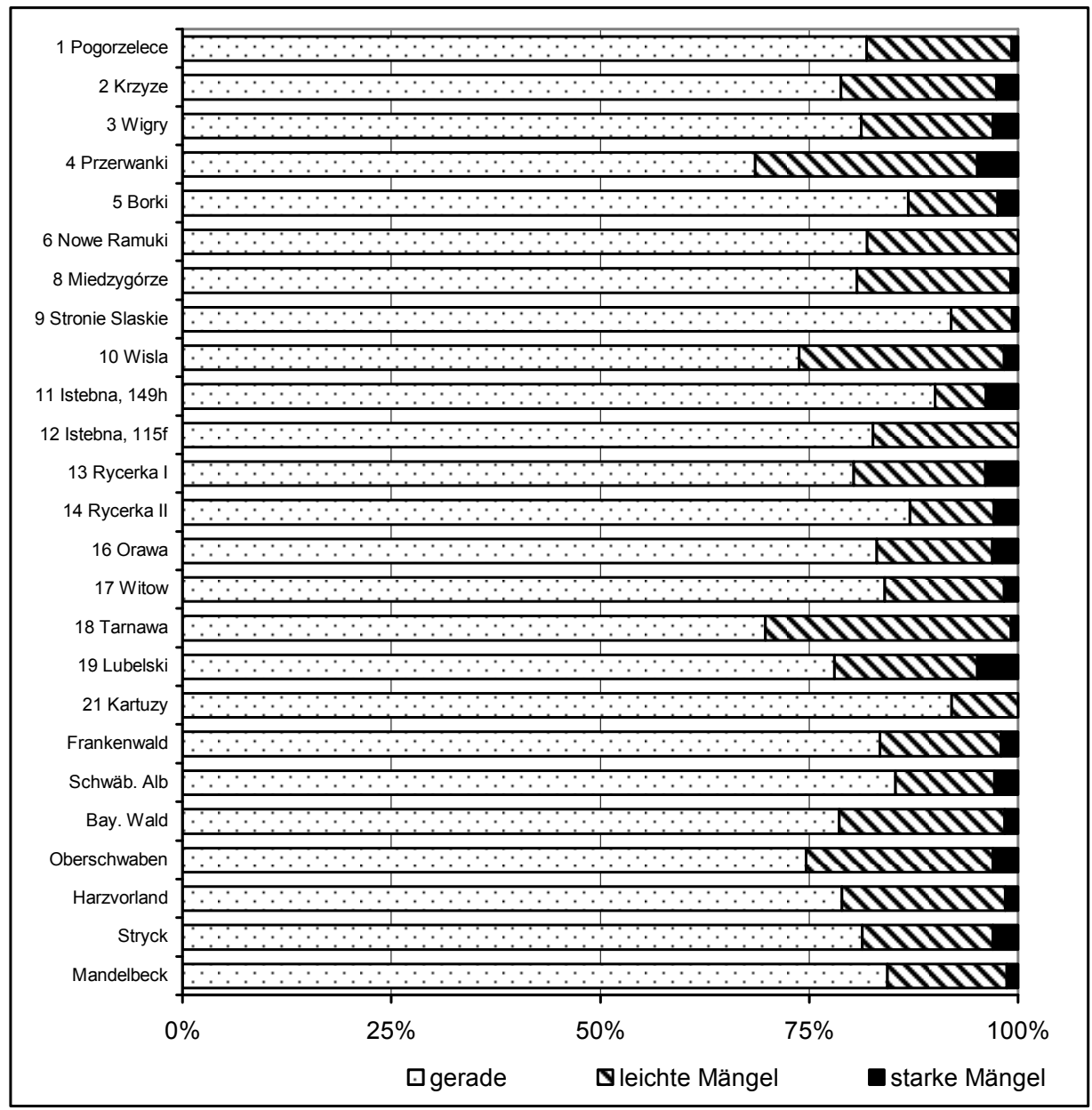

Abb.3.13 Ergebnis der Beurteilung der Stammform der 25 Prüfglieder auf der Fläche Reinhardsbagen / Hessen im Alter von 23 Jahren

\section{Ovalität}

Ein weiteres Maß zur Beurteilung der Qualität ist die Abweichung des Stammquerschnittes von der Kreisform. Die Ovalität lässt sich für das Alter von 32 Jahren bestimmen, da in diesem Alter der BHD durch zwei Messungen (kreuzweise) mit der Kluppe gemessen und notiert wurde. Die Ovalität beträgt im Mittel der IUFRO-Herkünfte auf der Versuchsfläche Reinhardshagen 3,4\% und variiert zwischen den Herkünften von 2,8\% (Nr. 16 Orawa und Nr. 17 Witów) mit den geringsten Abweichungen bis 4,2\% (Nr. 2 Krzyze) mit der größten Abweichung von der Kreisform. 
Unter Berücksichtigung der zusätzlichen sieben deutschen Prüfglieder verringert sich die mittlere Ovalität auf 3,4\%. An den Extremwerten ändert sich nichts. Absichern lassen sich die Unterschiede $(\alpha=0,05)$ in multiplen Mittelwertvergleichen (Tukey-Test bzw. Dunnett-Test) nicht. Die Ovalitäten der einzelnen Prüfglieder sind in Anhang 2.2 zusammengestellt.

Die Güte dieses Maßes lässt sich nicht beurteilen, da keine Aufzeichnungen vorliegen, aus denen hervorgeht, dass jeweils der dickste und dünnste Durchmesser in 1,3 m Höhe gemessen wurde.

\section{H/D-Verbältnis}

Für die 18 polnischen Herkünfte beträgt das mittlere Höhen-DurchmesserVerhältnis 81 im Alter 32 und variiert zwischen 76 (Nr. 17 Witów) und 85 (Nr. 2 Krzyze und Nr. 18 Tarnawa). Unter Einbeziehung aller 25 Prüfglieder beträgt der mittlere H/D-Wert 80,6. Einen geringeren H/D-Wert und damit eine stärkere Abholzigkeit als die polnische Herkunft Nr. 17 (Witów) hat die Absaat Mandelbeck $(\mathrm{H} / \mathrm{D}=75)$.

Im Alter von 23 Jahren hatten die Fichten der IUFRO-Herkünfte einen H/DWert von 85,1 und alle 25 Prüfglieder einen mittleren H/D-Wert von 84,5. Die schlanksten Herkünfte (Nr. 6 Nowe Ramuki, Nr. 3 Wigry, Nr. 4 Przerwanki und Nr. 16 Orawa) hatten einen H/D-Verhältnis von 90 und die abholzigste Herkunft eines von 75 (Nr. 17 Witów).

Die H/D-Verhältnisse der einzelnen Prüfglieder im Alter von 23 und 32 Jahren sind in Anhang 2.3 zusammengestellt. Die Unterschiede $(\alpha=0,05)$ zwischen den 25 Prüfgliedern im Alter von 23 bzw. 32 Jahren lassen sich in multiplen Mittelwertvergleichen (Tukey-Test bzw. Dunnett-Test) nicht absichern.

\section{Höhen- und BHD-Wachstum}

Das Wachstum der Fichte ist im Vergleich zur Ertragstafel (WIEDEMANN 1936/1942, mäßige Durchforstung) auf der Fläche Reinhardshagen sehr gut. Für alle Fichten, die keinen Kronenbruch, keinen Zwiesel und keine Stammrisse hatten, wird im Alter von 32 Jahren ein mittlerer BHD von 19,8 cm $(\mathrm{n}=3087)$ und eine mittlere Höhe von 20,3 m ( $\mathrm{n}=607)$ errechnet.

Bei der neun Jahre zuvor erfolgten Messung lag der mittlere BHD über alle Prüfglieder bei 13,9 cm ( $\mathrm{n}=3220)$ und die Höhe bei 11,6 $\mathrm{m}(\mathrm{n}=756)$.

In Abbildung 3.14 ist die Entwicklung des Höhenwachstums und in Abbildung 3.15 die des BHD-Wachstums der 18 polnischen IUFRO-Herkünfte dargestellt. Im Alter von 32 Jahren sind die zusätzlichen sieben Herkünfte bezüglich der erreichten Höhe relativ ähnlich. Lediglich die Herkunft Nr. 17 (Witów, Tatra) zeigt ein signifikant geringeres (Tukey-Test, $\alpha=0,05)$ bzw. abweichendes (DunnettTest, $\alpha=0,05)$ Wachstum im multiplen Vergleich der 25 Prüfglieder (Anhang 2.4). 
Im Alter von 23 Jahren führt der Test zu vier, davon drei stark überlappenden, Tukey-Gruppierungen (Anhang 2.5). Im Dunnett-Test unterscheiden sich die mattwüchsigen Prüfglieder (Nr. 9 Stronie Slaskie, Nr. 17 Witów und „Bayerischer Wald") vom Standard.

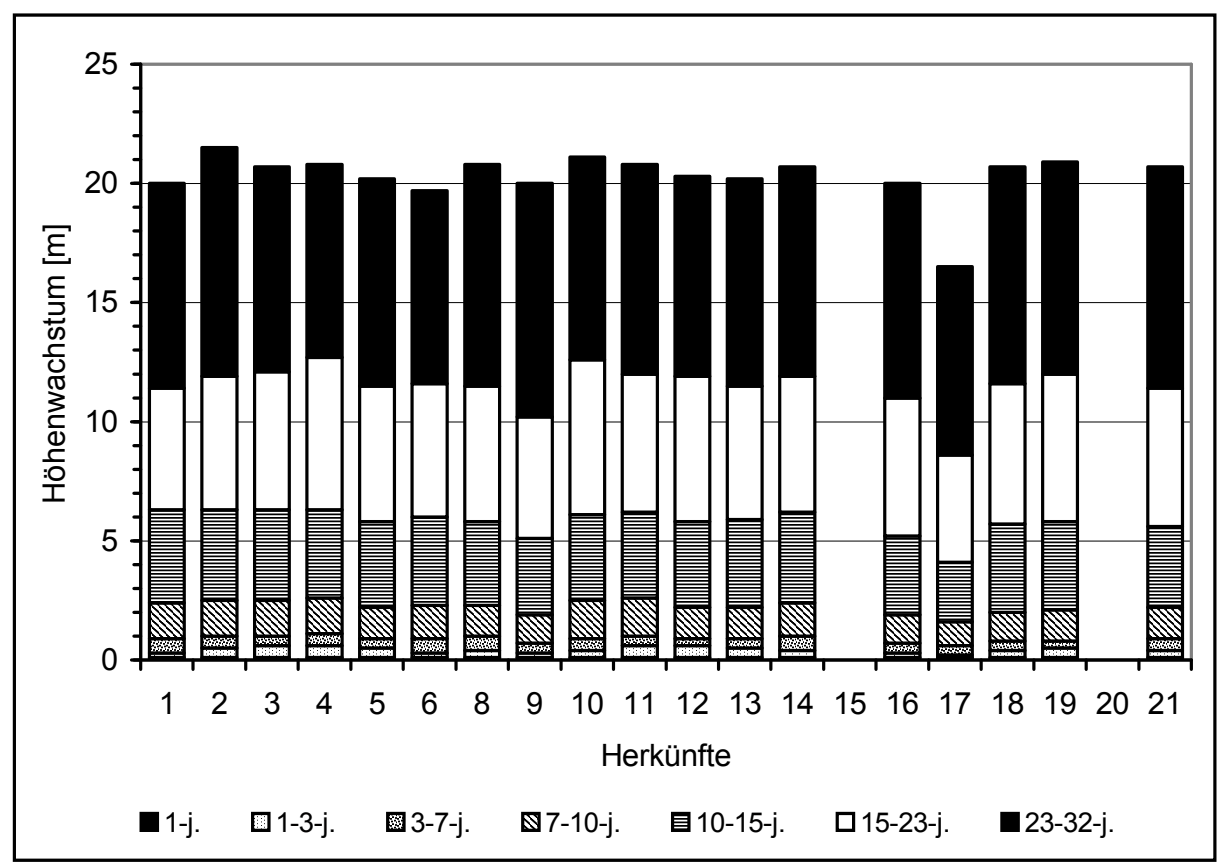

Abb. 3.14: $\quad$ Entwicklung des Höhenwachstums der 18 polnischen Herkë̈fte bis zum Alter von 32 Jahren auf der Fläche Reinhardshagen / Hessen

Im mittleren BHD variieren die 18 Herkünfte stärker. Auch hier ist die Herkunft Nr. 17 (Witów) die mattwüchsigste. Der Wuchsunterschied im Alter von 32 Jahren ist signifikant (Tukey-Test, $\alpha=0,05)$ zu den vier wüchsigen Prüfgliedern (Anhang 2.4). Die Herkunft Nr. 17 unterscheidet sich auch vom Standard im Dunnett-Test. Auch im Alter von 23 Jahren gibt es gesicherte Unterschiede (Tukey-Test, $\alpha=0,05$; Anhang 2.5), im Vergleich zum Standard sind dies die Prüfglieder Nr. 17 (Witów) und Nr. 10 (Wisła). 


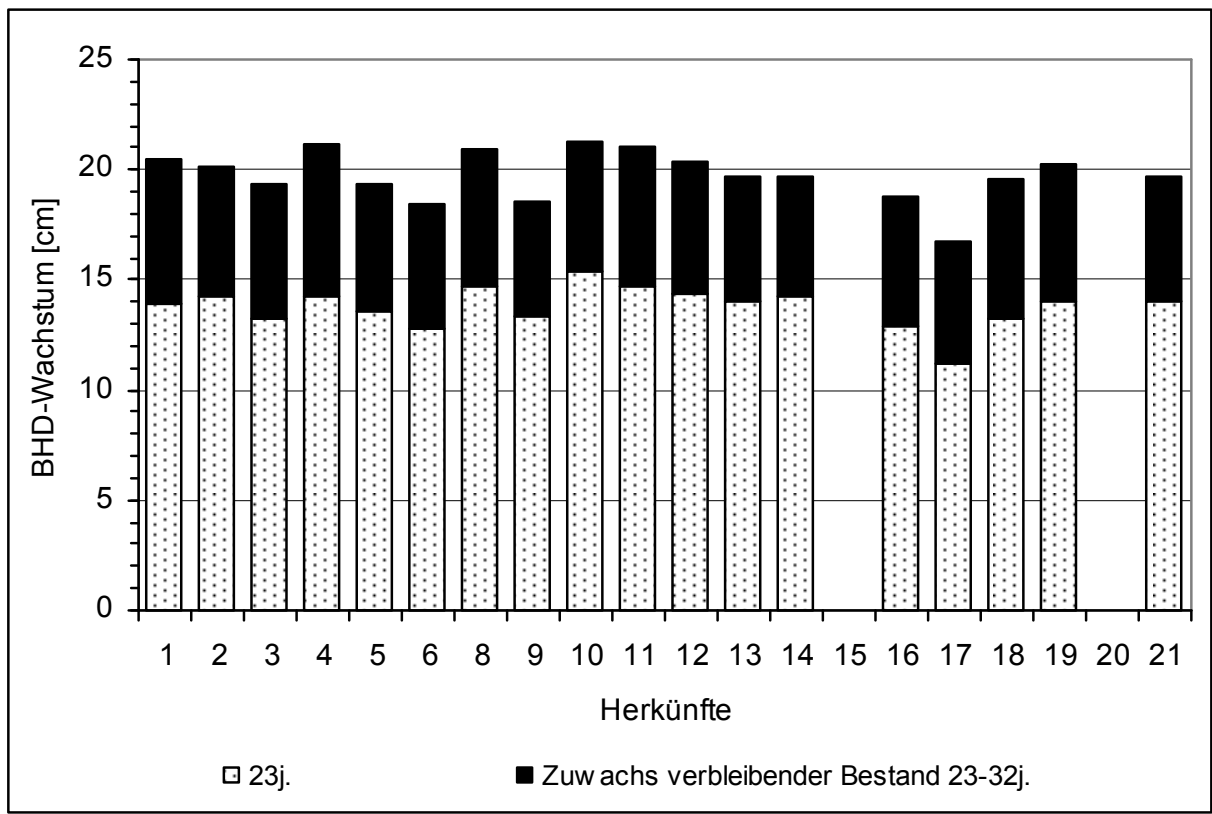

Abb. 3.15: Entwicklung des BHD-Wachstums der 18 polnischen Herkünfte auf der Fläche Reinbardshagen / Hessen

Die Streuung der Einzelwerte um den Mittelwert nimmt beim Merkmal Höhenwachstum im Alter von 23 Jahren $(\mathrm{s} \%=13,3)$ zum Alter von 32 Jahren $\left(\mathrm{s}^{\%} \%=8,1\right)$ ab. Auch beim H/D-Verhältnis sinkt die Streuung von $\mathrm{s} \%=18,5$ auf $\mathrm{s} \%=11,5$. Anders sieht es beim BHD aus, hier steigt die Streuung von s\% = 23,8 (BHD Alter 23) auf $\mathrm{s} \%=26,6$ (Alter 32) an.

Der Vergleich des Wachstums im Beobachtungszeitraum zeigt, dass die Wachstumsmerkmale überwiegend korreliert sind (Tab. 3.11). Der engste Zusammenhang besteht zwischen den mittleren Durchmessern im Alter 23 und 32. 
Tab. 3.11: $\quad$ Produkt-Momenten-Korrelationsmatrix der Wachstumsmerkmale Höhe und BHD

\begin{tabular}{|c|c|c|c|c|c|c|c|}
\hline Merkmal & $\mathrm{H} 7$ & $\mathrm{H} 10$ & H15 & $\mathrm{H} 23$ & H32 & D23 & D32 \\
\hline H7 & \multirow[t]{7}{*}{-} & $0,945^{* * *}$ & $0,877 * * *$ & $0,800^{* * *}$ & $0,695^{* *}$ & $0,727 * * *$ & $0,741 * * *$ \\
\hline $\mathrm{H} 10$ & & \multirow[t]{6}{*}{-} & $0,932 * * *$ & $0,857 * * *$ & $0,712^{* * *}$ & $0,725^{* * *}$ & $0,744 * * *$ \\
\hline H15 & & & \multirow[t]{5}{*}{-} & $0,904 * * *$ & $0,795^{* * *}$ & $0,693 * *$ & $0,733^{* * *}$ \\
\hline $\mathrm{H} 23$ & & & & \multirow[t]{4}{*}{-} & $0,871 * * *$ & $0,781^{* * *}$ & $0,826^{* * *}$ \\
\hline H32 & & & & & \multirow[t]{3}{*}{-} & $0,813^{* * *}$ & $0,796^{* * *}$ \\
\hline D23 & & & & & & \multirow[t]{2}{*}{-} & $0,943 * * *$ \\
\hline D32 & & & & & & & - \\
\hline
\end{tabular}

Einzelbaumvolumen und Vorrat pro Hektar

Aus den Merkmalen Baumhöhe und BHD wurde das mittlere Einzelbaumvolumen je Herkunft errechnet. Es beträgt im Alter von 32 Jahren 0,2737 $\mathrm{m}^{3}$ im Mittel über die 25 Prüfglieder der Versuchsfläche Reinhardshagen. Die höchste mittlere Stückmasse hat die Absaat aus der Plantage Mandelbeck $\left(0,3462 \mathrm{~m}^{3}\right)$ und die geringste die Herkunft Nr.17 (Witów: 0,1809 $\mathrm{m}^{3}$ ). Der multiple Mittelwertvergleich $(\alpha=0,05)$ führt zu zwei sich stark überlappenden Tukey-Gruppen (Anhang 2.6). Gegenüber dem Standard lässt sich kein Unterschied sichern (Dunnett-Test, $\alpha=0,05)$. Aus den neun Jahre zuvor gemessenen Werten errechnet sich eine mittlere Stückmasse von $0,0935 \mathrm{~m}^{3}$. Zwischen den Herkünften variiert die Stückmasse von $0,132 \mathrm{~m}^{3}$ (Nr. 10 Wisła) und 0,0475 (Nr. 17 Witów). Die multiplen Tests (Tukey-Test, $\alpha=0,05$ ) ergeben drei sich überlappende Gruppen (Anhang 2.6). Vom Standard unterscheidet sich die stückmassereichste Herkunft Nr. 10 (Wisła) und die stückmasseärmste Herkunft Nr. 17 (Witów).

In die Vorratsermittlung je Hektar gehen die drei Merkmale Anzahl lebender Bäume, BHD- und Höhenwachstum ein. Im Alter von 32 Jahren beträgt im Mittel über die 18 polnischen Herkünfte der Vorrat $333 \mathrm{~m}^{3} / \mathrm{ha}$. Zwischen den Herkünften (Abb. 3.16) variiert der errechnete Vorrat zwischen $191 \mathrm{~m}^{3} /$ ha (Herkunft Nr. 17 Witów) und $408 \mathrm{~m}^{3} /$ ha (Herkunft Nr. 10 Wisła). Dies entspricht $60 \%$ bzw. $128 \%$ vom Mittel der 18 polnischen IUFRO-Herkünfte. In der Wuchsleistung steht die Herkunft Nr. 11 (Istebna 149h) der Herkunft Nr. 10 (Wisła) nicht nach. 


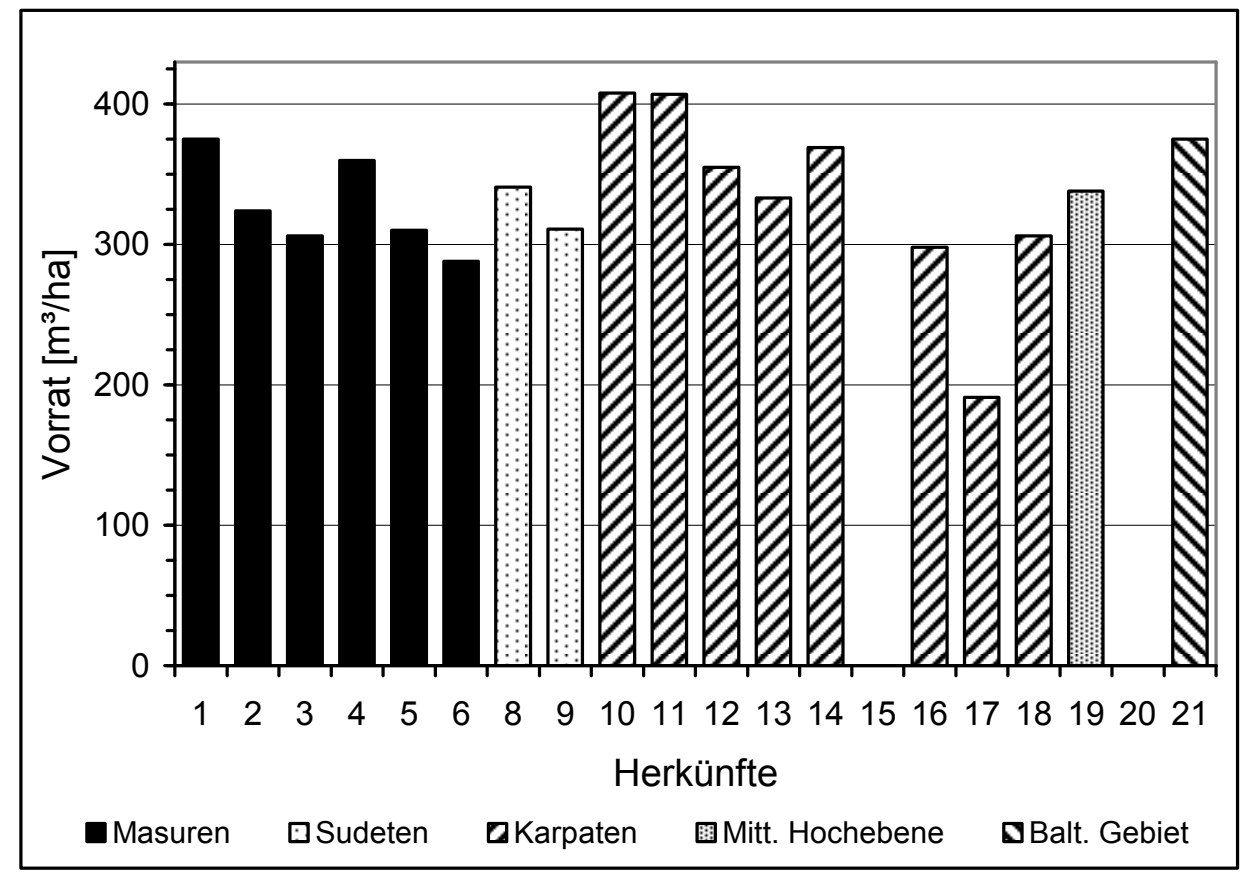

Abb.3.16 Hochgerechneter Vorrat je Hektar der 18 polnischen Herkünfte auf der Versuchsfläche Reinhardshagen / Hessen im Alter von 32 Jahren

Für diese Herkunft (Nr. 11 Istebna 149h) werden $407 \mathrm{~m}^{3} /$ ha errechnet, was ebenfalls $128 \%$ des Versuchsflächenmittels entspricht. Die Abbildung 3.16 zeigt auch, dass die Herkünfte innerhalb einer geografischen Region im Volumen stark divergieren. $\mathrm{Zu}$ den vorratsreichen Herkünften $(118 \%)$ zählt auch die nicht autochthone Herkunft aus dem Baltischen Gebiet (Nr. 21).

Im Alter von 23 Jahren betrug der Vorrat im Mittel über die 18 polnischen Herkünfte $121 \mathrm{~m}^{3} /$ ha. In Abbildung 3.17 ist der Vorrat für die einzelnen polnischen Herkünfte dargestellt. Die Unterschiede zwischen der wüchsigen Herkunft Nr. 10 (Wisła) mit $141 \%$ und der mattwüchsigen Herkunft Nr. 17 (Witów) mit $47 \%$ fallen größer aus als neun Jahre später.

Die rechnerischen Vorräte der beiden Erhebungen im Alter von 23 und 32 Jahren sind sehr hoch korreliert $\left(\mathrm{r}_{\mathrm{P}}=0,958^{* * *}\right)$. 


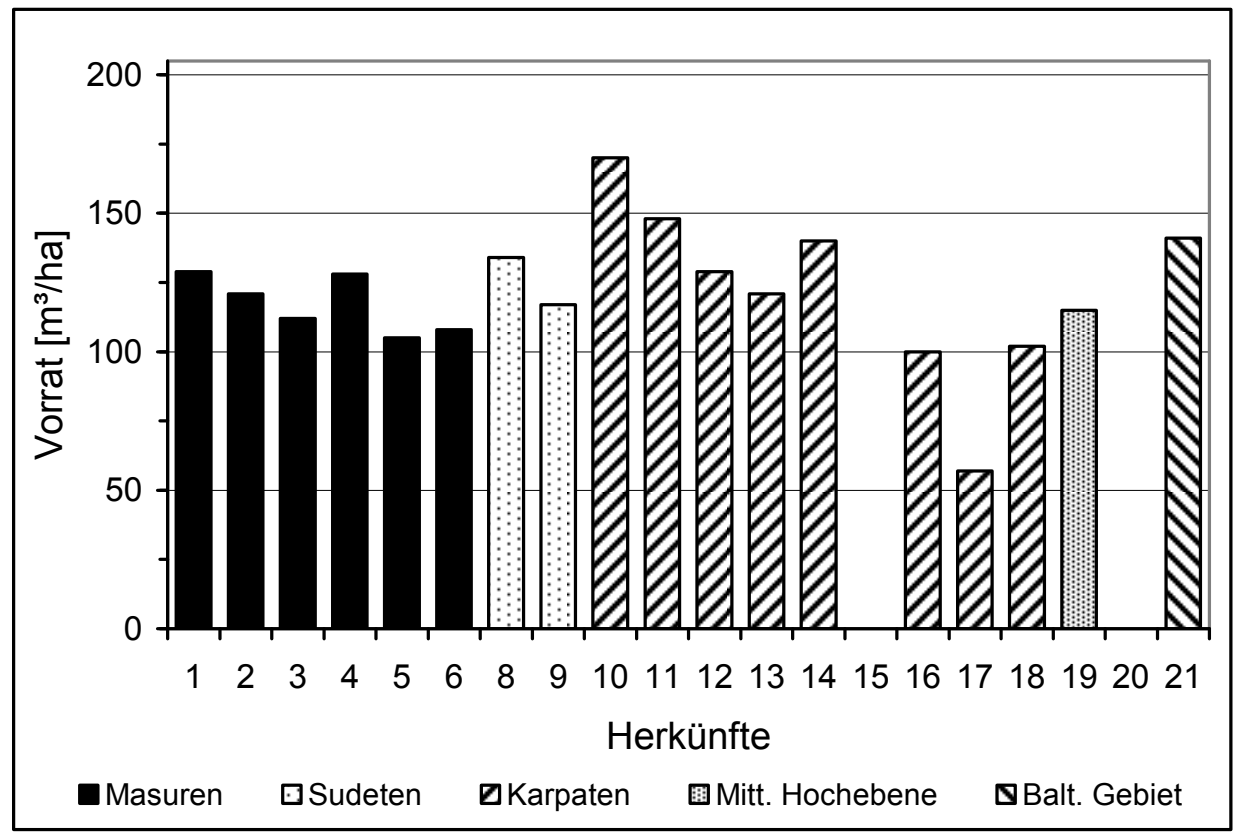

Abb. 3.17: Hochgerechneter Vorrat je Hektar der 18 polnischen Herkünfte auf der Versuchsfläche Reinhardshagen / Hessen im Alter von 23 Jahren

In Abbildung 3.18 sind die für die zusätzlichen sieben deutschen Prüfglieder errechneten Vorräte dargestellt. Zum Vergleich wurden in die Abbildung die beste und die mattwüchsigste Herkunft sowie das Mittel über die 18 polnischen IUFROHerkünfte aufgenommen. Im Alter von 32 Jahren sind mit Ausnahme der Herkunft „Bayerischer Wald“ alle zusätzlichen deutschen Prüfglieder wüchsiger als das Mittel der polnischen IUFRO-Herkünfte. Die Absaat aus der Plantage Mandelbeck hat einen höheren Vorrat als die bestwüchsige polnische Herkunft.

Im Alter von 23 Jahren wurde für die bestwüchsige polnische Herkunft noch ein höherer Vorrat als für die Absaat der Plantage Mandelbeck errechnet. 


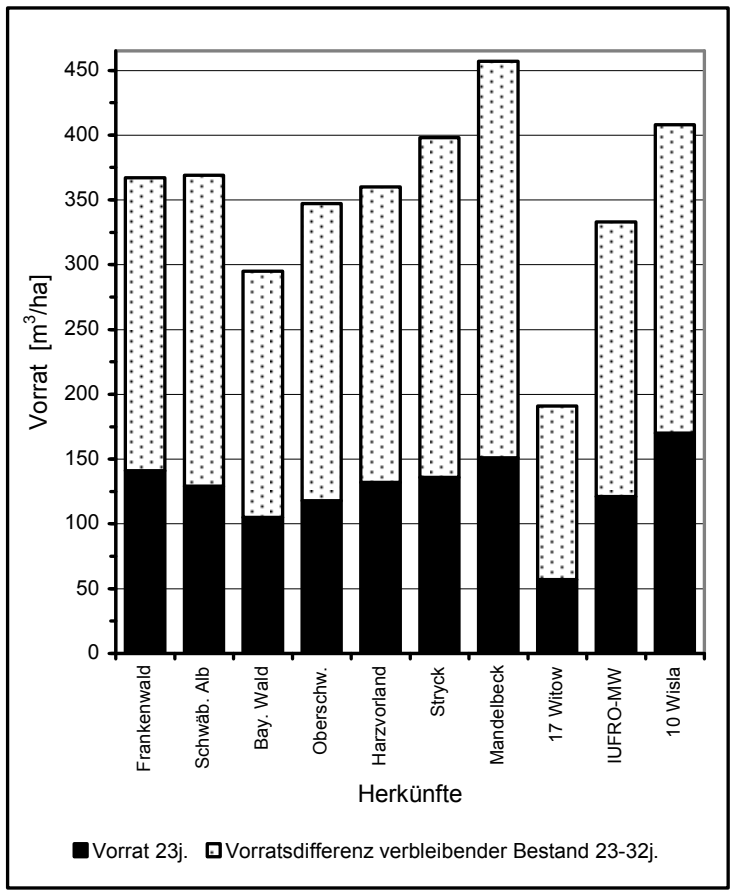

Abb. 3.18: Hochgerechneter Vorrat/ha der sieben zusätzlichen Prüfglieder auf der Versuchsfläche Reinhardshagen / Hessen im Alter von 23 und 32 Jahren. Zum Vergleich sind die beste und die mattwüchsigste Herkunft sowie das Mittel über die 18 polnischen IUFRO-Herkünfte aufgenommen.

Die Vorräte der 25 Prüfglieder auf der Versuchsfläche wurden im multiplen Mittelwertvergleich mit der Tukey-Prozedur $(\alpha=0,05)$ getestet. Der Mittelwertvergleich zeigt (Tab. 3.12), dass im Alter 32 die polnische Herkunft Witów (Nr. 17) sich von den Prüfgliedern Pogorcelece (Nr. 1), Wisła (Nr. 10), Istebna 149h (Nr. 11), Rycerka I (Nr. 14), Kartyzy (Nr. 21), „Schwäb. Alb und Bay. Jura“ sowie den Absaaten aus den Plantagen Stryck und Mandelbeck im Vorrat im Alter 32 signifikant $(\alpha=0,05)$ unterscheidet.

Auch im Alter von 23 Jahren hatte die polnische Herkunft Witów (Nr. 17) einen signifikant geringeren Vorrat als neun Prüfglieder (Tab. 3.12). Unter den neun Prüfgliedern sind sechs, die auch neun Jahre später signifikant mehr Vorrat haben.

Parallel zur Tukey-Prozedur wurden auch zweiseitige Dunnett-Tests gegen eine Kontrollgruppe bestehend aus den acht polnischen Herkünften, die auf allen Versuchsflächen ausgepflanzt wurden, durchgeführt. Beim Vorrat im Alter 32 unterschieden sich die Prüfglieder Mandelbeck und Witów (Nr. 17) signifikant $(\alpha=0,05)$ von der Kontrollgruppe. Im Alter von 23 Jahren war der Unterschied nur zur polnischen Herkunft Witów (Nr. 17) signifikant. 
Tab.3.12: $\quad$ Mittelwerte und Tukey-Gruppierung (T-G) der 25 Prüfglieder der Fläche Reinhardshagen / Hessen für den Vorrat/ ha im Alter 23 und 32

\begin{tabular}{|c|c|c|c|c|c|c|}
\hline \multirow{2}{*}{$\begin{array}{c}\text { IUFRO- } \\
\text { Nr. }\end{array}$} & \multirow{2}{*}{ Prüfglied } & \multicolumn{2}{|c|}{ Vorrat $\left[\mathrm{m}^{3} / \mathrm{ha}\right]$} & \multicolumn{3}{|c|}{ T-G } \\
\hline & & $23-j$. & $32-j$. & 23 & & $32-j$. \\
\hline & Mandelbeck & 151 & 457 & A & & A \\
\hline 10 & Wisła & 170 & 408 & A & & A \\
\hline \multirow[t]{2}{*}{11} & Istebna $149 \mathrm{~h}$ & 148 & 407 & A & & A \\
\hline & Stryck & 136 & 398 & A & & A \\
\hline 1 & Pogorzelece & 129 & 375 & A & B & A \\
\hline 21 & Kartuzy & 141 & 375 & A & & A \\
\hline \multirow[t]{4}{*}{14} & Rycerka I & 141 & 369 & A & & A \\
\hline & Schwäbisch Alb und Bayer. Jura & 130 & 369 & A & B & A \\
\hline & Frankenwald & 141 & 367 & A & & A B \\
\hline & Harzvorland & 132 & 360 & A & & A B \\
\hline 4 & Przerwanki & 128 & 360 & A & B & A B \\
\hline \multirow[t]{2}{*}{12} & Istebna $115 \mathrm{f}$ & 129 & 355 & A & $\mathrm{B}$ & A B \\
\hline & Südbayern, Oberschwaben, Bodenseegeb. & 118 & 347 & A & $\mathrm{B}$ & A B \\
\hline 8 & Miedzygórze & 134 & 341 & A & & A B \\
\hline 19 & Lubelski & 115 & 338 & A & B & A B \\
\hline 13 & Zwardon & 121 & 333 & A & B & A B \\
\hline 2 & Krzyze & 121 & 324 & A & B & A B \\
\hline 9 & Stronie Slaskie & 117 & 311 & A & B & A B \\
\hline 5 & Borki & 105 & 310 & A & B & A \\
\hline 3 & Wigry & 112 & 306 & A & B & A B \\
\hline 18 & Tarnawa & 102 & 306 & A & B & A B \\
\hline \multirow[t]{2}{*}{16} & Orawa & 100 & 298 & A & B & A B \\
\hline & Bayerischer Wald & 105 & 295 & A & B & A B \\
\hline 6 & Nowe Ramuki & 108 & 288 & A & B & A $B$ \\
\hline 17 & Witów & 57 & 191 & & $\mathrm{~B}$ & $\mathrm{~B}$ \\
\hline
\end{tabular}

Die zuvor erfolgten Tests basieren auf der Auswertung der Versuchsfläche als Blockversuch. Erfolgt die Analyse unter Berücksichtigung des Alpha-Designs (Gitter), d. h. als kombinierte Inter-Intra-Block-Analyse mit Nutzung der InterBlock-Information, verringert sich der mittlere Standardfehler im Alter 32 von $3,7943723(100 \%)$ auf 3,7930596 (99,97\%) im Tukey-Test und von 3,3399811 $(100 \%)$ auf 3,3378029 (99,94\%) im Dunnett-Test. Im Alter 23 verringerte sich der mittlere Standardfehler auf 99,98\% im Tukey-Test und auf 99,96\% im Dunnett-Test. Die etwas kleineren Standardfehler zeigen, dass die Nutzung der Inter- 
Block-Information in allen Fällen nur einen verschwindend geringen Gewinn erbracht hat. Die Ergebnisse der Auswertung als Gitteranlage werden daher hier nicht dargestellt.

\subsubsection{Wanfried}

\section{Entwicklung der Pflanzenanzabl}

Auf der Versuchsfläche Wanfried leben im Alter von 32 Jahren noch $46 \%$ der ursprünglich gepflanzten Fichten. Werden nur die IUFRO-Herkünfte betrachtet, ist der Anteil lebender Bäume (45\%) etwas geringer. Zwischen den drei Wiederholungen betragen die Unterschiede im Anteil lebender Fichten der IUFRO-Herkünfte maximal $6 \%$-Punkte.

Auf der Fläche Wanfried findet man zwischen den beiden geografischen Regionen (Masuren und Karpaten), in den jeweils mehrere Herkünfte zusammengefasst sind, im Alter von 32 Jahren einen schwachen Unterschied (Tab. 3.13).

Tab. 3.13: $\quad$ Anteil lebender Bäume der zu fünf geografischen Regionen zusammengefassten polnischen Herkünfte (IUFRO), der IUFRO-PG, der zusätzlichen PG und aller PG auf der Fläche Wanfried

\begin{tabular}{lccccc}
\hline Geografische Region & IUFRO-Nr. & $\begin{array}{c}\text { Anzahl } \\
\text { PG }\end{array}$ & $\begin{array}{c}1976 \\
(4-j .)\end{array}$ & $\begin{array}{c}1995 \\
(23-j .)\end{array}$ & $\begin{array}{c}2004 \\
(32-j .\end{array}$ \\
\hline Masuren-Podlasie & $1-6$ & 6 & $78 \%$ & $50 \%$ & $42 \%$ \\
Sudeten & $8-9$ & 2 & $78 \%$ & $50 \%$ & $48 \%$ \\
Karpaten (Beskiden) & $10-14,16-18$ & 8 & $77 \%$ & $51 \%$ & $47 \%$ \\
Mittelpolnische Hochebene & 19 & 1 & $92 \%$ & $53 \%$ & $40 \%$ \\
Baltisches Gebiet & 21 & 1 & $72 \%$ & $51 \%$ & $50 \%$ \\
\hline IUFRO-Herkünfte & & 18 & $78 \%$ & $51 \%$ & $45 \%$ \\
\hline zusätzliche PG & 7 & $77 \%$ & $51 \%$ & $49 \%$ \\
\hline alle PG & & 25 & $78 \%$ & $51 \%$ & $46 \%$ \\
\hline
\end{tabular}

Im Vergleich zur Erhebung im Alter von 23 Jahren ist der Anteil lebender Bäume auf der Fläche Wanfried stärker zurückgegangen als auf der Fläche Reinhardshagen. Die Stammzahlverminderung ist bei den polnischen Herkünften der Regionen Masuren-Podlasie und Mittelpolnische Hochebene am höchsten. So beträgt die Veränderung für die Region Masuren-Podlasie $8 \%$-Punkte und für die Mittelpolnische Hochebene sogar $13 \%$-Punkte.

Auf der Fläche Wanfried gibt es im Anteil lebender Bäume Unterschiede zwischen den einzelnen IUFRO-Herkünften (Abb. 3.19). Im Alter von 32 Jahren variiert der Anteil der noch vorhandenen Fichten zwischen $51 \%$ (Nr. 11 Istebna 149h und 16 Orawa) und $33 \%$ (Nr. 4 Przerwanki). Der Anteil lebender Bäume der 
sieben zusätzlichen Prüfglieder beträgt im Mittel $49 \%$ und variiert zwischen den Prüfgliedern kaum (Abb. 3.20).

Die Unterschiede $(\alpha=0,05)$ zwischen den 25 Prüfgliedern lassen sich in multiplen Mittelwertvergleichen (Tukey-Test bzw. Dunnett-Test) nicht absichern.

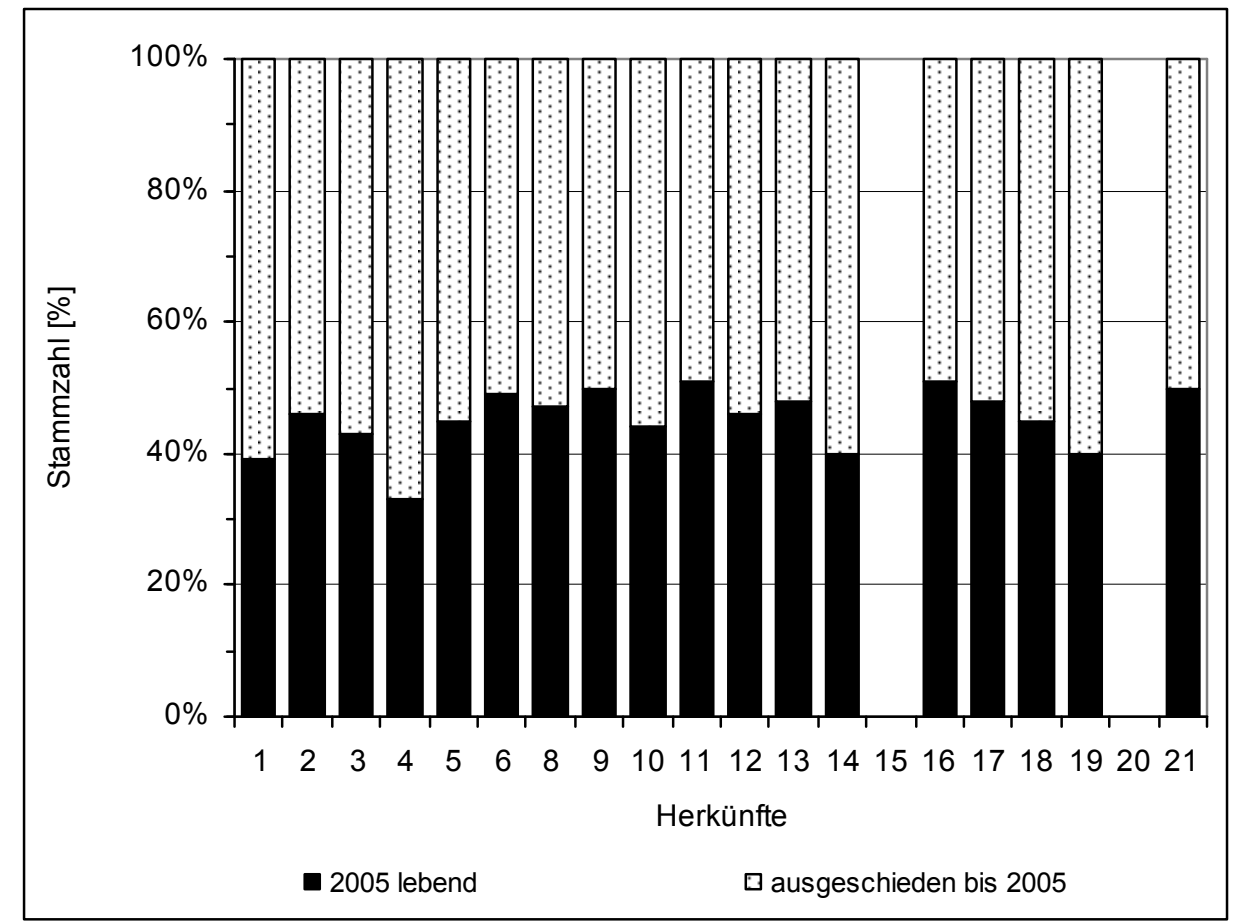

Abb. 3.19: Entwicklung der Pflanzenanzabl der IUFRO-Herkünfte auf der Fläche Wanfried / Hessen 


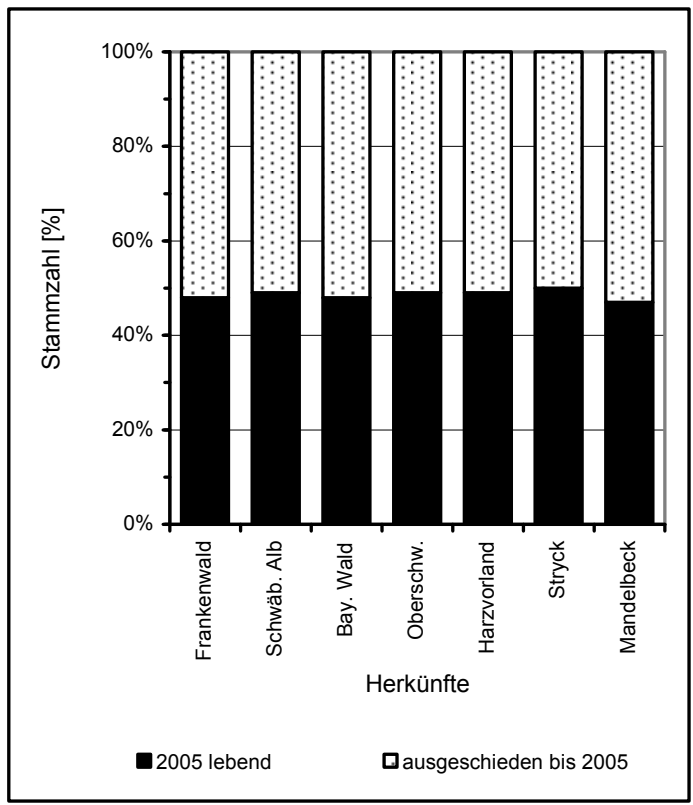

Abb. 3.20: Entwicklung der Pflanzenanzabl der sieben zusätzlich auf der Fläche Wanfried angebauten Prüfglieder

\section{Schadmerkmale}

Wie auf der Fläche Reinhardshagen wurden auf der Fläche Wanfried im Alter von 32 Jahren vier Schadmerkmale aufgenommen. Die erfassten Schäden sind insgesamt etwas häufiger, aber dennoch gering. So ist ein Kronenbruch bei insgesamt 27 Bäumen festgestellt. Die Anzahl der Bäume mit einem Zwiesel beläuft sich auf 29. Auch auf dieser Fläche ist die Anzahl gering. Auch wenn die Versuchsakte keinen expliziten Hinweis enthält, ist davon auszugehen, dass die Fichten entzwieselt wurden. Rückeschäden werden an 76 Bäumen beobachtet. Zwei Drittel der Rückeschäden sind gering und an 22 Fichten mäßig sowie an vier Fichten wird der Schaden als schwer eingestuft. Bei dem vierten Schadmerkmal, das aufgenommen wurde, handelt es sich um Stammrisse. Diese traten an 96 Bäumen auf. Das Ausmaß der Risse wurde an 79 Bäumen als gering und bei 17 Bäumen als mäßig eingestuft. Bei der Herkunft Nr. 4 (Przerwanki) wurden an neun Fichten Stammrisse beobachtet und bei den Herkünften 13 (Zwardon) und 16 (Orawa) an jeweils sieben Fichten. Unter den deutschen Prüfgliedern sind zwei („Frankenwald“ und „Schwäb. Alb und Bay. Jura"), von denen jeweils fünf Fichten Stammrisse haben (Abb. 3. 21). Eine Konzentration auf bestimmte Herkünfte kann nicht festgestellt werden, da die Risse bei allen Prüfgliedern auftreten. 
Auch bei den weiteren Schäden liegt keine Konzentration auf ein oder wenige Prüfglieder vor. Die Bäume mit Kronenschaden, Zwiesel und mit Stammrissen wurden nur in die Berechnung des Anteils lebender Bäume einbezogen.

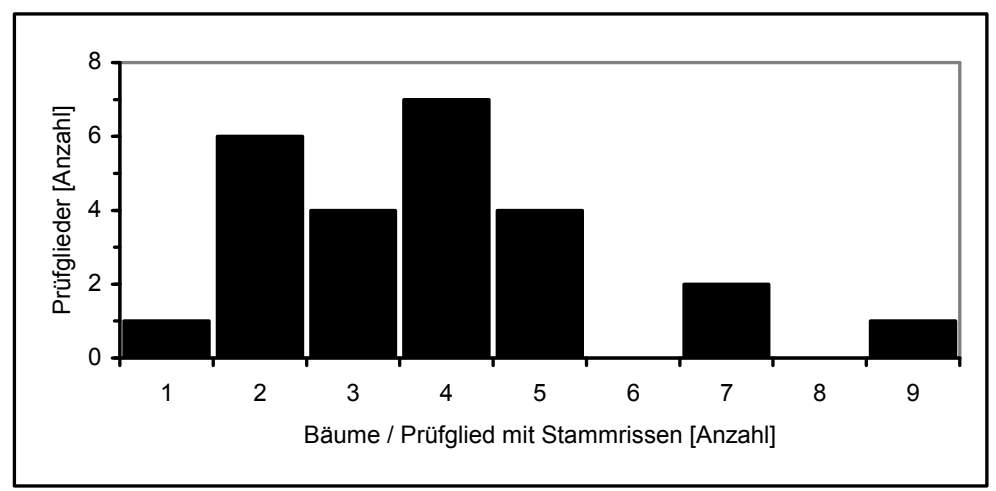

Abb. 3.21

Histogramm für die absoluten Häufigkeiten der Stammrisse

Im Alter von 23 Jahren wurden Nadelschäden, und zwar Verfärbung bzw. Verlust, aufgenommen. Insgesamt wurde bei nur 1,2\% der Fichten Nadelschäden beobachtet. Dabei wurde der Nadelverlust (an 71 Bäumen) nahezu doppelt so häufig wie eine Nadelverfärbung (bei 34 Bäumen) angesprochen. Die Nadelschäden verteilten sich mehr oder weniger gleichmäßig über die Prüfglieder. Die meisten Nadelschäden wurden bei der Herkunft Nr. 17 (Witów) notiert: mit neun betroffenen Bäumen (7,4\%), gefolgt von dem Prüfglied „Bayerischer Wald“: mit acht betroffenen Bäumen (6,3\%).

Als weiteres Merkmal wurde im Alter von 23 Jahren die Vitalität der Bäume und der Ausfallgrund angesprochen. Die Bonitur kommt zu folgendem Ergebnis:

3081 voll lebensfähige Fichten (50\%),

3 Fichten, deren Überleben fraglich ist $(0,05 \%)$,

10 tote Fichten $(0,2 \%)$,

1 nicht ausgepflanzte Pflanzstelle $(<0,02 \%)$,

321 Fichten, die zu einem früheren Zeitpunkt ausgefallen sind (5\%), und

2659 Fichten, die bei Durchforstung entnommen wurden (44\%).

Bei der Anlage der Rückegassen wurden die Parzellen nicht einheitlich behandelt. So gibt es bei den fünf Herkünften Nr. 4 (Przerwanki), Nr. 11 (Istebna 149h), Nr. 12 (Istebna 115f), Nr. 18 (Tarnawa) und „Harzvorland“, jeweils eine Randparzelle, in der keine Entnahme einer Reihe zur Anlage einer Rückegasse erfolgte.

Für die Berechnungen von mittlerer Höhe, mittlerem BHD, Einzelbaumvolumen und Vorrat wurden nur die voll lebensfähigen Bäume herangezogen. 


\section{Stammform}

Die Stammform wurde im Alter von 32 Jahren an 2804 vitalen Fichten beurteilt. $90 \%$ der Stämme werden als gerade und 9\% mit einem leichten Mangel eingestuft. 22 Bäume (0,8 \%) weisen einen mittleren bzw. starken Mangel auf. Zwischen den Prüfgliedern treten geringe Unterschiede auf (Abb. 3.22). Herkünfte mit nahezu ausschließlich mangelfreien Stämmen $(>95 \%)$ sind die beiden Herkünfte aus den Sudeten, Nr. 8 (Miedzygórze) und Nr. 9 (Stronie Slaskie), die beiden Herkünfte Nr. 11 und Nr. 12 (Istebna 149h und 115f) sowie die zusätzlichen Prüfglieder „Schwäb. Alb und Bay. Jura“ und Mandelbeck. Den geringsten Anteil gerader Stämme $(71 \%)$ hat die Herkunft Nr. 4 (Przerwanki).

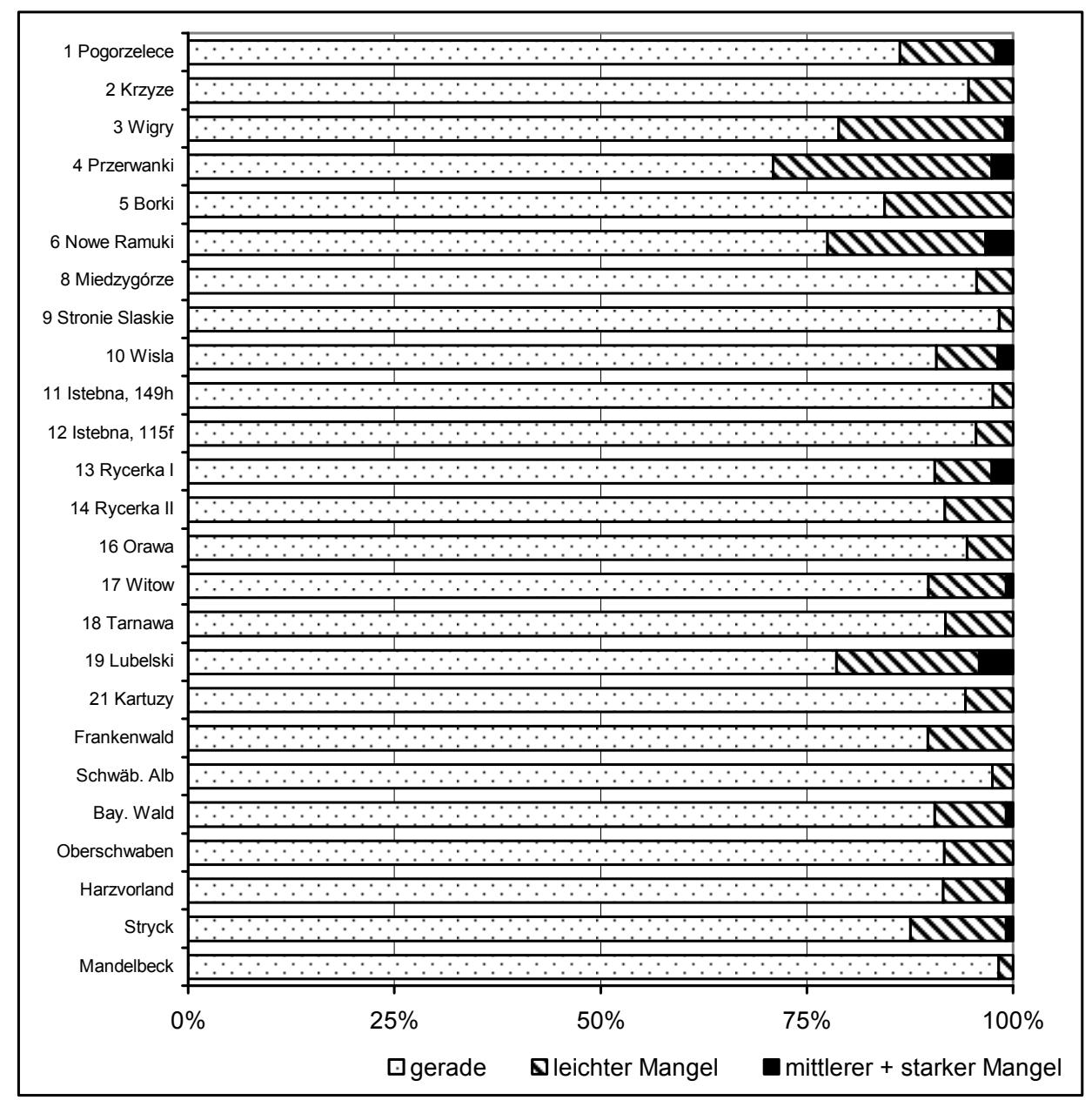

Abb.3.22: $\quad$ Ergebnis der Beurteilung der Stammform der 25 Prüfglieder auf der Fläche Wanfried / Hessen im Alter von 32 Jahren 
Im Alter von 23 Jahren wurde von 3079 Fichten die Form anhand einer 3-stufigen Skala beurteilt. Es waren $86 \%$ der Stämme gerade, $12 \%$ hatten einen leichten und $2 \%$ einen starken Formmangel. Die Unterschiede zwischen den Prüfgliedern (Abb. 3.23) fallen nicht so stark aus wie bei der zuvor beschriebenen jüngsten Erfassung. Die meisten geraden Stämme treten bei den Herkünften Nr. 9 (Stronie Slaskie) $94 \%$, Nr. 12 (Istebna 115f) $94 \%$ und „Frankenwald“ $93 \%$ auf. Den geringsten Anteil gerader Stämme, weniger als $75 \%$, haben die Prüfglieder Nr. 3 (Wigry) und Nr. 4 (Przerwanki).

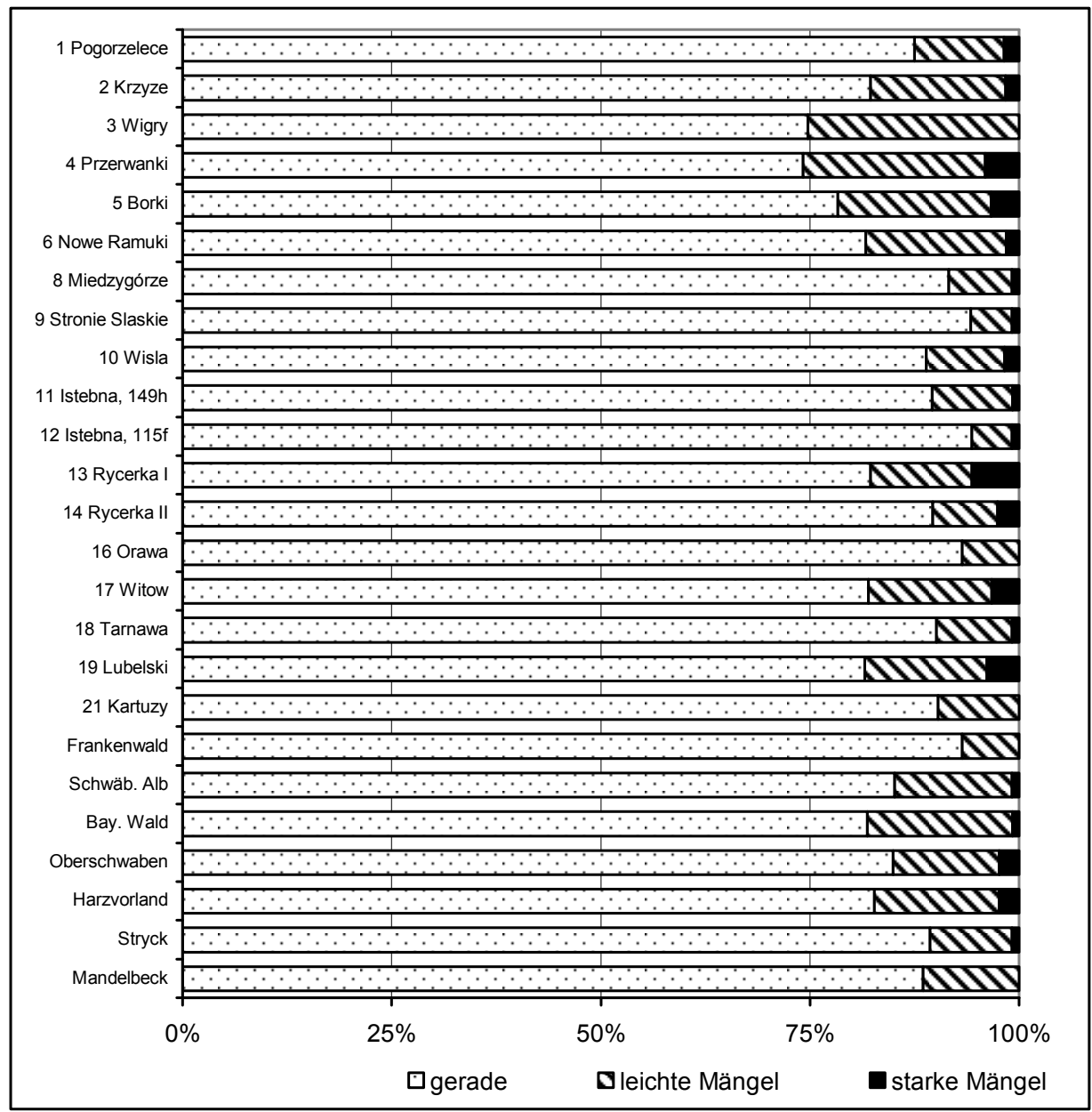

Abb. 3.23: $\quad$ Ergebnis der Beurteilung der Stammform der 25 Prüfglieder auf der Fläche Wanfried / Hessen im Alter von 23 Jahren 
Anders als auf der Fläche Reinhardshagen wurde auf der Fläche Wanfried bei den beiden Formbonituren der Anteil gerader Stämme ähnlich hoch eingestuft. Zwischen den Formansprachen auf der Fläche Wanfried im Alter 23 und 32 besteht ein Zusammenhang ( $\left.\mathrm{r}_{\mathrm{S}}=0,675^{* * *}\right)$.

\section{Ovalität}

Die Abweichung des Stammquerschnittes von der Kreisform ist ein weiteres Maß zur Qualitätsbeurteilung. Die Ovalität beträgt im Mittel der IUFRO-Herkünfte auf der Versuchsfläche Wanfried 2,8\% und variiert zwischen den Herkünften von 2,3\% (Nr. 12 Istebna 115f) mit den geringsten Abweichungen bis 3,3\% (Nr. 19 Lubelski und Nr. 21 Kartuzy) mit der größten Abweichung von der Kreisform. Die Ovalität ist insgesamt geringer als auf der Fläche Reinhardshagen.

Unter Berücksichtigung der zusätzlichen deutschen Prüfglieder erhöht sich die mittlere Ovalität leicht auf 2,9 \%. Die größten Abweichungen von der Kreisform $(3,7 \%)$ hat die Herkunft „Schwäbische Alb und Bayerischer Jura“. Absichern lassen sich die Unterschiede $(\alpha=0,05)$ in multiplen Mittelwertvergleichen (TukeyTest bzw. Dunnett-Test) nicht. Die Ovalitäten der einzelnen Prüfglieder sind in Anhang 2.2 zusammengestellt.

Die Güte dieses Maßes lässt sich nicht beurteilen, da keine Aufzeichnungen vorliegen, aus denen hervorgeht, ob jeweils der dickste und dünnste Durchmesser in 1,3 m Höhe gemessen wurde.

\section{H/D-Verbältnis}

Das Höhen-Durchmesser-Verhältnis (H/D-Verhältnis) ist ein weiteres Qualitätsmaß und wird auch als Parameter zur Beurteilung der Stabilität von Beständen herangezogen. Für die 18 polnischen Herkünfte beträgt der mittlere H/D-Wert 85 im Alter 32 und variiert zwischen 81 (Nr. 4 Przerwanki) und 89 (Nr. 2 Krzyze und Nr. 5 Borki). Unter Einbeziehung aller 25 Prüfglieder beträgt der mittlere H/DWert unverändert auch 85. Die H/D-Werte der zusätzlichen Prüfglieder variieren in derselben Größenordnung zwischen 83 und 88.

Im Alter von 23 Jahren haben sowohl nur die IUFRO-Herkünfte als auch alle 25 Prüfglieder einen mittleren H/D-Wert von rund 90. Die schlanksten Herkünfte haben ein H/D-Verhältnis von 95 (Nr. 1 Pogorzelece, Nr. 3 Wigry und Nr. 4 Przerwanki) und die abholzigste Herkunft eines von 81 („Bayerischer Wald“).

Die H/D-Verhältnisse der einzelnen Prüfglieder im Alter von 23 und 32 Jahren sind in Anhang 2.3 zusammengestellt. Die Unterschiede $(\alpha=0,05)$ zwischen den 25 Prüfgliedern im Alter von 32 Jahren lassen sich in multiplen Mittelwertvergleichen (Tukey-Test bzw. Dunnett-Test) nicht absichern. Im Alter von 23 Jahren gibt es zwei sich stark überlappende Gruppen (Tukey-Test; Anhang 2.7). 


\section{Höhen- und BHD-Wachstum}

Das Wachstum der Fichten ist im Vergleich mit der Ertragstafel (WIEDEMANN 1936/1942, mäßige Durchforstung) auf der Fläche Wanfried sehr gut. Für alle Fichten, die keinen Kronenbruch, keinen Zwiesel und keine Stammrisse haben, wird im Alter von 32 Jahren ein mittlerer BHD von 19,1 cm $(\mathrm{n}=2661)$ und eine mittlere Höhe von 19,9 m ( $\mathrm{n}=583)$ errechnet.

Bei der neun Jahre zuvor erfolgten Messung liegt der mittlere BHD über alle Prüfglieder bei $14,1 \mathrm{~cm}(\mathrm{n}=3081)$ und die Höhe bei $12,8 \mathrm{~m}(\mathrm{n}=750)$. Das H/DVerhältnis betrug seinerzeit $89(\mathrm{n}=750)$.

In Abbildung 3.24 ist die Entwicklung des Höhenwachstums und in Abbildung 3.25 die des BHD-Wachstums der 18 polnischen IUFRO-Herkünfte dargestellt. Im Alter von 32 Jahren sind die zusätzlichen Herkünfte bezüglich der erreichten Höhe relativ ähnlich. Lediglich die Herkünfte Nr. 4 (Przerwanki: 19,0 m), Nr. 9 (Stronie Slaskie: 18,9 m) und Nr. 17 (Witów: 18,6 m) zeigen ein etwas geringeres Höhenwachstum. Die größte mittlere Höhe von 20,6 m haben die Herkünfte Nr. 10 (Wisła), Nr. 11 (Istebna 149h) und Nr. 21 (Kartuzy). Zwischen den 25 Herkünften gibt es keine signifikanten Unterschiede (Tukey-Test bzw. Dunnett-Test, $\alpha=0,05)$ im Höhenwachstum.

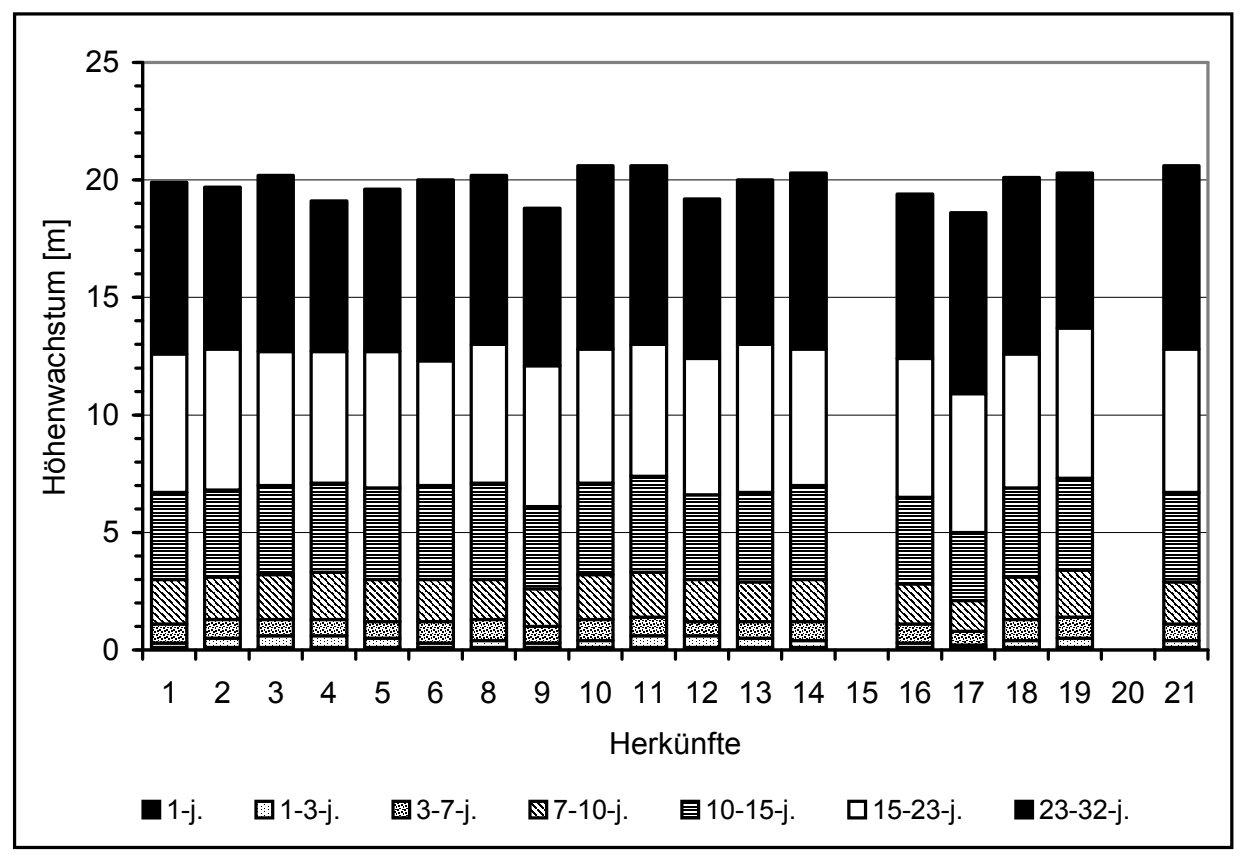

Abb. 3.24 Entwicklung des Höhenwachstums der 18 polnischen Herkünfte bis zum Alter von 32 Jahren auf der Fläche Wanfried / Hessen 
Beim mittleren BHD (Abb. 3.25) variieren die 18 Herkünfte etwas stärker. Auch hier ist die Herkunft Nr. 17 (Witów: 17,1 cm) die mattwüchsigste. Die Herkunft mit dem größten BHD ist die Nr. 19 (Lubelski: 20,4 cm). In den multiplen Vergleichen der 25 Prüfglieder werden zwei stark sich überlappende Gruppen (TukeyTest, $\alpha=0,05$ ) gebildet (Anhang 2.8).

Im Alter von 23 Jahren führt der Tukey-Test $(\alpha=0,05)$ zu zwei sich überlappenden Gruppen sowohl beim Höhen- als auch beim BHD-Wachstum (Anhang 2.9). Im Dunnett-Test unterscheiden sich die mattwüchsigen Prüfglieder (Nr. 17 Witów und „Bayerischer Wald“) im Höhenwachstum vom Standard und im BHD-Wachstum das Prüfglied Nr. 17 (Witów).

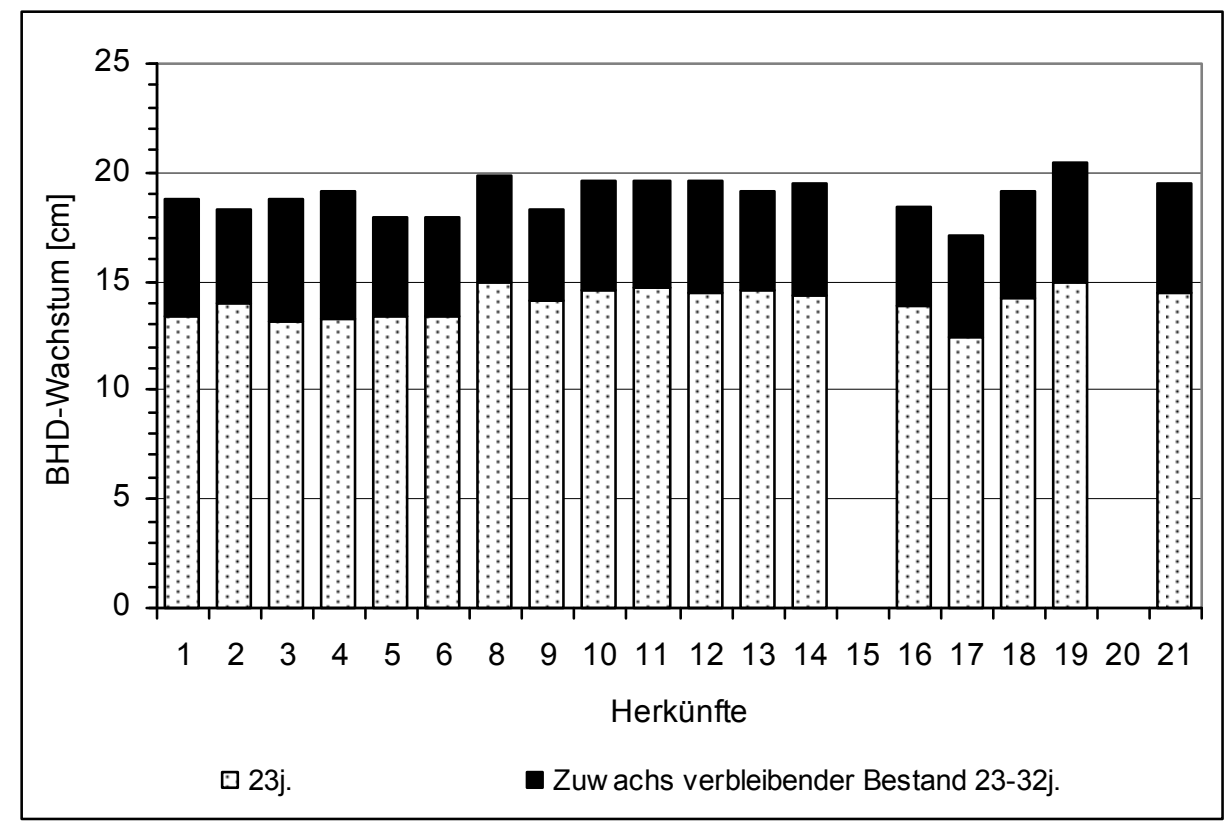

Abb.3.25 Entwicklung des BHD-Wachstums der 18 polnischen Herkünfte auf der Fläche Wanfried / Hessen

Die Streuung der Einzelwerte um den Mittelwert nimmt beim Merkmal Höhenwachstum im Alter von 23 Jahren $(\mathrm{s} \%=10,5)$ zum Alter von 32 Jahren $(\mathrm{s} \%=7,5)$ geringfügig ab. Auch beim H/D-Verhältnis sinkt die Streuung von s\% $\% 13,1$ auf $\mathrm{s} \%=10,2$. Anders sieht es beim BHD aus, hier steigt die Streuung von s\% $=19,6$ (BHD Alter 23) auf $\mathrm{s} \%=22,6$ (Alter 32) leicht an. Die Veränderungen fallen geringer aus als auf der Fläche Reinhardshagen.

Der Vergleich des Wachstums im Beobachtungszeitraum zeigt, dass die Wachstumsmerkmale überwiegend korreliert sind. Auffallend ist jedoch in der Korrelationsmatrix (Tab. 3.14), dass die BHD-Werte im Alter 23 nur schwach mit 
den Höhen im Alter 10 und 15 korrelieren. Der engste Zusammenhang besteht zwischen den mittleren Höhen im Alter 7 und denen im Alter 10 bzw. 15.

Tab.3.14 Produkt-Momenten-Korrelationsmatrix der Wachstumsmerkmale Höhe und BHD

\begin{tabular}{|c|c|c|c|c|c|c|c|}
\hline Merkmal & $\mathrm{H} 7$ & $\mathrm{H} 10$ & H15 & $\mathrm{H} 23$ & H32 & D23 & D32 \\
\hline $\mathrm{H} 7$ & \multirow[t]{7}{*}{-} & $0,970 * * *$ & $0,956^{* * *}$ & $0,908^{* * *}$ & $0,675^{* *}$ & $0,610^{* *}$ & $0,748^{* * *}$ \\
\hline $\mathrm{H} 10$ & & \multirow[t]{6}{*}{-} & $0,959 * * *$ & $0,871^{* * *}$ & $0,654 * *$ & $0,490 *$ & $0,707 * *$ \\
\hline H15 & & & \multirow[t]{5}{*}{-} & $0,879 * * *$ & $0,727^{* * *}$ & $0,564^{*}$ & $0,697 * *$ \\
\hline $\mathrm{H} 23$ & & & & \multirow[t]{4}{*}{-} & $0,722^{* * *}$ & $0,740^{* * *}$ & $0,814^{* * *}$ \\
\hline $\mathrm{H} 32$ & & & & & \multirow[t]{3}{*}{-} & $0,624^{* *}$ & $0,659^{* *}$ \\
\hline $\mathrm{D} 23$ & & & & & & \multirow[t]{2}{*}{-} & $0,826^{* * *}$ \\
\hline D32 & & & & & & & - \\
\hline
\end{tabular}

\section{Einzelbaumvolumen und Vorrat pro Hektar}

Aus den Merkmalen Baumhöhe und BHD wurde das mittlere Einzelbaumvolumen je Herkunft errechnet. Es beträgt im Alter von 32 Jahren 0,2462 $\mathrm{m}^{3} \mathrm{im}$ Mittel über die 25 Prüfglieder der Versuchsfläche Wanfried. Die höchste mittlere Stückmasse hat die Herkunft Nr. 19 Lubelski $\left(0,3043 \mathrm{~m}^{3}\right)$ und die geringste die Herkunft Nr. 17 (Witów: 0,1840 $\mathrm{m}^{3}$ ). Die multiplen Mittelwertvergleiche (Tukey- bzw. DunnettTest, $\alpha=0,05)$ sichern keine Unterschiede im Alter von 32 Jahren ab. Aus den neun Jahre zuvor gemessenen Werten errechnet sich eine mittlere Stückmasse von $0,0983 \mathrm{~m}^{3}$. Zwischen den Herkünften variiert die Stückmasse zwischen $0,1154 \mathrm{~m}^{3}$ (Nr. 8 Miedzygórze) und 0,0742 (Nr. 17 Witów). Der multiple Test (Tukey-Test, $\alpha=0,05$ ) ergibt zwei sich stark überlappende Gruppen (Anhang 2.9). Vom Standard (Dunnett-Test, $\alpha=0,05)$ unterscheidet sich die stückmasseärmste Herkunft Nr. 17 (Witów).

Bei der Vorratsermittlung wurden die drei Merkmale Anzahl lebender Bäume, BHD- und Höhenwachstum berücksichtigt. Im Alter von 32 Jahren beträgt der Vorrat im Mittel über die 18 polnischen Herkünfte $254 \mathrm{~m}^{3} /$ ha. Zwischen den Herkünften (Abb. 3.26) variiert der errechnete Vorrat zwischen $165 \mathrm{~m}^{3} / \mathrm{ha}$ (Herkunft Nr. 4 Przerwanki) und $314 \mathrm{~m}^{3} /$ ha (Herkunft Nr. 21 Kartuzy). Dies entspricht $65 \%$ bzw. $124 \%$ vom Mittel der 18 polnischen IUFRO-Herkünfte. Damit fallen die Unterschiede etwas geringer aus als auf der Fläche Reinhardshagen. Die Abbildung 3.26 zeigt auch, dass die Herkünfte aus einer geografischen Region im Volumen stark divergieren. $\mathrm{Zu}$ den vorratsreichen Herkünften zählt die nicht autochthone Herkunft aus dem Baltischen Gebiet (Nr. 21). Die Herkünfte aus Masuren sind insgesamt etwas vorratsärmer. 


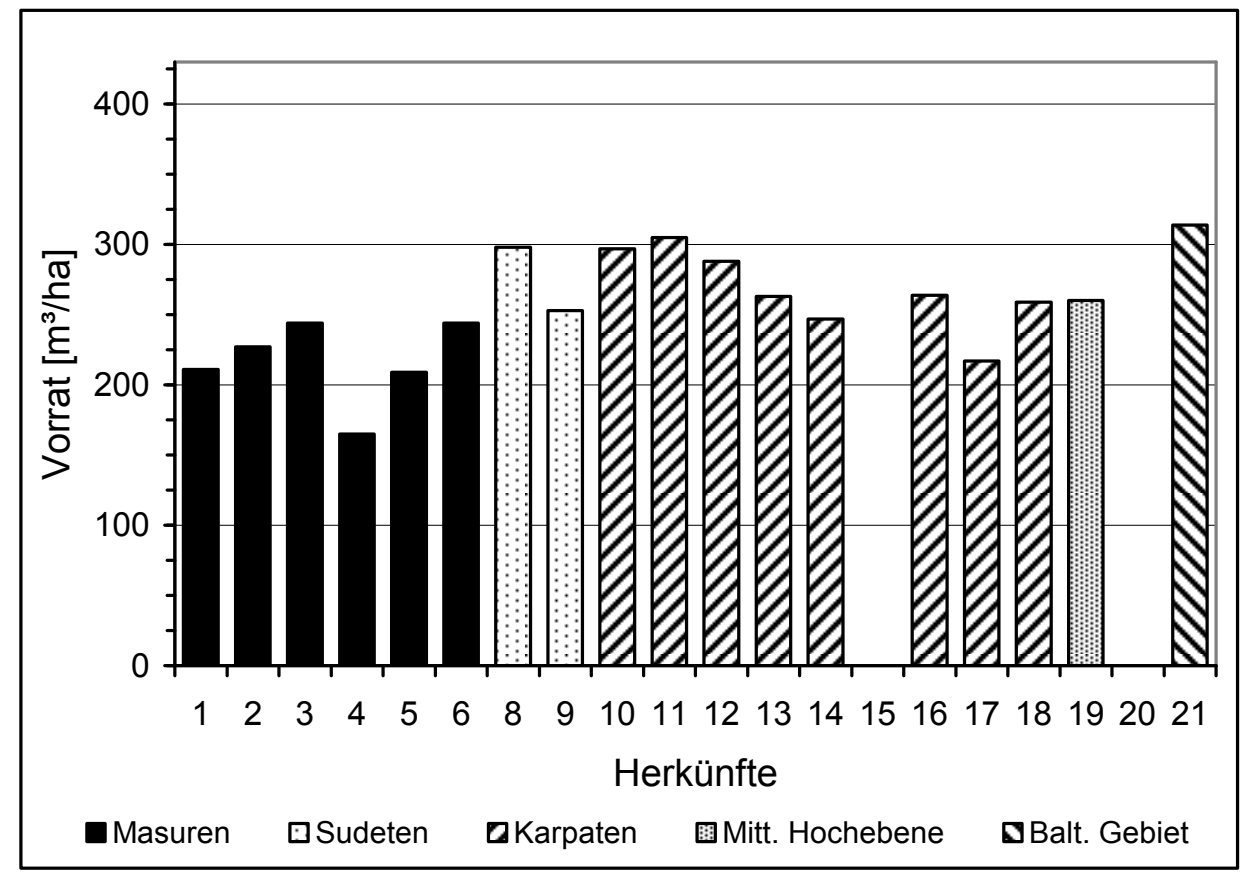

Abb. 3.26: Hochgerechneter Vorrat je Hektar der 18 polnischen Herkünfte auf der Versuchsfläche Wanfried / Hessen im Alter von 32 Jahren

Im Alter von 23 Jahren betrug der Vorrat im Mittel über die 18 polnischen Herkünfte $124 \mathrm{~m}^{3} /$ ha. In Abbildung 3.27 ist der Vorrat für die polnischen Herkünfte im Alter von 23 Jahren dargestellt. Die Unterschiede zwischen der wüchsigsten Herkunft Nr. 11 (Istebna 149h) mit 126 \% des Mittels der 18 polnischen IUFROHerkünfte und der mattwüchsigsten Herkunft Nr. 17 (Witów) mit $75 \%$ fallen nur wenig geringer aus als neun Jahre später.

Die Vorräte der beiden Erhebungen im Alter von 23 und 32 Jahren sind hoch korreliert $\left(\mathrm{r}_{\mathrm{P}}=0,750^{* * *}\right)$. 


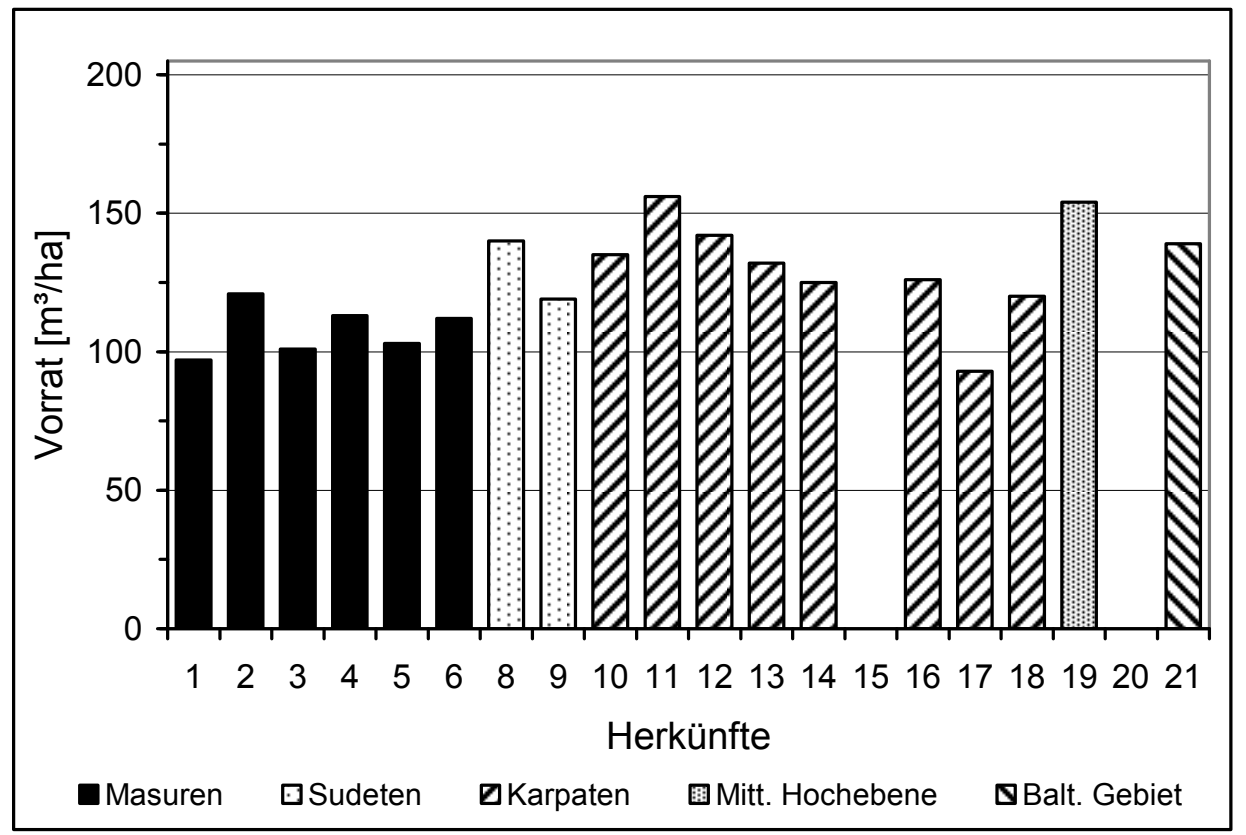

Abb. 3.27: Hochgerechneter Vorrat je Hektar der 18 polnischen Herkünfte auf der Versuchsfläche Wanfried / Hessen im Alter von 23 Jahren

In Abbildung 3.28 ist der für die zusätzlichen sieben deutschen Prüfglieder errechnete Vorrat dargestellt. Zum Vergleich wurden in die Abbildung die wüchsigste und die mattwüchsigste Herkunft sowie das Mittel über die 18 polnischen IUFROHerkünfte aufgenommen. Im Alter von 32 Jahren sind mit Ausnahme der Herkunft „Bayerischer Wald“ alle zusätzlichen deutschen Prüfglieder wüchsiger als das Mittel der polnischen IUFRO-Herkünfte. Die Prüfglieder „Frankenwald“, „Harzvorland" sowie die Absaaten aus den Plantagen Stryck und Mandelbeck haben einen höheren Vorrat als die bestwüchsige polnische Herkunft Nr. 11 (Istebna 149h).

Im Alter von 23 Jahren wurde für die wüchsigste polnische Herkunft Nr. 11 (Istebna 149h) noch ein höherer Vorrat als für alle sieben deutschen Prüfglieder errechnet. 


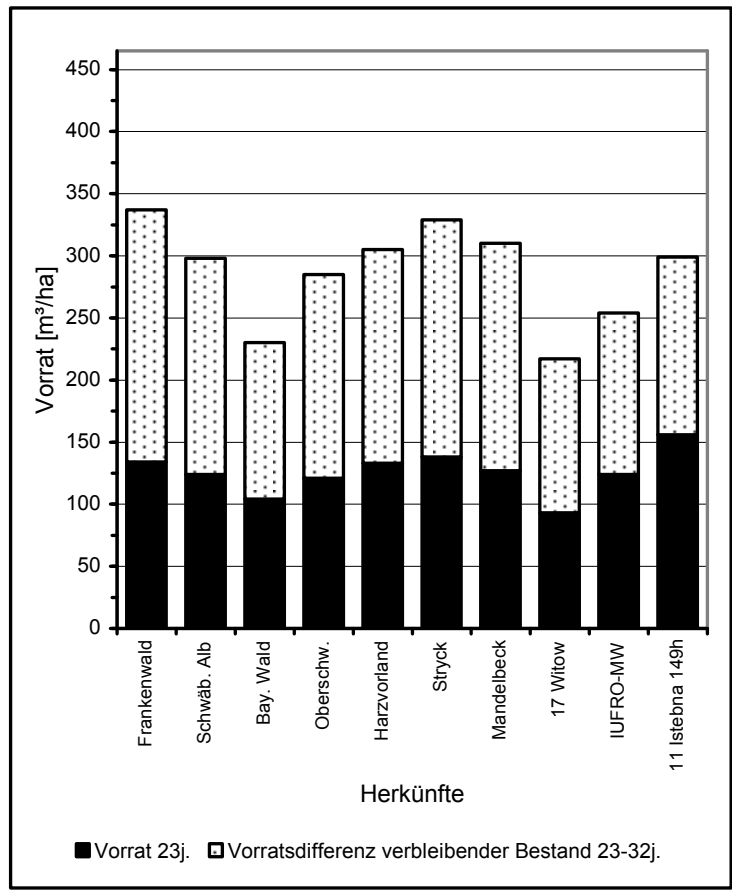

Abb. 3.28: Hochgerechneter Vorrat je Hektar der sieben zusätzlichen Prüfglieder auf der Versuchsfläche Wanfried / Hessen im Alter von 23 und 32 Jabren. Zum Vergleich sind die beste und die mattwü̈hsigste Herkunft sowie das Mittel über die 18 polnischen IUFRO-Herkünfte zusätzlich aufgenommen.

Die Vorräte der 25 Prüfglieder auf der Versuchsfläche wurden im multiplen Mittelwertvergleich mit der Tukey-Prozedur $(\alpha=0,05)$ getestet. Der Mittelwertvergleich zeigt (Tab. 3.15), dass sich die polnische Herkunft Nr. 4 (Przerwanki) im Alter von 32 Jahren von den vorratsreicheren Prüfgliedern Nr. 8 (Miedzygórze), Nr. 10 (Wisła), Nr. 11 (Istebna 149h), Nr. 12 (Istebna 115f), Nr. 21 (Kartuzy), „Frankenwald“, „Schwäb. Alb und Bay. Jura“, „Südbayern, Oberschwaben, Bodenseegebiet“, „Harzvorland“ sowie den Absaaten aus den Plantagen Stryck und Mandelbeck signifikant $(\alpha=0,05)$ unterscheidet. Außerdem unterscheidet sich signifikant die Herkunft „Frankenwald“ von den vorratsärmeren Prüfgliedern Nr. 1 (Pogorcelece), Nr. 5 (Borki) und Nr. 17 (Witów), signifikant ist außerdem der Unterschied der Absaat aus der Plantage Stryck im Vergleich zu den Herkünften Nr. 4 (Przerwanki) und Nr. 5 (Borki).

Auch im Alter von 23 Jahren gab es gesicherte Unterschiede zwischen den Herkünften (Tab. 3.15). So unterschieden sich die vorratsreichen Herkünfte Nr. 11 (Istebna 149h) und Nr. 19 (Lubelski) von den vorratsarmen „Bayerischer Wald“, Nr. 1 (Pogorzelece), Nr. 3 (Wigry), Nr. 5 (Borki) und Nr. 17 (Witów). 
Tab. 3.15: $\quad$ Mittelwerte und Tukey-Gruppierung (T-G) der 25 Prüfglieder für den Vorrat/ha im Alter 23 und 32

\begin{tabular}{|c|c|c|c|c|c|c|c|c|c|c|}
\hline \multirow{2}{*}{$\begin{array}{c}\text { IUFRO- } \\
\text { Nr. }\end{array}$} & \multirow{2}{*}{ Prüfglied } & \multicolumn{2}{|c|}{ Vorrat $\left[\mathrm{m}^{3} / \mathrm{ha}\right]$} & \multicolumn{7}{|c|}{$\mathrm{T}-\mathrm{G}$} \\
\hline & & $23-j$. & $32-j$. & & $23-\mathrm{j}$. & & & 32 & & \\
\hline \multirow{5}{*}{21} & Frankenwald & 134 & 337 & A & $\mathrm{B}$ & $\mathrm{C}$ & A & & & \\
\hline & Stryck & 138 & 329 & A & B & $\mathrm{C}$ & A & B & & \\
\hline & Kartuzy & 139 & 314 & A & B & $\mathrm{C}$ & A & B & $\mathrm{C}$ & \\
\hline & Mandelbeck & 127 & 310 & A & B & $\mathrm{C}$ & A & B & $\mathrm{C}$ & \\
\hline & Harzvorland & 133 & 305 & A & $\mathrm{B}$ & $\mathrm{C}$ & A & B & $\mathrm{C}$ & \\
\hline 11 & Istebna $149 \mathrm{~h}$ & 156 & 304 & A & & & A & $\mathrm{B}$ & $\mathrm{C}$ & \\
\hline \multirow[t]{2}{*}{8} & Miedzygórze & 140 & 298 & A & B & $\mathrm{C}$ & A & B & $\mathrm{C}$ & \\
\hline & Schwäb. Alb und Bay. Jura & 124 & 298 & A & B & $\mathrm{C}$ & A & B & $\mathrm{C}$ & \\
\hline 10 & Wisła & 142 & 297 & A & $\mathrm{B}$ & & A & $\mathrm{B}$ & $\mathrm{C}$ & \\
\hline \multirow[t]{2}{*}{12} & Istebna $115 \mathrm{f}$ & 142 & 288 & A & B & & A & $\mathrm{B}$ & $\mathrm{C}$ & \\
\hline & Südbayern, Oberschwaben, Bod. & 121 & 285 & A & B & $\mathrm{C}$ & A & B & $\mathrm{C}$ & \\
\hline 16 & Orawa & 126 & 264 & A & $\mathrm{B}$ & $\mathrm{C}$ & A & B & $\mathrm{C}$ & $\mathrm{D}$ \\
\hline 13 & Zwardon & 132 & 263 & A & B & $\mathrm{C}$ & A & B & $\mathrm{C}$ & $\mathrm{D}$ \\
\hline 19 & Lubelski & 154 & 260 & A & & & A & B & $\mathrm{C}$ & $\mathrm{D}$ \\
\hline 18 & Tarnawa & 120 & 259 & A & B & $\mathrm{C}$ & A & B & C & $\mathrm{D}$ \\
\hline 9 & Stronie Slaskie & 119 & 253 & A & B & $\mathrm{C}$ & A & B & $\mathrm{C}$ & $\mathrm{D}$ \\
\hline 14 & Rycerka I & 125 & 247 & A & B & $\mathrm{C}$ & A & B & $\mathrm{C}$ & $\mathrm{D}$ \\
\hline 6 & Nowe Ramuki & 112 & 244 & A & $\mathrm{B}$ & $\mathrm{C}$ & A & B & $\mathrm{C}$ & $\mathrm{D}$ \\
\hline \multirow[t]{2}{*}{3} & Wigry & 101 & 244 & & B & C & A & B & $\mathrm{C}$ & $\mathrm{D}$ \\
\hline & Bayerischer Wald & 104 & 230 & & B & $\mathrm{C}$ & A & B & $\mathrm{C}$ & $\mathrm{D}$ \\
\hline 2 & Krzyze & 121 & 227 & A & B & C & A & B & $\mathrm{C}$ & $\mathrm{D}$ \\
\hline 17 & Witów & 93 & 217 & & & $\mathrm{C}$ & & B & $\mathrm{C}$ & $\mathrm{D}$ \\
\hline 1 & Pogorzelece & 97 & 211 & & B & $\mathrm{C}$ & & B & $\mathrm{C}$ & $\mathrm{D}$ \\
\hline 5 & Borki & 103 & 209 & & $\mathrm{~B}$ & C & & & $\mathrm{C}$ & $\mathrm{D}$ \\
\hline 4 & Przerwanki & 113 & 265 & A & $\mathrm{B}$ & $\mathrm{C}$ & & & & $\mathrm{D}$ \\
\hline
\end{tabular}

Parallel zur Tukey-Prozedur wurden auch zweiseitige Dunnett-Tests gegen eine Kontrollgruppe bestehend aus den acht polnischen Herkünften, die auf allen Versuchsflächen ausgepflanzt wurden, durchgeführt. Beim Vorrat im Alter 32 gibt es keine gesicherten Unterschiede. Im Alter von 23 Jahren war der Unterschied der polnischen Herkunft Nr. 17 (Witów) zur Kontrollgruppe signifikant $(\alpha=0,05)$.

Die zuvor erfolgten Tests basieren auf der Auswertung der Versuchsfläche als Blockversuch. Erfolgt die Analyse unter Berücksichtigung des Alpha-Designs (Gitter), d. h. als kombinierte Inter-Intra-Block-Analyse mit Nutzung der Inter- 
Block-Information, verringert sich der mittlere Standardfehler im Alter 32 von $2,3734735(100 \%)$ auf 2,3729332 (99,98\%) im Tukey-Test und von 2,6975756 $(100 \%)$ auf 2,6963521 (99,95\%) im Dunnettt-Test. Im Alter 23 waren die Unterschiede noch geringer; der mittlere Standardfehler betrug im Tukey-Test 99,99\% und im Dunnett-Test 99,98 \%. Die etwas kleineren Standardfehler zeigen, dass die Nutzung der Inter-Block-Information in allen Fällen nur einen verschwindend geringen Gewinn erbracht hat. Die Ergebnisse der Auswertung als Gitteranlage werden daher hier nicht dargestellt.

\subsubsection{Niedersachsen}

\subsubsection{Dassel}

\section{Entwicklung der Pflanzenanzabl}

Im Alter von 32 Jahren leben auf der Versuchsfläche noch $39 \%$ der ursprünglich gepflanzten Fichten sowohl aller 100 Prüfglieder als auch der 20 IUFRO-Herkünfte. Die Unterschiede im Anteil lebender Bäume der 20 IUFRO-Herkünfte liegen zwischen den Wiederholungen bei $13 \%$-Punkten.

Betrachtet man die Anteile lebender Bäume der zu fünf geografischen Regionen zusammengefassten IUFRO-Herkünfte, so findet man zwischen den beiden, mit mehreren Herkünfen vertretenen Regionen Masuren und Karpaten einen Unterschied von $9 \%$-Punkten (Tab. 3.16).

Tab.3.16 Anteil lebender Bäume der zu fünf geografischen Regionen zusammengefassten polnischen Herkïnfte (IUFRO), der IUFRO-PG, der zusätzlichen PG und aller PG auf der Fläche Dassel

\begin{tabular}{lcccc}
\hline Geografische Region & IUFRO-Nr. & Anzahl PG & $\begin{array}{c}1995 \\
(23-j .)\end{array}$ & $\begin{array}{c}2004 \\
(32-j .)\end{array}$ \\
\hline Masuren-Podlasie & $1-6$ & 6 & $36 \%$ & $35 \%$ \\
Sudeten & 8,9 & 2 & $42 \%$ & $41 \%$ \\
Karpaten (Beskiden) & $10-18$ & $9+1$ & $45 \%$ & $44 \%$ \\
Mittelpolnische Hochebene & 19,20 & 2 & $36 \%$ & $33 \%$ \\
Baltisches Gebiet & 21 & 1 & $37 \%$ & $33 \%$ \\
\hline IUFRO-Herkünfte & & $20+1$ & $41 \%$ & $39 \%$ \\
\hline zusätzliche PG & & 79 & $41 \%$ & $38 \%$ \\
\hline alle PG & & 100 & $41 \%$ & $39 \%$ \\
\hline
\end{tabular}


Zwischen den einzelnen Herkünften gibt es Unterschiede (Abb. 3.29). Im Alter von 32 Jahren variiert der Anteil der noch vorhandenen Fichten zwischen $52 \%$ Nr. 14 (Rycerka I) und $27 \%$ Nr. 1 (Pogorzelece). Der mittlere Anteil lebender Bäume der Herkunft Istebna 115f, die auf der Versuchsfläche Dassel doppelt vertreten ist, beträgt $41 \%$ (Nr. 12: $44 \%$ und Nr. 404: $37 \%$ ). Zwischen den Aufnahmen im Alter von 23 Jahren und 32 Jahren nahmen die Ausfälle um $2 \%$ Punkte zu. Bei den IUFRO-Herkünften waren die Ausfälle unverändert. So sind in dieser Zeit bei einigen IUFRO-Herkünften keine weiteren Bäume ausgefallen, bei anderen sind bis zu $4 \%$ der Bäume ausgefallen (Abb. 3.29).

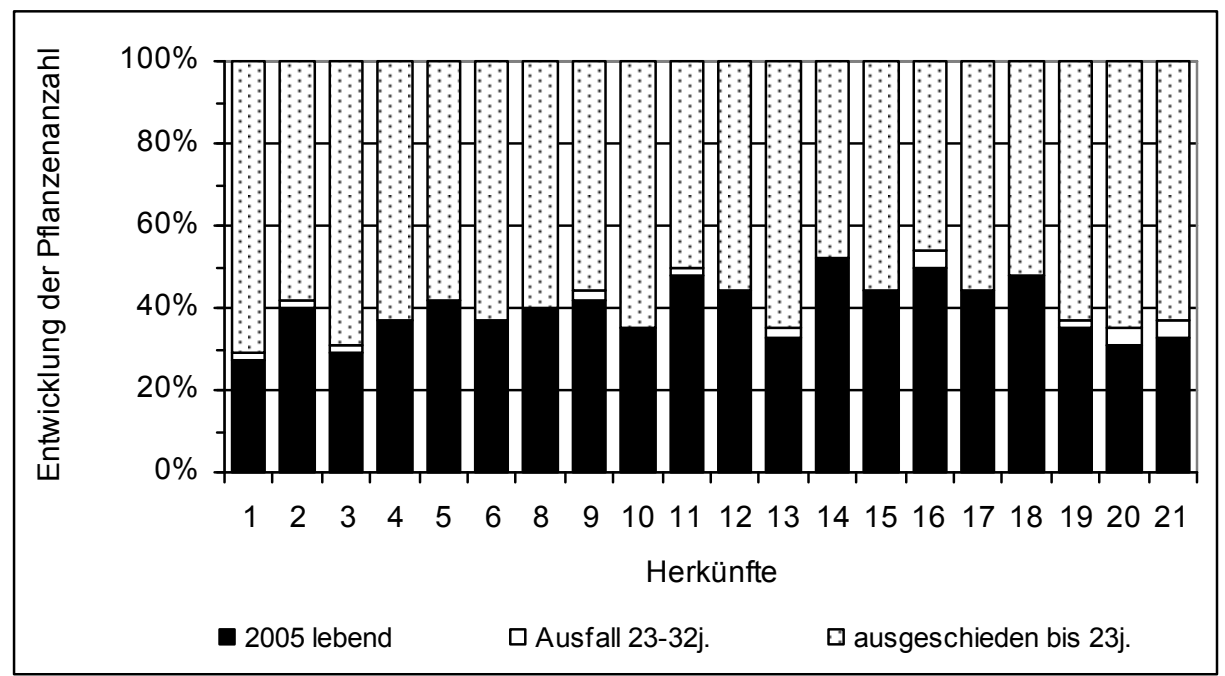

Abb. 3.29: Entwicklung der Pflanzenanzabl auf der Fläche Dassel / Niedersachsen

In der Abbildung 3.30 ist die Entwicklung der Pflanzenanzahl der zu neun Herkünften zusammengefassten, zusätzlich auf der Fläche angebauten 79 Prüfglieder dargestellt. Acht dieser polnischen Herkünfte setzten sich aus neun bzw. zehn Einzelbaumnachkommenschaften zusammen, die Herkunft Nr. 10 (Wisła) ist nur mit einer Einzelbaumnachkommenschaft vertreten. Die Unterschiede zwischen den Herkünften der gemittelten Einzelbaumnachkommenschaften sind äußerst gering. 


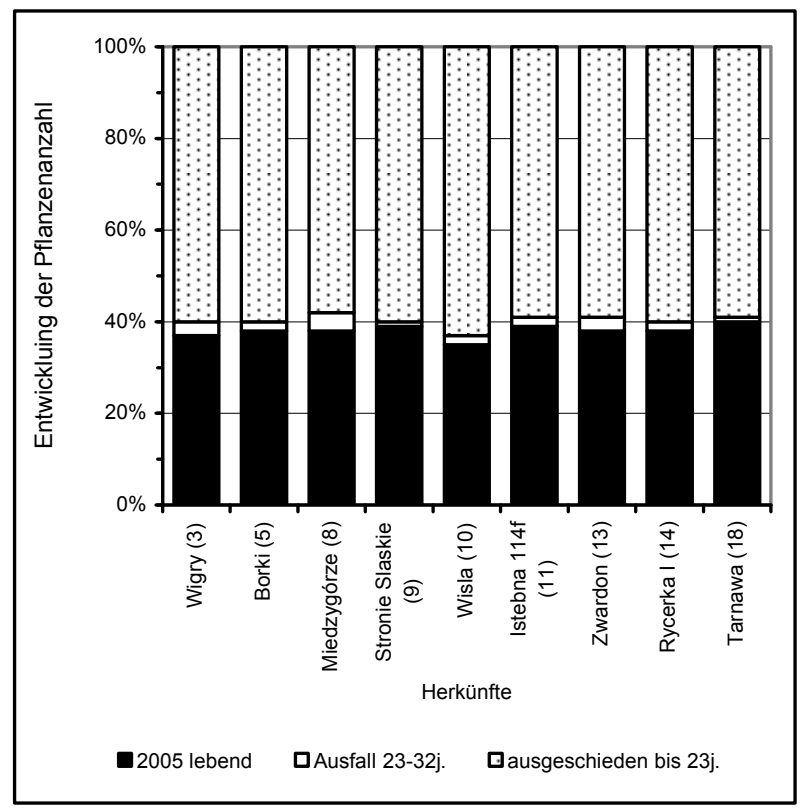

Abb. 3.30: Entwicklung der Pflanzenanzabl der zu neun Herkünften (Nr. der IUFRO-Herkunft) zusammengefassten zusätzlichen 79 Prüfglieder auf der Fläche Dassel / Niedersachsen

Dennoch variieren die Anteile ausgeschiedener Fichten zwischen den einzelnen Nachkommenschaften der jeweiligen polnischen Herkunft (Abb. 3.31). Die Unterschiede sind am höchsten bei den Nachkommenschaften der Herkunft Nr. 14 (Rycerka I: 27 \%-Punkte) bzw. Herkunft Nr. 3 (Wigry: 23 \%-Punkte). Bei folgenden Herkünften sind die Ausfälle der Einzelbaumnachkommenschaften höher als die der IUFRO-Herkunftsabsaaten: Herkunft Nr. 14 (Rycerka I), Nr. 11 (Istebna 114f) und Nr. 18 (Tarnawa). 


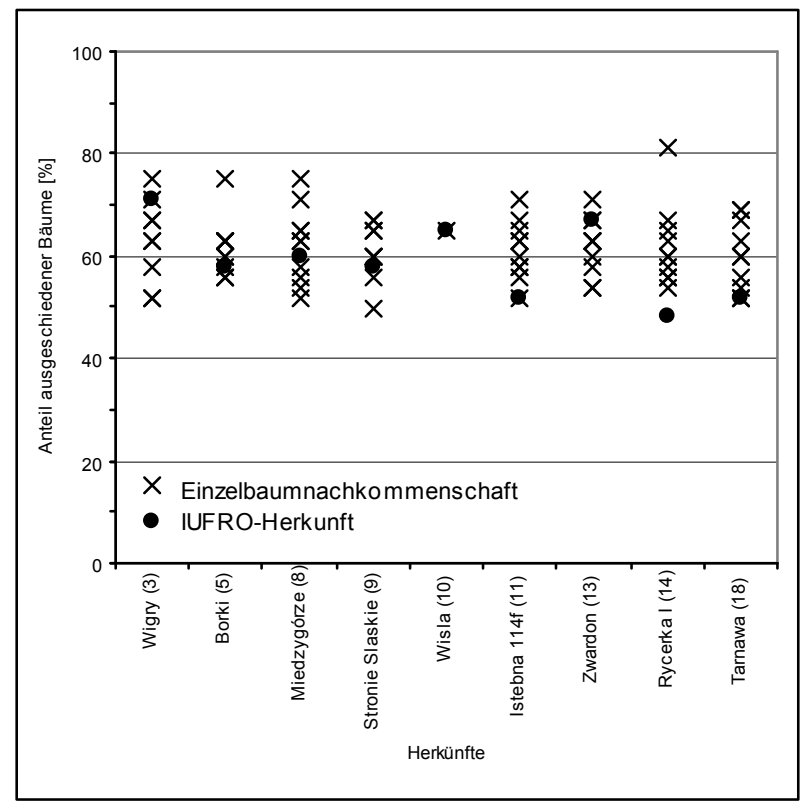

Abb. 3.31: Anteil ausgeschiedener Bäume der 79 Einzelbaumnachkommenschaften und der jeweiligen IUFRO-Herkunft auf der Fläche Dassel / Niedersachsen

Die Unterschiede $(\alpha=0,05)$ zwischen den 100 Prüfgliedern lassen sich in multiplen Mittelwertvergleichen (Tukey-Test bzw. Dunnett-Test) nicht absichern.

\section{Schadmerkmale}

Auf der Versuchsfläche Dassel wurden im Alter von 32 Jahren fünf Schadmerkmale aufgenommen. Die erfassten Schäden sind insgesamt sehr gering. So werden keine Fichten mit Käferschäden und bei insgesamt 13 Bäumen Kronenbrüche notiert. Die Anzahl der Bäume mit einem Zwiesel beläuft sich auf sechs. Rückeschäden wurden an 289 Bäumen beobachtet. 86\% der Schäden waren gering, $13 \%$ mäßig und an vier Bäumen wurde der Schaden als schwer eingestuft. Bei dem fünften Schadmerkmal, das aufgenommen wurde, handelt es sich um Stammrisse. Diese traten an 22 Bäumen auf; 18 dieser Bäume haben eine gute Schaftform. Eine Konzentration eines Schadens auf ein oder wenige Prüfglieder liegt nicht vor. Die Bäume mit Kronenbruch und Zwiesel wurden nur in die Berechnung des Anteils lebender Bäume einbezogen. Von der Aufnahme im Alter von 23 Jahren (1995) liegen keine Daten einer Bonitur der Schäden vor. 


\section{Stammform}

Im Alter von 32 Jahren wurde bei 1852 Fichten die Stammform beurteilt. $89 \%$ der Stämme werden als gerade, $9 \%$ mit einem leichten Mangel und $1 \%$ mit mittlerem Mangel eingestuft. Ein Baum weist einen starken Mangel auf. Bei der Interpretation der Abbildung 3.32 ist zu beachten, dass die Formbonitur der IUFRO-Herkünfte nur auf 13 bis 25 Bäumen pro Herkunft beruht. Bei den zu Herkünften zusammengefassten Einzelbaumnachkommen sind dagegen zwischen 161 und 191 Fichten bonitiert wurden, mit Ausnahme der Herkunft Nr. 10 (Wisła) mit nur einer Einzelbaumnachkommenschaft (17 Fichten).

Auffallend ist, dass zwischen den Einzelbaumnachkommenschaften, die zu Herkünften zusammengefasst sind, die Form der Herkünfte ähnlich ist (im unteren Teil der Abb. 3.32). Fasst man die beiden Herkünfte Nr. 12 und Nr. 404 (beide Istebna 115f) zusammen, beträgt der Anteil der mangelfreien Stämme ebenso $90 \%$. Es ist davon auszugehen, dass die Formunterschiede der IUFRO-Herkünfte auf die geringen Stammzahlen pro Herkunft zurückgeführt werden können und damit zufällig sind. Lediglich die Herkunft Nr. 16 (Orawa) neigt anscheinend zu schlechteren Stammformen, was im insgesamt geringen Anteil mangelfreier Stämme und im hohen Anteil an Stämme mit mindestens mittlerem Mangel zum Ausdruck kommt.

Werden die IUFRO-Herkünfte zu geografischen Regionen gruppiert, sind weiterhin zwei Regionen mit weniger als 40 Bäumen besetzt, und zwischen den Regionen variiert der Anteil der mangelfreien Stämme zwischen 84 und $90 \%$, wenn die nicht autochthone Herkunft unberücksichtigt bleibt.

Aus dem Jahr 1995 liegt keine Bonitur der Form vor. 


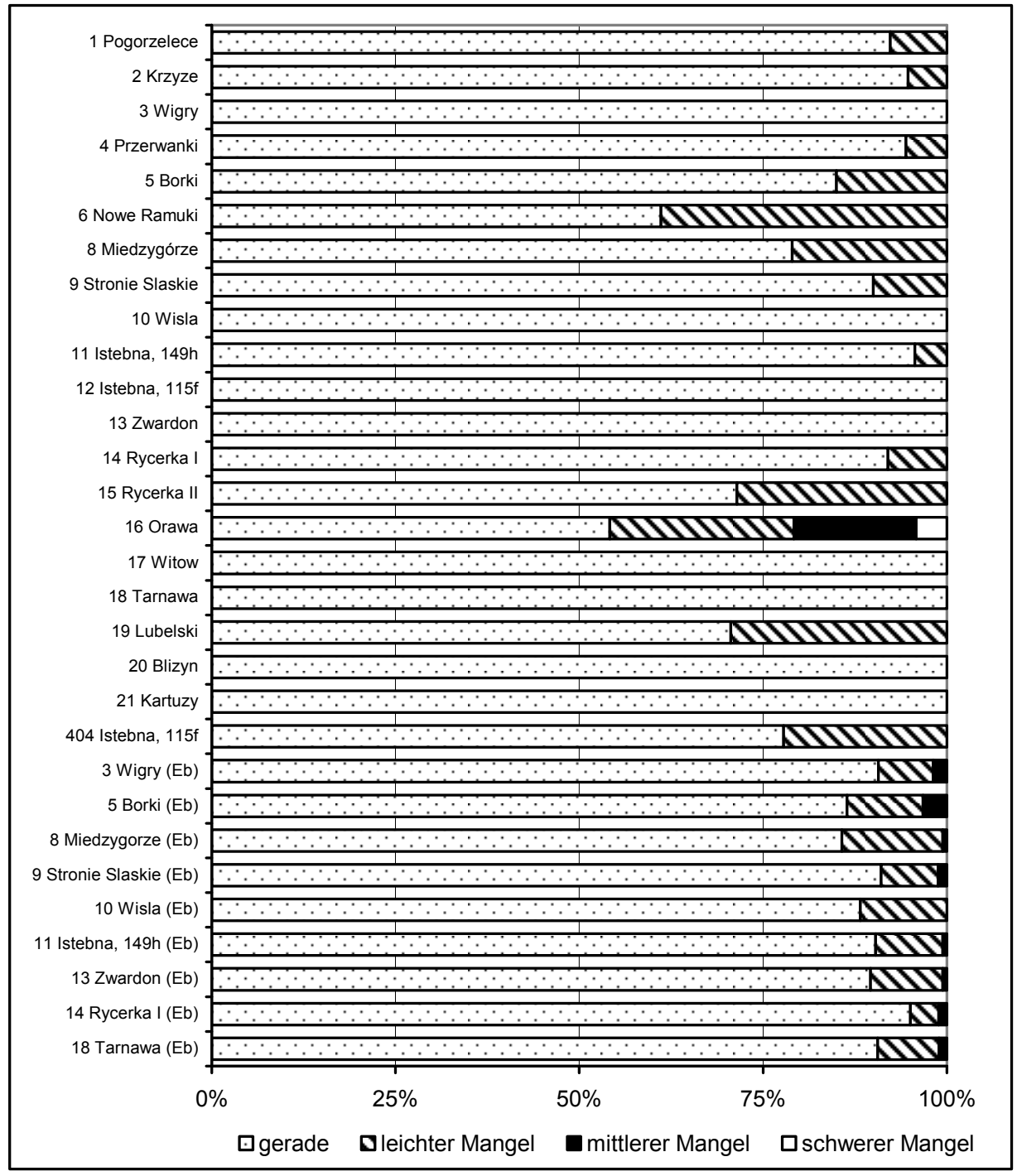

Abb.3.32: Ergebnis der Beurteilung der Stammform der 30 Prïfglieder auf der Fläche Dassel / Niedersachsen im Alter von 32 Jahren (Eb = Einzelbaumabsaaten zusammengefasst)

\section{Ovalität}

Die Abweichung des Stammquerschnittes von der Kreisform beträgt im Mittel der IUFRO-Herkünfte auf der Versuchsfläche Dassel 3,2 und variiert zwischen den Herkünften von 2,0 (Nr. 13 Zwardon) mit den geringsten Abweichungen bis 4,6 (Nr. 1 Pogorzelece) mit der größten Abweichung von der Kreisform. 
Auch bei Einbeziehung der zusätzlichen Einzelbaumnachkommenschaften bleibt die mittlere Ovalität bei 3,2. Die Extremwerte variieren zwischen 1,8 und 5,5, beide werden bei Einzelbaumnachkommenschaften der Herkunft Nr. 13 (Zwardon) errechnet. Die Ovalitäten der einzelnen Prüfglieder sind in Anhang 2.10 zusammengestellt. Die Mittel über die Einzelbaumnachkommenschaften sind in einigen Fällen mehr oder weniger identisch mit den Werten, die für die IUFROHerkünfte berechnet wurden: Nr. 3 (Wigry), 5 (Borki), 9 (Stronie Slaskie) und 14 (Rycerka I). Der größte Unterschied (Differenz: 1,5) tritt bei der Herkunft Nr. 13 (Zwardon) auf. Absichern lassen sich die Unterschiede $(\alpha=0,05)$ in multiplen Mittelwertvergleichen (Tukey-Test bzw. Dunnett-Test) nicht.

Die Güte dieses Maßes lässt sich nicht beurteilen, da keine Aufzeichnungen vorliegen, aus denen hervorgeht, ob jeweils die Bäume an der dicksten bzw. dünnsten Stelle in 1,3 m Höhe gemessen wurden.

\section{H/D-Verbältnis}

Das Höhen-Durchmesser-Verhältnis (H/D-Verhältnis) beträgt im Alter 32 für die 21 polnischen Herkünfte im Mittel 85 und variiert zwischen 74 (Nr. 21 Kartuzy) und 96 (Nr. 5 Borki). Unter Einbeziehung der 79 Einzelbaumnachkommenschaften beträgt der mittlere H/D-Wert auch 85. Für die nach Herkünften zusammengefassten Einzelbaumnachkommenschaften werden mittlere H/D-Verhältnisse zwischen 76 und 93 errechnet.

Im Alter von 23 Jahren haben die Fichten der IUFRO-Herkünfte einen H/DWert von 75 und alle 100 Prüfglieder einen mittleren H/D-Wert von 77. Die schlankste IUFRO-Herkunft hatte ein H/D-Verhältnis von 84 (Nr. 5 Borki) und die abholzigste Herkunft eines von 67 (Nr. 21 Kartuzy).

Die H/D-Verhältnisse der einzelnen Prüfglieder im Alter von 23 und 32 Jahren sind in Anhang 2.11 zusammengestellt. Die Unterschiede $(\alpha=0,05)$ zwischen den 100 Prüfgliedern im Alter von 23 bzw. 32 Jahren lassen sich im multiplen Mittelwertvergleich (Tukey-Test) nicht absichern. Im Vergleich mit dem Standard (Dunnett-Test) liegt im Alter von 23 Jahren ein gesicherter Unterschied zu der schlanksten Einzelbaumnachkommenschaft $(\mathrm{H} / \mathrm{D}=87)$ der Herkunft Nr. 18 (Tarnawa) vor.

\section{Höhen- und BHD-Wachstum}

Das Wachstum der Fichte auf der Fläche ist sehr gut. Für alle Fichten, die weder Kronenbruch noch einen Zwiesel hatten, wird im Alter von 32 Jahren ein mittlerer BHD von 19,6 cm $(n=1832)$ und eine mittlere Höhe von 18,5 m $(\mathrm{n}=862)$ errechnet. Bei der neun Jahre zuvor erfolgten Messung liegt der mittlere BHD über alle Prüfglieder bei 13,8 cm $(\mathrm{n}=1952)$ und die Höhe bei 11,7 $\mathrm{m}(\mathrm{n}=879)$. 
In Abbildung 3.33 ist die Entwicklung des Höhenwachstums und in Abbildung 3.34 die des BHD-Wachstums der 20 polnischen Herkünfte dargestellt. Im Alter von 32 Jahren sind sowohl die 20 IUFRO-Herkünfte als auch die zu sieben Herkünften zusammengefassten zusätzlichen Einzelbaumnachkommenschaften bezüglich der erreichten Baumhöhe ähnlich. Lediglich die Einzelbaumnachkommenschaft Nr. 77 (Stronie Slaskie 9-69) zeigt ein signifikant geringeres (TukeyTest, $\alpha=0,05)$ Höhenwachstum im Alter von 32 Jahren im multiplen Vergleich gegenüber 66 Prüfgliedern (Anhang 2.12). Diese Einzelbaumnachkommenschaft unterscheidet sich auch vom Standard (Dunnett-Test, $\alpha=0,05$ ).

Im Alter von 23 Jahren werden zwei sich stark überlappende Tukey-Gruppen gebildet (Anhang 2.12). Die Einzelbaumnachkommenschaft Nr. 77 (Stronie Slaskie 9-69) zeigt ein signifikant geringeres Höhenwachstum im Alter 23 (Tukey-Test, $\alpha=0,05)$ gegenüber den beiden wüchsigen Einzelbaumnachkommenschaften $\mathrm{Nr}$. 35 und 37 (Istebna 149h, 11-40 bzw. 11-53) (Anhang 2.12). Im Dunnett-Test unterscheidet sich die wüchsige Einzelbaumnachkommenschaft Nr. 35 (Istebna 149h, 11-40) vom Standard.

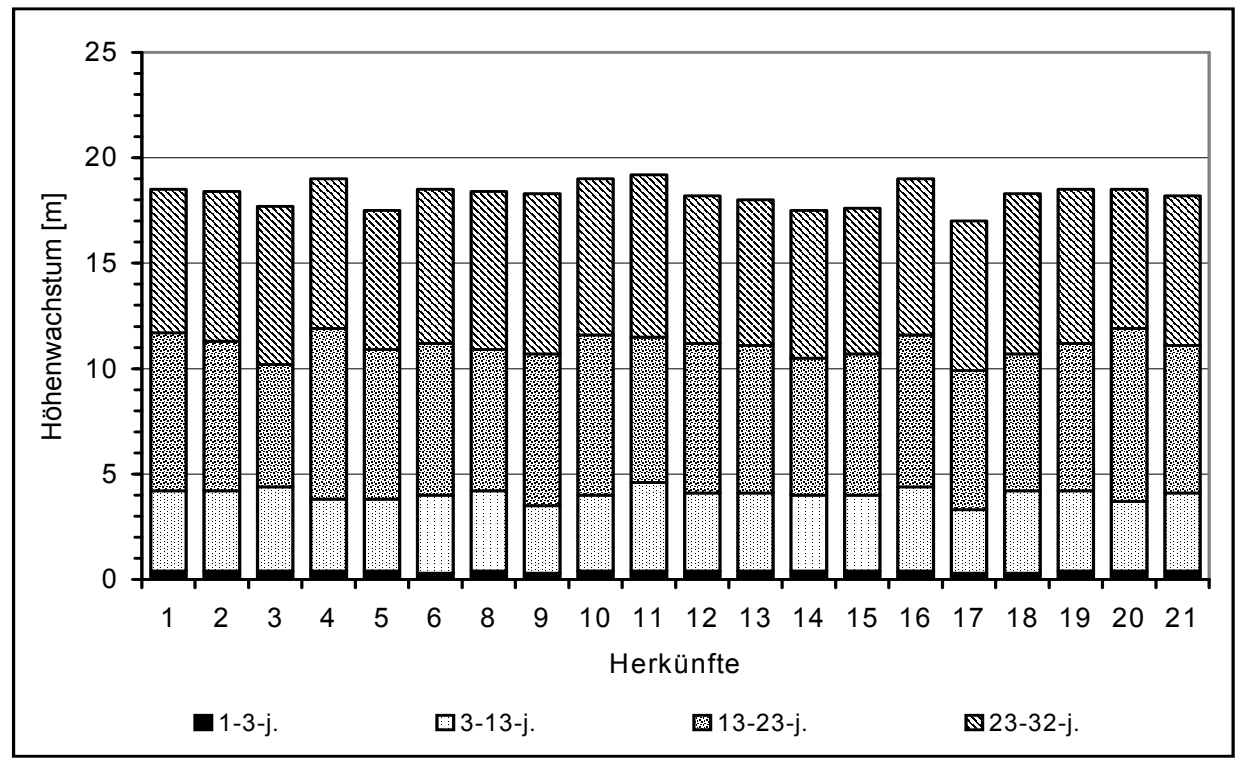

Abb.3.33: Entwicklung des Höhenwachstums der 20 polnischen Herkünfte bis zum Alter von 32 Jabren auf der Fläche Dassel / Niedersachsen

Im mittleren BHD variieren die 20 Herkünfte stärker. Auch hier ist die Herkunft Nr. 10 (Wisła) die beste und die Nr. 17 (Witów) die mattwüchsigste. Der Wuchsunterschied im Alter von 32 Jahren ist (Tukey-Test bzw. Dunnett-Test, $\alpha=0,05$ ) nicht signifikant. Auch im Alter von 23 Jahren gibt es keine gesicherten Unterschiede (Tukey-Test bzw. Dunnett-Test, $\alpha=0,05$ ). 


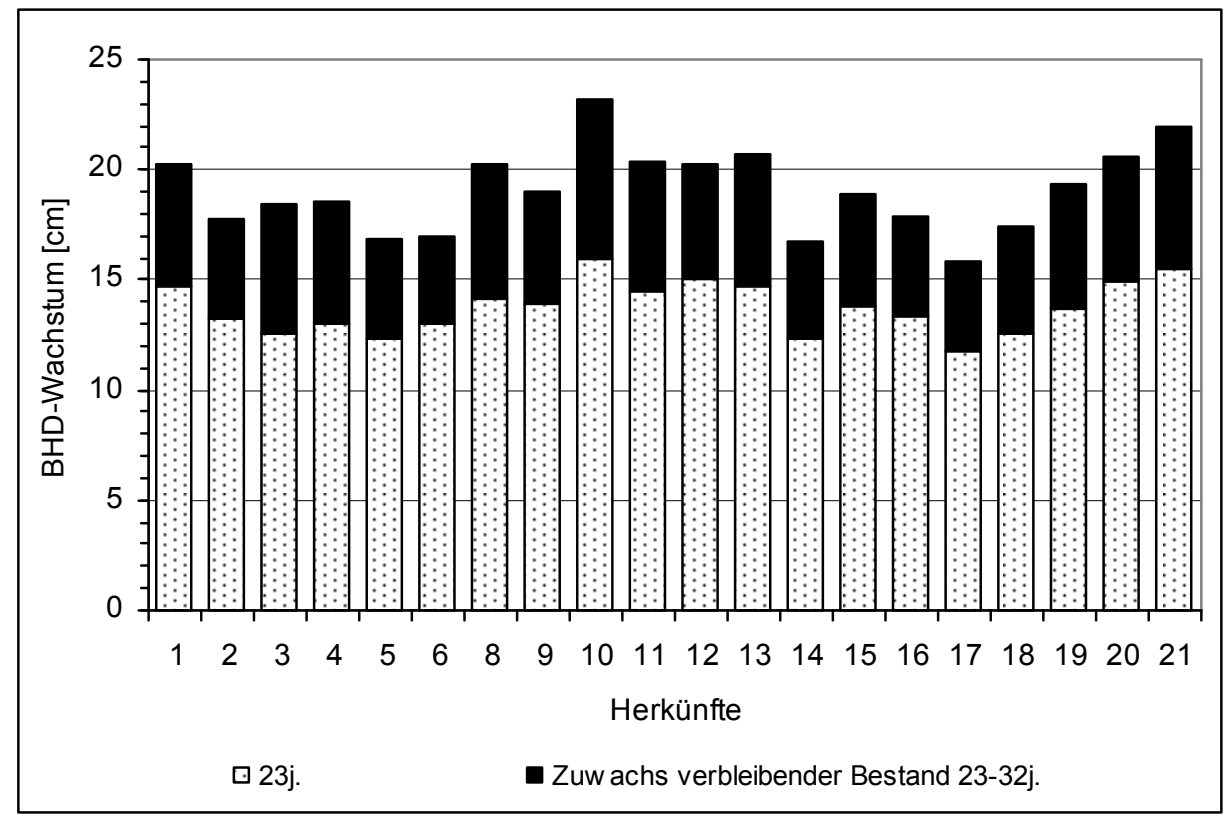

Abb. 3.34: Entwicklung des BHD-Wachstums der 20 polnischen Herkünfte auf der Fläche Dassel / Niedersachsen

Die Streuung der Einzelwerte um den Mittelwert ändert sich nur gering im Alter von 23 auf 32 Jahre. So nimmt sie beim Merkmal Höhenwachstum im Alter von 23 Jahren $(\mathrm{s} \%=11,0)$ zum Alter von 32 Jahren $(\mathrm{s} \%=8,9)$ leicht ab, bleibt beim H/D-Verhältnis etwa gleich $(23-\mathrm{j} .: \mathrm{s} \%=13,1,32-\mathrm{j} .: \mathrm{s} \%=13,9)$ und steigt beim BHD gering von $\mathrm{s} \%=21,4$ (Alter 23) auf s\% $=23,5$ (Alter 32) an.

Ein Vergleich des Wachstums im Beobachtungszeitraum zeigt, dass diese Merkmale nur selten korreliert sind (Tab. 3.17). So ist nur das Durchmesserwachstum im Alter von 23 Jahren mit dem Durchmesser im Alter von 32 Jahren sowie die Höhen der beiden Alter hoch korreliert. Der engste Zusammenhang besteht zwischen den mittleren Durchmessern im Alter 23 und 32. 
Tab.3.17 Produkt-Momenten-Korrelationsmatrix der Wachstumsmerkmale Höhe und BHD

\begin{tabular}{|c|c|c|c|c|c|c|}
\hline Merkmal & $\mathrm{H} 3$ & $\mathrm{H} 13$ & $\mathrm{H} 23$ & H32 & D23 & D32 \\
\hline $\mathrm{H} 3$ & \multirow[t]{6}{*}{ - } & 0,364 & $0,537 *$ & 0,338 & 0,379 & 0,463 \\
\hline $\mathrm{H} 13$ & & - & 0,249 & $0,477 *$ & 0,226 & 0,285 \\
\hline $\mathrm{H} 23$ & & & - & $0,811^{* * * *}$ & $0,583^{* *}$ & $0,535^{*}$ \\
\hline H32 & & & & - & $0,488^{*}$ & $0,504 *$ \\
\hline D23 & & & & & - & $0,963^{* * *}$ \\
\hline D32 & & & & & & - \\
\hline
\end{tabular}

\section{Einzelbaumvolumen und Vorrat pro Hektar}

Das Einzelbaumvolumen wird aus den Wachstumsmerkmalen Baumhöhe und BHD errechnet. Im Alter von 32 Jahren beträgt es $0,2710 \mathrm{~m}^{3}$ und variiert zwischen den 100 Prüfgliedern von 0,1485 $\mathrm{m}^{3}$ (Herkunft Nr. 17 Witów) bis $0,41605 \mathrm{~m}^{3}$ (Einzelbaumabsaat Nr. 35: Istebna 149h, 11-40). Die Unterschiede lassen sich in multiplen Mittelwertvergleichen (Tukey-Test bzw. Dunnett-Test, $\alpha=0,05$ ) nicht absichern.

Aus den Messwerten der neun Jahre zuvor erfolgten Erhebung errechnet sich ein mittleres Einzelbaumvolumen von $0,0819 \mathrm{~m}^{3}$. Zwischen den einzelnen Prüfgliedern variieren die Werte von $0,0518 \mathrm{~m}^{3}$ (Herkunft $\mathrm{Nr}$. 17 Witów) bis $0,1286 \mathrm{~m}^{3}$ (Einzelbaumabsaat Nr. 35: Istebna 149h, 11-40). Die Tukey-Prozedur führt zu zwei sich stark überlappenden Gruppen, in denen sich nur die beiden Extreme signifikant unterscheiden. Im Vergleich gegen den Standard (Dunnett-Test, $\alpha=0,05$ ) ist die Einzelbaumabsaat Nr. 35 (Istebna 149h, 11-40) signifikant überlegen.

In die Vorratsermittlung gehen die drei Merkmale Anzahl lebender Bäume, BHD- und Höhenwachstum ein. Im Alter von 32 Jahren beträgt im Mittel über die 20 polnischen Herkünfte der Vorrat $236 \mathrm{~m}^{3} / \mathrm{ha}$. Zwischen den Herkünften (Abb. 3.35) variiert der errechnete Vorrat zwischen $140 \mathrm{~m}^{3} / \mathrm{ha}$ (Herkunft Nr. 3 Wigry) und $349 \mathrm{~m}^{3} /$ ha (Herkunft Nr. 11 Istebna 149h). Dies entspricht $59 \%$ bzw. $148 \%$ vom Mittel der 20 polnischen Herkünfte. In der Wuchsleistung steht die Herkunft Nr. 10 (Wisła) der Herkunft Nr. 11 (Istebna 149h) nicht nach. Für diese Herkunft werden $343 \mathrm{~m}^{3} /$ ha errechnet, was $146 \%$ des Versuchsflächenmittels entspricht. 


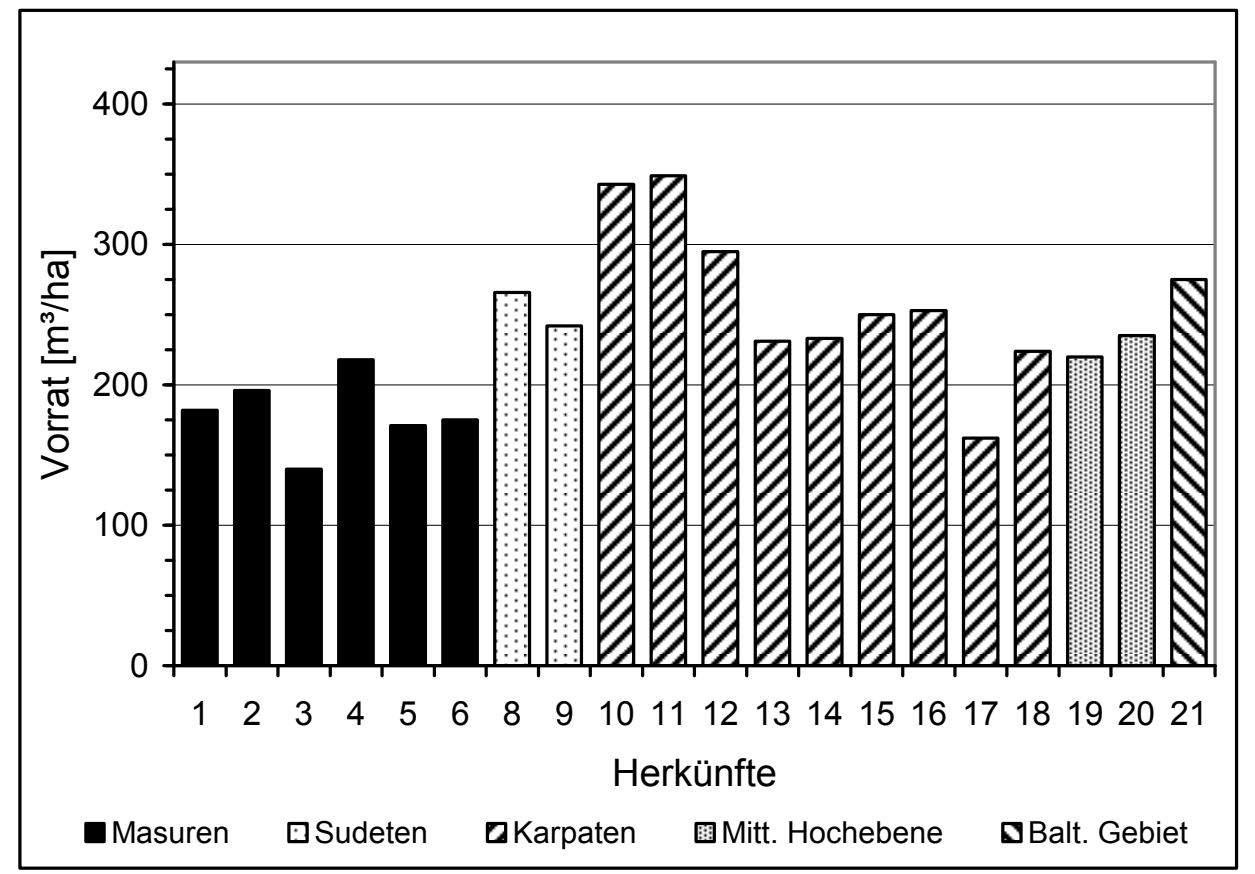

Abb. 3.35: Hochgerechneter Vorrat je Hektar der 20 polnischen Herkünfte auf der Versuchsfläche Dassel / Niedersachsen im Alter von 32 Jahren

Die Abbildung 3.35 zeigt auch, dass die Herkünfte aus einer geografischen Region im Volumen stark divergieren. Zu den vorratsreichen Herkünften zählt auch die nicht autochthone Herkunft aus dem Baltischen Gebiet (Nr. 21: 125 \%). Für die doppelt vertretene Herkunft (Istebna $115 \mathrm{f}$ (Nr. 12 und 404) wird jeweils ein Vorrat von $295 \mathrm{~m}^{3} /$ ha $(125 \%)$ errechnet.

Im Alter von 23 Jahren beträgt der Vorrat im Mittel über die 20 polnischen Herkünfte $82 \mathrm{~m}^{3} /$ ha. Die Fichten hatten somit in den neun Jahren (Alter von 23 bis 32 Jahren) einen mittleren Zuwachs von 17,1 $\mathrm{m}^{3} /$ ha und Jahr. In Abbildung 3.36 ist der Vorrat im Alter von 23 Jahren für die IUFRO-Herkünfte dargestellt. Die Unterschiede zwischen der wüchsigen Herkunft Nr. 11 (Istebna 149h) mit $146 \%$ und der mattwüchsigen Herkunft Nr. 3 (Wigry) mit $63 \%$ fallen etwas geringer aus als neun Jahre später.

Die Vorräte der IUFRO-Herkünfte sind zwischen den beiden Erhebungen im Alter von 23 und 32 Jahren sehr hoch korreliert ( $\left.r_{P}=0,933^{* * *}\right)$, dies gilt auch für alle 100 Prüfglieder $\left(\mathrm{r}_{\mathrm{P}}=0,935^{* * *}\right)$. 


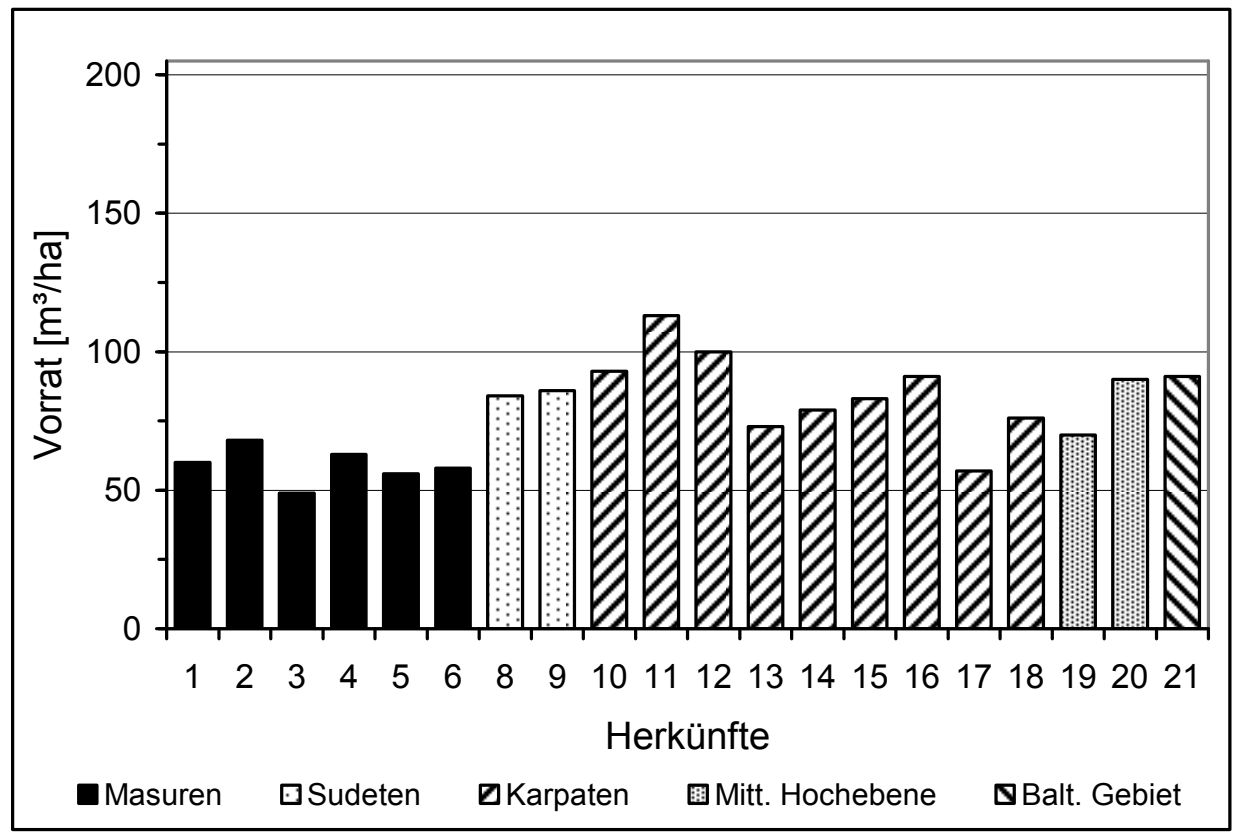

Abb. 3.36: Hochgerechneter Vorrat je Hektar der 20 polnischen Herkünfte auf der Versuchsfläche Dassel / Niedersachsen im Alter von 23 Jahren

In Abbildung 3.37 ist mittlere Vorrat der Einzelbaumnachkommenschaften dem der Herkünfte gegenübergestellt. Im Alter von 32 Jahren sind die Herkünfte Nr. 10 (Wisła) und Nr. 11 (Istebna 149h) wüchsiger als das Mittel der Einzelbaumnachkommenschaften. Bei der Herkunft Nr. 3 (Wigry) zeigt das Mittel der Einzelbaumnachkommenschaften eine höhere Volumenleistung als die Herkunftsabsaat. Dieses deutet sich auch bei der Herkunft Nr. 13 (Zwardon) sowie schwächer bei den Herkünften Nr. 5 (Borki) und Nr. 18 (Tarnawa) an. Bei den weiteren Herkünften gibt es keine Unterschiede. Im Alter von 23 Jahren waren die Unterschiede noch nicht so stark ausgeprägt. 


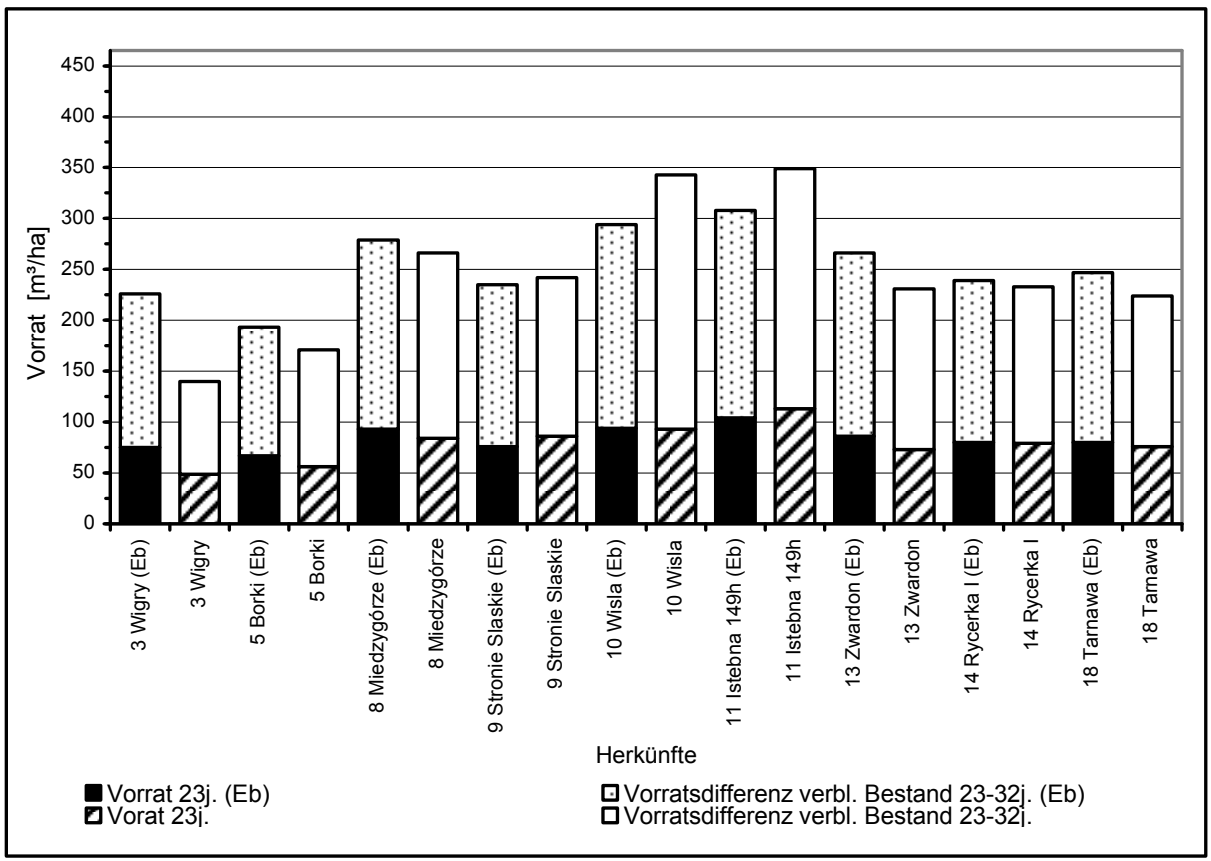

Abb. 3.37: Hochgerechneter Vorrat je Hektar der neun zu Herkünften zusammengefassten Einzelbaumnachkommenschaften (Eb) auf der Versuchsfläche Dassel / Niedersachsen im Alter von 23 und 32 Jahren. Zum Vergleich sind diesen jeweils die Herkunftsabsaaten gegenübergestellt.

Die Vorräte der 100 Prüfglieder auf der Versuchsfläche wurden im multiplen Mittelwertvergleich der Tukey-Prozedur $(\alpha=0,05)$ getestet. Der Mittelwertvergleich ergibt drei sich stark überlappende Gruppen im Alter 32 (Anhang 2.13). Im Alter von 23 Jahren führt der multiple Mittelwertvergleich der Tukey-Prozedur zu zwei sich stark überlappenden Gruppen.

Parallel zur Tukey-Prozedur wurden auch zweiseitige Dunnett-Tests gegen eine Kontrollgruppe bestehend aus den acht polnischen Herkünften, die auf allen Versuchsflächen ausgepflanzt wurden, durchgeführt. Beim Vorrat im Alter 32 unterschied sich die wüchsige Einzelbaumnachkommenschaft Nr. 48 (Miedzygórze, 8-56) signifikant ( $\alpha=0,05)$ von der Kontrollgruppe. Im Alter von 23 Jahren war der Unterschied zur Einzelbaumnachkommenschaft Nr. 36 (Istebna 149h, 1145) signifikant.

Die zuvor durchgeführten Tests basieren auf der Auswertung der Versuchsfläche als Blockversuch. Erfolgt die Analyse unter Berücksichtigung des AlphaDesigns (Gitter), d. h. als kombinierte Inter-Intra-Block-Analyse mit Nutzung der Inter-Block-Information, verringert sich der mittlere Standardfehler im Alter 32 von 11,0611026 (100\%) auf 11,0467667 (99,87\%) im Tukey-Test und von 
8,5414362 (100\%) auf 8,5281267 (99,84\%) im Dunnett-Test. Im Alter 23 verringerte sich der mittlere Standardfehler auf 99,94\% im Tukey-Test und auf 99,93\% im Dunnett-Test. Die etwas kleineren Standardfehler zeigen, dass die Nutzung der Inter-Block-Information in allen Fällen nur einen verschwindend geringen Gewinn erbracht hat. Die Ergebnisse der Auswertung als Gitteranlage werden daher nicht dargestellt.

\subsubsection{Seesen}

\section{Entwicklung der Pflanzenanzahl}

Auf der Fläche Seesen wurden nur zehn IUFRO-Herkünfte angebaut. Im Alter von 32 Jahren leben auf der Versuchsfläche noch $40 \%$ der ursprünglich gepflanzten Fichten der IUFRO-Herkünfte. Die Unterschiede im Anteil lebender Bäume zwischen den Wiederholungen sind sehr gering und variieren nur um 4 \%-Punkte.

Betrachtet man den Anteil lebender Fichten der zu fünf geografischen Regionen zusammengefassten Herkünfte, so findet man im Alter von 32 Jahren die höchsten Anteile in der Region Karpaten (Tab. 3.18).

Tab. 3.18: Anteil lebender Bäume der zu fünf geografischen Regionen zusammengefassten polnischen Herkïnfte (IUFRO), der IUFRO-PG, der zusätzlichen PG und aller PG

\begin{tabular}{lcccc}
\hline Geografische Region & IUFRO-Nr. & Anzahl PG & $1995(23-\mathrm{j})$. & $2004(32-\mathrm{j})$. \\
\hline Masuren-Podlasie & $4-6$ & 3 & $59 \%$ & $38 \%$ \\
Sudeten & 8 & 1 & $65 \%$ & $40 \%$ \\
Karpaten (Beskiden) & $11-13,16$ & 4 & $62 \%$ & $45 \%$ \\
Mittelpolnische Hochebene & 20 & 1 & $50 \%$ & $29 \%$ \\
Baltisches Gebiet & 21 & 1 & $58 \%$ & $37 \%$ \\
\hline IUFRO-Herkünfte & & 10 & $60 \%$ & $40 \%$ \\
\hline zusätzliche PG & & 100 & $61 \%$ & $43 \%$ \\
\hline alle PG & & $61 \%$ & $43 \%$ \\
\hline
\end{tabular}

Zwischen den einzelnen IUFRO-Herkünften variiert der Anteil der noch vorhandenen Fichten zwischen 48 \% (Nr. 12 Istebna 115f, 16 Orawa) und 29 \% (Nr. 20 Blizyn) im Alter von 32 Jahren (Abb. 3.38). Die Unterschiede im Anteil lebender Bäume belaufen sich zwischen den beiden Aufnahmen im Alter von 23 und 32 Jahren auf $20 \%$ bei den IUFRO-Herkünften und auf $18 \%$ zwischen allen Prüfgliedern. 


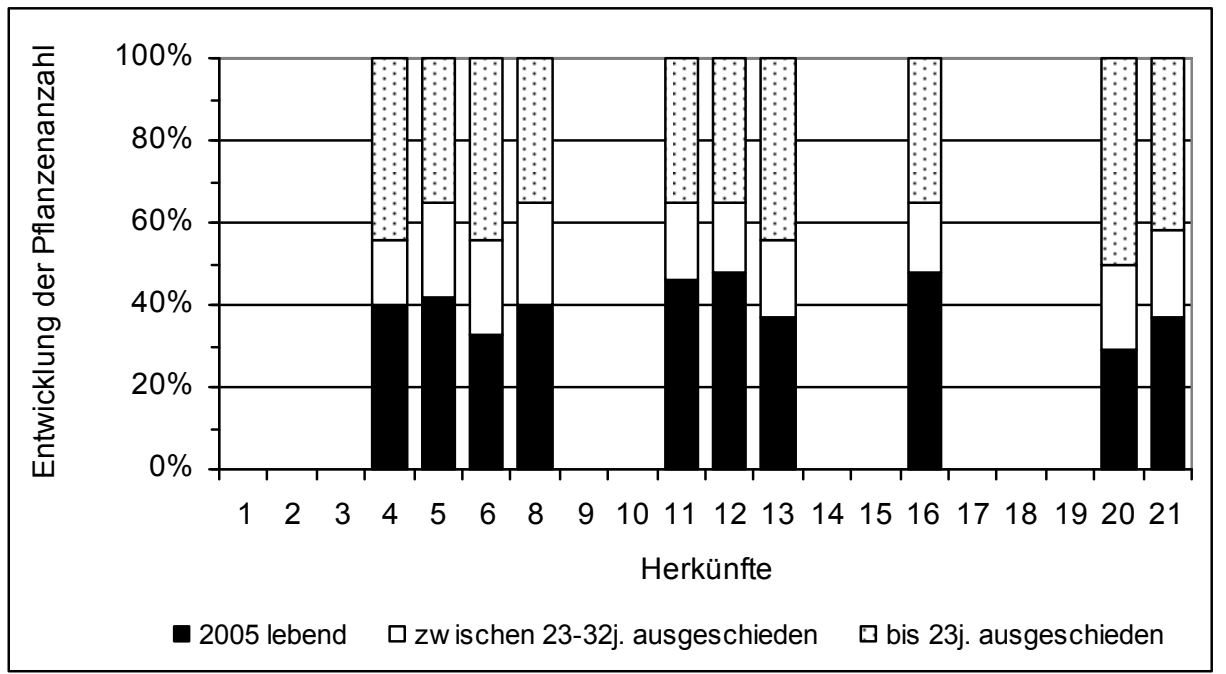

Abb. 3.38: Entwicklung der Pflanzenanzabl auf der Fläche Seesen / Niedersachsen

Auf der Fläche Seesen sind zusätzlich 90 Einzelbaumnachkommenschaften aus sechs Beständen angebaut (Abb. 3.39). Die beiden IUFRO-Herkünfte Nr. 1 (Pogorzelece) und 10 (Wisła) sind nur als Einzelbaumabsaaten mit zehn bzw. neun Bäumen und nicht als IUFRO-Herkunft auf der Versuchsfläche angebaut. Es gibt keine Einzelbaumabsaat, die auch auf der niedersächsischen Fläche Dassel angebaut ist. Die Anteile lebender Fichten als Mittel aus den Einzelbaumabsaaten betragen für Herkunft Nr. 1 (Pogorzelece) $40 \%$ und für die Nr. 10 (Wisła) 43\% im Alter von 32 Jahren. Beide Werte liegen somit im Streubereich der Herkünfte der Regionen „Masuren-Podlasie“ (Nr. 4-6, Abb. 3.38) und „Karpaten (Beskiden)“ (Nr. 11-13, 16, Abb. 3.38). Die Variation zwischen den Einzelbaumnachkommenschaften einer Herkunft ist gering und beträgt 9 bzw. $13 \%$-Punkte.

Bei den weiteren vier Herkünften handelt es sich um Bestandesabsaaten aus vier Abteilungen des Kloster-Forstamtes Westerhof. Die mittleren Anteile lebender Fichten weichen nicht von denen der polnischen Absaaten ab (Abb. 3.39). Die vier Bestände sind durch 2 bis 43 Einzelbaumabsaaten auf der Fläche vertreten. Zwischen den Absaaten einer Herkunft variieren die Unterschiede zwischen 8 und $19 \%$-Punkten. Der Anteil ausscheidender Bäume je Einzelbaumabsaat beträgt im Minimum $50 \%$ und im Maximum $69 \%$. 


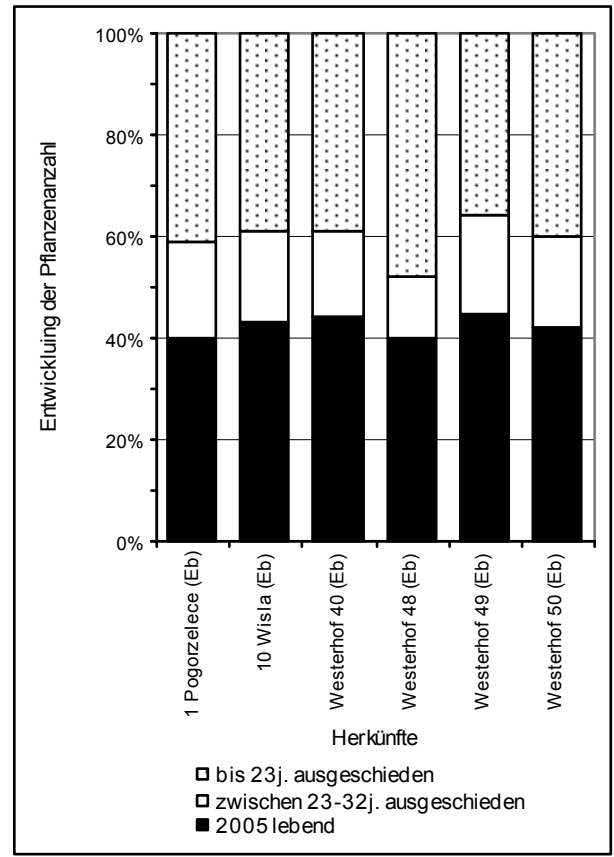

Abb. 3.39: Entwicklung der Pfanzenanzabl der zu sechs Herkünften (Nr. der IUFRO-Herkunft) zusammengefassten Einzelbaumnachkommenschaften (Eb) der zusätzlichen 90 Prüfglieder auf der Fläche Seesen / Niedersachsen

Die Unterschiede $(\alpha=0,05)$ zwischen den 100 Prüfgliedern lassen sich in multiplen Mittelwertvergleichen (Tukey-Test bzw. Dunnett-Test) nicht absichern.

\section{Schadmerkmale}

Auf der Versuchsfläche Seesen wurden im Alter von 32 Jahren fünf Schadmerkmale aufgenommen. Die erfassten Schäden sind insgesamt sehr gering. So wurde an fünf Bäumen (Borken-)Käferbefall und bei insgesamt 48 Bäumen Kronenbrüche notiert. Die Anzahl der Bäume mit einem Zwiesel beläuft sich auf 43. Rückeschäden wurden an 181 Bäumen beobachtet: $56 \%$ der Schäden sind gering, $32 \%$ mäßig und $12 \%$ schwer. Bei dem fünften Schadmerkmal, das aufgenommen wurde, handelt es sich um Stammrisse. Diese traten an 54 Bäumen auf, von denen 53 eine gute Schaftform haben. Eine Konzentration eines Schadens auf ein oder wenige Prüfglieder liegt nicht vor. Die Bäume mit Käferbefall, Kronenbruch und Zwiesel wurden nur in die Berechnung des Anteils lebender Bäume einbezogen. Von der Aufnahme im Alter von 23 Jahren (1995) liegen keine Daten einer Schadbonitur vor. 


\section{Stammform}

Im Alter von 32 Jahren wurde bei 2049 Fichten die Stammform beurteilt. $98 \%$ der Stämme wurden als gerade, $1 \%$ mit einem leichten Mangel und $1 \%$ mit mittlerem bzw. starkem Mangel eingestuft.

Berücksichtigt man bei der Interpretation der Formbonitur die Stammzahl (zwischen 14 und 23), die je Prüfglied beurteilt wurde, liegen zwischen den IUFRO-Herkünften keine Unterschiede vor. Bei den zu Herkünften zusammengefassten Einzelbaumnachkommen sind jeweils zwischen 185 und 925 Fichten bonitiert worden, mit Ausnahme der Herkunft Westerhof Abt. 48 mit nur zwei Einzelbaumnachkommenschaften, bei der 38 Fichten bonitiert wurden. Entsprechend der geringen Differenzierung des Merkmals gibt es keine Unterschiede zwischen den Herkünften (Abb. 3.40). Für das Alter 23 liegt keine Bonitur der Form vor.

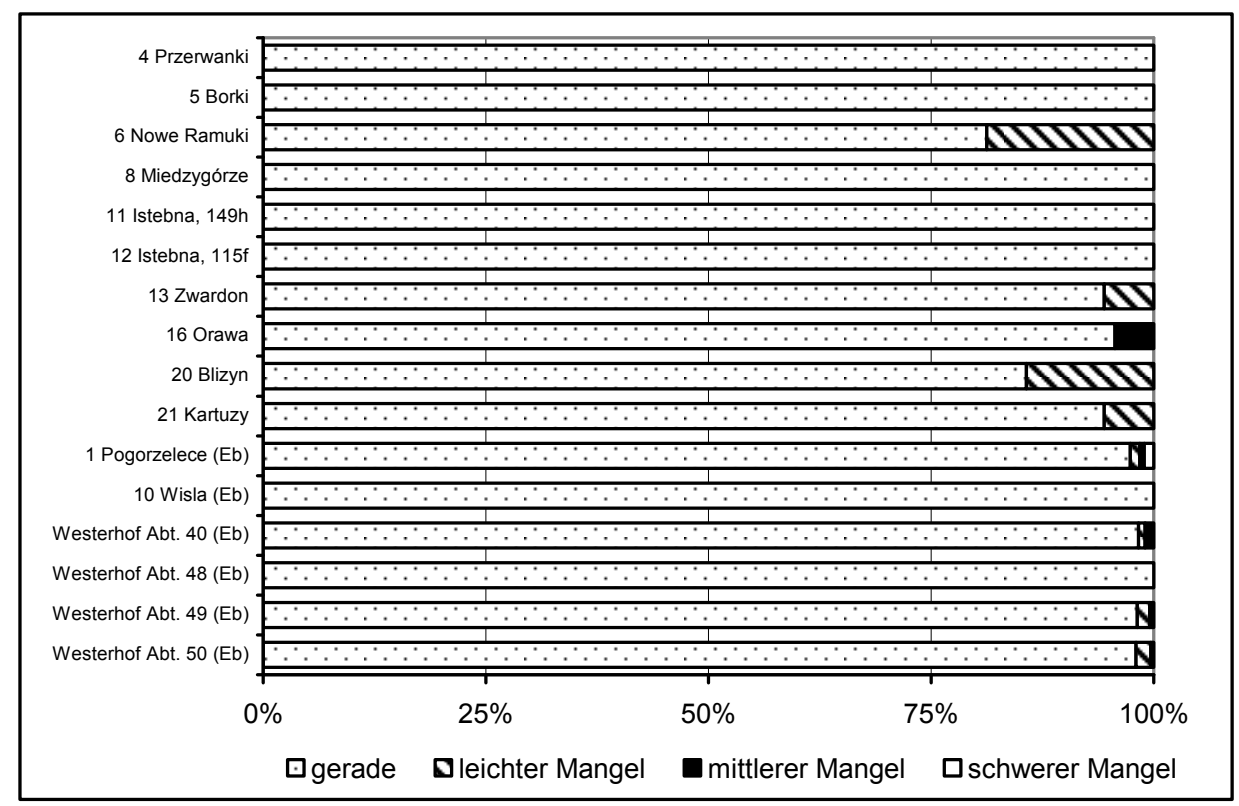

Abb. 3.40: Ergebnis der Beurteilung der Stammform der 16 Prüfglieder auf der Fläche Seesen / Niedersachsen im Alter von 32 Jahren (Eb = Einzelbaumabsaaten zusammengefasst)

\section{Ovalität}

Die Abweichung des Stammquerschnittes von der Kreisform beträgt im Mittel der IUFRO-Herkünfte auf der Versuchsfläche Seesen 3,3 und variiert zwischen den Herkünften von 2,1 (Nr. 12 Istebna 115f) mit den geringsten Abweichungen bis 5,7 (Nr. 21 Kartuzy) mit der größten Abweichung von der Kreisform. 
Auch unter Einbeziehung der zusätzlichen 90 Einzelbaumnachkommenschaften bleibt die mittlere Ovalität bei 3,0. Die Extremwerte variieren zwischen 1,6 und 6,3 (Anhang 2.14). Zwischen den 100 Prüfgliedern ergeben die multiplen Mittelwertvergleiche (Tukey-Test bzw. Dunnett-Test) keine gesicherten $(\alpha=0,05)$ Unterschiede.

Die Güte dieses Maßes lässt sich nicht beurteilen, da keine Aufzeichnungen vorliegen, aus denen hervorgeht, ob jeweils die Bäume an der dicksten bzw. dünnsten Stelle in 1,3 m Höhe gemessen wurden.

\section{H/D-Verbältnis}

Für die zehn polnischen Herkünfte beträgt der mittlere H/D-Wert 74 im Alter 32 und variiert zwischen 67 (Nr. 8 Miedzygórze) und 81 (Nr. 4 Przerwanki). Unter Einbeziehung der 90 Einzelbaumnachkommenschaften beträgt der mittlere H/DWert 73. Für die nach Herkünften zusammengefassten Einzelbaumnachkommenschaften werden mittlere H/D-Verhältnisse zwischen 71 und 78 errechnet. Die vier zusammengefassten Herkünfte Westerhof haben H/D-Verhältnisse zwischen 71 und 73 .

Im Alter von 23 Jahren hatten die Fichten der IUFRO-Herkünfte einen H/DWert von 73 und alle 100 Prüfglieder einen mittleren H/D-Wert von 72. Die schlankste IUFRO-Herkunft hatte ein H/D-Verhältnis von 79 (Nr. 4 Przerwanki) und die abholzigste Herkunft eines von 67 (Nr. 21 Kartuzy).

Die H/D-Verhältnisse der einzelnen Prüfglieder im Alter von 23 und 32 Jahren sind in Anhang 2.15 zusammengestellt. Die Unterschiede $(\alpha=0,05)$ zwischen den 100 Prüfgliedern im Alter von 23 bzw. 32 Jahren lassen sich in multiplen Mittelwertvergleichen (Tukey-Test und Dunnett-Test) nicht absichern.

\section{Höhen- und BHD-Wachstum}

Das Höhenwachstum auf der Fläche Seesen ist geringer als auf der Fläche Dassel. So haben die Fichten ohne Kronenbruch und ohne Zwiesel im Alter von 23 Jahren eine mittlere Höhe von 9,96 m ( $\mathrm{n}=900)$ erreicht und bei der letzten Messung im Alter von 32 Jahren liegt die mittlere Höhe bei 15,67 m ( $\mathrm{n}=872)$.

Der mittlere Durchmesser der Fichten beträgt im Alter von 32 Jahren $20,9 \mathrm{~cm}$ $(\mathrm{n}=1982)$ und hat neun Jahre zuvor bei $13,3 \mathrm{~cm}$ gelegen $(\mathrm{n}=2913)$.

Die Streuung der Höhen-Einzelwerte um den Mittelwert ist zwischen den beiden Messungen im Alter von 23 und 32 Jahren gering und nahezu gleich. So beträgt die relative Streuung (Variationskoeffizient) der gemessenen Baumhöhen im Alter von 23 Jahren für den Gesamtversuch noch 9,6\% und liegt im Alter von 32 Jahren bei 7,4\%. Beim BHD streuen die Werte mehr. Aber auch hier gibt es keine Unterschiede, der Variationskoeffizient im Alter von 23 Jahren beträgt 16,6 \% und im Alter von 32 Jahren 16,9\%. 
In Abbildung 3.41 ist die Entwicklung des Höhenwachstums und in Abbildung 3.42 die des BHD-Wachstums der zehn polnischen IUFRO-Herkünfte sowie in Abbildung 3.43 die Höhen und die BHD im Alter 32 der zu sechs Herkünften zusammengefassten zusätzlichen Einzelbaumnachkommenschaften dargestellt. Im Alter von 32 Jahren sind sowohl die zehn IUFRO-Herkünfte als auch die zusätzlichen sechs Herkünfte bezüglich der erreichten Baumhöhen ähnlich. Die mittleren Durchmesser variieren etwas stärker als die mittleren Höhen. Hier sind die IUFRO-Herkünfte Nr. 8 (Miedzygórze) und Nr. 21 (Kartuzy) die wüchsigsten und die Nr. 20 (Blizyn) die mattwüchsigste (Abb. 3.42). Dennoch lassen sich im Alter von 32 Jahren keine Unterschiede absichern (Tukey-Test bzw. Dunnett-Test, $\alpha=0,05)$.

Im Alter von 23 Jahren werden drei sich stark überlappende Tukey-Gruppen für das Merkmal Baumhöhe gebildet (Anhang 2.16). Die Herkunft Nr. 20 (Blizyn) ist im Höhenwachstum signifikant geringer als die Einzelbaumnachkommenschaft Nr. 170 (Westerhof Abt. 40, 40-45) im Alter 23 (Tukey-Test, $\alpha=0,05$ ). Vom Standard unterscheidet sich kein Prüfglied (Dunnett-Test, $\alpha=0,05$ ).

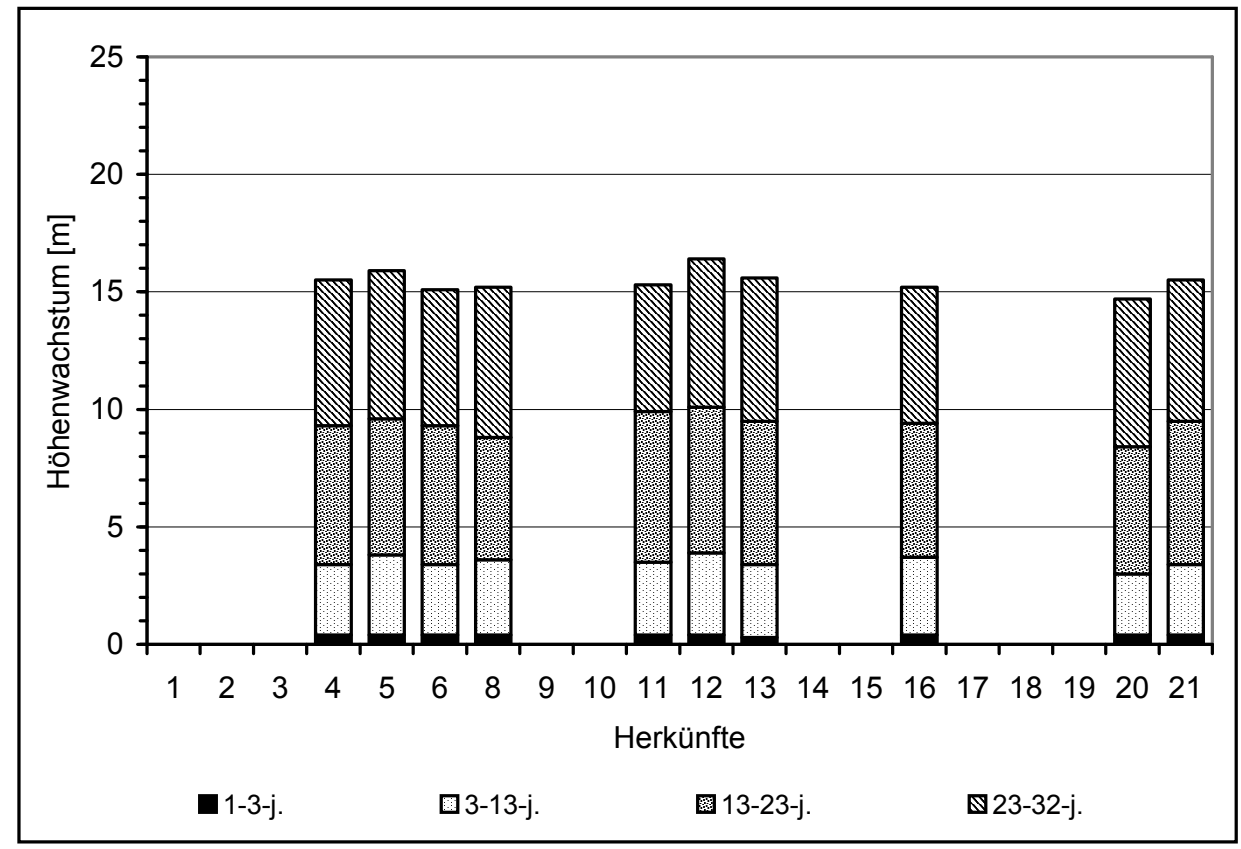

Abb. 3.41: Entwicklung des Höhenwachstums der zehn polnischen Herkünfte bis zum Alter von 32 Jahren auf der Fläche Seesen / Niedersachsen 
Im Alter von 23 Jahren werden fünf sich stark überlappende Tukey-Gruppierungen für das Merkmal BHD gebildet (Anhang 2.16). Zu den Prüfgliedern, die signifikant geringwüchsig sind, zählt wie bei der Baumhöhe die IUFRO-Herkunft Nr. 20 (Blizyn). Unter den wüchsigen Einzelbaumnachkommenschaften sind die Prüfglieder Nr. 109 (Wisła, 10-55) und Nr. 186 (Westerhof Abt. 40, 40-61). Vom Standard unterscheidet sich kein Prüfglied (Dunnett-Test, $\alpha=0,05)$.

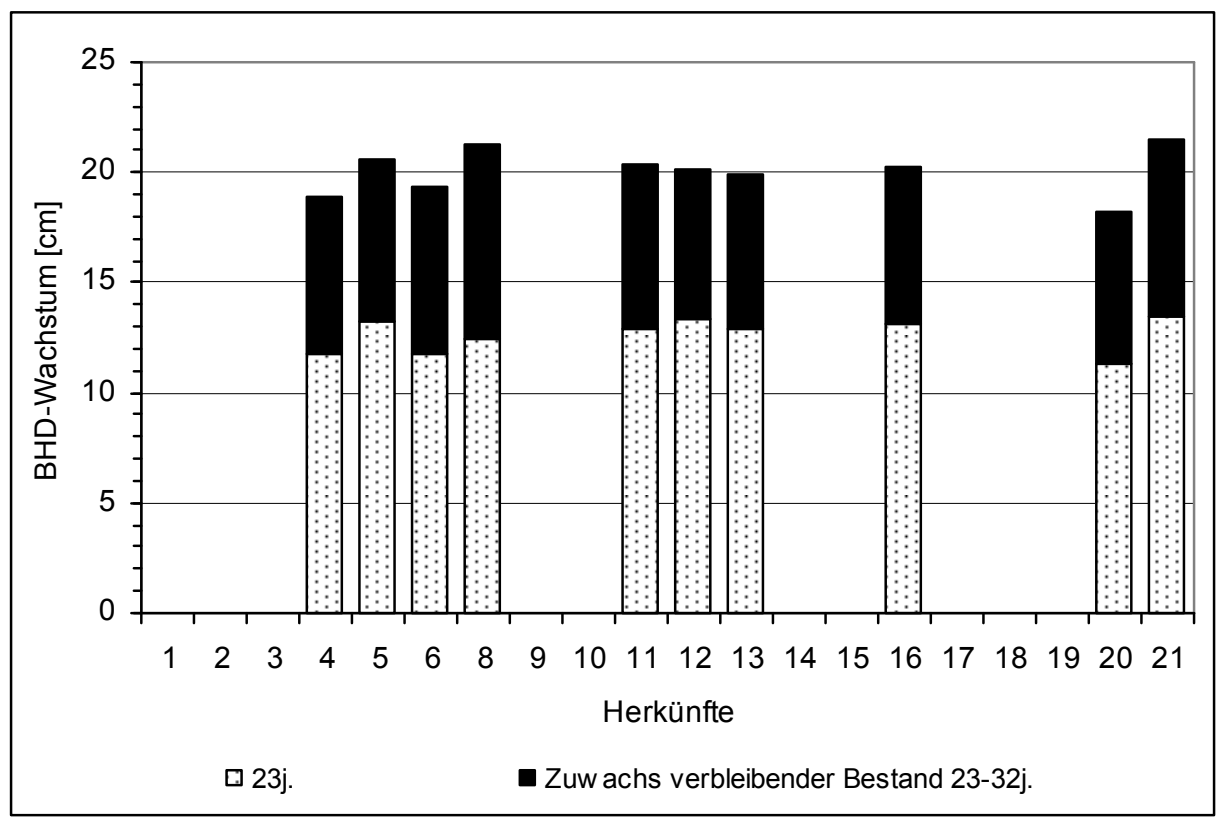

Abb. 3.42: Entwicklung des BHD-Wachstums der zehn polnischen Herkünfte auf der Fläche Seesen / Niedersachsen 


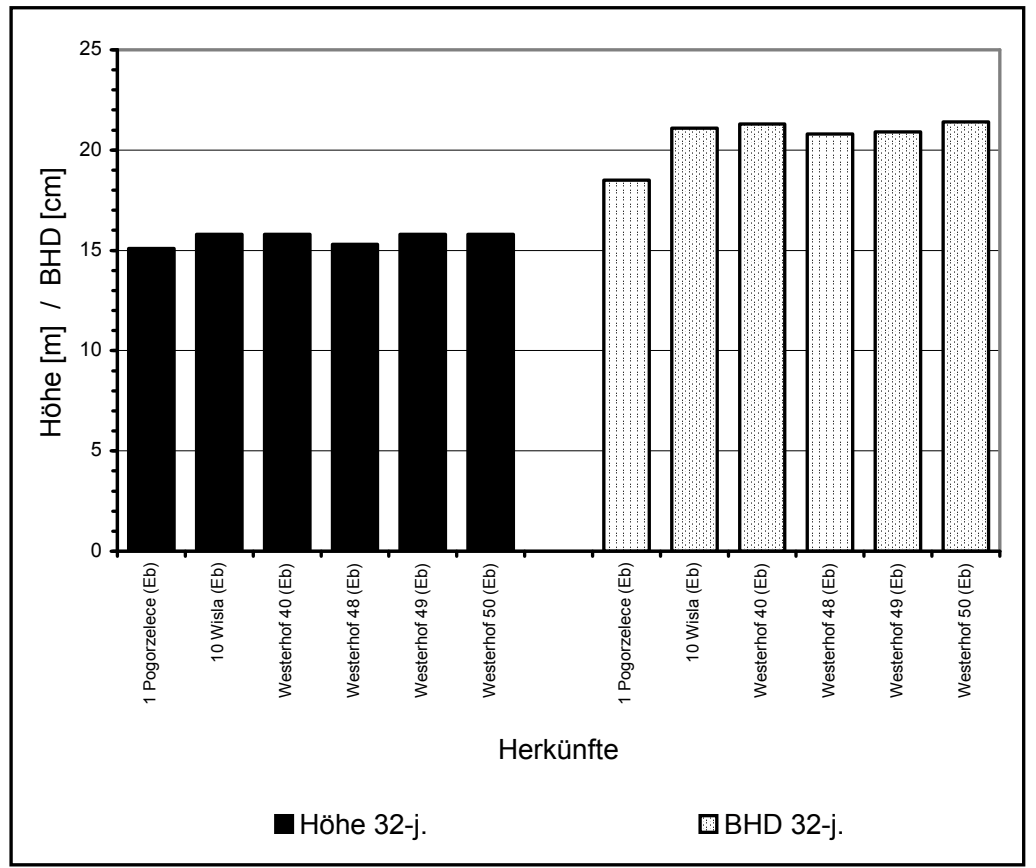

Abb. 3.43: Höhenwachstum (links) und BHD-Wachstum (rechts) der zu sechs Herkë̈ften zusammengefassten Einzelbaumnachkommenschaften (Eb) der zusätzlichen 90 Prüfglieder im Alter von 32 Jahren auf der Fläche Seesen / Niedersachsen

Ein Vergleich der Wachstumsparameter im Beobachtungszeitraum zeigt, dass diese Merkmale nur selten korreliert sind (Tab. 3.19). So ist das Höhenwachstum im Alter von 23 Jahren mit dem im Alter von 32 Jahren am engsten korreliert.

Tab. 3.19: $\quad$ Produkt-Momenten-Korrelationsmatrix der Wachstumsmerkmale Höhe und BHD

\begin{tabular}{|c|c|c|c|c|c|c|}
\hline Merkmal & $\mathrm{H} 3$ & H13 & $\mathrm{H} 23$ & H32 & D23 & D32 \\
\hline $\mathrm{H} 3$ & \multirow[t]{6}{*}{ - } & $-0,97$ & 0,199 & 0,124 & 0,045 & $-0,113$ \\
\hline H13 & & \multirow[t]{5}{*}{-} & $0,719 *$ & $0,784^{* *}$ & $0,740 *$ & 0,518 \\
\hline $\mathrm{H} 23$ & & & \multirow[t]{4}{*}{-} & $0,810^{* *}$ & $0,694 *$ & 0,322 \\
\hline H32 & & & & \multirow[t]{3}{*}{ - } & $0,670^{*}$ & 0,335 \\
\hline D23 & & & & & \multirow[t]{2}{*}{-} & $0,805^{* *}$ \\
\hline D32 & & & & & & - \\
\hline
\end{tabular}

\section{Einzelbaumvolumen und Vorrat pro Hektar}

Das Einzelbaumvolumen errechnet sich aus den Wachstumsmerkmalen Baumhöhe und BHD und beträgt im Mittel der Versuchsfläche Seesen 0,2758 $\mathrm{m}^{3} \mathrm{im}$ Alter von 32 Jahren. Es variiert zwischen 0,1667 $\mathrm{m}^{3}$ (Prüfglied 113: Pogorezelece, 
1-28) und 0,3605 $\mathrm{m}^{3}$ (Prüfglied 181: Westerhof Abt. 40, 40-56). Aus den Messwerten der Erhebung im Alter von 23 Jahren errechnet sich ein mittleres Einzelbaumvolumen von $0,0658 \mathrm{~m}^{3}$. Zwischen den Prüfgliedern variiert es von 0,0359 (Prüfglied 119: Pogorzelece, 1-75) bis $0,0841 \mathrm{~m}^{3}$ (Prüfglied 109: Wisła 10-55). Die Unterschiede $(\alpha=0,05)$ zwischen den 100 Prüfgliedern im Alter von 23 bzw. 32 Jahren lassen sich in multiplen Mittelwertvergleichen (Tukey-Test und DunnettTest) nicht absichern.

In die Vorratsermittlung gehen die drei Merkmale Anzahl lebender Bäume, BHD- und Höhenwachstum ein. Im Alter von 32 Jahren beträgt der Vorrat $240 \mathrm{~m}^{3} / \mathrm{ha}$ im Mittel über die 10 polnischen Herkünfte. Zwischen den IUFROHerkünften (Abb. 3.44) variiert der errechnete Vorrat zwischen $135 \mathrm{~m}^{3} / \mathrm{ha}(\mathrm{Nr} .20$ Blizyn) und $297 \mathrm{~m}^{3} /$ ha (Nr. 11 Istebna 149h). Dies entspricht $57 \%$ bzw. $126 \%$ vom Mittel der zehn polnischen Herkünfte. Ähnliche Wuchsleistung wie die Herkunft Nr. 11 (Istebna 149h) zeigen noch weitere Herkünfte. Die Abbildung 3.44 zeigt auch, dass die Herkünfte einer geografischen Region im Vorrat stark divergieren. $\mathrm{Zu}$ den vorratsreicheren Herkünften zählt die nicht autochthone Herkunft aus dem Baltischen Gebiet (Nr. 21: $125 \%$ ).

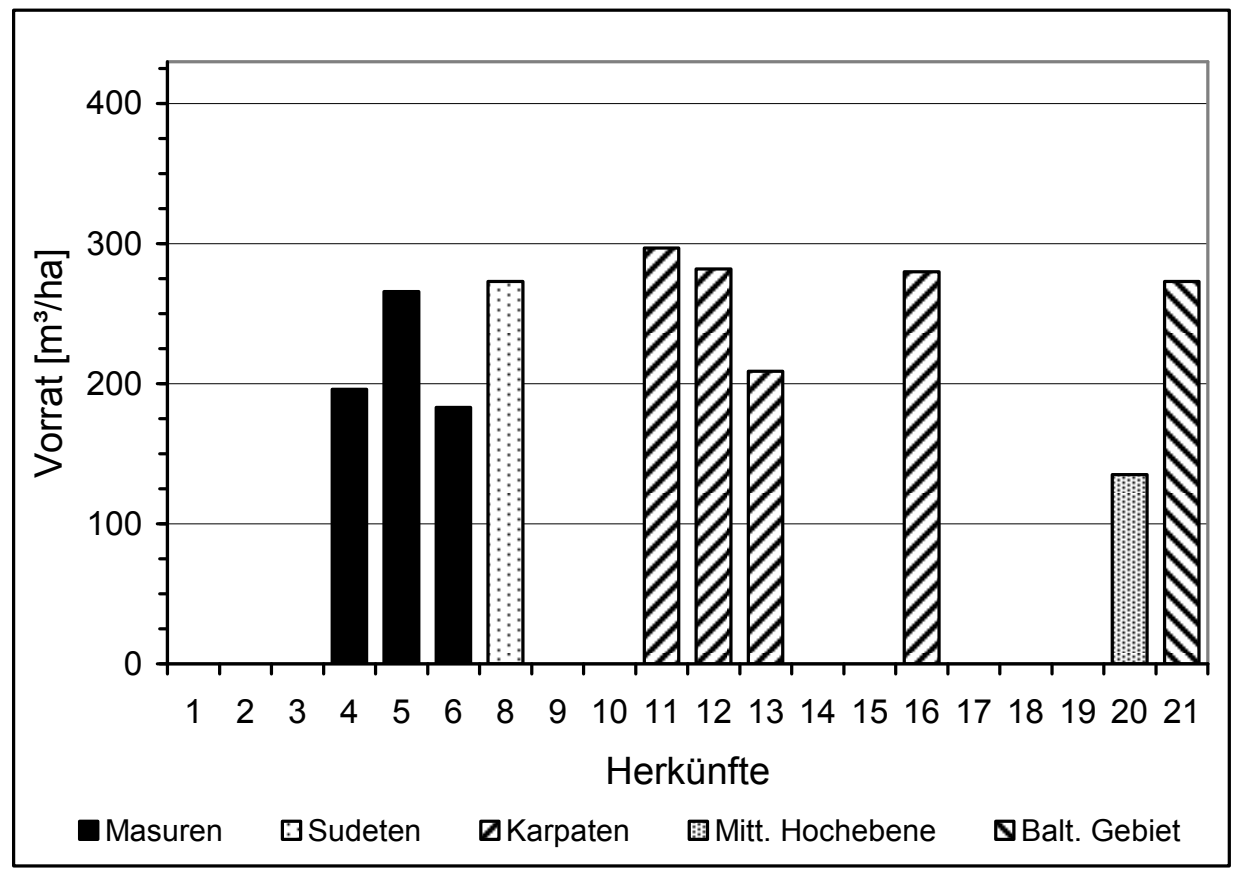

Abb. 3.44: Hochgerechneter Vorrat je Hektar der zehn polnischen Herkünfte auf der Versuchsfläche Seesen / Niedersachsen im Alter von 32 Jabren 
Im Alter von 23 Jahren betrug der Vorrat im Mittel über die zehn polnischen Herkünfte $84 \mathrm{~m}^{3} /$ ha. In Abbildung 3.45 ist der Vorrat im Alter von 23 Jahren für die IUFRO-Herkünfte dargestellt. Die Unterschiede zwischen den wüchsigen Herkünften Nr. 12 (Istebna 115f) und Nr. 21 (Kartuzy) mit 122\% und der mattwüchsigen Herkunft Nr. 20 (Blizyn) mit $60 \%$ fallen etwas geringer aus als neun Jahre später.

Die Vorräte der IUFRO-Herkünfte sind zwischen den beiden Erhebungen im Alter von 23 und 32 Jahren korreliert $\left(r_{P}=0,958^{* *}\right)$ und für alle 100 Prüfglieder sehr stark korreliert ( $\left.\mathrm{r}_{\mathrm{P}}=0,850 * * *\right)$.

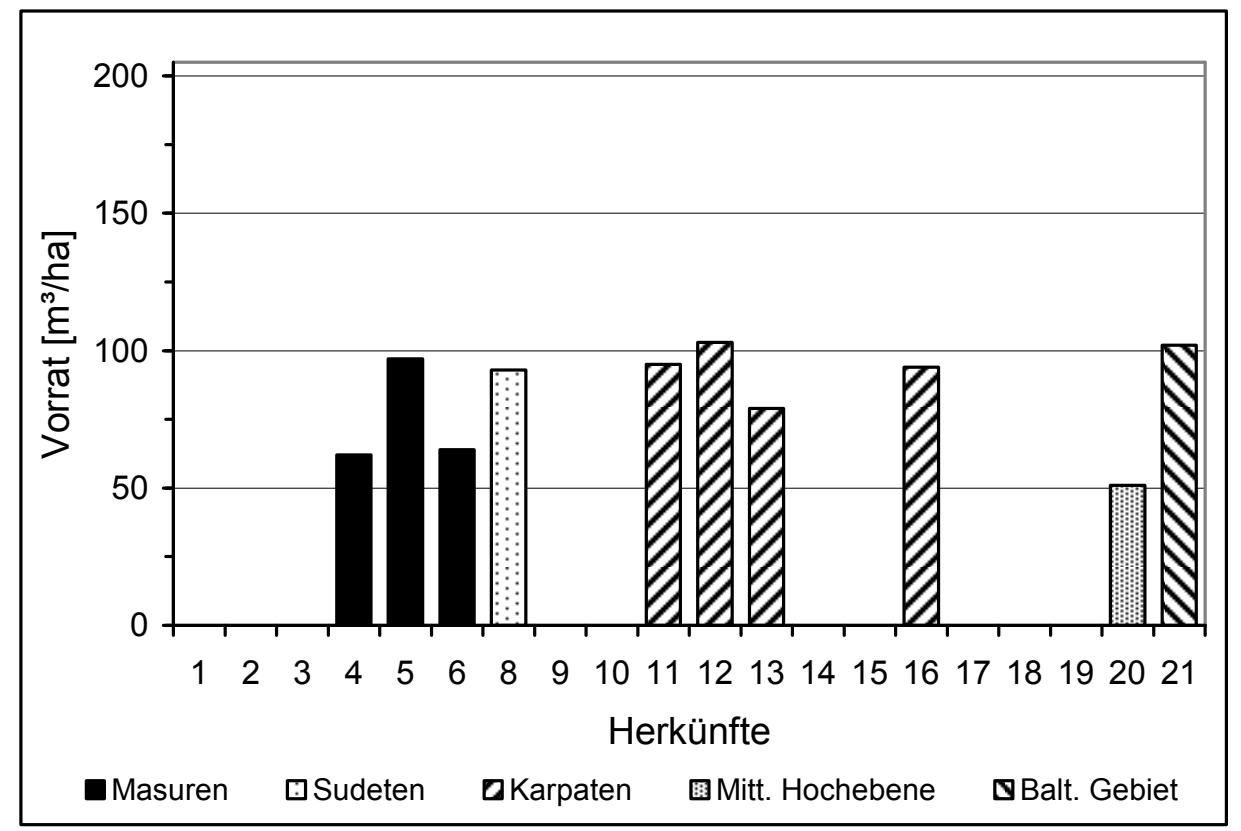

Abb. 3.45: Hochgerechneter Vorrat je Hektar der zehn polnischen Herkünfte auf der Versuchsfläche Seesen / Niedersachsen im Alter von 23 Jahren

In Abbildung 3.46 sind die mittleren Vorräte der zu Herkünften zusammengefassten Einzelbaumnachkommenschaften dargestellt. Die rechnerischen Vorräte im Alter von 23 und 32 Jahren betragen zwischen 260 und $310 \mathrm{~m}^{3} /$ ha und entsprechen damit den wüchsigeren IUFRO-Herkünften. Nur der Vorrat der zusammengesetzten Herkunft Nr. 1 (Pogorzelece) ist geringer und beträgt im Alter von 32 Jahren $180 \mathrm{~m}^{3} /$ ha. 


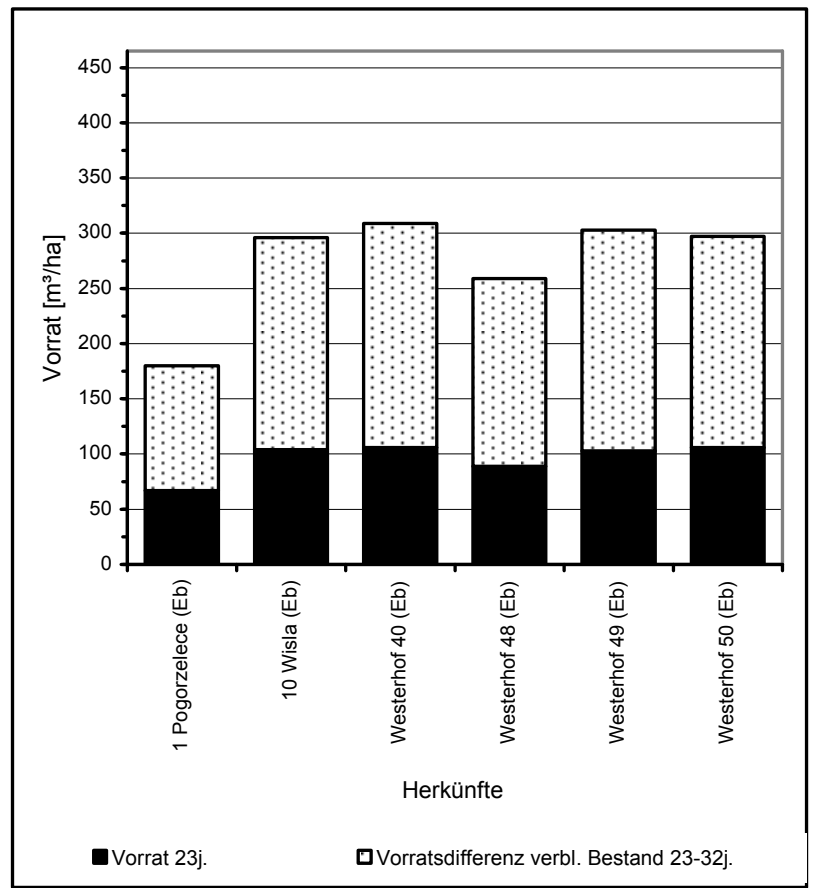

Abb. 3.46: Hochgerechneter Vorrat je Hektar der zu sechs Herkïnften zusammengefassten Einzelbaumnachkommenschaften (Eb) auf der Versuchsfläche Seesen / Niedersachsen im Alter von 23 und 32 Jahren

Die Vorräte der 100 Prüfglieder auf der Versuchsfläche wurden im multiplen Mittelwertvergleich mit der Tukey-Prozedur $(\alpha=0,05)$ getestet. Der Mittelwertvergleich ergibt im Alter 32 zwei sich stark überlappende Gruppen (Anhang 2.17). Dabei ist die Herkunft Nr. 20 (Blizyn) signifikant vorratsärmer als die Einzelbaumabsaat Nr. 147 (Westerhof Abt. 40, 40-22). Im Alter von 23 Jahren ergibt der multiple Mittelwertvergleich mit der Tukey-Prozedur drei sich stark überlappende Gruppen. Auch hier ist die IUFRO-Herkunft Nr. 20 (Blizyn) signifikant vorratsärmer als mehrere Einzelbaumabsaaten aus den Westerhofer Beständen und einer polnischen Herkunft aus Wisła.

Parallel zur Tukey-Prozedur wurden auch zweiseitige Dunnett-Tests gegen eine Kontrollgruppe bestehend aus den acht polnischen Herkünften, die auf allen Versuchsflächen ausgepflanzt wurden, durchgeführt. Beim Vorrat im Alter 32 unterscheidet sich die vorratsreichste Einzelbaumnachkommenschaft Nr. 147 (Westerhof Abt. 40,40-22) signifikant $(\alpha=0,05)$ von der Kontrollgruppe. Im Alter von 23 Jahren war der Unterschied der Einzelbaumnachkommenschaft Nr. 170 (Westerhof Abt. 40, 40-45) zum Standard signifikant. 
Die zuvor dargestellten Tests basieren auf der Auswertung der Versuchsfläche als Blockversuch. Erfolgt die Analyse unter Berücksichtigung des Alpha-Designs (Gitter), d. h. als kombinierte Inter-Intra-Block-Analyse mit Nutzung der InterBlock-Information, verringert sich der mittlere Standardfehler im Alter 32 von 9,9685778 (100\%) auf 9,959974 (99,91\%) im Tukey-Test und von 7,9074554 $(100 \%)$ auf 7,8995324 (99,90\%) im Dunnett-Test. Im Alter 23 verringert sich der mittlere Standardfehler auf 99,94\% im Tukey-Test und auf 99,93\% im DunnettTest. Die etwas kleineren Standardfehler zeigen, dass die Nutzung der Inter-BlockInformation in allen Fällen nur einen verschwindend geringen Gewinn erbracht hat. Die Ergebnisse der Auswertung als Gitteranlage werden daher nicht dargestellt.

\subsubsection{Baden-Württemberg}

\subsubsection{Ochsenhausen $A$}

\section{Entwicklung der Pflanzenanzabl}

Im Alter von 22 Jahren leben auf der Versuchsfläche noch $45 \%$ der ursprünglich gepflanzten Fichten der 23 Herkünfte. Im Mittel der 20 IUFRO-Herkünfte sind die Ausfälle ein Prozent höher und bei den zusätzlichen drei Herkünften ein Prozent geringer. Die Unterschiede im Ausfall der IUFRO-Herkünfte liegen bei $13 \%$-Punkten zwischen den Wiederholungen.

Betrachtet man die Überlebensraten der zu fünf geografischen Regionen zusammengefassten Herkünfte, so sind diese ähnlich (Tab. 3.20). Insgesamt ist davon auszugehen, dass vermeintliche Unterschiede in den Überlebensraten der geografischen Regionen auf die geringe Anzahl an Herkünften zurückgeführt werden können und damit zufällig sind.

Tab. 3.20: Mittlere Überlebensraten der zu fünf geografischen Regionen zusammengefassten polnischen Herkünfte (IUFRO), der IUFRO-PG, der zusätzlichen PG und aller PG auf der Fläche Ochsenhausen $A$

\begin{tabular}{lccc}
\hline Geografische Region & IUFRO-Nr. & Anzahl PG & $1993(22-\mathrm{j})$. \\
\hline Masuren-Podlasie & $1-6$ & 6 & $46 \%$ \\
Sudeten & 8,9 & 2 & $34 \%$ \\
Karpaten (Beskiden) & $10-18$ & 9 & $45 \%$ \\
Mittelpolnische Hochebene & 19,20 & 2 & $48 \%$ \\
Baltisches Gebiet & 21 & 1 & $45 \%$ \\
\hline IUFRO-Herkünfte & & 20 & $44 \%$ \\
\hline zusätzliche PG & 3 & $46 \%$ \\
alle PG & & 23 & $45 \%$ \\
\hline
\end{tabular}


Im Alter von 22 Jahren variiert der Anteil der noch vorhandenen Fichten zwischen $73 \%$ (Nr. 2 Krzyze) und $24 \%$ (Nr. 10 Wisła) (Abb. 3.47).

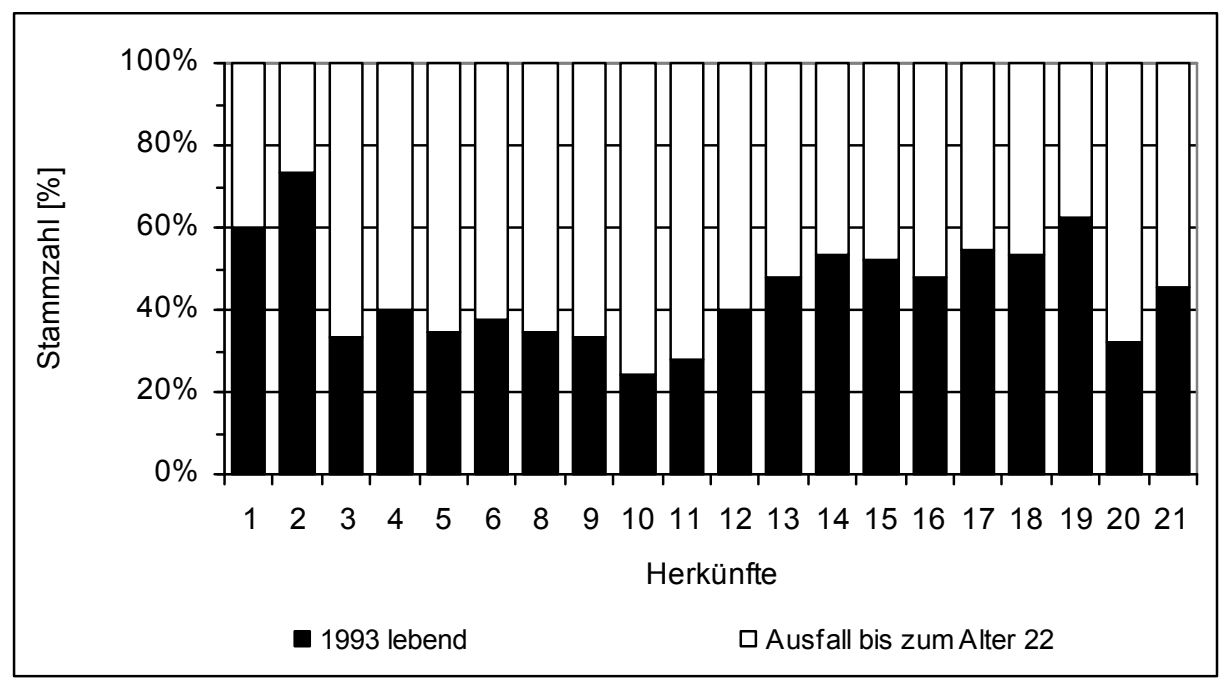

Abb. 3.47: Entwicklung der Pflanzenanzabl der IUFRO-Herkünfte auf der Fläche Ochsenhausen A / Baden-Württemberg

In der Abbildung 3.48 sind die Ausfälle der drei zusätzlich auf der Fläche angebauten und gemessenen Herkünfte dargestellt. Diese drei Herkünfte haben im Alter 22 Überlebensraten zwischen 40 und $55 \%$. 


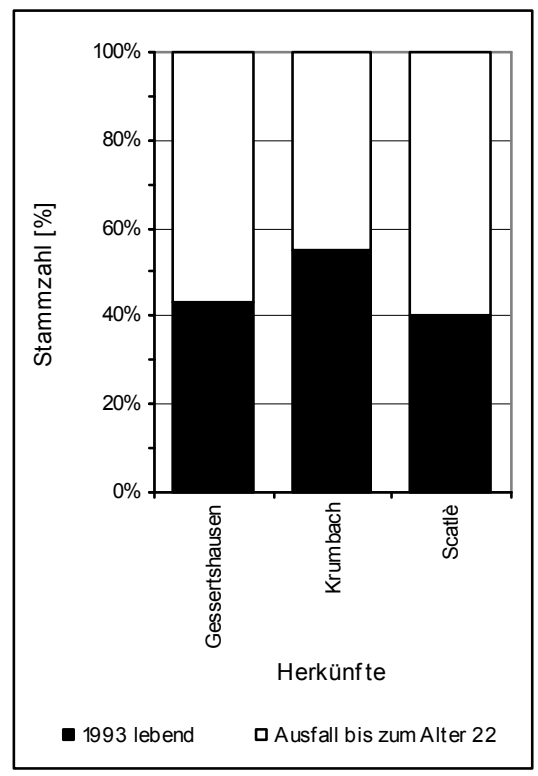

Abb. 3.48: Entwicklung der Pflanzenanzabl der drei zusätzlichen Herkünfte auf der Fläche Ocbsenhausen A / BadenWürttemberg

Die Unterschiede $(\alpha=0,05)$ zwischen den 23 Prüfgliedern lassen sich im multiplen Mittelwertvergleich (Tukey-Test) nicht absichern. Im Vergleich zum Standard, den acht auf allen Versuchsflächen angebauten polnischen Prüfgliedern, unterscheidet sich die IUFRO-Herkunft Nr. 2 Krzyze (Dunnett-Test, $\alpha=0,05)$ durch eine höhere Überlebensrate.

\section{Schad-und Formmerkmale}

Für die Versuchsfläche Ochsenhausen A liegen keine Aufnahmen von Schäden bzw. der Form vor.

\section{Höhenwachstum}

Das Wachstum der Fichte auf der Fläche ist im Vergleich zur Ertragstafel (WIEDEMANN 1936/1942, mäßige Durchforstung) gut. Im Alter von 22 Jahren haben die Fichten eine mittlere Höhe von 9,1 m $(n=769)$. Die Streuung der Einzelwerte um den Mittelwert beträgt für die Fläche Ochsenhausen A s\% $\%=14,4$.

In Abbildung 3.49 ist die Entwicklung des Höhenwachstums der 20 polnischen IUFRO-Herkünfte dargestellt. Die IUFRO-Herkünfte variieren mit mittleren Höhen von 8,0 m (Nr. 17 Witów, 88 \% vom Versuchsflächenmittel) bis 9,9 m (Nr. 18 Tarnawa und 19 Lubelski, $109 \%$ ). Auch innerhalb der geografischen Regionen gibt es Unterschiede zwischen den Herkünften. Die drei zusätzlichen 
Herkünfte erreichten folgende mittlere Höhen: Gessertshausen 9,7 m (107\%), Krumbach 9,2 m (102\%) und Scatlè 6,6 m (73\%).

Der multiple Mittelwertvergleich ergibt zwei stark überlappende Gruppen (Tukey-Test, $\alpha=0,05$ ), in denen sich die mattwüchsige Herkunft Scatlè von den beiden bestwüchsigen Nr. 17 (Tarnawa) und Nr. 19 (Lubelski) im Höhenwachstum im Alter 22 signifikant unterscheidet. Die Herkunft Scatlè unterscheidet sich auch vom Standard der acht polnischen Herkünfte signifikant (Dunnett-Test, $\alpha=0,05$ ).

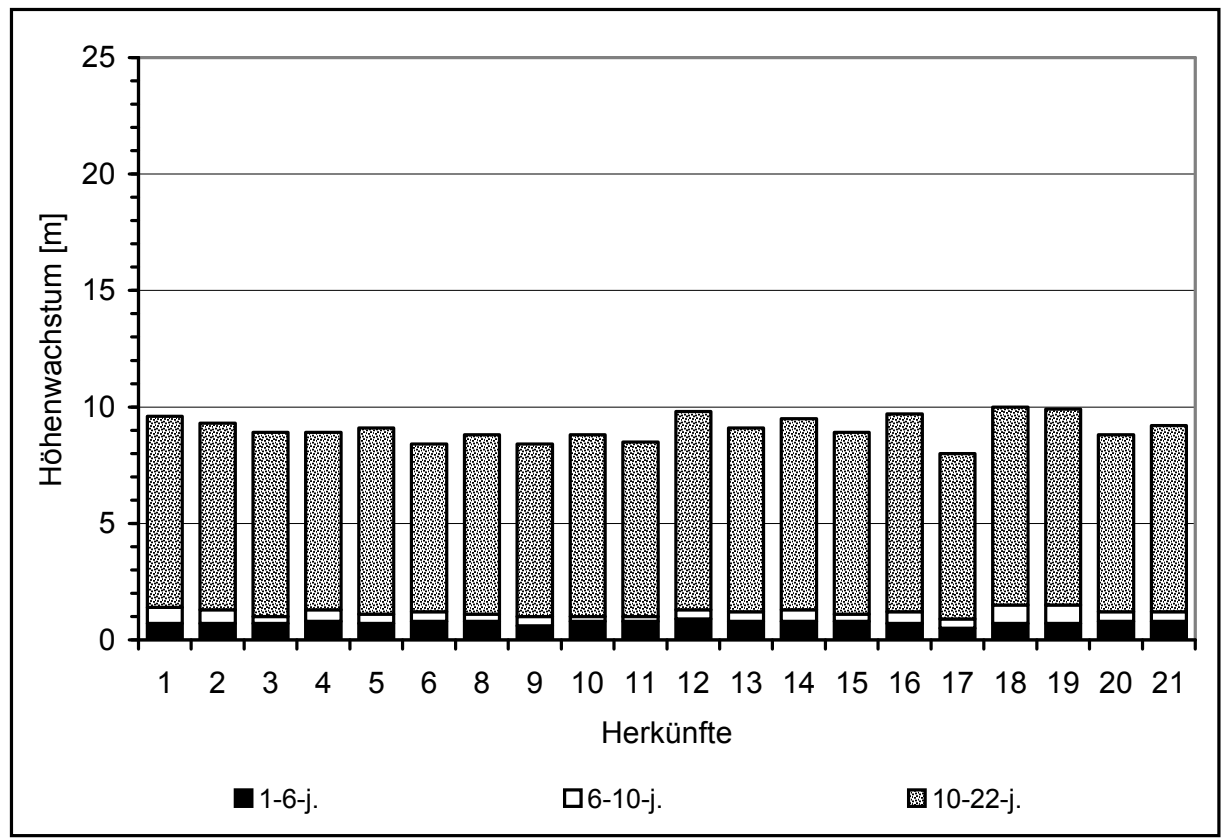

Abb. 3.49: Entwicklung des Höhenwachstums der 20 polnischen Herkïnfte bis zum Alter von 22 Jabren auf der Fläcbe Ochsenbausen A / Baden-Württemberg

Ein Vergleich des Wachstums im Beobachtungszeitraum zeigt, dass die Baumhöhen der Prüfglieder im Alter 10 mit denen im Alter 22 korrelieren (Tab. 3.21).

Tab. 3.21: $\quad$ Produkt-Momenten-Korrelationsmatrix des Wachstumsmerkmals Höhe

\begin{tabular}{c|c|c|c}
\hline Merkmal & H6 & H10 & H22 \\
\cline { 1 - 1 } H6 & - & 0,095 & 0,183 \\
H10 & & - & $0,839^{* * *}$ \\
H22 & & & - \\
\hline
\end{tabular}




\section{Einzelbaumvolumen und Vorrat pro Hektar}

Da für die Fläche Ochsenhausen A keine BHD-Messwerte vorliegen, wurden die Durchmesser in Abhängigkeit von der Baumhöhe geschätzt: BHD = Höhe / 0,8. Aus den Merkmalen BHD und Höhe wurden zunächst Einzelbaumvolumina berechnet. Pro Parzelle wurde anschließend unter Hinzuziehung der Anzahl lebender Bäume der Vorrat/ha ermittelt.

Das mittlere Einzelbaumvolumen beträgt $0,042 \mathrm{~m}^{3}$ im Alter von 22 Jahren und variiert von $0,020 \mathrm{~m}^{3}$ (Scatlè) bis $0,057 \mathrm{~m}^{3}$ (Nr. 19 Lubelski). Der multiple Mittelwertvergleich mit der Tukey-Prozedur $(\alpha=0,05)$ ergibt zwei sich überlappende Gruppen, in denen sich die Herkunft Scatlè von den vier volumenreichsten IUFRO-Herkünften (Nr. 19 Lubelski, Nr. 18 Tarnawa, Nr. 12 Istebna 115f, Nr. 16 Orawa) signifikant unterscheidet (Anhang 2.18). Die Herkunft Scatlè unterscheidet sich auch vom Standard signifikant (Dunnett-Test, $\alpha=0,05$ ).

Im Alter von 22 Jahren beträgt der Vorrat über die 23 Herkünfte im Mittel $88 \mathrm{~m}^{3} /$ ha. Zwischen den Herkünften (Abb. 3.50) variiert der errechnete Vorrat zwischen $31 \mathrm{~m}^{3} / \mathrm{ha}$ (Scatlè, $35 \%$ vom Versuchsflächenmittel) und $156 \mathrm{~m}^{3} / \mathrm{ha}(\mathrm{Nr}$. 19 Lubelski, $177 \%$ ). Die IUFRO-Herkunft mit dem geringsten Vorrat $\left(44 \mathrm{~m}^{3} / \mathrm{ha}\right.$, $50 \%$ ) ist die Nr. 10 (Wisła). Die beiden zusätzlichen deutschen Herkünfte haben einen rechnerischen Vorrat von $111 \mathrm{~m}^{3} / \mathrm{ha}$ (Krumbach, $126 \%$ ) und $102 \mathrm{~m}^{3} / \mathrm{ha}$ (Gessertshausen, $116 \%$ ). Vorratsreicher als die beiden deutschen Herkünfte sind neben der IUFRO-Herkunft Nr. 19 noch die Herkünfte Nr. 2 Krzyze (173 \%), Nr. 18 Tarnawa (153\%), Nr. 1 Pogorzelece (149\%), Nr. 16 Orawa (131\%) und Nr. 14 Rycerka I (129\%).

Der multiple Mittelwertvergleich (Tukey-Test, $\alpha=0,05$ ) führt zu keiner gesicherten Gruppierung. Im Vergleich gegen den Standard sind die beiden vorratsreichen IUFRO-Herkünfte Nr. 19 (Lubelski) und Nr. 2 (Krzyze) signifikant überlegen. 


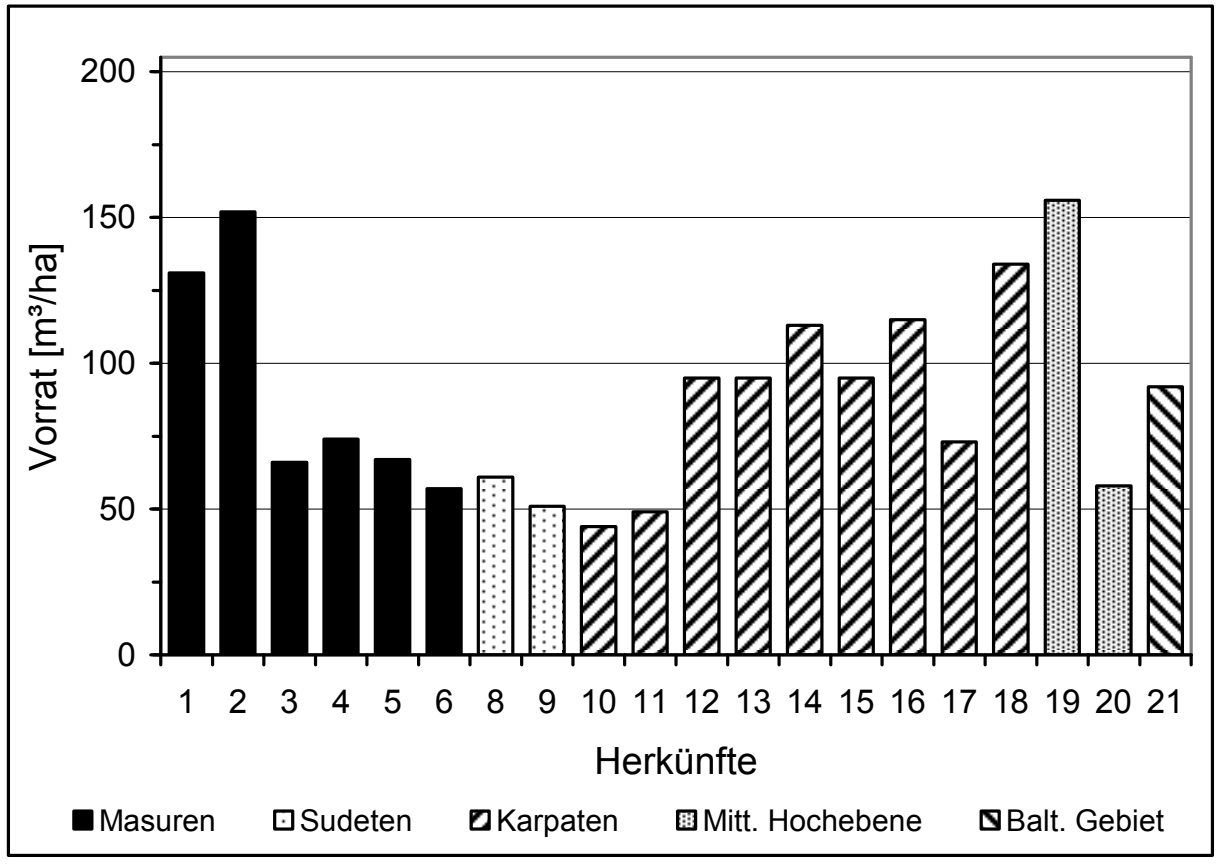

Abb. 3.50: Hochgerechneter Vorrat je Hektar der 20 polnischen Herkünfte auf der Versuchsfläche Ochsenhausen A / Baden-Württemberg im Alter von 22 Jahren

\subsubsection{Ochsenhausen B}

\section{Entwicklung der Pflanzenanzahl}

Im Alter von 21 Jahren leben auf der Versuchsfläche noch $42 \%$ der ursprünglich gepflanzten Fichten der Herkünfte. Im Mittel der 20 IUFRO-Herkünfte sind die Ausfälle $1 \%$-Punkt geringer und bei den zusätzlichen drei Herkünften, die im Alter von 21 Jahren aufgenommen wurden, $8 \%$-Punkte höher. Die Unterschiede im Ausfall der IUFRO-Herkünfte liegen bei $7 \%$-Punkten zwischen den Wiederholungen.

Betrachtet man die Überlebensraten der zu fünf geografischen Regionen zusammengefassten Herkünfte, so findet man eine geringe Überlebensrate in der Region Karpaten (Tab. 3.22). Insgesamt ist jedoch davon auszugehen, dass Unterschiede in den Überlebensraten auf die geringe Anzahl an Herkünften zurückgeführt werden können und damit zufällig sind. 
Tab.3.22: $\quad$ Mittlere Überlebensraten der zu fün geografischen Regionen zusammengefassten polnischen Herkïnfte (IUFRO), der IUFRO-PG, der zusätzlichen PG und aller PG auf der Fläche Ochsenhausen B

\begin{tabular}{lccc}
\hline Geografische Region & IUFRO-Nr. & Anzahl PG & $1993(21-\mathrm{j})$. \\
\hline Masuren-Podlasie & $1-6$ & 6 & $47 \%$ \\
Sudeten & 8,9 & 2 & $41 \%$ \\
Karpaten (Beskiden) & $10-18$ & 9 & $39 \%$ \\
Mittelpolnische Hochebene & 19,20 & 2 & $45 \%$ \\
Baltisches Gebiet & 21 & 1 & $60 \%$ \\
\hline IUFRO-Herkünfte & & 20 & $43 \%$ \\
\hline zusätzliche PG & 3 & $34 \%$ \\
\hline alle PG & & 23 & $42 \%$ \\
\hline
\end{tabular}

Zwischen den einzelnen Herkünften und innerhalb der geografischen Regionen gibt es Unterschiede (Abb. 3.51). Im Alter von 21 Jahren variiert der Anteil der noch vorhandenen Fichten zwischen $61 \%$ (Nr. 17 Witów) und 28\% (Nr. 13 Zwardon). Beide Herkünfte sind der geografischen Region „Karpaten (Beskiden)“ zugehörig.

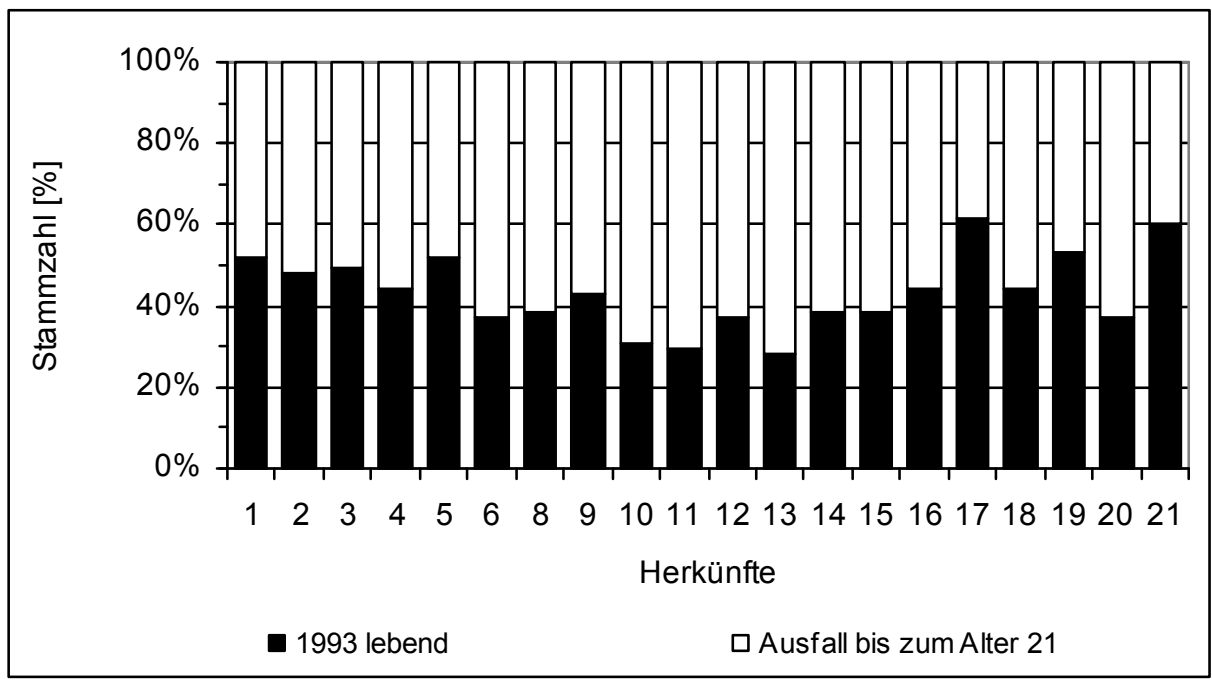

Abb.3.51 Entwicklung der Pflanzenanz̧abl der IUFRO-Herkïnfte auf der Fläche Ochsenbausen B / Baden-Württemberg 
In der Abbildung 3.52 sind die Ausfälle der zusätzlich auf der Fläche angebauten und gemessenen Herkünfte dargestellt. Diese drei Herkünfte haben im Alter 21 einen Anteil lebender Fichten zwischen 31 und $40 \%$.

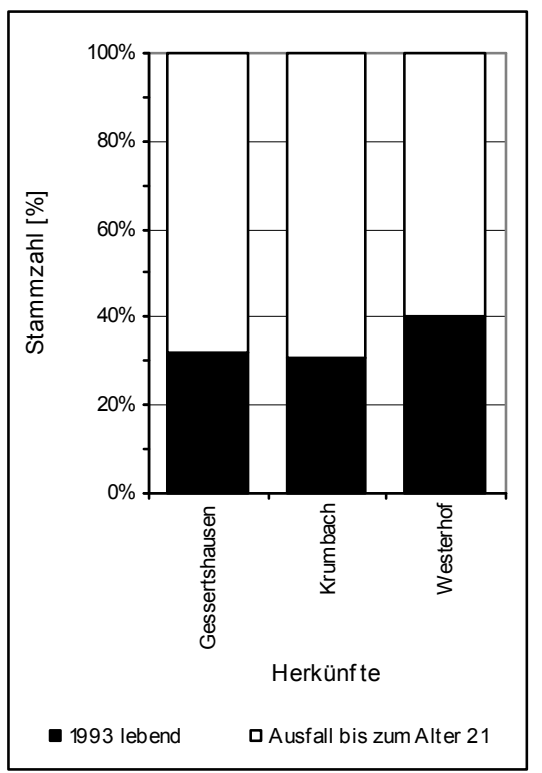

Abb.3.52: Entwicklung der Pflanzenanzabl der drei zusätzlichen Herkinfte auf der Fläche Ochsenbausen B / Baden-Württemberg

Die Unterschiede $(\alpha=0,05)$ zwischen den 23 Prüfgliedern lassen sich im multiplen Mittelwertvergleich (Tukey-Test) nicht absichern. Auch im Vergleich zum Standard gibt es keinen gesicherten Unterschied.

\section{Schad- und Formmerkmale}

Für die Versuchsfläche Ochsenhausen B liegen keine Daten von Aufnahmen von Schäden bzw. der Form vor.

\section{Höhenwachstum}

Das Wachstum der Fichte auf der Fläche ist gut. Im Alter von 21 Jahren haben die Fichten eine mittlere Höhe von 8,6 m $(\mathrm{n}=727)$ erreicht. Die Streuung der Einzelwerte um den Mittelwert beträgt für die Fläche Ochsenhausen B s\% $=12,5$.

In Abbildung 3.53 ist die Entwicklung des Höhenwachstums der 20 polnischen IUFRO-Herkünfte dargestellt. Die IUFRO-Herkünfte variieren mit mittleren Höhen von 7,5 m (Nr. 9, Stronie Slaskie, 87 \% vom Versuchsflächenmittel) bis 9,3 m (Nr. 19 Lubelski, 107 \%). Insgesamt ist die Variation zwischen den Herkünften gering. Die drei zusätzlichen deutschen Herkünfte erreichten folgende 
mittleren Höhen: Krumbach 8,8 m (102\%), Westerhof 8,8 m (101\%) und Gessertshausen 8,4 m (98\%).

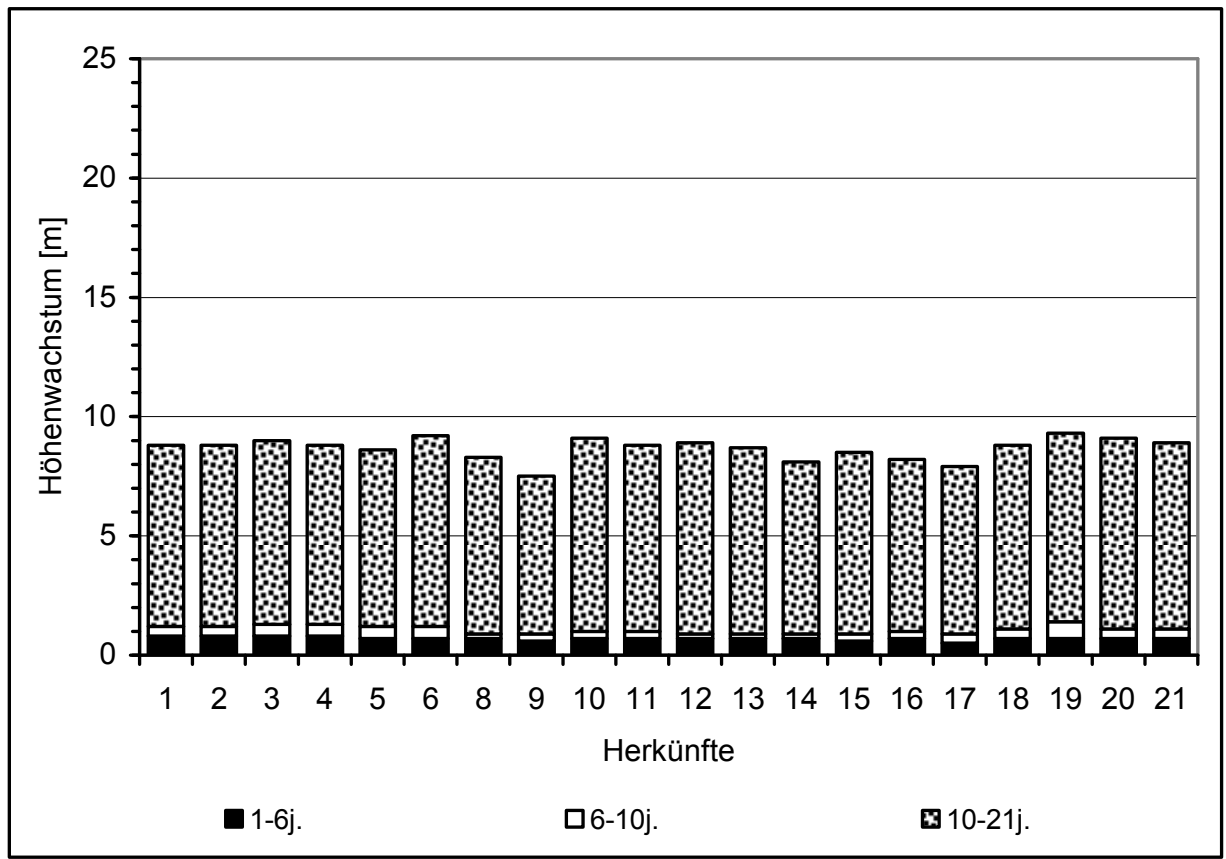

Abb. 3.53: Entwicklung des Höhenwachstums der 20 polnischen Herkünfte bis zum Alter von 21 Jahren auf der Fläche Ochsenhausen B / Baden-Württemberg

Der multiple Mittelwertvergleich ergibt zwei sich stark überlappende Gruppen (Tukey-Test, $\alpha=0,05)$, in denen sich nur die mattwüchsigste Herkunft Nr. 9 (Stronie Slaskie) von der bestwüchsigsten Herkunft Nr. 19 (Lubelski) im Höhenwachstum im Alter 21 signifikant unterscheidet (Anhang 2.19). Die Herkunft Nr. 9 (Stronie Slaskie) unterscheidet sich auch vom Standard der acht polnischen Herkünfte signifikant (Dunnett-Test, $\alpha=0,05$ ).

Ein Vergleich des Wachstums im Beobachtungszeitraum zeigt, dass die Höhen der Prüfglieder im Alter 6 mit denen im Alter 10 sowie die im Alter 10 mit denen im Alter 21 korreliert sind (Tab. 3.23).

Tab. 3.23: $\quad$ Produkt-Momenten-Korrelationsmatrix des Wachstumsmerkmals Höhe

\begin{tabular}{c|cccc}
\hline Merkmal & H6 & H10 & H21 \\
\cline { 1 - 1 } H6 & - & $0,675^{* *}$ & $0,568^{* *}$ \\
\cline { 1 - 1 } H10 & & - & $0,580^{* *}$ \\
\cline { 1 - 1 } H21 & & & - \\
\hline
\end{tabular}




\section{Einzelbaumvolumen und Vorrat pro Hektar}

Da auch für die Fläche Ochsenhausen B keine BHD-Messungen vorliegen, wurden die Durchmesser in Abhängigkeit von der Baumhöhe geschätzt: BHD = Höhe / 0,8. Aus den Merkmalen BHD und Höhe wurden zunächst Einzelbaumvolumina berechnet. Pro Parzelle wurde anschließend unter Hinzuziehung der Anzahl lebender Fichten der Vorrat/ha ermittelt.

Das mittlere Einzelbaumvolumen beträgt $0,038 \mathrm{~m}^{3}$ im Alter von 21 Jahren und variiert von $0,025 \mathrm{~m}^{3}$ (Nr. 9, Stronie Slaskie) bis $0,046 \mathrm{~m}^{3}$ (Nr. 19 Lubelski). Der multiple Mittelwertvergleich mit der Tukey-Prozedur $(\alpha=0,05)$ ergibt zwei sich überlappende Gruppen, in denen sich die Herkunft Nr. 9 (Stronie Slaskie) von der volumenreichsten IUFRO-Herkunft Nr. 19 (Lubelski) signifikant unterscheidet (Anhang 2.19). Die Herkunft Nr. 9 (Stronie Slaskie) unterscheidet sich auch signifikant vom Standard (Dunnett-Test, $\alpha=0,05$ ).

Im Alter von 21 Jahren wird für die 23 Herkünfte ein mittlerer Vorrat von $71 \mathrm{~m}^{3} /$ ha errechnet. Zwischen den Herkünften (Abb. 3.54) variiert der errechnete Vorrat zwischen $47 \mathrm{~m}^{3} /$ ha (Nr. 9 Stronie Slaskie, $65 \%$ vom Versuchsflächenmittel) und $109 \mathrm{~m}^{3} /$ ha (Nr. 19 Lubelski, 153 \%). Die zusätzliche Herkunft Westerhof erzielt einen rechnerischen Vorrat in Höhe des mittleren Vorrats der Versuchsfläche $\left(71 \mathrm{~m}^{3} / \mathrm{ha}\right)$. Die beiden weiteren deutschen Herkünfte haben einen deutlich geringeren rechnerischen Vorrat von 51 bzw. $53 \mathrm{~m}^{3} / \mathrm{ha}$ (Gessertshausen: $71 \%$ bzw. Krumbach: $75 \%$ ). Weitere vorratsreiche IUFRO-Herkünfte sind Nr. 3 (Wigry: $132 \%$ ) und die Nr. 1 (Pogorzelece: $131 \%$ ). In den multiplen Mittelwertvergleichen (Tukey- bzw. Dunnett-Test $\alpha=0,05$ ) lassen sich die Unterschiede nicht statistisch absichern. 


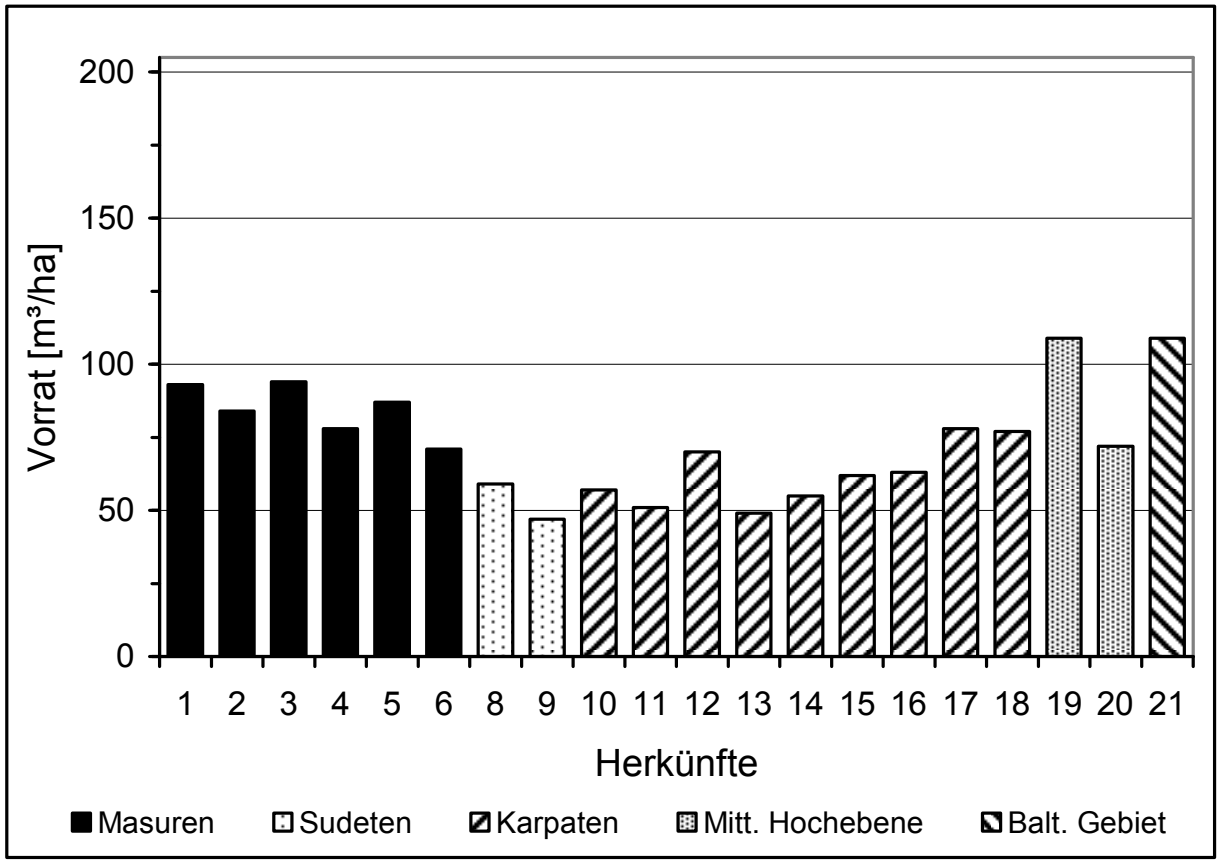

Abb. 3.54: Hochgerechneter Vorrat je Hektar der 20 polnischen Herkünfte auf der Versuchsfläche Ochsenhausen B / Baden-Württemberg im Alter von 21 Jahren

\subsubsection{Bayern}

\subsubsection{Sauerlach $A$}

\section{Entwicklung der Pflanzenanzahl}

Zu den Versuchsflächen, auf denen alle 20 IUFRO-Herkünfte angebaut wurden, gehören auch Sauerlach A und B in Bayern. Im Alter von 25 Jahren sind auf der Versuchsfläche Sauerlach A noch $49 \%$ der ursprünglich gepflanzten Fichten der Herkünfte anzutreffen. Im Mittel der 20 IUFRO-Herkünfte beträgt die Überlebensrate $45 \%$, während sich die der zusätzlichen 14 Herkünften auf $55 \%$ beläuft. Die Unterschiede im Ausfall betragen bei den IUFRO-Herkünften $17 \%$ Punkte zwischen den Wiederholungen und bei den zusätzlichen Herkünften 11 \%Punkte.

Für die zu fünf geografischen Regionen zusammengefassten IUFRO-Herkünfte (Tab. 3.24) ist davon auszugehen, dass vermeintliche Unterschiede in den Überlebensraten auf die geringe Anzahl an Herkünften zurückgeführt werden können und damit zufällig sind. 
Tab.3.24: $\quad$ Mittlere Überlebensraten der zu fünf geografischen Regionen zusammengefassten polnischen Herkünfte (IUFRO), der IUFRO-PG, der zusätzlichen PG und aller PG auf der Fläche Sauerlach $A$

\begin{tabular}{lccc}
\hline Geografische Region & IUFRO-Nr. & Anzahl PG & $1996(25-\mathrm{j})$. \\
\hline Masuren-Podlasie & $1-6$ & 6 & $38 \%$ \\
Sudeten & 8,9 & 2 & $39 \%$ \\
Karpaten (Beskiden) & $10-18$ & 9 & $50 \%$ \\
Mittelpolnische Hochebene & 19,20 & 2 & $49 \%$ \\
Baltisches Gebiet & 21 & 1 & $48 \%$ \\
\hline IUFRO-Herkünfte & & 20 & $45 \%$ \\
\hline zusätzliche PG & & 14 & $55 \%$ \\
alle PG & & 34 & $49 \%$ \\
\hline
\end{tabular}

Zwischen den einzelnen Herkünften variiert im Alter von 25 Jahren der Anteil der noch vorhandenen Fichten (Abb. 3.55) zwischen 61\% (Nr. 14 Rycerka I) und $21 \%$ (Nr. 3 Wigry). Auch innerhalb einer geografischen Region variiert der Anteil zwischen den Herkünften beträchtlich.

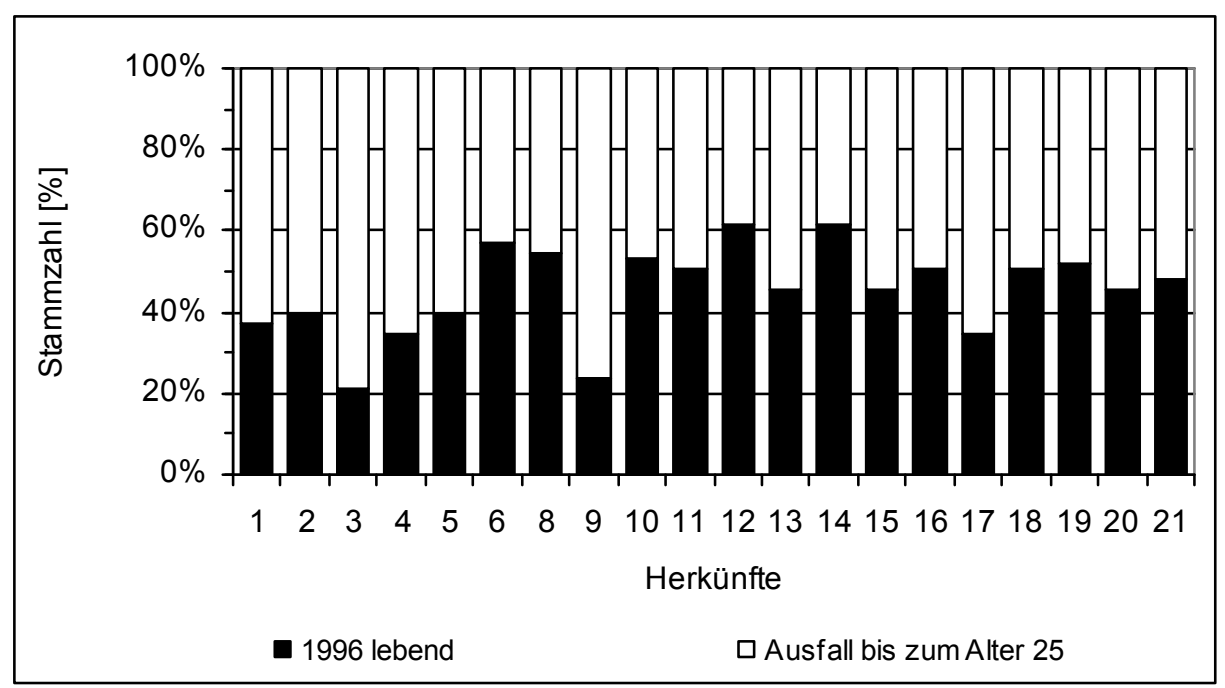

Abb. 3.55: Entwicklung der Pflanzenanzabl der IUFRO-Herkünfte auf der Fläche Sauerlach A / Bayern

In der Abbildung 3.56 sind die Ausfälle der zusätzlich auf der Fläche angebauten 14 Herkünfte dargestellt. Diese Herkünfte haben Überlebensraten zwischen $36 \%$ (Zwiesel VI Haselau) und 80 \% (Klingenbrunn, Ernte 1958). 


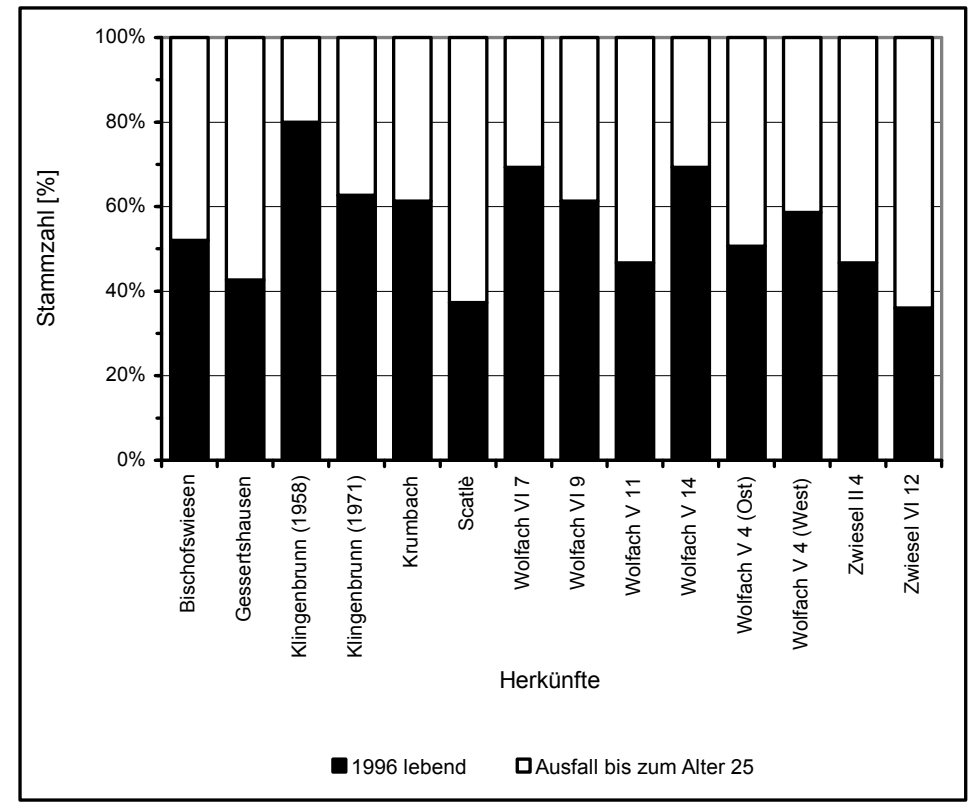

Abb. 3.56: Entwicklung der Pflanzenanzabl der 14 zusätzlichen Herkünfte auf der Fläche Sauerlach A / Bayern

Die Unterschiede $(\alpha=0,05)$ zwischen den 34 Herkünften lassen sich in multiplen Mittelwertvergleichen (Tukey- und Dunnett-Test, $\alpha=0,05$ ) nicht absichern. Da die Unterschiede zwischen den Prüfgliedern sehr hoch erschienen, ist zusätzlich ein Homogenitätstest durchgeführt worden. Der globale Test bestätigt die Vermutung. Für die Herkunft mit den höchsten Ausfällen (Nr. 3 Wigry) und die mit den geringsten Ausfällen (Klingenbrunn Ernte 1958) sind Einzelvergleiche mit den weiteren Prüfgliedern durchgeführt worden. Diese ergeben für die Herkunft Nr. 3 Wigry eine signifikant höhere Ausfallrate zu allen weiteren Prüfgliedern mit Ausnahme der Herkunft Nr. 9 (Stronie Slaskie) und für Herkunft Klingenbrunn Ernte 1958 eine signifikant geringere Ausfallrate als bei den weiteren Prüfgliedern.

\section{Schadmerkmale}

Auf der Versuchsfläche Sauerlach A wurden im Alter von 25 Jahren drei Schadmerkmale aufgenommen. Die erfassten Schäden sind insgesamt sehr gering (3\%). Es wurden an 22 Bäumen Rückeschäden, an fünf Schneedruck und an einem Baum ein Fällungsschaden notiert. Die Schädigung durch Schneedruck ist zufällig verteilt, so dass eine Konzentration auf ein oder wenige Prüfglieder nicht vorliegt. Alle Bäume mit einem Schaden wurden ausschließlich in die Berechnung der Überlebensraten einbezogen. 


\section{Stammform}

Im Alter von 25 Jahren wurde bei 1262 Fichten die Stammform beurteilt. Die Stammform wurde anhand einer dreistufigen Skala bonitiert. Im Ergebnis sind $97 \%$ der Stämme gerade, $2 \%$ wiesen einen leichten Mangel und $1 \%$ der Fichten einen schweren Mangel in der Stammform auf. Die Fichten mit mangelnder Stammform sind zufällig über die Herkünfte verteilt. In Abbildung 3.57 sind daher die Herkünfte zu geografischen Regionen zusammengefasst dargestellt. Zu beachten ist, dass die Anzahlen der beurteilten Stämme und Herkünfte der Regionen unterschiedlich sind. Die Herkunft Scatlè hat den geringsten Anteil gerader Stämme.

Außerdem ist an 11 Fichten ein Zwiesel notiert worden. Die Zwiesel sind zufällig über die Herkünfte verteilt. Die Fichten mit einem Zwiesel wurden nur in die Berechnung der Überlebensraten einbezogen.

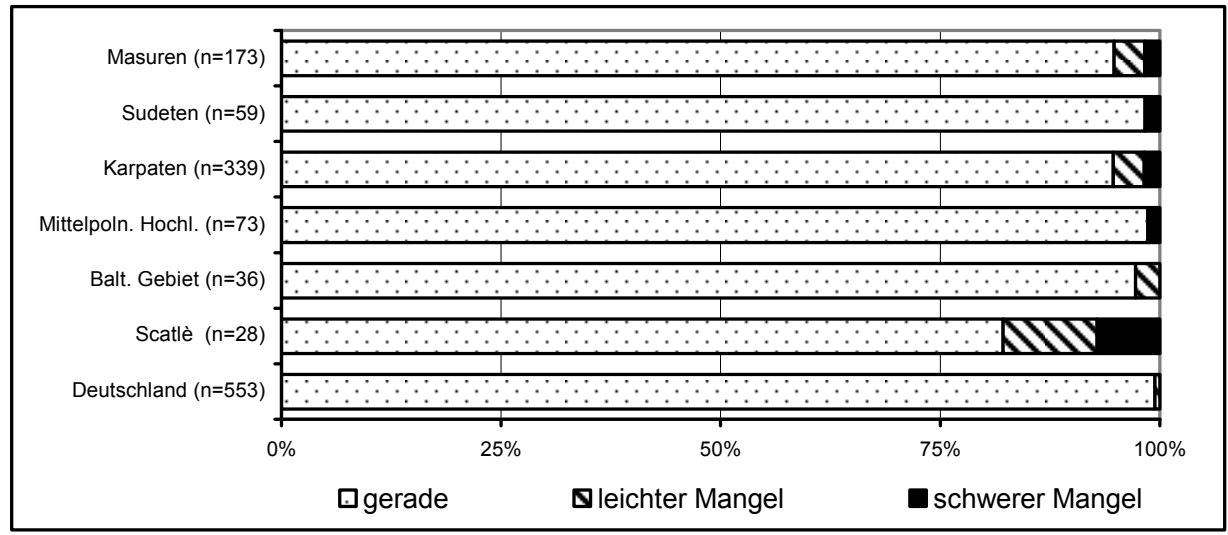

Abb. 3.57: Ergebnis der Beurteilung der Stammform der zu sieben geografischen Regionen zusammengefassten 34 Herkünfte der Fläche Sauerlach A / Bayern im Alter von 25 Jabren $(n=$ Anzabl beurteilter Stämme)

\section{BHD-Wachstum}

Das Wachstum der Fichte auf der Fläche ist gut. Für die Fichten ohne Kronenbruch und ohne Zwiesel wird im Alter von 25 Jahren ein mittlerer BHD von $13,0 \mathrm{~cm}(\mathrm{n}=1222)$ errechnet. Die Streuung der Einzelwerte um den Mittelwert beträgt für die Fläche Sauerlach A s\% $\%=27,4$.

In Abbildung 3.58 sind die BHD der 20 polnischen Herkünfte dargestellt. Im Alter von 25 Jahren sind die 20 IUFRO-Herkünfte im Mittel $1 \mathrm{~cm}$ dicker $(13,5 \mathrm{~cm})$ als die 14 zusätzlichen Herkünfte $(12,5 \mathrm{~cm})$. Die wüchsigste IUFRO-Herkunft (Nr. 15 Rycerka II) erreicht einen BHD von 15,0 cm (115\% vom Versuchsmittel) und die mattwüchsigste (Nr. 6 Nowe Ramuki) einen BHD von 11,5 cm (88\%). Der BHD der zusätzlichen 14 Herkünfte ist in Abbildung 3.59 dargestellt. Sowohl die zusätzliche Herkunft mit dem größten als auch die mit dem geringsten BHD 
kommen aus dem Forstamt Zwiesel: Zwiesel VI 12 Haselau (14,6 cm, $112 \%)$ und die als „geprüft“ zugelassene Herkunft Zwiesel II 4 Sulzschachten (10,3 cm, 79 \%).

Die geringen Wuchsunterschiede zwischen den 34 Herkünften im Alter von 25 Jahren sind statistisch nicht signifikant (Tukey-Test bzw. Dunnett-Test, $\alpha=0,05$ ).

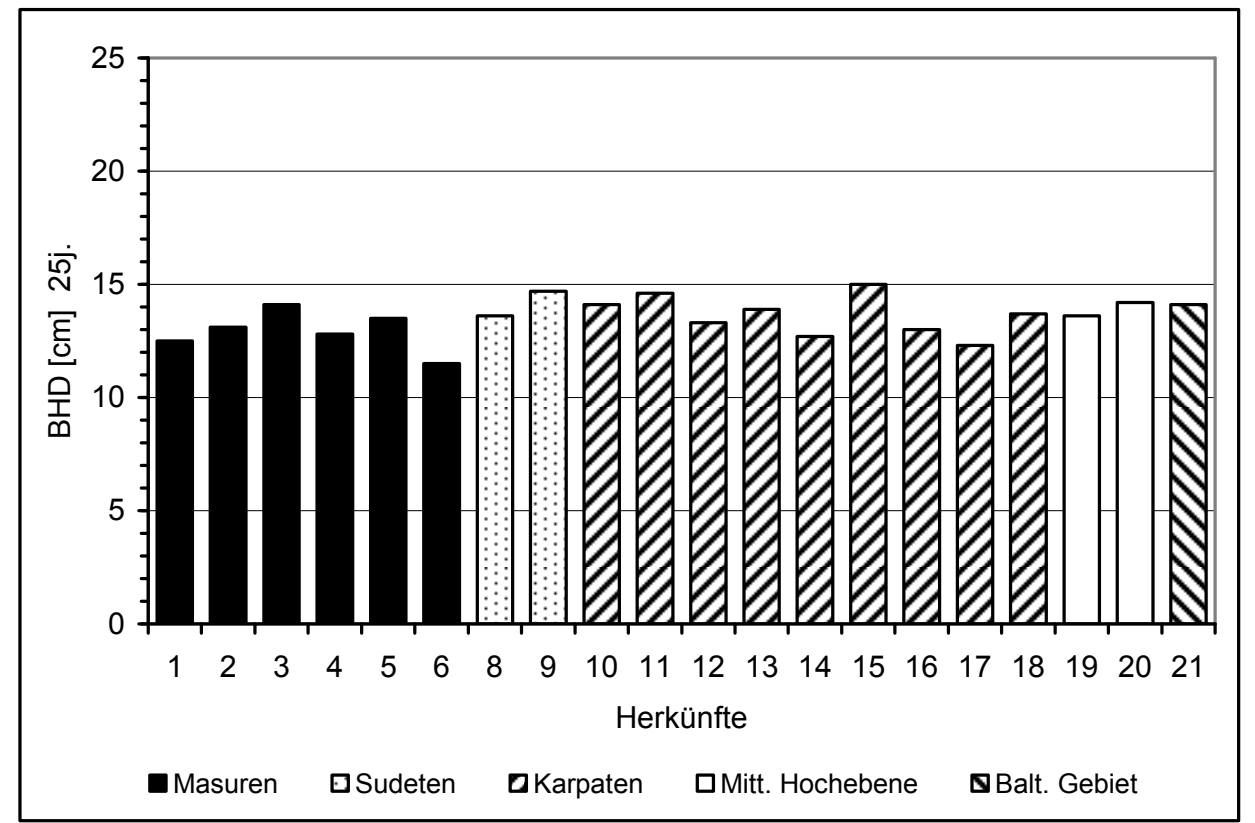

Abb.3.58: Mittlere BHD der 20 polnischen Herkünfte im Alter von 25 Jahren auf der Fläche Sauerlach A / Bayern. Die Herkïnfte sind nach geografischen Regionen gruppiert. 


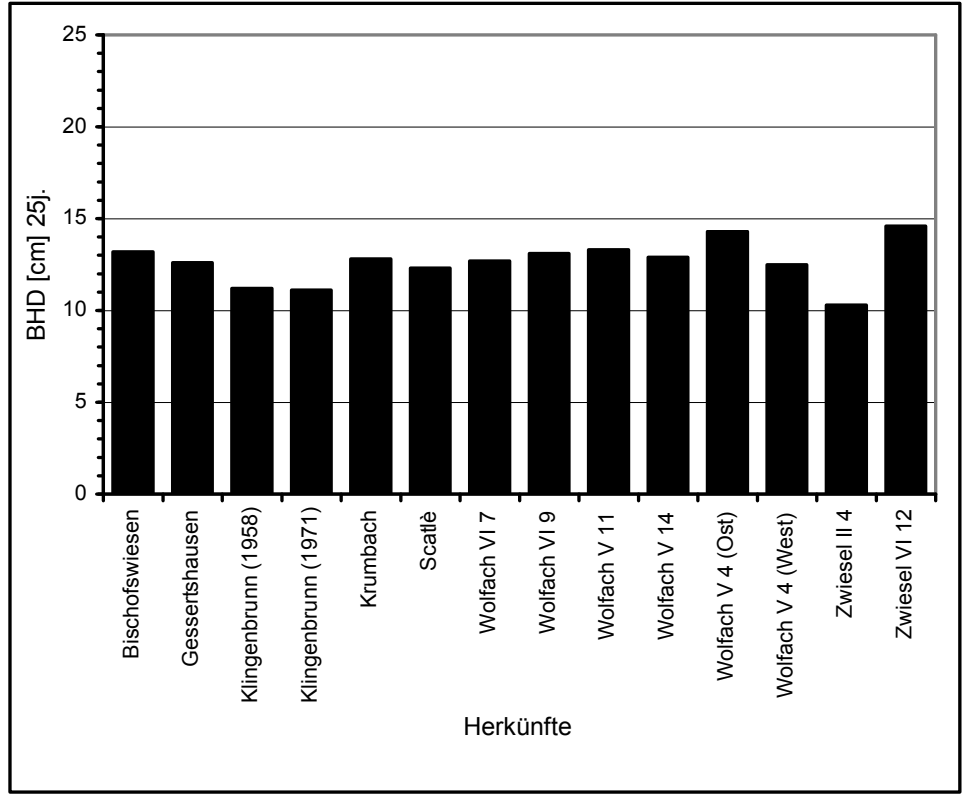

Abb. 3.59: Mittlere BHD der 14 zusätzlichen Herkünfte im Alter von 25 Jahren auf der Fläche Sauerlach A / Bayern

\section{Einzelbaumvolumen und Vorrat pro Hektar}

Da von der Fläche Sauerlach A keine Höhenmessungen vorliegen, wurden die Baumhöhen in Abhängigkeit der BHD geschätzt: Höhe $=0,8 * \mathrm{BHD}$. Aus den Merkmalen BHD und Höhe wurden zunächst Einzelbaumvolumina berechnet. Pro Parzelle wurde anschließend unter Hinzuziehung der Anzahl lebender Fichten der Vorrat/ha ermittelt.

Das mittlere Einzelbaumvolumen beträgt $0,078 \mathrm{~m}^{3}$ im Alter von 25 Jahren auf der Versuchsfläche Sauerlach A und variiert von $0,048 \mathrm{~m}^{3}$ (Zwiesel II Sulzschachten) bis $0,114 \mathrm{~m}^{3}$ (Nr. 9, Stronie Slaskie). Die multiplen Mittelwertvergleiche (Tukey- und Dunnett-Test, $\alpha=0,05$ ) ergeben keine gesicherten Unterschiede zwischen den 34 Herkünften.

Im Alter von 25 Jahren wird ein mittlerer Vorrat von $167 \mathrm{~m}^{3} /$ ha über die 34 Herkünfte errechnet. Zwischen den Herkünften variiert der errechnete Vorrat zwischen $88 \mathrm{~m}^{3} /$ ha (Scatlè: $53 \%$ ) und $232 \mathrm{~m}^{3} / \mathrm{ha}$ (Nr. 11 Istebna 149h: $139 \%$ ).

In Abbildung 3.60 sind die IUFRO-Herkünfte zusammengestellt und in Abbildung 3.61 die zusätzlichen 14 Herkünfte. Der Abbildung 3.60 ist zu entnehmen, dass die IUFRO-Herkunft Nr. 3 (Wigry) ebenso vorratsarm ist wie die Herkunft Scatlè (Abb. 3.61). In der Abbildung 3.60 fällt auf, dass auf der Versuchsfläche Sauerlach A alle sechs Herkünfte aus Masuren einen Vorrat von weniger als 
$150 \mathrm{~m}^{3} /$ ha haben. Die drei wüchsigen polnischen Herkünfte sind: Nr. 11 Istebna $149 \mathrm{~h}\left(232 \mathrm{~m}^{3} / \mathrm{ha}\right)$, Nr. 15 Ryycerka II $\left(218 \mathrm{~m}^{3} / \mathrm{ha}\right)$ und Nr. 21 Kartuzy $\left(213 \mathrm{~m}^{3} /\right.$ ha). Unter den zusätzlichen Herkünften ist die Herkunft Wolfach, V 14 Hölle $\left(229 \mathrm{~m}^{3} / \mathrm{ha}\right)$ so vorratsreich wie die polnische IUFRO-Herkunft Nr. 11 (Istebna 149h).

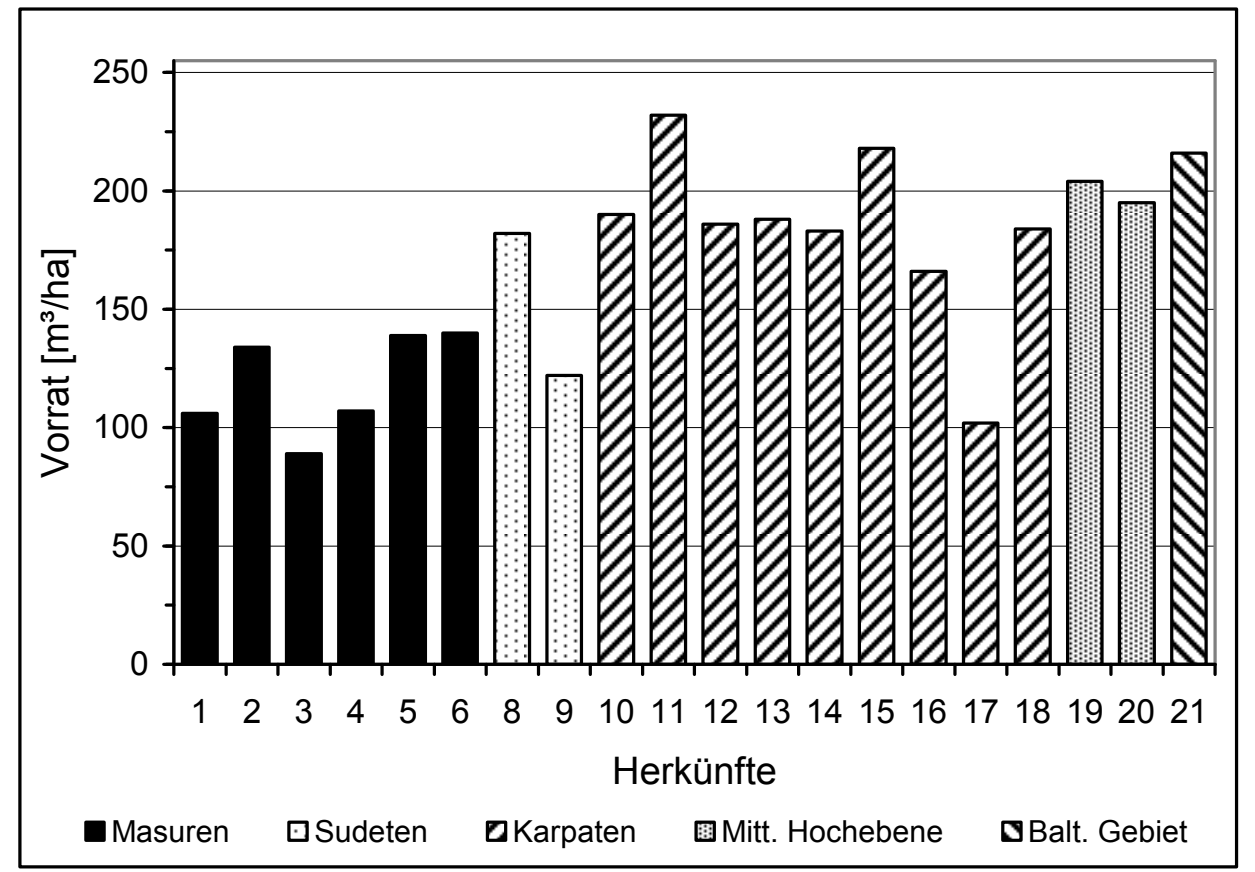

Abb. 3.60: Hochgerechneter Vorrat je Hektar der 20 polnischen Herkünfte auf der Versuchsfläche Sauerlach A / Bayern im Alter von 25 Jahren

In den multiplen Mittelwertvergleichen (Tukey- bzw. Dunnett-Test $\alpha=0,05$ ) lassen sich die Unterschiede zwischen den 34 Herkünften nicht statistisch absichern. 


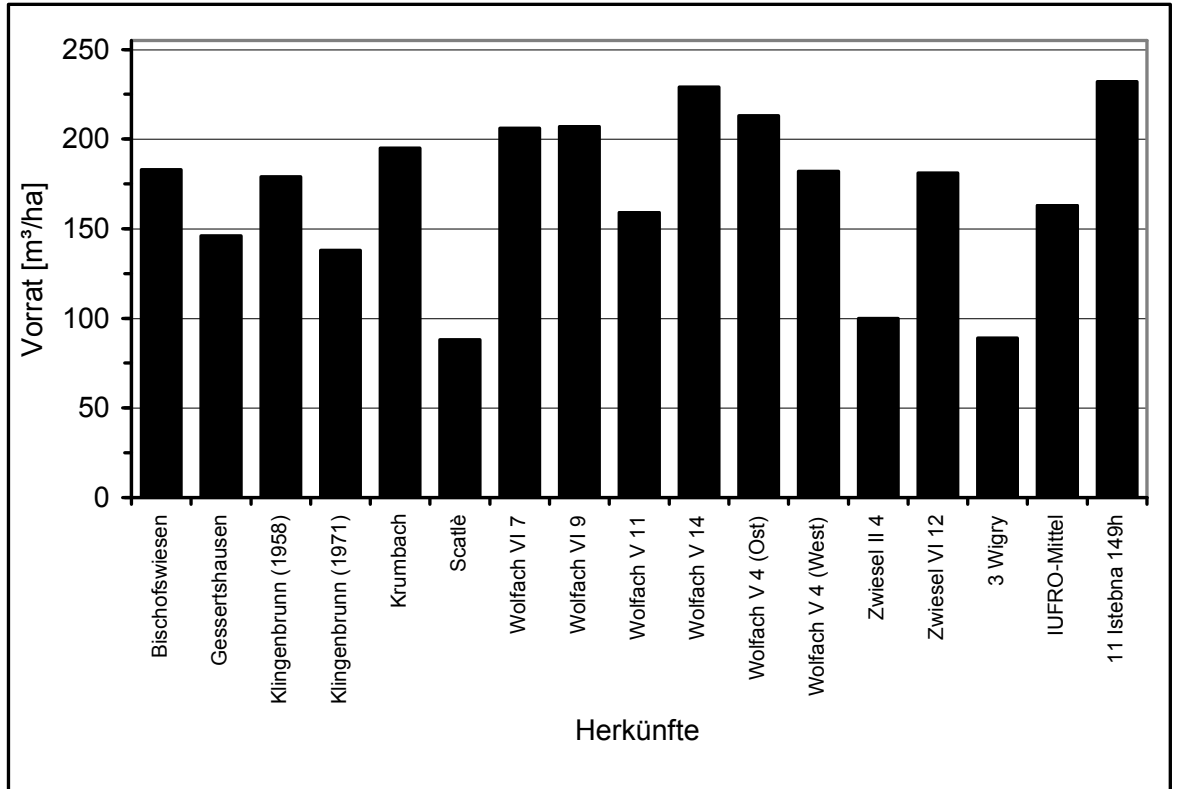

Abb. 3.61: Hochgerechneter Vorrat je Hektar der 14 zusätzlichen Herkë̈fte auf der Versuchsfläche Sauerlach A / Bayern im Alter von 25 Jahren. Zum Vergleich sind die beste und die mattwiuchsigste Herkunft sowie das Mittel über die 20 polnischen IUFRO-Herkünfte aufgenommen.

\subsubsection{Sauerlach B}

\section{Entwicklung der Pflanzenanzahl}

Auf der Versuchsfläche Sauerlach B leben im Alter von 25 Jahren noch 53 \% der ursprünglich gepflanzten Fichten. Im Mittel der 20 IUFRO-Herkünfte beträgt die Überlebensrate $52 \%$, während sich die der zusätzlichen 14 Herkünfte auf $53 \%$ beläuft. Die Unterschiede im Ausfall betragen bei den IUFRO-Herkünften nur $1 \%$-Punkt zwischen den Wiederholungen und bei den zusätzlichen Herkünften $17 \%$-Punkte.

Bei den zu fünf geografischen Regionen zusammengefassten IUFRO-Herkünften (Tab. 3.25) ist davon auszugehen, dass vermeintliche Unterschiede in den Überlebensraten auf die geringe Anzahl an Herkünften zurückgeführt werden können und damit zufällig sind. 
Tab.3.25: Mittlere Überlebensraten der zu fünf geografischen Regionen zusammengefassten polnischen Herk:ünfte (IUFRO), der IUFRO-PG, der zusätzliche PG und aller PG auf der Fläche Sauerlach B

\begin{tabular}{lccc}
\hline Geografische Region & IUFRO-Nr. & Anzahl PG & $1996(25-\mathrm{j})$. \\
\hline Masuren-Podlasie & $1-6$ & 6 & $53 \%$ \\
Sudeten & 8,9 & 2 & $53 \%$ \\
Karpaten (Beskiden) & $10-18$ & 9 & $51 \%$ \\
Mittelpolnische Hochebene & 19,20 & 2 & $53 \%$ \\
Baltisches Gebiet & 21 & 1 & $60 \%$ \\
\hline IUFRO-Herkünfte & & 20 & $52 \%$ \\
\hline zusätzliche PG & & 14 & $53 \%$ \\
alle PG & & 34 & $53 \%$ \\
\hline
\end{tabular}

In dem Anteil der im Alter von 25 Jahren noch vorhandenen Fichten gibt es Unterschiede zwischen den einzelnen Herkünften (Abb. 3.62). So variiert der Anteil innerhalb der IUFRO-Herkünfte zwischen $71 \%$ (Nr. 6 Nowe Ramuki) und $35 \%$ (Nr. 11 Istebna 149h). Auch innerhalb einer geografischen Region variiert der Anteil zwischen den Herkünften. Eine hohe Überlebensrate (68\%) hat auch die Herkunft Nr. 12 (Istebna 115f) und eine weitere geringe Rate (36\%) die Herkunft Nr. 1 (Pogorzelece).

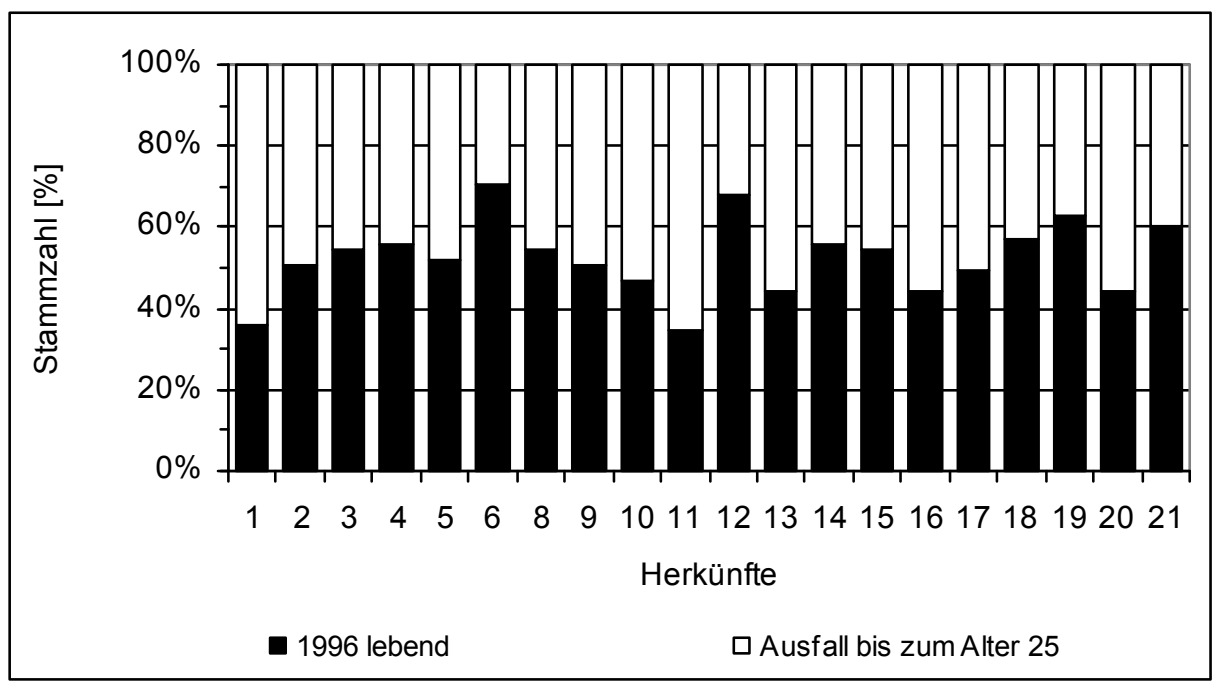

Abb. 3.62: Entwicklung der Pflanzenanzahl der IUFRO-Herkünfte auf der Fläche Sauerlach B / Bayern 
In der Abbildung 3.63 ist der Anteil lebender und ausgeschiedener Fichten der zusätzlich auf der Fläche angebauten 14 Herkünfte dargestellt. Bei diesen Herkünften variiert der Anteil der noch vorhandenen Fichten geringer und liegt zwischen $44 \%$ (Wolfach VI 9) und $64 \%$ (Wolfach V 4 Ostteil).

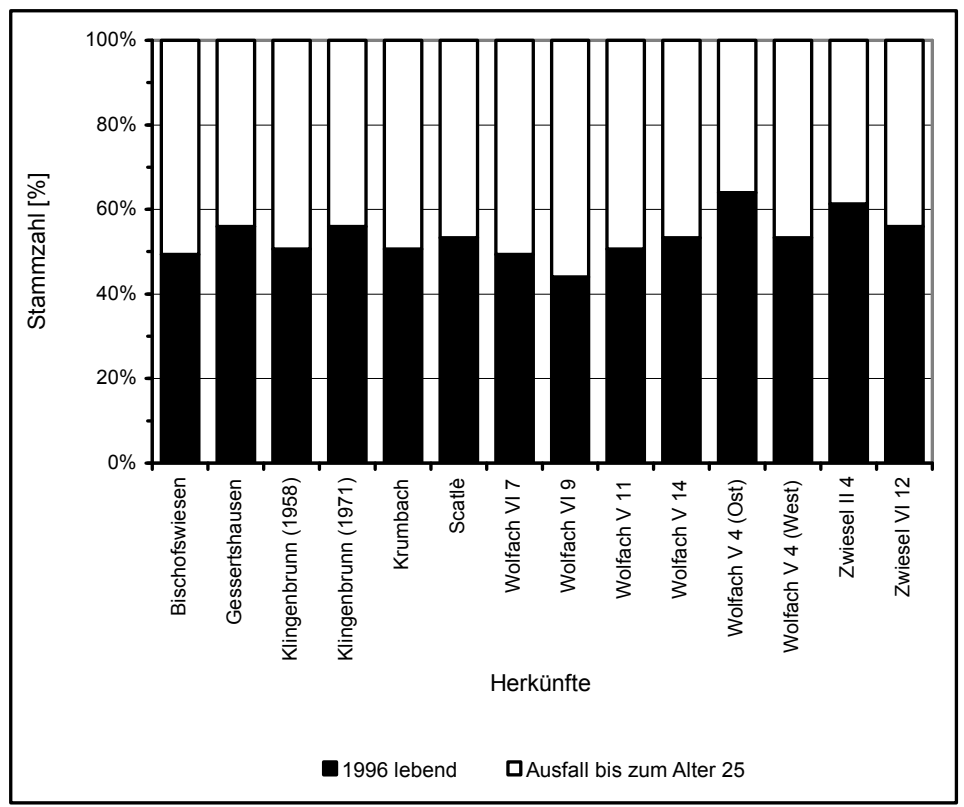

Abb. 3.63: Entwicklung der Pflanzenanzabl der 14 zusätzlichen Herkünfte auf der Fläche Sauerlach B / Bayern

Die Unterschiede $(\alpha=0,05)$ zwischen den 34 Herkünften lassen sich in multiplen Mittelwertvergleichen (Tukey- und Dunnett-Test, $\alpha=0,05$ ) nicht absichern.

\section{Schadmerkmale}

Auf der Versuchsfläche Sauerlach B wurde im Alter von 25 Jahren nur ein Baum mit Schälschaden notiert. Dieser wurde nicht in die nachfolgenden Berechnungen einbezogen.

\section{Stammform}

Im Alter von 25 Jahren wurde bei 1346 Fichten die Stammform beurteilt. Die Stammform wurde anhand einer dreistufigen Skala bonitiert. Im Ergebnis sind $99 \%$ der Stämme gerade, zehn Fichten wiesen einen leichten Mangel und sieben Fichten einen schweren Stammformmangel auf. Die Fichten mit mangelnder Stammform sind zufällig über die Herkünfte verteilt. In Abbildung 3.64 sind daher 
die Herkünfte zu geografischen Regionen zusammengefasst dargestellt. Zu beachten ist, dass die Anzahlen der beurteilten Stämme und Herkünfte der Regionen unterschiedlich sind.

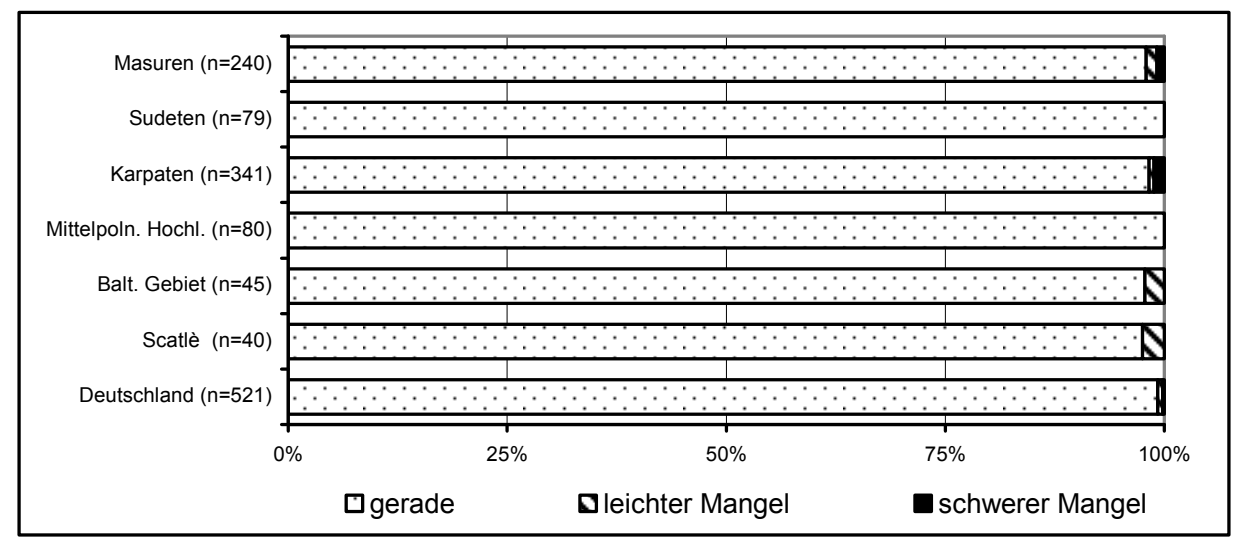

Abb. 3.64: Ergebnis der Beurteilung der Stammform der zu sieben geografischen Regionen zusammengefassten 34 Herkünfte der Fläche Sauerlach B / Bayern im Alter von 25 Jahren ( $n=$ Anzabl beurteilter Stämme)

\section{BHD-Wachstum}

Das Wachstum der Fichte ist auf der Fläche im Vergleich zur Ertragstafel (WIEDEMANN 1936/1942, mäßige Durchforstung) gut. Für die Fichten wird im Alter von 25 Jahren ein mittlerer BHD von $12,9 \mathrm{~cm}(\mathrm{n}=1345)$ errechnet. Die Streuung der Einzelwerte um den Mittelwert beträgt für die Fläche Sauerlach B s\% = 30,2.

In Abbildung 3.65 sind die BHD der 20 polnischen Herkünfte im Alter von 25 Jahren dargestellt. Die wüchsigste IUFRO-Herkunft (Nr. 11 Istebna 115f) erreicht einen BHD von 15,9 cm (123\% vom Versuchsmittel) und die mattwüchsigste (Nr. 17 Witów) einen BHD von 10,3 cm (80 \%). Der BHD der zusätzlichen 14 Herkünfte ist in Abbildung 3.66 dargestellt. Von diesen Herkünften hat die Herkunft Wolfach V 11 den größten mittleren BHD (14,8 cm, $114 \%$ und die Herkunft Scatlè den geringsten BHD (10,5 m, $81 \%)$.

Die Tukey-Prozedur $(\alpha=0,05)$ weist vier stark überlappende Gruppen aus (Anhang 2.20). Vom Standard aus acht auf allen Versuchsflächen vertretenen IUFRO-Herkünften unterscheidet sich keine Herkunft signifikant (Dunnett-Test, $\alpha=0,05)$. 


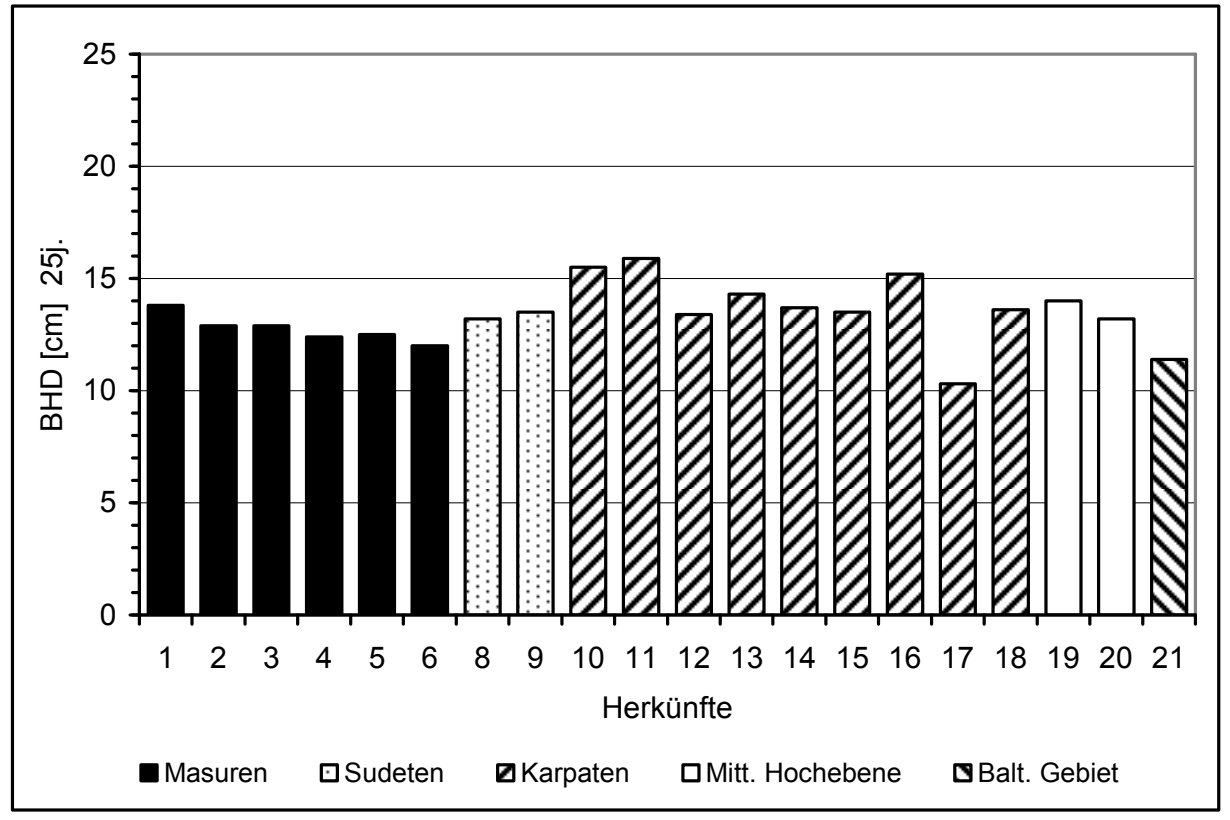

Abb. 3.65: Mittlere BHD der 20 polnischen Herkünfte im Alter von 25 Jabren auf der Fläche Sauerlach B / Bayern. Die Herkünfte sind nach geografischen Regionen gruppiert.

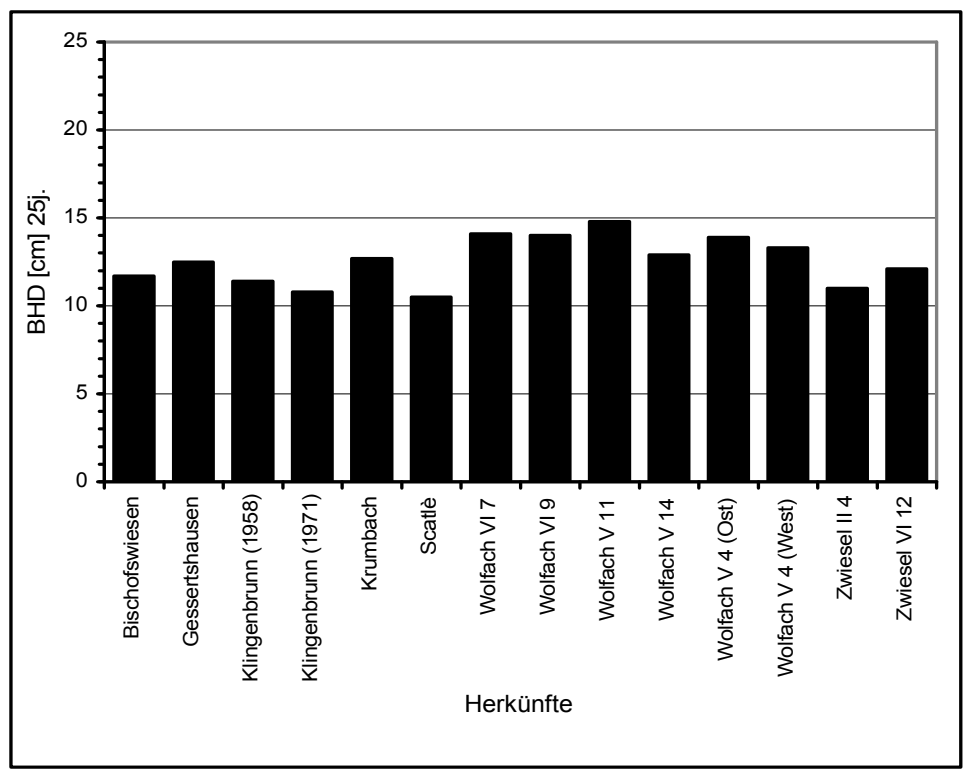

Abb. 3.66: $\quad$ Mittlere BHD der 14 zusätzlichen Herkünfte im Alter von 25 Jahren auf der Fläche Sauerlach B / Bayern 


\section{Einzelbaumvolumen und Vorrat pro Hektar}

Auch von der Fläche Sauerlach B liegen keine Höhenmessungen vor, so dass die Baumhöhen in Abhängigkeit der BHD geschätzt wurden: Höhe $=0,8 *$ BHD. Aus den Merkmalen BHD und Höhe wurden zunächst Einzelbaumvolumina berechnet. Pro Parzelle wurde anschließend unter Hinzuziehung der vorhandenen Fichten der Vorrat/ha ermittelt.

Das mittlere Einzelbaumvolumen beträgt $0,080 \mathrm{~m}^{3}$ im Alter von 25 Jahren auf der Versuchsfläche Sauerlach B und variiert von $0,040 \mathrm{~m}^{3}$ (Scatlè) bis $0,141 \mathrm{~m}^{3}$ (Nr. 11 Istebna 149h). Der multiple Mittelwertvergleich (Tukey-Test, $\alpha=0,05$ ) ergibt drei sich überlappende Gruppen (Anhang 2.20). Vom Standard unterscheidet sich keine Herkunft signifikant (Dunnett-Test, $\alpha=0,05$ ).

Der mittlere Vorrat über die 34 Herkünfte wird im Alter von 25 Jahren mit $187 \mathrm{~m}^{3} /$ ha errechnet. Zwischen den Herkünften variiert der errechnete Vorrat zwischen $88 \mathrm{~m}^{3} /$ ha (Nr. 17 Witów: $49 \%$ ) und $273 \mathrm{~m}^{3} /$ ha (Nr. 10 Wisła: $146 \%$ ).

In Abbildung 3.67 sind die IUFRO-Herkünfte zusammengestellt und in Abbildung 3.68 die zusätzlichen 14 Herkünfte. Der Abbildung 3.67 ist zu entnehmen, dass zu den vorratsreichen IUFRO-Herkünften neben der Herkunft Nr. 10 (Wisła) auch die Nr. 19 (Lubelski: $264 \mathrm{~m}^{3} / \mathrm{ha}$ ) und Nr. 12 (Istebna 115f: $251 \mathrm{~m}^{3} / \mathrm{ha}$ ) zählen. Vergleichbare Vorräte haben die beiden zusätzlichen Herkünfte Wolfach V 4 Westteil $\left(272 \mathrm{~m}^{3} / \mathrm{ha}\right)$ und Wolfach V $11\left(250 \mathrm{~m}^{3} / \mathrm{ha}\right)$. Unter den zusätzlichen Herkünften sind die Herkünfte Scatlè $\left(95 \mathrm{~m}^{3} / \mathrm{ha}\right)$ und Klingenbrunn Ernte 1971 $\left(107 \mathrm{~m}^{3} / \mathrm{ha}\right)$ vorratsarm. 


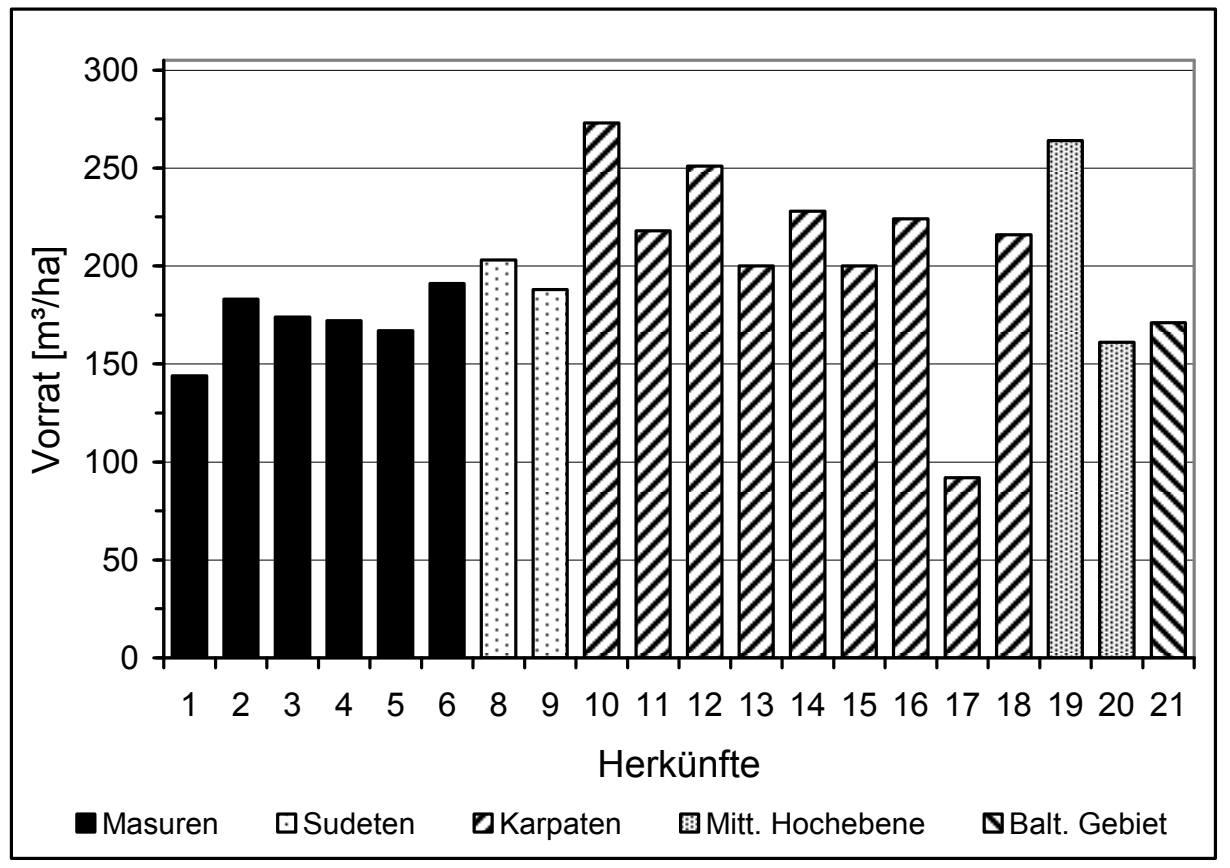

Abb. 3.67: Hochgerechneter Vorrat je Hektar der 20 polnischen Herkünfte auf der Versuchsfläche Sauerlach B / Bayern im Alter von 25 Jahren

In den multiplen Mittelwertvergleichen (Tukey- bzw. Dunnett-Test $\alpha=0,05$ ) lassen sich die Unterschiede zwischen den 34 Herkünften nicht statistisch absichern. 


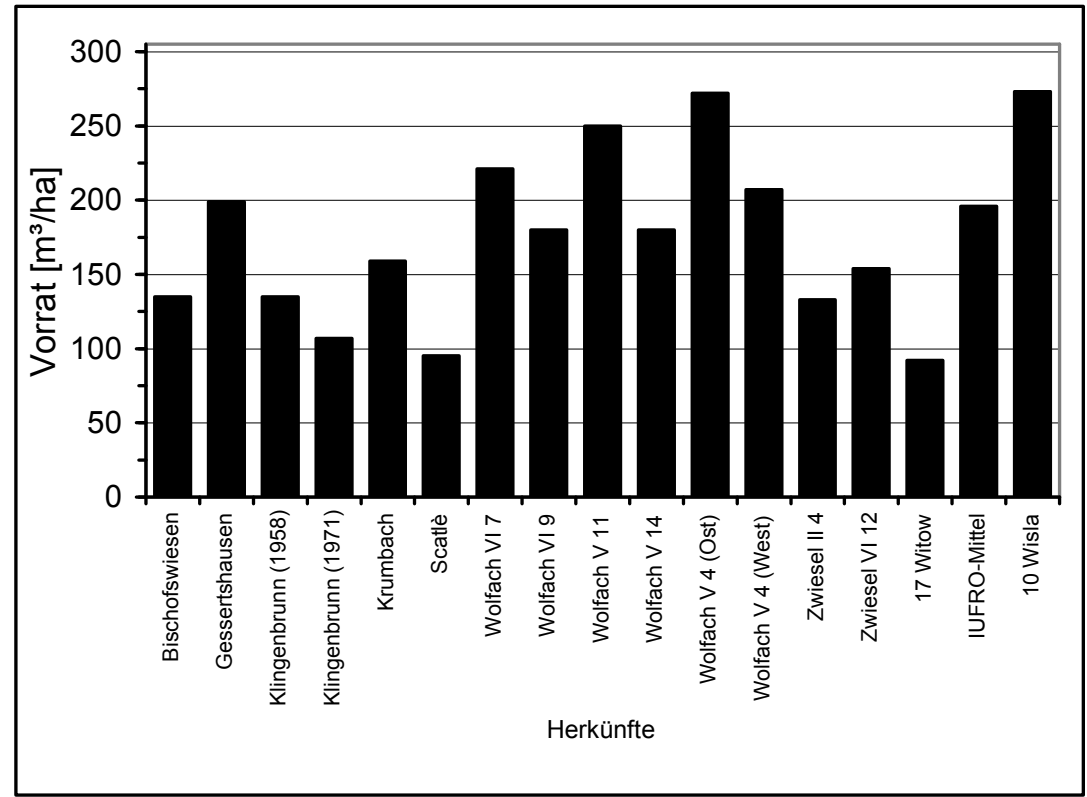

Abb. 3.68 Hochgerechneter Vorrat je Hektar der 14 zusätzlichen Herkünfte auf der Versuchsfläche Sauerlach B / Bayern im Alter von 25 Jahren. Zum Vergleich sind die beste Herkunft (Nr. 10) und die mattwüchsigste Herkunft (Nr. 17) sowie das Mittel über die 20 polnischen IUFRO-Herkünfte aufgenommen.

\subsubsection{Neureichenau (BFH)}

\section{Entwicklung der Pflanzenanzahl}

Im Alter von zehn Jahren lebten auf der Versuchsfläche noch $91 \%$ der ursprünglich gepflanzten Fichten. Im Alter von 23 bzw. 25 Jahren waren es noch 86 \% bzw. $85 \%$. Nach starken Nassschneefällen im März 1999 ging der Anteil der lebenden Pflanzen auf $20 \%$ im Alter von 34 Jahren zurück.

Gab es bei den Erhebungen der Überlebensraten bis 1996 Unterschiede von bis zu $14 \%$-Punkten, so waren bei der letzten Erfassung im Jahr 2005 keine Unterschiede zwischen den Wiederholungen zu verzeichnen. Die Überlebensraten beliefen sich auf 21 bzw. $20 \%$ in den einzelnen Wiederholungen.

In Tabelle 3.26 sind die Überlebensraten der zu fünf geografischen Regionen zusammengefassten Herkünfte dargestellt. im Alter 34 reichen sie von $11 \%$ bei den Herkünften der Mittelpolnischen Hochebene bis $41 \%$ bei den Herkünften aus den Sudeten. 
Tab.3.26: $\quad$ Mittlere Überlebensraten der zu fünf geografischen Regionen zusammengefassten Herkünfte und der IUFRO-Prüfglieder auf der Fläche Neureichenau

\begin{tabular}{lcccccc}
\hline Geografische Region & IUFRO-Nr. & $\begin{array}{c}\text { Anzahl } \\
\text { Herkünfte }\end{array}$ & $\begin{array}{c}1981 \\
(10-\mathrm{j} .)\end{array}$ & $\begin{array}{c}1994 \\
(23-\mathrm{j} .)\end{array}$ & $\begin{array}{c}1996 \\
(25-\mathrm{j} .)\end{array}$ & $\begin{array}{c}2005 \\
(34-\mathrm{j} .\end{array}$ \\
\hline Masuren-Podlasie & $1,2,4,5$ & 4 & $90 \%$ & $84 \%$ & $83 \%$ & $21 \%$ \\
Sudeten & 8,9 & 2 & $96 \%$ & $92 \%$ & $92 \%$ & $41 \%$ \\
Karpaten (Beskiden) & $10-15,18$ & 7 & $93 \%$ & $89 \%$ & $87 \%$ & $23 \%$ \\
Mittelpolnische & 19,20 & 2 & $83 \%$ & $75 \%$ & $74 \%$ & $11 \%$ \\
Hochebene & & 1 & $95 \%$ & $93 \%$ & $91 \%$ & $22 \%$ \\
Baltisches Gebiet & 21 & 16 & $91 \%$ & $86 \%$ & $85 \%$ & $20 \%$ \\
\hline IUFRO-Herkünfte & & & & &
\end{tabular}

Die Entwicklung der Pflanzenanzahl bei den einzelnen Herkünften ist in Abbildung 3.69 dargestellt. In den fünf Jahren von der Flächenanlage bis zur ersten Messung im Jahre 1981 hat die Herkunft Nr. 19 (Zwierzyniec) mit 20\% die höchste Mortalität. Die geringsten Mortalitäten hatten die Herkünfte Nr. 10 (Wisła: $2 \%$ ), Nr. 8 (Miedzygórze: 3\%), Nr. 13 (Zwardon: $4 \%$ ) und Nr. 15 (Rycerka II: 4 \%). In den folgenden 15 Jahren (1981 bis 1996) fallen die Ausfälle geringer aus und variieren zwischen $2 \%$ (Nr. 9 Stronie Slaskie und Nr. 14 Rycerka I) und $15 \%$ (Nr. 20 Blizyn). In der sich anschließenden Periode mit dem Nassschneeereignis sterben $65 \%$ der ursprünglich gepflanzten Fichten ab. Die geringsten Ausfälle hat in dieser Periode die Herkunft Nr. 9 (Stronie Slaskie: $45 \%$ ) und die höchsten die Herkunft Nr. 5 (Borki: 82 \%).

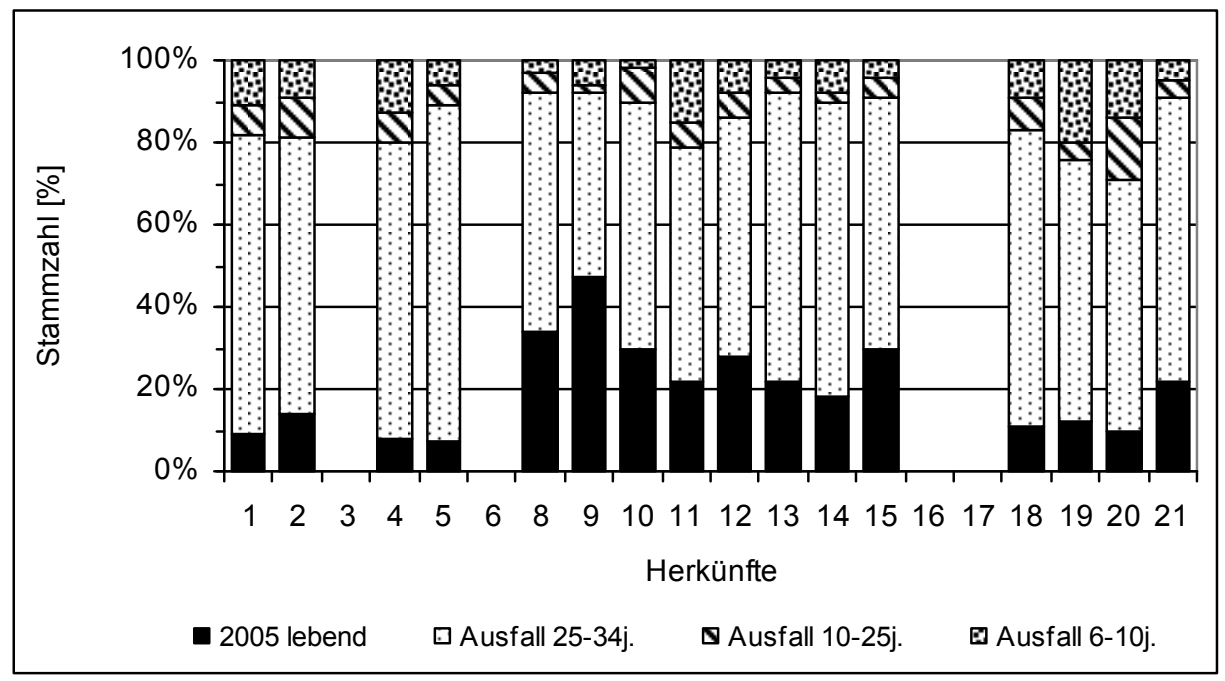

Abb. 3.69: Entwicklung der Pflanzenanzabl auf der Fläche Neureichenau / Bayern 
Der multiple Mittelwertvergleich (Tukey-Test, $\alpha=0,05)$ ergibt fünf sich überlappende Gruppen (Anhang 2.21). Gegenüber dem Standard aus sieben Herkünften (die achte Herkunft Nr. 6 Nowe Ramuki ist auf dieser Versuchsfläche nur im Rand angepflanzt) gibt es eine signifikant höhere Überlebensrate (DunnettTest, $\alpha=0,05)$ der Herkunft Nr. 9 (Stronie Slaskie).

\section{Schadmerkmale}

Bei der Messung im Alter von 10 Jahren wurden $63 \%$ der Fichten ohne Schaden notiert. Es folgen Bäume mit Krümmungen (20\%) und Bäume mit Bruchstellen (11\%). Im Alter von 23 Jahren wurden bis zu zwei Schäden pro Baum erfasst. $77 \%$ der Bäume hatten keinen Schaden und $5 \%$ wurden mit zwei Schäden notiert. Häufigster Schaden waren Krümmungen (18\%). Da es sich bei Krümmungen eigentlich um ein Formkriterium handelt, wird davon ausgegangen, dass damit ein ausgewachsener leichter Schaden durch Schneebruch oder der Verlust der Gipfelknospe gemeint sein könnte. Bei den weiteren, mengenmäßig unbedeutenden Schäden handelt es sich um: Astabrisse, absterbender Baum, Zwiesel, Schneedruck. Bei der Erhebung im Alter von 25 Jahren wurden $87 \%$ als ohne Schaden bonitiert, weitere $9 \%$ hatten Krümmungen.

Im Alter von 34 Jahren tritt Schneebruch als häufigster Schaden auf. Etwa die Hälfte der noch lebenden Fichten aus der Mittelpolnischen Hochebene und aus Masuren sind durch Schnee gebrochen gewesen (Abb. 3.70). Am geringsten waren die Schäden bei den Fichten der Sudeten und der Karpaten. Schneedruck sowie Schäl-/Rückeschäden waren unbedeutend und wurden für nur 2,5\% der Bäume notiert.

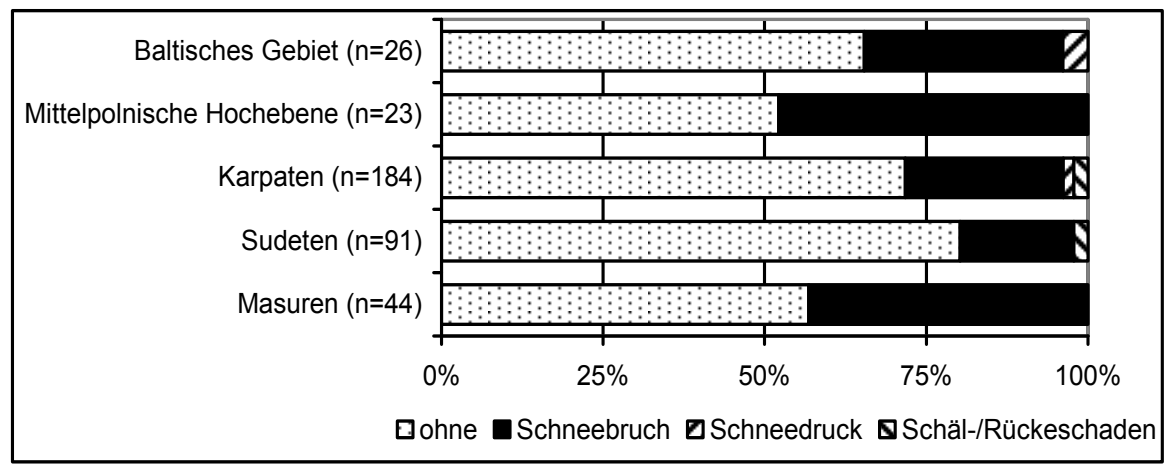

Abb. 3.70: $\quad$ Schäden an den zu fünf geografischen Regionen zusammengefassten Herkünften im Alter 34 auf der Fläche Neureichenau / Bayern ( $n=$ Anzabl der Fichten) 


\section{Stammform}

Für 369 Fichten wurde im Alter von 34 Jahren die Stammform nach zwei Schlüsseln beurteilt: Form A der Stammform und Form B der Mehrstämmigkeit. Bei Form A (Stammform) waren $60 \%$ der Stämme gerade und $33 \%$ hatten einen leichten und $7 \%$ einen starken Mangel. Bei Form B (Mehrstämmigkeit) waren $71 \%$ der Fichten einstämmig, und $17 \%$ hatten Kronenzwiesel als Folge von Schneebruch. Die restlichen 2\% hatten Stamm- oder (Boden-)Tiefzwiesel. Beurteilt man die Stammform nach beiden Schlüsseln zugleich, so ergibt sich folgendes Bild: Etwa die Hälfte der Fichten (48\%) ist einstämmig und gerade. $20 \%$ sind gerade mit leichten Mängeln. Je $12 \%$ sind gerade bzw. mit leichten Mängeln und haben einen Kronenzwiesel. Der verbleibende Anteil hat starke Mängel und verteilt sich über die verschiedenen Ausprägungen der Form B.

In Abbildung 3.71 sind die Stammformen (Form A) für die zu fünf geografischen Regionen zusammengefassten Herkünfte dargestellt. Den höchsten Anteil (65\%) gerader Stämme haben die Prüfglieder der Karpaten. Überwiegend gerade Stämme (> 60\%) haben die Prüfglieder aus dem südlichen Polen (Karpaten $65 \%$ und Sudeten $61 \%$ ) sowie die nicht autochthone Herkunft aus dem Baltischen Gebiet (61\%). Die Herkünfte aus den Masuren haben etwa 45\% gerade Fichten und die aus der Mittelpolnischen Hochebene $40 \%$. Etwa $13 \%$ der Fichten dieser beiden Regionen haben starke Mängel in der Stammform.

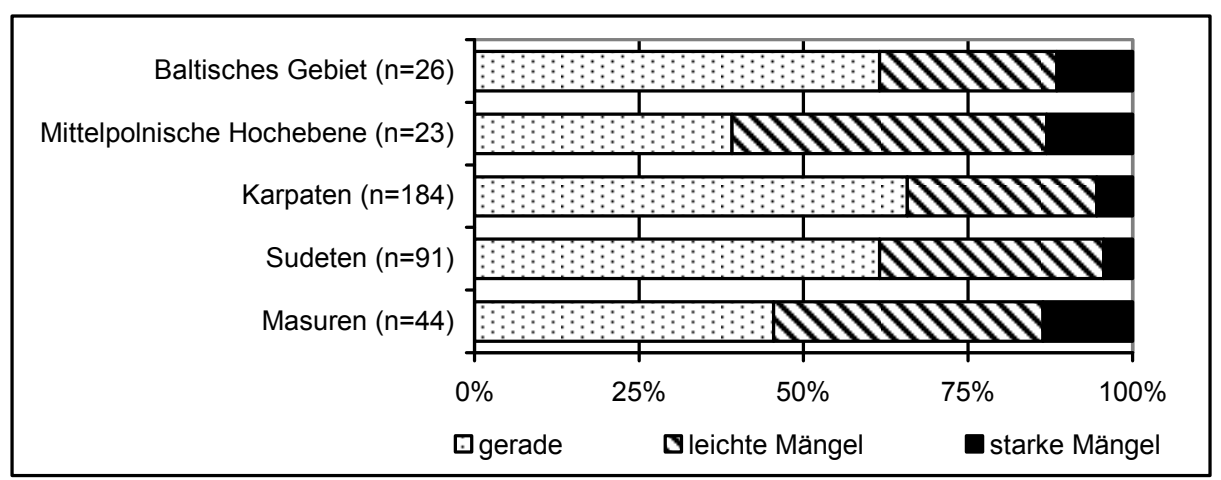

Abb. 3.71: Stammform der zu fünf geografischen Regionen zusammengefassten Herkünfte im Alter 34 auf der Fläche Neureichenau / Bayern ( $n=$ Anzabl der Fichten) 


\section{Ovalität}

Die Abweichung des Stammquerschnittes von der Kreisform beträgt im Mittel der polnischen Herkünfte auf der Versuchsfläche Neureichenau 2,8 und variiert zwischen den Herkünften von 0,7 (Nr. 20 Blizyn) mit den geringsten Abweichungen bis 4,4 (Nr. 18 Tarnawa) mit der größten Abweichung von der Kreisform. Absichern lassen sich die Unterschiede $(\alpha=0,05)$ in multiplen Mittelwertvergleichen (Tukey-Test bzw. Dunnett-Test) nicht.

Die Güte dieses Maßes lässt sich nicht beurteilen, da keine Aufzeichnungen vorliegen, aus denen hervorgeht, ob jeweils die Bäume an der dicksten bzw. dünnsten Stelle in 1,3 m Höhe gemessen wurden.

\section{H/D-Verbältnis}

Für die 16 polnischen Herkünfte beträgt im Alter 34 der mittlere H/D-Wert 70 und variiert zwischen 62 (Nr. 19 Lubelski und Nr. 20 Blizyn) und 80 (Nr. 5 Borki). Im Alter von 25 Jahren haben die Fichten der IUFRO-Herkünfte einen H/D-Wert von 82. Die schlankste Herkunft hat ein H/D-Verhältnis von 90 (Nr. 19 Lubelski) und die abholzigste eines von 76 (Nr. 9 Stronie Slaskie).

Die H/D-Verhältnisse der einzelnen Prüfglieder im Alter von 25 und 34 Jahren sind in Anhang 2.22 zusammengestellt. Die Unterschiede $(\alpha=0,05)$ zwischen den 16 Herkünften im Alter von 25 bzw. 34 Jahren lassen sich in multiplen Mittelwertvergleichen (Tukey-Test bzw. Dunnett-Test) nicht absichern.

\section{Höhen- und BHD-Wachstum}

Das Wachstum auf der Fläche ist entsprechend den Standortverhältnissen erwartungsgemäß gering. So haben die Fichten ohne Schaden im Alter von 10 Jahren (1981) eine mittlere Höhe von 0,8 m. 15 Jahre später im Alter von 25 Jahren hatten sie eine mittlere Höhe von 8,9 m erreicht und bei der letzten Messung im Alter von 34 Jahren lag die mittlere Höhe bei 14,8 m (Abb. 3.72). Während im Alter von 25 Jahren keine größeren Unterschiede im Höhenwachstum zwischen den 16 Herkünften auffallen, hat sich dieses im Alter von 34 Jahren geändert. Die wüchsige Herkunft Nr. 18 (Tarnawa) hat eine mittlere Höhe von 16,1 m (110\%) und die mattwüchsigste Herkunft Nr. 4 (Przerwanki) eine von 12,6 m (86 \%). 


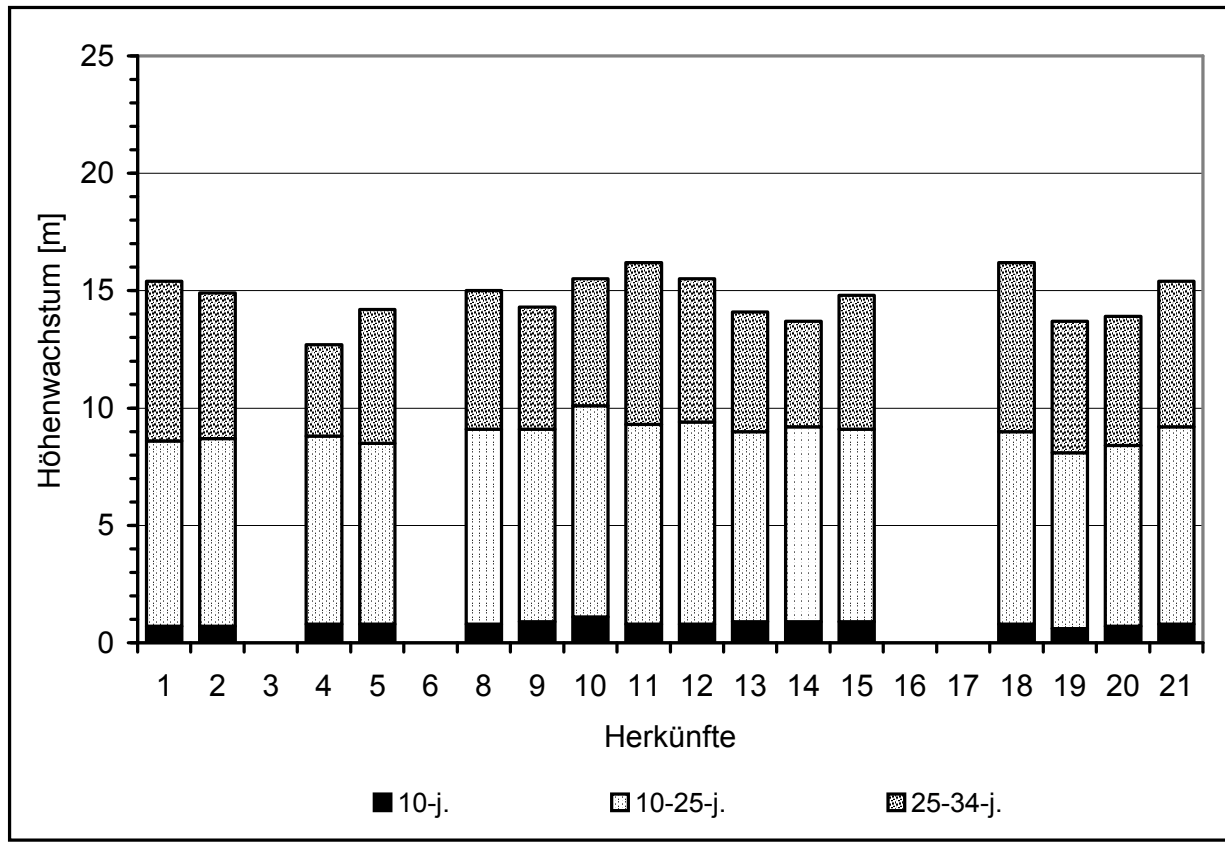

Abb. 3.72: Entwicklung des Höhenwachstums der 16 polnischen Herkünfte bis zum Alter von 34 Jahren auf der Fläche Neureichenau / Bayern

Die Unterschiede $(\alpha=0,05)$ zwischen den 16 Prüfgliedern lassen sich im Alter von 34 Jahren in multiplen Mittelwertvergleichen (Tukey-Test bzw. Dunnett-Test) nicht absichern. Im Alter von 25 Jahren unterscheiden sich die vier mattwüchsigsten Herkünfte (Nr. 19 Blizyn, Nr. 20 Kartuzy, Nr. 5 Borki, Nr. 1 Pogorzelece) von der wüchsigsten Herkunft Nr. 10 (Wisła) (Anhang 2.23). Im Vergleich mit dem Standard lassen sich keine Unterschiede absichern (Dunnett-Test, $\alpha=0,05)$.

Der mittlere BHD beträgt 20,3 cm im Alter von 34 Jahren auf der Fläche Neureichenau (Abb. 3.73). Den größten mittleren BHD 22,4 cm (111\%) hat die Herkunft Nr. 12 (Istebna 115f), es folgt die Herkunft Nr. 20 (Blizyn) mit 21,7 cm $(107 \%)$. Den geringsten mittleren BHD $(17,4 \mathrm{~cm}, 86 \%)$ und auch den geringsten Dickenzuwachs in den vergangenen neun Jahren hat die Herkunft Nr. 4 (Przerwanki).

Im Alter von 34 Jahren lassen sich die Unterschiede $(\alpha=0,05)$ zwischen den 16 Prüfgliedern im multiplen Mittelwertvergleich (Tukey-Test bzw. Dunnett-Test) nicht absichern. Im Alter von 25 Jahren unterscheiden sich die beiden mattwüchsigsten Herkünfte (Nr. 19 Blizyn und Nr. 5 Borki) von der wüchsigsten Herkunft Nr. 10 (Wisła) (Anhang 2.23). Im Vergleich mit dem Standard lassen sich keine Unterschiede absichern (Dunnett-Test, $\alpha=0,05$ ). 


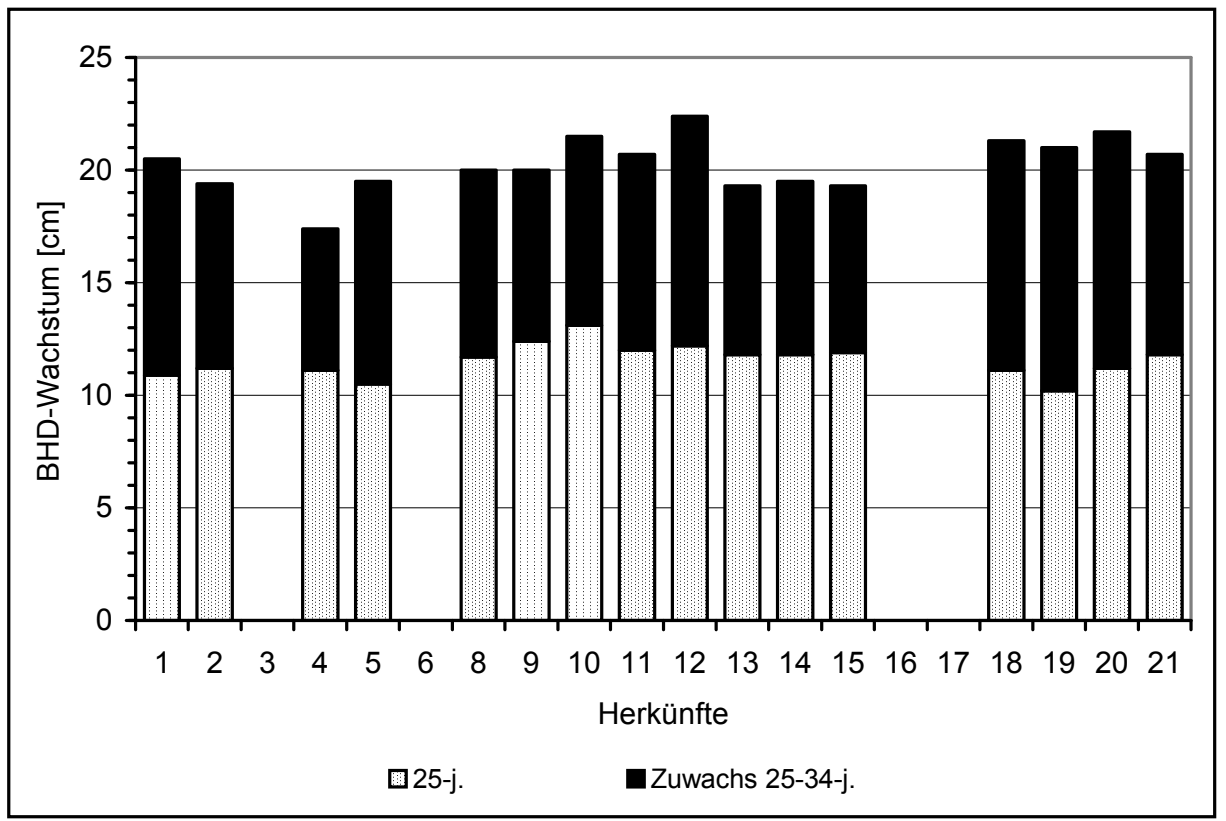

Abb. 3.73: Entwicklung des BHD-Wachstums der 16 polnischen Herkünfte auf der Fläche Neureichenau / Bayern

Hervorzuheben ist, dass diese Werte von forstlichen Eingriffen unbeeinflusst sind, da die Fläche bislang nicht durchforstet wurde. Die Änderungen beruhen einzig auf Konkurrenzeinflüssen und dem Nassschneeereignis vom März 1999.

Die Streuung der Einzelwerte um den Mittelwert nimmt sowohl bei der Höhe als auch beim Durchmesser mit zunehmendem Alter ab. So beträgt die relative Streuung (Variationskoeffizient) der gemessenen Baumhöhen im Alter von 10 Jahren für den Gesamtversuch noch $40 \%$ und liegt im Alter von 34 Jahren bei $19 \%$. Dieses ist auch beim BHD der Fall, wobei hier der Variationskoeffizient im Alter von 25 Jahren $32 \%$ beträgt und somit über dem der Baumhöhen $(26 \%)$ liegt. Im Alter von 34 Jahren ist die Streuung beim BHD nach dem Nassschneeereignis so groß wie bei der Baumhöhe.

Korreliert sind die Merkmale Höhe und BHD, wenn sie in einem Jahr gemessen wurden (Tab. 3.27). Weiterhin lässt sich ein Zusammenhang zwischen der Höhe im Alter 10 und der Höhe im Alter 25 sowie dem Durchmesser im Alter 25 feststellen. 
Tab. 3.27: $\quad$ Produkt-Momenten-Korrelationsmatrix der Wachstumsmerkmale Höhe und BHD

\begin{tabular}{c|cccccc}
\hline Merkmal & H10 & H25 & H34 & D25 & D34 \\
\cline { 1 - 2 } H10 & - & $0,797 * * *$ & 0,111 & $0,807 * * *$ & 0,007 \\
H25 & & - & 0,485 & $0,933^{* * *}$ & 0,225 \\
\cline { 1 - 1 } H34 & & & - & 0,360 & $0,609 *$ \\
\cline { 1 - 1 } D25 & & & & - & 0,213 \\
D34 & & & & & - \\
\hline
\end{tabular}

\section{Einzelbaumvolumen und Vorrat pro Hektar}

Im Alter von 34 Jahren beträgt das mittlere Einzelbaumvolumen $0,233 \mathrm{~m}^{3}$ auf der Versuchsfläche Neureichenau und variiert von $0,093 \mathrm{~m}^{3}$ (Nr. 4 Przerwanki) bis $0,312 \mathrm{~m}^{3}$ (Nr. 20 Blizyn). Der multiple Mittelwertvergleich (Tukey-Test, $\alpha=0,05$ ) ergibt zwei sich überlappende Gruppen (Anhang 2.24). Vom Standard unterscheidet sich keine Herkunft signifikant (Dunnett-Test, $\alpha=0,05)$. Aus den Daten der neun Jahre zuvor erfolgten Messung errechnet sich ein mittleres Einzelbaumvolumen von $0,051 \mathrm{~m}^{3}$. Das geringste mittlere Einzelbaumvolumen $\left(0,039 \mathrm{~m}^{3}\right) \mathrm{im}$ Alter 25 hat die Herkunft Nr. 21 (Kartuzy) und das höchste $\left(0,069 \mathrm{~m}^{3}\right)$ die Herkunft Nr. 1 (Pogorzelece). Auch hier ergibt der multiple Mittelwertvergleich (Tukey-Test, $\alpha=0,05$ ) zwei sich überlappende Gruppen (s. o.). Vom Standard unterscheidet sich keine Herkunft (Dunnett-Test, $\alpha=0,05$ ) signifikant.

Bei der Berechnung des mittleren Vorrats im Alter von 34 Jahren ergeben sich $111 \mathrm{~m}^{3} /$ ha. Diese geringe Menge hängt mit dem Nassschneeereignis vom März 1999 zusammen. Im Alter von 34 Jahren fallen die Unterschiede zwischen den Herkünften beachtlich aus (Abb. 3.74). Der größte Unterschied im Vorrat liegt zwischen der schlechtesten Herkunft (Nr. 4 Przerwanki) mit $33 \mathrm{~m}^{3} / \mathrm{ha}(30 \%$ vom Versuchsflächenmittel) und der besten (Nr. 9 Stronie Slaskie) mit $236 \mathrm{~m}^{3} / \mathrm{ha}$ (213\% des Flächenmittels). Weiterhin erzielen die Herkünfte aus den Sudeten und die meisten aus den Karpaten sowie die nicht autochthone Herkunft aus dem Baltischen Gebiet noch einen über dem Versuchsmittel liegenden Vorrat. In der Folge des Nassschnees liegen zwei Herkünfte (Nr. 14 Rycerka I und Nr. 18 Tarnawa) aus den Karpaten jedoch unter dem Durchschnitt. 


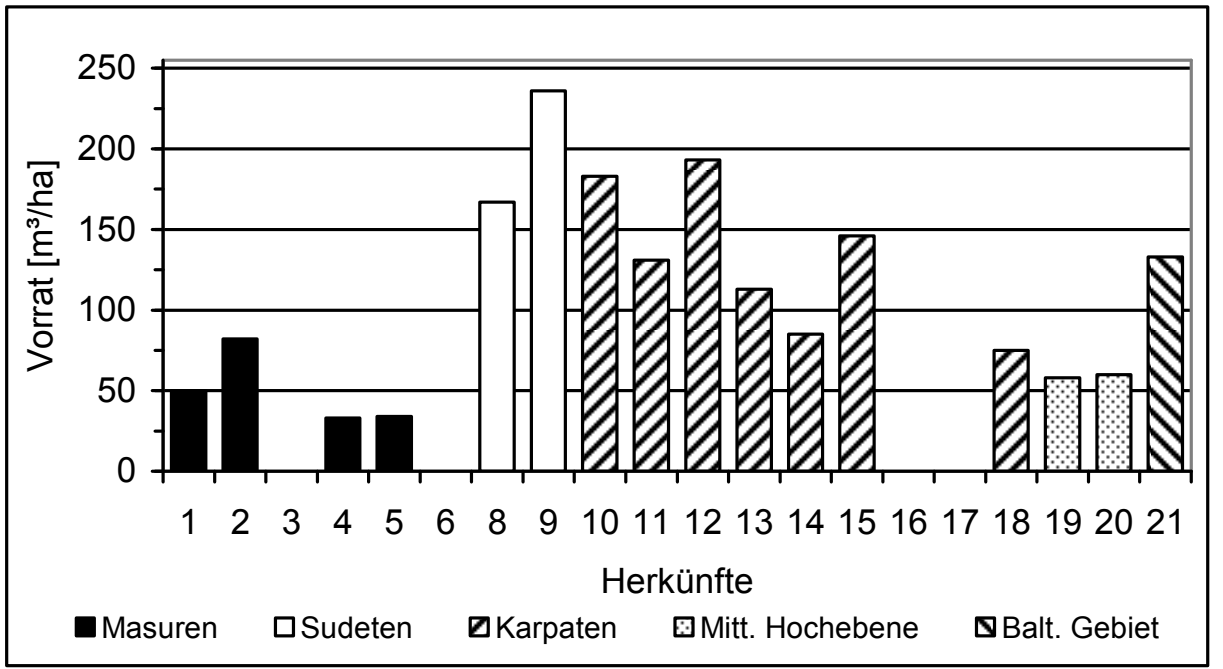

Abb. 3.74: Hochgerechneter Vorrat je Hektar der 16 Herkünfte auf der Versuchsfläche Neureichenau im Alter von 34 Jabren

Im Alter von 25 Jahren beträgt der Vorrat im Mittel über die 16 Herkünfte bereits $94 \mathrm{~m}^{3} / \mathrm{ha}$. Zwischen den Herkünften gibt es offensichtliche Unterschiede (Abb. 3.75). So variiert der Vorrat zwischen $58 \mathrm{~m}^{3} / \mathrm{ha}\left(\mathrm{Nr}\right.$. 19 Lubelski) und $141 \mathrm{~m}^{3} / \mathrm{ha}$ (Nr. 10 Wisła). Dieses entspricht $62 \%$ bzw. $150 \%$ vom Mittel der Fläche. Bei den zu geografischen Regionen zusammengefassten Herkünften liegen die beiden Herkünfte der Sudeten sowie sechs Herkünfte der Karpaten über dem Versuchsmittel. Lediglich die östlichste Herkunft der Karpaten (Nr. 18 Tarnawa) liegt unterhalb des Versuchsflächenmittels. Zu den vorratsreichen Herkünften zählt auch die nicht autochthone Herkunft aus dem Baltischen Gebiet (Nr. 21). Die beiden Herkünfte der Mittelpolnischen Hochebene (Nr. 19 und 20) erreichen rund $65 \%$ des mittleren Vorrats und die aus Masuren im Mittel $72 \%$. 


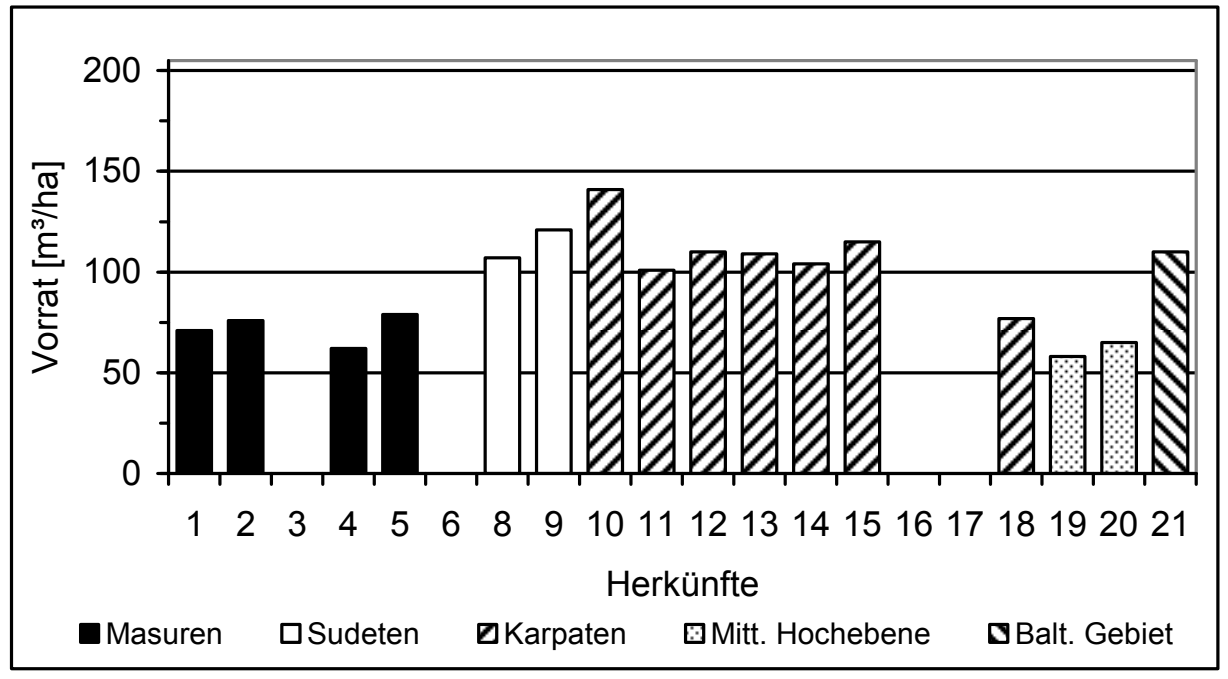

Abb.3.75: Hochgerechneter Vorrat je Hektar der 16 Herkü̈fte auf der Versuchsfläche Neureichenau im Alter von 25 Jahren

Der multiple Mittelwertvergleich (Tukey-Test, $\alpha=0,05)$ ergibt für den Vorrat im Alter von 34 Jahren fünf sich überlappende Gruppen und im Alter von 25 Jahren sechs Gruppen (Anhang 2.25). Vom Standard aus sieben Herkünften unterscheidet (Dunnett-Test, $\alpha=0,05)$ sich die vorratsreichste Herkunft Nr. 9 (Stronie Slaskie) im Alter von 34 Jahren. Neun Jahre zuvor waren es die vorratsreichste Herkunft Nr. 10 (Wisła) sowie die beiden vorratsarmen Herkünfte Nr. 19 (Lubelski) und 20 (Blizyn).

Trotz des Nassschneeereignisses ist der Vorrat je Hektar zwischen den beiden Erhebungen im Alter von 25 und 34 Jahren hoch korreliert $\left(r_{\mathrm{P}}=0,861^{* * *}\right)$. 


\subsubsection{Vergleich der IUFRO-Herkünfte zwischen den Versuchsflächen}

In den folgenden Vergleichen zwischen den Versuchsflächen werden nur die 20 IUFRO-Herkünfte (Tab. 3.28) berücksichtigt. Bei einigen Merkmalen werden die Herkunftsmittel für die Vergleiche ins Verhältnis zu den sieben auf allen Flächen angebauten Herkünfte gesetzt (= Standard). Die Herkünfte sind in der Tabelle 3.28 gekennzeichnet. Erschwert werden die Vergleiche durch die Tatsache, dass die Erhebungen zu unterschiedlichen Zeitpunkten erfolgten. Im Vordergrund der Analysen stehen daher Rangvergleiche.

Tab. 3.28: Verteilung der polnischen Herkünfte im IUFRO-Fichtenherkunftsversuchs von 1972

\begin{tabular}{|c|c|c|c|c|c|c|c|c|c|c|c|c|}
\hline \multirow{2}{*}{$\begin{array}{c}\text { IUFRO } \\
\text { Nr. }\end{array}$} & \multirow{2}{*}{ Herkunft } & \multicolumn{10}{|c|}{ Versuchsflächen * } & \multirow{2}{*}{$\begin{array}{l}\text { Stan- } \\
\text { dard }\end{array}$} \\
\hline & & $\mathrm{R}$ & $\mathrm{W}$ & $\mathrm{Ha}$ & $\mathrm{D}$ & $\mathrm{S}$ & O.A & O.B & A & $\mathrm{B}$ & $\mathrm{N}$ & \\
\hline 1 & Pogorzelece & $\mathrm{x}$ & $\mathrm{x}$ & $\mathrm{x}$ & $\mathrm{x}$ & & $\mathrm{x}$ & $\mathrm{x}$ & $\mathrm{x}$ & $\mathrm{x}$ & $\mathrm{x}$ & \\
\hline 2 & Krzyze & $\mathrm{x}$ & $\mathrm{x}$ & $\mathrm{x}$ & $\mathrm{x}$ & & $\mathrm{x}$ & $\mathrm{x}$ & $\mathrm{x}$ & $\mathrm{x}$ & $\mathrm{x}$ & \\
\hline 3 & Wigry & $\mathrm{x}$ & $\mathrm{x}$ & $\mathrm{x}$ & $\mathrm{x}$ & & $\mathrm{x}$ & $\mathrm{x}$ & $\mathrm{x}$ & $\mathrm{x}$ & & \\
\hline 4 & Przerwanki & $\mathrm{x}$ & $\mathrm{x}$ & $\mathrm{x}$ & $\mathrm{x}$ & $\mathrm{x}$ & $\mathrm{x}$ & $\mathrm{x}$ & $\mathrm{x}$ & $\mathrm{x}$ & $\mathrm{x}$ & $\mathrm{S}$ \\
\hline 5 & Borki & $\mathrm{x}$ & $\mathrm{x}$ & $\mathrm{x}$ & $\mathrm{x}$ & $\mathrm{x}$ & $\mathrm{x}$ & $\mathrm{x}$ & $\mathrm{x}$ & $\mathrm{x}$ & $\mathrm{x}$ & $\mathrm{S}$ \\
\hline 6 & Nowe Ramuki & $\mathrm{x}$ & $\mathrm{x}$ & $\mathrm{x}$ & $\mathrm{x}$ & $\mathrm{x}$ & $\mathrm{x}$ & $\mathrm{x}$ & $\mathrm{x}$ & $\mathrm{x}$ & & \\
\hline 8 & Miedzygórze & $\mathrm{x}$ & $\mathrm{x}$ & $\mathrm{x}$ & $\mathrm{x}$ & $\mathrm{x}$ & $\mathrm{x}$ & $\mathrm{x}$ & $\mathrm{x}$ & $\mathrm{x}$ & $\mathrm{x}$ & $S$ \\
\hline 9 & Stronie Slaskie & $\mathrm{x}$ & $\mathrm{x}$ & $\mathrm{x}$ & $\mathrm{x}$ & & $\mathrm{x}$ & $\mathrm{x}$ & $\mathrm{x}$ & $\mathrm{x}$ & $\mathrm{x}$ & \\
\hline 10 & Wisła & $\mathrm{x}$ & $\mathrm{x}$ & $\mathrm{x}$ & $\mathrm{x}$ & & $\mathrm{x}$ & $\mathrm{x}$ & $\mathrm{x}$ & $\mathrm{x}$ & $\mathrm{x}$ & \\
\hline 11 & Istebna $149 \mathrm{~h}$ & $\mathrm{x}$ & $\mathrm{x}$ & $\mathrm{x}$ & $\mathrm{x}$ & $\mathrm{x}$ & $\mathrm{x}$ & $\mathrm{x}$ & $\mathrm{x}$ & $\mathrm{x}$ & $\mathrm{x}$ & S \\
\hline 12 & Istebna $115 f$ & $\mathrm{x}$ & $\mathrm{x}$ & $\mathrm{x}$ & $\mathrm{x}$ & $\mathrm{x}$ & $\mathrm{x}$ & $\mathrm{x}$ & $\mathrm{x}$ & $\mathrm{x}$ & $\mathrm{x}$ & S \\
\hline 13 & Zwardon & $\mathrm{x}$ & $\mathrm{x}$ & $\mathrm{x}$ & $\mathrm{x}$ & $\mathrm{x}$ & $\mathrm{x}$ & $\mathrm{x}$ & $\mathrm{x}$ & $\mathrm{x}$ & $\mathrm{x}$ & $\mathrm{S}$ \\
\hline 14 & Rycerka I & $\mathrm{x}$ & $\mathrm{x}$ & $\mathrm{x}$ & $\mathrm{x}$ & & $\mathrm{x}$ & $\mathrm{x}$ & $\mathrm{x}$ & $\mathrm{x}$ & $\mathrm{x}$ & \\
\hline 15 & Rycerka II & & & & $\mathrm{x}$ & & $\mathrm{x}$ & $\mathrm{x}$ & $\mathrm{x}$ & $\mathrm{x}$ & $\mathrm{x}$ & \\
\hline 16 & Orawa & $\mathrm{x}$ & $\mathrm{x}$ & $\mathrm{x}$ & $\mathrm{x}$ & $\mathrm{x}$ & $\mathrm{x}$ & $\mathrm{x}$ & $\mathrm{x}$ & $\mathrm{x}$ & & \\
\hline 17 & Witów & $\mathrm{x}$ & $\mathrm{x}$ & $\mathrm{x}$ & $\mathrm{x}$ & & $\mathrm{x}$ & $\mathrm{x}$ & $\mathrm{x}$ & $\mathrm{x}$ & & \\
\hline 18 & Tarnawa & $\mathrm{x}$ & $\mathrm{x}$ & $\mathrm{x}$ & $\mathrm{x}$ & & $\mathrm{x}$ & $\mathrm{x}$ & $\mathrm{x}$ & $\mathrm{x}$ & $\mathrm{x}$ & \\
\hline 19 & Lubelski & $\mathrm{x}$ & $\mathrm{x}$ & $\mathrm{x}$ & $\mathrm{x}$ & & $\mathrm{x}$ & $\mathrm{x}$ & $\mathrm{x}$ & $\mathrm{x}$ & $\mathrm{x}$ & \\
\hline 20 & Blizyn & & & & $\mathrm{x}$ & $\mathrm{x}$ & $\mathrm{x}$ & $\mathrm{x}$ & $\mathrm{x}$ & $\mathrm{x}$ & $\mathrm{x}$ & \\
\hline 21 & Kartuzy & $\mathrm{x}$ & $\mathrm{x}$ & $\mathrm{x}$ & $\mathrm{x}$ & $\mathrm{x}$ & $\mathrm{x}$ & $\mathrm{x}$ & $\mathrm{x}$ & $\mathrm{x}$ & $\mathrm{x}$ & $\mathrm{S}$ \\
\hline
\end{tabular}

*Abkürzungen der Versuchsflächen: $\mathrm{R}=$ Reinhardshagen / HE, $\mathrm{W}=$ Wanfried / HE, Ha = Hatzfeld / HE, D = Dassel / NI, S = Seesen / NI, O.A = Ochsenhausen A / BW, O.B = Ochsenhausen B / BW, A = Sauerlach A / BY, B = Sauerlach B / BY, N = Neureichenau / BY 


\subsubsection{Entwicklung der Pflanæenanzabl}

Die Entwicklung der Pflanzenzahlen wird beeinflusst durch die Mortalität und die Entnahme bei Durchforstungen. Sie ist auf den einzelnen Versuchsflächen unterschiedlich (Abb. 3.76) Eine eindeutige Trennung in natürliche Ausfälle und Durchforstungsentnahme ist nicht immer möglich (s. Kapitel „3.13 Behandlung und Beschreibung des Gesamteindrucks der Versuchsflächen").

Die Pflanzenzahl hat im höheren Alter nur eine eingeschränkte Aussagekraft, da sie von der Behandlung der Flächen abhängt. Durch forstliche Eingriffe ist die Stammzahl auf vielen Versuchsflächen reduziert und insbesondere auf den Flächen in Hessen vereinheitlicht. Beeinflusst wird die Entwicklung der Pflanzenanzahl auch durch die Nachbesserungen ausgefallener Pflanzen, die sich zum Teil über längere Zeiträume erstreckten.

Die Anzahl der Fehlstellen der jeweils jüngsten Erhebung, d. h. für die Flächen Reinhardshagen, Wanfried, Dassel und Seesen im Jahr 2004, Ochsenhausen A + B sowie Sauerlach A + B in den Jahren 1995 bzw. 1997, sind zusammen einer unbalancierten zweifaktoriellen Varianzanalyse (VA) unterzogen worden. Es ergeben sich signifikante Unterschiede zwischen den Versuchsflächen und zwischen den Herkünften, während die Wechselwirkungen nicht signifikant sind. Der anschließenden Varianzkomponentenschätzung ist zu entnehmen, dass jedoch nur $10 \%$ erklärt sind, nämlich $7 \%$ durch die Versuchsfläche und 3\% durch die Herkunft. Geht die Fläche Neureichenau (2005) mit in die VA ein, treten beträchtliche Wechselwirkungen zwischen Versuchsfläche und Herkunft auf.

Zwischen den Versuchsflächen deckt die Korrelationsanalyse signifikante Zusammenhänge zwischen den zwei Flächen in Hessen (Hatzfeld und Reinhardshagen im höheren Alter), zwischen den beiden Flächen in Niedersachsen und zwischen den beiden Flächen Ochsenhausen (Baden-Württemberg) sowie zwischen Ochsenhausen B und Sauerlach A (Bayern) auf. Außerdem gibt es einen statistischen Zusammenhang zwischen den 14 gemeinsamen Herkünften der Flächen Wanfried und Neureichenau in der Fehlstellenzahl der jüngsten Erhebung im Jahr 2004 bzw. 2005. Häufiger sind Korrelationen zwischen den in unterschiedlichem Alter durchgeführten Erhebungen auf einer Versuchsfläche. Die vollständige Korrelationsmatrix befindet sich im Anhang 2.26.

Zwischen den von einem Versuchsansteller betreuten Flächen sind die Zahlen der Fehlstellen häufiger korreliert. Dieses deutet auf einen Behandlungseffekt, zum Beispiel bei der Nachbesserung ausgefallener Pflanzen oder der Pflege, hin. Im Folgenden werden daher die Versuchsflächen gruppiert nach Bundesländern analysiert.

Von den ursprünglich drei in Hessen im Frühjahr 1976 angelegten Versuchsflächen liegt aus dem Herbst des gleichen Jahres eine erste Erfassung der Ausfallraten vor. Auf den Flächen in Hessen hatte der trockene Sommer zum Teil erhebliche Ausfälle bewirkt, was die Aufgabe der Fläche Hatzfeld zur Folge hatte. 


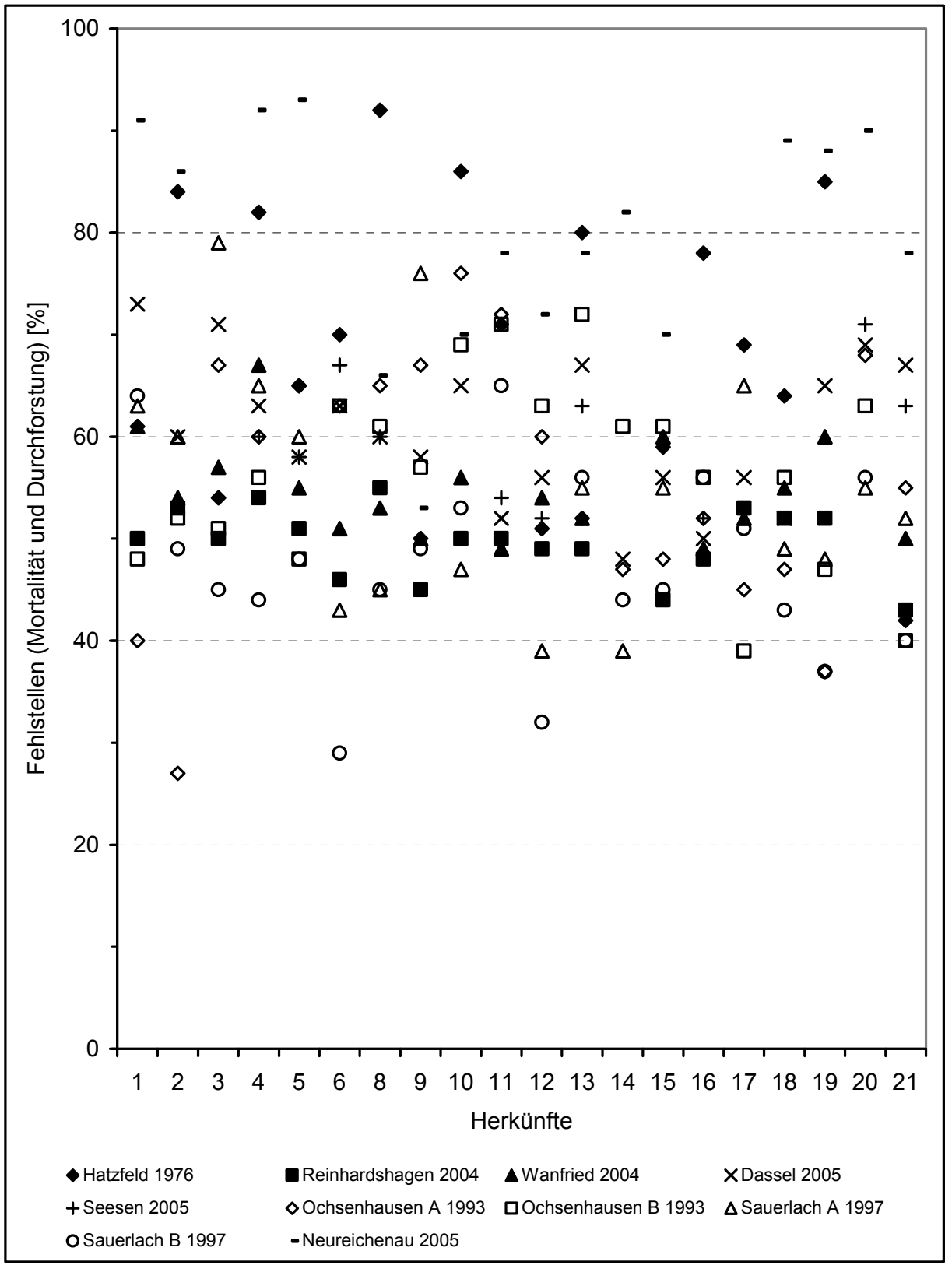

Abb. 3.76: Feblstellenanteil (Mortalität und Durchforstung) auf den Versuchsflächen 
Der Vergleich der Fehlstellenanzahl im Herbst 1976 (Pflanzenalter 4) zwischen den Versuchsflächen in Hessen zeigt, dass diese nicht oder bestenfalls schwach korreliert sind (Tab. 3.29). Dieses kann für diese Flächen als Indiz gedeutet werden, dass der herkunftsbedingte Anteil der Ausfälle geringer als der standortbedingte ist.

Mit den Pflanzen von der Fläche Hatzfeld sind auf den beiden anderen Flächen in Hessen Nachbesserungen erfolgt. Ein Vergleich der Daten von 1976 mit denen aus dem Jahr 1995 ist somit nur sehr eingeschränkt aussagefähig. Außerdem sind die Flächen in Hessen vor der Erfassung der Ausfälle im Jahre 1995 (Alter 23) durchforstet worden, wobei $25 \%$ der Fichten je Parzelle entnommen werden sollten. Die Erfassung aus dem Jahre 1995 zeigt, dass auf der Fläche Reinhardshagen der Anteil der entnommene Fichten zwischen 23 und $35 \%$ je Herkunft variierte und auf der Fläche Wanfried zwischen 26 und $41 \%$. Die Anzahl der toten bzw. fehlenden Bäume ist negativ korreliert mit der Anzahl der entnommenen Bäume je Herkunft. Dieses bedeutet, dass bei Herkünften mit geringer Mortalität mehr Bäume entnommen wurden als bei Herkünften mit höherer Mortalität und damit eine Vereinheitlichung die Stammzahl erwirkt wurde.

Die Zahl der Fehlstellen bei der jüngsten Erfassung im Jahre 2004 (Alter 32) ist mit denen der neun Jahre zuvor errechneten Raten korreliert. Zwischen den Erfassungen an den gleichen 18 Herkünften auf der Fläche Reinhardshagen sind die Korrelationen enger als auf der Fläche Wanfried. Zwischen beiden Flächen besteht kein statistischer Zusammenhang im Fehlstellenanteil (Tab. 3.29). Es liegt daher nahe, dass die beobachteten Unterschiede im Fehlstellenanteil nicht herkunftsbedingt sind.

Tab.3.29: Produkt-Momenten-Korrelationsmatrix des Feblstellenanteils auf den Versuchsflächen Hatzfeld, Reinhardshagen und Wanfried in Hessen (Anzabl Herkünfte $=18$ )

\begin{tabular}{|c|c|c|c|c|c|c|c|c|}
\hline \multirow[t]{2}{*}{ Fläche } & \multirow[b]{2}{*}{ Jahr } & Hatzfeld & \multicolumn{3}{|c|}{ Reinhardshagen } & \multicolumn{3}{|c|}{ Wanfried } \\
\hline & & $\begin{array}{l}1976 \\
(4-\mathrm{j} .)\end{array}$ & $\begin{array}{l}1976 \\
(4-j .)\end{array}$ & $\begin{array}{l}1995 \\
(23-j .)\end{array}$ & $\begin{array}{l}2004 \\
(32-j .)\end{array}$ & $\begin{array}{l}1976 \\
(4-j .)\end{array}$ & $\begin{array}{l}1995 \\
(23-j .) \\
\end{array}$ & $\begin{array}{l}2004 \\
(32-j .) \\
\end{array}$ \\
\hline Hatzfeld & 1976 & \multirow[t]{7}{*}{ - } & $0,489 *$ & $0,640 * *$ & $0,670^{* *}$ & $-0,077$ & $-0,179$ & 0,177 \\
\hline \multirow{3}{*}{$\begin{array}{l}\text { Reinhards } \\
\text { hagen }\end{array}$} & 1976 & & - & $0,489^{*}$ & $0,581 *$ & $-0,116$ & 0,025 & 0,373 \\
\hline & 1995 & & & - & $0,941 * * *$ & $-0,128$ & 0,062 & 0,248 \\
\hline & 2004 & & & & - & $-0,200$ & 0,073 & 0,344 \\
\hline \multirow[t]{3}{*}{ Wanfried } & 1976 & & & & & - & 0,040 & $-0,338$ \\
\hline & 1995 & & & & & & - & 0,457 \\
\hline & 2004 & & & & & & & - \\
\hline
\end{tabular}


Auf der Fläche Dassel hat die erste Durchforstung vor der Erhebung 1995 stattgefunden und auf der Fläche Seesen danach. Auf der Fläche Seesen sind nur halb so viele Herkünfte wie in Dassel angepflanzt. Unabhängig vom Zeitpunkt der Durchforstung und der Anzahl der zu testenden Herkünfte sind die Fehlstellenanteile auf einer Fläche und zwischen den Flächen korreliert (Tab. 3.30). Letzteres ist auf den beiden Flächen in Hessen nicht der Fall.

Die vier Flächen Ochsenhausen A und B (Baden-Württemberg) sowie Sauerlach A und B (Bayern) sind vom Waldbau-Institut der Universität Freiburg betreut worden und werden daher zusammen dargestellt. Die Fehlstellenanzahl der beiden Flächen Ochsenhausen ist korreliert, ebenso die der Fläche Sauerlach A mit denen der Fläche Ochsenhausen A (Tab. 3.31). Der Fehlstellenanteil, der mit einem Erlen-Voranbau versehenen Fläche Sauerlach B, steht in keinem Zusammenhang mit den anderen Flächen.

Tab.3.30: Produkt-Momenten-Korrelationsmatrix des Feblstellenanteils auf den Versuchsflächen Dassel und Seesen in Niedersachsen

\begin{tabular}{|c|c|c|c|c|c|}
\hline \multirow[t]{2}{*}{ Fläche } & \multirow[b]{2}{*}{ Jahr } & \multicolumn{2}{|c|}{ Dassel } & \multicolumn{2}{|c|}{ Seesen } \\
\hline & & $\begin{array}{c}1995 \\
(23-j .)\end{array}$ & $\begin{array}{c}2004 \\
(32-j .)\end{array}$ & $\begin{array}{l}1995 \\
(23-j .)\end{array}$ & $\begin{array}{c}2004 \\
(32-j .)\end{array}$ \\
\hline \multirow[t]{2}{*}{ Dassel } & 1995 & - & $\begin{array}{c}0,978^{* * *} \\
(\mathrm{n}=20)\end{array}$ & $\begin{array}{l}0,766^{* *} \\
(\mathrm{n}=10)\end{array}$ & $\begin{array}{l}0,836^{* *} \\
(\mathrm{n}=10)\end{array}$ \\
\hline & 2004 & & - & $\begin{array}{l}0,854 * * \\
(\mathrm{n}=10)\end{array}$ & $\begin{array}{c}0,888 * * * \\
(\mathrm{n}=10)\end{array}$ \\
\hline \multirow[t]{2}{*}{ Seesen } & 1995 & & & - & $\begin{array}{c}0,879 * * * \\
(\mathrm{n}=10)\end{array}$ \\
\hline & 2004 & & & & - \\
\hline
\end{tabular}

Tab.3.31: Produkt-Momenten-Korrelationsmatrix des Feblstellenanteils auf den Versuchsflächen Ochsenhausen $A$ und $B$ in Baden-Württemberg sowie Sauerlach $A$ und $B$ in Bayern (Anzabl Herkünfte $=20)$

\begin{tabular}{|c|c|c|c|c|c|}
\hline Fläche & Jahr & $\begin{array}{c}\text { Ochsenh. A } \\
1993 \\
(22-\mathrm{j} .)\end{array}$ & $\begin{array}{c}\text { Ochsenh. B } \\
\begin{array}{c}1993 \\
(21-\mathrm{j} .)\end{array}\end{array}$ & $\begin{array}{c}\text { Sauerlach A } \\
1997 \\
(25-\mathrm{j} .) \\
\end{array}$ & $\begin{array}{c}\text { Sauerlach B } \\
1997 \\
(25-j .) \\
\end{array}$ \\
\hline Ochsenhausen A & 1993 & \multirow[t]{4}{*}{-} & \multirow{4}{*}{$\begin{array}{c}0,468^{*} \\
-\end{array}$} & \multirow{4}{*}{$\begin{array}{l}0,022 \\
-0,408\end{array}$} & 0,063 \\
\hline Ochsenhausen B & 1993 & & & & 0,166 \\
\hline Sauerlach A & 1997 & & & & 0,300 \\
\hline Sauerlach B & 1997 & & & & - \\
\hline
\end{tabular}


Auf der Fläche Neureichenau sind die Fehlstellenanteile aller drei Aufnahmen korreliert. Bemerkenswert ist dabei, dass dieses auch bei der Erfassung im Jahr 2005 nach den Nassschneefällen vom März 1999 erhalten blieb (Tab. 3.32). Das Fehlen der Herkünfte Nr. 16 (Orawa) und Nr. 17 (Witów), die beide aus Hochlagen (1050 m bzw. $1420 \mathrm{~m}$ ü. NN) stammen, führt KÖNIG (2002) darauf zurück, dass diese beiden Herkünfte möglicherweise nicht an die Bedingungen in der Tiefland-Baumschule angepasst waren und daher keine Pflanzen bei der Anlage der Versuchsfläche zur Verfügung standen.

Tab.3.32: Produkt-Momenten-Korrelationsmatrix des Feblstellenanteils auf der Versuchsfläche Neureichenau in Bayern (Anzabl Herkünfte $=16$ )

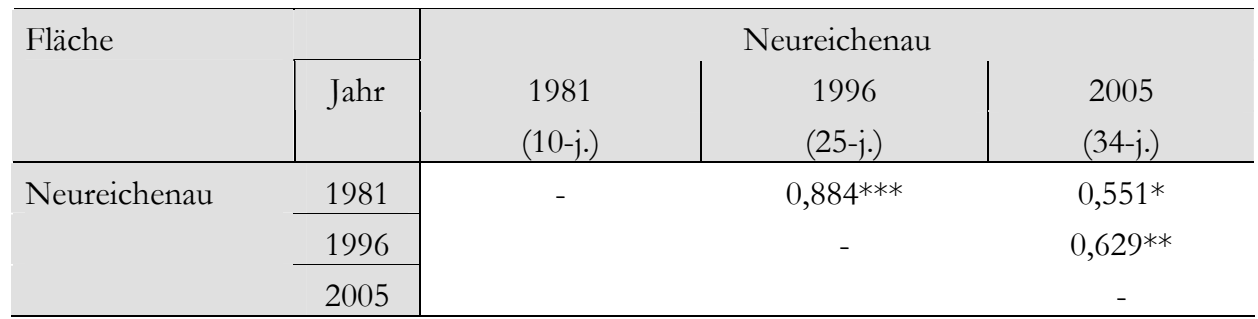

\subsubsection{Schadmerkmale}

Die Erfassung von Schadmerkmalen ist nicht einheitlich gewesen. Die Bonituren wurden sowohl zwischen den Flächen als auch zwischen den Erhebungsjahren verändert, so dass Aussagen nicht verallgemeinert werden können.

Auf der hessischen Fläche Wanfried sind im Jahr 1979 (Alter 7) Spätfrostschäden aufgetreten (RAU 1983). 39 \% der bonitierten Fichten wiesen eine leichte Schädigung auf. Die häufigsten Schädigungen sind bei der Herkunft Nr. 11 (Istebna 149h) zu finden, die mit $66 \%$ geschädigter Pflanzen im Gegensatz zur benachbarten Herkunft Nr. 12 (Istebna 115f) steht. Diese war nur etwa halb so stark geschädigt. Zu den Herkünften, bei denen über der Hälfe der Bäume geschädigt waren, gehören Nr. 8 (Miedzygórze) und vier der zusätzlichen deutschen Prüfglieder (RAU 1983). Die geringsten Schäden (<20\%) finden sich bei den Herkünften Nr. 6 (Nowe Ramuki), Nr. 13 (Zwardon) und Nr. 16 (Orawa). Ein Zusammenhang mit der geografischen Lage und der Meereshöhe des Herkunftsortes ist nicht erkennbar gewesen (RAU 1983).

Für die Fläche Neureichenau konnte KÖNIG $(1998,2002)$ zeigen, dass im Alter von 25 Jahren die Herkünfte aus den Sudeten und den schlesischen Beskiden weniger Stamm- und Wipfelbrüche nach den Nassschneefällen im März 1999 hatten als Herkünfte aus dem nordostpolnischen Verbreitungsgebiet und aus der Mittelpolnischen Hochebene. 
Bei den Bonituren im Alter von 34 Jahren ist die Häufigkeit von Schadmerkmalen so gering gewesen, dass Vergleiche zwischen den Flächen keine Aussagekraft haben.

\subsubsection{Formmerkmale}

\section{Stammform}

Zwischen den Versuchsflächen ist die Bonitur der Stammform unterschiedlich ausgefallen. In den vorangegangenen Beschreibungen der einzelnen Versuchsflächen sind bereits mögliche Ursachen für Unterschiede zwischen zwei Erhebungszeitpunkten angeführt. Die genannten Ursachen sind, (1) dass die Beurteilung unterschiedlich kritisch erfolgte, (2) dass die Formmängel in einem Jahr offensichtlicher waren als in einem anderen Jahr oder (3) dass der Mangel zum Zeitpunkt der Folgeerhebung bereits ausgewachsen war.

Zwischen den Versuchsflächen gibt es keine statistischen Zusammenhänge im Anteil der geraden Stämme einer Herkunft (Produkt-Momenten-Korrelation). Ein Grund hierfür kann sein, dass die Beurteilung der Stammform stark dem subjektiven Einfluss unterliegt. Gerade bei einer Baumart, die in ihrer Stammform nur geringe Variation zeigt, ist ein geschulter Blick erforderlich, um Unterschiede zu erkennen. Trotz der gering erscheinenden Differenzierung und dem möglichen subjektiven Einfluss bei der Ansprache der Form deuten sich Unterschiede zwischen den Herkünften an.

Die 20 IUFRO-Herkünfte sind daher Homogenitätstests (RASCH et al. 1998) unterzogen worden. Getestet wurde je Herkunft, ob das Verhältnis gerader Bäume $\mathrm{zu}$ solchen mit einem Mangel zwischen den Versuchsflächen gleich ist. Da die Klassen der stärkeren Mängelausprägung äußerst gering besetzt waren, sind die Klassen leichter bis starker Formmangel zusammengefasst worden. Das Ergebnis der Homogenitätstests (Fisher's Exact Test, $\alpha=0,05)$ weist für alle Herkünfte global Unterschiede zwischen den Standorten aus.

Im zweiten Schritt sind in paarweisen Vergleichen zwischen den Versuchsflächen die einzelnen Herkünfte auf Homogenität getestet worden (Fisher's Exact Test, $\alpha=0,05)$. Das Ergebnis dieser Vergleiche ist in Tabelle 3.33 zusammengestellt. In der Tabelle sind die Felder mit einem „=“ versehen, für die eine Herkunft in einem Vergleich zweier Versuchsflächen eine homogene Form hat; weist der Test Unterschiede zwischen zwei Flächen für eine Herkunft aus, so ist ein „O eingetragen. 
Tab. 3.33: $\quad$ Stammform: Ergebnis der paarweisen Homogenitätstests (Fisher's Exact Test, $a=0,05$ ) je Herkunft

\begin{tabular}{|c|c|c|c|c|c|c|c|c|c|c|c|c|c|c|c|c|c|c|c|c|c|}
\hline \multirow{3}{*}{$\begin{array}{c}\text { Nr. } \\
*\end{array}$} & \multicolumn{21}{|c|}{ Paarweiser Vergleich der Versuchsflächen ** } \\
\hline & \multirow{2}{*}{$\begin{array}{l}\mathrm{B} \\
\mathrm{A}\end{array}$} & \multicolumn{2}{|c|}{ Seesen } & \multicolumn{3}{|c|}{ Dassel } & \multicolumn{4}{|c|}{ Wanfried } & \multicolumn{5}{|c|}{ Reinhardshagen } & \multicolumn{6}{|c|}{ Neureichenau } \\
\hline & & A & $\mathrm{B}$ & A & $\mathrm{B}$ & $\mathrm{S}$ & A & $\mathrm{B}$ & $\mathrm{S}$ & $\mathrm{D}$ & $\mathrm{A}$ & B & $\mathrm{S}$ & $\mathrm{D}$ & $\mathrm{W}$ & A & B & $\mathrm{S}$ & $\mathrm{D}$ & W & $\mathrm{R}$ \\
\hline 1 & $=$ & & & $=$ & $=$ & & $=$ & O & & $=$ & $=$ & $=$ & & $=$ & O & O & $\mathrm{O}$ & & $=$ & $=$ & $\mathrm{O}$ \\
\hline 2 & $=$ & & & $=$ & $=$ & & $=$ & $=$ & & $=$ & $=$ & $=$ & & $=$ & $\mathrm{O}$ & $\mathrm{O}$ & O & & O & O & $\mathrm{O}$ \\
\hline 3 & $=$ & & & $=$ & $=$ & & $=$ & $\mathrm{O}$ & & O & $=$ & $=$ & & $=$ & $\mathrm{O}$ & & & & & & \\
\hline 4 & $=$ & $=$ & $=$ & $=$ & $=$ & $=$ & O & O & O & $\mathrm{O}$ & $=$ & $=$ & $=$ & $=$ & $\mathrm{O}$ & & & & & & \\
\hline 5 & $=$ & $=$ & $=$ & $=$ & $=$ & $=$ & $=$ & $\mathrm{O}$ & O & $=$ & o & $=$ & $=$ & o & O & O & O & O & O & $\mathrm{O}$ & $\mathrm{O}$ \\
\hline 6 & $=$ & $=$ & $=$ & O & O & $=$ & O & $\mathrm{O}$ & $=$ & $=$ & O & $=$ & O & o & o & $=$ & O & $=$ & $=$ & $=$ & $\mathrm{O}$ \\
\hline 8 & $=$ & $=$ & $=$ & O & $\mathrm{O}$ & $=$ & $=$ & $=$ & $=$ & O & $=$ & $=$ & $=$ & O & $=$ & O & $\mathrm{O}$ & O & $=$ & $\mathrm{O}$ & $\mathrm{O}$ \\
\hline 9 & $=$ & & & $=$ & $=$ & & $=$ & $=$ & & $=$ & $=$ & $=$ & & O & $=$ & $\mathrm{O}$ & $\mathrm{O}$ & & $\mathrm{O}$ & O & O \\
\hline 10 & $=$ & & & $=$ & $=$ & . & $=$ & $=$ & & $=$ & o & $=$ & & $=$ & O & O & O & & o & $\mathrm{O}$ & $\mathrm{O}$ \\
\hline 11 & $=$ & $=$ & $=$ & $=$ & $=$ & $=$ & O & $=$ & $=$ & $=$ & O & $=$ & $=$ & $=$ & $=$ & O & O & O & $\mathrm{O}$ & o & o \\
\hline 12 & O & $=$ & $=$ & $=$ & $=$ & $=$ & $=$ & $=$ & $=$ & $=$ & $=$ & $=$ & $=$ & $=$ & $=$ & $=$ & O & $\mathrm{O}$ & O & $\mathrm{O}$ & $\mathrm{O}$ \\
\hline 13 & $=$ & $=$ & $=$ & $=$ & $=$ & $=$ & $=$ & $=$ & $=$ & $=$ & $=$ & $=$ & $=$ & $=$ & o & o & $\mathrm{O}$ & O & $\mathrm{O}$ & $\mathrm{O}$ & O \\
\hline 14 & $=$ & & & $=$ & $=$ & & $=$ & $=$ & & $=$ & $=$ & $=$ & & O & O & O & O & & O & O & $\mathrm{O}$ \\
\hline 15 & $=$ & & & $\mathrm{O}$ & O & & & & & & & & & & & O & $\mathrm{O}$ & & $=$ & & \\
\hline 16 & $=$ & $=$ & $=$ & O & $\mathrm{O}$ & $\mathrm{O}$ & $=$ & $=$ & $=$ & $\mathrm{O}$ & $=$ & $=$ & $=$ & o & o & & & & & & \\
\hline 17 & $=$ & & & $=$ & $=$ & & $=$ & $=$ & & $=$ & $=$ & $=$ & & $=$ & O & & & & & & \\
\hline 18 & $=$ & & & $=$ & $=$ & & $=$ & O & & $=$ & $=$ & O & & $=$ & o & $=$ & $=$ & & $=$ & $=$ & $\mathrm{O}$ \\
\hline 19 & $=$ & & & $\mathrm{O}$ & O & & O & O & & $=$ & $=$ & $\mathrm{O}$ & & $\mathrm{O}$ & $\mathrm{O}$ & $\mathrm{O}$ & O & & $\mathrm{O}$ & $\mathrm{O}$ & $\mathrm{O}$ \\
\hline 20 & $=$ & $=$ & $=$ & $=$ & $=$ & $=$ & & & & & & & & & & o & $\mathrm{O}$ & $=$ & O & & \\
\hline 21 & $=$ & $=$ & $=$ & $=$ & $=$ & $=$ & $=$ & $=$ & $=$ & $=$ & $=$ & $=$ & $=$ & $=$ & $\mathrm{O}$ & $\mathrm{O}$ & $\mathrm{O}$ & $\mathrm{O}$ & $\mathrm{O}$ & $\mathrm{O}$ & $\mathrm{O}$ \\
\hline
\end{tabular}

* IUFRO-Herkunfts-Nr.

** Versuchsflächen: $A=$ Sauerlach $A / B Y, B=$ Sauerlach B / BY, S = Seesen / NI, D = Dassel / NI, $W=W$ anfried / HE, $R=$ Reinhardshagen / HE.

=: Herkunft hat homogene Form; o: Herkunft hat keine homogene Form

Die Tabelle zeigt, dass am häufigsten Unterschiede in der Stammformverteilung zwischen der Fläche Neureichenau und den anderen Flächen auftreten. Dieses wird auf zwei Ursachen zurückgeführt. Zum einen ist die Fläche Neureichenau geprägt von starken Schneeschäden. Zum anderen kann es in der Person desjenigen liegen, der die Stammform aufgenommen hat. Weiterhin sind Unterschiede zwischen den Flächen Reinhardshagen und Wanfried in Hessen zu beobachten. Diese deuten auf Standorteinflüsse hin, da die Flächen vom gleichen Team aufgenommen wurden. 
In den weiteren Vergleichen haben sich die Herkünfte Nr. 12 (Istebna 115f), Nr. 13 (Zwardon) und Nr. 21 (Kartuzy) in ihrer Stammform (d. h. der Anteil der geraden Stämme liegt über dem Gesamtmittel) von den Bedingungen auf den Versuchsflächen als unabhängig dargestellt. Gleiches gilt für die Herkünfte Nr. 1 (Pogorzelece), Nr. 2 (Krzyze), Nr. 9 (Stronie Slaskie), Nr. 10 (Wisła), Nr. 14 (Rycerka I), Nr. 17 (Witów) und Nr. 20 (Blizyn) mit der Einschränkung, dass diese Herkünfte nicht auf allen Flächen angebaut sind. Nicht ganz so einheitlich schneiden die Herkünfte Nr. 3 (Wigry), Nr. 11 (Istebna 149h) und Nr. 18 (Tarnawa) ab. Äußerst unterschiedlich ist die Stammform der Herkünfte Nr. 4 (Przerwanki), Nr. 5 (Borki), Nr. 6 (Nowe Ramuki), Nr. 8 (Miedzygórze), Nr. 15 (Rycerka II), Nr. 16 (Orawa) und Nr. 19 (Lubelski) beurteilt worden. Die Herkünfte Nr. 5 Borki und Nr. 19 (Lubelski) haben den geringsten Anteil gerader Stämme.

Für die IUFRO-Herkünfte ist bekannt, wie viele Einzelbäume beerntet wurden (Anhang 2.1). Für die beernteten Herkünfte und Einzelbäume liegen keine Formparameter aus Polen vor, die mit denen auf der Versuchsfläche vergleichbar wären. In Polen werden in qualitativ hochwertigen Beständen zahlreiche Plus-Bäume ausgewiesen (SZOZDA und SABOR 1998). Es könnte sich daher bei den auf den Flächen in Niedersachsen angebauten Einzelbaumnachkommenschaften um Absaaten dieser Plusbäume handeln. Ob und in welchem Anteil diese Einzelbaumabsaaten in den Herkünften enthalten sind, ist nicht bekannt.

Um zu beurteilen, ob die Stammformverteilung in Nachkommenschaften der Einzelbaumabsaaten und der jeweiligen Herkunftsabsaat ähnlich ist, sind sie Homogenitätstests unterzogen worden. Da die Herkünfte Nr. 1 und Nr. 10 auf der Fläche Seesen nicht vertreten sind, werden die Einzelbaumnachkommenschaften mit den Herkünften der Fläche Dassel verglichen. Die gemeinsamen Herkünfte haben auf beiden Flächen ähnliche Stammformen gezeigt.

Die paarweisen Vergleiche (Fisher's Exact Test, $\alpha=0,05$ ) zwischen der Herkunftsabsaat und den Nachkommenschaften der einzelnen Klone der Herkunft decken nur in einem Fall die Abweichung von der Homogenität auf. Die IUFRO-Herkunft Nr. 13 (Zwardon) hat einen signifikant höheren Anteil gerader Stämme als die Einzelbaumnachkommenschaft (Zwardon 13-86).

Unter der Annahme, dass es sich bei den Einzelbaumnachkommenschaften um Plusbäume handelt, lässt der Vergleich der Herkünfte mit den Einzelbaumnachkommenschaften für diese IUFRO-Herkünfte den Schluss zu, dass diese Bestände bester Qualität sind und eine Plusbaum-Auslese keine weiteren Vorzüge bezüglich der Stammform bringen wird.

Als Fazit ist davon auszugehen, dass die Stammform unabhängig von ökologischen Variablen (geogr. Breite, geogr. Länge, Höhenlage) und somit zufällig verteilt ist. 


\section{Ovalität}

Als weiteres Merkmal zur Beurteilung der Stammqualität liegt die Ovalität im Alter von 32 bzw. 34 Jahren von fünf Versuchsflächen vor. Der mittlere Wert beträgt 3,13 \% und variiert zwischen den Herkünften von 2,0 \% bis 5,7\% (Abb. 3.77). Die Herkunftsmittel liegen zwischen 2,3\% (Nr. 12 Istebna 115f) und 3,8\% (Nr. 21 Kartuzy).

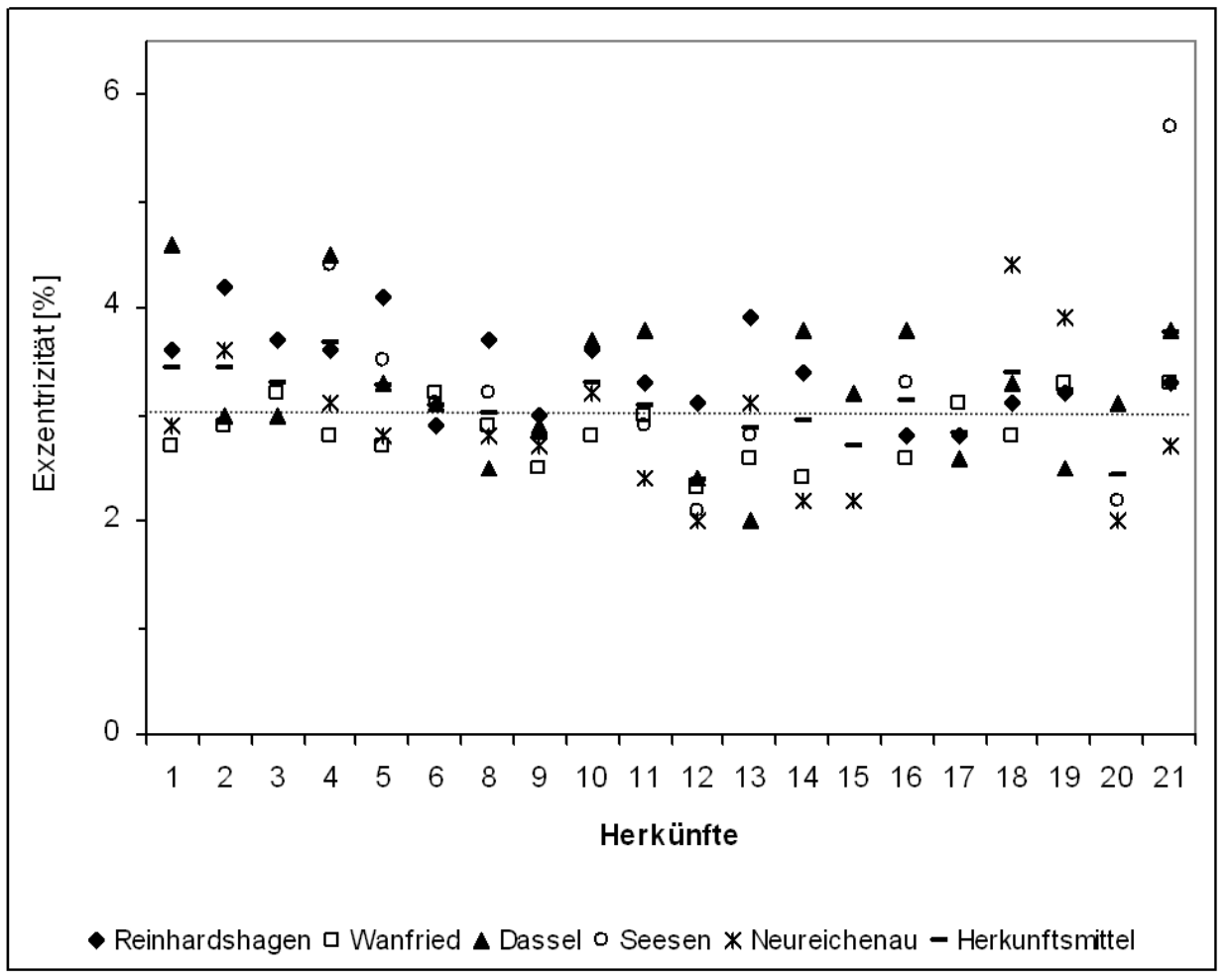

Abb.3.77: Mittlere Ovalitäten der Herkünfte auf fünf Versuchsflächen und Herkunftsmittel im Alter von 32 bzw. 34 Jabren

Der Vergleich der Ovalitäten zwischen den Versuchsflächen zeigt, dass keine Korrelationen (Produkt-Momenten-Korrelation) vorliegen.

Eine geringe Variabilität der Ovalität zwischen den Versuchsflächen ist bei den Herkünften Nr. 6 (Nowe Ramuki), Nr. 9 (Stronie Slaskie) und Nr. 17 (Witów) zu erkennen. Die größten Unterschiede zwischen den Versuchsflächen treten bei den Herkünften Nr. 1 (Pogorzelece), Nr. 4 (Przerwanki), Nr. 13 (Zwardon) und Nr. 21 (Kartuzy) auf. Zu den Herkünften mit auf fast allen Versuchsflächen unter dem Mittel liegenden Werten, d. h. kaum von der Kreisform abweichenden Quer- 
schnitten, gehören die Herkünfte Nr. 9 (Stronie Slaskie), Nr. 12 (Istebna 115f), Nr. 17 (Witów) und Nr. 20 (Blizyn).

Da keine Aufzeichnungen vorliegen, aus denen hervorgeht, ob jeweils die Bäume an der dicksten bzw. dünnsten Stelle in 1,3 m Höhe gemessen wurden, lässt sich über die Güte dieses Maßes keine Aussage treffen.

\section{$H / D-V e r h a ̈ l t n i s$}

Das H/D-Verhältnis (Schlankheitsgrad) wird häufig auch als formbestimmender Faktor genutzt, obwohl es zur Bestimmung der Schaftform als zu grob beurteilt wird (KRAMER und AKCA 1995), da Bäume mit gleicher Höhe und gleichem Brusthöhendurchmesser und somit gleichem H/D-Wert sehr unterschiedliche Schaftkurven aufweisen können. Im Alter von 32 bzw. 34 Jahren beträgt das mittlere H/D-Verhältnis auf fünf Versuchsflächen (Reinhardshagen, Wanfried, Dassel, Seesen und Neureichenau) 80 und variiert zwischen den Herkünften von 62 bis 96 (Abb. 3.78). Die Herkunftsmittel liegen zwischen 76 (Nr. 8 Miedzygórze) und 86 (Nr. 3 Wigry).

Mit zunehmendem Alter, etwa ab Alter 20 (KERN 1966; KRAMER 1975, 1988), sinkt der H/D-Wert ab. Die niedrigsten H/D-Werte sind auf der Fläche Neureichenau anzutreffen, auf der die Pflanzen zwei Jahre später gemessen wurden als auf den anderen vier Flächen. Der geringere H/D-Wert wird durch die besonderen Standorteinflüsse verstärkt. Nach dem Schneebruch im Jahre 1999 sind die verbliebenen Bäume einem vermehrten Lichtgenuss ausgesetzt gewesen und konnten so ihre Kronen gut entwickeln.

Die H/D-Werte sind auf der Fläche Wanfried etwas höher als auf der Fläche Reinhardshagen. Die H/D-Verhältnisse beider Flächen sind als einzige korreliert (Tab. 3.34).

Tab.3.34: Produkt-Momenten-Korrelationsmatrix der H/D-Verbältnisse auf fünf Versuchsflächen, die im Jahr 2004 bzw. 2005 gemessen wurden ( $n=$ Anzabl Herkünfte)

\begin{tabular}{|c|c|c|c|c|c|}
\hline $\begin{array}{l}\text { Versuchsfläche } \\
\text { (Alter) }\end{array}$ & $\begin{array}{c}\text { Reinhards- } \\
\text { hagen }(32-\mathrm{j} .)\end{array}$ & $\begin{array}{c}\text { Wanfried } \\
(32-j .)\end{array}$ & $\begin{array}{c}\text { Dassel } \\
(32-\mathrm{j} .)\end{array}$ & $\begin{array}{c}\text { Seesen } \\
(32-j .)\end{array}$ & $\begin{array}{l}\text { Neureiche- } \\
\text { nau (34-j.) }\end{array}$ \\
\hline $\begin{array}{l}\text { Reinhardshagen } \\
(32-j .)\end{array}$ & \multirow[t]{5}{*}{-} & \multirow{5}{*}{$\begin{array}{c}0,627^{*} \\
(\mathrm{n}=18) \\
-\end{array}$} & \multirow{5}{*}{$\begin{array}{c}0,414 \\
(\mathrm{n}=18) \\
0,394 \\
(\mathrm{n}=18) \\
-\end{array}$} & \multirow{2}{*}{$\begin{array}{c}-0,031 \\
(\mathrm{n}=9) \\
0,039 \\
(\mathrm{n}=9)\end{array}$} & \multirow{2}{*}{$\begin{array}{c}0,145 \\
(\mathrm{n}=14) \\
0,346 \\
(\mathrm{n}=14)\end{array}$} \\
\hline $\begin{array}{l}\text { Wanfried } \\
(32-j .)\end{array}$ & & & & & \\
\hline $\begin{array}{l}\text { Dassel } \\
(32-j .) \\
\end{array}$ & & & & $\begin{array}{c}0,564 \\
(\mathrm{n}=10)\end{array}$ & $\begin{array}{c}0,235 \\
(\mathrm{n}=16)\end{array}$ \\
\hline $\begin{array}{l}\text { Seesen } \\
(32-j .)\end{array}$ & & & & - & $\begin{array}{c}0,018 \\
(\mathrm{n}=8)\end{array}$ \\
\hline $\begin{array}{l}\text { Neureichenau } \\
(34-j .)\end{array}$ & & & & & - \\
\hline
\end{tabular}


Mit der multiplen Regressionsanalyse ist untersucht worden, inwieweit ein Einfluss von geografischer Breite, geografischer Länge und Seehöhe des Erntebestandes und des Versuchsortes auf die Ausprägung des Merkmals H/D-Wert vorliegt. Die multiple Regressionsanalyse zeigt, dass der H/D-Wert von den geografischen Lage der Ernte- und Versuchsstandorte abhängt $\left(\mathrm{r}^{2}=0,76\right)$. Dabei haben die drei Einflussfaktoren geografische Länge des Herkunftsortes sowie geografische Breite und Länge des Versuchsortes den höchsten Anteil $\left(r^{2}=0,74\right)$.

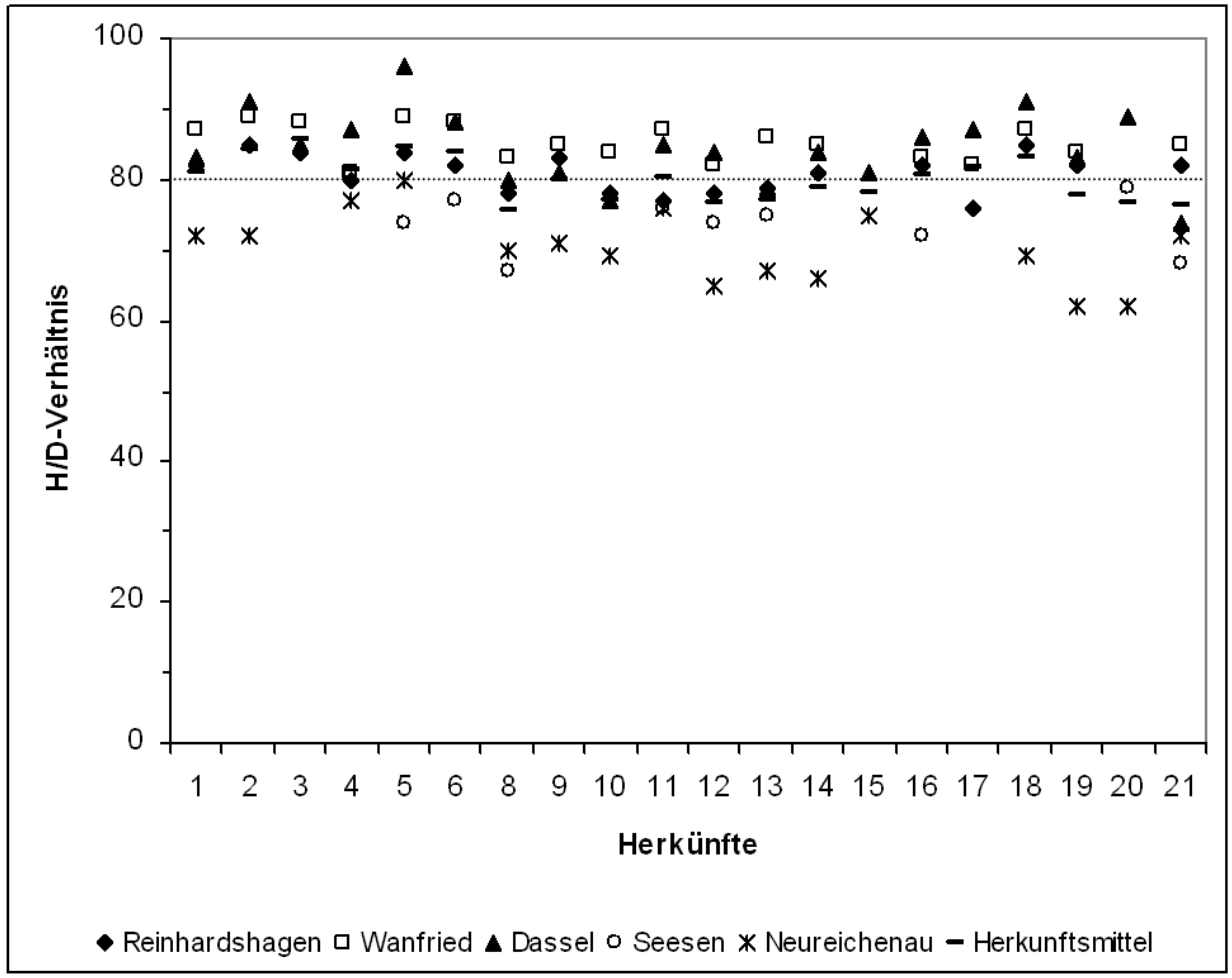

Abb. 3.78: H/D-Verbältnis der 20 IUFRO-Herkünfte auf fünf Versuchsflächen und dem Herkunftsmittel im Alter von 32 bzw. 34 Jabren

\subsubsection{Höhen- und BHD-W achstum}

Wie bei den vorangegangenen Merkmalen liegen auch für die Wachstumsparameter Messungen in unterschiedlichen Pflanzenaltern vor. Die ProduktMomenten-Korrelationen der jüngsten Höhenmessungen von sieben Versuchsflächen ergeben einen signifikanten Zusammenhang zwischen den Flächen Reinhardshagen und Wanfried in Hessen (Tab. 3.35). Sie zeigen außerdem einen Zusammenhang zwischen dem Höhenwachstum in Reinhardshagen zu einer Fläche in Niedersachsen (Dassel) und den beiden Flächen Ochsenhausen in 
Baden-Württemberg. Einen weiteren Zusammenhang gibt es zwischen den Flächen Wanfried in Hessen und Ochsenhausen B in Baden-Württemberg.

Die mittlere Merkmalsausprägung der Baumhöhe pro Parzelle ist für die vier Versuchsflächen Reinhardshagen, Wanfried, Dassel und Neureichenau (nur die Parzellen der Wiederholung 1, 3 und 5) für 14 gemeinsame Herkünfte varianzanalytisch untersucht worden. Dabei wurde der Einfluss der Versuchsflächen, der Herkünfte sowie der Interaktion aus Versuchsfläche und Herkunft berücksichtigt. Das Varianzmodell ist signifikant $\left(\mathrm{r}^{2}=0,80\right)$ und weist einen signifikanten Einfluss der Versuchsflächen auf die Baumhöhe aus. Mit der Varianzkomponentenschätzung lässt sich der Anteil der Komponente der Versuchsfläche auf $79 \%$ quantifizieren. Der multiple Mittelwertvergleich ('Tukey-Test, $\alpha=0,05$ ) weist drei voneinander getrennte Gruppen aus: Gruppe A (Reinhardshagen, Wanfried), Gruppe B (Dassel) und Gruppe C (Neureichenau).

Wird die Varianzanalyse über die sieben gemeinsamen Herkünfte unter Berücksichtigung der Fläche Seesen durchgeführt, ergibt sich ein vergleichbares Ergebnis, die Fläche Seesen ist im multiplen Mittelwertvergleich zusammen mit Neureichenau in einer Tukey-Gruppe.

Tab. 3.35: Produkt-Momenten-Korrelationsmatrix des Höhenwachstums auf sieben Versuchsflächen ( $n=$ Anzabl Herkünfte)

\begin{tabular}{|c|c|c|c|c|c|c|c|}
\hline $\begin{array}{l}\text { Versuchsfläche } \\
\text { (Alter) }\end{array}$ & $\begin{array}{c}\text { Reinhards- } \\
\text { hagen } \\
(32-\mathrm{j} .)\end{array}$ & $\begin{array}{l}\text { Wan- } \\
\text { fried } \\
(32-j .) \\
\end{array}$ & $\begin{array}{l}\text { Dassel } \\
(32-j .)\end{array}$ & $\begin{array}{l}\text { Seesen } \\
(32-j .)\end{array}$ & $\begin{array}{c}\text { Ochsen- } \\
\text { hausen A } \\
(22-\mathrm{j} .)\end{array}$ & $\begin{array}{c}\text { Ochsen- } \\
\text { hausen B } \\
(21-\mathrm{j} .)\end{array}$ & $\begin{array}{c}\text { Neurei- } \\
\text { chenau } \\
(34-j .)\end{array}$ \\
\hline $\begin{array}{l}\text { Reinhardshagen } \\
(32-j .)\end{array}$ & \multirow[t]{7}{*}{-} & $\begin{array}{l}0,605^{* *} \\
(\mathrm{n}=18)\end{array}$ & $\begin{array}{c}0,588^{*} \\
(\mathrm{n}=18)\end{array}$ & $\begin{array}{c}0,031 \\
(\mathrm{n}=9)\end{array}$ & $\begin{array}{c}0,498^{*} \\
(\mathrm{n}=18)\end{array}$ & $\begin{array}{c}0,473^{*} \\
(\mathrm{n}=18)\end{array}$ & $\begin{array}{c}0,044 \\
(\mathrm{n}=14)\end{array}$ \\
\hline $\begin{array}{l}\text { Wanfried } \\
(32-j .)\end{array}$ & & \multirow[t]{6}{*}{-} & $\begin{array}{c}0,342 \\
(\mathrm{n}=18)\end{array}$ & $\begin{array}{l}-0,338 \\
(\mathrm{n}=9)\end{array}$ & $\begin{array}{c}0,280 \\
(\mathrm{n}=18)\end{array}$ & $\begin{array}{c}0,530 * \\
(\mathrm{n}=18)\end{array}$ & $\begin{array}{c}0,458 \\
(\mathrm{n}=14)\end{array}$ \\
\hline $\begin{array}{l}\text { Dassel } \\
(32-j .)\end{array}$ & & & \multirow[t]{5}{*}{-} & $\begin{array}{c}-0,417 \\
(\mathrm{n}=10)\end{array}$ & $\begin{array}{c}0,189 \\
(\mathrm{n}=20)\end{array}$ & $\begin{array}{c}0,304 \\
(\mathrm{n}=20)\end{array}$ & $\begin{array}{c}0,167 \\
(\mathrm{n}=16)\end{array}$ \\
\hline $\begin{array}{l}\text { Seesen } \\
(32-j .)\end{array}$ & & & & \multirow[t]{4}{*}{ - } & $\begin{array}{c}0,516 \\
(\mathrm{n}=10)\end{array}$ & $\begin{array}{c}0,107 \\
(\mathrm{n}=10)\end{array}$ & $\begin{array}{c}0,242 \\
(\mathrm{n}=8)\end{array}$ \\
\hline $\begin{array}{l}\text { Ochsenhausen A } \\
(22-\mathrm{j} .)\end{array}$ & & & & & \multirow[t]{3}{*}{-} & $\begin{array}{c}0,337 \\
(\mathrm{n}=20)\end{array}$ & $\begin{array}{c}0,111 \\
(\mathrm{n}=16)\end{array}$ \\
\hline $\begin{array}{l}\text { Ochsenhausen B } \\
(21-\text { j. })\end{array}$ & & & & & & - & $\begin{array}{c}0,142 \\
(\mathrm{n}=16)\end{array}$ \\
\hline $\begin{array}{l}\text { Neureichenau } \\
(34-j .)\end{array}$ & & & & & & & - \\
\hline
\end{tabular}

Wie beim Höhenwachstum sind beim Durchmesser die Werte auf der Fläche Reinhardshagen mit denen der Fläche Wanfried und Dassel (NI) korreliert (Tab. 3.36). Zusammenhänge bestehen auch zwischen den Flächen Dassel und Wanfried bzw. Sauerlach A (BY). Die BHD auf der Fläche Sauerlach B, auf der die Fichten zusammen mit einem Erlen-Voranbau gepflanzt wurden, sind mit den Durch- 
messern auf den beiden hessischen (Reinhardshagen, Wanfried) und einer niedersächsischen Fläche (Dassel) korreliert, nicht jedoch mit den Fichten der angrenzenden Fläche Sauerlach A.

Auch die mittlere Merkmalsausprägung des BHD pro Parzelle ist für die vier Versuchsflächen Reinhardshagen, Wanfried, Dassel und Neureichenau für 14 gemeinsame Herkünfte varianzanalytisch untersucht worden. Das Varianzmodell ist signifikant $\left(\mathrm{r}^{2}=0,44\right)$ und weist einen signifikanten Einfluss der Versuchsflächen und der Herkünfte auf den BHD aus. Mittels Varianzanalyse lässt sich der Anteil der Komponente der Versuchsfläche auf $4 \%$, der der Herkunft auf $9 \%$ und der nicht erklärte Rest mit $87 \%$ quantifizieren. Der multiple Mittelwertvergleich (Tukey-Test, $\alpha=0,05$ ) weist zwei überlappende Gruppen aus, danach unterscheidet sich das BHD-Wachstum zwischen den Flächen Wanfried und Neureichenau.

Wird die Varianzanalyse über die sieben gemeinsamen Herkünfte unter Berücksichtigung der Fläche Seesen durchgeführt, lassen sich keine Unterschiede nachweisen (Tukey-Test, $\alpha=0,05$ ).

Tab.3.36: Produkt-Momenten-Korrelationsmatrix des BHD-Wachstums auf sieben Versuchsflächen ( $n=$ Anz̧abl Herkünfte)

\begin{tabular}{|c|c|c|c|c|c|c|c|}
\hline $\begin{array}{l}\text { Versuchsfläche } \\
\text { (Alter) }\end{array}$ & $\begin{array}{c}\text { Reinhards- } \\
\text { hagen } \\
(32-\mathrm{j} .)\end{array}$ & $\begin{array}{l}\text { Wanfried } \\
(32-j .)\end{array}$ & $\begin{array}{l}\text { Dassel } \\
(32-j .)\end{array}$ & $\begin{array}{l}\text { Seesen } \\
(32-j .)\end{array}$ & $\begin{array}{l}\text { Sauer- } \\
\text { lach A } \\
(25-\mathrm{j} .)\end{array}$ & $\begin{array}{l}\text { Sauer- } \\
\text { lach B } \\
(25-\mathrm{j} .)\end{array}$ & $\begin{array}{c}\text { Neurei- } \\
\text { chenau } \\
(34-j .)\end{array}$ \\
\hline $\begin{array}{l}\text { Reinhardshagen } \\
(32-\mathrm{j} .)\end{array}$ & \multirow[t]{7}{*}{-} & \multirow{7}{*}{$\begin{array}{c}0,793 * * * \\
(\mathrm{n}=18) \\
-\end{array}$} & $\begin{array}{l}0,672^{* *} \\
(\mathrm{n}=18)\end{array}$ & $\begin{array}{c}0,092 \\
(\mathrm{n}=9)\end{array}$ & $\begin{array}{c}0,351 \\
(\mathrm{n}=18)\end{array}$ & $\begin{array}{c}0,568^{*} \\
(\mathrm{n}=18)\end{array}$ & $\begin{array}{c}0,065 \\
(\mathrm{n}=14)\end{array}$ \\
\hline $\begin{array}{l}\text { Wanfried } \\
(32-\mathrm{j} .)\end{array}$ & & & \multirow{6}{*}{$\begin{array}{c}0,651 * * \\
(\mathrm{n}=18) \\
-\end{array}$} & $\begin{array}{l}0,416 \\
(\mathrm{n}=9)\end{array}$ & $\begin{array}{c}0,441 \\
(\mathrm{n}=18)\end{array}$ & $\begin{array}{c}0,509^{*} \\
(\mathrm{n}=18)\end{array}$ & $\begin{array}{c}0,404 \\
(\mathrm{n}=14)\end{array}$ \\
\hline $\begin{array}{l}\text { Dassel } \\
(32-j .)\end{array}$ & & & & $\begin{array}{c}0,235 \\
(\mathrm{n}=10)\end{array}$ & $\begin{array}{c}0,522^{*} \\
(\mathrm{n}=20)\end{array}$ & $\begin{array}{c}0,452 * \\
(\mathrm{n}=20)\end{array}$ & $\begin{array}{c}0,459 \\
(\mathrm{n}=16)\end{array}$ \\
\hline $\begin{array}{l}\text { Seesen } \\
(32-j .)\end{array}$ & & & & \multirow[t]{4}{*}{-} & $\begin{array}{c}0,276 \\
(\mathrm{n}=10)\end{array}$ & $\begin{array}{c}-0,005 \\
(\mathrm{n}=10)\end{array}$ & $\begin{array}{c}0,078 \\
(\mathrm{n}=8)\end{array}$ \\
\hline $\begin{array}{l}\text { Sauerlach A } \\
(25-\mathrm{j} .)\end{array}$ & & & & & - & $\begin{array}{c}0,405 \\
(\mathrm{n}=20)\end{array}$ & $\begin{array}{c}0,218 \\
(\mathrm{n}=16)\end{array}$ \\
\hline $\begin{array}{l}\text { Sauerlach B } \\
(25-\mathrm{j} .)\end{array}$ & & & & & & - & $\begin{array}{c}0,305 \\
(\mathrm{n}=16)\end{array}$ \\
\hline $\begin{array}{l}\text { Neureichenau } \\
(34-j .)\end{array}$ & & & & & & & - \\
\hline
\end{tabular}

Für einen Vergleich aller neun Versuchsflächen sind für die sieben auf allen Flächen vertretenen Herkünften die mittlere Baumhöhe und der mittlere BHD bestimmt worden. Die Ergebnisse sind in Tabelle 3.37 zusammengestellt. Auf den beiden höher gelegenen Versuchsflächen Neureichenau (950 m ü. NN) und Seesen (520 $\mathrm{m}$ ü. NN) sind im Alter von über 30 Jahren die mittleren Baumhöhen des Standards etwa 3 bis $5,5 \mathrm{~m}$ geringer als auf den tiefer gelegenen Flächen Dassel 
(240 m ü. NN), Reinhardshagen (260 m ü. NN) und Wanfried (320 m ü. NN). Beim BHD unterscheiden sich diese fünf Versuchsflächen nicht. Um die Flächen Ochsenhausen A + B sowie Sauerlach A + B in einen Vergleich einbeziehen zu können, werden für alle Flächen die jeweiligen Herkunftsmittel im Verhältnis zum Standard ausgedrückt.

Tab.3.37: Mittelwerte und Variationskoeffizienten des Höhen- und BHD-Wachstums der sieben gemeinsamen Herkünfte (= Standard) auf den einzelnen Versuchsflächen

\begin{tabular}{l|c|c|c|c|c|c|c}
\hline \multirow{2}{*}{ Versuch } & Alter & \multicolumn{3}{|c|}{ Mittlere Höhe } & \multicolumn{3}{c}{ Mittlerer BHD } \\
& [jahre] & $\mathrm{n}$ & {$[\mathrm{m}]$} & $\mathrm{s} \%$ & $\mathrm{n}$ & {$[\mathrm{cm}]$} & $\mathrm{s} \%$ \\
\hline Reinhardshagen & 32 & 176 & 20,5 & 7 & 839 & 20,3 & 27 \\
Wanfried & 32 & 163 & 19,9 & 9 & 721 & 19,3 & 22 \\
Dassel & 32 & 62 & 18,4 & 8 & 132 & 19,8 & 23 \\
Seesen & 32 & 61 & 15,6 & 8 & 133 & 20,4 & 19 \\
Ochsenhausen A & 22 & 203 & 9,1 & 14 & - & - & - \\
Ochsenhausen B & 21 & 217 & 8,7 & 12 & - & - & - \\
Sauerlach A & 25 & - & - & - & 234 & 13,7 & 25 \\
Sauerlach B & 25 & - & - & - & 277 & 13,1 & 32 \\
Neureichenau & 34 & 98 & 15,1 & 19 & 164 & 20,4 & 21 \\
\hline
\end{tabular}

In der Abbildung 3.79 sind für die 20 Herkünfte die Höhen im Verhältnis zum Standard dargestellt. Gleiches ist für den BHD in Abbildung 3.80 geschehen. $\mathrm{Zu}$ erkennen ist, dass die Höhen deutlich geringer variieren als die BHD.

Ein auf allen Flächen unter dem Standard liegendes Höhenwachstum haben die Herkünfte Nr. 17 (Witów), die Nr. 9 (Stronie Slaskie) und die Nr. 15 (Rycerka II) (Abb. 3.79). Nur die Herkunft Nr. 18 (Tarnawa) ist dem Standard auf allen sieben Versuchsflächen mindestens gleichwertig. Die Spannweite zwischen der Herkunft mit dem geringsten Höhenwachstum auf einer Fläche und der mit dem besten Höhenwachstum beträgt im Vergleich zum Standard $28 \%$-Punkte (Tab. 3.38). Bei den drei Herkünften Nr. 2 (Krzyze), Nr. 15 (Ryceraka II) und Nr. 21 (Kartuzy) unterscheiden sich die Verhältnisse zum Standard um maximal $5 \%$ Punkte. Diese Herkünfte und acht weitere, bei denen die Spannweiten zwischen kleinstem und größtem Wert bis einschließlich 10 \%-Punkte betragen, weisen ein im Vergleich zum Standard ähnliches Wachstum unabhängig von den jeweiligen Standortbedingungen am Versuchsort auf. Etwas stärker auf die Umwelt an den Versuchsorten reagieren die neun Herkünfte, bei denen die Spannweiten zwischen 11 und $19 \%$-Punkte betragen. 


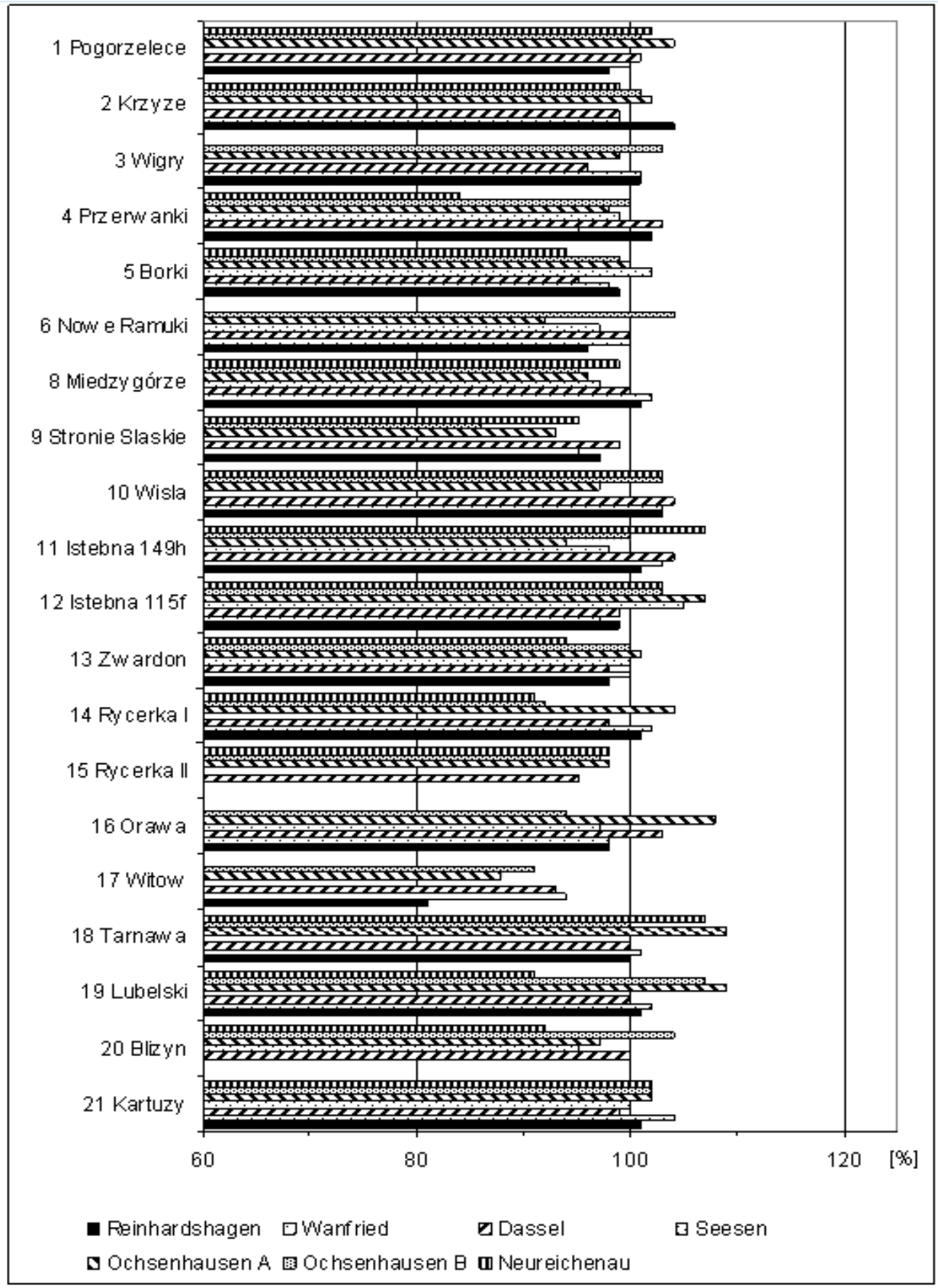

Abb. 3.79: Relative Höhen (Alter: s. Tab. 3.37) der 20 Herkë̈fte im Vergleich zum Versuchsflächenmittel des Standards auf sieben Versuchsflächen 


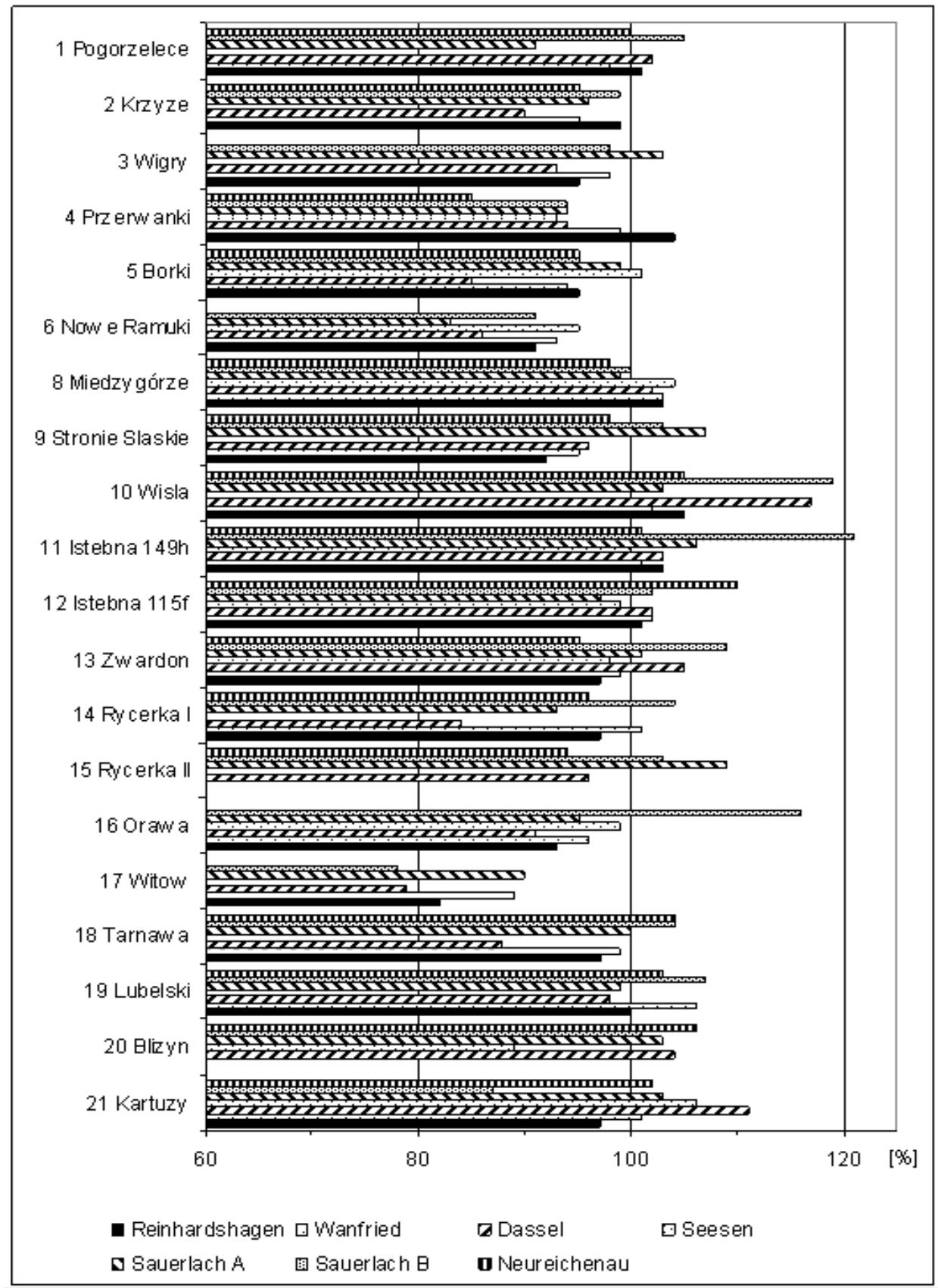

Abb. 3.80: Relative BHD (Alter: s. Tab. 3.37) der 20 Herkünfte im Vergleich zum Versuchsflächenmittel des Standards auf sieben Versuchsflächen 
Tab. 3.38: Spannweiten (Rangfolge) zwischen den relativen kleinsten und größten Höhen- und BHD-Wachstumswerten der 20 Herkünfte im Vergleich zu den sieben gemeinsamen Herkünften (= Standard) auf den einzelnen Versuchsflächen $(n=$ Anzabl Versuchsflächen)

\begin{tabular}{cll|c|c|c|c}
\hline \multirow{2}{*}{$\begin{array}{c}\text { IUFRO- } \\
\text { Nr. }\end{array}$} & Herkunft & $\mathrm{n}$ & \multicolumn{2}{|c|}{ Höhe $[\%]$} & \multicolumn{2}{|c}{ BHD [\%] } \\
\hline 1 & Pogorzelece & 6 & $98-104$ & $6(4)$ & $91-105$ & $14(8)$ \\
2 & Krzyze & 6 & $99-104$ & $5(2)$ & $90-99$ & $9(2)$ \\
3 & Wigry & 5 & $96-103$ & $7(5)$ & $93-103$ & $10(4)$ \\
4 & Przerwanki & 7 & $84-103$ & $19(20)$ & $85-104$ & $19(16)$ \\
5 & Borki & 7 & $94-102$ & $8(9)$ & $85-101$ & $16(12)$ \\
6 & Nowe Ramuki & 6 & $92-104$ & $12(12)$ & $83-95$ & $12(5)$ \\
8 & Miedzygórze & 7 & $95-102$ & $7(5)$ & $98-104$ & $6(1)$ \\
9 & Stronie Slaskie & 6 & $86-99$ & $13(14)$ & $92-107$ & $15(10)$ \\
10 & Wisła & 6 & $97-104$ & $7(5)$ & $102-119$ & $17(14)$ \\
11 & Istebna 149h & 7 & $94-107$ & $13(14)$ & $100-121$ & $21(18)$ \\
12 & Istebna 115f & 7 & $97-107$ & $10(11)$ & $97-110$ & $13(7)$ \\
13 & Zwardon & 7 & $94-101$ & $7(5)$ & $95-109$ & $14(9)$ \\
14 & Rycerka I & 6 & $91-104$ & $13(14)$ & $84-104$ & $20(17)$ \\
15 & Rycerka II & 4 & $95-98$ & $3(1)$ & $94-109$ & $15(11)$ \\
16 & Orawa & 6 & $94-108$ & $14(18)$ & $91-116$ & $25(20)$ \\
17 & Witów & 5 & $81-94$ & $13(14)$ & $78-90$ & $12(6)$ \\
18 & Tarnawa & 6 & $100-109$ & $9(10)$ & $88-104$ & $16(13)$ \\
19 & Lubelski & 6 & $91-109$ & $18(19)$ & $98-107$ & $9(3)$ \\
20 & Blizyn & 5 & $92-104$ & $12(12)$ & $89-106$ & $17(15)$ \\
21 & Kartuzy & 7 & $99-104$ & $5(2)$ & $87-111$ & $24(19)$ \\
\hline & insgesamt & 122 & $81-109$ & 28 & $78-121$ & 43 \\
\hline
\end{tabular}

Beim BHD-Wachstum sind es auch drei Herkünfte, deren Durchmesserwachstum auf allen Versuchsflächen geringer als das Mittel aus den sieben gemeinsamen Herkünften ausfällt: die Nr. 2 (Krzyze), die Nr. 6 (Nowe Ramuki) und die Nr. 17 (Witów), die auch bereits beim Höhenwachstum das geringste Wachstum zeigte. Die Herkünfte Nr. 10 (Wisła) und Nr. 11 (Istebna 149h) haben ein BHD-Wachstum, das im Vergleich zum Standard diesem entspricht oder besser ist. Die Spannweite zwischen der Herkunft mit dem geringsten BHD-Wachstum auf einer Fläche und der mit dem besten BHD-Wachstum beträgt im Vergleich zum Standard $43 \%$-Punkte (Tab. 3.38). Bei vier Herkünften beträgt die Spannweite zwischen 6 und $10 \%$-Punkten, d. h. diese Herkünfte haben unabhängig von der Umwelt und der forstlichen Behandlung ein konstantes Dickenwachstum. Es folgen 13 Herkünfte mit 12 bis $20 \%$-Punkten. Ein sehr stark von den Standortbedingungen 
abhängiges Dickenwachstum zeigen die Herkünfte Nr. 11 (Istebna 149h), Nr. 21 (Kartuzy) und Nr. 16 (Orawa), deren Spannweiten zwischen 21 und 25 \%-Punkten liegen.

Zwischen den Spannweiten beim Höhenwachstum und denen beim BHDWachstum besteht kein statistischer Zusammenhang $\left(\mathrm{r}_{\mathrm{P}}=0,182^{\mathrm{ns}}\right)$.

Den Unterschieden im Höhen- und BHD-Wachstum ist etwas genauer nachgegangen worden, da die Vermutung nahe liegt, dass es sich bei den Bäumen, von denen Höhen gemessen wurden, um keine Zufallsstichprobe handelt. Dazu wurden nur die Bäume berücksichtigt, von denen sowohl Höhe als auch BHD vorliegen. Dieses ist bei insgesamt 560 Bäumen der fünf Versuchsflächen Reinhardshagen (HE), Wanfried (HE), Dassel (NI), Seesen (NI) und Neureichenau (BY) der Fall.

Werden die mittleren Durchmesser über die sieben gemeinsamen Herkünfte der fünf Versuchsflächen, auf denen sowohl Höhen und BHD gemessen wurden, verglichen, so zeigt sich, dass der mittlere BHD von allen Bäumen der sieben Herkünfte geringer ist als der der Bäume, von denen nur die Höhen bekannt sind (Tab. 3.39). Auf den beiden Flächen in Hessen betragen die Unterschiede zwischen beiden Kollektiven 28\% (Reinhardshagen) bzw. 23\% (Wanfried). Auf den Flächen Seesen und Neureichenau unterschieden sich die BHD-Werte beider Kollektive um nur $5 \%$ bzw. $7 \%$. Auf den Flächen in Hessen sind die Parzellen größer als auf jenen in Niedersachsen. Vorrangig wurden die Z-Bäume gemessen und erst wenn damit die erforderliche Anzahl an Höhen nicht erreicht war, sind Nicht-Z-Bäume gemessen worden. Dieses trat bei den kleineren Parzellen in Niedersachsen häufiger auf als in Hessen, was sich letztendlich auch in einem geringeren BHD der Fichten, an denen die Höhen gemessen wurden, ausdrückt. Damit ist das Höhenwachstum als Einzelmerkmal nur beschränkt aussagefähig.

Tab.3.39: $\quad$ Mittlerer BHD der sieben gemeinsamen Herkünfte (= Standard) auf den fünf Versuchsflächen: aller Bäume und nur von denen, für die die Höhen bekannt sind

\begin{tabular}{|c|c|c|c|c|c|}
\hline \multirow[t]{2}{*}{ Versuchsfläche } & \multicolumn{2}{|c|}{ BHD aller Bäume } & \multicolumn{2}{|c|}{$\begin{array}{l}\text { BHD, nur von Bäumen, von } \\
\text { denen Höhe bekannt }\end{array}$} & \multirow{2}{*}{$\begin{array}{c}\text { Diff. } \\
{[\mathrm{cm}]([\%])}\end{array}$} \\
\hline & {$[\mathrm{cm}]$} & Anzahl & {$[\mathrm{cm}]$} & Anzahl & \\
\hline Reinhardshagen & 20,3 & 839 & 26,0 & 176 & $5,7(28 \%)$ \\
\hline Wanfried & 19,3 & 721 & 23,7 & 163 & $4,4(23 \%)$ \\
\hline Dassel & 19,8 & 132 & 22,4 & 62 & $2,6(13 \%)$ \\
\hline Seesen & 20,4 & 133 & 21,5 & 61 & $1,1 \quad(5 \%)$ \\
\hline Neureichenau & 20,4 & 164 & 21,9 & 98 & $1,5 \quad(7 \%)$ \\
\hline
\end{tabular}

In Tabelle 3.40 sind nur die Bäume berücksichtigt, für die sowohl die Höhe als auch der BHD bekannt sind, d. h. dass die Höhenwuchsdaten der Flächen Ochsenhausen A und B (BW) weggelassen wurden. Im Unterschied zur Aus- 
wertung aller Bäume (Tab. 3.38) hat sich bei der Höhe die Spannweite kaum verändert. Im Gegensatz zum BHD ändert sich an der Anzahl der Bäume auf den fünf Flächen nichts, da von diesen alle Bäume mit gemessenen Höhen berücksichtigt werden. Auch unter den geänderten Voraussetzungen bleiben weiterhin die drei Herkünfte Nr. 9 (Stronie Slaskie), Nr. 15 (Rycerka II) und Nr. 17 (Witów) auf allen fünf Versuchsflächen hinter dem Standard im Höhenwachstum zurück. Neben der Herkunft Nr. 18 (Tarnawa) gibt es jetzt eine weitere Herkunft Nr. 10 (Wisła), die auf den fünf Flächen besser als der Standard ausfällt.

Tab. 3.40: Spannweiten (Rangfolge) zwischen den relativen kleinsten und größten Höhen- und BHD-Wachstumswerten der 20 Herkünfte im Vergleich zu den sieben gemeinsamen Herkü̈ften (= Standard) auf den fünf Versuchsflächen, jedoch nur für die Bäume, von denen Höbe und BHD bekannt sind

\begin{tabular}{|c|c|c|c|c|c|c|}
\hline \multirow{2}{*}{$\begin{array}{c}\text { IUFRO } \\
\text { Nr. }\end{array}$} & \multirow[b]{2}{*}{ Herkunft } & \multirow[b]{2}{*}{$\mathrm{n}$} & \multicolumn{2}{|c|}{ Höhe $[\%]$} & \multicolumn{2}{|c|}{$\mathrm{BHD}[\%]$} \\
\hline & & & Min. - Max. & $\begin{array}{c}\text { Spannweite } \\
\text { (Rang) }\end{array}$ & Min. - Max. & $\begin{array}{c}\text { Spannweite } \\
\text { (Rang) }\end{array}$ \\
\hline 1 & Pogorzelece & 4 & $98-102$ & 4 (3) & $95-100$ & 5 (4) \\
\hline 2 & Krzyze & 4 & $99-104$ & $5(6)$ & $91-100$ & $9(11)$ \\
\hline 3 & Wigry & 3 & $96-101$ & $5(6)$ & $93-98$ & $5 \quad(5)$ \\
\hline 4 & Przerwanki & 5 & $84-103$ & $19(20)$ & $75-101$ & $26(20)$ \\
\hline 5 & Borki & 5 & $94-102$ & $8 \quad(13)$ & $82-100$ & $18(19)$ \\
\hline 6 & Nowe Ramuki & 4 & $96-100$ & 4 (3) & $93-96$ & 3 (1) \\
\hline 8 & Miedzygórze & 5 & $97-102$ & $5(6)$ & $99-105$ & $6(6)$ \\
\hline 9 & Stronie Slaskie & 4 & $95-99$ & $4 \quad(3)$ & $93-103$ & $10(12)$ \\
\hline 10 & Wisła & 4 & $103-104$ & 1 (1) & $104-111$ & 7 (9) \\
\hline 11 & Istebna $149 \mathrm{~h}$ & 5 & $98-107$ & $9(16)$ & $94-105$ & $11(14)$ \\
\hline 12 & Istebna $115 \mathrm{f}$ & 5 & $97-105$ & $8(13)$ & $98-109$ & $11(15)$ \\
\hline 13 & Zwardon & 5 & $94-100$ & $6(10)$ & $98-102$ & $4 \quad(2)$ \\
\hline 14 & Rycerka I & 4 & $91-102$ & $11(17)$ & $95-103$ & $8(10)$ \\
\hline 15 & Rycerka II & 2 & $95-98$ & 3 (2) & $92-98$ & $6(7)$ \\
\hline 16 & Orawa & 4 & $97-103$ & $6(10)$ & $95-99$ & $4 \quad(3)$ \\
\hline 17 & Witów & 3 & $81-94$ & $13(19)$ & $87-97$ & $10(13)$ \\
\hline 18 & Tarnawa & 4 & $100-107$ & $7(12)$ & $90-106$ & $16(17)$ \\
\hline 19 & Lubelski & 4 & $91-102$ & $11(17)$ & $98-104$ & $6(8)$ \\
\hline 20 & Blizyn & 3 & $92-100$ & $8(13)$ & $87-103$ & $16(18)$ \\
\hline \multirow[t]{2}{*}{21} & Kartuzy & 5 & $99-104$ & $5(6)$ & $98-113$ & $15(16)$ \\
\hline & insgesamt & 82 & $81-107$ & 26 & $75-113$ & 38 \\
\hline
\end{tabular}


Beim BHD-Wachstum hat sich bei ausschließlicher Auswertung der Bäume mit gemessenen Höhen im Vergleich zur Auswertung aller Bäume, die mittlere Spannweite um $5 \%$-Punkte auf $38 \%$ verringert (Tab. 3.38 und Tab. 3.40). Das Weglassen der Flächen Sauerlach A und B (BY), für die Höhenmessungen fehlen, sowie die Berücksichtigung ausschließlich der 560 Bäume, von denen Höhe und BHD bekannt sind, führt zu fünf Herkünften (Nr. 3 Wigry, Nr. 6 Nowe Ramuki, Nr. 15 Rycerka II, Nr. 16 Orawa und Nr. 17 Witów), deren BHD-Wachstum auf den fünf Versuchsflächen unter dem des Standards bleibt (Abb. 3.81). Nur die Herkunft Nr. 10 zeigt auf den fünf Versuchsflächen ein Wachstum, das über dem Standard liegt.

Zwischen den Spannweiten beim Höhenwachstum und denen beim BHDWachstum der Bäume, von denen beide Wachstumsmerkmale vorliegen, besteht ein statistischer Zusammenhang $\left(\mathrm{r}_{\mathrm{P}}=0,612^{* *}\right)$.

In der Abbildung 3.81 sind für die Bäume, für die sowohl Höhe als auch BHD gemessen wurden, die mittleren Durchmesser der 20 Herkünfte auf den fünf Versuchsflächen dargestellt. Zum Vergleich sind in Abb. 3.82 die mittleren Durchmesser aller Bäume der fünf Versuchsflächen gegenübergestellt.

Es zeigt sich, dass die Verteilung in Abbildung 3.81 etwas homogener ist als in Abbildung 3.82. Zwischen den Spannweiten von geringstem zu bestem relativen Durchmesserwachstum einer Herkunft auf den Versuchsflächen aller Bäume, von denen die BHD bekannt sind, einerseits (Abb. 3.82) und nur der Bäume, von denen sowohl Höhe als auch BHD vorliegen, andererseits (Abb. 3.81), besteht kein statistischer Zusammenhang ( $\left.\mathrm{r}_{\mathrm{P}}=0,338^{\mathrm{ns}}\right)$.

Zwischen den Spannweiten beim Höhenwachstum und denen beim BHDWachstum nur der Bäume, von denen auch Höhen vorliegen, besteht nun dagegen ein statistischer Zusammenhang ( $\left.\mathrm{r}_{\mathrm{P}}=0,612^{* *}\right)$.

Die mittlere Merkmalsausprägung des BHD pro Parzelle ist für die Bäume, von denen Höhen und BHD vorliegen, für die vier Versuchsflächen Reinhardshagen, Wanfried, Dassel und Neureichenau für 14 gemeinsame Herkünfte varianzanalytisch untersucht worden. Dabei wurde der Einfluss der Versuchsflächen, der Herkünfte sowie der Interaktion aus Versuchsfläche und Herkunft berücksichtigt. Das Varianzmodell ist signifikant $\left(\mathrm{r}^{2}=0,59\right)$ und weist einen signifikanten Einfluss der Versuchsflächen und der Herkünfte auf den BHD aus. Mittels Varianzanalyse lässt sich der Anteil der Komponente der Versuchsfläche auf 30,3\%, der der Herkunft auf 9,1\% und der nicht erklärte Rest auf 60,6\% quantifizieren. Der multiple Mittelwertvergleich (Tukey-Test, $\alpha=0,05)$ weist für die Versuchsflächen drei Gruppen aus: Gruppe A (Reinhardshagen), Gruppe B (Wanfried, Dassel) und Gruppe C (Neureichenau). Für die Herkünfte ergeben sich aus dem multiplen Mittelwertvergleich (Tukey-Test, $\alpha=0,05$ ) drei sich stark überlappende Gruppen. Die drei stark überlappenden Gruppen bestätigen den vorherigen Befund, dass die Stichprobe der Bäume, von denen Höhen gemessen wurden, nicht zufällig war. 


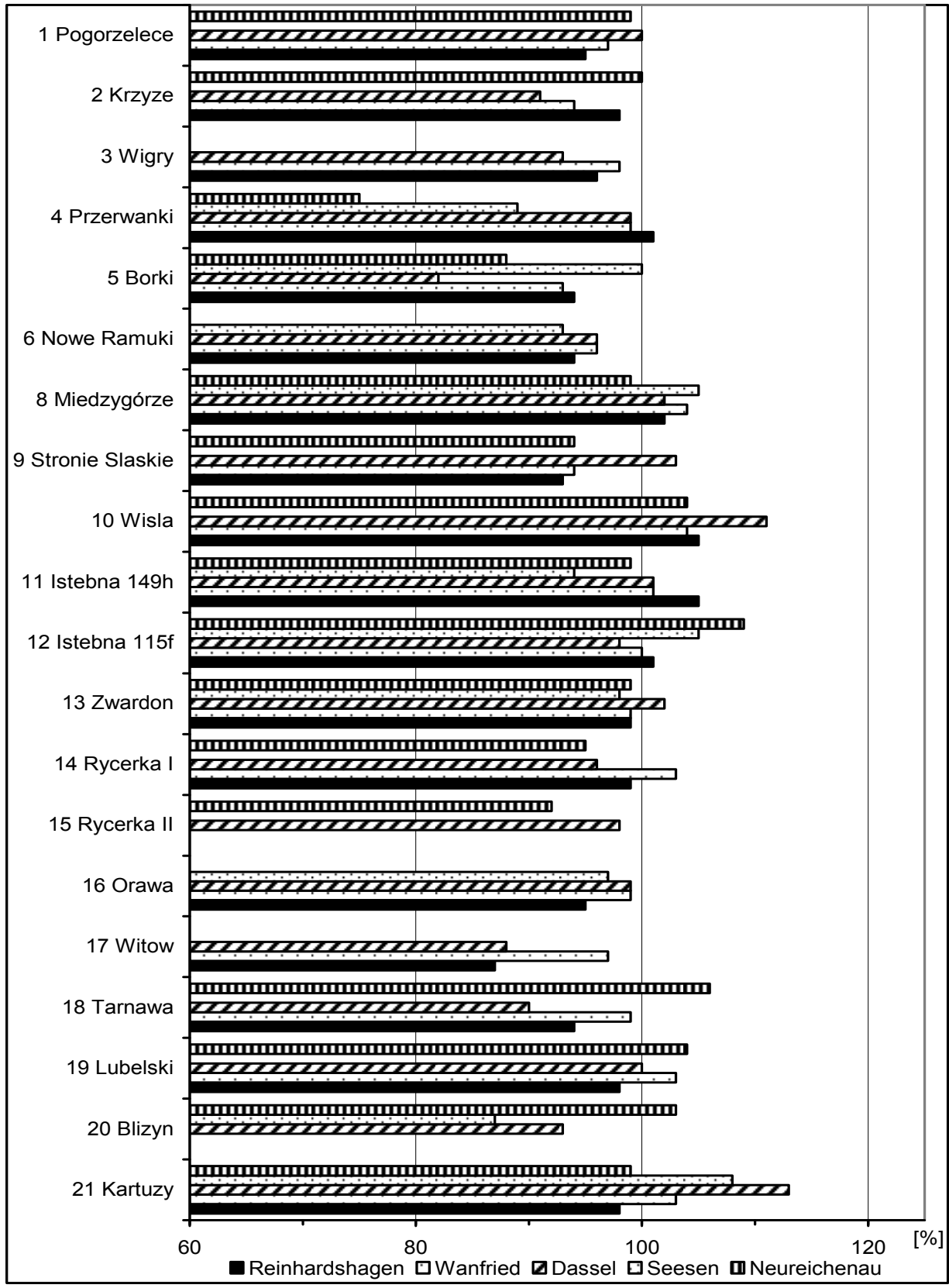

Abb. 3.81: Relative BHD der 20 Herkünfte im Vergleich zum Versuchsflächenmittel des Standards, jedoch nur der Bäume, von denen Höhe und BHD vorliegen, für fünf Versuchsflächen 


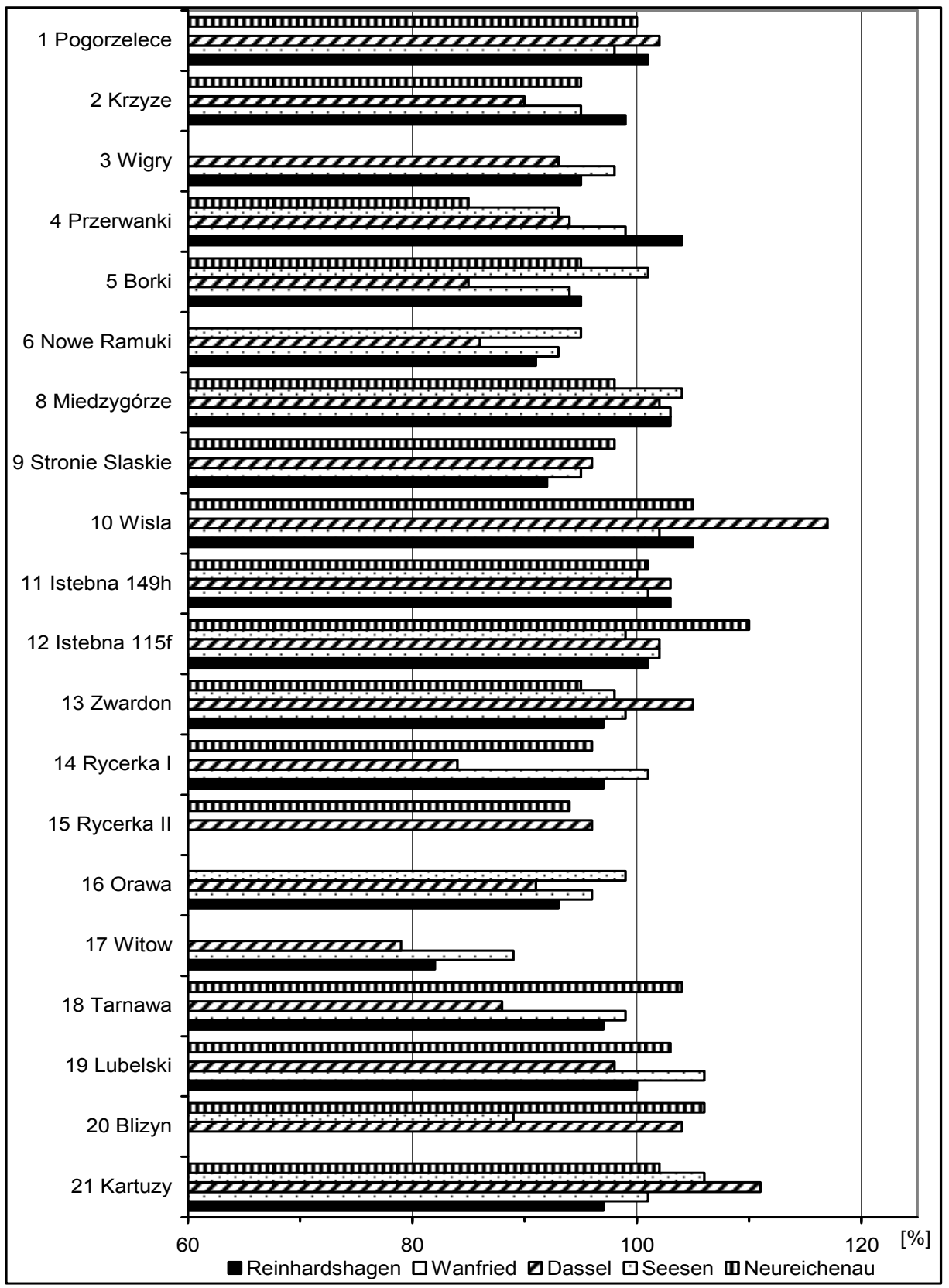

Abb. 3.82: Relative BHD der 20 Herkünfte im Vergleich zum Versuchsflächenmittel des Standards von allen Bäumen, von denen BHD vorliegen, für fünf Versuchsflächen (wie Abb. 3.80, jedoch zur Vergleichbarkeit mit Abb. 3.81 obne die Flächen Sauerlach A und B) 


\section{Wachstumsverlauf der einzelnen 20 Herkünfte}

Im Folgenden sind für jede der 20 Herkünfte der Verlauf des Höhen- und BHDWachstums auf den neun Versuchsflächen dargestellt. In den Abbildungen 3.83 bis 3.102 sind für die Versuchsflächen folgende Symbole verwendet worden:

$\begin{array}{llll}\diamond & \text { (Raute) } & \text { Reinhardshagen (HE) } & \text { Höhe, BHD } \\ \circ & \text { (Kreis) } & \text { Wanfried (HE) } & \text { Höhe, BHD } \\ \Delta & \text { (Dreieck) } & \text { Dassel (NI) } & \text { Höhe, BHD } \\ \bullet & \text { (Punkt) } & \text { Seesen (NI) } & \text { Höhe, BHD } \\ + & \text { (Plus) } & \text { Ochsenhausen (BW) } & \text { Höhe } \\ \text { x } & (\text { x) } & \text { Ochsenhausen (BW) } & \text { Höhe } \\ * & \text { (Strich-Stern) } & \text { Sauerlach A (BY) } & \text { BHD } \\ \square & \text { (Quadrat) } & \text { Sauerlach B (BY) } & \text { BHD } \\ \star & \text { (Stern) } & \text { Neureichenau (BY) } & \text { Höhe, BHD }\end{array}$

Nachfolgend fällt bei allen Herkünften auf, dass das Höhenwachstum auf der Fläche Reinhardshagen in den letzten neun Jahren im Alter von 23 bis 32 stärker angestiegen ist als auf den anderen Flächen.

(Nr. 1) Pogorzelece (Abb. 3.83)

Die Herkunft Nr. 1 (Pogorzelece) zeigt auf den beiden hessischen Flächen und auf der etwa 30 bzw. $60 \mathrm{~km}$ entfernten Fläche Dassel ein ähnlich gutes Höhenwachstum. Etwas geringer fällt das Höhenwachstum auf den beiden Flächen in BadenWürttemberg aus, das jedoch nur bis zum Alter 21 bzw. 22 vorliegt. Abgesetzt ist die Wachstumskurve auf der in $950 \mathrm{~m}$ Seehöhe gelegenen Fläche Neureichenau.

Beim BHD ist das Wachstum auf den drei norddeutschen Flächen auch sehr ähnlich. Dennoch ist auf der Fläche Reinhardshagen sowohl beim BHD als auch bei der Höhe im Alter 23 bis 32 ein leichter Anstieg der Wachstumskurve zu verzeichnen. Auffallend ist der Durchmesserzuwachs auf der Fläche Neureichenau, der auch mit der Standraumerweiterung nach den Nassschneefällen im März 1999 zusammenhängen kann.

(Nr. 2) Krayze (Abb. 3.84)

Die Herkunft Nr. 2 (Krzyze) hat ein mit der Herkunft Nr. 1 (Pogorzelece) vergleichbares Wachstum. Beim Durchmesserwachstum ist der Zuwachs im Alter 23 bis 32 auf den Flächen Wanfried und Dassel etwas geringer als bei der Herkunft Nr. 1. 
(1) Pogorzelece
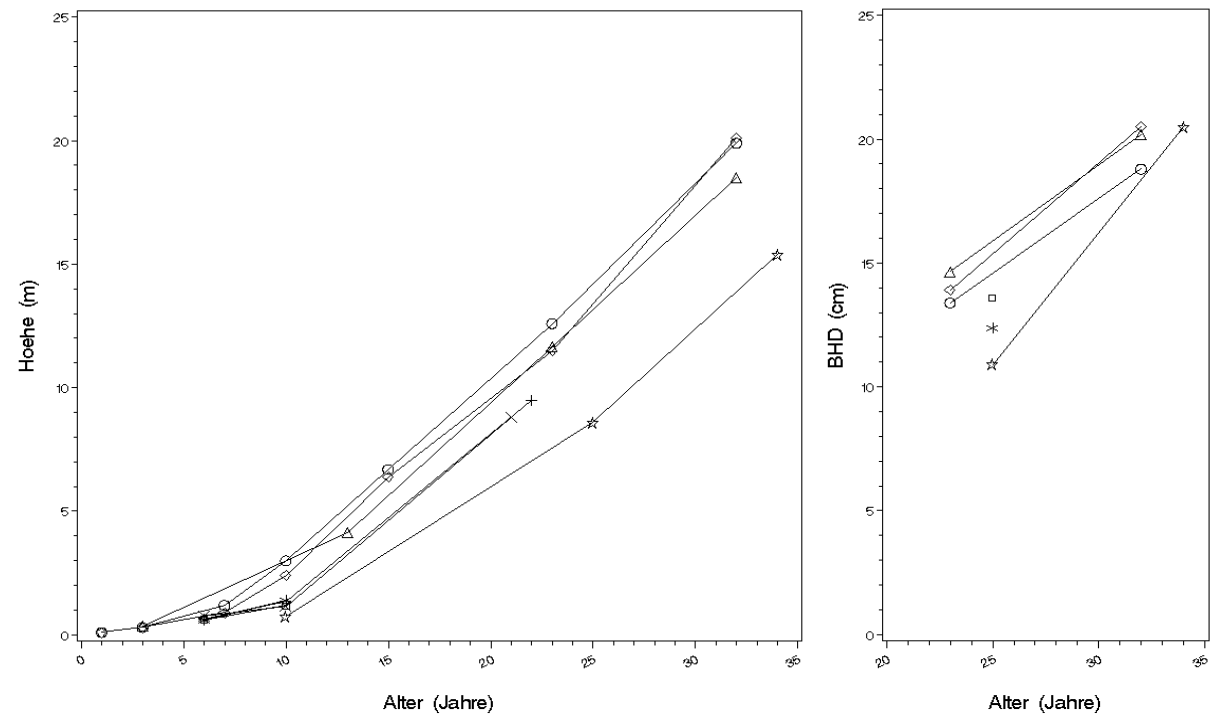

Abb. 3.83: Höhen- und Durchmesserwachstum der Herkunft Nr. 1 (Pogorzelece)

(2) Krzyze

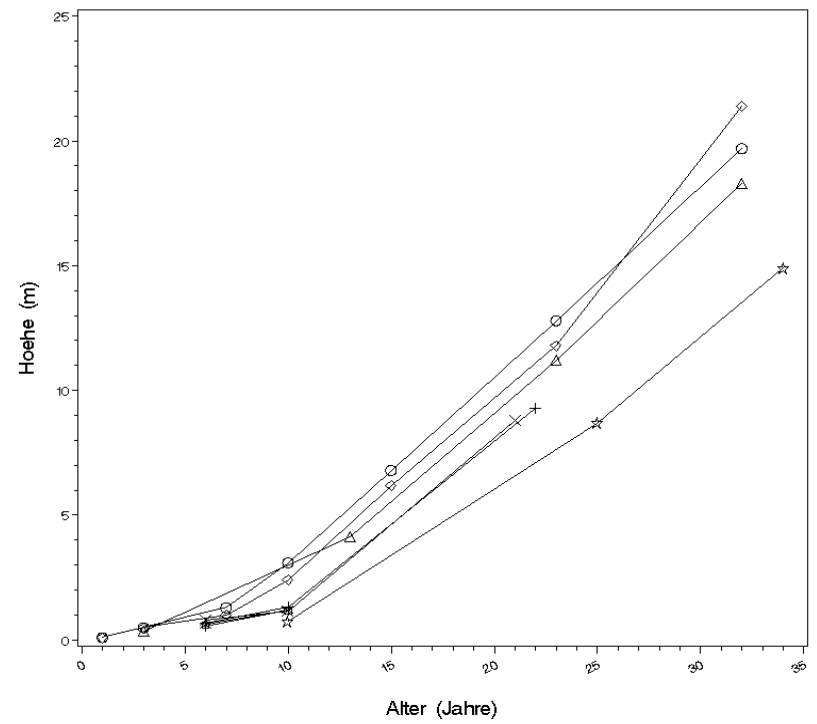

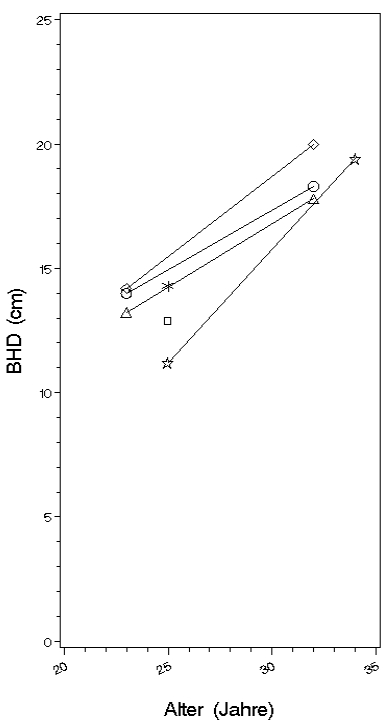

Alter (Jahre)

Abb. 3.84: Höhen- und Durchmesserwachstum der Herkunft Nr. 2 (Krzyze)

Beiträge aus der NW-FVA, Band 5, 2010 
(3) Wigry
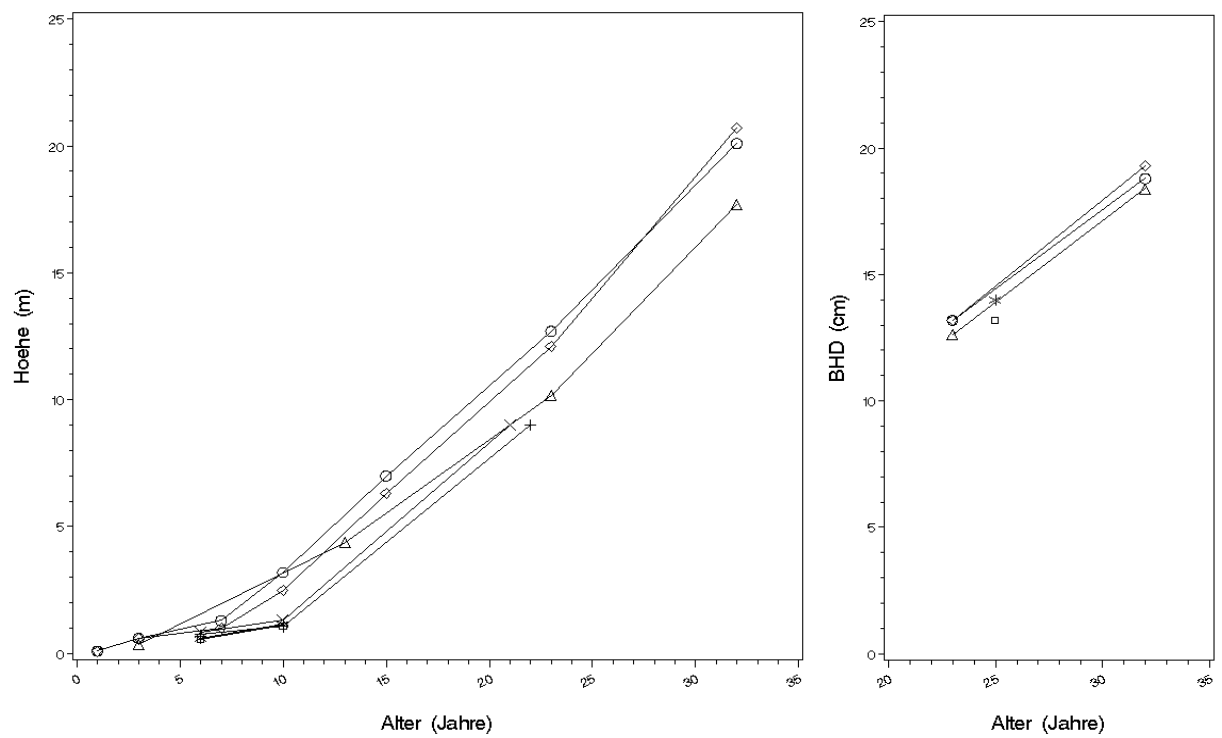

Abb. 3.85: Höhen-und Durchmesserwachstum der Herkunft Nr. 3 (Wigry)

(Nr. 3) Wigry (Abb. 3.85)

Die Höhenwachstumskurven verlaufen auf den Versuchsflächen ähnlich. Im Dickenwachstum erscheint die Herkunft sehr einheitlich. Es fehlen jedoch Anbauerfahrungen von höher gelegenen Standorten.

(Nr. 4) Przerwanki (Abb. 3.86)

Auffallend ist bei der Herkunft Nr. 4 das sich verringernde Höhenwachstum auf der Fläche Neureichenau, das der stärkste Rückgang von allen Herkünften ist. Beim Dickenwachstum ist anders als bei der Herkunft Nr. 21 aus dem Baltischen Gebiet keine auffällige Wuchssteigerung im Alter von 25 auf 34 festzustellen. Nur der Dickenzuwachs auf den Flächen Seesen und Neureichenau hat etwas stärker zugenommen als auf den anderen Flächen.

(Nr. 5) Borki (Abb. 3.87)

Die Herkunft Nr. 3 (Borki) ist im Wachstum mit den Herkünften Nr. 1 und Nr. 2 vergleichbar. Im Vergleich zur Herkunft Nr. 4 ist der Dickenzuwachs auf der Fläche Neureichenau ausgeprägter als auf den Flächen Reinhardshagen, Wanfried und Dassel. 
(4) Przerwanki
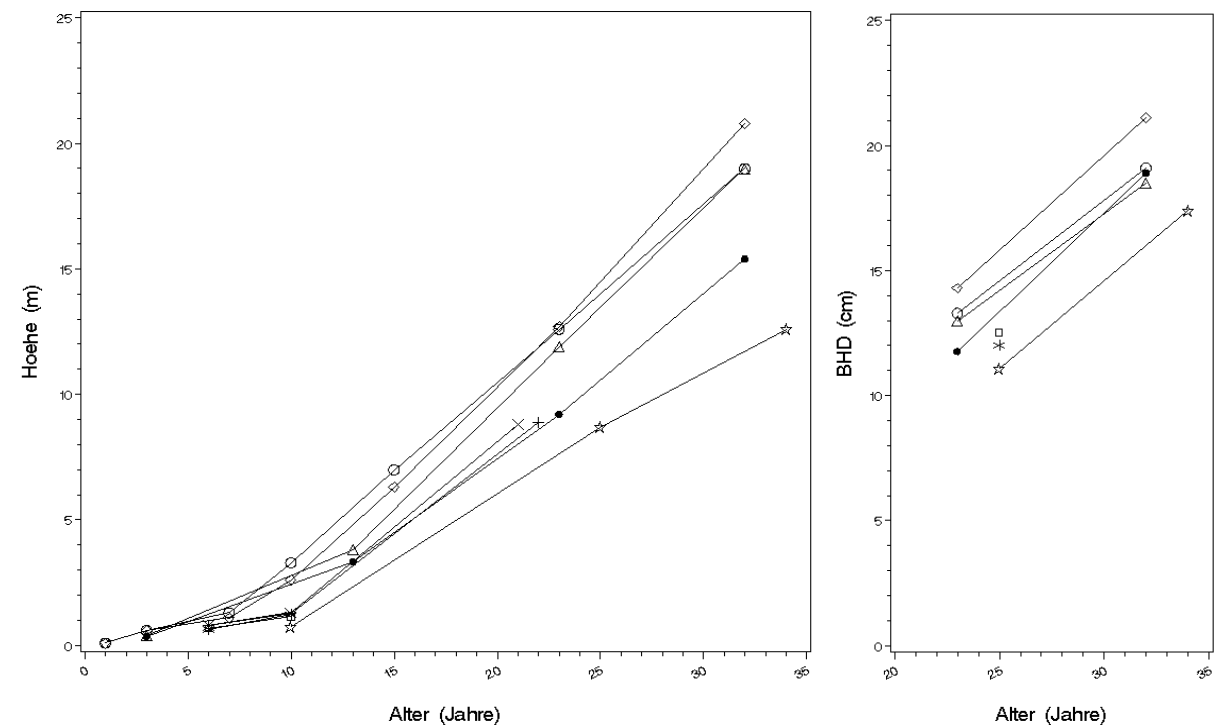

Abb. 3.86: Höhen- und Durchmesserwachstum der Herkunft Nr. 4 (Przerwanki)

(5) Borki
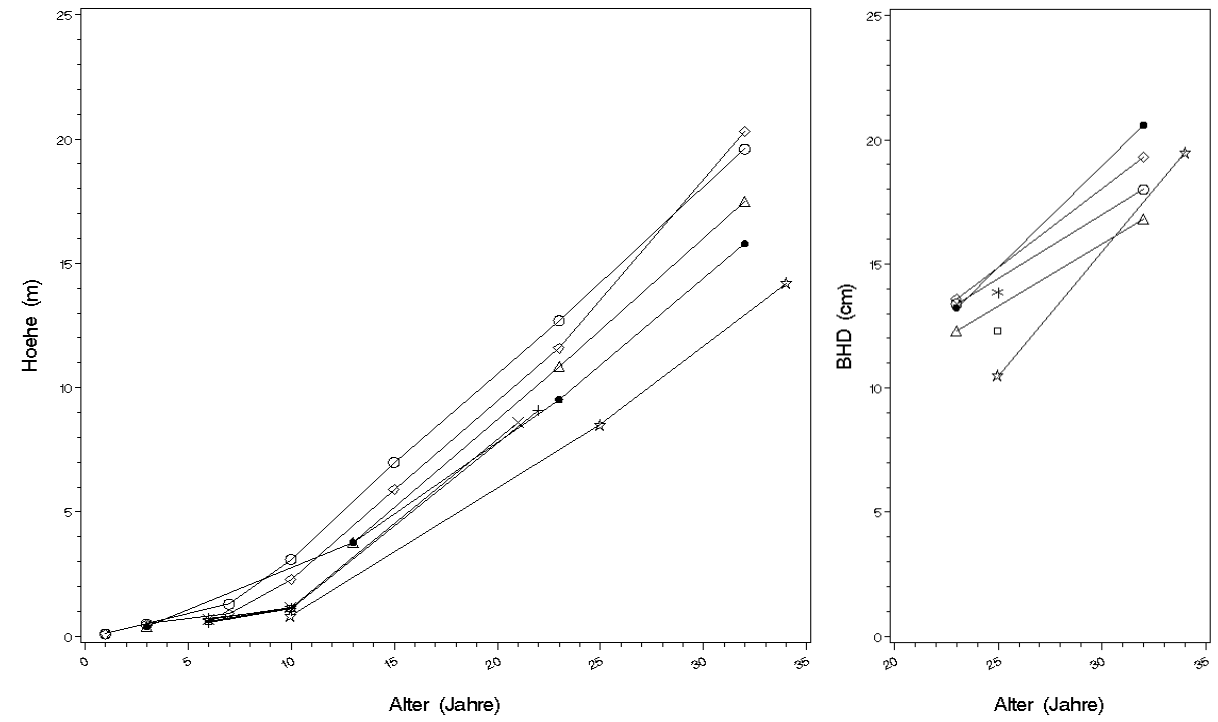

Abb. 3.87: Höhen- und Durchmesserwachstum der Herkunft Nr. 5 (Borki) 
(Nr. 6) Nowe Ramuki (Abb. 3.88)

Die Herkunft ist insgesamt nicht so wuchskräftig. Die Wachstumskurven verlaufen für die Anbauorte sehr ähnlich. Beim Durchmesserzuwachs fällt der bessere Wuchs auf der etwas höher gelegenen Fläche Seesen auf.

(Nr. 8) Miedrygórze (Abb. 3.89)

In den Wachstumskurven der Baumhöhe zeichnet sich vage eine Zweiteilung ab. In der einen Gruppe die Flächen Reinhardshagen, Wanfried und Dassel, wo die Herkunft Nr. 8 sich wüchsiger zeigt, und in der anderen Gruppe die Standorte Seesen und Neureichenau, auf denen ein geringerer Höhenwuchs vorliegt. Der Durchmesserzuwachs ist dagegen im Messzeitraum auf den höher gelegenen Versuchsflächen Seesen und Neureichenau besser.

(Nr.9) Stronie Slaskie (Abb. 3.90)

Die Herkunft Nr. 9 Stronie Slaskie aus den Sudeten ist im Vergleich zum Standard der sieben gemeinsamen Herkünfte im Höhen- und Durchmesserwuchs auf allen Flächen unterlegen. Auffallend ist der Zuwachsschub bei der Baumhöhe im Alter von 23 auf 32 Jahre auf der Fläche Reinhardshagen. Der BHD-Zuwachs ist auf der Fläche Neureichenau wieder besser als auf den anderen Flächen.

(6) Nowe Ramuki

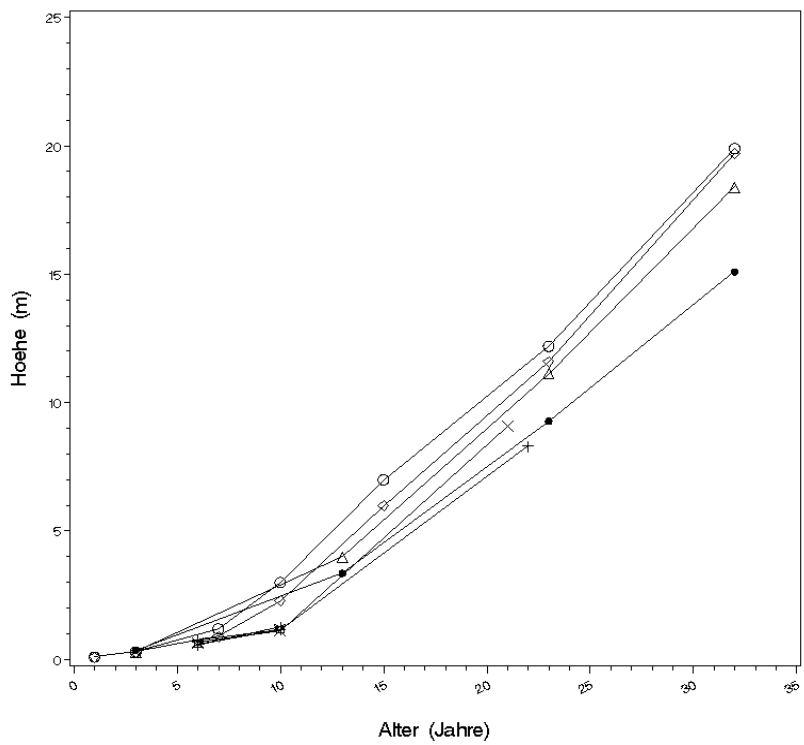

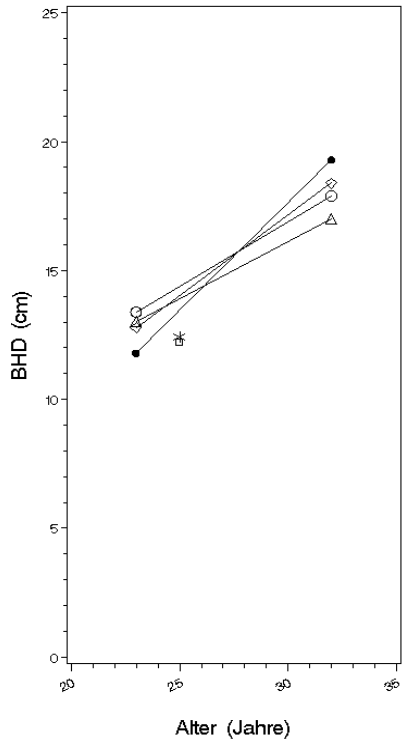

Alter (Jahre)

Abb. 3.88: Höhen- und Durchmesserwachstum der Herkunft Nr. 6 (Nowe Ramuki) 
(8) Miedzygorze
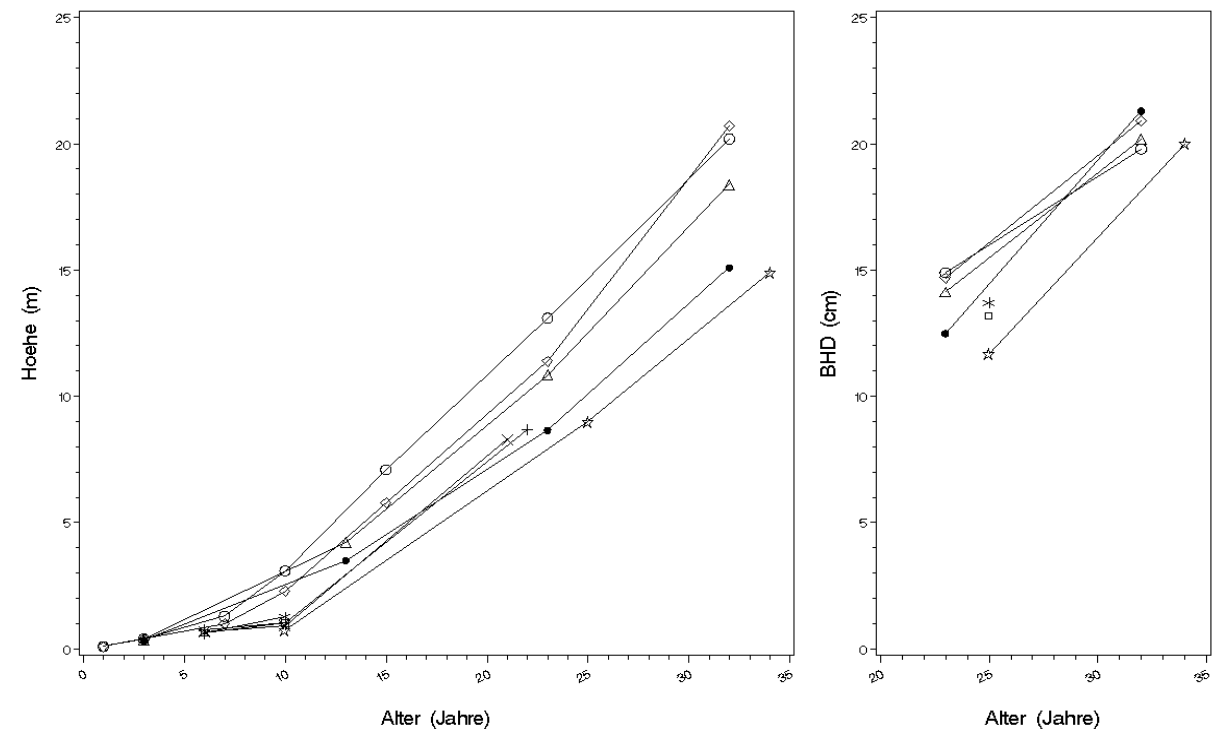

Abb. 3.89: Höhen- und Durchmesserwachstum der Herkunft Nr. 8 (Miedżygórze)

(9) Stronie Slaskie

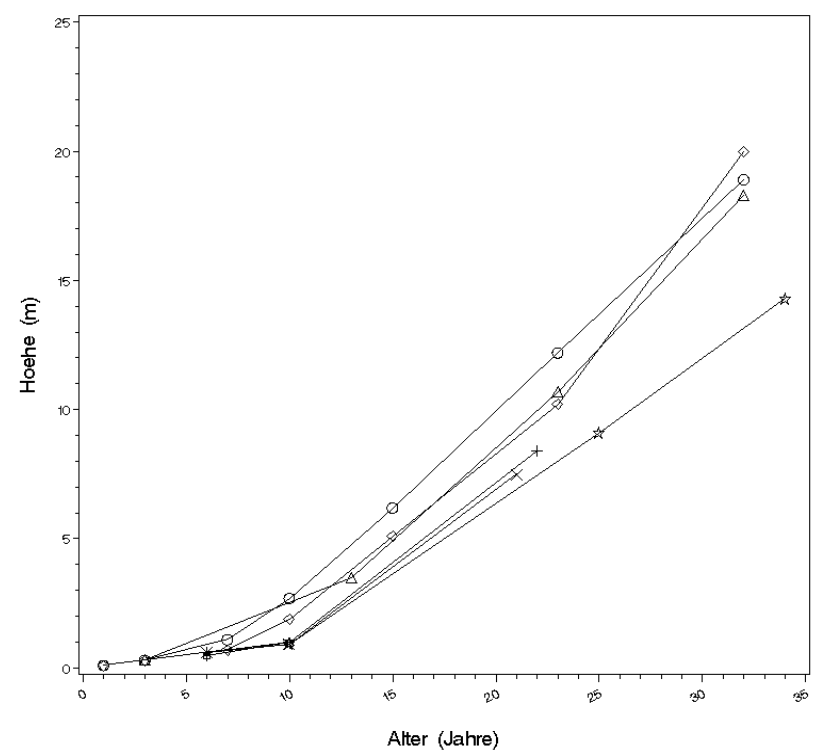

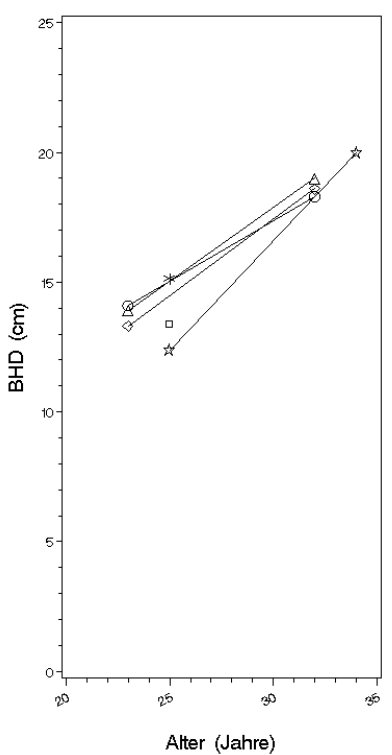

Alter (Jahre)

Abb.3.90: Höhen-und Durchmesserwachstum der Herkunft Nr. 9 (Stronie Slaskie) 
(10) Wisla

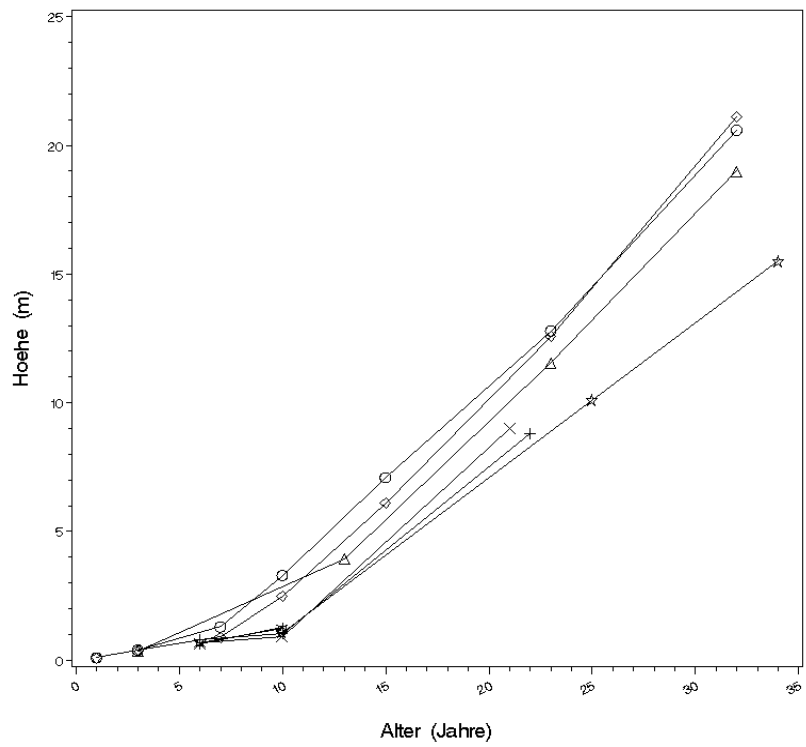

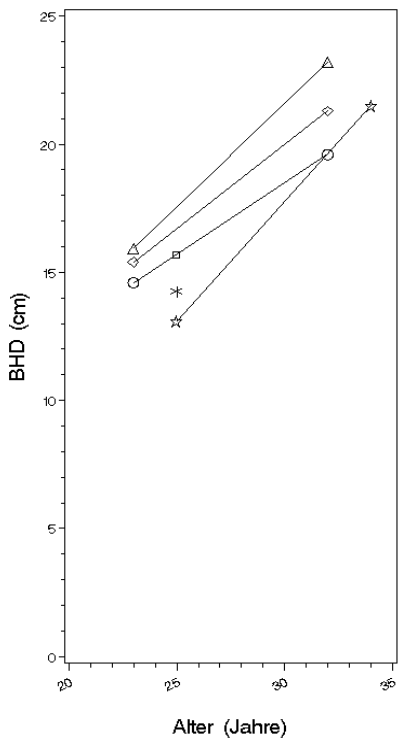

Abb. 3.91: Höhen- und Durchmesserwachstum der Herkunft Nr. 10 (Wisła)

(Nr. 10) Wista (Abb. 3.91)

Die Herkunft Nr. 10 (Wisła) gehört zu den wüchsigen Herkünften, auch wenn sie sich im Höhenzuwachs nicht zusätzlich hervorhebt. Die Durchmesserzuwächse sind im Messzeitraum auf der Fläche Neureichenau am größten. Es folgen die Flächen Dassel sowie Reinhardshagen; am geringsten sind die Durchmesserzuwächse auf der Fläche Wanfried.

(Nr. 11) Istebna 149h (Abb. 3.92)

Der Höhenzuwachs der letzten Messperiode ist auf den Flächen ähnlich, wobei auf der Fläche Seesen ein geringer Abfall und auf der Fläche Reinhardshagen ein leichter Anstieg erkennbar ist. Die Durchmesserzuwächse sind im Messzeitraum auf den beiden höher gelegenen Flächen Neureichenau und Seesen am größten.

(Nr. 12) Istebna $115 f(A b b .3 .93)$

Der Höhenzuwachs der letzten Messperiode ist, abgesehen von dem leichten Anstieg auf der Fläche Reinhardshagen, annähernd gleich. Der Durchmesserzuwachs ist auf der Fläche Neureichenau deutlich stärker als auf den anderen Flächen. 
(11) Istebna $149 \mathrm{~h}$
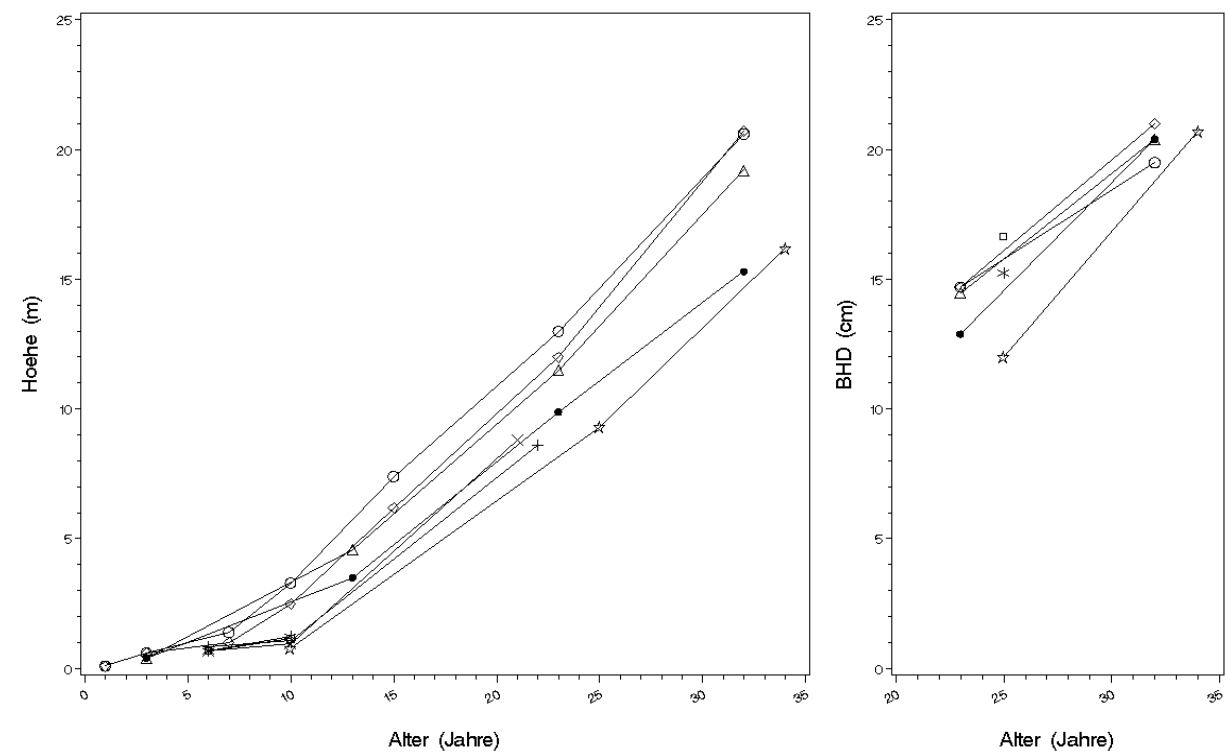

Abb. 3.92: Höhen- und Durchmesserwachstum der Herkunft Nr.11 (Istebna 149b)

(12) Istebna $115 f$

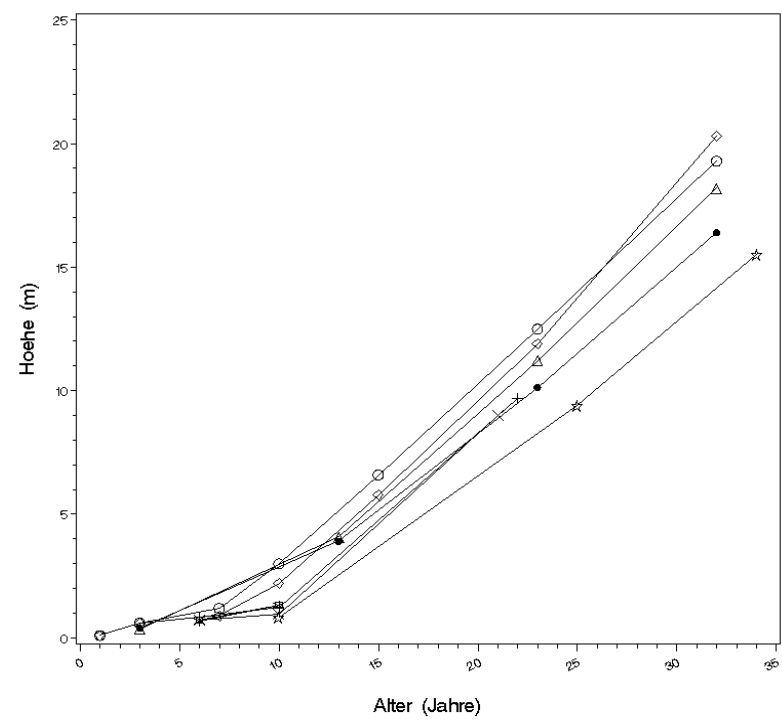

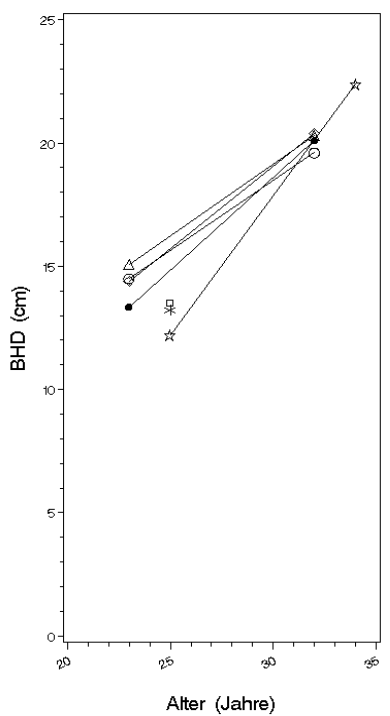

Abb. 3.93: Höhen-und Durchmesserwachstum der Herkunft Nr. 12 (Istebna 115f) 
(Nr. 13) Zwardon (Abb. 3.94)

Bei der Herkunft Nr. 13 (Zwardon) fächern sich die Höhenwachstumskurven etwas auf. Die Fläche Reinhardshagen hat in der letzten Messperiode einen deutlich gestiegenen Höhenzuwachs. Beim BHD zeichnet sich ein Zuwachsrückgang auf der Fläche Wanfried ab. Anders als bei anderen Herkünften sind auf den Flächen Neureichenau und Seesen die Zuwächse im Vergleich zu Dassel nicht deutlich höher.

(Nr. 14) Rycerka I (Abb. 3.95)

Auf den drei Anbauorten dieser Herkunft in Norddeutschland hat die Nr. 14 (Rycerka I) noch einen Anstieg in der Höhenzuwachskurve, während der Zuwachs auf der Fläche Neureichenau leicht abnimmt. Beim Durchmesser ist ein deutlicher Anstieg auf der Fläche Neureichenau vorhanden.

(Nr. 15) Rycerka II (Abb. 3.96)

Die Herkunft Nr. 15 (Rycerka II) ist nur auf wenigen Flächen angebaut. Dennoch hat sie in den letzten beiden Messperioden konstante Höhenzuwächse und auf der Fläche in Neureichenau einen stärkeren Dickenzuwachs als in Dassel.

(13) Zwardon

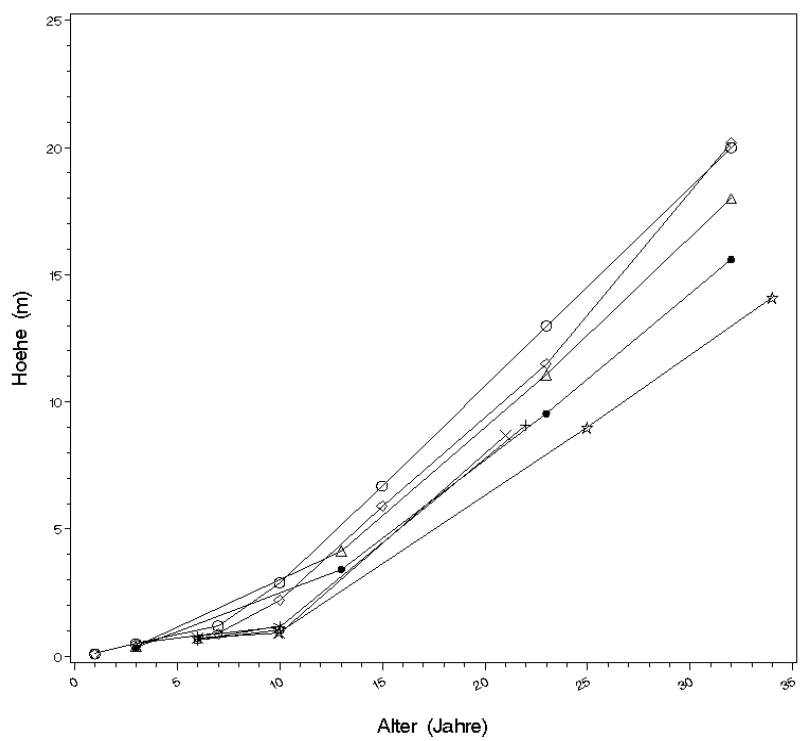

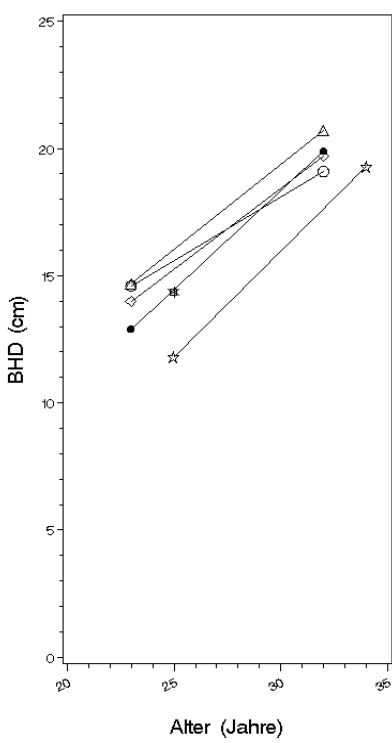

Abb. 3.94: Höhen-und Durchmesserwachstum der Herkunft Nr.13 (Zwardon) 
(14) Rycerka I
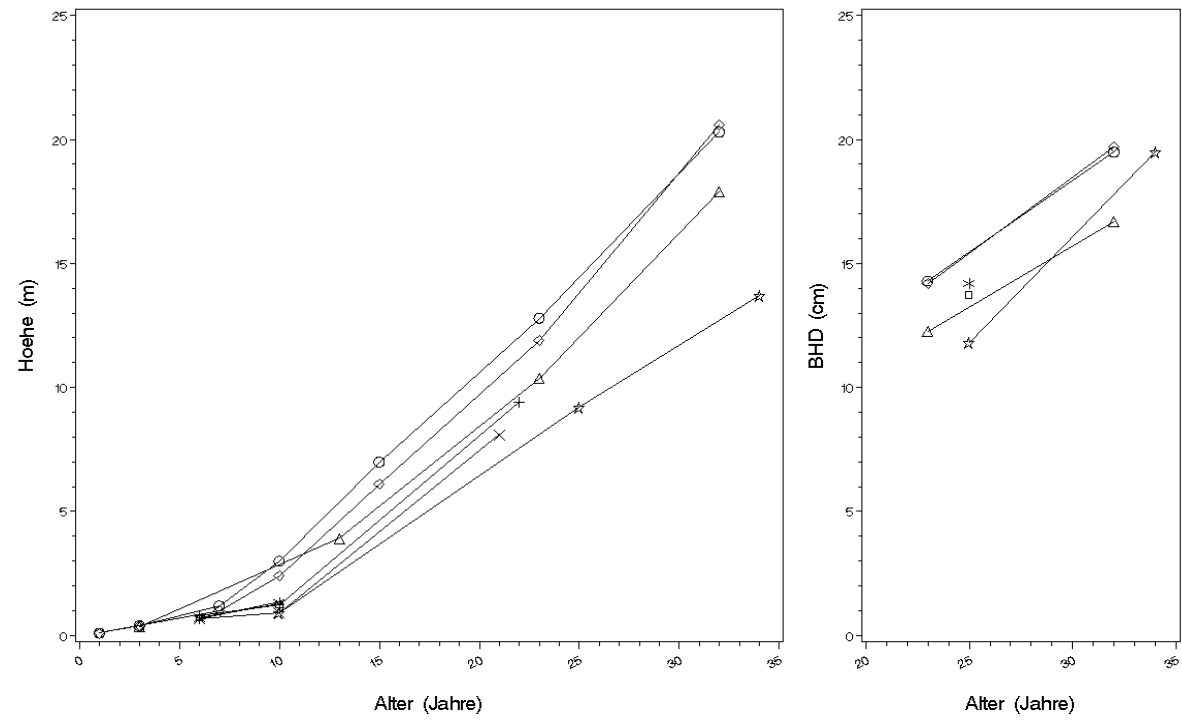

Abb. 3.95: Höhen- und Durchmesserwachstum der Herkunft Nr. 14 (Rycerka I)

(5) Rycerka II

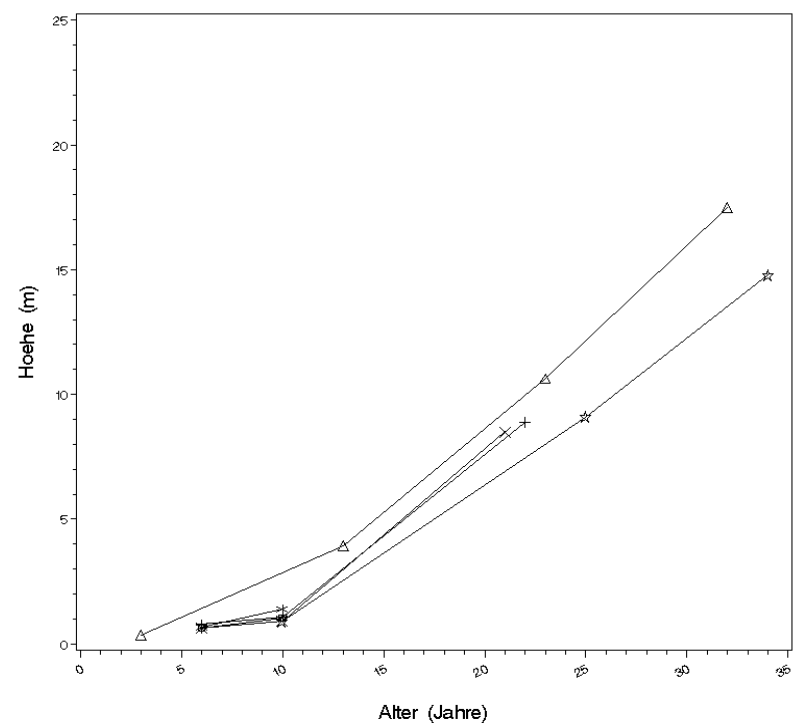

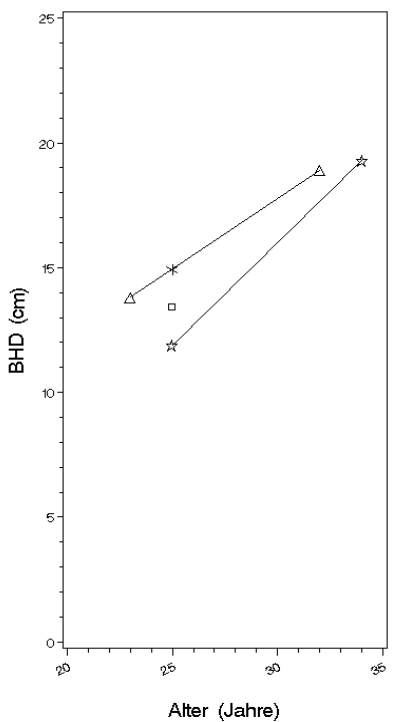

Alter (Jahre)

Abb. 3.96: Höhen-und Durchmesserwachstum der Herkunft Nr. 15 (Rycerka II) 
(16) Orawa

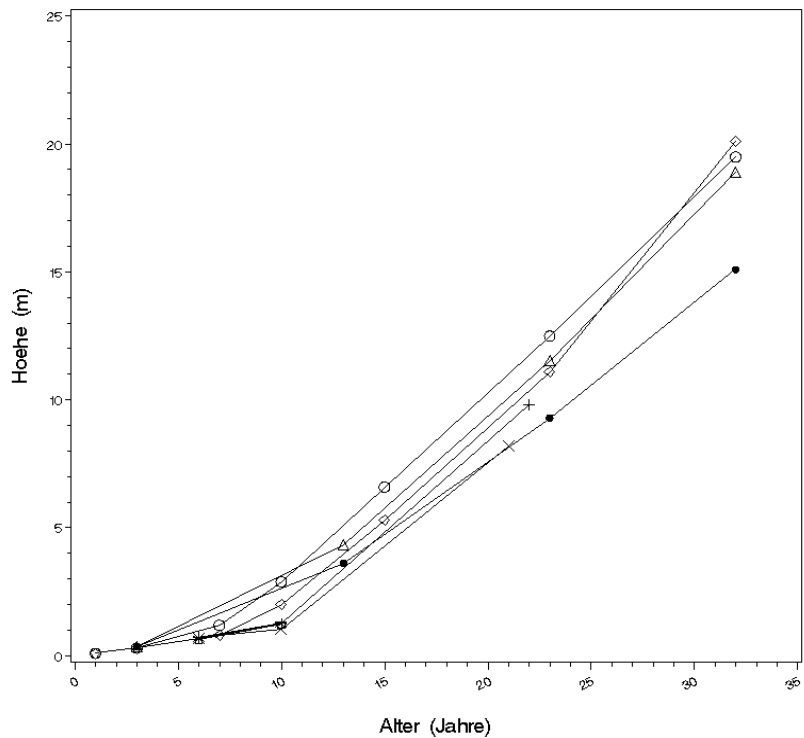

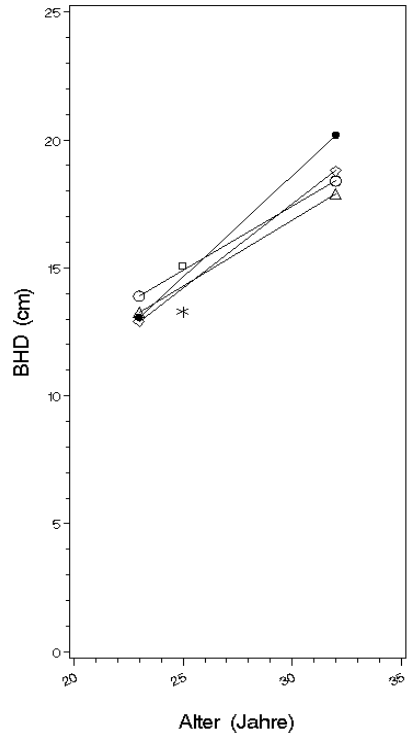

Abb. 3.97: Höhen- und Durchmesserwachstum der Herkunft Nr. 16 (Orawa)

(Nr. 16) Orawa (Abb. 3.97)

Die Höhenwachstumskurven der Herkunft Nr. 16 (Orawa) liegen eng beisammen, lediglich die der Fläche Seesen ist leicht abgesetzt darunter. Der Durchmesserzuwachs ist auf der höher gelegenen Fläche Seesen dagegen besser als auf den übrigen Flächen.

(Nr. 17) Witów (Abb. 3.98)

Die insgesamt mattwüchsige Herkunft Nr. 17 (Witów) zeigt im Vergleich zum Standard ein im Höhen- und Durchmesserwachstum unterdurchschnittliches Wachstum. Die Herkunft, die aus $1420 \mathrm{~m}$ ü. NN stammt, ist leider nicht auf den höher gelegenen Versuchsflächen Neureichenau und Seesen vorhanden. Allein bei ihr liegt die Fläche Reinhardshagen bei der Höhe unterhalb der Spitze.

(Nr. 18) Tarnawa (Abb. 3.99)

Die Höhenwachstumskurven der Herkunft Nr. 18 (Tarnawa) liegen relativ eng beisammen, lediglich die der Fläche Neureichenau ist abgesetzt darunter. Der Durchmesserzuwachs ist auf der höher gelegenen Fläche Neureichenau dagegen deutlich besser als auf den anderen Flächen. 
(17) Witow
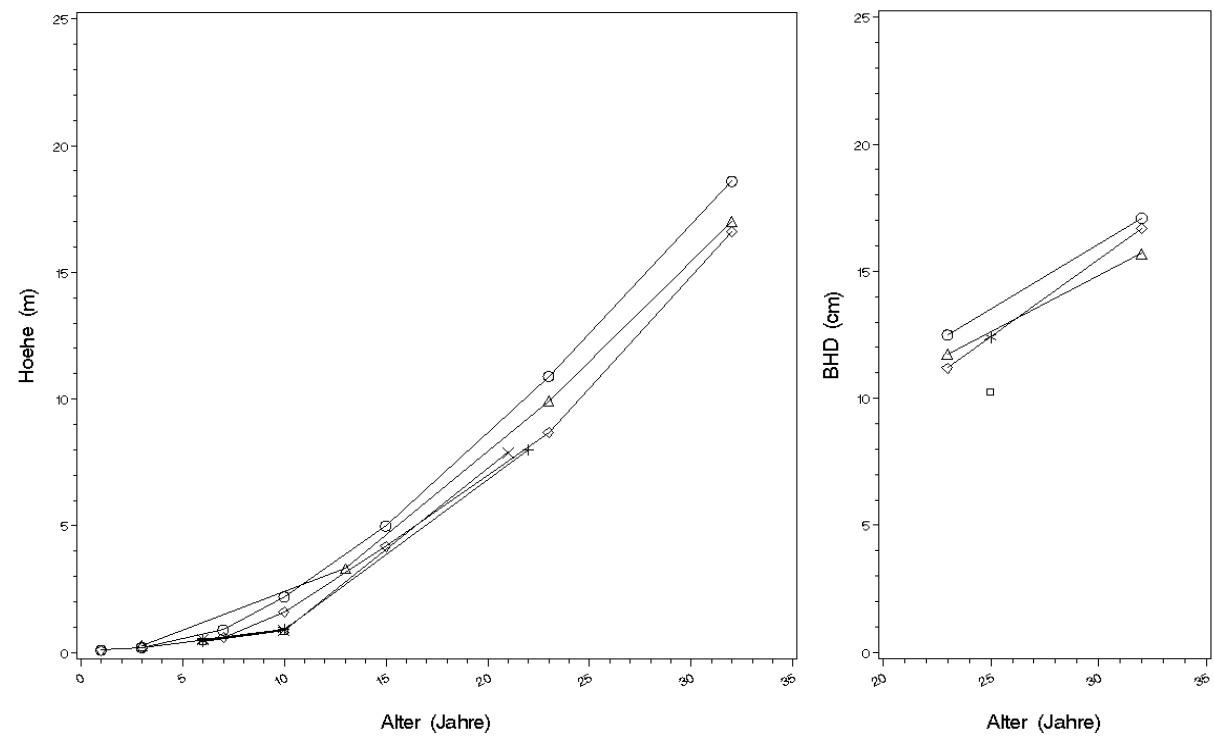

Abb. 3.98: Höhen- und Durchmesserwachstum der Herkunft Nr. 17 (Witów)

(18) Tarnawa

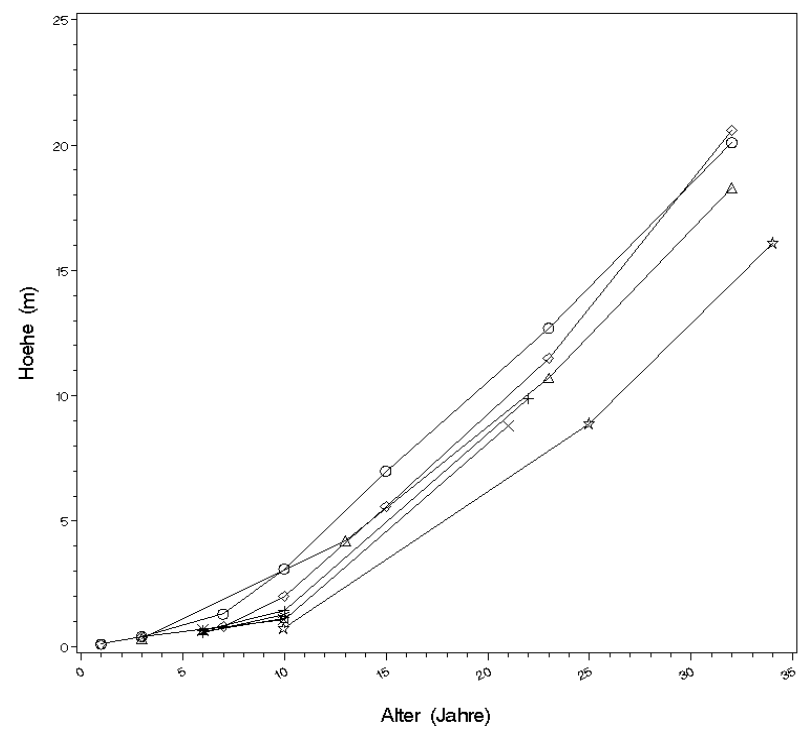

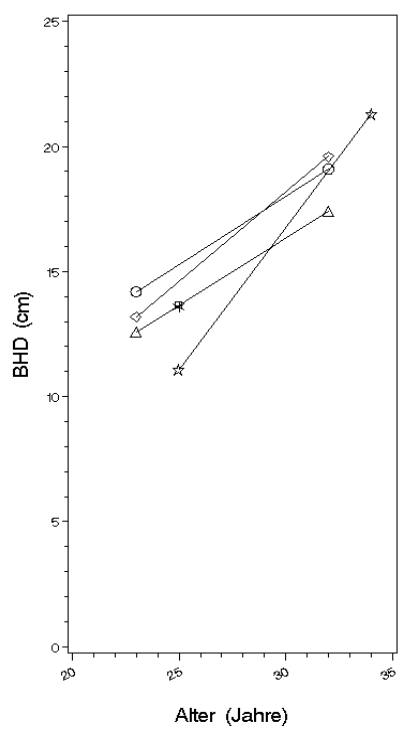

Alter (Jahre)

Abb. 3.99: Höhen-und Durchmesserwachstum der Herkunft Nr. 18 (Tarnawa) 
(Nr.19) Lubelski (Abb. 3.100)

Bei der Herkunft Nr. 19 (Lubelski) sind die Höhenwachstumskurven relativ weit gefächert, d. h. das der Höhenwuchs stärker als bei anderen Herkünften von den jeweiligen Standortbedingungen abhängt. Wie bei der Herkunft Nr. 18 (Tarnawa) ist beim Durchmesserwachstum ein deutlicher Anstieg auf der Fläche Neureichenau erkennbar. Aber auch auf der Fläche Reinhardshagen ist ein vergleichsweise besserer Dickenzuwachs festzustellen.

(Nr. 20) Blisyn (Abb. 3.101)

Anders als die anderen Herkünfte ist die Herkunft Nr. 20 (Blizyn) nicht auf den tiefer gelegenen Flächen in Hessen angebaut. Beim Durchmesserzuwachs tritt ein Anstieg auf der Fläche Neureichenau auf.

(Nr. 21) Kartusy (Abb. 3.102)

Die Höhenzuwächse dieser Herkunft Nr. 21 sind mit Ausnahme der Fläche Reinhardshagen auf den anderen Flächen annähernd gleich. Auffallend hoch sind die Durchmesserzuwächse auf mehreren Versuchsflächen dieser nicht autochthonen Herkunft aus dem Baltischen Raum.

(19) Lubelski

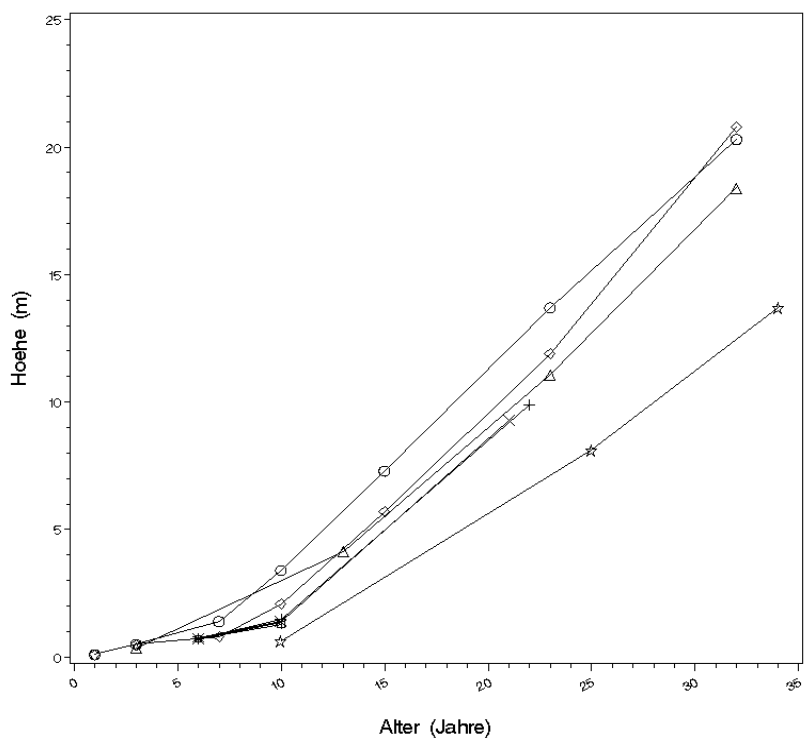

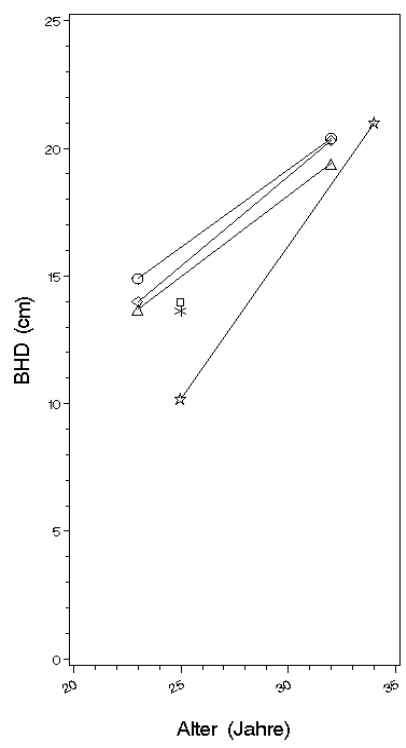

Abb. 3.100: Höhen-und Durchmesserwachstum der Herkunft Nr. 19 (Lubelski) 
(20) Blizyn
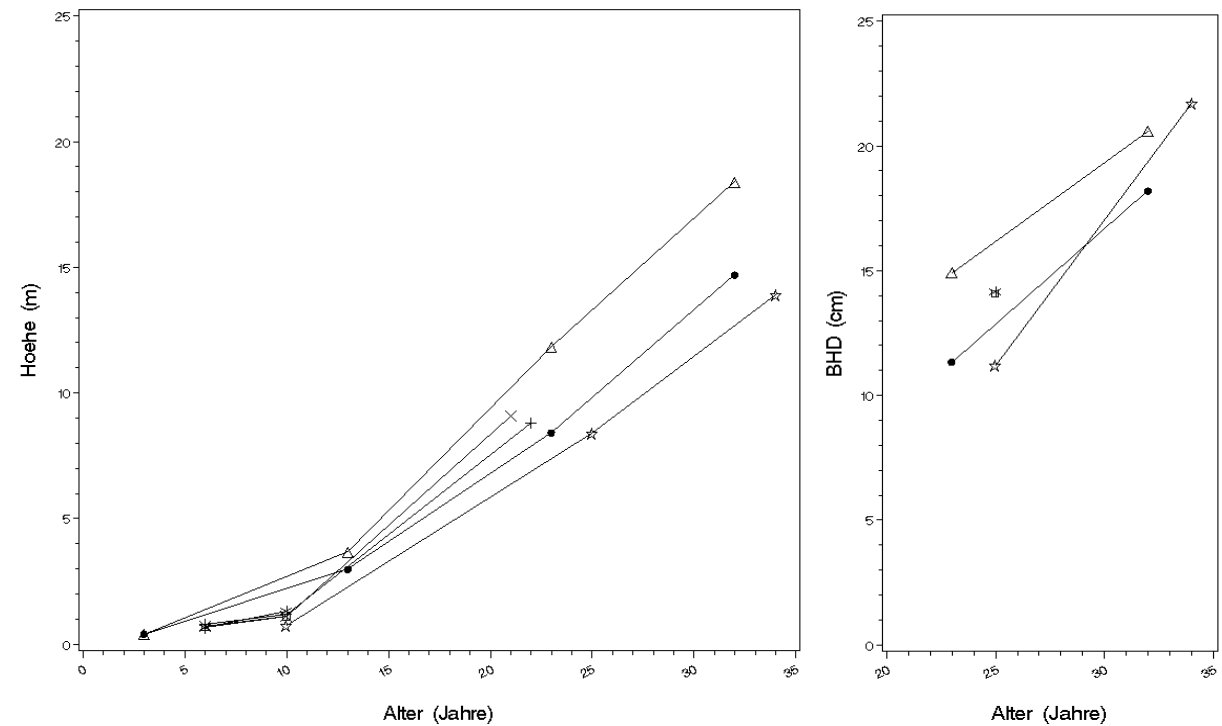

Abb. 3.101: Höhen-und Durchmesserwachstum der Herkunft Nr. 20 (Blizyn)

(21) Kartuzy

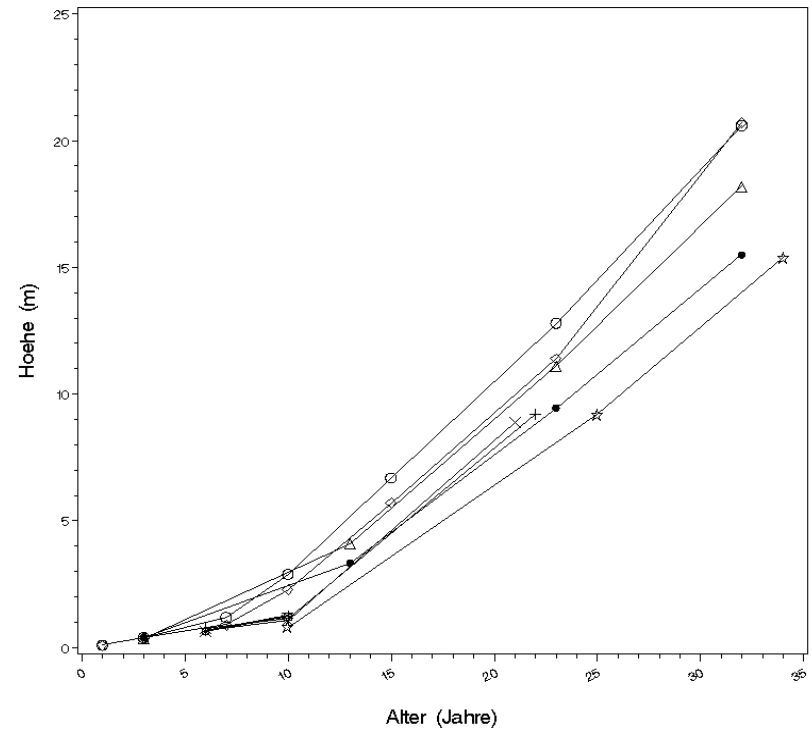

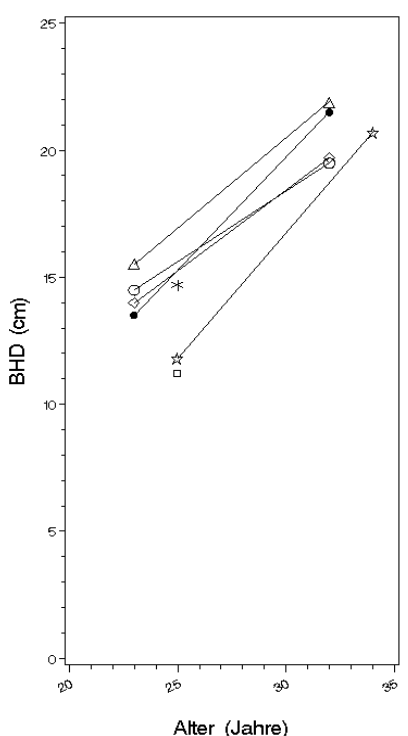

Alter (Jahre)

Abb. 3.102: Höhen- und Durchmesserwachstum der Herkunft Nr. 21 (Kartusy)

Beiträge aus der NW-FVA, Band 5, 2010 


\subsubsection{Einzelbaumvolumen und Vorrat}

\section{Einzelbaumvolumen}

Die varianzanalytische Untersuchung des mittleren Einzelbaumvolumens pro Parzelle für 14 gemeinsame Herkünfte auf den vier Versuchsflächen Reinhardshagen, Wanfried, Dassel und Neureichenau (nur die Parzellen der Wiederholung 1, 3 und 5, damit die gleiche Anzahl an Wiederholungen in das Modell eingeht) ergibt einen signifikanten Einfluss von Versuchsfläche und Herkunft $\left(\mathrm{r}^{2}=0,47\right)$. Interaktionen zwischen Versuchsfläche und Herkunft liegen nicht vor. Mit der Varianzkomponentenschätzung lässt sich der Anteil der Komponente der Versuchsfläche mit 8,3\% und der der Herkunft mit 9,6\% quantifizieren. Die verbleibenden $82,1 \%$ werden vom Modell nicht erklärt.

Dieses Ergebnis stimmt mit dem des BHD-Wachstums erwartungsgemäß überein. Die Einzelbaumvolumina hängen stark vom Durchmesser ab, da dieser als Quadrat in die Berechnung eingeht und der überwiegende Teil der Höhen über den BHD hergeleitet worden ist.

Der multiple Mittelwertvergleich (Tukey-Test, $\alpha=0,05$ ) weist zwei sich überlappende Gruppen aus, in denen sich die volumenreichen Bäume der Fläche Reinhardshagen von den volumenarmen der Fläche Neureichenau unterscheiden. Auch für die 14 gemeinsamen Herkünfte führt der Tukey-Test zu zwei sich überlappenden Gruppen. Hier unterscheiden sich die volumenreichen Bäume der Herkunft Nr. 10 (Wisła) von den volumenarmen der Herkunft Nr. 5 (Borki).

Wird die Varianzanalyse über die sieben gemeinsamen Herkünfte unter zusätzlicher Berücksichtigung der Fläche Seesen durchgeführt, weist der Tukey-Test $(\alpha=0,05)$ ebenfalls zwei sich überlappende Gruppen aus. Die Fläche Seesen liegt im Überlappungsbereich. Am Anteil der Varianzkomponenten treten keine nennenswerten Änderungen auf, und zwischen den sieben Herkünften gibt es keine Unterschiede.

\section{Vorrat pro Hektar}

Wie bei den Wachstumsmerkmalen basieren auch beim Vorrat pro Hektar die Berechnungen auf unterschiedlichen Pflanzenaltern. Für die jeweils jüngste Aufnahme einer Fläche sind die berechneten Vorräte in Abbildung 3.103 absolut und in Abbildung $3.104 \mathrm{im}$ Verhältnis zum jeweiligen Versuchsflächenmittel dargestellt. Aus Abbildung 3.103 wird der Einfluss der Versuchsfläche deutlich, während der Einfluss der Herkunft (Abb. 3.104) deutlich geringer ist, wie auch die im Folgenden beschriebene Varianzkomponentenschätzung bestätigt. 


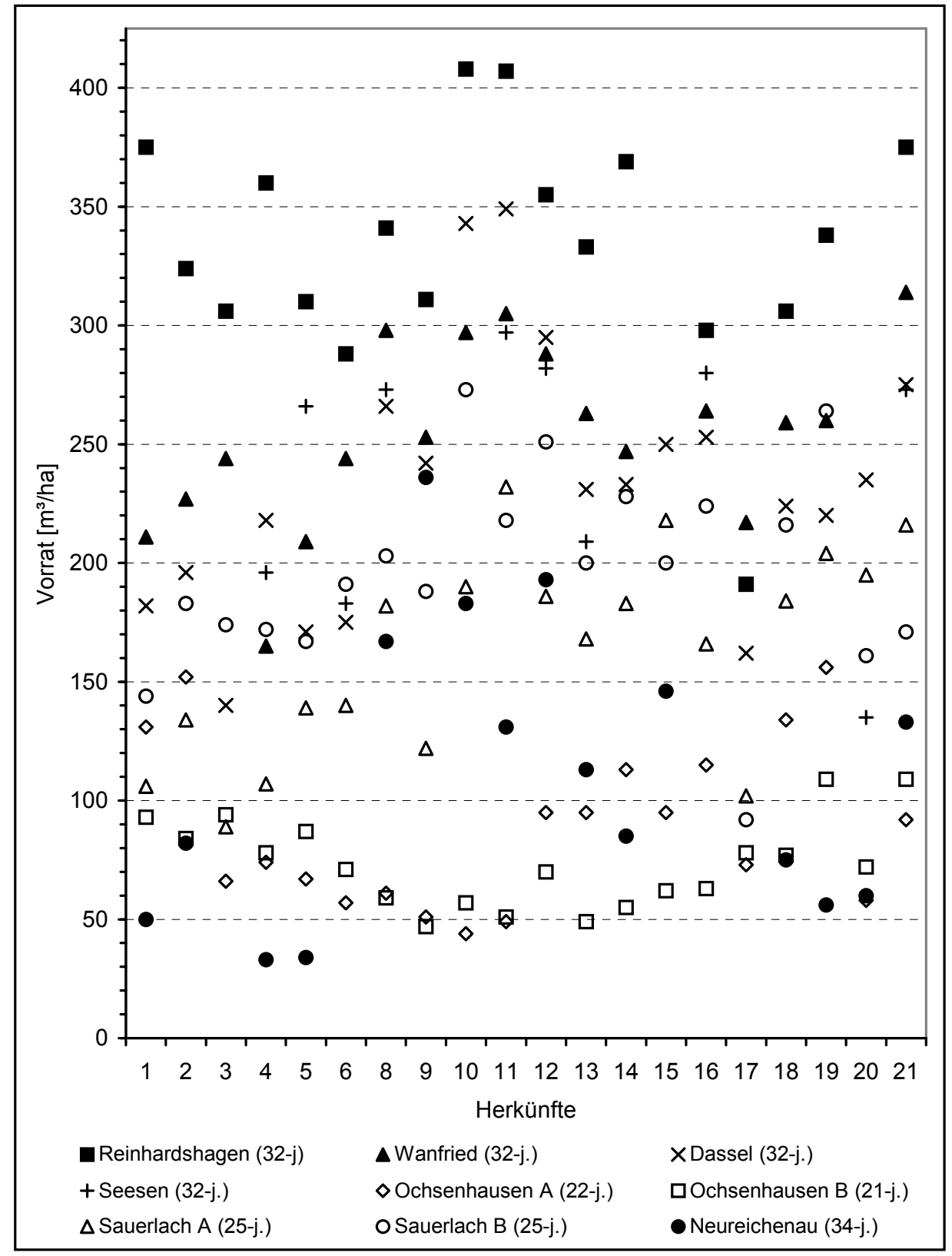

Abb. 3.103: Vorrat pro Hektar (absolut) auf den neun Versuchsflächen berechnet auf der Grundlage der jeweils jüngsten Außenaufnabme 


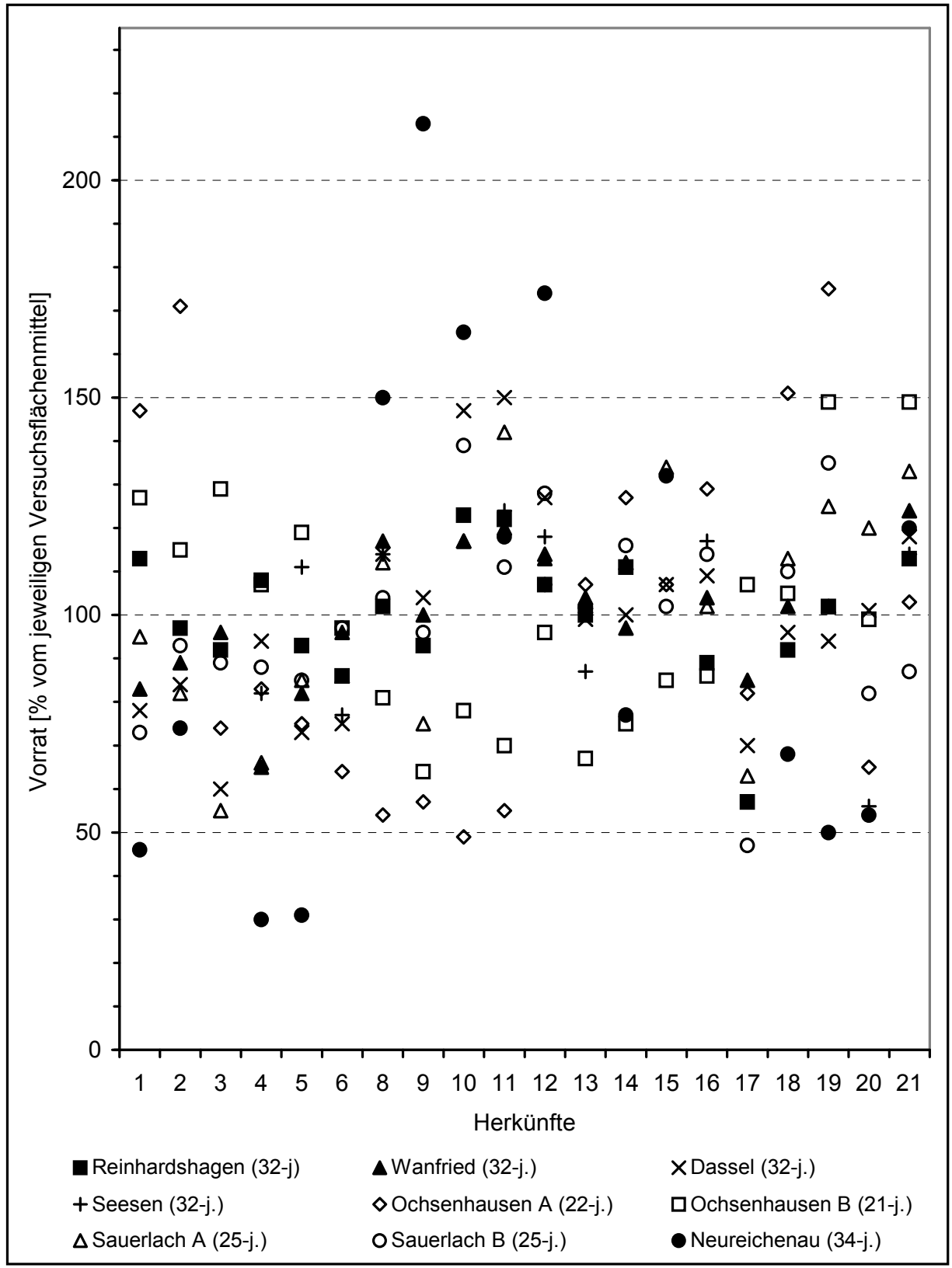

Abb. 3.104: Vorrat pro Hektar (relativ) auf den neun Versuchsflächen berechnet auf der Grundlage der jeweils jüngsten Außenaufnahme 
Die Produkt-Momenten-Korrelationen des auf den Hektar hochgerechneten Vorrats von den neun Versuchsflächen ergeben einen signifikanten Zusammenhang zwischen der Fläche Dassel (NI) und den beiden Flächen Reinhardshagen und Wanfried in Hessen (Tab. 3.41). Außerdem gibt es einen Zusammenhang zwischen den Flächen Dassel (NI) und Wanfried (HE) einerseits und den Flächen Sauerlach A und B sowie Neureichenau andererseits. Einen weiteren Zusammenhang gibt es zwischen der Fläche Reinhardshagen und den Flächen Sauerlach A und B. Bemerkenswert ist auch der Zusammenhang zwischen den Flächen Sauerlach A und B; hier ist somit im Alter von 25 Jahren kein Unterschied zwischen den Herkünften bezüglich eines Einflusses des Erlen-Voranbaus mehr feststellbar.

Tab. 3.41: Produkt-Momenten-Korrelationsmatrix des hochgerechneten Vorrats pro Hektar von neun Versuchsflächen $(a=0,05)$

\begin{tabular}{|c|c|c|c|c|c|c|c|c|c|}
\hline $\begin{array}{l}\text { Versuchs- } \\
\text { fläche } \\
\text { (Alter) }\end{array}$ & $\begin{array}{l}\text { Rein- } \\
\text { hards- } \\
\text { hagen } \\
(32-\mathrm{j} .)\end{array}$ & $\begin{array}{l}\text { Wan- } \\
\text { fried } \\
(32-j .)\end{array}$ & $\begin{array}{c}\text { Dassel } \\
(32-\mathrm{j} .)\end{array}$ & $\begin{array}{c}\text { Seesen } \\
(32-\mathrm{j} .)\end{array}$ & $\begin{array}{c}\text { Ochsen- } \\
\text { hausen A } \\
\quad(22-\mathrm{j} .)\end{array}$ & $\begin{array}{c}\text { Ochsen- } \\
\text { hausen B } \\
(21-j .)\end{array}$ & $\begin{array}{c}\text { Sauer- } \\
\text { lach A } \\
(25-j .)\end{array}$ & $\begin{array}{l}\text { Sauer- } \\
\text { lach B } \\
(25-j .)\end{array}$ & $\begin{array}{c}\text { Neurei- } \\
\text { chenau } \\
\text { (34-j.) }\end{array}$ \\
\hline $\begin{array}{l}\text { Reinhards- } \\
\text { hagen (32-j.) }\end{array}$ & - & $\begin{array}{c}0,391 \\
(\mathrm{n}=18)\end{array}$ & $\begin{array}{c}0,677^{*} \\
(\mathrm{n}=18 \\
)\end{array}$ & $\begin{array}{l}0,413 \\
(\mathrm{n}=9)\end{array}$ & $\begin{array}{c}-0,025 \\
(\mathrm{n}=18)\end{array}$ & $\begin{array}{c}-0,107 \\
(\mathrm{n}=18)\end{array}$ & $\begin{array}{c}0,544^{*} \\
(\mathrm{n}=18)\end{array}$ & $\begin{array}{c}0,568^{*} \\
(\mathrm{n}=18)\end{array}$ & $\begin{array}{c}0,148 \\
(\mathrm{n}=14)\end{array}$ \\
\hline $\begin{array}{l}\text { Wanfried } \\
(32-j .)\end{array}$ & & - & $\begin{array}{c}0,733^{*} \\
(\mathrm{n}=18 \\
)\end{array}$ & $\begin{array}{c}0,631 \\
(\mathrm{n}=9)\end{array}$ & $\begin{array}{c}-0,171 \\
(\mathrm{n}=18)\end{array}$ & $\begin{array}{c}-0,226 \\
(\mathrm{n}=18)\end{array}$ & $\begin{array}{c}0,798^{*} \\
(\mathrm{n}=18)\end{array}$ & $\begin{array}{c}0,551^{*} \\
(\mathrm{n}=18)\end{array}$ & $\begin{array}{c}0,678^{*} \\
(\mathrm{n}=14)\end{array}$ \\
\hline $\begin{array}{l}\text { Dassel } \\
(32-j .)\end{array}$ & & & - & $\begin{array}{c}0,561 \\
(\mathrm{n}=10 \\
)^{2}\end{array}$ & $\begin{array}{c}-0,242 \\
(n=20)\end{array}$ & $\begin{array}{l}-0,464^{*} \\
(\mathrm{n}=20)\end{array}$ & $\begin{array}{c}0,754^{*} \\
(\mathrm{n}=20)\end{array}$ & $\begin{array}{c}0,630^{*} \\
(\mathrm{n}=20)\end{array}$ & $\begin{array}{l}0,660^{*} \\
(\mathrm{n}=16)\end{array}$ \\
\hline $\begin{array}{l}\text { Seesen } \\
(32-j .)\end{array}$ & & & & - & $\begin{array}{c}0,292 \\
(\mathrm{n}=10)\end{array}$ & $\begin{array}{c}0,005 \\
(\mathrm{n}=10)\end{array}$ & $\begin{array}{c}0,385 \\
(\mathrm{n}=10)\end{array}$ & $\begin{array}{c}0,576 \\
(\mathrm{n}=10)\end{array}$ & $\begin{array}{c}0,593 \\
(\mathrm{n}=8)\end{array}$ \\
\hline $\begin{array}{l}\text { Ochsenhau- } \\
\text { sen A (22-j.) }\end{array}$ & & & & & - & $\begin{array}{c}0,444 \\
(\mathrm{n}=20)\end{array}$ & $\begin{array}{c}0,054 \\
(n=20)\end{array}$ & $\begin{array}{c}0,159 \\
(\mathrm{n}=20)\end{array}$ & $\begin{array}{c}-0,451 \\
(\mathrm{n}=16)\end{array}$ \\
\hline $\begin{array}{l}\text { Ochsenhau- } \\
\text { sen B (21-j.) }\end{array}$ & & & & & & - & $\begin{array}{c}-0,184 \\
(\mathrm{n}=20)\end{array}$ & $\begin{array}{c}-0,254 \\
(n=20)\end{array}$ & $\begin{array}{l}-0,545^{*} \\
(\mathrm{n}=16)\end{array}$ \\
\hline $\begin{array}{l}\text { Sauerlach A } \\
(25-\mathrm{j} .)\end{array}$ & & & & & & & - & $\begin{array}{c}0,596^{*} \\
(\mathrm{n}=20)\end{array}$ & $\begin{array}{c}0,264 \\
(\mathrm{n}=16)\end{array}$ \\
\hline $\begin{array}{l}\text { Sauerlach B } \\
(25-\mathrm{j} .)\end{array}$ & & & & & & & & - & $\begin{array}{c}0,397 \\
(\mathrm{n}=16)\end{array}$ \\
\hline $\begin{array}{l}\text { Neureiche- } \\
\text { nau (34-j.) }\end{array}$ & & & & & & & & & - \\
\hline
\end{tabular}

Die mittlere Merkmalsausprägung des Vorrats pro Hektar ist für die vier Versuchsflächen Reinhardshagen, Wanfried, Dassel und Neureichenau (nur die Parzellen der Wiederholung 1, 3 und 5) für 14 gemeinsame Herkünfte varianzanalytisch untersucht worden. Dabei wurde der Einfluss der Versuchsflächen, der Herkünfte sowie der Interaktion von Versuchsfläche und Herkunft berücksichtigt. Das Varianzmodell ist signifikant $\left(\mathrm{r}^{2}=0,83\right)$ und weist einen signifikanten Einfluss der Versuchsflächen und der Herkünfte auf den errechneten Vorrat aus. Mittels 
Varianzkomponentenschätzung lässt sich der Anteil der Komponente der Versuchsfläche auf 69,0 \% und der der Herkunft auf 8,5\% quantifizieren.

Der multiple Mittelwertvergleich (Tukey-Test, $\alpha=0,05)$ weist drei voneinander getrennte Gruppen aus: Gruppe A (Reinhardshagen), Gruppe B (Wanfried, Dassel) und Gruppe C (Neureichenau). Für die Herkünfte ergibt der Test vier sich überlappende Gruppen (Tab. 3.42). Es unterschieden sich die beiden vorratsreichen Herkünfte Nr. 11 (Istebna 149h) und Nr. 10 (Wisła) aus den Karpaten von den beiden vorratsarmen Herkünften Nr. 4 (Przerwanki) und Nr. 5 (Borki) aus den niederen Lagen in Masuren. Auffallend vorratsreich ist die nicht autochthone Herkunft Nr. 21 (Kartuzy), die im Baltischen Gebiet beerntet wurde.

Tab: 3.42: Tukey-Gruppen für den Vorrat pro Hektar von 14 Herkünften auf den vier Versuchsflächen Reinhardshagen, Wanfried, Dassel und Neureichenau

\begin{tabular}{|c|c|c|c|c|c|c|}
\hline $\begin{array}{c}\text { IUFRO } \\
\text { Nr. }\end{array}$ & Herkunft & Region & \multicolumn{4}{|c|}{ Tukey-Gruppe } \\
\hline 11 & Istebna $149 \mathrm{~h}$ & Karpaten & A & & & \\
\hline 10 & Wisła & Karpaten & A & & & \\
\hline 12 & Istebna $115 \mathrm{f}$ & Karpaten & A & B & & \\
\hline 21 & Kartuzy & Balt. Gebiet (nicht autochthon) & A & B & & \\
\hline 8 & Miedzygórze & Sudeten & A & B & $\mathrm{C}$ & \\
\hline 9 & Stronie Slaskie & Sudeten & A & B & $\mathrm{C}$ & \\
\hline 14 & Rycerka I & Karpaten & A & B & $\mathrm{C}$ & $\mathrm{D}$ \\
\hline 13 & Zwardon & Karpaten & A & B & $\mathrm{C}$ & $\mathrm{D}$ \\
\hline 19 & Lubelski & Mittelpolnische Hochebene & & B & $\mathrm{C}$ & $\mathrm{D}$ \\
\hline 18 & Tarnawa & Karpaten & & B & $\mathrm{C}$ & $\mathrm{D}$ \\
\hline 2 & Krzyze & Masuren & & B & $\mathrm{C}$ & $\mathrm{D}$ \\
\hline 1 & Pogorzelece & Masuren & & B & $\mathrm{C}$ & $\mathrm{D}$ \\
\hline 4 & Przerwanki & Masuren & & & $\mathrm{C}$ & $\mathrm{D}$ \\
\hline 5 & Borki & Masuren & & & & $\mathrm{D}$ \\
\hline
\end{tabular}

Wird die Varianzanalyse über die sieben gemeinsamen Herkünfte unter zusätzlicher Berücksichtigung der Fläche Seesen durchgeführt, ergibt sich ein ähnliches Ergebnis. Das Varianzmodell $\left(\mathrm{r}^{2}=0,78\right)$ weist einen signifikanten Einfluss der Versuchsflächen und der Herkünfte auf den errechneten Vorrat aus. Der geschätzte Varianzkomponentenanteil der Versuchsfläche auf den Vorrat beträgt 61,9\%, der der Herkunft 11,9\% und der nicht erklärte Rest 26,2\%. Die Wechselwirkungen zwischen Versuchsfläche und Herkunft sind nicht signifikant. 
Der multiple Mittelwertvergleich (Tukey-Test, $\alpha=0,05)$ weist drei voneinander getrennte Gruppe aus: Gruppe A (Reinhardshagen), Gruppe B (Wanfried, Dassel, Seesen) und Gruppe C (Neureichenau). Für die Herkünfte ergibt der Test drei sich überlappende Gruppen (Tab. 3.43). Es unterschieden sich die vorratsreiche Herkunft Nr. 11 (Istebna 149h) aus den Karpaten von den beiden vorratsarmen Herkünften Nr. 4 (Przerwanki) und Nr. 5 (Borki) aus den niederen Lagen in Masuren.

Tab: 3.43: Tukey-Gruppen für den Vorrat pro Hektar von sieben gemeinsamen Herkünften auf den fünf Versuchsflächen Reinhardshagen, W anfried, Dassel, Seesen und Neureichenau

\begin{tabular}{c|l|l|lcl}
\hline $\begin{array}{c}\text { IUFRO- } \\
\text { Nr. }\end{array}$ & Herkunft & Region & \multicolumn{2}{l}{ Tukey-Gruppe } \\
\hline 11 & Istebna 149h & Karpaten & A & & \\
12 & Istebna 115f & Karpaten & A & B & \\
21 & Kartuzy & Balt. Gebiet (nicht autochthon) & A & B & \\
8 & Miedzygórze & Sudeten & A & B & \\
13 & Zwardon & Karpaten & & B & C \\
5 & Borki & Masuren & & & C \\
4 & Przerwanki & Masuren & & C \\
\hline
\end{tabular}




\section{Abschließende Wertung}

Picea abies gehört in Europa zu den wirtschaftlich wichtigsten Nadelbaumarten. In der jüngsten Zeit haben Stürme, zuletzt Kyrill im Januar 2007, zahlreiche Fichtenbestände in Deutschland zerstört. Auch wenn auf den betroffenen Standorten vielleicht falsche Herkünfte verwendet wurden oder Fichte von einigen an sich als Fehlbestockung angesehen wird, und für Fichte geeignete Standorte durch den Klimawandel deutlich abnehmen werden, sind im großen Umfang Standorte vorhanden, auf denen die Fichte auch in Zukunft angebaut werden kann.

Die langen Produktionszeiträume erfordern die Bereitstellung von Vermehrungsgut, aus dem Bestände mit guter Wuchsleistung und hoher Widerstandsfähigkeit gegenüber biotischen und abiotischen Schädigungen sowie günstigen Holzeigenschaften erwachsen können. Die Auslese durch Herkunftswahl ist einer der ersten Züchtungsschritte, die zu einer Erhöhung der Leistungsfähigkeit führen und zugleich mit verhältnismäßig geringen Kosten verbunden sind (GÄRTNER 1980). Bei der Auswahl von Beständen zur Saatguternte aufgrund ihres Erscheinungsbildes erfolgt häufig eine indirekte Standortsbonitierung. Der Einfluss der Umwelt auf den Phänotyp einer Population kann nur durch Feldversuche eingeschätzt werden, was für eine richtige Beurteilung von Herkünften unbedingt erforderlich ist (FRÖHLICH 1966).

Bislang liegen nur wenige Auswertungen von Versuchen im höheren Alter mit einem derartigen Umfang an Prüfgliedern wie in dieser Arbeit vor. Das Wachstum der Herkünfte in den beiden hier analysierten Versuchen variiert auf den Flächen in Deutschland.

Die Ergebnisse beider Versuchsserien zeigen, dass die an den Testorten gegebenen Standortbedingungen den größten Einfluss auf die Ausprägung der untersuchten Merkmale haben. Dennoch kommt der Herkunft eine nicht zu unterschätzende Bedeutung zu. Für den in Einbaumparzellen mit 20- bzw. 25-facher Wiederholung angelegten IUFRO-Fichtenherkunftsversuch von 1964/1968 ergaben Varianzkomponentenschätzungen für das Merkmal BHD im Alter von 29 Jahren einen Einfluss der Herkunft von 10 bis $15 \%$ und der Versuchsfläche von $40 \%$ bis $45 \%$ (LIESEBACH et al. 2001, LIESEBACH 2005). In die Analysen sind 100 Herkünfte von vier Versuchsflächen (drei in Deutschland, eine in Ungarn gelegen) bzw. im Jahr 2005 von fünf Versuchsflächen (eine zusätzliche, in Österreich gelegene Fläche) eingegangen.

Für den Fichtenherkunftsversuch von 1962 konnte im höheren Alter statistisch gesehen keine Herkunft gefunden werden, die unter allen Standortbedingungen gute Wuchsleistungen verspricht. Es zeigte sich aber, dass insbesondere die Höhenlage des Einsammlungsortes auf die Wuchsleistung entscheidenden Einfluss 
hat. In der vorliegenden Auswertung wurde keine Korrektur bezüglich des Breitengrads vorgenommen.

Anders sieht dies bei den mattwüchsigen Herkünften aus. Hier gibt es einige Herkünfte, die durchgehend oder zumindest fast durchgehend schlechten Wuchs auf allen Flächen zeigen; dabei handelt es sich um Hochlagenherkünfte. Selbst auf den beiden Hochlagenflächen in Bayern zeigten diese Herkünfte überwiegend ein bislang unterdurchschnittliches Wachstum. Ein Grund hierfür könnte in der Anzucht der Versuchspflanzen liegen. Der Anzuchtort befand sich in $420 \mathrm{~m}$ Meereshöhe und damit über $800 \mathrm{~m}$ unter den Einsammlungs- und Testorten. Dieser Höhenunterschied kann die Anpassungsfähigkeit der Fichten an die Bedingungen in den Hochlagen bereits verändert haben. Dem Einfluss von unterschiedlicher Höhenlage der Anzuchtorte sollte daher in einem Feldversuch nachgegangen werden.

Für Flächen in Hochlagen ist neben der Wuchsleistung eine höhere Schneebruchstabilität wichtig. Diese wurde auf der Fläche Berchtesgaden / Bayern für Herkünfte aus über $1000 \mathrm{~m}$ ü. NN nachgewiesen. Hochlagenherkünfte haben ihren Kulminationszeitpunkt des Zuwaches unter Umständen deutlich später als Herkünfte aus Tieflagen (DKV 1967).

Im Vergleich der Versuchsflächen des Fichtenherkunftsversuchs von 1962 sind im Kapitel 2.2.3.4 (Höhen- und BHD-Wachstum) mittlere Ränge für die einzelnen Herkünfte gebildet worden. Diese sind für die vier Teilversuche in Tabellen in den Anhängen 1.26 und 1.27 aufgelistet. Bei der Analyse der Tabellen tritt eine Herkunft (114 Winterberg) auf den Teilflächen mit 169 Herkünften auf, die in ihrem Wachstum auf allen vier Teilflächen (Reinhardshagen / Hessen, Hasbruch / Niedersachsen, Sonthofen / Bayern und Münsingen / Baden-Württemberg) im ersten Quartil zu finden ist. Im vierten Quartil, das die mattwüchsigen Herkünfte beinhaltet, finden sich auf den vier Flächen drei Hochlagenherkünfte (über $1100 \mathrm{~m}$ ü. NN) 725 Airolo / CH, 1111 Peisey-Nancroix / F und 1112 Autrans / F sowie aus einem spezifischen Teil des Verbreitungsgebiets die Herkunft 1117 Plan Bois / F (aus $500 \mathrm{~m}$ ü. NN).

Auf den beiden Teilflächen in Hessen (Reinhardshagen) und Niedersachsen (Hasbruch) mit 81 Herkünften sind im ersten Quartil (= gut wüchsige Herkünfte) zwei aus Deutschland (3503 Eibenstock Abt. 214 und 3519 Mechterstädt) und eine aus Polen (6510 Boleslawiec) (Anhänge 1.28 und 1.29). Vier weitere Herkünfte aus Deutschland nehmen ebenfalls einen Rang im ersten Quartil ein. Diese sind aber nur auf einer der beiden Teilversuche angebaut: Es sind dies auf der Fläche Reinhardshagen (Hessen): 3501 Rungstock und 3504 Eibenstock Abt. 233 und auf der Fläche Hasbruch (Niedersachsen): 3323 Mauth / Ost und 3211 Moosburg / Isar. Im mattwüchsigen Quartil gibt es drei Herkünfte, die auf nur einer Versuchsfläche getestet werden. Auf der Fläche Reinhardshagen (Hessen) sind es die deutsche Herkunft 3334 Zwiesel-Ost (Plattenfichten) und die russische Herkunft 7422 
Rjasan und auf der Fläche Hasbruch (Niedersachsen) die deutsche Herkunft 3003 Blumberg.

Auf den drei Teilflächen mit 36 Herkünften in Reinhardshagen (Hessen), Hasbruch (Niedersachsen) und Berchtesgaden (Bayern) gibt es keine Herkunft, die durchgehend entweder im ersten oder im vierten Quartil hinsichtlich ihrer Wuchsleistung anzutreffen ist (Anhänge 1.30 und 1.31). Die nur auf der Fläche Reinhardshagen angebaute Herkunft 113 Walsrode hat einen Rang im ersten Quartil und die Herkunft 7400 Kaluga / SU einen im vierten Quartil.

Es zeigt sich aber auch, dass zwischen räumlich nahe liegenden Populationen größere Unterschiede in der Merkmalsausprägung auftreten. Dies kann seine Ursache darin haben, dass es sich bei den beernteten Beständen nicht mehr um ursprüngliche / autochthone Populationen handelt. Hier können frühere Saatgutverfrachtungen das räumliche Muster bereits beeinflusst haben.

Auch über die Zeit haben die Herkünfte ihre Ränge geändert. Derartige Wechsel beschreibt ebenfalls GÜNZL (1979) für einen von CIESLAR 1899 in Österreich ausgepflanzten Herkunftsversuch mit Fichte.

\subsection{Reinhardshagen / Hessen - zwei Versuche an einem Standort}

Bemerkenswert ist bei der vorliegenden Auswertung, dass in Reinhardshagen / Hessen die Flächen des Fichtenherkunftsversuchs von 1962 und die des IUFRO-Fichtenherkunftsversuchs von 1972 benachbart angelegt worden sind. Mit einigen Abstrichen, das heißt insbesondere aufgrund ungenauer Herkunftsangaben sowie kleinflächigen Standortsunterschieden, ließen sich Ergebnisse aus diesen beiden Versuchen vergleichen.

Es gibt kein Prüfglied, das eindeutig auf beiden Versuchsflächen getestet wird. Die in beiden Versuchen angebauten ähnlichen Herkünfte (Bezeichnungen: D: Westerhof; PL: Wisła, Istebna, Borki, Przerwanki, Białowieża, Zwierzyniec, Witów) unterscheiden sich hinsichtlich ihrer Herkunftsangabe (z. B. Name, Abteilung, Höhenangabe). In der Tabelle 4.1 sind der absolute rechnerische Vorrat je Herkunft und der relative (= bezogen auf das jeweilige Versuchsflächenmittel) der „gemeinsamen“ Herkünfte gegenübergestellt. Einige der Herkünfte weisen einen vergleichbaren relativen Vorrat in den beiden Versuchen auf (z. B. Wisła), andere haben einen Unterschied von 20 Prozentpunkten und mehr (z. B. Borki, Przerwanki). 
Tab.4.1: Gegenüberstellung des rechnerischen Vorrats möglicher, gemeinsamer" Herkünfte auf den benachbarten Flächen der Versuche von 1962 und 1972 in Reinhardshagen / Hessen

\begin{tabular}{|c|c|c|c|c|}
\hline Herkunft (PG-Nr.) & $\begin{array}{c}\text { Versuch } 19 \\
{\left[\mathrm{~m}^{3} / \mathrm{ha}\right]}\end{array}$ & $\begin{array}{l}\text { rrat 39-j. } \\
{[\%]^{*}}\end{array}$ & $\begin{array}{c}\text { Versuch } 1 \\
{\left[\mathrm{~m}^{3} / \mathrm{ha}\right]}\end{array}$ & $\begin{array}{l}\text { rrat 32-j. } \\
{[\%]^{*}}\end{array}$ \\
\hline Westerhof (115) & 559 & 128 & & \\
\hline Westerhof, 51b (3404) & 462 & 105 & & \\
\hline Westerhof, 48a (26) & & & 360 & 105 \\
\hline Istebna-Wisła (124) & 526 & 120 & & \\
\hline Istebna-Wisła (202) & 534 & 122 & & \\
\hline Wisła, Malinka (10) & & & 408 & 119 \\
\hline Istebna (208) & 542 & 124 & & \\
\hline Istebna $149 \mathrm{~h}$ (11) & & & 407 & 119 \\
\hline Istebna 115f (12) & & & 355 & 104 \\
\hline Borki Knieja (6222) & 491 & 112 & & \\
\hline Borki, Sarnianka (5) & & & 310 & 90 \\
\hline Przerwanki (6223) & 352 & 80 & & \\
\hline Przerwanki (4) & & & 360 & 105 \\
\hline Białowieża (6234) & 373 & 85 & & \\
\hline Białowieża (6236) & 296 & 68 & & \\
\hline Biał., Pogorzelece (1) & & & 375 & 109 \\
\hline Biał., Krzyze (2) & & & 324 & 95 \\
\hline Zwierzyniec (6235) & 354 & 81 & & \\
\hline Zwierzyniec (19) & & & 338 & 99 \\
\hline Witów (6894) & 391 & 68 & & \\
\hline Witów (17) & & & 191 & 56 \\
\hline Mittel & 438,2 & 100 & 342,8 & 100 \\
\hline
\end{tabular}

* Anteil im Vergleich zum Versuchsflächenmittel

Selbst wenn die Herkünfte aus demselben Bestand stammten, könnte Art und Zeitpunkt der Einsammlung, die für die beiden Versuche getrennt erfolgte, einen Einfluss auch die Merkmalsausprägung haben.

\subsection{Einflussfaktor Ernte}

Auf den beiden Versuchsflächen Sauerlach A und B / Bayern des IUFRO-Fichtenherkunftsversuchs von 1972 ist das Prüfglied Klingenbrunn jeweils aus Saatgut zweier Beerntungen vertreten. Zwischen den Nachkommen der beiden Beern- 
tungen sind Unterschiede insbesondere in der Anzahl der noch vorhandenen Pflanzen und dadurch im rechnerischen Bestandesvorrat im Alter von 25 Jahren aufgetreten. Auch der Fichtenherkunftsversuch von 1962 hat einige Prüfglieder, die aus unterschiedlichen Erntejahren stammen können und sich in ihrer Merkmalsausprägung unterscheiden.

Für die Anlage eines Versuches wird entweder eigens eine Beerntung der gewünschten Bestände vorgenommen oder es wird auf Saatgut aus routinemäßigen Beerntungen zurückgegriffen. In beiden Fällen handelt es sich um eine Teilmenge der gesamten Samenmenge eines Bestandes, deren genetische Zusammensetzung von zahlreichen Faktoren beeinflusst wird. Deshalb können sich Saatgutpartien aus derselben Population von Jahr zu Jahr in ihrer genetischen Struktur und die daraus angezogenen Pflanzen in ihrer Merkmalsausprägung mehr oder weniger stark unterscheiden. Außerdem wird die genetische Struktur einzelner Saatgutpartien einer Ernte beeinflusst, wenn eine mangelnde Durchmischung der Gesamtprobe vorliegt. Auch das Ausmaß der genetischen Variation innerhalb der einzelnen Bestände unterliegt starken Schwankungen.

Am Bayerischen Amt für Saat- und Pflanzenzucht, Teisendorf, sind in einer Genbank eingelagerte Saatgutpartien aus dem gleichen Fichtenbestand (Zwiesel) aus vier Erntejahren auf ihre genetische Struktur hin untersucht worden (KONNERT und BEHM 1999). Die Ergebnisse der Isoenzym-Analysen zeigen qualitative Unterschiede in der Gesamtanzahl der Allele, wobei es sich überwiegend um seltene Varianten handelt, die mit Häufigkeiten von unter 5\% auftreten. Die Autoren schließen nicht aus, dass ein Teil der Unterschiede stichprobenbedingt ist. In dem festgestellten Ausmaß sind sie jedoch ein Hinweis auf eine unterschiedliche genetische Struktur des Saatguts der vier Jahrgänge.

In den einzelnen Erntejahren können unterschiedliche Blüh- und Befruchtungsverhältnisse vorgelegen haben, was Einfluss auf die reproduktionseffektive Populationsgröße haben kann. Weiterhin können die Bestandesdichte und die Witterungsverhältnisse die Zusammensetzung einer Erntepartie beeinflussen. Die Samenmenge der einzelnen Bäume eines Bestandes variiert daher von Jahr zu Jahr erheblich. Weitere Gründe für die unterschiedliche genetische Zusammensetzung stehen direkt mit der Samenernte in Zusammenhang. In den einzelnen Erntejahren werden nicht immer die gleichen Altbäume beerntet. Entscheidend sind weiterhin der Erntezeitpunkt, die Anzahl der beernteten Bäume und deren Verteilung im Bestand sowie die pro Baum geerntete Samenmenge. Eine zusammenfassende Darstellung findet sich z. B. in MÜLLER-STARCK (1996). Durch die Lagerung des Saatgutes über mehrere Jahre lässt zudem die Keimkraft geringfügig nach (GÜNTHER 1987, SCHUBERT 1999).

Weil die die genetische Zusammensetzung beeinflussenden Faktoren variieren, besteht die Gefahr, dass genetische Information schon allein aufgrund von Zufallseffekten (genetische Drift) verloren geht, wenn in einem Bestand nur wenige Bäume beerntet werden. Bei der Fichte, einer Baumart mit vielen seltenen Allelen, 
müssen z. B. mehr Bäume als bei der Weiß-Tanne beerntet werden, um den Verlust an Genvarianten möglichst gering zu halten (KONNERT und BEHM 1999).

Beim Vergleich der Nachkommenschaften der Einzelbaumabsaaten und der Herkunftsabsaaten im IUFRO-Fichtenherkunftsversuch von 1972 zeigt sich, dass der Variationskoeffizient der Herkunftsabsaaten erwartungsgemäß größer ist als der von Einzelbaumnachkommenschaften. In Polen werden in qualitativ hochwertigen Beständen zahlreiche Plus-Bäume ausgewiesen (SZOZDA und SABOR 1998). Es könnte daher sein, dass es sich bei den auf den Flächen in Niedersachsen angebauten Einzelbaumnachkommenschaften um Absaaten dieser Plus-Bäume handelt. Der Vergleich der Herkunftsabsaaten und der nach Herkunftszugehörigkeit zusammengefassten Einzelbaumnachkommenschaften zeigt, dass in einigen Fällen die Herkünfte einen rechnerisch höheren oder auch geringeren Bestandesvorrat auswiesen (vgl. Abb. 3.37) als die zu Herkünften zusammengefassten Einzelbaumnachkommenschaften. Diese Unterschiede lassen sich dadurch erklären, dass durch die Anzahl der beernteten Fichten und durch die Beerntung verschiedener Bäume Unterschiede auftreten. Dies kann u. a. auch die Unterschiede in den Ergebnissen beim Vergleich ähnlicher Herkünfte der Versuchsserien 1962 und 1972 erklären.

In den Versuchsserien ist nicht bekannt, ob und mit welchem Anteil die Einzelbaumabsaaten in den Herkünften enthalten sind. Wenn jedoch angenommen wird, dass die Einzelbaumabsaaten in den Herkünften enthalten sind, bedeutet dies, dass mit einer größeren Anzahl beernteter Plus-Bäume ein höherer Bestandesvorrat erzielt werden könnte.

Die mit Abstand mattwüchsigste Herkunft Witów ist sowohl im Fichtenherkunftsversuch von 1962 als auch 1972 vertreten. In Ersterem zeigt die Herkunft, deren Saatgut zumindest aus einem anderen Erntejahr stammt und womöglich auch in einem anderen Bestand geerntet wurde, ein abweichendes Wuchsverhalten. Auf der Fläche Reinhardshagen / Hessen gehört sie zu den Herkünften, die im BHD im Alter 32 und im Höhenwuchs im Alter 39 signifikant besser sind als andere Herkünfte. Auf der Fläche Hasbruch / Niedersachsen lässt sich keine signifikante Überlegenheit absichern. Insgesamt ist aber auf beiden Flächen der rechnerische Vorrat pro Hektar im Vergleich zum jeweiligen Versuchsmittel durchschnittlich (Reinhardshagen: 96\%) oder leicht höher (Hasbruch: $114 \%$ ). Die insgesamt bessere Wuchsleistung im Fichtenherkunftsversuch von 1962 im Vergleich zum IUFRO-Fichtenherkunftsversuch von 1972 legt die Vermutung nahe, dass es sich bei den beiden Herkünften Witów um Nachkommen unterschiedlicher Ausgangsbestände handelt.

Zusammenfassend ist festzuhalten, dass in einem Feldversuch der Einfluss unterschiedlicher Erntejahrgänge auf die Merkmalsausprägung untersucht werden sollte. Hierfür eignet sich die Fichte ganz besonders, da die Keimkraft im Laufe der Saatgutlagerung nur wenig nachlässt und damit das Ergebnis kaum beeinflusst. 


\subsection{Standortabhängigkeit am Beispiel der polnischen Herkünfte des}

IUFRO-Fichtenherkunftsversuchs von 1972

In Europa befinden sich insgesamt 21 Flächen dieses Versuchs mit bis zu 20 polnischen Herkünften. Die bisher nicht aufgeführten Flächen sind in Tabelle 4.2 zusammengestellt. Die in Istebna / Polen angelegte Fläche wurde 1981 durch ein Feuer zerstört (MATRAS 2004).

Sind bereits zwischen den Herkünften auf den Versuchsflächen in Deutschland Unterschiede in der Merkmalsausprägung der gemeinsamen Herkünfte aufgetreten, so sind diese noch auffälliger, wenn alle 21 Flächen in Europa in den Vergleich einbezogen werden. Diese Variation ist bereits in den veröffentlichten Ergebnissen früherer Messungen und auf weiteren Versuchsflächen dieser Serie beschrieben worden (z. B. HOLST 1963; GIERTYCH 1976, 1991; HOLUBČIK 1979; MATRAS 1993; BARZDAJN 1995; RAU et al. 1998; KÖNIG 2002, MATRAS 2004).

Um das Höhenwachstum im Alter zwischen 10 und 15 Jahren zu vergleichen, wird für jede Herkunft der jeweilige Rang auf einer Fläche bestimmt. Für höhere Alter liegen nur teilweise Messungen vor. Die Herkunft mit dem besten Höhenwuchs erhält den Rang 1. Die Herkunft mit dem geringsten Höhenwuchs hat die jeweils höchste Zahl, die der Anzahl der Herkünfte auf einer Fläche entspricht. Anschließend wird ein mittlerer Rang für jede Herkunft über alle Flächen gebildet. Von den mattwüchsigeren Herkünften waren bei der Anlage nicht ausreichend Pflanzen für alle Flächen verfügbar. Diese Prüfglieder werden bei der gewählten Methode nicht überbewertet. 
Tab.4.2: $\quad$ Ausgewäblte Daten zur Charakterisierung von elf weiteren und nicht in Tab. 3.6 aufgeführten, in Europa gelegenen Flächen des IUFRO-Fichtenherkunftsversuchs von 1972

\begin{tabular}{c|l|c|c|c|c|c|c}
\hline Land & Versuchsfläche & $\begin{array}{c}\text { geogr. } \\
\text { Länge } \\
\text { N }\end{array}$ & $\begin{array}{c}\text { geogr. } \\
\text { Breite } \\
\text { O }\end{array}$ & $\begin{array}{c}\text { Höhe } \\
\text { ü. NN } \\
{[\mathrm{m}]}\end{array}$ & $\begin{array}{c}\text { Anlage- } \\
\text { jahr }\end{array}$ & PG & $\begin{array}{c}\text { Größe } \\
\text { [ha] }\end{array}$ \\
\hline PL & Knyszyn & $53^{\circ} 20^{\prime}$ & $23^{\circ} 05^{\prime}$ & 150 & 1975 & 20 & 3,75 \\
PL & Istebna & $4^{\circ} 34^{\prime}$ & $18^{\circ} 44^{\prime}$ & 550 & 1976 & 20 & 1,00 \\
PL & Kórnik & $52^{\circ} 15^{\prime}$ & $17^{\circ} 04^{\prime}$ & 70 & 1976 & 20 & 1,09 \\
PL & Siemianice & $51^{\circ} 11^{\prime}$ & $18^{\circ} 07^{\prime}$ & 180 & 1975 & 20 & 3,63 \\
PL & Gluchów & $51^{\circ} 47^{\prime}$ & $20^{\circ} 04^{\prime}$ & 180 & k. A. & 17 & k. A. \\
CS & Veĺka Straž & k. A. & k. A. & 380 & 1977 & 20 & 1,48 \\
CS & Bujakovo & k. A. & k. A. & 650 & 1977 & 20 & 1,48 \\
CS & Parač & k. A. & k. A. & 790 & 1977 & 20 & 1,48 \\
CS & Klobašova & k. A. & k. A. & 1000 & 1977 & 20 & 1,48 \\
B & Hives & $50^{\circ} 09^{\prime}$ & $05^{\circ} 34^{\prime}$ & 390 & 1979 & 17 & 2,41 \\
F & Champenoux & $48^{\circ} 45^{\prime}$ & $06^{\circ} 18^{\prime}$ & 220 & 1976 & 20 & 5,87 \\
\hline
\end{tabular}

k. A. = keine Angabe

$P G=$ Prüfglied

Für jeweils vier Versuchsflächen in Polen (alle außer Istebna) und in der ehemaligen Tschechoslowakischen Republik sowie den beiden Flächen Reinhardshagen und Wanfried in Hessen lagen Messungen zum Höhenwachstum im Alter von 15 Jahren vor. Von den beiden Flächen Dassel und Seesen in Niedersachsen sind es die Werte aus dem Alter 13 und von der Fläche in Frankreich und Belgien im Alter von elf Jahren. Von der Fläche Istebna und sechs weiteren Flächen in Deutschland (Ochsenhausen A und B, Sauerlach A und B, Biburg, Neureichenau) ist das Höhenwachstum im Alter von 10 Jahren in den Vergleich eingegangen.

In Tabelle 4.3 ist aufgelistet, wie häufig eine Herkunft einen Rang auf den 21 Versuchsflächen belegt hat. Auffallend ist die große Spannweite von sieben bis 19 Rängen. Eine Ausnahme bildet die Herkunft Witów (Nr. 17) mit einer Spannweite von sieben Rängen, wobei der Rang 20 allein 13-mal vergeben wurde. Die größte Spannweite tritt bei der Herkunft Wisła (Nr. 10) auf, die auch schon auf den Flächen in Deutschland eine große Standortabhängigkeit zeigte. Anhand dieser Zusammenstellung (Tab. 4.3) kann das Höhenwachstum als stabil geringwüchsig bei der Herkunft Witów (Nr. 17) und stabil gutwüchsig bei der Herkunft Lubelski (Nr. 19) beurteilt werden. Die weiteren Herkünfte zeigen eine mehr oder weniger stark ausgeprägte Standortabhängigkeit. Diese ist zum Beispiel bei den beiden besserwüchsigen Herkünften Istebna 149h (Nr. 11) und Wigry (Nr. 3) geringer ausgeprägt als bei den Herkünften Pogorzelece (Nr. 1) und Przerwanki (Nr. 4). 
Tab.4.3: Häufigkeitsverteilung der von den 20 polnischen Fichtenherkünften auf den 21 europäischen Versuchsflächen belegten Ränge im Höhenwachstum im Alter zwischen 10 und 15 Jabren (PG = Prüfglied bzw. Herkunft)

\begin{tabular}{|c|c|c|c|c|c|c|c|c|c|c|c|c|c|c|c|c|c|c|c|c|}
\hline Rang & & & & & & & & & & & & & & & & & & & & \\
\hline 1 & 4 & & 2 & & & & & & 3 & 3 & 3 & & & & & & & 5 & & \\
\hline 2 & 2 & 2 & 4 & & 2 & & & & & 2 & & 3 & 1 & 1 & & & 1 & 4 & & \\
\hline 3 & 1 & 1 & 4 & 2 & 1 & 1 & 1 & & 1 & 1 & & & 2 & & 2 & & & 2 & 1 & \\
\hline 4 & 1 & 4 & & & 1 & 1 & & & 2 & 2 & 3 & & 2 & & & & 1 & 3 & & 2 \\
\hline 5 & & 2 & & 3 & & & 2 & & & 4 & 1 & 1 & & & 1 & & 1 & 2 & 1 & 1 \\
\hline 6 & 2 & 1 & 1 & 2 & 1 & 1 & & & 1 & & 3 & 3 & 2 & 1 & 1 & & 2 & & 2 & \\
\hline 7 & 1 & & 2 & & & 1 & 1 & & 3 & 1 & & & 2 & 1 & & & 2 & 2 & 2 & \\
\hline 8 & 1 & 2 & & 2 & 4 & 3 & 2 & 2 & 1 & 1 & 2 & 1 & & 1 & 1 & & 1 & & & 1 \\
\hline 9 & & & & 1 & & 1 & 2 & & 1 & & 1 & 2 & & 1 & 1 & & 4 & & 2 & 1 \\
\hline 10 & 1 & 2 & & 1 & 2 & & & 3 & 1 & 3 & & 1 & 3 & & 1 & & & & 1 & 5 \\
\hline 11 & 1 & 2 & 1 & 2 & & 1 & & & 2 & & 2 & 3 & & & 1 & & & & 2 & 1 \\
\hline 12 & & 2 & & & 2 & 3 & 1 & & 1 & 1 & 4 & 2 & 1 & & 1 & & & & 2 & 1 \\
\hline 13 & 3 & & & 1 & 1 & 1 & & 1 & 1 & 1 & & 1 & 1 & & 1 & 1 & 1 & 1 & 1 & 2 \\
\hline 14 & 2 & & 1 & 1 & & & 3 & 1 & & 1 & & 1 & 2 & 3 & 3 & & 1 & & 2 & 1 \\
\hline 15 & 1 & 1 & 1 & 2 & 1 & 1 & 2 & 1 & & 1 & 1 & & 2 & 2 & 1 & & 2 & & & 1 \\
\hline 16 & & & 1 & 2 & & & 1 & 3 & 1 & & & 2 & 1 & 2 & 4 & & & 1 & & 1 \\
\hline 17 & & & 1 & & 2 & 1 & 3 & 4 & & & 1 & & 1 & 2 & 1 & 1 & 2 & & 1 & \\
\hline 18 & & 1 & & & 2 & 2 & 2 & 1 & 1 & & & & & 1 & 1 & 2 & 1 & & 1 & 3 \\
\hline 19 & & & & & 2 & 3 & 1 & 4 & & & & 1 & & 1 & & 1 & 1 & & & 1 \\
\hline 20 & & & & & & & & & 1 & & & & & 1 & & 13 & & & & \\
\hline PG & 1 & 2 & 3 & 4 & 5 & 6 & 8 & 9 & 10 & 11 & 12 & 13 & 14 & 15 & 16 & 17 & 18 & 19 & 20 & 21 \\
\hline
\end{tabular}

In Abbildung 4.1 sind die mittleren Ränge der 20 Herkünfte der 21 Versuchsflächen in Europa dargestellt. Hier zeigt sich deutlich die stabile Stellung der gutwüchsigen Herkunft Lubelski (Nr. 19) und der geringwüchsigen Herkunft Witów (Nr. 17). Auch in dem Fichtenherkunftsversuch von 1962 überwiegen die standortabhängigen Herkünfte. Wegen der Vielzahl der Herkünfte lässt sich dieses nicht so anschaulich darstellen. 


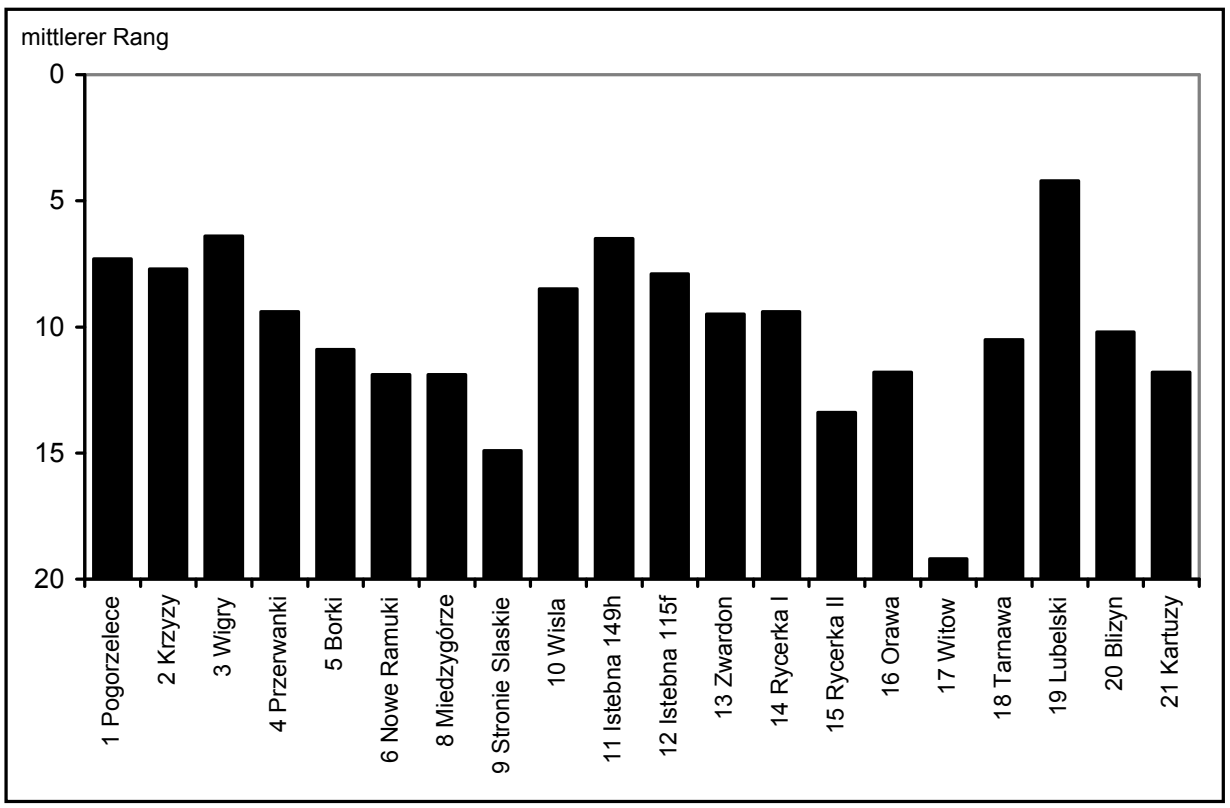

Abb.4.1: Mittlere Ränge bezüglich des Höhenwachstums der 20 polnischen Herkünfte auf 21 Versuchsflächen in Europa

Die Korrelationsanalysen (Tab. 4.4) zwischen den Versuchsflächen beim Merkmal relatives Höhenwachstum im Alter zwischen 10 und 15 Jahren zeigen, dass Flächen, auf denen alle 20 Herkünfte getestet wurden, in der Regel eng korreliert sind. Anders sieht es aus, wenn auf einzelnen Flächen wenige Herkünfte angebaut sind. Hier besteht häufiger kein Zusammenhang beim untersuchten Merkmal. 
Tab.4.4: Korrelationsanalyse $(a=0,05)$ der 21 Versuchsflächen mit bis zu 20 polnischen Fichtenherkünften beim Merkmal relatives Höhenwachstum im Alter zwischen 10 und 15 Jahren

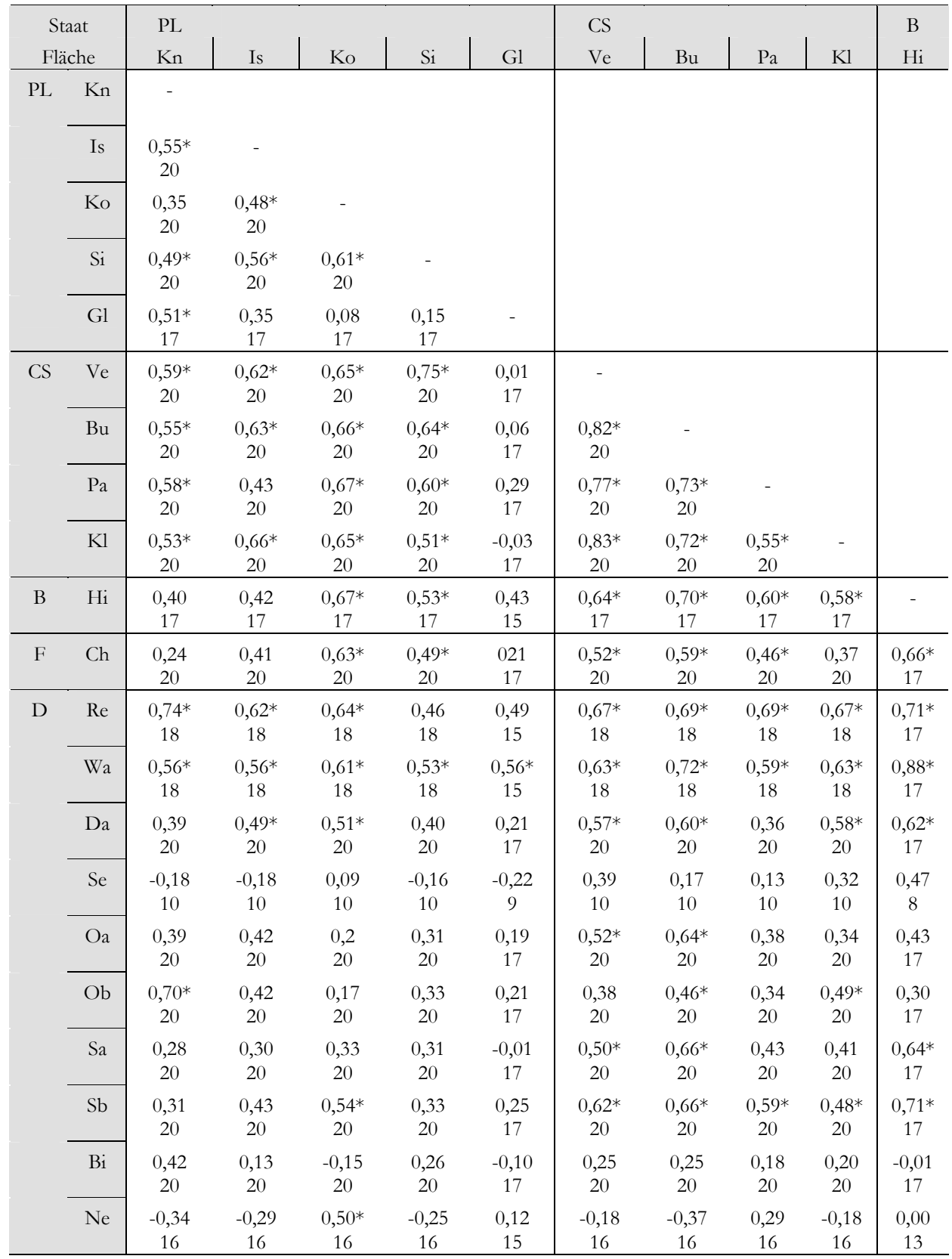

(Fortsetzung) 
(Fortsetzung Tabelle 4.4)

\begin{tabular}{|c|c|c|c|c|c|c|c|c|c|c|c|c|}
\hline \multirow{2}{*}{\multicolumn{2}{|c|}{$\begin{array}{l}\text { Staat } \\
\text { Fläche }\end{array}$}} & \multirow{3}{*}{$\begin{array}{l}\text { F } \\
\text { Ch } \\
- \\
\end{array}$} & \multicolumn{10}{|l|}{ D } \\
\hline & & & $\operatorname{Re}$ & $\mathrm{Wa}$ & $\mathrm{Da}$ & $\mathrm{Se}$ & $\mathrm{Oa}$ & $\mathrm{Ob}$ & $\mathrm{Sa}$ & $\mathrm{Sb}$ & $\mathrm{Bi}$ & $\mathrm{Ne}$ \\
\hline $\mathrm{F}$ & $\mathrm{Ch}$ & & & & & & & & & & & \\
\hline D & $\operatorname{Re}$ & $\begin{array}{c}0,50^{*} \\
18\end{array}$ & - & & & & & & & & & \\
\hline & Wa & $\begin{array}{c}0,71 * \\
18\end{array}$ & $\begin{array}{c}0,82 * \\
20\end{array}$ & - & & & & & & & & \\
\hline & $\mathrm{Da}$ & $\begin{array}{c}0,47^{*} \\
20\end{array}$ & $\begin{array}{c}0,61 * \\
18\end{array}$ & $\begin{array}{c}0,70^{*} \\
18\end{array}$ & - & & & & & & & \\
\hline & $\mathrm{Se}$ & $\begin{array}{c}-0,11 \\
10\end{array}$ & $\begin{array}{c}-0,36 \\
9\end{array}$ & $\begin{array}{c}-0,27 \\
9\end{array}$ & $\begin{array}{c}0,33 \\
10\end{array}$ & - & & & & & & \\
\hline & $\mathrm{Oa}$ & $\begin{array}{c}0,21 \\
20\end{array}$ & $\begin{array}{c}0,38 \\
18\end{array}$ & $\begin{array}{c}0,43 \\
18\end{array}$ & $\begin{array}{c}0,37 \\
20\end{array}$ & $\begin{array}{c}-0,07 \\
10\end{array}$ & - & & & & & \\
\hline & $\mathrm{Ob}$ & $\begin{array}{c}-0,04 \\
20\end{array}$ & $\begin{array}{c}0,42 \\
18\end{array}$ & $\begin{array}{c}0,39 \\
18\end{array}$ & $\begin{array}{c}0,20 \\
20\end{array}$ & $\begin{array}{c}-0,29 \\
10\end{array}$ & $\begin{array}{c}0,57^{*} \\
20\end{array}$ & - & & & & \\
\hline & $\mathrm{Sa}$ & $\begin{array}{c}0,63^{*} \\
20\end{array}$ & $\begin{array}{c}0,70^{*} \\
18\end{array}$ & $\begin{array}{c}0,73^{*} \\
18\end{array}$ & $\begin{array}{c}0,49 * \\
20\end{array}$ & $\begin{array}{c}-0,41 \\
10\end{array}$ & $\begin{array}{c}0,59 * \\
20\end{array}$ & $\begin{array}{c}0,20 \\
20\end{array}$ & - & & & \\
\hline & $\mathrm{Sb}$ & $\begin{array}{c}0,54 * \\
20\end{array}$ & $\begin{array}{c}0,57 * \\
18\end{array}$ & $\begin{array}{c}0,63 * \\
18\end{array}$ & $\begin{array}{c}0,49 * \\
20\end{array}$ & $\begin{array}{c}0,50 \\
10\end{array}$ & $\begin{array}{c}0,63 * \\
20\end{array}$ & $\begin{array}{c}0,34 \\
20\end{array}$ & $\begin{array}{c}0,65^{*} \\
20\end{array}$ & - & & \\
\hline & $\mathrm{Bi}$ & $\begin{array}{c}-0,51^{*} \\
20\end{array}$ & $\begin{array}{c}0,12 \\
18\end{array}$ & $\begin{array}{c}-0,04 \\
18\end{array}$ & $\begin{array}{c}0,16 \\
20\end{array}$ & $\begin{array}{c}0,16 \\
10\end{array}$ & $\begin{array}{c}0,45^{*} \\
20\end{array}$ & $\begin{array}{c}0,55^{*} \\
20\end{array}$ & $\begin{array}{c}-0,09 \\
20\end{array}$ & $\begin{array}{c}-0,06 \\
20\end{array}$ & - & \\
\hline & $\mathrm{Ne}$ & $\begin{array}{c}0,23 \\
16\end{array}$ & $\begin{array}{c}0,14 \\
14\end{array}$ & $\begin{array}{c}-0,12 \\
14\end{array}$ & $\begin{array}{c}-0,15 \\
16\end{array}$ & $\begin{array}{c}0,36 \\
8\end{array}$ & $\begin{array}{c}-0,65^{*} \\
16\end{array}$ & $\begin{array}{c}-0,58^{*} \\
16\end{array}$ & $\begin{array}{c}-0,29 \\
16\end{array}$ & $\begin{array}{c}-0,06 \\
16\end{array}$ & $\begin{array}{c}-0,57^{*} \\
16\end{array}$ & - \\
\hline
\end{tabular}

Staat: $\quad P L=$ Polen, $C S=$ ehem. Tschechoslowakei, $B=$ Belgien, $F=$ Frankreich, $D=$ Deutschland

Versuchsfläche: $K n=K n y s z y n, I s=I$ stebna, Si $=$ Siemianice, $K_{o}=$ Kórnik, Gl $=$ Gtuchów, Ve $=$ Velkea Straž, $\mathrm{Bu}=$ Bujakova, $\mathrm{Pa}=$ Parač, $\mathrm{Kl}=$ Klobašova, $\mathrm{Hi}=$ Hives, $\mathrm{Ch}=$ Champenoux, $\mathrm{R} e=$ Reinhardshagen, $W a=W$ anfried, $D a=$ Dassel, $S_{e}=$ Seesen, $O a, O b=O$ chsenhausen $A, B, S a, S b=$ Sauerlach $A, B$; $B i=$ Biburg, $N e=$ Neureichenau)

Da die Versuchsanstalten mit Saatgut der 20 Herkünfte versorgt wurden, ist davon auszugehen, dass Unterschiede in der Anzucht der Pflanzen bereits selektiv gewirkt haben. Im Extremfall führte dieses dazu, dass von einzelnen Herkünften nicht ausreichend Pflanzen verfügbar waren, und daher einzelne Herkünfte nicht auf allen Flächen angebaut werden konnten. Eine zentrale Pflanzenanzucht hätte eventuell eine höhere Ausbeute erbracht. Das Risiko, einen Fehlschlag durch Witterungsbedingungen zu erleiden, wäre jedoch ungemein höher gewesen. Und letztendlich hätten nur die Selektionskriterien eines Anzuchtortes gewirkt, die für entfernte Testorte nicht zwingend relevant sein müssen. 
4.4 Sonderherkünfte und als „geprüft“ zugelassene Bestände im Herkunftsversuch von 1962

Der Fichtenherkunftsversuch von 1962 enthält vermutlich zahlreiche Versuchsglieder, die als Sonderherkünfte (SHK) ausgewiesen sind, ohne dass diese in der Herkunftsliste als solche gekennzeichnet sind. Bei den SHK handelte es sich um Herkünfte der Kategorie „Ausgewählt" (ANONYMUS 2002), die sich in phänotypischen Merkmalen besonders hervorheben. Diese besonders hochwertigen Erntevorkommen werden von der DKV - Gütegemeinschaft für forstliches Vermehrungsgut e. V. (bis Februar 2005: Deutsche Kontrollvereinigung für forstliches Saat- und Pflanzgut e. V.) als SHK ausgewiesen (DKV 1967; www.dkv-net.de).

Bei vier Prüfgliedern ist vermerkt, dass es sich um SHK handelt (3415 SHK Hochsauerland, 3416 SHK Höhenfichten, 3406 SHK Stryck und 3413 SHK Winterberg). Anhand der Herkunftsnamen, insbesondere der Abteilungsangaben, der geografischen Koordinaten und der Höhenlage ist zu vermuten, dass es sich bei weiteren Herkünften aus Deutschland ebenfalls um SHK handelt. Vermutlich sind zusätzliche Bezeichnungen entweder entfallen oder nicht gemeldet worden, da sie für das Ausland nicht relevant waren.

Bei den Sonderherkünften handelt es sich häufig um die Zusammenfassung mehrerer Ernteeinheiten einer Region. Die einzelnen Ernteeinheiten sind nach dem Forstvermehrungsgutgesetz (ANONYMUS 2002) (zuvor nach dem Gesetz über forstliches Saat- und Pflanzgut) zur Gewinnung von Vermehrungsgut zugelassen. Aus den Angaben zu den Prüfgliedern des Fichtenherkunftsversuchs von 1962 geht häufig nicht hervor, ob es sich um eine repräsentative Stichprobe aus der gesamten Sonderherkunft handelt oder in welcher Ernteeinheit das zu testende Prüfglied geerntet wurde. Eine Herkunft mit dem gleichen Namen kann somit aus unterschiedlichen Beerntungseinheiten stammen.

Es wird davon ausgegangen, dass es sich bei den in den Tabellen 4.5 und 4.6 aufgeführten Prüfgliedern um sogenannte SHK handelt, da man bei der Versuchsanlage bestrebt war, seine besseren Herkünfte im Vergleich vertreten zu sehen. Dies hat selbstverständlich auch Auswirkungen auf die Auswertungen, da es schwierig ist, die bereits ausgesuchten Herkünfte noch zu überbieten, da bekannt schlechte Herkünfte nicht aufgenommen wurden. 
Tab. 4.5: Mögliche Sonderherkünfte (SHK) im Fichtenherkunftsversuch von 1962. Herkünfte der Kategorie „Geprüft" sind zusätzlich gekennzeichnet (GVG).

\begin{tabular}{|c|c|c|}
\hline Herkunftsname (Bundesland) & PG-Nr. & GVG \\
\hline \multicolumn{3}{|l|}{ SHK „Höhenficbte des Schwarzwaldes": } \\
\hline Schluchsee Eschenmoos (BW) & 3102 & \\
\hline SHK Höhenfichte (BW) & 3416 & \\
\hline \multicolumn{3}{|l|}{ SHK „Hocblagenfichte des Bayerischen Waldes": } \\
\hline Mauth-Ost (BY) & 3323 & \\
\hline Neureichenau (3326 $=$ Typengemisch) (BY) & $3325,3326,3435,3436,3437$ & $\mathrm{x}$ \\
\hline Rabenstein (Typengemisch) (BY) & 3337 & \\
\hline St. Oswald (Plattenfichten) (BY) & 3331 & \\
\hline Zwiesel-Ost (BY) & 3332,3334 & \\
\hline \multicolumn{3}{|l|}{ SHK ,Jurafichte": } \\
\hline Riedenburg (BY) & 3431 & \\
\hline \multicolumn{3}{|l|}{ SHK „V orallgäuer Fichte“: } \\
\hline Sachsenried (BY) & 3418 & \\
\hline \multicolumn{3}{|l|}{ SHK „W unsiedler Fichte“: } \\
\hline Wunsiedel (BY) & 103 & \\
\hline \multicolumn{3}{|l|}{ SHK „Burgjoß“: } \\
\hline Burgjoß (HE) & 3498 & \\
\hline \multicolumn{3}{|l|}{ SHK „Chauseehaus": } \\
\hline Chausseehaus (HE) & 3499 & $\mathrm{x}$ \\
\hline \multicolumn{3}{|l|}{ SHK „Stryck": } \\
\hline Stryck (HE) & 3406,3422 & \\
\hline \multicolumn{3}{|l|}{ SHK „Autocbthone Haraficbte": } \\
\hline Oderhaus (NI) & 3427,3438 & \\
\hline Sieber $(\mathrm{NI})$ & 93 & \\
\hline \multicolumn{3}{|l|}{ SHK „Elitebestände“: } \\
\hline Westerhof, bzw. 51b (NI) & 115,3404 & $\mathrm{x}$ \\
\hline \multicolumn{3}{|l|}{ SHK „Fichte Hochsauerland“: } \\
\hline SHK Hochsauerland (NW) & 3415 & \\
\hline SHK Winterberg (NW) & $3413,114,3412,3424$ & \\
\hline
\end{tabular}

$$
P G=\text { Prüfglied }
$$


Tab. 4.6: Mögliche Sonderherkünfte (SHK) im IUFRO-Fichtenherkunftsversuch von 1972. Herkïnfte der Kategorie „Geprüft" sind zusätzlich gekennzeichnet (GVG).

\begin{tabular}{|c|c|c|c|}
\hline Herkunftsname (Bundesl.) & Versuchsfläche & PG-Nr. & GVG \\
\hline $\begin{array}{l}\text { SHK „Frankenwaldfichte“ } \\
\text { Rothenkirchen (BY) }\end{array}$ & $\begin{array}{l}\text { Reinhardshagen (HE) } \\
\text { Wanfried (HE) }\end{array}$ & $\begin{array}{l}22 \\
22\end{array}$ & $\mathrm{x}$ \\
\hline $\begin{array}{l}\text { SHK „Hocblagenficbte“ } \\
\text { Zwiesel II } 4 \mathrm{c}^{\circ}(\mathrm{BY})\end{array}$ & $\begin{array}{l}\text { Ochsenhausen A (BW) } \\
\text { Sauerlach A (BY) } \\
\text { Sauerlach B (BY) }\end{array}$ & $\begin{array}{l}29 a \\
29 a \\
29 a\end{array}$ & $\mathrm{x}$ \\
\hline $\begin{array}{l}\text { SHK ,Jurafichte" } \\
\text { Kehlheim-Nord (BY) }\end{array}$ & $\begin{array}{l}\text { Ochsenhausen B (BW) } \\
\text { Biburg (BY) } \\
\text { Schwabmünchen (BY) }\end{array}$ & $\begin{array}{l}34 \mathrm{~b} \\
34 \mathrm{~b} \\
34 \mathrm{~b}\end{array}$ & \\
\hline $\begin{array}{l}\text { SHK „Elitebestände“ } \\
\text { Westerhof (NI) }\end{array}$ & $\begin{array}{l}\text { Ochsenhausen B (BW) } \\
\text { Biburg (BY) } \\
\text { Schwabmünchen (BY) } \\
\text { Reinhardshagen (HE) } \\
\text { Wanfried (HE) } \\
\text { Seesen (NI) als Einzelbaumabsaaten }\end{array}$ & $\begin{array}{c}7 \mathrm{~b} \\
7 \mathrm{~b} \\
7 \mathrm{~b} \\
26 \\
26 \\
146-191\end{array}$ & $\mathrm{x}$ \\
\hline
\end{tabular}

$P G=$ Prüfglied

Außerdem sind Herkünfte einer zweiten Kategorie in den beiden Versuchen enthalten: Kategorie „Geprüft“ (ANONYMUS 2002). Diese Kategorie bezeichnet Vermehrungsgut, dessen Ausgangsmaterial auf Grund aufwändiger und erfolgreich durchgeführter Prüfungen zugelassen wurde. Vermehrungsgut dieser Kategorie verfügt unter den Standortbedingungen der Prüforte über eine erblich bedingte Überlegenheit bei bestimmten Merkmalen. Die derzeit als „Geprüft“ zugelassenen Bestände und Samenplantagen der Fichte sind von RAU (2007) zusammengestellt worden. Die möglichen Herkünfte der Kategorie „Geprüft“ (geprüftes Vermehrungsgut $=\mathrm{GVG})$, die in den Versuchen angebaut wurden, sind ebenfalls in den Tabellen 4.5 und 4.6 gekennzeichnet.

Auch im IUFRO-Fichtenherkunftsversuch von 1972 sind als zusätzliche Herkünfte insgesamt vier Sonderherkünfte zum Anbau gekommen (Tab. 4.6). Die Einzelbaumnachkommenschaften (PG-Nr. 146 - 191) Westerhof Abt. 40 und 48 auf der Fläche Seesen gehören der SHK Westerhof Elite an.

Die Auswertung der einzelnen Flächen hat keinen statisch besseren Wuchs der Herkünfte der Kategorie „Geprüft“ bzw. der Sonderherkünfte absichern können. Dieses passt zur postulierten Vermutung, dass in beide Versuche gezielt besserwüchsige Herkünfte aus Deutschland eingegangen sind.

Es ist daher nicht überraschend, dass die statistischen Tests keine oder nur selten Unterschiede zwischen Herkünften aus Deutschland absichern. Bei den 
statistischen Tests wird über die Annahme oder Ablehnung einer statistischen Hypothese über Parameter der untersuchten Merkmalsausprägung entschieden. Dabei gibt es zwei Möglichkeiten der Entscheidungsfindung und somit auch zwei Fehlermöglichkeiten. Gegen eine falsche Entscheidung gibt man eine Fehlerwahrscheinlichkeit, die sogenannte Irrtumswahrscheinlichkeit $\alpha$ (Risiko 1. Art) vor. Dabei geht man von einer Nullhypothese aus (anders ausgedrückt: es liegen keine Unterschiede vor, die gefundenen Differenzen existieren nicht): Wird die Nullhypothese abgelehnt, obwohl sie richtig ist, liegt ein Fehler 1. Art vor (THOMAS 2006).

Der zweite Fehler, auch als Trennschärfe bezeichnet, ist die Wahrscheinlichkeit $\beta$ (Risiko 2. Art) eine unzutreffende Nullhypothese abzulehnen (d. h.: signifikante Differenzen werden nicht erkannt). Gerade bei kleinen Stichproben kann so die Entscheidung mit einem eventuell unvertretbar großen Risiko $\beta$ behaftet sein (RASCH et al. 1996). Für das Risiko 2. Art gibt es bislang nur wenige Empfehlungen (THOMAS 2006).

Beide Risiken sollten vor dem Versuch bei der Versuchsplanung festgelegt werden. Mit der Versuchsplanung wird im Vorfeld aus der zu erwartenden Streuung und dem kleinsten nachzuweisenden Unterschied zwischen zwei Mittelwerten das geeignete Test-Verfahren bestimmt (SUMPF und MOLL 2004). Obwohl Unterschiede aus fachlicher Sicht erkennbar waren, sind sie statistisch nicht nachweisbar, da die Teststatistik bei drei Wiederholungen zu konservativ ist und nur sehr große Unterschiede nachgewiesen werden können.

Gutachtlich lassen sich die Herkünfte aus Deutschland dennoch beurteilen. Dazu bieten sich die gebildeten Ränge bei den Merkmalen Wachstum und Vorrat pro Hektar an. In den Tabellen 4.7 bis 4.9 sind die im Fichtenherkunftsversuch von 1962 geprüften Herkünfte aus Deutschland zusammengestellt. Für die darunter enthaltenen möglichen Sonderherkünfte sind die Prüfgliednummern in den Tabellen grau hinterlegt. Nach der Herkunftsbezeichnung und ihrer Höhenlage folgt der Rang im Höhen- bzw. Durchmesserwachstum der jüngsten Messung auf den einzelnen Versuchsflächen. Außerdem ist der über die Versuchsflächen berechnete mittlere Rang einer Herkunft aufgenommen. Die beiden letzten Spalten der Tabellen enthalten den Rang im rechnerischen Vorrat im Alter 39 auf den Flächen Reinhardshagen (Hessen) und Hasbruch (Niedersachsen). In den Spalten sind die Ränge entsprechend ihrer Quartilszugehörigkeit markiert:

1. Quartil (gut): fett und grau unterlegt

2. + 3. Quartil (mittel): grau unterlegt

4. Quartil (schlecht): ohne Hervorhebung

Die Tabellen 4.7 bis 4.9 sind nach dem mittleren Rang beim Merkmal Wachstum über alle Flächen sortiert. Die Herkünfte, die auf den Teilflächen mit 81 bzw. 36 Herkünften nicht auf allen Flächen getestet werden, sind mit ihrer Rangfolge jeweils am Ende der Tabellen 4.8 und 4.9 angeführt. Auf den beiden Teilflächen, 
auf denen mehrere mögliche Sonderherkünfte bzw. Herkünfte der Kategorie „Geprüft“ angebaut sind, fällt auf, dass diese über die gesamte Streubreite der deutschen Herkünfte verteilt sind.

Im Teilversuch mit den 169 Herkünften (Flächen 14, 24, 34 und 44) (Tab. 4.7) gehört keine deutsche Herkunft nach ihrer Wuchsleistung über alle vier Versuchsflächen dem vierten Quartil, der schlechtestwüchsigen Herkünfte, an. Die Herkunft 114 Winterberg ist als einzige Herkunft auf allen vier Flächen im ersten Quartil. Auf dem für Fichte ungünstigen Standort Hasbruch (44) sind alle deutschen Herkünfte gut bzw. mittel im Wuchs. Auf der Fläche Reinhardshagen (Hessen) gehören zwei Hochlagenherkünfte (3416 SHK Höhenfichte und 3326 Neureichenau) dem vierten Quartil an. Auf den Flächen Sonthofen (Bayern) sind fünf Herkünfte aufgrund ihrer Rangfolge im Wachstum dem vierten Quartil zugeordnet und auf der Fläche Münsingen (Baden-Württemberg) neun Herkünfte.

Tab.4.7: $\quad$ Deutsche Herkünfte des Teilversuchs des Fichtenherkunftsversuchs von 1962 mit 169 Herkünften: Rang im Höhen- bzw. Duchmesserwachstum auf den vier Flächen Münsingen (14), Sonthofen (24), Reinhardshagen (34) und Hasbruch (44) und im Mittel über die vier Flächen sowie Rang im Vorrat (Alter 39) auf den Flächen 34 und 44. PG-Nummern möglicher SHK grau binterlegt. (Weitere Erläuterungen im Text)

\begin{tabular}{|c|c|c|c|c|c|c|c|c|c|}
\hline \multirow{2}{*}{$\begin{array}{l}\text { PG- } \\
\text { Nr. }\end{array}$} & \multirow[t]{2}{*}{ Herkunft } & \multirow{2}{*}{$\begin{array}{c}\text { Höhe } \\
\text { ü. NN } \\
{[\mathrm{m}]}\end{array}$} & \multicolumn{5}{|c|}{ Wachstum } & \multicolumn{2}{|c|}{$\begin{array}{l}\text { Vorrat } \\
\text { Fläche }\end{array}$} \\
\hline & & & 14 & 24 & 34 & 44 & $\mathrm{X}$ & 34 & 44 \\
\hline 3499 & Chausseehaus & & 4 & 27 & 59 & 43 & 33 & 30 & 10 \\
\hline 114 & Winterberg & 800 & 27 & 41 & 29 & 41 & 34 & 17 & 80 \\
\hline 3329 & Spiegelau & 1200 & 89 & 16 & 18 & 52 & 44 & 13 & 34 \\
\hline 3436 & Neureichenau (2) & 1050 & 24 & 70 & 32 & 54 & 45 & 22 & 63 \\
\hline 9417 & Marsberg & 500 & 3 & 89 & 77 & 15 & 46 & 22 & 2 \\
\hline 3447 & Nationalp. Hüttenschlag XIX 1b & 750 & 10 & 40 & 39 & 40 & 57 & 25 & 45 \\
\hline 3445 & Zwiesel, Haselau XXI $12(3,6)$ & 650 & 74 & 55 & 51 & 50 & 57 & 28 & 73 \\
\hline 3444 & Zwiesel, Scheicherau XXI 14a/b & 650 & 41 & 42 & 96 & 54 & 59 & 30 & 37 \\
\hline 3412 & Winterberg & 750 & 91 & 51 & 44 & 50 & 59 & 4 & 103 \\
\hline 227 & Thüringen & 300 & 73 & 82 & 68 & 22 & 61 & 19 & 5 \\
\hline 3433 & Selb-Kirchenlamitz (1) & 800 & 108 & 46 & 41 & 52 & 62 & 50 & 82 \\
\hline 3332 & Zwiesel-Ost & 1000 & 85 & 73 & 77 & 20 & 64 & 40 & 8 \\
\hline 3434 & Miele & 90 & 35 & 143 & 57 & 27 & 65 & 54 & 4 \\
\hline 3498 & Burgjoß & 450 & 72 & 102 & 28 & 64 & 66 & 12 & 67 \\
\hline 3419 & Schwarzwald Baar, VIII/6 & 700 & 108 & 49 & 51 & 60 & 67 & 47 & 30 \\
\hline 110 & Medebach & 600 & 55 & 16 & 83 & 115 & 67 & 128 & 121 \\
\hline 103 & Wunsiedel & 900 & 84 & 83 & 84 & 26 & 69 & 72 & 18 \\
\hline 3437 & Neureichenau (2) & 1050 & 77 & 73 & 74 & 58 & 70 & 33 & 14 \\
\hline 3430 & Diessen & 850 & 28 & 111 & 86 & 57 & 71 & 28 & 9 \\
\hline
\end{tabular}




\begin{tabular}{|c|c|c|c|c|c|c|c|c|c|}
\hline \multirow[t]{2}{*}{$\begin{array}{l}\text { PG- } \\
\text { Nr. }\end{array}$} & \multirow[t]{2}{*}{ Herkunft } & \multirow{2}{*}{$\begin{array}{l}\text { Höhe } \\
\text { ü. NN } \\
{[\mathrm{m}]}\end{array}$} & \multicolumn{5}{|c|}{ Wachstum } & \multicolumn{2}{|c|}{$\begin{array}{l}\text { Vorrat } \\
\text { Fläche }\end{array}$} \\
\hline & & & 14 & 24 & 34 & 44 & $\mathrm{X}$ & 34 & 44 \\
\hline 41 & Spiegelau & 750 & 19 & 51 & 100 & 115 & 71 & 116 & 131 \\
\hline 3420 & Daun/Ost & 450 & 92 & 78 & 75 & 44 & 72 & 40 & 55 \\
\hline 3425 & Waldmünchen & 850 & 88 & 67 & 105 & 36 & 74 & 124 & 123 \\
\hline 3417 & Marsberg & 500 & 25 & 107 & 48 & 122 & 76 & 45 & 92 \\
\hline 3426 & Uelzen & 50 & 62 & 85 & 81 & 76 & 76 & 54 & 67 \\
\hline 3428 & Schernfeld & 450 & 80 & 27 & 109 & 98 & 79 & 116 & 161 \\
\hline 3406 & SHK Stryck Willingen & 550 & 146 & 27 & 83 & 62 & 80 & 72 & 70 \\
\hline 3422 & Stryck & 650 & 120 & 70 & 88 & 42 & 80 & 76 & 41 \\
\hline 3415 & SHK Hochsauerland & 600 & 100 & 84 & 105 & 32 & 80 & 83 & 103 \\
\hline 3424 & Winterberg & 450 & 142 & 111 & 57 & 11 & 81 & 45 & 3 \\
\hline 3617 & Torgelow & 100 & 144 & 104 & 13 & 62 & 81 & 9 & 73 \\
\hline 3432 & Walsrode & 30 & 50 & 130 & 83 & 64 & 82 & 40 & 92 \\
\hline 3418 & Sachsenried & 900 & 75 & 137 & 54 & 68 & 83 & 33 & 49 \\
\hline 3449 & Nationalp. Neubruck 1a10,b10/11,c10 & 740 & 113 & 18 & 102 & 107 & 85 & 106 & 37 \\
\hline 9432 & Walsrode & 30 & 130 & 64 & 100 & 51 & 86 & 128 & 35 \\
\hline 3505 & Eibenst. Carlsf. 275 & 925 & 127 & 150 & 46 & 23 & 86 & 45 & 58 \\
\hline 3438 & Oderhaus & 650 & 76 & 137 & 107 & 43 & 91 & 93 & 63 \\
\hline 3410 & Traunstein & 850 & 153 & 33 & 95 & 83 & 91 & 57 & 116 \\
\hline 3431 & Riedenburg & 500 & 119 & 89 & 120 & 41 & 92 & 110 & 16 \\
\hline 3413 & SHK Winterberg & 750 & 57 & 142 & 117 & 62 & 95 & 134 & 106 \\
\hline 3411 & Bischofswiesen & 950 & 140 & 61 & 117 & 62 & 95 & 124 & 49 \\
\hline 3427 & Oderhaus & 650 & 163 & 71 & 67 & 82 & 95 & 150 & 58 \\
\hline 3423 & Kohlstetten & 750 & 89 & 113 & 92 & 91 & 96 & 131 & 16 \\
\hline 3416 & SHK Höhenfichten & 1050 & 104 & 41 & 148 & 94 & 97 & $158^{*}$ & 139 \\
\hline 3435 & Neureichenau (2) & 1050 & 116 & 108 & 75 & 91 & 97 & 62 & 33 \\
\hline 3429 & Villingen & 850 & 129 & 148 & 78 & 36 & 98 & 79 & 27 \\
\hline 3328 & Spiegelau & 1200 & 125 & 57 & 113 & 105 & 100 & 98 & 92 \\
\hline 3448 & Nationalp. Filzwald IX 3a 10/11 & 750 & 158 & 56 & 119 & 70 & 100 & 140 & 49 \\
\hline 9423 & Kohlstetten & 750 & 116 & 57 & 121 & 113 & 102 & 141 & 96 \\
\hline 3326 & Neureichenau & 1200 & 111 & 98 & 146 & 83 & 109 & 158 & 47 \\
\hline 3421 & Dombühl & 450 & 57 & 73 & 39 & . & . & 6 & \\
\hline
\end{tabular}

* Vorrat ist höher als der rechnerische, da nicht alle Pflanzplätze bepflanzt sind

Von den auf allen Versuchsflächen des Teilversuchs mit 81 Herkünften angebauten Prüfgliedern gehören zwei Prüfglieder (3503 Eibenstock und 3519 Mechterstädt) dem ersten Quartil an (Tab. 4.8). Drei Herkünfte (111 Bodenmais, 
107 Donaueschingen und 3337 Rabenstein, Typengemisch) sind im Mittel über beide Versuchsstandorte dem vierten Quartil zugeordnet.

Tab. 4.8: $\quad$ Deutsche Herkünfte des Teilversuches des Fichtenherkunftsversuchs von 1962 mit 81 Herkünften: Rang im Höhen- brw. Duchmesserwachstum auf den beiden Flächen Reinhardshagen (35) und Hasbruch (45) und im Mittel über die zwei Flächen sowie Rang im Vorrat (Alter 39) auf den Flächen 35 und 45. PG-Nummern möglicher SHK grau binterlegt. (Weitere Erläuterungen im Text)

\begin{tabular}{|c|c|c|c|c|c|c|c|}
\hline \multirow{2}{*}{$\begin{array}{l}\text { PG- } \\
\text { Nr. }\end{array}$} & \multirow[t]{2}{*}{ Herkunft } & \multirow{2}{*}{$\begin{array}{l}\text { Höhe } \\
\text { ü. NN } \\
{[\mathrm{m}]}\end{array}$} & & $\begin{array}{l}\text { Vachs } \\
\text { ch e }\end{array}$ & - & \multicolumn{2}{|c|}{$\begin{array}{l}\text { Vorrat } \\
\text { Fläche }\end{array}$} \\
\hline & & & 35 & 45 & $\mathrm{X}$ & 35 & 45 \\
\hline 3503 & Eibenst. Carlsf. Wiesenh. 214 & 720 & 8 & 13 & 11 & 6 & 49 \\
\hline 115 & Westerhof & 200 & 23 & 9 & 16 & 7 & 3 \\
\hline 3519 & Mechterstädt & 200 & 15 & 18 & 17 & 23 & 6 \\
\hline 3511 & Innenau Elgersburg & 800 & 34 & 12 & 23 & 33 & 16 \\
\hline 3417 & Marsberg & 500 & 24 & 23 & 24 & 1 & 24 \\
\hline 3404 & Westerhof Abt. $51 \mathrm{~B}$ & 200 & 14 & 38 & 26 & 26 & 27 \\
\hline 3606 & Templin, Bad Doberan Nr. 9 & 50 & 23 & 38 & 30 & 6 & 11 \\
\hline 3615 & Neustrelitz & 100 & 31 & 30 & 31 & 43 & 46 \\
\hline 3518 & Suhl, Oberhofer Schloßbergkopf & 900 & 65 & 6 & 35 & 47 & 9 \\
\hline 3432 & Walsrode & 30 & 50 & 23 & 36 & 70 & 8 \\
\hline 3433 & Selb-Kirchenlamitz (1) & 800 & 18 & 60 & 39 & 4 & 53 \\
\hline 3510 & Sonneb. Steinheid, Kieferleskopf & 886 & 56 & 27 & 41 & 57 & 12 \\
\hline 3423 & Kohlstetten & 750 & 35 & 51 & 43 & 15 & 60 \\
\hline 3102 & Schluchsee-Eschenmoos & 1200 & 44 & 51 & 47 & 64 & 52 \\
\hline 3430 & Diessen & 850 & 37 & 60 & 48 & 13 & 47 \\
\hline 3310 & Zwiesel-West/Ruselhänge X/68 & 750 & 42 & 55 & 49 & 18 & 13 \\
\hline 3139 & Isny $\mathrm{Ba} / \mathrm{Wü}$ & 850 & 39 & 59 & 49 & 74 & 68 \\
\hline 3443 & Zwiesel, Scheichereb. XXI 13b1 & 650 & 52 & 55 & 53 & 40 & 45 \\
\hline 3331 & St. Oswald I/3,4,6 Typengemisch & 1200 & 70 & 40 & 55 & 50 & 57 \\
\hline 3042 & Walchensee & 1100 & 63 & 54 & 58 & 72 & 61 \\
\hline 111 & Bodenmais & 1000 & 67 & 59 & 63 & 63 & 24 \\
\hline 107 & Donaueschingen & 650 & 71 & 55 & 63 & 63 & 17 \\
\hline 3337 & Rabenstein Typengemisch & 1200 & 75 & 72 & 74 & 74 & 79 \\
\hline 3003 & Blumberg & 800 & . & 63 & . & . & 68 \\
\hline 3204 & Burghausen/Salzach & 400 & . & 48 & . & 25 & . \\
\hline 3205 & Ebersberg & 555 & . & 36 & . & . & 54 \\
\hline 3211 & Moosburg/Isar & 500 & . & 20 & . & . & 22 \\
\hline 3320 & Bischofsreut & 970 & 46 & . & . & 34 & . \\
\hline 3323 & Mauth/Ost & 1000 & . & 11 & . & . & 2 \\
\hline 3325 & Neureichenau/Typengemisch & 1000 & . & 24 & . & . & 14 \\
\hline 3327 & Passau/Nord & 1000 & . & 57 & . & . & 42 \\
\hline 3334 & Zwiesel-Ost, V/1,2, Plattenfichten & 1200 & 67 & . & . & 75 & . \\
\hline
\end{tabular}


(Fortsetzung Tabelle 4.8)

\begin{tabular}{|c|c|c|c|c|c|c|c|}
\hline \multirow{3}{*}{$\begin{array}{l}\text { PG- } \\
\text { Nr. }\end{array}$} & \multirow{3}{*}{ Herkunft } & \multirow{3}{*}{$\begin{array}{l}\text { Höhe } \\
\text { ü. NN } \\
{[\mathrm{m}]}\end{array}$} & \multicolumn{3}{|c|}{ Wachstum } & \multirow{2}{*}{\multicolumn{2}{|c|}{$\begin{array}{l}\text { Vorrat } \\
\text { Fläche }\end{array}$}} \\
\hline & & & \multicolumn{2}{|c|}{ Fläche } & \multirow{2}{*}{$\begin{array}{l}- \\
\mathrm{X}\end{array}$} & & \\
\hline & & & 35 & 45 & & 35 & 45 \\
\hline 3501 & Rungstock, 46 A & 560 & 12 & . & . & 12 & . \\
\hline 3504 & Eibenst. Carlsf. Wilschm. 233 & 720 & 18 & . & . & & 57 \\
\hline 3506 & Tellerhaeuser, 44 & 980 & 44 & . & . & 36 & . \\
\hline 3508 & Rehefeld, 146 & 810 & 34 & . & . & 33 & . \\
\hline 3512 & Peitz/Tannenwald & 60 & 43 & . & . & 50 & . \\
\hline 3601 & Cottbus, Tannenwald 17AB & 80 & 49 & . & . & 50 & . \\
\hline
\end{tabular}

Im Teilversuch mit den 36 Herkünften ist nur eine Sonderherkunft auf zwei Teilflächen vertreten (Tab. 4.9). Keine der deutschen Herkünfte ist aufgrund ihres Wachstums auf allen drei Teilflächen dem ersten oder vierten Quartil zugeordnet.

Tab.4.9 Deutsche Herkünfte des Teilversuches des Fichtenherkunftsversuchs von 1962 mit 36 Herkünften: Rang im Höhen- bzw. Duchmesserwachstum auf den drei Flächen Berchtesgaden (26), Reinhardshagen (36) und Hasbruch (46) und im Mittel über die drei Flächen sowie Rang im Vorrat (Alter 39) auf den Flächen 36 und 46. PG-Nummern möglicher SHK grau binterlegt. (Weitere Erläuterungen im Text)

\begin{tabular}{|c|c|c|c|c|c|c|c|c|}
\hline \multirow{2}{*}{$\begin{array}{l}\text { PG- } \\
\text { Nr. }\end{array}$} & \multirow[t]{2}{*}{ Herkunft } & \multirow{2}{*}{$\begin{array}{l}\text { Höhe } \\
\text { ü. NN } \\
{[\mathrm{m}]}\end{array}$} & \multicolumn{4}{|c|}{ Wachstum } & \multicolumn{2}{|c|}{$\begin{array}{l}\text { Vorrat } \\
\text { Fläche }\end{array}$} \\
\hline & & & 26 & 36 & 46 & $\mathrm{X}$ & 36 & 46 \\
\hline 3432 & Walsrode & 30 & 14 & 10 & 9 & 11 & 7 & 36 \\
\hline 3414 & Bodensee Oberschwab. VIII/13 & 650 & 11 & 17 & 5 & 11 & 5 & 2 \\
\hline 3433 & Selb-Kirchenlamitz (1) & 800 & 5 & 16 & 15 & 12 & 1 & 13 \\
\hline 3213 & Mühldorf/Inn & 440 & 13 & 14 & 16 & 14 & 16 & 10 \\
\hline 3417 & Marsberg & 500 & 20 & 9 & 13 & 14 & 9 & 35 \\
\hline 3206 & Eglharting XIV/17,19 & 580 & 23 & 12 & 8 & 14 & 25 & 7 \\
\hline 3446 & Zwiesel, Schmalzau IX 3c & 620 & 11 & 21 & 14 & 15 & 17 & 11 \\
\hline 3150 & Dillingen a.d.D. Bay. & 500 & 20 & 15 & 15 & 17 & 14 & 5 \\
\hline 3423 & Kohlstetten & 750 & 29 & 26 & 8 & 21 & 30 & 14 \\
\hline 105 & Hohenschwangau & 800 & 24 & 12 & 28 & 21 & 4 & 28 \\
\hline 3430 & Diessen & 850 & 15 & 18 & 32 & 22 & 33 & 18 \\
\hline 230 & Elbingerode & 550 & 31 & 16 & 20 & 22 & 14 & 17 \\
\hline 93 & Sieber & 400 & 2 & . & 27 & . & . & 29 \\
\hline 108 & Lauterberg & 700 & 16 & . & 8 & . & . & 3 \\
\hline 113 & Walsrode & 100 & & 8 & . & . & 10 & . \\
\hline
\end{tabular}

Zu den Fichten aus Hochlagen führt KIRSCHFELD (DKV 1967) aus, dass Stammscheibenanalysen gezeigt haben, dass Hochlagenfichten in der Jugend ein sehr langsames Wachstum haben. Danach steigt der Dickenzuwachs ab etwa Alter 20 
bis 30 an, nimmt vom Alter 60 bis 70 weiter zu und bleibt anschließend bis ins hohe Alter gleich. Der Fichtenherkunftsversuch von 1962 bietet mit seiner Herkunftsvielfalt ein ideales Material, um diese Aussage zu überprüfen. Dazu wird empfohlen, auf den parallelen Versuchsflächen in Bayern (24 Sonthofen, 26 Berchtesgaden) und Hessen (34 und 36 Reinhardshagen) im Alter von etwa 50 Jahren an Fichten ausgewählter Herkünfte den Durchmesserzuwachs an Stammscheiben zu analysieren.

In allen drei Teilversuchen gibt es auf den einzelnen Flächen einige Herkünfte, die dem vierten Quartil der schlechter wüchsigen Herkünfte angehören. Diese Herkünfte sollten möglichst auf vergleichbaren Standorten nicht angebaut werden, da deren Wuchsleistung bzw. rechnerischer Vorrat pro Hektar unzureichend ist.

Um das Wachstum besser beurteilen zu können, sollte bei der Anlage von Herkunftsversuchen darauf geachtet werden, dass immer auch in Form und Wuchsleistung schlechte Herkünfte in den Versuch aufgenommen werden; nur so lässt sich die Qualität und Quantität einer Herkunft auch differenziert nach unten beurteilen. Außerdem demonstrieren diese Versuchsergebnisse, welches Risiko eingegangen wird, wenn der Herkunft nicht der angemessene Stellenwert bei einer Aufforstung oder Anpflanzung eingeräumt wird (LIESEBACH et al. 2006).

Im IUFRO-Fichtenherkunftsversuch von 1972 liegen die beiden Sonderherkünfte Rothenkirchen und Westerhof auf der Fläche Reinhardshagen / Hessen beim rechnerischen Vorrat im Alter von 32 Jahren im zweiten Quartil. Auf der zweiten Versuchsfläche in Hessen, Wanfried, sind diese beiden Herkünfte sogar im ersten Quartil. Für die SHK Rothenkirchen ließ sich hier der höchste Vorrat aller getesteten Herkünfte errechnen. Von den deutschen Herkünften war auf beiden Flächen die Herkunft Bayerischer Wald eher vorratsarm und ist daher jeweils im vierten Quartil zu finden. Vom Anbau dieser Herkunft sollte daher auf den hessischen Versuchsorten mit vergleichbaren Standorten abgesehen werden.

Auf der Fläche Ochsenhausen B (Baden-Württemberg) erzielte die Herkunft Westerhof einen rechnerischen Vorrat, der dem mittleren Vorrat der Versuchsfläche entsprach. Die Herkunft Zwiesel II $4 \mathrm{c}^{\circ}$ hatte auf der wenige Kilometer südlich von München gelegenen Fläche Sauerlach A einen geringen rechnerischen Vorrat (4. Quartil). Auch auf der benachbarten Fläche Sauerlach B, auf der ein Erlenvoranbau erfolgte, schnitt die Herkunft nicht besser ab. Für die Schotterstandorte südlich von München ist der Anbau dieser Herkunft aufgrund der vorliegenden Versuchsergebnisse im Alter von 25 Jahren daher nicht erfolgversprechend. Die weiteren in den Tabellen 4.5 und 4.6 aufgeführten Herkünfte sind an den genannten Standorten nicht mehr gemessen worden, so dass zu den polnischen Herkünften und den weiteren zusätzlichen Herkünften keine Vergleiche möglich sind.

Die Herkünfte der Kategorie „Geprüft" zeichneten sich alle im Zulassungsverfahren durch eine signifikante Überlegenheit in ihrer Wuchsleistung aus. Selbst wenn in den beiden analysierten Versuchen diese Herkünfte im Alter von 30 bis 40 
Jahren nicht die Spitzenposition im Wachstum einnehmen, waren sie in der Kulturphase wüchsiger als andere und sind schneller den in dieser Zeit vorliegenden Gefahren entwachsen.

\subsection{Angepasstheit an Klimaänderungen}

Die meisten Fichtenherkünfte stammen im Vergleich zu den Testorten aus weiter östlich gelegenen Gebieten oder aus höheren Lagen der Alpen. Damit sind zumindest die Testorte Reinhardshagen / Hessen, Hasbruch / Niedersachsen und Münsingen / Baden-Württemberg atlantischer geprägt als die Einsammlungsorte.

Von den Herkünften, die auch im IUFRO-Versuch von 1964/1968 geprüft wurden, liegen für die Einsammlungsorte langjährige Temperatur- und Niederschlagsmittelwerte vor. Bei den Klimadaten handelt es sich um auf die Höhenlage der Einsammlungsorte interpolierte Werte von europäischen Messstationen (WALTER und LIETH 1960, LIESEBACH et al. 2001).

Die in Tabelle 4.10 zusammengestellten Korrelationskoeffizienten $\left(r_{P}\right)$ zeigen, dass zwischen den analysierten Wachstumsmerkmalen und ausgewählten Klimaparametern sehr differenzierte Abhängigkeiten bestehen. Die niederschlagsbezogenen Klimaparameter zeigen nur beim Durchmesserwachstum im Alter von 39 Jahren Abhängigkeiten, während zwischen den temperaturbezogenen Klimaparametern und dem Höhenwachstum bzw. dem Durchmesserwachstum auf der Fläche Berchtesgaden im jüngeren Alter Abhängigkeiten vorliegen. Die gefundenen Abhängigkeiten sind vermutlich zufälliger Natur und als Einzelmerkmal für eine weitergehende Interpretation des Wachstums ungeeignet. Auch können bei verfrachteten Herkünften Anpassungsprozesse noch bis zum Tod des Baumes andauern, was die Daten verzerrt.

Tab.4.10: Korrelationskoeffizienten $(a=0,05)$ zwischen ausgewäblten Wachstumsmerkmalen an den fünf Versuchsorten und ausgewählten Klimaparametern der Einsammlungsorte

\begin{tabular}{l|c|c|c|c|c|c}
\hline & & & \multicolumn{4}{|c}{ Klimaparameter } \\
Fläche & PG & Merkmal & $\begin{array}{c}\text { mittl. } \\
\text { Temp. } \\
\text { (im Jahr) }\end{array}$ & $\begin{array}{c}\text { Temp.- } \\
\text { spanne } \\
\text { (Jan.-Juli) }\end{array}$ & \multicolumn{2}{|c}{ Niederschlag } \\
(im Jahr) & (Mai-Sept.) \\
\hline Reinhardshagen (HE) & 152 & BHD 39-j. & 0,134 & $-0,084$ & $-0,210^{*}$ & $-0,149$ \\
Hasbruch (NI) & 151 & BHD 39-j. & 0,052 & $-0,124$ & $-0,165^{*}$ & $-0,168^{*}$ \\
Sonthofen (BY) & 73 & BHD 32-j. & $-0,001$ & 0,018 & $-0,181$ & $-0,124$ \\
Berchtesgaden (BY) & 17 & BHD 32-j. & $-0,173$ & $-0,594^{*}$ & 0,447 & 0,337 \\
Münsingen (BW) & 73 & Höhe 26-j. & $-0,300^{*}$ & $0,403^{*}$ & $-0,156$ & 0,026 \\
\hline
\end{tabular}


Die verfügbaren Klimawerte zu den Versuchsorten sind in Tabelle 2.4 zusammengestellt. Zwischen den Versuchsflächen (Hasbruch / Niedersachsen und den beiden bayerischen Flächen) gibt es mit $3,3{ }^{\circ} \mathrm{C}$ den größten Unterschied in der mittleren Jahresdurchschnittstemperatur. In der Vegetationszeit (Mai bis September) beträgt der Unterschied zwischen den Flächen Sonthofen / Bayern und Hasbruch / Niedersachsen $3{ }^{\circ} \mathrm{C}$. Im mittleren Niederschlag pro Jahr unterscheiden sich die Versuchsstandorte Reinhardshagen / Hessen und Sonthofen / Bayern um $1275 \mathrm{~mm}$ und in der Vegetationsperiode um etwa $650 \mathrm{~mm}$.

Um die Anpassungsfähigkeit einer Provenienz an geänderte Klimabedingungen zu beurteilen, sind die klimatischen Unterschiede zwischen dem Einsammlungsort des Saatgutes und den Versuchsorten entscheidend. Dazu sind für die einzelnen Versuchsflächen die Klimaunterschiede zwischen Einsammlungsort der Herkünfte und Versuchsort berechnet worden und mit dem Durchmesser- (Reinhardshagen, Hasbruch, Sonthofen, Berchtesgaden) bzw. Höhenwuchs (Münsingen) ins Verhältnis gesetzt worden (Abb. 4.2-4.6). Auf der x-Achse sind jeweils die Unterschiede bei der Jahresdurchschnittstemperatur zwischen Versuchsfläche und Einsammlungsort abgetragen. Auf der y-Achse ist das Verhältnis der Niederschlagsmenge zwischen Einsammlungsort und Versuchsort dargestellt. Die 25\% wüchsigsten Herkünfte sind als Punkte in der Abbildung eingezeichnet, die $25 \%$ mattwüchsigsten Herkünfte als offene Kreise und Herkünfte aus dem mittleren BHD- bzw. Höhen-Bereich als Sterne.

In die Punktwolke sind jeweils die Koordinatenachsen eingezeichnet und die Achsenskalierung am linken und unteren Rand des Koordinatenraumes. Die Koordinatenachsen besagen, dass Herkünfte, die rechts der y-Achse (vertikale Linie) liegen, aus kälteren Gegenden als der Versuchsort stammen, und Herkünfte, die unterhalb der x-Achse (horizontale Linie) liegen, aus trockeneren. 
In Abbildung 4.2 zeigt sich, dass für die Mehrheit der Herkünfte ein Transfer auf die Versuchsfläche Reinhardshagen einem Transfer an einen Ort mit höherer Jahresdurchschnittstemperatur und geringeren Niederschlägen entspricht. Für 152 Herkünfte der drei Teilflächen in Reinhardshagen liegen Klimawerte vor. Unter den 152 Herkünften sind 29, die dem $25 \%$-Quartil (BHD Alter 39) angehören. Etwa die Hälfte dieser Herkünfte (durch die Ellipse, die die meisten bestwüchsigen Herkünfte erfasst, in der Abbildung hervorgehoben) stammt von Einsammlungsorten mit mittleren Jahresdurchschnittstemperaturen, die zwischen $1{ }^{\circ} \mathrm{C}$ unter und $3{ }^{\circ} \mathrm{C}$ über der der Versuchsfläche liegen. Die mittleren jährlichen Niederschläge der Einsammlungsorte dieser Herkünfte betragen zwischen 90 und $120 \%$ des mittleren jährlichen Niederschlags der Versuchsfläche Reinhardshagen.

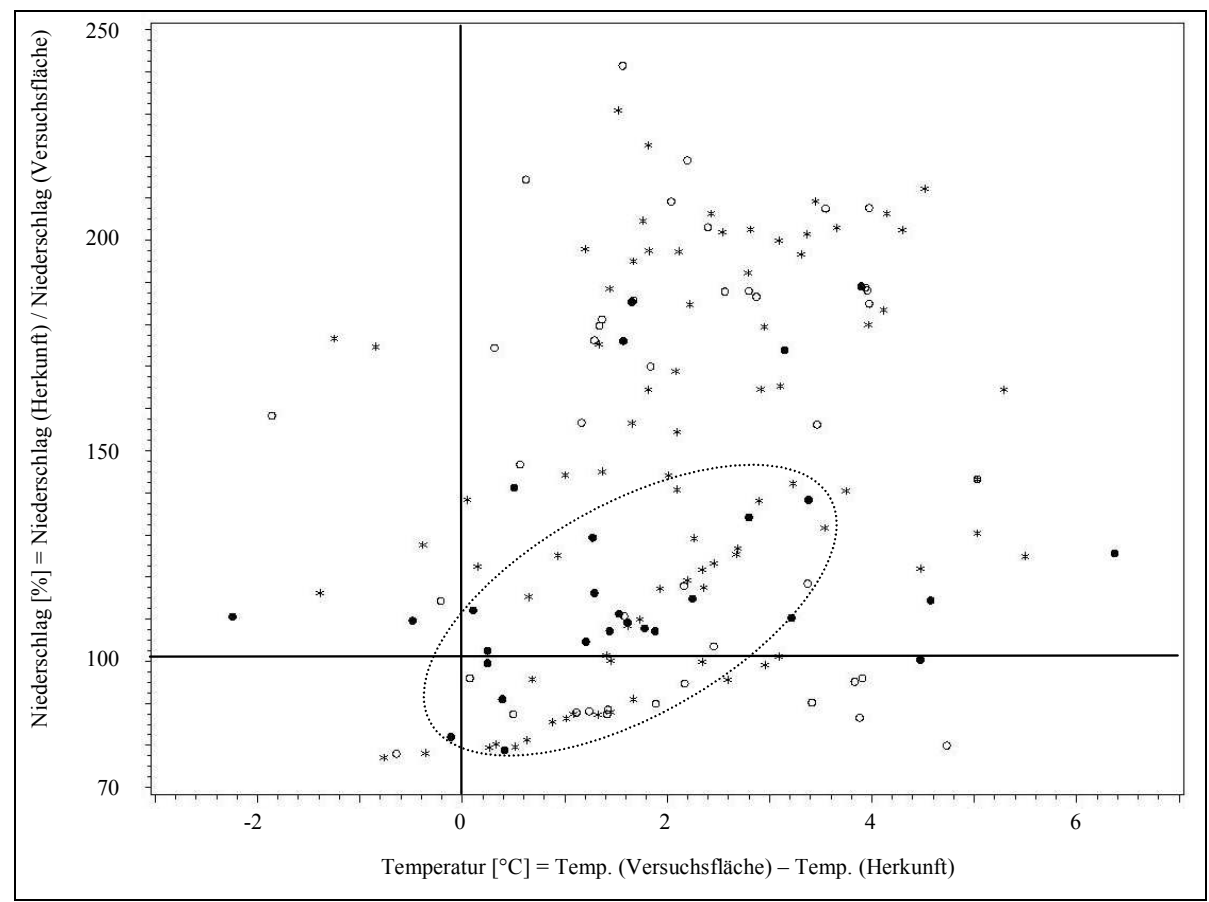

Abb.4.2: Angepasstheit an den Standort Reinhardshagen: Darstellung der Unterschiede in der mittleren Jahresdurchschnittstemperatur und im Jahresniederschlag zwischen dem Einsammlungsort der Herkünfte und dem Versuchsstandort. Die Herkünfte sind entsprechend ibrem Durchmesserwuchs gekennzeichnet: Punkte $=25 \%$ wüchsigste, Sterne $=50 \%$ mittlerer Bereich, offene Kreise $=25 \%$ mattwüchsigste. 
Auch der Anbau auf der Versuchsfläche Hasbruch in Niedersachsen bedeutet für die Mehrheit der Herkünfte einen Transfer an einen Ort mit höherer Jahresdurchschnittstemperatur und geringeren Niederschlägen (Abb. 4.3).

Von den hier angebauten 151 Herkünften, für deren Einsammlungsorte die Klimawerte bekannt sind, gehören 42 bezüglich des Durchmesserwachstums im Alter 39 zum $25 \%$-Quartil der bestwüchsigen Herkünfte. Diese Herkünfte sind alle an Orten eingesammelt worden, die durch eine geringere mittlere Jahresdurchschnittstemperatur beschrieben sind. Knapp drei Viertel dieser wüchsigen Herkünfte sind an Orten eingesammelt worden, deren mittlere Jahresdurchschnittstemperaturen um bis zu $4{ }^{\circ} \mathrm{C}$ geringer sind als die des Versuchsortes Hasbruch. Die mittleren jährlichen Niederschläge dieser Einsammlungsorte betragen zwischen 80 und $150 \%$ desjenigen des Versuchsortes.

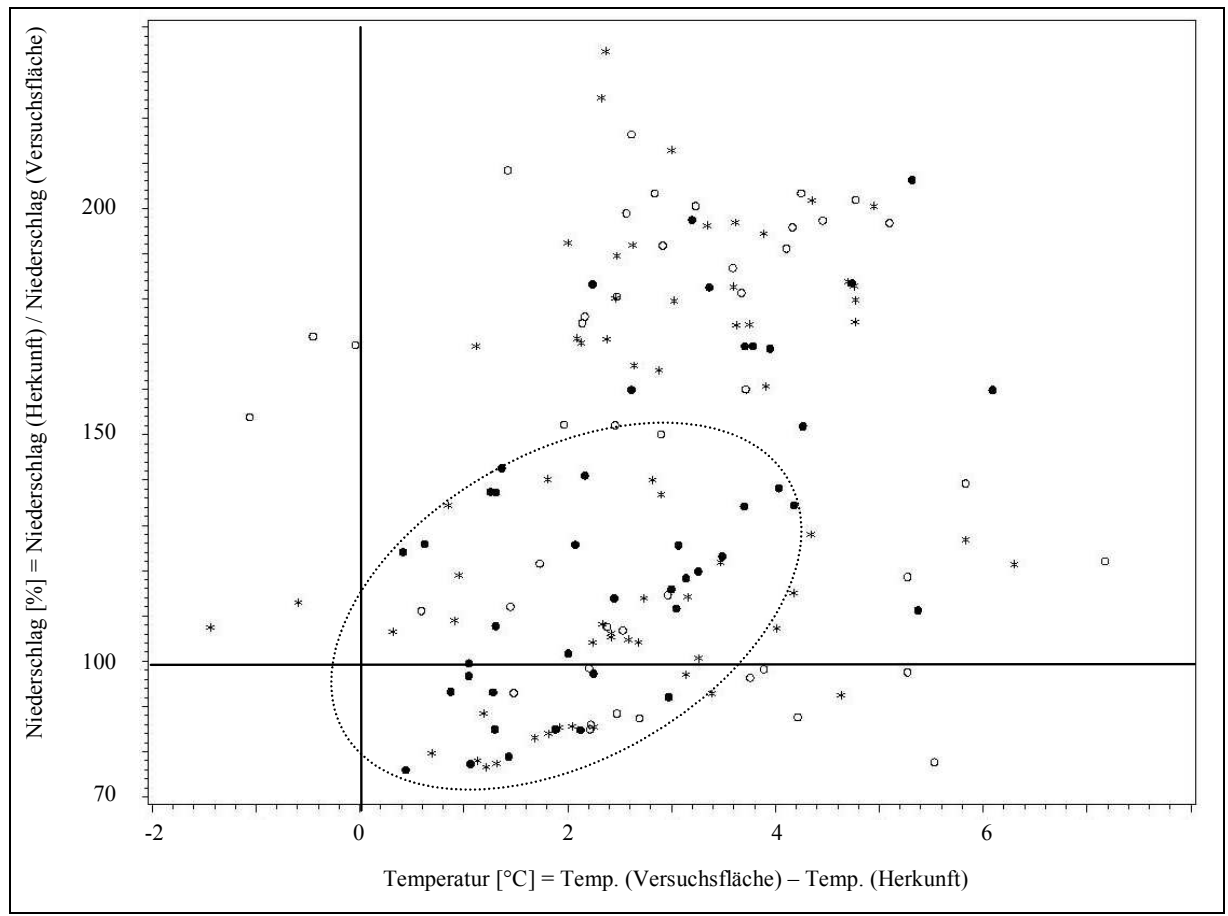

Abb. 4.3: Angepasstheit an den Standort Hasbruch: Darstellung der Unterschiede in der mittleren Jahresdurchschnittstemperatur und im Jahresniederschlag zwischen dem Einsammlungsort der Herkünfte und dem Versuchsstandort. Die Herkünfte sind entsprechend ibrem Durchmesserwuchs gekennzeichnet: Punkte $=25 \%$ wüchsigste, Sterne $=50 \%$ mittlerer Bereich, offene Kreise $=25 \%$ mattwüchsigste. 
Die beiden bayerischen Versuchsflächen zeichnen sich durch eine für viele der getesteten Herkünfte niedrigere Jahresdurchschnittstemperatur und eine kürzere Vegetationsperiode im Vergleich zum Einsammlungsort aus. Die Fläche Sonthofen hat deutlich höhere Niederschläge als die Einsammlungsorte der Herkünfte (Abb. 4.4). Von 73 Herkünften sind Klimawerte vom Einsammlungsort bekannt, davon gehören 21 zum 25 \%-Quartil der gutwüchsigen Herkünfte. Drei Viertel der Herkünfte mit dem besten Durchmesserwuchs im Alter von 32 Jahren stammen von Orten, deren durchschnittliche Jahresmitteltemperatur $2^{\circ} \mathrm{C}$ höher bis $0,5^{\circ} \mathrm{C}$ geringer als am Versuchsort Sonthofen ist. Die Niederschläge belaufen sich auf 30 bis $70 \%$ im Vergleich zu Sonthofen.

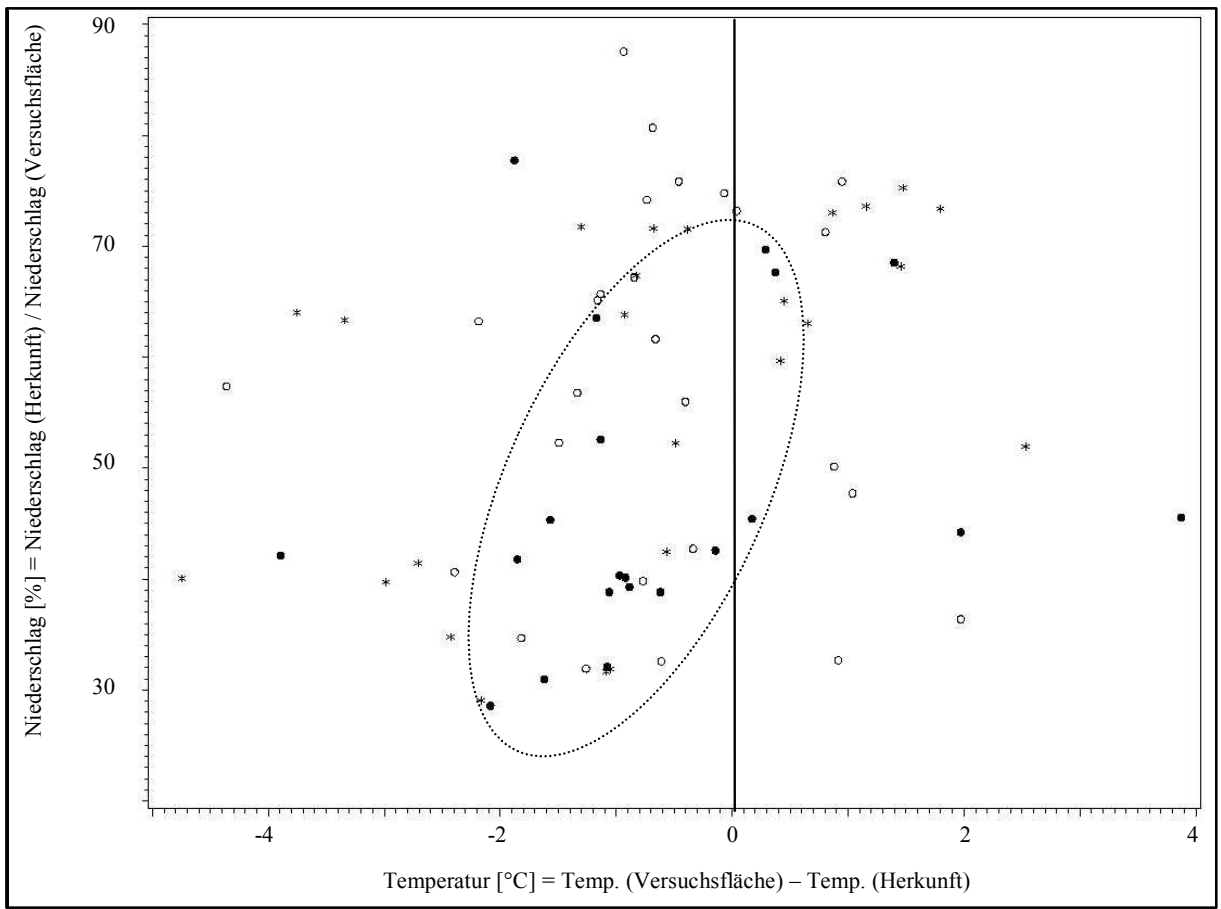

Abb.4.4: Angepasstheit an den Standort Sonthofen: Darstellung der Unterschiede in der mittleren Jabresdurschnittstemperatur und im Jabresniederschlag zwischen dem Einsammlungsort der Herkünfte und dem Versuchsstandort. Die Herkünfte sind entsprechend ihrem Durchmessernuchs gekennzeichnet: Punkte $=25 \%$ wüchsigste, Sterne $=50 \%$ mittlerer Bereich, offene Kreise $=25 \%$ mattwüchsigste. 
Auch die Fläche Berchtesgaden hat deutlich höhere Niederschläge als die Einsammlungsorte der Herkünfte (Abb. 4.5). Von 17 Herkünften liegen Klimawerte zu den Einsammlungsorten vor, darunter sind sechs, die dem $25 \%$-Quartil der bestwüchsigen Herkünfte angehören. Auf Grund der geringen Anzahl an Herkünften und der Streuung im Diagramm sind keine differenzierten Aussagen möglich. Auffallend ist dennoch, dass vier der gutwüchsigen Herkünfte an Orten eingesammelt wurden, die eine geringere Jahresmitteltemperatur haben als der Versuchsort Berchtesgaden.

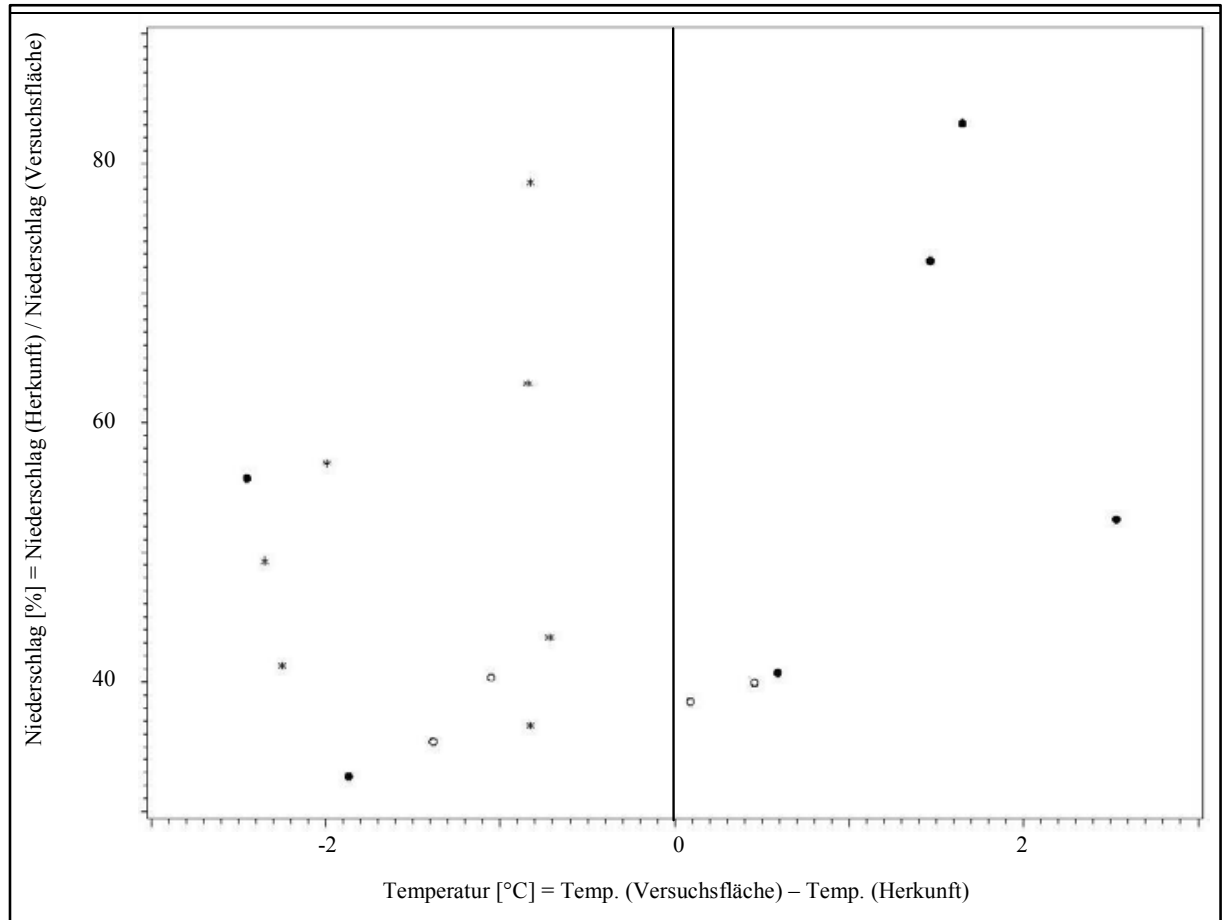

Abb. 4.5: Angepasstheit an den Standort Berchtesgaden: Darstellung der Unterschiede in der mittleren Jahresdurchschnittstemperatur und im Jahresniederschlag zwischen dem Einsammlungsort der Herkünfte und dem Versuchsstandort. Die Herkünfte sind entsprechend ihrem Durchmesserwuchs gekennzeichnet: Punkte $=25 \%$ wüchsigste, Sterne $=50 \%$ mittlerer Bereich, offene Kreise $=25 \%$ mattwüchsigste. 
Für die Fläche Münsingen / Baden-Württemberg lässt sich nur das Höhenwachstum im Alter 26 von 73 Herkünften mit den Klimawerten analysieren (Abb. 4.6). Die Mehrheit der Herkünfte auf der Fläche Münsingen stammt von einem niederschlagsreicheren Einsammlungsort. Etwa drei Viertel der dem 25 \%-Quartil angehörenden wüchsigen Herkünfte wurde an Orten eingesammelt, an denen es im Vergleich zum Versuchsort $1{ }^{\circ} \mathrm{C}$ wärmer bis $1,5^{\circ} \mathrm{C}$ kühler ist. An diesen Orten beträgt die mittlere jährliche Niederschlagsmenge im Vergleich zum Versuchsort zwischen 70 und $170 \%$.

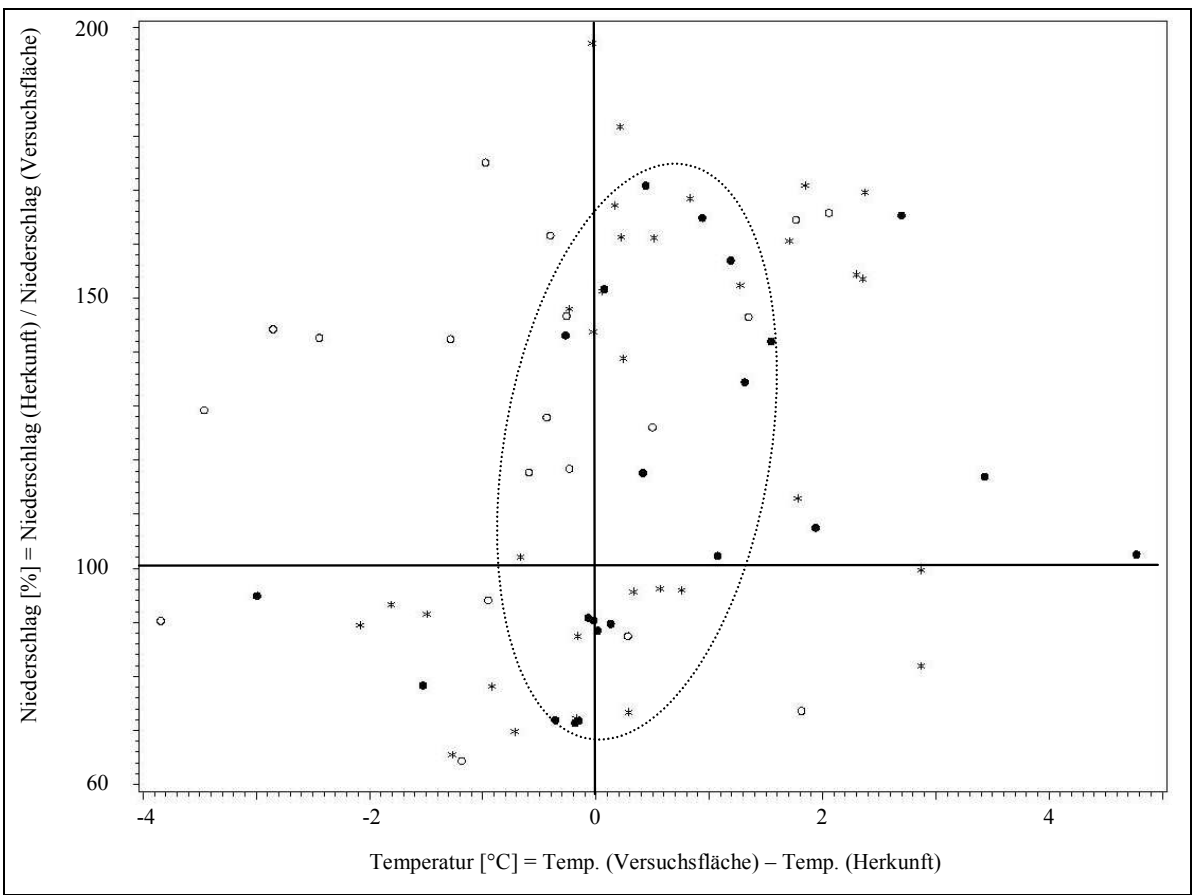

Abb. 4.6: $\quad$ Angepasstheit an den Standort Münsingen: Darstellung der Unterschiede in der mittleren Jahresdurchschnittstemperatur und im Jahresniederschlag zwischen dem Einsammlungsort der Herkünfte und dem Versuchsstandort. Die Herkünfte sind entsprechend ihrem Höhenwuchs gekennzeichnet: Punkte $=25 \%$ wüchsigste, Sterne $=50 \%$ mittlerer Bereich, offene Kreise $=25 \%$ mattwüchsigste.

Eine eindeutige Gruppierung der wüchsigen bzw. mattwüchsigen Herkünfte ist auf keiner der Flächen gegeben. Auf allen Versuchsflächen gibt es Unterschiede in der Merkmalsausprägung zwischen und innerhalb der Herkünfte. Die Ergebnisse machen es schwer, generelle Schlussfolgerungen zu ziehen. Man muss berücksichtigen, dass diese Versuche nicht speziell zur Beantwortung der Fragestellung der Auswirkung möglicher Klimaänderungen angelegt wurden. So ist es möglich, dass 
interpolierte Klimaangaben nicht mit den realen kleinräumigen Standortsgegebenheiten übereinstimmen. Außerdem ist bekannt, dass viele der untersuchten Herkünfte nicht autochthon sind, so dass die beobachtete Reaktion von der erwarteten abweicht, da die Herkunft eine Generation zuvor verbracht wurde (LIESEBACH et al. 2001, LIESEBACH 2005).

Trotz der Einschränkungen, die durch das Versuchsmaterial bedingt sind, stammen die meisten wüchsigen Herkünfte von Standorten, die bezüglich der mittleren Jahresdurchschnittstemperatur und des mittleren jährlichen Niederschlags dem Versuchsort ähnlich sind. Dieses Ergebnis zeigten auch die bislang vorliegenden Analysen aus dem IUFRO-Versuch von 1964/1968, wobei die Streuung der wüchsigen Herkünfte dort etwas geringer ausfiel (LIESEBACH et al. 2001, LIESEBACH 2005). An den Standorten in Hessen und Niedersachsen zeigt sich, dass für viele der wüchsigen Herkünfte die Jahresdurchschnittstemperatur am jeweiligen Versuchsort bis zu 2 bzw. $4{ }^{\circ} \mathrm{C}$ höher liegt. Auf der Fläche Hasbruch / Niedersachsen ist dabei die Differenz in den Niederschlägen zwischen Anbauort und Versuchsort größer als in Reinhardshagen / Hessen. Durch die Nähe zum Meer ist vermutlich die Luftfeuchte auf der Fläche Hasbruch höher, dadurch wird ein Teil der fehlenden Niederschläge kompensiert. Gleichzeitig leidet die Fichte unter den Salzeinwehungen, was als ein Grund für den insgesamt schlechten Zustand der Fichten in Hasbruch gewertet wird.

Die in Kapitel 4.3 am Beispiel des IUFRO-Fichtenherkunftsversuchs von 1972 dargestellte Standortunabhängigkeit von Herkünften (z. B. Lubelski Nr. 19) hat vor dem Hintergrund prognostizierter Klimaänderungen besondere Bedeutung. Im Zuge des Klimawandels haben diese Herkünfte einen Vorteil. 


\section{Literatur}

ANONYMUS (1968): Population Studies of Norway Spruce in Poland. Forest Research Institute Warsaw. $180 \mathrm{~S}$.

ANONYMUS (2002): Forstvermehrungsgutgesetz (FoVG) vom 22. Mai 2002. BGB1 I 32, S. 1658-1666

ASSMANN, E.; FRANZ, F. (1963): Ertragstafel Fichte - mittleres Ertragsniveau. In: BAYERISCHES STAATSMINISTERIUM FÜR ERNÄHRUNG, LANDWIRTSCHAFT UND FORSTEN (Hrsg.) (1990): Hilfstafeln für die Forsteinrichtung

BARZDAJN, W. (1995): Dwudziestoletnie doświadczenie proweniencyjne ze świerkiem (Picea abies (L.) Karst.) serii IUFRO 1972 w Leśnym Zakładzie Doświadczalnym Siemianice. III. Cechy fenologiczne. Sylwan 7, S. 33-49

CiEslar, A. (1899): Neues aus dem Gebiete der forstlichen Zuchtwahl. Centralbl. f. d. ges. Forstwes. 25. Jg. (Separatabdruck 44 S.)

DiETRICHSON, J. (1969): The Geographic Variation of Spring-frost Resistance and Growth Cessation in Norway Spruce (Picea abies [L.] Karst.). Meddr norske Skogfors Ves. 27, S. 94-106

DiETRICHSON, J. (ed.) (1973): Abstracts of papers. (IUFRO-) Meeting of the w.p. 2.02.11 on Norway spruce provenances, Biri / Norway, Aug. 14-20, 1973. The Norwegian For. Res. Inst., $54 \mathrm{~S}$.

Dietrichson, J.; Christophe, C.; Coles, J.F.; Jamblinne, A. DE; Krutzsch, P.; KÖnIG, A.; Lines, R.; MAgnesen, S.; NAnson, A.; Vins, B. (1976): The IUFRO provenance experiment of 1964/68 on Norway spruce (Picea abies [L.] Karst.). A joint voluntary paper with height data from 8 countries. Compl. and ed. by J. Dietrichson. The Norwegian For. Res. Inst., Ås / Norway

Dietrichson, J.; Rognerud, P.A.; HaveraAen, O.; SkrøPPA, T. (1985): Stem cracks in Norway spruce (Picea abies [L.] Karst.). Reports of the Norwegian Forest Research Institute 38.21

DiETZE, W.; RÁCZ; J. (1973): Phenological observations and height growth of the International Norway Spruce Provenance Trial from 1964/68 during the nursery stage. In: DIETRICHSON, J. (ed.): Abstracts of papers. IUFRO-meeting of the w.p. 2.02.11 on Norway spruce provenances, Biri / Norway, Aug. 14-20, 1973. The Norwegian For. Res. Inst., S. 18-19

DKV [Deutsche Kontrollvereinigung für forstliches Saat- und Pflanzgut e. V.] (Hrsg.) (1967): Wertvolle Herkünfte forstlicher Baumarten in der Bundesrepublik Deutschland. BLV, München Basel Wien 
FISCHER, F. (1949/50): Ergebnisse von Anbauversuchen mit verschiedenen Fichtenherkünften (Picea abies [L.] Karst.). Mitt. Schweiz. Anst. forstl. Versuchswesen 26, S. 153-204

FOTTLAND, H.; SKRøPPA, T. (1989): The IUFRO 1964/68 provenance experiment with Norway spruce (Picea abies) in Norway. Variation in mortality and height growth. Communications of the Norwegian Forest Research Institute 43.1

FRÖHLICH, H.J. (1966): Sonderherkünfte und Forstpflanzenzüchtung, dargestellt am Beispiel der Fichte. Mitt. Hess. Landesforstverwaltung 4, S. 36-56

GÄRTNER, E.J. (1980): Beiträge zur Beurteilung der Jugendentwicklung von Fichtenprovenienzen. Mitt. Hess. Landesforstverwaltung 15

GIERTYCH, M. (1976): Zmienność genetyczna polskich ras świerka (Picea abies [L.] Karst.). Arboretum Kórnickie 21, S. 107-120

GIERTyCH, M. (1977): Genetyka. In: BIAlOBOK, S. (Red.): Swierk pospolity Picea abies (L.) Karst. Nasze Drzewa Le'sne 5. Warszawa, Poznan Polen, S. 287-331

GIERTYCH, M. (1984): Report on the IUFRO 1938 and 1939 provenance experiments on Norway spruce (Picea abies [L.] Karst.). Polish Academy of Science Institute of Dendrology. Kórnik, Poland. $177 \mathrm{~S}$.

GIERTYCH, M. (1991): Selekcja proweniencyjna, rodowa I indywidualna w doświadczeniach wieloczynnikowych ze świerkiem pospolitym (Picea abies [L.] Karst.). Arboretum Kórnickie 36, S. 27-42

GÜNTHER, T. (1987): Lagerung von forstlichem Saatgut - eine Literaturauswertung. Diplomarbeit, Forstwissenschaftliche Fakultät der LMU, München

GÜNZL, L. (1969): Ergebnisse aus einer Fichtenprovenienzforschung. Forstl. Bundesvers. Anst., Informationsdienst 120

GÜNZL, L. (1979): Internationale Fichten-Provenienzversuche der IUFRO 1938 und 1964/68 sowie Versuche mit österreichischen Herkünften. Allg. Forstztg. (Wien) 90 (7), S. 182-190

GUTTENBERG (1915): Ertragstafel Fichte - Hochgebirge. In: BAYERISCHES STAATSMINISTERIUM FÜR ERNÄHRUNG, LANDWIRTSCHAFT UND FORSTEN (Hrsg.) (1990): Hilfstafeln für die Forsteinrichtung

Holst, M. (1963): Growth of Norway spruce (Picea abies [L.] Karst.) provenances in Eastern North America. World Consulting in Forest Genetics and Tree Improvement, Stockholm

HOLUBČIK, M. (1979): Juvenilny rast polskych a domacich provenienci smreka obycajnego (Picea excelsa Karst.). Lesnicky casopis 25 (4), S. 255-270 
KAnNEnBERG, N.; Gross, K. (1999): Allozymic variation in some Norway spruce populations in the International IUFRO Provenance-testing Programme of 1964/1968. Silvae Genet. 48 (5), S. 209-217

KERN, K.G. (1966): Wachstum und Umweltfaktoren im Schlag- und Plenterwald. Schriftenreihe Forstl. Abt. Univ. Freiburg 5, S. 41-62

KIENITZ, M. (1879): Vergleichende Keimversuche mit Waldbaum-Samen aus klimatisch verschieden gelegenen Orten Mitteleuropas. Bot. Untersuch., Heidelberg, 2, S. 1-54

KLEINSCHMIT, J.; SVOLBA, J.; KLEINSCHMIT, J.R.G. (1996): Variation anpassungsrelevanter, phänotypischer Merkmale. In: MÜLlER-STARCK, G. (Hrsg.): Biodiversität und nachhaltige Forstwirtschaft. Ecomed, Landsberg, S. 38-59

KNABE, W.; URFER, W.; VENNE, H. (1990): Die Variabilität der Immissionsresistenz von Fichtenherkünften - ein Beitrag zum IUFRO-Fichtenprovenienzversuch 1964/68. Silvae Genet. 39 (1), S. 8-17

KÖNIG, A. (1981): Einige Ergebnisse aus dem IUFRO-Fichtenprovenienzversuch von 1964/68 in der Bundesrepublik Deutschland. Allg. Forstztg. (Wien) 92, S. $300-303$

KÖNIG, A. (1989): Correlations between growth data in the IUFRO 1964/68 Norway spruce provenance experiment. In: STENER, L.-G. u. WERNER, M. (eds.) 1989: Norway Spruce; Provenances, Breeding and Genetic Conservation. Proc. IUFRO W.P. meeting, S2.02-11, in Tjörnap, Sweden, Sept. 5-10, 1988, Inst. f. For. Improvement, Rep. no. 11, Uppsala, Sweden, S. 249-254

KÖNIG, A. (1998): Performance of Polish provenances of Picea abies in the Bavarian Forest. In: SKRØPPA, T.; PAule, L. u. GÖMÖRY, J. (eds.): Genetics and Breeding of Norway Spruce, 1998, Proceedings (unveröffentlichtes Manuskript)

KÖNIG, A.O. (2002): Growth and snowbreak damage of Norway spruce provenances from Poland under harsh site conditions. In: MEIER-DINKEL, A. u. STEINER, W. (comp.): Forest Tree Breeding in an Ecologically Oriented Forest Management System. Proc. of the meeting in Escherode (Germany), 28-29 June 2001. Schriften aus der Forstlichen Fakultät der Universität Göttingen und der Niedersächsischen Forstlichen Versuchsanstalt, Band 134, S. 139-150

KÖNIG, A.O. (2005): Provenance research: evaluating the spatial pattern of genetic variation. In: GEBUREK, T. u. TuroK, J. (Hrsg.): Conservation and Management of Forest Genetic Resources in Europe. Arbora Pub., Zvolen, S. 275-333

KONNERT, M.; BEHM, A. (1999): Genetische Strukturen einer Saatgutpartie - Einflußfaktoren und Einflußmöglichkeiten. Beitr. Forstwirtsch. u. Landsch.ökol. 33 (4); S. 152-156 
KRAMER, H. (1975): Erhöhung der Produktionssicherheit zur Förderung einer nachhaltigen Fichtenwirtschaft. Forstarchiv 46 (1), S. 9-13

Kramer, H. (1988): Waldwachstumslehre. Verlag P. Parey, Hamburg, Berlin. 374 S.

KRAMER, H.; AKCA, A. (1995): Leitfaden zur Waldmeßlehre. Sauerländer's Verlag, Frankfurt am Main. 266 S.

KRUTZSCH, P. (1973): The inventory provenance test with Norway spruce. In: Dietrichson, J. (ed.): Abstracts of papers. (IUFRO-) Meeting of the w.p. 2.02.11 on Norway spruce provenances, Biri / Norway, Aug. 14-20, 1973. The Norwegian For. Res. Inst., S. 17

KrutzsCH, P. (1974): The IUFRO 1964/68 Provenance Test with Norway Spruce (Picea abies [L.] Karst.). Silvae Genet. 23 (1-3), S. 58-62

KRUTZSCH, P. (1975): Die Pflanzenschulenergebnisse eines inventierenden Herkunftsversuches mit Fichte (Picea abies Karst. und Picea obovata Ledeb.). Inst. Skogsgen. Royal Coll. For. Stockholm, Rapp. 14, 64 S.

KRUTZSCH, P. (1992): IUFRO's Role in Coniferous Tree Improvement: Norway Spruce (Picea abies [L.] Karst.). Silvae Genet. 41 (3), S. 143-150

LANGLET, O. (1960): Mellaneuropeiska granprovenienser i svenskt skogbruk. K. Skogs- o. Lantbr. Akad. T. 99, S. 259- 329

LIESEBACH, M. (1994): Untersuchungen an ausgewählten Herkünften des internationalen Fichtenprovenienzversuchs 1964/68 über den Zusammenhang zwischen Isoenzym-Merkmalen und morphologischen, phänologischen sowie Wachstums-Merkmalen. Dissertation Universität Hamburg. 210 S.

LIESEBACH, M. (2005): Statistische Untersuchungen zur Verbesserung der Kenntnisse über die Angepasstheit von Fichtenpopulationen im Hinblick auf die Verschiebung von Vegetationszonen. In: LIESEBACH, M. u. SEMMLER-BUSCH, A.U. (Hrsg.): Tagungsberichte der Arbeitsgruppe Ökologie und Umwelt, Heft 15. IBG-DR AG Ökologie und Umwelt, Waldsieversdorf und Tübingen, S. 32 40

LiesebaCH, M.; KÖNIG, A.; UjVÁRI-JÁRMAY, E. (2001): Provenance-environment interactions of Norway spruce (Picea abies [L.] Karst.) on German and Hungarian test sites. In: MÜller-STARCK, G. u. SCHUBERT, R. (eds.): Genetic Response of Forest Systems to Changing Environmental Conditions. Vol. 70 (For. Sci.), Kluwer Academic Publishers, Dordrecht, Boston, London, S. 353363

LiESEBACH, M.; MENGL, M.; WeißENBACHER, L. (2006): 100 Jahre Eichenforschung in Mariabrunn. In: HESSEN-FORST (Hrsg.): Forstliche Genressourcen als Produktionsfaktor. 26. Tagung der Arbeitsgemeinschaft für Forstgenetik 
und Forstpflanzenzüchtung vom 20. bis 22. Oktober 2005 in Fuldatal. HessenForst, Hann. Münden, S. 170-179

MATRAS, J. (1993): Growth of Norway spruce in IUFRO 1972 experiment. In: RONE, V. (ed.): Norway spruce provenances and breeding. Proc. of the IUFRO S2.2-11 symposium Latvia 1993. Latvian For. Res. Inst. 'Silava', Riga 1993, S. 100-104

MATRAS, J. (2004): Genetic value of the Silesian Beskid populations of Norway spruce Picea abies (L.) Karst. in the IUFRO 1972 provenance experiment. Dendrobiology 51, Supplement, S. 71-80

MELZER, H. (1937): Der Fichten-Herkunftsversuch in Loimannshagen, Ergebnisse einer Aufnahme im Jahre 1936. Cbl. ges. Forstwesen 63, S. 225-232

Mold, E.; GrÖGER, J.; LiesebaCH, M.; RudolPh, P.E.; STAUber, T.; Ziller, M. (Hrsg.) (2004): Einführung in die Biometrie. 4 Bände. Saphir-Verlag, Ribesbüttel, 2. Auflg.

MÜLLER-STARCK, G. (Hrsg.) (1996): Biodiversität und nachhaltige Forstwirtschaft. Ecomed Verlagsgesellschaft, Landsberg

Persson, A.; Persson, B. (1992): Survival, growth and quality of Norway spruce (Picea abies [L.] Karst.) provenances at the three Swedish sites of the IUFRO 1964/68 provenance experiment. Swedish University of Agricultural Sciences. Report No. 29

RASCH, D.; HERRENDÖRFER, G.; BOCK, J.; ViCTOR, N.; GUIARD V. (1996): Verfahrensbibliothek. Versuchsplanung und -auswertung Band I. Oldenbourg Verlag, München Wien

RASCH, D.; HERRENDÖRFER, G.; BOCK, J.; ViCTOR, N.; GUIARD V. (1998): Verfahrensbibliothek. Versuchsplanung und -auswertung Band II. Oldenbourg Verlag, München Wien

RAU, H.-M. (1983): Die Entwicklung des deutsch-polnischen Fichtenprovenienzversuches in Hessen. Forstarchiv 54, S. 15-19

RAU, H.-M. (1993): The IUFRO 1964/68 Norway spruce provenances trial in Germany after 25 years of observation. In: RONE, V. (ed.): Norway Spruce Provenances and Breeding. Proc. of the IUFRO S. 2.2-11 Symposium Latvia 1993. Latvian For. Res. Inst. 'Silava', Riga 1993, S. 128-132

RAU, H.-M. (2007): Geprüftes Vermehrungsgut, Folge 5: Samenplantagen und Bestände von Fichte. AFZ/Der Wald 62 (8), S. 418-419

RAU, H.-M.; KÖNIG, A.; RUETZ, W.; SvOLBA, J. (1998): Wachstum polnischer Fichtenherkünfte auf westdeutschen Versuchsflächen. AFZ/Der Wald 53 (8), S. 411-413 
RICHTER, C. (2002): Holzmerkmale: Ovalität/Exzentrizität. Teil 3 der Serie „Äußerlich erkennbare Holzmerkmale“. Holz-Zent.Bl. 128 (121), S. 1430-1431

RICHTER, C. (2007): Holzmerkmale. DRW-Verlag, Leinfelden-Echterdingen

RoHMEDER, E.; BeusCHeL, G. (1970): Der Fichtenherkunftsversuch in Bischofsreuth / Bayer. Wald nach 32jähriger Wuchszeit. Forstwiss. Cent.bl. 89, S. 78-87

RUBNER, K. (1957): Ergebnisse eines heute 20-jährigen Fichtenherkunftsversuches - I. Teil: Die Fläche in Bayern. Silvae Genet. 6, S. 65-74

RuBNER, K. (1960): Die pflanzengeographischen Grundlagen des Waldbaus. 5. Aufl. Neumann, Radebeul und Berlin

SCHMidT, P.A. (2002): Picea abies [L.] H. Karst., 1881. In: SCHÜTT, P.; WeISGERBER, H.; SCHUCK, H.J.; LANG, U. u. ROLOFF, A. (Hrsg.): Enzyklopädie der Holzgewächse. Handbuch und Atlas der Dendrologie. Ecomed, Landsberg. 28. Erg.Lfg. 7/02. $18 \mathrm{~S}$.

SCHMIDT-VOGT, H. (1972): Wachstum und Schneebruchresistenz von Fichtenherkünften des Bayerischen Alpenvorlandes, der Bayerischen Alpen und des Bayerischen Waldes. Forstw. Cbl. 91, S. 339-357

SCHMidT-VogT, H. (1977-1991): Die Fichte. Ein Handbuch in zwei Bänden. Bd. 1 (1977, 2. Aufl. 1987), Bd. 2/1 (1986), Bd. 2/2 (1989), Bd. 2/3 (1991). Verlag P. Parey Hamburg und Berlin

SCHMIDT-VOGT, H.; KOCIECKI, S. (1985): Entwicklung des IUFRO-Fichtenprovenienzversuches 1972 auf deutschen Versuchsflächen bis zum Alter 10. Forstarchiv 56, S. 138-142

SCHUBERT, J. (1999): Lagerung und Vorbehandlung von Saatgut wichtiger Baumund Straucharten. Hrsg. von der Landesanstalt für Ökologie, Bodenordnung und Forsten / Landesamt für Agrarordnung Nordrhein-Westfalen

SumpF, D.; MOLL, E. (2004): Schätzen eines Parameters und Vergleich von bis zu zwei Parametern. In: MOLL, E.; GRÖGER, J.; LIESEBACH, M.; RUdOLPH, P.E.; Stauber, T. u. Ziller, M. (Hrsg.): Einführung in die Biometrie. Band 2. Saphir Verlag Ribbesbüttel, 2. Aufl.

SzOZDA, W.; SABOR, J. (1998): Wisła Forest District. Unveröffentlichtes Manuskript. $16 \mathrm{~S}$.

THOMAS, E. (2006): Feldversuchswesen. Verlag E. Ulmer Stuttgart

Thomasius, H. (1990): Vorkommen, Bedeutung und Bewirtschaftung der Fichte in der DDR. Forstw. Cbl. 109, S. 138-152

WALTER, H.; LIETH, H. (1960): Klimadiagramm-Weltatlas. VEB Gustav Fischer Verlag Jena 
Weisgerber, H. (1983): Forstpflanzenzüchtung. Aufgaben, Ergebnisse und Ziele von Züchtungsarbeiten mit Waldbäumen in Hessen. Mitt. der Hess. Landesforstverwaltung, Band 19., J.D. Sauerländer's Verlag Frankfurt am Main

WEIsGERBER, H. (1990): Beiträge zur genetischen Variation der Waldbäume und Gefahren der Genverarmung durch Pflanzenzüchtung. Forstliche Forschungsberichte München, Nr. 107

Weisgerber, H.; Dietze, W.; Kleinschmit, J.; RACZ, J.; Dieterich, H.; DIMPFLMEIER, R. (1976a): Der Internationale Fichten-Herkunftsversuch von 1962 in der Bundesrepublik Deutschland. Beobachtungen im Anzuchtstadium sowie nach drei- und achtjähriger Freilandpflanzung. Diskussionspapier, XVI IUFRO World-Congress, Oslo/Norwegen, 20.6.-2.7.1976. WP S 2.02.11 Norway spruce provenances. $7 \mathrm{~S}$.

Weisgerber, H.; Dietze, W.; Kleinschmit, J.; RACZ, J.; DieteriCH, H.; DIMPFLMEIER, R. (1976b): Ergebnisse des internationalen Fichten-Provenienzversuches 1962. Teil I: Phänologische Beobachtungen und Höhenwachstum bis zur ersten Freilandaufnahme. Allg. Forst- u. J.-Ztg. 147 (12), 227-235

Weisgerber, H.; Dietze, W.; Kleinschmit, J.; RACZ, J.; Dieterich, H.; DIMPFLMEIER, R. (1977): Ergebnisse des internationalen Fichten-Provenienzversuches 1962. Teil II: Weitere Entwicklung bis zum Alter 13. Allg. Forst- u. J.-Ztg. 148 (12), 217-226

Weisgerber, H.; Dimpflmeier, R.; RuETZ, W.; KLEINSCHMiT, J.; WidMAIER, T.; (1984): Ergebnisse des internationalen Fichten-Provenienzversuches 1962. Entwicklung bis zum Alter 18. Allg. Forst- Jagdztg. 155 (4/5), 110-121

WiEDEMANN (1936/1942): Ertragstafeln - Fichte. In: SCHOBER, R. (1979): Ertragstafeln wichtiger Baumarten. J.D. Sauerländer's Verlag Frankfurt am Main 


\section{Danksagung}

An der fast 100 Jahre alten Aussage des Münchner Lehrstuhlinhabers für Betriebswirtschaft und Forstpolitik Professor ENDRES: „Die Herkunftsfrage ist in der Forstwirtschaft von zentraler Bedeutung "hat sich bis heute nichts geändert, was Schadereignisse immer wieder belegen. Die von verschiedenen Instituten für Forstpflanzenzüchtung und für Waldbau angelegten Feldversuche liefern der forstlichen Praxis und der Forschung wichtige Ergebnisse. Solche Versuche sind aber nur möglich, wenn langfristig stabile Bedingungen für Personen und Institutionen gegeben sind. Derart langfristig angelegte Versuche sind auch nicht das Werk eines einzelnen oder weniger. Daher schließt die Arbeit mit einem Dank an alle, die nicht als Autoren in Erscheinung treten.

Der Fichtenherkunftsversuch von 1962 wurde von H. J. FRÖHLICH ${ }^{1)}$, R. KLEINSCHMiT'2), H. GONSER ${ }^{3)}$ und R. DimpflmeIER ${ }^{4)}$ begonnen. Fortgeführt wurde er unter anderem von H. WEISGERBER ${ }^{1)}$, W. DIETZE ${ }^{1)}$, J. KLEINSCHMIT'2), R. RACZ2), H. Dieterich ${ }^{3)}$, T. WIDMAIER ${ }^{3)}$ und W. RUETZ ${ }^{4}$. An dem zehn Jahre später angelegten IUFRO-Fichtenherkunftsversuch von 1972 haben außerdem H. SCHMIDT-VOGT ${ }^{5}$, A. FRANKE $\left.{ }^{3}\right)$ und J. SvOLBA ${ }^{2}$ ) mitgearbeitet. Hervorzuheben ist, dass bei der vorliegenden abschließenden Auswertung der Versuche auch eine von der Bundesforschungsanstalt für Forst- und Holzwirtschaft (heute Johann Heinrich von Thünen-Institut), Großhansdorf, angelegte Fläche einbezogen werden konnte. Besonderer Dank gilt E. SCHÖNFELDER ${ }^{1)}$ für die Aufarbeitung und Pflege der Daten sowie deren früherer Auswertung. Für die Erstellung der digitalen Karten danken wir besonders T. STAUBER vom Institut für Forstgenetik und Forstpflanzenzüchtung der Bundesforschungsanstalt für Forst- und Holzwirtschaft (heute Johann Heinrich von Thünen-Institut), Waldsieversdorf. Auch den zahlreichen namentlich nicht genannten Mitarbeitern aller beteiligten Institute, die im Laufe der Jahre die Messungen durchgeführt haben, die Daten eingegeben haben bzw. die Versuchsflächen betreut haben, wird für ihre Mitarbeit gedankt. Für das entgegengebrachte Verständnis und die Hilfsbereitschaft wird den Forstämtern und den Forstrevieren gedankt, die die Flächen bereitgestellt und gepflegt haben.

\footnotetext{
1) Hessische Forstliche Versuchsanstalt, Hann. Münden (heute Nordwestdeutsche Forstliche Versuchsanstalt)

2) Niedersächsische Forstliche Versuchsanstalt, Escherode (heute Nordwestdeutsche Forstliche Versuchsanstalt)

3) Forstliche Versuchs- und Forschungsanstalt Baden-Württemberg, Stuttgart und Freiburg

4) Bayerische Landesanstalt für forstliche Saat- und Pflanzenzucht, Teisendorf (heute Bayerisches Amt für forstliche Saat- und Pflanzenzucht)

5) Institut für Waldbau, Universität Freiburg
} 
Besonderer Dank gilt der Nordwestdeutschen Forstlichen Versuchsanstalt, die durch die Bereitstellung von Finanzmitteln die vorliegende Auswertung erst ermöglicht hat. Frau C. BUDNIK, Frau E. PAAR und Frau U. GAERTNER wird für die Neuformatierung des Textes gedankt, die erforderlich wurde, da die ursprünglich vorgesehene Schriftenreihe bei der Fertigstellung der Arbeit eingestellt wurde. Frau I. KEHR danken wir für die abschließende kritische Durchsicht des Manuskripts.

Die gemeinschaftliche Auswertung hat gezeigt, dass die Abstimmung zwischen den beteiligten Instituten nicht immer einfach war. Dennoch ist es gelungen, die Arbeiten weitgehend miteinander abzustimmen, so dass am Ende doch zahlreiche Vergleiche zwischen den Flächen, die von verschiedenen Instituten betreut werden, möglich waren. Mit diesen Versuchen werden bereits seit ihrer Anlage Synergien genutzt, die heute von anderen Disziplinen erst entdeckt werden. 


\section{Autoren}

\section{Dr. Mirko Liesebach}

Vormals in:

Nordwestdeutsche Forstliche Versuchsanstalt

Abteilung Waldgenressourcen

Prof.-Oelkers-Straße 6

D-34346 Hann. Münden

Aktuell:

Johann Heinrich von Thünen-Institut

Institut für Forstgenetik

Sieker Landstraße 2

D-22927 Großhansdorf

mirko.liesebach@vti.bund.de

\section{Hans-Martin Rau}

Nordwestdeutsche Forstliche Versuchsanstalt Abteilung Waldgenressourcen

Prof.-Oelkers-Straße 6

D-34346 Hann. Münden

hans-martin.rau@nw-fva.de

\section{Dr. Armin O. König}

Bis zum Ruhestand:

Johann Heinrich von Thünen-Institut

Institut für Forstgenetik

Sieker Landstraße 2

D-22927 Großhansdorf 


\section{Anhang}

In den nicht sortierten Tabellen des Anhangs sind die Extremwerte hervorgehoben.

\section{Übersicht}

\section{Anhang 1: Der Fichtenherkunftsversuch von 1962}

Anhang 1.1 Herkunftsangaben zum Internationalen Fichtenherkunftsversuch 1962 und Verbindung zum IUFRO-Versuch 1964/68....................

Anhang 1.2 Zusammenstellung der mittleren Stammzahl im Alter von 32 und 39 Jahren auf den drei Versuchsflächen Reinhardshagen / Hessen............

Anhang 1.3 Zusammenstellung der mittleren Ovalitäten [\%] im Alter von 32 und 39 Jahren sowie des H/D-Verhältnisses im Alter von 39 Jahren auf den drei Versuchsflächen Reinhardshagen / Hessen...

Anhang 1.4 Zusammenstellung der sich signifikant von mindestens einer anderen Herkunft im Tukey-Kramer-Test für das Merkmal Ovalität [\%] im Alter 32 auf der Versuchsfläche Reinhardshagen / Hessen (34) unterscheidenden Herkünfte.

Anhang 1.5 Zusammenstellung der sich signifikant von mindestens einer anderen Herkunft im Tukey-Kramer-Test für das Merkmal Ovalität [\%] im Alter 32 auf der Versuchsfläche Reinhardshagen / Hessen (35) unterscheidenden Herkünfte...

Anhang 1.6 Zusammenstellung der mittleren BHD [cm] im Alter von 32 und 39 Jahren sowie der mittleren Höhe [m] im Alter von 39 Jahren auf den drei Versuchsflächen Reinhardshagen / Hessen. ...

Anhang 1.7 Zusammenstellung der sich signifikant von mindestens einer anderen Herkunft im Tukey-Kramer-Test für das Merkmal Höhen-Wachstum [m] im Alter 39 auf der Versuchsfläche 34 Reinhardshagen / Hessen unterscheidenden Herkünfte. ...

Anhang 1.8 Zusammenstellung der sich signifikant von mindestens einer anderen Herkunft im Tukey-Kramer-Test für das Merkmal Höhen-Wachstum [m] im Alter 39 auf der Versuchsfläche 35 Reinhardshagen / Hessen unterscheidenden Herkünfte.

Anhang 1.9 Zusammenstellung der sich signifikant von mindestens einer anderen Herkunft im Tukey-Kramer-Test für das Merkmal BHD-Wachstum [cm] im Alter 39 auf der Versuchsfläche 34 Reinhardshagen / Hessen unterscheidenden Herkünfte. ...

Anhang 1.10 Zusammenstellung der sich signifikant von mindestens einer anderen Herkunft im Tukey-Kramer-Test für das Merkmal BHD-Wachstum [cm] im Alter 39 auf der Versuchsfläche 35 Reinhardshagen / Hessen unterscheidenden Herkünfte.

Anhang 1.11 Zusammenstellung der sich signifikant von mindestens einer anderen Herkunft im Tukey-Kramer-Test für das Merkmal BHD-Wachstum [cm] im Alter 32 auf der Versuchsfläche 34 Reinhardshagen / Hessen unterscheidenden Herkünfte. 
Anhang 1.12 Zusammenstellung der sich signifikant von mindestens einer anderen Herkunft im Tukey-Kramer-Test für das Merkmal BHD-Wachstum [cm] im Alter 32 auf der Versuchsfläche 35 Reinhardshagen / Hessen unterscheidenden Herkünfte.

Anhang 1.13 Zusammenstellung der mittleren Einzelbaumvolumina und Vorräte pro Hektar im Alter von 39 Jahren auf den hessischen drei Versuchsflächen Reinhardshagen (absolut und relativ im Verhältnis zum Mittel der 3 Versuchsflächen)....

Anhang 1.14 Zusammenstellung der sich signifikant von mindestens einer anderen Herkunft im Tukey-Kramer-Test beim Einzelbaumvolumen $\left[\mathrm{m}^{3}\right]$ im Alter 39 auf der Versuchsfläche 34 Reinhardshagen / Hessen unterscheidenden Herkünfte....

Anhang $1.15 \quad$ Zusammenstellung der sich signifikant von mindestens einer anderen Herkunft im Tukey-Kramer-Test beim Einzelbaumvolumen $\left[\mathrm{m}^{3}\right]$ im Alter 39 auf der Versuchsfläche 35 Reinhardshagen / Hessen unterscheidenden Herkünfte.

Anhang 1.16 Zusammenstellung der sich signifikant von mindestens einer anderen Herkunft im Tukey-Kramer-Test beim rechnerischen Vorrat/ha $\left[\mathrm{m}^{3} / \mathrm{ha}\right]$ im Alter 39 auf der Versuchsfläche 34 Reinhardshagen / Hessen unterscheidenden Herkünfte.

Anhang 1.17 Zusammenstellung der sich signifikant von mindestens einer anderen Herkunft im Tukey-Kramer-Test beim rechnerischen Vorrat $\left./ \mathrm{ha}^{3} \mathrm{~m}^{3} / \mathrm{ha}\right]$ im Alter 39 auf der Versuchsfläche 35 Reinhardshagen / Hessen unterscheidenden Herkünfte.

Anhang 1.18 Zusammenstellung der mittleren Stammzahl im Alter von 32 und 39 Jahren auf den drei Versuchsflächen Hasbruch / Niedersachsen............

Anhang 1.19 Zusammenstellung der mittleren Ovalitäten [\%] im Alter von 32 und 39 Jahren sowie des H/D-Verhältnisses im Alter von 39 Jahren auf den drei Versuchsflächen Hasbruch / Niedersachsen.

Anhang 1.20 Zusammenstellung der sich signifikant von mindestens einer anderen Herkunft im Tukey-Kramer-Test beim Merkmal Ovalität [\%] im Alter 39 auf der Versuchsfläche 44 Hasbruch / Niedersachsen unterscheidenden Herkünfte.

Anhang 1.21 Zusammenstellung der sich signifikant von mindestens einer anderen Herkunft im Tukey-Kramer-Test beim H/D-Verhältnis im Alter 39 auf der Versuchsfläche 45 Hasbruch / Niedersachsen unterscheidenden Herkünfte.

Anhang 1.22 Zusammenstellung der mittleren BHD [cm] im Alter von 32 und 39 Jahren sowie der mittleren Höhe $[\mathrm{m}]$ im Alter von 39 Jahren auf den drei Versuchsflächen Hasbruch / Niedersachsen............................

Anhang 1.23 Zusammenstellung der sich signifikant von mindestens einer anderen Herkunft im Tukey-Kramer-Test beim BHD-Wachstum [cm] im Alter 32 auf der Versuchsfläche 44 Hasbruch / Niedersachsen unterscheidenden Herkünfte.

Zusammenstellung der mittleren Einzelbaumvolumina und Vorräte pro Hektar im Alter von 39 Jahren auf den niedersächsischen drei Versuchsflächen Hasbruch (alsolut und relativ im Verhältnis zum Mittel der 3 Versuchsflächen) 
Anhang 1.25 Zusammenstellung der mittleren Stammzahl und des mittleren BHD [cm] im Alter von 32 Jahren auf den zwei Versuchsflächen Sonthofen (24) und Berchtesgaden (26) / Bayern sowie der mittleren Ovalität [\%] auf der Versuchsfläche Berchtesgaden (26).....

Anhang 1.26 Mittlerer Rang im Wachstum auf den Flächen mit 169 Herkünften Münsingen (14), Sonthofen (24), Reinhardshagen (34) und Hasbruch (44) sowie über die vier Flächen..........................................

Anhang 1.27 Spannweite zwischen den Rängen im Wachstum auf den 4 Versuchsflächen Münsingen (14), Sonthofen (24), Reinhardshagen (34) und Hasbruch (44) und mittlerer Rang über die vier Flächen der 168 gemeinsamen Herkünfte....

Anhang 1.28 Mittlerer Rang im Wachstum auf den Flächen mit 81 Herkünften Reinhardshagen (35) und Hasbruch (45) sowie über die beiden Flächen.........

Anhang 1.29 Spannweite zwischen den Rängen im Wachstum auf den beiden Versuchsflächen Reinhardshagen (35) und Hasbruch (45) und mittlerer Rang über die beiden Flächen der 72 gemeinsamen Herkünfte..............

Anhang 1.30 Spannweite zwischen den Rängen im Wachstum auf den drei Versuchsflächen Berchtesgaden (26), Reinhardshagen (36) und Hasbruch (46) und mittlerer Rang über die beiden Flächen der 34 gemeinsamen Herkünfte...

Anhang 1.31 Spannweite zwischen den Rängen im Wachstum auf den drei Versuchsflächen Berchtesgaden (26), Reinhardshagen (36) und Hasbruch (46) und mittlerer Rang über die beiden Flächen der 34 gemeinsamen Herkünfte...

Anhang 1.32 Ränge und Spannweiten im Einzelstammvolumen $\left[\mathrm{m}^{3}\right]$ auf den Flächen Reinhardshagen $(34,35,36)$ und Hasbruch $(44,45,46) \ldots \ldots \ldots \ldots \ldots \ldots \ldots$.

Anhang 1.33 Ränge und Spannweite im Vorrat $\left[\mathrm{m}^{3} / \mathrm{ha}\right.$ auf den Flächen Reinhardshagen $(34,35,36)$ und Hasbruch $(44,45,46)$

\section{Anhang 2: Der IUFRO-Fichtenherkunftsversuch von 1972}

Anhang 2.1 Angaben zu den polnischen Erntebeständen zum Zeitpunkt der Beern-

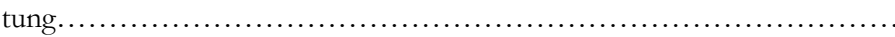

Anhang 2.2 Zusammenstellung der Ovalitäten [\%] auf den hessischen Versuchsflächen Reinhardshagen und Wanfried......

Anhang 2.3 Zusammenstellung der H/D-Verhältnisse auf den hessischen Versuchsflächen Reinhardshagen und Wanfried.

Anhang 2.4 Tukey-Gruppen $(\alpha=0,05)$ für die Wachstumsmerkmale BHD [cm] und Höhe $[\mathrm{m}]$ auf der Versuchsfläche Reinhardshagen / Hessen (32-j.)........

Anhang 2.5 Tukey-Gruppen für die Wachstumsmerkmale Höhe $[\mathrm{m}]$ und BHD $[\mathrm{cm}]$ auf der Versuchsfläche Reinhardshagen / Hessen (23-j.). . .

Anhang 2.6 Tukey-Gruppen für das Merkmal Einzelbaumvolumen $\left[\mathrm{m}^{3}\right]$ auf der Versuchsfläche Reinhardshagen / Hessen (23-j. und 32-j.)

Anhang 2.7 Tukey-Gruppen für das H/D-Verhältnis auf der Versuchsfläche Wanfried / Hessen (23-j.).

Anhang 2.8 Tukey-Gruppen $(\alpha=0,05)$ für das Wachstumsmerkmal BHD $[\mathrm{cm}]$ auf

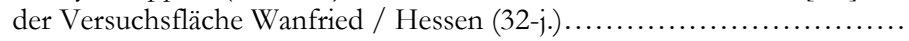


Anhang 2.9 Tukey-Gruppen $(\alpha=0,05)$ für die Wachstumsmerkmale Höhe $[\mathrm{m}]$, BHD $[\mathrm{cm}]$ und Einzelbaumvolumen $\left[\mathrm{m}^{3}\right]$ auf der Versuchsfläche Wan-

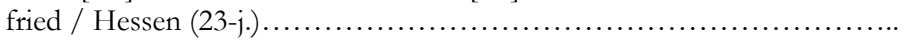

Anhang 2.10 Zusammenstellung der Ovalitäten [\%] der IUFRO-Herkünfte und ihrer Einzelbaumnachkommenschaften auf der niedersächsischen Versuchs-

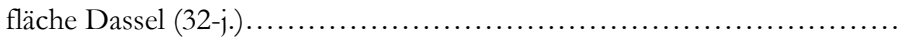

Anhang 2.11 Zusammenstellung der H/D-Verhältnisse der IUFRO-Herkünfte und ihrer Einzelbaumnachkommenschaften auf der niedersächsischen Versuchsfläche Dassel. ...

Anhang 2.12

Tukey-Gruppen $(\alpha=0,05)$ für das Wachstumsmerkmal Höhe $[\mathrm{m}]$ auf der Versuchsfläche Dassel / Niedersachsen (23-j. und 32-j.). .

Anhang 2.13

Tukey-Gruppen $(\alpha=0,05)$ für den Vorrat $\left[\mathrm{m}^{3} / \mathrm{ha}\right]$ auf der Versuchsfläche

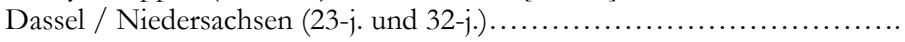

Anhang 2.14 Zusammenstellung der Ovalitäten [\%] auf der niedersächsischen Versuchsfläche Seesen (32-j.)...

Anhang 2.15

Zusammenstellung der H/D-Verhältnisse auf der niedersächsischen Versuchsfläche Seesen.

Anhang 2.16

Tukey-Gruppen $(\alpha=0,05)$ für die Wachstumsmerkmale Höhe $[\mathrm{m}]$ und BHD [cm] auf der Versuchsfläche Seesen / Niedersachsen (23-j.)..........

Anhang 2.17 Tukey-Gruppen $(\alpha=0,05)$ für den Bestandesvorrat $\left[\mathrm{m}^{3} / \mathrm{ha}\right]$ auf der Versuchsfläche Seesen / Niedersachsen (23-j. und 32-j.)....................

Anhang 2.18 Tukey-Gruppen $(\alpha=0,05)$ für die Merkmale Baumhöhe [m] und Einzelbaumvolumen $\left[\mathrm{m}^{3}\right]$ auf der Versuchsfläche Ochsenhausen A / Baden-

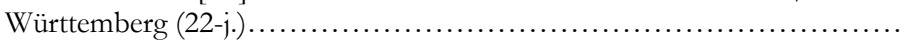

Anhang 2.19 Tukey-Gruppen $(\alpha=0,05)$ für die Merkmale Baumhöhe [m] und Einzelbaumvolumen $\left[\mathrm{m}^{3}\right]$ auf der Versuchsfläche Ochsenhausen B / BadenWürttemberg (21-j.)

Anhang 2.20 Tukey-Gruppen $(\alpha=0,05)$ für die Merkmale BHD [cm] und Einzelbaumvolumen $\left[\mathrm{m}^{3}\right]$ auf der Versuchsfläche Sauerlach B / Bayern (25-j.).........

Anhang 2.21 Tukey-Gruppen $(\alpha=0,05)$ für das Merkmal Ausfallrate [\%] auf der Versuchsfläche Neureichenau / Bayern (34-j.).........................

Anhang 2.22 H/D-Verhältnisse auf der Versuchsfläche Neureichenau / Bayern (25-j. und 34-j.).

Anhang 2.23 Tukey-Gruppen $(\alpha=0,05)$ für die Wachstumsmerkmale Höhe [m] und BHD [cm] auf der Versuchsfläche Neureichenau / Bayern (25-j.)..........

Anhang 2.24 Tukey-Gruppen $(\alpha=0,05)$ für das Merkmal Einzelbaumvolumen $\left[\mathrm{m}^{3}\right]$ auf der Versuchsfläche Neureichenau / Bayern (25-j. [links] und 34-j. [rechts])

Anhang 2.25

Tukey-Gruppen $(\alpha=0,05)$ für das Merkmal Vorrat $\left[\mathrm{m}^{3} / \mathrm{ha}\right]$ auf der Versuchsfläche Neureichenau / Bayern: 25-j. (oben) und 34-j. (unten)..........

Anhang 2.26 Produkt-Momenten-Korrelationsmatrix (rP) des Fehlstellenanteils auf den Versuchsflächen des IUFRO-Fichtenherkunftsversuchs 1972 (Anzahl Prüfglieder) 


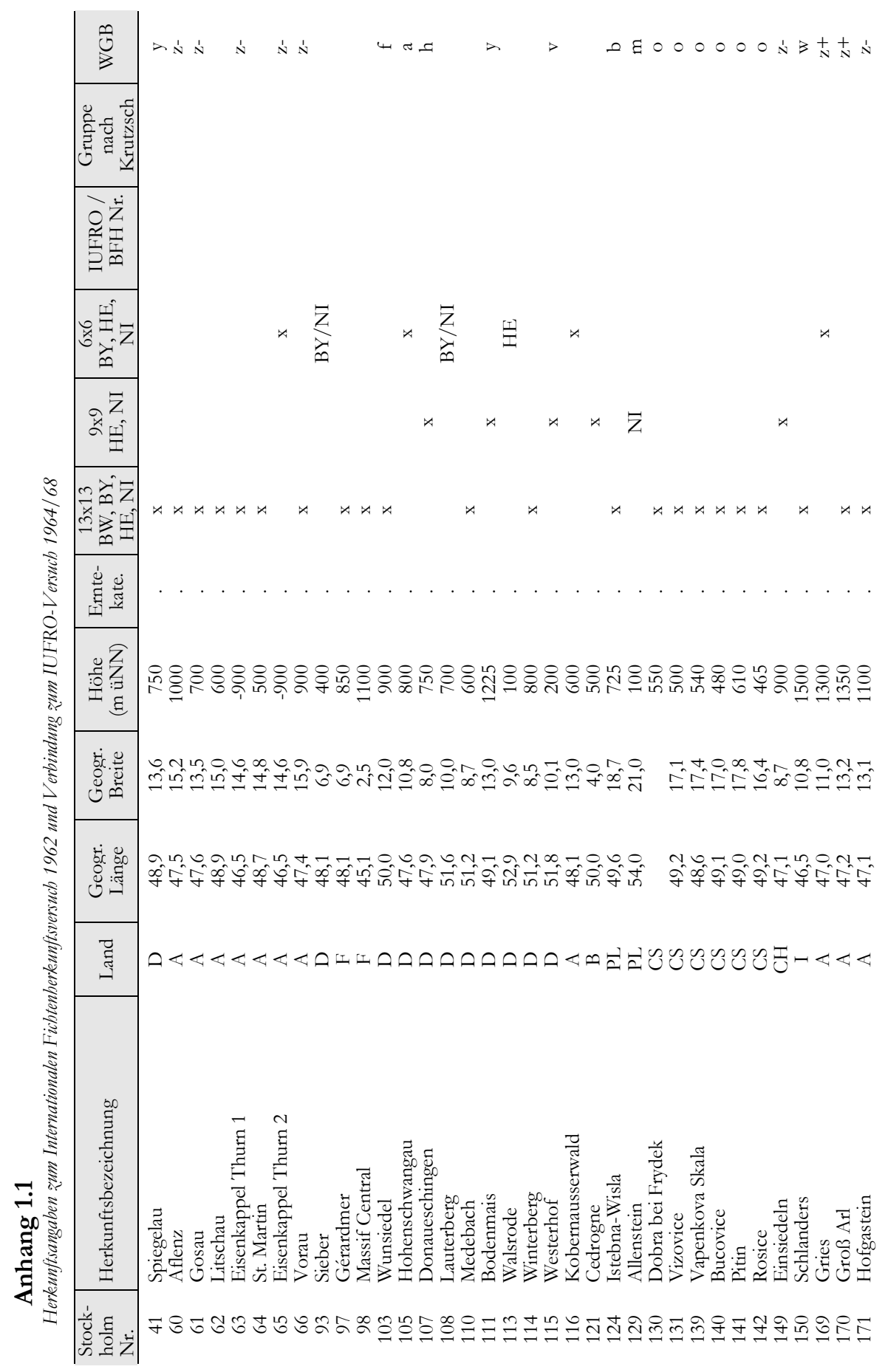

Beiträge aus der NW-FVA, Band 5, 2010 


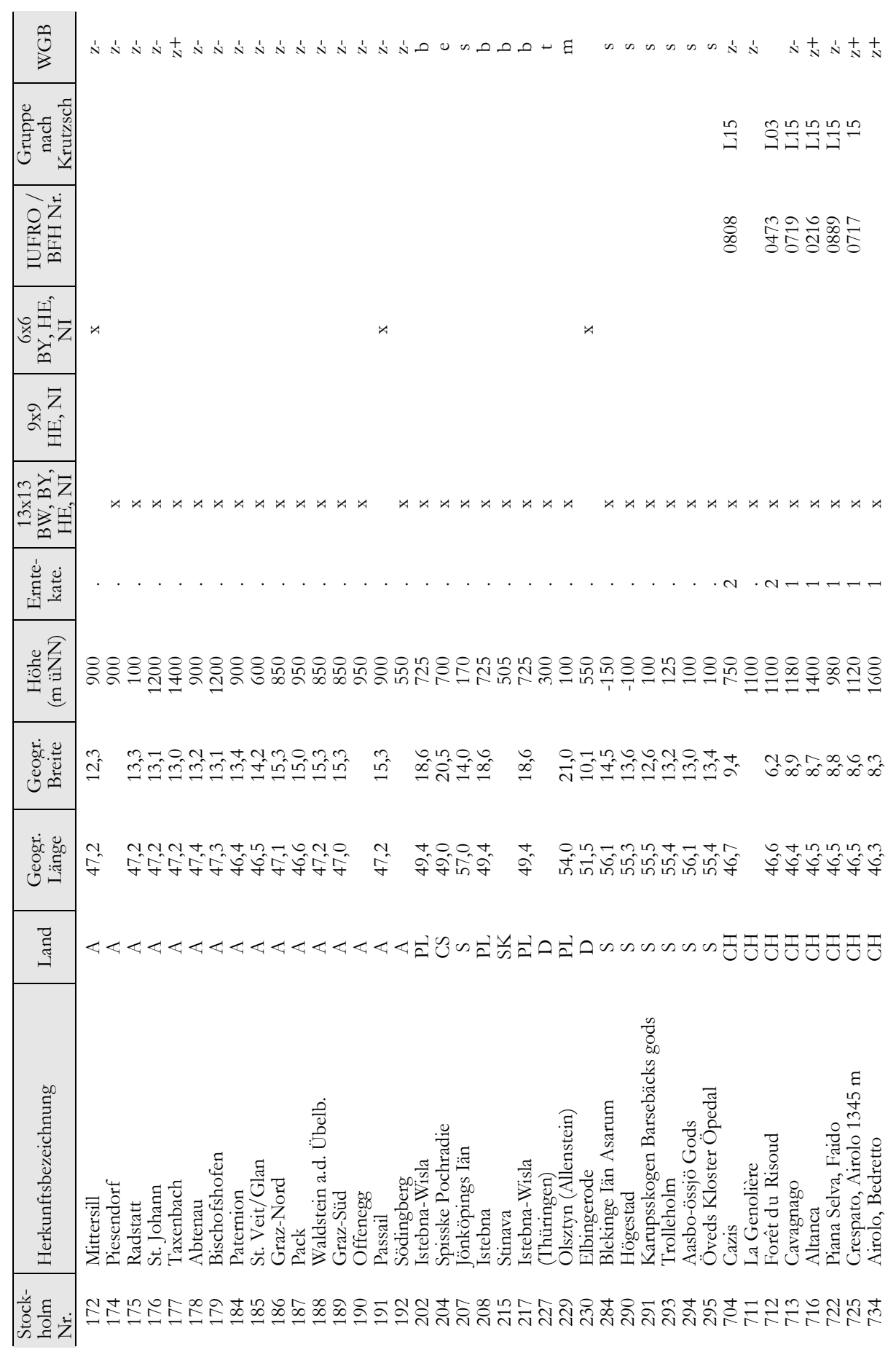




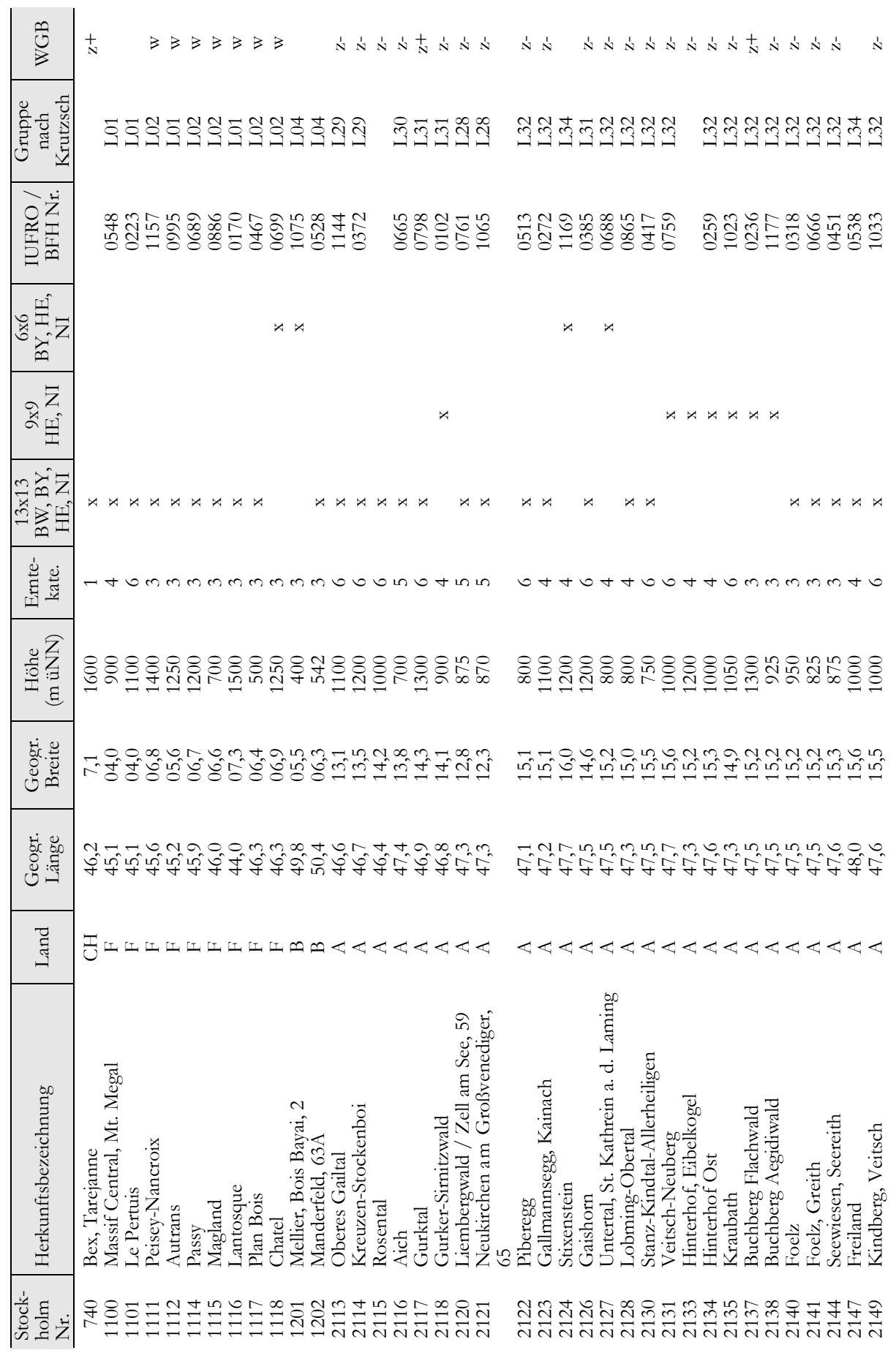




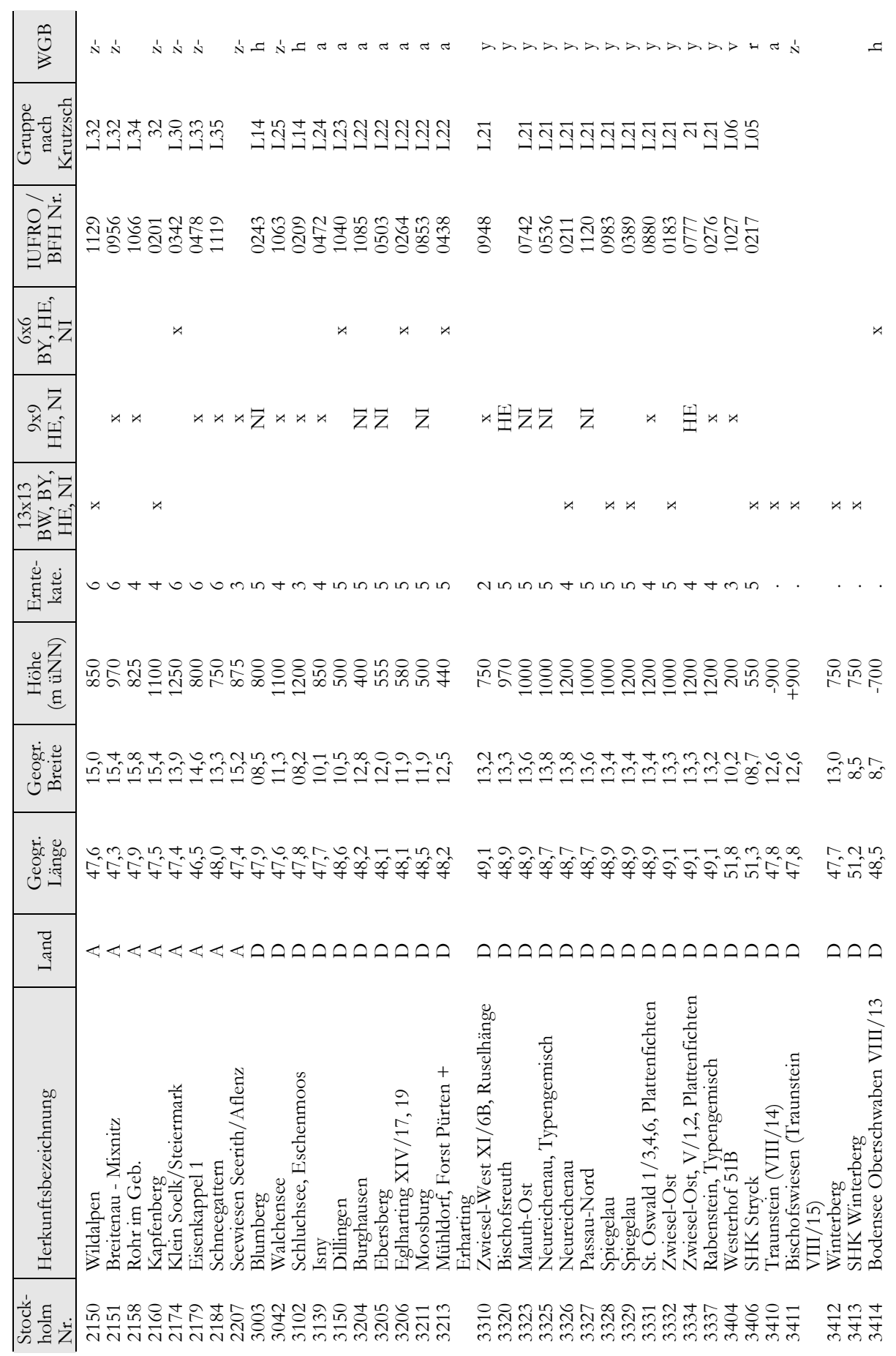




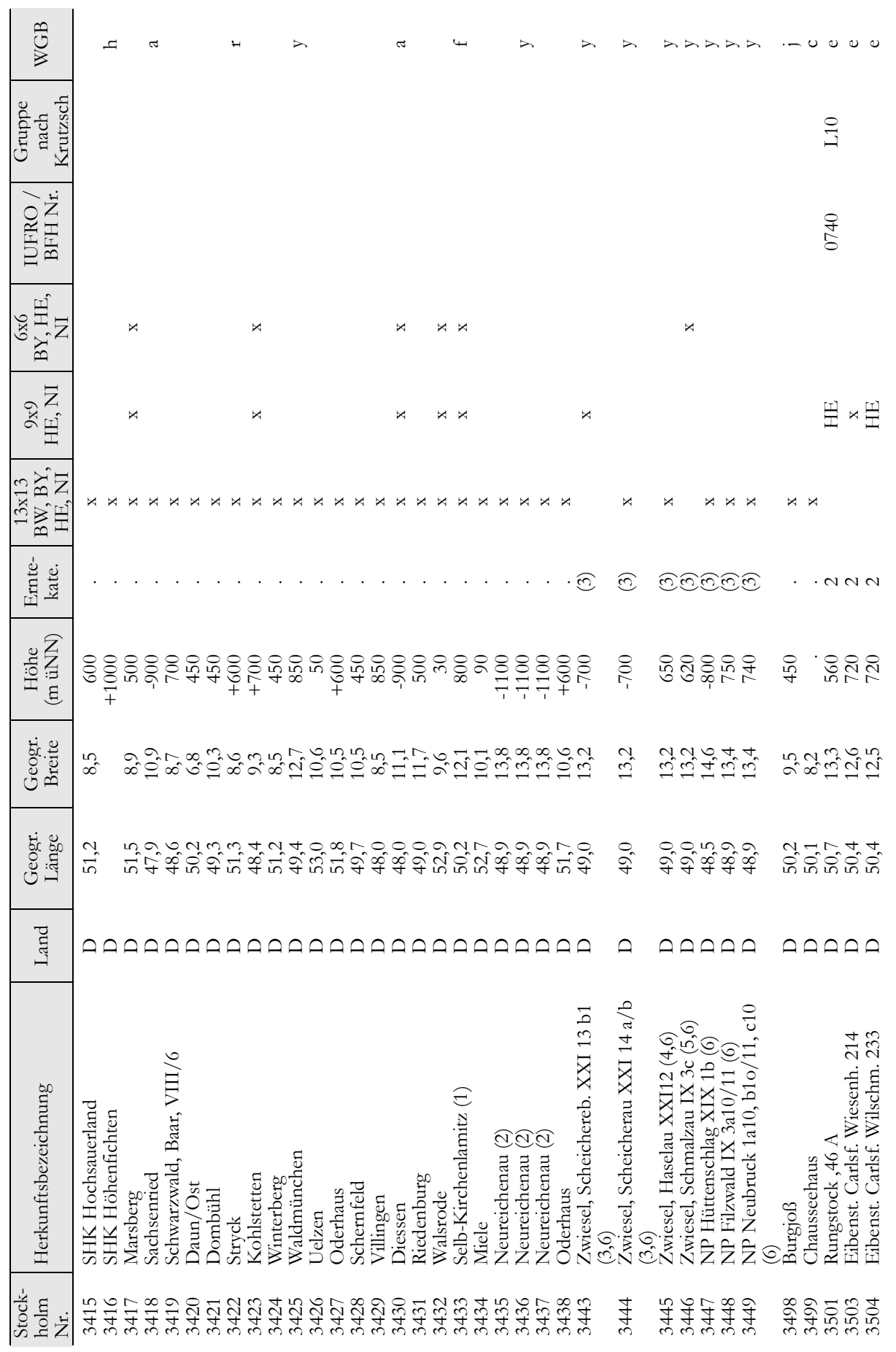

Beiträge aus der NW-FVA, Band 5, 2010 


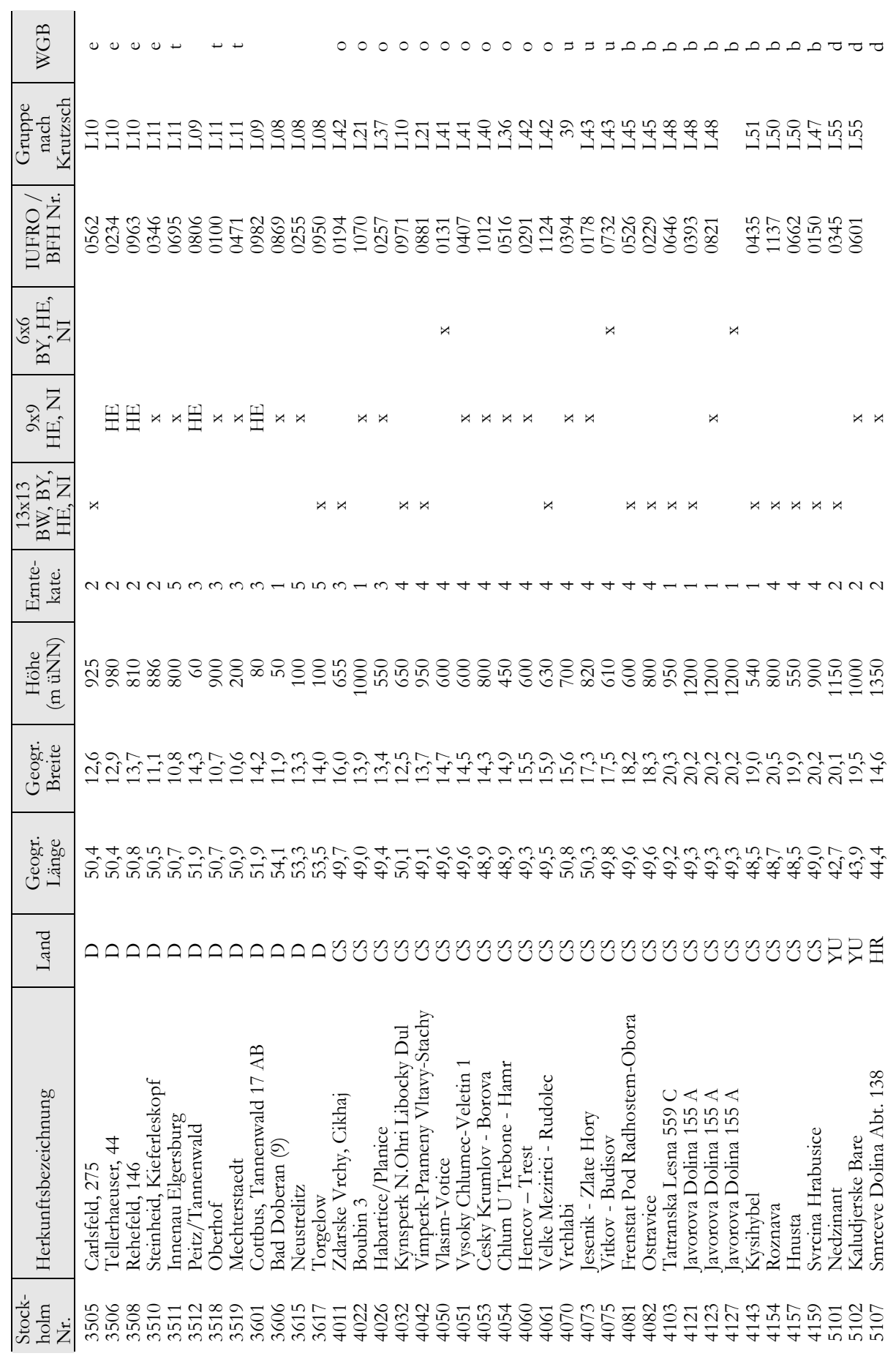




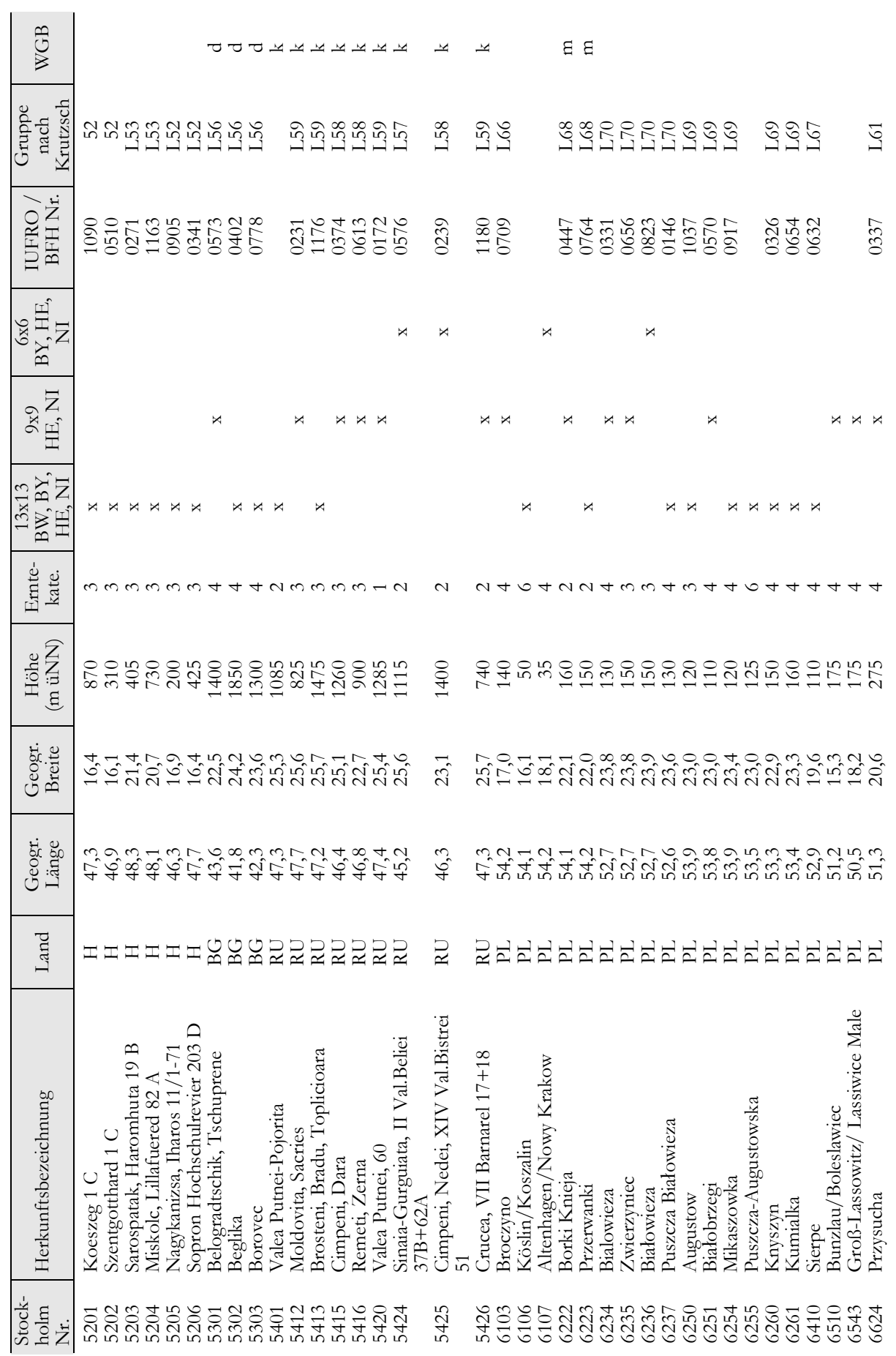




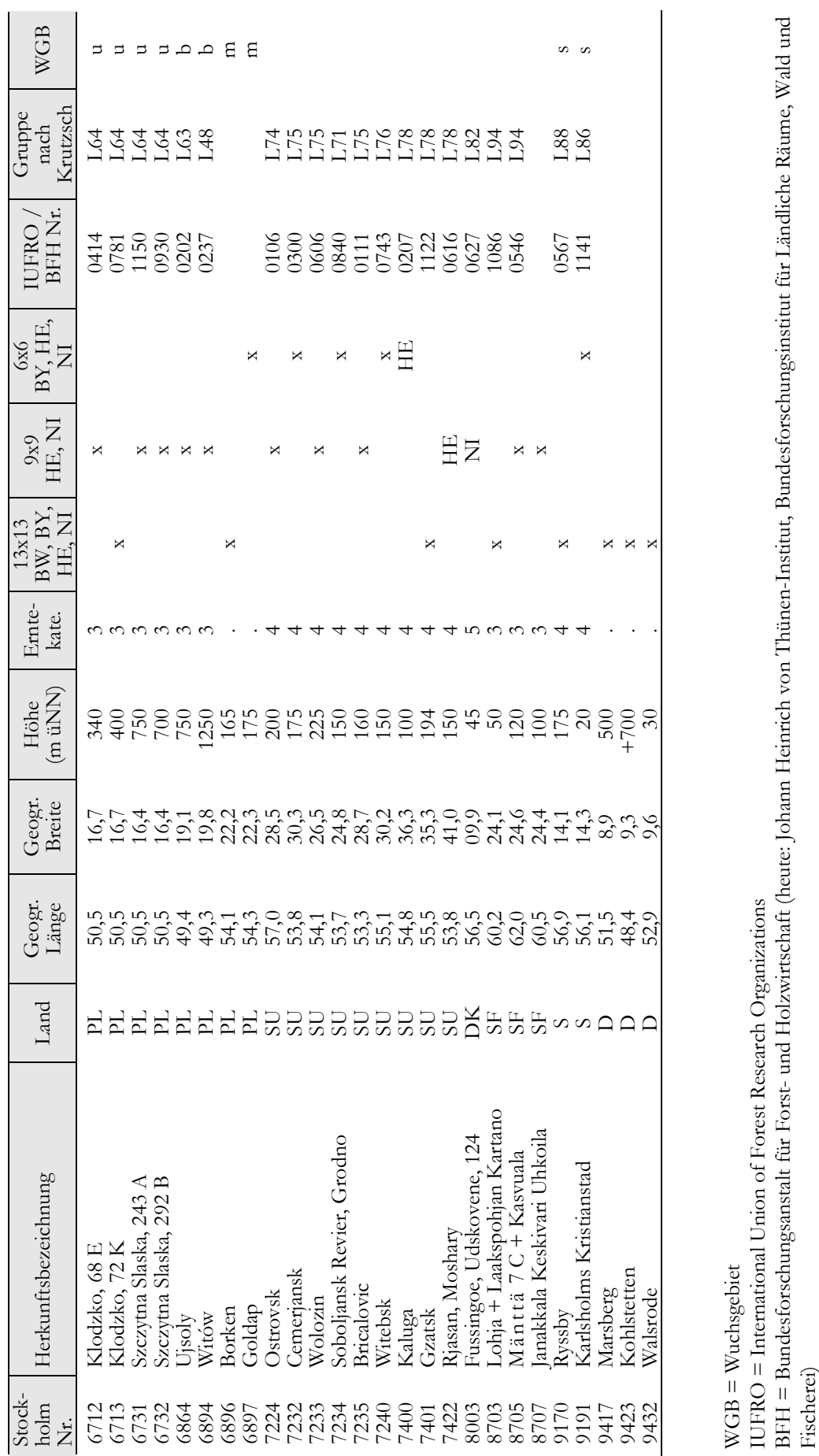




\section{Anhang 1.2}

Zusammenstellung der mittleren Stammzahl im Alter von 32 und 39 Jahren auf den drei Versuchsflächen Reinhardshagen / Hessen

Versuchsfläche 34

\begin{tabular}{|c|c|c|c|c|}
\hline \multirow[b]{2}{*}{ PG-Nr. } & \multirow[b]{2}{*}{ Herkunft } & \multicolumn{3}{|c|}{ Stammzahl bei der Messung } \\
\hline & & $\begin{array}{c}\text { BHD } \\
32-j .\end{array}$ & $\begin{array}{l}\text { Höhe } \\
\text { 39-j. }\end{array}$ & $\begin{array}{l}\text { BHD } \\
39-j .\end{array}$ \\
\hline 41 & Spiegelau & 18 & 9 & 18 \\
\hline 60 & Aflenz & 18 & 9 & 16 \\
\hline 61 & Gosau & 18 & 9 & 15 \\
\hline 62 & Litschau & 13 & 8 & 13 \\
\hline 63 & Eisenkappel Thurn 1 & 18 & 9 & 15 \\
\hline 64 & St. Martin & 19 & 9 & 12 \\
\hline 66 & Vorau & 16 & 9 & 15 \\
\hline 97 & Gérardmer & 18 & 9 & 12 \\
\hline 98 & Massif Central & 19 & 9 & 15 \\
\hline 103 & Wunsiedel & 17 & 9 & 13 \\
\hline 110 & Medebach & 20 & 9 & 13 \\
\hline 114 & Winterberg & 19 & 9 & 15 \\
\hline 124 & Istebna-Wisła & 18 & 9 & 14 \\
\hline 130 & Dobra bei Frydek & 17 & 9 & 14 \\
\hline 131 & Vizovice & 19 & 9 & 13 \\
\hline 139 & Vapenkova Skala & 20 & 9 & 15 \\
\hline 140 & Bucovice & 20 & 9 & 13 \\
\hline 141 & Pitin & 20 & 9 & 12 \\
\hline 142 & Rosice & 20 & 9 & 12 \\
\hline 150 & Schlanders & 18 & 7 & 11 \\
\hline 170 & Groß Arl & 14 & 7 & 10 \\
\hline 171 & Hofgastein & 19 & 9 & 14 \\
\hline 174 & Piesendorf & 18 & 9 & 14 \\
\hline 175 & Radstatt & 18 & 9 & 12 \\
\hline 176 & St. Johann & 18 & 9 & 15 \\
\hline 177 & Taxenbach & 18 & 9 & 14 \\
\hline 178 & Abtenau & 17 & 10 & 13 \\
\hline 179 & Bischofshofen & 18 & 9 & 14 \\
\hline 184 & Paternion & 17 & 9 & 13 \\
\hline 185 & St. Veit/Glan & 18 & 9 & 13 \\
\hline 186 & Graz-Nord & 18 & 9 & 14 \\
\hline 187 & Pack & 18 & 9 & 13 \\
\hline 188 & Waldstein a.d. Übelb. & 19 & 9 & 15 \\
\hline 189 & Graz-Süd & 20 & 9 & 15 \\
\hline 190 & Offenegg & 16 & 9 & 13 \\
\hline 192 & Södingberg & 18 & 9 & 14 \\
\hline 202 & Istebna-Wisła & 19 & 9 & 16 \\
\hline 204 & Spisske Pochradie & 19 & 9 & 12 \\
\hline 207 & Jönköpings län & 19 & 9 & 12 \\
\hline 208 & Istebna & 21 & 9 & 16 \\
\hline 215 & Stinava & 19 & 9 & 15 \\
\hline 217 & Istebna-Wisła & 17 & 9 & 12 \\
\hline
\end{tabular}


Versuchsfläche 34

\begin{tabular}{|c|c|c|c|c|}
\hline \multirow[b]{2}{*}{ PG-Nr. } & \multirow[b]{2}{*}{ Herkunft } & \multicolumn{3}{|c|}{ Stammzahl bei der Messung } \\
\hline & & $\begin{array}{c}\text { BHD } \\
32-j .\end{array}$ & $\begin{array}{l}\text { Höhe } \\
39-\text { j. }\end{array}$ & $\begin{array}{c}\text { BHD } \\
39-j .\end{array}$ \\
\hline 227 & Thüringen & 18 & 9 & 16 \\
\hline 229 & Olsztyn & 18 & 9 & 13 \\
\hline 284 & Blekinge län Asarum & 18 & 9 & 13 \\
\hline 290 & Högestad & 19 & 9 & 14 \\
\hline 291 & Karupsskogen Barsebäcks gods & 19 & 9 & 13 \\
\hline 293 & Trolleholm & 18 & 9 & 12 \\
\hline 294 & Aasbo-össjö Gods & 18 & 9 & 14 \\
\hline 295 & Öveds Kloster Öpedal & 19 & 9 & 12 \\
\hline 704 & Cazis Tschartlina & 21 & 6 & 10 \\
\hline 711 & La Genolière & 18 & 9 & 14 \\
\hline 712 & Forêt du Risoud & 15 & 9 & 11 \\
\hline 713 & Caragnago & 18 & 9 & 13 \\
\hline 716 & Altacanta & 18 & 9 & 11 \\
\hline 722 & Piana Selva, Faido & 18 & 9 & 14 \\
\hline 725 & Airolo, Crespato-Ressia & 17 & 9 & 13 \\
\hline 734 & Airolo, Bedretto & 15 & 9 & 11 \\
\hline 740 & Bex, Tarejanne & 17 & 9 & 11 \\
\hline 1100 & Monts Megal, Le Portius & 17 & 9 & 12 \\
\hline 1101 & Le Pertuis, Monts du Velay & 18 & 9 & 12 \\
\hline 1111 & Peisey-Nancroix, Grd. Bois & 18 & 9 & 14 \\
\hline 1112 & Autrans, Isère & 18 & 9 & 13 \\
\hline 1114 & Passy & 18 & 9 & 15 \\
\hline 1115 & Magland & 18 & 9 & 13 \\
\hline 1116 & Lantosque & 19 & 9 & 12 \\
\hline 1117 & Plan Bois, Ballandes & 18 & 9 & 12 \\
\hline 1202 & Manderfeld Gilbuschek 63 A & 12 & 6 & 9 \\
\hline 2113 & Oberes Gailtal & 18 & 9 & 12 \\
\hline 2114 & Kreuzen-Stockenboi & 18 & 9 & 16 \\
\hline 2115 & Rosental & 18 & 9 & 14 \\
\hline 2116 & Aich & 15 & 8 & 11 \\
\hline 2117 & Gurktal & 18 & 9 & 13 \\
\hline 2120 & Liembergwald Zell a. S. & 18 & 9 & 11 \\
\hline 2121 & Neukirchen Großvenediger & 17 & 9 & 13 \\
\hline 2122 & Piberegg & 18 & 9 & 11 \\
\hline 2123 & Gallmannsegg Kainach & 19 & 9 & 15 \\
\hline 2126 & Gaishorn & 18 & 9 & 17 \\
\hline 2128 & Lobming-Oberth. St. Stefan/Kraubath & 14 & 8 & 12 \\
\hline 2130 & Stanz-Kindthal-Allerheiligen & 18 & 9 & 14 \\
\hline 2140 & Fölz, Mayerberg & 18 & 10 & 15 \\
\hline 2141 & Fölz, Greith & 16 & 9 & 13 \\
\hline 2144 & Seewiesen, Seereith & 17 & 9 & 12 \\
\hline 2147 & Freiland, Gschwend & 19 & 9 & 16 \\
\hline 2149 & Kindberg/Eisenerzer Alpen & 18 & 9 & 14 \\
\hline 2150 & Siebensee Wildalpen & 17 & 9 & 15 \\
\hline 2160 & Turnau, Kapfenberg & 18 & 9 & 15 \\
\hline 3326 & Neureichenau & 18 & 9 & 12 \\
\hline 3328 & Spiegelau & 19 & 9 & 13 \\
\hline 3329 & Spiegelau & 17 & 9 & 12 \\
\hline
\end{tabular}


Versuchsfläche 34

\begin{tabular}{|c|c|c|c|c|}
\hline \multirow[b]{2}{*}{ PG-Nr. } & \multirow[b]{2}{*}{ Herkunft } & \multicolumn{3}{|c|}{ Stammzahl bei der Messung } \\
\hline & & $\begin{array}{l}\text { BHD } \\
32-j .\end{array}$ & $\begin{array}{c}\text { Höhe } \\
39-j .\end{array}$ & $\begin{array}{c}\text { BHD } \\
39-j .\end{array}$ \\
\hline 3332 & Zwiesel-Ost & 18 & 9 & 14 \\
\hline 3406 & SHK Stryck Willingen & 18 & 9 & 15 \\
\hline 3410 & Traunstein & 18 & 9 & 13 \\
\hline 3411 & Bischofswiesen & 18 & 9 & 13 \\
\hline 3412 & Winterberg & 18 & 9 & 15 \\
\hline 3413 & SHK Winterberg & 18 & 9 & 13 \\
\hline 3415 & SHK Hochsauerland & 18 & 9 & 15 \\
\hline 3416 & SHK Höhenfichten & 17 & 8 & 11 \\
\hline 3417 & Marsberg & 18 & 9 & 13 \\
\hline 3418 & Sachsenried & 19 & 9 & 15 \\
\hline 3419 & Schwarzwald Baar, VIII/6 & 18 & 9 & 14 \\
\hline 3420 & Daun/Ost & 18 & 9 & 15 \\
\hline 3421 & Dombühl & 18 & 9 & 16 \\
\hline 3422 & Stryck & 18 & 9 & 15 \\
\hline 3423 & Kohlstetten & 18 & 8 & 10 \\
\hline 3424 & Winterberg & 18 & 9 & 14 \\
\hline 3425 & Waldmünchen & 19 & 9 & 15 \\
\hline 3426 & Uelzen & 17 & 9 & 16 \\
\hline 3427 & Oderhaus & 15 & 6 & 8 \\
\hline 3428 & Schernfeld & 18 & 9 & 13 \\
\hline 3429 & Villingen & 18 & 8 & 11 \\
\hline 3430 & Diessen & 17 & 10 & 15 \\
\hline 3431 & Riedenburg & 18 & 9 & 12 \\
\hline 3432 & Walsrode & 18 & 9 & 15 \\
\hline 3433 & Selb-Kirchenlamitz (1) & 19 & 9 & 13 \\
\hline 3434 & Miele & 17 & 9 & 14 \\
\hline 3435 & Neureichenau (2) & 18 & 9 & 13 \\
\hline 3436 & Neureichenau (2) & 20 & 9 & 13 \\
\hline 3437 & Neureichenau (2) & 18 & 9 & 14 \\
\hline 3438 & Oderhaus & 17 & 9 & 14 \\
\hline 3444 & Zwiesel, Scheicherau XXI 14a/b $(3,6)$ & 20 & 9 & 15 \\
\hline 3445 & Zwiesel, Haselau XXI $12(3,6)$ & 19 & 9 & 13 \\
\hline 3447 & Nationalp. Hüttenschlag XIX 1b (6) & 18 & 9 & 14 \\
\hline 3448 & Nationalp. Filzwald IX 3a 10/11 (6) & 18 & 9 & 14 \\
\hline 3449 & Nationalp. Neubruck 1a10,b10/11,c10 (6) & 18 & 9 & 13 \\
\hline 3498 & Burgjoß & 18 & 9 & 15 \\
\hline 3499 & Chausseehaus & 18 & 9 & 15 \\
\hline 3505 & Eibenst. Carlsf. 275 & 18 & 9 & 12 \\
\hline 3617 & Torgelow & 19 & 9 & 14 \\
\hline 4011 & Cikaaj, Zdarska Vrchy & 18 & 9 & 16 \\
\hline 4032 & Kynsperk nad Ohri Libocky Dul & 21 & 9 & 16 \\
\hline 4042 & Vimperk-Prameny Vltury Stachy & 18 & 9 & 15 \\
\hline 4061 & Velke Mezirici-Rudolec & 18 & 9 & 15 \\
\hline 4081 & Frenstat pod Radhosten-Obora & 19 & 9 & 14 \\
\hline 4082 & Ostravice & 20 & 9 & 13 \\
\hline 4103 & Tatranska Lesna 559 C & 24 & 9 & 14 \\
\hline 4121 & Javorova Dolina 155 A, Nr. 4121 & 15 & 9 & 13 \\
\hline 4143 & Kysihybel & 18 & 9 & 13 \\
\hline
\end{tabular}


Versuchsfläche 34

\begin{tabular}{|c|c|c|c|c|}
\hline \multirow[b]{2}{*}{ PG-Nr. } & \multirow[b]{2}{*}{ Herkunft } & \multicolumn{3}{|c|}{ Stammzahl bei der Messung } \\
\hline & & $\begin{array}{c}\text { BHD } \\
32-j .\end{array}$ & $\begin{array}{c}\text { Höhe } \\
39-j .\end{array}$ & $\begin{array}{l}\text { BHD } \\
39-j .\end{array}$ \\
\hline 4154 & Roznava & 18 & 9 & 12 \\
\hline 4157 & Hnusta & 19 & 9 & 18 \\
\hline 4159 & Svrcina Hrabusice & 18 & 9 & 13 \\
\hline 5101 & Nedzinant, Prokletije (Geb.) & 18 & 9 & 17 \\
\hline 5201 & Köszeg 1 C & 18 & 9 & 12 \\
\hline 5202 & Szentgotthard $1 \mathrm{C}$ & 17 & 9 & 16 \\
\hline 5203 & Sarospatak-Haromhuta 19 B Zempl. Geb. & 18 & 9 & 13 \\
\hline 5204 & Miskolc-Lillafüred 82 A Bükker Geb. & 18 & 9 & 15 \\
\hline 5205 & Nagykanizsa-Iharos Plattensee 11/1-71 & 18 & 9 & 12 \\
\hline 5206 & Sopron (Hochschulrev.) 203 D & 18 & 9 & 13 \\
\hline 5302 & Beglika & 19 & 9 & 13 \\
\hline 5303 & Borovec (Rila-Geb.) & 17 & 9 & 13 \\
\hline 5401 & Valea Putnei-Pojorita & 19 & 9 & 13 \\
\hline 5413 & Brosteni Bradu/Bastitei & 18 & 9 & 12 \\
\hline 6106 & Köslin/Koszalin & 18 & 9 & 12 \\
\hline 6223 & Przerwanki & 19 & 9 & 14 \\
\hline 6237 & Puszcza-Białowieska & 19 & 9 & 13 \\
\hline 6250 & Augustow Abt. 95 b & 18 & 9 & 15 \\
\hline 6254 & Mikaszowka & 19 & 8 & 14 \\
\hline 6255 & Puszcza-Augustowska & 11 & 6 & 7 \\
\hline 6260 & Knyszyn & 15 & 9 & 13 \\
\hline 6261 & Kumialka (Kumialska) & 18 & 9 & 14 \\
\hline 6410 & Sierpc & 15 & 8 & 11 \\
\hline 6713 & Klodzko-Nynow $72 \mathrm{k}$ & 18 & 9 & 13 \\
\hline 6896 & Borken & 18 & 9 & 14 \\
\hline 7401 & Gzatsk-Smolensk & 9 & 5 & 5 \\
\hline 8703 & Lohja Laaskspohjan & 15 & 7 & 9 \\
\hline 9170 & Ryssby-Kronobergs & 20 & 7 & 9 \\
\hline 9417 & Marsberg & 18 & 9 & 14 \\
\hline 9423 & Kohlstetten & 19 & 8 & 11 \\
\hline 9432 & Walsrode & 18 & 9 & 13 \\
\hline
\end{tabular}

Versuchsfläche 35

\begin{tabular}{c|l|c|c|c}
\hline \multirow{2}{*}{ PG-Nr. } & Herkunft & \multicolumn{3}{|c}{ Stammzahl bei der Messung } \\
& & $\begin{array}{c}\text { BHD } \\
32-j .\end{array}$ & $\begin{array}{c}\text { Höhe } \\
39-j .\end{array}$ & $\begin{array}{c}\text { BHD } \\
39-j .\end{array}$ \\
\hline 107 & Donaueschingen & 20 & 9 & 15 \\
111 & Bodenmais & 21 & 9 & 13 \\
115 & Westerhof & 18 & 9 & 13 \\
121 & Cedrogne & 20 & 9 & 14 \\
149 & Einsiedeln & 18 & 9 & 13 \\
2118 & Gurker Sirnitzwald & 20 & 9 & 14 \\
2131 & Veitsch-Neuberg & 20 & 9 & 14 \\
2133 & Hinterhof, Eibelkogel & 18 & 9 & 13 \\
2134 & Hinterhof, Ostbrenner u. Tiefental & 18 & 9 & 16 \\
2135 & Kraubath, Seckauer Tauern & 21 & 9 & 17 \\
2137 & Buchberg, Flachwald/Aflenz & 19 & 9 & 12
\end{tabular}


Versuchsfläche 35

\begin{tabular}{|c|c|c|c|c|}
\hline \multirow[b]{2}{*}{ PG-Nr. } & \multirow[b]{2}{*}{ Herkunft } & \multicolumn{3}{|c|}{ Stammzahl bei der Messung } \\
\hline & & $\begin{array}{l}\text { BHD } \\
32-j .\end{array}$ & $\begin{array}{c}\text { Höhe } \\
39-j .\end{array}$ & $\begin{array}{c}\text { BHD } \\
39-j .\end{array}$ \\
\hline 2138 & Buchberg, Ägidiwald/Aflenz & 19 & 9 & 14 \\
\hline 2151 & Breitenau-Mixnitz/Fischbacher Alp. & 18 & 8 & 10 \\
\hline 2158 & Rohr im Gebirge, Kirchwald & 19 & 9 & 12 \\
\hline 2179 & Eisenkappel/Karaw. & 21 & 9 & 14 \\
\hline 2184 & Schneegattern & 20 & 9 & 15 \\
\hline 2207 & Seewiesen Seereith/Aflenz & 19 & 9 & 12 \\
\hline 3042 & Walchensee & 19 & 9 & 13 \\
\hline 3102 & Schluchsee-Eschenmoos & 18 & 9 & 13 \\
\hline 3139 & Isny Ba/Wü & 18 & 9 & 10 \\
\hline 3310 & Zwiesel-West/Ruselhänge X/68 & 19 & 9 & 16 \\
\hline 3320 & Bischofsreut & 19 & 8 & 11 \\
\hline 3331 & St. Oswald I/3,4,6 Typengemisch & 19 & 9 & 15 \\
\hline 3334 & Zwiesel-Ost, V/1,2, Plattenfichten & 18 & 8 & 10 \\
\hline 3337 & Rabenstein Typengemisch & 19 & 9 & 14 \\
\hline 3404 & Westerhof Abt. $51 \mathrm{~B}$ & 20 & 9 & 13 \\
\hline 3417 & Marsberg & 19 & 9 & 16 \\
\hline 3423 & Kohlstetten & 20 & 9 & 13 \\
\hline 3430 & Diessen & 21 & 9 & 15 \\
\hline 3432 & Walsrode & 18 & 7 & 10 \\
\hline 3433 & Selb-Kirchenlamitz (1) & 20 & 9 & 15 \\
\hline 3443 & Zwiesel, Scheichereb. XXI 13b1 $(3,6)$ & 22 & 9 & 16 \\
\hline 3501 & Rungstock, 46 A & 20 & 9 & 13 \\
\hline 3503 & Eibenst. Carlsf. Wiesenh. 214 & 20 & 9 & 14 \\
\hline 3504 & Eibenst. Carlsf. Wilschm. 233 & 20 & 9 & 15 \\
\hline 3506 & Tellerhaeuser, 44 & 19 & 9 & 15 \\
\hline 3508 & Rehefeld, 146 & 19 & 9 & 12 \\
\hline 3510 & Sonneb. Steinheid, Kieferleskopf & 19 & 9 & 12 \\
\hline 3511 & Innenau Elgersburg & 19 & 9 & 13 \\
\hline 3512 & Peitz/Tannenwald & 19 & 9 & 14 \\
\hline 3518 & Suhl, Oberhofer Schloßbergkopf & 20 & 9 & 15 \\
\hline 3519 & Mechterstädt & 21 & 9 & 14 \\
\hline 3601 & Cottbus, Tannenwald 17AB & 20 & 9 & 14 \\
\hline 3606 & Templin, Bad Doberan Nr. 9 & 20 & 9 & 15 \\
\hline 3615 & Neustrelitz & 20 & 7 & 12 \\
\hline 4022 & Boubin III & 20 & 9 & 13 \\
\hline 4026 & Habartice, Planice & 18 & 9 & 13 \\
\hline 4051 & Vysoky Chlumec Veletin & 20 & 9 & 15 \\
\hline 4053 & Cesky Krumlov Borova & 19 & 9 & 14 \\
\hline 4054 & Chlum u. Trebone-Hamr & 21 & 9 & 14 \\
\hline 4060 & Hencov-Trest & 18 & 9 & 13 \\
\hline 4070 & Vrchlabi & 22 & 9 & 13 \\
\hline 4073 & Jesenik-Zlate Hory & 17 & 9 & 13 \\
\hline 4123 & Javorova Dolina 155 A, Nr.4123 & 17 & 9 & 13 \\
\hline 5102 & Kaludjerske Bore Taram Kremma & 20 & 9 & 13 \\
\hline 5107 & Smrceve Dolina Abt. 138 & 20 & 9 & 13 \\
\hline 5301 & Belogradchik-Tschupreno & 19 & 9 & 14 \\
\hline 5412 & Moldovita-Sacries & 19 & 9 & 13 \\
\hline 5415 & Cimpeni-Dara & 21 & 9 & 12 \\
\hline
\end{tabular}

Beiträge aus der NW-FVA, Band 5, 2010 
Versuchsfläche 35

\begin{tabular}{l|l|c|c|c}
\hline & & \multicolumn{3}{c}{ Stammzahl bei der Messung } \\
PG-Nr. & Herkunft & BHD & Höhe & BHD \\
& & $32-j$. & $39-j$. & $39-j$. \\
\hline 5416 & Remeti-Zerna & 22 & 9 & 14 \\
5420 & Valea Putnei-Pojorita III/60 & 19 & 9 & 17 \\
5426 & Crucea-Barnavel Abt. 17/18 & 20 & 9 & 13 \\
6103 & Brotzen/Broczyno & 19 & 8 & 11 \\
6222 & Borken/Borki & 17 & 9 & 12 \\
6234 & Białowieża & 17 & 9 & 11 \\
6235 & Zwierzyniec & 19 & 9 & 12 \\
6251 & Białobrzegi & 12 & 7 & 9 \\
6510 & Bunzlau/Boleslawiec & 19 & 9 & 15 \\
6543 & Groß-Lassowitz/Lassowice Male & 20 & 9 & 14 \\
6624 & Przysucha & 19 & 9 & 16 \\
6712 & Klodzko-Glatz/Nynow 68 e & 19 & 9 & 16 \\
6731 & Szcytna-Slaska Karlow 243 a & 18 & 9 & 13 \\
6732 & Szcytna-Slaska Karlow 292 b & 18 & 9 & 12 \\
6864 & Istebna-Ujsoly & 21 & 9 & 16 \\
6894 & Witów & 20 & 9 & 14 \\
7224 & Ostrovskij-Pskow & 19 & 9 & 14 \\
7233 & Wolozin & 17 & 9 & 14 \\
7235 & Brigalovic-Mogilev & 19 & 9 & 14 \\
7422 & Rjasan, Moshary & 19 & 9 & 12 \\
8705 & Mänttä & 3 & 3 & 3 \\
8707 & Janakkala Keskivari Uhkoila & 18 & 7 & 9 \\
\hline
\end{tabular}

Versuchsfläche 36

\begin{tabular}{c|l|c|c|c}
\hline \multirow{2}{*}{ PG-Nr. } & Herkunft & \multicolumn{3}{c}{ Stammzahl bei der Messung } \\
& & $\begin{array}{c}\text { BHD } \\
32-j .\end{array}$ & $\begin{array}{c}\text { Höhe } \\
39-j .\end{array}$ & $\begin{array}{c}\text { BHD } \\
39-j .\end{array}$ \\
\hline 65 & Eisenkappel Thurn 2 & 19 & 9 & 13 \\
105 & Hohenschwangau & 17 & 8 & 12 \\
113 & Walsrode & 17 & 9 & 14 \\
116 & Kobernausserwald & 18 & 9 & 13 \\
169 & Gries & 18 & 9 & 15 \\
172 & Mittersill & 18 & 9 & 13 \\
191 & Passail & 19 & 9 & 16 \\
230 & Elbingerode & 19 & 9 & 14 \\
1118 & Chatel, 1 Aity" & 17 & 8 & 11 \\
1201 & Mellier, Bois Bayai, 2 & 18 & 8 & 12 \\
2124 & Stixenstein, Gahns & 20 & 9 & 13 \\
2127 & Unterhal, St. Kathrein a.d. Lamming & 20 & 9 & 15 \\
2174 & Klein-Sölk/Niedertauern & 16 & 8 & 10 \\
3150 & Dillingen a.d.D. Bay. & 18 & 9 & 13 \\
3206 & Eglharting XIV/17,19 & 17 & 9 & 12 \\
3213 & Mühldorf/Inn & 17 & 9 & 13 \\
3414 & Bodensee Oberschwab. VIII/13 & 19 & 9 & 14 \\
3417 & Marsberg & 18 & 9 & 13 \\
3423 & Kohlstetten & 17 & 8 & 11
\end{tabular}


Versuchsfläche 36

\begin{tabular}{l|l|c|c|c}
\hline \multirow{2}{*}{ PG-Nr. } & Herkunft & \multicolumn{3}{c}{ Stammzahl bei der Messung } \\
& & $\begin{array}{c}\text { BHD } \\
32-j .\end{array}$ & $\begin{array}{c}\text { Höhe } \\
39-j .\end{array}$ & BHD \\
$39-j$. \\
\hline 3430 & Diessen & 16 & 8 & 8 \\
3432 & Walsrode & 21 & 9 & 13 \\
3433 & Selb-Kirchenlamitz (1) & 19 & 9 & 17 \\
3446 & Zwiesel, Schmalzau IX 3c (5,6) & 17 & 9 & 13 \\
4050 & Vlasim-Votice & 15 & 9 & 13 \\
4075 & Vitkov-Budisov & 15 & 9 & 13 \\
4127 & Javorova Dolina 155 A, Nr.4127 & 18 & 9 & 15 \\
5424 & Valea Beliei-Sinaia Gurguiata & 15 & 9 & 11 \\
5425 & Cimpeni-Nedei & 19 & 9 & 14 \\
6107 & Altenhagen/Nowy Krakow & 19 & 9 & 15 \\
6236 & Białowieża & 18 & 9 & 11 \\
6897 & Goldap & 19 & 9 & 13 \\
7232 & Cemerjanskoe-Mogilev & 17 & 9 & 15 \\
7234 & Soboljanskoe-Grodno & 19 & 9 & 13 \\
7240 & Witebsk & 17 & 9 & 13 \\
7400 & Kaluga & 15 & 9 & 15 \\
9191 & Karlsholms-Kristianstad & 19 & 9 & 12 \\
\hline
\end{tabular}

\section{Anhang 1.3}

Zusammenstellung der mittleren Ovalitäten [\%] im Alter von 32 und 39 Jahren sowie des H/D-Verbältnisses im Alter von 39 Jahren auf den drei Versuchsflächen Reinhardshagen / Hessen

Versuchsfläche 34

\begin{tabular}{c|l|c|c|c}
\hline \multirow{2}{*}{ PG-Nr. } & \multirow{2}{*}{ Herkunft } & \multicolumn{2}{|c|}{ Ovalität } & HD \\
& & $32-j$. & $39-j$. & $39-j$. \\
\hline 41 & Spiegelau & 3.5 & 2.9 & 88 \\
60 & Aflenz & 3.4 & 4.0 & 77 \\
61 & Gosau & 3.0 & 3.6 & 80 \\
62 & Litschau & 3.3 & 6.1 & 66 \\
63 & Eisenkappel Thurn 1 & 2.7 & 3.1 & 73 \\
64 & St. Martin & 4.1 & 3.9 & 77 \\
66 & Vorau & 4.8 & 5.1 & 79 \\
97 & Gérardmer & 3.0 & 3.2 & 73 \\
98 & Massif Central & 2.6 & 4.3 & 77 \\
103 & Wunsiedel & 2.4 & 2.5 & 74 \\
110 & Medebach & 3.5 & 3.3 & 85 \\
114 & Winterberg & 4.0 & 4.5 & 77 \\
124 & Istebna-Wisła & 3.5 & 5.8 & 68 \\
130 & Dobra bei Frydek & 4.4 & 4.4 & 76 \\
131 & Vizovice & 5.2 & 5.0 & 66 \\
139 & Vapenkova Skala & 2.2 & 2.6 & 74 \\
140 & Bucovice & 2.7 & 3.7 & 73 \\
141 & Pitin & 2.9 & 4.3 & 69 \\
142 & Rosice & 3.7 & 5.7 & 71 \\
150 & Schlanders & 3.4 & 3.7 & 71
\end{tabular}

Beiträge aus der NW-FVA, Band 5, 2010 
Versuchsfläche 34

\begin{tabular}{|c|c|c|c|c|}
\hline \multirow{2}{*}{ PG-Nr. } & \multirow{2}{*}{ Herkunft } & \multicolumn{2}{|c|}{ Ovalität } & \multirow{2}{*}{$\begin{array}{l}\text { HD } \\
39-\mathrm{j} .\end{array}$} \\
\hline & & $32-j$. & $39-\mathrm{j}$. & \\
\hline 170 & Groß Arl & 5.0 & 3.9 & 70 \\
\hline 171 & Hofgastein & 3.1 & 3.0 & 80 \\
\hline 174 & Piesendorf & 2.7 & 6.3 & 76 \\
\hline 175 & Radstatt & 3.7 & 2.2 & 75 \\
\hline 176 & St. Johann & 3.2 & 3.5 & 79 \\
\hline 177 & Taxenbach & 3.0 & 4.4 & 77 \\
\hline 178 & Abtenau & 4.0 & 3.3 & 73 \\
\hline 179 & Bischofshofen & 3.2 & 2.6 & 75 \\
\hline 184 & Paternion & 3.5 & 2.5 & 81 \\
\hline 185 & St. Veit/Glan & 5.1 & 3.0 & 78 \\
\hline 186 & Graz-Nord & 3.5 & 4.5 & 81 \\
\hline 187 & Pack & 4.9 & 2.9 & 75 \\
\hline 188 & Waldstein a.d. Übelb. & 3.2 & 3.1 & 80 \\
\hline 189 & Graz-Süd & 3.0 & 2.9 & 74 \\
\hline 190 & Offenegg & 2.9 & 3.0 & 81 \\
\hline 192 & Södingberg & 4.3 & 4.7 & 82 \\
\hline 202 & Istebna-Wisła & 2.2 & 3.1 & 73 \\
\hline 204 & Spisske Pochradie & 3.3 & 3.3 & 77 \\
\hline 207 & Jönköpings län & 5.0 & 5.7 & 75 \\
\hline 208 & Istebna & 3.4 & 2.7 & 73 \\
\hline 215 & Stinava & 3.4 & 4.2 & 69 \\
\hline 217 & Istebna-Wisła & 3.1 & 2.0 & 75 \\
\hline 227 & Thüringen & 3.0 & 3.5 & 74 \\
\hline 229 & Olsztyn & 4.2 & 3.4 & 81 \\
\hline 284 & Blekinge län Asarum & 3.8 & 4.1 & 80 \\
\hline 290 & Högestad & 3.6 & 2.7 & 70 \\
\hline 291 & Karupsskogen Barsebäcks gods & 3.8 & 3.7 & 80 \\
\hline 293 & Trolleholm & 8.5 & 3.7 & 69 \\
\hline 294 & Aasbo-össjö Gods & 1.9 & 3.5 & 77 \\
\hline 295 & Öveds Kloster Öpedal & 2.7 & 3.0 & 79 \\
\hline 704 & Cazis Tschartlina & 3.4 & 5.5 & 74 \\
\hline 711 & La Genolière & 2.3 & 2.5 & 79 \\
\hline 712 & Forêt du Risoud & 3.3 & 4.1 & 78 \\
\hline 713 & Caragnago & 4.0 & 4.2 & 76 \\
\hline 716 & Altacanta & 3.2 & 3.6 & 80 \\
\hline 722 & Piana Selva, Faido & 2.9 & 3.4 & 76 \\
\hline 725 & Airolo, Crespato-Ressia & 1.8 & 2.5 & 77 \\
\hline 734 & Airolo, Bedretto & 3.9 & 2.7 & 87 \\
\hline 740 & Bex, Tarejanne & 5.9 & 3.4 & 87 \\
\hline 1100 & Monts Megal, Le Portius & 3.1 & 3.4 & 88 \\
\hline 1101 & Le Pertuis, Monts du Velay & 3.2 & 3.9 & 80 \\
\hline 1111 & Peisey-Nancroix, Grd. Bois & 3.6 & 3.3 & 74 \\
\hline 1112 & Autrans, Isère & 2.5 & 3.0 & 80 \\
\hline 1114 & Passy & 2.3 & 2.3 & 70 \\
\hline 1115 & Magland & 3.6 & 3.4 & 76 \\
\hline 1116 & Lantosque & 3.8 & 3.5 & 76 \\
\hline 1117 & Plan Bois, Ballandes & 3.4 & 1.9 & 89 \\
\hline 1202 & Manderfeld Gilbuschek 63 A & 2.6 & 6.3 & 81 \\
\hline 2113 & Oberes Gailtal & 3.1 & 2.3 & 75 \\
\hline
\end{tabular}


Versuchsfläche 34

\begin{tabular}{|c|c|c|c|c|}
\hline \multirow{2}{*}{ PG-Nr. } & \multirow{2}{*}{ Herkunft } & \multicolumn{2}{|c|}{ Ovalität } & \multirow{2}{*}{$\begin{array}{l}\text { HD } \\
39-j .\end{array}$} \\
\hline & & $32-j$. & $39-\mathrm{j}$. & \\
\hline 2114 & Kreuzen-Stockenboi & 3.6 & 5.1 & 74 \\
\hline 2115 & Rosental & 2.9 & 3.3 & 79 \\
\hline 2116 & Aich & 3.0 & 4.3 & 86 \\
\hline 2117 & Gurktal & 2.9 & 3.9 & 81 \\
\hline 2120 & Liembergwald Zell a. S. & 3.4 & 3.1 & 87 \\
\hline 2121 & Neukirchen Großvenediger & 3.2 & 3.8 & 73 \\
\hline 2122 & Piberegg & 3.2 & 3.3 & 75 \\
\hline 2123 & Gallmannsegg Kainach & 2.5 & 3.3 & 81 \\
\hline 2126 & Gaishorn & 3.3 & 5.2 & 77 \\
\hline 2128 & Lobming-Oberth. St. Stefan/Kraubath & 3.0 & 3.2 & 80 \\
\hline 2130 & Stanz-Kindthal-Allerheiligen & 4.2 & 3.3 & 81 \\
\hline 2140 & Fölz, Mayerberg & 2.6 & 2.9 & 81 \\
\hline 2141 & Fölz, Greith & 3.4 & 3.4 & 80 \\
\hline 2144 & Seewiesen, Seereith & 6.1 & 3.5 & 75 \\
\hline 2147 & Freiland, Gschwend & 3.1 & 3.0 & 79 \\
\hline 2149 & Kindberg/Eisenerzer Alpen & 2.2 & 3.7 & 77 \\
\hline 2150 & Siebensee Wildalpen & 2.4 & 1.4 & 82 \\
\hline 2160 & Turnau, Kapfenberg & 3.9 & 2.0 & 73 \\
\hline 3326 & Neureichenau & 3.1 & 6.2 & 81 \\
\hline 3328 & Spiegelau & 3.5 & 3.6 & 76 \\
\hline 3329 & Spiegelau & 2.9 & 3.9 & 71 \\
\hline 3332 & Zwiesel-Ost & 3.2 & 4.1 & 70 \\
\hline 3406 & SHK Stryck Willingen & 2.9 & 3.6 & 75 \\
\hline 3410 & Traunstein & 5.2 & 4.1 & 72 \\
\hline 3411 & Bischofswiesen & 2.8 & 3.3 & 76 \\
\hline 3412 & Winterberg & 4.7 & 3.8 & 74 \\
\hline 3413 & SHK Winterberg & 3.7 & 4.1 & 87 \\
\hline 3415 & SHK Hochsauerland & 2.4 & 2.7 & 85 \\
\hline 3416 & SHK Höhenfichten & 2.5 & 5.2 & 76 \\
\hline 3417 & Marsberg & 3.5 & 5.6 & 79 \\
\hline 3418 & Sachsenried & 3.3 & 4.0 & 80 \\
\hline 3419 & Schwarzwald Baar, VIII/6 & 3.2 & 2.9 & 78 \\
\hline 3420 & Daun/Ost & 2.1 & 4.1 & 79 \\
\hline 3421 & Dombühl & 3.0 & 3.7 & 73 \\
\hline 3422 & Stryck & 4.3 & 3.5 & 78 \\
\hline 3423 & Kohlstetten & 3.4 & 3.8 & 78 \\
\hline 3424 & Winterberg & 4.0 & 3.8 & 78 \\
\hline 3425 & Waldmünchen & 4.3 & 3.9 & 83 \\
\hline 3426 & Uelzen & 4.7 & 6.1 & 81 \\
\hline 3427 & Oderhaus & 3.1 & 4.8 & 79 \\
\hline 3428 & Schernfeld & 3.0 & 4.5 & 80 \\
\hline 3429 & Villingen & 2.3 & 3.6 & 75 \\
\hline 3430 & Diessen & 3.7 & 2.9 & 75 \\
\hline 3431 & Riedenburg & 2.8 & 3.1 & 74 \\
\hline 3432 & Walsrode & 2.6 & 3.2 & 75 \\
\hline 3433 & Selb-Kirchenlamitz (1) & 3.0 & 2.5 & 76 \\
\hline 3434 & Miele & 2.3 & 3.5 & 77 \\
\hline 3435 & Neureichenau (2) & 4.6 & 4.9 & 75 \\
\hline 3436 & Neureichenau (2) & 2.4 & 3.0 & 75 \\
\hline
\end{tabular}


Versuchsfläche 34

\begin{tabular}{|c|c|c|c|c|}
\hline \multirow{2}{*}{ PG-Nr. } & \multirow{2}{*}{ Herkunft } & \multicolumn{2}{|c|}{ Ovalität } & \multirow{2}{*}{$\begin{array}{l}\text { HD } \\
39-j\end{array}$} \\
\hline & & $32-j$. & $39-\mathrm{j}$. & \\
\hline 3437 & Neureichenau (2) & 3.5 & 3.9 & 72 \\
\hline 3438 & Oderhaus & 2.1 & 2.5 & 80 \\
\hline 3444 & Zwiesel, Scheicherau XXI 14a/b $(3,6)$ & 4.1 & 2.9 & 78 \\
\hline 3445 & Zwiesel, Haselau XXI $12(3,6)$ & 2.5 & 2.1 & 75 \\
\hline 3447 & Nationalp. Hüttenschlag XIX 1b (6) & 2.6 & 3.8 & 77 \\
\hline 3448 & Nationalp. Filzwald IX 3a 10/11 (6) & 1.6 & 4.7 & 85 \\
\hline 3449 & Nationalp. Neubruck 1a10,b10/11,c10 (6) & 3.8 & 3.9 & 80 \\
\hline 3498 & Burgjoß & 3.9 & 2.8 & 77 \\
\hline 3499 & Chausseehaus & 4.1 & 2.9 & 77 \\
\hline 3505 & Eibenst. Carlsf. 275 & 3.6 & 3.9 & 75 \\
\hline 3617 & Torgelow & 4.3 & 4.1 & 73 \\
\hline 4011 & Cikaaj, Zdarska Vrchy & 3.8 & 3.9 & 77 \\
\hline 4032 & Kynsperk nad Ohri Libocky Dul & 2.7 & 2.1 & 74 \\
\hline 4042 & Vimperk-Prameny Vltury Stachy & 2.8 & 4.2 & 77 \\
\hline 4061 & Velke Mezirici-Rudolec & 2.8 & 3.8 & 71 \\
\hline 4081 & Frenstat pod Radhosten-Obora & 3.2 & 3.2 & 70 \\
\hline 4082 & Ostravice & 3.1 & 3.2 & 72 \\
\hline 4103 & Tatranska Lesna 559 C & 3.7 & 5.2 & 80 \\
\hline 4121 & Javorova Dolina 155 A, Nr. 4121 & 3.9 & 4.1 & 89 \\
\hline 4143 & Kysihybel & 3.3 & 4.2 & 73 \\
\hline 4154 & Roznava & 3.2 & 4.1 & 76 \\
\hline 4157 & Hnusta & 3.4 & 3.1 & 74 \\
\hline 4159 & Svrcina Hrabusice & 3.1 & 2.7 & 76 \\
\hline 5101 & Nedzinant, Prokletije (Geb.) & 1.9 & 2.4 & 74 \\
\hline 5201 & Köszeg 1 C & 3.7 & 3.9 & 82 \\
\hline 5202 & Szentgotthard $1 \mathrm{C}$ & 2.6 & 4.3 & 72 \\
\hline 5203 & Sarospatak-Haromhuta 19 B Zempl. Geb. & 2.5 & 3.1 & 80 \\
\hline 5204 & Miskolc-Lillafüred 82 A Bükker Geb. & 3.7 & 3.8 & 76 \\
\hline 5205 & Nagykanizsa-Iharos Plattensee 11/1-71 & 4.0 & 7.4 & 78 \\
\hline 5206 & Sopron (Hochschulrev.) 203 D & 3.7 & 3.1 & 72 \\
\hline 5302 & Beglika & 3.6 & 4.6 & 75 \\
\hline 5303 & Borovec (Rila-Geb.) & 2.5 & 2.7 & 83 \\
\hline 5401 & Valea Putnei-Poiorita & 2.8 & 2.9 & 77 \\
\hline 5413 & Brosteni Bradu/Bastitei & 3.7 & 2.7 & 74 \\
\hline 6106 & Köslin/Koszalin & 3.1 & 2.1 & 78 \\
\hline 6223 & Przerwanki & 4.9 & 3.0 & 84 \\
\hline 6237 & Puszcza-Białowieska & 2.8 & 4.4 & 79 \\
\hline 6250 & Augustow Abt. $95 \mathrm{~b}$ & 3.0 & 2.5 & 84 \\
\hline 6254 & Mikaszowka & 3.7 & 3.0 & 76 \\
\hline 6255 & Puszcza-Augustowska & 3.1 & 3.4 & 71 \\
\hline 6260 & Knyszyn & 4.0 & 4.1 & 81 \\
\hline 6261 & Kumialka (Kumialska) & 3.1 & 4.4 & 79 \\
\hline 6410 & Sierpc & 4.6 & 4.1 & 75 \\
\hline 6713 & Klodzko-Nynow $72 \mathrm{k}$ & 2.8 & 3.3 & 73 \\
\hline 6896 & Borken & 4.5 & 4.3 & 74 \\
\hline 7401 & Gzatsk-Smolensk & 3.2 & 2.8 & 74 \\
\hline 8703 & Lohja Laaskspohjan & 2.9 & 2.6 & 75 \\
\hline 9170 & Ryssby-Kronobergs & 2.7 & 3.8 & 71 \\
\hline 9417 & Marsberg & 3.8 & 5.2 & 75 \\
\hline 9423 & Kohlstetten & 2.9 & 3.4 & 75 \\
\hline 9432 & Walsrode & 3.5 & 3.4 & 82 \\
\hline
\end{tabular}


Versuchsfläche 35

\begin{tabular}{|c|c|c|c|c|}
\hline \multirow{2}{*}{ PG-Nr. } & \multirow{2}{*}{ Herkunft } & \multicolumn{2}{|c|}{ Ovalität } & \multirow{2}{*}{$\begin{array}{l}\text { HD } \\
39-j .\end{array}$} \\
\hline & & $32-j$. & $39-j$. & \\
\hline 107 & Donaueschingen & 2.6 & 2.1 & 82 \\
\hline 111 & Bodenmais & 2.7 & 6.1 & 74 \\
\hline 115 & Westerhof & 3.2 & 3.7 & 69 \\
\hline 121 & Cedrogne & 3.1 & 2.3 & 70 \\
\hline 149 & Einsiedeln & 3.0 & 2.8 & 78 \\
\hline 2118 & Gurker Sirnitzwald & 3.8 & 3.5 & 75 \\
\hline 2131 & Veitsch-Neuberg & 2.8 & 2.1 & 82 \\
\hline 2133 & Hinterhof, Eibelkogel & 2.0 & 2.4 & 83 \\
\hline 2134 & Hinterhof, Ostbrenner u. Tiefental & 1.9 & 2.1 & 80 \\
\hline 2135 & Kraubath, Seckauer Tauern & 2.5 & 2.4 & 77 \\
\hline 2137 & Buchberg, Flachwald/Aflenz & 3.0 & 1.8 & 82 \\
\hline 2138 & Buchberg, Ägidiwald/Aflenz & 2.2 & 2.5 & 88 \\
\hline 2151 & Breitenau-Mixnitz/Fischbacher Alp. & 2.5 & 2.7 & 79 \\
\hline 2158 & Rohr im Gebirge, Kirchwald & 3.3 & 1.6 & 76 \\
\hline 2179 & Eisenkappel/Karaw. & 2.6 & 3.1 & 84 \\
\hline 2184 & Schneegattern & 3.0 & 4.0 & 73 \\
\hline 2207 & Seewiesen Seereith/Aflenz & 3.1 & 2.6 & 86 \\
\hline 3042 & Walchensee & 3.8 & 4.9 & 85 \\
\hline 3102 & Schluchsee-Eschenmoos & 2.7 & 2.9 & 86 \\
\hline 3139 & Isny Ba/Wü & 2.8 & 2.7 & 83 \\
\hline 3310 & Zwiesel-West/Ruselhänge X/68 & 3.1 & 3.2 & 76 \\
\hline 3320 & Bischofsreut & 2.8 & 2.6 & 71 \\
\hline 3331 & St. Oswald I/3,4,6 Typengemisch & 2.8 & 3.9 & 72 \\
\hline 3334 & Zwiesel-Ost, V/1,2, Plattenfichten & 3.0 & 3.2 & 78 \\
\hline 3337 & Rabenstein Typengemisch & 2.5 & 2.6 & 78 \\
\hline 3404 & Westerhof Abt. $51 \mathrm{~B}$ & 3.5 & 3.1 & 78 \\
\hline 3417 & Marsberg & 7.4 & 3.8 & 76 \\
\hline 3423 & Kohlstetten & 3.4 & 3.3 & 72 \\
\hline 3430 & Diessen & 3.8 & 4.2 & 75 \\
\hline 3432 & Walsrode & 3.0 & 4.2 & 80 \\
\hline 3433 & Selb-Kirchenlamitz (1) & 2.9 & 4.1 & 74 \\
\hline 3443 & Zwiesel, Scheichereb. XXI 13b1 $(3,6)$ & 2.7 & 3.0 & 82 \\
\hline 3501 & Rungstock, 46 A & 3.6 & 2.2 & 79 \\
\hline 3503 & Eibenst. Carlsf. Wiesenh. 214 & 2.6 & 3.4 & 74 \\
\hline 3504 & Eibenst. Carlsf. Wilschm. 233 & 2.8 & 2.7 & 81 \\
\hline 3506 & Tellerhaeuser, 44 & 3.1 & 3.6 & 77 \\
\hline 3508 & Rehefeld, 146 & 3.0 & 3.2 & 77 \\
\hline 3510 & Sonneb. Steinheid, Kieferleskopf & 3.0 & 2.5 & 80 \\
\hline 3511 & Innenau Elgersburg & 3.1 & 3.2 & 80 \\
\hline 3512 & Peitz/Tannenwald & 3.1 & 2.3 & 86 \\
\hline 3518 & Suhl, Oberhofer Schloßbergkopf & 2.4 & 2.4 & 78 \\
\hline 3519 & Mechterstädt & 3.6 & 2.3 & 82 \\
\hline 3601 & Cottbus, Tannenwald 17AB & 2.8 & 3.3 & 84 \\
\hline 3606 & Templin, Bad Doberan Nr. 9 & 2.5 & 2.4 & 72 \\
\hline 3615 & Neustrelitz & 2.7 & 2.8 & 78 \\
\hline 4022 & Boubin III & 2.2 & 2.5 & 85 \\
\hline 4026 & Habartice, Planice & 2.7 & 5.2 & 77 \\
\hline 4051 & Vysoky Chlumec Veletin & 3.3 & 4.1 & 79 \\
\hline 4053 & Cesky Krumlov Borova & 3.0 & 4.2 & 81 \\
\hline
\end{tabular}


Versuchsfläche 35

\begin{tabular}{|c|c|c|c|c|}
\hline \multirow{2}{*}{ PG-Nr. } & \multirow{2}{*}{ Herkunft } & \multicolumn{2}{|c|}{ Ovalität } & \multirow{2}{*}{$\begin{array}{l}\text { HD } \\
39-j .\end{array}$} \\
\hline & & $32-j$. & $39-j$. & \\
\hline 4054 & Chlum u. Trebone-Hamr & 2.9 & 2.5 & 79 \\
\hline 4060 & Hencov-Trest & 3.8 & 2.8 & 75 \\
\hline 4070 & Vrchlabi & 2.9 & 2.2 & 80 \\
\hline 4073 & Jesenik-Zlate Hory & 3.9 & 3.6 & 77 \\
\hline 4123 & Javorova Dolina 155 A, Nr.4123 & 4.6 & 5.0 & 79 \\
\hline 5102 & Kaludjerske Bore Taram Kremma & 2.9 & 2.2 & 84 \\
\hline 5107 & Smrceve Dolina Abt. 138 & 3.1 & 2.3 & 81 \\
\hline 5301 & Belogradchik-Tschupreno & 4.1 & 2.1 & 84 \\
\hline 5412 & Moldovita-Sacries & 2.6 & 2.4 & 78 \\
\hline 5415 & Cimpeni-Dara & 3.3 & 4.1 & 77 \\
\hline 5416 & Remeti-Zerna & 3.4 & 3.1 & 78 \\
\hline 5420 & Valea Putnei-Pojorita III/ 60 & 2.5 & 3.7 & 76 \\
\hline 5426 & Crucea-Barnavel Abt. 17/18 & 3.0 & 2.4 & 80 \\
\hline 6103 & Brotzen/Broczyno & 3.9 & 2.5 & 76 \\
\hline 6222 & Borken/Borki & 3.1 & 2.2 & 71 \\
\hline 6234 & Białowieża & 3.0 & 3.9 & 82 \\
\hline 6235 & Zwierzyniec & 3.3 & 3.1 & 82 \\
\hline 6251 & Białobrzegi & 2.0 & 2.7 & 80 \\
\hline 6510 & Bunzlau/Boleslawiec & 2.8 & 4.4 & 82 \\
\hline 6543 & Groß-Lassowitz/Lassowice Male & 3.7 & 2.2 & 78 \\
\hline 6624 & Przysucha & 2.5 & 2.6 & 86 \\
\hline 6712 & Klodzko-Glatz/Nynow 68 e & 3.4 & 3.7 & 71 \\
\hline 6731 & Szcytna-Slaska Karlow 243 a & 2.3 & 2.6 & 79 \\
\hline 6732 & Szcytna-Slaska Karlow 292 b & 2.3 & 2.4 & 78 \\
\hline 6864 & Istebna-Ujsoly & 2.9 & 3.4 & 83 \\
\hline 6894 & Witów & 2.6 & 1.9 & 83 \\
\hline 7224 & Ostrovskij-Pskow & 1.8 & 2.8 & 84 \\
\hline 7233 & Wolozin & 5.6 & 3.8 & 85 \\
\hline 7235 & Brigalovic-Mogilev & 3.5 & 4.2 & 87 \\
\hline 7422 & Rjasan, Moshary & 2.7 & 3.2 & 88 \\
\hline 8705 & Mänttä & 1.5 & 2.5 & 97 \\
\hline 8707 & Janakkala Keskivari Uhkoila & 3.5 & 2.2 & 87 \\
\hline
\end{tabular}

Versuchsfläche 36

\begin{tabular}{c|l|c|c|c}
\hline \multirow{2}{*}{ PG-Nr. } & \multirow{2}{*}{ Herkunft } & \multicolumn{2}{|c|}{ Ovalität } & HD \\
& & $32-\mathrm{j}$. & $39-\mathrm{j}$. & $39-\mathrm{j}$. \\
\hline 65 & Eisenkappel Thurn 2 & 4.0 & 3.2 & 75 \\
105 & Hohenschwangau & 3.2 & 3.6 & 73 \\
113 & Walsrode & 3.0 & 2.9 & 79 \\
116 & Kobernausserwald & 4.0 & 2.7 & 80 \\
169 & Gries & 3.5 & 4.0 & 81 \\
172 & Mittersill & 4.8 & 4.1 & 66 \\
191 & Passail & 5.5 & 4.2 & 76 \\
230 & Elbingerode & 2.7 & 2.8 & 82 \\
1118 & Chatel, Aity" & 3.3 & 1.7 & 78 \\
1201 & Mellier, Bois Bayai, 2 & 4.7 & 2.9 & 80
\end{tabular}


Versuchsfläche 36

\begin{tabular}{|c|c|c|c|c|}
\hline \multirow{2}{*}{ PG-Nr. } & \multirow{2}{*}{ Herkunft } & \multicolumn{2}{|c|}{ Ovalität } & \multirow{2}{*}{$\begin{array}{l}\text { HD } \\
39-\mathrm{j}\end{array}$} \\
\hline & & $32-j$. & $39-j$. & \\
\hline 2124 & Stixenstein, Gahns & 3.9 & 3.9 & 83 \\
\hline 2127 & Unterhal, St. Kathrein a.d. Lamming & 4.6 & 2.3 & 80 \\
\hline 2174 & Klein-Sölk/Niedertauern & 5.9 & 4.2 & 81 \\
\hline 3150 & Dillingen a.d.D. Bay. & 3.2 & 2.7 & 78 \\
\hline 3206 & Eglharting XIV/17,19 & 4.0 & 4.5 & 78 \\
\hline 3213 & Mühldorf/Inn & 3.3 & 3.3 & 82 \\
\hline 3414 & Bodensee Oberschwab. VIII/13 & 2.8 & 2.7 & 76 \\
\hline 3417 & Marsberg & 3.3 & 3.0 & 77 \\
\hline 3423 & Kohlstetten & 3.9 & 1.8 & 74 \\
\hline 3430 & Diessen & 5.1 & 4.8 & 76 \\
\hline 3432 & Walsrode & 4.9 & 5.8 & 74 \\
\hline 3433 & Selb-Kirchenlamitz (1) & 6.7 & 2.9 & 75 \\
\hline 3446 & Zwiesel, Schmalzau IX 3c $(5,6)$ & 2.8 & 2.8 & 73 \\
\hline 4050 & Vlasim-Votice & 3.3 & 3.9 & 77 \\
\hline 4075 & Vitkov-Budisov & 3.2 & 2.4 & 76 \\
\hline 4127 & Javorova Dolina 155 A, Nr.4127 & 2.7 & 3.4 & 85 \\
\hline 5424 & Valea Beliei-Sinaia Gurguiata & 2.1 & 3.0 & 83 \\
\hline 5425 & Cimpeni-Nedei & 5.4 & 4.5 & 80 \\
\hline 6107 & Altenhagen/Nowy Krakow & 2.2 & 2.5 & 79 \\
\hline 6236 & Białowieża & 2.6 & 2.5 & 91 \\
\hline 6897 & Goldap & 5.0 & 2.9 & 82 \\
\hline 7232 & Cemerjanskoe-Mogilev & 3.5 & 2.8 & 79 \\
\hline 7234 & Soboljanskoe-Grodno & 4.6 & 2.8 & 82 \\
\hline 7240 & Witebsk & 3.0 & 4.8 & 76 \\
\hline 7400 & Kaluga & 3.6 & 2.7 & 86 \\
\hline 9191 & Karlsholms-Kristianstad & 3.2 & 3.4 & 81 \\
\hline
\end{tabular}

\section{Anhang 1.4}

Zusammenstellung der sich signifikeant von mindestens einer anderen Herkunft im Tukey-Kramer-Test für das Merkmal Ovalität [\%] im Alter 32 auf der Versuchsfläche Reinhardshagen / Hessen (34) unterscheidenden Herkünfte

\begin{tabular}{c|r|l|c|c|c}
\hline Rang & $\begin{array}{c}\text { PG- } \\
\text { Nr. }\end{array}$ & Herkunft & Land & $\begin{array}{c}\text { Höhe } \\
\text { m ü. NN }\end{array}$ & $\begin{array}{c}\text { Oval. } \\
{[\%]}\end{array}$ \\
\hline 1 & 3448 & Nationalp. Filzwald IX 3a 10/11 (6) & D & 750 & 1.6 \\
2 & 725 & Airolo, Crespato-Ressia & CH & 1120 & 1.8 \\
3 & 5101 & Nedzinant, Prokletije (Geb.) & YU & 1150 & 1.9 \\
4 & 294 & Aasbo-össjö Gods & $\mathrm{S}$ & 50 & 1.9 \\
5 & 3420 & Daun/Ost & $\mathrm{D}$ & 450 & 2.1 \\
6 & 3438 & Oderhaus & $\mathrm{D}$ & 650 & 2.1 \\
7 & 139 & Vapenkova Skala & $\mathrm{CS}$ & 540 & 2.2 \\
8 & 202 & Istebna-Wisła & $\mathrm{PL}$ & 725 & 2.2 \\
9 & 2149 & Kindberg/Eisenerzer Alpen & $\mathrm{A}$ & 1000 & 2.2 \\
10 & 3429 & Villingen & $\mathrm{D}$ & 850 & 2.3 \\
11 & 1114 & Passy & $\mathrm{F}$ & 1200 & 2.3 \\
12 & 711 & La Genolière & $\mathrm{CH}$ &. & 2.3 \\
13 & 3434 & Miele & $\mathrm{D}$ & 90 & 2.3
\end{tabular}

Beiträge aus der NW-FVA, Band 5, 2010 


\begin{tabular}{|c|c|c|c|c|c|}
\hline Rang & $\begin{array}{l}\text { PG- } \\
\text { Nr. }\end{array}$ & Herkunft & Land & $\begin{array}{c}\text { Höhe } \\
\text { m ü. NN }\end{array}$ & $\begin{array}{c}\text { Oval. } \\
{[\%]}\end{array}$ \\
\hline 14 & 2150 & Siebensee Wildalpen & A & 850 & 2.4 \\
\hline 15 & 3415 & SHK Hochsauerland & $\mathrm{D}$ & 600 & 2.4 \\
\hline 16 & 3436 & Neureichenau (2) & $\mathrm{D}$ & 1050 & 2.4 \\
\hline 17 & 2123 & Gallmannsegg Kainach & A & 1100 & 2.4 \\
\hline 18 & 5203 & Sarospatak-Haromhuta 19 B Zempl. Geb. & $\mathrm{H}$ & 405 & 2.5 \\
\hline 19 & 3445 & Zwiesel, Haselau XXI $12(3,6)$ & $\mathrm{D}$ & 650 & 2.5 \\
\hline 20 & 1112 & Autrans, Isère & $\mathrm{F}$ & 1250 & 2.5 \\
\hline 21 & 3416 & SHK Höhenfichten & $\mathrm{D}$ & 1050 & 2.5 \\
\hline 22 & 5303 & Borovec (Rila-Geb.) & $\mathrm{BG}$ & 1300 & 2.5 \\
\hline 23 & 103 & Wunsiedel & $\mathrm{D}$ & 900 & 2.5 \\
\hline 24 & 2140 & Fölz, Mayerberg & A & 950 & 2.6 \\
\hline 25 & 3432 & Walsrode & $\mathrm{D}$ & 30 & 2.6 \\
\hline 26 & 3447 & Nationalp. Hüttenschlag XIX 1b (6) & $\mathrm{D}$ & 750 & 2.6 \\
\hline 27 & 1202 & Manderfeld Gilbuschek 63 A & $\mathrm{B}$ & 542 & 2.6 \\
\hline 28 & 140 & Bucovice & $\mathrm{CS}$ & 480 & 2.6 \\
\hline 29 & 98 & Massif Central & $\mathrm{F}$ & 1100 & 2.6 \\
\hline 30 & 5202 & Szentgotthard $1 \mathrm{C}$ & $\mathrm{H}$ & 310 & 2.6 \\
\hline 31 & 7401 & Gzatsk-Smolensk & SU & 194 & 2.7 \\
\hline 32 & 174 & Piesendorf & A & 900 & 2.7 \\
\hline 33 & 8703 & Lohja Laaskspohjan & $\mathrm{SF}$ & 50 & 2.7 \\
\hline 34 & 63 & Eisenkappel Thurn 1 & A & 850 & 2.7 \\
\hline 35 & 295 & Öveds Kloster Öpedal & $\mathrm{S}$ & 50 & 2.7 \\
\hline 36 & 3329 & Spiegelau & $\mathrm{D}$ & 1200 & 2.7 \\
\hline 37 & 4032 & Kynsperk nad Ohri Libocky Dul & CS & 650 & 2.7 \\
\hline 38 & 4042 & Vimperk-Prameny Vltury Stachy & CS & 950 & 2.8 \\
\hline 39 & 62 & Litschau & A & 600 & 2.8 \\
\hline 40 & 190 & Offenegg & A & 950 & 2.8 \\
\hline 41 & 2116 & Aich & A & 700 & 2.8 \\
\hline 42 & 6237 & Puszcza-Białowieska & PL & 130 & 2.8 \\
\hline 43 & 9170 & Ryssby-Kronobergs & $\mathrm{S}$ & 175 & 2.8 \\
\hline 44 & 5401 & Valea Putnei-Pojorita & RU & 1085 & 2.8 \\
\hline 45 & 6713 & Klodzko-Nynow $72 \mathrm{k}$ & PL & 400 & 2.8 \\
\hline 46 & 4061 & Velke Mezirici-Rudolec & $\mathrm{CS}$ & 630 & 2.8 \\
\hline 47 & 3431 & Riedenburg & $\mathrm{D}$ & 500 & 2.8 \\
\hline 48 & 3411 & Bischofswiesen & $\mathrm{D}$ & 950 & 2.8 \\
\hline 49 & 141 & Pitin & $\mathrm{CS}$ & 610 & 2.9 \\
\hline 50 & 3433 & Selb-Kirchenlamitz (1) & $\mathrm{D}$ & 800 & 2.9 \\
\hline 51 & 3406 & SHK Stryck Willingen & $\mathrm{D}$ & 550 & 2.9 \\
\hline 52 & 722 & Piana Selva, Faido & $\mathrm{CH}$ & 980 & 2.9 \\
\hline 53 & 6250 & Augustow Abt. $95 \mathrm{~b}$ & PL & 120 & 2.9 \\
\hline 54 & 2117 & Gurktal & $\mathrm{A}$ & 1300 & 2.9 \\
\hline 55 & 2115 & Rosental & A & 1000 & 2.9 \\
\hline 56 & 97 & Gérardmer & $\mathrm{F}$ & 850 & 3.0 \\
\hline 57 & 9423 & Kohlstetten & $\mathrm{D}$ & 750 & 3.0 \\
\hline 58 & 227 & Thüringen & $\mathrm{D}$ & 300 & 3.0 \\
\hline 59 & 177 & Taxenbach & A & 1400 & 3.0 \\
\hline 60 & 3428 & Schernfeld & $\mathrm{D}$ & 450 & 3.0 \\
\hline 61 & 189 & Graz-Süd & A & 850 & 3.0 \\
\hline 62 & 3421 & Dombühl & $\mathrm{D}$ & 450 & 3.0 \\
\hline 63 & 61 & Gosau & $\mathrm{A}$ & 700 & 3.0 \\
\hline 64 & 217 & Istebna-Wisła & PL & 725 & 3.0 \\
\hline
\end{tabular}




\begin{tabular}{|c|c|c|c|c|c|}
\hline Rang & $\begin{array}{l}\text { PG- } \\
\text { Nr. }\end{array}$ & Herkunft & Land & $\begin{array}{c}\text { Höhe } \\
\text { m ü. NN }\end{array}$ & $\begin{array}{c}\text { Oval. } \\
{[\%]}\end{array}$ \\
\hline 64 & 217 & Istebna-Wisła & PL & 725 & 3.0 \\
\hline 65 & 2113 & Oberes Gailtal & A & 1100 & 3.1 \\
\hline 66 & 6106 & Köslin/Koszalin & PL & 50 & 3.1 \\
\hline 67 & 2147 & Freiland, Gschwend & A & 1000 & 3.1 \\
\hline 68 & 6261 & Kumialka (Kumialska) & PL & 160 & 3.1 \\
\hline 69 & 4159 & Svrcina Hrabusice & CS & 900 & 3.1 \\
\hline 70 & 3326 & Neureichenau & $\mathrm{D}$ & 1200 & 3.1 \\
\hline 71 & 171 & Hofgastein & A & 1100 & 3.1 \\
\hline 72 & 1100 & Monts Megal, Le Portius & $\mathrm{F}$ & 900 & 3.1 \\
\hline 73 & 1101 & Le Pertuis, Monts du Velay & $\mathrm{F}$ & 1100 & 3.2 \\
\hline 74 & 188 & Waldstein a.d. Übelb. & A & 850 & 3.2 \\
\hline 75 & 716 & Altacanta & $\mathrm{CH}$ & 1400 & 3.2 \\
\hline 76 & 3332 & Zwiesel-Ost & $\mathrm{D}$ & 1000 & 3.2 \\
\hline 77 & 4081 & Frenstat pod Radhosten-Obora & CS & 600 & 3.2 \\
\hline 78 & 4082 & Ostravice & CS & 800 & 3.2 \\
\hline 79 & 3427 & Oderhaus & $\mathrm{D}$ & 650 & 3.2 \\
\hline 80 & 3419 & Schwarzwald Baar, VIII/6 & $\mathrm{D}$ & 700 & 3.2 \\
\hline 81 & 2122 & Piberegg & A & 800 & 3.2 \\
\hline 82 & 204 & Spisske Pochradie & CS & 700 & 3.2 \\
\hline 83 & 2121 & Neukirchen Großvenediger & A & 870 & 3.2 \\
\hline 84 & 176 & St. Johann & A & 1200 & 3.2 \\
\hline 85 & 179 & Bischofshofen & A & 1200 & 3.2 \\
\hline 86 & 4154 & Roznava & CS & 800 & 3.2 \\
\hline 87 & 4143 & Kysihybel & CS & 540 & 3.3 \\
\hline 88 & 3418 & Sachsenried & $\mathrm{D}$ & 900 & 3.3 \\
\hline 89 & 6255 & Puszcza-Augustowska & PL & 125 & 3.3 \\
\hline 90 & 2126 & Gaishorn & A & 1200 & 3.3 \\
\hline 91 & 3423 & Kohlstetten & $\mathrm{D}$ & 750 & 3.4 \\
\hline 92 & 2141 & Fölz, Greith & A & 825 & 3.4 \\
\hline 93 & 1117 & Plan Bois, Ballandes & $\mathrm{F}$ & 500 & 3.4 \\
\hline 94 & 208 & Istebna & PL & 725 & 3.4 \\
\hline 95 & 712 & Forêt du Risoud & $\mathrm{CH}$ & 1100 & 3.4 \\
\hline 96 & 60 & Aflenz & A & 1000 & 3.4 \\
\hline 97 & 2120 & Liembergwald Zell a. S. & A & 875 & 3.4 \\
\hline 98 & 215 & Stinava & SK & & 3.4 \\
\hline 99 & 150 & Schlanders & I & 1500 & 3.4 \\
\hline 100 & 9432 & Walsrode & $\mathrm{D}$ & 30 & 3.5 \\
\hline 101 & 3437 & Neureichenau (2) & $\mathrm{D}$ & 1050 & 3.5 \\
\hline 102 & 3328 & Spiegelau & $\mathrm{D}$ & 1200 & 3.5 \\
\hline 103 & 4157 & Hnusta & CS & 550 & 3.5 \\
\hline 104 & 704 & Cazis Tschartlina & $\mathrm{CH}$ & 750 & 3.5 \\
\hline 105 & 41 & Spiegelau & $\mathrm{D}$ & 750 & 3.5 \\
\hline 106 & 110 & Medebach & $\mathrm{D}$ & 600 & 3.5 \\
\hline 107 & 290 & Högestad & $\mathrm{S}$ & 50 & 3.5 \\
\hline 108 & 124 & Istebna-Wisła & PL & 725 & 3.5 \\
\hline 109 & 3417 & Marsberg & $\mathrm{D}$ & 500 & 3.5 \\
\hline 110 & 184 & Paternion & A & 900 & 3.5 \\
\hline \multicolumn{6}{|c|}{ “67 Herkünfte } \\
\hline$\ddot{169}$ & 293 & Trolleholm & $\mathrm{S}$ & 125 & 8.5 \\
\hline
\end{tabular}




\section{Anhang 1.5}

Zusammenstellung der sich signifikant von mindestens einer anderen Herkunft im Tukey-Kramer-Test für das Merkmal Ovalität [\%] im Alter 32 auf der Versuchsfläche Reinhardshagen / Hessen (35) unterscheidenden Herkë̈fte

\begin{tabular}{|c|c|c|c|c|c|}
\hline Rang & $\begin{array}{l}\text { PG- } \\
\text { Nr. }\end{array}$ & Herkunft & Land & $\begin{array}{c}\text { Höhe } \\
\mathrm{m} \text { ü. NN }\end{array}$ & $\begin{array}{l}\text { Oval. } \\
{[\%]}\end{array}$ \\
\hline 1 & 8705 & Mänttä & SF & 120 & 1.4 \\
\hline 2 & 7224 & Ostrovskij-Pskow & SU & 200 & 1.8 \\
\hline 3 & 2134 & Hinterhof, Ostbrenner u. Tiefental & A & 1000 & 1.9 \\
\hline 4 & 2133 & Hinterhof, Eibelkogel & A & 1150 & 2.0 \\
\hline 5 & 4022 & Boubin III & CS & 1000 & 2.2 \\
\hline 6 & 2138 & Buchberg, Ägidiwald/Aflenz & A & 925 & 2.2 \\
\hline 7 & 6732 & Szcytna-Slaska Karlow 292 b & PL & 700 & 2.3 \\
\hline 8 & 6731 & Szcytna-Slaska Karlow 243 a & PL & 750 & 2.3 \\
\hline 9 & 5420 & Valea Putnei-Pojorita III/60 & RU & 1285 & 2.4 \\
\hline 10 & 3518 & Suhl, Oberhofer Schloßbergkopf & $\mathrm{D}$ & 900 & 2.4 \\
\hline 11 & 2151 & Breitenau-Mixnitz/Fischbacher Alp. & A & 970 & 2.5 \\
\hline 12 & 5412 & Moldovita-Sacries & RU & 825 & 2.5 \\
\hline 13 & 2135 & Kraubath, Seckauer Tauern & A & 1050 & 2.5 \\
\hline 14 & 107 & Donaueschingen & $\mathrm{D}$ & 650 & 2.5 \\
\hline 15 & 6624 & Przysucha & PL & 275 & 2.5 \\
\hline 16 & 3443 & Zwiesel, Scheichereb. XXI 13b1 $(3,6)$ & $\mathrm{D}$ & 650 & 2.5 \\
\hline 17 & 3337 & Rabenstein Typengemisch & $\mathrm{D}$ & 1200 & 2.6 \\
\hline 18 & 2179 & Eisenkappel/Karaw. & A & 800 & 2.6 \\
\hline 19 & 6894 & Witów & PL & 1250 & 2.6 \\
\hline 20 & 3606 & Templin, Bad Doberan Nr. 9 & $\mathrm{D}$ & 50 & 2.6 \\
\hline 21 & 6251 & Białobrzegi & PL & 110 & 2.6 \\
\hline 22 & 3102 & Schluchsee-Eschenmoos & $\mathrm{D}$ & 1200 & 2.7 \\
\hline 23 & 111 & Bodenmais & $\mathrm{D}$ & 1000 & 2.7 \\
\hline 24 & 3503 & Eibenst. Carlsf. Wiesenh. 214 & D & 720 & 2.7 \\
\hline 25 & 3615 & Neustrelitz & $\mathrm{D}$ & 100 & 2.7 \\
\hline 26 & 3331 & St. Oswald I/3,4,6 Typengemisch & $\mathrm{D}$ & 1200 & 2.7 \\
\hline 27 & 7422 & Rjasan, Moshary & SU & 150 & 2.7 \\
\hline 28 & 4026 & Habartice, Planice & CS & 550 & 2.7 \\
\hline 29 & 3320 & Bischofsreut & $\mathrm{D}$ & 970 & 2.8 \\
\hline 30 & 3601 & Cottbus, Tannenwald 17AB & $\mathrm{D}$ & 80 & 2.8 \\
\hline 31 & 2131 & Veitsch-Neuberg & A & 1000 & 2.8 \\
\hline 32 & 3139 & Isny $\mathrm{Ba} / \mathrm{Wü}$ & $\mathrm{D}$ & 850 & 2.8 \\
\hline 33 & 6510 & Bunzlau/Boleslawiec & PL & 175 & 2.8 \\
\hline 34 & 3310 & Zwiesel-West/Ruselhänge X/68 & $\mathrm{D}$ & 750 & 2.8 \\
\hline \multicolumn{6}{|c|}{46 Herkünfte } \\
\hline 81 & 3417 & Marsberg & D & 500 & 7.2 \\
\hline
\end{tabular}




\section{Anhang 1.6}

Zusammenstellung der mittleren BHD [cm] im Alter von 32 und 39 Jahren sowie der mittleren Höhe $[\mathrm{m}]$ im Alter von 39 Jahren auf den drei Versuchsflächen Reinhardshagen / Hessen

* BHD nur von den Bäumen, von denen Höhen gemessen wurden

Versuchsfläche 34

\begin{tabular}{|c|c|c|c|c|c|}
\hline PG-Nr. & Herkunft & $\begin{array}{l}\text { BHD } \\
32-j .\end{array}$ & $\begin{array}{c}\text { BHD. } \\
39-j .\end{array}$ & $\begin{array}{c}\text { BHD* }^{*} \\
39-j .\end{array}$ & $\begin{array}{l}\text { Höhe } \\
39-\text { j. }\end{array}$ \\
\hline 41 & Spiegelau & 18.5 & 22.7 & 25.0 & 21.7 \\
\hline 60 & Aflenz & 21.0 & 25.8 & 29.0 & 22.0 \\
\hline 61 & Gosau & 22.6 & 29.6 & 30.0 & 23.4 \\
\hline 62 & Litschau & 24.8 & 31.3 & 34.3 & 22.5 \\
\hline 63 & Eisenkappel Thurn 1 & 21.4 & 28.2 & 31.8 & 22.6 \\
\hline 64 & St. Martin & 20.3 & 28.1 & 29.3 & 22.3 \\
\hline 66 & Vorau & 19.8 & 25.2 & 28.4 & 22.2 \\
\hline 97 & Gérardmer & 21.0 & 27.7 & 30.3 & 21.6 \\
\hline 98 & Massif Central & 20.8 & 27.1 & 29.5 & 22.4 \\
\hline 103 & Wunsiedel & 21.6 & 26.9 & 31.2 & 22.9 \\
\hline 110 & Medebach & 20.3 & 25.4 & 26.3 & 22.1 \\
\hline 114 & Winterberg & 21.8 & 28.2 & 30.7 & 23.3 \\
\hline 124 & Istebna-Wisła & 23.7 & 30.2 & 32.0 & 21.4 \\
\hline 130 & Dobra bei Frydek & 21.7 & 27.4 & 29.4 & 22.1 \\
\hline 131 & Vizovice & 21.1 & 29.2 & 31.5 & 20.4 \\
\hline 139 & Vapenkova Skala & 22.3 & 27.8 & 29.6 & 21.7 \\
\hline 140 & Bucovice & 21.0 & 28.3 & 29.8 & 21.8 \\
\hline 141 & Pitin & 21.0 & 28.0 & 30.3 & 20.9 \\
\hline 142 & Rosice & 20.3 & 29.3 & 30.7 & 21.4 \\
\hline 150 & Schlanders & 17.9 & 23.6 & 27.4 & 18.0 \\
\hline 170 & Groß Arl & 20.9 & 28.8 & 31.6 & 22.0 \\
\hline 171 & Hofgastein & 20.2 & 26.3 & 27.7 & 21.8 \\
\hline 174 & Piesendorf & 20.7 & 26.7 & 30.6 & 22.8 \\
\hline 175 & Radstatt & 20.9 & 28.2 & 30.1 & 22.4 \\
\hline 176 & St. Johann & 19.9 & 24.7 & 27.9 & 21.6 \\
\hline 177 & Taxenbach & 20.0 & 25.5 & 29.1 & 22.3 \\
\hline 178 & Abtenau & 22.7 & 29.5 & 30.7 & 22.0 \\
\hline 179 & Bischofshofen & 21.8 & 27.2 & 29.5 & 22.1 \\
\hline 184 & Paternion & 20.9 & 26.4 & 27.7 & 22.0 \\
\hline 185 & St. Veit/Glan & 20.2 & 25.9 & 28.7 & 21.7 \\
\hline 186 & Graz-Nord & 18.2 & 23.6 & 27.2 & 21.5 \\
\hline 187 & Pack & 21.6 & 27.6 & 30.1 & 21.8 \\
\hline 188 & Waldstein a.d. Übelb. & 19.9 & 24.5 & 27.6 & 21.6 \\
\hline 189 & Graz-Süd & 18.9 & 25.9 & 29.2 & 21.4 \\
\hline 190 & Offenegg & 21.0 & 26.3 & 27.9 & 21.6 \\
\hline 192 & Södingberg & 19.9 & 25.2 & 27.9 & 22.3 \\
\hline 202 & Istebna-Wisła & 21.5 & 28.1 & 31.1 & 22.5 \\
\hline 204 & Spisske Pochradie & 20.5 & 27.0 & 28.1 & 21.6 \\
\hline 207 & Jönköpings län & 19.2 & 25.0 & 28.6 & 20.3 \\
\hline 208 & Istebna & 22.1 & 28.4 & 31.0 & 22.6 \\
\hline 215 & Stinava & 21.6 & 28.6 & 31.4 & 21.4 \\
\hline 217 & Istebna-Wisła & 21.1 & 28.0 & 29.3 & 21.7 \\
\hline 227 & Thüringen & 22.0 & 27.0 & 30.7 & 22.2 \\
\hline 229 & Olsztyn & 20.2 & 25.6 & 27.6 & 22.2 \\
\hline
\end{tabular}


Versuchsfläche 34

\begin{tabular}{|c|c|c|c|c|c|}
\hline PG-Nr. & Herkunft & $\begin{array}{c}\text { BHD } \\
32-j .\end{array}$ & $\begin{array}{c}\text { BHD. } \\
39-j .\end{array}$ & $\begin{array}{c}\text { BHD* }^{*} \\
39-j .\end{array}$ & $\begin{array}{l}\text { Höhe } \\
39-j .\end{array}$ \\
\hline 284 & Blekinge län Asarum & 18.9 & 23.8 & 25.8 & 20.4 \\
\hline 290 & Högestad & 22.2 & 29.4 & 30.4 & 21.0 \\
\hline 291 & Karupsskogen Barsebäcks gods & 20.8 & 26.4 & 28.5 & 22.3 \\
\hline 293 & Trolleholm & 23.7 & 31.3 & 32.7 & 22.4 \\
\hline 294 & Aasbo-össjö Gods & 20.6 & 26.1 & 28.3 & 21.6 \\
\hline 295 & Öveds Kloster Öpedal & 20.8 & 26.3 & 28.5 & 22.1 \\
\hline 704 & Cazis Tschartlina & 15.4 & 25.9 & 30.0 & 21.5 \\
\hline 711 & La Genolière & 17.7 & 20.9 & 25.1 & 19.4 \\
\hline 712 & Forêt du Risoud & 19.2 & 24.5 & 26.0 & 19.7 \\
\hline 713 & Caragnago & 20.3 & 26.1 & 28.4 & 21.2 \\
\hline 716 & Altacanta & 19.9 & 26.8 & 28.3 & 21.7 \\
\hline 722 & Piana Selva, Faido & 20.3 & 25.2 & 28.3 & 20.9 \\
\hline 725 & Airolo, Crespato-Ressia & 19.4 & 25.6 & 27.4 & 21.0 \\
\hline 734 & Airolo, Bedretto & 15.0 & 20.0 & 21.6 & 17.7 \\
\hline 740 & Bex, Tarejanne & 17.4 & 19.6 & 21.4 & 17.7 \\
\hline 1100 & Monts Megal, Le Portius & 19.5 & 25.1 & 25.8 & 22.4 \\
\hline 1101 & Le Pertuis, Monts du Velay & 21.9 & 26.3 & 27.9 & 21.9 \\
\hline 1111 & Peisey-Nancroix, Grd. Bois & 19.1 & 26.0 & 29.1 & 21.4 \\
\hline 1112 & Autrans, Isère & 17.5 & 21.4 & 24.5 & 19.4 \\
\hline 1114 & Passy & 18.7 & 24.0 & 27.8 & 19.5 \\
\hline 1115 & Magland & 20.2 & 27.1 & 29.6 & 22.2 \\
\hline 1116 & Lantosque & 19.9 & 25.7 & 27.0 & 20.2 \\
\hline 1117 & Plan Bois, Ballandes & 19.0 & 25.3 & 25.9 & 20.9 \\
\hline 1202 & Manderfeld Gilbuschek 63 A & 21.8 & 27.8 & 29.4 & 23.4 \\
\hline 2113 & Oberes Gailtal & 19.4 & 26.8 & 30.4 & 21.8 \\
\hline 2114 & Kreuzen-Stockenboi & 21.5 & 26.0 & 31.1 & 22.3 \\
\hline 2115 & Rosental & 19.5 & 24.5 & 27.7 & 21.8 \\
\hline 2116 & Aich & 19.5 & 24.7 & 25.9 & 21.4 \\
\hline 2117 & Gurktal & 20.0 & 25.9 & 27.6 & 22.2 \\
\hline 2120 & Liembergwald Zell a. S. & 18.3 & 24.5 & 25.8 & 22.1 \\
\hline 2121 & Neukirchen Großvenediger & 22.8 & 30.3 & 31.3 & 22.4 \\
\hline 2122 & Piberegg & 21.3 & 30.3 & 31.1 & 22.8 \\
\hline 2123 & Gallmannsegg Kainach & 20.5 & 25.8 & 28.0 & 21.9 \\
\hline 2126 & Gaishorn & 19.7 & 24.3 & 31.1 & 23.5 \\
\hline 2128 & Lobming-Oberth. St. Stefan/Kraubath & 16.9 & 22.7 & 27.0 & 20.2 \\
\hline 2130 & Stanz-Kindthal-Allerheiligen & 20.4 & 26.3 & 27.7 & 22.2 \\
\hline 2140 & Fölz, Maverberg & 21.4 & 26.2 & 28.4 & 22.6 \\
\hline 2141 & Fölz, Greith & 20.8 & 26.7 & 28.8 & 22.6 \\
\hline 2144 & Seewiesen, Seereith & 19.7 & 28.1 & 29.9 & 21.7 \\
\hline 2147 & Freiland, Gschwend & 20.2 & 25.0 & 28.5 & 22.5 \\
\hline 2149 & Kindberg/Eisenerzer Alpen & 21.4 & 26.9 & 29.9 & 22.8 \\
\hline 2150 & Siebensee Wildalpen & 18.3 & 23.4 & 26.0 & 21.3 \\
\hline 2160 & Turnau, Kapfenberg & 21.2 & 27.3 & 30.6 & 22.4 \\
\hline 3326 & Neureichenau & 18.9 & 23.8 & 26.0 & 20.2 \\
\hline 3328 & Spiegelau & 19.6 & 26.7 & 29.0 & 21.7 \\
\hline 3329 & Spiegelau & 23.2 & 31.6 & 32.3 & 22.5 \\
\hline 3332 & Zwiesel-Ost & 22.7 & 28.6 & 31.2 & 21.5 \\
\hline 3406 & SHK Stryck Willingen & 20.8 & 26.3 & 29.3 & 21.7 \\
\hline 3410 & Traunstein & 21.5 & 28.4 & 30.8 & 21.9 \\
\hline 3411 & Bischofswiesen & 19.5 & 25.4 & 28.9 & 21.7 \\
\hline
\end{tabular}


Versuchsfläche 34

\begin{tabular}{|c|c|c|c|c|c|}
\hline PG-Nr. & Herkunft & $\begin{array}{l}\text { BHD } \\
32-j .\end{array}$ & $\begin{array}{c}\text { BHD. } \\
39-j .\end{array}$ & $\begin{array}{c}\text { BHD* } \\
39-j .\end{array}$ & $\begin{array}{l}\text { Höhe } \\
39-j .\end{array}$ \\
\hline 3412 & Winterberg & 23.6 & 29.9 & 31.3 & 23.2 \\
\hline 3413 & SHK Winterberg & 20.0 & 24.7 & 26.1 & 22.1 \\
\hline 3415 & SHK Hochsauerland & 20.2 & 25.4 & 26.5 & 22.0 \\
\hline 3416 & SHK Höhenfichten & 19.3 & 24.9 & 28.0 & 20.9 \\
\hline 3417 & Marsberg & 22.7 & 28.7 & 29.7 & 23.0 \\
\hline 3418 & Sachsenried & 20.8 & 26.8 & 29.2 & 22.9 \\
\hline 3419 & Schwarzwald Baar, VIII/6 & 22.1 & 27.9 & 29.1 & 22.6 \\
\hline 3420 & Daun/Ost & 21.2 & 26.9 & 28.6 & 22.2 \\
\hline 3421 & Dombühl & 22.4 & 28.8 & 31.5 & 22.8 \\
\hline 3422 & Stryck & 20.2 & 26.0 & 29.0 & 22.1 \\
\hline 3423 & Kohlstetten & 19.9 & 28.5 & 29.1 & 22.4 \\
\hline 3424 & Winterberg & 20.8 & 27.6 & 29.7 & 22.8 \\
\hline 3425 & Waldmünchen & 20.0 & 24.2 & 26.6 & 21.8 \\
\hline 3426 & Uelzen & 20.6 & 26.0 & 28.2 & 22.4 \\
\hline 3427 & Oderhaus & 21.4 & 28.6 & 30.1 & 23.1 \\
\hline 3428 & Schernfeld & 19.9 & 25.4 & 28.2 & 22.3 \\
\hline 3429 & Villingen & 21.7 & 28.9 & 29.7 & 21.7 \\
\hline 3430 & Diessen & 21.4 & 27.4 & 30.6 & 22.8 \\
\hline 3431 & Riedenburg & 20.0 & 26.9 & 29.7 & 21.5 \\
\hline 3432 & Walsrode & 22.1 & 27.5 & 29.9 & 22.1 \\
\hline 3433 & Selb-Kirchenlamitz (1) & 22.3 & 28.5 & 29.9 & 22.4 \\
\hline 3434 & Miele & 21.8 & 27.2 & 29.1 & 22.0 \\
\hline 3435 & Neureichenau (2) & 21.2 & 28.2 & 30.4 & 22.7 \\
\hline 3436 & Neureichenau (2) & 22.9 & 29.8 & 31.2 & 22.9 \\
\hline 3437 & Neureichenau (2) & 21.4 & 28.6 & 30.8 & 22.1 \\
\hline 3438 & Oderhaus & 21.0 & 25.9 & 27.6 & 21.7 \\
\hline 3444 & Zwiesel, Scheicherau XXI 14a/b (3,6) & 20.2 & 26.8 & 29.0 & 22.0 \\
\hline 3445 & Zwiesel, Haselau XXI $12(3,6)$ & 21.9 & 29.4 & 30.4 & 22.6 \\
\hline 3447 & Nationalp. Hüttenschlag XIX 1b (6) & 22.7 & 28.5 & 30.7 & 23.2 \\
\hline 3448 & Nationalp. Filzwald IX 3a 10/11 (6) & 18.7 & 23.3 & 26.9 & 22.2 \\
\hline 3449 & Nationalp. Neubruck 1a10,b10/11,c10 (6) & 20.5 & 26.0 & 28.2 & 21.8 \\
\hline 3498 & Burgjoß & 22.6 & 28.5 & 30.7 & 23.5 \\
\hline 3499 & Chausseehaus & 22.0 & 27.7 & 29.6 & 22.5 \\
\hline 3505 & Eibenst. Carlsf. 275 & 23.1 & 29.8 & 30.0 & 21.9 \\
\hline 3617 & Torgelow & 23.1 & 30.1 & 32.0 & 23.0 \\
\hline 4011 & Cikaaj, Zdarska Vrchy & 21.7 & 27.1 & 29.4 & 22.6 \\
\hline 4032 & Kynsperk nad Ohri Libocky Dul & 22.7 & 28.5 & 31.7 & 23.1 \\
\hline 4042 & Vimperk-Prameny Vltury Stachy & 20.4 & 26.7 & 29.9 & 22.8 \\
\hline 4061 & Velke Mezirici-Rudolec & 23.5 & 29.7 & 32.9 & 23.0 \\
\hline 4081 & Frenstat pod Radhosten-Obora & 24.8 & 32.0 & 34.0 & 23.5 \\
\hline 4082 & Ostravice & 21.7 & 28.3 & 30.5 & 21.8 \\
\hline 4103 & Tatranska Lesna 559 C & 20.7 & 27.2 & 29.1 & 23.2 \\
\hline 4121 & Javorova Dolina 155 A, Nr. 4121 & 18.7 & 23.5 & 24.8 & 21.7 \\
\hline 4143 & Kysihybel & 21.2 & 28.7 & 30.9 & 22.2 \\
\hline 4154 & Roznava & 21.0 & 26.8 & 28.4 & 21.3 \\
\hline 4157 & Hnusta & 22.5 & 27.8 & 31.1 & 22.8 \\
\hline 4159 & Svrcina Hrabusice & 20.6 & 26.1 & 28.3 & 21.3 \\
\hline 5101 & Nedzinant, Prokletije (Geb.) & 17.9 & 21.9 & 26.6 & 19.5 \\
\hline 5201 & Köszeg 1 C & 21.3 & 27.3 & 27.8 & 21.8 \\
\hline 5202 & Szentgotthard $1 \mathrm{C}$ & 21.9 & 27.3 & 31.1 & 22.2 \\
\hline
\end{tabular}


Versuchsfläche 34

\begin{tabular}{c|l|c|c|c|c}
\hline PG-Nr. & Herkunft & $\begin{array}{c}\text { BHD } \\
32-j .\end{array}$ & $\begin{array}{c}\text { BHD. } \\
39-j .\end{array}$ & $\begin{array}{c}\text { BHD* } \\
39-j .\end{array}$ & $\begin{array}{c}\text { Höhe } \\
39-j .\end{array}$ \\
\hline 5203 & Sarospatak-Haromhuta 19 B Zempl. Geb. & 19.4 & 25.4 & 27.2 & 21.4 \\
5204 & Miskolc-Lillafüred 82 A Bükker Geb. & 22.1 & 27.6 & 29.4 & 22.2 \\
5205 & Nagykanizsa-Iharos Plattensee 11/1-71 & 22.0 & 28.6 & 28.4 & 22.0 \\
5206 & Sopron (Hochschulrev.) 203 D & 21.9 & 28.8 & 30.9 & 22.0 \\
5302 & Beglika & 21.7 & 26.9 & 29.1 & 21.5 \\
5303 & Borovec (Rila-Geb.) & 17.7 & 21.4 & 24.4 & 19.0 \\
5401 & Valea Putnei-Pojorita & 21.0 & 28.1 & 30.1 & 22.9 \\
5413 & Brosteni Bradu/Bastitei & 21.3 & 29.0 & 29.5 & 21.9 \\
6106 & Köslin/Koszalin & 20.9 & 27.2 & 28.3 & 21.5 \\
6223 & Przerwanki & 19.4 & 24.9 & 26.8 & 22.4 \\
6237 & Puszcza-Białowieska & 20.4 & 27.0 & 28.8 & 22.5 \\
6250 & Augustow Abt. 95 b & 19.2 & 23.2 & 26.3 & 21.7 \\
6254 & Mikaszowka & 22.9 & 27.5 & 30.8 & 22.8 \\
6255 & Puszcza-Augustowska & 23.8 & 31.5 & 31.8 & 22.2 \\
6260 & Knyszyn & 20.3 & 24.6 & 26.7 & 21.3 \\
6261 & Kumialka (Kumialska) & 19.1 & 23.4 & 27.1 & 21.0 \\
6410 & Sierpc & 20.9 & 28.0 & 29.6 & 21.7 \\
6713 & Klodzko-Nynow 72 k & 21.3 & 28.1 & 30.0 & 21.4 \\
6896 & Borken & 21.0 & 28.1 & 29.6 & 21.8 \\
7401 & Gzatsk-Smolensk & 21.7 & 30.2 & 30.2 & 22.0 \\
8703 & Lohja Laaskspohjan & 16.6 & 23.9 & 25.8 & 18.7 \\
9170 & Ryssby-Kronobergs & 16.1 & 25.0 & 27.7 & 19.4 \\
9417 & Marsberg & 20.8 & 28.7 & 30.7 & 22.9 \\
9423 & Kohlstetten & 19.8 & 26.9 & 29.1 & 21.8 \\
9432 & Walsrode & 19.3 & 25.5 & 27.1 & 22.1 \\
\hline
\end{tabular}

Versuchsfläche 35

\begin{tabular}{c|l|c|c|c|c}
\hline PG-Nr. & Herkunft & $\begin{array}{c}\text { BHD } \\
32-j .\end{array}$ & $\begin{array}{c}\text { BHD. } \\
39-j .\end{array}$ & $\begin{array}{c}\text { BHD* } \\
39-j .\end{array}$ & $\begin{array}{c}\text { Höhe } \\
39-j .\end{array}$ \\
\hline 107 & Donaueschingen & 19.5 & 24.3 & 25.4 & 20.5 \\
111 & Bodenmais & 19.6 & 25.6 & 29.1 & 21.1 \\
115 & Westerhof & 23.2 & 30.9 & 34.2 & 23.3 \\
121 & Cedrogne & 21.7 & 28.1 & 31.8 & 21.7 \\
149 & Einsiedeln & 21.2 & 27.1 & 28.1 & 21.5 \\
2118 & Gurker Sirnitzwald & 21.7 & 27.8 & 30.7 & 22.8 \\
2131 & Veitsch-Neuberg & 20.0 & 25.5 & 28.1 & 22.5 \\
2133 & Hinterhof, Eibelkogel & 20.4 & 26.0 & 27.4 & 22.4 \\
2134 & Hinterhof, Ostbrenner u. Tiefental & 20.9 & 26.2 & 29.4 & 23.3 \\
2135 & Kraubath, Seckauer Tauern & 21.8 & 27.4 & 30.2 & 22.8 \\
2137 & Buchberg, Flachwald/Aflenz & 20.6 & 25.6 & 27.1 & 22.0 \\
2138 & Buchberg, Ägidiwald/Aflenz & 19.1 & 24.0 & 25.8 & 22.0 \\
2151 & Breitenau-Mixnitz/Fischbacher Alp. & 18.7 & 25.5 & 27.7 & 21.9 \\
2158 & Rohr im Gebirge, Kirchwald & 20.4 & 26.7 & 29.4 & 22.2 \\
2179 & Eisenkappel/Karaw. & 19.6 & 25.5 & 27.2 & 22.4 \\
2184 & Schneegattern & 20.5 & 26.3 & 29.8 & 21.7 \\
2207 & Seewiesen Seereith/Aflenz & 19.6 & 24.6 & 26.7 & 22.9 \\
3042 & Walchensee & 19.5 & 23.6 & 26.3 & 21.7
\end{tabular}


Versuchsfläche 35

\begin{tabular}{|c|c|c|c|c|c|}
\hline PG-Nr. & Herkunft & $\begin{array}{l}\text { BHD } \\
32-j .\end{array}$ & $\begin{array}{c}\text { BHD. } \\
39-j .\end{array}$ & $\begin{array}{c}\text { BHD* } \\
39-j .\end{array}$ & $\begin{array}{l}\text { Höhe } \\
39-\text { j. }\end{array}$ \\
\hline 3102 & Schluchsee-Eschenmoos & 20.3 & 25.1 & 26.6 & 22.7 \\
\hline 3139 & Isny $\mathrm{Ba} / \mathrm{Wü}$ & 20.4 & 26.6 & 26.8 & 22.0 \\
\hline 3310 & Zwiesel-West/Ruselhänge X/68 & 21.4 & 27.0 & 29.5 & 22.4 \\
\hline 3320 & Bischofsreut & 21.9 & 30.3 & 31.5 & 21.9 \\
\hline 3331 & St. Oswald I/3,4,6 Typengemisch & 20.5 & 25.4 & 28.0 & 19.3 \\
\hline 3334 & Zwiesel-Ost, V/1,2, Plattenfichten & 18.4 & 25.8 & 28.4 & 21.8 \\
\hline 3337 & Rabenstein Typengemisch & 18.3 & 22.9 & 27.0 & 20.4 \\
\hline 3404 & Westerhof Abt. $51 \mathrm{~B}$ & 22.1 & 28.2 & 31.0 & 24.0 \\
\hline 3417 & Marsberg & 24.6 & 32.0 & 32.0 & 23.8 \\
\hline 3423 & Kohlstetten & 22.3 & 29.5 & 32.8 & 22.9 \\
\hline 3430 & Diessen & 21.7 & 27.7 & 31.1 & 22.7 \\
\hline 3432 & Walsrode & 19.8 & 26.6 & 29.5 & 22.9 \\
\hline 3433 & Selb-Kirchenlamitz (1) & 22.6 & 29.9 & 30.8 & 22.7 \\
\hline 3443 & Zwiesel, Scheichereb. XXI 13b1 $(3,6)$ & 19.6 & 25.0 & 28.2 & 22.8 \\
\hline 3501 & Rungstock, 46 A & 22.0 & 29.6 & 30.9 & 24.1 \\
\hline 3503 & Eibenst. Carlsf. Wiesenh. 214 & 24.0 & 30.5 & 32.4 & 23.4 \\
\hline 3504 & Eibenst. Carlsf. Wilschm. 233 & 22.5 & 27.3 & 29.0 & 23.2 \\
\hline 3506 & Tellerhaeuser, 44 & 21.6 & 26.5 & 28.8 & 22.0 \\
\hline 3508 & Rehefeld, 146 & 22.4 & 28.9 & 30.5 & 23.4 \\
\hline 3510 & Sonneb. Steinheid, Kieferleskopf & 20.4 & 26.9 & 28.4 & 22.5 \\
\hline 3511 & Innenau Elgersburg & 20.5 & 28.1 & 29.7 & 23.6 \\
\hline 3512 & Peitz/Tannenwald & 20.1 & 25.6 & 27.1 & 23.2 \\
\hline 3518 & Suhl, Oberhofer Schloßbergkopf & 19.9 & 25.3 & 27.8 & 21.2 \\
\hline 3519 & Mechterstädt & 21.6 & 27.5 & 29.3 & 23.6 \\
\hline 3601 & Cottbus, Tannenwald 17AB & 20.7 & 25.3 & 27.7 & 22.7 \\
\hline 3606 & Templin, Bad Doberan Nr. 9 & 23.4 & 29.7 & 32.8 & 23.4 \\
\hline 3615 & Neustrelitz & 21.4 & 27.6 & 31.0 & 23.8 \\
\hline 4022 & Boubin III & 20.5 & 26.8 & 27.9 & 23.3 \\
\hline 4026 & Habartice, Planice & 22.2 & 29.3 & 31.2 & 23.6 \\
\hline 4051 & Vysoky Chlumec Veletin & 21.8 & 28.2 & 31.2 & 24.4 \\
\hline 4053 & Cesky Krumlov Borova & 19.9 & 26.8 & 29.9 & 24.1 \\
\hline 4054 & Chlum u. Trebone-Hamr & 21.5 & 29.2 & 31.5 & 24.6 \\
\hline 4060 & Hencov-Trest & 22.8 & 29.7 & 30.9 & 22.9 \\
\hline 4070 & Vrchlabi & 19.6 & 27.6 & 29.6 & 23.5 \\
\hline 4073 & Jesenik-Zlate Hory & 21.3 & 28.1 & 29.9 & 22.9 \\
\hline 4123 & Javorova Dolina 155 A, Nr.4123 & 19.6 & 25.8 & 27.9 & 22.0 \\
\hline 5102 & Kaludjerske Bore Taram Kremma & 19.1 & 22.6 & 25.8 & 21.1 \\
\hline 5107 & Smrceve Dolina Abt. 138 & 16.8 & 19.4 & 21.9 & 17.3 \\
\hline 5301 & Belogradchik-Tschupreno & 18.4 & 20.9 & 23.7 & 19.6 \\
\hline 5412 & Moldovita-Sacries & 21.6 & 28.6 & 31.4 & 24.3 \\
\hline 5415 & Cimpeni-Dara & 20.6 & 28.7 & 31.4 & 24.0 \\
\hline 5416 & Remeti-Zerna & 21.5 & 29.2 & 31.4 & 24.3 \\
\hline 5420 & Valea Putnei-Pojorita III/60 & 22.2 & 28.0 & 31.9 & 24.2 \\
\hline 5426 & Crucea-Barnavel Abt. 17/18 & 21.1 & 27.4 & 29.5 & 23.4 \\
\hline 6103 & Brotzen/Broczyno & 21.2 & 28.0 & 30.4 & 22.8 \\
\hline 6222 & Borken/Borki & 23.8 & 30.5 & 32.6 & 23.0 \\
\hline 6234 & Białowieża & 21.3 & 27.6 & 28.2 & 22.5 \\
\hline 6235 & Zwierzyniec & 19.9 & 26.2 & 28.5 & 23.0 \\
\hline 6251 & Białobrzegi & 21.5 & 28.0 & 30.9 & 24.0 \\
\hline 6510 & Bunzlau/Boleslawiec & 20.6 & 27.2 & 29.1 & 23.6 \\
\hline
\end{tabular}

Beiträge aus der NW-FVA, Band 5, 2010 
Versuchsfläche 35

\begin{tabular}{l|l|c|c|c|c}
\hline PG-Nr. & Herkunft & $\begin{array}{c}\text { BHD } \\
32-j .\end{array}$ & $\begin{array}{c}\text { BHD. } \\
39-j .\end{array}$ & $\begin{array}{c}\text { BHD* } \\
39-j .\end{array}$ & $\begin{array}{c}\text { Höhe } \\
39-j .\end{array}$ \\
\hline 6543 & Groß-Lassowitz/Lassowice Male & 20.4 & 28.1 & 30.4 & 23.4 \\
6624 & Przysucha & 19.1 & 24.0 & 27.5 & 23.6 \\
6712 & Klodzko-Glatz/Nynow 68 e & 23.7 & 29.8 & 33.8 & 23.6 \\
6731 & Szcytna-Slaska Karlow 243 a & 21.4 & 27.9 & 29.5 & 23.2 \\
6732 & Szcytna-Slaska Karlow 292 b & 20.3 & 26.6 & 28.7 & 22.2 \\
6864 & Istebna-Ujsoly & 21.6 & 26.5 & 29.0 & 23.8 \\
6894 & Witów & 20.9 & 25.7 & 28.0 & 23.2 \\
7224 & Ostrovskij-Pskow & 18.4 & 24.4 & 26.9 & 22.3 \\
7233 & Wolozin & 20.5 & 25.3 & 27.8 & 23.6 \\
7235 & Brigalovic-Mogilev & 19.4 & 24.7 & 27.4 & 23.5 \\
7422 & Rjasan, Moshary & 18.4 & 24.7 & 25.8 & 22.5 \\
8705 & Mänttä & 16.1 & 19.2 & 19.2 & 18.3 \\
8707 & Janakkala Keskivari Uhkoila & 14.6 & 22.6 & 24.6 & 20.6 \\
\hline
\end{tabular}

Versuchsfläche 36

\begin{tabular}{c|l|c|c|c|c}
\hline PG-Nr. & Herkunft & $\begin{array}{c}\text { BHD } \\
32-j .\end{array}$ & $\begin{array}{c}\text { BHD. } \\
39-j .\end{array}$ & $\begin{array}{c}\text { BHD* } \\
39-j .\end{array}$ & $\begin{array}{c}\text { Höhe } \\
39-j .\end{array}$ \\
\hline 65 & Eisenkappel Thurn 2 & 20.4 & 28.3 & 30.6 & 23.0 \\
105 & Hohenschwangau & 23.5 & 31.8 & 32.9 & 23.7 \\
113 & Walsrode & 21.7 & 28.4 & 30.5 & 23.8 \\
116 & Kobernausserwald & 21.5 & 27.6 & 28.7 & 22.8 \\
169 & Gries & 21.7 & 27.5 & 28.3 & 22.6 \\
172 & Mittersill & 21.6 & 30.1 & 32.8 & 21.0 \\
191 & Passail & 22.7 & 28.5 & 29.6 & 22.2 \\
230 & Elbingerode & 21.4 & 27.8 & 28.9 & 23.6 \\
1118 & Chatel, Aity" & 20.4 & 26.6 & 28.3 & 21.9 \\
1201 & Mellier, Bois Bayai, 2 & 21.6 & 27.4 & 28.6 & 22.7 \\
2124 & Stixenstein, Gahns & 19.5 & 26.0 & 28.1 & 22.7 \\
2127 & Unterhal, St. Kathrein a.d. Lamming & 20.3 & 26.0 & 28.5 & 22.5 \\
2174 & Klein-Sölk/Niedertauern & 18.9 & 27.1 & 27.9 & 22.2 \\
3150 & Dillingen a.d.D. Bay. & 21.9 & 28.9 & 29.5 & 22.3 \\
3206 & Eglharting XIV/17,19 & 22.4 & 28.5 & 29.9 & 23.0 \\
3213 & Mühldorf/Inn & 21.3 & 28.2 & 29.5 & 23.4 \\
3414 & Bodensee Oberschwab. VIII/13 & 22.2 & 29.4 & 31.1 & 23.3 \\
3417 & Marsberg & 23.5 & 29.5 & 30.0 & 22.8 \\
3423 & Kohlstetten & 20.3 & 28.4 & 30.5 & 22.0 \\
3430 & Diessen & 20.9 & 30.0 & 30.0 & 22.4 \\
3432 & Walsrode & 22.1 & 30.0 & 32.0 & 23.2 \\
3433 & Selb-Kirchenlamitz (1) & 23.3 & 29.0 & 30.6 & 22.7 \\
3446 & Zwiesel, Schmalzau IX 3c (5,6) & 22.3 & 28.5 & 31.5 & 23.0 \\
4050 & Vlasim-Votice & 21.7 & 28.2 & 29.8 & 22.5 \\
4075 & Vitkov-Budisov & 23.3 & 30.4 & 31.3 & 23.3 \\
4127 & Javorova Dolina 155 A, Nr.4127 & 19.5 & 24.9 & 26.0 & 21.7 \\
5424 & Valea Beliei-Sinaia Gurguiata & 19.8 & 26.5 & 27.7 & 22.5 \\
5425 & Cimpeni-Nedei & 22.3 & 28.3 & 30.3 & 23.7 \\
6107 & Altenhagen/Nowy Krakow & 22.4 & 28.9 & 30.2 & 23.5 \\
6236 & Białowieża & 19.4 & 25.1 & 24.9 & 22.5 \\
& & & & &
\end{tabular}


Versuchsfläche 36

\begin{tabular}{c|l|c|c|c|c}
\hline PG-Nr. & Herkunft & $\begin{array}{c}\text { BHD } \\
32-j .\end{array}$ & $\begin{array}{c}\text { BHD. } \\
39-j .\end{array}$ & $\begin{array}{c}\text { BHD* } \\
39-j .\end{array}$ & $\begin{array}{c}\text { Höhe } \\
39-j .\end{array}$ \\
\hline 6897 & Goldap & 21.3 & 28.1 & 28.7 & 23.2 \\
7232 & Cemerjanskoe-Mogilev & 20.7 & 26.7 & 29.9 & 23.1 \\
7234 & Soboljanskoe-Grodno & 20.5 & 26.8 & 29.7 & 24.2 \\
7240 & Witebsk & 22.0 & 27.9 & 31.1 & 23.4 \\
7400 & Kaluga & 18.8 & 24.1 & 26.8 & 22.7 \\
9191 & Karlsholms-Kristianstad & 21.1 & 27.5 & 28.5 & 22.4 \\
\hline
\end{tabular}

\section{Anhang 1.7}

Zusammenstellung der sich signifikant von mindestens einer anderen Herkunft im Tukey-Kramer-Test für das Merkmal Höhen-Wachstum [m] im Alter 39 auf der Versuchsfläche 34 Reinhardshagen / Hessen unterscheidenden Herkünfte

\begin{tabular}{|c|c|c|c|c|c|}
\hline Rang & $\begin{array}{l}\text { PG- } \\
\text { Nr. }\end{array}$ & Herkunft & Land & $\begin{array}{c}\text { Höhe } \\
\text { m ü. NN }\end{array}$ & $\begin{array}{l}\text { Höhe } \\
{[\mathrm{m}]}\end{array}$ \\
\hline 1 & 4081 & Frenstat pod Radhosten-Obora & CS & 600 & 23.5 \\
\hline 2 & 2126 & Gaishorn & A & 1200 & 23.5 \\
\hline 3 & 3498 & Burgjoß & $\mathrm{D}$ & 450 & 23.5 \\
\hline 4 & 1202 & Manderfeld Gilbuschek 63 A & B & 542 & 23.5 \\
\hline 5 & 61 & Gosau & A & 700 & 23.4 \\
\hline 6 & 114 & Winterberg & $\mathrm{D}$ & 800 & 23.3 \\
\hline 7 & 3427 & Oderhaus & $\mathrm{D}$ & 650 & 23.3 \\
\hline 8 & 4103 & Tatranska Lesna 559 C & CS & 950 & 23.2 \\
\hline 9 & 3447 & Nationalp. Hüttenschlag XIX 1b (6) & $\mathrm{D}$ & 750 & 23.2 \\
\hline 10 & 3412 & Winterberg & $\mathrm{D}$ & 750 & 23.2 \\
\hline 11 & 4032 & Kynsperk nad Ohri Libocky Dul & CS & 650 & 23.1 \\
\hline 12 & 3617 & Torgelow & $\mathrm{D}$ & 100 & 23.0 \\
\hline 13 & 4061 & Velke Mezirici-Rudolec & CS & 630 & 23.0 \\
\hline 14 & 3417 & Marsberg & $\mathrm{D}$ & 500 & 23.0 \\
\hline 15 & 9417 & Marsberg & $\mathrm{D}$ & 500 & 22.9 \\
\hline 16 & 3436 & Neureichenau (2) & $\mathrm{D}$ & 1050 & 22.9 \\
\hline 17 & 5401 & Valea Putnei-Pojorita & RU & 1085 & 22.9 \\
\hline 18 & 3418 & Sachsenried & $\mathrm{D}$ & 900 & 22.9 \\
\hline 19 & 103 & Wunsiedel & $\mathrm{D}$ & 900 & 22.9 \\
\hline 20 & 6254 & Mikaszowka & PL & 120 & 22.9 \\
\hline 21 & 3421 & Dombühl & $\mathrm{D}$ & 450 & 22.8 \\
\hline 22 & 4042 & Vimperk-Prameny Vltury Stachy & CS & 950 & 22.8 \\
\hline 23 & 2149 & Kindberg/Eisenerzer Alpen & A & 1000 & 22.8 \\
\hline 24 & 3424 & Winterberg & $\mathrm{D}$ & 450 & 22.8 \\
\hline 25 & 174 & Piesendorf & A & 900 & 22.8 \\
\hline 26 & 2122 & Piberegg & A & 800 & 22.8 \\
\hline 27 & 4157 & Hnusta & CS & 550 & 22.8 \\
\hline 28 & 3430 & Diessen & $\mathrm{D}$ & 850 & 22.7 \\
\hline 29 & 3435 & Neureichenau (2) & $\mathrm{D}$ & 1050 & 22.7 \\
\hline 30 & 2140 & Fölz, Mayerberg & A & 950 & 22.6 \\
\hline 31 & 3445 & Zwiesel, Haselau XXI $12(3,6)$ & $\mathrm{D}$ & 650 & 22.6 \\
\hline 32 & 63 & Eisenkappel Thurn 1 & A & 850 & 22.6 \\
\hline 33 & 4011 & Cikaaj, Zdarska Vrchy & CS & 655 & 22.6 \\
\hline
\end{tabular}




\begin{tabular}{|c|c|c|c|c|c|}
\hline Rang & $\begin{array}{l}\text { PG- } \\
\text { Nr. }\end{array}$ & Herkunft & Land & $\begin{array}{c}\text { Höhe } \\
\mathrm{m} \text { ü. NN }\end{array}$ & $\begin{array}{l}\text { Höhe } \\
{[\mathrm{m}]}\end{array}$ \\
\hline 34 & 208 & Istebna & PL & 725 & 22.6 \\
\hline 35 & 3419 & Schwarzwald Baar, VIII/6 & $\mathrm{D}$ & 700 & 22.6 \\
\hline 36 & 2141 & Fölz, Greith & A & 825 & 22.6 \\
\hline 37 & 3329 & Spiegelau & $\mathrm{D}$ & 1200 & 22.5 \\
\hline 38 & 202 & Istebna-Wisła & PL & 725 & 22.5 \\
\hline 39 & 6237 & Puszcza-Białowieska & PL & 130 & 22.5 \\
\hline 40 & 3499 & Chausseehaus & $\mathrm{D}$ & & 22.5 \\
\hline 41 & 2147 & Freiland, Gschwend & A & 1000 & 22.5 \\
\hline 42 & 98 & Massif Central & $\mathrm{F}$ & 1100 & 22.4 \\
\hline 43 & 3426 & Uelzen & $\mathrm{D}$ & 50 & 22.4 \\
\hline 44 & 293 & Trolleholm & $\mathrm{S}$ & 125 & 22.4 \\
\hline 45 & 2121 & Neukirchen Großvenediger & A & 870 & 22.4 \\
\hline 46 & 6223 & Przerwanki & PL & 150 & 22.4 \\
\hline 47 & 1100 & Monts Megal, Le Portius & $\mathrm{F}$ & 900 & 22.4 \\
\hline 48 & 2160 & Turnau, Kapfenberg & A & 1100 & 22.4 \\
\hline 49 & 3423 & Kohlstetten & $\mathrm{D}$ & 750 & 22.4 \\
\hline 50 & 175 & Radstatt & A & 1000 & 22.4 \\
\hline 51 & 3433 & Selb-Kirchenlamitz (1) & $\mathrm{D}$ & 800 & 22.4 \\
\hline 52 & 192 & Södingberg & A & 550 & 22.3 \\
\hline 53 & 177 & Taxenbach & A & 1400 & 22.3 \\
\hline 54 & 3428 & Schernfeld & $\mathrm{D}$ & 450 & 22.3 \\
\hline 55 & 291 & Karupsskogen Barsebäcks gods & $\mathrm{S}$ & 100 & 22.3 \\
\hline 56 & 2114 & Kreuzen-Stockenboi & A & 1200 & 22.3 \\
\hline 57 & 64 & St. Martin & A & 500 & 22.3 \\
\hline 58 & 62 & Litschau & A & 600 & 22.3 \\
\hline 59 & 5202 & Szentgotthard $1 \mathrm{C}$ & $\mathrm{H}$ & 310 & 22.2 \\
\hline 60 & 229 & Olsztyn & PL & 100 & 22.2 \\
\hline 61 & 3448 & Nationalp. Filzwald IX 3a 10/11 (6) & $\mathrm{D}$ & 750 & 22.2 \\
\hline 62 & 4143 & Kysihybel & CS & 540 & 22.2 \\
\hline 63 & 3420 & Daun/Ost & $\mathrm{D}$ & 450 & 22.2 \\
\hline 64 & 227 & Thüringen & $\mathrm{D}$ & 300 & 22.2 \\
\hline 65 & 2130 & Stanz-Kindthal-Allerheiligen & A & 750 & 22.2 \\
\hline 66 & 66 & Vorau & A & 900 & 22.2 \\
\hline 67 & 5204 & Miskolc-Lillafüred 82 A Bükker Geb. & $\mathrm{H}$ & 730 & 22.2 \\
\hline \multicolumn{6}{|c|}{98 Herkünfte } \\
\hline 165 & 5303 & Borovec (Rila-Geb.) & BG & 1300 & 19.0 \\
\hline 166 & 9170 & Ryssby-Kronobergs & $\mathrm{S}$ & 175 & 19.0 \\
\hline 167 & 150 & Schlanders & I & 1500 & 18.4 \\
\hline 168 & 740 & Bex, Tarejanne & $\mathrm{CH}$ & 1600 & 17.7 \\
\hline 169 & 734 & Airolo, Bedretto & $\mathrm{CH}$ & 1600 & 17.7 \\
\hline
\end{tabular}


Anhang 1.8

Zusammenstellung der sich signifikant von mindestens einer anderen Herkunft im Tukey-Kramer-Test für das Merkmal Höhen-Wachstum [m] im Alter 39 auf der Versuchsfläche 35 Reinhardshagen / Hessen unterscheidenden Herkünfte

\begin{tabular}{|c|c|c|c|c|c|}
\hline Rang & $\begin{array}{l}\text { PG- } \\
\text { Nr. }\end{array}$ & Herkunft & Land & $\begin{array}{l}\text { Höhe } \\
\text { m ü. NN }\end{array}$ & $\begin{array}{c}\text { Höhe } \\
\text { [m] }\end{array}$ \\
\hline 1 & 4054 & Chlum u. Trebone-Hamr & CS & 450 & 24.6 \\
\hline 2 & 4051 & Vysoky Chlumec Veletin & CS & 600 & 24.4 \\
\hline 3 & 5416 & Remeti-Zerna & RU & 900 & 24.3 \\
\hline 4 & 5412 & Moldovita-Sacries & RU & 825 & 24.3 \\
\hline 5 & 5420 & Valea Putnei-Pojorita III/60 & RU & 1285 & 24.2 \\
\hline 6 & 3501 & Rungstock, 46 A & $\mathrm{D}$ & 560 & 24.1 \\
\hline 7 & 4053 & Cesky Krumlov Borova & CS & 800 & 24.1 \\
\hline 8 & 3404 & Westerhof Abt. 51 B & $\mathrm{D}$ & 200 & 24.0 \\
\hline 9 & 5415 & Cimpeni-Dara & RU & 1260 & 24.0 \\
\hline 10 & 6251 & Białobrzegi & PL & 110 & 23.9 \\
\hline 11 & 3417 & Marsberg & $\mathrm{D}$ & 500 & 23.8 \\
\hline 12 & 6864 & Istebna-Ujsoly & PL & 750 & 23.8 \\
\hline 13 & 6712 & Klodzko-Glatz/Nynow 68 e & PL & 340 & 23.6 \\
\hline 14 & 3511 & Innenau Elgersburg & $\mathrm{D}$ & 800 & 23.6 \\
\hline 15 & 4026 & Habartice, Planice & CS & 550 & 23.6 \\
\hline 16 & 7233 & Wolozin & SU & 225 & 23.6 \\
\hline 17 & 3519 & Mechterstädt & $\mathrm{D}$ & 200 & 23.6 \\
\hline 18 & 6510 & Bunzlau/Boleslawiec & PL & 175 & 23.6 \\
\hline 19 & 6624 & Przysucha & PL & 275 & 23.6 \\
\hline 20 & 7235 & Brigalovic-Mogilev & SU & 160 & 23.5 \\
\hline 21 & 4070 & Vrchlabi & CS & 700 & 23.5 \\
\hline 22 & 6543 & Groß-Lassowitz/Lassowice Male & PL & 175 & 23.4 \\
\hline 23 & 3503 & Eibenst. Carlsf. Wiesenh. 214 & $\mathrm{D}$ & 720 & 23.4 \\
\hline 24 & 3606 & Templin, Bad Doberan Nr. 9 & $\mathrm{D}$ & 50 & 23.4 \\
\hline 25 & 5426 & Crucea-Barnavel Abt. 17/18 & RU & 740 & 23.4 \\
\hline 26 & 3508 & Rehefeld, 146 & $\mathrm{D}$ & 810 & 23.4 \\
\hline 27 & 115 & Westerhof & $\mathrm{D}$ & 200 & 23.3 \\
\hline 28 & 3615 & Neustrelitz & $\mathrm{D}$ & 100 & 23.3 \\
\hline 29 & 2134 & Hinterhof, Ostbrenner u. Tiefental & A & 1000 & 23.3 \\
\hline 30 & 4022 & Boubin III & CS & 1000 & 23.3 \\
\hline 31 & 6894 & Witów & PL & 1250 & 23.2 \\
\hline 32 & 6731 & Szcytna-Slaska Karlow 243 a & PL & 750 & 23.2 \\
\hline 33 & 3512 & Peitz/Tannenwald & $\mathrm{D}$ & 60 & 23.2 \\
\hline 34 & 3504 & Eibenst. Carlsf. Wilschm. 233 & $\mathrm{D}$ & 720 & 23.2 \\
\hline 35 & 6222 & Borken/Borki & PL & 160 & 23.0 \\
\hline 36 & 6235 & Zwierzyniec & PL & 150 & 23.0 \\
\hline 37 & 2207 & Seewiesen Seereith/Aflenz & A & 875 & 22.9 \\
\hline 38 & 3423 & Kohlstetten & $\mathrm{D}$ & 750 & 22.9 \\
\hline 39 & 4073 & Jesenik-Zlate Hory & CS & 820 & 22.9 \\
\hline 40 & 4060 & Hencov-Trest & CS & 600 & 22.9 \\
\hline 41 & 3443 & Zwiesel, Scheichereb. XXI 13b1 $(3,6)$ & $\mathrm{D}$ & 650 & 22.8 \\
\hline 42 & 2135 & Kraubath, Seckauer Tauern & A & 1050 & 22.8 \\
\hline 43 & 2118 & Gurker Sirnitzwald & A & 900 & 22.8 \\
\hline 44 & 3432 & Walsrode & $\mathrm{D}$ & 30 & 22.8 \\
\hline 45 & 3430 & Diessen & $\mathrm{D}$ & 850 & 22.7 \\
\hline 46 & 3433 & Selb-Kirchenlamitz (1) & $\mathrm{D}$ & 800 & 22.7 \\
\hline
\end{tabular}

Beiträge aus der NW-FVA, Band 5, 2010 


\begin{tabular}{|c|c|c|c|c|c|}
\hline Rang & $\begin{array}{l}\text { PG- } \\
\text { Nr. }\end{array}$ & Herkunft & Land & $\begin{array}{c}\text { Höhe } \\
\text { m ü. NN }\end{array}$ & $\begin{array}{c}\text { Höhe } \\
{[\mathrm{m}]}\end{array}$ \\
\hline 47 & 3102 & Schluchsee-Eschenmoos & $\mathrm{D}$ & 1200 & 22.7 \\
\hline 48 & 3601 & Cottbus, Tannenwald $17 \mathrm{AB}$ & $\mathrm{D}$ & 80 & 22.7 \\
\hline 49 & 3510 & Sonneb. Steinheid, Kieferleskopf & $\mathrm{D}$ & 886 & 22.5 \\
\hline 50 & 2131 & Veitsch-Neuberg & A & 1000 & 22.5 \\
\hline 51 & 7422 & Rjasan, Moshary & SU & 150 & 22.5 \\
\hline 52 & 6234 & Białowieża & PL & 130 & 22.5 \\
\hline 53 & 3310 & Zwiesel-West/Ruselhänge X/68 & $\mathrm{D}$ & 750 & 22.4 \\
\hline 54 & 2179 & Eisenkappel/Karaw. & A & 800 & 22.4 \\
\hline 55 & 2133 & Hinterhof, Eibelkogel & $\mathrm{A}$ & 1150 & 22.4 \\
\hline 56 & 6103 & Brotzen/Broczyno & PL & 140 & 22.4 \\
\hline 57 & 7224 & Ostrovskij-Pskow & SU & 200 & 22.3 \\
\hline 58 & 2158 & Rohr im Gebirge, Kirchwald & A & 825 & 22.2 \\
\hline 59 & 6732 & Szcytna-Slaska Karlow 292 b & PL & 700 & 22.2 \\
\hline 60 & 3506 & Tellerhaeuser, 44 & $\mathrm{D}$ & 980 & 22.0 \\
\hline 61 & 4123 & Javorova Dolina 155 A, Nr.4123 & CS & 1200 & 22.0 \\
\hline 62 & 3139 & Isny $\mathrm{Ba} / \mathrm{Wü}$ & $\mathrm{D}$ & 850 & 22.0 \\
\hline 63 & 2137 & Buchberg, Flachwald/Aflenz & A & 1300 & 22.0 \\
\hline 64 & 2138 & Buchberg, Ägidiwald/Aflenz & A & 925 & 22.0 \\
\hline 65 & 2184 & Schneegattern & $\mathrm{A}$ & 750 & 21.7 \\
\hline 66 & 3042 & Walchensee & $\mathrm{D}$ & 1100 & 21.7 \\
\hline 67 & 121 & Cedrogne & $\mathrm{B}$ & 500 & 21.7 \\
\hline 68 & 3320 & Bischofsreut & $\mathrm{D}$ & 970 & 21.7 \\
\hline 69 & 3334 & Zwiesel-Ost, V/1,2, Plattenfichten & $\mathrm{D}$ & 1200 & 21.6 \\
\hline 70 & 2151 & Breitenau-Mixnitz/Fischbacher Alp. & $\mathrm{A}$ & 970 & 21.6 \\
\hline \multicolumn{6}{|c|}{ 흐 Herkünfte } \\
\hline 77 & 8707 & Janakkala Keskivari Uhkoila & SF & 100 & 20.3 \\
\hline 78 & 5301 & Belogradchik-Tschupreno & BG & 1400 & 19.6 \\
\hline 79 & 3331 & St. Oswald I/3,4,6 Typengemisch & $\mathrm{D}$ & 1200 & 19.3 \\
\hline 80 & 8705 & Mänttä & $\mathrm{SF}$ & 120 & 18.6 \\
\hline 81 & 5107 & Smrceve Dolina Abt. 138 & HR & 1350 & 17.0 \\
\hline
\end{tabular}

\section{Anhang 1.9}

Zusammenstellung der sich signifikant von mindestens einer anderen Herkunft im Tukey-Kramer-Test für das Merkmal BHD-Wachstum [cm] im Alter 39 auf der Versuchsfläche 34 Reinhardshagen / Hessen unterscheidenden Herkë̈fte

\begin{tabular}{c|c|l|c|c|c}
\hline Rang & $\begin{array}{c}\text { PG- } \\
\text { Nr. }\end{array}$ & Herkunft & Land & $\begin{array}{c}\text { Höhe } \\
\text { m ü. NN }\end{array}$ & $\begin{array}{c}\text { BHD } \\
{[\mathrm{cm}]}\end{array}$ \\
\hline 1 & 4081 & Frenstat pod Radhosten-Obora & CS & 600 & 32.0 \\
2 & 62 & Litschau & A & 600 & 31.9 \\
3 & 3329 & Spiegelau & D & 1200 & 31.4 \\
4 & 293 & Trolleholm & S & 125 & 31.3 \\
5 & 2122 & Piberegg & A & 800 & 30.9 \\
6 & 6255 & Puszcza-Augustowska & PL & 125 & 30.6 \\
7 & 2121 & Neukirchen Großvenediger & A & 870 & 30.1 \\
8 & 7401 & Gzatsk-Smolensk & SU & 194 & 30.1
\end{tabular}




\begin{tabular}{crr|l|c|c|c}
\hline Rang & $\begin{array}{c}\text { PG- } \\
\text { Nr. }\end{array}$ & Herkunft & Land & $\begin{array}{c}\text { Höhe } \\
\text { m ü. NN }\end{array}$ & $\begin{array}{c}\text { BHD } \\
{[\mathrm{cm}]}\end{array}$ \\
\hline 9 & 124 & Istebna-Wisła & PL & 725 & 29.9 \\
10 & 3412 & Winterberg & $\mathrm{D}$ & 750 & 29.9 \\
11 & 61 & Gosau & $\mathrm{A}$ & 700 & 29.9 \\
12 & 3505 & Eibenst. Carlsf. 275 & $\mathrm{D}$ & 925 & 29.8 \\
13 & 4061 & Velke Mezirici-Rudolec & $\mathrm{CS}$ & 630 & 29.8 \\
14 & 3617 & Torgelow & $\mathrm{D}$ & 100 & 29.7 \\
15 & 3436 & Neureichenau (2) & $\mathrm{D}$ & 1050 & 29.7 \\
16 & 290 & Högestad & $\mathrm{S}$ & 50 & 29.6 \\
17 & 3445 & Zwiesel, Haselau XXI 12 (3,6) & $\mathrm{D}$ & 650 & 29.5 \\
18 & 131 & Vizovice & $\mathrm{CS}$ & 500 & 29.4 \\
19 & 178 & Abtenau & $\mathrm{A}$ & 900 & 29.4 \\
20 & 3429 & Villingen & $\mathrm{D}$ & 850 & 29.4 \\
21 & 9417 & Marsberg & $\mathrm{D}$ & 500 & 29.2 \\
22 & 3421 & Dombühl & $\mathrm{D}$ & 450 & 29.2 \\
$\ldots$ & & & & & \\
141 & Herkünfte & & & \\
$\ldots$ & & & & & \\
164 & 5101 & Nedzinant, Prokletije (Geb.) & YU & 1150 & 22.0 \\
165 & 5303 & Borovec (Rila-Geb.) & BG & 1300 & 21.9 \\
166 & 1112 & Autrans, Isère & F & 1250 & 21.7 \\
167 & 711 & La Genolière & CH &. & 21.0 \\
168 & 740 & Bex, Tarejanne & CH & 1600 & 20.1 \\
169 & 734 & Airolo, Bedretto & CH & 1600 & 19.7 \\
\hline
\end{tabular}

\section{Anhang 1.10}

Zusammenstellung der sich signifikant von mindestens einer anderen Herkunft im Tukey-Kramer-Test für das Merkmal BHD-Wachstum [cm] im Alter 39 auf der Versuchsfläche 35 Reinhardshagen / Hessen unterscheidenden Herkünfte

\begin{tabular}{c|c|l|c|c|c}
\hline Rang & $\begin{array}{c}\text { PG- } \\
\text { Nr. }\end{array}$ & Herkunft & Land & $\begin{array}{c}\text { Höhe } \\
\text { m ü. NN }\end{array}$ & $\begin{array}{c}\text { BHD } \\
{[\mathrm{cm}]}\end{array}$ \\
\hline 1 & 3417 & Marsberg & D & 500 & 32.1 \\
2 & 6251 & Białobrzegi & PL & 110 & 31.5 \\
3 & 115 & Westerhof & D & 200 & 31.3 \\
4 & 3320 & Bischofsreut & D & 970 & 30.7 \\
5 & 3503 & Eibenst. Carlsf. Wiesenh. 214 & D & 720 & 30.3 \\
6 & 6222 & Borken/Borki & PL & 160 & 30.3 \\
7 & 3433 & Selb-Kirchenlamitz (1) & D & 800 & 30.3 \\
8 & 6712 & Klodzko-Glatz/Nynow 68 e & PL & 340 & 30.0 \\
9 & 3606 & Templin, Bad Doberan Nr. 9 & D & 50 & 29.9 \\
10 & 4060 & Hencov-Trest & CS & 600 & 29.8 \\
11 & 3501 & Rungstock, 46 A & D & 560 & 29.7 \\
$\ldots$ & & & & \\
67 Herkünfte & & & & \\
$\ldots$ & & & BG & 1400 & 21.1 \\
79 & 5301 & Belogradchik-Tschupreno & HR & 1350 & 20.1 \\
80 & 5107 & Smrceve Dolina Abt. 138 & SF & 120 & 20.1 \\
81 & 8705 & Mänttä & \multicolumn{3}{c}{} \\
\hline \multicolumn{7}{r}{} & &
\end{tabular}


Anhang 1.11

Zusammenstellung der sich signifikant von mindestens einer anderen Herkunft im Tukey-Kramer-Test für das Merkmal BHD-Wachstum [cm] im Alter 32 auf der Versuchsfläche 34 Reinhardshagen / Hessen unterscheidenden Herkünfte

\begin{tabular}{|c|c|c|c|c|c|}
\hline Rang & $\begin{array}{l}\text { PG- } \\
\text { Nr. }\end{array}$ & Herkunft & Land & $\begin{array}{c}\text { Höhe } \\
\text { m ü. NN }\end{array}$ & $\begin{array}{l}\mathrm{BHD} \\
{[\mathrm{cm}]}\end{array}$ \\
\hline 1 & 62 & Litschau & A & 600 & 25.3 \\
\hline 2 & 4081 & Frenstat pod Radhosten-Obora & CS & 600 & 24.9 \\
\hline 3 & 124 & Istebna-Wisła & PL & 725 & 23.7 \\
\hline 4 & 293 & Trolleholm & $\mathrm{S}$ & 125 & 23.7 \\
\hline 5 & 3412 & Winterberg & $\mathrm{D}$ & 750 & 23.6 \\
\hline 6 & 6255 & Puszcza-Augustowska & PL & 125 & 23.6 \\
\hline 7 & 4061 & Velke Mezirici-Rudolec & $\mathrm{CS}$ & 630 & 23.5 \\
\hline 8 & 3505 & Eibenst. Carlsf. 275 & $\mathrm{D}$ & 925 & 23.1 \\
\hline 9 & 3617 & Torgelow & $\mathrm{D}$ & 100 & 23.1 \\
\hline 10 & 3329 & Spiegelau & $\mathrm{D}$ & 1200 & 23.0 \\
\hline 11 & 6254 & Mikaszowka & PL & 120 & 22.9 \\
\hline 12 & 2121 & Neukirchen Großvenediger & A & 870 & 22.8 \\
\hline 13 & 61 & Gosau & A & 700 & 22.8 \\
\hline 14 & 3436 & Neureichenau (2) & $\mathrm{D}$ & 1050 & 22.8 \\
\hline 15 & 3332 & Zwiesel-Ost & $\mathrm{D}$ & 1000 & 22.7 \\
\hline 16 & 3417 & Marsberg & $\mathrm{D}$ & 500 & 22.7 \\
\hline 17 & 3447 & Nationalp. Hüttenschlag XIX 1b (6) & $\mathrm{D}$ & 750 & 22.7 \\
\hline 18 & 4032 & Kynsperk nad Ohri Libocky Dul & CS & 650 & 22.7 \\
\hline 19 & 3498 & Burgjoß & $\mathrm{D}$ & 450 & 22.6 \\
\hline 20 & 178 & Abtenau & $\mathrm{A}$ & 900 & 22.5 \\
\hline 21 & 4157 & Hnusta & CS & 550 & 22.5 \\
\hline 22 & 3433 & Selb-Kirchenlamitz (1) & $\mathrm{D}$ & 800 & 22.4 \\
\hline 23 & 3421 & Dombühl & $\mathrm{D}$ & 450 & 22.4 \\
\hline 24 & 139 & Vapenkova Skala & CS & 540 & 22.3 \\
\hline 25 & 208 & Istebna & PL & 725 & 22.1 \\
\hline 26 & 3419 & Schwarzwald Baar, VIII/6 & $\mathrm{D}$ & 700 & 22.1 \\
\hline 27 & 5204 & Miskolc-Lillafüred 82 A Bükker Geb. & $\mathrm{H}$ & 730 & 22.1 \\
\hline 28 & 290 & Högestad & $\mathrm{S}$ & 50 & 22.1 \\
\hline 29 & 3432 & Walsrode & $\mathrm{D}$ & 30 & 22.1 \\
\hline 30 & 1202 & Manderfeld Gilbuschek 63 A & $\mathrm{B}$ & 542 & 22.0 \\
\hline 31 & 3499 & Chausseehaus & $\mathrm{D}$ & . & 22.0 \\
\hline 32 & 5205 & Nagykanizsa-Iharos Plattensee 11/1-71 & $\mathrm{H}$ & 200 & 22.0 \\
\hline 33 & 227 & Thüringen & $\mathrm{D}$ & 300 & 22.0 \\
\hline 34 & 3434 & Miele & $\mathrm{D}$ & 90 & 22.0 \\
\hline 35 & 5206 & Sopron (Hochschulrev.) 203 D & $\mathrm{H}$ & 425 & 21.9 \\
\hline 36 & 1101 & Le Pertuis, Monts du Velay & $\mathrm{F}$ & 1100 & 21.9 \\
\hline 37 & 3445 & Zwiesel, Haselau XXI $12(3,6)$ & $\mathrm{D}$ & 650 & 21.9 \\
\hline 38 & 5202 & Szentgotthard $1 \mathrm{C}$ & $\mathrm{H}$ & 310 & 21.9 \\
\hline 39 & 179 & Bischofshofen & A & 1200 & 21.8 \\
\hline 40 & 4082 & Ostravice & CS & 800 & 21.8 \\
\hline 41 & 114 & Winterberg & $\mathrm{D}$ & 800 & 21.7 \\
\hline 42 & 3429 & Villingen & $\mathrm{D}$ & 850 & 21.7 \\
\hline 43 & 130 & Dobra bei Frydek & CS & 550 & 21.7 \\
\hline 44 & 4011 & Cikaaj, Zdarska Vrchy & CS & 655 & 21.7 \\
\hline 45 & 5302 & Beglika & $\mathrm{BG}$ & 1850 & 21.7 \\
\hline 46 & 6410 & Sierpc & PL & 110 & 21.7 \\
\hline
\end{tabular}




\begin{tabular}{cr|l|c|c|c}
\hline Rang & $\begin{array}{c}\text { PG- } \\
\text { Nr. }\end{array}$ & Herkunft & Land & $\begin{array}{c}\text { Höhe } \\
\text { m ü. NN }\end{array}$ & $\begin{array}{c}\text { BHD } \\
{[\mathrm{cm}]}\end{array}$ \\
\hline 47 & 202 & Istebna-Wisła & PL & 725 & 21.6 \\
48 & 103 & Wunsiedel & $\mathrm{D}$ & 900 & 21.6 \\
49 & 215 & Stinava & $\mathrm{SK}$ &. & 21.6 \\
50 & 187 & Pack & $\mathrm{A}$ & 950 & 21.6 \\
51 & 3410 & Traunstein & $\mathrm{D}$ & 850 & 21.5 \\
$\ldots$ & & & & & \\
104 & Herkünfte & & & \\
$\ldots$ & & & & & \\
156 & 2120 & Liembergwald Zell a. S. & $\mathrm{A}$ & 875 & 18.3 \\
157 & 186 & Graz-Nord & $\mathrm{A}$ & 850 & 18.2 \\
158 & 2150 & Siebensee Wildalpen & $\mathrm{A}$ & 850 & 18.2 \\
159 & 2128 & Lobming-Oberth. St. Stefan/Kraubath & $\mathrm{A}$ & 800 & 18.2 \\
160 & 5101 & Nedzinant, Prokletije (Geb.) & $\mathrm{YU}$ & 1150 & 17.9 \\
161 & 150 & Schlanders & $\mathrm{I}$ & 1500 & 17.9 \\
162 & 5303 & Borovec (Rila-Geb.) & $\mathrm{BG}$ & 1300 & 17.7 \\
163 & 711 & La Genolière & $\mathrm{CH}$ &. & 17.7 \\
164 & 1112 & Autrans, Isère & $\mathrm{F}$ & 1250 & 17.5 \\
165 & 740 & Bex, Tarejanne & $\mathrm{CH}$ & 1600 & 17.3 \\
166 & 8703 & Lohja Laaskspohjan & $\mathrm{SF}$ & 50 & 16.7 \\
167 & 9170 & Ryssby-Kronobergs & $\mathrm{S}$ & 175 & 16.4 \\
168 & 704 & Cazis Tschartlina & $\mathrm{CH}$ & 750 & 16.4 \\
169 & 734 & Airolo, Bedretto & $\mathrm{CH}$ & 1600 & 14.6 \\
\hline
\end{tabular}

\section{Anhang 1.12}

Zusammenstellung der sich signifikant von mindestens einer anderen Herkunft im Tukey-Kramer-Test für das Merkmal BHD-Wachstum [cm] im Alter 32 auf der Versuchsfläche 35 Reinhardshagen / Hessen unterscheidenden Herkünfte

\begin{tabular}{c|c|l|c|c|c}
\hline Rang & $\begin{array}{c}\text { PG- } \\
\text { Nr. }\end{array}$ & Herkunft & Land & $\begin{array}{c}\text { Höhe } \\
\text { m ü. NN }\end{array}$ & $\begin{array}{c}\text { BHD } \\
{[\mathrm{cm}]}\end{array}$ \\
\hline 1 & 6251 & Białobrzegi & PL & 110 & 25.0 \\
2 & 3417 & Marsberg & D & 500 & 24.6 \\
3 & 3503 & Eibenst. Carlsf. Wiesenh. 214 & D & 720 & 23.9 \\
4 & 6712 & Klodzko-Glatz/Nynow 68 e & PL & 340 & 23.8 \\
5 & 6222 & Borken/Borki & PL & 160 & 23.7 \\
6 & 3606 & Templin, Bad Doberan Nr. 9 & D & 50 & 23.4 \\
7 & 115 & Westerhof & D & 200 & 23.2 \\
8 & 4060 & Hencov-Trest & CS & 600 & 23.0 \\
9 & 3433 & Selb-Kirchenlamitz (1) & D & 800 & 22.7 \\
10 & 3504 & Eibenst. Carlsf. Wilschm. 233 & D & 720 & 22.4 \\
11 & 3508 & Rehefeld, 146 & D & 810 & 22.4 \\
12 & 5420 & Valea Putnei-Pojorita III/60 & RU & 1285 & 22.4 \\
13 & 4026 & Habartice, Planice & CS & 550 & 22.2 \\
14 & 3423 & Kohlstetten & D & 750 & 22.2 \\
15 & 3404 & Westerhof Abt. 51 B & D & 200 & 22.1 \\
16 & 3501 & Rungstock, 46 A & D & 560 & 22.0 \\
17 & 3320 & Bischofsreut & D & 970 & 21.9 \\
18 & 2135 & Kraubath, Seckauer Tauern & A & 1050 & 21.8
\end{tabular}




\begin{tabular}{|c|c|c|c|c|c|}
\hline Rang & $\begin{array}{l}\text { PG- } \\
\text { Nr. }\end{array}$ & Herkunft & Land & $\begin{array}{c}\text { Höhe } \\
\text { m ü. NN }\end{array}$ & $\begin{array}{l}\text { BHD } \\
{[\mathrm{cm}]}\end{array}$ \\
\hline 19 & 4051 & Vysoky Chlumec Veletin & CS & 600 & 21.8 \\
\hline 20 & 121 & Cedrogne & B & 500 & 21.7 \\
\hline 21 & 3506 & Tellerhaeuser, 44 & $\mathrm{D}$ & 980 & 21.7 \\
\hline 22 & 2118 & Gurker Sirnitzwald & A & 900 & 21.7 \\
\hline 23 & 5412 & Moldovita-Sacries & RU & 825 & 21.6 \\
\hline 24 & 6864 & Istebna-Ujsoly & PL & 750 & 21.6 \\
\hline 25 & 5416 & Remeti-Zerna & RU & 900 & 21.6 \\
\hline 26 & 3519 & Mechterstädt & $\mathrm{D}$ & 200 & 21.5 \\
\hline 27 & 3430 & Diessen & $\mathrm{D}$ & 850 & 21.5 \\
\hline 28 & 3310 & Zwiesel-West/Ruselhänge X/68 & $\mathrm{D}$ & 750 & 21.5 \\
\hline 29 & 4054 & Chlum u. Trebone-Hamr & CS & 450 & 21.5 \\
\hline 30 & 3615 & Neustrelitz & $\mathrm{D}$ & 100 & 21.4 \\
\hline 31 & 6234 & Białowieża & PL & 130 & 21.4 \\
\hline 32 & 6731 & Szcytna-Slaska Karlow 243 a & PL & 750 & 21.4 \\
\hline 33 & 4073 & Jesenik-Zlate Hory & CS & 820 & 21.2 \\
\hline 34 & 149 & Einsiedeln & $\mathrm{CH}$ & 900 & 21.2 \\
\hline 35 & 6103 & Brotzen/Broczyno & PL & 140 & 21.2 \\
\hline 36 & 5426 & Crucea-Barnavel Abt. 17/18 & RU & 740 & 21.1 \\
\hline 37 & 6894 & Witów & PL & 1250 & 21.0 \\
\hline 38 & 2134 & Hinterhof, Ostbrenner u. Tiefental & A & 1000 & 20.9 \\
\hline 39 & 3601 & Cottbus, Tannenwald 17AB & $\mathrm{D}$ & 80 & 20.8 \\
\hline 40 & 2184 & Schneegattern & A & 750 & 20.7 \\
\hline 41 & 5415 & Cimpeni-Dara & RU & 1260 & 20.7 \\
\hline 42 & 7233 & Wolozin & SU & 225 & 20.7 \\
\hline 43 & 2137 & Buchberg, Flachwald/Aflenz & A & 1300 & 20.6 \\
\hline 44 & 4022 & Boubin III & CS & 1000 & 20.6 \\
\hline 45 & 6510 & Bunzlau/Boleslawiec & PL & 175 & 20.6 \\
\hline 46 & 6543 & Groß-Lassowitz/Lassowice Male & PL & 175 & 20.5 \\
\hline 47 & 3511 & Innenau Elgersburg & $\mathrm{D}$ & 800 & 20.5 \\
\hline 48 & 2158 & Rohr im Gebirge, Kirchwald & A & 825 & 20.5 \\
\hline \multicolumn{6}{|c|}{24 Herkünfte } \\
\hline 73 & 2151 & Breitenau-Mixnitz/Fischbacher Alp. & A & 970 & 18.7 \\
\hline 74 & 5301 & Belogradchik-Tschupreno & BG & 1400 & 18.5 \\
\hline 75 & 7422 & Rjasan, Moshary & SU & 150 & 18.5 \\
\hline 76 & 3337 & Rabenstein Typengemisch & $\mathrm{D}$ & 1200 & 18.4 \\
\hline 77 & 3334 & Zwiesel-Ost, V/1,2, Plattenfichten & $\mathrm{D}$ & 1200 & 18.4 \\
\hline 78 & 7224 & Ostrovskij-Pskow & SU & 200 & 18.4 \\
\hline 79 & 8705 & Mänttä & SF & 120 & 16.9 \\
\hline 80 & 5107 & Smrceve Dolina Abt. 138 & HR & 1350 & 16.9 \\
\hline 81 & 8707 & Janakkala Keskivari Uhkoila & SF & 100 & 14.2 \\
\hline
\end{tabular}




\section{Anhang 1.13}

Zusammenstellung der mittleren Einzelbaumvolumina und Vorräte pro Hektar im Alter von 39 Jahren auf den hessischen drei Versuchsflächen Reinhardshagen (absolut und relativ im Verbältnis zum Mittel der 3 Versuchsflächen)

\# Vorrat / ha ist höher als der rechnerische, da nicht alle Pflanzplätze bepflanzt sind Versuchsfläche 34

\begin{tabular}{|c|c|c|c|c|c|c|}
\hline $\begin{array}{l}\text { PG- } \\
\text { Nr. }\end{array}$ & Herkunft & Land & \multicolumn{2}{|c|}{ Einzelbaumv. } & \multicolumn{2}{|c|}{ Vorrat } \\
\hline 41 & Spiegelau & $\mathrm{D}$ & 0.382 & 64 & 358 & 87 \\
\hline 60 & Aflenz & A & 0.528 & 89 & 440 & 108 \\
\hline 61 & Gosau & A & 0.756 & 128 & 591 & 144 \\
\hline 62 & Litschau & A & 0.804 & 136 & 544 & 133 \\
\hline 63 & Eisenkappel Thurn 1 & A & 0.665 & 112 & 519 & 127 \\
\hline 64 & St. Martin & A & 0.631 & 107 & 394 & 96 \\
\hline 66 & Vorau & A & 0.502 & 85 & 392 & 96 \\
\hline 97 & Gérardmer & $\mathrm{F}$ & 0.605 & 102 & 378 & 93 \\
\hline 98 & Massif Central & $\mathrm{F}$ & 0.586 & 99 & 458 & 112 \\
\hline 103 & Wunsiedel & $\mathrm{D}$ & 0.624 & 105 & 422 & 103 \\
\hline 110 & Medebach & $\mathrm{D}$ & 0.506 & 85 & 342 & 84 \\
\hline 114 & Winterberg & $\mathrm{D}$ & 0.660 & 112 & 516 & 126 \\
\hline 124 & Istebna-Wisła & PL & 0.722 & 122 & 526 & 129 \\
\hline 130 & Dobra bei Frydek & CS & 0.594 & 100 & 433 & 106 \\
\hline 131 & Vizovice & CS & 0.629 & 106 & 426 & 104 \\
\hline 139 & Vapenkova Skala & CS & 0.599 & 101 & 468 & 114 \\
\hline 140 & Bucovice & CS & 0.623 & 105 & 422 & 103 \\
\hline 141 & Pitin & CS & 0.606 & 102 & 379 & 93 \\
\hline 142 & Rosice & CS & 0.678 & 114 & 423 & 104 \\
\hline 150 & Schlanders & I & 0.468 & 79 & 268 & 66 \\
\hline 170 & Groß Arl & A & 0.662 & 112 & 345 & 84 \\
\hline 171 & Hofgastein & A & 0.542 & 91 & 395 & 97 \\
\hline 174 & Piesendorf & A & 0.583 & 99 & 425 & 104 \\
\hline 175 & Radstatt & A & 0.638 & 108 & 399 & 97 \\
\hline 176 & St. Johann & A & 0.467 & 79 & 365 & 89 \\
\hline 177 & Taxenbach & A & 0.520 & 88 & 379 & 93 \\
\hline 178 & Abtenau & A & 0.704 & 119 & 477 & 117 \\
\hline 179 & Bischofshofen & A & 0.592 & 100 & 432 & 106 \\
\hline 184 & Paternion & A & 0.566 & 96 & 383 & 94 \\
\hline 185 & St. Veit/Glan & A & 0.545 & 92 & 369 & 90 \\
\hline 186 & Graz-Nord & A & 0.453 & 76 & 330 & 81 \\
\hline 187 & Pack & A & 0.608 & 103 & 411 & 101 \\
\hline 188 & Waldstein a.d. Übelb. & A & 0.473 & 80 & 370 & 90 \\
\hline 189 & Graz-Süd & A & 0.502 & 85 & 392 & 96 \\
\hline 190 & Offenegg & A & 0.554 & 94 & 375 & 92 \\
\hline 192 & Södingberg & A & 0.526 & 89 & 384 & 94 \\
\hline 202 & Istebna-Wisła & PL & 0.641 & 108 & 534 & 131 \\
\hline 204 & Spisske Pochradie & CS & 0.568 & 96 & 355 & 87 \# \\
\hline 207 & Jönköpings län & $\mathrm{S}$ & 0.527 & 89 & 329 & 80 \\
\hline 208 & Istebna & PL & 0.650 & 110 & 542 & 133 \\
\hline 215 & Stinava & SK & 0.650 & 110 & 508 & 124 \\
\hline 217 & Istebna-Wisła & PL & 0.605 & 102 & 378 & 92 \\
\hline 227 & Thüringen & $\mathrm{D}$ & 0.608 & 103 & 507 & 124 \\
\hline 229 & Olsztyn & PL & 0.517 & 87 & 350 & 86 \\
\hline
\end{tabular}


Versuchsfläche 34

\begin{tabular}{|c|c|c|c|c|c|c|}
\hline \multirow{2}{*}{$\begin{array}{c}\text { PG- } \\
\text { Nr. }\end{array}$} & \multirow{2}{*}{ Herkunft } & \multirow{2}{*}{ Land } & \multicolumn{2}{|c|}{ Einzelbaumv. } & \multicolumn{2}{|c|}{ Vorrat } \\
\hline & & & {$\left[\mathrm{m}^{3}\right]$} & {$[\%]$} & {$\left[\mathrm{m}^{3} / \mathrm{ha}\right]$} & $\mid[\%]$ \\
\hline 284 & Blekinge län Asarum & $\mathrm{S}$ & 0.414 & 70 & 280 & 69 \\
\hline 290 & Högestad & $\mathrm{S}$ & 0.678 & 115 & 494 & 121 \\
\hline 291 & Karupsskogen Barsebäcks gods & $\mathrm{S}$ & 0.578 & 98 & 391 & 96 \\
\hline 293 & Trolleholm & $\mathrm{S}$ & 0.804 & 136 & 502 & 123 \\
\hline 294 & Aasbo-össjö Gods & $\mathrm{S}$ & 0.518 & 88 & 378 & 92 \\
\hline 295 & Öveds Kloster Öpedal & $\mathrm{S}$ & 0.561 & 95 & 350 & 86 \\
\hline 704 & Cazis Tschartlina & $\mathrm{CH}$ & 0.551 & 93 & 287 & 70 \\
\hline 711 & La Genolière & $\mathrm{CH}$ & 0.322 & 54 & 235 & 57 \\
\hline 712 & Forêt du Risoud & $\mathrm{CH}$ & 0.459 & 78 & 263 & 64 \\
\hline 713 & Caragnago & $\mathrm{CH}$ & 0.527 & 89 & 357 & 87 \\
\hline 716 & Altacanta & $\mathrm{CH}$ & 0.585 & 99 & 335 & 82 \\
\hline 722 & Piana Selva, Faido & $\mathrm{CH}$ & 0.508 & 86 & 371 & 91 \\
\hline 725 & Airolo, Crespato-Ressia & $\mathrm{CH}$ & 0.498 & 84 & 337 & 82 \\
\hline 734 & Airolo, Bedretto & $\mathrm{CH}$ & 0.320 & 54 & 183 & 45 \\
\hline 740 & Bex, Tarejanne & $\mathrm{CH}$ & 0.288 & 49 & 165 & 40 \\
\hline 1100 & Monts Megal, Le Portius & $\mathrm{F}$ & 0.504 & 85 & 315 & 77 \\
\hline 1101 & Le Pertuis, Monts du Velay & $\mathrm{F}$ & 0.546 & 92 & 342 & 84 \\
\hline 1111 & Peisey-Nancroix, Grd. Bois & $\mathrm{F}$ & 0.512 & 86 & 373 & 91 \# \\
\hline 1112 & Autrans, Isère & $\mathrm{F}$ & 0.322 & 54 & 218 & 53 \\
\hline 1114 & Passy & $\mathrm{F}$ & 0.411 & 69 & 321 & 78 \\
\hline 1115 & Magland & $\mathrm{F}$ & 0.587 & 99 & 397 & 97 \\
\hline 1116 & Lantosque & $\mathrm{F}$ & 0.487 & 82 & 304 & 74 \\
\hline 1117 & Plan Bois, Ballandes & $\mathrm{F}$ & 0.489 & 83 & 305 & 75 \\
\hline 1202 & Manderfeld Gilbuschek 63 A & B & 0.646 & 109 & 303 & 74 \# \\
\hline 2113 & Oberes Gailtal & A & 0.597 & 101 & 373 & 91 \\
\hline 2114 & Kreuzen-Stockenboi & A & 0.561 & 95 & 468 & 114 \\
\hline 2115 & Rosental & A & 0.467 & 79 & 340 & 83 \\
\hline 2116 & Aich & A & 0.502 & 85 & 288 & 70 \\
\hline 2117 & Gurktal & A & 0.542 & 92 & 367 & 90 \\
\hline 2120 & Liembergwald Zell a. S. & A & 0.487 & 82 & 279 & 68 \\
\hline 2121 & Neukirchen Großvenediger & A & 0.759 & 128 & 514 & 126 \\
\hline 2122 & Piberegg & A & 0.776 & 131 & 445 & 109 \\
\hline 2123 & Gallmannsegg Kainach & A & 0.538 & 91 & 420 & 103 \\
\hline 2126 & Gaishorn & A & 0.527 & 89 & 466 & 114 \\
\hline 2128 & Lobming-Oberth. St. Stefan/Kraubath & A & 0.467 & 79 & 292 & 71 \\
\hline 2130 & Stanz-Kindthal-Allerheiligen & A & 0.544 & 92 & 396 & 97 \\
\hline 2140 & Fölz, Mayerberg & A & 0.555 & 94 & 433 & 106 \\
\hline 2141 & Fölz, Greith & A & 0.630 & 106 & 394 & $96 \#$ \\
\hline 2144 & Seewiesen, Seereith & A & 0.633 & 107 & 396 & 97 \\
\hline 2147 & Freiland, Gschwend & A & 0.494 & 83 & 412 & 101 \\
\hline 2149 & Kindberg/Eisenerzer Alpen & A & 0.595 & 100 & 434 & 106 \\
\hline 2150 & Siebensee Wildalpen & A & 0.429 & 73 & 335 & 82 \\
\hline 2160 & Turnau, Kapfenberg & A & 0.589 & 100 & 460 & 113 \\
\hline 3326 & Neureichenau & $\mathrm{D}$ & 0.445 & 75 & 278 & 68 \\
\hline 3328 & Spiegelau & D & 0.563 & 95 & 381 & 93 \\
\hline 3329 & Spiegelau & D & 0.849 & 143 & 531 & 130 \\
\hline 3332 & Zwiesel-Ost & D & 0.636 & 107 & 464 & 113 \\
\hline 3406 & SHK Stryck Willingen & $\mathrm{D}$ & 0.541 & 91 & 423 & 103 \\
\hline 3410 & Traunstein & D & 0.651 & 110 & 441 & 108 \\
\hline 3411 & Bischofswiesen & $\mathrm{D}$ & 0.513 & 87 & 347 & 85 \\
\hline
\end{tabular}


Versuchsfläche 34

\begin{tabular}{|c|c|c|c|c|c|c|}
\hline $\begin{array}{l}\text { PG- } \\
\text { Nr. }\end{array}$ & Herkunft & Land & $\begin{array}{l}\text { Einze } \\
{\left[\mathrm{m}^{3}\right]}\end{array}$ & $\begin{array}{l}\text { umv. } \\
{[\%]}\end{array}$ & $\begin{array}{r}\text { Vor } \\
{\left[\mathrm{m}^{3} / \mathrm{ha}\right]}\end{array}$ & {$[\%]$} \\
\hline 3412 & Winterberg & D & 0.740 & 125 & 578 & 141 \\
\hline 3413 & SHK Winterberg & $\mathrm{D}$ & 0.496 & 84 & 336 & 82 \\
\hline 3415 & SHK Hochsauerland & D & 0.509 & 86 & 397 & 97 \\
\hline 3416 & SHK Höhenfichten & $\mathrm{D}$ & 0.489 & 83 & 280 & $68 \#$ \\
\hline 3417 & Marsberg & $\mathrm{D}$ & 0.678 & 114 & 459 & 112 \\
\hline 3418 & Sachsenried & D & 0.600 & 101 & 469 & 115 \\
\hline 3419 & Schwarzwald Baar, VIII/6 & $\mathrm{D}$ & 0.625 & 106 & 455 & 111 \\
\hline 3420 & Daun/Ost & $\mathrm{D}$ & 0.589 & 100 & 460 & 113 \\
\hline 3421 & Dombühl & $\mathrm{D}$ & 0.688 & 116 & 573 & 140 \\
\hline 3422 & Stryck & D & 0.536 & 90 & 418 & 102 \\
\hline 3423 & Kohlstetten & $\mathrm{D}$ & 0.655 & 111 & 341 & 83 \\
\hline 3424 & Winterberg & $\mathrm{D}$ & 0.626 & 106 & 457 & 112 \\
\hline 3425 & Waldmünchen & D & 0.447 & 76 & 349 & 85 \\
\hline 3426 & Uelzen & $\mathrm{D}$ & 0.536 & 90 & 446 & 109 \\
\hline 3427 & Oderhaus & $\mathrm{D}$ & 0.718 & 121 & 299 & 73 \\
\hline 3428 & Schernfeld & $\mathrm{D}$ & 0.523 & 88 & 354 & 87 \\
\hline 3429 & Villingen & $\mathrm{D}$ & 0.699 & 118 & 400 & 98 \\
\hline 3430 & Diessen & $\mathrm{D}$ & 0.625 & 106 & 488 & 119 \\
\hline 3431 & Riedenburg & $\mathrm{D}$ & 0.586 & 99 & 366 & 90 \\
\hline 3432 & Walsrode & D & 0.590 & 100 & 461 & 113 \\
\hline 3433 & Selb-Kirchenlamitz (1) & $\mathrm{D}$ & 0.666 & 113 & 451 & 110 \\
\hline 3434 & Miele & $\mathrm{D}$ & 0.612 & 103 & 446 & 109 \\
\hline 3435 & Neureichenau (2) & $\mathrm{D}$ & 0.638 & 108 & 432 & 106 \\
\hline 3436 & Neureichenau (2) & D & 0.734 & 124 & 497 & 121 \\
\hline 3437 & Neureichenau (2) & $\mathrm{D}$ & 0.647 & 109 & 472 & 115 \\
\hline 3438 & Oderhaus & $\mathrm{D}$ & 0.531 & 90 & 387 & 95 \\
\hline 3444 & Zwiesel, Scheicherau XXI 14a/b $(3,6)$ & $\mathrm{D}$ & 0.616 & 104 & 481 & 118 \\
\hline 3445 & Zwiesel, Haselau XXI $12(3,6)$ & $\mathrm{D}$ & 0.716 & 121 & 485 & 119 \\
\hline 3447 & Nationalp. Hüttenschlag XIX 1b (6) & $\mathrm{D}$ & 0.671 & 113 & 489 & 120 \\
\hline 3448 & Nationalp. Filzwald IX 3a 10/11 (6) & $\mathrm{D}$ & 0.446 & 75 & 325 & 80 \\
\hline 3449 & Nationalp. Neubruck 1a10,b10/11,c10 (6) & 6) $\mathrm{D}$ & 0.549 & 93 & 372 & 91 \\
\hline 3498 & Burgjoß & $\mathrm{D}$ & 0.684 & 116 & 534 & 131 \\
\hline 3499 & Chausseehaus & $\mathrm{D}$ & 0.617 & 104 & 482 & 118 \\
\hline 3505 & Eibenst. Carlsf. 275 & $\mathrm{D}$ & 0.730 & 123 & 456 & 112 \\
\hline 3617 & Torgelow & $\mathrm{D}$ & 0.747 & 126 & 545 & 133 \\
\hline 4011 & Cikaaj, Zdarska Vrchy & CS & 0.590 & 100 & 492 & 120 \\
\hline 4032 & Kynsperk nad Ohri Libocky Dul & CS & 0.659 & 111 & 550 & 134 \\
\hline 4042 & Vimperk-Prameny Vltury Stachy & CS & 0.591 & 100 & 462 & 113 \\
\hline 4061 & Velke Mezirici-Rudolec & CS & 0.738 & 125 & 576 & 141 \\
\hline 4081 & Frenstat pod Radhosten-Obora & CS & 0.911 & 154 & 664 & 162 \\
\hline 4082 & Ostravice & CS & 0.628 & 106 & 425 & 104 \\
\hline 4103 & Tatranska Lesna 559 C & CS & 0.601 & 101 & 438 & 107 \\
\hline 4121 & Javorova Dolina 155 A, Nr. 4121 & CS & 0.419 & 71 & 284 & 69 \\
\hline 4143 & Kysihybel & CS & 0.661 & 112 & 448 & 109 \\
\hline 4154 & Roznava & CS & 0.563 & 95 & 352 & 86 \\
\hline 4157 & Hnusta & $\mathrm{CS}$ & 0.616 & 104 & 577 & 141 \\
\hline 4159 & Svrcina Hrabusice & CS & 0.515 & 87 & 348 & 85 \\
\hline 5101 & Nedzinant, Prokletije (Geb.) & YU & 0.336 & 57 & 298 & 73 \\
\hline 5201 & Köszeg 1 C & $\mathrm{H}$ & 0.606 & 102 & 379 & 93 \\
\hline 5202 & Szentgotthard $1 \mathrm{C}$ & $\mathrm{H}$ & 0.590 & 100 & 491 & 120 \\
\hline
\end{tabular}


Versuchsfläche 34

\begin{tabular}{|c|c|c|c|c|c|c|}
\hline $\begin{array}{l}\text { PG- } \\
\text { Nr. }\end{array}$ & Herkunft & Land & \multicolumn{2}{|c|}{ Einzelbaumv. } & \multicolumn{2}{|c|}{\begin{tabular}{c|}
\multicolumn{2}{c}{ Vorrat } \\
{$\left[\mathrm{m}^{3} / \mathrm{ha}\right]$}
\end{tabular}} \\
\hline 5203 & Sarospatak-Haromhuta 19 B Zempl. Geb & b. $\mathrm{H}$ & 0.491 & 83 & 332 & 81 \\
\hline 5204 & Miskolc-Lillafüred 82 A Bükker Geb & ว. $\mathrm{H}$ & 0.591 & 100 & 462 & 113 \\
\hline 5205 & Nagykanizsa-Iharos Plattensee 11/1-71 & $\mathrm{H}$ & 0.673 & 114 & 421 & 103 \\
\hline 5206 & Sopron (Hochschulrev.) 203 D & $\mathrm{H}$ & 0.667 & 113 & 452 & 110 \\
\hline 5302 & Beglika & BG & 0.578 & 98 & 391 & 96 \\
\hline 5303 & Borovec (Rila-Geb.) & $\mathrm{BG}$ & 0.321 & 54 & 218 & 53 \\
\hline 5401 & Valea Putnei-Pojorita & RU & 0.639 & 108 & 433 & 106 \\
\hline 5413 & Brosteni Bradu/Bastitei & RU & 0.667 & 113 & 417 & 102 \\
\hline 6106 & Köslin/Koszalin & PL & 0.581 & 98 & 363 & 89 \\
\hline 6223 & Przerwanki & PL & 0.483 & 82 & 352 & 86 \\
\hline 6237 & Puszcza-Białowieska & PL & 0.583 & 99 & 395 & 97 \\
\hline 6250 & Augustow Abt. 95 b & PL & 0.429 & 72 & 335 & $82 \#$ \\
\hline 6254 & Mikaszowka & PL & 0.614 & 104 & 448 & $110 \#$ \\
\hline 6255 & Puszcza-Augustowska & PL & 0.815 & 138 & 297 & 73 \\
\hline 6260 & Knyszyn & PL & 0.453 & 77 & 307 & $75 \#$ \\
\hline 6261 & Kumialka (Kumialska) & PL & 0.423 & 71 & 308 & 75 \\
\hline 6410 & Sierpc & PL & 0.618 & 104 & 354 & 87 \\
\hline 6713 & Klodzko-Nynow $72 \mathrm{k}$ & PL & 0.623 & 105 & 422 & 103 \\
\hline 6896 & Borken & PL & 0.619 & 105 & 451 & 110 \\
\hline 7401 & Gzatsk-Smolensk & SU & 0.737 & 124 & 192 & 47 \# \\
\hline 8703 & Lohja Laaskspohjan & SF & 0.396 & 67 & 186 & 45 \# \\
\hline 9170 & Ryssby-Kronobergs & $\mathrm{S}$ & 0.442 & 75 & 207 & 51 \\
\hline 9417 & Marsberg & $\mathrm{D}$ & 0.677 & 114 & 493 & 121 \\
\hline 9423 & Kohlstetten & $\mathrm{D}$ & 0.565 & 95 & 323 & 79 \\
\hline 9432 & Walsrode & $\mathrm{D}$ & 0.506 & 86 & 343 & 84 \\
\hline
\end{tabular}

Versuchsfläche 35

\begin{tabular}{c|l|r|rr|rr}
\hline PG- & \multirow{2}{*}{ Herkunft } & \multirow{2}{*}{ Land } & \multicolumn{2}{c|}{ Einzelbaumv. } & \multicolumn{2}{c}{ Vorrat } \\
Nr. & & & {$\left[\mathrm{m}^{3}\right]$} & {$[\%]$} & {$\left[\mathrm{m}^{3} / \mathrm{ha}\right]$} & {$[\%]$} \\
\hline 107 & Donaueschingen & $\mathrm{D}$ & 0.445 & 75 & 348 & 85 \\
111 & Bodenmais & $\mathrm{D}$ & 0.512 & 86 & 346 & 85 \\
115 & Westerhof & $\mathrm{D}$ & 0.826 & 139 & 559 & 137 \\
121 & Cedrogne & $\mathrm{B}$ & 0.630 & 106 & 459 & 112 \\
149 & Einsiedeln & $\mathrm{CH}$ & 0.593 & 100 & 401 & 98 \\
2118 & Gurker Sirnitzwald & $\mathrm{A}$ & 0.628 & 106 & 458 & 112 \\
2131 & Veitsch-Neuberg & $\mathrm{A}$ & 0.533 & 90 & 389 & 95 \\
2133 & Hinterhof, Eibelkogel & $\mathrm{A}$ & 0.546 & 92 & 370 & 90 \\
2134 & Hinterhof, Ostbrenner u. Tiefental & $\mathrm{A}$ & 0.570 & 96 & 475 & 116 \\
2135 & Kraubath, Seckauer Tauern & $\mathrm{A}$ & 0.597 & 101 & 528 & 129 \\
2137 & Buchberg, Flachwald/Aflenz & $\mathrm{A}$ & 0.513 & 87 & 321 & 78 \\
2138 & Buchberg, Ägidiwald/Aflenz & $\mathrm{A}$ & 0.441 & 75 & 322 & 79 \\
2151 & Breitenau-Mixnitz/Fischbacher Alp. & $\mathrm{A}$ & 0.524 & 89 & 273 & 67 \\
2158 & Rohr im Gebirge, Kirchwald & $\mathrm{A}$ & 0.574 & 97 & 359 & 88 \\
2179 & Eisenkappel/Karaw. & $\mathrm{A}$ & 0.513 & 87 & 374 & 91 \\
2184 & Schneegattern & $\mathrm{A}$ & 0.547 & 92 & 427 & 105 \\
2207 & Seewiesen Seereith/Aflenz & $\mathrm{A}$ & 0.495 & 84 & 309 & 76 \\
3042 & Walchensee & $\mathrm{D}$ & 0.448 & 76 & 303 & 74
\end{tabular}


Versuchsfläche 35

\begin{tabular}{|c|c|c|c|c|c|c|}
\hline $\begin{array}{l}\text { PG- } \\
\text { Nr. }\end{array}$ & Herkunft & Land & $\begin{array}{l}\text { Einze } \\
{\left[\mathrm{m}^{3}\right]}\end{array}$ & $\begin{array}{l}\text { umv. } \\
{[\%]}\end{array}$ & $\begin{array}{r}\text { Vor } \\
{\left[\mathrm{m}^{3} / \mathrm{ha}\right]}\end{array}$ & {$[\%]$} \\
\hline 3102 & Schluchsee-Eschenmoos & D & 0.505 & 85 & 342 & 84 \\
\hline 3139 & Isny Ba/Wü & $\mathrm{D}$ & 0.575 & 97 & 300 & 73 \\
\hline 3310 & Zwiesel-West/Ruselhänge X/68 & $\mathrm{D}$ & 0.590 & 100 & 492 & 120 \\
\hline 3320 & Bischofsreut & $\mathrm{D}$ & 0.761 & 129 & 436 & 107 \\
\hline 3331 & St. Oswald I/3,4,6 Typengemisch & $\mathrm{D}$ & 0.483 & 82 & 377 & 92 \\
\hline 3334 & Zwiesel-Ost, V/1,2, Plattenfichten & $\mathrm{D}$ & 0.545 & 92 & 284 & 69 \\
\hline 3337 & Rabenstein Typengemisch & $\mathrm{D}$ & 0.409 & 69 & 298 & 73 \\
\hline 3404 & Westerhof Abt. 51 B & $\mathrm{D}$ & 0.683 & 115 & 462 & 113 \\
\hline 3417 & Marsberg & $\mathrm{D}$ & 0.966 & 163 & 805 & 197 \\
\hline 3423 & Kohlstetten & D & 0.744 & 126 & 504 & 123 \\
\hline 3430 & Diessen & $\mathrm{D}$ & 0.655 & 111 & 511 & 125 \\
\hline 3432 & Walsrode & $\mathrm{D}$ & 0.599 & 101 & 312 & 76 \# \\
\hline 3433 & Selb-Kirchenlamitz (1) & D & 0.750 & 127 & 586 & 143 \\
\hline 3443 & Zwiesel, Scheichereb. XXI 13b1 (3,0) & $\mathrm{D}$ & 0.504 & 85 & 420 & 103 \\
\hline 3501 & Rungstock, 46 A & $\mathrm{D}$ & 0.770 & 130 & 521 & 127 \\
\hline 3503 & Eibenst. Carlsf. Wiesenh. 214 & $\mathrm{D}$ & 0.793 & 134 & 578 & 141 \\
\hline 3504 & Eibenst. Carlsf. Wilschm. 233 & $\mathrm{D}$ & 0.597 & 101 & 466 & 114 \\
\hline 3506 & Tellerhaeuser, 44 & $\mathrm{D}$ & 0.557 & 94 & 435 & 106 \\
\hline 3508 & Rehefeld, 146 & $\mathrm{D}$ & 0.709 & 120 & 443 & 108 \\
\hline 3510 & Sonneb. Steinheid, Kieferleskopf & $\mathrm{D}$ & 0.579 & 98 & 362 & 89 \\
\hline 3511 & Innenau Elgersburg & $\mathrm{D}$ & 0.655 & 111 & 443 & 108 \\
\hline 3512 & Peitz/Tannenwald & $\mathrm{D}$ & 0.518 & 87 & 377 & 92 \\
\hline 3518 & Suhl, Oberhofer Schloßbergkopf & $\mathrm{D}$ & 0.490 & 83 & 383 & 94 \\
\hline 3519 & Mechterstädt & D & 0.650 & 110 & 474 & 116 \\
\hline 3601 & Cottbus, Tannenwald 17AB & $\mathrm{D}$ & 0.518 & 88 & 378 & 92 \\
\hline 3606 & Templin, Bad Doberan Nr. 9 & $\mathrm{D}$ & 0.739 & 125 & 577 & 141 \\
\hline 3615 & Neustrelitz & $\mathrm{D}$ & 0.639 & 108 & 399 & 98 \\
\hline 4022 & Boubin III & CS & 0.598 & 101 & 405 & 99 \\
\hline 4026 & Habartice, Planice & CS & 0.741 & 125 & 502 & 123 \\
\hline 4051 & Vysoky Chlumec Veletin & CS & 0.675 & 114 & 527 & 129 \\
\hline 4053 & Cesky Krumlov Borova & CS & 0.616 & 104 & 449 & 110 \\
\hline 4054 & Chlum u. Trebone-Hamr & CS & 0.738 & 125 & 538 & 132 \\
\hline 4060 & Hencov-Trest & CS & 0.724 & 122 & 490 & 120 \\
\hline 4070 & Vrchlabi & CS & 0.637 & 108 & 431 & 105 \\
\hline 4073 & Jesenik-Zlate Hory & CS & 0.660 & 111 & 447 & 109 \\
\hline 4123 & Javorova Dolina 155 A, Nr.4123 & CS & 0.524 & 89 & 355 & 87 \# \\
\hline 5102 & Kaludjerske Bore Taram Kremma & YU & 0.406 & 69 & 275 & 67 \\
\hline 5107 & Smrceve Dolina Abt. 138 & HR & 0.241 & 41 & 163 & 40 \\
\hline 5301 & Belogradchik-Tschupreno & BG & 0.303 & 51 & 221 & 54 \\
\hline 5412 & Moldovita-Sacries & RU & 0.704 & 119 & 477 & 117 \\
\hline 5415 & Cimpeni-Dara & RU & 0.735 & 124 & 459 & 112 \\
\hline 5416 & Remeti-Zerna & RU & 0.730 & 123 & 532 & 130 \\
\hline 5420 & Valea Putnei-Pojorita III/60 & RU & 0.670 & 113 & 594 & 145 \\
\hline 5426 & Crucea-Barnavel Abt. 17/18 & RU & 0.621 & 105 & 421 & 103 \\
\hline 6103 & Brotzen/Broczyno & PL & 0.640 & 108 & 367 & 90 \\
\hline 6222 & Borken/Borki & PL & 0.785 & 133 & 491 & 120 \\
\hline 6234 & Białowieża & PL & 0.650 & 110 & 373 & 91 \\
\hline 6235 & Zwierzyniec & PL & 0.566 & 96 & 354 & 86 \\
\hline 6251 & Białobrzegi & PL & 0.718 & 121 & 336 & $82 \#$ \\
\hline 6510 & Bunzlau/Boleslawiec & PL & 0.613 & 104 & 479 & 117 \\
\hline
\end{tabular}


Versuchsfläche 35

\begin{tabular}{|c|c|c|c|c|c|c|}
\hline $\begin{array}{l}\text { PG- } \\
\text { Nr. }\end{array}$ & Herkunft & Land & $\begin{array}{l}\text { Einze } \\
{\left[\mathrm{m}^{3}\right]}\end{array}$ & $\begin{array}{l}\text { iumv. } \\
{[\%]}\end{array}$ & $\begin{array}{r}\text { Vor } \\
{\left[\mathrm{m}^{3} / \mathrm{ha}\right]}\end{array}$ & $\left.\begin{array}{l}\text { at } \\
\end{array} \%\right]$ \\
\hline 6543 & Groß-Lassowitz/Lassowice Male & PL & 0.648 & 110 & 473 & 116 \\
\hline 6624 & Przysucha & PL & 0.463 & 78 & 386 & 94 \\
\hline 6712 & Klodzko-Glatz/Nynow 68 e & PL & 0.766 & 129 & 638 & 156 \\
\hline 6731 & Szcytna-Slaska Karlow 243 a & PL & 0.638 & 108 & 432 & 106 \\
\hline 6732 & Szcytna-Slaska Karlow 292 b & PL & 0.564 & 95 & 352 & 86 \\
\hline 6864 & Istebna-Ujsoly & PL & 0.588 & 99 & 490 & 120 \\
\hline 6894 & Witów & PL & 0.536 & 91 & 391 & 96 \\
\hline 7224 & Ostrovskij-Pskow & SU & 0.466 & 79 & 339 & 83 \\
\hline 7233 & Wolozin & SU & 0.524 & 88 & 382 & 93 \\
\hline 7235 & Brigalovic-Mogilev & SU & 0.499 & 84 & 364 & 89 \\
\hline 7422 & Rjasan, Moshary & SU & 0.485 & 82 & 303 & 74 \\
\hline 8705 & Mänttä & SF & 0.259 & 44 & 41 & $10 \#$ \\
\hline 8707 & Janakkala Keskivari Uhkoila & SF & 0.402 & 68 & 188 & 46 \# \\
\hline
\end{tabular}

Versuchsfläche 36

\begin{tabular}{|c|c|c|c|c|c|c|}
\hline \multirow{2}{*}{$\begin{array}{l}\text { PG- } \\
\text { Nr. }\end{array}$} & \multirow{2}{*}{ Herkunft } & \multirow{2}{*}{ Land } & \multicolumn{2}{|c|}{ Einzelbaumv. } & \multicolumn{2}{|c|}{ Vorrat } \\
\hline & & & {$\left[\mathrm{m}^{3}\right]$} & {$[\%]$} & {$\left[\mathrm{m}^{3} / \mathrm{ha}\right]$} & {$[\%]$} \\
\hline 65 & Eisenkappel Thurn 2 & A & 0.653 & 110 & 442 & 108 \\
\hline 105 & Hohenschwangau & $\mathrm{D}$ & 0.873 & 148 & 546 & 133 \\
\hline 113 & Walsrode & $\mathrm{D}$ & 0.677 & 114 & 494 & 121 \\
\hline 116 & Kobernausserwald & A & 0.628 & 106 & 425 & 104 \\
\hline 169 & Gries & A & 0.621 & 105 & 485 & 119 \\
\hline 172 & Mittersill & A & 0.718 & 121 & 486 & 119 \\
\hline 191 & Passail & A & 0.692 & 117 & 577 & 141 \\
\hline 230 & Elbingerode & $\mathrm{D}$ & 0.651 & 110 & 475 & 116 \\
\hline 1118 & Chatel, 1 Aity" & $\mathrm{F}$ & 0.553 & 93 & 317 & 77 \\
\hline 1201 & Mellier, Bois Bayai, 2 & B & 0.613 & 103 & 383 & 94 \\
\hline 2124 & Stixenstein, Gahns & A & 0.548 & 93 & 371 & 91 \\
\hline 2127 & Unterhal, St.Kathrein a.d. Lamming & A & 0.547 & 92 & 427 & 105 \\
\hline 2174 & Klein-Sölk/Niedertauern & A & 0.602 & 102 & 313 & 77 \\
\hline 3150 & Dillingen a.d.D. Bay. & $\mathrm{D}$ & 0.699 & 118 & 473 & 116 \\
\hline 3206 & Eglharting XIV/17,19 & $\mathrm{D}$ & 0.672 & 113 & 420 & 103 \\
\hline 3213 & Mühldorf/Inn & $\mathrm{D}$ & 0.684 & 116 & 463 & 113 \\
\hline 3414 & Bodensee Oberschwab. VIII/13 & $\mathrm{D}$ & 0.728 & 123 & 531 & 130 \\
\hline 3417 & Marsberg & $\mathrm{D}$ & 0.734 & 124 & 497 & 122 \\
\hline 3423 & Kohlstetten & $\mathrm{D}$ & 0.647 & 109 & 371 & 91 \\
\hline 3430 & Diessen & $\mathrm{D}$ & 0.770 & 130 & 321 & 78 \\
\hline 3432 & Walsrode & $\mathrm{D}$ & 0.757 & 128 & 512 & 125 \\
\hline 3433 & Selb-Kirchenlamitz (1) & $\mathrm{D}$ & 0.700 & 118 & 620 & 152 \\
\hline 3446 & Zwiesel, Schmalzau IX 3c $(5,6)$ & $\mathrm{D}$ & 0.679 & 115 & 459 & 112 \\
\hline 4050 & Vlasim-Votice & CS & 0.643 & 109 & 435 & 106 \\
\hline 4075 & Vitkov-Budisov & CS & 0.776 & 131 & 525 & 128 \\
\hline 4127 & Javorova Dolina 155 A, Nr.4127 & CS & 0.503 & 85 & 393 & 96 \\
\hline 5424 & Valea Beliei-Sinaia Gurguiata & RU & 0.578 & 98 & 331 & 81 \\
\hline 5425 & Cimpeni-Nedei & RU & 0.694 & 117 & 506 & $124 \#$ \\
\hline 6107 & Altenhagen/Nowy Krakow & PL & 0.712 & 120 & 557 & 136 \\
\hline 6236 & Białowieża & PL & 0.516 & 87 & 296 & 72 \\
\hline
\end{tabular}


Versuchsfläche 36

\begin{tabular}{c|l|c|c|c|cc}
\hline PG- & \multirow{2}{*}{ Herkunft } & \multirow{2}{*}{ Land } & \multicolumn{2}{c|}{ Einzelbaumv. } & \multicolumn{2}{c}{ Vorrat } \\
Nr. & & & {$\left[\mathrm{m}^{3}\right]$} & {$[\%]$} & {$\left[\mathrm{m}^{3} / \mathrm{ha}\right]$} & {$[\%]$} \\
\hline 6897 & Goldap & PL & 0.653 & 110 & 442 & 108 \\
7232 & Cemerjanskoe-Mogilev & SU & 0.591 & 100 & 461 & 113 \\
7234 & Soboljanskoe-Grodno & SU & 0.626 & 106 & 424 & 104 \\
7240 & Witebsk & SU & 0.650 & 110 & 440 & 108 \\
7400 & Kaluga & SU & 0.467 & 79 & 365 & $89 \#$ \\
9191 & Karlsholms-Kristianstad & S & 0.644 & 109 & 402 & 98 \\
\hline
\end{tabular}

\section{Anhang 1.14}

Zusammenstellung der sich signifikant von mindestens einer anderen Herkunft im Tukey-Kramer-Test beim Einzelbaumvolumen $\left[\mathrm{m}^{3}\right]$ im Alter 39 auf der Versuchsfläche 34 Reinhardshagen / Hessen unterscheidenden Herkünfte

\begin{tabular}{|c|c|c|c|c|c|}
\hline Rang & $\begin{array}{l}\text { PG- } \\
\text { Nr. }\end{array}$ & Herkunft & Land & $\begin{array}{c}\text { Höhe } \\
\text { m ü. NN }\end{array}$ & $\begin{array}{l}\text { Vol. } \\
{\left[\mathrm{m}^{3}\right]}\end{array}$ \\
\hline 1 & 4081 & Frenstat pod Radhosten-Obora & CS & 600 & 0.909 \\
\hline 2 & 3329 & Spiegelau & $\mathrm{D}$ & 1200 & 0.837 \\
\hline 3 & 62 & Litschau & A & 600 & 0.832 \\
\hline 4 & 2122 & Piberegg & A & 800 & 0.804 \\
\hline 5 & 293 & Trolleholm & $\mathrm{S}$ & 125 & 0.804 \\
\hline 6 & 61 & Gosau & A & 700 & 0.773 \\
\hline 7 & 6255 & Puszcza-Augustowska & PL & 125 & 0.764 \\
\hline 8 & 2121 & Neukirchen Großvenediger & A & 870 & 0.749 \\
\hline 9 & 3429 & Villingen & $\mathrm{D}$ & 850 & 0.743 \\
\hline \multicolumn{6}{|c|}{142 Herkünfte } \\
\hline 152 & 3416 & SHK Höhenfichten & $\mathrm{D}$ & 1050 & 0.461 \\
\hline 153 & 6260 & Knyszyn & PL & 150 & 0.457 \\
\hline 154 & 3448 & Nationalp. Filzwald IX 3a 10/11 (6) & $\mathrm{D}$ & 750 & 0.456 \\
\hline 155 & 186 & Graz-Nord & A & 850 & 0.454 \\
\hline 156 & 3425 & Waldmünchen & $\mathrm{D}$ & 850 & 0.452 \\
\hline 157 & 6250 & Augustow Abt. $95 \mathrm{~b}$ & PL & 120 & 0.423 \\
\hline 158 & 1114 & Passy & $\mathrm{F}$ & 1200 & 0.420 \\
\hline 159 & 2150 & Siebensee Wildalpen & A & 850 & 0.418 \\
\hline 160 & 4121 & Javorova Dolina 155 A, Nr.4121 & CS & 1200 & 0.414 \\
\hline 161 & 284 & Blekinge län Asarum & $\mathrm{S}$ & 100 & 0.413 \\
\hline 162 & 6261 & Kumialka (Kumialska) & PL & 160 & 0.412 \\
\hline 163 & 41 & Spiegelau & $\mathrm{D}$ & 750 & 0.382 \\
\hline 164 & 5303 & Borovec (Rila-Geb.) & BG & 1300 & 0.346 \\
\hline 165 & 5101 & Nedzinant, Prokletije (Geb.) & YU & 1150 & 0.338 \\
\hline 166 & 1112 & Autrans, Isère & $\mathrm{F}$ & 1250 & 0.332 \\
\hline 167 & 711 & La Genolière & $\mathrm{CH}$ & & 0.322 \\
\hline 168 & 734 & Airolo, Bedretto & $\mathrm{CH}$ & 1600 & 0.310 \\
\hline 169 & 740 & Bex, Tarejanne & $\mathrm{CH}$ & 1600 & 0.297 \\
\hline
\end{tabular}




\section{Anhang 1.15}

Zusammenstellung der sich signifikant von mindestens einer anderen Herkunft im Tukey-Kramer-Test beim Einzelbaumvolumen $\left[\mathrm{m}^{3}\right]$ im Alter 39 auf der Versuchsfläche 35 Reinhardshagen / Hessen unterscheidenden Herkünfte

\begin{tabular}{c|c|l|c|c|c}
\hline Rang & $\begin{array}{l}\text { PG- } \\
\text { Nr. }\end{array}$ & Herkunft & Land & $\begin{array}{c}\text { Höhe } \\
\text { m ü. NN }\end{array}$ & $\begin{array}{c}\text { Vol. } \\
{\left[\mathrm{m}^{3}\right]}\end{array}$ \\
\hline 1 & 3417 & Marsberg & D & 500 & 0.977 \\
2 & 6251 & Białobrzegi & PL & 110 & 0.909 \\
3 & 115 & Westerhof & D & 200 & 0.841 \\
4 & 3503 & Eibenst. Carlsf. Wiesenh. 214 & D & 720 & 0.785 \\
5 & 6712 & Klodzko-Glatz/Nynow 68 e & PL & 340 & 0.776 \\
6 & 3501 & Rungstock, 46 A & D & 560 & 0.771 \\
7 & 3320 & Bischofsreut & D & 970 & 0.768 \\
8 & 6222 & Borken/Borki & PL & 160 & 0.768 \\
9 & 3433 & Selb-Kirchenlamitz (1) & D & 800 & 0.755 \\
10 & 3606 & Templin, Bad Doberan Nr. 9 & D & 50 & 0.754 \\
11 & 4054 & Chlum u. Trebone-Hamr & CS & 450 & 0.751 \\
$\ldots$ & & & & & \\
55 & Herkünfte & & & & \\
$\ldots$ & & & A & 875 & 0.495 \\
67 & 2207 & Seewiesen Seereith/Aflenz & D & 900 & 0.492 \\
68 & 3518 & Suhl, Oberhofer Schloßbergkopf & SU & 200 & 0.488 \\
69 & 7224 & Ostrovskij-Pskow & SU & 150 & 0.485 \\
70 & 7422 & Rjasan, Moshary & D & 1200 & 0.483 \\
71 & 3331 & St. Oswald I/3,4,6 Typengemisch & PL & 275 & 0.482 \\
72 & 6624 & Przysucha & SF & 100 & 0.461 \\
73 & 8707 & Janakkala Keskivari Uhkoila & D & 650 & 0.446 \\
74 & 107 & Donaueschingen & D & 1100 & 0.444 \\
75 & 3042 & Walchensee & A & 925 & 0.436 \\
76 & 2138 & Buchberg, Ägidiwald/Aflenz & D & 1200 & 0.418 \\
77 & 3337 & Rabenstein Typengemisch & YU & 1000 & 0.417 \\
78 & 5102 & Kaludjerske Bore Taram Kremma & BG & 1400 & 0.310 \\
79 & 5301 & Belogradchik-Tschupreno & SF & 120 & 0.283 \\
80 & 8705 & Mänttä & HR & 1350 & 0.261 \\
81 & 5107 & Smrceve Dolina Abt. 138 & & &
\end{tabular}

\section{Anhang 1.16}

Zusammenstellung der sich signifikant von mindestens einer anderen Herkunft im Tukey-Kramer-Test beim rechnerischen Vorrat/ha $\left[\mathrm{m}^{3} / \mathrm{ha}\right]$ im Alter 39 auf der Versuchsfläche 34 Reinhardshagen / Hessen unterscheidenden Herkünfte

\begin{tabular}{c|r|l|c|c|c}
\hline Rang & $\begin{array}{c}\text { PG- } \\
\text { Nr. }\end{array}$ & Herkunft & Land & $\begin{array}{c}\text { Höhe } \\
\mathrm{m} \text { ü. NN }\end{array}$ & $\begin{array}{c}\text { Vorrat } \\
{\left[\mathrm{m}^{3}\right]}\end{array}$ \\
\hline 1 & 4081 & Frenstat pod Radhosten-Obora & CS & 600 & 664 \\
2 & 61 & Gosau & A & 700 & 591 \\
3 & 3412 & Winterberg & D & 750 & 578 \\
4 & 4157 & Hnusta & CS & 550 & 577 \\
5 & 4061 & Velke Mezirici-Rudolec & CS & 630 & 576 \\
6 & 3421 & Dombühl & D & 450 & 573
\end{tabular}




\begin{tabular}{crl|l|c|c}
\hline Rang & $\begin{array}{c}\text { PG- } \\
\text { Nr. }\end{array}$ & Herkunft & Land & $\begin{array}{c}\text { Höhe } \\
\text { m ü. NN }\end{array}$ & $\begin{array}{c}\text { Vorrat } \\
{\left[\mathrm{m}^{3}\right]}\end{array}$ \\
\hline 7 & 4032 & Kynsperk nad Ohri Libocky Dul & CS & 650 & 550 \\
$\ldots$ & & & & \\
140 & Herkünfte & & & \\
$\ldots$ & & & 1200 & 284 \\
148 & 4121 & Javorova Dolina 155 A, Nr. 4121 & CS & 100 & 280 \\
149 & 284 & Blekinge län Asarum & S & 875 & 279 \\
150 & 2120 & Liembergwald Zell a. S. & A & 1200 & 278 \\
151 & 3326 & Neureichenau & D & 1500 & 268 \\
152 & 150 & Schlanders & I H & 1100 & 263 \\
153 & 712 & Forêt du Risoud & CH & & 235 \\
154 & 711 & La Genolière & F & 1250 & 218 \\
155 & 1112 & Autrans, Isère & BG & 1300 & 218 \\
156 & 5303 & Borovec (Rila-Geb.) & S & 175 & 207 \\
157 & 9170 & Ryssby-Kronobergs & CH & 1600 & 183 \\
158 & 734 & Airolo, Bedretto & CH & 1600 & 165 \\
159 & 740 & Bex, Tarejanne & & & \\
\hline
\end{tabular}

\section{Anhang 1.17}

Zusammenstellung der sich signifikant von mindestens einer anderen Herkunft im Tukey-Kramer-Test beim rechnerischen Vorrat/ha $\left[\mathrm{m}^{3} / \mathrm{ha}\right]$ im Alter 39 auf der Versuchsfläche 35 Reinhardshagen / Hessen unterscheidenden Herkünfte

\begin{tabular}{|c|c|c|c|c|c|}
\hline Rang & $\begin{array}{l}\text { PG- } \\
\text { Nr. }\end{array}$ & Herkunft & Land & $\begin{array}{l}\text { Höhe } \\
\text { m ü. NN }\end{array}$ & $\begin{array}{c}\text { Vorrat } \\
{\left[\mathrm{m}^{3}\right\rceil}\end{array}$ \\
\hline 1 & 3417 & Marsberg & $\mathrm{D}$ & 500 & 805 \\
\hline 2 & 6712 & Klodzko-Glatz/Nynow 68 e & PL & 340 & 638 \\
\hline 3 & 5420 & Valea Putnei-Pojorita III/60 & RU & 1285 & 594 \\
\hline 4 & 3433 & Selb-Kirchenlamitz (1) & $\mathrm{D}$ & 800 & 586 \\
\hline 5 & 3503 & Eibenst. Carlsf. Wiesenh. 214 & $\mathrm{D}$ & 720 & 578 \\
\hline 6 & 3606 & Templin, Bad Doberan Nr. 9 & $\mathrm{D}$ & 50 & 577 \\
\hline 7 & 115 & Westerhof & $\mathrm{D}$ & 200 & 559 \\
\hline 8 & 4054 & Chlum u. Trebone-Hamr & CS & 450 & 538 \\
\hline 9 & 5416 & Remeti-Zerna & RU & 900 & 532 \\
\hline 10 & 2135 & Kraubath, Seckauer Tauern & A & 1050 & 528 \\
\hline 11 & 4051 & Vysoky Chlumec Veletin & CS & 600 & 527 \\
\hline \multicolumn{6}{|c|}{22 Herkünfte } \\
\hline 34 & 3320 & Bischofsreut & $\mathrm{D}$ & 970 & 436 \\
\hline 35 & 3506 & Tellerhaeuser, 44 & $\mathrm{D}$ & 980 & 435 \\
\hline 36 & 6731 & Szcytna-Slaska Karlow 243 a & PL & 750 & 432 \\
\hline 37 & 4070 & Vrchlabi & CS & 700 & 431 \\
\hline 38 & 2184 & Schneegattern & A & 750 & 427 \\
\hline 39 & 5426 & Crucea-Barnavel Abt. 17/18 & RU & 740 & 421 \\
\hline 40 & 3443 & Zwiesel, Scheichereb. XXI 13b1 $(3,6)$ & $\mathrm{D}$ & 650 & 420 \\
\hline 41 & 4022 & Boubin III & CS & 1000 & 405 \\
\hline 42 & 149 & Einsiedeln & $\mathrm{CH}$ & 900 & 401 \\
\hline 43 & 3615 & Neustrelitz & $\mathrm{D}$ & 100 & 399 \\
\hline
\end{tabular}




\begin{tabular}{c|c|l|c|c|c}
\hline Rang & $\begin{array}{c}\text { PG- } \\
\text { Nr. }\end{array}$ & Herkunft & Land & $\begin{array}{c}\text { Höhe } \\
\text { m ü. NN }\end{array}$ & $\begin{array}{c}\text { Vorrat } \\
{\left[\mathrm{m}^{3}\right]}\end{array}$ \\
\hline 44 & 6894 & Witów & PL & 1250 & 391 \\
45 & 2131 & Veitsch-Neuberg & $\mathrm{A}$ & 1000 & 389 \\
46 & 6624 & Przysucha & $\mathrm{PL}$ & 275 & 386 \\
47 & 3518 & Suhl, Oberhofer Schloßbergkopf & $\mathrm{D}$ & 900 & 383 \\
48 & 7233 & Wolozin & $\mathrm{SU}$ & 225 & 382 \\
49 & 3601 & Cottbus, Tannenwald 17AB & $\mathrm{D}$ & 80 & 378 \\
50 & 3512 & Peitz/Tannenwald & $\mathrm{D}$ & 60 & 377 \\
51 & 3331 & St. Oswald I/3,4,6 Typengemisch & $\mathrm{D}$ & 1200 & 377 \\
52 & 2179 & Eisenkappel/Karaw. & $\mathrm{A}$ & 800 & 374 \\
53 & 6234 & Białowieża & $\mathrm{PL}$ & 130 & 373 \\
54 & 2133 & Hinterhof, Eibelkogel & $\mathrm{A}$ & 1150 & 370 \\
55 & 6103 & Brotzen/Broczyno & $\mathrm{PL}$ & 140 & 367 \\
56 & 7235 & Brigalovic-Mogilev & $\mathrm{SU}$ & 160 & 364 \\
57 & 3510 & Sonneb. Steinheid, Kieferleskopf & $\mathrm{D}$ & 886 & 362 \\
58 & 2158 & Rohr im Gebirge, Kirchwald & $\mathrm{A}$ & 825 & 359 \\
59 & 6235 & Zwierzyniec & $\mathrm{PL}$ & 150 & 354 \\
60 & 6732 & Szcytna-Slaska Karlow 292 b & $\mathrm{PL}$ & 700 & 352 \\
61 & 107 & Donaueschingen & $\mathrm{D}$ & 650 & 348 \\
62 & 111 & Bodenmais & $\mathrm{D}$ & 1000 & 346 \\
63 & 3102 & Schluchsee-Eschenmoos & $\mathrm{D}$ & 1200 & 342 \\
64 & 7224 & Ostrovskij-Pskow & $\mathrm{SU}$ & 200 & 339 \\
65 & 2138 & Buchberg, Ägidiwald/Aflenz & $\mathrm{A}$ & 925 & 322 \\
66 & 2137 & Buchberg, Flachwald/Aflenz & $\mathrm{A}$ & 1300 & 321 \\
67 & 2207 & Seewiesen Seereith/Aflenz & $\mathrm{A}$ & 875 & 309 \\
68 & 7422 & Rjasan, Moshary & $\mathrm{SU}$ & 150 & 303 \\
69 & 3042 & Walchensee & $\mathrm{D}$ & 1100 & 303 \\
70 & 3139 & Isny Ba/Wü & $\mathrm{D}$ & 850 & 300 \\
71 & 3337 & Rabenstein Typengemisch & $\mathrm{D}$ & 1200 & 298 \\
72 & 3334 & Zwiesel-Ost, V/1,2, Plattenfichten & 1200 & 284 \\
73 & 5102 & Kaludjerske Bore Taram Kremma & $\mathrm{D}$ & 1000 & 275 \\
74 & 2151 & Breitenau-Mixnitz/Fischbacher Alp. & 970 & 273 \\
75 & 5301 & Belogradchik-Tschupreno & 1400 & 221 \\
76 & 5107 & Smrceve Dolina Abt. 138 & HR & 1350 & 163 \\
\hline
\end{tabular}

\section{Anhang 1.18}

Zusammenstellung der mittleren Stammzabl im Alter von 32 und 39 Jahren auf den drei Versuchsflächen Hasbruch / Niedersachsen

Versuchsfläche 44

\begin{tabular}{|c|c|c|c|c|c|c|}
\hline \multirow{2}{*}{$\begin{array}{l}\text { PG- } \\
\text { Nr. }\end{array}$} & \multirow{2}{*}{ Herkunft } & \multirow{2}{*}{ Land } & \multirow{2}{*}{$\begin{array}{l}\text { Höhe } \\
\text { m ü. NN }\end{array}$} & \multicolumn{3}{|c|}{$\begin{array}{c}\text { Stammzahl bei der } \\
\text { Messung }\end{array}$} \\
\hline & & & & $\begin{array}{l}\text { BHD } \\
32-j .\end{array}$ & $\begin{array}{l}\text { Höhe } \\
39-\mathrm{j} .\end{array}$ & $\begin{array}{l}\text { BHD } \\
39-\mathrm{j} .\end{array}$ \\
\hline 41 & Spiegelau & D & 750 & 27 & 7 & 11 \\
\hline 60 & Aflenz & A & 1000 & 28 & 7 & 10 \\
\hline 61 & Gosau & A & 700 & 31 & 4 & 13 \\
\hline 62 & Litschau & A & 600 & 34 & 6 & 9 \\
\hline 63 & Eisenkappel Thurn 1 & A & 850 & 34 & 5 & 12 \\
\hline
\end{tabular}


Versuchsfläche 44

\begin{tabular}{|c|c|c|c|c|c|c|}
\hline \multirow{2}{*}{$\begin{array}{l}\text { PG- } \\
\text { Nr. }\end{array}$} & \multirow{2}{*}{ Herkunft } & \multirow{2}{*}{ Land } & \multirow{2}{*}{$\begin{array}{l}\text { Höhe } \\
\text { m ü. NN }\end{array}$} & \multicolumn{3}{|c|}{$\begin{array}{c}\text { Stammzahl bei der } \\
\text { Messung }\end{array}$} \\
\hline & & & & $\begin{array}{l}\text { BHD } \\
32-j .\end{array}$ & $\begin{array}{l}\text { Höhe } \\
39-j .\end{array}$ & $\begin{array}{l}\text { BHD } \\
39-j .\end{array}$ \\
\hline 64 & St. Martin & A & 500 & 30 & 5 & 9 \\
\hline 66 & Vorau & A & 900 & 35 & 4 & 11 \\
\hline 97 & Gérardmer & $\mathrm{F}$ & 850 & 30 & 7 & 15 \\
\hline 98 & Massif Central & $\mathrm{F}$ & 1100 & 35 & 7 & 15 \\
\hline 103 & Wunsiedel & $\mathrm{D}$ & 900 & 32 & 6 & 12 \\
\hline 110 & Medebach & $\mathrm{D}$ & 600 & 30 & 7 & 10 \\
\hline 114 & Winterberg & $\mathrm{D}$ & 800 & 24 & 5 & 10 \\
\hline 124 & Istebna-Wisła & PL & 725 & 31 & 6 & 12 \\
\hline 130 & Dobra bei Frydek & CS & 550 & 31 & 5 & 11 \\
\hline 131 & Vizovice & CS & 500 & 27 & 6 & 12 \\
\hline 139 & Vapenkova Skala & CS & 540 & 24 & 6 & 8 \\
\hline 140 & Bucovice & CS & 480 & 33 & 6 & 9 \\
\hline 141 & Pitin & CS & 610 & 31 & 8 & 11 \\
\hline 142 & Rosice & CS & 465 & 34 & 6 & 15 \\
\hline 150 & Schlanders & I & 1500 & 30 & 7 & 13 \\
\hline 170 & Groß Arl & A & 1350 & 26 & 7 & 9 \\
\hline 171 & Hofgastein & A & 1100 & 33 & 6 & 12 \\
\hline 174 & Piesendorf & A & 900 & 32 & 6 & 14 \\
\hline 175 & Radstatt & A & 1000 & 30 & 7 & 14 \\
\hline 176 & St. Johann & A & 1200 & 27 & 7 & 13 \\
\hline 177 & Taxenbach & A & 1400 & 25 & 6 & 10 \\
\hline 178 & Abtenau & A & 900 & 29 & 5 & 9 \\
\hline 179 & Bischofshofen & A & 1200 & 29 & 5 & 13 \\
\hline 184 & Paternion & A & 900 & 28 & 6 & 9 \\
\hline 185 & St. Veit/Glan & A & 600 & 33 & 6 & 9 \\
\hline 186 & Graz-Nord & A & 850 & 29 & 7 & 10 \\
\hline 187 & Pack & A & 950 & 29 & 6 & 12 \\
\hline 188 & Waldstein a.d. Übelb. & A & 850 & 34 & 8 & 14 \\
\hline 189 & Graz-Süd & A & 850 & 34 & 6 & 12 \\
\hline 190 & Offenegg & A & 950 & 33 & 7 & 12 \\
\hline 192 & Södingberg & A & 550 & 28 & 7 & 11 \\
\hline 202 & Istebna-Wisła & PL & 725 & 29 & 5 & 6 \\
\hline 204 & Spisske Pochradie & $\mathrm{S}$ & 700 & 26 & 6 & 10 \\
\hline 207 & Jönköpings län & $\mathrm{S}$ & 170 & 33 & 6 & 15 \\
\hline 208 & Istebna & PL & 725 & 21 & 4 & 7 \\
\hline 215 & Stinava & SK & & 32 & 7 & 13 \\
\hline 217 & Istebna-Wisła & PL & 725 & 17 & 4 & 7 \\
\hline 227 & Thüringen & $\mathrm{D}$ & 300 & 34 & 8 & 14 \\
\hline 229 & Olsztyn & PL & 100 & 30 & 6 & 9 \\
\hline 284 & Blekinge län Asarum & $\mathrm{S}$ & 100 & 35 & 5 & 12 \\
\hline 290 & Högestad & S & 50 & 30 & 7 & 13 \\
\hline 291 & Karupsskogen Barsebäcks gods & S & 100 & 35 & 5 & 7 \\
\hline 293 & Trolleholm & S & 125 & 36 & 7 & 11 \\
\hline 294 & Aasbo-össjö Gods & $\mathrm{S}$ & 50 & 35 & 6 & 8 \\
\hline 295 & Öveds Kloster Öpedal & $\mathrm{S}$ & 50 & 30 & 5 & 11 \\
\hline 704 & Cazis Tschartlina & $\mathrm{CH}$ & 750 & 29 & 9 & 17 \\
\hline 711 & La Genolière & $\mathrm{CH}$ & & 34 & 6 & 13 \\
\hline 712 & Forêt du Risoud & $\mathrm{CH}$ & 1100 & 35 & 6 & 10 \\
\hline
\end{tabular}


Versuchsfläche 44

\begin{tabular}{|c|c|c|c|c|c|c|}
\hline \multirow{2}{*}{$\begin{array}{l}\text { PG- } \\
\text { Nr. }\end{array}$} & \multirow{2}{*}{ Herkunft } & \multirow{2}{*}{ Land } & \multirow{2}{*}{$\begin{array}{l}\text { Höhe } \\
\text { m ü. NN }\end{array}$} & \multicolumn{3}{|c|}{$\begin{array}{c}\text { Stammzahl bei der } \\
\text { Messung }\end{array}$} \\
\hline & & & & $\begin{array}{l}\text { BHD } \\
32-j .\end{array}$ & $\begin{array}{l}\text { Höhe } \\
39-j .\end{array}$ & $\begin{array}{l}\text { BHD } \\
39-\mathrm{i} .\end{array}$ \\
\hline 713 & Caragnago & $\mathrm{CH}$ & 1180 & 35 & 6 & 14 \\
\hline 716 & Altacanta & $\mathrm{CH}$ & 1400 & 28 & 6 & 11 \\
\hline 722 & Piana Selva, Faido & $\mathrm{CH}$ & 980 & 35 & 6 & 11 \\
\hline 725 & Airolo, Crespato-Ressia & $\mathrm{CH}$ & 1120 & 26 & 6 & 13 \\
\hline 734 & Airolo, Bedretto & $\mathrm{CH}$ & 1600 & 31 & 7 & 14 \\
\hline 740 & Bex, Tarejanne & $\mathrm{CH}$ & 1600 & 34 & 8 & 16 \\
\hline 1100 & Monts Megal, Le Portius & $\mathrm{F}$ & 900 & 35 & 6 & 10 \\
\hline 1101 & Le Pertuis, Monts du Velay & $\mathrm{F}$ & 1100 & 35 & 4 & 14 \\
\hline 1111 & Peisey-Nancroix, Grd. Bois & $\mathrm{F}$ & 1400 & 30 & 6 & 13 \\
\hline 1112 & Autrans, Isère & $\mathrm{F}$ & 1250 & 29 & 5 & 10 \\
\hline 1114 & Passy & $\mathrm{F}$ & 1200 & 33 & 7 & 21 \\
\hline 1115 & Magland & $\mathrm{F}$ & 700 & 30 & 6 & 9 \\
\hline 1116 & Lantosque & $\mathrm{F}$ & 1500 & 25 & 7 & 13 \\
\hline 1117 & Plan Bois, Ballandes & $\mathrm{F}$ & 500 & 23 & 8 & 14 \\
\hline 1202 & Manderfeld Gilbuschek 63 A & $\mathrm{B}$ & 542 & 29 & 7 & 15 \\
\hline 2113 & Oberes Gailtal & A & 1100 & 24 & 8 & 12 \\
\hline 2114 & Kreuzen-Stockenboi & A & 1200 & 27 & 8 & 17 \\
\hline 2115 & Rosental & A & 1000 & 25 & 8 & 11 \\
\hline 2116 & Aich & A & 700 & 30 & 7 & 13 \\
\hline 2117 & Gurktal & A & 1300 & 29 & 7 & 10 \\
\hline 2120 & Liemberowald Zell a. S. & A & 875 & 24 & 6 & 8 \\
\hline 2121 & Neukirchen Großvenediger & A & 870 & 27 & 6 & 11 \\
\hline 2122 & Piberegg & A & 800 & 29 & 5 & 6 \\
\hline 2123 & Gallmannsegg Kainach & $\mathrm{A}$ & 1100 & 23 & 6 & 11 \\
\hline 2126 & Gaishorn & A & 1200 & 33 & 6 & 12 \\
\hline 2128 & Lobming-Oberth. St. Stefan/Kr & ath A & 800 & 21 & 4 & 5 \\
\hline 2130 & Stanz-Kindthal-Allerheiligen & A & 750 & 26 & 6 & 10 \\
\hline 2140 & Fölz, Mayerberg & A & 950 & 32 & 6 & 6 \\
\hline 2141 & Fölz, Greith & $\mathrm{A}$ & 825 & 25 & 7 & 9 \\
\hline 2144 & Seewiesen, Seereith & A & 875 & 22 & 7 & 9 \\
\hline 2147 & Freiland, Gschwend & A & 1000 & 29 & 6 & 11 \\
\hline 2149 & Kindberg/Eisenerzer Alpen & A & 1000 & 20 & 6 & 11 \\
\hline 2150 & Siebensee Wildalpen & A & 850 & 30 & 8 & 12 \\
\hline 2160 & Turnau, Kapfenberg & A & 1100 & 24 & 5 & 9 \\
\hline 3326 & Neureichenau & $\mathrm{D}$ & 1200 & 32 & 8 & 13 \\
\hline 3328 & Spiegelau & $\mathrm{D}$ & 1200 & 31 & 7 & 10 \\
\hline 3329 & Spiegelau & $\mathrm{D}$ & 1200 & 32 & 7 & 11 \\
\hline 3332 & Zwiesel-Ost & $\mathrm{D}$ & 1000 & 33 & 6 & 10 \\
\hline 3406 & SHK Stryck Willingen & $\mathrm{D}$ & 550 & 27 & 7 & 8 \\
\hline 3410 & Traunstein & $\mathrm{D}$ & 850 & 32 & 6 & 10 \\
\hline 3411 & Bischofswiesen & $\mathrm{D}$ & 950 & 25 & 7 & 10 \\
\hline 3412 & Winterberg & $\mathrm{D}$ & 750 & 20 & 6 & 7 \\
\hline 3413 & SHK Winterberg & $\mathrm{D}$ & 750 & 28 & 6 & 8 \\
\hline 3415 & SHK Hochsauerland & $\mathrm{D}$ & 600 & 34 & 4 & 8 \\
\hline 3416 & SHK Höhenfichten & $\mathrm{D}$ & 1050 & 30 & 6 & 9 \\
\hline 3417 & Marsberg & $\mathrm{D}$ & 500 & 23 & 6 & 13 \\
\hline 3418 & Sachsenried & $\mathrm{D}$ & 900 & 32 & 8 & 11 \\
\hline 3419 & Schwarzwald Baar, VIII/6 & $\mathrm{D}$ & 700 & 27 & 7 & 10 \\
\hline
\end{tabular}


Versuchsfläche 44

\begin{tabular}{|c|c|c|c|c|c|c|}
\hline \multirow{2}{*}{$\begin{array}{l}\text { PG- } \\
\text { Nr. }\end{array}$} & \multirow{2}{*}{ Herkunft } & \multirow{2}{*}{ Land } & \multirow{2}{*}{$\begin{array}{l}\text { Höhe } \\
\text { m ü. NN }\end{array}$} & \multicolumn{3}{|c|}{$\begin{array}{c}\text { Stammzahl bei der } \\
\text { Messung }\end{array}$} \\
\hline & & & & $\begin{array}{l}\text { BHD } \\
32-j .\end{array}$ & $\begin{array}{c}\text { Höhe } \\
39-\mathrm{j} .\end{array}$ & $\begin{array}{l}\text { BHD } \\
39-j .\end{array}$ \\
\hline 3420 & Daun/Ost & D & 450 & 34 & 7 & 11 \\
\hline 3421 & Dombühl & $\mathrm{D}$ & 450 & 34 & 5 & 10 \\
\hline 3422 & Stryck & $\mathrm{D}$ & 650 & 32 & 5 & 8 \\
\hline 3423 & Kohlstetten & $\mathrm{D}$ & 750 & 33 & 6 & 14 \\
\hline 3424 & Winterberg & $\mathrm{D}$ & 450 & 32 & 6 & 10 \\
\hline 3425 & Waldmünchen & $\mathrm{D}$ & 850 & 23 & 5 & 6 \\
\hline 3426 & Uelzen & $\mathrm{D}$ & 50 & 23 & 5 & 6 \\
\hline 3427 & Oderhaus & $\mathrm{D}$ & 650 & 34 & 8 & 10 \\
\hline 3428 & Schernfeld & $\mathrm{D}$ & 450 & 20 & 5 & 7 \\
\hline 3429 & Villingen & $\mathrm{D}$ & 850 & 28 & 6 & 9 \\
\hline 3430 & Diessen & $\mathrm{D}$ & 850 & 31 & 7 & 13 \\
\hline 3431 & Riedenburg & $\mathrm{D}$ & 500 & 35 & 7 & 13 \\
\hline 3432 & Walsrode & $\mathrm{D}$ & 30 & 29 & 6 & 8 \\
\hline 3433 & Selb-Kirchenlamitz (1) & $\mathrm{D}$ & 800 & 32 & 6 & 9 \\
\hline 3434 & Miele & $\mathrm{D}$ & 90 & 34 & 6 & 14 \\
\hline 3435 & Neureichenau (2) & $\mathrm{D}$ & 1050 & 33 & 8 & 14 \\
\hline 3436 & Neureichenau (2) & $\mathrm{D}$ & 1050 & 29 & 6 & 10 \\
\hline 3437 & Neureichenau (2) & $\mathrm{D}$ & 1050 & 36 & 8 & 14 \\
\hline 3438 & Oderhaus & $\mathrm{D}$ & 650 & 29 & 9 & 10 \\
\hline 3444 & Zwiesel, Scheicherau XXI 14a/b $(3,6)$ & $\mathrm{D}$ & 650 & 28 & 7 & 13 \\
\hline 3445 & Zwiesel, Haselau XXI $12(3,6)$ & $\mathrm{D}$ & 650 & 31 & 5 & 6 \\
\hline 3447 & Nationalp. Hüttenschlag XIX 1b (6) & $\mathrm{D}$ & 750 & 31 & 6 & 8 \\
\hline 3448 & Nationalp. Filzwald IX 3a 10/11 (6) & $\mathrm{D}$ & 750 & 29 & 6 & 9 \\
\hline 3449 & Nationalp. Neubruck 1a10,b10/11,c10 (6) & (6) $\mathrm{D}$ & 740 & 34 & 6 & 15 \\
\hline 3498 & Burgjoß & $\mathrm{D}$ & 450 & 28 & 8 & 11 \\
\hline 3499 & Chausseehaus & $\mathrm{D}$ & & 32 & 8 & 15 \\
\hline 3505 & Eibenst. Carlsf. 275 & $\mathrm{D}$ & 925 & 27 & 2 & 5 \\
\hline 3617 & Torgelow & $\mathrm{D}$ & 100 & 28 & 6 & 11 \\
\hline 4011 & Cikaaj, Zdarska Vrchy & CS & 655 & 29 & 5 & 12 \\
\hline 4032 & Kynsperk nad Ohri Libocky Dul & CS & 650 & 27 & 4 & 9 \\
\hline 4042 & Vimperk-Prameny Vltury Stachy & CS & 950 & 25 & 9 & 13 \\
\hline 4061 & Velke Mezirici-Rudolec & CS & 630 & 29 & 6 & 9 \\
\hline 4081 & Frenstat pod Radhosten-Obora & CS & 600 & 32 & 5 & 10 \\
\hline 4082 & Ostravice & CS & 800 & 26 & 7 & 10 \\
\hline 4103 & Tatranska Lesna 559 C & CS & 950 & 27 & 6 & 11 \\
\hline 4121 & Javorova Dolina 155 A, Nr. 4121 & CS & 1200 & 36 & 6 & 16 \\
\hline 4143 & Kysihybel & CS & 540 & 24 & 6 & 10 \\
\hline 4154 & Roznava & CS & 800 & 22 & 7 & 10 \\
\hline 4157 & Hnusta & CS & 550 & 11 & 3 & 6 \\
\hline 4159 & Svrcina Hrabusice & CS & 900 & 19 & 3 & 8 \\
\hline 5101 & Nedzinant, Prokletije (Geb.) & YU & 1150 & 16 & 5 & 9 \\
\hline 5201 & Köszeg 1 C & $\mathrm{H}$ & 870 & 34 & 6 & 12 \\
\hline 5202 & Szentgotthard $1 \mathrm{C}$ & $\mathrm{H}$ & 310 & 19 & 6 & 8 \\
\hline 5203 & Sarospatak-Haromhuta 19 B Zempl.Geb. & b. $\mathrm{H}$ & 405 & 19 & 6 & 7 \\
\hline 5204 & Miskolc-Lillafüred 82 A Bükker Geb. & $\mathrm{H}$ & 730 & 16 & 6 & 10 \\
\hline 5205 & Nagykanizsa-Iharos Plattensee 11/1-71 & $\mathrm{H}$ & 200 & 30 & 7 & 10 \\
\hline 5206 & Sopron (Hochschulrev.) 203 D & $\mathrm{H}$ & 425 & 30 & 5 & 13 \\
\hline 5302 & Beglika & BG & 1850 & 32 & 8 & 17 \\
\hline
\end{tabular}


Versuchsfläche 44

\begin{tabular}{|c|c|c|c|c|c|c|}
\hline \multirow{2}{*}{$\begin{array}{l}\text { PG- } \\
\text { Nr. }\end{array}$} & \multirow{2}{*}{ Herkunft } & \multirow{2}{*}{ Land } & \multirow{2}{*}{$\begin{array}{l}\text { Höhe } \\
\text { m ü. NN }\end{array}$} & \multicolumn{3}{|c|}{$\begin{array}{c}\text { Stammzahl bei der } \\
\text { Messung }\end{array}$} \\
\hline & & & & $\begin{array}{l}\text { BHD } \\
32-j .\end{array}$ & $\begin{array}{l}\text { Höhe } \\
39-j .\end{array}$ & $\begin{array}{l}\text { BHD } \\
39-j .\end{array}$ \\
\hline 5303 & Borovec (Rila-Geb.) & BG & 1300 & 21 & 4 & 7 \\
\hline 5401 & Valea Putnei-Pojorita & RU & 1085 & 31 & 8 & 8 \\
\hline 5413 & Brosteni Bradu/Bastitei & RU & 1475 & 29 & 7 & 10 \\
\hline 6106 & Köslin/Koszalin & PL & 50 & 31 & 7 & 11 \\
\hline 6223 & Przerwanki & PL & 150 & 28 & 6 & 13 \\
\hline 6237 & Puszcza-Białowieska & PL & 130 & 20 & 7 & 12 \\
\hline 6250 & Augustow Abt. 95 b & PL & 120 & 24 & 5 & 7 \\
\hline 6254 & Mikaszowka & PL & 120 & 27 & 6 & 10 \\
\hline 6255 & Puszcza-Augustowska & PL & 125 & 30 & 6 & 13 \\
\hline 6260 & Knyszyn & PL & 150 & 22 & 7 & 9 \\
\hline 6261 & Kumialka (Kumialska) & PL & 160 & 24 & 7 & 7 \\
\hline 6410 & Sierpc & PL & 110 & 14 & 2 & 4 \\
\hline 6896 & Borken & PL & 165 & 36 & 7 & 18 \\
\hline 7401 & Gzatsk-Smolensk & SU & 194 & 28 & 5 & 9 \\
\hline 8703 & Lohja Laaskspohjan & $\mathrm{SF}$ & 50 & 34 & 6 & 13 \\
\hline 9170 & Ryssby-Kronobergs & $\mathrm{S}$ & 175 & 32 & 6 & 16 \\
\hline 9417 & Marsberg & $\mathrm{D}$ & 500 & 34 & 6 & 10 \\
\hline 9423 & Kohlstetten & $\mathrm{D}$ & 750 & 29 & 6 & 11 \\
\hline 9432 & Walsrode & $\mathrm{D}$ & 30 & 34 & 7 & 9 \\
\hline
\end{tabular}

Versuchsfläche 45

\begin{tabular}{|c|c|c|c|c|c|c|}
\hline \multirow{2}{*}{$\begin{array}{l}\text { PG- } \\
\text { Nr. }\end{array}$} & \multirow{2}{*}{ Herkunft } & \multirow{2}{*}{ Land } & \multirow{2}{*}{$\begin{array}{l}\text { Höhe } \\
\text { m ü. NN }\end{array}$} & \multicolumn{3}{|c|}{$\begin{array}{c}\text { Stammzahl bei der } \\
\text { Messung }\end{array}$} \\
\hline & & & & $\begin{array}{l}\text { BHD } \\
32-j .\end{array}$ & $\begin{array}{l}\text { Höhe } \\
39-j .\end{array}$ & $\begin{array}{l}\text { BHD } \\
39-j .\end{array}$ \\
\hline 107 & Donaueschingen & $\mathrm{D}$ & 650 & 33 & 7 & 9 \\
\hline 111 & Bodenmais & $\mathrm{D}$ & 1000 & 34 & 8 & 12 \\
\hline 115 & Westerhof & $\mathrm{D}$ & 200 & 30 & 7 & 8 \\
\hline 121 & Cedrogne & $\mathrm{B}$ & 500 & 26 & 8 & 9 \\
\hline 129 & Allenstein & PL & 100 & 30 & 6 & 11 \\
\hline 149 & Einsiedeln & $\mathrm{CH}$ & 900 & 28 & 7 & 9 \\
\hline 2118 & Gurker Sirnitzwald & A & 900 & 32 & 6 & 8 \\
\hline 2131 & Veitsch-Neuberg & A & 1000 & 24 & 5 & 8 \\
\hline 2133 & Hinterhof, Eibelkogel & A & 1150 & 28 & 4 & 5 \\
\hline 2134 & Hinterhof, Ostbrenner u. Tiefental & A & 1000 & 33 & 4 & 11 \\
\hline 2135 & Kraubath, Seckauer Tauern & A & 1050 & 30 & 5 & 7 \\
\hline 2137 & Buchberg, Flachwald/Aflenz & A & 1300 & 33 & 4 & 6 \\
\hline 2138 & Buchberg, Ägidiwald/Aflenz & A & 925 & 30 & 4 & 5 \\
\hline 2151 & Breitenau-Mixnitz/Fischbacher Alp. & A & 970 & 34 & 5 & 7 \\
\hline 2158 & Rohr im Gebirge, Kirchwald & A & 825 & 28 & 8 & 12 \\
\hline 2179 & Eisenkappel/Karaw. & A & 800 & 35 & 7 & 10 \\
\hline 2184 & Schneegattern & A & 750 & 28 & 5 & 6 \\
\hline 2207 & Seewiesen Seereith/Aflenz & A & 875 & 27 & 2 & 3 \\
\hline 3003 & Blumberg & $\mathrm{D}$ & 800 & 35 & 5 & 6 \\
\hline 3042 & Walchensee & $\mathrm{D}$ & 1100 & 30 & 4 & 9 \\
\hline
\end{tabular}


Versuchsfläche 45

\begin{tabular}{|c|c|c|c|c|c|c|}
\hline \multirow{2}{*}{$\begin{array}{l}\text { PG- } \\
\text { Nr. }\end{array}$} & \multirow{2}{*}{ Herkunft } & \multirow{2}{*}{ Land } & \multirow{2}{*}{$\begin{array}{l}\text { Höhe } \\
\text { m ü. NN }\end{array}$} & \multicolumn{3}{|c|}{$\begin{array}{c}\text { Stammzahl bei der } \\
\text { Messung }\end{array}$} \\
\hline & & & & $\begin{array}{l}\text { BHD } \\
32-j .\end{array}$ & $\begin{array}{l}\text { Höhe } \\
39-j .\end{array}$ & $\begin{array}{l}\text { BHD } \\
39-j .\end{array}$ \\
\hline 3102 & Schluchsee-Eschenmoos & $\mathrm{D}$ & 1200 & 30 & 5 & 9 \\
\hline 3139 & Isny $\mathrm{Ba} / \mathrm{Wü}$ & $\mathrm{D}$ & 850 & 31 & 4 & 7 \\
\hline 3204 & Burghausen/Salzach & $\mathrm{D}$ & 400 & 27 & 6 & 7 \\
\hline 3205 & Ebersberg & $\mathrm{D}$ & 555 & 29 & 6 & 6 \\
\hline 3211 & Moosburg/Isar & $\mathrm{D}$ & 500 & 25 & 6 & 8 \\
\hline 3310 & Zwiesel-West/Ruselhänge X/68 & $\mathrm{D}$ & 750 & 33 & 7 & 12 \\
\hline 3323 & Mauth/Ost & $\mathrm{D}$ & 1000 & 29 & 7 & 9 \\
\hline 3325 & Neureichenau/Typengemisch & $\mathrm{D}$ & 1000 & 32 & 6 & 7 \\
\hline 3327 & Passau/Nord & $\mathrm{D}$ & 1000 & 33 & 6 & 9 \\
\hline 3331 & St. Oswald I/3,4,6 Typengemisch & $\mathrm{D}$ & 1200 & 35 & 3 & 4 \\
\hline 3337 & Rabenstein Typengemisch & $\mathrm{D}$ & 1200 & 29 & 7 & 7 \\
\hline 3404 & Westerhof Abt. 51 B & $\mathrm{D}$ & 200 & 32 & 8 & 9 \\
\hline 3417 & Marsberg & $\mathrm{D}$ & 500 & 27 & 5 & 6 \\
\hline 3423 & Kohlstetten & $\mathrm{D}$ & 750 & 27 & 5 & 5 \\
\hline 3430 & Diessen & $\mathrm{D}$ & 850 & 27 & 8 & 11 \\
\hline 3432 & Walsrode & $\mathrm{D}$ & 30 & 35 & 5 & 10 \\
\hline 3433 & Selb-Kirchenlamitz (1) & $\mathrm{D}$ & 800 & 30 & 5 & 10 \\
\hline 3443 & Zwiesel, Scheichereb. XXI 13b1 $(3,6)$ & $\mathrm{D}$ & 650 & 32 & 7 & 9 \\
\hline 3503 & Eibenst. Carlsf. Wiesenh. 214 & $\mathrm{D}$ & 720 & 26 & 3 & 4 \\
\hline 3510 & Sonneb. Steinheid, Kieferleskopf & $\mathrm{D}$ & 886 & 35 & 6 & 11 \\
\hline 3511 & Innenau Elgersburg & $\mathrm{D}$ & 800 & 28 & 7 & 9 \\
\hline 3518 & Suhl, Oberhofer Schloßbergkopf & $\mathrm{D}$ & 900 & 32 & 6 & 7 \\
\hline 3519 & Mechterstädt & $\mathrm{D}$ & 200 & 33 & 8 & 11 \\
\hline 3606 & Templin, Bad Doberan Nr. 9 & $\mathrm{D}$ & 50 & 34 & 8 & 14 \\
\hline 3615 & Neustrelitz & $\mathrm{D}$ & 100 & 27 & 6 & 7 \\
\hline 4022 & Boubin III & CS & 1000 & 31 & 6 & 10 \\
\hline 4026 & Habartice, Planice & CS & 550 & 27 & 5 & 6 \\
\hline 4051 & Vysoky Chlumec Veletin & CS & 600 & 33 & 6 & 14 \\
\hline 4053 & Cesky Krumlov Borova & CS & 800 & 27 & 6 & 11 \\
\hline 4054 & Chlum u. Trebone-Hamr & CS & 450 & 29 & 6 & 10 \\
\hline 4060 & Hencov-Trest & CS & 600 & 32 & 6 & 9 \\
\hline 4070 & Vrchlabi & CS & 700 & 31 & 6 & 9 \\
\hline 4073 & Jesenik-Zlate Hory & CS & 820 & 30 & 8 & 11 \\
\hline 4123 & Javorova Dolina 155 A, Nr.4123 & CS & 1200 & 22 & 3 & 4 \\
\hline 5102 & Kaludjerske Bore Taram Kremma & YU & 1000 & 30 & 6 & 7 \\
\hline 5107 & Smrceve Dolina Abt. 138 & HR & 1350 & 36 & 6 & 14 \\
\hline 5301 & Belogradchik-Tschupreno & BG & 1400 & 32 & 8 & 11 \\
\hline 5412 & Moldovita-Sacries & RU & 825 & 27 & 5 & 7 \\
\hline 5415 & Cimpeni-Dara & RU & 1260 & 28 & 6 & 10 \\
\hline 5416 & Remeti-Zerna & RU & 900 & 25 & 4 & 5 \\
\hline 5420 & Valea Putnei-Pojorita III/60 & RU & 1285 & 29 & 7 & 9 \\
\hline 5426 & Crucea-Barnavel Abt. 17/18 & RU & 740 & 29 & 5 & 9 \\
\hline 6103 & Brotzen/Broczyno & PL & 140 & 33 & 5 & 7 \\
\hline 6222 & Borken/Borki & PL & 160 & 28 & 7 & 10 \\
\hline 6234 & Białowieża & PL & 130 & 26 & 6 & 10 \\
\hline 6235 & Zwierzyniec & PL & 150 & 29 & 4 & 5 \\
\hline 6251 & Białobrzegi & PL & 110 & 29 & 7 & 7 \\
\hline 6510 & Bunzlau/Boleslawiec & PL & 175 & 28 & 7 & 9 \\
\hline
\end{tabular}


Versuchsfläche 45

\begin{tabular}{|c|c|c|c|c|c|c|}
\hline \multirow{2}{*}{$\begin{array}{l}\text { PG- } \\
\text { Nr. }\end{array}$} & \multirow{2}{*}{ Herkunft } & \multirow{2}{*}{ Land } & \multirow{2}{*}{$\begin{array}{l}\text { Höhe } \\
\text { m ü. NN }\end{array}$} & \multicolumn{3}{|c|}{$\begin{array}{c}\text { Stammzahl bei der } \\
\text { Messung }\end{array}$} \\
\hline & & & & $\begin{array}{l}\text { BHD } \\
32-j .\end{array}$ & $\begin{array}{l}\text { Höhe } \\
39-j .\end{array}$ & $\begin{array}{l}\text { BHD } \\
39-j .\end{array}$ \\
\hline 6543 & Groß-Lassowitz/Lassowice Male & PL & 175 & 35 & 6 & 7 \\
\hline 6624 & Przysucha & PL & 275 & 28 & 4 & 4 \\
\hline 6712 & Klodzko-Glatz/Nynow $68 \mathrm{e}$ & PL & 340 & 32 & 4 & 11 \\
\hline 6731 & Szcytna-Slaska Karlow 243 a & PL & 750 & 30 & 7 & 11 \\
\hline 6732 & Szcytna-Slaska Karlow 292 b & PL & 700 & 32 & 7 & 8 \\
\hline 6864 & Istebna-Ujsoly & PL & 750 & 24 & 5 & 6 \\
\hline 6894 & Witów & PL & 1250 & 26 & 6 & 8 \\
\hline 7224 & Ostrovskij-Pskow & SU & 200 & 32 & 6 & 8 \\
\hline 7233 & Wolozin & SU & 225 & 28 & 7 & 9 \\
\hline 7235 & Brigalovic-Mogilev & $\mathrm{SU}$ & 160 & 28 & 8 & 14 \\
\hline 8003 & Fussinge & DK & 45 & 34 & 5 & 8 \\
\hline 8705 & Mänttä & $\mathrm{SF}$ & 120 & 29 & 7 & 12 \\
\hline 8707 & Janakkala Keskivari Uhkoila & $\mathrm{SF}$ & 100 & 26 & 8 & 13 \\
\hline
\end{tabular}

Versuchsfläche 46

\begin{tabular}{|c|c|c|c|c|c|c|}
\hline \multirow{2}{*}{$\begin{array}{l}\text { PG- } \\
\text { Nr. }\end{array}$} & \multirow{2}{*}{ Herkunft } & \multirow{2}{*}{ Land } & \multirow{2}{*}{$\begin{array}{l}\text { Höhe } \\
\text { m ü. NN }\end{array}$} & \multicolumn{3}{|c|}{$\begin{array}{c}\text { Stammzahl bei der } \\
\text { Messung }\end{array}$} \\
\hline & & & & $\begin{array}{l}\text { BHD } \\
32-j .\end{array}$ & $\begin{array}{c}\text { Höhe } \\
39-\text { i. }\end{array}$ & $\begin{array}{l}\text { BHD } \\
39-j .\end{array}$ \\
\hline 65 & Eisenkappel Thurn 2 & A & 850 & 35 & 8 & 15 \\
\hline 93 & Sieber & $\mathrm{D}$ & 400 & 32 & 7 & 8 \\
\hline 105 & Hohenschwangau & $\mathrm{D}$ & 800 & 33 & 5 & 11 \\
\hline 108 & Lauterberg & $\mathrm{D}$ & 700 & 34 & 6 & 10 \\
\hline 116 & Kobernausserwald & A & 600 & 34 & 5 & 9 \\
\hline 169 & Gries & A & 1300 & 35 & 9 & 14 \\
\hline 172 & Mittersill & A & 900 & 29 & 6 & 9 \\
\hline 191 & Passail & A & 900 & 31 & 6 & 10 \\
\hline 230 & Elbingerode & $\mathrm{D}$ & 550 & 27 & 5 & 7 \\
\hline 1118 & Chatel, 1 Aity" & $\mathrm{F}$ & 1250 & 35 & 5 & 10 \\
\hline 1201 & Mellier, Bois Bayai, 2 & B & 400 & 33 & 4 & 6 \\
\hline 2124 & Stixenstein, Gahns & A & 1200 & 31 & 7 & 9 \\
\hline 2127 & Unterhal, St. Kathrein a.d. Lamming & A & 800 & 33 & 6 & 14 \\
\hline 2174 & Klein-Sölk/Niedertauern & A & 1250 & 30 & 7 & 9 \\
\hline 3150 & Dillingen a.d.D. Bay. & $\mathrm{D}$ & 500 & 33 & 7 & 11 \\
\hline 3206 & Eglharting XIV/17,19 & $\mathrm{D}$ & 580 & 25 & 6 & 9 \\
\hline 3213 & Mühldorf/Inn & $\mathrm{D}$ & 440 & 34 & 6 & 10 \\
\hline 3414 & Bodensee Oberschwab. VIII/13 & $\mathrm{D}$ & 650 & 35 & 7 & 11 \\
\hline 3417 & Marsberg & $\mathrm{D}$ & 500 & 30 & 4 & 4 \\
\hline 3423 & Kohlstetten & $\mathrm{D}$ & 750 & 25 & 4 & 5 \\
\hline 3430 & Diessen & $\mathrm{D}$ & 850 & 30 & 8 & 11 \\
\hline 3432 & Walsrode & $\mathrm{D}$ & 30 & 29 & 3 & 3 \\
\hline 3433 & Selb-Kirchenlamitz (1) & $\mathrm{D}$ & 800 & 36 & 5 & 9 \\
\hline 3446 & Zwiesel, Schmalzau IX 3c $(5,6)$ & $\mathrm{D}$ & 620 & 34 & 8 & 10 \\
\hline 4050 & Vlasim-Votice & CS & 600 & 28 & 5 & 6 \\
\hline 4075 & Vitkov-Budisov & CS & 610 & 34 & 5 & 12 \\
\hline
\end{tabular}


Versuchsfläche 46

\begin{tabular}{|c|c|c|c|c|c|c|}
\hline \multirow{2}{*}{$\begin{array}{l}\text { PG- } \\
\text { Nr. }\end{array}$} & \multirow{2}{*}{ Herkunft } & \multirow{2}{*}{ Land } & \multirow{2}{*}{$\begin{array}{l}\text { Höhe } \\
\text { m ü. NN }\end{array}$} & \multicolumn{3}{|c|}{$\begin{array}{c}\text { Stammzahl bei der } \\
\text { Messung }\end{array}$} \\
\hline & & & & $\begin{array}{l}\text { BHD } \\
32-j .\end{array}$ & $\begin{array}{l}\text { Höhe } \\
39-j .\end{array}$ & $\begin{array}{l}\text { BHD } \\
39-j .\end{array}$ \\
\hline 4127 & Javorova Dolina 155 A, Nr.4127 & CS & 1200 & 31 & 7 & 7 \\
\hline 5424 & Valea Beliei-Sinaia Gurguiata & RU & 1115 & 36 & 4 & 10 \\
\hline 5425 & Cimpeni-Nedei & RU & 1400 & 30 & 7 & 11 \\
\hline 6107 & Altenhagen/Nowy Krakow & PL & 200 & 35 & 4 & 7 \\
\hline 6236 & Białowieża & PL & 150 & 32 & 6 & 8 \\
\hline 6897 & Goldap & PL & 175 & 33 & 7 & 10 \\
\hline 7232 & Cemerjanskoe-Mogilev & SU & 175 & 35 & 4 & 6 \\
\hline 7234 & Soboljanskoe-Grodno & SU & 150 & 26 & 5 & 9 \\
\hline 7240 & Witebsk & SU & 150 & 34 & 6 & 11 \\
\hline 9191 & Karlsholms-Kristianstad & $\mathrm{S}$ & 20 & 35 & 8 & 12 \\
\hline
\end{tabular}

\section{Anhang 1.19}

Zusammenstellung der mittleren Ovalitäten [\%] im Alter von 32 und 39 Jahren sowie des H/D-Verbältnisses im Alter von 39 Jahren auf den drei Versuchsflächen Hasbruch / Niedersachsen

Versuchsfläche 44

\begin{tabular}{rl|r|r|rc|c}
\hline $\begin{array}{c}\text { PG- } \\
\text { Nr. }\end{array}$ & Herkunft & \multirow{2}{*}{ Land } & Höhe & \multicolumn{2}{|c|}{ Ovalität } & HD \\
\hline 41 & Spiegelau & D N & $32-j$. & $39-j$. & $39-j$. \\
60 & Aflenz & D & 750 & 2.3 & 3.9 & 82 \\
61 & Gosau & A & 1000 & 4.3 & 3.5 & 80 \\
62 & Litschau & A & 700 & 3.2 & 2.8 & 72 \\
63 & Eisenkappel Thurn 1 & A & 600 & 2.7 & 1.9 & 80 \\
64 & St. Martin & A & 850 & 4.0 & 2.3 & 70 \\
66 & Vorau & A & 500 & 4.2 & 4.5 & 70 \\
97 & Gérardmer & A & 900 & 3.3 & 1.9 & 72 \\
98 & Massif Central & F & 850 & 2.5 & 2.2 & 75 \\
103 & Wunsiedel & F & 1100 & 3.5 & 2.9 & 72 \\
110 & Medebach & D & 900 & 3.3 & 3.4 & 66 \\
114 & Winterberg & D & 600 & 2.7 & 2.1 & 73 \\
124 & Istebna-Wisła & D & 800 & 2.6 & 3.8 & 75 \\
130 & Dobra bei Frydek & PL & 725 & 2.4 & 2.1 & 83 \\
131 & Vizovice & CS & 550 & 3.6 & 3.7 & 66 \\
139 & Vapenkova Skala & CS & 500 & 3.0 & 3.5 & 64 \\
140 & Bucovice & CS & 540 & 3.6 & 2.2 & 71 \\
141 & Pitin & CS & 480 & 2.8 & 2.3 & 74 \\
142 & Rosice & CS & 610 & 3.9 & 4.3 & 68 \\
150 & Schlanders & CS & 465 & 2.9 & 3.3 & 71 \\
170 & Groß Arl & I & 1500 & 3.0 & 4.3 & 76 \\
171 & Hofgastein & A & 1350 & 3.6 & 6.9 & 70 \\
174 & Piesendorf & A & 1100 & 3.3 & 2.9 & 65 \\
175 & Radstatt & A & 900 & 2.6 & 1.7 & 74 \\
176 & St. Johann & A & 1000 & 3.3 & 2.3 & 74 \\
177 & Taxenbach & A & 1200 & 2.5 & 2.7 & 71 \\
178 & Abtenau & A & 1400 & 4.5 & 3.6 & 76 \\
& & A & 900 & 3.5 & 11.0 & 76
\end{tabular}


Versuchsfläche 44

\begin{tabular}{|c|c|c|c|c|c|c|}
\hline \multirow{2}{*}{$\begin{array}{l}\text { PG- } \\
\text { Nr. }\end{array}$} & \multirow{2}{*}{ Herkunft } & \multirow{2}{*}{ Land } & \multirow{2}{*}{$\begin{array}{c}\text { Höhe } \\
\text { m ü. NN }\end{array}$} & \multicolumn{2}{|c|}{ Ovalität } & \multirow{2}{*}{$\begin{array}{l}\text { HD } \\
39-j .\end{array}$} \\
\hline & & & & $32-j$. & $39-\mathrm{j}$. & \\
\hline 179 & Bischofshofen & A & 1200 & 3.2 & 2.9 & 82 \\
\hline 184 & Paternion & A & 900 & 2.8 & 3.9 & 72 \\
\hline 185 & St. Veit/Glan & A & 600 & 3.4 & 3.2 & 82 \\
\hline 186 & Graz-Nord & A & 850 & 3.2 & 4.0 & 74 \\
\hline 187 & Pack & A & 950 & 2.8 & 3.0 & 82 \\
\hline 188 & Waldstein a.d. Übelb. & A & 850 & 2.7 & 3.3 & 74 \\
\hline 189 & Graz-Süd & A & 850 & 3.0 & 3.4 & 81 \\
\hline 190 & Offenegg & A & 950 & 2.8 & 2.2 & 82 \\
\hline 192 & Södingberg & A & 550 & 3.4 & 3.7 & 80 \\
\hline 202 & Istebna-Wisła & PL & 725 & 5.3 & 3.5 & 80 \\
\hline 204 & Spisske Pochradie & CS & 700 & 4.2 & 5.2 & 77 \\
\hline 207 & Jönköpings län & $\mathrm{S}$ & 170 & 2.3 & 3.3 & 82 \\
\hline 208 & Istebna & PL & 725 & 3.0 & 3.4 & 72 \\
\hline 215 & Stinava & SK & . & 2.9 & 2.7 & 71 \\
\hline 217 & Istebna-Wisła & PL & 725 & 2.5 & 1.8 & 72 \\
\hline 227 & Thüringen & $\mathrm{D}$ & 300 & 2.7 & 3.6 & 75 \\
\hline 229 & Olsztyn & PL & 100 & 2.5 & 2.8 & 82 \\
\hline 284 & Blekinge län Asarum & $\mathrm{S}$ & 100 & 2.5 & 1.7 & 86 \\
\hline 290 & Högestad & $\mathrm{S}$ & 50 & 3.2 & 2.2 & 72 \\
\hline 291 & Karupsskogen Barsebäcks gods & $\mathrm{S}$ & 100 & 2.6 & 3.3 & 72 \\
\hline 293 & Trolleholm & $\mathrm{S}$ & 125 & 3.4 & 3.3 & 81 \\
\hline 294 & Aasbo-össjö Gods & $\mathrm{S}$ & 50 & 3.9 & 3.5 & 83 \\
\hline 295 & Öveds Kloster Öpedal & $\mathrm{S}$ & 50 & 3.2 & 2.2 & 86 \\
\hline 704 & Cazis Tschartlina & $\mathrm{CH}$ & 750 & 3.0 & 2.8 & 86 \\
\hline 711 & La Genolière & $\mathrm{CH}$ & & 3.2 & 3.0 & 78 \\
\hline 712 & Forêt du Risoud & $\mathrm{CH}$ & 1100 & 2.2 & 2.1 & 81 \\
\hline 713 & Caragnago & $\mathrm{CH}$ & 1180 & 2.8 & 2.7 & 71 \\
\hline 716 & Altacanta & $\mathrm{CH}$ & 1400 & 3.1 & 2.0 & 73 \\
\hline 722 & Piana Selva, Faido & $\mathrm{CH}$ & 980 & 2.9 & 2.2 & 71 \\
\hline 725 & Airolo, Crespato-Ressia & $\mathrm{CH}$ & 1120 & 3.0 & 3.3 & 75 \\
\hline 734 & Airolo, Bedretto & $\mathrm{CH}$ & 1600 & 2.7 & 1.3 & 79 \\
\hline 740 & Bex, Tarejanne & $\mathrm{CH}$ & 1600 & 2.9 & 2.5 & 79 \\
\hline 1100 & Monts Megal, Le Portius & $\mathrm{F}$ & 900 & 3.8 & 4.9 & 77 \\
\hline 1101 & Le Pertuis, Monts du Velay & $\mathrm{F}$ & 1100 & 2.9 & 2.2 & 74 \\
\hline 1111 & Peisey-Nancroix, Grd. Bois & $\mathrm{F}$ & 1400 & 3.8 & 3.3 & 86 \\
\hline 1112 & Autrans, Isère & $\mathrm{F}$ & 1250 & 3.3 & 3.2 & 68 \\
\hline 1114 & Passy & $\mathrm{F}$ & 1200 & 3.1 & 2.4 & 66 \\
\hline 1115 & Magland & $\mathrm{F}$ & 700 & 4.0 & 2.8 & 77 \\
\hline 1116 & Lantosque & $\mathrm{F}$ & 1500 & 3.7 & 4.1 & 67 \\
\hline 1117 & Plan Bois, Ballandes & $\mathrm{F}$ & 500 & 2.9 & 2.4 & 66 \\
\hline 1202 & Manderfeld Gilbuschek 63 A & $\mathrm{B}$ & 542 & 2.7 & 2.1 & 71 \\
\hline 2113 & Oberes Gailtal & A & 1100 & 2.3 & 4.1 & 85 \\
\hline 2114 & Kreuzen-Stockenboi & A & 1200 & 3.3 & 2.7 & 78 \\
\hline 2115 & Rosental & A & 1000 & 4.2 & 2.4 & 84 \\
\hline 2116 & Aich & A & 700 & 3.6 & 3.0 & 84 \\
\hline 2117 & Gurktal & $\mathrm{A}$ & 1300 & 2.7 & 3.1 & 78 \\
\hline 2120 & Liembergwald Zell a. S. & A & 875 & 3.6 & 3.7 & 76 \\
\hline 2121 & Neukirchen Großvenediger & A & 870 & 3.1 & 3.7 & 73 \\
\hline 2122 & Piberegg & A & 800 & 2.8 & 2.9 & 74 \\
\hline 2123 & Gallmannsegg Kainach & A & 1100 & 3.0 & 2.0 & 80 \\
\hline
\end{tabular}


Versuchsfläche 44

\begin{tabular}{|c|c|c|c|c|c|c|}
\hline \multirow{2}{*}{$\begin{array}{l}\text { PG- } \\
\text { Nr. }\end{array}$} & \multirow{2}{*}{ Herkunft } & \multirow{2}{*}{ Land } & \multirow{2}{*}{$\begin{array}{c}\text { Höhe } \\
\text { m ü. NN }\end{array}$} & \multicolumn{2}{|c|}{ Ovalität } & \multirow{2}{*}{$\begin{array}{l}\text { HD } \\
39-j .\end{array}$} \\
\hline & & & & $32-j$. & $39-j$. & \\
\hline 2126 & Gaishorn & A & 1200 & 3.8 & 3.8 & 73 \\
\hline 2128 & Lobming-Oberth. St. Stefan/Kraubath & A & 800 & 4.9 & 3.3 & 84 \\
\hline 2130 & Stanz-Kindthal-Allerheiligen & A & 750 & 2.5 & 2.6 & 72 \\
\hline 2140 & Fölz, Mayerberg & $\mathrm{A}$ & 950 & 3.1 & 3.7 & 78 \\
\hline 2141 & Fölz, Greith & A & 825 & 4.4 & 4.8 & 83 \\
\hline 2144 & Seewiesen, Seereith & A & 875 & 2.6 & 4.0 & 81 \\
\hline 2147 & Freiland, Gschwend & A & 1000 & 2.6 & 2.9 & 74 \\
\hline 2149 & Kindberg/Eisenerzer Alpen & A & 1000 & 3.0 & 2.4 & 77 \\
\hline 2150 & Siebensee Wildalpen & A & 850 & 2.9 & 3.1 & 78 \\
\hline 2160 & Turnau, Kapfenberg & A & 1100 & 3.2 & 1.7 & 82 \\
\hline 3326 & Neureichenau & $\mathrm{D}$ & 1200 & 3.1 & 2.9 & 74 \\
\hline 3328 & Spiegelau & $\mathrm{D}$ & 1200 & 3.3 & 2.6 & 77 \\
\hline 3329 & Spiegelau & $\mathrm{D}$ & 1200 & 3.6 & 1.7 & 70 \\
\hline 3332 & Zwiesel-Ost & $\mathrm{D}$ & 1000 & 2.9 & 3.1 & 68 \\
\hline 3406 & SHK Stryck Willingen & $\mathrm{D}$ & 550 & 3.6 & 3.5 & 73 \\
\hline 3410 & Traunstein & $\mathrm{D}$ & 850 & 3.9 & 6.4 & 81 \\
\hline 3411 & Bischofswiesen & $\mathrm{D}$ & 950 & 3.5 & 2.7 & 71 \\
\hline 3412 & Winterberg & $\mathrm{D}$ & 750 & 4.2 & 4.1 & 70 \\
\hline 3413 & SHK Winterberg & $\mathrm{D}$ & 750 & 4.8 & 3.2 & 70 \\
\hline 3415 & SHK Hochsauerland & $\mathrm{D}$ & 600 & 3.2 & 5.1 & 71 \\
\hline 3416 & SHK Höhenfichten & $\mathrm{D}$ & 1050 & 3.0 & 3.8 & 83 \\
\hline 3417 & Marsberg & $\mathrm{D}$ & 500 & 3.6 & 5.9 & 70 \\
\hline 3418 & Sachsenried & $\mathrm{D}$ & 900 & 3.3 & 4.1 & 74 \\
\hline 3419 & Schwarzwald Baar, VIII/6 & $\mathrm{D}$ & 700 & 2.9 & 3.3 & 70 \\
\hline 3420 & Daun/Ost & $\mathrm{D}$ & 450 & 3.6 & 3.9 & 74 \\
\hline 3421 & Dombühl & $\mathrm{D}$ & 450 & 3.1 & 4.8 & 73 \\
\hline 3422 & Stryck & $\mathrm{D}$ & 650 & 3.7 & 2.9 & 70 \\
\hline 3423 & Kohlstetten & $\mathrm{D}$ & 750 & 3.4 & 4.5 & 66 \\
\hline 3424 & Winterberg & $\mathrm{D}$ & 450 & 3.5 & 3.3 & 73 \\
\hline 3425 & Waldmünchen & $\mathrm{D}$ & 850 & 3.1 & 1.0 & 79 \\
\hline 3426 & Uelzen & $\mathrm{D}$ & 50 & 3.0 & 4.0 & 72 \\
\hline 3427 & Oderhaus & $\mathrm{D}$ & 650 & 3.8 & 1.3 & 74 \\
\hline 3428 & Schernfeld & $\mathrm{D}$ & 450 & 2.5 & 3.2 & 87 \\
\hline 3429 & Villingen & $\mathrm{D}$ & 850 & 3.6 & 2.9 & 72 \\
\hline 3430 & Diessen & $\mathrm{D}$ & 850 & 3.9 & 3.2 & 75 \\
\hline 3431 & Riedenburg & $\mathrm{D}$ & 500 & 3.5 & 3.6 & 81 \\
\hline 3432 & Walsrode & $\mathrm{D}$ & 30 & 3.8 & 3.3 & 81 \\
\hline 3433 & Selb-Kirchenlamitz (1) & $\mathrm{D}$ & 800 & 2.9 & 2.7 & 74 \\
\hline 3434 & Miele & $\mathrm{D}$ & 90 & 3.4 & 5.5 & 77 \\
\hline 3435 & Neureichenau (2) & $\mathrm{D}$ & 1050 & 3.1 & 2.8 & 72 \\
\hline 3436 & Neureichenau (2) & $\mathrm{D}$ & 1050 & 3.3 & 3.1 & 68 \\
\hline 3437 & Neureichenau (2) & $\mathrm{D}$ & 1050 & 3.4 & 3.1 & 70 \\
\hline 3438 & Oderhaus & $\mathrm{D}$ & 650 & 3.2 & 2.6 & 82 \\
\hline 3444 & Zwiesel, Scheicherau XXI 14a/b $(3,6)$ & $\mathrm{D}$ & 650 & 3.0 & 2.7 & 75 \\
\hline 3445 & Zwiesel, Haselau XXI $12(3,6)$ & $\mathrm{D}$ & 650 & 3.9 & 3.3 & 68 \\
\hline 3447 & Nationalp. Hüttenschlag XIX 1b (6) & $\mathrm{D}$ & 750 & 2.8 & 2.1 & 80 \\
\hline 3448 & Nationalp. Filzwald IX 3a 10/11 (6) & $\mathrm{D}$ & 750 & 3.1 & 3.3 & 72 \\
\hline 3449 & Nationalp. Neubruck 1a10,b10/11,c10 (6) & $\mathrm{D}$ & 740 & 3.6 & 3.7 & 70 \\
\hline 3498 & Burgjoß & $\mathrm{D}$ & 450 & 3.5 & 4.1 & 79 \\
\hline 3499 & Chausseehaus & $\mathrm{D}$ & & 3.2 & 2.4 & 80 \\
\hline
\end{tabular}


Versuchsfläche 44

\begin{tabular}{|c|c|c|c|c|c|c|}
\hline \multirow{2}{*}{$\begin{array}{l}\text { PG- } \\
\text { Nr. }\end{array}$} & \multirow{2}{*}{ Herkunft } & \multirow{2}{*}{ Land } & \multirow{2}{*}{$\begin{array}{c}\text { Höhe } \\
\mathrm{m} \text { ü. NN }\end{array}$} & \multicolumn{2}{|c|}{ Ovalität } & \multirow{2}{*}{$\begin{array}{l}\text { HD } \\
39-j .\end{array}$} \\
\hline & & & & $32-j$. & $39-\mathrm{j}$. & \\
\hline 3505 & Eibenst. Carlsf. 275 & $\mathrm{D}$ & 925 & 2.4 & 2.6 & 63 \\
\hline 3617 & Torgelow & $\mathrm{D}$ & 100 & 3.4 & 3.4 & 72 \\
\hline 4011 & Cikaaj, Zdarska Vrchy & CS & 655 & 3.5 & 3.8 & 67 \\
\hline 4032 & Kynsperk nad Ohri Libocky Dul & CS & 650 & 4.1 & 2.3 & 70 \\
\hline 4042 & Vimperk-Prameny Vltury Stachy & CS & 950 & 3.9 & 2.8 & 79 \\
\hline 4061 & Velke Mezirici-Rudolec & CS & 630 & 4.2 & 5.4 & 85 \\
\hline 4081 & Frenstat pod Radhosten-Obora & CS & 600 & 3.7 & 2.4 & 73 \\
\hline 4082 & Ostravice & CS & 800 & 3.2 & 2.4 & 78 \\
\hline 4103 & Tatranska Lesna 559 C & CS & 950 & 3.2 & 3.9 & 73 \\
\hline 4121 & Javorova Dolina 155 A, Nr. 4121 & CS & 1200 & 2.7 & 3.1 & 81 \\
\hline 4143 & Kysihybel & CS & 540 & 3.7 & 3.5 & 72 \\
\hline 4154 & Roznava & CS & 800 & 2.9 & 3.1 & 76 \\
\hline 4157 & Hnusta & CS & 550 & 3.2 & 3.2 & 82 \\
\hline 4159 & Svrcina Hrabusice & CS & 900 & 4.1 & 3.2 & 66 \\
\hline 5101 & Nedzinant, Prokletije (Geb.) & YU & 1150 & 4.0 & 2.5 & 63 \\
\hline 5201 & Köszeg 1 C & $\mathrm{H}$ & 870 & 3.8 & 2.3 & 76 \\
\hline 5202 & Szentgotthard $1 \mathrm{C}$ & $\mathrm{H}$ & 310 & 3.0 & 3.6 & 78 \\
\hline 5203 & Sarospatak-Haromhuta 19 B Zempl. Geb. & $\mathrm{H}$ & 405 & 3.3 & 3.2 & 71 \\
\hline 5204 & Miskolc-Lillafüred 82 A Bükker Geb. & $\mathrm{H}$ & 730 & 2.6 & 3.2 & 72 \\
\hline 5205 & Nagykanizsa-Iharos Plattensee 11/1-71 & $\mathrm{H}$ & 200 & 4.0 & 2.9 & 69 \\
\hline 5206 & Sopron (Hochschulrev.) 203 D & $\mathrm{H}$ & 425 & 2.4 & 2.5 & 75 \\
\hline 5302 & Beglika & BG & 1850 & 4.4 & 5.5 & 74 \\
\hline 5303 & Borovec (Rila-Geb.) & BG & 1300 & 3.2 & 3.0 & 69 \\
\hline 5401 & Valea Putnei-Pojorita & RU & 1085 & 3.1 & 2.8 & 75 \\
\hline 5413 & Brosteni Bradu/Bastitei & RU & 1475 & 3.9 & 1.4 & 83 \\
\hline 6106 & Köslin/Koszalin & PL & 50 & 2.5 & 2.4 & 72 \\
\hline 6223 & Przerwanki & PL & 150 & 3.4 & 2.9 & 79 \\
\hline 6237 & Puszcza-Białowieska & PL & 130 & 3.0 & 4.4 & 78 \\
\hline 6250 & Augustow Abt. 95 b & PL & 120 & 3.3 & 4.8 & 78 \\
\hline 6254 & Mikaszowka & PL & 120 & 3.8 & 3.4 & 74 \\
\hline 6255 & Puszcza-Augustowska & PL & 125 & 2.4 & 4.9 & 86 \\
\hline 6260 & Knyszyn & PL & 150 & 3.8 & 2.7 & 73 \\
\hline 6261 & Kumialka (Kumialska) & PL & 160 & 3.5 & 3.5 & 87 \\
\hline 6410 & Sierpc & PL & 110 & 4.2 & 2.7 & 78 \\
\hline 6896 & Borken & PL & 165 & 3.6 & 4.4 & 77 \\
\hline 7401 & Gzatsk-Smolensk & SU & 194 & 3.6 & 3.0 & 83 \\
\hline 8703 & Lohja Laaskspohjan & SF & 50 & 3.1 & 4.4 & 85 \\
\hline 9170 & Ryssby-Kronobergs & $\mathrm{S}$ & 175 & 3.2 & 3.6 & 81 \\
\hline 9417 & Marsberg & $\mathrm{D}$ & 500 & 4.0 & 4.1 & 69 \\
\hline 9423 & Kohlstetten & $\mathrm{D}$ & 750 & 3.7 & 2.7 & 76 \\
\hline 9432 & Walsrode & $\mathrm{D}$ & 30 & 3.9 & 3.2 & 73 \\
\hline
\end{tabular}


Versuchsfläche 45

\begin{tabular}{|c|c|c|c|c|c|c|}
\hline \multirow{2}{*}{$\begin{array}{l}\text { PG- } \\
\text { Nr. }\end{array}$} & \multirow{2}{*}{ Herkunft } & \multirow{2}{*}{ Land } & \multirow{2}{*}{$\begin{array}{c}\text { Höhe } \\
\text { m ü. NN }\end{array}$} & \multicolumn{2}{|c|}{ Ovalität } & \multirow{2}{*}{$\begin{array}{l}\text { HD } \\
39-j .\end{array}$} \\
\hline & & & & $32-j$. & $39-j$. & \\
\hline 107 & Donaueschingen & $\mathrm{D}$ & 650 & 3.6 & 4.3 & 71 \\
\hline 111 & Bodenmais & $\mathrm{D}$ & 1000 & 2.9 & 4.1 & 71 \\
\hline 115 & Westerhof & $\mathrm{D}$ & 200 & 3.1 & 4.5 & 71 \\
\hline 121 & Cedrogne & B & 500 & 3.9 & 3.3 & 79 \\
\hline 129 & Allenstein & PL & 100 & 3.0 & 4.9 & 75 \\
\hline 149 & Einsiedeln & $\mathrm{CH}$ & 900 & 2.6 & 2.8 & 84 \\
\hline 2118 & Gurker Sirnitzwald & A & 900 & 5.0 & 4.0 & 78 \\
\hline 2131 & Veitsch-Neuberg & A & 1000 & 3.2 & 5.2 & 82 \\
\hline 2133 & Hinterhof, Eibelkogel & A & 1150 & 2.6 & 2.1 & 72 \\
\hline 2134 & Hinterhof, Ostbrenner u. Tiefental & A & 1000 & 4.6 & 3.4 & 70 \\
\hline 2135 & Kraubath, Seckauer Tauern & A & 1050 & 2.5 & 4.1 & 79 \\
\hline 2137 & Buchberg, Flachwald/Aflenz & A & 1300 & 3.8 & 2.0 & 77 \\
\hline 2138 & Buchberg, Ägidiwald/Aflenz & A & 925 & 3.2 & 3.6 & 71 \\
\hline 2151 & Breitenau-Mixnitz/Fischbacher Alp. & A & 970 & 3.5 & 4.6 & 69 \\
\hline 2158 & Rohr im Gebirge, Kirchwald & A & 825 & 3.0 & 3.2 & 73 \\
\hline 2179 & Eisenkappel/Karaw. & A & 800 & 2.9 & 2.5 & 74 \\
\hline 2184 & Schneegattern & A & 750 & 3.7 & 9.7 & 78 \\
\hline 2207 & Seewiesen Seereith/Aflenz & A & 875 & 3.7 & 5.3 & 79 \\
\hline 3003 & Blumberg & $\mathrm{D}$ & 800 & 3.5 & 4.5 & 83 \\
\hline 3042 & Walchensee & $\mathrm{D}$ & 1100 & 3.5 & 4.2 & 67 \\
\hline 3102 & Schluchsee-Eschenmoos & $\mathrm{D}$ & 1200 & 4.3 & 2.3 & 72 \\
\hline 3139 & Isny Ba/Wü & $\mathrm{D}$ & 850 & 2.6 & 2.5 & 75 \\
\hline 3204 & Burghausen/Salzach & $\mathrm{D}$ & 400 & 3.6 & 10.8 & 81 \\
\hline 3205 & Ebersberg & $\mathrm{D}$ & 555 & 4.4 & 4.5 & 77 \\
\hline 3211 & Moosburg/Isar & $\mathrm{D}$ & 500 & 3.3 & 4.7 & 74 \\
\hline 3310 & Zwiesel-West/Ruselhänge X/68 & $\mathrm{D}$ & 750 & 4.2 & 3.6 & 75 \\
\hline 3323 & Mauth/Ost & $\mathrm{D}$ & 1000 & 2.6 & 2.1 & 68 \\
\hline 3325 & Neureichenau/Typengemisch & $\mathrm{D}$ & 1000 & 3.7 & 2.1 & 68 \\
\hline 3327 & Passau/Nord & $\mathrm{D}$ & 1000 & 2.5 & 3.0 & 79 \\
\hline 3331 & St. Oswald I/3,4,6 Typengemisch & $\mathrm{D}$ & 1200 & 2.7 & 2.3 & 70 \\
\hline 3337 & Rabenstein Typengemisch & $\mathrm{D}$ & 1200 & 2.7 & 2.9 & 81 \\
\hline 3404 & Westerhof Abt. $51 \mathrm{~B}$ & $\mathrm{D}$ & 200 & 3.7 & 3.1 & 72 \\
\hline 3417 & Marsberg & $\mathrm{D}$ & 500 & 3.5 & 2.3 & 67 \\
\hline 3423 & Kohlstetten & $\mathrm{D}$ & 750 & 3.7 & 2.6 & 76 \\
\hline 3430 & Diessen & $\mathrm{D}$ & 850 & 3.1 & 3.2 & 77 \\
\hline 3432 & Walsrode & $\mathrm{D}$ & 30 & 3.7 & 4.5 & 77 \\
\hline 3433 & Selb-Kirchenlamitz (1) & $\mathrm{D}$ & 800 & 6.1 & 3.3 & 72 \\
\hline 3443 & Zwiesel, Scheichereb. XXI 13b1 $(3,6)$ & $\mathrm{D}$ & 650 & 3.5 & 2.8 & 70 \\
\hline 3503 & Eibenst. Carlsf. Wiesenh. 214 & $\mathrm{D}$ & 720 & 3.3 & 3.0 & 71 \\
\hline 3510 & Sonneb. Steinheid, Kieferleskopf & $\mathrm{D}$ & 886 & 2.7 & 2.7 & 73 \\
\hline 3511 & Innenau Elgersburg & $\mathrm{D}$ & 800 & 4.0 & 2.6 & 74 \\
\hline 3518 & Suhl, Oberhofer Schloßbergkopf & $\mathrm{D}$ & 900 & 3.7 & 7.2 & 67 \\
\hline 3519 & Mechterstädt & $\mathrm{D}$ & 200 & 3.0 & 3.5 & 75 \\
\hline 3606 & Templin, Bad Doberan Nr. 9 & $\mathrm{D}$ & 50 & 2.8 & 2.3 & 84 \\
\hline 3615 & Neustrelitz & $\mathrm{D}$ & 100 & 3.6 & 4.6 & 81 \\
\hline 4022 & Boubin III & CS & 1000 & 2.7 & 1.8 & 75 \\
\hline 4026 & Habartice, Planice & CS & 550 & 3.9 & 3.2 & 79 \\
\hline 4051 & Vysoky Chlumec Veletin & CS & 600 & 3.3 & 4.9 & 74 \\
\hline 4053 & Cesky Krumlov Borova & CS & 800 & 3.5 & 3.9 & 71 \\
\hline 4054 & Chlum u. Trebone-Hamr & CS & 450 & 3.6 & 4.3 & 72 \\
\hline
\end{tabular}


Versuchsfläche 45

\begin{tabular}{|c|c|c|c|c|c|c|}
\hline \multirow{2}{*}{$\begin{array}{l}\text { PG- } \\
\text { Nr. }\end{array}$} & \multirow{2}{*}{ Herkunft } & \multirow{2}{*}{ Land } & \multirow{2}{*}{$\begin{array}{c}\text { Höhe } \\
\mathrm{m} \text { ü. NN }\end{array}$} & \multicolumn{2}{|c|}{ Ovalität } & \multirow{2}{*}{$\begin{array}{l}\text { HD } \\
39-\mathrm{j} .\end{array}$} \\
\hline & & & & $32-j$. & 39-j. & \\
\hline 4060 & Hencov-Trest & CS & 600 & 3.9 & 2.9 & 72 \\
\hline 4070 & Vrchlabi & CS & 700 & 3.4 & 3.6 & 76 \\
\hline 4073 & Jesenik-Zlate Hory & CS & 820 & 3.3 & 5.2 & 81 \\
\hline 4123 & Javorova Dolina 155 A, Nr.4123 & CS & 1200 & 3.0 & 3.8 & 115 \\
\hline 5102 & Kaludjerske Bore Taram Kremma & YU & 1000 & 3.9 & 3.3 & 75 \\
\hline 5107 & Smrceve Dolina Abt. 138 & HR & 1350 & 2.4 & 2.4 & 77 \\
\hline 5301 & Belogradchik-Tschupreno & BG & 1400 & 3.3 & 4.1 & 91 \\
\hline 5412 & Moldovita-Sacries & RU & 825 & 3.3 & 2.5 & 85 \\
\hline 5415 & Cimpeni-Dara & RU & 1260 & 3.4 & 3.1 & 74 \\
\hline 5416 & Remeti-Zerna & RU & 900 & 3.7 & 3.9 & 70 \\
\hline 5420 & Valea Putnei-Pojorita III/60 & RU & 1285 & 3.9 & 3.7 & 78 \\
\hline 5426 & Crucea-Barnavel Abt. 17/18 & RU & 740 & 4.3 & 3.7 & 75 \\
\hline 6103 & Brotzen/Broczyno & PL & 140 & 3.4 & 4.5 & 77 \\
\hline 6222 & Borken/Borki & PL & 160 & 2.5 & 4.2 & 83 \\
\hline 6234 & Białowieża & PL & 130 & 3.4 & 3.3 & 80 \\
\hline 6235 & Zwierzyniec & PL & 150 & 2.7 & 2.6 & 84 \\
\hline 6251 & Białobrzegi & PL & 110 & 4.3 & 6.1 & 75 \\
\hline 6510 & Bunzlau/Boleslawiec & PL & 175 & 2.9 & 3.3 & 85 \\
\hline 6543 & Groß-Lassowitz/Lassowice Male & PL & 175 & 3.5 & 7.7 & 80 \\
\hline 6624 & Przysucha & PL & 275 & 3.2 & 16.2 & 73 \\
\hline 6712 & Klodzko-Glatz/Nynow 68 e & PL & 340 & 3.5 & 3.5 & 78 \\
\hline 6731 & Szcytna-Slaska Karlow 243 a & PL & 750 & 3.9 & 4.6 & 73 \\
\hline 6732 & Szcytna-Slaska Karlow 292 b & PL & 700 & 3.8 & 3.7 & 73 \\
\hline 6864 & Istebna-Ujsoly & PL & 750 & 3.5 & 1.7 & 81 \\
\hline 6894 & Witów & PL & 1250 & 2.7 & 3.9 & 75 \\
\hline 7224 & Ostrovskij-Pskow & SU & 200 & 2.7 & 2.3 & 91 \\
\hline 7233 & Wolozin & SU & 225 & 2.9 & 2.9 & 83 \\
\hline 7235 & Brigalovic-Mogilev & SU & 160 & 3.0 & 3.2 & 77 \\
\hline 8003 & Fussinge & DK & 45 & 4.0 & 4.8 & 75 \\
\hline 8705 & Mänttä & SF & 120 & 4.4 & 3.9 & 84 \\
\hline 8707 & Janakkala Keskivari Uhkoila & SF & 100 & 2.8 & 3.2 & 88 \\
\hline
\end{tabular}

Versuchsfläche 46

\begin{tabular}{|c|c|c|c|c|c|c|}
\hline PG- & & & Höhe & $\mathrm{Ov}$ & & HD \\
\hline $\mathrm{Nr}$. & Herkuntt & Land & $\mathrm{m}$ ü. NN & $32-j$. & $39-j$. & 39-j. \\
\hline 65 & Eisenkappel Thurn 2 & A & 850 & 3.6 & 3.7 & 78 \\
\hline 93 & Sieber & $\mathrm{D}$ & 400 & 2.2 & 2.3 & 77 \\
\hline 105 & Hohenschwangau & $\mathrm{D}$ & 800 & 3.2 & 3.4 & 78 \\
\hline 108 & Lauterberg & $\mathrm{D}$ & 700 & 3.2 & 2.4 & 69 \\
\hline 116 & Kobernausserwald & A & 600 & 3.5 & 2.0 & 85 \\
\hline 169 & Gries & A & 1300 & 3.2 & 4.9 & 83 \\
\hline 172 & Mittersill & A & 900 & 2.6 & 2.1 & 85 \\
\hline 191 & Passail & A & 900 & 2.9 & 3.7 & 75 \\
\hline 230 & Elbingerode & $\mathrm{D}$ & 550 & 3.3 & 2.8 & 76 \\
\hline 1118 & Chatel, 1 Aity" & $\mathrm{F}$ & 1250 & 3.4 & 5.2 & 76 \\
\hline 1201 & Mellier, Bois Bayai, 2 & B & 400 & 2.9 & 2.2 & 78 \\
\hline 2124 & Stixenstein, Gahns & A & 1200 & 3.5 & 4.1 & 86 \\
\hline
\end{tabular}




\begin{tabular}{|c|c|c|c|c|c|c|}
\hline \\
\hline $\begin{array}{l}\text { PG- } \\
\text { Nr. }\end{array}$ & Herkunft & Land & $\begin{array}{c}\text { Höhe } \\
\text { m ü. NN }\end{array}$ & $\begin{array}{r}\text { Ovi } \\
32-j .\end{array}$ & $\begin{array}{l}\text { tät } \\
39-j .\end{array}$ & $\begin{array}{l}\text { HD } \\
39-j .\end{array}$ \\
\hline 2127 & Unterhal, St. Kathrein a.d. Lamming & A & 800 & 2.6 & 3.7 & 83 \\
\hline 2174 & Klein-Sölk/Niedertauern & A & 1250 & 3.1 & 3.5 & 80 \\
\hline 3150 & Dillingen a.d.D. Bay. & $\mathrm{D}$ & 500 & 3.9 & 2.5 & 74 \\
\hline 3206 & Eglharting XIV/17,19 & $\mathrm{D}$ & 580 & 3.8 & 3.8 & 77 \\
\hline 3213 & Mühldorf/Inn & $\mathrm{D}$ & 440 & 3.6 & 2.4 & 77 \\
\hline 3414 & Bodensee Oberschwab. VIII/13 & $\mathrm{D}$ & 650 & 3.2 & 5.0 & 78 \\
\hline 3417 & Marsberg & $\mathrm{D}$ & 500 & 4.2 & 3.5 & 75 \\
\hline 3423 & Kohlstetten & $\mathrm{D}$ & 750 & 3.5 & 3.5 & 70 \\
\hline 3430 & Diessen & $\mathrm{D}$ & 850 & 3.4 & 2.7 & 78 \\
\hline 3432 & Walsrode & $\mathrm{D}$ & 30 & 4.0 & 3.2 & 73 \\
\hline 3433 & Selb-Kirchenlamitz (1) & $\mathrm{D}$ & 800 & 3.4 & 5.2 & 76 \\
\hline 3446 & Zwiesel, Schmalzau IX 3c $(5,6)$ & $\mathrm{D}$ & 620 & 2.9 & 3.3 & 77 \\
\hline 4050 & Vlasim-Votice & CS & 600 & 3.0 & 3.0 & 78 \\
\hline 4075 & Vitkov-Budisov & CS & 610 & 4.0 & 2.7 & 77 \\
\hline 4127 & Javorova Dolina 155 A, Nr.4127 & CS & 1200 & 3.4 & 2.3 & 78 \\
\hline 5424 & Valea Beliei-Sinaia Gurguiata & RU & 1115 & 3.5 & 1.9 & 79 \\
\hline 5425 & Cimpeni-Nedei & RU & 1400 & 3.1 & 3.5 & 80 \\
\hline 6107 & Altenhagen/Nowy Krakow & PL & 200 & 4.3 & 4.3 & 76 \\
\hline 6236 & Białowieża & PL & 150 & 3.5 & 4.2 & 85 \\
\hline 6897 & Goldap & PL & 175 & 2.8 & 3.5 & 89 \\
\hline 7232 & Cemerjanskoe-Mogilev & SU & 175 & 3.5 & 4.3 & 91 \\
\hline 7234 & Soboljanskoe-Grodno & SU & 150 & 4.0 & 2.7 & 84 \\
\hline 7240 & Witebsk & SU & 150 & 2.9 & 3.0 & 93 \\
\hline 9191 & Karlsholms-Kristianstad & $\mathrm{S}$ & 20 & 4.4 & 4.2 & 77 \\
\hline
\end{tabular}

\section{Anhang 1.20}

Zusammenstellung der sich signifikant von mindestens einer anderen Herkunft im Tukey-Kramer-Test beim Merkmal Ovalität [\%] im Alter 39 auf der Versuchsfläche 44 Hasbruch / Niedersachsen unterscheidenden Herkünfte

\begin{tabular}{cr|l|c|r|c}
\hline Rang & $\begin{array}{c}\text { PG- } \\
\text { Nr. }\end{array}$ & Herkunft & Land & $\begin{array}{c}\text { Höhe } \\
\text { m ü. NN }\end{array}$ & $\begin{array}{c}\text { Oval. } \\
{[\%]}\end{array}$ \\
\hline 1 & 5413 & Brosteni Bradu/Bastitei & RU & 1475 & 1.11 \\
2 & 3425 & Waldmünchen & $\mathrm{D}$ & 850 & 1.18 \\
3 & 3427 & Oderhaus & $\mathrm{D}$ & 650 & 1.22 \\
4 & 734 & Airolo, Bedretto & $\mathrm{CH}$ & 1600 & 1.29 \\
5 & 62 & Litschau & $\mathrm{A}$ & 600 & 1.48 \\
6 & 3447 & Nationalp. Hüttenschlag XIX 1b (6) & $\mathrm{D}$ & 750 & 1.59 \\
7 & 139 & Vapenkova Skala & $\mathrm{CS}$ & 540 & 1.67 \\
8 & 174 & Piesendorf & $\mathrm{A}$ & 900 & 1.79 \\
9 & 2123 & Gallmannsegg Kainach & $\mathrm{A}$ & 1100 & 1.82 \\
10 & 66 & Vorau & $\mathrm{A}$ & 900 & 1.83 \\
11 & 284 & Blekinge län Asarum & $\mathrm{S}$ & 100 & 1.85 \\
12 & 217 & Istebna-Wisła & $\mathrm{PL}$ & 725 & 1.90 \\
13 & 3329 & Spiegelau & $\mathrm{D}$ & 1200 & 1.92 \\
14 & 6410 & Sierpc & $\mathrm{PL}$ & 110 & 1.95 \\
15 & 716 & Altacanta & $\mathrm{CH}$ & 1400 & 1.98
\end{tabular}




\begin{tabular}{|c|c|c|c|c|c|}
\hline Rang & $\begin{array}{l}\text { PG- } \\
\text { Nr. }\end{array}$ & Herkunft & Land & $\begin{array}{c}\text { Höhe } \\
\text { m ü. NN }\end{array}$ & $\begin{array}{c}\text { Oval. } \\
{[\%]}\end{array}$ \\
\hline 16 & 295 & Öveds Kloster Öpedal & $\mathrm{S}$ & 50 & 2.00 \\
\hline 17 & 2160 & Turnau, Kapfenberg & $\mathrm{A}$ & 1100 & 2.02 \\
\hline 18 & 190 & Offenegg & A & 950 & 2.11 \\
\hline 19 & 712 & Forêt du Risoud & $\mathrm{CH}$ & 1100 & 2.17 \\
\hline 20 & 124 & Istebna-Wisła & PL & 725 & 2.19 \\
\hline 21 & 1202 & Manderfeld Gilbuschek 63 A & $\mathrm{B}$ & 542 & 2.19 \\
\hline 22 & 2149 & Kindberg/Eisenerzer Alpen & $\mathrm{A}$ & 1000 & 2.22 \\
\hline 23 & 4082 & Ostravice & CS & 800 & 2.25 \\
\hline 24 & 97 & Gérardmer & $\mathrm{F}$ & 850 & 2.32 \\
\hline 25 & 2115 & Rosental & $\mathrm{A}$ & 1000 & 2.33 \\
\hline 26 & 1114 & Passy & $\mathrm{F}$ & 1200 & 2.35 \\
\hline 27 & 6106 & Köslin/Koszalin & PL & 50 & 2.36 \\
\hline 28 & 1101 & Le Pertuis, Monts du Velay & $\mathrm{F}$ & 1100 & 2.37 \\
\hline 29 & 290 & Högestad & S & 50 & 2.38 \\
\hline 30 & 63 & Eisenkappel Thurn 1 & A & 850 & 2.38 \\
\hline 31 & 4081 & Frenstat pod Radhosten-Obora & CS & 600 & 2.39 \\
\hline 32 & 3424 & Winterberg & $\mathrm{D}$ & 450 & 2.42 \\
\hline 33 & 5201 & Köszeg 1 C & $\mathrm{H}$ & 870 & 2.44 \\
\hline 34 & 3499 & Chausseehaus & $\mathrm{D}$ & & 2.45 \\
\hline 35 & 110 & Medebach & $\mathrm{D}$ & 600 & 2.45 \\
\hline 36 & 5101 & Nedzinant, Prokletije (Geb.) & YU & 1150 & 2.46 \\
\hline 37 & 4032 & Kynsperk nad Ohri Libocky Dul & CS & 650 & 2.46 \\
\hline 38 & 2122 & Piberegg & A & 800 & 2.47 \\
\hline 39 & 175 & Radstatt & $\mathrm{A}$ & 1000 & 2.48 \\
\hline 40 & 713 & Caragnago & $\mathrm{CH}$ & 1180 & 2.48 \\
\hline 41 & 4042 & Vimperk-Prameny Vltury Stachy & CS & 950 & 2.49 \\
\hline 42 & 704 & Cazis Tschartlina & $\mathrm{CH}$ & 750 & 2.49 \\
\hline 43 & 1117 & Plan Bois, Ballandes & $\mathrm{F}$ & 500 & 2.51 \\
\hline 44 & 711 & La Genolière & $\mathrm{CH}$ & & 2.52 \\
\hline 45 & 61 & Gosau & A & 700 & 2.55 \\
\hline 46 & 3429 & Villingen & $\mathrm{D}$ & 850 & 2.56 \\
\hline 47 & 5206 & Sopron (Hochschulrev.) 203 D & $\mathrm{H}$ & 425 & 2.58 \\
\hline 48 & 9423 & Kohlstetten & $\mathrm{D}$ & 750 & 2.58 \\
\hline 49 & 179 & Bischofshofen & $\mathrm{A}$ & 1200 & 2.59 \\
\hline 50 & 740 & Bex, Tarejanne & $\mathrm{CH}$ & 1600 & 2.60 \\
\hline 51 & 1115 & Magland & $\mathrm{F}$ & 700 & 2.61 \\
\hline 52 & 3328 & Spiegelau & $\mathrm{D}$ & 1200 & 2.62 \\
\hline 53 & 140 & Bucovice & CS & 480 & 2.62 \\
\hline 54 & 215 & Stinava & SK & & 2.63 \\
\hline 55 & 176 & St. Johann & A & 1200 & 2.66 \\
\hline 56 & 3438 & Oderhaus & $\mathrm{D}$ & 650 & 2.69 \\
\hline 57 & 5205 & Nagykanizsa-Iharos Plattensee 11/1-71 & $\mathrm{H}$ & 200 & 2.70 \\
\hline 58 & 3411 & Bischofswiesen & $\mathrm{D}$ & 950 & 2.75 \\
\hline 59 & 5401 & Valea Putnei-Pojorita & RU & 1085 & 2.75 \\
\hline 60 & 722 & Piana Selva, Faido & $\mathrm{CH}$ & 980 & 2.76 \\
\hline 61 & 3444 & Zwiesel, Scheicherau XXI 14a/b $(3,6)$ & $\mathrm{D}$ & 650 & 2.77 \\
\hline 62 & 2114 & Kreuzen-Stockenboi & A & 1200 & 2.78 \\
\hline 63 & 5204 & Miskolc-Lillafüred 82 A Bükker Geb. & $\mathrm{H}$ & 730 & 2.80 \\
\hline 64 & 6223 & Przerwanki & PL & 150 & 2.82 \\
\hline 65 & 3435 & Neureichenau (2) & $\mathrm{D}$ & 1050 & 2.82 \\
\hline 66 & 3413 & SHK Winterberg & $\mathrm{D}$ & 750 & 2.83 \\
\hline
\end{tabular}




\begin{tabular}{|c|c|c|c|c|c|}
\hline Rang & $\begin{array}{l}\text { PG- } \\
\text { Nr. }\end{array}$ & Herkunft & Land & $\begin{array}{c}\text { Höhe } \\
\mathrm{m} \text { ü. NN }\end{array}$ & $\begin{array}{c}\text { Oval. } \\
{[\%]}\end{array}$ \\
\hline 67 & 6260 & Knyszyn & PL & 150 & 2.87 \\
\hline 68 & 3433 & Selb-Kirchenlamitz (1) & $\mathrm{D}$ & 800 & 2.88 \\
\hline 69 & 2130 & Stanz-Kindthal-Allerheiligen & A & 750 & 2.91 \\
\hline 70 & 229 & Olsztyn & PL & 100 & 2.92 \\
\hline 71 & 98 & Massif Central & $\mathrm{F}$ & 1100 & 2.93 \\
\hline 72 & 188 & Waldstein a.d. Übelb. & A & 850 & 2.96 \\
\hline 73 & 2116 & Aich & A & 700 & 2.97 \\
\hline 74 & 5202 & Szentgotthard $1 \mathrm{C}$ & $\mathrm{H}$ & 310 & 2.97 \\
\hline 75 & 3422 & Stryck & $\mathrm{D}$ & 650 & 2.98 \\
\hline 76 & 142 & Rosice & CS & 465 & 2.98 \\
\hline 77 & 3505 & Eibenst. Carlsf. 275 & $\mathrm{D}$ & 925 & 2.99 \\
\hline 78 & 3326 & Neureichenau & $\mathrm{D}$ & 1200 & 3.01 \\
\hline 79 & 202 & Istebna-Wisła & PL & 725 & 3.03 \\
\hline 80 & 2147 & Freiland, Gschwend & A & 1000 & 3.03 \\
\hline 81 & 114 & Winterberg & $\mathrm{D}$ & 800 & 3.04 \\
\hline 82 & 5303 & Borovec (Rila-Geb.) & BG & 1300 & 3.06 \\
\hline 83 & 3437 & Neureichenau (2) & $\mathrm{D}$ & 1050 & 3.07 \\
\hline 84 & 4154 & Roznava & CS & 800 & 3.09 \\
\hline 85 & 4121 & Javorova Dolina 155 A, Nr. 4121 & CS & 1200 & 3.11 \\
\hline 86 & 1111 & Peisey-Nancroix, Grd. Bois & $\mathrm{F}$ & 1400 & 3.12 \\
\hline 87 & 2150 & Siebensee Wildalpen & A & 850 & 3.13 \\
\hline 88 & 5203 & Sarospatak-Haromhuta 19 B Zempl. Geb. & $\mathrm{H}$ & 405 & 3.15 \\
\hline 89 & 185 & St. Veit/Glan & A & 600 & 3.16 \\
\hline 90 & 3332 & Zwiesel-Ost & $\mathrm{D}$ & 1000 & 3.16 \\
\hline 91 & 3428 & Schernfeld & $\mathrm{D}$ & 450 & 3.16 \\
\hline 92 & 4157 & Hnusta & CS & 550 & 3.17 \\
\hline 93 & 9432 & Walsrode & $\mathrm{D}$ & 30 & 3.17 \\
\hline 94 & 103 & Wunsiedel & $\mathrm{D}$ & 900 & 3.19 \\
\hline 95 & 3430 & Diessen & $\mathrm{D}$ & 850 & 3.20 \\
\hline 96 & 4143 & Kysihybel & CS & 540 & 3.24 \\
\hline 97 & 4011 & Cikaaj, Zdarska Vrchy & CS & 655 & 3.25 \\
\hline 98 & 725 & Airolo, Crespato-Ressia & $\mathrm{CH}$ & 1120 & 3.26 \\
\hline 99 & 9170 & Ryssby-Kronobergs & $\mathrm{S}$ & 175 & 3.29 \\
\hline 100 & 6261 & Kumialka (Kumialska) & PL & 160 & 3.31 \\
\hline 101 & 2117 & Gurktal & A & 1300 & 3.33 \\
\hline 102 & 3448 & Nationalp. Filzwald IX 3a 10/11 (6) & D & 750 & 3.34 \\
\hline 103 & 192 & Södingberg & A & 550 & 3.34 \\
\hline 104 & 3436 & Neureichenau (2) & $\mathrm{D}$ & 1050 & 3.37 \\
\hline 105 & 189 & Graz-Süd & A & 850 & 3.43 \\
\hline 106 & 3432 & Walsrode & $\mathrm{D}$ & 30 & 3.47 \\
\hline 107 & 131 & Vizovice & CS & 500 & 3.48 \\
\hline 108 & 184 & Paternion & A & 900 & 3.52 \\
\hline 109 & 291 & Karupsskogen Barsebäcks gods & $\mathrm{S}$ & 100 & 3.53 \\
\hline 110 & 2121 & Neukirchen Großvenediger & A & 870 & 3.53 \\
\hline 111 & 171 & Hofgastein & A & 1100 & 3.56 \\
\hline 112 & 208 & Istebna & PL & 725 & 3.60 \\
\hline 113 & 130 & Dobra bei Frydek & CS & 550 & 3,61 \\
\hline 114 & 7401 & Gzatsk-Smolensk & SU & 194 & 3.63 \\
\hline 115 & 3406 & SHK Stryck Willingen & $\mathrm{D}$ & 550 & 3.64 \\
\hline 116 & 3445 & Zwiesel, Haselau XXI $12(3,6)$ & D & 650 & 3.65 \\
\hline 117 & 187 & Pack & A & 950 & 3.65 \\
\hline
\end{tabular}




\begin{tabular}{|c|c|c|c|c|c|}
\hline Rang & $\begin{array}{l}\text { PG- } \\
\text { Nr. }\end{array}$ & Herkunft & Land & $\begin{array}{c}\text { Höhe } \\
\text { m ü. NN }\end{array}$ & $\begin{array}{c}\text { Oval. } \\
{[\%]}\end{array}$ \\
\hline 118 & 3449 & Nationalp. Neubruck 1a10,b10/11,c10 (6) & $\mathrm{D}$ & 740 & 3.70 \\
\hline 119 & 186 & Graz-Nord & A & 850 & 3.71 \\
\hline 120 & 3419 & Schwarzwald Baar, VIII/6 & $\mathrm{D}$ & 700 & 3.71 \\
\hline 121 & 2140 & Fölz, Maverberg & A & 950 & 3.72 \\
\hline 122 & 227 & Thüringen & $\mathrm{D}$ & 300 & 3.72 \\
\hline 123 & 4103 & Tatranska Lesna 559 C & CS & 950 & $3.7 \overline{3}$ \\
\hline 124 & 60 & Aflenz & A & 1000 & 3.75 \\
\hline 125 & 293 & Trolleholm & $\mathrm{S}$ & 125 & 3.76 \\
\hline 126 & 177 & Taxenbach & A & 1400 & 3.78 \\
\hline 127 & 3617 & Torgelow & $\mathrm{D}$ & 100 & 3.83 \\
\hline 128 & 3416 & SHK Höhenfichten & $\mathrm{D}$ & 1050 & 3.83 \\
\hline 129 & 294 & Aasbo-össjö Gods & $\mathrm{S}$ & 50 & 3.83 \\
\hline 130 & 2144 & Seewiesen, Seereith & A & 875 & 3.90 \\
\hline 131 & 1112 & Autrans, Isère & $\mathrm{F}$ & 1250 & 3.93 \\
\hline 132 & 6254 & Mikaszowka & PL & 120 & 3.97 \\
\hline 133 & 3412 & Winterberg & $\mathrm{D}$ & 750 & 4.02 \\
\hline 134 & 9417 & Marsberg & $\mathrm{D}$ & 500 & 4.02 \\
\hline 135 & 207 & Jönköpings län & $\mathrm{S}$ & 170 & 4.05 \\
\hline 136 & 3420 & Daun/Ost & $\mathrm{D}$ & 450 & 4.06 \\
\hline 137 & 2113 & Oberes Gailtal & $\mathrm{A}$ & 1100 & 4.06 \\
\hline 138 & 2126 & Gaishorn & A & 1200 & 4.07 \\
\hline 139 & 6237 & Puszcza-Białowieska & PL & 130 & 4.08 \\
\hline 140 & 3498 & Burgjoß & $\mathrm{D}$ & 450 & 4.08 \\
\hline 141 & 8703 & Lohja Laaskspohjan & SF & 50 & 4.18 \\
\hline 142 & 4159 & Svrcina Hrabusice & CS & 900 & 4.19 \\
\hline 143 & 1116 & Lantosque & $\mathrm{F}$ & 1500 & 4.20 \\
\hline 144 & 3418 & Sachsenried & $\mathrm{D}$ & 900 & 4.23 \\
\hline 145 & 2120 & Liembergwald Zell a. S. & A & 875 & 4.24 \\
\hline 146 & 3426 & Uelzen & $\mathrm{D}$ & 50 & 4.33 \\
\hline 147 & 3431 & Riedenburg & $\mathrm{D}$ & 500 & 4.41 \\
\hline 148 & 6896 & Borken & PL & 165 & 4.51 \\
\hline 149 & 1100 & Monts Megal, Le Portius & $\mathrm{F}$ & 900 & 4.73 \\
\hline 150 & 6250 & Augustow Abt. 95 b & PL & 120 & 4.80 \\
\hline 151 & 3415 & SHK Hochsauerland & $\mathrm{D}$ & 600 & 4.81 \\
\hline 152 & 3421 & Dombühl & $\mathrm{D}$ & 450 & 4.82 \\
\hline 153 & 2141 & Fölz, Greith & $\mathrm{A}$ & 825 & 4.87 \\
\hline 154 & 6255 & Puszcza-Augustowska & PL & 125 & 4.88 \\
\hline 155 & 141 & Pitin & $\mathrm{CS}$ & 610 & 4.89 \\
\hline 156 & 150 & Schlanders & I & 1500 & 4.95 \\
\hline 157 & 2128 & Lobming-Oberth. St. Stefan/Kraubath & A & 800 & 5.18 \\
\hline 158 & 41 & Spiegelau & $\mathrm{D}$ & 750 & 5.20 \\
\hline 159 & 3417 & Marsberg & $\mathrm{D}$ & 500 & 5.23 \\
\hline 160 & 3423 & Kohlstetten & $\mathrm{D}$ & 750 & 5.30 \\
\hline 161 & 204 & Spisske Pochradie & CS & 700 & 5.40 \\
\hline 162 & 4061 & Velke Mezirici-Rudolec & CS & 630 & 5.43 \\
\hline 163 & 5302 & Beglika & BG & 1850 & 5.55 \\
\hline 164 & 3434 & Miele & $\mathrm{D}$ & 90 & 5.72 \\
\hline 165 & 64 & St. Martin & A & 500 & 5.80 \\
\hline 166 & 170 & Groß Arl & A & 1350 & 5.80 \\
\hline \multicolumn{6}{|c|}{1 Herkunft } \\
\hline 168 & 178 & Abtenau & A & 900 & 14.41 \\
\hline
\end{tabular}




\section{Anhang 1.21}

Zusammenstellung der sich signifikant von mindestens einer anderen Herkunft im Tukey-Kramer-Test beim H/D-Verhältnis im Alter 39 auf der Versuchsfläche 45 Hasbruch / Niedersachsen unterscheidenden Herkünfte

\begin{tabular}{|c|c|c|c|c|c|}
\hline Rang & $\begin{array}{l}\text { PG- } \\
\text { Nr. }\end{array}$ & Herkunft & Land & $\begin{array}{c}\text { Höhe } \\
\text { m ü. NN }\end{array}$ & $\begin{array}{l}\mathrm{HD} \\
{[\%]}\end{array}$ \\
\hline 1 & 3042 & Walchensee & $\mathrm{D}$ & 1100 & 65 \\
\hline 2 & 3518 & Suhl, Oberhofer Schloßbergkopf & $\mathrm{D}$ & 900 & 67 \\
\hline 3 & 3417 & Marsberg & $\mathrm{D}$ & 500 & 67 \\
\hline 4 & 3323 & Mauth/Ost & $\mathrm{D}$ & 1000 & 68 \\
\hline 5 & 3325 & Neureichenau/Typengemisch & $\mathrm{D}$ & 1000 & 68 \\
\hline 6 & 2134 & Hinterhof, Ostbrenner u. Tiefental & A & 1000 & 69 \\
\hline 7 & 3443 & Zwiesel, Scheichereb. XXI 13b1 $(3,6)$ & $\mathrm{D}$ & 650 & 70 \\
\hline 8 & 115 & Westerhof & $\mathrm{D}$ & 200 & 70 \\
\hline 9 & 5416 & Remeti-Zerna & RU & 900 & 70 \\
\hline 10 & 3423 & Kohlstetten & $\mathrm{D}$ & 750 & 70 \\
\hline 11 & 107 & Donaueschingen & $\mathrm{D}$ & 650 & 70 \\
\hline 12 & 4053 & Cesky Krumlov Borova & CS & 800 & 71 \\
\hline 13 & 3510 & Sonneb. Steinheid, Kieferleskopf & $\mathrm{D}$ & 886 & 71 \\
\hline 14 & 111 & Bodenmais & $\mathrm{D}$ & 1000 & 71 \\
\hline 15 & 6624 & Przysucha & PL & 275 & 71 \\
\hline 16 & 3404 & Westerhof Abt. $51 \mathrm{~B}$ & $\mathrm{D}$ & 200 & 71 \\
\hline 17 & 2151 & Breitenau-Mixnitz/Fischbacher Alp. & A & 970 & 72 \\
\hline 18 & 4054 & Chlum u. Trebone-Hamr & CS & 450 & 72 \\
\hline 19 & 6732 & Szcytna-Slaska Karlow 292 b & PL & 700 & 72 \\
\hline 20 & 8003 & Fussinge & $\mathrm{DK}$ & 45 & 72 \\
\hline 21 & 2138 & Buchberg, Ägidiwald/Aflenz & A & 925 & 72 \\
\hline 22 & 4060 & Hencov-Trest & CS & 600 & 72 \\
\hline 23 & 6731 & Szcytna-Slaska Karlow 243 a & PL & 750 & 73 \\
\hline 24 & 5426 & Crucea-Barnavel Abt. 17/18 & RU & 740 & 73 \\
\hline 25 & 6894 & Witów & PL & 1250 & 73 \\
\hline 26 & 3331 & St. Oswald I/3,4,6 Typengemisch & $\mathrm{D}$ & 1200 & 73 \\
\hline 27 & 3503 & Eibenst. Carlsf. Wiesenh. 214 & $\mathrm{D}$ & 720 & 73 \\
\hline 28 & 5415 & Cimpeni-Dara & RU & 1260 & 73 \\
\hline 29 & 4051 & Vysoky Chlumec Veletin & CS & 600 & 74 \\
\hline 30 & 3211 & Moosburg/Isar & $\mathrm{D}$ & 500 & 74 \\
\hline 31 & 3433 & Selb-Kirchenlamitz (1) & $\mathrm{D}$ & 800 & 74 \\
\hline 32 & 2158 & Rohr im Gebirge, Kirchwald & $\mathrm{A}$ & 825 & 74 \\
\hline 33 & 6251 & Białobrzegi & PL & 110 & 74 \\
\hline 34 & 5102 & Kaludjerske Bore Taram Kremma & YU & 1000 & 75 \\
\hline 35 & 129 & Allenstein & PL & 100 & 75 \\
\hline 36 & 3205 & Ebersberg & $\mathrm{D}$ & 555 & 75 \\
\hline 37 & 3102 & Schluchsee-Eschenmoos & $\mathrm{D}$ & 1200 & 75 \\
\hline 38 & 5107 & Smrceve Dolina Abt. 138 & HR & 1350 & 75 \\
\hline 39 & 2133 & Hinterhof, Eibelkogel & A & 1150 & 75 \\
\hline 40 & 4022 & Boubin III & CS & 1000 & 75 \\
\hline 41 & 3511 & Innenau Elgersburg & $\mathrm{D}$ & 800 & 75 \\
\hline 42 & 3310 & Zwiesel-West/Ruselhänge X/68 & $\mathrm{D}$ & 750 & 75 \\
\hline 43 & 2179 & Eisenkappel/Karaw. & A & 800 & 76 \\
\hline 44 & 6712 & Klodzko-Glatz/Nynow 68 e & PL & 340 & 76 \\
\hline 45 & 4070 & Vrchlabi & $\mathrm{CS}$ & 700 & 76 \\
\hline 46 & 3519 & Mechterstädt & $\mathrm{D}$ & 200 & 76 \\
\hline
\end{tabular}




\begin{tabular}{|c|c|c|c|c|c|}
\hline Rang & $\begin{array}{l}\text { PG- } \\
\text { Nr. }\end{array}$ & Herkunft & Land & $\begin{array}{c}\text { Höhe } \\
\text { m ü. NN }\end{array}$ & $\begin{array}{l}\mathrm{HD} \\
{[\%]}\end{array}$ \\
\hline 47 & 3139 & Isny $\mathrm{Ba} / \mathrm{Wü}$ & $\mathrm{D}$ & 850 & 77 \\
\hline 48 & 4026 & Habartice, Planice & CS & 550 & 77 \\
\hline 49 & 6103 & Brotzen/Broczyno & PL & 140 & 77 \\
\hline 50 & 2184 & Schneegattern & A & 750 & 77 \\
\hline 51 & 121 & Cedrogne & $\mathrm{B}$ & 500 & 77 \\
\hline 52 & 5420 & Valea Putnei-Pojorita III/60 & $\mathrm{RU}$ & 1285 & 78 \\
\hline 53 & 3430 & Diessen & $\mathrm{D}$ & 850 & 78 \\
\hline 54 & 7235 & Brigalovic-Mogilev & SU & 160 & 78 \\
\hline 55 & 3615 & Neustrelitz & $\mathrm{D}$ & 100 & 78 \\
\hline 56 & 2118 & Gurker Sirnitzwald & A & 900 & 78 \\
\hline 57 & 2135 & Kraubath, Seckauer Tauern & A & 1050 & 78 \\
\hline 58 & 2137 & Buchberg, Flachwald/Aflenz & A & 1300 & 79 \\
\hline 59 & 3432 & Walsrode & $\mathrm{D}$ & 30 & 79 \\
\hline 60 & 3327 & Passau/Nord & $\mathrm{D}$ & 1000 & 79 \\
\hline 61 & 6543 & Groß-Lassowitz/Lassowice Male & PL & 175 & 79 \\
\hline 62 & 2131 & Veitsch-Neuberg & A & 1000 & 79 \\
\hline 63 & 3204 & Burghausen/Salzach & $\mathrm{D}$ & 400 & 80 \\
\hline 64 & 6234 & Białowieża & PL & 130 & 80 \\
\hline 65 & 2207 & Seewiesen Seereith/Aflenz & $\mathrm{A}$ & 875 & 81 \\
\hline 66 & 4073 & Jesenik-Zlate Hory & CS & 820 & 82 \\
\hline 67 & 3337 & Rabenstein Typengemisch & $\mathrm{D}$ & 1200 & 82 \\
\hline 68 & 7233 & Wolozin & SU & 225 & 82 \\
\hline 69 & 3003 & Blumberg & $\mathrm{D}$ & 800 & 82 \\
\hline 70 & 149 & Einsiedeln & $\mathrm{CH}$ & 900 & 82 \\
\hline 71 & 5412 & Moldovita-Sacries & RU & 825 & 83 \\
\hline 72 & 6222 & Borken/Borki & PL & 160 & 83 \\
\hline 73 & 8705 & Mänttä & SF & 120 & 83 \\
\hline 74 & 6510 & Bunzlau/Boleslawiec & PL & 175 & 84 \\
\hline 75 & 3606 & Templin, Bad Doberan Nr. 9 & $\mathrm{D}$ & 50 & 84 \\
\hline \multicolumn{6}{|c|}{ 5 Herkünfte } \\
\hline$\dddot{81}$ & 4123 & Javorova Dolina 155 A, & $\mathrm{CS}$ & 1200 & 125 \\
\hline
\end{tabular}

\section{Anhang 1.22}

Zusammenstellung der mittleren BHD [cm] im Alter von 32 und 39 Jahren sowie der mittleren Höhe $[\mathrm{m}]$ im Alter von 39 Jahren auf den drei Versuchsflächen Hasbruch / Niedersachsen

* BHD nur von den Bäumen, von denen Höhen gemessen wurden

Versuchsfläche 44

\begin{tabular}{c|l|c|c|c|c}
\hline $\begin{array}{c}\text { PG- } \\
\text { Nr. }\end{array}$ & Herkunft & $\begin{array}{c}\text { BHD } \\
32-j .\end{array}$ & $\begin{array}{c}\text { BHD. } \\
39-j .\end{array}$ & $\begin{array}{c}\text { BHD* } \\
39-j .\end{array}$ & $\begin{array}{c}\text { Höhe } \\
39-j .\end{array}$ \\
\hline 41 & Spiegelau & 10.7 & 13.0 & 15.2 & 12.3 \\
60 & Aflenz & 12.2 & 16.1 & 18.8 & 14.6 \\
61 & Gosau & 10.4 & 12.1 & 18.5 & 13.4 \\
62 & Litschau & 12.4 & 15.7 & 19.1 & 13.9 \\
63 & Eisenkappel Thurn 1 & 12.6 & 15.6 & 21.3 & 14.4 \\
64 & St. Martin & 12.5 & 14.8 & 20.6 & 14.2 \\
66 & Vorau & 12.2 & 15.2 & 20.4 & 13.7
\end{tabular}


Versuchsfläche 44

\begin{tabular}{|c|c|c|c|c|c|}
\hline $\begin{array}{l}\text { PG- } \\
\text { Nr. }\end{array}$ & Herkunft & $\begin{array}{c}\text { BHD } \\
32-j .\end{array}$ & $\begin{array}{c}\text { BHD. } \\
39-j .\end{array}$ & $\begin{array}{c}\text { BHD* } \\
39-j .\end{array}$ & $\begin{array}{c}\text { Höhe } \\
39-\text { j. }\end{array}$ \\
\hline 97 & Gérardmer & 9.8 & 12.4 & 16.0 & 12.1 \\
\hline 98 & Massif Central & 12.6 & 14.8 & 20.1 & 14.5 \\
\hline 103 & Wunsiedel & 13.8 & 17.3 & 21.8 & 14.3 \\
\hline 110 & Medebach & 11.7 & 14.3 & 17.4 & 12.7 \\
\hline 114 & Winterberg & 13.2 & 15.5 & 19.6 & 14.1 \\
\hline 124 & Istebna-Wisła & 11.7 & 11.6 & 15.3 & 11.9 \\
\hline 130 & Dobra bei Frydek & 14.2 & 17.1 & 22.3 & 14.6 \\
\hline 131 & Vizovice & 13.6 & 17.0 & 22.2 & 14.1 \\
\hline 139 & Vapenkova Skala & 16.0 & 19.7 & 21.6 & 15.2 \\
\hline 140 & Bucovice & 12.8 & 15.5 & 19.2 & 13.1 \\
\hline 141 & Pitin & 13.1 & 19.1 & 22.1 & 15.0 \\
\hline 142 & Rosice & 12.9 & 14.8 & 22.2 & 15.2 \\
\hline 150 & Schlanders & 10.3 & 11.3 & 15.0 & 11.3 \\
\hline 170 & Groß Arl & 12.6 & 17.4 & 19.7 & 13.3 \\
\hline 171 & Hofgastein & 12.7 & 16.4 & 22.4 & 14.1 \\
\hline 174 & Piesendorf & 11.7 & 13.9 & 18.8 & 13.8 \\
\hline 175 & Radstatt & 12.2 & 13.8 & 17.8 & 12.6 \\
\hline 176 & St. Johann & 12.8 & 14.2 & 18.1 & 12.8 \\
\hline 177 & Taxenbach & 12.2 & 14.3 & 18.9 & 14.2 \\
\hline 178 & Abtenau & 13.5 & 17.4 & 21.3 & 15.7 \\
\hline 179 & Bischofshofen & 12.7 & 14.2 & 18.9 & 14.7 \\
\hline 184 & Paternion & 12.5 & 15.9 & 19.8 & 13.9 \\
\hline 185 & St. Veit/Glan & 11.9 & 14.5 & 15.6 & 12.3 \\
\hline 186 & Graz-Nord & 12.9 & 17.5 & 21.8 & 15.2 \\
\hline 187 & Pack & 12.9 & 13.5 & 17.8 & 14.4 \\
\hline 188 & Waldstein a.d. Übelb. & 12.5 & 15.2 & 20.0 & 14.5 \\
\hline 189 & Graz-Süd & 11.2 & 12.6 & 15.0 & 11.9 \\
\hline 190 & Offenegg & 11.2 & 13.2 & 15.3 & 12.2 \\
\hline 192 & Södingberg & 13.1 & 16.6 & 18.1 & 13.9 \\
\hline 202 & Istebna-Wisła & 13.4 & 16.1 & 16.6 & 12.8 \\
\hline 204 & Spisske Pochradie & 14.4 & 15.7 & 19.5 & 14.6 \\
\hline 207 & Jönköpings län & 9.6 & 10.6 & 14.9 & 11.8 \\
\hline 208 & Istebna & 16.1 & 18.5 & 21.1 & 14.9 \\
\hline 215 & Stinava & 13.8 & 17.5 & 21.0 & 14.8 \\
\hline 217 & Istebna-Wisła & 13.8 & 15.8 & 19.0 & 13.6 \\
\hline 227 & Thüringen & 13.7 & 17.2 & 19.5 & 14.3 \\
\hline 229 & Olsztyn & 11.0 & 13.6 & 15.3 & 12.0 \\
\hline 284 & Blekinge län Asarum & 11.8 & 11.7 & 16.0 & 12.7 \\
\hline 290 & Högestad & 12.9 & 14.7 & 19.1 & 13.7 \\
\hline 291 & Karupsskogen Barsebäcks gods & 14.4 & 19.2 & 21.6 & 15.3 \\
\hline 293 & Trolleholm & 13.4 & 16.7 & 18.8 & 14.7 \\
\hline 294 & Aasbo-össiö Gods & 12.7 & 16.9 & 16.5 & 13.4 \\
\hline 295 & Öveds Kloster Öpedal & 12.4 & 13.8 & 15.3 & 12.9 \\
\hline 704 & Cazis Tschartlina & 9.4 & 10.4 & 13.3 & 11.3 \\
\hline 711 & La Genolière & 10.3 & 12.7 & 17.6 & 13.5 \\
\hline 712 & Forêt du Risoud & 11.4 & 14.9 & 16.5 & 13.4 \\
\hline 713 & Caragnago & 11.6 & 12.4 & 16.2 & 11.1 \\
\hline 716 & Altacanta & 11.7 & 12.9 & 18.6 & 13.3 \\
\hline 722 & Piana Selva, Faido & 12.4 & 13.8 & 18.9 & 12.9 \\
\hline 725 & Airolo, Crespato-Ressia & 11.6 & 12.1 & 14.8 & 10.7 \\
\hline
\end{tabular}

Beiträge aus der NW-FVA, Band 5, 2010 
Versuchsfläche 44

\begin{tabular}{|c|c|c|c|c|c|}
\hline $\begin{array}{c}\text { PG- } \\
\text { Nr. }\end{array}$ & Herkunft & $\begin{array}{l}\text { BHD } \\
32-j .\end{array}$ & $\begin{array}{c}\text { BHD. } \\
39-j .\end{array}$ & $\begin{array}{c}\text { BHD* } \\
39-j .\end{array}$ & $\begin{array}{l}\text { Höhe } \\
39-j .\end{array}$ \\
\hline 734 & Airolo, Bedretto & 9.5 & 9.7 & 12.9 & 10.4 \\
\hline 740 & Bex, Tarejanne & 9.9 & 11.5 & 14.8 & 11.7 \\
\hline 1100 & Monts Megal, Le Portius & 11.8 & 13.4 & 16.1 & 12.3 \\
\hline 1101 & Le Pertuis, Monts du Velay & 13.0 & 14.0 & 19.8 & 14.4 \\
\hline 1111 & Peisey-Nancroix, Grd. Bois & 9.5 & 10.0 & 13.1 & 10.5 \\
\hline 1112 & Autrans, Isère & 9.8 & 10.4 & 13.7 & 9.3 \\
\hline 1114 & Passy & 10.7 & 12.7 & 16.2 & 10.8 \\
\hline 1115 & Magland & 10.6 & 11.7 & 14.9 & 11.3 \\
\hline 1116 & Lantosque & 13.1 & 15.6 & 19.5 & 11.9 \\
\hline 1117 & Plan Bois, Ballandes & 10.6 & 11.4 & 14.5 & 9.5 \\
\hline 1202 & Manderfeld Gilbuschek 63 A & 12.7 & 15.0 & 19.4 & 13.7 \\
\hline 2113 & Oberes Gailtal & 11.5 & 12.2 & 13.5 & 11.2 \\
\hline 2114 & Kreuzen-Stockenboi & 10.3 & 11.9 & 15.8 & 12.0 \\
\hline 2115 & Rosental & 11.2 & 14.5 & 16.4 & 13.3 \\
\hline 2116 & Aich & 10.1 & 11.6 & 13.0 & 10.6 \\
\hline 2117 & Gurktal & 10.9 & 13.9 & 17.5 & 13.3 \\
\hline 2120 & Liembergwald Zell a. S. & 11.1 & 14.9 & 17.3 & 12.5 \\
\hline 2121 & Neukirchen Großvenediger & 13.5 & 15.9 & 19.3 & 13.2 \\
\hline 2122 & Piberegg & 11.9 & 15.7 & 16.4 & 11.4 \\
\hline 2123 & Gallmannsegg Kainach & 10.4 & 12.8 & 15.9 & 12.3 \\
\hline 2126 & Gaishorn & 11.5 & 14.1 & 16.5 & 11.7 \\
\hline 2128 & Lobming-Oberth. St. Stefan/Kraubath & 12.8 & 10.8 & 12.2 & 10.0 \\
\hline 2130 & Stanz-Kindthal-Allerheiligen & 13.4 & 15.7 & 20.3 & 14.0 \\
\hline 2140 & Fölz, Mayerberg & 10.2 & 15.3 & 15.3 & 11.6 \\
\hline 2141 & Fölz, Greith & 12.8 & 17.5 & 17.3 & 13.1 \\
\hline 2144 & Seewiesen, Seereith & 12.6 & 13.2 & 14.3 & 11.3 \\
\hline 2147 & Freiland, Gschwend & 10.5 & 12.5 & 16.4 & 12.0 \\
\hline 2149 & Kindberg/Eisenerzer Alpen & 11.4 & 13.0 & 15.1 & 11.5 \\
\hline 2150 & Siebensee Wildalpen & 11.8 & 13.9 & 16.8 & 12.8 \\
\hline 2160 & Turnau, Kapfenberg & 10.7 & 12.7 & 15.5 & 12.4 \\
\hline 3326 & Neureichenau & 13.4 & 15.2 & 18.8 & 13.7 \\
\hline 3328 & Spiegelau & 11.7 & 15.2 & 17.0 & 12.7 \\
\hline 3329 & Spiegelau & 13.0 & 15.6 & 19.6 & 13.1 \\
\hline 3332 & Zwiesel-Ost & 14.9 & 19.6 & 22.1 & 14.9 \\
\hline 3406 & SHK Stryck Willingen & 14.1 & 17.7 & 18.6 & 12.6 \\
\hline 3410 & Traunstein & 13.4 & 15.0 & 17.1 & 13.7 \\
\hline 3411 & Bischofswiesen & 13.0 & 16.7 & 19.9 & 13.7 \\
\hline 3412 & Winterberg & 13.8 & 17.4 & 19.1 & 12.9 \\
\hline 3413 & SHK Winterberg & 13.1 & 16.4 & 18.2 & 12.3 \\
\hline 3415 & SHK Hochsauerland & 13.7 & 17.1 & 20.3 & 14.2 \\
\hline 3416 & SHK Höhenfichten & 12.4 & 14.0 & 16.1 & 12.8 \\
\hline 3417 & Marsberg & 12.1 & 13.6 & 18.2 & 12.5 \\
\hline 3418 & Sachsenried & 12.8 & 16.0 & 18.4 & 13.4 \\
\hline 3419 & Schwarzwald Baar, VIII/6 & 13.2 & 18.5 & 20.3 & 14.0 \\
\hline 3420 & Daun/Ost & 13.5 & 15.4 & 19.3 & 14.3 \\
\hline 3421 & Dombühl & 13.1 & 17.0 & 19.8 & 14.2 \\
\hline 3422 & Stryck & 14.2 & 19.5 & 21.9 & 15.2 \\
\hline 3423 & Kohlstetten & 12.7 & 15.0 & 22.8 & 14.6 \\
\hline 3424 & Winterberg & 15.4 & 20.2 & 22.2 & 16.1 \\
\hline 3425 & Waldmünchen & 14.8 & 17.5 & 17.8 & 13.7 \\
\hline
\end{tabular}


Versuchsfläche 44

\begin{tabular}{|c|c|c|c|c|c|}
\hline $\begin{array}{l}\text { PG- } \\
\text { Nr. }\end{array}$ & Herkunft & $\begin{array}{c}\text { BHD } \\
32-j .\end{array}$ & $\begin{array}{c}\text { BHD. } \\
39-\mathrm{j} .\end{array}$ & $\begin{array}{c}\text { BHD* } \\
39-j .\end{array}$ & $\begin{array}{l}\text { Höhe } \\
39-\text { j. }\end{array}$ \\
\hline 3426 & Uelzen & 14.5 & 20.8 & 21.4 & 15.2 \\
\hline 3427 & Oderhaus & 12.4 & 16.2 & 18.1 & 12.6 \\
\hline 3428 & Schernfeld & 13.5 & 14.0 & 15.7 & 13.4 \\
\hline 3429 & Villingen & 14.0 & 18.3 & 19.6 & 13.9 \\
\hline 3430 & Diessen & 13.0 & 15.7 & 21.2 & 15.6 \\
\hline 3431 & Riedenburg & 13.1 & 16.4 & 18.8 & 14.7 \\
\hline 3432 & Walsrode & 13.3 & 16.6 & 16.9 & 12.6 \\
\hline 3433 & Selb-Kirchenlamitz (1) & 13.5 & 16.8 & 19.1 & 14.1 \\
\hline 3434 & Miele & 13.7 & 17.4 & 19.5 & 14.9 \\
\hline 3435 & Neureichenau (2) & 12.2 & 14.9 & 19.0 & 13.6 \\
\hline 3436 & Neureichenau (2) & 13.8 & 16.9 & 20.7 & 14.0 \\
\hline 3437 & Neureichenau (2) & 13.3 & 16.6 & 19.2 & 13.4 \\
\hline 3438 & Oderhaus & 13.3 & 16.7 & 16.4 & 13.3 \\
\hline 3444 & Zwiesel, Scheicherau XXI 14a/b $(3,6)$ & 13.8 & 15.4 & 18.5 & 13.7 \\
\hline 3445 & Zwiesel, Haselau XXI $12(3,6)$ & 13.5 & 19.9 & 22.1 & 14.7 \\
\hline 3447 & Nationalp. Hüttenschlag XIX 1b (6) & 14.0 & 18.2 & 18.9 & 13.9 \\
\hline 3448 & Nationalp. Filzwald IX 3a 10/11 (6) & 12.7 & 17.9 & 20.2 & 14.4 \\
\hline 3449 & Nationalp. Neubruck 1a10,b10/11,c10 (6) & 12.6 & 14.2 & 20.7 & 14.3 \\
\hline 3498 & Burgjoß & 13.3 & 14.8 & 17.4 & 13.2 \\
\hline 3499 & Chausseehaus & 13.2 & 15.2 & 19.5 & 14.9 \\
\hline 3505 & Eibenst. Carlsf. 275 & 18.2 & 21.6 & 27.4 & 16.4 \\
\hline 3617 & Torgelow & 12.8 & 15.7 & 18.8 & 13.4 \\
\hline 4011 & Cikaaj, Zdarska Vrchy & 12.3 & 14.1 & 21.2 & 14.1 \\
\hline 4032 & Kynsperk nad Ohri Libocky Dul & 15.0 & 16.4 & 21.0 & 14.6 \\
\hline 4042 & Vimperk-Prameny Vltury Stachy & 11.0 & 13.5 & 16.2 & 12.3 \\
\hline 4061 & Velke Mezirici-Rudolec & 12.9 & 15.3 & 17.2 & 13.8 \\
\hline 4081 & Frenstat pod Radhosten-Obora & 12.6 & 15.5 & 18.9 & 13.3 \\
\hline 4082 & Ostravice & 13.5 & 15.9 & 17.9 & 13.8 \\
\hline 4103 & Tatranska Lesna 559 C & 12.8 & 16.4 & 19.1 & 13.9 \\
\hline 4121 & Javorova Dolina 155 A, Nr. 4121 & 11.3 & 13.0 & 16.9 & 13.7 \\
\hline 4143 & Kysihybel & 12.8 & 16.1 & 20.0 & 14.5 \\
\hline 4154 & Roznava & 14.8 & 17.2 & 20.0 & 14.8 \\
\hline 4157 & Hnusta & 13.1 & 12.2 & 16.1 & 12.9 \\
\hline 4159 & Svrcina Hrabusice & 15.4 & 16.4 & 21.9 & 14.0 \\
\hline 5101 & Nedzinant, Prokletije (Geb.) & 13.0 & 15.4 & 18.5 & 11.7 \\
\hline 5201 & Köszeg 1 C & 13.3 & 15.5 & 18.9 & 14.3 \\
\hline 5202 & Szentgotthard $1 \mathrm{C}$ & 12.8 & 15.6 & 17.2 & 12.9 \\
\hline 5203 & Sarospatak-Haromhuta 19 B Zempl. Geb. & 13.0 & 18.3 & 19.1 & 13.3 \\
\hline 5204 & Miskolc-Lillafüred 82 A Bükker Geb. & 13.2 & 14.6 & 19.3 & 13.8 \\
\hline 5205 & Nagykanizsa-Iharos Plattensee 11/1-71 & 12.3 & 15.5 & 19.0 & 12.7 \\
\hline 5206 & Sopron (Hochschulrev.) 203 D & 12.4 & 15.1 & 19.8 & 14.7 \\
\hline 5302 & Beglika & 10.7 & 12.1 & 16.8 & 12.3 \\
\hline 5303 & Borovec (Rila-Geb.) & 9.9 & 13.4 & 18.6 & 12.7 \\
\hline 5401 & Valea Putnei-Pojorita & 13.5 & 20.1 & 20.1 & 14.8 \\
\hline 5413 & Brosteni Bradu/Bastitei & 11.7 & 12.8 & 14.8 & 12.1 \\
\hline 6106 & Köslin/Koszalin & 13.3 & 16.9 & 19.7 & 14.0 \\
\hline 6223 & Przerwanki & 11.8 & 13.0 & 16.9 & 13.1 \\
\hline 6237 & Puszcza-Białowieska & 12.4 & 15.4 & 19.2 & 14.2 \\
\hline 6250 & Augustow Abt. 95 b & 12.3 & 14.1 & 16.9 & 13.1 \\
\hline 6254 & Mikaszowka & 11.8 & 14.9 & 18.7 & 13.5 \\
\hline
\end{tabular}


Versuchsfläche 44

\begin{tabular}{c|l|c|c|c|c}
\hline $\begin{array}{c}\text { PG- } \\
\text { Nr. }\end{array}$ & Herkunft & $\begin{array}{c}\text { BHD } \\
32-j .\end{array}$ & $\begin{array}{c}\text { BHD. } \\
39-j .\end{array}$ & $\begin{array}{c}\text { BHD* } \\
39-j .\end{array}$ & $\begin{array}{c}\text { Höhe } \\
39-j .\end{array}$ \\
\hline 6255 & Puszcza-Augustowska & 11.0 & 12.7 & 14.4 & 12.1 \\
6260 & Knyszyn & 12.2 & 16.2 & 18.0 & 13.1 \\
6261 & Kumialka (Kumialska) & 12.2 & 11.9 & 11.9 & 10.0 \\
6410 & Sierpc & 13.1 & 16.8 & 18.4 & 14.3 \\
6896 & Borken & 10.6 & 11.8 & 16.3 & 12.5 \\
7401 & Gzatsk-Smolensk & 11.0 & 12.8 & 16.0 & 13.2 \\
8703 & Lohja Laaskspohjan & 9.9 & 10.4 & 14.4 & 11.3 \\
9170 & Ryssby-Kronobergs & 10.1 & 10.6 & 15.4 & 12.3 \\
9417 & Marsberg & 13.9 & 20.2 & 23.9 & 16.2 \\
9423 & Kohlstetten & 12.2 & 14.7 & 18.8 & 13.8 \\
9432 & Walsrode & 13.5 & 19.0 & 19.7 & 14.2 \\
\hline
\end{tabular}

Versuchsfläche 45

\begin{tabular}{clc|c|c|c}
\hline $\begin{array}{c}\text { PG- } \\
\text { Nr. }\end{array}$ & Herkunft & $\begin{array}{c}\text { BHD } \\
32-j .\end{array}$ & $\begin{array}{c}\text { BHD. } \\
39-j .\end{array}$ & $\begin{array}{c}\text { BHD* } \\
39-j .\end{array}$ & $\begin{array}{c}\text { Höhe } \\
39-j .\end{array}$ \\
\hline 107 & Donaueschingen & 14.5 & 19.0 & 20.7 & 13.9 \\
111 & Bodenmais & 13.8 & 16.9 & 20.0 & 14.1 \\
115 & Westerhof & 16.0 & 23.2 & 24.9 & 17.1 \\
121 & Cedrogne & 13.9 & 17.0 & 18.2 & 13.1 \\
129 & Allenstein & 12.1 & 16.2 & 18.8 & 13.4 \\
149 & Einsiedeln & 11.9 & 11.3 & 12.8 & 10.4 \\
2118 & Gurker Sirnitzwald & 13.5 & 15.7 & 18.8 & 14.0 \\
2131 & Veitsch-Neuberg & 15.2 & 15.8 & 18.6 & 14.5 \\
2133 & Hinterhof, Eibelkogel & 13.8 & 18.2 & 20.2 & 13.9 \\
2134 & Hinterhof, Ostbrenner u. Tiefental & 14.0 & 17.4 & 22.9 & 15.8 \\
2135 & Kraubath, Seckauer Tauern & 11.0 & 15.0 & 17.3 & 13.6 \\
2137 & Buchberg, Flachwald/Aflenz & 12.0 & 17.7 & 20.1 & 15.4 \\
2138 & Buchberg, Ägidiwald/Aflenz & 13.8 & 19.5 & 22.3 & 15.4 \\
2151 & Breitenau-Mixnitz/Fischbacher Alp. & 13.6 & 20.1 & 22.5 & 15.4 \\
2158 & Rohr im Gebirge, Kirchwald & 14.7 & 17.9 & 22.9 & 16.2 \\
2179 & Eisenkappel/Karaw. & 14.1 & 17.5 & 20.5 & 15.1 \\
2184 & Schneegattern & 14.8 & 18.7 & 20.4 & 15.6 \\
2207 & Seewiesen Seereith/Aflenz & 13.8 & 21.5 & 23.2 & 17.8 \\
3003 & Blumberg & 13.3 & 18.3 & 18.1 & 14.4 \\
3042 & Walchensee & 13.6 & 15.5 & 21.9 & 14.6 \\
3102 & Schluchsee-Eschenmoos & 14.0 & 16.7 & 20.0 & 14.3 \\
3139 & Isny Ba/Wü & 13.2 & 16.8 & 21.0 & 15.8 \\
3204 & Burghausen/Salzach & 13.7 & 18.0 & 16.9 & 13.6 \\
3205 & Ebersberg & 13.8 & 19.3 & 19.3 & 14.4 \\
3211 & Moosburg/Isar & 15.6 & 20.1 & 23.0 & 16.7 \\
3310 & Zwiesel-West/Ruselhänge X/68 & 13.8 & 16.6 & 20.9 & 14.7 \\
3323 & Mauth/Ost & 16.9 & 24.2 & 25.3 & 16.9 \\
3325 & Neureichenau/Typengemisch & 15.1 & 23.0 & 23.2 & 15.4 \\
3327 & Passau/Nord & 13.6 & 17.5 & 17.9 & 13.2 \\
3331 & St. Oswald I/3,4,6 Typengemisch & 14.4 & 22.6 & 25.0 & 16.8 \\
3337 & Rabenstein Typengemisch & 12.3 & 15.2 & 15.2 & 12.0 \\
3404 & Westerhof Abt. 51 B & 14.5 & 19.0 & 20.6 & 14.7
\end{tabular}


Versuchsfläche 45

\begin{tabular}{|c|c|c|c|c|c|}
\hline $\begin{array}{l}\text { PG- } \\
\text { Nr. }\end{array}$ & Herkunft & $\begin{array}{l}\text { BHD } \\
32-j .\end{array}$ & $\begin{array}{c}\text { BHD. } \\
39-j .\end{array}$ & $\begin{array}{c}\text { BHD* }^{*} \\
39-\mathrm{j} .\end{array}$ & $\begin{array}{l}\text { Höhe } \\
39-j .\end{array}$ \\
\hline 3417 & Marsberg & 16.0 & 23.8 & 24.8 & 16.6 \\
\hline 3423 & Kohlstetten & 14.4 & 20.2 & 20.2 & 14.5 \\
\hline 3430 & Diessen & 14.5 & 15.7 & 18.3 & 13.9 \\
\hline 3432 & Walsrode & 15.3 & 20.1 & 22.8 & 17.2 \\
\hline 3433 & Selb-Kirchenlamitz (1) & 13.8 & 16.1 & 19.9 & 14.2 \\
\hline 3443 & Zwiesel, Scheichereb. XXI 13b1 $(3,6)$ & 12.7 & 16.8 & 19.1 & 13.3 \\
\hline 3503 & Eibenst. Carlsf. Wiesenh. 214 & 17.8 & 24.0 & 25.0 & 17.6 \\
\hline 3510 & Sonneb. Steinheid, Kieferleskopf & 14.9 & 18.9 & 20.2 & 14.5 \\
\hline 3511 & Innenau Elgersburg & 15.2 & 20.7 & 21.2 & 15.7 \\
\hline 3518 & Suhl, Oberhofer Schloßbergkopf & 17.1 & 24.1 & 25.1 & 16.5 \\
\hline 3519 & Mechterstädt & 16.4 & 20.0 & 22.9 & 16.9 \\
\hline 3606 & Templin, Bad Doberan Nr. 9 & 13.9 & 17.1 & 19.5 & 16.1 \\
\hline 3615 & Neustrelitz & 16.9 & 18.8 & 20.1 & 15.3 \\
\hline 4022 & Boubin III & 14.1 & 14.8 & 18.9 & 13.3 \\
\hline 4026 & Habartice, Planice & 13.4 & 18.3 & 19.3 & 13.7 \\
\hline 4051 & Vysoky Chlumec Veletin & 14.2 & 13.1 & 19.4 & 14.3 \\
\hline 4053 & Cesky Krumlov Borova & 13.2 & 16.3 & 21.0 & 14.3 \\
\hline 4054 & Chlum u. Trebone-Hamr & 14.8 & 19.2 & 21.4 & 15.1 \\
\hline 4060 & Hencov-Trest & 13.6 & 19.9 & 22.3 & 15.2 \\
\hline 4070 & Vrchlabi & 14.7 & 18.5 & 19.9 & 14.8 \\
\hline 4073 & Jesenik-Zlate Hory & 14.8 & 19.6 & 20.5 & 16.5 \\
\hline 4123 & Javorova Dolina 155 A, Nr.4123 & 13.3 & 11.5 & 12.1 & 12.7 \\
\hline 5102 & Kaludjerske Bore Taram Kremma & 15.2 & 20.9 & 21.4 & 15.6 \\
\hline 5107 & Smrceve Dolina Abt. 138 & 13.1 & 15.3 & 20.0 & 15.2 \\
\hline 5301 & Belogradchik-Tschupreno & 12.7 & 16.4 & 16.6 & 14.0 \\
\hline 5412 & Moldovita-Sacries & 12.5 & 15.9 & 18.1 & 14.7 \\
\hline 5415 & Cimpeni-Dara & 15.1 & 19.0 & 22.0 & 16.1 \\
\hline 5416 & Remeti-Zerna & 14.8 & 22.2 & 23.4 & 16.4 \\
\hline 5420 & Valea Putnei-Pojorita III/60 & 14.1 & 17.6 & 19.5 & 14.9 \\
\hline 5426 & Crucea-Barnavel Abt. 17/18 & 12.1 & 14.8 & 18.7 & 13.5 \\
\hline 6103 & Brotzen/Broczyno & 13.9 & 16.4 & 19.7 & 15.1 \\
\hline 6222 & Borken/Borki & 13.3 & 15.6 & 18.5 & 14.5 \\
\hline 6234 & Białowieża & 14.2 & 17.1 & 20.1 & 15.8 \\
\hline 6235 & Zwierzyniec & 14.6 & 18.1 & 20.2 & 16.9 \\
\hline 6251 & Białobrzegi & 14.2 & 20.6 & 20.6 & 15.1 \\
\hline 6510 & Bunzlau/Boleslawiec & 14.0 & 18.2 & 20.6 & 16.6 \\
\hline 6543 & Groß-Lassowitz/Lassowice Male & 13.5 & 20.4 & 21.2 & 16.4 \\
\hline 6624 & Przysucha & 15.1 & 21.6 & 21.6 & 15.6 \\
\hline 6712 & Klodzko-Glatz/Nynow 68 e & 14.1 & 16.0 & 20.0 & 15.2 \\
\hline 6731 & Szcytna-Slaska Karlow 243 a & 15.9 & 20.2 & 22.7 & 16.1 \\
\hline 6732 & Szcytna-Slaska Karlow 292 b & 16.7 & 21.4 & 21.8 & 15.0 \\
\hline 6864 & Istebna-Ujsoly & 14.2 & 18.4 & 18.5 & 14.2 \\
\hline 6894 & Witów & 13.7 & 18.2 & 20.4 & 14.7 \\
\hline 7224 & Ostrovskij-Pskow & 11.5 & 16.0 & 16.9 & 15.0 \\
\hline 7233 & Wolozin & 14.0 & 17.5 & 19.5 & 16.0 \\
\hline 7235 & Brigalovic-Mogilev & 14.7 & 19.1 & 24.0 & 18.2 \\
\hline 8003 & Fussinge & 16.1 & 20.0 & 23.3 & 17.1 \\
\hline 8705 & Mänttä & 10.9 & 13.2 & 16.2 & 13.6 \\
\hline 8707 & Janakkala Keskivari Uhkoila & 11.5 & 12.0 & 13.9 & 11.8 \\
\hline
\end{tabular}


Versuchsfläche 46

\begin{tabular}{|c|c|c|c|c|c|}
\hline $\begin{array}{c}\text { PG- } \\
\text { Nr. }\end{array}$ & Herkunft & $\begin{array}{l}\text { BHD } \\
32-j .\end{array}$ & $\begin{array}{c}\text { BHD. } \\
39-j .\end{array}$ & $\begin{array}{c}\text { BHD* } \\
39-j .\end{array}$ & $\begin{array}{c}\text { Höhe } \\
39-j .\end{array}$ \\
\hline 65 & Eisenkappel Thurn 2 & 12.1 & 15.3 & 21.5 & 16.0 \\
\hline 93 & Sieber & 12.8 & 15.2 & 16.0 & 11.9 \\
\hline 105 & Hohenschwangau & 11.8 & 14.0 & 18.8 & 14.7 \\
\hline 108 & Lauterberg & 16.1 & 21.5 & 24.8 & 16.6 \\
\hline 116 & Kobernausserwald & 13.5 & 16.1 & 19.6 & 15.7 \\
\hline 169 & Gries & 12.7 & 15.4 & 18.1 & 14.9 \\
\hline 172 & Mittersill & 12.5 & 13.1 & 15.5 & 12.8 \\
\hline 191 & Passail & 12.9 & 17.1 & 20.2 & 14.6 \\
\hline 230 & Elbingerode & 15.0 & 17.1 & 20.2 & 14.3 \\
\hline 1118 & Chatel, 1 Aity" & 12.1 & 13.9 & 17.8 & 13.3 \\
\hline 1201 & Mellier, Bois Bayai, 2 & 15.6 & 17.4 & 19.3 & 15.1 \\
\hline 2124 & Stixenstein, Gahns & 12.5 & 16.2 & 17.1 & 14.3 \\
\hline 2127 & Unterhal, St. Kathrein a.d. Lamming & 12.8 & 15.5 & 18.6 & 15.2 \\
\hline 2174 & Klein-Sölk/Niedertauern & 11.6 & 14.7 & 17.1 & 13.5 \\
\hline 3150 & Dillingen a.d.D. Bay. & 13.6 & 17.8 & 21.1 & 15.3 \\
\hline 3206 & Eglharting XIV/17,19 & 15.0 & 18.3 & 21.7 & 15.9 \\
\hline 3213 & Mühldorf/Inn & 14.7 & 17.0 & 20.0 & 15.0 \\
\hline 3414 & Bodensee Oberschwab. VIII/13 & 14.6 & 20.8 & 22.1 & 16.8 \\
\hline 3417 & Marsberg & 13.9 & 17.5 & 17.5 & 13.2 \\
\hline 3423 & Kohlstetten & 17.0 & 23.6 & 23.8 & 16.6 \\
\hline 3430 & Diessen & 11.4 & 14.5 & 16.9 & 12.4 \\
\hline 3432 & Walsrode & 14.6 & 19.3 & 19.3 & 14.1 \\
\hline 3433 & Selb-Kirchenlamitz (1) & 14.0 & 17.5 & 22.0 & 16.5 \\
\hline 3446 & Zwiesel, Schmalzau IX 3c $(5,6)$ & 14.6 & 18.0 & 20.1 & 15.4 \\
\hline 4050 & Vlasim-Votice & 13.6 & 18.9 & 18.3 & 14.4 \\
\hline 4075 & Vitkov-Budisov & 14.5 & 17.1 & 22.5 & 17.2 \\
\hline 4127 & Javorova Dolina 155 A, Nr.4127 & 12.3 & 17.6 & 17.6 & 13.4 \\
\hline 5424 & Valea Beliei-Sinaia Gurguiata & 12.3 & 11.9 & 16.7 & 12.9 \\
\hline 5425 & Cimpeni-Nedei & 13.9 & 15.9 & 18.4 & 14.5 \\
\hline 6107 & Altenhagen/Nowy Krakow & 14.1 & 17.6 & 20.7 & 14.9 \\
\hline 6236 & Białowieża & 10.9 & 15.9 & 18.6 & 15.1 \\
\hline 6897 & Goldap & 11.3 & 14.5 & 17.3 & 15.1 \\
\hline 7232 & Cemerjanskoe-Mogilev & 12.7 & 14.8 & 16.0 & 14.5 \\
\hline 7234 & Soboljanskoe-Grodno & 12.6 & 13.8 & 17.5 & 14.4 \\
\hline 7240 & Witebsk & 11.8 & 13.3 & 16.6 & 15.2 \\
\hline 9191 & Karlsholms-Kristianstad & 15.3 & 19.5 & 23.1 & 17.1 \\
\hline
\end{tabular}




\section{Anhang 1.23}

Zusammenstellung der sich signifikant von mindestens einer anderen Herkunft im Tukey-Kramer-Test beim BHD-Wachstum [cm] im Alter 32 auf der Versuchsfläche 44 Hasbruch / Niedersachsen unterscheidenden Herkünfte

\begin{tabular}{|c|c|c|c|c|c|}
\hline Rang & $\begin{array}{l}\text { PG- } \\
\text { Nr. }\end{array}$ & Herkunft & Land & $\begin{array}{c}\text { Höhe } \\
\text { m ü. NN }\end{array}$ & $\begin{array}{l}\text { BHD } \\
{[\mathrm{cm}]}\end{array}$ \\
\hline 1 & 3505 & Eibenst. Carlsf. 275 & $\mathrm{D}$ & 925 & 18.46 \\
\hline 2 & 4157 & Hnusta & CS & 550 & 17.05 \\
\hline 3 & 139 & Vapenkova Skala & CS & 540 & 16.53 \\
\hline \multicolumn{6}{|c|}{123 Herkünfte } \\
\hline$\dddot{127}$ & 2149 & Kindberg/Eisenerzer Alpen & A & 1000 & 11.64 \\
\hline 128 & 174 & Piesendorf & A & 900 & 11.64 \\
\hline 129 & 5413 & Brosteni Bradu/Bastitei & RU & 1475 & 11.63 \\
\hline 130 & 2120 & Liembergwald Zell a. S. & A & 875 & 11.56 \\
\hline 131 & 2126 & Gaishorn & A & 1200 & 11.55 \\
\hline 132 & 2115 & Rosental & A & 1000 & 11.50 \\
\hline 133 & 712 & Forêt du Risoud & $\mathrm{CH}$ & 1100 & 11.46 \\
\hline 134 & 725 & Airolo, Crespato-Ressia & $\mathrm{CH}$ & 1120 & 11.42 \\
\hline 135 & 4121 & Javorova Dolina 155 A, Nr. 4121 & CS & 1200 & 11.35 \\
\hline 136 & 229 & Olsztyn & PL & 100 & 11.29 \\
\hline 137 & 190 & Offenegg & A & 950 & 11.24 \\
\hline 138 & 189 & Graz-Süd & A & 850 & 11.18 \\
\hline 139 & 7401 & Gzatsk-Smolensk & SU & 194 & 11.11 \\
\hline 140 & 41 & Spiegelau & $\mathrm{D}$ & 750 & 11.07 \\
\hline 141 & 4042 & Vimperk-Prameny Vltury Stachy & CS & 950 & 11.06 \\
\hline 142 & 6255 & Puszcza-Augustowska & PL & 125 & 11.05 \\
\hline 143 & 2160 & Turnau, Kapfenberg & A & 1100 & 10.99 \\
\hline 144 & 2117 & Gurktal i & A & 1300 & 10.91 \\
\hline 145 & 6896 & Borken & PL & 165 & 10.68 \\
\hline 146 & 1114 & Passy & $\mathrm{F}$ & 1200 & 10.68 \\
\hline 147 & 5302 & Beglika & BG & 1850 & 10.67 \\
\hline 148 & 1117 & Plan Bois, Ballandes & $\mathrm{F}$ & 500 & 10.63 \\
\hline 149 & 2123 & Gallmannsegg Kainach & A & 1100 & 10.57 \\
\hline 150 & 2147 & Freiland, Gschwend & A & 1000 & 10.51 \\
\hline 151 & 1115 & Magland & $\mathrm{F}$ & 700 & 10.50 \\
\hline 152 & 2113 & Oberes Gailtal & A & 1100 & 10.40 \\
\hline 153 & 61 & Gosau & A & 700 & 10.38 \\
\hline 154 & 711 & La Genolière & $\mathrm{CH}$ & & 10.31 \\
\hline 155 & 150 & Schlanders & I & 1500 & 10.31 \\
\hline 156 & 2114 & Kreuzen-Stockenboi & A & 1200 & 10.26 \\
\hline 157 & 2140 & Fölz, Maverberg & A & 950 & 10.17 \\
\hline 158 & 9170 & Ryssby-Kronobergs & $\mathrm{S}$ & 175 & 10.10 \\
\hline 159 & 5303 & Borovec (Rila-Geb.) & BG & 1300 & 9.94 \\
\hline 160 & 97 & Gérardmer & $\mathrm{F}$ & 850 & 9.94 \\
\hline 161 & 2116 & Aich & A & 700 & 9.90 \\
\hline 162 & 740 & Bex, Tarejanne & $\mathrm{CH}$ & 1600 & 9.90 \\
\hline 163 & 8703 & Lohja Laaskspohjan & SF & 50 & 9.89 \\
\hline 164 & 1112 & Autrans, Isère & $\mathrm{F}$ & 1250 & 9.78 \\
\hline 165 & 207 & Jönköpings län & $\mathrm{S}$ & 170 & 9.65 \\
\hline 166 & 704 & Cazis Tschartlina & $\mathrm{CH}$ & 750 & 9.50 \\
\hline 167 & 1111 & Peisey-Nancroix, Grd. Bois & $\mathrm{F}$ & 1400 & 9.41 \\
\hline 168 & 734 & Airolo, Bedretto & $\mathrm{CH}$ & 1600 & 9.41 \\
\hline
\end{tabular}




\section{Anhang 1.24}

Zusammenstellung der mittleren Einzelbaumvolumina und Vorräte pro Hektar im Alter von 39 Jahren auf den drei niedersächsischen Versuchsflächen Hasbruch (alsolut und relativ im Verbältnis zum Mittel der 3 Versuchsflächen)

\begin{tabular}{|c|c|c|c|c|c|c|c|}
\hline \multicolumn{8}{|c|}{ 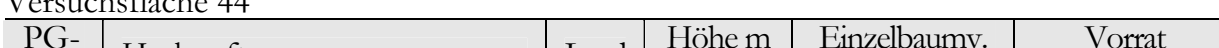 } \\
\hline Nr. & Herkunft & Land & ü. NN & {$\left[\mathrm{m}^{3}\right]$} & {$[\%]$} & {$\left[\mathrm{m}^{3} / \mathrm{ha}\right]$} & $\mid[\%]$ \\
\hline 41 & Spiegelau & D & 750 & 0.084 & 53 & 48 & 63 \\
\hline 60 & Aflenz & A & 1000 & 0.145 & 92 & 76 & 98 \\
\hline 61 & Gosau & A & 700 & 0.074 & 47 & 50 & 65 \\
\hline 62 & Litschau & A & 600 & 0.149 & 94 & 70 & 91 \\
\hline 63 & Eisenkappel Thurn 1 & A & 850 & 0.153 & 97 & 96 & 124 \\
\hline 64 & St. Martin & A & 500 & 0.139 & 88 & 65 & 84 \\
\hline 66 & Vorau & A & 900 & 0.126 & 80 & 72 & 94 \\
\hline 97 & Gérardmer & $\mathrm{F}$ & 850 & 0.070 & 44 & 54 & 71 \\
\hline 98 & Massif Central & $\mathrm{F}$ & 1100 & 0.125 & 79 & 97 & 127 \\
\hline 103 & Wunsiedel & $\mathrm{D}$ & 900 & 0.163 & 103 & 102 & 133 \\
\hline 110 & Medebach & $\mathrm{D}$ & 600 & 0.105 & 66 & 55 & 71 \\
\hline 114 & Winterberg & $\mathrm{D}$ & 800 & 0.137 & 87 & 72 & 93 \\
\hline 124 & Istebna-Wisła & PL & 725 & 0.087 & 55 & 55 & 71 \\
\hline 130 & Dobra bei Frydek & CS & 550 & 0.180 & 114 & 103 & 134 \\
\hline 131 & Vizovice & CS & 500 & 0.160 & 101 & 100 & 130 \\
\hline 139 & Vapenkova Skala & CS & 540 & 0.228 & 144 & 95 & 124 \\
\hline 140 & Bucovice & CS & 480 & 0.158 & 100 & 74 & 96 \\
\hline 141 & Pitin & CS & 610 & 0.234 & 148 & 134 & 174 \\
\hline 142 & Rosice & CS & 465 & 0.138 & 87 & 108 & 140 \\
\hline 150 & Schlanders & I & 1500 & 0.064 & 40 & 43 & 56 \\
\hline 170 & Groß Arl & A & 1350 & 0.167 & 106 & 78 & 102 \\
\hline 171 & Hofgastein & A & 1100 & 0.167 & 105 & 104 & 135 \\
\hline 174 & Piesendorf & A & 900 & 0.099 & 63 & 72 & 94 \\
\hline 175 & Radstatt & A & 1000 & 0.106 & 67 & 77 & 100 \\
\hline 176 & St. Johann & A & 1200 & 0.100 & 63 & 68 & 88 \\
\hline 177 & Taxenbach & A & 1400 & 0.126 & 80 & 65 & 85 \\
\hline 178 & Abtenau & A & 900 & 0.169 & 107 & 79 & 103 \\
\hline 179 & Bischofshofen & A & 1200 & 0.124 & 78 & 84 & 109 \\
\hline 184 & Paternion & A & 900 & 0.150 & 95 & 70 & 91 \\
\hline 185 & St. Veit/Glan & A & 600 & 0.103 & 65 & 48 & 63 \\
\hline 186 & Graz-Nord & A & 850 & 0.214 & 136 & 112 & 145 \\
\hline 187 & Pack & A & 950 & 0.101 & 64 & 63 & 82 \\
\hline 188 & Waldstein a.d. Übelb. & A & 850 & 0.138 & 88 & 101 & 131 \\
\hline 189 & Graz-Süd & A & 850 & 0.074 & 47 & 46 & 60 \\
\hline 190 & Offenegg & A & 950 & 0.078 & 49 & 49 & 63 \\
\hline 192 & Södingberg & A & 550 & 0.148 & 94 & 85 & 110 \\
\hline 202 & Istebna-Wisła & PL & 725 & 0.134 & 85 & 42 & 54 \\
\hline 204 & Spisske Pochradie & CS & 700 & 0.146 & 92 & 76 & 99 \\
\hline 207 & Jönköpings län & $\mathrm{S}$ & 170 & 0.054 & 34 & 42 & 55 \\
\hline 208 & Istebna & PL & 725 & 0.229 & 145 & 83 & 108 \\
\hline 215 & Stinava & SK & & 0.164 & 104 & 111 & 144 \\
\hline 217 & Istebna-Wisła & PL & 725 & 0.128 & 81 & 47 & 60 \\
\hline 227 & Thüringen & $\mathrm{D}$ & 300 & 0.167 & 105 & 121 & 158 \\
\hline 229 & Olsztyn & PL & 100 & 0.089 & 57 & 42 & 54 \\
\hline 284 & Blekinge län Asarum & S & 100 & 0.067 & 43 & 42 & 55 \\
\hline
\end{tabular}


Versuchsfläche 44

\begin{tabular}{|c|c|c|c|c|c|c|c|}
\hline \multirow{2}{*}{$\begin{array}{l}\text { PG- } \\
\text { Nr. }\end{array}$} & \multirow{2}{*}{ Herkunft } & \multirow{2}{*}{ Land } & \multirow{2}{*}{$\begin{array}{l}\text { Höhe m } \\
\text { ü. NN }\end{array}$} & \multicolumn{2}{|c|}{ Einzelbaumv. } & \multicolumn{2}{|c|}{ Vorrat } \\
\hline & & & & {$\left[\mathrm{m}^{3}\right]$} & {$[\%]$} & {$\left[\mathrm{m}^{3} / \mathrm{ha}\right]$} & {$[\%]$} \\
\hline 290 & Högestad & $\mathrm{S}$ & 50 & 0.113 & 72 & 77 & 100 \\
\hline 291 & Karupsskogen Barsebäcks gods & $\mathrm{S}$ & 100 & 0.216 & 137 & 79 & 102 \\
\hline 293 & Trolleholm & $\mathrm{S}$ & 125 & 0.164 & 104 & 94 & 122 \\
\hline 294 & Aasbo-össjö Gods & $\mathrm{S}$ & 50 & 0.163 & 103 & 68 & 88 \\
\hline 295 & Öveds Kloster Öpedal & $\mathrm{S}$ & 50 & 0.097 & 61 & 55 & 72 \\
\hline 704 & Cazis Tschartlina & $\mathrm{CH}$ & 750 & 0.051 & 32 & 45 & 59 \\
\hline 711 & La Genolière & $\mathrm{CH}$ & & 0.091 & 58 & 62 & 80 \\
\hline 712 & Forêt du Risoud & $\mathrm{CH}$ & 1100 & 0.117 & 74 & 61 & 79 \\
\hline 713 & Caragnago & $\mathrm{CH}$ & 1180 & 0.072 & 46 & 53 & 68 \\
\hline 716 & Altacanta & $\mathrm{CH}$ & 1400 & 0.098 & 62 & 56 & 73 \\
\hline 722 & Piana Selva, Faido & $\mathrm{CH}$ & 980 & 0.118 & 74 & 67 & 88 \\
\hline 725 & Airolo, Crespato-Ressia & $\mathrm{CH}$ & 1120 & 0.071 & 45 & 48 & 62 \\
\hline 734 & Airolo, Bedretto & $\mathrm{CH}$ & 1600 & 0.041 & 26 & 30 & 39 \\
\hline 740 & Bex, Tarejanne & $\mathrm{CH}$ & 1600 & 0.060 & 38 & 50 & 65 \\
\hline 1100 & Monts Megal, Le Portius & $\mathrm{F}$ & 900 & 0.088 & 55 & 46 & 59 \\
\hline 1101 & Le Pertuis, Monts du Velay & $\mathrm{F}$ & 1100 & 0.106 & 67 & 77 & 100 \\
\hline 1111 & Peisey-Nancroix, Grd. Bois & $\mathrm{F}$ & 1400 & 0.052 & 33 & 35 & 46 \\
\hline 1112 & Autrans, Isère & $\mathrm{F}$ & 1250 & 0.045 & 29 & 24 & 31 \\
\hline 1114 & Passy & $\mathrm{F}$ & 1200 & 0.073 & 46 & 80 & 104 \\
\hline 1115 & Magland & $\mathrm{F}$ & 700 & 0.077 & 49 & 36 & 47 \\
\hline 1116 & Lantosque & $\mathrm{F}$ & 1500 & 0.158 & 100 & 107 & 139 \\
\hline 1117 & Plan Bois, Ballandes & $\mathrm{F}$ & 500 & 0.061 & 38 & 44 & 57 \\
\hline 1202 & Manderfeld Gilbuschek 63 A & B & 542 & 0.119 & 75 & 93 & 121 \\
\hline 2113 & Oberes Gailtal & A & 1100 & 0.076 & 48 & 47 & 62 \\
\hline 2114 & Kreuzen-Stockenboi & A & 1200 & 0.067 & 43 & 60 & 78 \\
\hline 2115 & Rosental & A & 1000 & 0.109 & 69 & 62 & 81 \\
\hline 2116 & Aich & A & 700 & 0.066 & 41 & 44 & 58 \\
\hline 2117 & Gurktal & A & 1300 & 0.116 & 74 & 61 & 79 \\
\hline 2120 & Liembergwald Zell a. S. & A & 875 & 0.140 & 88 & 58 & 76 \\
\hline 2121 & Neukirchen Großvenediger & A & 870 & 0.152 & 96 & 87 & 113 \\
\hline 2122 & Piberegg & A & 800 & 0.140 & 89 & 44 & 57 \\
\hline 2123 & Gallmannsegg Kainach & A & 1100 & 0.077 & 49 & 44 & 57 \\
\hline 2126 & Gaishorn & A & 1200 & 0.101 & 64 & 63 & 82 \\
\hline 2128 & Lobming-Oberth. St. Stefan/Kraubath & & 800 & 0.051 & 33 & 13 & 17 \\
\hline 2130 & Stanz-Kindthal-Allerheiligen & A & 750 & 0.157 & 99 & 82 & 106 \\
\hline 2140 & Fölz, Mayerberg & A & 950 & 0.106 & 67 & 33 & 43 \\
\hline 2141 & Fölz, Greith & A & 825 & 0.198 & 126 & 93 & 121 \\
\hline 2144 & Seewiesen, Seereith & A & 875 & 0.081 & 51 & 38 & 49 \\
\hline 2147 & Freiland, Gschwend & A & 1000 & 0.084 & 53 & 48 & 62 \\
\hline 2149 & Kindberg/Eisenerzer Alpen & A & 1000 & 0.074 & 47 & 43 & 55 \\
\hline 2150 & Siebensee Wildalpen & A & 850 & 0.101 & 64 & 63 & 82 \\
\hline 2160 & Turnau, Kapfenberg & A & 1100 & 0.079 & 50 & 37 & 48 \\
\hline 3326 & Neureichenau & $\mathrm{D}$ & 1200 & 0.123 & 78 & 83 & 108 \\
\hline 3328 & Spiegelau & $\mathrm{D}$ & 1200 & 0.125 & 79 & 65 & 85 \\
\hline 3329 & Spiegelau & $\mathrm{D}$ & 1200 & 0.156 & 98 & 89 & 116 \\
\hline 3332 & Zwiesel-Ost & $\mathrm{D}$ & 1000 & 0.212 & 134 & 111 & 144 \\
\hline 3406 & SHK Stryck Willingen & $\mathrm{D}$ & 550 & 0.182 & 115 & 76 & 98 \\
\hline 3410 & Traunstein & $\mathrm{D}$ & 850 & 0.112 & 71 & 59 & 76 \\
\hline 3411 & Bischofswiesen & $\mathrm{D}$ & 950 & 0.158 & 100 & 82 & 107 \\
\hline 3412 & Winterberg & $\mathrm{D}$ & 750 & 0.170 & 108 & 62 & 81 \\
\hline
\end{tabular}


Versuchsfläche 44

\begin{tabular}{|c|c|c|c|c|c|c|c|}
\hline \multirow{2}{*}{$\begin{array}{l}\text { PG- } \\
\text { Nr. }\end{array}$} & \multirow{2}{*}{ Herkunft } & \multirow{2}{*}{ Land } & \multirow{2}{*}{$\begin{array}{c}\text { Höhe m } \\
\text { ü. NN }\end{array}$} & \multicolumn{2}{|c|}{ Einzelbaumv. } & \multicolumn{2}{|c|}{ Vorrat } \\
\hline & & & & {$\left[\mathrm{m}^{3}\right]$} & {$[\%]$} & {$\left[\mathrm{m}^{3} / \mathrm{ha}\right]$} & {$[\%]$} \\
\hline 3413 & SHK Winterberg & $\mathrm{D}$ & 750 & 0.148 & 94 & 62 & 80 \\
\hline 3415 & SHK Hochsauerland & $\mathrm{D}$ & 600 & 0.149 & 95 & 62 & 81 \\
\hline 3416 & SHK Höhenfichten & $\mathrm{D}$ & 1050 & 0.096 & 61 & 45 & 59 \\
\hline 3417 & Marsberg & $\mathrm{D}$ & 500 & 0.097 & 61 & 66 & 85 \\
\hline 3418 & Sachsenried & $\mathrm{D}$ & 900 & 0.144 & 91 & 82 & 107 \\
\hline 3419 & Schwarzwald Baar, VIII/6 & $\mathrm{D}$ & 700 & 0.177 & 112 & 92 & 120 \\
\hline 3420 & Daun/Ost & $\mathrm{D}$ & 450 & 0.139 & 88 & 80 & 103 \\
\hline 3421 & Dombühl & $\mathrm{D}$ & 450 & 0.162 & 103 & 84 & 110 \\
\hline 3422 & Stryck & $\mathrm{D}$ & 650 & 0.206 & 130 & 86 & 111 \\
\hline 3423 & Kohlstetten & $\mathrm{D}$ & 750 & 0.141 & 89 & 103 & 134 \\
\hline 3424 & Winterberg & $\mathrm{D}$ & 450 & 0.251 & 159 & 131 & 170 \\
\hline 3425 & Waldmünchen & $\mathrm{D}$ & 850 & 0.170 & 107 & 53 & 69 \\
\hline 3426 & Uelzen & $\mathrm{D}$ & 50 & 0.243 & 154 & 76 & 99 \\
\hline 3427 & Oderhaus & $\mathrm{D}$ & 650 & 0.151 & 95 & 78 & 102 \\
\hline 3428 & Schernfeld & $\mathrm{D}$ & 450 & 0.098 & 62 & 36 & 46 \\
\hline 3429 & Villingen & $\mathrm{D}$ & 850 & 0.198 & 126 & 93 & 121 \\
\hline 3430 & Diessen & $\mathrm{D}$ & 850 & 0.161 & 102 & 109 & 142 \\
\hline 3431 & Riedenburg & $\mathrm{D}$ & 500 & 0.152 & 96 & 103 & 134 \\
\hline 3432 & Walsrode & $\mathrm{D}$ & 30 & 0.158 & 100 & 66 & 85 \\
\hline 3433 & Selb-Kirchenlamitz (1) & $\mathrm{D}$ & 800 & 0.152 & 96 & 71 & 92 \\
\hline 3434 & Miele & $\mathrm{D}$ & 90 & 0.176 & 111 & 128 & 167 \\
\hline 3435 & Neureichenau (2) & $\mathrm{D}$ & 1050 & 0.123 & 78 & 90 & 117 \\
\hline 3436 & Neureichenau (2) & $\mathrm{D}$ & 1050 & 0.148 & 93 & 77 & 100 \\
\hline 3437 & Neureichenau (2) & $\mathrm{D}$ & 1050 & 0.142 & 90 & 104 & 135 \\
\hline 3438 & Oderhaus & $\mathrm{D}$ & 650 & 0.148 & 94 & 77 & 100 \\
\hline 3444 & Zwiesel, Scheicherau XXI 14a/b $(3,6)$ & 6) $\mathrm{D}$ & 650 & 0.130 & 82 & 88 & 114 \\
\hline 3445 & Zwiesel, Haselau XXI $12(3,6)$ & $\mathrm{D}$ & 650 & 0.240 & 152 & 75 & 97 \\
\hline 3447 & Nationalp. Hüttenschlag XIX 1b (6) & $\mathrm{D}$ & 750 & 0.201 & 127 & 84 & 109 \\
\hline 3448 & Nationalp. Filzwald IX 3a 10/11 (6) & $\mathrm{D}$ & 750 & 0.175 & 111 & 82 & 107 \\
\hline 3449 & Nationalp. Neubruck 1a10,b10/11,c10 (6) & 9) $\mathrm{D}$ & 740 & 0.112 & 71 & 88 & 114 \\
\hline 3498 & Burgjoß & $\mathrm{D}$ & 450 & 0.133 & 84 & 76 & 99 \\
\hline 3499 & Chausseehaus & $\mathrm{D}$ & & 0.139 & 88 & 109 & 141 \\
\hline 3505 & Eibenst. Carlsf. 275 & $\mathrm{D}$ & 925 & 0.302 & 191 & 79 & 102 \\
\hline 3617 & Torgelow & D & 100 & 0.131 & 83 & 75 & 97 \\
\hline 4011 & Cikaaj, Zdarska Vrchy & CS & 655 & 0.115 & 73 & 72 & 93 \\
\hline 4032 & Kynsperk nad Ohri Libocky Dul & CS & 650 & 0.158 & 100 & 74 & 96 \\
\hline 4042 & Vimperk-Prameny Vltury Stachy & CS & 950 & 0.100 & 63 & 68 & 88 \\
\hline 4061 & Velke Mezirici-Rudolec & CS & 630 & 0.130 & 82 & 61 & 79 \\
\hline 4081 & Frenstat pod Radhosten-Obora & CS & 600 & 0.117 & 74 & 61 & 79 \\
\hline 4082 & Ostravice & CS & 800 & 0.137 & 87 & 71 & 93 \\
\hline 4103 & Tatranska Lesna 559 C & CS & 950 & 0.153 & 97 & 88 & 114 \\
\hline 4121 & Javorova Dolina 155 A, Nr. 4121 & CS & 1200 & 0.078 & 50 & 65 & 85 \\
\hline 4143 & Kysihybel & CS & 540 & 0.149 & 94 & 77 & 100 \\
\hline 4154 & Roznava & CS & 800 & 0.178 & 113 & 93 & 120 \\
\hline 4157 & Hnusta & CS & 550 & 0.074 & 47 & 23 & 30 \\
\hline 4159 & Svrcina Hrabusice & CS & 900 & 0.181 & 115 & 75 & 98 \\
\hline 5101 & Nedzinant, Prokletije (Geb.) & YU & 1150 & 0.104 & 66 & 49 & 63 \\
\hline 5201 & Köszeg 1 C & $\mathrm{H}$ & 870 & 0.138 & 87 & 86 & 112 \\
\hline 5202 & Szentgotthard $1 \mathrm{C}$ & $\mathrm{H}$ & 310 & 0.126 & 79 & 52 & 68 \\
\hline 5203 & Sarospatak-Haromhuta 19 B Zempl. Geb. & b. $\mathrm{H}$ & 405 & 0.162 & 103 & 59 & 77 \\
\hline
\end{tabular}


Versuchsfläche 44

\begin{tabular}{|c|c|c|c|c|c|c|c|}
\hline \multirow{2}{*}{$\begin{array}{l}\text { PG- } \\
\text { Nr. }\end{array}$} & \multirow{2}{*}{ Herkunft } & \multirow{2}{*}{ Land } & \multirow{2}{*}{$\begin{array}{l}\text { Höhe m } \\
\text { ü. NN }\end{array}$} & \multicolumn{2}{|c|}{ Einzelbaumv. } & \multicolumn{2}{|c|}{ Vorrat } \\
\hline & & & & {$\left[\mathrm{m}^{3}\right]$} & {$[\%]$} & {$\left[\mathrm{m}^{3} / \mathrm{ha}\right]$} & {$[\%]$} \\
\hline 5204 & Miskolc-Lillafüred 82 A Bükker Ge & eb. $\mathrm{H}$ & 730 & 0.131 & 83 & 68 & 89 \\
\hline 5205 & Nagykanizsa-Iharos Plattensee 11/1 & $-71 \mathrm{H}$ & 200 & 0.137 & 87 & 72 & 93 \\
\hline 5206 & Sopron (Hochschulrev.) 203 D & $\mathrm{H}$ & 425 & 0.120 & 76 & 82 & 106 \\
\hline 5302 & Beglika & $\mathrm{BG}$ & 1850 & 0.072 & 45 & 64 & 83 \\
\hline 5303 & Borovec (Rila-Geb.) & $\mathrm{BG}$ & 1300 & 0.097 & 61 & 35 & 46 \\
\hline 5401 & Valea Putnei-Pojorita & RU & 1085 & 0.220 & 140 & 92 & 119 \\
\hline 5413 & Brosteni Bradu/Bastitei & RU & 1475 & 0.083 & 52 & 43 & 56 \\
\hline 6106 & Köslin/Koszalin & PL & 50 & 0.162 & 102 & 93 & 120 \\
\hline 6223 & Przerwanki & PL & 150 & 0.083 & 52 & 56 & 73 \\
\hline 6237 & Puszcza-Białowieska & PL & 130 & 0.156 & 99 & 97 & 126 \\
\hline 6250 & Augustow Abt. $95 \mathrm{~b}$ & PL & 120 & 0.108 & 68 & 39 & 51 \\
\hline 6254 & Mikaszowka & PL & 120 & 0.120 & 76 & 62 & 81 \\
\hline 6255 & Puszcza-Augustowska & PL & 125 & 0.074 & 47 & 50 & 65 \\
\hline 6260 & Knyszyn & PL & 150 & 0.130 & 82 & 61 & 79 \\
\hline 6261 & Kumialka (Kumialska) & PL & 160 & 0.070 & 44 & 25 & 33 \\
\hline 6410 & Sierpc & PL & 110 & 0.174 & 110 & 36 & 47 \\
\hline 6896 & Borken & PL & 165 & 0.065 & 41 & 61 & 80 \\
\hline 7401 & Gzatsk-Smolensk & SU & 194 & 0.083 & 53 & 39 & 51 \\
\hline 8703 & Lohja Laaskspohjan & SF & 50 & 0.058 & 37 & 39 & 51 \\
\hline 9170 & Ryssby-Kronobergs & $\mathrm{S}$ & 175 & 0.054 & 34 & 45 & 58 \\
\hline 9417 & Marsberg & $\mathrm{D}$ & 500 & 0.255 & 161 & 133 & 172 \\
\hline 9423 & Kohlstetten & $\mathrm{D}$ & 750 & 0.113 & 72 & 65 & 84 \\
\hline 9432 & Walsrode & $\mathrm{D}$ & 30 & 0.189 & 120 & 89 & 115 \\
\hline
\end{tabular}

Versuchsfläche 45

\begin{tabular}{|c|c|c|c|c|c|c|c|}
\hline \multirow{2}{*}{$\begin{array}{l}\text { PG- } \\
\text { Nr. }\end{array}$} & \multirow{2}{*}{ Herkunft } & \multirow{2}{*}{ Land } & \multirow{2}{*}{$\begin{array}{l}\text { Höhe m } \\
\text { ü. NN }\end{array}$} & \multicolumn{2}{|c|}{ Einzelbaumv. } & \multicolumn{2}{|c|}{ Vorrat } \\
\hline & & & & {$\left[\mathrm{m}^{3}\right]$} & $\mid[\%]$ & {$\left[\mathrm{m}^{3} / \mathrm{ha}\right]$} & {$[\%]$} \\
\hline 107 & Donaueschingen & D & 650 & 0.247 & 156 & 116 & 150 \\
\hline 111 & Bodenmais & $\mathrm{D}$ & 1000 & 0.171 & 108 & 107 & 139 \\
\hline 115 & Westerhof & $\mathrm{D}$ & 200 & 0.384 & 243 & 160 & 208 \\
\hline 121 & Cedrogne & B & 500 & 0.196 & 124 & 92 & 120 \\
\hline 129 & Allenstein & PL & 100 & 0.147 & 93 & 84 & 109 \\
\hline 149 & Einsiedeln & $\mathrm{CH}$ & 900 & 0.057 & 36 & 27 & 35 \\
\hline 2118 & Gurker Sirnitzwald & A & 900 & 0.167 & 106 & 69 & 90 \\
\hline 2131 & Veitsch-Neuberg & A & 1000 & 0.149 & 94 & 62 & 81 \\
\hline 2133 & Hinterhof, Eibelkogel & A & 1150 & 0.215 & 136 & 56 & 73 \\
\hline 2134 & Hinterhof, Ostbrenner u. Tiefental & A & 1000 & 0.229 & 145 & 131 & 170 \\
\hline 2135 & Kraubath, Seckauer Tauern & A & 1050 & 0.128 & 81 & 47 & 61 \\
\hline 2137 & Buchberg, Flachwald/Aflenz & A & 1300 & 0.171 & 108 & 53 & 69 \\
\hline 2138 & Buchberg, Ägidiwald/Aflenz & A & 925 & 0.246 & 156 & 64 & 83 \\
\hline 2151 & Breitenau-Mixnitz/Fischbacher Alp. & D. A & 970 & 0.236 & 150 & 86 & 112 \\
\hline 2158 & Rohr im Gebirge, Kirchwald & A & 825 & 0.236 & 149 & 148 & 192 \\
\hline 2179 & Eisenkappel/Karaw. & A & 800 & 0.188 & 119 & 98 & 127 \\
\hline 2184 & Schneegattern & A & 750 & 0.216 & 137 & 68 & 88 \\
\hline 2207 & Seewiesen Seereith/Aflenz & A & 875 & 0.296 & 187 & 46 & 60 \\
\hline 3003 & Blumberg & $\mathrm{D}$ & 800 & 0.189 & 119 & 59 & 77 \\
\hline 3042 & Walchensee & $\mathrm{D}$ & 1100 & 0.139 & 88 & 65 & 85 \\
\hline
\end{tabular}


Versuchsfläche 45

\begin{tabular}{|c|c|c|c|c|c|c|c|}
\hline $\begin{array}{l}\text { PG- } \\
\text { Nr. }\end{array}$ & Herkunft & Land & $\begin{array}{c}\text { Höhe m } \\
\text { ü. NN }\end{array}$ & \multicolumn{2}{|c|}{ Einzelbaumv. } & \multicolumn{2}{|c|}{ Vorrat } \\
\hline 3102 & Schluchsee-Eschenmoos & $\mathrm{D}$ & 1200 & 0.155 & 98 & 73 & 94 \\
\hline 3139 & Isny Ba/Wü & $\mathrm{D}$ & 850 & 0.164 & 104 & 60 & 77 \\
\hline 3204 & Burghausen/Salzach & $\mathrm{D}$ & 400 & 0.189 & 119 & 69 & 89 \\
\hline 3205 & Ebersberg & $\mathrm{D}$ & 555 & 0.224 & 142 & 70 & 91 \\
\hline 3211 & Moosburg/Isar & $\mathrm{D}$ & 500 & 0.262 & 166 & 109 & 142 \\
\hline 3310 & Zwiesel-West/Ruselhänge X/68 & $\mathrm{D}$ & 750 & 0.193 & 122 & 121 & 156 \\
\hline 3323 & Mauth/Ost & $\mathrm{D}$ & 1000 & 0.367 & 233 & 172 & 224 \\
\hline 3325 & Neureichenau/Typengemisch & $\mathrm{D}$ & 1000 & 0.325 & 206 & 118 & 154 \\
\hline 3327 & Passau/Nord & $\mathrm{D}$ & 1000 & 0.184 & 117 & 86 & 112 \\
\hline 3331 & St. Oswald I/3,4,6 Typengemisch & h D & 1200 & 0.331 & 209 & 69 & 89 \\
\hline 3337 & Rabenstein Typengemisch & $\mathrm{D}$ & 1200 & 0.118 & 74 & 43 & 56 \\
\hline 3404 & Westerhof Abt. $51 \mathrm{~B}$ & $\mathrm{D}$ & 200 & 0.219 & 139 & 103 & 133 \\
\hline 3417 & Marsberg & $\mathrm{D}$ & 500 & 0.342 & 217 & 107 & 139 \\
\hline 3423 & Kohlstetten & $\mathrm{D}$ & 750 & 0.256 & 162 & 67 & 86 \\
\hline 3430 & Diessen & $\mathrm{D}$ & 850 & 0.134 & 85 & 77 & 100 \\
\hline 3432 & Walsrode & $\mathrm{D}$ & 30 & 0.268 & 170 & 140 & 181 \\
\hline 3433 & Selb-Kirchenlamitz (1) & $\mathrm{D}$ & 800 & 0.136 & 86 & 71 & 92 \\
\hline 3443 & Zwiesel, Scheichereb. XXI 13b1 (3, & ,6) D & 650 & 0.179 & 114 & 84 & 109 \\
\hline 3503 & Eibenst. Carlsf. Wiesenh. 214 & $\mathrm{D}$ & 720 & 0.362 & 229 & 75 & 98 \\
\hline 3510 & Sonneb. Steinheid, Kieferleskopf & $\mathrm{D}$ & 886 & 0.210 & 133 & 121 & 157 \\
\hline 3511 & Innenau Elgersburg & $\mathrm{D}$ & 800 & 0.248 & 157 & 116 & 151 \\
\hline 3518 & Suhl, Oberhofer Schloßbergkopf & $\mathrm{D}$ & 900 & 0.380 & 240 & 138 & 180 \\
\hline 3519 & Mechterstädt & $\mathrm{D}$ & 200 & 0.258 & 163 & 148 & 192 \\
\hline 3606 & Templin, Bad Doberan Nr. 9 & $\mathrm{D}$ & 50 & 0.175 & 111 & 127 & 165 \\
\hline 3615 & Neustrelitz & $\mathrm{D}$ & 100 & 0.226 & 143 & 82 & 107 \\
\hline 4022 & Boubin III & CS & 1000 & 0.127 & 80 & 66 & 86 \\
\hline 4026 & Habartice, Planice & CS & 550 & 0.240 & 152 & 75 & 98 \\
\hline 4051 & Vysoky Chlumec Veletin & CS & 600 & 0.100 & 63 & 73 & 95 \\
\hline 4053 & Cesky Krumlov Borova & CS & 800 & 0.175 & 111 & 100 & 130 \\
\hline 4054 & Chlum u. Trebone-Hamr & CS & 450 & 0.210 & 133 & 109 & 142 \\
\hline 4060 & Hencov-Trest & CS & 600 & 0.236 & 149 & 111 & 144 \\
\hline 4070 & Vrchlabi & CS & 700 & 0.198 & 126 & 93 & 121 \\
\hline 4073 & Jesenik-Zlate Hory & CS & 820 & 0.261 & 165 & 149 & 194 \\
\hline 4123 & Javorova Dolina 155 A, Nr.4123 & CS & 1200 & 0.064 & 41 & 13 & 17 \\
\hline 5102 & Kaludjerske Bore Taram Kremma & $\mathrm{YU}$ & 1000 & 0.259 & 164 & 94 & 123 \\
\hline 5107 & Smrceve Dolina Abt. 138 & HR & 1350 & 0.131 & 83 & 96 & 124 \\
\hline 5301 & Belogradchik-Tschupreno & BG & 1400 & 0.156 & 99 & 89 & 116 \\
\hline 5412 & Moldovita-Sacries & RU & 825 & 0.148 & 94 & 54 & 70 \\
\hline 5415 & Cimpeni-Dara & RU & 1260 & 0.215 & 136 & 112 & 145 \\
\hline 5416 & Remeti-Zerna & RU & 900 & 0.291 & 184 & 76 & 98 \\
\hline 5420 & Valea Putnei-Pojorita III/60 & RU & 1285 & 0.193 & 122 & 91 & 118 \\
\hline 5426 & Crucea-Barnavel Abt. 17/18 & RU & 740 & 0.127 & 81 & 60 & 77 \\
\hline 6103 & Brotzen/Broczyno & PL & 140 & 0.157 & 99 & 57 & 74 \\
\hline 6222 & Borken/Borki & PL & 160 & 0.164 & 104 & 85 & 111 \\
\hline 6234 & Białowieża & PL & 130 & 0.174 & 110 & 91 & 118 \\
\hline 6235 & Zwierzyniec & PL & 150 & 0.206 & 130 & 54 & 70 \\
\hline 6251 & Białobrzegi & PL & 110 & 0.284 & 179 & 103 & 134 \\
\hline 6510 & Bunzlau/Boleslawiec & PL & 175 & 0.237 & 150 & 111 & 145 \\
\hline 6543 & Groß-Lassowitz/Lassowice Male & PL & 175 & 0.252 & 159 & 92 & 119 \\
\hline 6624 & Przysucha & PL & 275 & 0.291 & 184 & 61 & 79 \\
\hline
\end{tabular}


Versuchsfläche 45

\begin{tabular}{|c|c|c|c|c|c|c|c|}
\hline \multirow{2}{*}{$\begin{array}{l}\text { PG- } \\
\text { Nr. }\end{array}$} & \multirow{2}{*}{ Herkunft } & \multirow{2}{*}{ Land } & \multirow{2}{*}{$\begin{array}{l}\text { Höhe m } \\
\text { ü. NN }\end{array}$} & \multicolumn{2}{|c|}{ Einzelbaumv. } & \multicolumn{2}{|c|}{ Vorrat } \\
\hline & & & & {$\left[\mathrm{m}^{3}\right]$} & {$[\%]$} & {$\left[\mathrm{m}^{3} / \mathrm{ha}\right]$} & $\mid[\%]$ \\
\hline 6712 & Klodzko-Glatz/Nynow 68 e & PL & 340 & 0.156 & 99 & 89 & 116 \\
\hline 6731 & Szcytna-Slaska Karlow 243 a & PL & 750 & 0.246 & 156 & 141 & 183 \\
\hline 6732 & Szcytna-Slaska Karlow 292 b & PL & 700 & 0.283 & 179 & 118 & 153 \\
\hline 6864 & Istebna-Ujsoly & PL & 750 & 0.198 & 126 & 62 & 81 \\
\hline 6894 & Witów & PL & 1250 & 0.210 & 133 & 87 & 114 \\
\hline 7224 & Ostrovskij-Pskow & SU & 200 & 0.145 & 92 & 60 & 78 \\
\hline 7233 & Wolozin & SU & 225 & 0.190 & 120 & 89 & 116 \\
\hline 7235 & Brigalovic-Mogilev & SU & 160 & 0.268 & 170 & 196 & 254 \\
\hline 8003 & Fussinge & DK & 45 & 0.257 & 163 & 107 & 139 \\
\hline 8705 & Mänttä & SF & 120 & 0.091 & 58 & 57 & 74 \\
\hline 8707 & Janakkala Keskivari Uhkoila & SF & 100 & 0.085 & 54 & 57 & 74 \\
\hline
\end{tabular}

Versuchsfläche 46

\begin{tabular}{|c|c|c|c|c|c|c|c|}
\hline \multirow{2}{*}{$\begin{array}{l}\text { PG- } \\
\text { Nr. }\end{array}$} & \multirow{2}{*}{ Herkunft } & \multirow{2}{*}{ Land } & \multirow{2}{*}{$\begin{array}{l}\text { Höhe m } \\
\text { ü. NN }\end{array}$} & \multicolumn{2}{|c|}{ Einzelbaumv. } & \multicolumn{2}{|c|}{ Vorrat } \\
\hline & & & & {$\left[\mathrm{m}^{3}\right]$} & {$[\%]$} & {$\left[\mathrm{m}^{3} / \mathrm{ha}\right]$} & {$[\%]$} \\
\hline 65 & Eisenkappel Thurn 2 & A & 850 & 0.175 & 111 & 137 & 178 \\
\hline 93 & Sieber & $\mathrm{D}$ & 400 & 0.140 & 89 & 58 & 76 \\
\hline 105 & Hohenschwangau & $\mathrm{D}$ & 800 & 0.109 & 69 & 62 & 81 \\
\hline 108 & Lauterberg & $\mathrm{D}$ & 700 & 0.293 & 185 & 152 & 198 \\
\hline 116 & Kobernausserwald & A & 600 & 0.180 & 114 & 84 & 109 \\
\hline 169 & Gries & A & 1300 & 0.145 & 92 & 106 & 137 \\
\hline 172 & Mittersill & A & 900 & 0.092 & 58 & 43 & 56 \\
\hline 191 & Passail & A & 900 & 0.188 & 119 & 98 & 127 \\
\hline 230 & Elbingerode & $\mathrm{D}$ & 550 & 0.217 & 137 & 79 & 103 \\
\hline 1118 & Chatel, 1 Aity" & $\mathrm{F}$ & 1250 & 0.129 & 82 & 67 & 87 \\
\hline 1201 & Mellier, Bois Bavai, 2 & B & 400 & 0.168 & 107 & 53 & 68 \\
\hline 2124 & Stixenstein, Gahns & A & 1200 & 0.150 & 95 & 70 & 92 \\
\hline 2127 & Unterhal, St. Kathrein a.d. Lamming & $\mathrm{g} \mathrm{A}$ & 800 & 0.149 & 94 & 109 & 141 \\
\hline 2174 & Klein-Sölk/Niedertauern & A & 1250 & 0.140 & 89 & 66 & 85 \\
\hline 3150 & Dillingen a.d.D. Bay. & $\mathrm{D}$ & 500 & 0.209 & 132 & 120 & 156 \\
\hline 3206 & Eglharting XIV/17,19 & $\mathrm{D}$ & 580 & 0.233 & 148 & 109 & 142 \\
\hline 3213 & Mühldorf/Inn & $\mathrm{D}$ & 440 & 0.197 & 125 & 102 & 133 \\
\hline 3414 & Bodensee Oberschwab. VIII/13 & $\mathrm{D}$ & 650 & 0.300 & 190 & 172 & 223 \\
\hline 3417 & Marsberg & $\mathrm{D}$ & 500 & 0.156 & 99 & 32 & 42 \\
\hline 3423 & Kohlstetten & $\mathrm{D}$ & 750 & 0.359 & 227 & 94 & 121 \\
\hline 3430 & Diessen & $\mathrm{D}$ & 850 & 0.132 & 84 & 76 & 98 \\
\hline 3432 & Walsrode & $\mathrm{D}$ & 30 & 0.192 & 122 & 30 & 39 \\
\hline 3433 & Selb-Kirchenlamitz (1) & $\mathrm{D}$ & 800 & 0.201 & 127 & 94 & 122 \\
\hline 3446 & Zwiesel, Schmalzau IX 3c $(5,6)$ & $\mathrm{D}$ & 620 & 0.190 & 120 & 99 & 128 \\
\hline 4050 & Vlasim-Votice & CS & 600 & 0.224 & 142 & 70 & 91 \\
\hline 4075 & Vitkov-Budisov & CS & 610 & 0.181 & 115 & 113 & 147 \\
\hline 4127 & Javorova Dolina 155 A, Nr.4127 & CS & 1200 & 0.184 & 116 & 67 & 87 \\
\hline 5424 & Valea Beliei-Sinaia Gurguiata & RU & 1115 & 0.074 & 47 & 38 & 50 \\
\hline 5425 & Cimpeni-Nedei & RU & 1400 & 0.152 & 96 & 87 & 113 \\
\hline 6107 & Altenhagen/Nowy Krakow & PL & 200 & 0.176 & 111 & 64 & 83 \\
\hline 6236 & Białowieża & PL & 150 & 0.175 & 111 & 73 & 95 \\
\hline 6897 & Goldap & PL & 175 & 0.130 & 82 & 68 & 88 \\
\hline
\end{tabular}


Versuchsfläche 46

\begin{tabular}{l|l|r|r|r|r|rr}
\hline PG- & \multirow{2}{*}{ Herkunft } & \multirow{2}{*}{ Land } & Höhe m & \multicolumn{2}{c|}{ Einzelbaumv. } & \multicolumn{2}{|c}{ Vorrat } \\
Nr. & & & ü. NN & {$\left[\mathrm{m}^{3}\right]$} & {$[\%]$} & {$\left[\mathrm{m}^{3} / \mathrm{ha}\right]$} & {$[\%]$} \\
\hline 7232 & Cemerjanskoe-Mogilev & SU & 175 & 0.111 & 70 & 35 & 45 \\
7234 & Soboljanskoe-Grodno & SU & 150 & 0.111 & 70 & 52 & 67 \\
7240 & Witebsk & SU & 150 & 0.118 & 75 & 68 & 88 \\
9191 & Karlsholms-Kristianstad & S & 20 & 0.291 & 184 & 182 & 236 \\
\hline
\end{tabular}

\section{Anhang 1.25}

Zusammenstellung der mittleren Stammzabl und des mittleren BHD [cm] im Alter von 32 Jahren auf den zwei Versuchsflächen Sonthofen (24) und Berchtesgaden (26) / Bayern sowie der mittleren Ovalität [\%] auf der Versuchsfläche Berchtesgaden (26)

Versuchsfläche 24 (Sonthofen)

\begin{tabular}{rl|c|c|c|c}
\hline $\begin{array}{c}\text { PG- } \\
\text { Nr. }\end{array}$ & Herkunft & Land & $\begin{array}{r}\text { Höhe } \\
\text { m ü. NN }\end{array}$ & $\begin{array}{c}\text { An- } \\
\text { zahl }\end{array}$ & $\begin{array}{r}\text { BHD } \\
{[\mathrm{cm}]}\end{array}$ \\
\hline 41 & Spiegelau & D & 750 & 27 & 15.1 \\
60 & Aflenz & A & 1000 & 10 & 15.9 \\
61 & Gosau & A & 700 & 20 & 16.5 \\
62 & Litschau & A & 600 & 16 & 20.3 \\
63 & Eisenkappel Thurn 1 & A & 850 & 34 & 13.0 \\
64 & St. Martin & A & 500 & 19 & 19.5 \\
66 & Vorau & A & 900 & 21 & 18.6 \\
97 & Gérardmer & F & 850 & 15 & 11.9 \\
98 & Massif Central & F & 1100 & 23 & 16.5 \\
103 & Wunsiedel & D & 900 & 24 & 16.5 \\
110 & Medebach & D & 600 & 20 & 18.7 \\
114 & Winterberg & D & 800 & 19 & 18.8 \\
124 & Istebna-Wisła & PL & 725 & 16 & 18.3 \\
130 & Dobra bei Frydek & CS & 550 & 14 & 14.3 \\
131 & Vizovice & CS & 500 & 17 & 15.6 \\
139 & Vapenkova Skala & CS & 540 & 14 & 19.5 \\
140 & Bucovice & CS & 480 & 19 & 14.6 \\
141 & Pitin & CS & 610 & 33 & 16.8 \\
142 & Rosice & CS & 465 & 18 & 22.8 \\
150 & Schlanders & I & 1500 & 25 & 12.1 \\
170 & Groß Arl & A & 1350 & 16 & 15.2 \\
171 & Hofgastein & A & 1100 & 30 & 11.7 \\
174 & Piesendorf & A & 900 & 11 & 14.4 \\
175 & Radstatt & A & 1000 & 21 & 15.2 \\
176 & St. Johann & A & 1200 & 24 & 17.2 \\
177 & Taxenbach & A & 1400 & 21 & 16.8 \\
178 & Abtenau & A & 900 & 23 & 14.7 \\
179 & Bischofshofen & A & 1200 & 24 & 16.2 \\
184 & Paternion & A & 900 & 30 & 18.0 \\
185 & St. Veit/Glan & A & 600 & 11 & 16.8 \\
186 & Graz-Nord & A & 850 & 17 & 13.6 \\
187 & Pack & A & 950 & 32 & 10.3 \\
188 & Waldstein a.d. Übelb. & A & 850 & 28 & 10.8 \\
189 & Graz-Süd & 850 & 13 & 13.3 \\
& & & & &
\end{tabular}


Versuchsfläche 24 (Sonthofen)

\begin{tabular}{|c|c|c|c|c|c|}
\hline $\begin{array}{l}\text { PG- } \\
\text { Nr. }\end{array}$ & Herkunft & Land & $\begin{array}{c}\text { Höhe } \\
\text { m ü. NN }\end{array}$ & $\begin{array}{l}\text { An- } \\
\text { zahl }\end{array}$ & $\begin{array}{l}\text { BHD } \\
{[\mathrm{cm}]}\end{array}$ \\
\hline 190 & Offenegg & A & 950 & 29 & 10.1 \\
\hline 192 & Södingberg & A & 550 & 21 & 16.3 \\
\hline 202 & Istebna-Wisła & PL & 725 & 18 & 17.5 \\
\hline 204 & Spisske Pochradie & $\mathrm{CS}$ & 700 & 12 & 19.5 \\
\hline 207 & Jönköpings län & $\mathrm{S}$ & 170 & 17 & 11.7 \\
\hline 208 & Istebna & PL & 725 & 22 & 14.3 \\
\hline 215 & Stinava & SK & & 18 & 18.5 \\
\hline 217 & Istebna-Wisła & PL & 725 & 22 & 17.7 \\
\hline 227 & Thüringen & $\mathrm{D}$ & 300 & 9 & 19.7 \\
\hline 229 & Olsztyn & PL & 100 & 9 & 25.1 \\
\hline 284 & Blekinge län Asarum & $\mathrm{S}$ & 100 & 23 & 13.7 \\
\hline 290 & Högestad & S & 50 & 21 & 9.5 \\
\hline 291 & Karupsskogen Barsebäcks gods & $\mathrm{S}$ & 100 & 11 & 11.9 \\
\hline 293 & Trolleholm & $\mathrm{S}$ & 125 & 19 & 10.1 \\
\hline 294 & Aasbo-össjö Gods & $\mathrm{S}$ & 50 & 35 & 18.4 \\
\hline 295 & Öveds Kloster Öpedal & $\mathrm{S}$ & 50 & 21 & 16.7 \\
\hline 704 & Cazis Tschartlina & $\mathrm{CH}$ & 750 & 18 & 13.8 \\
\hline 711 & La Genolière & $\mathrm{CH}$ & & 30 & 11.6 \\
\hline 712 & Forêt du Risoud & $\mathrm{CH}$ & 1100 & 34 & 10.8 \\
\hline 713 & Caragnago & $\mathrm{CH}$ & 1180 & 21 & 10.3 \\
\hline 716 & Altacanta & $\mathrm{CH}$ & 1400 & 22 & 14.8 \\
\hline 722 & Piana Selva, Faido & $\mathrm{CH}$ & 980 & 7 & 16.4 \\
\hline 725 & Airolo, Crespato-Ressia & $\mathrm{CH}$ & 1120 & 22 & 10.5 \\
\hline 734 & Airolo, Bedretto & $\mathrm{CH}$ & 1600 & 21 & 14.9 \\
\hline 740 & Bex, Tarejanne & $\mathrm{CH}$ & 1600 & 30 & 15.8 \\
\hline 1100 & Monts Megal, Le Portius & $\mathrm{F}$ & 900 & 26 & 15.1 \\
\hline 1101 & Le Pertuis, Monts du Velay & $\mathrm{F}$ & 1100 & 28 & 17.0 \\
\hline 1111 & Peisey-Nancroix, Grd. Bois & $\mathrm{F}$ & 1400 & 26 & 9.8 \\
\hline 1112 & Autrans, Isère & $\mathrm{F}$ & 1250 & 26 & 9.9 \\
\hline 1114 & Passy & $\mathrm{F}$ & 1200 & 26 & 10.0 \\
\hline 1115 & Magland & $\mathrm{F}$ & 700 & 29 & 12.5 \\
\hline 1116 & Lantosque & F & 1500 & 24 & 13.2 \\
\hline 1117 & Plan Bois, Ballandes & $\mathrm{F}$ & 500 & 16 & 6.2 \\
\hline 1202 & Manderfeld Gilbuschek 63 A & B & 542 & 15 & 6.3 \\
\hline 2113 & Oberes Gailtal & A & 1100 & 33 & 10.4 \\
\hline 2114 & Kreuzen-Stockenboi & A & 1200 & 28 & 10.8 \\
\hline 2115 & Rosental & A & 1000 & 23 & 12.5 \\
\hline 2116 & Aich & A & 700 & 18 & 10.6 \\
\hline 2117 & Gurktal & A & 1300 & 34 & 12.3 \\
\hline 2120 & Liembergwald Zell a. S. & A & 875 & 19 & 8.3 \\
\hline 2121 & Neukirchen Großvenediger & A & 870 & 28 & 10.7 \\
\hline 2122 & Piberegg & A & 800 & 16 & 12.0 \\
\hline 2123 & Gallmannsegg Kainach & A & 1100 & 28 & 10.1 \\
\hline 2126 & Gaishorn & A & 1200 & 9 & 12.8 \\
\hline 2128 & Lobming-Oberth. St. Stefan/Kraubath & A & 800 & 15 & 12.1 \\
\hline 2130 & Stanz-Kindthal-Allerheiligen & A & 750 & 31 & 16.2 \\
\hline 2140 & Fölz, Mayerberg & A & 950 & 27 & 9.6 \\
\hline 2141 & Fölz, Greith & A & 825 & 27 & 14.8 \\
\hline 2144 & Seewiesen, Seereith & A & 875 & 24 & 13.6 \\
\hline 2147 & Freiland, Gschwend & A & 1000 & 5 & 16.1 \\
\hline
\end{tabular}


Versuchsfläche 24 (Sonthofen)

\begin{tabular}{|c|c|c|c|c|c|}
\hline $\begin{array}{l}\text { PG- } \\
\text { Nr. }\end{array}$ & Herkunft & Land & $\begin{array}{c}\text { Höhe } \\
\text { m ü. NN }\end{array}$ & $\begin{array}{l}\text { An- } \\
\text { zahl }\end{array}$ & $\begin{array}{l}\text { BHD } \\
{[\mathrm{cm}]}\end{array}$ \\
\hline 2149 & Kindberg/Eisenerzer Alpen & A & 1000 & 23 & 17.9 \\
\hline 2150 & Siebensee Wildalpen & A & 850 & 23 & 10.0 \\
\hline 2160 & Turnau, Kapfenberg & A & 1100 & 29 & 15.5 \\
\hline 3326 & Neureichenau & $\mathrm{D}$ & 1200 & 21 & 14.4 \\
\hline 3328 & Spiegelau & $\mathrm{D}$ & 1200 & 31 & 15.1 \\
\hline 3329 & Spiegelau & $\mathrm{D}$ & 1200 & 15 & 19.8 \\
\hline 3332 & Zwiesel-Ost & $\mathrm{D}$ & 1000 & 35 & 14.1 \\
\hline 3406 & SHK Stryck Willingen & $\mathrm{D}$ & 550 & 30 & 18.2 \\
\hline 3410 & Traunstein & $\mathrm{D}$ & 850 & 18 & 16.6 \\
\hline 3411 & Bischofswiesen & $\mathrm{D}$ & 950 & 23 & 16.3 \\
\hline 3412 & Winterberg & $\mathrm{D}$ & 750 & 8 & 18.1 \\
\hline 3413 & SHK Winterberg & $\mathrm{D}$ & 750 & 9 & 11.0 \\
\hline 3415 & SHK Hochsauerland & $\mathrm{D}$ & 600 & 22 & 14.6 \\
\hline 3416 & SHK Höhenfichten & $\mathrm{D}$ & 1050 & 27 & 15.6 \\
\hline 3417 & Marsberg & $\mathrm{D}$ & 500 & 21 & 14.3 \\
\hline 3418 & Sachsenried & $\mathrm{D}$ & 900 & 28 & 9.8 \\
\hline 3419 & Schwarzwald Baar, VIII/6 & $\mathrm{D}$ & 700 & 25 & 15.1 \\
\hline 3420 & Daun/Ost & $\mathrm{D}$ & 450 & 19 & 18.4 \\
\hline 3421 & Dombühl & $\mathrm{D}$ & 450 & 21 & 16.0 \\
\hline 3422 & Stryck & $\mathrm{D}$ & 650 & 18 & 16.6 \\
\hline 3423 & Kohlstetten & $\mathrm{D}$ & 750 & 18 & 12.2 \\
\hline 3424 & Winterberg & $\mathrm{D}$ & 450 & 21 & 11.2 \\
\hline 3425 & Waldmünchen & $\mathrm{D}$ & 850 & 19 & 16.9 \\
\hline 3426 & Uelzen & $\mathrm{D}$ & 50 & 19 & 14.3 \\
\hline 3427 & Oderhaus & $\mathrm{D}$ & 650 & 25 & 13.6 \\
\hline 3428 & Schernfeld & $\mathrm{D}$ & 450 & 18 & 20.6 \\
\hline 3429 & Villingen & $\mathrm{D}$ & 850 & 22 & 10.0 \\
\hline 3430 & Diessen & $\mathrm{D}$ & 850 & 17 & 17.0 \\
\hline 3431 & Riedenburg & $\mathrm{D}$ & 500 & 15 & 14.4 \\
\hline 3432 & Walsrode & $\mathrm{D}$ & 30 & 14 & 13.7 \\
\hline 3433 & Selb-Kirchenlamitz (1) & $\mathrm{D}$ & 800 & 23 & 16.3 \\
\hline 3434 & Miele & $\mathrm{D}$ & 90 & 23 & 10.3 \\
\hline 3435 & Neureichenau (2) & $\mathrm{D}$ & 1050 & 23 & 12.7 \\
\hline 3436 & Neureichenau (2) & $\mathrm{D}$ & 1050 & 24 & 14.4 \\
\hline 3437 & Neureichenau (2) & $\mathrm{D}$ & 1050 & 23 & 14.3 \\
\hline 3438 & Oderhaus & $\mathrm{D}$ & 650 & 24 & 11.5 \\
\hline 3444 & Zwiesel, Scheicherau XXI 14a/b (3,6) & 6) $\mathrm{D}$ & 650 & 14 & 19.1 \\
\hline 3445 & Zwiesel, Haselau XXI $12(3,6)$ & $\mathrm{D}$ & 650 & 31 & 16.0 \\
\hline 3447 & Nationalp. Hüttenschlag XIX 1b (6) & $\mathrm{D}$ & 750 & 30 & 15.6 \\
\hline 3448 & Nationalp. Filzwald IX 3a 10/11 (6) & $\mathrm{D}$ & 750 & 23 & 15.3 \\
\hline 3449 & Nationalp. Neubruck 1a10,b10/11,c10 (6) & 6) $\mathrm{D}$ & 740 & 27 & 16.7 \\
\hline 3498 & Burgjoß & $\mathrm{D}$ & 450 & 7 & 14.1 \\
\hline 3499 & Chausseehaus & $\mathrm{D}$ & & 16 & 21.2 \\
\hline 3505 & Eibenst. Carlsf. 275 & $\mathrm{D}$ & 925 & 8 & 11.7 \\
\hline 3617 & Torgelow & $\mathrm{D}$ & 100 & 9 & 17.4 \\
\hline 4011 & Cikaaj, Zdarska Vrchy & CS & 655 & 17 & 9.3 \\
\hline 4032 & Kynsperk nad Ohri Libocky Dul & CS & 650 & 22 & 18.3 \\
\hline 4042 & Vimperk-Prameny Vltury Stachy & CS & 950 & 23 & 13.8 \\
\hline 4061 & Velke Mezirici-Rudolec & CS & 630 & 24 & 16.8 \\
\hline 4081 & Frenstat pod Radhosten-Obora & CS & 600 & 24 & 18.5 \\
\hline
\end{tabular}


Versuchsfläche 24 (Sonthofen)

\begin{tabular}{|c|c|c|c|c|c|}
\hline $\begin{array}{l}\text { PG- } \\
\text { Nr. }\end{array}$ & Herkunft & Land & $\begin{array}{c}\text { Höhe } \\
\text { m ü. NN }\end{array}$ & $\begin{array}{l}\text { An- } \\
\text { zahl }\end{array}$ & $\begin{array}{l}\text { BHD } \\
{[\mathrm{cm}]}\end{array}$ \\
\hline 4082 & Ostravice & CS & 800 & 14 & 20.4 \\
\hline 4103 & Tatranska Lesna 559 C & CS & 950 & 18 & 9.4 \\
\hline 4121 & Javorova Dolina 155 A, Nr. 4121 & CS & 1200 & 16 & 13.6 \\
\hline 4143 & Kysihybel & CS & 540 & 13 & 10.5 \\
\hline 4154 & Roznava & CS & 800 & 19 & 18.4 \\
\hline 4157 & Hnusta & CS & 550 & 17 & 23.1 \\
\hline 4159 & Svrcina Hrabusice & CS & 900 & 8 & 14.7 \\
\hline 5101 & Nedzinant, Prokletije (Geb.) & YU & 1150 & 18 & 11.1 \\
\hline 5201 & Köszeg 1 C & $\mathrm{H}$ & 870 & 21 & 14.6 \\
\hline 5202 & Szentgotthard 1 C & $\mathrm{H}$ & 310 & 24 & 17.1 \\
\hline 5203 & Sarospatak-Haromhuta 19 B Zempl. Geb & b. $\mathrm{H}$ & 405 & 21 & 13.7 \\
\hline 5204 & Miskolc-Lillafüred 82 A Bükker Geb. & $\mathrm{H}$ & 730 & 27 & 20.2 \\
\hline 5205 & Nagykanizsa-Iharos Plattensee 11/1-71 & $\mathrm{H}$ & 200 & 28 & 12.2 \\
\hline 5206 & Sopron (Hochschulrev.) 203 D & $\mathrm{H}$ & 425 & 13 & 13.4 \\
\hline 5302 & Beglika & BG & 1850 & 14 & 16.3 \\
\hline 5303 & Borovec (Rila-Geb.) & BG & 1300 & 17 & 10.3 \\
\hline 5401 & Valea Putnei-Pojorita & RU & 1085 & 12 & 17.0 \\
\hline 5413 & Brosteni Bradu/Bastitei & RU & 1475 & 10 & 16.0 \\
\hline 6106 & Köslin/Koszalin & PL & 50 & 13 & 15.2 \\
\hline 6223 & Przerwanki & PL & 150 & 12 & 16.6 \\
\hline 6237 & Puszcza-Białowieska & PL & 130 & 3 & 22.2 \\
\hline 6250 & Augustow Abt. 95 b & PL & 120 & 10 & 15.8 \\
\hline 6254 & Mikaszowka & PL & 120 & 16 & 14.9 \\
\hline 6255 & Puszcza-Augustowska & PL & 125 & 12 & 15.6 \\
\hline 6260 & Knyszyn & PL & 150 & 11 & 9.0 \\
\hline 6261 & Kumialka (Kumialska) & PL & 160 & 11 & 15.0 \\
\hline 6410 & Sierpc & PL & 110 & 16 & 12.8 \\
\hline 6713 & Klodzko-Nynow $72 \mathrm{k}$ & PL & 400 & 24 & 11.2 \\
\hline 6896 & Borken & PL & 165 & 14 & 9.1 \\
\hline 7401 & Gzatsk-Smolensk & SU & 194 & 6 & 3.8 \\
\hline 8703 & Lohja Laaskspohjan & SF & 50 & 7 & 9.1 \\
\hline 9170 & Ryssby-Kronobergs & $\mathrm{S}$ & 175 & 11 & 5.8 \\
\hline 9417 & Marsberg & $\mathrm{D}$ & 500 & 17 & 17.3 \\
\hline 9423 & Kohlstetten & $\mathrm{D}$ & 750 & 16 & 18.5 \\
\hline 9432 & Walsrode & $\mathrm{D}$ & 30 & 18 & 11.1 \\
\hline
\end{tabular}

Versuchsfläche 26 (Berchtesgaden)

\begin{tabular}{c|l|c|c|c|r|r}
\hline $\begin{array}{c}\text { PG- } \\
\text { Nr. }\end{array}$ & Herkunft & Land & $\begin{array}{c}\text { Höhe } \\
\text { m ü. NN }\end{array}$ & $\begin{array}{c}\text { An- } \\
\text { zahl }\end{array}$ & $\begin{array}{c}\text { BHD } \\
{[\mathrm{cm}]}\end{array}$ & $\begin{array}{c}\text { Oval. } \\
{[\%]}\end{array}$ \\
\hline 65 & Eisenkappel Thurn 2 & A & 850 & 28 & 9.4 & 2.3 \\
93 & Sieber & D & 400 & 27 & 11.7 & 3.3 \\
105 & Hohenschwangau & D & 800 & 34 & 8.4 & 1.4 \\
108 & Lauterberg & D & 700 & 28 & 8.8 & 3.0 \\
116 & Kobernausserwald & A & 600 & 19 & 6.4 & 1.6 \\
169 & Gries & A & 1300 & 23 & 8.6 & 1.4 \\
172 & Mittersill & A & 900 & 32 & 9.7 & 1.7 \\
191 & Passail & A & 900 & 14 & 7.4 & 3.2
\end{tabular}


Versuchsfläche 26 (Berchtesgaden)

\begin{tabular}{c|l|c|r|r|r|r}
\hline $\begin{array}{c}\text { PG- } \\
\text { Nr. }\end{array}$ & Herkunft & Land & $\begin{array}{r}\text { Höhe } \\
\text { m ü. NN }\end{array}$ & $\begin{array}{r}\text { An- } \\
\text { zahl }\end{array}$ & $\begin{array}{r}\text { BHD } \\
{[\mathrm{cm}]}\end{array}$ & $\begin{array}{c}\text { Oval. } \\
{[\%]}\end{array}$ \\
\hline 230 & Elbingerode & $\mathrm{D}$ & 550 & 7 & 8.0 & 1.8 \\
1118 & Chatel, 1 Aity" & $\mathrm{F}$ & 1250 & 32 & 8.6 & 1.9 \\
1201 & Mellier, Bois Bayai, 2 & $\mathrm{B}$ & 400 & 27 & 11.1 & 2.3 \\
2124 & Stixenstein, Gahns & $\mathrm{A}$ & 1200 & 23 & 10.1 & 3.7 \\
2127 & Unterhal, St. Kathrein a.d. Lamming & $\mathrm{A}$ & 800 & 20 & 8.7 & 4.7 \\
2174 & Klein-Sölk/Niedertauern & $\mathrm{A}$ & 1250 & 12 & 11.0 & 4.5 \\
3150 & Dillingen a.d.D. Bay. & $\mathrm{D}$ & 500 & 27 & 8.3 & 2.1 \\
3206 & Eglharting XIV/17,19 & $\mathrm{D}$ & 580 & 27 & 8.1 & 2.2 \\
3213 & Mühldorf/Inn & $\mathrm{D}$ & 440 & 31 & 8.0 & 1.8 \\
3414 & Bodensee Oberschwab. VIII/13 & $\mathrm{D}$ & 650 & 35 & 9.0 & 2.2 \\
3417 & Marsberg & $\mathrm{D}$ & 500 & 15 & 8.5 & 2.9 \\
3423 & Kohlstetten & $\mathrm{D}$ & 750 & 10 & 7.1 & 7.1 \\
3430 & Diessen & $\mathrm{D}$ & 850 & 23 & 9.3 & 4.0 \\
3432 & Walsrode & $\mathrm{D}$ & 30 & 29 & 9.3 & 6.8 \\
3433 & Selb-Kirchenlamitz (1) & $\mathrm{D}$ & 800 & 11 & 11.9 & 5.0 \\
3446 & Zwiesel, Schmalzau IX 3c (5,6) & $\mathrm{D}$ & 620 & 32 & 8.6 & 3.7 \\
4050 & Vlasim-Votice & $\mathrm{CS}$ & 600 & 5 & 7.5 & 2.5 \\
4075 & Vitkov-Budisov & $\mathrm{CS}$ & 610 & 3 & 8.2 & 4.5 \\
4127 & Javorova Dolina 155 A, Nr.4127 & $\mathrm{CS}$ & 1200 & 21 & 5.7 & 0.5 \\
5424 & Valea Beliei-Sinaia Gurguiata & $\mathrm{RU}$ & 1115 & 15 & 10.5 & 3.2 \\
5425 & Cimpeni-Nedei & $\mathrm{RU}$ & 1400 & 7 & 9.5 & 6.6 \\
6107 & Altenhagen/Nowy Krakow & PL & 200 & 38 & 9.0 & 4.2 \\
6236 & Białowieża & PL & 150 & 23 & 6.4 & 1.7 \\
6897 & Goldap & PL & 175 & 21 & 6.7 & 2.8 \\
7232 & Cemerjanskoe-Mogilev & SU & 175 & 19 & 6.7 & 4.2 \\
7234 & Soboljanskoe-Grodno & SU & 150 & 16 & 8.5 & 6.0 \\
7240 & Witebsk & SU & 150 & 12 & 5.7 & 3.5 \\
9191 & Karlsholms-Kristianstad & $\mathrm{S}$ & 20 & 36 & 10.5 & 3.9 \\
\hline
\end{tabular}

\section{Anhang 1.26}

Mittlerer Rang im Wachstum auf den Flächen mit 169 Herkünften Münsingen (14), Sonthofen (24), Reinhardshagen (34) und Hasbruch (44) sowie über die vier Flächen

\begin{tabular}{|c|c|c|c|c|c|c|c|c|}
\hline \multirow{2}{*}{$\begin{array}{l}\text { PG- } \\
\text { Nr. }\end{array}$} & \multirow{2}{*}{ Herkunft } & \multirow{2}{*}{ Land } & \multirow{2}{*}{$\begin{array}{c}\text { Höhe m } \\
\text { ü. NN }\end{array}$} & \multicolumn{4}{|c|}{ Fläche } & \multirow[b]{2}{*}{$\overline{\mathrm{X}}$} \\
\hline & & & & 14 & 24 & 34 & 44 & \\
\hline 4082 & Ostravice & CS & 800 & 3 & 14 & 47 & 44 & 27 \\
\hline 3499 & Chausseehaus & $\mathrm{D}$ & & 4 & 27 & 59 & 43 & 33 \\
\hline 114 & Winterberg & $\mathrm{D}$ & 800 & 27 & 41 & 29 & 41 & 34 \\
\hline 208 & Istebna & PL & 725 & 21 & 72 & 23 & 23 & 35 \\
\hline 4081 & Frenstat pod Radhosten-Obora & CS & 600 & 54 & 26 & 14 & 49 & 35 \\
\hline 4061 & Velke Mezirici-Rudolec & CS & 630 & 49 & 35 & 14 & 57 & 39 \\
\hline 142 & Rosice & CS & 465 & 44 & 2 & 66 & 56 & 42 \\
\hline 202 & Istebna-Wisła & PL & 725 & 16 & 67 & 40 & 51 & 43 \\
\hline 4154 & Roznava & CS & 800 & 44 & 28 & 93 & 10 & 43 \\
\hline 3329 & Spiegelau & $\mathrm{D}$ & 1200 & 89 & 16 & 18 & 52 & 44 \\
\hline 3436 & Neureichenau (2) & $\mathrm{D}$ & 1050 & 24 & 70 & 32 & 54 & 45 \\
\hline 5201 & Köszeg 1 C & $\mathrm{H}$ & 870 & 13 & 74 & 52 & 43 & 46 \\
\hline
\end{tabular}




\begin{tabular}{|c|c|c|c|c|c|c|c|c|}
\hline \multirow{2}{*}{$\begin{array}{l}\text { PG- } \\
\text { Nr. }\end{array}$} & \multirow{2}{*}{ Herkunft } & \multirow{2}{*}{ Land } & Höhe $\mathrm{m}$ & \multicolumn{4}{|c|}{ Flä c he } & \multirow[b]{2}{*}{$\mathrm{X}$} \\
\hline & & & ü. NN & 14 & 24 & & 44 & \\
\hline 9417 & Marsberg & $\mathrm{D}$ & 500 & 3 & 89 & 77 & 15 & 46 \\
\hline 131 & Vizovice & CS & 500 & 12 & 43 & 92 & 40 & 47 \\
\hline 2130 & Stanz-Kindthal-Allerheiligen & A & 750 & 15 & 25 & 111 & 37 & 47 \\
\hline 139 & Vapenkova Skala & CS & 540 & 119 & 23 & 35 & 11 & 47 \\
\hline 5401 & Valea Putnei-Pojorita & RU & 1085 & 73 & 56 & 53 & 13 & 48 \\
\hline 124 & Istebna-Wisła & PL & 725 & 7 & 56 & 39 & 96 & 49 \\
\hline 130 & Dobra bei Frydek & CS & 550 & 44 & 103 & 34 & 17 & 49 \\
\hline 140 & Bucovice & CS & 480 & 21 & 75 & 52 & 54 & 50 \\
\hline 215 & Stinava & SK & & 83 & 39 & 72 & 15 & 52 \\
\hline 3421 & Dombühl & $\mathrm{D}$ & 450 & 57 & 73 & 39 & 39 & 52 \\
\hline 3447 & Nationalp. Hüttenschlag XIX 1b (6) & $\mathrm{D}$ & 750 & 110 & 40 & 39 & 40 & 57 \\
\hline 3445 & Zwiesel, Haselau XXI $12(3,6)$ & $\mathrm{D}$ & 650 & 74 & 55 & 51 & 50 & 57 \\
\hline 3444 & Zwiesel, Scheicherau XXI 14a/b $(3,6)$ & ) D & 650 & 41 & 42 & 96 & 54 & 59 \\
\hline 3412 & Winterberg & $\mathrm{D}$ & 750 & 91 & 51 & 44 & 50 & 59 \\
\hline 5202 & Szentgotthard $1 \mathrm{C}$ & $\mathrm{H}$ & 310 & 31 & 44 & 60 & 102 & 59 \\
\hline 98 & Massif Central & $\mathrm{F}$ & 1100 & 22 & 71 & 78 & 70 & 60 \\
\hline 62 & Litschau & A & 600 & 128 & 16 & 34 & 63 & 60 \\
\hline 227 & Thüringen & $\mathrm{D}$ & 300 & 73 & 82 & 68 & 22 & 61 \\
\hline 192 & Södingberg & A & 550 & 28 & 45 & 97 & 76 & 61 \\
\hline 3433 & Selb-Kirchenlamitz (1) & $\mathrm{D}$ & 800 & 108 & 46 & 41 & 52 & 62 \\
\hline 5204 & Miskolc-Lillafüred 82 A Bükker Geb. & . $\mathrm{H}$ & 730 & 94 & 20 & 59 & 76 & 62 \\
\hline 3332 & Zwiesel-Ost & $\mathrm{D}$ & 1000 & 85 & 73 & 77 & 20 & 64 \\
\hline 4032 & Kynsperk nad Ohri Libocky Dul & CS & 650 & 167 & 57 & 15 & 18 & 64 \\
\hline 3434 & Miele & $\mathrm{D}$ & 90 & 35 & 143 & 57 & 27 & 65 \\
\hline 294 & Aasbo-össjö Gods & $\mathrm{S}$ & 50 & 94 & 22 & 68 & 78 & 65 \\
\hline 291 & Karupsskogen Barsebäcks gods & $\mathrm{S}$ & 100 & 61 & 128 & 62 & 14 & 66 \\
\hline 3498 & Burgjoß & $\mathrm{D}$ & 450 & 72 & 102 & 28 & 64 & 66 \\
\hline 179 & Bischofshofen & A & 1200 & 90 & 35 & 53 & 90 & 67 \\
\hline 6254 & Mikaszowka & PL & 120 & 87 & 59 & 44 & 78 & 67 \\
\hline 3419 & Schwarzwald Baar, VIII/6 & $\mathrm{D}$ & 700 & 108 & 49 & 51 & 60 & 67 \\
\hline 110 & Medebach & $\mathrm{D}$ & 600 & 55 & 16 & 83 & 115 & 67 \\
\hline 4157 & Hnusta & CS & 550 & 123 & 2 & 26 & 117 & 67 \\
\hline 103 & Wunsiedel & $\mathrm{D}$ & 900 & 84 & 83 & 84 & 26 & 69 \\
\hline 177 & Taxenbach & A & 1400 & 45 & 44 & 97 & 91 & 69 \\
\hline 6250 & Augustow Abt. 95 b & PL & 120 & 75 & 39 & 77 & 89 & 70 \\
\hline 2141 & Fölz, Greith & A & 825 & 71 & 65 & 79 & 65 & 70 \\
\hline 66 & Vorau & A & 900 & 83 & 28 & 92 & 79 & 70 \\
\hline 3437 & Neureichenau (2) & $\mathrm{D}$ & 1050 & 77 & 73 & 74 & 58 & 70 \\
\hline 141 & Pitin & CS & 610 & 131 & 30 & 63 & 58 & 71 \\
\hline 3430 & Diessen & $\mathrm{D}$ & 850 & 28 & 111 & 86 & 57 & 71 \\
\hline 5203 & Sarospatak-Haromhuta 19 B Zempl. Geb. & . $\mathrm{H}$ & 405 & 12 & 67 & 116 & 90 & 71 \\
\hline 41 & Spiegelau & $\mathrm{D}$ & 750 & 19 & 51 & 100 & 115 & 71 \\
\hline 3420 & Daun/Ost & $\mathrm{D}$ & 450 & 92 & 78 & 75 & 44 & 72 \\
\hline 63 & Eisenkappel Thurn 1 & A & 850 & 50 & 99 & 64 & 78 & 73 \\
\hline 178 & Abtenau & A & 900 & 116 & 66 & 67 & 45 & 73 \\
\hline 4143 & Kysihybel & CS & 540 & 94 & 111 & 47 & 42 & 74 \\
\hline 3425 & Waldmünchen & $\mathrm{D}$ & 850 & 88 & 67 & 105 & 36 & 74 \\
\hline 1101 & Le Pertuis, Monts du Velay & $\mathrm{F}$ & 1100 & 62 & 55 & 97 & 83 & 74 \\
\hline 2149 & Kindberg/Eisenerzer Alpen & A & 1000 & 62 & 50 & 50 & 136 & 74 \\
\hline 3417 & Marsberg & D & 500 & 25 & 107 & 48 & 122 & 76 \\
\hline 3426 & Uelzen & $\mathrm{D}$ & 50 & 62 & 85 & 81 & 76 & 76 \\
\hline
\end{tabular}




\begin{tabular}{|c|c|c|c|c|c|c|c|c|}
\hline \multirow{2}{*}{$\begin{array}{l}\text { PG- } \\
\text { Nr. }\end{array}$} & \multirow{2}{*}{ Herkunft } & \multirow{2}{*}{ Land } & Höhe m & \multicolumn{4}{|c|}{ Fläche } & \multirow[b]{2}{*}{$\mathrm{X}$} \\
\hline & & & ü. NN & 14 & 24 & $\mid 34$ & 44 & \\
\hline 217 & Istebna-Wisła & PL & 725 & 122 & 31 & 47 & 102 & 76 \\
\hline 5413 & Brosteni Bradu/Bastitei & RU & 1475 & 91 & 81 & 48 & 86 & 76 \\
\hline 204 & Spisske Pochradie & CS & 700 & 135 & 53 & 82 & 42 & 78 \\
\hline 6106 & Köslin/Koszalin & PL & 50 & 104 & 79 & 77 & 53 & 78 \\
\hline 171 & Hofgastein & A & 1100 & 42 & 78 & 113 & 80 & 78 \\
\hline 3428 & Schernfeld & $\mathrm{D}$ & 450 & 80 & 27 & 109 & 98 & 79 \\
\hline 4042 & Vimperk-Prameny Vltury Stachy & CS & 950 & 28 & 74 & 92 & 122 & 79 \\
\hline 3406 & SHK Stryck Willingen & $\mathrm{D}$ & 550 & 146 & 27 & 83 & 62 & 80 \\
\hline 60 & Aflenz & A & 1000 & 95 & 88 & 67 & 69 & 80 \\
\hline 293 & Trolleholm & $\mathrm{S}$ & 125 & 138 & 120 & 13 & 49 & 80 \\
\hline 61 & Gosau & A & 700 & 50 & 88 & 42 & 140 & 80 \\
\hline 3422 & Stryck & $\mathrm{D}$ & 650 & 120 & 70 & 88 & 42 & 80 \\
\hline 3415 & SHK Hochsauerland & $\mathrm{D}$ & 600 & 100 & 84 & 105 & 32 & 80 \\
\hline 2160 & Turnau, Kapfenberg & A & 1100 & 116 & 31 & 65 & 110 & 80 \\
\hline 4103 & Tatranska Lesna 559 C & CS & 950 & 67 & 162 & 34 & 59 & 80 \\
\hline 187 & Pack & A & 950 & 93 & 100 & 59 & 70 & 80 \\
\hline 3424 & Winterberg & $\mathrm{D}$ & 450 & 142 & 111 & 57 & 11 & 81 \\
\hline 3617 & Torgelow & $\mathrm{D}$ & 100 & 144 & 104 & 13 & 62 & 81 \\
\hline 229 & Olsztyn & PL & 100 & 131 & 17 & 60 & 116 & 81 \\
\hline 4159 & Svrcina Hrabusice & CS & 900 & 38 & 86 & 111 & 89 & 81 \\
\hline 6410 & Sierpc & PL & 110 & 50 & 110 & 64 & 103 & 81 \\
\hline 188 & Waldstein a.d. Übelb. & A & 850 & 31 & 131 & 104 & 60 & 82 \\
\hline 3432 & Walsrode & $\mathrm{D}$ & 30 & 50 & 130 & 83 & 64 & 82 \\
\hline 6223 & Przerwanki & PL & 150 & 90 & 37 & 105 & 100 & 83 \\
\hline 6261 & Kumialka (Kumialska) & PL & 160 & 9 & 122 & 102 & 98 & 83 \\
\hline 6255 & Puszcza-Augustowska & PL & 125 & 90 & 66 & 61 & 116 & 83 \\
\hline 3418 & Sachsenried & $\mathrm{D}$ & 900 & 75 & 137 & 54 & 68 & 83 \\
\hline 3449 & Nationalp. Neubruck 1a10,b10/11,c10 (6) & ) $\mathrm{D}$ & 740 & 113 & 18 & 102 & 107 & 85 \\
\hline 4011 & Cikaaj, Zdarska Vrchy & CS & 655 & 47 & 154 & 62 & 78 & 85 \\
\hline 295 & Öveds Kloster Öpedal & $\mathrm{S}$ & 50 & 100 & 67 & 75 & 103 & 86 \\
\hline 9432 & Walsrode & $\mathrm{D}$ & 30 & 130 & 64 & 100 & 51 & 86 \\
\hline 3505 & Eibenst. Carlsf. 275 & $\mathrm{D}$ & 925 & 127 & 150 & 46 & 23 & 86 \\
\hline 2121 & Neukirchen Großvenediger & A & 870 & 82 & 126 & 53 & 86 & 87 \\
\hline 6260 & Knyszyn & PL & 150 & 42 & 129 & 111 & 67 & 87 \\
\hline 184 & Paternion & A & 900 & 147 & 44 & 77 & 84 & 88 \\
\hline 2117 & Gurktal & A & 1300 & 28 & 71 & 122 & 134 & 89 \\
\hline 64 & St. Martin & A & 500 & 158 & 16 & 88 & 93 & 89 \\
\hline 4121 & Javorova Dolina 155 A, Nr. 4121 & CS & 1200 & 29 & 116 & 112 & 99 & 89 \\
\hline 5206 & Sopron (Hochschulrev.) 203 D & $\mathrm{H}$ & 425 & 90 & 136 & 40 & 92 & 90 \\
\hline 2147 & Freiland, Gschwend & A & 1000 & 38 & 102 & 87 & 132 & 90 \\
\hline 189 & Graz-Süd & A & 850 & 14 & 107 & 126 & 116 & 91 \\
\hline 3438 & Oderhaus & $\mathrm{D}$ & 650 & 76 & 137 & 107 & 43 & 91 \\
\hline 3410 & Traunstein & $\mathrm{D}$ & 850 & 153 & 33 & 95 & 83 & 91 \\
\hline 3431 & Riedenburg & $\mathrm{D}$ & 500 & 119 & 89 & 120 & 41 & 92 \\
\hline 2144 & Seewiesen, Seereith & A & 875 & 89 & 65 & 114 & 105 & 93 \\
\hline 290 & Högestad & $\mathrm{S}$ & 50 & 85 & 143 & 54 & 92 & 93 \\
\hline 6237 & Puszcza-Białowieska & PL & 130 & 116 & 93 & 66 & 101 & 94 \\
\hline 5205 & Nagykanizsa-Iharos Plattensee 11/1-71 & $\mathrm{H}$ & 200 & 165 & 85 & 51 & 76 & 94 \\
\hline 3413 & SHK Winterberg & $\mathrm{D}$ & 750 & 57 & 142 & 117 & 62 & 95 \\
\hline 3411 & Bischofswiesen & $\mathrm{D}$ & 950 & 140 & 61 & 117 & 62 & 95 \\
\hline 2128 & Lobming-Oberth. St. Stefan/Kraubath & A & 800 & 19 & 106 & 161 & 95 & 95 \\
\hline
\end{tabular}




\begin{tabular}{|c|c|c|c|c|c|c|c|c|}
\hline PG- & Herlounft & & Höhe $\mathrm{m}$ & & Flä & $\mathrm{chc}$ & & \\
\hline Nr. & Herkuntt & Land & ü. NN & 14 & 24 & 34 & 44 & $\mathrm{X}$ \\
\hline 3427 & Oderhaus & $\mathrm{D}$ & 650 & 163 & 71 & 67 & 82 & 95 \\
\hline 3423 & Kohlstetten & $\mathrm{D}$ & 750 & 89 & 113 & 92 & 91 & 96 \\
\hline 3416 & SHK Höhenfichten & $\mathrm{D}$ & 1050 & 104 & 41 & 148 & 94 & 97 \\
\hline 3435 & Neureichenau (2) & $\mathrm{D}$ & 1050 & 116 & 108 & 75 & 91 & 97 \\
\hline 1100 & Monts Megal, Le Portius & $\mathrm{F}$ & 900 & 77 & 83 & 111 & 119 & 98 \\
\hline 2150 & Siebensee Wildalpen & A & 850 & 9 & 124 & 141 & 118 & 98 \\
\hline 3429 & Villingen & $\mathrm{D}$ & 850 & 129 & 148 & 78 & 36 & 98 \\
\hline 174 & Piesendorf & A & 900 & 97 & 117 & 84 & 95 & 98 \\
\hline 170 & Groß Arl & A & 1350 & 145 & 65 & 97 & 89 & 99 \\
\hline 740 & Bex, Tarejanne & $\mathrm{CH}$ & 1600 & 60 & 37 & 161 & 137 & 99 \\
\hline 5302 & Beglika & $B G$ & 1850 & 108 & 80 & 70 & 141 & 99 \\
\hline 1202 & Manderfeld Gilbuschek 63 A & B & 542 & 98 & 159 & 76 & 66 & 100 \\
\hline 3328 & Spiegelau & $\mathrm{D}$ & 1200 & 125 & 57 & 113 & 105 & 100 \\
\hline 185 & St. Veit/Glan & A & 600 & 104 & 109 & 91 & 95 & 100 \\
\hline 3448 & Nationalp. Filzwald IX 3a 10/11 (6) & $\mathrm{D}$ & 750 & 158 & 56 & 119 & 70 & 100 \\
\hline 2122 & Piberegg & A & 800 & 120 & 128 & 49 & 108 & 101 \\
\hline 9423 & Kohlstetten & $\mathrm{D}$ & 750 & 116 & 57 & 121 & 113 & 102 \\
\hline 176 & St. Johann & A & 1200 & 125 & 57 & 120 & 107 & 102 \\
\hline 284 & Blekinge län Asarum & $\mathrm{S}$ & 100 & 129 & 58 & 126 & 96 & 102 \\
\hline 2140 & Fölz, Mayerberg & A & 950 & 67 & 149 & 61 & 133 & 102 \\
\hline 2126 & Gaishorn & A & 1200 & 87 & 123 & 88 & 113 & 103 \\
\hline 722 & Piana Selva, Faido & $\mathrm{CH}$ & 980 & 85 & 109 & 133 & 105 & 108 \\
\hline 186 & Graz-Nord & A & 850 & 107 & 109 & 142 & 76 & 108 \\
\hline 7401 & Gzatsk-Smolensk & SU & 194 & 118 & 154 & 75 & 88 & 109 \\
\hline 175 & Radstatt & A & 1000 & 139 & 95 & 84 & 118 & 109 \\
\hline 3326 & Neureichenau & $\mathrm{D}$ & 1200 & 111 & 98 & 146 & 83 & 109 \\
\hline 2123 & Gallmannsegg Kainach & A & 1100 & 91 & 122 & 84 & 145 & 110 \\
\hline 716 & Altacanta & $\mathrm{CH}$ & 1400 & 96 & 92 & 129 & 129 & 111 \\
\hline 6896 & Borken & PL & 165 & 107 & 141 & 60 & 139 & 112 \\
\hline 713 & Caragnago & $\mathrm{CH}$ & 1180 & 51 & 142 & 123 & 131 & 112 \\
\hline 207 & Jönköpings län & S & 170 & 38 & 113 & 138 & 158 & 112 \\
\hline 2115 & Rosental & A & 1000 & 89 & 112 & 122 & 126 & 112 \\
\hline 8703 & Lohja Laaskspohjan & $\mathrm{SF}$ & 50 & 67 & 135 & 145 & 130 & 119 \\
\hline 2116 & Aich & A & 700 & 106 & 96 & 125 & 155 & 121 \\
\hline 712 & Forêt du Risoud & $\mathrm{CH}$ & 1100 & 106 & 127 & 147 & 105 & 121 \\
\hline 2120 & Liembergwald Zell a. S. & A & 875 & 78 & 152 & 127 & 129 & 121 \\
\hline 2113 & Oberes Gailtal & A & 1100 & 82 & 138 & 122 & 148 & 122 \\
\hline 711 & La Genolière & $\mathrm{CH}$ & & 63 & 125 & 156 & 146 & 123 \\
\hline 1115 & Magland & $\mathrm{F}$ & 700 & 131 & 122 & 98 & 141 & 123 \\
\hline 2114 & Kreuzen-Stockenboi & A & 1200 & 93 & 151 & 106 & 149 & 125 \\
\hline 97 & Gérardmer & $\mathrm{F}$ & 850 & 132 & 139 & 104 & 146 & 130 \\
\hline 190 & Offenegg & A & 950 & 166 & 133 & 93 & 130 & 130 \\
\hline 150 & Schlanders & I & 1500 & 114 & 109 & 143 & 159 & 131 \\
\hline 704 & Cazis Tschartlina & $\mathrm{CH}$ & 750 & 149 & 88 & 146 & 150 & 133 \\
\hline 1116 & Lantosque & $\mathrm{F}$ & 1500 & 160 & 123 & 146 & 107 & 134 \\
\hline 734 & Airolo, Bedretto & $\mathrm{CH}$ & 1600 & 100 & 125 & 157 & 161 & 136 \\
\hline 9170 & Ryssby-Kronobergs & S & 175 & 80 & 166 & 152 & 145 & 136 \\
\hline 725 & Airolo, Crespato-Ressia & $\mathrm{CH}$ & 1120 & 144 & 128 & 141 & 137 & 138 \\
\hline 1114 & Passy & $\mathrm{F}$ & 1200 & 112 & 148 & 149 & 149 & 139 \\
\hline 5101 & Nedzinant, Prokletije (Geb.) & YU & 1150 & 169 & 136 & 148 & 112 & 141 \\
\hline 1111 & Peisey-Nancroix, Grd. Bois & $\mathrm{F}$ & 1400 & 136 & 146 & 139 & 146 & 142 \\
\hline
\end{tabular}




\begin{tabular}{|c|c|c|c|c|c|c|c|c|}
\hline PG- & & & Höhe m & \multicolumn{4}{|c|}{ Fläche } & \multirow[b]{2}{*}{$\mathrm{X}$} \\
\hline Nr. & Herkuntt & Land & ü. NN & 14 & 24 & 34 & 44 & \\
\hline 5303 & Borovec (Rila-Geb.) & BG & 1300 & 111 & 156 & 160 & 141 & 142 \\
\hline 1117 & Plan Bois, Ballandes & $\mathrm{F}$ & 500 & 154 & 159 & 135 & 143 & 147 \\
\hline 1112 & Autrans, Isère & $\mathrm{F}$ & 1250 & 151 & 144 & 165 & 160 & 155 \\
\hline 6713 & Klodzko-Nynow $72 \mathrm{k}$ & PL & 400 & 104 & 142 & 78 & . & . \\
\hline
\end{tabular}

\section{Anhang 1.27}

Spannweite zwischen den Rängen im Wachstum auf den 4 Versuchsflächen Münsingen (14), Sonthofen (24), Reinhardshagen (34) und Hasbruch (44) und mittlerer Rang über die vier Flächen der 168 gemeinsamen Herkünfte

\begin{tabular}{|c|c|c|c|c|c|}
\hline $\begin{array}{l}\text { PG- } \\
\mathrm{Nr} \text {. }\end{array}$ & Herkunft & Land & $\begin{array}{c}\text { Höhe m } \\
\text { ü. NN }\end{array}$ & Spannweite & $\overline{\mathrm{X}}$ \\
\hline 1111 & Peisey-Nancroix, Grd. Bois & $\mathrm{F}$ & 1400 & 10 & 142 \\
\hline 114 & Winterberg & $\mathrm{D}$ & 800 & 14 & 34 \\
\hline 2141 & Fölz, Greith & A & 825 & 14 & 70 \\
\hline 725 & Airolo, Crespato-Ressia & $\mathrm{CH}$ & 1120 & 16 & 138 \\
\hline 185 & St. Veit/Glan & A & 600 & 18 & 100 \\
\hline 3437 & Neureichenau (2) & $\mathrm{D}$ & 1050 & 19 & 70 \\
\hline 1112 & Autrans, Isère & $\mathrm{F}$ & 1250 & 21 & 155 \\
\hline 3426 & Uelzen & $\mathrm{D}$ & 50 & 23 & 76 \\
\hline 1117 & Plan Bois, Ballandes & $\mathrm{F}$ & 500 & 24 & 147 \\
\hline 3423 & Kohlstetten & $\mathrm{D}$ & 750 & 24 & 96 \\
\hline 3445 & Zwiesel, Haselau XXI $12(3,6)$ & $\mathrm{D}$ & 650 & 25 & 57 \\
\hline 60 & Aflenz & A & 1000 & 28 & 80 \\
\hline 174 & Piesendorf & A & 900 & 33 & 98 \\
\hline 3421 & Dombühl & $\mathrm{D}$ & 450 & 34 & 52 \\
\hline 295 & Öveds Kloster Öpedal & $\mathrm{S}$ & 50 & 36 & 86 \\
\hline 716 & Altacanta & $\mathrm{CH}$ & 1400 & 37 & 111 \\
\hline 1114 & Passy & $\mathrm{F}$ & 1200 & 37 & 139 \\
\hline 2126 & Gaishorn & A & 1200 & 37 & 103 \\
\hline 2115 & Rosental & A & 1000 & 38 & 112 \\
\hline 4081 & Frenstat pod Radhosten-Obora & CS & 600 & 40 & 35 \\
\hline 187 & Pack & A & 950 & 41 & 80 \\
\hline 1101 & Le Pertuis, Monts du Velay & $\mathrm{F}$ & 1100 & 41 & 74 \\
\hline 97 & Gérardmer & $\mathrm{F}$ & 850 & 42 & 130 \\
\hline 712 & Forêt du Risoud & $\mathrm{CH}$ & 1100 & 42 & 121 \\
\hline 3435 & Neureichenau (2) & $\mathrm{D}$ & 1050 & 42 & 97 \\
\hline 6254 & Mikaszowka & PL & 120 & 42 & 67 \\
\hline 1100 & Monts Megal, Le Portius & $\mathrm{F}$ & 900 & 43 & 98 \\
\hline 1115 & Magland & $\mathrm{F}$ & 700 & 43 & 123 \\
\hline 4061 & Velke Mezirici-Rudolec & CS & 630 & 43 & 39 \\
\hline 5413 & Brosteni Bradu/Bastitei & RU & 1475 & 43 & 76 \\
\hline 4082 & Ostravice & CS & 800 & 44 & 27 \\
\hline 3436 & Neureichenau (2) & $\mathrm{D}$ & 1050 & 45 & 45 \\
\hline 3412 & Winterberg & $\mathrm{D}$ & 750 & 47 & 59 \\
\hline 722 & Piana Selva, Faido & $\mathrm{CH}$ & 980 & 48 & 108 \\
\hline 3420 & Daun/Ost & $\mathrm{D}$ & 450 & 48 & 72 \\
\hline 63 & Eisenkappel Thurn 1 & A & 850 & 49 & 73 \\
\hline
\end{tabular}




\begin{tabular}{|c|c|c|c|c|c|}
\hline $\begin{array}{l}\text { PG- } \\
\text { Nr. }\end{array}$ & Herkunft & Land & $\begin{array}{c}\text { Höhe m } \\
\text { ü. NN }\end{array}$ & Spannweite & $\overline{\mathrm{X}}$ \\
\hline 2144 & Seewiesen, Seereith & A & 875 & 49 & 93 \\
\hline 150 & Schlanders & $\mathrm{I}$ & 1500 & 50 & 131 \\
\hline 5303 & Borovec (Rila-Geb.) & BG & 1300 & 50 & 142 \\
\hline 6237 & Puszcza-Białowieska & PL & 130 & 50 & 94 \\
\hline 6250 & Augustow Abt. 95 b & PL & 120 & 50 & 70 \\
\hline 202 & Istebna-Wisła & PL & 725 & 51 & 43 \\
\hline 208 & Istebna & PL & 725 & 51 & 35 \\
\hline 6106 & Köslin/Koszalin & PL & 50 & 51 & 78 \\
\hline 1116 & Lantosque & $\mathrm{F}$ & 1500 & 53 & 134 \\
\hline 177 & Taxenbach & A & 1400 & 54 & 69 \\
\hline 98 & Massif Central & $\mathrm{F}$ & 1100 & 55 & 60 \\
\hline 140 & Bucovice & CS & 480 & 55 & 50 \\
\hline 175 & Radstatt & A & 1000 & 55 & 109 \\
\hline 179 & Bischofshofen & A & 1200 & 55 & 67 \\
\hline 3444 & Zwiesel, Scheicherau XXI 14a/b $(3,6)$ & $\mathrm{D}$ & 650 & 55 & 59 \\
\hline 3499 & Chausseehaus & $\mathrm{D}$ & & 55 & 33 \\
\hline 6255 & Puszcza-Augustowska & PL & 125 & 55 & 83 \\
\hline 5101 & Nedzinant, Prokletije (Geb.) & YU & 1150 & 57 & 141 \\
\hline 103 & Wunsiedel & $\mathrm{D}$ & 900 & 58 & 69 \\
\hline 2114 & Kreuzen-Stockenboi & A & 1200 & 58 & 125 \\
\hline 2116 & Aich & A & 700 & 59 & 121 \\
\hline 3419 & Schwarzwald Baar, VIII/6 & $\mathrm{D}$ & 700 & 59 & 67 \\
\hline 227 & Thüringen & $\mathrm{D}$ & 300 & 60 & 61 \\
\hline 5401 & Valea Putnei-Pojorita & RU & 1085 & 60 & 48 \\
\hline 6410 & Sierpc & PL & 110 & 60 & 81 \\
\hline 734 & Airolo, Bedretto & $\mathrm{CH}$ & 1600 & 61 & 136 \\
\hline 2123 & Gallmannsegg Kainach & A & 1100 & 61 & 110 \\
\hline 704 & Cazis Tschartlina & $\mathrm{CH}$ & 750 & 62 & 133 \\
\hline 3326 & Neureichenau & $\mathrm{D}$ & 1200 & 62 & 109 \\
\hline 5201 & Köszeg 1 C & $\mathrm{H}$ & 870 & 62 & 46 \\
\hline 142 & Rosice & CS & 465 & 64 & 42 \\
\hline 9423 & Kohlstetten & $\mathrm{D}$ & 750 & 64 & 102 \\
\hline 66 & Vorau & A & 900 & 65 & 70 \\
\hline 3332 & Zwiesel-Ost & $\mathrm{D}$ & 1000 & 65 & 64 \\
\hline 186 & Graz-Nord & A & 850 & 66 & 108 \\
\hline 176 & St. Johann & A & 1200 & 67 & 102 \\
\hline 2113 & Oberes Gailtal & A & 1100 & 67 & 122 \\
\hline 3433 & Selb-Kirchenlamitz (1) & $\mathrm{D}$ & 800 & 67 & 62 \\
\hline 215 & Stinava & SK & & 68 & 52 \\
\hline 3328 & Spiegelau & $\mathrm{D}$ & 1200 & 68 & 100 \\
\hline 6223 & Przerwanki & PL & 150 & 68 & 83 \\
\hline 4143 & Kysihybel & CS & 540 & 69 & 74 \\
\hline 192 & Södingberg & A & 550 & 70 & 61 \\
\hline 3425 & Waldmünchen & D & 850 & 70 & 74 \\
\hline 171 & Hofgastein & A & 1100 & 71 & 78 \\
\hline 178 & Abtenau & A & 900 & 71 & 73 \\
\hline 284 & Blekinge län Asarum & $\mathrm{S}$ & 100 & 71 & 102 \\
\hline 3447 & Nationalp. Hüttenschlag XIX 1b (6) & $\mathrm{D}$ & 750 & 71 & 57 \\
\hline 5202 & Szentgotthard $1 \mathrm{C}$ & $\mathrm{H}$ & 310 & 71 & 59 \\
\hline 5302 & Beglika & BG & 1850 & 71 & 99 \\
\hline 294 & Aasbo-össjö Gods & $\mathrm{S}$ & 50 & 72 & 65 \\
\hline
\end{tabular}




\begin{tabular}{|c|c|c|c|c|c|}
\hline $\begin{array}{l}\text { PG- } \\
\text { Nr. }\end{array}$ & Herkunft & Land & $\begin{array}{c}\text { Höhe m } \\
\text { ü. NN }\end{array}$ & Spannweite & $\overline{\mathrm{X}}$ \\
\hline 4159 & Svrcina Hrabusice & CS & 900 & 72 & 81 \\
\hline 190 & Offenegg & A & 950 & 73 & 130 \\
\hline 2121 & Neukirchen Großvenediger & $\mathrm{A}$ & 870 & 73 & 87 \\
\hline 3329 & Spiegelau & $\mathrm{D}$ & 1200 & 73 & 44 \\
\hline 3415 & SHK Hochsauerland & $\mathrm{D}$ & 600 & 73 & 80 \\
\hline 3498 & Burgjoß & $\mathrm{D}$ & 450 & 74 & 66 \\
\hline 5204 & Miskolc-Lillafüred 82 A Bükker Geb. & $\mathrm{H}$ & 730 & 74 & 62 \\
\hline 2120 & Liemberowald Zell a. S. & A & 875 & 75 & 121 \\
\hline 3422 & Stryck & $\mathrm{D}$ & 650 & 78 & 80 \\
\hline 7401 & Gzatsk-Smolensk & SU & 194 & 78 & 109 \\
\hline 8703 & Lohja Laaskspohjan & SF & 50 & 78 & 119 \\
\hline 2122 & Piberegg & A & 800 & 79 & 101 \\
\hline 3431 & Riedenburg & $\mathrm{D}$ & 500 & 79 & 92 \\
\hline 9432 & Walsrode & $\mathrm{D}$ & 30 & 79 & 86 \\
\hline 131 & Vizovice & $\mathrm{CS}$ & 500 & 80 & 47 \\
\hline 170 & Groß Arl & A & 1350 & 80 & 99 \\
\hline 3411 & Bischofswiesen & $\mathrm{D}$ & 950 & 80 & 95 \\
\hline 3432 & Walsrode & $\mathrm{D}$ & 30 & 80 & 82 \\
\hline 6896 & Borken & PL & 165 & 81 & 112 \\
\hline 3428 & Schernfeld & $\mathrm{D}$ & 450 & 82 & 79 \\
\hline 4154 & Roznava & CS & 800 & 82 & 43 \\
\hline 3418 & Sachsenried & $\mathrm{D}$ & 900 & 83 & 83 \\
\hline 3430 & Diessen & $\mathrm{D}$ & 850 & 83 & 71 \\
\hline 9170 & Ryssby-Kronobergs & $\mathrm{S}$ & 175 & 85 & 136 \\
\hline 130 & Dobra bei Frydek & CS & 550 & 86 & 49 \\
\hline 2149 & Kindberg/Eisenerzer Alpen & A & 1000 & 86 & 74 \\
\hline 2160 & Turnau, Kapfenberg & A & 1100 & 86 & 80 \\
\hline 3413 & SHK Winterberg & $\mathrm{D}$ & 750 & 86 & 95 \\
\hline 9417 & Marsberg & $\mathrm{D}$ & 500 & 86 & 46 \\
\hline 2140 & Fölz, Mayerberg & $\mathrm{A}$ & 950 & 87 & 102 \\
\hline 4121 & Javorova Dolina 155 A, Nr. 4121 & CS & 1200 & 87 & 89 \\
\hline 6260 & $\begin{array}{l}\text { Knyszyn } \\
\text { Kna }\end{array}$ & PL & 150 & 87 & 87 \\
\hline 124 & Istebna-Wisła & PL & 725 & 88 & 49 \\
\hline 290 & Högestad & $\mathrm{S}$ & 50 & 88 & 93 \\
\hline 217 & Istebna-Wisła & PL & 725 & 90 & 76 \\
\hline 204 & Spisske Pochradie & $\mathrm{CS}$ & 700 & 92 & 78 \\
\hline 713 & Caragnago & $\mathrm{CH}$ & 1180 & 92 & 112 \\
\hline 711 & La Genolière & $\mathrm{CH}$ & & 93 & 123 \\
\hline 1202 & Manderfeld Gilbuschek 63 A & $\mathrm{B}$ & 542 & 93 & 100 \\
\hline 2147 & Freiland, Gschwend & $\mathrm{A}$ & 1000 & 94 & 90 \\
\hline 3438 & Oderhaus & $\mathrm{D}$ & 650 & 94 & 91 \\
\hline 3449 & Nationalp. Neubruck 1a10,b10/11,c10 (6) & $\mathrm{D}$ & 740 & 94 & 85 \\
\hline 4042 & Vimperk-Prameny Vltury Stachy & CS & 950 & 94 & 79 \\
\hline 41 & Spiegelau & $\mathrm{D}$ & 750 & 96 & 71 \\
\hline 2130 & Stanz-Kindthal-Allerheiligen & A & 750 & 96 & 47 \\
\hline 3427 & Oderhaus & $\mathrm{D}$ & 650 & 96 & 95 \\
\hline 5206 & Sopron (Hochschulrev.) 203 D & $\mathrm{H}$ & 425 & 96 & 90 \\
\hline 3417 & Marsberg & $\mathrm{D}$ & 500 & 97 & 76 \\
\hline 61 & Gosau & A & 700 & 99 & 80 \\
\hline 110 & Medebach & $\mathrm{D}$ & 600 & 99 & 67 \\
\hline 188 & Waldstein a.d. Übelb. & A & 850 & 100 & 82 \\
\hline
\end{tabular}




\begin{tabular}{c|l|c|c|c|c}
\hline $\begin{array}{c}\text { PG- } \\
\text { Nr. }\end{array}$ & Herkunft & Land & $\begin{array}{c}\text { Höhe } \mathrm{m} \\
\text { ü. NN }\end{array}$ & Spannweite & $\overline{\text { X }}$ \\
\hline 141 & Pitin & CS & 610 & 101 & 71 \\
184 & Paternion & A & 900 & 102 & 88 \\
3448 & Nationalp. Filzwald IX 3a 10/11 (6) & D & 750 & 103 & 100 \\
5203 & Sarospatak-Haromhuta 19 B Zempl. Geb. & H & 405 & 104 & 71 \\
2117 & Gurktal & A & 1300 & 106 & 89 \\
3416 & SHK Höhenfichten & D & 1050 & 107 & 97 \\
4011 & Cikaaj, Zdarska Vrchy & CS & 655 & 107 & 85 \\
139 & Vapenkova Skala & CS & 540 & 108 & 47 \\
62 & Litschau & A & 600 & 111 & 60 \\
189 & Graz-Süd & A & 850 & 112 & 91 \\
3429 & Villingen & D & 850 & 112 & 98 \\
291 & Karupsskogen Barsebäcks gods & S & 100 & 113 & 66 \\
6261 & Kumialka (Kumialska) & PL & 160 & 113 & 83 \\
229 & Olsztyn & PL & 100 & 114 & 81 \\
5205 & Nagykanizsa-Iharos Plattensee 11/1-71 & H & 200 & 114 & 94 \\
3434 & Miele & D & 90 & 116 & 65 \\
3406 & SHK Stryck Willingen & D & 550 & 119 & 80 \\
3410 & Traunstein & D & 850 & 119 & 91 \\
207 & Jönköpings län & S & 170 & 120 & 112 \\
4157 & Hnusta & CS & 550 & 121 & 67 \\
740 & Bex, Tarejanne & CH & 1600 & 124 & 99 \\
293 & Trolleholm & S & 125 & 125 & 80 \\
4103 & Tatranska Lesna 559 C & CS & 950 & 127 & 80 \\
3505 & Eibenst. Carlsf. 275 & D & 925 & 128 & 86 \\
3424 & Winterberg & D & 450 & 131 & 81 \\
3617 & Torgelow & D & 100 & 131 & 81 \\
2150 & Siebensee Wildalpen & A & 850 & 132 & 98 \\
2128 & Lobming-Oberth. St. Stefan/Kraubath & A & 800 & 141 & 95 \\
64 & St. Martin & A & 500 & 142 & 89 \\
4032 & Kynsperk nad Ohri Libocky Dul & CS & 650 & 152 & 64 \\
\hline
\end{tabular}

\section{Anhang 1.28}

Mittlerer Rang im Wachstum auf den Flächen mit 81 Herkünften Reinhardshagen (35) und Hasbruch (45) sowie über die beiden Flächen

\begin{tabular}{|c|c|c|c|c|c|c|}
\hline \multirow{2}{*}{$\begin{array}{l}\text { PG- } \\
\text { Nr. }\end{array}$} & \multirow{2}{*}{ Herkunft } & \multirow{2}{*}{ Land } & \multirow{2}{*}{$\begin{array}{c}\text { Höhe m } \\
\text { ü. NN }\end{array}$} & \multicolumn{2}{|c|}{ Fläche } & \multirow[b]{2}{*}{$\overline{\mathrm{X}}$} \\
\hline & & & & 35 & 45 & \\
\hline 3503 & Eibenst. Carlsf. Wiesenh. 214 & $\mathrm{D}$ & 720 & 8 & 13 & 11 \\
\hline 115 & Westerhof & $\mathrm{D}$ & 200 & 23 & 9 & 16 \\
\hline 3519 & Mechterstädt & $\mathrm{D}$ & 200 & 15 & 18 & 17 \\
\hline 5416 & Remeti-Zerna & RU & 900 & 22 & 13 & 17 \\
\hline 5415 & Cimpeni-Dara & RU & 1260 & 18 & 22 & 20 \\
\hline 6510 & Bunzlau/Boleslawiec & PL & 175 & 20 & 20 & 20 \\
\hline 5420 & Valea Putnei-Pojorita III/60 & RU & 1285 & 12 & 29 & 20 \\
\hline 4054 & Chlum u. Trebone-Hamr & CS & 450 & 16 & 30 & 23 \\
\hline 3511 & Innenau Elgersburg & $\mathrm{D}$ & 800 & 34 & 12 & 23 \\
\hline 3417 & Marsberg & $\mathrm{D}$ & 500 & 24 & 23 & 24 \\
\hline 6543 & Groß-Lassowitz/Lassowice Male & PL & 175 & 22 & 30 & 26 \\
\hline
\end{tabular}




\begin{tabular}{|c|c|c|c|c|c|c|}
\hline \multirow{2}{*}{$\begin{array}{l}\text { PG- } \\
\text { Nr. }\end{array}$} & \multirow{2}{*}{ Herkunft } & \multirow{2}{*}{ Land } & \multirow{2}{*}{$\begin{array}{l}\text { Höhe m } \\
\text { ü. NN }\end{array}$} & \multicolumn{2}{|c|}{ Fläche } & \multirow[b]{2}{*}{$\mathrm{X}$} \\
\hline & & & & 35 & 45 & \\
\hline 3404 & Westerhof Abt. $51 \mathrm{~B}$ & D & 200 & 14 & 38 & 26 \\
\hline 6251 & Białobrzegi & PL & 110 & 32 & 21 & 27 \\
\hline 4073 & Jesenik-Zlate Hory & CS & 820 & 31 & 24 & 27 \\
\hline 7235 & Brigalovic-Mogilev & SU & 160 & 39 & 16 & 28 \\
\hline 6864 & Istebna-Ujsoly & PL & 750 & 19 & 37 & 28 \\
\hline 6624 & Przysucha & PL & 275 & 46 & 12 & 29 \\
\hline 6712 & Klodzko-Glatz/Nynow 68 e & PL & 340 & 13 & 46 & 30 \\
\hline 3606 & Templin, Bad Doberan Nr. 9 & $\mathrm{D}$ & 50 & 23 & 38 & 30 \\
\hline 3615 & Neustrelitz & $\mathrm{D}$ & 100 & 31 & 30 & 31 \\
\hline 6731 & Szcytna-Slaska Karlow 243 a & PL & 750 & 44 & 21 & 32 \\
\hline 6235 & Zwierzyniec & PL & 150 & 48 & 18 & 33 \\
\hline 5412 & Moldovita-Sacries & RU & 825 & 20 & 46 & 33 \\
\hline 2158 & Rohr im Gebirge, Kirchwald & A & 825 & 43 & 24 & 34 \\
\hline 4060 & Hencov-Trest & CS & 600 & 24 & 44 & 34 \\
\hline 7233 & Wolozin & SU & 225 & 34 & 34 & 34 \\
\hline 4051 & Vysoky Chlumec Veletin & CS & 600 & 15 & 55 & 35 \\
\hline 2207 & Seewiesen Seereith/Aflenz & A & 875 & 40 & 30 & 35 \\
\hline 3518 & Suhl, Oberhofer Schloßbergkopf & $\mathrm{D}$ & 900 & 65 & 6 & 35 \\
\hline 6222 & Borken/Borki & PL & 160 & 30 & 40 & 35 \\
\hline 4070 & Vrchlabi & CS & 700 & 35 & 35 & 35 \\
\hline 2184 & Schneegattern & A & 750 & 42 & 30 & 36 \\
\hline 3432 & Walsrode & $\mathrm{D}$ & 30 & 50 & 23 & 36 \\
\hline 6894 & Witów & PL & 1250 & 36 & 37 & 36 \\
\hline 6732 & Szcytna-Slaska Karlow 292 b & PL & 700 & 57 & 19 & 38 \\
\hline 3433 & Selb-Kirchenlamitz (1) & $\mathrm{D}$ & 800 & 18 & 60 & 39 \\
\hline 2134 & Hinterhof, Ostbrenner u. Tiefental & A & 1000 & 35 & 46 & 40 \\
\hline 3510 & Sonneb. Steinheid, Kieferleskopf & $\mathrm{D}$ & 886 & 56 & 27 & 41 \\
\hline 6234 & Białowieża & PL & 130 & 43 & 40 & 41 \\
\hline 121 & Cedrogne & $\mathrm{B}$ & 500 & 38 & 46 & 42 \\
\hline 6103 & Brotzen/Broczyno & PL & 140 & 40 & 45 & 42 \\
\hline 2131 & Veitsch-Neuberg & A & 1000 & 47 & 38 & 42 \\
\hline 3423 & Kohlstetten & $\mathrm{D}$ & 750 & 35 & 51 & 43 \\
\hline 2179 & Eisenkappel/Karaw. & A & 800 & 42 & 44 & 43 \\
\hline 4022 & Boubin III & CS & 1000 & 41 & 46 & 43 \\
\hline 4026 & Habartice, Planice & CS & 550 & 25 & 63 & 44 \\
\hline 2138 & Buchberg, Ägidiwald/Aflenz & A & 925 & 63 & 32 & 47 \\
\hline 3102 & Schluchsee-Eschenmoos & $\mathrm{D}$ & 1200 & 44 & 51 & 47 \\
\hline 3430 & Diessen & $\mathrm{D}$ & 850 & 37 & 60 & 48 \\
\hline 3310 & Zwiesel-West/Ruselhänge X/68 & $\mathrm{D}$ & 750 & 42 & 55 & 49 \\
\hline 3139 & Isny Ba/Wü & $\mathrm{D}$ & 850 & 39 & 59 & 49 \\
\hline 5426 & Crucea-Barnavel Abt. 17/18 & RU & 740 & 31 & 68 & 50 \\
\hline 2118 & Gurker Sirnitzwald & A & 900 & 40 & 61 & 50 \\
\hline 4053 & Cesky Krumlov Borova & CS & 800 & 36 & 65 & 50 \\
\hline 5102 & Kaludjerske Bore Taram Kremma & YU & 1000 & 66 & 35 & 50 \\
\hline 2135 & Kraubath, Seckauer Tauern & A & 1050 & 33 & 69 & 51 \\
\hline 2151 & Breitenau-Mixnitz/Fischbacher Alp. & A & 970 & 56 & 46 & 51 \\
\hline 3443 & Zwiesel, Scheichereb. XXI 13b1 $(3,6)$ & $\mathrm{D}$ & 650 & 52 & 55 & 53 \\
\hline 2137 & Buchberg, Flachwald/Aflenz & A & 1300 & 54 & 54 & 54 \\
\hline 3331 & St. Oswald I/3,4,6 Typengemisch & $\mathrm{D}$ & 1200 & 70 & 40 & 55 \\
\hline 2133 & Hinterhof, Eibelkogel & A & 1150 & 57 & 54 & 55 \\
\hline 3042 & Walchensee & $\mathrm{D}$ & 1100 & 63 & 54 & 58 \\
\hline
\end{tabular}




\begin{tabular}{|c|c|c|c|c|c|c|}
\hline \multirow{2}{*}{$\begin{array}{l}\text { PG- } \\
\text { Nr. }\end{array}$} & \multirow{2}{*}{ Herkunft } & \multirow{2}{*}{ Land } & \multirow{2}{*}{$\begin{array}{l}\text { Höhe m } \\
\text { ü. NN }\end{array}$} & \multicolumn{2}{|c|}{ Fläche } & \multirow[b]{2}{*}{$\overline{\mathrm{X}}$} \\
\hline & & & & 35 & 45 & \\
\hline 7224 & Ostrovskij-Pskow & SU & 200 & 63 & 58 & 60 \\
\hline 111 & Bodenmais & $\mathrm{D}$ & 1000 & 67 & 59 & 63 \\
\hline 107 & Donaueschingen & $\mathrm{D}$ & 650 & 71 & 55 & 63 \\
\hline 149 & Einsiedeln & $\mathrm{CH}$ & 900 & 57 & 77 & 67 \\
\hline 4123 & Javorova Dolina 155 A, Nr.4123 & $\mathrm{CS}$ & 1200 & 61 & 75 & 68 \\
\hline 5301 & Belogradchik-Tschupreno & BG & 1400 & 74 & 67 & 70 \\
\hline 5107 & Smrceve Dolina Abt. 138 & HR & 1350 & 77 & 69 & 73 \\
\hline 3337 & Rabenstein Typengemisch & $\mathrm{D}$ & 1200 & 75 & 72 & 73 \\
\hline 8707 & Janakkala Keskivari Uhkoila & SF & 100 & 78 & 75 & 76 \\
\hline 8705 & Mänttä & SF & 120 & 78 & 75 & 77 \\
\hline 129 & Allenstein & PL & 100 & . & 56 & . \\
\hline 3003 & Blumberg & $\mathrm{D}$ & 800 & . & 63 & . \\
\hline 3204 & Burghausen/Salzach & $\mathrm{D}$ & 400 & . & 46 & . \\
\hline 3205 & Ebersberg & $\mathrm{D}$ & 555 & . & 36 & . \\
\hline 3211 & Moosburg/Isar & $\mathrm{D}$ & 500 & . & 20 & . \\
\hline 3320 & Bischofsreut & $\mathrm{D}$ & 970 & 46 & & . \\
\hline 3323 & Mauth/Ost & $\mathrm{D}$ & 1000 & . & 11 & . \\
\hline 3325 & Neureichenau/Typengemisch & $\mathrm{D}$ & 1000 & . & 24 & . \\
\hline 3327 & Passau/Nord & $\mathrm{D}$ & 1000 & & 57 & . \\
\hline 3334 & Zwiesel-Ost, V/1,2, Plattenfichten & $\mathrm{D}$ & 1200 & 67 & $\cdot$ & . \\
\hline 3501 & Rungstock, 46 A & $\mathrm{D}$ & 560 & 12 & . & . \\
\hline 3504 & Eibenst. Carlsf. Wilschm. 233 & $\mathrm{D}$ & 720 & 18 & . & . \\
\hline 3506 & Tellerhaeuser, 44 & $\mathrm{D}$ & 980 & 44 & • & . \\
\hline 3508 & Rehefeld, 146 & $\mathrm{D}$ & 810 & 34 & . & . \\
\hline 3512 & Peitz/Tannenwald & $\mathrm{D}$ & 60 & 43 & . & . \\
\hline 3601 & Cottbus, Tannenwald 17AB & $\mathrm{D}$ & 80 & 49 & . & . \\
\hline 7422 & Rjasan, Moshary & SU & 150 & 63 & & \\
\hline 8003 & Fussinge & DK & 45 & . & 22 & . \\
\hline
\end{tabular}

\section{Anhang 1.29}

Spannweite zwischen den Rängen im Wachstum auf den beiden Versuchsflächen Reinhardshagen (35) und Hasbruch (45) und mittlerer Rang über die beiden Flächen der 72 gemeinsamen Herkünfte

\begin{tabular}{c|l|r|r|r|r}
\hline $\begin{array}{c}\text { PG- } \\
\text { Nr. }\end{array}$ & Herkunft & Land & $\begin{array}{c}\text { Höhe } \mathrm{m} \\
\text { ü. NN }\end{array}$ & Spannweite & $\overline{\mathrm{X}}$ \\
\hline 2137 & Buchberg, Flachwald/Aflenz & $\mathrm{A}$ & 1300 & 0 & 54 \\
4070 & Vrchlabi & $\mathrm{CS}$ & 700 & 0 & 35 \\
6510 & Bunzlau/Boleslawiec & $\mathrm{PL}$ & 175 & 0 & 20 \\
7233 & Wolozin & $\mathrm{SU}$ & 225 & 0 & 34 \\
3417 & Marsberg & $\mathrm{D}$ & 500 & 1 & 24 \\
3615 & Neustrelitz & $\mathrm{D}$ & 100 & 1 & 31 \\
6894 & Witów & $\mathrm{PL}$ & 1250 & 1 & 36 \\
2179 & Eisenkappel/Karaw. & $\mathrm{A}$ & 800 & 2 & 43 \\
3443 & Zwiesel, Scheichereb. XXI 13b1 (3,6) & $\mathrm{D}$ & 650 & 2 & 53 \\
6234 & Białowieża & PL & 130 & 2 & 41 \\
2133 & Hinterhof, Eibelkogel & $\mathrm{A}$ & 1150 & 3 & 55 \\
3337 & Rabenstein Typengemisch & $\mathrm{D}$ & 1200 & 3 & 73 \\
3519 & Mechterstädt & $\mathrm{D}$ & 200 & 3 & 17
\end{tabular}




\begin{tabular}{|c|c|c|c|c|c|}
\hline $\begin{array}{l}\text { PG- } \\
\text { Nr. }\end{array}$ & Herkunft & Land & $\begin{array}{c}\text { Höhe m } \\
\text { ü. NN }\end{array}$ & Spannweite & $\overline{\mathrm{X}}$ \\
\hline 5415 & Cimpeni-Dara & RU & 1260 & 3 & 20 \\
\hline 8705 & Mänttä & $\mathrm{SF}$ & 120 & 3 & 77 \\
\hline 8707 & Janakkala Keskivari Uhkoila & SF & 100 & 3 & 76 \\
\hline 3503 & Eibenst. Carlsf. Wiesenh. 214 & $\mathrm{D}$ & 720 & 5 & 11 \\
\hline 4022 & Boubin III & CS & 1000 & 5 & 43 \\
\hline 6103 & Brotzen/Broczyno & PL & 140 & 5 & 42 \\
\hline 7224 & Ostrovskij-Pskow & SU & 200 & 5 & 60 \\
\hline 5301 & Belogradchik-Tschupreno & BG & 1400 & 7 & 70 \\
\hline 111 & Bodenmais & $\mathrm{D}$ & 1000 & 8 & 63 \\
\hline 121 & Cedrogne & $\mathrm{B}$ & 500 & 8 & 42 \\
\hline 3102 & Schluchsee-Eschenmoos & $\mathrm{D}$ & 1200 & 8 & 47 \\
\hline 4073 & Jesenik-Zlate Hory & CS & 820 & 8 & 27 \\
\hline 6543 & Groß-Lassowitz/Lassowice Male & PL & 175 & 8 & 26 \\
\hline 2131 & Veitsch-Neuberg & A & 1000 & 9 & 42 \\
\hline 3042 & Walchensee & $\mathrm{D}$ & 1100 & 9 & 58 \\
\hline 5107 & Smrceve Dolina Abt. 138 & HR & 1350 & 9 & 73 \\
\hline 5416 & Remeti-Zerna & RU & 900 & 9 & 17 \\
\hline 2151 & Breitenau-Mixnitz/Fischbacher Alp. & A & 970 & 10 & 51 \\
\hline 2207 & Seewiesen Seereith/Aflenz & A & 875 & 10 & 35 \\
\hline 6222 & Borken/Borki & PL & 160 & 10 & 35 \\
\hline 2134 & Hinterhof, Ostbrenner u. Tiefental & $\mathrm{A}$ & 1000 & 11 & 40 \\
\hline 6251 & Białobrzegi & PL & 110 & 11 & 27 \\
\hline 2184 & Schneegattern & A & 750 & 12 & 36 \\
\hline 3310 & Zwiesel-West/Ruselhänge X/68 & $\mathrm{D}$ & 750 & 13 & 49 \\
\hline 115 & Westerhof & $\mathrm{D}$ & 200 & 14 & 16 \\
\hline 4054 & Chlum u. Trebone-Hamr & CS & 450 & 14 & 23 \\
\hline 4123 & Javorova Dolina 155 A, Nr.4123 & CS & 1200 & 14 & 68 \\
\hline 3606 & Templin, Bad Doberan Nr. 9 & $\mathrm{D}$ & 50 & 15 & 30 \\
\hline 107 & Donaueschingen & $\mathrm{D}$ & 650 & 16 & 63 \\
\hline 3423 & Kohlstetten & $\mathrm{D}$ & 750 & 16 & 43 \\
\hline 5420 & Valea Putnei-Pojorita III/60 & RU & 1285 & 17 & 20 \\
\hline 6864 & Istebna-Ujsoly & PL & 750 & 18 & 28 \\
\hline 2158 & Rohr im Gebirge, Kirchwald & A & 825 & 19 & 34 \\
\hline 149 & Einsiedeln & $\mathrm{CH}$ & 900 & 20 & 67 \\
\hline 3139 & Isny $\mathrm{Ba} / \mathrm{Wü}$ & $\mathrm{D}$ & 850 & 20 & 49 \\
\hline 2118 & Gurker Sirnitzwald & A & 900 & 21 & 50 \\
\hline 4060 & Hencov-Trest & CS & 600 & 21 & 34 \\
\hline 3511 & Innenau Elgersburg & $\mathrm{D}$ & 800 & 22 & 23 \\
\hline 6731 & Szcytna-Slaska Karlow 243 a & PL & 750 & 22 & 32 \\
\hline 3430 & Diessen & $\mathrm{D}$ & 850 & 23 & 48 \\
\hline 7235 & Brigalovic-Mogilev & SU & 160 & 23 & 28 \\
\hline 3404 & Westerhof Abt. $51 \mathrm{~B}$ & $\mathrm{D}$ & 200 & 25 & 26 \\
\hline 5412 & Moldovita-Sacries & RU & 825 & 26 & 33 \\
\hline 3432 & Walsrode & $\mathrm{D}$ & 30 & 27 & 36 \\
\hline 4053 & Cesky Krumlov Borova & CS & 800 & 28 & 50 \\
\hline 3510 & Sonneb. Steinheid, Kieferleskopf & $\mathrm{D}$ & 886 & 29 & 41 \\
\hline 3331 & St. Oswald I/3,4,6 Typengemisch & $\mathrm{D}$ & 1200 & 30 & 55 \\
\hline 6235 & Zwierzyniec & PL & 150 & 30 & 33 \\
\hline 2138 & Buchberg, Ägidiwald/Aflenz & A & 925 & 31 & 47 \\
\hline 5102 & Kaludjerske Bore Taram Kremma & YU & 1000 & 32 & 50 \\
\hline 6624 & Przysucha & PL & 275 & 33 & 29 \\
\hline
\end{tabular}




\begin{tabular}{c|l|c|c|c|c}
\hline $\begin{array}{l}\text { PG- } \\
\text { Nr. }\end{array}$ & Herkunft & Land & $\begin{array}{c}\text { Höhe } \mathrm{m} \\
\ddot{u} . \text { NN }\end{array}$ & Spannweite & $\overline{\mathrm{X}}$ \\
\hline 6712 & Klodzko-Glatz/Nynow 68 e & PL & 340 & 33 & 30 \\
2135 & Kraubath, Seckauer Tauern & A & 1050 & 36 & 51 \\
5426 & Crucea-Barnavel Abt. 17/18 & RU & 740 & 37 & 50 \\
4026 & Habartice, Planice & CS & 550 & 38 & 44 \\
6732 & Szcytna-Slaska Karlow 292 b & PL & 700 & 38 & 38 \\
4051 & Vysoky Chlumec Veletin & CS & 600 & 40 & 35 \\
3433 & Selb-Kirchenlamitz (1) & D & 800 & 42 & 39 \\
3518 & Suhl, Oberhofer Schloßbergkopf & D & 900 & 59 & 35 \\
\hline
\end{tabular}

\section{Anhang 1.30}

Spannweite zwischen den Rängen im Wachstum auf den drei Versuchsflächen Berchtesgaden (26), Reinbardshagen (36) und Hasbruch (46) und mittlerer Rang über die beiden Flächen der 34 gemeinsamen Herkünfte

\begin{tabular}{|c|c|c|c|c|c|c|c|}
\hline \multirow{2}{*}{$\begin{array}{l}\text { PG- } \\
\text { Nr. }\end{array}$} & \multirow{2}{*}{ Herkunft } & \multirow{2}{*}{ Land } & Höhe m & \multicolumn{3}{|c|}{ Fläche } & \multirow[b]{2}{*}{$\overline{\mathrm{X}}$} \\
\hline & & & ü. NN & 26 & 36 & 46 & \\
\hline 1201 & Mellier, Bois Bavai, 2 & $\mathrm{~B}$ & 400 & 5 & 15 & 8 & 9 \\
\hline 9191 & Karlsholms-Kristianstad & S & 20 & 3 & 23 & 6 & 11 \\
\hline 3432 & Walsrode & $\mathrm{D}$ & 30 & 14 & 10 & 9 & 11 \\
\hline 3414 & Bodensee Oberschwab. VIII/13 & $\mathrm{D}$ & 650 & 11 & 17 & 5 & 11 \\
\hline 3433 & Selb-Kirchenlamitz (1) & $\mathrm{D}$ & 800 & 5 & 16 & 15 & 12 \\
\hline 6107 & Altenhagen/Nowy Krakow & PL & 200 & 16 & 10 & 13 & 13 \\
\hline 5425 & Cimpeni-Nedei & RU & 1400 & 16 & 9 & 14 & 13 \\
\hline 3213 & Mühldorf/Inn & $\mathrm{D}$ & 440 & 13 & 14 & 16 & 14 \\
\hline 3417 & Marsberg & $\mathrm{D}$ & 500 & 20 & 9 & 13 & 14 \\
\hline 3206 & Eglharting XIV/17,19 & $\mathrm{D}$ & 580 & 23 & 12 & 8 & 14 \\
\hline 4075 & Vitkov-Budisov & CS & 610 & 29 & 4 & 12 & 15 \\
\hline 3446 & Zwiesel, Schmalzau IX 3c $(5,6)$ & $\mathrm{D}$ & 620 & 11 & 21 & 14 & 15 \\
\hline 3150 & Dillingen a.d.D. Bay. & $\mathrm{D}$ & 500 & 20 & 15 & 15 & 17 \\
\hline 7232 & Cemerjanskoe-Mogilev & SU & 175 & 23 & 14 & 16 & 18 \\
\hline 7234 & Soboljanskoe-Grodno & SU & 150 & 17 & 13 & 25 & 18 \\
\hline 65 & Eisenkappel Thurn 2 & A & 850 & 8 & 21 & 26 & 18 \\
\hline 172 & Mittersill & A & 900 & 6 & 22 & 31 & 20 \\
\hline 3423 & Kohlstetten & $\mathrm{D}$ & 750 & 29 & 26 & 8 & 21 \\
\hline 105 & Hohenschwangau & $\mathrm{D}$ & 800 & 24 & 12 & 28 & 21 \\
\hline 4050 & Vlasim-Votice & CS & 600 & 31 & 21 & 13 & 22 \\
\hline 3430 & Diessen & $\mathrm{D}$ & 850 & 15 & 18 & 32 & 22 \\
\hline 7240 & Witebsk & SU & 150 & 29 & 16 & 20 & 22 \\
\hline 169 & Gries & A & 1300 & 21 & 21 & 24 & 22 \\
\hline 230 & Elbingerode & $\mathrm{D}$ & 550 & 31 & 16 & 20 & 22 \\
\hline 116 & Kobernausserwald & A & 600 & 33 & 20 & 14 & 22 \\
\hline 5424 & Valea Beliei-Sinaia Gurguiata & RU & 1115 & 20 & 19 & 29 & 23 \\
\hline 191 & Passail & A & 900 & 28 & 20 & 20 & 23 \\
\hline 6897 & Goldap & PL & 175 & 30 & 17 & 23 & 23 \\
\hline 2127 & Unterhal, St. Kathrein a.d. Lamming & $\mathrm{A}$ & 800 & 16 & 31 & 23 & 23 \\
\hline 2124 & Stixenstein, Gahns & A & 1200 & 13 & 32 & 25 & 23 \\
\hline 2174 & Klein-Sölk/Niedertauern & A & 1250 & 12 & 32 & 28 & 24 \\
\hline 4127 & Javorova Dolina 155 A, Nr.4127 & CS & 1200 & 27 & 30 & 23 & 27 \\
\hline 1118 & Chatel, 1 Aity" & $\mathrm{F}$ & 1250 & 23 & 27 & 30 & 27 \\
\hline
\end{tabular}




\begin{tabular}{|c|c|c|c|c|c|c|c|}
\hline PG- & & & Höhe m & \multicolumn{3}{|c|}{ Fläche } & \\
\hline Nr. & Herkunft & Land & ü. NN & 26 & 36 & 46 & $\mathrm{X}$ \\
\hline 6236 & Białowieża & PL & 150 & 29 & 27 & 25 & 27 \\
\hline 93 & Sieber & D & 400 & 2 & . & 27 & . \\
\hline 108 & Lauterberg & D & 700 & 16 & & 8 & . \\
\hline 113 & Walsrode & $\mathrm{D}$ & 100 & r & 8 & $\cdot$ & . \\
\hline 7400 & Kaluga & SU & 100 & . & 29 & . & . \\
\hline
\end{tabular}

\section{Anhang 1.31}

Spannweite zwischen den Rängen im Wachstum auf den drei Versuchsflächen Berchtesgaden (26), Reinbardshagen (36) und Hasbruch (46) und mittlerer Rang über die beiden Flächen der 34 gemeinsamen Herkïnfte

\begin{tabular}{|c|c|c|c|c|c|}
\hline $\begin{array}{l}\text { PG- } \\
\text { Nr. }\end{array}$ & Herkunft & Land & $\begin{array}{c}\text { Höhe m } \\
\text { ü. NN }\end{array}$ & Spannweite & $\overline{\mathrm{X}}$ \\
\hline 169 & Gries & A & 1300 & 3 & 22 \\
\hline 3213 & Mühldorf/Inn & $\mathrm{D}$ & 440 & 3 & 14 \\
\hline 6236 & Białowieża & PL & 150 & 4 & 27 \\
\hline 3150 & Dillingen a.d.D. Bay. & $\mathrm{D}$ & 500 & 5 & 17 \\
\hline 3432 & Walsrode & $\mathrm{D}$ & 30 & 5 & 11 \\
\hline 4127 & Javorova Dolina 155 A, Nr.4127 & CS & 1200 & 7 & 27 \\
\hline 5425 & Cimpeni-Nedei & RU & 1400 & 7 & 13 \\
\hline 6107 & Altenhagen/Nowy Krakow & PL & 200 & 7 & 13 \\
\hline 191 & Passail & A & 900 & 8 & 23 \\
\hline 1118 & Chatel, 1 Aity" & $\mathrm{F}$ & 1250 & 8 & 27 \\
\hline 7232 & Cemerjanskoe-Mogilev & SU & 175 & 9 & 18 \\
\hline 1201 & Mellier, Bois Bayai, 2 & $\mathrm{~B}$ & 400 & 10 & 9 \\
\hline 3446 & Zwiesel, Schmalzau IX 3c $(5,6)$ & $\mathrm{D}$ & 620 & 10 & 15 \\
\hline 3417 & Marsberg & $\mathrm{D}$ & 500 & 11 & 14 \\
\hline 3433 & Selb-Kirchenlamitz (1) & $\mathrm{D}$ & 800 & 11 & 12 \\
\hline 5424 & Valea Beliei-Sinaia Gurguiata & RU & 1115 & 11 & 23 \\
\hline 3414 & Bodensee Oberschwab. VIII/13 & $\mathrm{D}$ & 650 & 12 & 11 \\
\hline 7234 & Soboljanskoe-Grodno & SU & 150 & 12 & 18 \\
\hline 6897 & Goldap & PL & 175 & 13 & 23 \\
\hline 7240 & Witebsk & SU & 150 & 13 & 22 \\
\hline 230 & Elbingerode & $\mathrm{D}$ & 550 & 15 & 22 \\
\hline 2127 & Unterhal, St. Kathrein a.d. Lamming & A & 800 & 15 & 23 \\
\hline 3206 & Eglharting XIV $/ 17,19$ & $\mathrm{D}$ & 580 & 15 & 14 \\
\hline 105 & Hohenschwangau & $\mathrm{D}$ & 800 & 16 & 21 \\
\hline 3430 & Diessen & $\mathrm{D}$ & 850 & 17 & 22 \\
\hline 65 & Eisenkappel Thurn 2 & A & 850 & 18 & 18 \\
\hline 116 & Kobernausserwald & A & 600 & 18 & 22 \\
\hline 4050 & Vlasim-Votice & CS & 600 & 18 & 22 \\
\hline 2124 & Stixenstein, Gahns & A & 1200 & 19 & 23 \\
\hline 2174 & Klein-Sölk/Niedertauern & $\mathrm{A}$ & 1250 & 20 & 24 \\
\hline 9191 & Karlsholms-Kristianstad & $\mathrm{S}$ & 20 & 20 & 11 \\
\hline 3423 & Kohlstetten & $\mathrm{D}$ & 750 & 21 & 21 \\
\hline 4075 & Vitkov-Budisov & CS & 610 & 24 & 15 \\
\hline 172 & Mittersill & A & 900 & 25 & 20 \\
\hline
\end{tabular}




\section{Anhang 1.32}

Ränge und Spannweiten im Einzelstammvolumen $\left[\mathrm{m}^{3}\right]$ auf den Flächen Reinhardshagen $(34,35,36)$ und Hasbruch $(44,45,46)$

Versuchsflächen 34 (Reinhardshagen) und 44 (Hasbruch)

\begin{tabular}{|c|c|c|c|c|c|c|c|}
\hline $\begin{array}{l}\text { PG- } \\
\text { Nr. }\end{array}$ & Herkunft & Land & $\begin{array}{l}\text { Höhe m } \\
\text { ü. NN }\end{array}$ & \multicolumn{2}{|c|}{$\begin{array}{l}\text { Rang auf } \\
\text { Fläche }\end{array}$} & $\begin{array}{l}- \\
\mathrm{X}\end{array}$ & $\begin{array}{l}\text { Spann- } \\
\text { weite }\end{array}$ \\
\hline 734 & Airolo, Bedretto & $\mathrm{CH}$ & 1600 & 168 & 168 & 168 & 0 \\
\hline 1112 & Autrans, Isère & $\mathrm{F}$ & 1250 & 166 & 167 & 167 & 1 \\
\hline 2126 & Gaishorn & A & 1200 & 117 & 116 & 117 & 1 \\
\hline 8703 & Lohja Laaskspohjan & SF & 50 & 162 & 161 & 162 & 1 \\
\hline 170 & Groß Arl & A & 1350 & 32 & 30 & 31 & 2 \\
\hline 1100 & Monts Megal, Le Portius & $\mathrm{F}$ & 900 & 131 & 129 & 130 & 2 \\
\hline 3428 & Schernfeld & $\mathrm{D}$ & 450 & 120 & 122 & 121 & 2 \\
\hline 3449 & Nationalp. Neubruck 1a10,b10/11,c10 (6) & $\mathrm{D}$ & 740 & 104 & 106 & 105 & 2 \\
\hline 3429 & Villingen & $\mathrm{D}$ & 850 & 19 & 16 & 18 & 3 \\
\hline 5204 & Miskolc-Lillafüred 82 A Bükker Geb. & $\mathrm{H}$ & 730 & 79 & 82 & 81 & 3 \\
\hline 98 & Massif Central & $\mathrm{F}$ & 1100 & 87 & 91 & 89 & 4 \\
\hline 229 & Olsztyn & PL & 100 & 123 & 128 & 126 & 5 \\
\hline 284 & Blekinge län Asarum & $\mathrm{S}$ & 100 & 160 & 155 & 158 & 5 \\
\hline 1101 & Le Pertuis, Monts du Velay & $\mathrm{F}$ & 1100 & 105 & 110 & 108 & 5 \\
\hline 2147 & Freiland, Gschwend & A & 1000 & 137 & 132 & 135 & 5 \\
\hline 6261 & Kumialka (Kumialska) & PL & 160 & 158 & 153 & 156 & 5 \\
\hline 215 & Stinava & SK & . & 39 & 33 & 36 & 6 \\
\hline 5201 & Köszeg 1 C & $\mathrm{H}$ & 870 & 68 & 74 & 71 & 6 \\
\hline 3328 & Spiegelau & $\mathrm{D}$ & 1200 & 98 & 91 & 95 & 7 \\
\hline 3418 & Sachsenried & $\mathrm{D}$ & 900 & 72 & 65 & 69 & 7 \\
\hline 5202 & Szentgotthard $1 \mathrm{C}$ & $\mathrm{H}$ & 310 & 81 & 88 & 85 & 7 \\
\hline 185 & St. Veit/Glan & A & 600 & 106 & 114 & 110 & 8 \\
\hline 2117 & Gurktal & A & 1300 & 109 & 101 & 105 & 8 \\
\hline 4032 & Kynsperk nad Ohri Libocky Dul & CS & 650 & 35 & 43 & 39 & 8 \\
\hline 9170 & Ryssby-Kronobergs & $\mathrm{S}$ & 175 & 155 & 163 & 159 & 8 \\
\hline 9423 & Kohlstetten & $\mathrm{D}$ & 750 & 96 & 104 & 100 & 8 \\
\hline 740 & Bex, Tarejanne & $\mathrm{CH}$ & 1600 & 169 & 160 & 165 & 9 \\
\hline 2140 & Fölz, Mayerberg & A & 950 & 101 & 110 & 106 & 9 \\
\hline 6223 & Przerwanki & PL & 150 & 143 & 134 & 139 & 9 \\
\hline 131 & Vizovice & CS & 500 & 50 & 40 & 45 & 10 \\
\hline 178 & Abtenau & A & 900 & 18 & 28 & 23 & 10 \\
\hline 3499 & Chausseehaus & $\mathrm{D}$ & . & 60 & 71 & 66 & 11 \\
\hline 189 & Graz-Süd & A & 850 & 133 & 145 & 139 & 12 \\
\hline 3445 & Zwiesel, Haselau XXI $12(3,6)$ & $\mathrm{D}$ & 650 & 17 & 5 & 11 & 12 \\
\hline 150 & Schlanders & I & 1500 & 145 & 158 & 152 & 13 \\
\hline 1114 & Passy & $\mathrm{F}$ & 1200 & 161 & 148 & 155 & 13 \\
\hline 3420 & Daun/Ost & $\mathrm{D}$ & 450 & 84 & 71 & 78 & 13 \\
\hline 3447 & Nationalp. Hüttenschlag XIX 1b (6) & $\mathrm{D}$ & 750 & 27 & 14 & 21 & 13 \\
\hline 3505 & Eibenst. Carlsf. 275 & $\mathrm{D}$ & 925 & 14 & 1 & 8 & 13 \\
\hline 140 & Bucovice & CS & 480 & 57 & 43 & 50 & 14 \\
\hline 3416 & SHK Höhenfichten & $\mathrm{D}$ & 1050 & 140 & 126 & 133 & 14 \\
\hline 179 & Bischofshofen & A & 1200 & 77 & 92 & 85 & 15 \\
\hline 3430 & Diessen & $\mathrm{D}$ & 850 & 54 & 39 & 47 & 15 \\
\hline 217 & Istebna-Wisła & PL & 725 & 70 & 86 & 78 & 16 \\
\hline 725 & Airolo, Crespato-Ressia & $\mathrm{CH}$ & 1120 & 135 & 151 & 143 & 16 \\
\hline
\end{tabular}

Beiträge aus der NW-FVA, Band 5, 2010 
Versuchsflächen 34 (Reinhardshagen) und 44 (Hasbruch)

\begin{tabular}{|c|c|c|c|c|c|c|c|}
\hline \multirow{2}{*}{$\begin{array}{l}\text { PG- } \\
\text { Nr. }\end{array}$} & \multirow[t]{2}{*}{ Herkunft } & \multirow[t]{2}{*}{ Land } & \multirow{2}{*}{$\begin{array}{l}\text { Höhe m } \\
\text { ü. NN }\end{array}$} & \multicolumn{2}{|c|}{$\begin{array}{l}\text { Rang auf } \\
\text { Fläche }\end{array}$} & \multirow{2}{*}{$\begin{array}{l}- \\
\mathrm{X}\end{array}$} & \multirow{2}{*}{$\begin{array}{l}\text { Spann- } \\
\text { weite }\end{array}$} \\
\hline & & & & 34 & 44 & & \\
\hline 3412 & Winterberg & $\mathrm{D}$ & 750 & 10 & 27 & 19 & 17 \\
\hline 3421 & Dombühl & $\mathrm{D}$ & 450 & 20 & 37 & 29 & 17 \\
\hline 110 & Medebach & $\mathrm{D}$ & 600 & 130 & 112 & 121 & 18 \\
\hline 63 & Eisenkappel Thurn 1 & A & 850 & 31 & 50 & 41 & 19 \\
\hline 1117 & Plan Bois, Ballandes & $\mathrm{F}$ & 500 & 140 & 159 & 150 & 19 \\
\hline 2128 & Lobming-Oberth. St. Stefan/Kraubath & A & 800 & 147 & 166 & 157 & 19 \\
\hline 103 & Wunsiedel & $\mathrm{D}$ & 900 & 55 & 35 & 45 & 20 \\
\hline 4121 & Javorova Dolina 155 A, Nr. 4121 & CS & 1200 & 159 & 139 & 149 & 20 \\
\hline 4011 & Cikaaj, Zdarska Vrchy & CS & 655 & 81 & 102 & 92 & 21 \\
\hline 4103 & Tatranska Lesna 559 C & CS & 950 & 71 & 50 & 61 & 21 \\
\hline 3433 & Selb-Kirchenlamitz (1) & $\mathrm{D}$ & 800 & 30 & 52 & 41 & 22 \\
\hline 3444 & Zwiesel, Scheicherau XXI 14a/b $(3,6)$ & $\mathrm{D}$ & 650 & 62 & 84 & 73 & 22 \\
\hline 64 & St. Martin & A & 500 & 48 & 71 & 60 & 23 \\
\hline 2116 & Aich & A & 700 & 133 & 156 & 145 & 23 \\
\hline 9417 & Marsberg & $\mathrm{D}$ & 500 & 25 & 2 & 14 & 23 \\
\hline 295 & Öveds Kloster Öpedal & $S$ & 50 & 100 & 124 & 112 & 24 \\
\hline 4143 & Kysihybel & CS & 540 & 33 & 57 & 45 & 24 \\
\hline 3437 & Neureichenau (2) & $\mathrm{D}$ & 1050 & 40 & 66 & 53 & 26 \\
\hline 4082 & Ostravice & CS & 800 & 51 & 77 & 64 & 26 \\
\hline 176 & St. Johann & A & 1200 & 147 & 119 & 133 & 28 \\
\hline 293 & Trolleholm & $\mathrm{S}$ & 125 & 5 & 33 & 19 & 28 \\
\hline 174 & Piesendorf & A & 900 & 90 & 120 & 105 & 30 \\
\hline 722 & Piana Selva, Faido & $\mathrm{CH}$ & 980 & 128 & 98 & 113 & 30 \\
\hline 2123 & Gallmannsegg Kainach & A & 1100 & 111 & 141 & 126 & 30 \\
\hline 41 & Spiegelau & $\mathrm{D}$ & 750 & 163 & 132 & 148 & 31 \\
\hline 204 & Spisske Pochradie & CS & 700 & 94 & 63 & 79 & 31 \\
\hline 3423 & Kohlstetten & $\mathrm{D}$ & 750 & 36 & 67 & 52 & 31 \\
\hline 208 & Istebna & PL & 725 & 39 & 7 & 23 & 32 \\
\hline 3419 & Schwarzwald Baar, VIII/6 & $\mathrm{D}$ & 700 & 54 & 22 & 38 & 32 \\
\hline 177 & Taxenbach & A & 1400 & 121 & 88 & 105 & 33 \\
\hline 713 & Caragnago & $\mathrm{CH}$ & 1180 & 117 & 150 & 134 & 33 \\
\hline 2141 & Fölz, Greith & A & 825 & 49 & 16 & 33 & 33 \\
\hline 6254 & Mikaszowka & PL & 120 & 63 & 96 & 80 & 33 \\
\hline 716 & Altacanta & $\mathrm{CH}$ & 1400 & 88 & 122 & 105 & 34 \\
\hline 3332 & Zwiesel-Ost & $\mathrm{D}$ & 1000 & 46 & 12 & 29 & 34 \\
\hline 5401 & Valea Putnei-Pojorita & RU & 1085 & 43 & 9 & 26 & 34 \\
\hline 6410 & Sierpc & PL & 110 & 59 & 25 & 42 & 34 \\
\hline 3431 & Riedenburg & $\mathrm{D}$ & 500 & 87 & 52 & 70 & 35 \\
\hline 227 & Thüringen & $\mathrm{D}$ & 300 & 66 & 30 & 48 & 36 \\
\hline 190 & Offenegg & A & 950 & 102 & 139 & 121 & 37 \\
\hline 202 & Istebna-Wisła & PL & 725 & 42 & 79 & 61 & 37 \\
\hline 1111 & Peisey-Nancroix, Grd. Bois & $\mathrm{F}$ & 1400 & 126 & 164 & 145 & 38 \\
\hline 3427 & Oderhaus & $\mathrm{D}$ & 650 & 16 & 54 & 35 & 38 \\
\hline 3432 & Walsrode & $\mathrm{D}$ & 30 & 81 & 43 & 62 & 38 \\
\hline 711 & La Genolière & $\mathrm{CH}$ & & 166 & 127 & 147 & 39 \\
\hline 184 & Paternion & A & 900 & 95 & 55 & 75 & 40 \\
\hline 2115 & Rosental & A & 1000 & 147 & 107 & 127 & 40 \\
\hline 4042 & Vimperk-Prameny Vltury Stachy & CS & 950 & 79 & 119 & 99 & 40 \\
\hline 2150 & Siebensee Wildalpen & A & 850 & 157 & 116 & 137 & 41 \\
\hline
\end{tabular}


Versuchsflächen 34 (Reinhardshagen) und 44 (Hasbruch)

\begin{tabular}{|c|c|c|c|c|c|c|c|}
\hline \multirow[t]{2}{*}{$\begin{array}{l}\text { PG- } \\
\text { Nr. }\end{array}$} & \multirow[t]{2}{*}{ Herkunft } & \multirow[t]{2}{*}{ Land } & \multirow{2}{*}{$\begin{array}{c}\text { Höhe m } \\
\text { ü. NN }\end{array}$} & \multicolumn{2}{|c|}{$\begin{array}{l}\text { Rang auf } \\
\text { Fläche }\end{array}$} & \multirow{2}{*}{$\begin{array}{l}- \\
\mathrm{X}\end{array}$} & \multirow{2}{*}{$\begin{array}{l}\text { Spann- } \\
\text { weite }\end{array}$} \\
\hline & & & & 34 & 44 & & \\
\hline 3434 & Miele & $\mathrm{D}$ & 90 & 64 & 23 & 44 & 41 \\
\hline 6237 & Puszcza-Białowieska & PL & 130 & 90 & 48 & 69 & 42 \\
\hline 114 & Winterberg & $\mathrm{D}$ & 800 & 34 & 77 & 56 & 43 \\
\hline 5303 & Borovec (Rila-Geb.) & BG & 1300 & 167 & 124 & 146 & 43 \\
\hline 66 & Vorau & A & 900 & 133 & 88 & 111 & 45 \\
\hline 2121 & Neukirchen Großvenediger & A & 870 & 7 & 52 & 30 & 45 \\
\hline 207 & Jönköpings län & $\mathrm{S}$ & 170 & 117 & 163 & 140 & 46 \\
\hline 3329 & Spiegelau & $\mathrm{D}$ & 1200 & 2 & 48 & 25 & 46 \\
\hline 3436 & Neureichenau (2) & $\mathrm{D}$ & 1050 & 13 & 61 & 37 & 48 \\
\hline 712 & Forêt du Risoud & $\mathrm{CH}$ & 1100 & 149 & 100 & 125 & 49 \\
\hline 3424 & Winterberg & $\mathrm{D}$ & 450 & 52 & 3 & 28 & 49 \\
\hline 3435 & Neureichenau (2) & $\mathrm{D}$ & 1050 & 45 & 94 & 70 & 49 \\
\hline 6250 & Augustow Abt. $95 \mathrm{~b}$ & PL & 120 & 157 & 108 & 133 & 49 \\
\hline 187 & Pack & A & 950 & 66 & 116 & 91 & 50 \\
\hline 60 & Aflenz & A & 1000 & 115 & 64 & 90 & 51 \\
\hline 142 & Rosice & CS & 465 & 23 & 74 & 49 & 51 \\
\hline 5101 & Nedzinant, Prokletije (Geb.) & YU & 1150 & 164 & 113 & 139 & 51 \\
\hline 5205 & Nagykanizsa-Iharos Plattensee 11/1-71 & $\mathrm{H}$ & 200 & 26 & 77 & 52 & 51 \\
\hline 62 & Litschau & A & 600 & 5 & 57 & 31 & 52 \\
\hline 2160 & Turnau, Kapfenberg & A & 1100 & 84 & 137 & 111 & 53 \\
\hline 3438 & Oderhaus & $\mathrm{D}$ & 650 & 114 & 61 & 88 & 53 \\
\hline 6106 & Köslin/Koszalin & PL & 50 & 91 & 37 & 64 & 54 \\
\hline 2114 & Kreuzen-Stockenboi & A & 1200 & 100 & 155 & 128 & 55 \\
\hline 130 & Dobra bei Frydek & CS & 550 & 76 & 20 & 48 & 56 \\
\hline 1115 & Magland & $\mathrm{F}$ & 700 & 85 & 141 & 113 & 56 \\
\hline 1202 & Manderfeld Gilbuschek 63 A & $\mathrm{B}$ & 542 & 41 & 97 & 69 & 56 \\
\hline 5302 & Beglika & BG & 1850 & 93 & 150 & 122 & 57 \\
\hline 192 & Södingberg & A & 550 & 119 & 61 & 90 & 58 \\
\hline 3498 & Burgjoß & $\mathrm{D}$ & 450 & 21 & 80 & 51 & 59 \\
\hline 3326 & Neureichenau & $\mathrm{D}$ & 1200 & 154 & 94 & 124 & 60 \\
\hline 2130 & Stanz-Kindthal-Allerheiligen & A & 750 & 107 & 46 & 77 & 61 \\
\hline 141 & Pitin & CS & 610 & 68 & 6 & 37 & 62 \\
\hline 704 & Cazis Tschartlina & $\mathrm{CH}$ & 750 & 103 & 166 & 135 & 63 \\
\hline 2122 & Piberegg & A & 800 & 6 & 69 & 38 & 63 \\
\hline 139 & Vapenkova Skala & $\mathrm{CS}$ & 540 & 73 & 8 & 41 & 65 \\
\hline 175 & Radstatt & A & 1000 & 45 & 110 & 78 & 65 \\
\hline 5206 & Sopron (Hochschulrev.) 203 D & $\mathrm{H}$ & 425 & 29 & 96 & 63 & 67 \\
\hline 6260 & Knyszyn & PL & 150 & 151 & 84 & 118 & 67 \\
\hline 2113 & Oberes Gailtal & A & 1100 & 74 & 142 & 108 & 68 \\
\hline 3410 & Traunstein & $\mathrm{D}$ & 850 & 37 & 106 & 72 & 69 \\
\hline 188 & Waldstein a.d. Übelb. & A & 850 & 144 & 74 & 109 & 70 \\
\hline 2149 & Kindberg/Eisenerzer Alpen & A & 1000 & 75 & 145 & 110 & 70 \\
\hline 3415 & SHK Hochsauerland & $\mathrm{D}$ & 600 & 127 & 57 & 92 & 70 \\
\hline 2120 & Liembergwald Zell a. S. & A & 875 & 142 & 69 & 106 & 73 \\
\hline 3617 & Torgelow & $\mathrm{D}$ & 100 & 9 & 82 & 46 & 73 \\
\hline 4061 & Velke Mezirici-Rudolec & CS & 630 & 11 & 84 & 48 & 73 \\
\hline 3413 & SHK Winterberg & $\mathrm{D}$ & 750 & 136 & 61 & 99 & 75 \\
\hline 4154 & Roznava & CS & 800 & 98 & 21 & 60 & 77 \\
\hline 171 & Hofgastein & A & 1100 & 109 & 30 & 70 & 79 \\
\hline
\end{tabular}

Beiträge aus der NW-FVA, Band 5, 2010 
Versuchsflächen 34 (Reinhardshagen) und 44 (Hasbruch)

\begin{tabular}{|c|c|c|c|c|c|c|c|}
\hline $\begin{array}{l}\text { PG- } \\
\text { Nr. }\end{array}$ & Herkunft & Land & $\begin{array}{c}\text { Höhe m } \\
\text { ü. NN }\end{array}$ & \multicolumn{2}{|c|}{$\begin{array}{l}\text { Rang auf } \\
\text { Fläche }\end{array}$} & $\begin{array}{l}- \\
\mathrm{X}\end{array}$ & $\begin{array}{l}\text { Spann- } \\
\text { weite }\end{array}$ \\
\hline 290 & Högestad & $\mathrm{S}$ & 50 & 23 & 104 & 64 & 81 \\
\hline 3411 & Bischofswiesen & $\mathrm{D}$ & 950 & 125 & 43 & 84 & 82 \\
\hline 97 & Gérardmer & $\mathrm{F}$ & 850 & 70 & 153 & 112 & 83 \\
\hline 291 & Karupsskogen Barsebäcks gods & $\mathrm{S}$ & 100 & 93 & 10 & 52 & 83 \\
\hline 4157 & Hnusta & CS & 550 & 62 & 145 & 104 & 83 \\
\hline 294 & Aasbo-össjö Gods & $\mathrm{S}$ & 50 & 122 & 35 & 79 & 87 \\
\hline 2144 & Seewiesen, Seereith & A & 875 & 47 & 136 & 92 & 89 \\
\hline 3406 & SHK Stryck Willingen & $\mathrm{D}$ & 550 & 110 & 18 & 64 & 92 \\
\hline 1116 & Lantosque & $\mathrm{F}$ & 1500 & 142 & 43 & 93 & 99 \\
\hline 4081 & Frenstat pod Radhosten-Obora & CS & 600 & 1 & 100 & 51 & 99 \\
\hline 6896 & Borken & PL & 165 & 58 & 157 & 108 & 99 \\
\hline 3422 & Stryck & $\mathrm{D}$ & 650 & 113 & 13 & 63 & 100 \\
\hline 3417 & Marsberg & $\mathrm{D}$ & 500 & 23 & 124 & 74 & 101 \\
\hline 5203 & Sarospatak-Haromhuta 19 B Zempl. Geb. & $\mathrm{H}$ & 405 & 138 & 37 & 88 & 101 \\
\hline 4159 & Svrcina Hrabusice & CS & 900 & 124 & 19 & 72 & 105 \\
\hline 5413 & Brosteni Bradu/Bastitei & RU & 1475 & 29 & 134 & 82 & 105 \\
\hline 3426 & Uelzen & $\mathrm{D}$ & 50 & 113 & 4 & 59 & 109 \\
\hline 9432 & Walsrode & $\mathrm{D}$ & 30 & 130 & 17 & 74 & 113 \\
\hline 124 & Istebna-Wisła & PL & 725 & 15 & 130 & 73 & 115 \\
\hline 7401 & Gzatsk-Smolensk & SU & 194 & 12 & 134 & 73 & 122 \\
\hline 3425 & Waldmünchen & $\mathrm{D}$ & 850 & 152 & 27 & 90 & 125 \\
\hline 3448 & Nationalp. Filzwald IX 3a 10/11 (6) & $\mathrm{D}$ & 750 & 153 & 24 & 89 & 129 \\
\hline 61 & Gosau & A & 700 & 8 & 145 & 77 & 137 \\
\hline 186 & Graz-Nord & A & 850 & 151 & 11 & 81 & 140 \\
\hline 6255 & Puszcza-Augustowska & PL & 125 & 3 & 145 & 74 & 142 \\
\hline 6713 & Klodzko-Nynow $72 \mathrm{k}$ & PL & 400 & 57 & . & . & . \\
\hline
\end{tabular}

Versuchsflächen 35 (Reinhardshagen) und 45 (Hasbruch)

\begin{tabular}{|c|c|c|c|c|c|c|c|}
\hline \multirow{2}{*}{$\begin{array}{l}\text { PG- } \\
\text { Nr. }\end{array}$} & \multirow[t]{2}{*}{ Herkunft } & \multirow[t]{2}{*}{ Land } & \multirow{2}{*}{$\begin{array}{c}\text { Höhe m } \\
\text { ü. NN }\end{array}$} & \multicolumn{2}{|c|}{$\begin{array}{l}\text { Rang auf } \\
\text { Fläche }\end{array}$} & \multirow{2}{*}{$\begin{array}{l}- \\
\mathrm{X}\end{array}$} & \multirow{2}{*}{$\begin{array}{l}\text { Spann- } \\
\text { weite }\end{array}$} \\
\hline & & & & 35 & 45 & & \\
\hline 3102 & Schluchsee-Eschenmoos & $\mathrm{D}$ & 1200 & 64 & 64 & 64 & 0 \\
\hline 3337 & Rabenstein Typengemisch & $\mathrm{D}$ & 1200 & 76 & 76 & 76 & 0 \\
\hline 6864 & Istebna-Ujsoly & PL & 750 & 43 & 43 & 43 & 0 \\
\hline 115 & Westerhof & $\mathrm{D}$ & 200 & 2 & 1 & 2 & 1 \\
\hline 3503 & Eibenst. Carlsf. Wiesenh. 214 & $\mathrm{D}$ & 720 & 3 & 4 & 4 & 1 \\
\hline 8707 & Janakkala Keskivari Uhkoila & $\mathrm{SF}$ & 100 & 78 & 79 & 79 & 1 \\
\hline 3511 & Innenau Elgersburg & $\mathrm{D}$ & 800 & 24 & 22 & 23 & 2 \\
\hline 8705 & Mänttä & $\mathrm{SF}$ & 120 & 80 & 78 & 79 & 2 \\
\hline 3615 & Neustrelitz & $\mathrm{D}$ & 100 & 29 & 32 & 31 & 3 \\
\hline 7224 & Ostrovskij-Pskow & SU & 200 & 71 & 68 & 70 & 3 \\
\hline 3042 & Walchensee & $\mathrm{D}$ & 1100 & 73 & 69 & 71 & 4 \\
\hline 3310 & Zwiesel-West/Ruselhänge X/68 & $\mathrm{D}$ & 750 & 42 & 46 & 44 & 4 \\
\hline 3417 & Marsberg & $\mathrm{D}$ & 500 & 1 & 5 & 3 & 4 \\
\hline 5416 & Remeti-Zerna & RU & 900 & 14 & 10 & 12 & 4 \\
\hline 2137 & Buchberg, Flachwald/Aflenz & A & 1300 & 62 & 57 & 60 & 5 \\
\hline
\end{tabular}


Versuchsflächen 35 (Reinhardshagen) und 45 (Hasbruch)

\begin{tabular}{|c|c|c|c|c|c|c|c|}
\hline \multirow{2}{*}{$\begin{array}{l}\text { PG- } \\
\text { Nr. }\end{array}$} & \multirow[t]{2}{*}{ Herkunft } & \multirow[t]{2}{*}{ Land } & \multirow{2}{*}{$\begin{array}{l}\text { Höhe m } \\
\text { ü. NN }\end{array}$} & \multicolumn{2}{|c|}{$\begin{array}{l}\text { Rang auf } \\
\text { Fläche }\end{array}$} & \multirow{2}{*}{$\begin{array}{l}- \\
\mathrm{X}\end{array}$} & \multirow{2}{*}{$\begin{array}{l}\text { Spann- } \\
\text { weite }\end{array}$} \\
\hline & & & & 35 & 45 & & \\
\hline 3510 & Sonneb. Steinheid, Kieferleskopf & $\mathrm{D}$ & 886 & 44 & 39 & 42 & 5 \\
\hline 6251 & Białobrzegi & PL & 110 & 16 & 11 & 14 & 5 \\
\hline 6731 & Szcytna-Slaska Karlow 243 a & PL & 750 & 30 & 25 & 28 & 5 \\
\hline 111 & Bodenmais & $\mathrm{D}$ & 1000 & 63 & 57 & 60 & 6 \\
\hline 4073 & Jesenik-Zlate Hory & CS & 820 & 22 & 16 & 19 & 6 \\
\hline 6543 & Groß-Lassowitz/Lassowice Male & PL & 175 & 27 & 21 & 24 & 6 \\
\hline 6235 & Zwierzyniec & PL & 150 & 48 & 41 & 45 & 7 \\
\hline 3519 & Mechterstädt & $\mathrm{D}$ & 200 & 26 & 18 & 22 & 8 \\
\hline 5107 & Smrceve Dolina Abt. 138 & HR & 1350 & 81 & 72 & 77 & 9 \\
\hline 6510 & Bunzlau/Boleslawiec & PL & 175 & 36 & 27 & 32 & 9 \\
\hline 2131 & Veitsch-Neuberg & A & 1000 & 55 & 65 & 60 & 10 \\
\hline 7233 & Wolozin & SU & 225 & 57 & 47 & 52 & 10 \\
\hline 3423 & Kohlstetten & $\mathrm{D}$ & 750 & 9 & 20 & 15 & 11 \\
\hline 121 & Cedrogne & $\mathrm{B}$ & 500 & 32 & 44 & 38 & 12 \\
\hline 2179 & Eisenkappel/Karaw. & A & 800 & 62 & 50 & 56 & 12 \\
\hline 4070 & Vrchlabi & CS & 700 & 31 & 43 & 37 & 12 \\
\hline 3443 & Zwiesel, Scheichereb. XXI 13b1 $(3,6)$ & $\mathrm{D}$ & 650 & 65 & 52 & 59 & 13 \\
\hline 4060 & Hencov-Trest & CS & 600 & 15 & 29 & 22 & 14 \\
\hline 2133 & Hinterhof, Eibelkogel & A & 1150 & 52 & 37 & 45 & 15 \\
\hline 3139 & Isny $\mathrm{Ba} / \mathrm{Wü}$ & $\mathrm{D}$ & 850 & 45 & 60 & 53 & 15 \\
\hline 3404 & Westerhof Abt. $51 \mathrm{~B}$ & $\mathrm{D}$ & 200 & 19 & 34 & 27 & 15 \\
\hline 6894 & Witów & PL & 1250 & 54 & 39 & 47 & 15 \\
\hline 2134 & Hinterhof, Ostbrenner u. Tiefental & A & 1000 & 47 & 31 & 39 & 16 \\
\hline 2184 & Schneegattern & A & 750 & 51 & 35 & 43 & 16 \\
\hline 4026 & Habartice, Planice & $\mathrm{CS}$ & 550 & 10 & 26 & 18 & 16 \\
\hline 5301 & Belogradchik-Tschupreno & BG & 1400 & 79 & 63 & 71 & 16 \\
\hline 2158 & Rohr im Gebirge, Kirchwald & A & 825 & 46 & 29 & 38 & 17 \\
\hline 4053 & Cesky Krumlov Borova & CS & 800 & 35 & 54 & 45 & 19 \\
\hline 3432 & Walsrode & $\mathrm{D}$ & 30 & 37 & 14 & 26 & 23 \\
\hline 4123 & Javorova Dolina 155 A, Nr.4123 & CS & 1200 & 57 & 80 & 69 & 23 \\
\hline 5415 & Cimpeni-Dara & RU & 1260 & 13 & 37 & 25 & 24 \\
\hline 2118 & Gurker Sirnitzwald & A & 900 & 33 & 58 & 46 & 25 \\
\hline 5420 & Valea Putnei-Pojorita III/60 & RU & 1285 & 21 & 46 & 34 & 25 \\
\hline 4054 & Chlum u. Trebone-Hamr & CS & 450 & 12 & 39 & 26 & 27 \\
\hline 2151 & Breitenau-Mixnitz/Fischbacher Alp. & A & 970 & 57 & 29 & 43 & 28 \\
\hline 6234 & Białowieża & PL & 130 & 26 & 55 & 41 & 29 \\
\hline 2135 & Kraubath, Seckauer Tauern & A & 1050 & 40 & 73 & 57 & 33 \\
\hline 6103 & Brotzen/Broczyno & PL & 140 & 28 & 61 & 45 & 33 \\
\hline 4022 & Boubin III & CS & 1000 & 38 & 75 & 57 & 37 \\
\hline 6732 & Szcytna-Slaska Karlow 292 b & PL & 700 & 49 & 12 & 31 & 37 \\
\hline 149 & Einsiedeln & $\mathrm{CH}$ & 900 & 41 & 81 & 61 & 40 \\
\hline 5426 & Crucea-Barnavel Abt. 17/18 & RU & 740 & 34 & 75 & 55 & 41 \\
\hline 3606 & Templin, Bad Doberan Nr. 9 & $\mathrm{D}$ & 50 & 11 & 54 & 33 & 43 \\
\hline 3430 & Diessen & $\mathrm{D}$ & 850 & 24 & 71 & 48 & 47 \\
\hline 5412 & Moldovita-Sacries & RU & 825 & 18 & 66 & 42 & 48 \\
\hline 2138 & Buchberg, Ägidiwald/Aflenz & $\mathrm{A}$ & 925 & 75 & 25 & 50 & 50 \\
\hline 107 & Donaueschingen & $\mathrm{D}$ & 650 & 74 & 23 & 49 & 51 \\
\hline 7235 & Brigalovic-Mogilev & SU & 160 & 66 & 14 & 40 & 52 \\
\hline 6222 & Borken/Borki & PL & 160 & 4 & 60 & 32 & 56 \\
\hline
\end{tabular}


Versuchsflächen 35 (Reinhardshagen) und 45 (Hasbruch)

\begin{tabular}{|c|c|c|c|c|c|c|c|}
\hline $\begin{array}{l}\text { PG- } \\
\text { Nr. }\end{array}$ & Herkunft & Land & $\begin{array}{c}\text { Höhe m } \\
\text { ü. NN }\end{array}$ & \multicolumn{2}{|c|}{$\begin{array}{l}\text { Rang auf } \\
\text { Fläche }\end{array}$} & $\begin{array}{l}- \\
\mathrm{X}\end{array}$ & $\begin{array}{l}\text { Spann- } \\
\text { weite }\end{array}$ \\
\hline 4051 & Vysoky Chlumec Veletin & CS & 600 & 20 & 77 & 49 & 57 \\
\hline 6712 & Klodzko-Glatz/Nynow $68 \mathrm{e}$ & PL & 340 & 6 & 63 & 35 & 57 \\
\hline 2207 & Seewiesen Seereith/Aflenz & A & 875 & 67 & 8 & 38 & 59 \\
\hline 5102 & Kaludjerske Bore Taram Kremma & YU & 1000 & 77 & 17 & 47 & 60 \\
\hline 3433 & Selb-Kirchenlamitz (1) & $\mathrm{D}$ & 800 & 8 & 70 & 39 & 62 \\
\hline 6624 & Przysucha & PL & 275 & 72 & 10 & 41 & 62 \\
\hline 3331 & St. Oswald I/3,4,6 Typengemisch & $\mathrm{D}$ & 1200 & 70 & 6 & 38 & 64 \\
\hline 3518 & Suhl, Oberhofer Schloßbergkopf & $\mathrm{D}$ & 900 & 68 & 2 & 35 & 66 \\
\hline 129 & Allenstein & PL & 100 & . & 67 & . & . \\
\hline 3003 & Blumberg & $\mathrm{D}$ & 800 & . & 49 & . & . \\
\hline 3204 & Burghausen/Salzach & $\mathrm{D}$ & 400 & . & 49 & . & . \\
\hline 3205 & Ebersberg & $\mathrm{D}$ & 555 & . & 33 & . & . \\
\hline 3211 & Moosburg/Isar & $\mathrm{D}$ & 500 & . & 15 & . & . \\
\hline 3320 & Bischofsreut & $\mathrm{D}$ & 970 & 7 & . & . & . \\
\hline 3323 & Mauth/Ost & $\mathrm{D}$ & 1000 & . & 3 & . & . \\
\hline 3325 & Neureichenau/Typengemisch & $\mathrm{D}$ & 1000 & . & 7 & . & . \\
\hline 3327 & Passau/Nord & $\mathrm{D}$ & 1000 & & 51 & . & . \\
\hline 3334 & Zwiesel-Ost, V/1,2, Plattenfichten & $\mathrm{D}$ & 1200 & 53 & . & . & . \\
\hline 3501 & Rungstock, 46 A & $\mathrm{D}$ & 560 & 5 & . & . & . \\
\hline 3504 & Eibenst. Carlsf. Wilschm. 233 & $\mathrm{D}$ & 720 & 40 & . & . & . \\
\hline 3506 & Tellerhaeuser, 44 & $\mathrm{D}$ & 980 & 50 & . & . & . \\
\hline 3508 & Rehefeld, 146 & $\mathrm{D}$ & 810 & 17 & . & . & . \\
\hline 3512 & Peitz/Tannenwald & $\mathrm{D}$ & 60 & 60 & . & . & . \\
\hline 3601 & Cottbus, Tannenwald 17AB & $\mathrm{D}$ & 80 & 60 & & & . \\
\hline 7422 & Rjasan, Moshary & SU & 50 & 69 & . & . & . \\
\hline 8003 & Fussinge & DK & 45 & . & 19 & . & . \\
\hline
\end{tabular}

Versuchsflächen 36 (Reinhardshagen) und 46 (Hasbruch)

\begin{tabular}{c|l|c|r|rrr|r|r}
\hline $\begin{array}{l}\text { PG- } \\
\text { Nr. }\end{array}$ & Herkunft & Land & Höhe m & \multicolumn{2}{|c|}{$\begin{array}{c}\text { Rang auf } \\
\text { Fläche }\end{array}$} & $\begin{array}{c}\text { Spann- } \\
\text { weite }\end{array}$ \\
\hline 3433 & Selb-Kirchenlamitz (1) & D & 800 & 9 & 9 & 9 & 0 \\
65 & Eisenkappel Thurn 2 & A & 850 & 18 & 19 & 19 & 1 \\
169 & Gries & A & 1300 & 26 & 25 & 26 & 1 \\
191 & Passail & A & 900 & 12 & 13 & 13 & 1 \\
1118 & Chatel, 1 Aity" & F & 1250 & 31 & 30 & 31 & 1 \\
2174 & Klein-Sölk/Niedertauern & A & 1250 & 28 & 27 & 28 & 1 \\
3150 & Dillingen a.d.D. Bay. & D & 500 & 10 & 8 & 9 & 2 \\
3446 & Zwiesel, Schmalzau IX 3c (5,6) & D & 620 & 14 & 12 & 13 & 2 \\
3213 & Mühldorf/Inn & D & 440 & 13 & 10 & 12 & 3 \\
3414 & Bodensee Oberschwab. VIII/13 & D & 650 & 6 & 2 & 4 & 4 \\
7232 & Cemerjanskoe-Mogilev & SU & 175 & 29 & 33 & 31 & 4 \\
5424 & Valea Beliei-Sinaia Gurguiata & RU & 1115 & 30 & 36 & 33 & 6 \\
1201 & Mellier, Bois Bayai, 2 & B & 400 & 27 & 20 & 24 & 7 \\
3432 & Walsrode & D & 30 & 4 & 11 & 8 & 7 \\
116 & Kobernausserwald & A & 600 & 24 & 16 & 20 & 8
\end{tabular}


Versuchsflächen 36 (Reinhardshagen) und 46 (Hasbruch)

\begin{tabular}{|c|c|c|c|c|c|c|c|}
\hline \multirow{2}{*}{$\begin{array}{l}\text { PG- } \\
\text { Nr. }\end{array}$} & \multirow[t]{2}{*}{ Herkunft } & \multirow[t]{2}{*}{ Land } & \multirow{2}{*}{$\begin{array}{l}\text { Höhe m } \\
\text { ü. NN }\end{array}$} & \multicolumn{2}{|c|}{$\begin{array}{l}\text { Rang auf } \\
\text { Fläche }\end{array}$} & \multirow{2}{*}{$\begin{array}{l}- \\
X\end{array}$} & \multirow{2}{*}{$\begin{array}{l}\text { Spann- } \\
\text { weite }\end{array}$} \\
\hline & & & & 36 & 46 & & \\
\hline 7234 & Soboljanskoe-Grodno & SU & 150 & 25 & 33 & 29 & 8 \\
\hline 2124 & Stixenstein, Gahns & A & 1200 & 32 & 23 & 28 & 9 \\
\hline 2127 & Unterhal, St. Kathrein a.d. Lamming & A & 800 & 33 & 24 & 29 & 9 \\
\hline 6107 & Altenhagen/Nowy Krakow & PL & 200 & 8 & 17 & 13 & 9 \\
\hline 3206 & Eglharting XIV/17,19 & $\mathrm{D}$ & 580 & 16 & 5 & 11 & 11 \\
\hline 5425 & Cimpeni-Nedei & RU & 1400 & 11 & 22 & 17 & 11 \\
\hline 6897 & Goldap & PL & 175 & 18 & 29 & 24 & 11 \\
\hline 7240 & Witebsk & SU & 150 & 20 & 31 & 26 & 11 \\
\hline 230 & Elbingerode & $\mathrm{D}$ & 550 & 19 & 7 & 13 & 12 \\
\hline 4075 & Vitkov-Budisov & CS & 610 & 2 & 15 & 9 & 13 \\
\hline 6236 & Białowieża & PL & 150 & 34 & 19 & 27 & 15 \\
\hline 3417 & Marsberg & $\mathrm{D}$ & 500 & 5 & 21 & 13 & 16 \\
\hline 4050 & Vlasim-Votice & CS & 600 & 23 & 6 & 15 & 17 \\
\hline 9191 & Karlsholms-Kristianstad & $\mathrm{S}$ & 20 & 22 & 4 & 13 & 18 \\
\hline 3423 & Kohlstetten & $\mathrm{D}$ & 750 & 21 & 1 & 11 & 20 \\
\hline 4127 & Javorova Dolina 155 A, Nr.4127 & CS & 1200 & 35 & 14 & 25 & 21 \\
\hline 3430 & Diessen & $\mathrm{D}$ & 850 & 3 & 28 & 16 & 25 \\
\hline 172 & Mittersill & A & 900 & 7 & 35 & 21 & 28 \\
\hline 105 & Hohenschwangau & $\mathrm{D}$ & 800 & 1 & 34 & 18 & 33 \\
\hline 93 & Sieber & $\mathrm{D}$ & 400 & . & 27 & . & . \\
\hline 108 & Lauterberg & $\mathrm{D}$ & 700 & . & 3 & . & . \\
\hline 113 & Walsrode & $\mathrm{D}$ & 100 & 15 & . & . & . \\
\hline 7400 & Kaluga & SU & 100 & 36 & & . & . \\
\hline
\end{tabular}

\section{Anhang 1.33}

Ränge und Spannweite im Vorrat $\left[\mathrm{m}^{3} / \mathrm{ha}\right]$ auf den Flächen Reinhardshagen $(34,35,36)$ und Hasbruch $(44,45,46)$

Versuchsflächen 34 (Reinhardshagen) und 44 (Hasbruch)

\begin{tabular}{|c|c|c|c|c|c|c|c|}
\hline \multirow[t]{2}{*}{$\begin{array}{l}\text { PG- } \\
\text { Nr. }\end{array}$} & \multirow[t]{2}{*}{ Herkunft } & \multirow[t]{2}{*}{ Land } & \multirow{2}{*}{$\begin{array}{l}\text { Höhe m } \\
\text { ü. NN }\end{array}$} & \multicolumn{2}{|c|}{$\begin{array}{l}\text { Rang auf } \\
\text { Fläche }\end{array}$} & \multirow{2}{*}{$\begin{array}{l}- \\
X \\
\end{array}$} & \multirow[t]{2}{*}{$\begin{array}{l}\text { Spann- } \\
\text { weite }\end{array}$} \\
\hline & & & & 34 & 44 & & \\
\hline 1100 & Monts Megal, Le Portius & $\mathrm{F}$ & 900 & 138 & 138 & 138 & 0 \\
\hline 3328 & Spiegelau & $\mathrm{D}$ & 1200 & 94 & 94 & 94 & 0 \\
\hline 3406 & SHK Stryck Willingen & $\mathrm{D}$ & 550 & 68 & 68 & 68 & 0 \\
\hline 177 & Taxenbach & A & 1400 & 96 & 94 & 95 & 2 \\
\hline 284 & Blekinge län Asarum & $\mathrm{s}$ & 100 & 149 & 151 & 150 & 2 \\
\hline 295 & Öveds Kloster Öpedal & $\mathrm{S}$ & 50 & 118 & 120 & 119 & 2 \\
\hline 2116 & Aich & A & 700 & 146 & 144 & 145 & 2 \\
\hline 5206 & Sopron (Hochschulrev.) 203 D & $\mathrm{H}$ & 425 & 48 & 50 & 49 & 2 \\
\hline 6223 & Przerwanki & PL & 150 & 116 & 118 & 117 & 2 \\
\hline 2117 & Gurktal & A & 1300 & 107 & 110 & 109 & 3 \\
\hline 1117 & Plan Bois, Ballandes & $\mathrm{F}$ & 500 & 140 & 144 & 142 & 4 \\
\hline 110 & Medebach & $\mathrm{D}$ & 600 & 125 & 120 & 123 & 5 \\
\hline 140 & Bucovice & CS & 480 & 70 & 75 & 73 & 5 \\
\hline 150 & Schlanders & I & 1500 & 152 & 147 & 150 & 5 \\
\hline
\end{tabular}

Beiträge aus der NW-FVA, Band 5, 2010 
Versuchsflächen 34 (Reinhardshagen) und 44 (Hasbruch)

\begin{tabular}{|c|c|c|c|c|c|c|c|}
\hline \multirow{2}{*}{$\begin{array}{l}\text { PG- } \\
\text { Nr. }\end{array}$} & \multirow[t]{2}{*}{ Herkunft } & \multirow[t]{2}{*}{ Land } & \multirow{2}{*}{$\begin{array}{c}\text { Höhe m } \\
\text { ü. NN }\end{array}$} & \multicolumn{2}{|c|}{$\begin{array}{l}\text { Rang auf } \\
\text { Fläche }\end{array}$} & \multirow{2}{*}{$\begin{array}{l}- \\
\mathrm{X}\end{array}$} & \multirow{2}{*}{$\begin{array}{l}\text { Spann- } \\
\text { weite }\end{array}$} \\
\hline & & & & 34 & 44 & & \\
\hline 293 & Trolleholm & $\mathrm{S}$ & 125 & 20 & 25 & 23 & 5 \\
\hline 725 & Airolo, Crespato-Ressia & $\mathrm{CH}$ & 1120 & 128 & 133 & 131 & 5 \\
\hline 3425 & Waldmünchen & $\mathrm{D}$ & 850 & 119 & 124 & 122 & 5 \\
\hline 734 & Airolo, Bedretto & $\mathrm{CH}$ & 1600 & 158 & 164 & 161 & 6 \\
\hline 5205 & Nagykanizsa-Iharos Plattensee 11/1-71 & $\mathrm{H}$ & 200 & 72 & 78 & 75 & 6 \\
\hline 5303 & Borovec (Rila-Geb.) & BG & 1300 & 156 & 162 & 159 & 6 \\
\hline 704 & Cazis Tschartlina & $\mathrm{CH}$ & 750 & 147 & 140 & 144 & 7 \\
\hline 3444 & Zwiesel, Scheicherau XXI 14a/b $(3,6)$ & $\mathrm{D}$ & 650 & 30 & 37 & 34 & 7 \\
\hline 5302 & Beglika & BG & 1850 & 90 & 97 & 94 & 7 \\
\hline 63 & Eisenkappel Thurn 1 & A & 850 & 15 & 23 & 19 & 8 \\
\hline 64 & St. Martin & A & 500 & 86 & 94 & 90 & 8 \\
\hline 184 & Paternion & A & 900 & 93 & 84 & 89 & 9 \\
\hline 66 & Vorau & A & 900 & 88 & 78 & 83 & 10 \\
\hline 215 & Stinava & SK & . & 18 & 8 & 13 & 10 \\
\hline 1112 & Autrans, Isère & $\mathrm{F}$ & 1250 & 156 & 166 & 161 & 10 \\
\hline 3505 & Eibenst. Carlsf. 275 & $\mathrm{D}$ & 925 & 46 & 56 & 51 & 10 \\
\hline 139 & Vapenkova Skala & CS & 540 & 35 & 24 & 30 & 11 \\
\hline 60 & Aflenz & A & 1000 & 56 & 68 & 62 & 12 \\
\hline 174 & Piesendorf & A & 900 & 66 & 78 & 72 & 12 \\
\hline 294 & Aasbo-össjö Gods & $\mathrm{S}$ & 50 & 99 & 87 & 93 & 12 \\
\hline 713 & Caragnago & $\mathrm{CH}$ & 1180 & 112 & 124 & 118 & 12 \\
\hline 3420 & Daun/Ost & $\mathrm{D}$ & 450 & 42 & 54 & 48 & 12 \\
\hline 4143 & Kysihybel & CS & 540 & 51 & 63 & 57 & 12 \\
\hline 716 & Altacanta & $\mathrm{CH}$ & 1400 & 131 & 118 & 125 & 13 \\
\hline 5101 & Nedzinant, Prokletije (Geb.) & YU & 1150 & 143 & 130 & 137 & 13 \\
\hline 227 & Thüringen & $\mathrm{D}$ & 300 & 19 & 5 & 12 & 14 \\
\hline 722 & Piana Selva, Faido & $\mathrm{CH}$ & 980 & 104 & 89 & 97 & 15 \\
\hline 3419 & Schwarzwald Baar, VIII/6 & $\mathrm{D}$ & 700 & 47 & 32 & 40 & 15 \\
\hline 3426 & Uelzen & $\mathrm{D}$ & 50 & 53 & 68 & 61 & 15 \\
\hline 175 & Radstatt & A & 1000 & 79 & 63 & 71 & 16 \\
\hline 4082 & Ostravice & CS & 800 & 66 & 82 & 74 & 16 \\
\hline 207 & Jönköpings län & $\mathrm{S}$ & 170 & 134 & 151 & 143 & 17 \\
\hline 3418 & Sachsenried & $\mathrm{D}$ & 900 & 33 & 50 & 42 & 17 \\
\hline 3430 & Diessen & $\mathrm{D}$ & 850 & 27 & 10 & 19 & 17 \\
\hline 5203 & Sarospatak-Haromhuta 19 B Zempl. Geb. & $\mathrm{H}$ & 405 & 132 & 115 & 124 & 17 \\
\hline 6255 & Puszcza-Augustowska & PL & 125 & 144 & 127 & 136 & 17 \\
\hline 9170 & Ryssby-Kronobergs & $\mathrm{S}$ & 175 & 157 & 140 & 149 & 17 \\
\hline 3437 & Neureichenau (2) & $\mathrm{D}$ & 1050 & 32 & 14 & 23 & 18 \\
\hline 3447 & Nationalp. Hüttenschlag XIX 1b (6) & $\mathrm{D}$ & 750 & 26 & 44 & 35 & 18 \\
\hline 179 & Bischofshofen & A & 1200 & 63 & 44 & 54 & 19 \\
\hline 3499 & Chausseehaus & $\mathrm{D}$ & . & 29 & 10 & 20 & 19 \\
\hline 4103 & Tatranska Lesna 559 C & CS & 950 & 57 & 37 & 47 & 20 \\
\hline 9417 & Marsberg & $\mathrm{D}$ & 500 & 23 & 2 & 13 & 21 \\
\hline 41 & Spiegelau & $\mathrm{D}$ & 750 & 111 & 133 & 122 & 22 \\
\hline 98 & Massif Central & $\mathrm{F}$ & 1100 & 44 & 22 & 33 & 22 \\
\hline 176 & St. Johann & A & 1200 & 109 & 87 & 98 & 22 \\
\hline 187 & Pack & A & 950 & 77 & 99 & 88 & 22 \\
\hline 2121 & Neukirchen Großvenediger & A & 870 & 17 & 39 & 28 & 22 \\
\hline 3329 & Spiegelau & $\mathrm{D}$ & 1200 & 13 & 35 & 24 & 22 \\
\hline
\end{tabular}


Versuchsflächen 34 (Reinhardshagen) und 44 (Hasbruch)

\begin{tabular}{|c|c|c|c|c|c|c|c|}
\hline \multirow{2}{*}{$\begin{array}{l}\text { PG- } \\
\text { Nr. }\end{array}$} & \multirow[t]{2}{*}{ Herkunft } & \multirow[t]{2}{*}{ Land } & \multirow{2}{*}{$\begin{array}{l}\text { Höhe m } \\
\text { ü. NN }\end{array}$} & \multicolumn{2}{|c|}{$\begin{array}{l}\text { Rang auf } \\
\text { Fläche }\end{array}$} & \multirow[b]{2}{*}{$\mathrm{X}$} & \multirow[t]{2}{*}{$\begin{array}{l}\text { Spann- } \\
\text { weite }\end{array}$} \\
\hline & & & & 34 & 44 & & \\
\hline 97 & Gérardmer & $\mathrm{F}$ & 850 & 99 & 122 & 111 & 23 \\
\hline 2115 & Rosental & A & 1000 & 127 & 104 & 116 & 23 \\
\hline 2128 & Lobming-Oberth. St. Stefan/Kraubath & A & 800 & 145 & 168 & 157 & 23 \\
\hline 3415 & SHK Hochsauerland & $\mathrm{D}$ & 600 & 81 & 104 & 93 & 23 \\
\hline 178 & Abtenau & A & 900 & 31 & 56 & 44 & 25 \\
\hline 3413 & SHK Winterberg & $\mathrm{D}$ & 750 & 129 & 104 & 117 & 25 \\
\hline 6261 & Kumialka (Kumialska) & PL & 160 & 139 & 165 & 152 & 26 \\
\hline 185 & St. Veit/Glan & A & 600 & 106 & 133 & 120 & 27 \\
\hline 3438 & Oderhaus & $\mathrm{D}$ & 650 & 91 & 63 & 77 & 28 \\
\hline 5401 & Valea Putnei-Pojorita & RU & 1085 & 60 & 32 & 46 & 28 \\
\hline 190 & Offenegg & A & 950 & 101 & 130 & 116 & 29 \\
\hline 3332 & Zwiesel-Ost & $\mathrm{D}$ & 1000 & 37 & 8 & 23 & 29 \\
\hline 3435 & Neureichenau (2) & $\mathrm{D}$ & 1050 & 63 & 33 & 48 & 30 \\
\hline 740 & Bex, Tarejanne & $\mathrm{CH}$ & 1600 & 159 & 127 & 143 & 32 \\
\hline 2150 & Siebensee Wildalpen & A & 850 & 131 & 99 & 115 & 32 \\
\hline 3433 & Selb-Kirchenlamitz (1) & $\mathrm{D}$ & 800 & 50 & 82 & 66 & 32 \\
\hline 229 & Olsztyn & PL & 100 & 118 & 151 & 135 & 33 \\
\hline 2130 & Stanz-Kindthal-Allerheiligen & A & 750 & 83 & 50 & 67 & 33 \\
\hline 3422 & Stryck & $\mathrm{D}$ & 650 & 74 & 41 & 58 & 33 \\
\hline 291 & Karupsskogen Barsebäcks gods & $\mathrm{S}$ & 100 & 90 & 56 & 73 & 34 \\
\hline 2113 & Oberes Gailtal & A & 1100 & 102 & 136 & 119 & 34 \\
\hline 2120 & Liembergwald Zell a. S. & A & 875 & 150 & 116 & 133 & 34 \\
\hline 208 & Istebna & PL & 725 & 10 & 47 & 29 & 37 \\
\hline 217 & Istebna-Wisła & PL & 725 & 99 & 136 & 118 & 37 \\
\hline 3421 & Dombühl & $\mathrm{D}$ & 450 & 6 & 44 & 25 & 38 \\
\hline 290 & Högestad & $\mathrm{S}$ & 50 & 22 & 63 & 43 & 41 \\
\hline 3424 & Winterberg & $\mathrm{D}$ & 450 & 45 & 3 & 24 & 42 \\
\hline 3436 & Neureichenau (2) & $\mathrm{D}$ & 1050 & 21 & 63 & 42 & 42 \\
\hline 9423 & Kohlstetten & $\mathrm{D}$ & 750 & 136 & 94 & 115 & 42 \\
\hline 712 & Forêt du Risoud & $\mathrm{CH}$ & 1100 & 153 & 110 & 132 & 43 \\
\hline 130 & Dobra bei Frydek & CS & 550 & 60 & 16 & 38 & 44 \\
\hline 131 & Vizovice & CS & 500 & 64 & 20 & 42 & 44 \\
\hline 3445 & Zwiesel, Haselau XXI $12(3,6)$ & $\mathrm{D}$ & 650 & 28 & 72 & 50 & 44 \\
\hline 3428 & Schernfeld & $\mathrm{D}$ & 450 & 114 & 159 & 137 & 45 \\
\hline 6410 & Sierpc & PL & 110 & 114 & 159 & 137 & 45 \\
\hline 3417 & Marsberg & $\mathrm{D}$ & 500 & 43 & 91 & 67 & 48 \\
\hline 4042 & Vimperk-Prameny Vltury Stachy & CS & 950 & 39 & 87 & 63 & 48 \\
\hline 4159 & Svrcina Hrabusice & CS & 900 & 120 & 72 & 96 & 48 \\
\hline 5204 & Miskolc-Lillafüred 82 A Bükker Geb. & $\mathrm{H}$ & 730 & 39 & 87 & 63 & 48 \\
\hline 3434 & Miele & $\mathrm{D}$ & 90 & 53 & 4 & 29 & 49 \\
\hline 189 & Graz-Süd & A & 850 & 88 & 138 & 113 & 50 \\
\hline 192 & Södingberg & A & 550 & 92 & 42 & 67 & 50 \\
\hline 711 & La Genolière & $\mathrm{CH}$ & & 154 & 104 & 129 & 50 \\
\hline 3429 & Villingen & $\mathrm{D}$ & 850 & 78 & 28 & 53 & 50 \\
\hline 3432 & Walsrode & $\mathrm{D}$ & 30 & 40 & 91 & 66 & 51 \\
\hline 103 & Wunsiedel & $\mathrm{D}$ & 900 & 70 & 18 & 44 & 52 \\
\hline 4011 & Cikaaj, Zdarska Vrchy & CS & 655 & 24 & 78 & 51 & 54 \\
\hline 4121 & Javorova Dolina 155 A, Nr. 4121 & CS & 1200 & 148 & 94 & 121 & 54 \\
\hline 5201 & Köszeg 1 C & $\mathrm{H}$ & 870 & 96 & 41 & 69 & 55 \\
\hline
\end{tabular}

Beiträge aus der NW-FVA, Band 5, 2010 
Versuchsflächen 34 (Reinhardshagen) und 44 (Hasbruch)

\begin{tabular}{|c|c|c|c|c|c|c|c|}
\hline \multirow{2}{*}{$\begin{array}{l}\text { PG- } \\
\text { Nr. }\end{array}$} & \multirow[t]{2}{*}{ Herkunft } & \multirow[t]{2}{*}{ Land } & \multirow{2}{*}{$\begin{array}{c}\text { Höhe m } \\
\text { ü. NN }\end{array}$} & \multicolumn{2}{|c|}{$\begin{array}{l}\text { Rang auf } \\
\text { Fläche }\end{array}$} & \multirow{2}{*}{$\begin{array}{l}- \\
X\end{array}$} & \multirow[t]{2}{*}{$\begin{array}{l}\text { Spann- } \\
\text { weite }\end{array}$} \\
\hline & & & & 34 & 44 & & \\
\hline 3498 & Burgjoß & $\mathrm{D}$ & 450 & 12 & 68 & 40 & 56 \\
\hline 142 & Rosice & CS & 465 & 68 & 11 & 40 & 57 \\
\hline 2147 & Freiland, Gschwend & A & 1000 & 76 & 133 & 105 & 57 \\
\hline 3410 & Traunstein & $\mathrm{D}$ & 850 & 55 & 115 & 85 & 60 \\
\hline 6896 & Borken & PL & 165 & 50 & 110 & 80 & 60 \\
\hline 114 & Winterberg & $\mathrm{D}$ & 800 & 16 & 78 & 47 & 62 \\
\hline 1101 & Le Pertuis, Monts du Velay & $\mathrm{F}$ & 1100 & 125 & 63 & 94 & 62 \\
\hline 170 & Groß Arl & A & 1350 & 122 & 59 & 91 & 63 \\
\hline 2126 & Gaishorn & A & 1200 & 36 & 99 & 68 & 63 \\
\hline 6237 & Puszcza-Białowieska & PL & 130 & 85 & 22 & 54 & 63 \\
\hline 3617 & Torgelow & $\mathrm{D}$ & 100 & 8 & 72 & 40 & 64 \\
\hline 3449 & Nationalp. Neubruck 1a10,b10/11,c10 (6) & $\mathrm{D}$ & 740 & 103 & 37 & 70 & 66 \\
\hline 4032 & Kynsperk nad Ohri Libocky Dul & CS & 650 & 7 & 75 & 41 & 68 \\
\hline 171 & Hofgastein & A & 1100 & 85 & 14 & 50 & 71 \\
\hline 2123 & Gallmannsegg Kainach & A & 1100 & 73 & 144 & 109 & 71 \\
\hline 3411 & Bischofswiesen & $\mathrm{D}$ & 950 & 121 & 50 & 86 & 71 \\
\hline 5413 & Brosteni Bradu/Bastitei & RU & 1475 & 75 & 147 & 111 & 72 \\
\hline 2144 & Seewiesen, Seereith & A & 875 & 83 & 156 & 120 & 73 \\
\hline 62 & Litschau & A & 600 & 9 & 84 & 47 & 75 \\
\hline 1115 & Magland & $\mathrm{F}$ & 700 & 81 & 159 & 120 & 78 \\
\hline 2114 & Kreuzen-Stockenboi & A & 1200 & 35 & 113 & 74 & 78 \\
\hline 6106 & Köslin/Koszalin & PL & 50 & 110 & 28 & 69 & 82 \\
\hline 1114 & Passy & $\mathrm{F}$ & 1200 & 137 & 54 & 96 & 83 \\
\hline 3427 & Oderhaus & $\mathrm{D}$ & 650 & 142 & 59 & 101 & 83 \\
\hline 3448 & Nationalp. Filzwald IX 3a 10/11 (6) & $\mathrm{D}$ & 750 & 135 & 50 & 93 & 85 \\
\hline 188 & Waldstein a.d. Übelb. & A & 850 & 105 & 19 & 62 & 86 \\
\hline 4154 & Roznava & CS & 800 & 116 & 28 & 72 & 88 \\
\hline 9432 & Walsrode & $\mathrm{D}$ & 30 & 123 & 35 & 79 & 88 \\
\hline 2149 & Kindberg/Eisenerzer Alpen & A & 1000 & 58 & 147 & 103 & 89 \\
\hline 2122 & Piberegg & A & 800 & 54 & 144 & 99 & 90 \\
\hline 3431 & Riedenburg & $\mathrm{D}$ & 500 & 108 & 16 & 62 & 92 \\
\hline 141 & Pitin & CS & 610 & 96 & 1 & 49 & 95 \\
\hline 5202 & Szentgotthard $1 \mathrm{C}$ & $\mathrm{H}$ & 310 & 25 & 125 & 75 & 100 \\
\hline 3412 & Winterberg & $\mathrm{D}$ & 750 & 3 & 104 & 54 & 101 \\
\hline 2140 & Fölz, Mayerberg & A & 950 & 60 & 163 & 112 & 103 \\
\hline 3326 & Neureichenau & $\mathrm{D}$ & 1200 & 151 & 47 & 99 & 104 \\
\hline 4061 & Velke Mezirici-Rudolec & CS & 630 & 5 & 110 & 58 & 105 \\
\hline 124 & Istebna-Wisła & PL & 725 & 14 & 120 & 67 & 106 \\
\hline 4081 & Frenstat pod Radhosten-Obora & CS & 600 & 1 & 110 & 56 & 109 \\
\hline 3423 & Kohlstetten & $\mathrm{D}$ & 750 & 126 & 16 & 71 & 110 \\
\hline 2160 & Turnau, Kapfenberg & A & 1100 & 42 & 157 & 100 & 115 \\
\hline 61 & Gosau & A & 700 & 2 & 127 & 65 & 125 \\
\hline 186 & Graz-Nord & A & 850 & 133 & 6 & 70 & 127 \\
\hline 1116 & Lantosque & $\mathrm{F}$ & 1500 & 141 & 12 & 77 & 129 \\
\hline 202 & Istebna-Wisła & PL & 725 & 12 & 151 & 82 & 139 \\
\hline 4157 & Hnusta & CS & 550 & 4 & 167 & 86 & 163 \\
\hline 204 & Spisske Pochradie & CS & 700 & . & 68 & . & . \\
\hline 1111 & Peisey-Nancroix, Grd. Bois & $\mathrm{F}$ & 1400 & . & 162 & . & . \\
\hline 1202 & Manderfeld Gilbuschek 63 A & B & 542 & & 28 & & \\
\hline
\end{tabular}


Versuchsflächen 34 (Reinhardshagen) und 44 (Hasbruch)

\begin{tabular}{l|l|c|c|c|c|c|c}
\hline $\begin{array}{l}\text { PG- } \\
\text { Nr. }\end{array}$ & Herkunft & Land & Höhe m & \multicolumn{2}{|c|}{$\begin{array}{c}\text { Rang auf } \\
\text { Fläche }\end{array}$} & $\begin{array}{c}- \\
\text { X }\end{array}$ & $\begin{array}{c}\text { Spann- } \\
\text { weite }\end{array}$ \\
\hline 2141 & Fölz, Greith & A & 825 &. & 28 &. &. \\
3416 & SHK Höhenfichten & D & 1050 &. & 140 &. &. \\
6250 & Augustow Abt. 95 b & PL & 120 &. & 154 &. &. \\
6254 & Mikaszowka & PL & 120 &. & 104 &. &. \\
6260 & Knyszyn & PL & 150 &. & 110 &. &. \\
6713 & Klodzko-Nynow 72 k & PL & 400 & 70 &. &. &. \\
7401 & Gzatsk-Smolensk & SU & 194 &. & 154 &. &. \\
8703 & Lohja Laaskspohjan & SF & 50 &. & 154 &. &. \\
\hline
\end{tabular}

Versuchsflächen 35 (Reinhardshagen) und 45 (Hasbruch)

\begin{tabular}{|c|c|c|c|c|c|c|c|}
\hline \multirow{2}{*}{$\begin{array}{l}\text { PG- } \\
\text { Nr. }\end{array}$} & \multirow[t]{2}{*}{ Herkunft } & \multirow[t]{2}{*}{ Land } & \multirow{2}{*}{$\begin{array}{l}\text { Höhe m } \\
\text { ü. NN }\end{array}$} & \multicolumn{2}{|c|}{$\begin{array}{l}\text { Rang auf } \\
\text { Fläche }\end{array}$} & \multirow{2}{*}{$\begin{array}{l}- \\
X\end{array}$} & \multirow{2}{*}{$\begin{array}{l}\text { Spann- } \\
\text { weite }\end{array}$} \\
\hline & & & & 35 & 45 & & \\
\hline 6510 & Bunzlau/Boleslawiec & PL & 175 & 20 & 20 & 20 & 0 \\
\hline 3404 & Westerhof Abt. 51 B & $\mathrm{D}$ & 200 & 26 & 27 & 27 & 1 \\
\hline 4060 & Hencov-Trest & CS & 600 & 19 & 20 & 20 & 1 \\
\hline 4053 & Cesky Krumlov Borova & CS & 800 & 30 & 28 & 29 & 2 \\
\hline 2138 & Buchberg, Ägidiwald/Aflenz & A & 925 & 65 & 62 & 64 & 3 \\
\hline 3139 & Isny $\mathrm{Ba} / \mathrm{Wü}$ & $\mathrm{D}$ & 850 & 70 & 67 & 69 & 3 \\
\hline 3310 & Zwiesel-West/Ruselhänge X/68 & $\mathrm{D}$ & 750 & 16 & 13 & 15 & 3 \\
\hline 3615 & Neustrelitz & $\mathrm{D}$ & 100 & 43 & 46 & 45 & 3 \\
\hline 7224 & Ostrovskij-Pskow & SU & 200 & 64 & 67 & 66 & 3 \\
\hline 115 & Westerhof & $\mathrm{D}$ & 200 & 7 & 3 & 5 & 4 \\
\hline 6894 & Witów & PL & 1250 & 44 & 40 & 42 & 4 \\
\hline 3331 & St. Oswald I/3,4,6 Typengemisch & $\mathrm{D}$ & 1200 & 51 & 56 & 54 & 5 \\
\hline 3443 & Zwiesel, Scheichereb. XXI 13b1 $(3,6)$ & $\mathrm{D}$ & 650 & 40 & 45 & 43 & 5 \\
\hline 3606 & Templin, Bad Doberan Nr. 9 & $\mathrm{D}$ & 50 & 6 & 11 & 9 & 5 \\
\hline 4070 & Vrchlabi & CS & 700 & 37 & 32 & 35 & 5 \\
\hline 121 & Cedrogne & $\mathrm{B}$ & 500 & 28 & 34 & 31 & 6 \\
\hline 3042 & Walchensee & $\mathrm{D}$ & 1100 & 69 & 61 & 65 & 8 \\
\hline 3337 & Rabenstein Typengemisch & $\mathrm{D}$ & 1200 & 71 & 79 & 75 & 8 \\
\hline 2137 & Buchberg, Flachwald/Aflenz & $\mathrm{A}$ & 1300 & 66 & 76 & 71 & 10 \\
\hline 5415 & Cimpeni-Dara & RU & 1260 & 28 & 18 & 23 & 10 \\
\hline 6543 & Groß-Lassowitz/Lassowice Male & PL & 175 & 24 & 34 & 29 & 10 \\
\hline 7233 & Wolozin & SU & 225 & 48 & 38 & 43 & 10 \\
\hline 2207 & Seewiesen Seereith/Aflenz & A & 875 & 67 & 78 & 73 & 11 \\
\hline 3102 & Schluchsee-Eschenmoos & $\mathrm{D}$ & 1200 & 63 & 52 & 58 & 11 \\
\hline 2134 & Hinterhof, Ostbrenner u. Tiefental & $\mathrm{A}$ & 1000 & 22 & 10 & 16 & 12 \\
\hline 4054 & Chlum u. Trebone-Hamr & CS & 450 & 8 & 22 & 15 & 14 \\
\hline 3511 & Innenau Elgersburg & $\mathrm{D}$ & 800 & 33 & 17 & 25 & 16 \\
\hline 6103 & Brotzen/Broczyno & PL & 140 & 55 & 71 & 63 & 16 \\
\hline 6235 & Zwierzyniec & PL & 150 & 59 & 75 & 67 & 16 \\
\hline 3519 & Mechterstädt & $\mathrm{D}$ & 200 & 23 & 6 & 15 & 17 \\
\hline 6234 & Białowieża & PL & 130 & 53 & 36 & 45 & 17 \\
\hline 2131 & Veitsch-Neuberg & A & 1000 & 45 & 64 & 55 & 19 \\
\hline 2133 & Hinterhof, Eibelkogel & A & 1150 & 54 & 73 & 64 & 19 \\
\hline
\end{tabular}


Versuchsflächen 35 (Reinhardshagen) und 45 (Hasbruch)

\begin{tabular}{|c|c|c|c|c|c|c|c|}
\hline \multirow{2}{*}{$\begin{array}{l}\text { PG- } \\
\text { Nr. }\end{array}$} & \multirow[t]{2}{*}{ Herkunft } & \multirow[t]{2}{*}{ Land } & \multirow{2}{*}{$\begin{array}{c}\text { Höhe m } \\
\text { ü. NN }\end{array}$} & \multicolumn{2}{|c|}{$\begin{array}{l}\text { Rang auf } \\
\text { Fläche }\end{array}$} & \multirow{2}{*}{$\begin{array}{l}- \\
X\end{array}$} & \multirow[t]{2}{*}{$\begin{array}{l}\text { Spann- } \\
\text { weite }\end{array}$} \\
\hline & & & & 35 & 45 & & \\
\hline 4022 & Boubin III & CS & 1000 & 41 & 60 & 51 & 19 \\
\hline 6624 & Przysucha & PL & 275 & 46 & 65 & 56 & 19 \\
\hline 2184 & Schneegattern & A & 750 & 38 & 58 & 48 & 20 \\
\hline 2179 & Eisenkappel/Karaw. & A & 800 & 52 & 29 & 41 & 23 \\
\hline 3417 & Marsberg & $\mathrm{D}$ & 500 & 1 & 24 & 13 & 23 \\
\hline 6222 & Borken/Borki & PL & 160 & 17 & 43 & 30 & 26 \\
\hline 2118 & Gurker Sirnitzwald & A & 900 & 29 & 56 & 43 & 27 \\
\hline 4073 & Jesenik-Zlate Hory & CS & 820 & 31 & 4 & 18 & 27 \\
\hline 5426 & Crucea-Barnavel Abt. 17/18 & RU & 740 & 39 & 67 & 53 & 28 \\
\hline 6731 & Szcytna-Slaska Karlow 243 a & PL & 750 & 36 & 7 & 22 & 29 \\
\hline 2151 & Breitenau-Mixnitz/Fischbacher Alp. & A & 970 & 74 & 42 & 58 & 32 \\
\hline 5420 & Valea Putnei-Pojorita III/60 & RU & 1285 & 3 & 36 & 20 & 33 \\
\hline 3430 & Diessen & $\mathrm{D}$ & 850 & 13 & 47 & 30 & 34 \\
\hline 4026 & Habartice, Planice & CS & 550 & 15 & 50 & 33 & 35 \\
\hline 6712 & Klodzko-Glatz/Nynow 68 e & PL & 340 & 2 & 38 & 20 & 36 \\
\hline 5301 & Belogradchik-Tschupreno & BG & 1400 & 75 & 38 & 57 & 37 \\
\hline 111 & Bodenmais & $\mathrm{D}$ & 1000 & 62 & 24 & 43 & 38 \\
\hline 149 & Einsiedeln & $\mathrm{CH}$ & 900 & 42 & 80 & 61 & 38 \\
\hline 3518 & Suhl, Oberhofer Schloßbergkopf & $\mathrm{D}$ & 900 & 47 & 9 & 28 & 38 \\
\hline 5416 & Remeti-Zerna & RU & 900 & 9 & 48 & 29 & 39 \\
\hline 4051 & Vysoky Chlumec Veletin & CS & 600 & 11 & 52 & 32 & 41 \\
\hline 5102 & Kaludjerske Bore Taram Kremma & YU & 1000 & 73 & 31 & 52 & 42 \\
\hline 107 & Donaueschingen & $\mathrm{D}$ & 650 & 61 & 17 & 39 & 44 \\
\hline 3510 & Sonneb. Steinheid, Kieferleskopf & $\mathrm{D}$ & 886 & 57 & 13 & 35 & 44 \\
\hline 3423 & Kohlstetten & $\mathrm{D}$ & 750 & 14 & 59 & 37 & 45 \\
\hline 3503 & Eibenst. Carlsf. Wiesenh. 214 & $\mathrm{D}$ & 720 & 5 & 50 & 28 & 45 \\
\hline 6732 & Szcytna-Slaska Karlow 292 b & PL & 700 & 60 & 15 & 38 & 45 \\
\hline 6864 & Istebna-Ujsoly & PL & 750 & 19 & 64 & 42 & 45 \\
\hline 5107 & Smrceve Dolina Abt. 138 & HR & 1350 & 76 & 30 & 53 & 46 \\
\hline 3433 & Selb-Kirchenlamitz (1) & $\mathrm{D}$ & 800 & 4 & 53 & 29 & 49 \\
\hline 2158 & Rohr im Gebirge, Kirchwald & A & 825 & 58 & 6 & 32 & 52 \\
\hline 5412 & Moldovita-Sacries & RU & 825 & 21 & 75 & 48 & 54 \\
\hline 7235 & Brigalovic-Mogilev & SU & 160 & 56 & 1 & 29 & 55 \\
\hline 2135 & Kraubath, Seckauer Tauern & A & 1050 & 10 & 77 & 44 & 67 \\
\hline 129 & Allenstein & PL & 100 & . & 45 & . & . \\
\hline 3003 & Blumberg & $\mathrm{D}$ & 800 & . & 69 & . & . \\
\hline 3204 & Burghausen/Salzach & $\mathrm{D}$ & 400 & . & 56 & . & . \\
\hline 3205 & Ebersberg & $\mathrm{D}$ & 555 & . & 54 & . & . \\
\hline 3211 & Moosburg/Isar & $\mathrm{D}$ & 500 & & 22 & . & . \\
\hline 3320 & Bischofsreut & $\mathrm{D}$ & 970 & 34 & . & . & . \\
\hline 3323 & Mauth/Ost & $\mathrm{D}$ & 1000 & . & 2 & . & . \\
\hline 3325 & Neureichenau/Typengemisch & $\mathrm{D}$ & 1000 & & 15 & . & . \\
\hline 3327 & Passau/Nord & $\mathrm{D}$ & 1000 & & 42 & . & . \\
\hline 3334 & Zwiesel-Ost, V/1,2, Plattenfichten & $\mathrm{D}$ & 1200 & 72 & . & . & . \\
\hline 3432 & Walsrode & $\mathrm{D}$ & 30 & & 8 & . & . \\
\hline 3501 & Rungstock, 46 A & $\mathrm{D}$ & 560 & 12 & . & . & . \\
\hline 3504 & Eibenst. Carlsf. Wilschm. 233 & $\mathrm{D}$ & 720 & 25 & . & . & . \\
\hline 3506 & Tellerhaeuser, 44 & $\mathrm{D}$ & 980 & 35 & . & . & . \\
\hline 3508 & Rehefeld, 146 & $\mathrm{D}$ & 810 & 33 & . & & \\
\hline
\end{tabular}


Versuchsflächen 35 (Reinhardshagen) und 45 (Hasbruch)

\begin{tabular}{l|l|c|c|c|c|c|c}
\hline $\begin{array}{l}\text { PG- } \\
\text { Nr. }\end{array}$ & Herkunft & Land & Höhe m & \multicolumn{2}{c|}{$\begin{array}{c}\text { Rang auf } \\
\text { Fläche }\end{array}$} & $\begin{array}{c}- \\
\text { X }\end{array}$ & $\begin{array}{c}\text { Spann- } \\
\text { weite }\end{array}$ \\
\hline 3512 & Peitz/Tannenwald & D & 60 & 51 &. &. &. \\
3601 & Cottbus, Tannenwald 17AB & D & 80 & 49 &. &. &. \\
4123 & Javorova Dolina 155 A, Nr.4123 & CS & 1200 &. & 81 &. &. \\
6251 & Białobrzegi & PL & 110 &. & 27 &. &. \\
7422 & Rjasan, Moshary & SU & 150 & 69 &. &. &. \\
8003 & Fussinge & DK & 45 &. & 24 &. &. \\
8705 & Mänttä & SF & 120 &. & 71 &. &. \\
8707 & Janakkala Keskivari Uhkoila & SF & 100 &. & 71 &. &. \\
\hline
\end{tabular}

Versuchsflächen 36 (Reinhardshagen) und 46 (Hasbruch)

\begin{tabular}{c|l|r|r|rrr|r|c}
\hline PG- & Herkunft & Land & Höhe m & \multicolumn{2}{|c|}{$\begin{array}{c}\text { Rang auf } \\
\text { Nr. }\end{array}$} & & \multicolumn{2}{c|}{$\begin{array}{c}\text { Spann- } \\
\text { weite }\end{array}$} \\
\hline 4075 & Vitkov-Budisov & CS & 610 & 6 & 6 & 6 & 0 \\
4050 & Vlasim-Votice & $\mathrm{CS}$ & 600 & 20 & 21 & 21 & 1 \\
4127 & Javorova Dolina 155 A, Nr.4127 & $\mathrm{CS}$ & 1200 & 26 & 25 & 26 & 1 \\
169 & Gries & $\mathrm{A}$ & 1300 & 11 & 9 & 10 & 2 \\
1201 & Mellier, Bois Bayai, 2 & $\mathrm{B}$ & 400 & 27 & 30 & 29 & 3 \\
3414 & Bodensee Oberschwab. VIII/13 & $\mathrm{D}$ & 650 & 5 & 2 & 4 & 3 \\
5424 & Valea Beliei-Sinaia Gurguiata & $\mathrm{RU}$ & 1115 & 30 & 33 & 32 & 3 \\
3213 & Mühldorf/Inn & $\mathrm{D}$ & 440 & 14 & 10 & 12 & 4 \\
7240 & Witebsk & $\mathrm{SU}$ & 150 & 19 & 23 & 21 & 4 \\
230 & Elbingerode & $\mathrm{D}$ & 550 & 12 & 17 & 15 & 5 \\
3446 & Zwiesel, Schmalzau IX 3c (5,6) & $\mathrm{D}$ & 620 & 16 & 11 & 14 & 5 \\
6897 & Goldap & $\mathrm{PL}$ & 175 & 18 & 23 & 21 & 5 \\
116 & Kobernausserwald & $\mathrm{A}$ & 600 & 22 & 16 & 19 & 6 \\
1118 & Chatel, 1 Aity" & $\mathrm{F}$ & 1250 & 32 & 25 & 29 & 7 \\
2174 & Klein-Sölk/Niedertauern & $\mathrm{A}$ & 1250 & 33 & 26 & 30 & 7 \\
2124 & Stixenstein, Gahns & $\mathrm{A}$ & 1200 & 29 & 21 & 25 & 8 \\
3150 & Dillingen a.d.D. Bay. & $\mathrm{D}$ & 500 & 13 & 5 & 9 & 8 \\
7234 & Soboljanskoe-Grodno & $\mathrm{SU}$ & 150 & 23 & 31 & 27 & 8 \\
191 & Passail & $\mathrm{A}$ & 900 & 2 & 12 & 7 & 10 \\
2127 & Unterhal, St. Kathrein a.d. Lamming & $\mathrm{A}$ & 800 & 21 & 8 & 15 & 13 \\
3430 & Diessen & $\mathrm{D}$ & 850 & 31 & 18 & 25 & 13 \\
3433 & Selb-Kirchenlamitz (1) & $\mathrm{D}$ & 800 & 1 & 14 & 8 & 13 \\
65 & Eisenkappel Thurn 2 & $\mathrm{A}$ & 850 & 18 & 4 & 11 & 14 \\
3423 & Kohlstetten & $\mathrm{D}$ & 750 & 29 & 14 & 22 & 15 \\
6236 & Białowieża & $\mathrm{PL}$ & 150 & 34 & 19 & 27 & 15 \\
3206 & Eglharting XIV/17,19 & $\mathrm{D}$ & 580 & 24 & 8 & 16 & 16 \\
7232 & Cemerjanskoe-Mogilev & $\mathrm{SU}$ & 175 & 15 & 34 & 25 & 19 \\
172 & Mittersill & $\mathrm{A}$ & 900 & 10 & 32 & 21 & 22 \\
105 & Hohenschwangau & $\mathrm{D}$ & 800 & 4 & 28 & 16 & 24 \\
6107 & Altenhagen/Nowy Krakow & $\mathrm{PL}$ & 200 & 3 & 27 & 15 & 24 \\
9191 & Karlsholms-Kristianstad & $\mathrm{S}$ & 20 & 25 & 1 & 13 & 24 \\
3417 & Marsberg & $\mathrm{D}$ & 500 & 8 & 35 & 22 & 27 \\
3432 & Walsrode & $\mathrm{D}$ & 30 & 7 & 36 & 22 & 29 \\
& & & & & & &
\end{tabular}


Versuchsflächen 36 (Reinhardshagen) und 46 (Hasbruch)

\begin{tabular}{|c|c|c|c|c|c|c|c|}
\hline \multirow[t]{2}{*}{$\begin{array}{l}\text { PG- } \\
\text { Nr. }\end{array}$} & \multirow[t]{2}{*}{ Herkunft } & \multirow[t]{2}{*}{ Land } & \multirow{2}{*}{$\begin{array}{c}\text { Höhe m } \\
\text { ü. NN }\end{array}$} & \multicolumn{2}{|c|}{$\begin{array}{l}\text { Rang auf } \\
\text { Fläche }\end{array}$} & \multirow{2}{*}{$\begin{array}{l}- \\
\mathrm{X}\end{array}$} & \multirow[t]{2}{*}{$\begin{array}{l}\text { Spann- } \\
\text { weite }\end{array}$} \\
\hline & & & & 36 & 46 & & \\
\hline 93 & Sieber & D & 400 & . & 29 & . & . \\
\hline 108 & Lauterberg & $\mathrm{D}$ & 700 & & 3 & . & . \\
\hline 113 & Walsrode & $\mathrm{D}$ & 100 & 9 & . & . & . \\
\hline 5425 & Cimpeni-Nedei & RU & 1400 & . & 15 & . & . \\
\hline
\end{tabular}




\section{Anhang 2: Der IUFRO-Fichtenherkunftsversuch von 1972}

\section{Anhang 2.1}

Angaben zu den polnischen Erntebeständen zum Zeitpunkt der Beerntung

\begin{tabular}{|c|c|c|c|c|c|c|c|c|}
\hline Nr. & Prüfglied (alle Ernte 1971) & $\begin{array}{c}\text { Bäume } \\
\text { /ha }\end{array}$ & $\begin{array}{c}\mathrm{Fi} \\
/ \mathrm{ha}\end{array}$ & $\begin{array}{c}\text { Fi- } \\
\text { Anteil } \\
{[\%]}\end{array}$ & Alter & $\begin{array}{l}\text { Beern- } \\
\text { tete } \\
\text { Bäume }\end{array}$ & $\begin{array}{l}\text { Mittl. } \\
\text { Höhe }\end{array}$ & BHD \\
\hline \multicolumn{9}{|c|}{$\underline{\text { Masuren-Podlasie }}$} \\
\hline 1 & Zwierzyniec Biał., Pogorzelece 281Ba & 240 & 200 & 83 & 98 & 26 & 30,2 & 44,1 \\
\hline 2 & Zwierzyniec Biał., Krzyze 449Ca & 288 & 248 & 86 & 84 & 27 & 36,6 & 53,0 \\
\hline 3 & Wigry, Krzywe 144b & 452 & 432 & 96 & 100 & 21 & 33,0 & 40,1 \\
\hline 4 & Przerwanki, Zawady 66b & 406 & 328 & 81 & 82 & 22 & 31,4 & 42,6 \\
\hline 5 & Borki, Sarnianka 141a & 376 & 368 & 98 & 71 & 20 & 36,3 & 50,2 \\
\hline 6 & Nowe Ramuki, Przykop 128d & 352 & 176 & 50 & 100 & 20 & 37,1 & 52,1 \\
\hline \multicolumn{9}{|c|}{$\underline{\text { Sudeten }}$} \\
\hline 8 & Miedzygórze, Wodospad 81a & 336 & 304 & 90 & 102 & 26 & 33,3 & 50,6 \\
\hline 9 & Stronie Slaskie, Kletno 200b & 320 & 264 & 83 & 123 & 25 & 32,2 & 47,2 \\
\hline \multicolumn{9}{|c|}{ Karpaten (Beskiden) } \\
\hline 10 & Wisła, Malinka 89c & 224 & 212 & 95 & 112 & 26 & 39,4 & 56,5 \\
\hline 11 & Istebna, Bukowiec 149h & 320 & 320 & 100 & 121 & 25 & 40,9 & 51,6 \\
\hline 12 & Istebna, Zapowiedz $115 f$ & 372 & 360 & 97 & 107 & 25 & 35,5 & 45,6 \\
\hline 13 & Rycerka, Zwardon 68d & 404 & 404 & 100 & 89 & 26 & 35,1 & 43,1 \\
\hline 14 & Rycerka, Praszywka I 125c & 256 & 248 & 97 & 93 & 26 & 36,9 & 46,8 \\
\hline 15 & Rycerka, Praszywka II 125c & 324 & 324 & 100 & 91 & 10 & 28,1 & 48,7 \\
\hline 16 & Orawa Stancowa 40c & 348 & 348 & 100 & 108 & 26 & 32,6 & 43,8 \\
\hline 17 & Witów (Tatry), ur. Chotorz 125f & 288 & 288 & 100 & 152 & 25 & 24,7 & 47,2 \\
\hline 18 & Tarnawa, Sokoliki 130a & 492 & 492 & 100 & 79 & 40 & 32,5 & 42,4 \\
\hline \multicolumn{9}{|c|}{ Mittelpolnische Hochebene } \\
\hline 19 & Zwierzyniec Lubelski, Obrocz $119 \mathrm{f}$ & 436 & 248 & 57 & 69 & 15 & 21,1 & 24,9 \\
\hline 20 & Blizyn, Swinia Gora 134i & 540 & 236 & 44 & 75 & 16 & 21,7 & 24,0 \\
\hline \multicolumn{9}{|c|}{ nicht autochthon (Baltisches Gebiet) } \\
\hline 21 & Kartuzy, Kosowo $67 d^{*}$ & 432 & 364 & 84 & 90 & 34 & 34,3 & 46,7 \\
\hline
\end{tabular}

* nicht autochthon 


\section{Anhang 2.2}

Zusammenstellung der Ovalitäten [\%] auf den hessischen Versuchsflächen Reinhardshagen und Wanfried

\begin{tabular}{|c|c|c|c|c|c|}
\hline \multirow{2}{*}{ Nr. } & \multirow{2}{*}{ Prüfglied } & \multicolumn{2}{|c|}{ Reinhardshagen (32-j.) } & \multicolumn{2}{|c|}{ Wanfried (32-j.) } \\
\hline & & Ovalität & Rang & Ovalität & Rang \\
\hline 1 & Zwierzyniec Biał., Pogorzelece & 3,6 & 19 & 2,7 & 10 \\
\hline 2 & Zwierzyniec Biał., Krzyze & 4,2 & 25 & 2,9 & 16 \\
\hline 3 & Wigry, Krzywe & 3,7 & 21 & 3,2 & 21 \\
\hline 4 & Przerwanki, Zawady & 3,6 & 18 & 2,8 & 14 \\
\hline 5 & Borki, Sarnianka & 4,1 & 24 & 2,7 & 11 \\
\hline 6 & Nowe Ramuki, Przykop & 2,9 & 5 & 3,2 & 22 \\
\hline 8 & Miedzygórze, Wodospad & 3,7 & 20 & 2,9 & 15 \\
\hline 9 & Stronie Slaskie, Kletno & 3,0 & 6 & 2,5 & 3 \\
\hline 10 & Wisła, Malinka & 3,6 & 17 & 2,8 & 12 \\
\hline 11 & Istebna, Bukowiec 149h & 3,3 & 12 & 3,0 & 18 \\
\hline 12 & Istebna, Zapowiedz $115 \mathrm{f}$ & 3,1 & 9 & 2,3 & 1 \\
\hline 13 & Rycerka, Zwardon & 3,9 & 22 & 2,6 & 5 \\
\hline 14 & Rycerka, Praszywka I 125c & 3,4 & 16 & 2,4 & 2 \\
\hline 16 & Orawa Stancowa & 2,8 & 1 & 2,6 & 4 \\
\hline 17 & Witów (Tatry), ur. Chotorz & 2,8 & 2 & 3,1 & 20 \\
\hline 18 & Tarnawa, Sokoliki & 3,1 & 8 & 2,8 & 13 \\
\hline 19 & Zwierzyniec Lubelski, Obrocz & 3,2 & 10 & 3,3 & 23 \\
\hline 21 & Kartuzy, Kosowo & 3,3 & 11 & 3,3 & 24 \\
\hline & Frankenwald & 2,8 & 3 & 2,6 & 6 \\
\hline & Schwäb. Alb und Bay. Jura & 3,4 & 15 & 3,7 & 25 \\
\hline & Bayerischer Wald & 4,0 & 23 & 3,0 & 19 \\
\hline & $\begin{array}{l}\text { Südbayern, Oberschwaben, } \\
\text { Bod. }\end{array}$ & 3,1 & 7 & 3,0 & 17 \\
\hline & Harzvorland & 3,3 & 14 & 2,6 & 7 \\
\hline & Stryck & 3,3 & 13 & 2,7 & 8 \\
\hline & Mandelbeck & 2,9 & 4 & 2,7 & 9 \\
\hline & IUFRO-Mittel & 3,40 & & 2,84 & \\
\hline & Versuchsflächen-Mittel & 3,36 & & 2,86 & \\
\hline
\end{tabular}




\section{Anhang 2.3}

Zusammenstellung der H/D-Verbältnisse auf den hessischen Versuchsflächen Reinhardshagen und $W$ anfried

\begin{tabular}{|c|c|c|c|c|c|c|c|c|c|}
\hline \multirow{3}{*}{ Nr. } & \multirow{3}{*}{ Prüfglied } & \multicolumn{4}{|c|}{ Reinhardshagen } & \multicolumn{4}{|c|}{ Wanfried } \\
\hline & & \multicolumn{2}{|c|}{$23-\mathrm{j}}$. & \multicolumn{2}{|c|}{$32-\mathrm{j}}$. & \multicolumn{2}{|c|}{$23-j$} & \multicolumn{2}{|c|}{$32-j}$. \\
\hline & & HD & Rang & HD & Rang & HD & Rang & $\mathrm{HD}$ & Rang \\
\hline 1 & Zwierzyniec Biał., Pogorzelece & 83 & 15 & 82 & 7 & 95 & 3 & 87 & 6 \\
\hline 2 & Zwierzyniec Biał., Krzyze & 87 & 7 & 85 & 1 & 90 & 9 & 89 & 2 \\
\hline 3 & Wigry, Krzywe & 90 & 2 & 84 & 4 & 95 & 2 & 88 & 3 \\
\hline 4 & Przerwanki, Zawady & 90 & 3 & 80 & 16 & 95 & 1 & 81 & 25 \\
\hline 5 & Borki, Sarnianka & 83 & 18 & 84 & 3 & 94 & 4 & 89 & 1 \\
\hline 6 & Nowe Ramuki, Przykop & 90 & 1 & 82 & 11 & 88 & 12 & 88 & 5 \\
\hline 8 & Miedzygórze, Wodospad & 79 & 24 & 78 & 19 & 88 & 16 & 83 & 22 \\
\hline 9 & Stronie Slaskie, Kletno & 80 & 23 & 83 & 6 & 86 & 20 & 85 & 12 \\
\hline 10 & Wisła, Malinka & 84 & 13 & 78 & 21 & 91 & 8 & 84 & 16 \\
\hline 11 & Istebna, Bukowiec 149h & 89 & 5 & 77 & 22 & 88 & 17 & 87 & 7 \\
\hline 12 & Istebna, Zapowiedz 115f & 85 & 12 & 78 & 20 & 86 & 22 & 82 & 24 \\
\hline 13 & Rycerka, Zwardon & 80 & 22 & 79 & 17 & 86 & 23 & 86 & 11 \\
\hline 14 & Rycerka, Praszywka I 125c & 89 & 6 & 81 & 13 & 88 & 18 & 85 & 13 \\
\hline 16 & Orawa Stancowa & 90 & 4 & 82 & 8 & 88 & 14 & 83 & 19 \\
\hline 17 & Witów (Tatry), ur. Chotorz & 75 & 25 & 76 & 24 & 82 & 24 & 82 & 23 \\
\hline 18 & Tarnawa, Sokoliki & 87 & 8 & 85 & 2 & 88 & 15 & 87 & 10 \\
\hline 19 & Zwierzyniec Lubelski, Obrocz & 85 & 11 & 82 & 9 & 92 & 6 & 84 & 17 \\
\hline 21 & Kartuzy, Kosowo & 85 & 9 & 82 & 10 & 92 & 5 & 85 & 14 \\
\hline & Frankenwald & 83 & 16 & 81 & 14 & 89 & 11 & 83 & 20 \\
\hline & Schwäb. Alb und Bay. Jura & 82 & 20 & 79 & 18 & 86 & 21 & 88 & 4 \\
\hline & Bayerischer Wald & 83 & 17 & 80 & 15 & 81 & 25 & 87 & 8 \\
\hline & Südbayern, Oberschwaben, Bod. & 81 & 21 & 77 & 23 & 90 & 10 & 83 & 21 \\
\hline & Harzvorland & 84 & 14 & 81 & 12 & 91 & 7 & 87 & 9 \\
\hline & Stryck & 85 & 10 & 83 & 5 & 87 & 19 & 84 & 18 \\
\hline & Mandelbeck & 83 & 19 & 75 & 25 & 88 & 13 & 84 & 15 \\
\hline & IUFRO-Mittel & 85,1 & & 81,0 & & 89,6 & & 85,3 & \\
\hline & Versuchsflächen-Mittel & 84,5 & & 80,6 & & 89,0 & & 85,3 & \\
\hline
\end{tabular}




\section{Anhang 2.4}

Tukey-Gruppen $(\alpha=0,05)$ für die Wachstumsmerkmale BHD [cm] und Höbe $[m]$ auf der Versuchsfläche Reinhardshagen / Hessen (32-j.)

\begin{tabular}{|c|c|c|c|c|c|c|}
\hline \multirow{2}{*}{ Nr. } & \multirow{2}{*}{ Prüfglied } & \multicolumn{5}{|c|}{ Reinhardshagen (32-j.) } \\
\hline & & BHD & \multicolumn{2}{|c|}{ T-G } & Höhe & T-G \\
\hline & Mandelbeck & 21,6 & \multicolumn{2}{|c|}{ A } & 20,2 & A \\
\hline 10 & Wisła, Malinka & 21,3 & \multicolumn{2}{|l|}{ A } & 21,0 & A \\
\hline 11 & Istebna, Bukowiec $149 \mathrm{~h}$ & 21,2 & \multicolumn{2}{|l|}{ A } & 20,7 & A \\
\hline 4 & Przerwanki, Zawady & 21,2 & \multicolumn{2}{|l|}{ A } & 20,8 & A \\
\hline \multirow[t]{2}{*}{8} & Miedzygórze, Wodospad & 21,0 & A & B & 20,7 & A \\
\hline & Stryck & 20,9 & A & B & 20,5 & A \\
\hline 12 & Istebna, Zapowiedz 115f & 20,5 & A & B & 20,3 & A \\
\hline 19 & Zwierzyniec Lubelski, Obrocz & 20,4 & A & B & 20,8 & A \\
\hline 1 & Zwierzyniec Biał., Pogorzelece & 20,4 & A & B & 20,1 & A \\
\hline \multirow[t]{2}{*}{2} & Zwierzyniec Biał., Krzyze & 20,1 & A & B & 21,4 & A \\
\hline & Harzvorland & 20,1 & A & $\mathrm{B}$ & 20,2 & A \\
\hline \multirow[t]{4}{*}{13} & Rycerka, Zwardon & 19,9 & A & $\mathrm{B}$ & 20,2 & A \\
\hline & Frankenwald & 19,9 & A & B & 21,0 & A \\
\hline & Südbayern, Oberschwaben, Bodenseegebiet & 19,8 & A & B & 20,1 & A \\
\hline & Schwäb. Alb und Bay. Jura & 19,8 & A & B & 19,7 & A \\
\hline 14 & Rycerka, Praszywka I 125c & 19,8 & A & B & 20,6 & A \\
\hline 21 & Kartuzy, Kosowo & 19,7 & A & B & 20,7 & A \\
\hline 18 & Tarnawa, Sokoliki & 19,6 & A & B & 20,6 & A \\
\hline 3 & Wigry, Krzywe & 19,4 & A & B & 20,7 & A \\
\hline 5 & Borki, Sarnianka & 19,3 & A & B & 20,3 & A \\
\hline \multirow[t]{2}{*}{16} & Orawa Stancowa & 18,8 & A & B & 20,1 & A \\
\hline & Bayerischer Wald & 18,7 & A & B & 19,7 & A \\
\hline 9 & Stronie Slaskie, Kletno & 18,6 & A & B & 20,0 & A \\
\hline 6 & Nowe Ramuki, Przykop & 18,4 & A & B & 19,7 & A \\
\hline 17 & Witów (Tatry), ur. Chotorz & 17,4 & & $\mathrm{~B}$ & 16,6 & $\mathrm{~B}$ \\
\hline
\end{tabular}




\section{Anhang 2.5}

Tukey-Gruppen für die Wachstumsmerkmale Höhe $[\mathrm{m}]$ und BHD [cm] auf der Versuchsfläche Reinhardshagen / Hessen (23-j.)

\begin{tabular}{|c|c|c|c|c|c|c|c|c|}
\hline \multirow{2}{*}{$\mathrm{Nr}$. } & \multirow{2}{*}{ Prüfglied } & \multicolumn{7}{|c|}{ Reinhardshagen (23-j.) } \\
\hline & & Höhe & \multicolumn{2}{|r|}{ T-G } & \multirow{2}{*}{$\frac{\mathrm{BHD}}{14,3}$} & \multicolumn{3}{|c|}{$\mathrm{T}-\mathrm{G}$} \\
\hline 4 & Przerwanki, Zawady & 12,7 & A & & & A & $\mathrm{B}$ & \\
\hline 10 & Wisła, Malinka & 12,4 & A & & 15,6 & A & & \\
\hline \multirow[t]{2}{*}{3} & Wigry, Krzywe & 12,3 & A & & 13,3 & & B & \\
\hline & Stryck & 12,1 & A & $\mathrm{B}$ & 14,5 & A & B & \\
\hline 5 & Borki, Sarnianka & 12,1 & A & $\mathrm{B}$ & 13,5 & & B & \\
\hline 14 & Rycerka, Praszywka I 125c & 12,0 & A & B & 14,2 & A & B & \\
\hline \multirow[t]{3}{*}{13} & Rycerka, Zwardon & 12,0 & A & B C & 14,0 & A & B & \\
\hline & Frankenwald & 11,9 & A & B C & 14,1 & A & B & \\
\hline & Mandelbeck & 11,8 & A & B C & 14,2 & A & B & \\
\hline \multirow[t]{2}{*}{19} & Zwierzyniec Lubelski, Obrocz & 11,8 & A & B C & 14,0 & A & B & \\
\hline & Harzvorland & 11,8 & A & B C & 14,4 & A & B & \\
\hline 6 & Nowe Ramuki, Przykop & 11,8 & A & B C & 13,0 & & B & $\mathrm{C}$ \\
\hline 2 & Zwierzyniec Biał., Krzyze & 11,7 & A & B C & 14,2 & A & B & \\
\hline 1 & Zwierzyniec Biał., Pogorzelece & 11,7 & A & B C & 14,0 & A & B & \\
\hline 12 & Istebna, Zapowiedz $115 \mathrm{f}$ & 11,7 & A & B C & 14,3 & A & B & \\
\hline 8 & Miedzygórze, Wodospad & 11,6 & A & B C & 14,8 & A & B & \\
\hline 11 & Istebna, Bukowiec 149h & 11,6 & A & B C & 14,8 & A & B & \\
\hline 18 & Tarnawa, Sokoliki & 11,5 & A & B C & 13,5 & & B & \\
\hline 21 & Kartuzy, Kosowo & 11,5 & A & B C & 14,1 & A & B & \\
\hline \multirow[t]{3}{*}{16} & Orawa Stancowa & 11,5 & A & B C & 12,9 & & B & $\mathrm{C}$ \\
\hline & Südbayern, Oberschwaben, Bod. & 11,1 & A & B C & 13,4 & & $\mathrm{~B}$ & \\
\hline & Schwäb. Alb und Bay. Jura & 11,0 & A & B C & 13,9 & A & B & \\
\hline \multirow[t]{2}{*}{9} & Stronie Slaskie, Kletno & 10,4 & & B C D & 13,4 & & B & \\
\hline & Bayerischer Wald & 10,1 & & C D & 13,2 & & $\mathrm{~B}$ & $\mathrm{C}$ \\
\hline 17 & Witów (Tatry), ur. Chotorz & 8,9 & & $\mathrm{D}$ & 11,3 & & & $\mathrm{C}$ \\
\hline
\end{tabular}

T-G = Tukey-Gruppe 


\section{Anhang 2.6}

Tukey-Gruppen für das Merkmal Einzelbaumvolumen [ $\left.\mathrm{m}^{3}\right]$ auf der Versuchsfläche Reinhardsbagen / Hessen (23-j. und 32-j.)

\begin{tabular}{|c|c|c|c|c|c|c|c|c|}
\hline \multirow{3}{*}{ Nr. } & \multirow{2}{*}{ Prüfglied } & \multicolumn{7}{|c|}{ Einzelbaumvolumen $\left[\mathrm{m}^{3}\right]$} \\
\hline & & \multirow{2}{*}{$\begin{array}{c}23-j . \\
0,10069\end{array}$} & \multicolumn{3}{|c|}{$\begin{array}{c}\text { Einzelbaum } \\
\text { T-G }\end{array}$} & \multirow{2}{*}{$\begin{array}{c}32-j . \\
0,34619\end{array}$} & \multicolumn{2}{|c|}{ T-G } \\
\hline & Mandelbeck & & A & $\mathrm{B}$ & & & A & \\
\hline 11 & Istebna, Bukowiec 149h & 0,11686 & A & $\mathrm{B}$ & & 0,33390 & A & \\
\hline 10 & Wisła, Malinka & 0,13204 & A & & & 0,33132 & A & \\
\hline 4 & Przerwanki, Zawady & 0,10203 & A & $\mathrm{B}$ & & 0,32003 & A & B \\
\hline \multirow[t]{2}{*}{8} & Miedzygórze, Wodospad & 0,11325 & A & B & & 0,31188 & A & B \\
\hline & Stryck & 0,10187 & A & B & & 0,30379 & A & B \\
\hline 1 & Zwierzyniec Biał., Pogorzelece & 0,09579 & $\mathrm{~A}$ & B & & 0,29968 & A & B \\
\hline 19 & Zwierzyniec Lubelski, Obrocz & 0,09403 & $\mathrm{~A}$ & B & & 0,28729 & A & B \\
\hline 12 & Istebna, Zapowiedz $115 \mathrm{f}$ & 0,10211 & $\mathrm{~A}$ & B & & 0,28724 & A & B \\
\hline \multirow[t]{2}{*}{2} & Zwierzyniec Biał., Krzyze & 0,09916 & A & B & & 0,28587 & A & B \\
\hline & Harzvorland & 0,10056 & A & B & & 0,27736 & $\mathrm{~A}$ & B \\
\hline \multirow[t]{2}{*}{13} & Rycerka, Zwardon & 0,09398 & A & B & & 0,27220 & A & $\mathrm{B}$ \\
\hline & Südbayern, Oberschwaben, Bod. & 0,08548 & & $\mathrm{~B}$ & $\mathrm{C}$ & 0,27075 & A & B \\
\hline \multirow[t]{2}{*}{14} & Rycerka, Praszywka I 125c & 0,09941 & A & B & & 0,26614 & A & $\mathrm{B}$ \\
\hline & Frankenwald & 0,09566 & A & B & & 0,26593 & A & B \\
\hline \multirow[t]{2}{*}{21} & Kartuzy, Kosowo & 0,09775 & A & $\mathrm{B}$ & & 0,26437 & A & B \\
\hline & Schwäb. Alb und Bay. Jura & 0,08995 & & B & & 0,26203 & A & B \\
\hline 18 & Tarnawa, Sokoliki & 0,08249 & & $\mathrm{~B}$ & $\mathrm{C}$ & 0,25800 & A & B \\
\hline 5 & Borki, Sarnianka & 0,08432 & & $\mathrm{~B}$ & $\mathrm{C}$ & 0,25325 & A & B \\
\hline 3 & Wigry, Krzywe & 0,08353 & & $\mathrm{~B}$ & $\mathrm{C}$ & 0,25259 & A & B \\
\hline \multirow[t]{2}{*}{16} & Orawa Stancowa & 0,07653 & & $\mathrm{~B}$ & $\mathrm{C}$ & 0,23467 & A & $\mathrm{B}$ \\
\hline & Bayerischer Wald & 0,08163 & & $\mathrm{~B}$ & $\mathrm{C}$ & 0,23269 & A & B \\
\hline 9 & Stronie Slaskie, Kletno & 0,08341 & & B & $\mathrm{C}$ & 0,22948 & A & B \\
\hline 6 & Nowe Ramuki, Przykop & 0,07763 & & B & $\mathrm{C}$ & 0,21400 & A & B \\
\hline 17 & Witów (Tatry), ur. Chotorz & 0,04754 & & & $\mathrm{C}$ & 0,18088 & & $\mathrm{~B}$ \\
\hline
\end{tabular}

T-G = Tukey-Gruppe 


\section{Anhang 2.7}

Tukey-Gruppen für das H/D-Verbältnis auf der Versuchsfläche Wanfried / Hessen (23-j.)

\begin{tabular}{ll|cccc}
\hline \multirow{2}{*}{ Nr. } & Prüfglied & \multicolumn{3}{|c}{ Wanfried (23-j.) } \\
\hline 4 & Przerwanki, Zawady & 95 & A & \\
3 & Wigry, Krzywe & 95 & A & \\
1 & Zwierzyniec Biał., Pogorzelece & 95 & A & B \\
5 & Borki, Sarnianka & 94 & A & B \\
21 & Kartuzy, Kosowo & 92 & A & B \\
19 & Zwierzyniec Lubelski, Obrocz & 92 & A & B \\
& Harzvorland & 91 & A & B \\
10 & Wisła, Malinka & 91 & A & B \\
2 & Zwierzyniec Biał., Krzyze & 90 & A & B \\
& Südbayern, Oberschwaben, ... & 90 & A & B \\
& Frankenwald & 89 & A & B \\
6 & Nowe Ramuki, Przykop & 88 & A & B \\
& Mandelbeck & 88 & A & B \\
16 & Orawa Stancowa & 88 & A & B \\
18 & Tarnawa, Sokoliki & 88 & A & B \\
8 & Miedzygórze, Wodospad & 88 & A & B \\
11 & Istebna, Bukowiec 149h & 88 & A & B \\
14 & Rycerka, Praszywka I 125c & 88 & A & B \\
& Stryck & 87 & A & B \\
9 & Stronie Slaskie, Kletno & 86 & A & B \\
& Schwäb. Alb und Bay. Jura & 86 & A & B \\
12 & Istebna, Zapowiedz 115f & 86 & A & B \\
17 & Rycerka, Zwardon & Witów (Tatry), ur. Chotorz & 86 & A & B \\
& Bayerischer Wald & A & B \\
\hline \multirow{2}{*}{ 1-G } & Tukey-Gruppe & & B \\
\hline \multirow{2}{*}{14} & & &
\end{tabular}

T-G = Tukey-Gruppe 


\section{Anhang 2.8}

Tukey-Gruppen $(\alpha=0,05)$ für das Wachstumsmerkmal BHD [cm] auf der Versuchsfläche Wanfried I Hessen (32-j.)

\begin{tabular}{|c|c|c|c|c|}
\hline \multirow{2}{*}{ Nr. } & \multirow{2}{*}{ Prüfglied } & \multicolumn{3}{|c|}{ Wanfried (32-j.) } \\
\hline & & BHD & $\mathrm{T}-$ & \\
\hline \multirow[t]{4}{*}{19} & Zwierzyniec Lubelski, Obrocz & 20,8 & A & \\
\hline & Frankenwald & 20,6 & A & \\
\hline & Stryck & 20,1 & A & B \\
\hline & Mandelbeck & 20,0 & A & B \\
\hline 4 & Przerwanki, Zawady & 19,9 & A & B \\
\hline 8 & Miedzygórze, Wodospad & 19,8 & A & B \\
\hline 10 & Wisła, Malinka & 19,8 & A & B \\
\hline 12 & Istebna, Zapowiedz $115 \mathrm{f}$ & 19,6 & A & B \\
\hline 11 & Istebna, Bukowiec 149h & 19,5 & A & B \\
\hline \multirow[t]{2}{*}{21} & Kartuzy, Kosowo & 19,5 & A & B \\
\hline & Harzvorland & 19,5 & A & B \\
\hline 14 & Rycerka, Praszywka I 125c & 19,4 & A & B \\
\hline \multirow[t]{2}{*}{13} & Rycerka, Zwardon & 19,2 & A & B \\
\hline & Schwäb. Alb und Bay. Jura & 19,2 & A & B \\
\hline \multirow[t]{2}{*}{18} & Tarnawa, Sokoliki & 19,1 & A & B \\
\hline & Südbayern, Oberschwaben, ... & 19,1 & A & B \\
\hline 1 & Zwierzyniec Biał., Pogorzelece & 18,9 & A & B \\
\hline 3 & Wigry, Krzywe & 18,8 & A & B \\
\hline 9 & Stronie Slaskie, Kletno & 18,6 & A & B \\
\hline 2 & Zwierzyniec Biał., Krzyze & 18,5 & A & B \\
\hline 16 & Orawa Stancowa & 18,5 & A & B \\
\hline 5 & Borki, Sarnianka & 18,0 & A & B \\
\hline \multirow[t]{2}{*}{6} & Nowe Ramuki, Przykop & 17,9 & A & B \\
\hline & Bayerischer Wald & 17,6 & A & B \\
\hline 17 & Witów (Tatry), ur. Chotorz & 17,1 & & B \\
\hline
\end{tabular}




\section{Anhang 2.9}

Tukey-Gruppen $(\alpha=0,05)$ für die Wachstumsmerkmale Höhe $[\mathrm{m}]$, BHD $[\mathrm{cm}]$ und Einzelbaumvolumen [m³] auf der Versuchsfläche Wanfried / Hessen (23-j.)

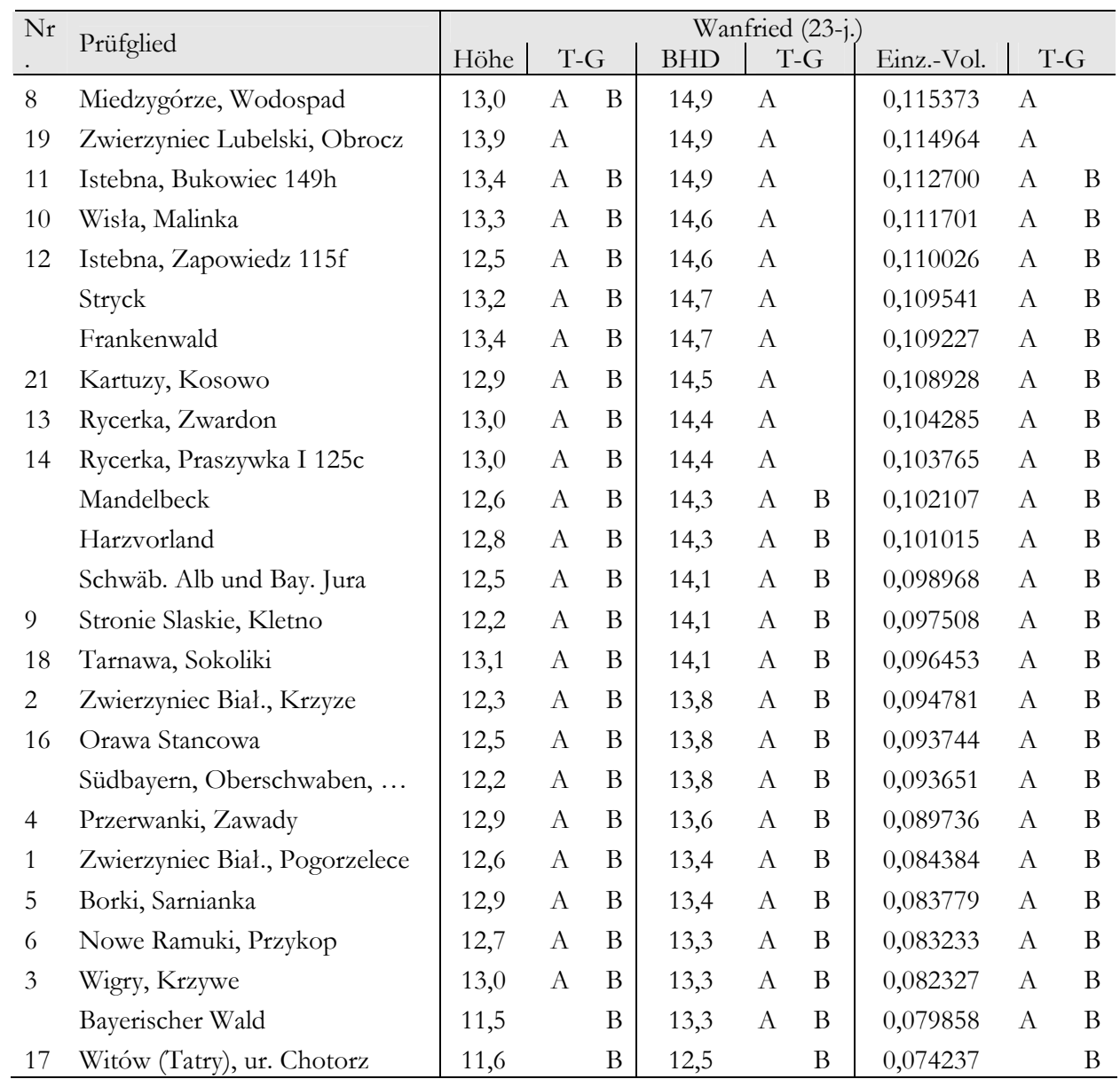

$\mathrm{T}-\mathrm{G}=$ Tukey-Gruppe 


\section{Anhang 2.10}

Zusammenstellung der Ovalitäten [\%] der IUFRO-Herkünfte und ibrer Einzelbaumnachkommenschaften auf der niedersächsischen Versuchsfläche Dassel (32-j.)

\begin{tabular}{|c|c|c|c|c|c|}
\hline \multirow{2}{*}{ Nr. } & \multirow{2}{*}{ Prüfglied } & \multicolumn{2}{|c|}{ IUFRO-Herkünfte } & \multicolumn{2}{|c|}{ Einzelbaumnachkommenschaften } \\
\hline & & Ovalität & Rang & Anzahl & Min ... Mittel ... Max \\
\hline 1 & Zwierzyniec Biał., Pogorzelece & 4,6 & 21 & & \\
\hline 2 & Zwierzyniec Biał., Krzyze & 3,0 & 8 & & \\
\hline 3 & Wigry, Krzywe & 3,0 & 7 & 9 & $1,9 \ldots 3,0 \ldots 4,2$ \\
\hline 4 & Przerwanki, Zawady & 4,5 & 20 & & \\
\hline 5 & Borki, Sarnianka & 3,3 & 14 & 10 & $2,5 \ldots 3,3 \ldots 4,3$ \\
\hline 6 & Nowe Ramuki, Przykop & 3,1 & 10 & & \\
\hline 8 & Miedzygórze, Wodospad & 2,5 & 4 & 10 & $2,0 \ldots 3,3 \ldots 4,9$ \\
\hline 9 & Stronie Slaskie, Kletno & 2,9 & 6 & 9 & $2,0 \ldots 3,1 \ldots 3,8$ \\
\hline 10 & Wisła, Malinka & 3,7 & 15 & 1 & 1,9 \\
\hline 11 & Istebna, Bukowiec 149h & 3,8 & 17 & 10 & $2,0 \ldots 3,2 \ldots 4,4$ \\
\hline 12 & Istebna, Zapowiedz $115 f$ & 2,4 & 2 & & \\
\hline$(404)$ & Istebna, Zapowiedz $115 f$ & 3,1 & 9 & & \\
\hline 13 & Rycerka, Zwardon & 2,0 & 1 & 10 & $1,8 \ldots 3,5 \ldots 5,5$ \\
\hline 14 & Rycerka, Praszywka I 125c & 3,8 & 16 & 10 & $2,8 \ldots 3,9 \ldots 4,5$ \\
\hline 15 & Rycerka, Praszywka II 125c & 3,2 & 12 & & \\
\hline 16 & Orawa Stancowa & 3,8 & 18 & & \\
\hline 17 & Witów (Tatry), ur. Chotorz & 2,6 & 5 & & \\
\hline 18 & Tarnawa, Sokoliki & 3,3 & 13 & 10 & $2,2 \ldots 2,7 \ldots 3,4$ \\
\hline 19 & Zwierzyniec Lubelski, Obrocz & 2,5 & 3 & & \\
\hline 20 & Blizyn, Swinia Gora & 3,1 & 11 & & \\
\hline 21 & Kartuzy, Kosowo & 3,8 & 19 & & \\
\hline & IUFRO-Mittel & 3,24 & & & \\
\hline & Versuchsflächen-Mittel & 3,24 & & & \\
\hline
\end{tabular}




\section{Anhang 2.11}

Zusammenstellung der H/D-Verbältnisse der IUFRO-Herkünfte und ibrer Einzelbaumnachkommenschaften auf der niedersächsischen Versuchsfläche Dassel

\begin{tabular}{|c|c|c|c|c|c|c|c|}
\hline \multirow[t]{2}{*}{ Nr. } & \multirow[t]{2}{*}{ Prüfglied } & & \multicolumn{3}{|c|}{$32-j}$. \\
\hline & & $\mathrm{HD}$ & Rang & $\begin{array}{l}\mathrm{Eb} \\
\mathrm{HD} \\
\end{array}$ & $\mathrm{HD}$ & Rang & $\begin{array}{r}\mathrm{Eb} \\
\mathrm{HD} \\
\end{array}$ \\
\hline 1 & Zwierzyniec Biał., Pogorzelece & 79 & 7 & & 83 & 14 & \\
\hline 2 & Zwierzyniec Biał., Krzyze & 82 & 3 & & 91 & 3 & \\
\hline 3 & Wigry, Krzywe & 77 & 10 & 82 & 85 & 11 & 91 \\
\hline 4 & Przerwanki, Zawady & 83 & 2 & & 87 & 7 & \\
\hline 5 & Borki, Sarnianka & 84 & 1 & 82 & 96 & 1 & 93 \\
\hline 6 & Nowe Ramuki, Przykop & 80 & 6 & & 88 & 5 & \\
\hline 8 & Miedzygórze, Wodospad & 71 & 19 & 73 & 80 & 18 & 80 \\
\hline 9 & Stronie Slaskie, Kletno & 72 & 15 & 69 & 81 & 17 & 79 \\
\hline 10 & Wisła, Malinka & 71 & 17 & 68 & 77 & 20 & 76 \\
\hline 11 & Istebna, Bukowiec 149h & 77 & 11 & 74 & 85 & 10 & 81 \\
\hline 12 & Istebna, Zapowiedz $115 f$ & 71 & 18 & & 84 & 13 & \\
\hline (404) & Istebna, Zapowiedz $115 \mathrm{f}$ & 78 & 9 & & 87 & 6 & \\
\hline 13 & Rycerka, Zwardon & 70 & 20 & 77 & 79 & 19 & 82 \\
\hline 14 & Rycerka, Praszywka I 125c & 72 & 16 & 77 & 84 & 12 & 86 \\
\hline 15 & Rycerka, Praszywka II 125c & 73 & 14 & & 81 & 16 & \\
\hline 16 & Orawa Stancowa & 79 & 8 & & 86 & 9 & \\
\hline 17 & Witów (Tatry), ur. Chotorz & 76 & 12 & & 87 & 8 & \\
\hline 18 & Tarnawa, Sokoliki & 81 & 5 & 80 & 91 & 2 & 88 \\
\hline 19 & Zwierzyniec Lubelski, Obrocz & 74 & 13 & & 83 & 15 & \\
\hline 20 & Blizyn, Swinia Gora & 81 & 4 & & 89 & 4 & \\
\hline 21 & Kartuzy, Kosowo & 67 & 21 & & 74 & 21 & \\
\hline \multirow{2}{*}{\multicolumn{2}{|c|}{$\begin{array}{l}\text { IUFRO-Mittel } \\
\text { Versuchsflächen-Mittel }\end{array}$}} & 75,1 & & & 84,6 & & \\
\hline & & 76,5 & & & 84,7 & & \\
\hline
\end{tabular}

$\mathrm{Eb}=$ Einzelbaumnachkommenschaften 
Anhang 2.12

Tukey-Gruppen $(\alpha=0,05)$ für das Wachstumsmerkmal Höhe $[\mathrm{m}]$ auf der Versuchsfläche Dassel / Niedersachsen (23-j. und 32-j.)

\begin{tabular}{|c|c|c|c|c|c|c|}
\hline Nr. * & $\begin{array}{c}\text { IUFRO- } \\
\text { Nr. }\end{array}$ & Prüfglied & $\begin{array}{l}23-\mathrm{j} . \\
\text { Höhe }[\mathrm{m}]\end{array}$ & T-G & $\begin{array}{l}32-\mathrm{i} \\
\text { Höhe }[\mathrm{m}]\end{array}$ & T-G \\
\hline 37 & $11 * *$ & Istebna $149 \mathrm{~h}, 11-53$ & 13,1 & A & 20,0 & A \\
\hline 91 & $3 * *$ & Wigry, 3-9 & 12,5 & $\mathrm{~A}$ & 19,9 & A \\
\hline 31 & $11 * *$ & Istebna $149 \mathrm{~h}, 11-14$ & 12,4 & A $B$ & 19,7 & A \\
\hline 63 & $14^{* *}$ & Rycerka I, 14-21 & 12,4 & A B & 19,7 & A \\
\hline 93 & $3 * *$ & Wigry, 3-19 & 12,1 & A $B$ & 19,7 & A \\
\hline 35 & $11 * *$ & Istebna $149 \mathrm{~h}, 11-40$ & 13,5 & A & 19,6 & A \\
\hline 96 & $3 * *$ & Wigry, 3-55 & 12,9 & A & 19,5 & A \\
\hline 49 & $8^{* *}$ & Miedzygórze, 8-60 & 12,3 & A B & 19,4 & A \\
\hline 23 & $5^{* *}$ & Borki, 5-95 & 12,2 & A B & 19,3 & A \\
\hline 36 & $11 * *$ & Istebna $149 \mathrm{~h}, 11-45$ & 12,5 & A $B$ & 19,3 & A \\
\hline 64 & $14^{* *}$ & Rycerka I, 14-52 & 12,1 & A & 19,3 & A \\
\hline 89 & $18^{* *}$ & Tarnawa, $18-96$ & 12,0 & A & 19,3 & A \\
\hline 97 & $3^{* *}$ & Wigry, 3-68 & 12,5 & A B & 19,3 & A \\
\hline 3 & 11 & Istebna, Bukowiec 149h & 12,2 & A B & 19,2 & A \\
\hline 33 & $11^{* *}$ & Istebna 149h, 11-37 & 11,6 & A & 19,2 & A \\
\hline 39 & $11 * *$ & Istebna $149 \mathrm{~h}, 11-60$ & 12,4 & A & 19,2 & A \\
\hline 40 & $11^{* *}$ & Istebna $149 \mathrm{~h}, 11-73$ & 12,3 & A $B$ & 19,2 & A \\
\hline 59 & $13^{* *}$ & Zwardon, 13-98 & 12,3 & A B & 19,2 & A \\
\hline 62 & $14 * *$ & Rycerka I, 14-20 & 12,5 & A B & 19,2 & A \\
\hline 27 & $5^{* *}$ & Borki, 5-101 & 12,1 & A & 19,1 & A \\
\hline 50 & $8^{* *}$ & Miedzygórze, 8-73 & 12,2 & A & 19,1 & A \\
\hline 56 & $13^{* *}$ & Zwardon, 13-86 & 12,8 & A B & 19,1 & A \\
\hline 8 & 16 & Orawa Stancowa & 12,3 & A B & 19,0 & A \\
\hline 9 & 4 & Przerwanki, Zawady & 12,1 & A B & 19,0 & A \\
\hline 16 & 10 & Wisła, Malinka & 11,8 & A B & 19,0 & A \\
\hline 22 & $5^{* *}$ & Borki, 5-94 & 11,7 & A B & 19,0 & A \\
\hline 34 & $11^{* *}$ & Istebna $149 \mathrm{~h}, 11-38$ & 11,7 & A B & 19,0 & A \\
\hline 52 & $13^{* *}$ & Zwardon, 13-6 & 12,1 & A $B$ & 19,0 & A \\
\hline 82 & $18^{* *}$ & Tarnawa, 18-48 & 12,4 & A & 19,0 & A \\
\hline 86 & $18^{* *}$ & Tarnawa, 18-67 & 11,9 & A $B$ & 19,0 & A \\
\hline 92 & $3 * *$ & Wigry, 3-14 & 12,4 & A B & 19,0 & $\mathrm{~A}$ \\
\hline 404 & $(404)$ & Istebna, Zapowiedz $115 f$ & 12,2 & A B & 19,0 & A \\
\hline 87 & $18^{* *}$ & Tarnawa, 18-71 & 12,0 & A & 18,9 & A \\
\hline 46 & $8^{* *}$ & Miedzygórze, 8-44 & 11,8 & A B & 18,8 & A \\
\hline 53 & $13^{* *}$ & Zwardon, 13-12 & 12,4 & A $B$ & 18,8 & A \\
\hline 55 & $13^{* *}$ & Zwardon, 13-14 & 11,3 & A B & 18,8 & A \\
\hline 70 & $14 * *$ & Rycerka I, 14-75 & 12,0 & A $B$ & 18,8 & A \\
\hline 84 & $18^{* *}$ & Tarnawa, 18-62 & 12,3 & A B & 18,8 & A \\
\hline 69 & $14 * *$ & Rycerka I, 14-73 & 11,8 & A B & 18,7 & A \\
\hline 90 & $18^{* *}$ & Tarnawa, 18-103 & 11,9 & A B & 18,7 & A \\
\hline 47 & $8^{* *}$ & Miedzygórze, 8-53 & 11,6 & A B & 18,6 & A \\
\hline 51 & $13^{* *}$ & Zwardon, 13-4 & 11,5 & A $B$ & 18,6 & A \\
\hline 60 & $13^{* *}$ & Zwardon, 13-99 & 11,9 & A & 18,6 & A \\
\hline 26 & $5^{* *}$ & Borki, 5-99 & 11,6 & A $B$ & 18,5 & A \\
\hline 58 & $13 * *$ & Zwardon, 13-96 & 11,8 & A B & 18,5 & A \\
\hline 95 & $3 * *$ & Wigry, 3-34 & 11,6 & A $B$ & 18,5 & A \\
\hline 99 & $3 * *$ & Wigry, 3-92 & 11,8 & A B & 18,5 & A \\
\hline 101 & $10^{* *}$ & Wisła, 10-1 & 11,3 & A B & 18,5 & A \\
\hline
\end{tabular}




\begin{tabular}{|c|c|c|c|c|c|c|c|}
\hline Nr. * & $\begin{array}{c}\text { IUFRO- } \\
\text { Nr. }\end{array}$ & Prüfglied & $\begin{array}{r}23-1 \\
\text { Höhe }[\mathrm{m}] \\
\end{array}$ & $\mathrm{T}-\mathrm{G}$ & $\begin{array}{c}32-1 \\
\text { Höhe }[\mathrm{m}] \\
\end{array}$ & \multicolumn{2}{|c|}{ T-G } \\
\hline 1 & 20 & Blizyn, Swinia Gora & 11,3 & A & 18,4 & A & \\
\hline 6 & 8 & Miedzygórze, Wodospad & 11,4 & A $B$ & 18,4 & A & \\
\hline 18 & 1 & Zwierzyniec Biał., Pogorzelece & 12,2 & A $B$ & 18,4 & A & \\
\hline 20 & 19 & Zwierzyniec Lubelski, Obrocz & 11,4 & A & 18,4 & A & \\
\hline 38 & $11^{* *}$ & Istebna $149 \mathrm{~h}, 11-56$ & 12,1 & A $B$ & 18,4 & A & \\
\hline 48 & $8^{* *}$ & Miedzygórze, 8-56 & 11,9 & A $B$ & 18,4 & A & \\
\hline 81 & $18^{* *}$ & Tarnawa, $18-10$ & 12,0 & A & 18,4 & A & \\
\hline 7 & 6 & Nowe Ramuki, Przykop & 11,7 & A & 18,3 & A & \\
\hline 13 & 9 & Stronie Slaskie, Kletno & 11,7 & A & 18,3 & A & \\
\hline 14 & 18 & Tarnawa, Sokoliki & 11,6 & A B & 18,3 & $\mathrm{~A}$ & \\
\hline 19 & 2 & Zwierzyniec Biał., Krzyze & 11,6 & A $B$ & 18,3 & A & \\
\hline 25 & $5^{* *}$ & Borki, 5-98 & 12,0 & A & 18,3 & A & \\
\hline 42 & $8^{* *}$ & Miedzygórze, 8-19 & 11,7 & A & 18,3 & A & \\
\hline 57 & $13 * *$ & Zwardon, 13-94 & 12,5 & A $B$ & 18,3 & A & \\
\hline 66 & $14 * *$ & Rycerka I, 14-62 & 11,6 & A B & 18,3 & $\mathrm{~A}$ & \\
\hline 83 & $18^{* *}$ & Tarnawa, $18-51$ & 11,7 & A & 18,3 & A & \\
\hline 85 & $18^{* *}$ & Tarnawa, 18-64 & 11,4 & A & 18,3 & A & \\
\hline 4 & 12 & Istebna, Zapowiedz $115 f$ & 11,7 & A & 18,2 & A & B \\
\hline 5 & 21 & Kartuzy, Kosowo & 11,3 & A $\mathrm{B}$ & 18,2 & A & B \\
\hline 32 & $11^{* *}$ & Istebna $149 \mathrm{~h}, 11-18$ & 11,2 & A B & 18,2 & A & B \\
\hline 68 & $14 * *$ & Rycerka I, 14-70 & 12,2 & A & 18,2 & A & B \\
\hline 45 & $8^{* *}$ & Miedzygórze, 8-40 & 11,6 & A & 18,1 & A & B \\
\hline 54 & $13^{* *}$ & Zwardon, 13-13 & 11,0 & A $B$ & 18,1 & A & B \\
\hline 10 & 13 & Rycerka, Zwardon & 11,2 & A & 18,0 & A & B \\
\hline 24 & $5^{* *}$ & Borki, 5-96 & 11,4 & A & 18,0 & A & B \\
\hline 41 & $8^{* *}$ & Miedzygórze, 8-3 & 11,0 & A & 18,0 & A & B \\
\hline 61 & $14 * *$ & Rycerka I, 14-8 & 11,6 & A B & 18,0 & A & B \\
\hline 98 & $3^{* *}$ & Wigry, 3-86 & 11,3 & A $\mathrm{B}$ & 18,0 & A & B \\
\hline 11 & 14 & Rycerka, Praszywka I 125c & 11,2 & A & 17,9 & A & B \\
\hline 29 & $5^{* *}$ & Borki, 5-103 & 10,8 & A & 17,9 & A & B \\
\hline 94 & $3 * *$ & Wigry, 3-29 & 11,5 & A & 17,9 & A & B \\
\hline 73 & $9 * *$ & Stronie Slaskie, 9-52 & 11,2 & A $B$ & 17,7 & A & B \\
\hline 76 & $9 * *$ & Stronie Slaskie, 9-64 & 10,7 & A $B$ & 17,7 & A & B \\
\hline 67 & $14 * *$ & Rycerka I, 14-68 & 10,2 & A & 17,6 & A & B \\
\hline 12 & 15 & Rycerka, Praszywka II 125c & 10,8 & A & 17,5 & A & B \\
\hline 30 & $5^{* *}$ & Borki, 5-104 & 10,9 & A & 17,5 & A & B \\
\hline 43 & $8^{* *}$ & Miedzygórze, 8-30 & 10,6 & A B & 17,5 & A & B \\
\hline 72 & $9 * *$ & Stronie Slaskie, 9-35 & 10,6 & A & 17,5 & A & B \\
\hline 78 & $9 * *$ & Stronie Slaskie, 9-71 & 11,0 & $\mathrm{~A}$ & 17,5 & A & B \\
\hline 80 & $9 * *$ & Stronie Slaskie, 9-75 & 11,0 & A B & 17,5 & $\mathrm{~A}$ & B \\
\hline 15 & 3 & Krzy & 10,5 & A $B$ & 17,3 & A & B \\
\hline 79 & $9 * *$ & Stronie Slaskie, 9-74 & 11,1 & A $B$ & 17,2 & A & B \\
\hline 28 & $5 * *$ & Borki, 5-102 & 12,0 & A & 17,1 & A & B \\
\hline 75 & $9 * *$ & Stronie Slaskie, 9-61 & 10,6 & A & 17,1 & A & B \\
\hline 88 & $18^{* *}$ & Tarnawa, $18-73$ & 11,1 & A B & 17,1 & A & B \\
\hline 17 & 17 & Witów (Tatry), ur. Chotorz & 10,8 & A $\mathrm{B}$ & 17,0 & A & $\mathrm{B}$ \\
\hline 44 & $8^{* *}$ & Miedzygórze, 8-33 & 10,7 & A $B$ & 17,0 & A & B \\
\hline 71 & $9 * *$ & Stronie Slaskie, 9-28 & 10,6 & A & 17,0 & A & B \\
\hline 2 & 5 & Borki, Sarnianka & 12,2 & A B & 16,9 & A & $\mathrm{B}$ \\
\hline 65 & $14 * *$ & Rvcerka I, 14-54 & 10,6 & A B & 16,9 & A & B \\
\hline 77 & $9 * *$ & Stronie Slaskie, 9-69 & 9,5 & $\mathrm{~B}$ & 14,3 & & B \\
\hline
\end{tabular}

* Prüfglied-Nr. auf der Versuchsfläche Dassel / NI ** Einzelbaumnachkommenschaft T-G = Tukey-Gruppe 
Anhang 2.13

Tukey-Gruppen $(\alpha=0,05)$ für den Vorrat $\left[\mathrm{m}^{3} / \mathrm{ha}\right]$ auf der Versuchsfläche Dassel / Niedersachsen (23-j. und 32-j.)

\begin{tabular}{|c|c|c|c|c|c|c|c|c|}
\hline Nr. * & $\begin{array}{c}\text { IUFRO- } \\
\text { Nr. }\end{array}$ & Prüfglied & $\begin{array}{r}23 \\
\text { Vorrat } \\
\end{array}$ & T-G & Vorrat & 32 & $\mathrm{~T}-\mathrm{C}$ & \\
\hline 48 & $8^{* *}$ & Miedzygórze, 8-56 & 134 & A & 404 & A & & \\
\hline 36 & $11 * *$ & Istebna $149 \mathrm{~h}, 11-45$ & 135 & A & 380 & A & B & \\
\hline 35 & $11 * *$ & Istebna $149 \mathrm{~h}, 11-40$ & 125 & A B & 353 & A & B & C \\
\hline 3 & 11 & Istebna, Bukowiec 149h & 113 & A B & 349 & A & B & $\mathrm{C}$ \\
\hline 37 & $11 * *$ & Istebna 149h, 11-53 & 123 & A B & 348 & A & B & $\mathrm{C}$ \\
\hline 16 & 10 & Wisła, Malinka & 93 & A B & 343 & A & B & $\mathrm{C}$ \\
\hline 50 & $8^{* *}$ & Miedzygórze, 8-73 & 102 & A B & 342 & A & B & $\mathrm{C}$ \\
\hline 31 & $11 * *$ & Istebna $149 \mathrm{~h}, 11-14$ & 106 & A B & 335 & A & B & $\mathrm{C}$ \\
\hline 91 & $3 * *$ & Wigry, 3-9 & 108 & A B & 335 & A & B & $\mathrm{C}$ \\
\hline 49 & $8^{* *}$ & Miedzygórze, 8-60 & 103 & A B & 330 & A & B & $\mathrm{C}$ \\
\hline 83 & $18^{* *}$ & Tarnawa, 18-51 & 100 & A B & 330 & A & B & $\mathrm{C}$ \\
\hline 38 & $11 * *$ & Istebna $149 \mathrm{~h}, 11-56$ & 114 & A B & 329 & A & B & $\mathrm{C}$ \\
\hline 47 & $8^{* *}$ & Miedzygórze, 8-53 & 117 & A B & 316 & A & B & C \\
\hline 63 & $14 * *$ & Rycerka I, 14-21 & 94 & A B & 305 & A & B & $\mathrm{C}$ \\
\hline 58 & $13 * *$ & Zwardon, 13-96 & 101 & A B & 304 & A & B & C \\
\hline 34 & $11 * *$ & Istebna $149 \mathrm{~h}, 11-38$ & 90 & A B & 299 & A & B & $\mathrm{C}$ \\
\hline 53 & $13^{* *}$ & Zwardon, 13-12 & 97 & A B & 296 & A & B & $\mathrm{C}$ \\
\hline 69 & $14 * *$ & Rycerka I, 14-73 & 100 & A B & 296 & A & B & $\mathrm{C}$ \\
\hline 4 & 12 & Istebna, Zapowiedz 115f & 100 & A B & 295 & A & B & C \\
\hline 101 & $10 * *$ & Wisła, 10-1 & 94 & A B & 294 & A & B & C \\
\hline 404 & $(404)$ & Istebna, Zapowiedz $115 f$ & 94 & A B & 294 & A & B & $\mathrm{C}$ \\
\hline 39 & $11^{* *}$ & Istebna 149h, 11-60 & 103 & A B & 287 & A & B & $\mathrm{C}$ \\
\hline 82 & $18^{* *}$ & Tarnawa, 18-48 & 101 & A B & 286 & A & B & C \\
\hline 96 & $3^{* *}$ & Wigry, 3-55 & 87 & A B & 285 & A & B & C \\
\hline 46 & $8^{* *}$ & Miedzygórze, 8-44 & 87 & & 284 & A & B & C \\
\hline 59 & $13^{* *}$ & Zwardon, 13-98 & 101 & A B & 284 & A & B & $\mathrm{C}$ \\
\hline 78 & $9 * *$ & Stronie Slaskie, 9-71 & 80 & A B & 284 & A & B & C \\
\hline 42 & $8^{* *}$ & Miedzygórze, 8-19 & 92 & A B & 280 & A & B & $\mathrm{C}$ \\
\hline 62 & $14 * *$ & Rycerka I, 14-20 & 88 & A B & 280 & A & B & $\mathrm{C}$ \\
\hline 5 & 21 & Kartuzy, Kosowo & 91 & A B & 275 & A & B & C \\
\hline 60 & $13 * *$ & Zwardon, 13-99 & 87 & A B & 275 & A & B & C \\
\hline 84 & $18^{* *}$ & Tarnawa, 18-62 & 96 & A B & 275 & A & B & $\mathrm{C}$ \\
\hline 41 & $8^{* *}$ & Miedzygórze, 8-3 & 102 & A B & 273 & A & B & C \\
\hline 80 & $9 * *$ & Stronie Slaskie, 9-75 & 86 & A B & 273 & A & B & $\mathrm{C}$ \\
\hline 56 & $13^{* *}$ & Zwardon, 13-86 & 90 & A B & 271 & A & B & C \\
\hline 6 & 8 & Miedzygórze, Wodospad & 84 & A B & 266 & A & B & $\mathrm{C}$ \\
\hline 93 & $3 * *$ & Wigry, 3-19 & 84 & A B & 263 & A & B & C \\
\hline 55 & $13^{* *}$ & Zwardon, 13-14 & 78 & A B & 260 & A & B & $\mathrm{C}$ \\
\hline 40 & $11 * *$ & Istebna $149 \mathrm{~h}, 11-73$ & 95 & A B & 258 & A & B & $\mathrm{C}$ \\
\hline 52 & $13 * *$ & Zwardon, 13-6 & 74 & A B & 256 & A & B & C \\
\hline 72 & $9 * *$ & Stronie Slaskie, 9-35 & 94 & A B & 255 & A & B & C \\
\hline 8 & 16 & Orawa Stancowa & 91 & A B & 253 & A & B & C \\
\hline 57 & $13^{* *}$ & Zwardon, 13-94 & 88 & A B & 253 & A & B & $\mathrm{C}$ \\
\hline 61 & $14 * *$ & Rycerka I, 14-8 & 84 & A B & 252 & A & B & C \\
\hline 32 & $11^{* *}$ & Istebna 149h, 11-18 & 79 & A B & 251 & A & B & $\mathrm{C}$ \\
\hline 12 & 15 & Rycerka, Praszywka II 125c & 83 & A B & 250 & A & B & $\mathrm{C}$ \\
\hline 23 & $5^{* *}$ & Borki, 5-95 & 95 & A B & 250 & A & B & C \\
\hline 51 & $13^{* *}$ & Zwardon, 13-4 & 77 & A B & 249 & A & B & $\mathrm{C}$ \\
\hline
\end{tabular}




\begin{tabular}{|c|c|c|c|c|c|c|c|c|}
\hline Nr. ${ }^{*}$ & $\begin{array}{c}\text { IUFRO- } \\
\text { Nr. }\end{array}$ & Prüfglied & $\begin{array}{r}23 \\
\text { Vorrat } \\
\end{array}$ & T-G & Vorrat & $32-i$ & T-G & \\
\hline 64 & $14^{* *}$ & Rycerka I, 14-52 & 90 & A B & 247 & A & B & $\mathrm{C}$ \\
\hline 90 & $18^{* *}$ & Tarnawa, $18-103$ & 80 & A B & 247 & A & B & $\mathrm{C}$ \\
\hline 13 & 9 & Stronie Slaskie, Kletno & 86 & A B & 242 & A & B & $\mathrm{C}$ \\
\hline 68 & $14 * *$ & Rycerka I, 14-70 & 92 & A B & 242 & A & B & $\mathrm{C}$ \\
\hline 86 & $18^{* *}$ & Tarnawa, 18-67 & 76 & A B & 240 & A & B & $\mathrm{C}$ \\
\hline 79 & $9 * *$ & Stronie Slaskie, 9-74 & 82 & A B & 239 & A & B & $\mathrm{C}$ \\
\hline 75 & $9 * *$ & Stronie Slaskie, 9-61 & 72 & A B & 238 & A & B & $\mathrm{C}$ \\
\hline 76 & $9 * *$ & Stronie Slaskie, 9-64 & 68 & A B & 238 & A & $\mathrm{B}$ & $\mathrm{C}$ \\
\hline 97 & $3^{* *}$ & Wigry, 3-68 & 86 & A B & 238 & A & B & $\mathrm{C}$ \\
\hline 85 & $18^{* *}$ & Tarnawa, 18-64 & 71 & A B & 237 & A & $\mathrm{B}$ & $\mathrm{C}$ \\
\hline 33 & $11 * *$ & Istebna 149h, 11-37 & 72 & A B & 236 & A & B & $\mathrm{C}$ \\
\hline 1 & 20 & Blizyn, Swinia Gora & 90 & A B & 235 & A & B & $\mathrm{C}$ \\
\hline 45 & $8^{* *}$ & Miedzygórze, 8-40 & 79 & A B & 235 & A & B & $\mathrm{C}$ \\
\hline 11 & 14 & Rycerka, Praszywka I 125c & 79 & A B & 233 & A & B & $\mathrm{C}$ \\
\hline 66 & $14^{* *}$ & Rycerka I, 14-62 & 80 & A B & 233 & A & $\mathrm{B}$ & $\mathrm{C}$ \\
\hline 89 & $18^{* *}$ & Tarnawa, 18-96 & 75 & A B & 233 & A & B & $\mathrm{C}$ \\
\hline 10 & 13 & Rycerka, Zwardon & 73 & A B & 231 & A & B & $\mathrm{C}$ \\
\hline 92 & $3 * *$ & Wigry, 3-14 & 81 & A B & 230 & A & B & $\mathrm{C}$ \\
\hline 14 & 18 & Tarnawa, Sokoliki & 76 & A B & 224 & A & $\mathrm{B}$ & $\mathrm{C}$ \\
\hline 71 & $9 * *$ & Stronie Slaskie, 9-28 & 76 & A $B$ & 222 & A & B & $\mathrm{C}$ \\
\hline 20 & 19 & Zwierzyniec Lubelski, Obrocz & 70 & A B & 220 & A & B & $\mathrm{C}$ \\
\hline 27 & $5^{* *}$ & Borki, 5-101 & 75 & A B & 220 & A & $\mathrm{B}$ & $\mathrm{C}$ \\
\hline 70 & $14 * *$ & Rycerka I, 14-75 & 73 & A B & 220 & A & B & $\mathrm{C}$ \\
\hline 9 & 4 & Przerwanki, Zawady & 63 & A B & 218 & A & $\mathrm{B}$ & $\mathrm{C}$ \\
\hline 73 & $9 * *$ & Stronie Slaskie, 9-52 & 78 & A B & 216 & A & B & $\mathrm{C}$ \\
\hline 22 & $5^{* *}$ & Borki, 5-94 & 63 & A B & 213 & A & B & $\mathrm{C}$ \\
\hline 29 & $5^{* *}$ & Borki, 5-103 & 68 & A B & 211 & A & B & $\mathrm{C}$ \\
\hline 81 & $18^{* *}$ & Tarnawa, $18-10$ & 70 & A B & 210 & A & B & $\mathrm{C}$ \\
\hline 88 & $18^{* *}$ & Tarnawa, 18-73 & 68 & A B & 208 & A & $\mathrm{B}$ & $\mathrm{C}$ \\
\hline 54 & $13^{* *}$ & Zwardon, 13-13 & 63 & A B & 205 & A & B & $\mathrm{C}$ \\
\hline 25 & $5^{* *}$ & Borki, 5-98 & 59 & A B & 203 & A & B & $\mathrm{C}$ \\
\hline 26 & $5^{* *}$ & Borki, 5-99 & 75 & A B & 201 & A & B & $\mathrm{C}$ \\
\hline 87 & $18^{* *}$ & Tarnawa, 18-71 & 59 & A B & 200 & A & B & $\mathrm{C}$ \\
\hline 19 & 2 & Zwierzyniec Biał., Krzyze & 68 & A B & 196 & A & B & $\mathrm{C}$ \\
\hline 44 & $8 * *$ & Miedzygórze, 8-33 & 55 & A B & 196 & A & B & $\mathrm{C}$ \\
\hline 24 & $5 * *$ & Borki, 5-96 & 69 & A B & 186 & A & B & $\mathrm{C}$ \\
\hline 18 & 1 & Zwierzyniec Biał., Pogorzelece & 60 & A B & 182 & A & B & $\mathrm{C}$ \\
\hline 95 & $3^{* *}$ & Wigry, 3-34 & 58 & A B & 182 & A & $\mathrm{B}$ & $\mathrm{C}$ \\
\hline 67 & $14 * *$ & Rycerka I, 14-68 & 57 & A B & 176 & A & B & $\mathrm{C}$ \\
\hline 94 & $3^{* *}$ & Wigry, 3-29 & 54 & A B & 176 & A & B & $\mathrm{C}$ \\
\hline 7 & 6 & Nowe Ramuki, Przykop & 58 & A B & 175 & A & B & $\mathrm{C}$ \\
\hline 2 & 5 & Borki, Sarnianka & 56 & A B & 171 & A & B & $\mathrm{C}$ \\
\hline 99 & $3 * *$ & Wigry, 3-92 & 58 & A B & 166 & A & B & $\mathrm{C}$ \\
\hline 17 & 17 & Witów (Tatry), ur. Chotorz & 57 & A B & 162 & A & B & $\mathrm{C}$ \\
\hline 98 & $3 * *$ & Wigry, 3-86 & 61 & A B & 162 & A & $\mathrm{B}$ & $\mathrm{C}$ \\
\hline 30 & $5^{* *}$ & Borki, 5-104 & 56 & A B & 161 & A & B & $\mathrm{C}$ \\
\hline 28 & $5^{* *}$ & Borki, 5-102 & 70 & A B & 154 & & B & $\mathrm{C}$ \\
\hline 77 & $9 * *$ & Stronie Slaskie, 9-69 & 50 & A B & 147 & & B & $\mathrm{C}$ \\
\hline 15 & 3 & Wigry, Krzywe & 49 & A B & 140 & & B & $\mathrm{C}$ \\
\hline 65 & $14^{* *}$ & Rycerka I, 14-54 & 39 & B & 137 & & B & $\mathrm{C}$ \\
\hline 43 & $8^{* *}$ & Miedzygórze, 8-30 & 57 & A B & 127 & & & $\mathrm{C}$ \\
\hline
\end{tabular}




\section{Anhang 2.14}

Zusammenstellung der Ovalitäten [\%] auf der niedersächsischen Versuchsfläche Seesen (32-j.)

\begin{tabular}{|c|c|c|c|c|c|}
\hline \multirow[t]{2}{*}{ Nr. } & \multirow[t]{2}{*}{ Prüfglied } & \multicolumn{2}{|c|}{ IUFRO-Herkünfte } & \multicolumn{2}{|c|}{$\begin{array}{l}\text { Einzelbaumnach- } \\
\text { kommenschaften }\end{array}$} \\
\hline & & Ovalität & Rang & Anzahl & Min ... Mittel .. \\
\hline 1 & Zwierzyniec Biał., Pogorzelece & & & 10 & $1,6 \ldots 3,5 \ldots 5,3$ \\
\hline 4 & Przerwanki, Zawady & 4,4 & 9 & & \\
\hline 5 & Borki, Sarnianka & 3,5 & 8 & & \\
\hline 6 & Nowe Ramuki, Przykop & 3,1 & 5 & & \\
\hline 8 & Miedzygórze, Wodospad & 3,2 & 6 & & \\
\hline 10 & Wisła, Malinka & & & 9 & $2,0 \ldots 3,3 \ldots 4,7$ \\
\hline 11 & Istebna, Bukowiec 149h & 2,9 & 4 & & \\
\hline 12 & Istebna, Zapowiedz $115 f$ & 2,1 & 1 & & \\
\hline 13 & Rycerka, Zwardon & 2,8 & 3 & & \\
\hline 16 & Orawa Stancowa & 3,3 & 7 & & \\
\hline 20 & Blizyn, Swinia Gora & 2,2 & 2 & & \\
\hline 21 & Kartuzy, Kosowo & 5,7 & 10 & & \\
\hline & Westerhof Abt. 40 & & & 44 & $2,1 \ldots 3,7 \ldots 6,3$ \\
\hline & Westerhof Abt. 48 & & & 2 & $3,2 \ldots 3,2 \ldots 3,3$ \\
\hline & Westerhof Abt. 49 & & & 10 & $2,3 \ldots 3,6 \ldots 5,0$ \\
\hline & Westerhof Abt. 50 & & & 15 & $2,1 \ldots 4,1 \ldots 6,2$ \\
\hline & IUFRO-Mittel & 3,33 & & & \\
\hline & Versuchsflächen-Mittel & 3,03 & & & \\
\hline
\end{tabular}

\section{Anhang 2.15}

Zusammenstellung der H/D-Verbältnisse auf der niedersächsischen Versuchsfläche Seesen

\begin{tabular}{|c|c|c|c|c|c|c|c|}
\hline \multirow[t]{2}{*}{ Nr. } & \multirow[t]{2}{*}{ Prüfglied } & \multicolumn{3}{|c|}{$23-j}$. & \multicolumn{2}{|r|}{$32-j}$. & $\mathrm{Eb}$ \\
\hline & & $\mathrm{HD}$ & Rang & $\mathrm{HD}$ & HD & Rang & $\mathrm{HD}$ \\
\hline 1 & Zwierzyniec Biał., Pogorzelece & & & 75 & & & 78 \\
\hline 4 & Przerwanki, Zawady & 79 & 1 & & 81 & 1 & \\
\hline 5 & Borki, Sarnianka & 72 & 7 & & 74 & 6 & \\
\hline 6 & Nowe Ramuki, Przykop & 77 & 3 & & 77 & 3 & \\
\hline 8 & Miedzygórze, Wodospad & 67 & 9 & & 67 & 10 & \\
\hline 10 & Wisła, Malinka & & & 71 & & & 72 \\
\hline 11 & Istebna, Bukowiec 149h & 77 & 2 & & 76 & 4 & \\
\hline 12 & Istebna, Zapowiedz 115f & 74 & 4 & & 74 & 7 & \\
\hline 13 & Rycerka, Zwardon & 72 & 6 & & 75 & 5 & \\
\hline 16 & Orawa Stancowa & 72 & 8 & & 72 & 8 & \\
\hline 20 & Blizyn, Swinia Gora & 73 & 5 & & 79 & 2 & \\
\hline 21 & Kartuzy, Kosowo & 66 & 10 & & 68 & 9 & \\
\hline & Westerhof Abt. 40 & & & 71 & & & 72 \\
\hline & Westerhof Abt. 48 & & & 68 & & & 71 \\
\hline & Westerhof Abt. 49 & & & 72 & & & 73 \\
\hline & Westerhof Abt. 50 & & & 72 & & & 71 \\
\hline & IUFRO-Mittel & 72,9 & & & 74,4 & & \\
\hline & Versuchsflächen-Mittel & 71,7 & & & 72,6 & & \\
\hline
\end{tabular}

Eb. = Einzelbaumnachkommenschaften 


\section{Anhang 2.16}

Tukey-Gruppen $(\alpha=0,05)$ für die Wachstumsmerkmale Höhe $[\mathrm{m}]$ und BHD [cm] auf der Versuchsfläche Seesen / Niedersachsen (23-j.)

\begin{tabular}{|c|c|c|c|c|c|c|c|c|c|c|c|c|}
\hline \multirow{3}{*}{$\begin{array}{l}\text { Nr. * } \\
109\end{array}$} & \multirow{3}{*}{$\begin{array}{c}\begin{array}{c}\text { IUFRO- } \\
\text { Nr. }\end{array} \\
10^{* *}\end{array}$} & \multirow{2}{*}{ Prüfglied } & \multicolumn{4}{|c|}{ Höhe } & \multicolumn{6}{|c|}{ BHD } \\
\hline & & & {$[\mathrm{m}]$} & & $\Gamma-G$ & & {$[\mathrm{~cm}]$} & & & & & \\
\hline & & Wisła, 10-55 & 9,7 & A & B & $\mathrm{C}$ & 14,8 & A & & & & \\
\hline 186 & & Westerhof Abt. 40, 40-61 & 9,8 & A & B & $\mathrm{C}$ & 14,6 & A & B & & & \\
\hline 125 & & Westerhof Abt. 50, 50-25 & 9,6 & A & B & $\mathrm{C}$ & 14,5 & A & B & $\mathrm{C}$ & & \\
\hline 147 & & Westerhof Abt. 40, 40-22 & 10,7 & A & B & $\mathrm{C}$ & 14,4 & A & B & $\mathrm{C}$ & & \\
\hline 170 & & Westerhof Abt. 40, 40-45 & 11,0 & A & & & 14,4 & A & B & $\mathrm{C}$ & $\mathrm{D}$ & \\
\hline 127 & & Westerhof Abt. 50, 50-27 & 10,2 & A & B & $\mathrm{C}$ & 14,3 & A & B & $\mathrm{C}$ & $\mathrm{D}$ & \\
\hline 129 & & Westerhof Abt. 50, 50-29 & 10,1 & A & B & $\mathrm{C}$ & 14,3 & A & B & $\mathrm{C}$ & $\mathrm{D}$ & \\
\hline 153 & & Westerhof Abt. 40, 40-28 & 9,9 & A & B & $\mathrm{C}$ & 14,3 & A & B & $\mathrm{C}$ & $\mathrm{D}$ & \\
\hline 185 & & Westerhof Abt. 40, 40-60 & 10,1 & A & B & $\mathrm{C}$ & 14,3 & A & B & $\mathrm{C}$ & $\mathrm{D}$ & \\
\hline 191 & & Westerhof Abt. 48, 48-22 & 9,3 & A & B & $\mathrm{C}$ & 14,3 & A & B & $\mathrm{C}$ & $\mathrm{D}$ & \\
\hline 104 & $10^{* *}$ & Wisła, 10-12 & 10,3 & A & B & $\mathrm{C}$ & 14,2 & A & B & $\mathrm{C}$ & $\mathrm{D}$ & \\
\hline 122 & & Westerhof Abt. 50, 50-22 & 9,6 & A & B & $\mathrm{C}$ & 14,2 & A & B & $\mathrm{C}$ & $\mathrm{D}$ & $\mathrm{E}$ \\
\hline 146 & & Westerhof Abt. 40, 40-21 & 10,5 & A & B & $\mathrm{C}$ & 14,2 & A & B & $\mathrm{C}$ & $\mathrm{D}$ & $\mathrm{E}$ \\
\hline 158 & & Westerhof Abt. 40, 40-33 & 10,7 & A & B & $\mathrm{C}$ & 14,2 & A & B & $\mathrm{C}$ & $\mathrm{D}$ & $\mathrm{E}$ \\
\hline 160 & & Westerhof Abt. 40, 40-35 & 10,0 & A & B & $\mathrm{C}$ & 14,2 & A & B & $\mathrm{C}$ & $\mathrm{D}$ & $\mathrm{E}$ \\
\hline 102 & $10^{* *}$ & Wisła, 10-4 & 10,4 & A & B & $\mathrm{C}$ & 14,1 & A & B & $\mathrm{C}$ & $\mathrm{D}$ & $\mathrm{E}$ \\
\hline 108 & $10^{* *}$ & Wisła, 10-50 & 10,6 & A & B & $\mathrm{C}$ & 14,1 & A & B & $\mathrm{C}$ & $\mathrm{D}$ & $\mathrm{E}$ \\
\hline 128 & & Westerhof Abt. 50, 50-28 & 9,9 & A & B & $\mathrm{C}$ & 14,1 & A & B & $\mathrm{C}$ & $\mathrm{D}$ & $\mathrm{E}$ \\
\hline 143 & & Westerhof Abt. 49, 49-28 & 10,0 & A & B & $\mathrm{C}$ & 14,0 & A & B & $\mathrm{C}$ & $\mathrm{D}$ & $\mathrm{E}$ \\
\hline 167 & & Westerhof Abt. 40, 40-42 & 10,2 & A & B & $\mathrm{C}$ & 14,0 & A & B & $\mathrm{C}$ & $\mathrm{D}$ & $\mathrm{E}$ \\
\hline 177 & & Westerhof Abt. 40, 40-52 & 10,4 & A & B & $\mathrm{C}$ & 14,0 & A & B & $\mathrm{C}$ & $\mathrm{D}$ & $\mathrm{E}$ \\
\hline 180 & & Westerhof Abt. 40, 40-55 & 9,5 & A & B & $\mathrm{C}$ & 14,0 & A & B & $\mathrm{C}$ & $\mathrm{D}$ & $\mathrm{E}$ \\
\hline 189 & & Westerhof Abt. 40, 40-64 & 10,2 & A & B & $\mathrm{C}$ & 14,0 & A & B & $\mathrm{C}$ & $\mathrm{D}$ & $\mathrm{E}$ \\
\hline 134 & & Westerhof Abt. 50, 50-34 & 10,5 & A & B & $\mathrm{C}$ & 13,9 & A & B & $\mathrm{C}$ & $\mathrm{D}$ & $\mathrm{E}$ \\
\hline 163 & & Westerhof Abt. 40, 40-38 & 10,5 & A & B & $\mathrm{C}$ & 13,9 & A & B & $\mathrm{C}$ & $\mathrm{D}$ & $\mathrm{E}$ \\
\hline 172 & & Westerhof Abt. 40, 40-47 & 10,0 & A & B & $\mathrm{C}$ & 13,9 & A & B & $\mathrm{C}$ & $\mathrm{D}$ & $\mathrm{E}$ \\
\hline 176 & & Westerhof Abt. 40, 40-51 & 10,5 & A & B & $\mathrm{C}$ & 13,9 & A & B & $\mathrm{C}$ & $\mathrm{D}$ & $\mathrm{E}$ \\
\hline 107 & $10^{* *}$ & Wisła, 10-33 & 10,6 & A & B & $\mathrm{C}$ & 13,8 & A & B & $\mathrm{C}$ & $\mathrm{D}$ & $\mathrm{E}$ \\
\hline 133 & & Westerhof Abt. 50, 50-33 & 10,2 & A & B & $\mathrm{C}$ & 13,8 & A & B & $\mathrm{C}$ & $\mathrm{D}$ & $\mathrm{E}$ \\
\hline 140 & & Westerhof Abt. 49, 49-25 & 10,2 & A & B & $\mathrm{C}$ & 13,8 & A & B & $\mathrm{C}$ & $\mathrm{D}$ & $\mathrm{E}$ \\
\hline 179 & & Westerhof Abt. 40, 40-54 & 10,7 & A & B & $\mathrm{C}$ & 13,8 & A & B & $\mathrm{C}$ & $\mathrm{D}$ & $\mathrm{E}$ \\
\hline 188 & & Westerhof Abt. 40, 40-63 & 9,6 & A & B & $\mathrm{C}$ & 13,8 & A & B & $\mathrm{C}$ & $\mathrm{D}$ & $\mathrm{E}$ \\
\hline 157 & & Westerhof Abt. 40, 40-32 & 9,9 & A & B & $\mathrm{C}$ & 13,7 & A & B & $\mathrm{C}$ & $\mathrm{D}$ & $\mathrm{E}$ \\
\hline 161 & & Westerhof Abt. 40, 40-36 & 10,3 & A & B & $\mathrm{C}$ & 13,7 & A & B & $\mathrm{C}$ & $\mathrm{D}$ & $\mathrm{E}$ \\
\hline 165 & & Westerhof Abt. 40, 40-40 & 10,2 & A & B & $\mathrm{C}$ & 13,7 & A & B & $\mathrm{C}$ & $\mathrm{D}$ & $\mathrm{E}$ \\
\hline 171 & & Westerhof Abt. 40, 40-46 & 10,6 & A & B & $\mathrm{C}$ & 13,7 & A & B & $\mathrm{C}$ & $\mathrm{D}$ & $\mathrm{E}$ \\
\hline 175 & & Westerhof Abt. 40, 40-50 & 10,0 & A & B & $\mathrm{C}$ & 13,7 & A & B & $\mathrm{C}$ & $\mathrm{D}$ & $\mathrm{E}$ \\
\hline 178 & & Westerhof Abt. 40, 40-53 & 10,7 & A & B & $\mathrm{C}$ & 13,7 & A & B & $\mathrm{C}$ & $\mathrm{D}$ & $\mathrm{E}$ \\
\hline 183 & & Westerhof Abt. 40, 40-58 & 9,7 & A & B & $\mathrm{C}$ & 13,7 & A & B & $\mathrm{C}$ & $\mathrm{D}$ & $\mathrm{E}$ \\
\hline 187 & & Westerhof Abt. 40, 40-62 & 9,6 & A & B & $\mathrm{C}$ & 13,7 & A & B & $\mathrm{C}$ & $\mathrm{D}$ & $\mathrm{E}$ \\
\hline 121 & & Westerhof Abt. 50, 50-21 & 10,4 & A & B & $\mathrm{C}$ & 13,6 & A & B & $\mathrm{C}$ & $\mathrm{D}$ & $\mathrm{E}$ \\
\hline 136 & & Westerhof Abt. 49, 49-21 & 10,1 & A & B & $\mathrm{C}$ & 13,6 & A & B & $\mathrm{C}$ & $\mathrm{D}$ & $\mathrm{E}$ \\
\hline 148 & & Westerhof Abt. 40, 40-23 & 9,5 & A & B & $\mathrm{C}$ & 13,6 & A & B & $\mathrm{C}$ & $\mathrm{D}$ & $\mathrm{E}$ \\
\hline 156 & & Westerhof Abt. 40, 40-31 & 10,0 & A & B & $\mathrm{C}$ & 13,6 & A & B & $\mathrm{C}$ & $\mathrm{D}$ & $\mathrm{E}$ \\
\hline 166 & & Westerhof Abt. 40, 40-41 & 10,8 & A & B & & 13,6 & A & B & $\mathrm{C}$ & $\mathrm{D}$ & $\mathrm{E}$ \\
\hline 181 & & Westerhof Abt. 40, 40-56 & 10,0 & A & B & $\mathrm{C}$ & 13,6 & A & B & $\mathrm{C}$ & $\mathrm{D}$ & $\mathrm{E}$ \\
\hline 182 & & Westerhof Abt. 40, 40-57 & 10,1 & A & B & $\mathrm{C}$ & 13,6 & A & B & $\mathrm{C}$ & $\mathrm{D}$ & $\mathrm{E}$ \\
\hline 5 & 21 & Kartuzy, Kosowo & 9,9 & A & B & $\mathrm{C}$ & 13,5 & A & B & $\mathrm{C}$ & $\mathrm{D}$ & $\mathrm{E}$ \\
\hline 126 & & Westerhof Abt. 50, 50-26 & 10,3 & A & B & $\mathrm{C}$ & 13,5 & A & B & $\mathrm{C}$ & $\mathrm{D}$ & $\mathrm{E}$ \\
\hline
\end{tabular}




\begin{tabular}{|c|c|c|c|c|c|c|c|c|c|c|c|c|}
\hline \multirow{3}{*}{$\frac{\text { Nr. * }}{130}$} & \multirow{3}{*}{$\begin{array}{c}\text { IUFRO- } \\
\text { Nr. }\end{array}$} & \multirow{2}{*}{ Prüfglied } & \multicolumn{4}{|c|}{ Höhe } & \multicolumn{6}{|c|}{ BHD } \\
\hline & & & {$[\mathrm{m}]$} & & $-G$ & & {$[\mathrm{~cm}]$} & & & T-G & & \\
\hline & & Westerhof Abt. 50, 50-30 & 10,0 & A & B & $\mathrm{C}$ & 13,5 & A & B & $\mathrm{C}$ & $\mathrm{D}$ & E \\
\hline 154 & & Westerhof Abt. 40, 40-29 & 10,0 & A & B & $\mathrm{C}$ & 13,5 & A & B & $\mathrm{C}$ & $\mathrm{D}$ & $\mathrm{E}$ \\
\hline 173 & & Westerhof Abt. 40, 40-48 & 10,0 & A & B & $\mathrm{C}$ & 13,5 & A & B & C & $\mathrm{D}$ & $\mathrm{E}$ \\
\hline 174 & & Westerhof Abt. 40, 40-49 & 9,4 & A & B & $\mathrm{C}$ & 13,5 & A & B & $\mathrm{C}$ & $\mathrm{D}$ & $\mathrm{E}$ \\
\hline 135 & & Westerhof Abt. 50, 50-35 & 9,8 & A & B & $\mathrm{C}$ & 13,4 & A & B & $\mathrm{C}$ & $\mathrm{D}$ & $\mathrm{E}$ \\
\hline 149 & & Westerhof Abt. 40, 40-24 & 9,9 & A & B & $\mathrm{C}$ & 13,4 & A & B & $\mathrm{C}$ & $\mathrm{D}$ & $\mathrm{E}$ \\
\hline 155 & & Westerhof Abt. 40, 40-30 & 9,8 & A & B & $\mathrm{C}$ & 13,4 & A & B & $\mathrm{C}$ & $\mathrm{D}$ & $\mathrm{E}$ \\
\hline 168 & & Westerhof Abt. 40, 40-43 & 10,2 & A & B & $\mathrm{C}$ & 13,4 & A & B & $\mathrm{C}$ & $\mathrm{D}$ & $\mathrm{E}$ \\
\hline 106 & $10^{* *}$ & Wisła, 10-17 & 9,6 & A & B & $\mathrm{C}$ & 13,3 & A & B & $\mathrm{C}$ & $\mathrm{D}$ & $\mathrm{E}$ \\
\hline 124 & & Westerhof Abt. 50, 50-24 & 9,9 & A & B & $\mathrm{C}$ & 13,3 & A & B & C & $\mathrm{D}$ & $\mathrm{E}$ \\
\hline 131 & & Westerhof Abt. 50, 50-31 & 10,0 & A & B & $\mathrm{C}$ & 13,3 & A & B & $\mathrm{C}$ & $\mathrm{D}$ & $\mathrm{E}$ \\
\hline 142 & & Westerhof Abt. 49, 49-27 & 9,7 & A & B & $\mathrm{C}$ & 13,3 & A & B & $\mathrm{C}$ & $\mathrm{D}$ & $\mathrm{E}$ \\
\hline 150 & & Westerhof Abt. 40, 40-25 & 9,7 & A & B & $\mathrm{C}$ & 13,3 & A & B & $\mathrm{C}$ & $\mathrm{D}$ & $\mathrm{E}$ \\
\hline 151 & & Westerhof Abt. 40, 40-26 & 10,0 & A & B & $\mathrm{C}$ & 13,3 & A & B & $\mathrm{C}$ & $\mathrm{D}$ & $\mathrm{E}$ \\
\hline 169 & & Westerhof Abt. 40, 40-44 & 10,1 & A & B & $\mathrm{C}$ & 13,3 & A & B & $\mathrm{C}$ & $\mathrm{D}$ & $\mathrm{E}$ \\
\hline 184 & & Westerhof Abt. 40, 40-59 & 9,2 & A & B & $\mathrm{C}$ & 13,3 & A & B & $\mathrm{C}$ & $\mathrm{D}$ & $\mathrm{E}$ \\
\hline 4 & 12 & Istebna, Zapowiedz $115 f$ & 10,4 & A & B & $\mathrm{C}$ & 13,2 & A & B & C & $\mathrm{D}$ & $\mathrm{E}$ \\
\hline 105 & $10^{* *}$ & Wisła, 10-15 & 10,6 & A & B & $\mathrm{C}$ & 13,2 & A & B & $\mathrm{C}$ & $\mathrm{D}$ & $\mathrm{E}$ \\
\hline 110 & $10^{* *}$ & Wisła, 10-56 & 10,3 & A & B & $\mathrm{C}$ & 13,2 & A & B & $\mathrm{C}$ & $\mathrm{D}$ & $\mathrm{E}$ \\
\hline 123 & & Westerhof Abt. 50, 50-23 & 10,4 & A & B & $\mathrm{C}$ & 13,2 & A & B & $\mathrm{C}$ & $\mathrm{D}$ & $\mathrm{E}$ \\
\hline 141 & & Westerhof Abt. 49, 49-26 & 10,3 & A & B & $\mathrm{C}$ & 13,2 & A & B & $\mathrm{C}$ & $\mathrm{D}$ & E \\
\hline 144 & & Westerhof Abt. 49, 49-29 & 9,7 & A & B & $\mathrm{C}$ & 13,2 & A & B & $\mathrm{C}$ & $\mathrm{D}$ & $\mathrm{E}$ \\
\hline 145 & & Westerhof Abt. 49, 49-31 & 9,7 & A & B & $\mathrm{C}$ & 13,2 & A & B & $\mathrm{C}$ & $\mathrm{D}$ & $\mathrm{E}$ \\
\hline 132 & & Westerhof Abt. 50, 50-32 & 10,5 & A & B & $\mathrm{C}$ & 13,1 & A & B & $\mathrm{C}$ & $\mathrm{D}$ & $\mathrm{E}$ \\
\hline 138 & & Westerhof Abt. 49, 49-23 & 9,9 & A & B & $\mathrm{C}$ & 13,1 & A & B & $\mathrm{C}$ & $\mathrm{D}$ & $\mathrm{E}$ \\
\hline 190 & & Westerhof Abt. 48, 48-21 & 9,4 & A & B & $\mathrm{C}$ & 13,1 & A & B & $\mathrm{C}$ & $\mathrm{D}$ & $\mathrm{E}$ \\
\hline 139 & & Westerhof Abt. 49, 49-24 & 10,4 & A & B & $\mathrm{C}$ & 13,0 & A & B & $\mathrm{C}$ & $\mathrm{D}$ & $\mathrm{E}$ \\
\hline 152 & & Westerhof Abt. 40, 40-27 & 9,5 & A & B & $\mathrm{C}$ & 13,0 & A & B & $\mathrm{C}$ & $\mathrm{D}$ & $\mathrm{E}$ \\
\hline 164 & & Westerhof Abt. 40, 40-39 & 10,0 & A & B & $\mathrm{C}$ & 13,0 & A & B & $\mathrm{C}$ & $\mathrm{D}$ & $\mathrm{E}$ \\
\hline 159 & & Westerhof Abt. 40, 40-34 & 9,9 & A & B & $\mathrm{C}$ & 12,9 & A & B & $\mathrm{C}$ & $\mathrm{D}$ & $\mathrm{E}$ \\
\hline 2 & 5 & Borki, Sarnianka & 9,7 & A & B & $\mathrm{C}$ & 12,8 & A & B & $\mathrm{C}$ & $\mathrm{D}$ & $\mathrm{E}$ \\
\hline 8 & 16 & Orawa Stancowa & 9,6 & A & B & $\mathrm{C}$ & 12,8 & A & B & $\mathrm{C}$ & $\mathrm{D}$ & $\mathrm{E}$ \\
\hline 137 & & Westerhof Abt. 49, 49-22 & 10,8 & A & B & $\mathrm{C}$ & 12,8 & A & B & $\mathrm{C}$ & $\mathrm{D}$ & $\mathrm{E}$ \\
\hline 3 & 11 & Istebna, Bukowiec 149h & 9,8 & A & B & $\mathrm{C}$ & 12,7 & A & B & $\mathrm{C}$ & $\mathrm{D}$ & $\mathrm{E}$ \\
\hline 6 & 8 & Miedzygórze, Wodospad & 9,4 & A & B & $\mathrm{C}$ & 12,7 & A & B & C & $\mathrm{D}$ & $\mathrm{E}$ \\
\hline 10 & 13 & Rycerka, Zwardon & 9,9 & A & B & $\mathrm{C}$ & 12,7 & A & B & $\mathrm{C}$ & $\mathrm{D}$ & $\mathrm{E}$ \\
\hline 118 & $1 * *$ & Pogorzelece, 1-66 & 10,4 & A & B & $\mathrm{C}$ & 12,6 & A & B & $\mathrm{C}$ & $\mathrm{D}$ & $\mathrm{E}$ \\
\hline 162 & & Westerhof Abt. 40, 40-37 & 10,0 & A & B & $\mathrm{C}$ & 12,5 & A & B & $\mathrm{C}$ & $\mathrm{D}$ & E \\
\hline 103 & $10^{* *}$ & Wisła, 10-11 & 9,7 & A & B & $\mathrm{C}$ & 12,3 & A & B & $\mathrm{C}$ & $\mathrm{D}$ & $\mathrm{E}$ \\
\hline 120 & $1^{* *}$ & Pogorzelece, 1-95 & 9,2 & A & B & $\mathrm{C}$ & 12,2 & A & B & $\mathrm{C}$ & $\mathrm{D}$ & $\mathrm{E}$ \\
\hline 112 & $1 * *$ & Pogorzelece, 1-27 & 9,4 & A & B & $\mathrm{C}$ & 12,1 & A & B & $\mathrm{C}$ & $\mathrm{D}$ & $\mathrm{E}$ \\
\hline 114 & $1 * *$ & Pogorzelece, 1-30 & 9,8 & A & B & $\mathrm{C}$ & 12,1 & A & B & C & $\mathrm{D}$ & $\mathrm{E}$ \\
\hline 115 & $1 * *$ & Pogorzelece, 1-50 & 9,6 & A & B & $\mathrm{C}$ & 12,1 & A & B & $\mathrm{C}$ & $\mathrm{D}$ & $\mathrm{E}$ \\
\hline 7 & 6 & Nowe Ramuki, Przykop & 9,6 & A & B & $\mathrm{C}$ & 11,8 & A & B & $\mathrm{C}$ & $\mathrm{D}$ & $\mathrm{E}$ \\
\hline 9 & 4 & Przerwanki, Zawady & 9,3 & A & B & $\mathrm{C}$ & 11,6 & A & B & $\mathrm{C}$ & $\mathrm{D}$ & $\mathrm{E}$ \\
\hline 117 & $1 * *$ & Pogorzelece, 1-65 & 9,5 & A & B & $\mathrm{C}$ & 11,5 & A & B & $\mathrm{C}$ & $\mathrm{D}$ & $\mathrm{E}$ \\
\hline 111 & $1 * *$ & Pogorzelece, 1-11 & 9,5 & A & B & $\mathrm{C}$ & 11,3 & & B & $\mathrm{C}$ & $\mathrm{D}$ & $\mathrm{E}$ \\
\hline 1 & 20 & Blizyn, Swinia Gora & 8,4 & & & $\mathrm{C}$ & 11,2 & & & $\mathrm{C}$ & $\mathrm{D}$ & $\mathrm{E}$ \\
\hline 116 & $1 * *$ & Pogorzelece, 1-52 & 9,4 & A & B & $\mathrm{C}$ & 11,2 & & & $\mathrm{C}$ & $\mathrm{D}$ & $\mathrm{E}$ \\
\hline 113 & $1 * *$ & Pogorzelece, 1-28 & 8,7 & & B & $\mathrm{C}$ & 11,0 & & & & $\mathrm{D}$ & $\mathrm{E}$ \\
\hline 119 & $1 * *$ & Pogorzelece, 1-75 & 9,3 & A & B & $\mathrm{C}$ & 10,9 & & & & & $\mathrm{E}$ \\
\hline
\end{tabular}

* Prüfglied-Nr. auf der Versuchsfläche Seesen / NI ** Einzelbaumnachkommenschaft T-G = Tukey-Gruppe 
Anhang 2.17

Tukey-Gruppen $(\alpha=0,05)$ für den Bestandesvorrat $\left[\mathrm{m}^{3} / \mathrm{ha}\right]$ auf der Versuchsfläche Seesen / Niedersachsen (23-j. und 32-j.)

\begin{tabular}{|c|c|c|c|c|c|c|c|c|c|}
\hline & IUFRO- & Prüfglied & & 23 & & & & & \\
\hline & & & {$\left[\mathrm{m}^{3}\right]$} & & $\mathrm{T}-\mathrm{C}$ & & {$\left[\mathrm{m}^{3}\right]$} & & \\
\hline 147 & & Westerhof Abt. 40, 40-22 & 121 & A & $\mathrm{B}$ & $\mathrm{C}$ & 414 & A & \\
\hline 177 & & Westerhof Abt. 40, 40-52 & 112 & $\mathrm{~A}$ & $\mathrm{~B}$ & $\mathrm{C}$ & 399 & A & B \\
\hline 185 & & Westerh of Abt. 40, 40-60 & 123 & A & $\mathrm{B}$ & $\mathrm{C}$ & 385 & A & $\mathrm{B}$ \\
\hline 186 & & Westerhof Abt. 40, 40-61 & 110 & A & B & $\mathrm{C}$ & 383 & A & B \\
\hline 102 & $10 * *$ & Wisła, $10-4$ & 113 & A & $\mathrm{B}$ & $\mathrm{C}$ & 381 & A & B \\
\hline 148 & & Westerhof Abt. 40, 40-23 & 122 & A & B & $\mathrm{C}$ & 376 & A & $\mathrm{B}$ \\
\hline 178 & & Westerhof Abt. 40, 40-53 & 111 & A & B & $\mathrm{C}$ & 372 & A & $\mathrm{B}$ \\
\hline 141 & & Westerhof Abt. 49, 49-26 & 116 & A & $\mathrm{B}$ & $\mathrm{C}$ & 366 & A & $\mathrm{B}$ \\
\hline 170 & & Westerhof Abt. 40, 40-45 & 134 & A & & & 366 & A & B \\
\hline 109 & $10 * *$ & Wisła, $10-55$ & 130 & A & & & 363 & A & $\mathrm{B}$ \\
\hline 125 & & Westerhof Abt. 50, 50-25 & 130 & A & & & 353 & A & B \\
\hline 181 & & Westerh of Abt. 40, 40-56 & 101 & A & B & $\mathrm{C}$ & 348 & A & B \\
\hline 163 & & Westerhof Abt. 40, 40-38 & 116 & A & $\mathrm{B}$ & $\mathrm{C}$ & 346 & A & B \\
\hline 121 & & Westerhof Abt. 50, 50-21 & 112 & A & $\mathrm{B}$ & $\mathrm{C}$ & 345 & A & B \\
\hline 146 & & Westerhof Abt. 40, 40-21 & 117 & A & $\mathrm{B}$ & $\mathrm{C}$ & 341 & A & $\mathrm{B}$ \\
\hline 152 & & Westerhof Abt. 40, 40-27 & 103 & A & $\mathrm{B}$ & $\mathrm{C}$ & 341 & A & $\mathrm{B}$ \\
\hline 165 & & Westerh of Abt. 40, 40-40 & 111 & A & B & $\mathrm{C}$ & 341 & A & $\mathrm{B}$ \\
\hline 129 & & Westerhof Abt. 50, 50-29 & 117 & A & B & $\mathrm{C}$ & 336 & A & B \\
\hline 140 & & Westerhof Abt. 49, 49-25 & 117 & A & $\mathrm{B}$ & $\mathrm{C}$ & 335 & A & $\mathrm{B}$ \\
\hline 189 & & Westerhof Abt. 40, 40-64 & 104 & A & $\mathrm{B}$ & $\mathrm{C}$ & 332 & A & B \\
\hline 108 & $10 * *$ & Wisła, 10-50 & 119 & A & B & $\mathrm{C}$ & 328 & A & B \\
\hline 131 & & Westerhof Abt. 50, 50-31 & 114 & A & $\mathrm{B}$ & $\mathrm{C}$ & 324 & A & $\mathrm{B}$ \\
\hline 155 & & Westerhof Abt. 40, 40-30 & 103 & A & B & $\mathrm{C}$ & 320 & A & B \\
\hline 171 & & Westerhof Abt. 40, 40-46 & 110 & A & B & $\mathrm{C}$ & 319 & A & B \\
\hline 180 & & Westerhof Abt. 40, 40-55 & 102 & A & B & $\mathrm{C}$ & 318 & A & B \\
\hline 167 & & Westerh of Abt. 40, 40-42 & 125 & A & B & & 315 & A & $\mathrm{B}$ \\
\hline 160 & & Westerhof Abt. 40, 40-35 & 114 & A & $\mathrm{B}$ & $\mathrm{C}$ & 313 & A & B \\
\hline 187 & & Westerh of Abt. 40, 40-62 & 113 & A & $\mathrm{B}$ & $\mathrm{C}$ & 312 & A & $\mathrm{B}$ \\
\hline 130 & & Westerhof Abt. 50, 50-30 & 92 & A & $\mathrm{B}$ & $\mathrm{C}$ & 311 & A & B \\
\hline 150 & & Westerhof Abt. 40, 40-25 & 104 & A & B & $\mathrm{C}$ & 311 & A & B \\
\hline 188 & & Westerhof Abt. 40, 40-63 & 115 & A & $\mathrm{B}$ & $\mathrm{C}$ & 311 & A & $\mathrm{B}$ \\
\hline 137 & & Westerhof Abt. 49, 49-22 & 97 & A & B & $\mathrm{C}$ & 309 & A & B \\
\hline 143 & & Westerhof Abt. 49, 49-28 & 104 & A & $\mathrm{B}$ & $\mathrm{C}$ & 309 & A & $\mathrm{B}$ \\
\hline 174 & & Westerhof Abt. 40, 40-49 & 102 & A & B & $\mathrm{C}$ & 309 & A & B \\
\hline 133 & & Westerhof Abt. 50, 50-33 & 105 & A & B & $\mathrm{C}$ & 307 & A & B \\
\hline 166 & & Westerhof Abt. 40, 40-41 & 110 & A & B & $\mathrm{C}$ & 305 & A & B \\
\hline 168 & & Westerhof Abt. 40, 40-43 & 122 & A & B & $\mathrm{C}$ & 304 & A & B \\
\hline 179 & & Westerhof Abt. 40, 40-54 & 106 & A & $\mathrm{B}$ & $\mathrm{C}$ & 303 & A & $\mathrm{B}$ \\
\hline 173 & & Westerhof Abt. 40, 40-48 & 120 & A & B & $\mathrm{C}$ & 302 & A & B \\
\hline 134 & & Westerh of Abt. 50, 50-34 & 105 & A & $\mathrm{B}$ & $\mathrm{C}$ & 301 & A & $\mathrm{B}$ \\
\hline 159 & & Westerhof Abt. 40, 40-34 & 99 & A & B & $\mathrm{C}$ & 301 & A & B \\
\hline 144 & & Westerh of Abt. 49, 49-29 & 90 & A & $\mathrm{B}$ & $\mathrm{C}$ & 300 & A & $\mathrm{B}$ \\
\hline 136 & & Westerhof Abt. 49, 49-21 & 101 & A & B & $\mathrm{C}$ & 299 & A & B \\
\hline 138 & & Westerhof Abt. 49, 49-23 & 104 & A & B & $\mathrm{C}$ & 298 & A & B \\
\hline 122 & & Westerhof Abt. 50, 50-22 & 105 & A & B & $\mathrm{C}$ & 297 & A & B \\
\hline 128 & & Westerhof Abt. 50, 50-28 & 100 & A & B & $\mathrm{C}$ & 297 & A & B \\
\hline 3 & 11 & Istebna, Bukowiec 149h & 95 & A & B & $\mathrm{C}$ & 297 & A & $\mathrm{B}$ \\
\hline 153 & & Westerhof Abt. 40, 40-28 & 102 & A & B & $\mathrm{C}$ & 296 & A & B \\
\hline 149 & & Westerh of Abt. 40, 40-24 & 105 & A & $\mathrm{B}$ & $\mathrm{C}$ & 294 & A & $\mathrm{B}$ \\
\hline 123 & & Westerhof Abt. 50, 50-23 & 87 & A & $\mathrm{B}$ & $\mathrm{C}$ & 293 & A & B \\
\hline
\end{tabular}




\begin{tabular}{|c|c|c|c|c|c|c|c|c|c|}
\hline $\mathrm{Nr} *$ & IUFRO- & & & $23-$ & & & & & \\
\hline Nr. ${ }^{\star}$ & $\mathrm{Nr}$. & Prutglied & {$\left[\mathrm{m}^{3}\right]$} & & $\mathrm{T}-\mathrm{G}$ & & {$\left[\mathrm{m}^{3}\right]$} & & \\
\hline 106 & $10^{* *}$ & Wisła, 10-17 & 94 & A & B & $\mathrm{C}$ & 292 & A & $\mathrm{B}$ \\
\hline 184 & & Westerhof Abt. 40, 40-59 & 89 & A & B & $\mathrm{C}$ & 292 & A & B \\
\hline 158 & & Westerhof Abt. 40, 40-33 & 102 & A & B & $\mathrm{C}$ & 291 & A & B \\
\hline 169 & & Westerhof Abt. 40, 40-44 & 93 & A & B & $\mathrm{C}$ & 288 & A & B \\
\hline 105 & $10 * *$ & Wisła, 10-15 & 93 & A & B & $\mathrm{C}$ & 287 & A & $\mathrm{B}$ \\
\hline 104 & $10 * *$ & Wisła, 10-12 & 114 & A & B & $\mathrm{C}$ & 286 & A & B \\
\hline 142 & & Westerhof Abt. 49, 49-27 & 92 & A & B & C & 283 & A & B \\
\hline 156 & & Westerh of Abt. 40, 40-31 & 87 & A & B & $\mathrm{C}$ & 282 & A & B \\
\hline 4 & 12 & Istebna, Zapowiedz $115 f$ & 103 & A & B & $\mathrm{C}$ & 282 & A & B \\
\hline 124 & & Westerhof Abt. 50, 50-24 & 107 & A & B & $\mathrm{C}$ & 281 & A & B \\
\hline 151 & & Westerhof Abt. 40, 40-26 & 103 & A & B & $\mathrm{C}$ & 281 & A & B \\
\hline 107 & $10^{* *}$ & Wisła, 10-33 & 106 & A & B & $\mathrm{C}$ & 280 & A & B \\
\hline 183 & & Westerhof Abt. 40, 40-58 & 110 & A & B & $\mathrm{C}$ & 280 & A & B \\
\hline 8 & 16 & Orawa Stancowa & 94 & A & B & $\mathrm{C}$ & 280 & A & B \\
\hline 182 & & Westerhof Abt. 40, 40-57 & 100 & A & B & $\mathrm{C}$ & 278 & A & B \\
\hline 176 & & Westerhof Abt. 40, 40-51 & 110 & A & B & $\mathrm{C}$ & 277 & A & B \\
\hline 139 & & Westerhof Abt. 49, 49-24 & 110 & A & B & $\mathrm{C}$ & 276 & A & B \\
\hline 127 & & Westerhof Abt. 50, 50-27 & 124 & A & B & & 273 & A & B \\
\hline 5 & 21 & Kartuzy, Kosowo & 102 & A & B & $\mathrm{C}$ & 273 & A & B \\
\hline 6 & 8 & Miedzygórze, Wodospad & 93 & A & $\mathrm{B}$ & $\mathrm{C}$ & 273 & A & B \\
\hline 164 & & Westerh of Abt. 40, 40-39 & 79 & A & B & $\mathrm{C}$ & 272 & A & B \\
\hline 126 & & Westerh of Abt. 50, 50-26 & 107 & A & B & $\mathrm{C}$ & 271 & A & B \\
\hline 154 & & Westerhof Abt. 40, 40-29 & 99 & A & B & $\mathrm{C}$ & 271 & A & B \\
\hline 190 & & Westerhof Abt. 48, 48-21 & 89 & A & B & $\mathrm{C}$ & 266 & A & B \\
\hline 2 & 5 & Borki, Sarnianka & 97 & A & B & $\mathrm{C}$ & 266 & A & B \\
\hline 110 & $10^{* *}$ & Wisła, 10-56 & 93 & A & B & $\mathrm{C}$ & 264 & A & B \\
\hline 132 & & Westerhof Abt. 50, 50-32 & 93 & A & B & $\mathrm{C}$ & 261 & A & B \\
\hline 157 & & Westerhof Abt. 40, 40-32 & 87 & A & B & $\mathrm{C}$ & 258 & A & $\mathrm{B}$ \\
\hline 191 & & Westerhof Abt. 48, 48-22 & 88 & A & B & $\mathrm{C}$ & 253 & A & B \\
\hline 145 & & Westerhof Abt. 49, 49-31 & 96 & A & B & $\mathrm{C}$ & 252 & A & B \\
\hline 172 & & Westerh of Abt. 40, 40-47 & 98 & A & B & $\mathrm{C}$ & 249 & A & $\mathrm{B}$ \\
\hline 120 & $1 * *$ & Pogorzelece, 1-95 & 82 & A & B & $\mathrm{C}$ & 240 & A & B \\
\hline 161 & & Westerh of Abt. 40, 40-36 & 110 & A & B & $\mathrm{C}$ & 237 & A & B \\
\hline 162 & & Westerhof Abt. 40, 40-37 & 85 & A & B & $\mathrm{C}$ & 212 & A & B \\
\hline 10 & 13 & Rycerka, Zwardon & 79 & A & B & $\mathrm{C}$ & 209 & A & B \\
\hline 135 & & Westerhof Abt. 50, 50-35 & 88 & A & B & $\mathrm{C}$ & 204 & A & $\mathrm{B}$ \\
\hline 118 & $1 * *$ & Pogorzelece, 1-66 & 75 & A & B & $\mathrm{C}$ & 202 & A & $\mathrm{B}$ \\
\hline 114 & $1 * *$ & Pogorzelece, $1-30$ & 69 & A & B & $\mathrm{C}$ & 198 & A & B \\
\hline 9 & 4 & Przerwanki, Zawady & 62 & A & B & $\mathrm{C}$ & 196 & A & B \\
\hline 103 & $10^{* *}$ & Wisła, 10-11 & 78 & A & B & $\mathrm{C}$ & 188 & A & B \\
\hline 115 & $1 * *$ & Pogorzelece, 1-50 & 75 & A & B & $\mathrm{C}$ & 185 & A & B \\
\hline 112 & $1 * *$ & Pogorzelece, 1-27 & 73 & A & B & $\mathrm{C}$ & 183 & A & B \\
\hline 7 & 6 & Nowe Ramuki, Przykop & 64 & A & B & $\mathrm{C}$ & 183 & A & B \\
\hline 175 & & Westerhof Abt. 40, 40-50 & 93 & A & B & $\mathrm{C}$ & 179 & A & B \\
\hline 119 & $1 * *$ & Pogorzelece, $1-75$ & 54 & & B & $\mathrm{C}$ & 177 & A & B \\
\hline 117 & $1 * *$ & Pogorzelece, 1-65 & 63 & A & B & $\mathrm{C}$ & 171 & A & B \\
\hline 116 & $1 * *$ & Pogorzelece, 1-52 & 61 & A & B & $\mathrm{C}$ & 160 & A & B \\
\hline 111 & $1 * *$ & Pogorzelece, 1-11 & 63 & A & B & $\mathrm{C}$ & 154 & A & B \\
\hline 1 & 20 & Blizyn, Swinia Gora & 51 & & & $\mathrm{C}$ & 135 & & B \\
\hline 113 & $1 * *$ & Pogorzelece, 1-28 & 53 & & B & $\mathrm{C}$ & 130 & & $\mathrm{~B}$ \\
\hline
\end{tabular}

* Prüfglied-Nr. auf der Versuchsfläche Seesen / NI ** Einzelbaumnachkommenschaft T-G $=$ Tukey-Gruppe 


\section{Anhang 2.18}

Tukey-Gruppen $(\alpha=0,05)$ für die Merkmale Baumböhe $[m]$ und Einzelbaumvolumen [ $\left.\mathrm{m}^{3}\right]$ auf der Versuchsfläche Ochsenhausen A / Baden-Württemberg (22-j.)

\begin{tabular}{|c|c|c|c|c|c|c|c|}
\hline $\begin{array}{l}\text { IUFRO- } \\
\text { Nr. }\end{array}$ & Herkunft & $\begin{array}{l}\text { Höhe } \\
\text { [m] }\end{array}$ & \multicolumn{2}{|c|}{ T-G } & $\begin{array}{l}\text { Einzelbaum- } \\
\text { volumen }\left[\mathrm{m}^{3}\right]\end{array}$ & \multicolumn{2}{|c|}{ T-G } \\
\hline 19 & Zwierzyniec Lubelski, Obrocz & 9,93 & \multicolumn{2}{|l|}{ A } & 0,056716 & \multicolumn{2}{|l|}{ A } \\
\hline 18 & Tarnawa, Sokoliki & 9,82 & \multicolumn{2}{|l|}{ A } & 0,055040 & \multicolumn{2}{|l|}{ A } \\
\hline 12 & Istebna, Zapowiedz $115 \mathrm{f}$ & 9,69 & & B & 0,053979 & \multicolumn{2}{|l|}{ A } \\
\hline 16 & Orawa Stancowa & 9,69 & A & $\mathrm{B}$ & 0,053015 & \multicolumn{2}{|l|}{ A } \\
\hline \multirow[t]{2}{*}{1} & Zwierzyniec Bial., Pogorzelece & 9,53 & A & B & 0,050261 & A & B \\
\hline & Gessertshausen & 9,45 & A & B & 0,049451 & A & B \\
\hline 14 & Rycerka, Praszywka I & 9,40 & A & B & 0,047786 & A & B \\
\hline \multirow[t]{2}{*}{2} & Zwierzyniec Biał., Krzyze & 9,25 & A & B & 0,046407 & A & B \\
\hline & Krumbach & 9,21 & $\mathrm{~A}$ & B & 0,045232 & A & B \\
\hline 21 & Kartuzy, Kosowo & 9,10 & A & B & 0,043939 & A & B \\
\hline 5 & Borki, Sarnianka & 9,06 & A & B & 0,042843 & A & B \\
\hline 13 & Rycerka, Zwardon & 8,99 & A & B & 0,042249 & A & B \\
\hline 4 & Przerwanki, Zawady & 8,78 & A & B & 0,040502 & A & B \\
\hline 20 & Blizyn & 8,82 & A & B & 0,040349 & A & B \\
\hline 15 & Rycerka, Praszywka II & 8,85 & A & B & 0,040273 & A & B \\
\hline 3 & Wigry, Krzywe & 8,56 & A & B & 0,039050 & A & B \\
\hline 8 & Miedzygórze, Wodospad & 8,55 & A & B & 0,038680 & A & B \\
\hline 6 & Nowe Ramuki, Przykop & 8,31 & A & B & 0,035535 & A & B \\
\hline 9 & Stronie Slaskie, Kletno & 8,20 & A & B & 0,033242 & A & B \\
\hline 10 & Wisła, Malinka & 7,86 & A & B & 0,032757 & A & B \\
\hline 11 & Istebna, Bukowiec 149h & 7,93 & A & B & 0,031815 & A & B \\
\hline \multirow[t]{2}{*}{17} & Witów (Tatry), ur. Chotorz & 8,03 & A & B & 0,030163 & A & B \\
\hline & Scatlè & 6,96 & & $\mathrm{~B}$ & 0,020090 & & B \\
\hline
\end{tabular}

T-G = Tukey-Gruppe 


\section{Anhang 2.19}

Tukey-Gruppen $(\alpha=0,05)$ für die Merkmale Baumböhe $[m]$ und Einzelbaumvolumen $\left[\mathrm{m}^{3}\right]$ auf der Versuchsfläche Ochsenhausen B / Baden-Württemberg (21-j.)

\begin{tabular}{|c|c|c|c|c|c|c|c|}
\hline $\begin{array}{l}\text { IUFRO- } \\
\text { Nr. }\end{array}$ & Herkunft & $\begin{array}{l}\text { Höhe } \\
{[\mathrm{m}]}\end{array}$ & \multicolumn{2}{|c|}{ T-G } & $\begin{array}{l}\text { Einzelbaum- } \\
\text { volumen }\left[\mathrm{m}^{3}\right]\end{array}$ & \multicolumn{2}{|c|}{ T-G } \\
\hline 19 & Zwierzyniec Lubelski, Obrocz & 9,29 & A & & 0,046016 & A & \\
\hline 20 & Blizyn & 9,16 & A & B & 0,044202 & A & B \\
\hline 3 & Wigry, Krzywe & 9,05 & A & B & 0,043362 & A & B \\
\hline 6 & Nowe Ramuki, Przykop & 9,06 & A & B & 0,042354 & A & B \\
\hline 10 & Wisła, Malinka & 9,00 & A & B & 0,042189 & A & B \\
\hline 12 & Istebna, Zapowiedz $115 f$ & 8,92 & A & B & 0,041012 & A & B \\
\hline 21 & Kartuzy, Kosowo & 8,88 & A & B & 0,040920 & A & B \\
\hline 18 & Tarnawa, Sokoliki & 8,81 & A & B & 0,040312 & A & B \\
\hline \multirow[t]{2}{*}{4} & Przerwanki, Zawady & 8,77 & A & B & 0,040154 & A & B \\
\hline & Westerhof & 8,79 & A & B & 0,040115 & A & B \\
\hline 1 & Zwierzyniec Biał., Pogorzelece & 8,77 & A & B & 0,039835 & A & B \\
\hline \multirow[t]{2}{*}{2} & Zwierzyniec Biał., Krzyze & 8,81 & A & B & 0,039323 & A & B \\
\hline & Krumbach & 8,79 & A & B & 0,039077 & A & B \\
\hline 13 & Rycerka, Zwardon & 8,72 & A & B & 0,039036 & A & B \\
\hline 11 & Istebna, Bukowiec 149h & 8,73 & A & B & 0,038685 & A & B \\
\hline \multirow[t]{2}{*}{5} & Borki, Sarnianka & 8,69 & A & B & 0,037562 & A & B \\
\hline & Gessertshausen & 8,48 & A & B & 0,036124 & A & B \\
\hline 15 & Rycerka, Praszywka II & 8,44 & A & B & 0,035601 & A & B \\
\hline 16 & Orawa Stancowa & 8,20 & A & B & 0,031977 & A & B \\
\hline 14 & Rycerka, Praszywka I & 8,08 & A & B & 0,031934 & A & B \\
\hline 8 & Miedzygórze, Wodospad & 8,04 & A & B & 0,031754 & A & B \\
\hline 17 & Witów (Tatry), ur. Chotorz & 7,91 & A & B & 0,028501 & A & B \\
\hline 9 & Stronie Slaskie, Kletno & 7,54 & & $\mathrm{~B}$ & 0,025032 & & $\mathrm{~B}$ \\
\hline
\end{tabular}

$\mathrm{T}-\mathrm{G}=$ Tukey-Gruppe 


\section{Anhang 2.20}

Tukey-Gruppen $(\alpha=0,05)$ für die Merkmale BHD [cm] und Einzelbaumvolumen $\left[\mathrm{m}^{3}\right]$ auf der Versuchsfläche Sauerlach B / Bayern (25-j.)

\begin{tabular}{|c|c|c|c|c|c|c|c|c|c|c|}
\hline \multirow{2}{*}{$\begin{array}{c}\text { IUFRO- } \\
\text { Nr. } \\
11\end{array}$} & \multirow{2}{*}{$\begin{array}{l}\text { Herkunft } \\
\text { Istebna, Bukowiec 149h }\end{array}$} & \multicolumn{2}{|l|}{$\begin{array}{l}\text { BHD } \\
{[\mathrm{cm}]}\end{array}$} & \multicolumn{3}{|c|}{ T-G } & \multicolumn{2}{|l|}{$\begin{array}{l}\text { Einzelbaum- } \\
\text { volumen }\left[\mathrm{m}^{3}\right]\end{array}$} & \multicolumn{2}{|c|}{ T-G } \\
\hline & & 16,7 & A & & & & 0,1611 & A & & \\
\hline \multirow[t]{2}{*}{10} & Wisła, Malinka & 15,7 & A & B & & & 0,1363 & A & B & \\
\hline & Wolfach V 11 & 15,2 & A & B & $\mathrm{C}$ & & 0,1216 & A & B & $\mathrm{C}$ \\
\hline 16 & Orawa Stancowa & 15,1 & A & B & & $\mathrm{D}$ & 0,1136 & A & B & $\mathrm{C}$ \\
\hline \multirow[t]{2}{*}{13} & Rycerka, Zwardon & 14,4 & A & B & $\mathrm{C}$ & $\mathrm{D}$ & 0,1028 & A & B & $\mathrm{C}$ \\
\hline & Wolfach VI 7 & 13,9 & A & B & $\mathrm{C}$ & $\mathrm{D}$ & 0,1026 & A & B & C \\
\hline \multirow[t]{2}{*}{20} & Blizyn & 14,1 & A & B & $\mathrm{C}$ & $\mathrm{D}$ & 0,0988 & A & B & $\mathrm{C}$ \\
\hline & Wolfach V 4 Ostteil & 14,0 & A & B & $\mathrm{C}$ & $\mathrm{D}$ & 0,0977 & A & B & $\mathrm{C}$ \\
\hline \multirow[t]{2}{*}{19} & Zwierzyniec Lubelski, Obrocz & 14,0 & A & B & $\mathrm{C}$ & $\mathrm{D}$ & 0,0946 & A & B & $\mathrm{C}$ \\
\hline & Wolfach VI 9 & 14,1 & A & B & $\mathrm{C}$ & $\mathrm{D}$ & 0,0946 & A & B & $\mathrm{C}$ \\
\hline 14 & Rycerka, Praszywka I & 13,7 & A & B & $\mathrm{C}$ & $\mathrm{D}$ & 0,0931 & A & B & $\mathrm{C}$ \\
\hline 1 & Zwierzyniec Biał., Pogorzelece & 13,6 & A & B & $\mathrm{C}$ & $\mathrm{D}$ & 0,0882 & A & B & $\mathrm{C}$ \\
\hline 18 & Tarnawa, Sokoliki & 13,7 & A & B & $\mathrm{C}$ & $\mathrm{D}$ & 0,0864 & A & B & $\mathrm{C}$ \\
\hline 8 & Miedzygórze, Wodospad & 13,2 & A & B & $\mathrm{C}$ & $\mathrm{D}$ & 0,0851 & A & B & $\mathrm{C}$ \\
\hline \multirow[t]{3}{*}{12} & Istebna, Zapowiedz $115 f$ & 13,5 & A & B & $\mathrm{C}$ & $\mathrm{D}$ & 0,0846 & A & B & $\mathrm{C}$ \\
\hline & Wolfach V 4 Westteil & 13,0 & A & B & $\mathrm{C}$ & $\mathrm{D}$ & 0,0825 & A & B & $\mathrm{C}$ \\
\hline & Gessertshausen & 12,6 & A & B & $\mathrm{C}$ & $\mathrm{D}$ & 0,0825 & A & B & $\mathrm{C}$ \\
\hline 15 & Rycerka, Praszywka II & 13,4 & A & B & $\mathrm{C}$ & $\mathrm{D}$ & 0,0817 & A & B & $\mathrm{C}$ \\
\hline 9 & Stronie Slaskie, Kletno & 13,4 & A & B & $\mathrm{C}$ & $\mathrm{D}$ & 0,0812 & A & B & $\mathrm{C}$ \\
\hline 2 & Zwierzyniec Biał., Krzyze & 12,9 & A & B & $\mathrm{C}$ & $\mathrm{D}$ & 0,0809 & A & B & $\mathrm{C}$ \\
\hline \multirow[t]{2}{*}{3} & Wigry, Krzywe & 13,2 & A & B & $\mathrm{C}$ & $\mathrm{D}$ & 0,0766 & A & B & $\mathrm{C}$ \\
\hline & Wolfach V 14 & 12,8 & A & B & $\mathrm{C}$ & $\mathrm{D}$ & 0,0757 & A & B & $\mathrm{C}$ \\
\hline 4 & Przerwanki, Zawady & 12,5 & A & B & $\mathrm{C}$ & $\mathrm{D}$ & 0,0707 & A & B & $\mathrm{C}$ \\
\hline \multirow[t]{2}{*}{5} & Borki, Sarnianka & 12,3 & A & B & $\mathrm{C}$ & $\mathrm{D}$ & 0,0705 & & B & $\mathrm{C}$ \\
\hline & Krumbach & 12,0 & A & B & $\mathrm{C}$ & $\mathrm{D}$ & 0,0679 & & B & $\mathrm{C}$ \\
\hline 21 & Kartuzy, Kosowo & 11,2 & & B & $\mathrm{C}$ & $\mathrm{D}$ & 0,0656 & & B & $\mathrm{C}$ \\
\hline \multirow[t]{6}{*}{6} & Nowe Ramuki, Przykop & 10,4 & & & $\mathrm{C}$ & & 0,0645 & & B & $\mathrm{C}$ \\
\hline & Bischofswiesen & 11,5 & & B & $\mathrm{C}$ & $\mathrm{D}$ & 0,0595 & & B & $\mathrm{C}$ \\
\hline & Klingenbrunn Ernte 1958 & 11,4 & & B & $\mathrm{C}$ & $\mathrm{D}$ & 0,0593 & & B & $\mathrm{C}$ \\
\hline & Zwiesel VI Haselau & 11,6 & & B & $\mathrm{C}$ & & 0,0572 & & B & $\mathrm{C}$ \\
\hline & Zwiesel II Sulzschachten & 11,1 & & B & $\mathrm{C}$ & $\mathrm{D}$ & 0,0507 & & B & $\mathrm{C}$ \\
\hline & Klingenbrunn Ernte 1971 & 11,0 & & B & $\mathrm{C}$ & $\mathrm{D}$ & 0,0443 & & & $\mathrm{C}$ \\
\hline \multirow[t]{2}{*}{17} & Witów (Tatry), ur. Chotorz & 10,3 & & & & $\mathrm{D}$ & 0,0423 & & & $\mathrm{C}$ \\
\hline & Scatlè & 12,2 & A & $\mathrm{B}$ & $\mathrm{C}$ & $\mathrm{D}$ & 0,0397 & & & C \\
\hline
\end{tabular}

T-G = Tukey-Gruppe 


\section{Anhang 2.21}

Tukey-Gruppen $(\alpha=0,05)$ für das Merkmal Ausfallrate [\%] auf der Versuchsfläche Neureichenau I Bayern (34-j.)

\begin{tabular}{cl|cccccc}
\hline IUFRO-Nr. & Herkunft & $\begin{array}{c}\text { Ausfälle } \\
{[\%]}\end{array}$ & & T-G & & \\
\hline 9 & Stronie Slaskie, Kletno & 53 & & & & E \\
8 & Miedzygórze, Wodospad & 66 & & & D & E \\
10 & Wisła, Malinka & 70 & & & C & D & E \\
15 & Rycerka, Praszywka II & 70 & & & C & D & E \\
12 & Istebna, Zapowiedz 115f & 72 & & B & C & D & E \\
13 & Rycerka, Zwardon & 78 & A & B & C & D & \\
11 & Istebna, Bukowiec 149h & 79 & A & B & C & D & \\
21 & Kartuzy, Kosowo & 79 & A & B & C & D & \\
14 & Rycerka, Praszywka I & 82 & A & B & C & D & \\
2 & Zwierzyniec Biał., Krzyze & 86 & A & B & C & D & \\
19 & Zwierzyniec Lubelski, Obrocz & 88 & A & B & C & & \\
18 & Tarnawa, Sokoliki & 89 & A & B & C & & \\
20 & Blizyn & 90 & A & B & C & & \\
1 & Zwierzyniec Biał., Pogorzelece & 91 & A & B & C & & \\
4 & Przerwanki, Zawady & 92 & A & B & & & \\
5 & Borki, Sarnianka & 93 & A & & & & \\
\hline
\end{tabular}

T-G = Tukey-Gruppe

\section{Anhang 2.22}

H/D-Verbältnisse auf der Versuchsfläche Neureichenau / Bayern (25-j. und 34-j.)

\begin{tabular}{cl|c|c}
\hline IUFRO-Nr. & Herkunft & HD (25-j.) & HD (34-j.) \\
\hline 1 & Zwierzyniec Biał., Pogorzelece & 84 & 72 \\
2 & Zwierzyniec Biał., Krzyze & 83 & 72 \\
4 & Przerwanki, Zawady & 85 & 77 \\
5 & Borki, Sarnianka & 84 & 80 \\
8 & Miedzygórze, Wodospad & 80 & 70 \\
9 & Stronie Slaskie, Kletno & 76 & 71 \\
10 & Wisła, Malinka & 79 & 69 \\
11 & Istebna, Bukowiec 149h & 82 & 76 \\
12 & Istebna, Zapowiedz 115f & 81 & 65 \\
13 & Rycerka, Zwardon & 80 & 67 \\
14 & Rycerka, Praszywka I & 81 & 66 \\
15 & Rycerka, Praszywka II & 79 & 75 \\
18 & Tarnawa, Sokoliki & 85 & 69 \\
19 & Zwierzyniec Lubelski, Obrocz & 90 & 62 \\
20 & Blizyn & 82 & 62 \\
21 & Kartuzy, Kosowo & 82 & 72 \\
\hline Mittel & \multicolumn{2}{|c}{} \\
\hline
\end{tabular}




\section{Anhang 2.23}

Tukey-Gruppen $(\alpha=0,05)$ für die Wachstumsmerkmale Höhe $[\mathrm{m}]$ und BHD [cm] auf der Versuchsfläche Neureichenau / Bayern (25-j.)

\begin{tabular}{cl|ccc|ccc}
\hline $\begin{array}{c}\text { IUFRO- } \\
\text { Nr. }\end{array}$ & Herkunft & Höhe $[\mathrm{cm}]$ & T-G & $\begin{array}{c}\text { BHD } \\
{[\mathrm{cm}]}\end{array}$ & \multicolumn{2}{c}{ T-G } \\
\hline 10 & Wisła, Malinka & 10,1 & A & & 13,1 & A & \\
9 & Stronie Slaskie, Kletno & 9,1 & A & B & 12,4 & A & B \\
12 & Istebna, Zapowiedz 115f & 9,4 & A & B & 12,2 & A & B \\
11 & Istebna, Bukowiec 149h & 9,3 & A & B & 12,0 & A & B \\
15 & Rycerka, Praszywka II & 9,1 & A & B & 11,9 & A & B \\
13 & Rycerka, Zwardon & 9,0 & A & B & 11,8 & A & B \\
14 & Rycerka, Praszywka I & 9,2 & A & B & 11,8 & A & B \\
21 & Kartuzy, Kosowo & 9,2 & A & B & 11,8 & A & B \\
8 & Miedzygórze, Wodospad & 9,0 & A & B & 11,7 & A & B \\
2 & Zwierzyniec Biał., Krzyze & 8,7 & A & B & 11,2 & A & B \\
20 & Blizyn & 8,7 & A & B & 11,1 & A & B \\
4 & Przerwanki, Zawady & 8,9 & A & B & 11,1 & A & B \\
18 & Tarnawa, Sokoliki & 8,6 & & B & 10,9 & A & B \\
1 & Zwierzyniec Biał., Pogorzelece & 8,5 & & B & 10,5 & & B \\
5 & Borki, Sarnianka & 8,1 & & B & 10,2 & & B \\
19 & Zwierzyniec Lubelski, Obrocz & & & & & & \\
\hline
\end{tabular}

T-G = Tukey-Gruppe 


\section{Anhang 2.24}

Tukey-Gruppen $(\alpha=0,05)$ für das Merkmal Einzelbaumvolumen $\left[\mathrm{m}^{3}\right]$ auf der Versuchsfläche Neureichenau / Bayern (25-j. [links] und 34-j. [rechts])

\begin{tabular}{|c|c|c|c|c|c|c|c|}
\hline $\begin{array}{c}\text { IUFRO- } \\
\text { Nr. }\end{array}$ & Herkunft & Einz.-V. $\left[\mathrm{m}^{3}\right]$ & \multicolumn{2}{|c|}{$\mathrm{T}-\mathrm{G}$} & Einz.-V. $\left[\mathrm{m}^{3}\right]$ & \multicolumn{2}{|c|}{ T-G } \\
\hline 20 & Blizyn & 0,039302 & & B & 0,31235 & A & \\
\hline 18 & Tarnawa, Sokoliki & 0,045270 & & B & 0,30869 & A & \\
\hline 12 & Istebna, Zapowiedz $115 f$ & 0,052312 & A & B & 0,30587 & A & \\
\hline 11 & Istebna, Bukowiec 149h & 0,052653 & A & B & 0,27304 & A & B \\
\hline 2 & Zwierzyniec Biał., Krzyze & 0,059373 & A & B & 0,25826 & A & B \\
\hline 10 & Wisła, Malinka & 0,053197 & A & B & 0,25690 & A & B \\
\hline 21 & Kartuzy, Kosowo & 0,039203 & & B & 0,25179 & A & B \\
\hline 19 & Zwierzyniec Lubelski, Obrocz & 0,044681 & & B & 0,23827 & A & B \\
\hline 13 & Rycerka, Zwardon & 0,048233 & A & B & 0,22462 & A & B \\
\hline 8 & Miedzygórze, Wodospad & 0,053596 & A & B & 0,21595 & A & B \\
\hline 14 & Rycerka, Praszywka I & 0,048092 & A & B & 0,21215 & A & B \\
\hline 15 & Rycerka, Praszywka II & 0,046650 & & B & 0,21107 & A & B \\
\hline 9 & Stronie Slaskie, Kletno & 0,053401 & A & B & 0,20958 & A & B \\
\hline 1 & Zwierzyniec Biał., Pogorzelece & 0,068857 & A & & 0,20067 & A & B \\
\hline 5 & Borki, Sarnianka & 0,056413 & A & B & 0,15051 & A & B \\
\hline 4 & Przerwanki, Zawady & 0,056852 & A & B & 0,09335 & & B \\
\hline
\end{tabular}

T-G = Tukey-Gruppe 


\section{Anhang 2.25}

Tukey-Gruppen $(\alpha=0,05)$ für das Merkmal Vorrat $\left[\mathrm{m}^{3} / \mathrm{ha}\right]$ auf der Versuchsfläche Neureichenau I Bayern: $25-j$. (oben) und 34-j. (unten)

\begin{tabular}{|c|c|c|c|c|c|c|c|c|}
\hline $\begin{array}{c}\text { IUFRO- } \\
\text { Nr. }\end{array}$ & Herkunft & $\begin{array}{c}\text { Vorrat } \\
{\left[\mathrm{m}^{3} / \text { ha }\right]}\end{array}$ & \multicolumn{6}{|c|}{ T-G } \\
\hline 9 & Stronie Slaskie, Kletno & 121 & & & & & & \\
\hline 12 & Istebna, Zapowiedz $115 f$ & 110 & A & B & $\mathrm{C}$ & & & \\
\hline 10 & Wisła, Malinka & 141 & A & & & & & \\
\hline 8 & Miedzygórze, Wodospad & 107 & & B & $\mathrm{C}$ & $\mathrm{D}$ & & \\
\hline 15 & Rycerka, Praszywka II & 115 & A & B & $\mathrm{C}$ & & & \\
\hline 21 & Kartuzy, Kosowo & 110 & A & B & $\mathrm{C}$ & & & \\
\hline 11 & Istebna, Bukowiec $149 \mathrm{~h}$ & 101 & A & B & $\mathrm{C}$ & $\mathrm{D}$ & $\mathrm{E}$ & $\mathrm{F}$ \\
\hline 13 & Rycerka, Zwardon & 109 & A & B & $\mathrm{C}$ & $\mathrm{D}$ & & \\
\hline 14 & Rycerka, Praszywka I & 104 & A & B & $\mathrm{C}$ & $\mathrm{D}$ & $\mathrm{E}$ & \\
\hline 2 & Zwierzyniec Biał., Krzyze & 76 & & B & $\mathrm{C}$ & $\mathrm{D}$ & $\mathrm{E}$ & $\mathrm{F}$ \\
\hline 18 & Tarnawa, Sokoliki & 77 & & B & $\mathrm{C}$ & $\mathrm{D}$ & $\mathrm{E}$ & $\mathrm{F}$ \\
\hline 20 & Blizyn & 65 & & & & $\mathrm{D}$ & $\mathrm{E}$ & $\mathrm{F}$ \\
\hline 19 & Zwierzyniec Lubelski, Obrocz & 58 & & & & & & $\mathrm{~F}$ \\
\hline 1 & Zwierzyniec Biał., Pogorzelece & 71 & & & $\mathrm{C}$ & $\mathrm{D}$ & $\mathrm{E}$ & $\mathrm{F}$ \\
\hline 5 & Borki, Sarnianka & 79 & & B & $\mathrm{C}$ & $\mathrm{D}$ & $\mathrm{E}$ & $\mathrm{F}$ \\
\hline 4 & Przerwanki, Zawady & 62 & & & & & $\mathrm{E}$ & $\mathrm{F}$ \\
\hline
\end{tabular}

\begin{tabular}{cl|cccccc}
\hline $\begin{array}{c}\text { IUFRO- } \\
\text { Nr. }\end{array}$ & Herkunft & $\begin{array}{c}\text { Vorrat } \\
{\left[\mathrm{m}^{3} / \mathrm{ha}\right]}\end{array}$ & & & T-G & \\
\hline 9 & Stronie Slaskie, Kletno & 236 & A & & & & \\
12 & Istebna, Zapowiedz 115f & 193 & A & B & & & \\
10 & Wisła, Malinka & 183 & A & B & C & & \\
8 & Miedzygórze, Wodospad & 167 & A & B & C & D & \\
15 & Rycerka, Praszywka II & 146 & A & B & C & D & E \\
21 & Kartuzy, Kosowo & 133 & A & B & C & D & E \\
11 & Istebna, Bukowiec 149h & 131 & A & B & C & D & E \\
13 & Rycerka, Zwardon & 113 & & B & C & D & E \\
14 & Rycerka, Praszywka I & 85 & & B & C & D & E \\
2 & Zwierzyniec Biał., Krzyze & 75 & & B & C & D & E \\
18 & Tarnawa, Sokoliki & 60 & & & & D & E \\
20 & Blizyn & 58 & & & & D & E \\
19 & Zwierzyniec Lubelski, Obrocz & 50 & & & & E \\
1 & Zwierzyniec Bial., Pogorzelece & 50 & 34 & & & & E \\
5 & Borki, Sarnianka & 33 & & & & & E \\
4 & Przerwanki, Zawady & & & & &
\end{tabular}

T-G = Tukey-Gruppe 


\section{Anhang 2.26}

Produk.t-Momenten-Korrelationsmatrix $\left(r_{P}\right)$ des Feblstellenanteils auf den Versuchsflächen des IUFROFichtenherkunftsversuchs 1972 (Anzahl Prüfglieder)

\begin{tabular}{|c|c|c|c|c|c|c|c|c|c|c|}
\hline \multirow[t]{2}{*}{ Versuch } & & \multirow{2}{*}{\begin{tabular}{|c} 
Hatzfeld \\
1976 \\
$(4-\mathrm{j})$.
\end{tabular}} & \multicolumn{3}{|c|}{ Reinhardshagen } & \multicolumn{3}{|c|}{ Wanfried } & \multicolumn{2}{|l|}{ Dassel } \\
\hline & Jahr & & $\begin{array}{l}1976 \\
(4 \mathrm{j} .)\end{array}$ & $\begin{array}{l}1995 \\
(23-\text {-i. }\end{array}$ & $\begin{array}{l}2004 \\
(32-j .)\end{array}$ & $\begin{array}{l}1976 \\
(4-j .)\end{array}$ & $\begin{array}{l}1995 \\
(23-\mathrm{j} .)\end{array}$ & $\begin{array}{l}2004 \\
(32-i .)\end{array}$ & $\begin{array}{l}1995 \\
(23-\mathrm{j} .)\end{array}$ & $\begin{array}{l}2004 \\
(32-j .)\end{array}$ \\
\hline Hatzfeld & 1976 & - & $\begin{array}{c}0,49 * \\
(18)\end{array}$ & $\begin{array}{c}0,64 * * \\
(18)\end{array}$ & $\begin{array}{c}0,67^{* *} \\
(18)\end{array}$ & $\begin{array}{c}-0,08 \\
(18)\end{array}$ & $\begin{array}{c}-0,18 \\
(18)\end{array}$ & $\begin{array}{l}0,18 \\
(18)\end{array}$ & $\begin{array}{l}0,04 \\
(18)\end{array}$ & $\begin{array}{c}-0,00 \\
(18)\end{array}$ \\
\hline \multirow{3}{*}{$\begin{array}{l}\text { Rein- } \\
\text { hards- } \\
\text { hagen }\end{array}$} & 1976 & & - & $\begin{array}{c}0,49 * \\
(18)\end{array}$ & $\begin{array}{c}0,58^{*} \\
(18)\end{array}$ & $\begin{array}{c}-0,12 \\
(18)\end{array}$ & $\begin{array}{l}0,03 \\
(18)\end{array}$ & $\begin{array}{l}0,37 \\
(18)\end{array}$ & $\begin{array}{l}0,20 \\
(18)\end{array}$ & $\begin{array}{l}0,10 \\
(18)\end{array}$ \\
\hline & 1995 & & & - & $\begin{array}{c}0,94 * * * * \\
(18)\end{array}$ & $\begin{array}{c}-0,13 \\
(18)\end{array}$ & $\begin{array}{l}0,06 \\
(18)\end{array}$ & $\begin{array}{l}0,25 \\
(18)\end{array}$ & $\begin{array}{l}0,07 \\
(18)\end{array}$ & $\begin{array}{c}-0,01 \\
(18)\end{array}$ \\
\hline & 2004 & & & & - & $\begin{array}{c}-0,20 \\
(18)\end{array}$ & $\begin{array}{l}0,07 \\
(18)\end{array}$ & $\begin{array}{l}0,34 \\
(18)\end{array}$ & $\begin{array}{l}0,15 \\
(18)\end{array}$ & $\begin{array}{l}0,08 \\
(18)\end{array}$ \\
\hline \multirow[t]{3}{*}{$\begin{array}{l}\text { Wan- } \\
\text { fried }\end{array}$} & 1976 & & & & & - & $\begin{array}{l}0,04 \\
(18)\end{array}$ & $\begin{array}{c}-0,34 \\
(18)\end{array}$ & $\begin{array}{l}0,17 \\
(18)\end{array}$ & $\begin{array}{l}0,19 \\
(18)\end{array}$ \\
\hline & 1995 & & & & & & - & $\begin{array}{l}0,46 \\
(18)\end{array}$ & $\begin{array}{l}0,40 \\
(18)\end{array}$ & $\begin{array}{l}0,33 \\
(18)\end{array}$ \\
\hline & 2004 & & & & & & & - & $\begin{array}{l}0,38 \\
(18)\end{array}$ & $\begin{array}{l}0,30 \\
(18)\end{array}$ \\
\hline \multirow[t]{2}{*}{ Dassel } & 1995 & & & & & & & & - & $\begin{array}{c}0,98^{* * *} \\
(20)\end{array}$ \\
\hline & 2004 & & & & & & & & & - \\
\hline \multirow[t]{2}{*}{ Seesen } & 1995 & & & & & & & & & \\
\hline & 2004 & & & & & & & & & \\
\hline $\begin{array}{l}\text { Ochsen- } \\
\text { haus. A }\end{array}$ & 1993 & & & & & & & & & \\
\hline $\begin{array}{l}\text { Ochsen- } \\
\text { haus. B }\end{array}$ & 1993 & & & & & & & & & \\
\hline $\begin{array}{l}\text { Sauer- } \\
\text { lach A }\end{array}$ & 1997 & & & & & & & & & \\
\hline $\begin{array}{l}\text { Sauer- } \\
\text { lach B }\end{array}$ & 1997 & & & & & & & & & \\
\hline \multirow[t]{3}{*}{$\begin{array}{l}\text { Neurei- } \\
\text { chenau }\end{array}$} & 1981 & & & & & & & & & \\
\hline & 1996 & & & & & & & & & \\
\hline & 2005 & & & & & & & & & \\
\hline
\end{tabular}




\begin{tabular}{|c|c|c|c|c|c|c|c|c|c|c|}
\hline \multicolumn{2}{|c|}{ Seesen } & \multirow{2}{*}{$\begin{array}{c}\text { O. A } \\
1993 \\
(22-j .) \\
\end{array}$} & \multirow{2}{*}{$\begin{array}{l}\text { O. B } \\
1993 \\
\text { (21j.) }\end{array}$} & \multirow{2}{*}{$\begin{array}{c}\text { S. A } \\
1997 \\
(25-j .)\end{array}$} & \multirow{2}{*}{$\begin{array}{c}\text { S. B } \\
1997 \\
(25-\text { j. }) \\
\end{array}$} & \multicolumn{3}{|c|}{ Neureichenau } & & \multirow[t]{2}{*}{ Versuch } \\
\hline $\begin{array}{c}1995 \\
(23-\mathrm{j} .)\end{array}$ & $\begin{array}{c}2004 \\
(32-j .)\end{array}$ & & & & & $\begin{array}{c}1981 \\
(10-j .)\end{array}$ & \begin{tabular}{|c|}
1996 \\
$(25-\mathrm{j})$.
\end{tabular} & $\begin{array}{c}2005 \\
(34-j .)\end{array}$ & Jahr & \\
\hline $\begin{array}{c}-0,00 \\
(9)\end{array}$ & $\begin{array}{c}0,06 \\
(9)\end{array}$ & $\begin{array}{c}-0,12 \\
(18)\end{array}$ & $\begin{array}{l}0,32 \\
(18)\end{array}$ & $\begin{array}{c}-0,22 \\
(18)\end{array}$ & $\begin{array}{l}0,19 \\
(18)\end{array}$ & $\begin{array}{l}0,12 \\
(14)\end{array}$ & $\begin{array}{l}0,27 \\
(14)\end{array}$ & $\begin{array}{l}0,15 \\
(14)\end{array}$ & 1976 & Hatzfeld \\
\hline $\begin{array}{c}0,18 \\
(9)\end{array}$ & $\begin{array}{c}0,18 \\
(9)\end{array}$ & $\begin{array}{l}0,10 \\
(18)\end{array}$ & $\begin{array}{l}0,20 \\
(18)\end{array}$ & $\begin{array}{l}0,02 \\
(18)\end{array}$ & $\begin{array}{l}0,02 \\
(18)\end{array}$ & $\begin{array}{l}0,03 \\
(14)\end{array}$ & $\begin{array}{l}0,22 \\
(14)\end{array}$ & $\begin{array}{l}0,46 \\
(14)\end{array}$ & 1976 & \multirow{3}{*}{$\begin{array}{l}\text { Rein- } \\
\text { hards- } \\
\text { hagen }\end{array}$} \\
\hline $\begin{array}{c}-0,39 \\
(9)\end{array}$ & $\begin{array}{c}-0,31 \\
(9)\end{array}$ & $\begin{array}{c}-0,25 \\
(18)\end{array}$ & $\begin{array}{c}-0,11 \\
(18)\end{array}$ & $\begin{array}{l}0,04 \\
(18)\end{array}$ & $\begin{array}{l}0,07 \\
(18)\end{array}$ & $\begin{array}{l}0,21 \\
(14)\end{array}$ & $\begin{array}{l}0,42 \\
(14)\end{array}$ & $\begin{array}{l}0,30 \\
(14)\end{array}$ & 1995 & \\
\hline $\begin{array}{c}-0,29 \\
(9)\end{array}$ & $\begin{array}{c}-0,23 \\
(9)\end{array}$ & $\begin{array}{c}-0,16 \\
(18)\end{array}$ & $\begin{array}{c}-0,07 \\
(18)\end{array}$ & $\begin{array}{l}0,15 \\
(18)\end{array}$ & $\begin{array}{l}0,16 \\
(18)\end{array}$ & $\begin{array}{l}0,25 \\
(14)\end{array}$ & $\begin{array}{l}0,48 \\
(14)\end{array}$ & $\begin{array}{l}0,35 \\
(14)\end{array}$ & 2004 & \\
\hline $\begin{array}{c}0,23 \\
(9)\end{array}$ & $\begin{array}{l}0,30 \\
(9)\end{array}$ & $\begin{array}{l}0,14 \\
(18)\end{array}$ & $\begin{array}{l}0,30 \\
(18)\end{array}$ & $\begin{array}{l}0,04 \\
(18)\end{array}$ & $\begin{array}{l}0,29 \\
(18)\end{array}$ & $\begin{array}{c}-0,46 \\
(14)\end{array}$ & $\begin{array}{c}-0,43 \\
(14)\end{array}$ & $\begin{array}{c}-0,29 \\
(14)\end{array}$ & 1976 & \multirow[t]{3}{*}{ Wanfried } \\
\hline $\begin{array}{c}-0,01 \\
(9)\end{array}$ & $\begin{array}{l}0,20 \\
(9)\end{array}$ & $\begin{array}{c}-0,08 \\
(18)\end{array}$ & $\begin{array}{c}-0,24 \\
(18)\end{array}$ & $\begin{array}{l}0,27 \\
(18)\end{array}$ & $\begin{array}{l}0,11 \\
(18)\end{array}$ & $\begin{array}{c}-0,53 \\
(14)\end{array}$ & $\begin{array}{c}-0,46 \\
(14)\end{array}$ & $\begin{array}{l}0,02 \\
(14)\end{array}$ & 1995 & \\
\hline $\begin{array}{c}0,33 \\
(9)\end{array}$ & $\begin{array}{c}0,09 \\
(9)\end{array}$ & $\begin{array}{c}-0,23 \\
(18)\end{array}$ & $\begin{array}{c}-0,15 \\
(18)\end{array}$ & $\begin{array}{l}0,13 \\
(18)\end{array}$ & $\begin{array}{l}-0,11 \\
(18)\end{array}$ & $\begin{array}{l}0,41 \\
(14)\end{array}$ & $\begin{array}{l}0,43 \\
(14)\end{array}$ & $\begin{array}{c}0,59 * \\
(14)\end{array}$ & 2004 & \\
\hline $\begin{array}{c}0,77^{* *} \\
(10)\end{array}$ & $\begin{array}{c}0,84 * * \\
(10)\end{array}$ & $\begin{array}{l}0,10 \\
(20)\end{array}$ & $\begin{array}{c}-0,14 \\
(20)\end{array}$ & $\begin{array}{l}0,37 \\
(20)\end{array}$ & $\begin{array}{l}-0,01 \\
(20)\end{array}$ & $\begin{array}{l}0,02 \\
(16)\end{array}$ & $\begin{array}{l}0,17 \\
(16)\end{array}$ & $\begin{array}{l}0,22 \\
(16)\end{array}$ & 1995 & \multirow[t]{2}{*}{ Dassel } \\
\hline $\begin{array}{c}0,85^{* *} \\
(10)\end{array}$ & $\begin{array}{c}0,89 * 4 * \\
(10)\end{array}$ & $\begin{array}{l}0,08 \\
(20)\end{array}$ & $\begin{array}{c}-0,16 \\
(20)\end{array}$ & $\begin{array}{l}0,40 \\
(20)\end{array}$ & $\begin{array}{l}0,07 \\
(20)\end{array}$ & $\begin{array}{l}0,09 \\
(16)\end{array}$ & $\begin{array}{l}0,23 \\
(16)\end{array}$ & $\begin{array}{l}0,22 \\
(16)\end{array}$ & 2004 & \\
\hline \multirow[t]{9}{*}{ - } & $\begin{array}{c}0,88^{* * *} * \\
(10)\end{array}$ & $\begin{array}{c}-0,06 \\
(10)\end{array}$ & $\begin{array}{l}0,08 \\
(10)\end{array}$ & $\begin{array}{l}0,37 \\
(10)\end{array}$ & $\begin{array}{c}-0,05 \\
(10)\end{array}$ & $\begin{array}{c}0,30 \\
(8)\end{array}$ & $\begin{array}{l}0,48 \\
(8)\end{array}$ & $\begin{array}{l}0,48 \\
(8)\end{array}$ & 1995 & Seesen \\
\hline & \multirow[t]{8}{*}{ - } & $\begin{array}{l}0,14 \\
(10)\end{array}$ & $\begin{array}{c}-0,01 \\
(10)\end{array}$ & $\begin{array}{l}0,24 \\
(10)\end{array}$ & $\begin{array}{c}-0,13 \\
(10)\end{array}$ & $\begin{array}{c}0,03 \\
(8)\end{array}$ & $\begin{array}{c}0,30 \\
(8)\end{array}$ & $\begin{array}{c}0,36 \\
(8)\end{array}$ & 2004 & \\
\hline & & \multirow[t]{7}{*}{ - } & $\begin{array}{c}0,47 * \\
(20)\end{array}$ & $\begin{array}{l}0,02 \\
(20)\end{array}$ & $\begin{array}{l}0,06 \\
(20)\end{array}$ & $\begin{array}{c}-0,25 \\
(16)\end{array}$ & $\begin{array}{c}-0,17 \\
(16)\end{array}$ & $\begin{array}{l}0,39 \\
(16)\end{array}$ & 1993 & $\begin{array}{l}\text { Ochsen- } \\
\text { haus. A }\end{array}$ \\
\hline & & & \multirow[t]{6}{*}{-} & $\begin{array}{c}-0,41 * \\
(20)\end{array}$ & $\begin{array}{l}0,17 \\
(20)\end{array}$ & $\begin{array}{c}-0,19 \\
(16)\end{array}$ & $\begin{array}{c}-0,09 \\
(16)\end{array}$ & $\begin{array}{c}-0,36 \\
(16)\end{array}$ & 1993 & $\begin{array}{l}\text { Ochsen- } \\
\text { haus. B }\end{array}$ \\
\hline & & & & \multirow[t]{5}{*}{-} & $\begin{array}{l}0,30 \\
(20)\end{array}$ & $\begin{array}{l}0,02 \\
(16)\end{array}$ & $\begin{array}{l}0,03 \\
(16)\end{array}$ & $\begin{array}{l}-0,03 \\
(16)\end{array}$ & 1997 & $\begin{array}{l}\text { Sauerlach } \\
\text { A }\end{array}$ \\
\hline & & & & & \multirow[t]{4}{*}{-} & $\begin{array}{l}0,07 \\
(16)\end{array}$ & $\begin{array}{l}0,19 \\
(16)\end{array}$ & $\begin{array}{l}0,11 \\
(16)\end{array}$ & 1997 & $\begin{array}{l}\text { Sauerlach } \\
\text { B }\end{array}$ \\
\hline & & & & & & - & $\begin{array}{c}0,88^{* * *} \\
(16)\end{array}$ & $\begin{array}{c}0,55^{*} \\
(16)\end{array}$ & 1981 & \multirow[t]{3}{*}{$\begin{array}{l}\text { Neurei- } \\
\text { chenau }\end{array}$} \\
\hline & & & & & & & - & $\begin{array}{c}0,63^{* *} \\
(16)\end{array}$ & 1996 & \\
\hline & & & & & & & & - & 2005 & \\
\hline
\end{tabular}

$\overline{\mathrm{O} . \mathrm{A} / \mathrm{O} . \mathrm{B}=\text { Ochsenhausen A bzw. B }}$

S. A / S. B = Sauerlach A bzw. B 



\section{Beiträge aus der Nordwestdeutschen Forstlichen Versuchsanstalt}

Band

1 (2007) Clusterstudie Forst und Holz Niedersachsen. Burkhard Rüther, Jan Hansen, Agatha Ludwig, Hermann Spellmann, Jürgen Nagel, Bernhard Möhring, Matthias Dieter. 92 S.

2 (2008) Die Waldkiefer - Fachtagung zum Baum des Jahres 2007. Nordwestdeutsche Forstliche Versuchsanstalt (Hrsg.). 98 S.

3 (2008) Ergebnisse angewandter Forschung zur Buche. Nordwestdeutsche Forstliche Versuchsanstalt (Hrsg.). 343 S.

4 (2008) Ergebnisse des westdeutschen IUFRO-Küstentannen-Provenienzversuches im Alter 27. Hans-Martin Rau, Armin König, Wolfhard Ruetz, Hendrik Rumpf, Egbert Schönfelder. $62 \mathrm{~S}$.

5 (2010) Fichtenherkunftsversuch von 1962 und IUFRO-Fichtenherkunftsversuch von 1972. Ergebnisse von mehr als 30jähriger Beobachtung in Deutschland. Mirko Liesebach, Hans-Martin Rau, Armin O. König. 467 S.

Alle Bände der „Beiträge aus der NW-FVA“ sind auch als freie Onlineversion über die Homepage der NW-FVA (www.nw-fva.de), des Verlages sowie über den OPAC der Niedersächsischen Staats- und Universitätsbibliothek

(http://www.sub.uni-goettingen.de) erreichbar und dürfen gelesen, heruntergeladen sowie als Privatkopie ausgedruckt werden. Es gelten die Lizenzbestimmungen der Onlineversion. Es ist nicht gestattet, Kopien oder gedruckte Fassungen der freien Onlineversion zu veräußern. 
Mit der weit über ihr natürliches Verbreitungsgebiet hinaus angebauten und in Deutschland wirtschaftlich bedeutendsten Baumart Fichte (Picea abies [L.] Karst.) wurden in der zweiten Hälfte des letzten Jahrhunderts mehrere größere Herkunftsversuche angelegt. Aus dieser Zeit stammen auch der Fichtenherkunftsversuch von 1962 und der IUFRO-Fichtenherkunftsversuch von 1972. In diesem Band wird die Auswertung der über 30-jährigen Beobachtung dieser Versuche vorgestellt. Neben der Entwicklung der Pflanzenanzahl, Schäden und Stammform wurden die Wachstums- und Vorratsentwicklungen besonders intensiv untersucht. Die Ergebnisse werden kritisch gewertet und die Anpassungsfähigkeit von Fichtenpopulationen an Klimaänderungen diskutiert. Der Band richtet sich im Wesentlichen an Wissenschaftler und zusätzlich an Praktiker, die sich intensiv mit Herkunftsfragen zur Fichte beschäftigen.
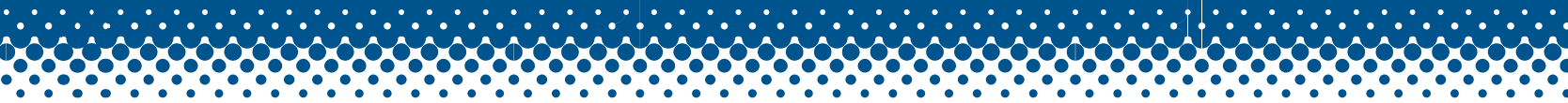

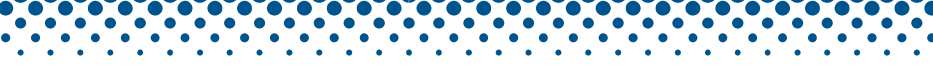

